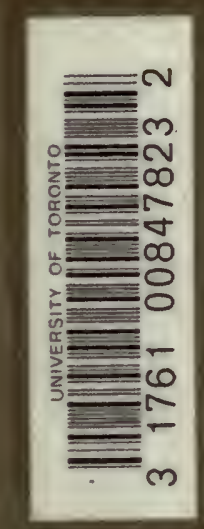

IINIVIITIT of 




\title{
ORGANOGRAPHIE DER PFLANZEN
}

INSBESONDERE DER

\section{ARCHEGONIATEN UND SAMENPFLANZEN}

\author{
VON \\ DR. K. GOEBEL
}

PROFESSOR AN DER UNIVERSITÄT MÜNCHEN

ERSTER TEIL

\section{ALLGEMEINE ORGANOGRAPHIE}

ZWEITE, UMGEARBEITETE AUFLAGE

MIT 459 ABBILDUNGEN IM TEXT

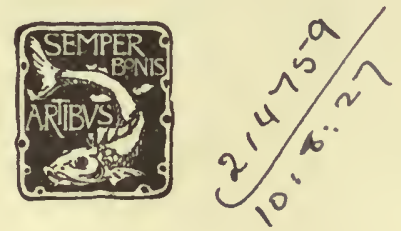

JENA

VERLAG VON GUSTAV FISCHER 


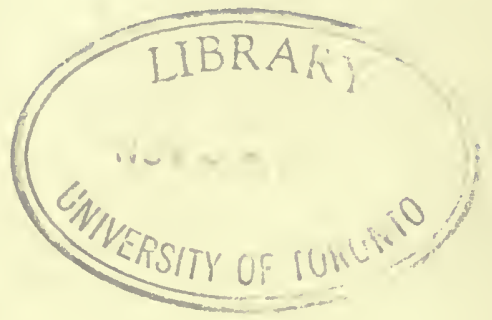

Alle Rechte vorbehalten.

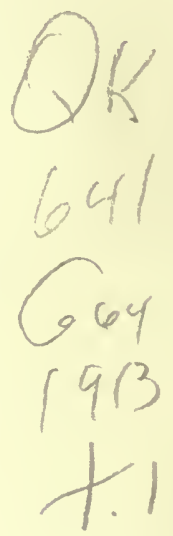

Germany 


\section{Vorwort zur zweiten Auflage.}

Die freundliche Aufnahme, welche die erste Auflage dieses Buches erfahren hat, ermutigte den Verfasser die große Arbeit der Bearbeitung einer zweiten nicht zu scheuen. - Die „allgemeine Organographie“ erfuhr erhebliche Änderungen in der Bearbeitung und Anordnung des Stoffes. Die früher darin enthaltene Darstellung der SchweNDENER'schen mechanischen Blattstellungslehre schien nicht mehr erforderlich. Bezüglich der Regenerationsprobleme, der Vererbung von Mißbildungen, der Gallenbildung konnte auf andere zusammenfassende Darstellungen hingewiesen werden. Dagegen wurden außer einer Einleitung Abschnitte ïber die Beziehungen zwischen Gestalt und Funktion, Verzweigung, Blattanordnung, sexuellen Dimorphismus, Generationswechsel u. a. hinzugefügt, was auch die Ausführung zahlreicher neuer Abbildungen bedingte. Da die Umarbeitung des speziellen Teiles (welcher übrigens in der alten Fassung vorläufig auch von Lesern der zweiten Auflage des allgemeinen verwendet werden kann), noch längere Zeit in Anspruch nehmen wird, wurde dem allgemeinen Teile ein Register beigegeben, für dessen Ausfïhrung (ebenso wie für Beihilfe bei den Korrekturen) ich Herrn Dr. SchüEPP zu Dank verpflichtet bin.

Fernerstehende könnten glauben, daß die Abwendung von den Problemen der Organographie, welche in der heutigen Botanik hervortritt, bedingt sei dadurch, daß diese Probleme gelöst seien. Nichts wäre irriger. Man hat die alten Arbeitsfelder verlassen, nicht weil sie erschöpft waren, sondern weil neue einen rascheren und reicheren Ertrag zu versprechen schienen. Vielfach auch wohl deshalb, weil das ,Problem der Mannigfaltigkeit" gerade auf dem Gebiete der Morphologie uns besonders beängstigend entgegentritt. Aber es erhebt sich - ganz zu schweigen von der Systematik - dem Experimentalphysiologen ebenso gegenüber wie dem Morphologen, und schleicht sich nicht weniger auch in die Präparatenmappen der Cytologen und Anatomen ein. Es ist also aufs Innigste verbunden mit allen Lebenserscheinungen. Und es ist schön, daß dem so ist!

München, April 1913.

Der Verfasser. 


\section{Vorwort zur ersten Auflage.}

Wenn der Teil der Botanik unserer Tage, den man gewöhnlich als "Morphologie" bezeichnet, einst einen Geschichtschreiber finden sollte, so wird dieser die letzten Jahrzehnte unseres Jahrhunderts wahrscheinlich als eine Übergangsperiode bezeichnen. Solche Übergangszeiten sind dadurch gekennzeichnet, daß die früher herrschend gewesenen Richtungen, nachdem sie das geleistet haben, was ihnen eigentümlich war, sich ausgelebt haben. Die neuen Bestrebungen, naturgemäß mit den alten und untereinander oft im Kampfe, haben noch keine allgemeine Anerkennung gefunden. Man sieht aber, daß die Dinge nicht so einfach liegen, wie man früher glaubte, daß das alte Schema vielfach nicht mehr passen will.

Das hängt in der "Morphologie" wesentlich damit zusammen, daß man dazu gelangt ist, die Gestaltung der Pflanzen als einen Teil der Lebenserscheinungen zu betrachten, nicht als eine Begriffskonstruktion, wie dies in der idealistischen Morphologie geschah. Alle Lebenserscheinungen aber stehen in bestimmter Beziehung zur Außenwelt, und für die Morphologie heißt das, wie in diesem Buche nachzuweisen versucht werden soll, daß sie vor allem die Gestaltung der Organbildung zu betrachten hat, daß sie nicht nur eine vergleichende historische Disziplin ist, sondern in erster Linie es mit Verhältnissen zu tun hat, wie wir jetzt sie vorfinden. Sie hat nachzuweisen, inwieweit die Organbildung eine Anpassung an äußere Verhältnisse darstellt und von diesen oder von inneren Beziehungen abhängig ist; ein solcher Nachweis ist auch notwendig, wenn die phylogenetische Betrachtung in den Vordergrund gestellt wird, denn auch die geschichtliche Entwicklung muß sich in steter Beeinflussung durch die Außenwelt vollzogen haben. Phylogenetische Spekulationen sind ohne Zweifel anziehender als die Beschäftigung mit unscheinbaren und vielen wohl sehr nebensächlich erscheinenden Gestaltungsverhältnissen der Pflanzen, die uns umgeben. Mir scheint es aber, daß z. B. die Erkennung der Faktoren, welche bedingen, daß die eine Hälfte eines Blattes größer wird als die andere, wichtiger ist als ein durch Tatsachen nicht gestiitztes phylogenetisches Hypothesengebäude; HoFMEIsTER, Sachs und Herbert Spencer haben diese Richtung, die wir als Organographie bezeichnen können, in den letzten Jahrzehnten vor allem gefördert. Freilich handelt es sich nur um Anfänge; ein weites, wenig bebautes, aber vielversprechendes Arbeitsfeld liegt vor uns. Die großen Schwierigkeiten, die namentlich in der richtigen Fragestellung liegen, treten in dem vorliegenden allgemeinen 'Teile besonders hervor, und ich habe lange geschwankt, ob ich ihn nicht ganz weglassen solle. Aber wenn er auch 
mehr Materialien zu einer allgemeinen Organographie statt einer von allgemeinen Gesichtspunkten ausgehenden Darstellung bietet, so wird er doch trotz aller Unvollkommenheit nicht überflüssig sein, schon deshalb, weil er zeigt, daß dieselben Probleme sich in den verschiedensten Verwandtschaftskreisen wiederholen, was bei einer Einzeldarstellung der verschiedenen Gruppen natürlich nicht hervortreten kann.

Die Ziele, welche das Buch verfolgt, mögen im übrigen aus der Darstellung selbst sich ergeben. Ausdriicklich bemerkt sei nur, daß es sich beschränkt auf die Archegoniaten und die Samenpflanzen, die Thallophyten aber nur im allgemeinen Teile vergleichsweise mit berïcksichtigt. Vollständigkeit ist in keiner Weise beabsichtigt, namentlich auch nicht in der Darstellung der Ansichten anderer, auf die ich nur insofern eingegangen bin, als es für die hier verfolgten Zwecke notwendig erschien. Mehrfach sind die Resultate noch nicht veröffentlichter ${ }^{2}$ Untersuchungen im Laufe der Darstellung mitgeteilt.

Betreffs der Abbildungen habe ich öfters auf die in meinem Buche "Pflanzenbiologische Schilderungen“ (Marburg 1889-1893) enthaltenen Bilder hingewiesen; dieselben sind der Kürze halber als S. Fig. ... zitiert, das Buch auch sonst als S. - Die Verfasser des in demselben Verlage erschienenen Lehrbuchs der Botanik (Strasburger, Noli, Schenck, Schimper) gestatteten die Verwendung einer Anzahl von Figuren, die, soweit sie Originale sind, mit Lehrb. bezeichnet wurden.

Die Darstellung der Grundzïge der mechanischen Blattstellungstheorie wurde von Herrn Dr. Arthur Weisse übernommen, der also für den betreffenden Abschnitt allein verantwortlich ist.

Ein Register wird erst dem Schlußband beigegeben werden, deshalb folgt hier zunächst eine ausführliche Inhaltsübersicht.

A mbach, 1. September 1897.

K. Goebel. 


\section{Inhaltsiibersicht.}

Einleitung. Aufgaben der Organographie erörtert an einem Einzelfall . . . . 1

\section{Erster Abschnitt. \\ Beziehungen zwischen Gestalt und Funktion.}

§ 1. Morphologie und Organographie . . . . . . . . . . . . . . . 7

$\$ 2$. Ausbildung von mechanischem Gewebe . . . . . . . . . . 9

\$ 3. Stellung der Archegonien am Farnprothallium, Einkrümmung geophiler Sprosse 10

$\S$ 4. Sind Etiolierungserscheinungen als Anpassungen zu betrachten? . . . . . 12

$\$$ 5. Schutz des Vegetationspunktes hypogäischer Pflanzenteile . . . . . . . 14

6. Ranken . . . . . . . . . . . . . . . . . . . . . 18

§ 7. Indirekte Beeinflussung . . . . . . . . . . . . . . . . . 21

Zufälliges Auftreten von Gestaltungsverhältnissen, die bei anderen Pflanzen als Anpassungen erscheinen . . . . . . . . . . . . . . 22

§ 8. Blattbildung . . . . . . . . . . . . . . 23

a) Schildförmige und schlauchförmige Blätter. . . . . . . . 23

b) Wendeltreppenblätter. . . . . . . . . . . . . . . . 25

c) Gliederung des Blattes . . . . . . . . . . . . . . . 26

d) Blattfunktionen durch die Nebenblätter übernommen . . . . 27

e) Ranken. . . . . . . . . . . . 27

f) Gestaltung der Kotyledonen . . . . . . . . . . . . 27

g) Doppelnadeln . . . . . . . . . . 28

h) Abweichende Stellung der Blattglieder : $: \div 28$

§ 9. Blüten . . . . . . . . . . . . . . . . . . . 29

10. Blütenstände

§ 11. Können die Lebensbedingungen die Reaktionsfähigkeit der Pflanzen ändern? 32

\section{Zweiter A bschnitt.}

\section{Die Organbildung auf den verschiedenen Stufen des Pflanzenreichs.}

Einleitung: Organbildung und Arbeitsteilung bei niederen Pflanzen (Thallophyten) 40

$\S$ 1. Ein- und mehrzellige Pflanzen . . . . . . . . . . . . 41

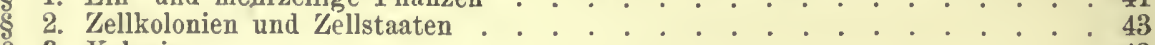

§ 3 . Kolonien

A. Nicht festsitzende Kolonien

1. Kolonien nackter Energiden (nichtzeliuläre Energidenkolonien) : : 43

2. Kolonien behäuteter Energiden (zelluläre Energidenkolonien) . . . . 45

B. Die festsitzenden Kolonien. . . . . . . . . 49

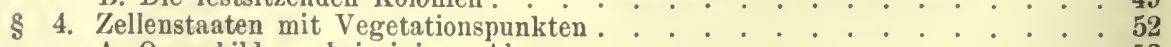

A. Organbildung bei einigen Algen.

B. Organbildung am vegetativen Thallus der Flechten $: 0^{\circ}: 0^{\circ}, 62$

$\S 4$ a. Organanlegung und Verzweigung . . . . . . . . . . . 65

I. Reihenfolge . . . . . . . . . . . . 65

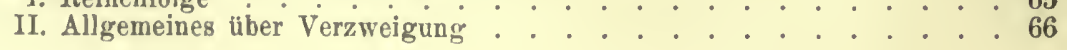


III. Verschiedene Arten der Verzweigung

IV. Exogene und endogene Verzweigung

VI. Änderungen in dem Verhältnis der Zweige zueinander

VII. Axilläre Verzweigung . . . . . . . . . .

§. Verzweigung bei Bryophyten . . . . . . . . . . . . . . . . . 75

6. Verzweigung der Lycopodinen . . . . . . . . . . . . . . . . 79

$\S$ 7. Verzweigung der Farne . . . . . . . . . . . . . . . . . . . 85

$\$$ 8. Equisetum . . . . . . . . . . . . . . . . . . . 90

$\S 9$. Allgemeines über die Verzweigung der Samenpflanzen . . . . . . . . . 95

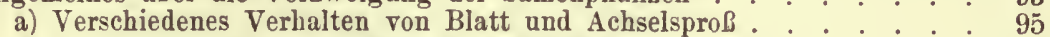

b) Die Bedeutung der axillären Verzweigung . . . . . . . . . . 97

$\S 10$. Dichotome Verzweigung und kongenitale Sympodienbildung bei Samenpflanzen 100
a) Sproßachsen . . . . . . . . . . . . . . . . . 100

b) Wurzeln . . . . . . . . . . . . . . . . . . . . 104

c) Blätter $: \div 0104$

$\S 11$. Weitere Beispiele für eigenartige Verzweigungen . . . . . . . . . 105

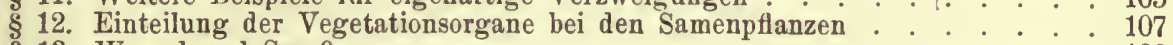

§ 13. Wurzel und SproB

1. Wurzelträger der Selaginellen . . . . . . . . . . . . . 110

§ 14. Blatt und Sproß

$\S 15$. Die Gametangien . . . . . . . . . . . . . . . . . . . . 128

1. Ihre verschiedene Ausbildung . . . . . . . . . . . . . . . 128

2. Homologie der beiderlei Gametangien : 129

A. Differenzierung der männlichen und weiblichen Gametangien bei Thallophyten : . . . . . . 129

B. Die Gametangien der Archegoniaten . . . . . . . 130

I. Pteridophyten . . . . . . . . . . . . . . . . . 131

II. Bryophyten $\cdots+\cdots$

1. Lebermoose . . . . . . . . . . . . 132

2. Laubmoose . . . . . . . . . . . . . . . 135

§ 16. Sporangien . . . . . . . . . . . . . . . . . . . 136

$\S 17$. Sexueller Dimorphismus

I. Allgemeines, Verschiedenheit ganzer männlicher und weiblicher Pflanzen 137

II. Einzelfälle; Verschiedenheit in der Ausbildung einzelner Teile. . . 142

Thallose Lebermoose . . . . . . . . . . . . . 145

Foliose Lebermoose und Laubmoose . . . . . . . . . . . . 148

Pteridophyten. A. Geschlechtsgeneration . . . . . . . . . . 149

B. Ungeschlechtliche Generation . . . . . . . . . . 151

Monocotylen . . . . . . . . . . . . . . . . . 154

Dicotylen . . . . . . . . . . . . . . . . . 158

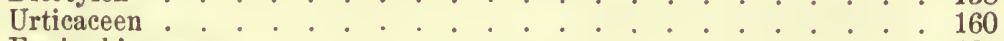

Euphorbiaceen. . . . . . . . . . . . . . . . . . . . 164

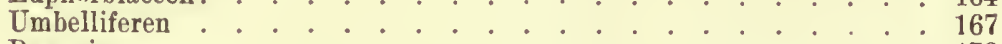

Begonia . . . . . . . . . . . . . . . . . 170

Valerianaceen . . . . . . . . . . . . . . . 173

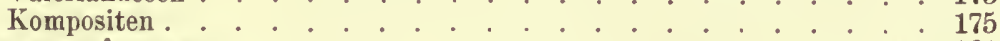

Zusammenfassung . . . . . . . . . . . . . 183

\section{Dritter Abschnitt.}

\section{Symmetrieverhältnisse.}

§ 1. Einleitung . . . . . . . . . . . . . . . . . . 185

§. Allgemeines über Stellungsverhälttnisse der Organe an radiären Achsen : 193

3. Regel der Äquidistanz, Quirlbildung... . . . . . . . . . . . 197

$\S$ 4. Pflanzen mit Wirtelstellung, welche Übergänge zu dorsiventraler, spirotropher oder bilateraler Ausbildung zeigen . . . . . . . . . . . . . . 199

\$ 5. Die zerstreute (spiralige) Blattstellung der Dikotylen. . . . . . . . . . . . . 203

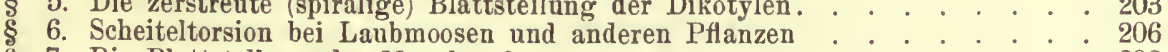

\$ 7. Die Blattstellung der Monokotylen . . . . . . . . . . . . . 208

$\S$ 8. Biologische Bedeutung der häufigsten ${ }_{n}$ spiraligen "Blattstellungsverhältnisse an radiären Sprossen. . . . . . . . 212

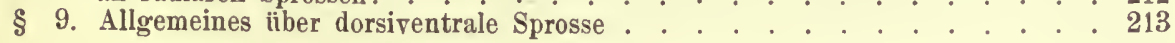


1. Verschiedener Ban von Ober- und Unterseite.

2. Symmetrie und Ernährung. 215 Einkrümmung des Vegetationspunktes, Beziehungen zum Muttersproß

§ 10. Kletternde und kriechende Sprosse . . . . . ., 220

\$ 11. Dorsiventrale Ausbildung der Seitensprosse . . . . . . . 223

\$12. Allgemeine Bemerkungen über Anisophyllie . . . . . . . . . . 229

13. Anisophyllie bei Laubmoosen . . . . . . . . . . . . . . . 231

$\$$ 14. Anisophylle Lebermoose . . . . . . . . . . . . . . . . 233

\$15. Anisophylle Lycopodinen . . . . . . . . . . . . . . . . . 236

A. Lycopodium . . . . . . . . . . . . . . . . . 236

B. Selaginella . . . . . . . . . 242

$\S 15$ a. Anisophyllie bei Coniferen . . . . . . . . . . . . . . . . 246

§ 16. Anisophyllie bei Angiospermen . . . . . . . . . . . . . . 248

A. Die laterale Anisophyllie . . . . . . . . . . . . . . . 248

B. Habituelle Anisophyllie . . . . . . . . . . . . 249

I. Urticaceen . . . . . . . . . . . . . . . . . 249

II. Melastomaceen . . . . . . . . . . . . . 226

III. Acanthaceen

§ 17. Allgemeines über asymmetrische Blätter . . . . . . . . . . . 257

18. Blattasymmetrie bei Begonia . . . . . . . . . . . . . . . 260

19. Blattasymmetrie bei Holzpflanzen . . . . . . . . . . . . . 263

20. Asymmetrie bei zusammengesetzten Blättern . . . . . . . . 265

21. Asymmetrische Teilblättchen . . . . . . . . . . . . . . 266

$\$ 22$. Asymmetrische Nebenblätter . . . . . . . . . . . . . . 269

23. Größenverschiedenheit der Blatteile untereinander . . . . . 272

$\$ 24$. Terminologisches über die Symmetrie im anatomischen Bau des Blattes 273

$\$ 25$. Bifaziale Blätter mit dorsiventralem oder invers dorsiventralem Bau 273

$\$ 25$ a. Äquifaziale Blätter .. . . . . . . . . . . . . . . 277

§ 26. Unifaziale Blätter . . . . . . . . . . . . . . . . . . 278

§ 27. Symmetrieverhältnisse von Bliiten . . . . . . . . . . . . . 290

a) Die verschiedenen Formen der Bliutensymmetrie . . . . . 290

b) Physiologische Gruppen . . . . . . . . . . . 296

c) Bedentung dorsiventraler Blüten . . . . . . . . . . . 297

§ 27 a. Dorsiventrale Infloreszenzen. .501

ऽ 28. Symmetrieverhältnisse der Wurzelı . . . . . . . . . . . 306

Vierter Abschnitt.

\section{Umbildung, Verkiinmerung, Verwachsung, Teilung.}

I. Organumbildung. A. Die normale Umbildung . . . . . . . . . 313

$\S$ 1. Allgemeines über den Begriff Umbildung oder Metamorphose . . . 313

$\$ 2$. Umbildungen ron Blattorganen . . . . . . . . . . . . . 317

\$. Umbildungen von Sprossen und Wurzeln . . . . . . . . . . . 321

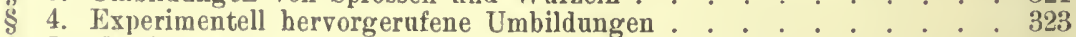

$\S$ 5. Umbildung oder Ersatz?. . . . . . . . . . . . . . . . 325

I. B. Abnorme Umbildungen (MiBbildungen) und ihre Bedeutung für die Auf-

fassung der normalen Organbildung . . . . . . . . . . . . . 327

§ 6. Allgemeines iiber abnorme Umbildung . . . . . . . . . . . . . . . . 327

$\$$ 7. Bedeutung der Mißbildungen für die Organographie. . . . . . . 328

8. Bedinguugen für das Auftreten abnormer Umbildungen . . . . 333

\$ 9. Abnorme Umbildungen durch direkte Änderung der Außenbedingungen 336

\$10. Mißbildungen veranlaßt durch Einwirkung parasitischer Organismen 337

1. Durch Pilze reranlaßte Umbildungen . . . . . . . . 337

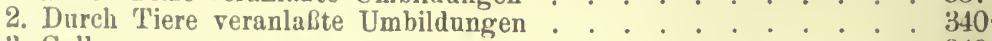

3. Gallen

II. Verkil mmerung . . . . . . . . . 345

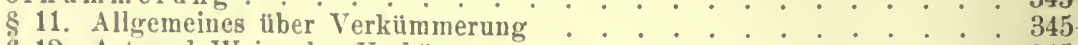

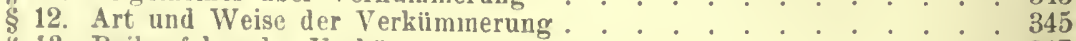

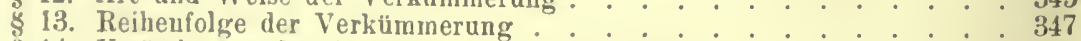

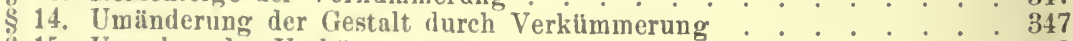

15. Ursachen der Verkímmerung.

§16. Die morphologische Bedeutung der verkümmernden Organe . . . 350 
III. Verwachsung und Spaltung . . . . . . . . . . . . . . . 351

\$17. Verwachsung . . . . . . . . . . . . . . . . . 351

§ 18. Spaltung. . . . . . . . . . . . . . . . . . . . 354

Fünfter Abschnitt.

\section{Verschiedenheit der Organbildung auf verschiedenen Entwicklungsstufen: Jugendformen und Folgeformen.}

$\S$ 1. Einleitung

$\S$ 2. Verschiedenheit in der Blattanordnung und im physiologischen $\dot{V}$ erhalten vou Jugend- und Folgeformen

3. Homoblastische und heteroblastische Entwicklung.

$\$$ 4. Verschiedene Dauer der Jugendform . . . . . . . . . . . . 362 Beispiele von Pflanzen mit Ausfall bestimmter Entwicklungsstadien ohne Verlängerung der Jugendform

§ 5. Ausfall von Folgestadien verknüpft mit starker Entwicklung der Jugendstadien aus ninnern" Gründen . . . . . . . . . . . . 368

§ 6. Wiederholung der Folgestadien . . . . . . . . . . 372

$\S$ 7. Auftreten von Jugendformen bei normalen Seitensprossen und bei Adventivsprossen .

$\begin{array}{ll}\S & \text { 8. Thallophyten . . } \\ \S & 9 \text {. Gefäßkryptogamen }\end{array}$

A. Farne . . . . . . . . . . . 377

B. Equiseten . . . . . . . . . . . . . 382

C. Lycopodinen . . . . . 382

§ 10. Gymnospermen . . . . . . . . . . . . . . . . 383

1. Pinus . . . . . . . . . . . . . . . . 383

2. Cupressineen i. a. . . . . . . . . . . . . . . . . . . . 384

§ 11. Angiospermen . . . . . . . . . . . . . . . . . . . . 387

A. Kletterpflanzen : . . . . . . . . . . . . . . . . . . . . . . 388

1. Wurzelkletterer . . . . . . . . . . . . 388

2. Ranken- und Schlingpflanzen . . . . . . . . . . . . 393

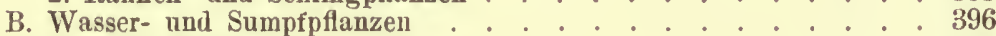

C. Xerophile Pflanzen . . . . . . . . . . . . . . . . . 398

D. Schattenpflanzen. . . . . . . . . . . . . . . . . . . . 402

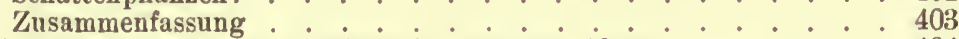

$\S$ 12. Wiederauftreten der Jugendform in späterem Alter . . . . . . . 404

§13. Generationswechsel . . . . . . . . . . . . . . . . . . . 413

a) Verhalten der zwei Generationen zueinander

b) Cytologische und morphologische Verschiedenheit zwischen Sporophyt und Gametophyt . . . . . . . . . . . . 4 414 Künstliche Hervorrufung von Aposporie . . . . . . . . . 421

\section{Sechster Abschnitt.}

Die Abhïnglgkeit der Organbildung von innern und ïßßern Faktoren.

I. Beeinflussung der Gestaltung durch Innenbedingungen

§ 1. Mechanische Beeinflussungen : . . . . . . . . . 426

2. Beeinflussung durch die Gestalt des Mutterorgans : . . . : . . 427

$\S$ 3. Beeinflussung der Gestalt durch den Ort . . . . . . . . . . . 429

Heteranthie . . . . . . . . . . 430

Heterocarpie . . . . . . . . . 431

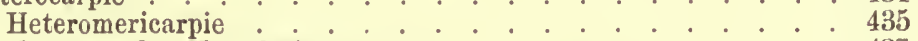

§ 4. Die Bedeutung der Korrelationen

II. Die Beeinflussung der Symmetrie und der Organausildung

durch Außenbedingungen. . . . . . . 446

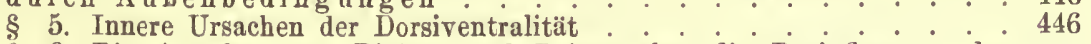

$\S$ 6. Die Angaben von Ricôme und Peirce über die Beeinflussung der Symmetrie durch äußere Faktoren . . . . . . . . . . . . 449

§ 7. Einseitige Ausbildung der Fruchtkörper von Pilzen . . . . . . . 451

8. Beeinflussung der Gestaltung bei Algen und Flechten . . .. . . 456

\$. Bryophyten. . . . . . . . . . . . 459

$\$ 10$. Pteridophyten . . . . . . . . . . . . . . 470 
\& 11. Samenpflanzen: Einfluß der Schwerkraft .

12. Samenpflanzen: Beeinflussung der Organverteilung bei dorsiventralen Sprossen durch das Licht. . . . . . . . . . . . . . . . . 477

§ 13, Oberflächenvergrößerung durch Lichteinfluß bei Samenpflanzen . . . 483

$\S$ 14. Die Bedingungen für das Zustandekommen der Anisophyllie. . . . 487

Bryophyten . . . . . . . . . . . . . . 487

Pteridophyten . . . . . . . . . . . . . . . . 487

Sempervivum . . . . . . . . . . . . . . . . 491

Laterale Anisophyllie von Dikotylen . . . . . . . . . . . 492

Habituelle Anisophyllie . . . . . . . . . . . . . . . 492

§ 15. Beeinflussung der Dorsiventralität im Blattbau : . . . . . . . 494

Namen- und Sachregister . . . . . . . . . . . . . . . 498 


\section{Einleitung.}

\section{Aufgaben der Organographie erörtert an einem Einzelfalle.}

Die Aufgaben, welche sich das vorliegende Buch stellt, lassen sich besser als durch eine lange allgemeine Auseinandersetzung durch Besprechung eines bestinmmten Beispieles erläutern.

Die Vegetationsorgane der Samenpflanzen sind der Hauptsache nach entwickelt als Wurzel und Sproß, deren wichtigste Funktionen wir als bekannt voraussetzen kömnen. Aber nicht bei allen Samenpflanzen finden wir diese beiderlei Organe. Sieht man sich die Gattung Genlisea, z. B. die in Brasilien stellenweise nicht seltene G. ornata oberflächlich an, so glaubt man auch bei ihr dieselbe Gliederung wiederzufinden, wie bei der Mehrzahl der Samenpflanzen. Sie besitzt eine Rosette dicht gedrängter, sich nur wenig über den Boden erhebender, spatelförmiger, mit Schleim überzogener Blätter. In Boden verlaufen lange weißliche Gebilde, die man zunächst fïr Wurzeln hielt: der Entdecker der Pflanze schrieb ihr eine "Radix fibrosa" z11.

Solange es sich, wie in der ersten Zeit der systematischen Botanik, nur darum handelte, gewissermaßen das Inventar der auf der Erde vorhandenen Pflanzen aufzunelımen, genügte schon die Untersuchung der Blütenbildung und die erwähnte oberflïchliche Beschreibung der Vegetationsorgane, um Genlisea in das System einzuordnen und als eine mit der auch in Europa vertretenen Gattung Utricularia verwandte Pflanze zu erkennen.

Aber schon eine vertiefte Auffassung der Aufgabe der Systematik erfordert eine Kenntnis des Gesam taufbaues der Pflanze und sucht die Gestaltungsverhältnisse nicht als Einzel tatsachen zu beschreiben, sondern in Beziehung zu setzen mit denen verwandter Pflanzen, mit anderen Worten sie zu verstehen. Denn Verstehen heißt Einzelwahrnehmungen miteinander verkniipfen und so die Auffindung von Gesetzmäßigkeiten anbahnen.

Die Organographie kann sich auch damit nicht begnügen. Sie fragt weiter, ob die Gestaltung in Bezieliung steht zu den Lebensverhältnissen und wie sie zustande gekommen ist.

Zur Beantwortung der ersten dieser Fragen ist zunächst die Kenntnis der Standortsverhältnisse notwendig.

Genlisea wächst in einem feuchten, moorigen Boden (nicht, wie aus Analogie mit europäischen Utricularien eine Zeitlang angenonmen wurde, im Wasser) zusammen mit anderen Pflanzen, z. B. Lycopodien und Cyperaceen, deren Wurzeln den Boden durchziehen. Genlisea hat aber keine Wurzeln. Was so aussieht, ist in Wirklichkeit etwas ganz anderes. Die

Goebel, Organographie der Pflanzen. 2. Aufl. Allgem. Teil. 
genauere Betrachtung erkennt nämlich die scheinbar wurzelähnlichen Organe als höchst merkwürdige langgestielte (st Fig. 1) zarte, mit zwei langen gedrehten Armen (A Fig. 1) versehene Schläuche, von denen in Fig. 1 nur ein einziger erhalten ist, da sie beim Herauspräparieren aus der Erde sehr leicht abreißen.

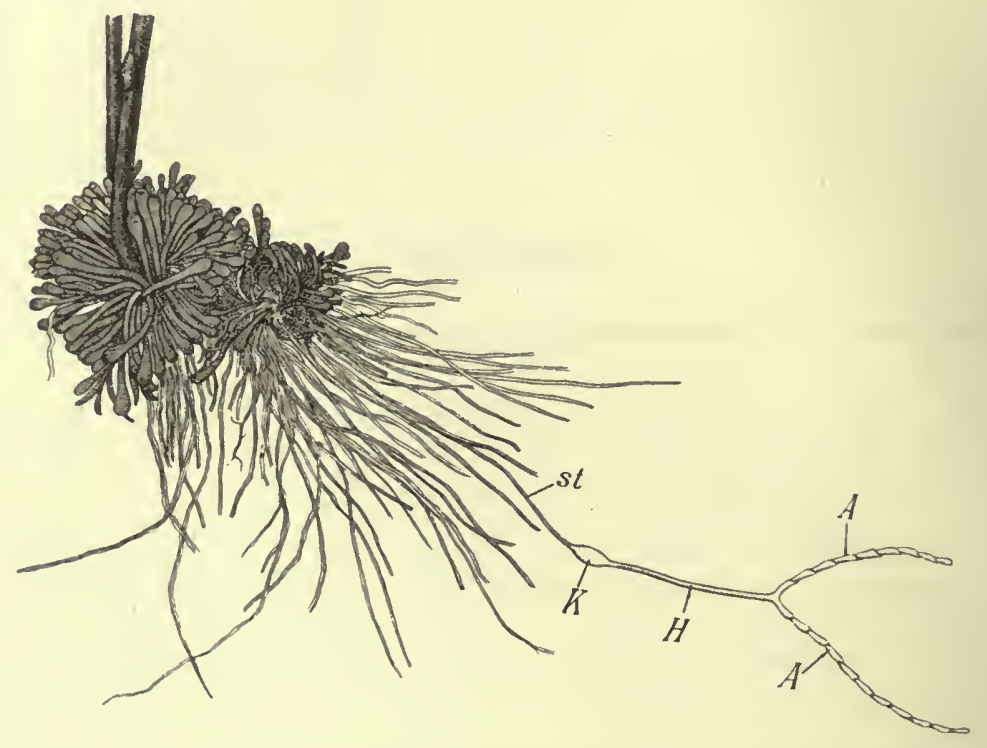

Fig. 1. Genlisea ornata. Habitusbild einer freipräparierten Pflanze. Die zwei Blütenstände sind nur in ihrem untersten Teile wiedergegeben. Die Schlauchblätter, welche die Stellen der Wurzeln vertreten, sind alle abgerissen, mit Ausnahme eines einzigen, an welchem man den Stiel $(s t)$, den Kessel $(K)$, den Halsteil $(H)$ und die Arme $(A)$ erkennt.

Die nächste Frage ist: Was sind die Schläuche morphologisch, d. h. wie fügen sie sich in den Gesamtaufbau der Pflanze ein? Sind sie etwa abweichend gestaltete Wurzeln, denen sie ja durch ihre Farbe und unterirdische Lebensweise gleichen; hat ein anderes Organ der Pflanze diese sonderbare Form angenommen, oder liegt hier ein bei anderen (namentlich bei den verwandten) Pflanzen nicht vorkommendes ganz neues Gebilde vor?

Wir werden später sehen, welche Hilfsmittel uns zur Entscheidung dieser Fragen zu Gebote stehen. Hier sei diè Beantwortung vorweggenommen. Die Untersuchung zeigt sofort, daß die Schläuche keine Wurzeln sein können. Sie weichen in ihrem Bau und ihrer Entstehung ganz und gar von Wurzeln ab. Die Entwicklungsgeschichte ergibt, daß sie ganz wie Blätter exōgen am Vegetationspunkt entstehen, daß schon der Keimling ein Laubblatt und diesem gegeniiberstehend ein Schlauchblatt hervorbringt und daß auch an älteren Keimpflanzen die Schläuche ( $S j$ Fig. 2) im Wechsel mit Blättern an der Sproßachse auftreten. Mit dem der Blätter stimmt, wie hier nicht näher ausgeführt werden kann, auch der anatomische Bau der Schläuche überein, während er von dem der Wurzeln ganz abweicht. Außerdem zeigt der Vergleich mit der verwandten Gattung Utricularia, daß auch hier Schlauchblätter - freilich von anderer Gestalt vorkommen. Damit haben wir die "Homologie" der Schläuche festgestellt. 
Wir betrachten sie als zu den Blättern gehörig, und nennen sie „umgebildete" Blätter.

Aber wir können unsere Betrachtung mit dieser Feststellung nicht abschließen. Es drängen sich sofort weitere Fragen auf: zunächst die: wie können denn so zarte Blattgebilde in den Boden eindringen und in ihm mehrere $\mathrm{cm}$ weiter wachsen? Ein Blatt mit der gewöhnlichen Wachstumsart wäre dazu sehr ungeeignet. Denn bei den "typischen" Blättern der Samenpflanzen erlischt das Wachstum an der Spitze zuerst, während an der Basis noch Streckung stattfindet. Ein solches Blatt müßte beim Vordringen im Boden starke Verbiegungen erleiden. Die Untersuchung zeigt nun, daß die Genliseablätter im Gegensatz zu denen der meisten anderen Dikotylen ein lange andauerndes Spitzenwachstum zeigen (auch bei den WVurzeln ist das Wachstum kurz hinter der Spitze lokalisiert). Dieses werden wir als eine der in $\mathrm{n}$ er en Bedingungen für die Möglichkeit eines Eindringens in den Boden und somit für das Vorkommen derartiger Blätter überhaupt zu betrachten haben. Außerdem sehen wir, daß die "Arme" anfangs sehr spitz sind ( $S a$, Fig. 2) und dann die Gestalt eines Bohrers annehmen, der sich sozusagen in den Boden. hineinschraubt. Nun verstehen wir einigermaßen, wie das Blatt in den Boden eindringen kann. Wir iiberlassen der Physiologie die Frage, ob negativer Heliotropismus, positiver Geotropismus oder andere Reize die Blätter veranlassen in das Substrat hineinzuwachsen. Für uns kommt vielmehr zunächst das in Betracht, daß diese Blätter der Genlisea ermöglichen, ohne

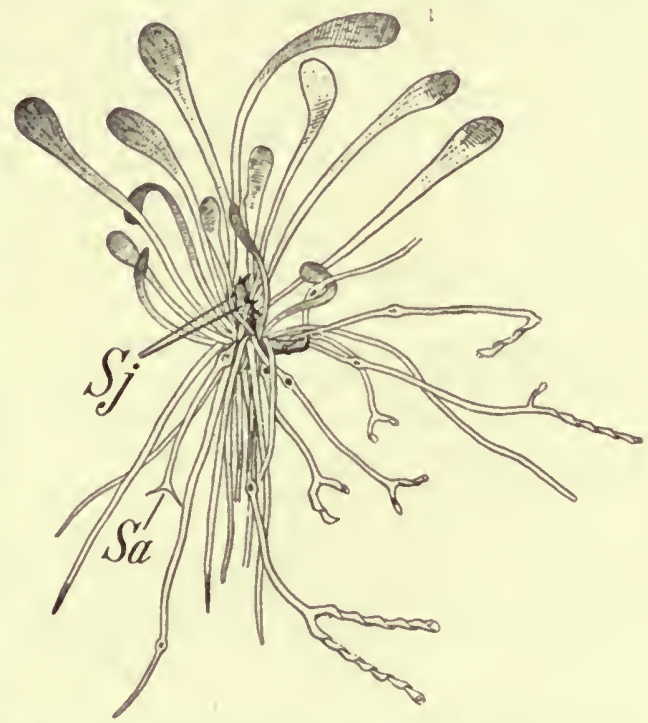

Fig. 2. Genlisea ornata, junge Pflanze, etwa zweimal vergrößert. Von der dunkler gehaltenen, unten umgebogenen Sproßachse gehen Laubblätter und teils ausgewachsene, teils noch junge $(S a$ nnd śj) Schlauchblätter aus, von den älteren sind einzelne Teile abgerissen.

Wurzeln auszukommen. Denn

die ersteren dienen statt der letzteren als Haftorgane und als Organe fiir Nahrungsaufnahme. Zweifellos ist dies ein abgeleitetes Verhalten. Denn Wurzeln sind bei allen Samenpflanzen sicher ursprünglich vorhanden. Und auch die mit Genlisea verwandte Gattung Pinguicula besitzt Wurzeln. Es ist also anzunehmen, $\mathrm{da} ß$ auch Genlisea von einer ursprünglich mit wirklichen Wurzeln versehenen Pflanze sich ableitet.

Eine genauere Betrachtung zeigt aber ferner, daß die Schlauchblätter von Genlisea nicht einfach (wie typische Erdwurzeln), nur Wasser und darin gelöste Salze aufnehmen. Sie stellen vielmehr höchst merkwïrdig gebaute, geradezu raffiniert konstruierte Tierfallen dar, in welche kleine Tiere sehr leicht hinein, aus denen sie aber nicht wieder herausgelangen können ${ }^{1}$ ).

1) Vgl. Goeber, Pflanzenbiolog. Schilderungen S. 121. 
Soweit können wir die Analyse auch an totem Material, etwa an einem Genlisea enthaltenden, in Alkohol aufbewahrten Erdklumpen führen. Die Frage, ob die gefangenen Tiere verdaut werden, ob sie für die Pflanze nützlich oder unentbehrlich sind, läßt sich nur an lebenden Pflanzen entscheiden. Doch lassen die für verwandte Pflanzen experimentell ermittelten Tatsachen Analogieschlüsse zu, deren wir uns auch sonst in ausgedehntem Maße bedienen müssen. Wir setzen z. B. roraus, daß die Chlorophyllkörper bei allen Pflänzen die Fähigkeit haben, Kohlensäure zu zerlegen, obwohl dies experimentell nur bei rerhältnismäßig wenigen bewiesen ist.

Wir können also einstweilen annehmen, Genlisea ziehe von dem Tierfang wie andere Lentibulariaceen Nutzen. Aber wie kommt denn die Pflanze zu einer solchen Ernährungsweise? Ist das ein "Zufall", oder eine „zweckmäßige Anpassung:"? Daß die Standortsrerhältnisse nicht direkt dafür maßgebend sein können (in der Art, daß anf den betreffenden Örtlichkeiten nur Pflanzen, welche die Fähigkeit des Tierfangs besitzen, wachsen können), geht aus der oben mitgeteilten Tatsache hervor, daß der Boden, auf welchem Genlisea wächst, ron anderen bewurzelten Pflanzen bewohnt ist $^{1}$ ). Genlisea ist also nicht etwa auf Standorte angewiesen, die anderen Pflanzen nicht zugänglich sind, kann auch diese im „Kampf ums Dasein“ nicht verdrängen. Damit stoßen wir auf ein Grundpróblem der Organographie, nämlich das: Ist die Mannigfaltigkeit der Organ bildung größer als die Mannigfaltigkeit der Lebensbedingungen, ist sie also, wenn wir nur auf die Funktionen Rücksicht nehmen, eine zufällige, oder ist sie eine notwendige?

Wenn wir diese Frage zu beantworten versuchen, dürfen wir die sozialen Beziehungen der Pflanzen nicht außer acht lassen. Könnte doch gerade der Tierfang in einem von anderen Pflanzen dicht besiedelten Boden Genlisea die Existenz ermöglichen, indem er sie von dem WVettbewerb um die Bodensalze wenigstens zum Teil unabhängig macht.

Wer lebende Genliseapflanzen zur Verfügung hat, wird weiter untersuchen können, ob die Schlauchblätter in ihrem Auftreten von anderen Bedingungen abhängig sind, als die gewöhnlichen Laubblätter (was bei Utricularia der Fall ist).

Es sind also eine Anzahl nicht leicht zu lösender Probleme, welche sich an die Betrachtung dieser Schlauchblätter knüpfen. Ferner sehen wir, daß bei Genlisea die TVurzeln ganz und gar verkiimmern. Die beliebte „Erklärung": ein Organ rerkiimmert, wenn es funktionslos geworden ist, bietet ohne experimentelle Belege nichts als eine Umschreibung der Tatsache, daß z. B. die WVurzelbildung unterbleiben kann, weil die physiologische Funktion der WVurzel ersetzt wird durch ein anderes Organ. Es ist aber ein großer Unterschied, ob es sich dabei $\mathrm{mm}$ ein ".post hoc" oder" „propter hoc" handelt. D. h. also, ob ich sage, die (an sich urspriinglich durchaus funktionsfähigen) TVurzeln k ön n e n - aus uns unbekannten Grïnden verkiimmern, weil für sie Ersatz da ist, oder sie verkiimmern deshalb, weil sie funktionslos geworden sind. Letzteres ist nur eine unbewiesene Annalıme; TVurzeln und Schlanchblïtter könnten auch nebeneinander funktionieren und es ist kein Grund vorhanden anzunelımen, daß äußere Bedingungen für das Verschwinden der WV urzeln maßgebend gewesen sein mïissen.

Jedenfalls bietet uns Genlisea ein Beispiel fiir die Mannigfaltigkeit, in der die Organbildung ror sich geht, für die Tatsache, daß teleo-

1) Ob diese etwa Mykorrhizen besitzen, wie man rernuten könnte, wurde nicht näher untersucht. 
logisch gesprochen, ein und dieselbe Funktion (hier die Festhaftung im Boden und die Nahrungsanfnahme aus ihm) in verschiedener Weise ror sich gehen kann.

Auch bei anderen Pflanzen treten uns dieselben Fragen immer wieder entgegen. Vielfach hat man sie beantwortet ron rein theoretischen Voraussetzungen oder Verallgemeinerungen ausgehend.

"Was wirklich ist, ist vernünftig." - Dieser Satz auf Lebewesen übertragen, ist ein mehrdeutiger. Man kann ihn so auffassen, daß die Mannigfaltigkeit der Gestaltung der Mannigfaltigkeit der Lebensbedingungen entspricht, $\mathrm{da} ß$ also alle Gestaltungsverhältnisse einen bestimmten Nutzen haben müssen. Dies ist im wesentlichen die Meinung der naiven Teleologie, wie sie z. B. von Chr. Konr. Sprengel vertreten wurde und die des - kaum minder naiven Neodarwinismus Wallace'scher Prägung. Es ist aber auch möglich, daß die Natur in ihren Gestaltungen sozusagen künstlerisch verfährt, d. h. frei und ungebunden, namentlich ohne Rïcksicht auf den Nutzen Gestaltungen herrorbringt, teils nuitzliche, teils gleichguiltige, teils unvorteilhafte. Dies ist u. a. der Standpunkt DARwis's, der ausdrücklich betont, daß auch für das Leben an sich gleichgültige Gestaltungsverhältnisse sich konstant erhalten können.

Es braucht kaum betont zu werden, wie schwierig bei unseren mangelhaften Kenntnissen der Lebenserscheinungen dieses Problem zu entscheiden ist. Es muß aber kurz erörtert werden, was in einem der folgenden Kapitel geschehen soll. Denn es hängt die organographische Betrachtung wesentlich $a b$ von dem Standpunkt, den man zu diesen Problemen einnimmt. Man wird sich hüten müssen, solchen fundamentalen Problemen mit feststehenden, aber sehr häufig gedankenlos wiederholten Formeln gegenübertreten zu wollen.

Zunächst handelte es sich darum, die einzelnen Formen der Organbildung kennen zu lernen. Diese Aufgabe ist zwar noch nicht vollständig gelöst - nicht nur sind gewiß manche Pflanzenformen uns unbekannt; auch der Formwechsel der schon bekannten ist noch vielfach zu erforschen. Immerhin wird die beschreibende und einordnende Tätigkeit, welche uns aus der Mannigfaltigkeit der Pflanzenformen erwächst, früher oder später zum Abschluß gelangen. Ein endloses Problem aber ist gegeben, wenn wir die Mannigfaltigkeit $\mathrm{zu}$ verstehen, also Zusammenhänge $\mathrm{zu}$ finden versuchen, Zusammenhänge der Formen untereinander und Zusammenhänge mit den Lebensbedingungen. $\mathrm{Da} \beta$ es bei solchen Versuchen nicht ohne Irrtiimer abgehen kann, ist selbstrerständlich. Irrtïmer im einzelnen sind meist leicht zu verbessern. Schwerwiegender sind Irrtïmer in der Gesamtauffassung. Nur ein solcher Irrtum sei hier kurz erwähnt.

Zur Orientierung in der Mannigfaltigkeit war man genötigt, allgemeine Begriffe zu bilden, gewissermaßen Schubladen, in welche man die Erscheinungen einordnete. Diese Begriffe hielt man dann für Gesetze, nach denen sich die Mannigfaltigkeit der Gestaltungen ordnen sollte. Was nicht in die Schubladen hineinpaßte, schnitt und zerknitterte man (aber nur im Kopfe) so lange zurecht, bis man sagen konnte, „es geht hinein“. Es ist diese Annalıme, daß die Mannigfaltigkeit der Gestaltungsverhältnisse der Lebewesen sich nach unseren Begriffen richten müsse, daß man z. B. die Eigenschaften eines Blattes ableiten könne aus dem „Begriffe des Blattes", eine der merkwürdigsten Äußerungen menschlichen Größenwahnes. Wir werden dagegen sehen, daß alle Begriffe nur subjektive Zusammenfassungen sind, Hilfsmittel zur Orientierung. 
Zunächst ist es ron Wichtigkeit, die Tragweite dieser Begriffe zu untersuchen. Daran schließt sich dann die Darstellung des Zustandekommens der Mannigfaltigkeit der Gestaltung.

Demgemäß gliedert sich der allgemeine Teil in folgende Abschnitte:

I. Zusammenhang zwischen Form und Funktion.

II. Die Organbildung auf den verschiedenen Stufen des Pflanzenreiches.

III. Die Symmetrieverhältnisse des Pflanzenkörpers.

IV. Umbildung („Metamorphose“), Verkümmerung, Verwachsung, Teilung.

V. Einzelentwicklung und Generationswechsel.

VI. Die Abhängigkeit der Organbildung ron inneren und äußeren Bedingungen. 


\section{Erster Abschnitt.}

\section{Beziehungen zwischen Gestalt und Funktion.}

\section{§ 1. Morphologie und Organographie.}

Das Verhältnis zwischen Morphologie und Organographie zu erörtern wird um so weniger iiberflüssig sein, als selbst die Verwendung des letzteren Namens als nicht richtig bezeichnet wurde $\left.{ }^{1}\right)$. Freilich man dürfte dann wohl auch nicht ron "Organismen" sprechen. Ein solcher Standpunkt ist erklärlich als Reaktion gegenüber manchen der exakten Grundlage entbehrenden teleologischen Deutungen. Aber, um ein triviales Beispiel zu benutzen: Die menschliche Nase ist unzweifelhaft ein Organ für den Gasaustausch und die Geruchswahrnehmung auch dann, wenn die verschiedenen Formen der Nasen sich als biologisch gleichgültig erweisen sollten (was sie tatsächlich durchaus nicht immer sind, da sie z. B. bei der sexuellen Auswahl eine Rolle spielen können).

Und wir sehen, daß selbst die einfachsten Lebewesen nicht aus homogener Substanz bestehen, sondern aus Teilen, die einander gegenseitig bedingen und deren Veränderungen so verlaufen, daß sie zusammen ein Ganzes bilden. Ebenso - nur noch weit auffallender - verhalten sich die höheren Lebewesen. Daß ein Laubblatt anders funktioniert als eine Wurzel und demgemäß für das Gesamtleben der Pflanze eine andere Bedeutung hat, wird niemand bestreiten, obwohl, wie wir in der Einleitung sahen, ein Blatt auch die Funktion einer Wurzel übernehmen kann und umgekehrt. Sobald ich aber nach den Funktionen frage, habe ich es mit Organen zu tun.

Allerdings hat man in der Morphologie zunächst von den Funktionen abstrahiert. Was an den Organismen zunächst auffiel, war ja die verschiedene Gestalt, die zugleich die Mittel bot, sie zu unterscheiden und sie in Gruppen anzuordnen. Dazu war auch eine bestimmte Terminologie notwendig. Diese nimmt in den alten Lehrbüchern die Stelle des Teiles der Botanik ein, den wir seit GoEvHE ${ }^{2}$ ) als Morphologie bezeichnen. "Es hat sich daher auch in dem wisssenschaftlichen Menschen zu allen Zeiten ein Trieb hervorgetan, die lebendigen Bildungen als solche $\mathrm{zu}$ erkennen, ihre äußeren, sichtbaren, greiflichen Teile im Zusammenhange zu er-

1) F. A. F. C. Wext, Über Zwecklosigkeit in der lebenden Natur. Biolog. Zentralblatt, Bd. XXVII (1907), p. 268.

2) GoETHe, Bildung und Umbildung organischer Naturen (Сотта'sche Gesamtausgabe 1869,36 . $\mathrm{Bd}$.). 
fassen, sie als Andeutungen des Innern aufzunehmen, und so das Ganze in der Anschauung gewissermaßen zu beherrschen.... Man findet daher in dem Gange der Kunst, des Wissens und der Wissenschaft mehrere Versuche, eine Lehre zu gründen und auszubilden, welche wir die Morphologie nennen möchten." Damit ist zugleich gesagt, daß es sich bei der Morphologie nicht mehr um. eine bloße Unterscheidung und Benennung der äußeren Teile der Pflanzen handeln kann. Ihr ist die Kenntnis der verschiedenen Erscheinungsformen der Gliederung des Pflanzenkörpers nur Mittel zum Zweck. Sie sucht nicht das einzelne, sondern die Beziehungen der Tatsachen untereinander. Eine Terminologie kann man auch auf Grund der Untersuchung toter Pflanzen aufstellen. Die Morphologie aber hat es, wie Gowthe schon hervorhebt, mit "le be ndigen Bildungen" zu tun, welche in steter Veränderung begriffen und den Einwirkungen der Außenwelt unterworfen sind. Es handelt sich also mit anderen Worten um den Teil der Lebenserscheinungen, der in den äußeren Gestaltungsverhältnissen seinen Ausdruck findet.

Wenn es nur um die Unterscheidung der einzelnen Arten der Vögel zu tun ist, kann ich die Gestaltung des Vogelkörpers auch an totem Material studieren, ohne mich darum zu kümmern, womit es zusammenhängt, daß der Albatros einen riesigen, der Kiwi einen ganz rückgebildeten Flügel hat. Wenn ich aber diese Tiere mit GowruE als "lebendige Bildungen" betrachten will, so tritt die Frage nach dem Zusammenhang von Gestalt und Funktion bzw. Lebensweise sofort in den Vordergrund.

Daß diese miteinander im Zusammenhang stehen, zeigt das oben gewählte Beispiel ohne weiteres: es ist klar, daß der Albatros seine hervorragende Flugfähigkeit seinen riesigen Flügeln verdankt, während der Kiwi nicht fliegt, sondern ein Laufvogel ist.

Wie ist aber der Zusammenhang zwischen Form und Funktion aufzufassen? In der ersten Auflage dieses Buches wurde ein Ausspruch Herbert Spencers ') zitiert: „Überall bestimmt die Struktur in beträchtlichem Maße die Funktion, und überall sind die Funktionen unaufhörlich tätig, die Struktur abzuändern. In der Natur sind beide untrennbar zusammenwirkende Faktoren, und die Wissenschaft kann keine wahre Erklärung der Natur geben, ohne ihr Zusammenwirken beständig im Auge zu behalten. Eine Darstellung der organischen Entwicklung nach ihren besonderen Eigentümlichkeiten muß im wesentlichen eine Darstellung der gegenseitigen Wirkungen von Struktur und Funktion aufeinander sein..."

$\mathrm{Ob}$ dieser Ausspruch zutrifft, bedarf der Prüfung. Denn ohne weiteres klar ist nur, daß die Struktur (im weitesten Sinne) die Funktion bedingt, wie wir das ja auch an jeder Maschine wahrnehmen. Dagegen fragt es sich, wieweit auch die Funktion auf die Struktur einwirken kann.

Es kommen hier folgende Möglichkeiten in Betracht: 1. Eine direkte Beeinflussung der Struktur findet z. B. statt in den von Tieren bekannten Fällen, wie bei der Verstärkung des geïbten Muskels, der Hautrerdickung an den stark in Ansprucl genommenen Stellen des menschlichen Fußes oder der Hand u. dgl. 2. Eine indirekte Beeinflussung ist speziell bei Pflanzen dadurch möglich, daß die Ausbildung eines im embryonalen Gewebe, z. B. am Vegetationspunkt oder im Cambium neu angelegten Organs beeinflußt werden kann durch die funktionelle Beanspruchung der älteren Triebe. Z. B. dann, wenn ein Sproß, der starker Transpiration aus-

1) Hrrbert Spexcer, Die Prinzipien der Biologie. Dentsche Ausgabe von B. Vetter, 2. Bd., p. 4. 
gesetzt ist, nun neue Blätter hervorbringt, in denen die Transpiration anders verläuft, als in den alten, weil sie eine andere Struktur besitzen. Sehen wir, wie weit für ein solches Verhalten Beispiele bekannt sind.

\section{§ 2. Ausbildung ron mechanischem Gewebe.}

Ein schönes Beispiel für „direkte Anpassung“ schien vorzuliegen in Heglers Angabe, daß die Tragfähigkeit von Pflanzenteilen sich infolge der Inanspruchnahime steigern lasse, $j a$ daß es dabei sogar zur Ausbildung vorher nicht vorhandener spezifisch mechanischer Zellformen kommen könne. Es wäre das zugleich ein Beispiel für den lamarckistischen Satz, daß das „Bedürfnis" als Reiz wirke. Leider haben sich diese Angaben aber nicht bestätigt, es ist eine Verstärkung des mechanischen Gewebes infolge von Zug nicht nachgewiesen.

Es ist hier nicht der Ort, auf eine Diskussion dieser Frage, sowie auf die verschiedene Ausbildung der mechanischen Gewebe auf der Ober- und Unterseite künstlich gebogener Pflanzenteile - die "Kamptotrophie" ${ }^{1}$ ) und "Geotrophie", einzugehen. Um eine durch direkt mechanische Inanspruchnahme bedingte Förderung der Ausbildung des mechanischen Gewebes kann es sich bei künstlich horizontal gehaltenen Blattstielen wohl kaum handeln, und wenn bei einem kiinstlich gekrümmten wachstumsfähigen Pflanzenteil die Wandverdickungen auf der konvexen Seite bei relatir kleiner Zellweite gefördert, auf der konkaven bei relativ großer Zellweite vermindert erscheinen, so liängt dies zwar

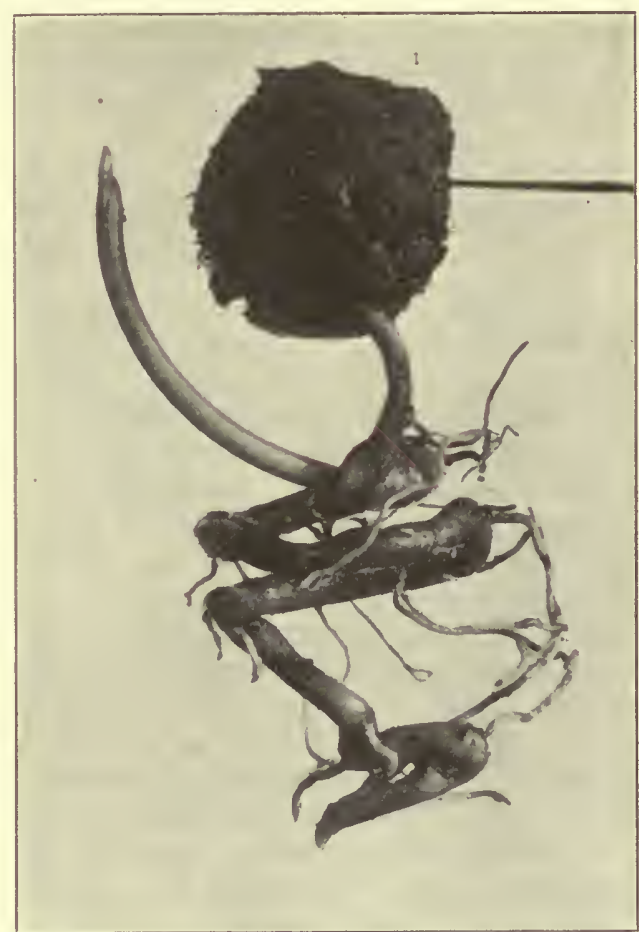

Fig. 3. Keimpflanze von Hyphaena ventricosa. Der Kotyledon steckt mit der Spitze noch im Endosperm, links die Stammknospe. Die Hanptwurzel ist (weil der Topf zu kurz war) schraubig gedreht. Nur auf der konvexen Außenseite entspringen Seitenwarzeln erster Ordnung.

vielleicht damit zusammen, daß auf der Konvexseite Zug-, anf der Konkarseite Druckspannung herrscht, aber es ist sehr wahrscheinlich, daß dies nicht durch die verschiedene Beanspruchung beider Seiten, sondern dadurch zustandekommt, daß durch die Krümmung eine verschiedene Stoffrer-

1) Vgl. Bücuer, Anatom. Veränderungen bei gewaltsamer Krümmung und geotrophischer Induktion. Jahrb. für wissensch. Botanik, 43 (1906), S. NeUnerT, Geotrophismus und Kamptotrophismus bei Blattstielen. Beitr. zur Biologie der Pflanzen. Begr. von F. Сонх, X (1911). 
teilung auf beiden Seiten zustandekommt ${ }^{1}$ ). Wir sehen nämlich, daß gekrümmte Pflanzenteile auch betreff der Organbildung sich rerschieden verhalten, daß also z. B. die in Fig. 3 abgebildete Wurzel nur auf der Konvexseite ihrer Krümmung Seitenwurzeln hervorgebracht hat; in diesem Falle kann es sich aber nicht um eine "funktionelle Hypertrophie" handeln. Eine solche ungleiche Stoffverteilung kann auch durch die Schwerkraft zustandekommen; so fanden z. B. Ewart und Masor, daß Rotholz - eine mechanisch besonders leistungsfähige Modifikation des Coniferenholzes - infolge der Schwerkraftswirkung (nicht durch Druck) auf der Unterseite der Cupressuszweige auftritt ${ }^{2}$ ).

Wie in diesem Falle eine Verstärkung der mechanischen Gewebe infolge bestimmter äußerer Reize, aber nicht infolge direkter Inanspruchnahme stattfindet, sehen wir auch sonst, daß der Faktor, dem ein bestimmtes Verhalten ,angepaBt ist", gar nicht immer derist, der es hervorgerufen hat.

\section{§ 3. Stellung der Archegonien am Farnprothallium, Einkrümmung geophiler Sprosse.}

Die Geschlechtsorgane der meisten Farne stehen auf der Unterseite der Prothallien. Diese Stellung ist vorteilhaft, weil hier am besten die Wassertropfen sich finden, welche zum Befruchtungsrorgange notwendig sind. Allein, die Geschlechtsorgane entwickeln sich nicht etwa auf der feuchteren Seite, ihre Stellung wird durch das Licht bestimmt, sie entstehen stets auf der Schattenseite; bei auf Wasser schwimmenden, von unten beleuchteten Prothallien auf der Oberseite, obwohl die Wahrscheinlichkeit der Befruchtung hier auf der Wasserseite größer wäre. Mit dem Lichte haben die Archegonien als solche nichts zu tun, bei zahlreichen anderen Pflanzen stehen sie auf der Lichtseite oder (wie z. B. bei den Lycopodien) rings um einen zylindrischen Körper herum; nur weil bei den dem Boden angeschmiegten Farnprothallien die Schattenseite zugleich die ist, welche die Befruchtung sichert, ist die Reaktion der Archegonien für sie vorteilhaft; wie kann aber ein "Bedürfnis" nach Wassertropfen ausgelöst werden durch eine Reaktion auf die Richtung der Lichstrahlen?

Dasselbe zeigen einige geophile Sprosse oder Blätter mit hakenförmiger Einkrümmung der Spitze. Diese Einkrümmung bedingt, daß nicht die Knospe, sondern ein älterer widerstandsfähigerer Sproßteil beim Durchwachsen durch den Boden vorangeht. Es können dann später die an der Sproßachse befestigten Blätter oder die Blattspreite ohne Beschädigung aus dem Boden herausgezogen werden. Diese Einkrümmung kann teils eine "autonome", teils eine von äußeren Einwirkungen bedingte sein. Bei den Blättern von Ranunculus acer ${ }^{8}$ ) tritt diese Einkrïmmung dann ein, wenn sie sich bei Lichtmangel entwickeln (Fig. 4), also auch oberhalb des Bodens. Es ist also nicht etwa die Berührung mit einem Hindernis, welche zu einer Reaktion führt, die das Hindernis leichter zu überwinden gestattet, sondern ein Faktor, welcher mit dem Durchbrechen des Bodens nichts zu tun hat (obwohl im Boden

1) Vgl. Goebrt, Einleitung in die exp. Morphologie (1908), p. 84, 224. Vol. XX.

2) Ewart and A. Masos, The formation of red wood in Conifers. Annals of botany.

8) Goвber, Die kleistogamen Blüten und die Anpassungstheorien. Biolog. Zentralblatt 1904, S. 121. 
natürlich Lichtmangel herrscht). Ebenso verhalten sich z. B. die Rhizomspitzen von Mercurialis perennis (Fig. כ̄), bei welchen besonders klar ist, daß sie, wenn sie gerade im Boden wachsen würden, dies nur unter Schädigung der Knospenspitze (die nicht geschlossen ist) erfolgen könnte. Am Licht strecken sich die Ausläuferspitzen gerade.

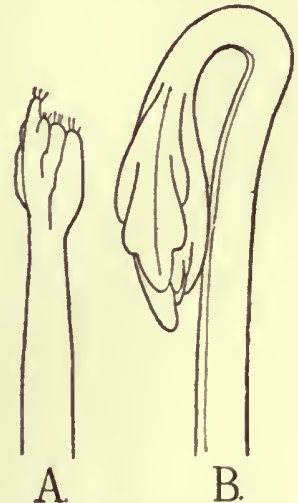

Fig. 4. Ranunculus repens. Zwei in Dunkelkultur entwickelte Blätter. Das jüngere ist noch anfrecht und bleibt so bei Beleuchtung. Das ältere, im Finstern weiter entwickelte, hat durch eine Krümmung des Blattstiels die Blattspreite nach unten gewendet.

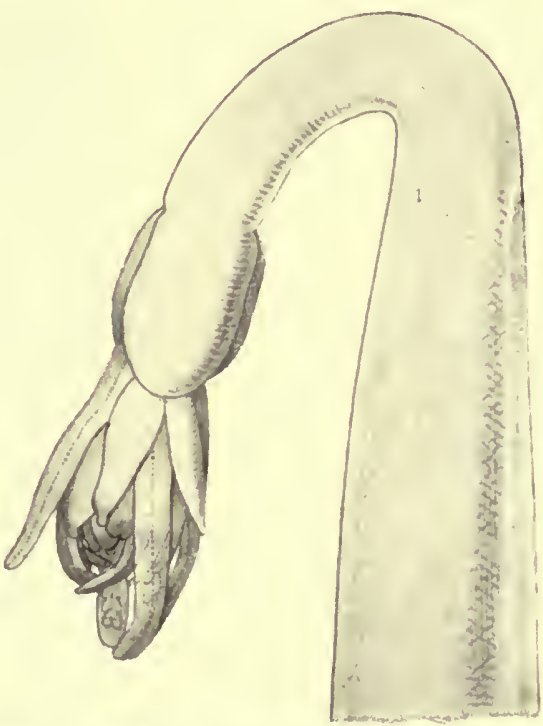

Fig. 5. Mercurialis perennis. Spitze eines horizontal im Boden vordringenden Ausläufers (vergr.).

Bei den Blattstielen von Ranunculus liegt offenbar eine "Hyponastie" vor, die dann, wenn das Blatt am Licht sich entwickelt, nicht zur Geltung kommt. Analog diurften sich die Mercurialisrhizome verhalten.

Was andere (anscheinend) autonom erfolgende Einrichtungen betrifft, so wird in der Literatur mit Recht darauf hingewiesen, daß für die den Grund aufrecht durchbrechenden Blätter von Podophyllum (Fig. $6 I 1$ ), die einem unterirdischen, durch Niederblätter geschützten Rhizom entspringen, besonders zweckmäßig die Lage der Blattspreite sei, die schürzenförmig am Blattstiel herabgeschlagen ist und erst am Lichte sich ausbreitet. Nun findet sich aber, wie Fig. 7 zeigt, eine ganz ähnliche Knospenlage der Blattspreite bei einer 'Composite (Erythrochaete pinnatifida), deren Blätter nicht hypogaeisch angelegt werden (wenigstens nicht bei den von mir beobachteten kräftig gedeihenden Gartenpflanzen). Geradesogut wie hier kann auch bei Podophyllum die eigentümliche Lage der Blattspreite aus „inneren Gründen“, zufällig entstanden sein. Bei einer teilweise hypogaeisch lebenden Pflanze wird sie sehr zweckmäßig sein, bei einer anderen könnte sie auch ganz anders sein, ohne daß das für die Pflanze von Bedeutung wäre. Ob Raumverhältnisse in der Knospe oder die Wachstumsverteilung innerhalb der jugendlichen Blattspreite die eigentümliche Knospenlage bedingen, bedarf näherer Untersuchung. 


\section{$\S 4$. Sind Etiolierungserscheinungen als Anpassungen zu betrachten?}

Im Anschluß an das in $\$ 3$ besprochene Verhalten hypogaeisch angelegter Pflanzenorgane mag kurz die Frage erörtert werden, ob Lichtmangel auch sonst bei Pflanzen "zweckmäßige" Reaktionen hervorruft.

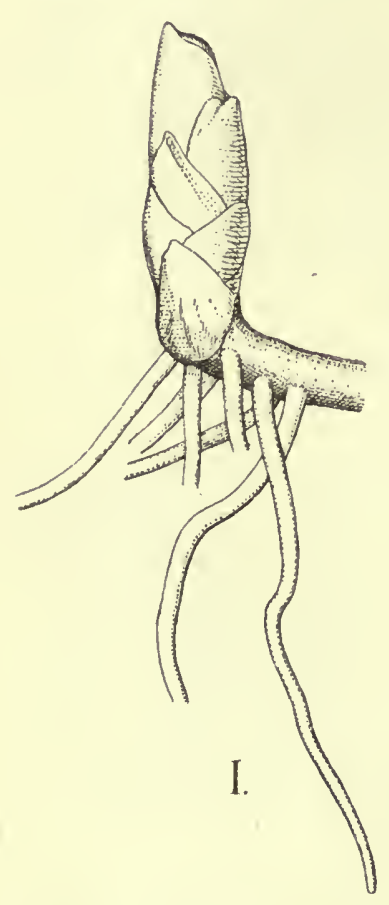

Fig. 6. Podophyllum peltatum. I Austreibendes Rhizomende durch Niederblätter geschützt. II Blatt, wie es den Grund durchbohrt, die Blattspreite nach unten hineingeschlagen.
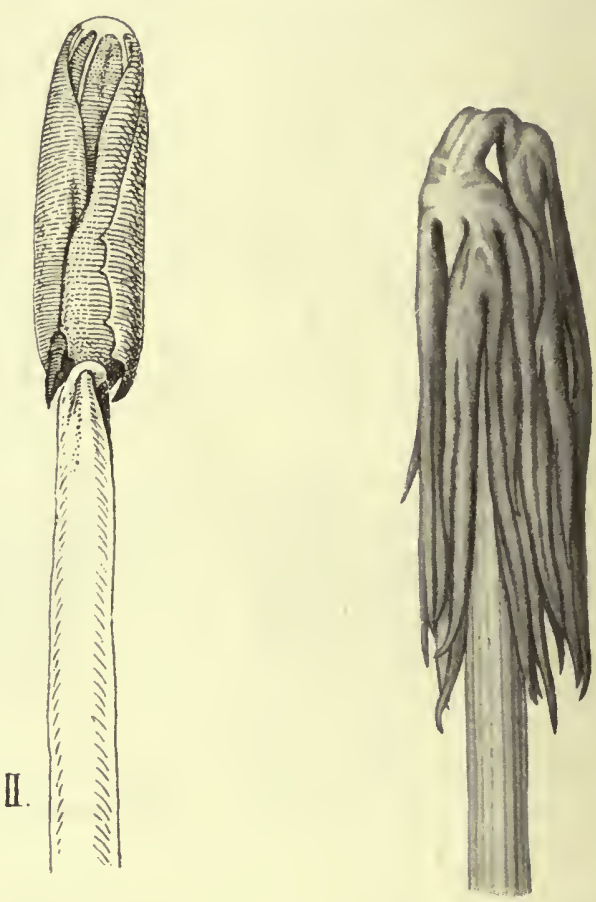

Fig. 7. Blatt von Erythrochaete pinnatifida vor der Entfaltung.

Daß die gewöhnlichsten Etiolierungserscheinungen bei Dikotylen - Überverlängerung der Internodien uud Kleinbleiben der Blätter im Finstern vorteilhaft sind für das Erreichen des Lichtes ist oft genug hervorgehoben worden, ebenso die Überverlängerung monokotyler Blätter z. B. mancher "Bohrblätter" im Dunkeln oder die Internodienstreckung an zu tief eingepflanzten Rhizomen mit normal "gestauchten" Internodien (Fig. 8), wobei nicht nur die Gestalt, sondern auch die Wachstumsrïchtung verändert ist. Auch bei Moosen treffen wir ähnliche Erscheinungen. Wenn z. B. die Thallus am Fegatella conica im Finstern austreibt, so richten sich die etiolierten Triebe auf (Fig. 9), bleiben schmal und können so, falls sie etwa in der Natur von einer nicht zu dicken Erd- oder Laubschicht bedeckt sind, diese durchbrechen ${ }^{1}$ ). Ebenso ist es "zweckmäßig", daß die

1) Da die abnorme Gestalt der etiolierten Pflanzenteile teilweise anch der Verhinderung resp. Verminderung der Transpiration zugeschriebell wird, so sei auf Fig. 10 hingewiesen, die zeigt, dab unter Wasser (dazu noch in trïben Tagen) entwickelte Fegatellatriebe $\mathrm{nich} \mathbf{t}$ etioliert sind. 
Astbildung bei normal verzweigten Moosen im Dunkeln unterbleibt, und die verfügbaren Baustoffe nur der Hauptachse zukommen.

Aber bei anderen Moosen treten Etiolierungserscheinungen auf, die man nicht als adaptative wird bezeichnen können. So machen die etiolierten Triebe von Lophocolea bidentata unregelmäßige Krümmungen, die Pflanze ist im Finstern desorientiert ${ }^{1}$ ) und Pellia epiphylla wächst im Dunkeln überhaupt nicht (wie auch manche höhere Pflanzen z. B. einige Selaginellaarten, Myriophyllum proserpinacoïdes u. a.). Bei etiolierten Kakteen aber sind meist die Internodien kürzer als bei am Lichte gewachsenen (können also zur Erreichung des Lichtes nichts beitragen) und manche Pflanzen wie Canna indica (Fig. 11) entfalten auch ihre Blätter im Dunkeln; diese sind also, obwohl die Pflanze ein hypogaeisches Rhizom besitzt, nicht auf Durchbrechung dicker Bodenschichten eingerichtet.

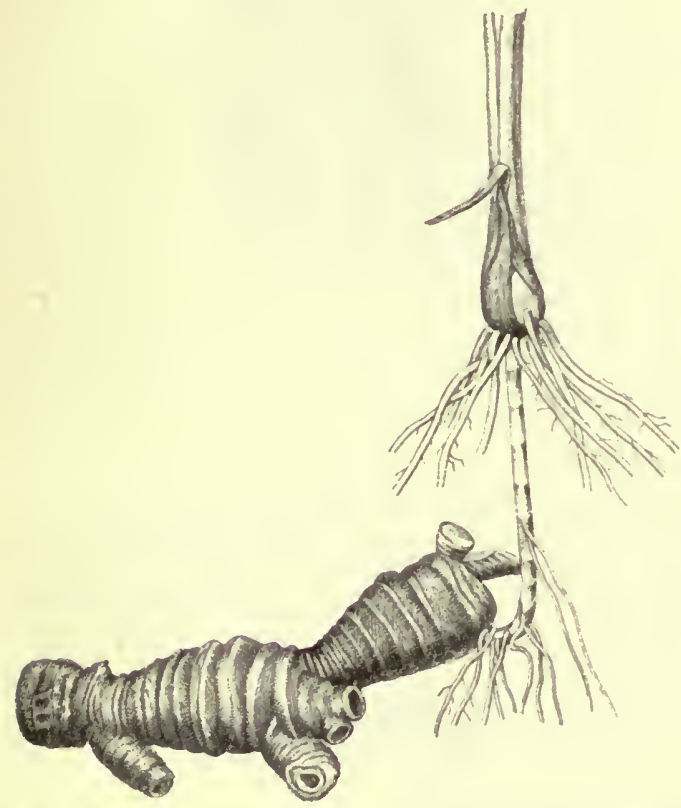

Fig. 8. Iris foetidissima. Rhizom tief eingepflanzt. Es hat einen Seitensproß getrieben, der statt horizontal vertikal nach oben wuchs und viel diinner ist als das Rhizom. Hier hat sich also die geotropische Stimmung des Rhizoms geändert, zugleich ist es auch etioliert. Die Reizkette ist hier nicht näher analysiert.

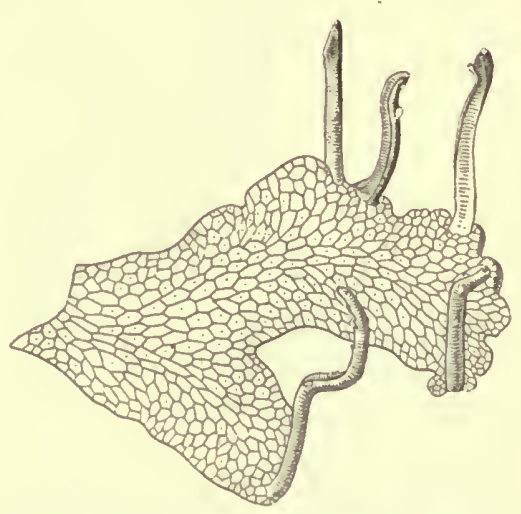

Fig. 9. Fegatella conica. Thallus, dessen Vegetationspunkte bei Lichtabschließung ausgetrieben haben.

Der Einwand, daß Pflanzen, die auf Verfinsterung nicht oder nicht "zweckmäßig" reagieren, solche seien, welche normal kaum je in die Lage kommen werden, im Finstern $\mathrm{zu}$ wachsen und den $\mathrm{T}$ eg zum Lichte suchen $\eta_{u}$ müissen, läßt sich wohl für einzelne, aber nicht für alle derartigen Fälle begründen, er liegt z. B. fuir die erwähnten Kakteen nahe, paßt aber nicht für die angeführten Moose und Canna. Auch die Sprosse von Chara sind nicht imstande zu etiolieren, obwohl sie gewiß häufig im Schlamm begraben werden, und ebensowenig die von Monotropa hypopitys, welche ihren Weg durch die Humusdecke des Waldes bohren müssen. Betreffs anderer Beispiele, sei auf die zusammenfassende Darstellung von Macdougal verwiesen ${ }^{2}$ ).

1) NeMEC, Die Wachstumsrichtungen einiger Lebermoose. Flora 96 (1906), p. 447.

$\left.{ }^{2}\right)$ D. T. MacdougaL, The influence of light and darkness upon growth and development, Memoirs of the New York botanical garden. Vol. II, 1903. 
Die Schlußfolgerung für die Erscheinungen des Etiolierens ist also die: sie können für die Pflanze nützlich sein, sind es aber nicht immer. Es ist also nicht berechtigt, die Etiolierungserscheinungen durchgehends als nuitzliche Reaktionen der Pflanzen zu betrachten.

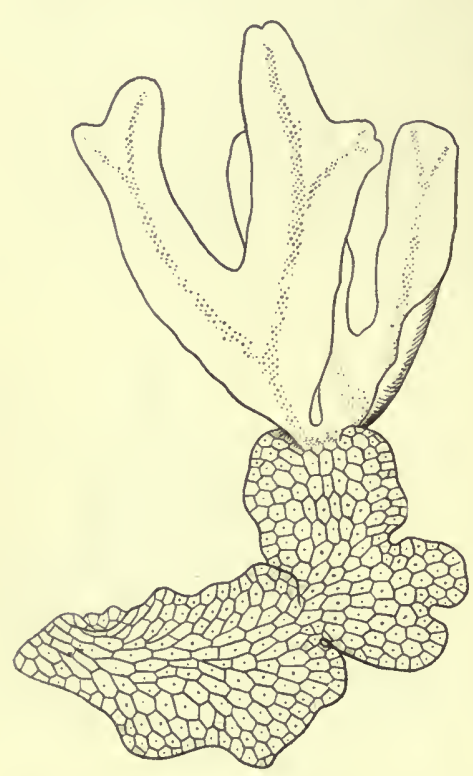

Fig. 10. Fegatella conica Thallus im Wasser (aber am Lichte) ausgetrieben. (Das Assimilationsparenchym der nenen Triebe bestand aus gewöhnlich zweizelligen Reihen.)

\section{$\S 5$. Schutz des Vegetations- punktes hypogäischer Pflanzenteile.}

1. Daß zart gebaute, namentlich embryonale Pflanzenteile nicht geeignet sind, beim Vordringen im Boden voranzugehen, ist selhstverständlich.

In Wirklichkeit sehen wir auch überall diese Aufgabe älteren, aus Dauergewebe bestehenden Pflanzenteilen zuerteilt; ein Beispiel dafür wurde schon in $\S 3$ angeführt. Dabei ist sehr lehrreich, daß die Art und Weise wie dies erfolgt, bei den verschiedenen Pflanzen sehr verschieden ist; die Mannigfaltigkeit der Gestaltbildung ist hier deutlich größer als 'die der Lebensbedingungen.

Wir wollen uns beschränken auf den Schutz der im Boden rorangehenden Pflanzenteile, da die nastischen Kriimmungen oben schon besprochen wurden.

1. Schutz des Vegetationspunktes durch eine Wurzelhaube. Dieser Typus ist allbekannt für die Wurzeln, er kehrt aber merkwürdigerweise 
wieder bei den eigentümlichen, äußerlich ganz Wurzeln gleichenden „Marsupien" einiger Lebermoose ${ }^{1}$ ), wie Fig. 12 und 13 zeigen.
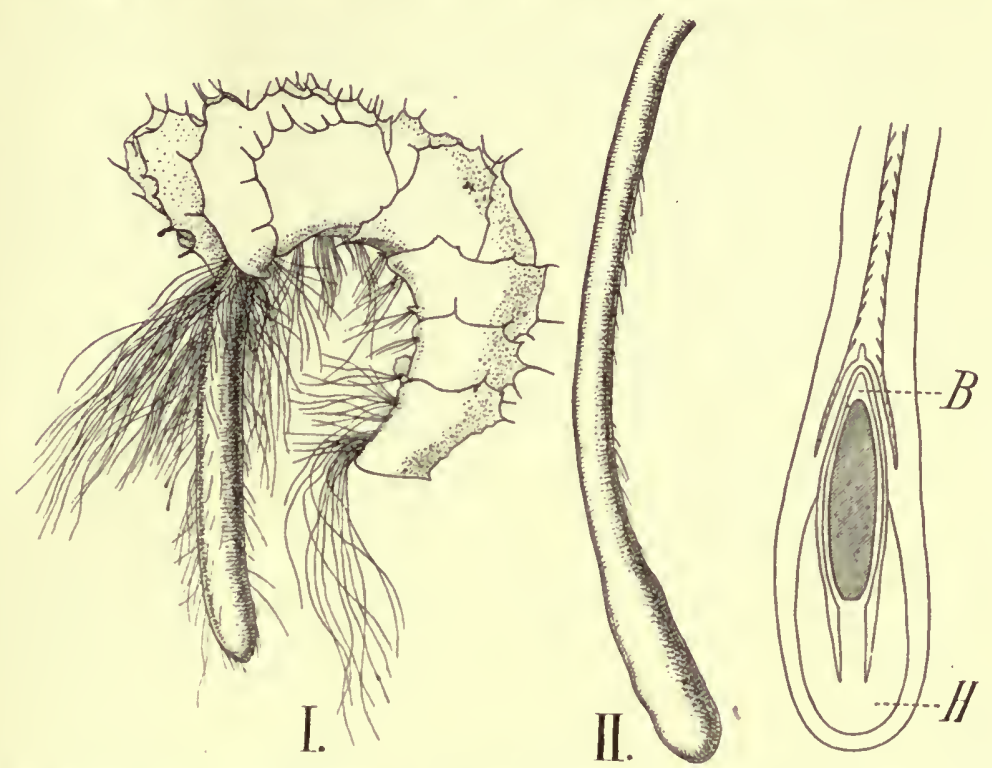

Fig. 12. Acrobolbus unguiculatus. 1 Habitusbild einer Pflanze mit jungem, noch nicht ausgewachsenem Marsupium 4:1. II Ausgewachsenes Marsupium. III Längsschnitt durch den unteren Teil eines solchen.

Es hat sehr viel Verlockendes diese Parallelbildung durch die direkte Einwirkung der $\mathrm{AuBenwelt}$ sich entstanden $\mathrm{zu}$ denken. Man kann annehmen, daß dadurch, daß die Spitze dem Druck der Erdteilchen ansgesetzt ist, die Teilungsfähigkeit der Zellen herabgesetzt wird, während sie weiter innen gesteigert auftritt. Eine solche Annahme ließe sich auch dadurch stiitzen, da B die Embryonen von Cephalotaxus und Araucaria, wie Strasburger fand, gleichfalls eine temporäre, aus Dauergewebe bestehende Bohrspitze - die einer Wurzelhaube entspricht - aufweisen; sie könnte auch ebenso entstanden sein, wie die letzteren, da der Embryo sich zwar nicht in die Erde, wohl aber in das Endosperm einbohrt. Auch die Wachstumsverteilung in der Wurzel wiederholt sicb bei unterirdischen Sprossen (z. B.

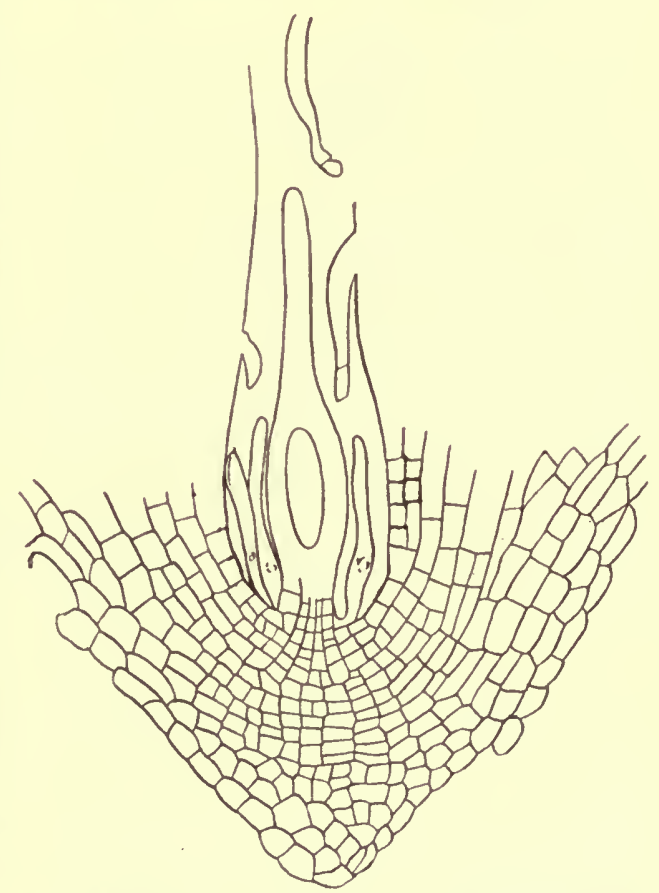

Fig. 13. Acrobolbus unguiculatus. Längsschnitt durch einen Beutel mit wurzelhaubenähnlicher Bohrspitze. 
denen ron Herminium Monorchis) und auch dieser Umstand legt die oben erwähnte Vermutung nahe.

Aber sie ist zunächst eben nur Vermutung, und sicher ist, daß andere Fälle von kaum weniger merkwiirdigem Schutz des Vegetationspunktes nicht als „direkte Anpassung" entstanden sein können.

2. "Nachgeahmte" Wurzelspitzen. Die Knollen der Colchicace Merendera sobolifera (Fig. 14) sind dadurch merkwürdig, daß die „Erneuerungsknospen" ( $K$ Fig. 14) je auf einer stielförmigen Verlängerung der alten Knolle von dieser entfernt werden und so wandern. Die Knolle $H$ hat in Fig. 14 drei solcher Erneuerungsknospen $(A, B, C)$, von denen (ebenso wie bei Colchicum selbst) die an der alten Knolle am tiefsten stehende die kräftigste ist. Bei ihrer Wanderung durch den Boden sind die Erneuerungsknospen $(K)$ geschuitzt dadurch, daß sie nicht an der Spitze, sondern auf der Oberseite der Ver-

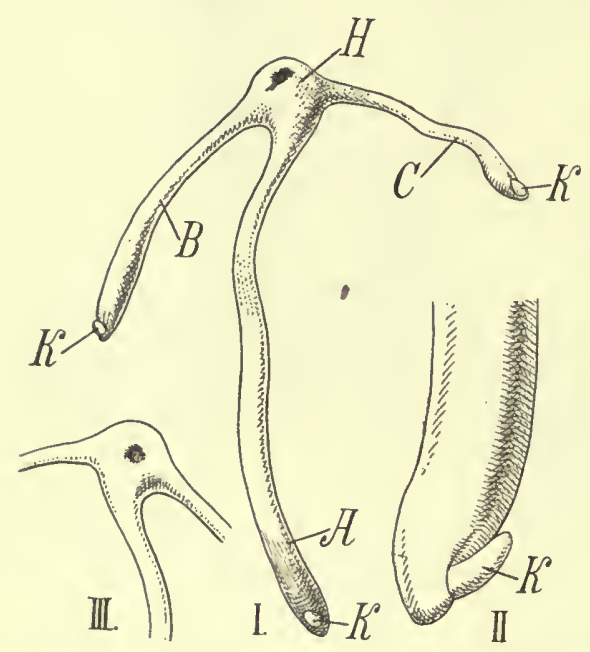

Fig. 14. Merendera sobolifera. $l$ Knolle $H$ mit drei stielförmigen Verlängerungen $(A, B, C)$, deren Endknospe nach oben geschoben ist, wie 11 noch deutlicher zeigt. Unterhalb $K$ eine Bohrspitze. längerung der alten Knolle stehen. Die Spitze selbst gleicht in ihrer kegelförmigen Gestalt einer Wurzelspitze. Dieses Verhalten leitet auch (wie hier nicht ausgeführt werden kann) morphologisch über zum Schutz des Vegetationspunktes durch Verlegung in das Innere eines wurzelähnlichen Gebildes.

Das ist der Fall bei einigen Liliaceen und Orchideen, welche wurzelähnliche Ausläufer bilden, an deren Spitze dann eine Zwiebel oder Knolle entsteht. Auf die morphologischen Verhältnisse ist hier nicht weiter einzugehen, es sei nur an der Hand der Abbildung ein Beispiel kurz erörtert.

Fig. 15 zeigt eine Pflanze von Tulipa praecox, welche einen durchaus wurzelähnlichen Ausläufer getrieben hat. Die Wurzelähnlichkeit tritt abgeschen von der Gestalt und namentlich auch der Zuspitzung des Endes darin hervor, daß dieses, wie ich mich an lebenden Pflanzen (in Bologna) überzeugte, ebenso wie eine Wurzelspitze Schleim absondert, und daß, wie Messungen zeigten, das Wachstum wie bei einer Wurzel, auf eine kurze Zone linter der Wurzelspitze beschränkt ist (vgl. die oben erwähnte Herminium Monorchis). Der Längsschnitt (Fig. $12 I I$ ) zeigt, daß, abgesehen von der Spitze, der Ausläufer röhrenförmig hohl ist und der Vegetationspunkt vortrefflich im Innern dieser Röhre geschïtzt liegt.

3. Schutz durch Niederblätter — so bei vielen Ausläıfern usw. ron Mono- und Dikotylen.

4. Interkalar wachsende Organe, wenn sie ungegliedert sind (wie die Coleoptile der Gräser, die den Grund durchbrechenden Laubblätter mancher Monokotylen), schiutzen die wachsende Region schon durch die Lage; die obcren T'eile haben nicht selten „.Bohrspitzen". Bei Hermodactylos tuberosus wurden die Bohrspitzen bei dunkel gehaltenen Blättern länger als bei beleuchteten. 
Aus der hier gegebenen kurzen Übersicht geht zweierlei herror: einmal, daß bei den erwähnten geophilen Pflanzenteilen das embryonale Gewebe beim Vordringen im Boden geschützt ist ${ }^{3}$ ), und zweitens, daß dies auf recht verschiedene Weise geschehen kann.

Über das Zustandekommen der Schutzvorrichtungen läßt sich nichts Sicheres aussagen. Die durch Niederblätter geschuitzten Sprosse behalten - mit nicht sehr.. tiefgreifenden Änderungen - eine auch bei oberirdischen Sprossen vorhandene Eigentïmlichkeit bei, d. h. den Schutz des Vegetationspunktes durch Blattanlagen. Die Monokotylen mit wurzelähnlichen Ausläufern sind dem Vordringen im Boden vorzüglich angepaßt, aber letztere sind offenbar nicht als zweckmäßige

Reaktion der Pflanze, sondern aus „inneren Gründen" entstanden. Es ist

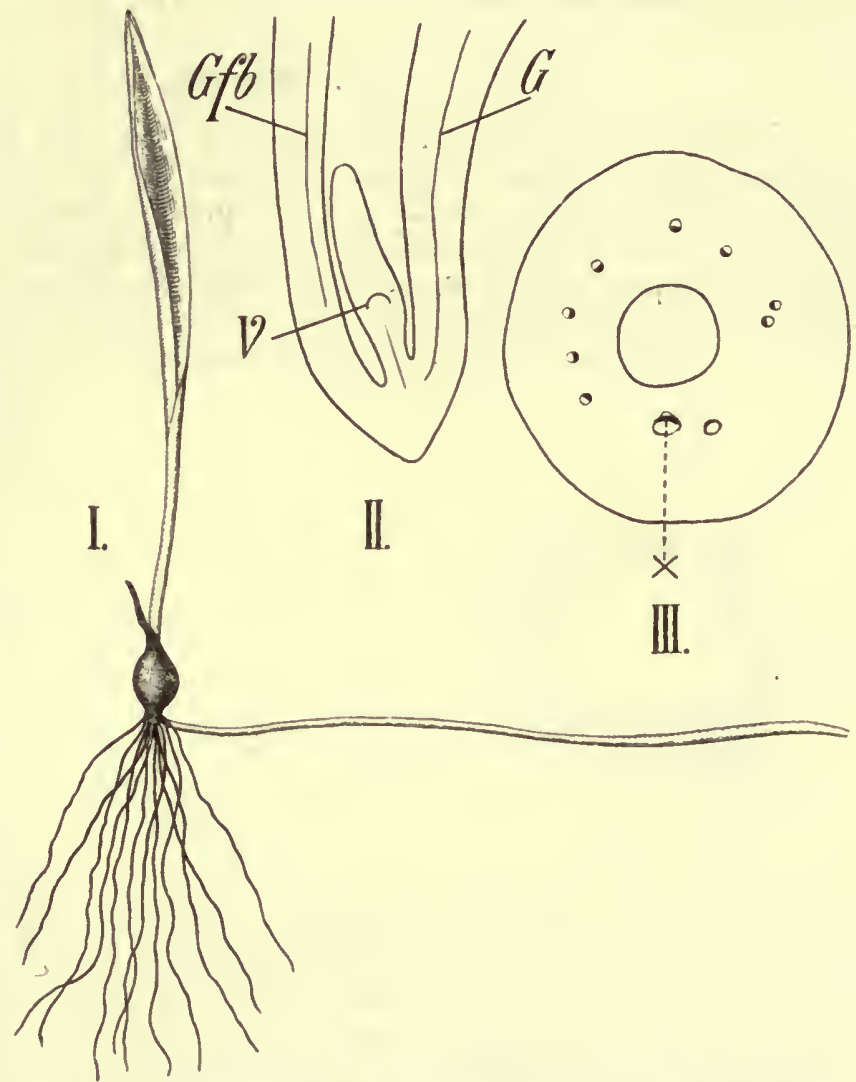

Fig. 15. Tulipa praecox. I Habitusbild einer nicht blühenden Pflanze mit Ausläufer ( $1 / 2$ nat. Gr.) $I I$ Längssclinitt durch die Spitze eines Ausläufers $V$ Vegetationspunkt (darüber ein Blatt) $G G f^{\circ} b \mathrm{Ge}$ faßbündel III Querschnitt durch deu Ausläufer. Alle Leitbündel mit Ausnahme des durch $X$ bezeichneten, welches zwei Phloëmteile hat. haben das Phloëm außen.

nicht unwahr-

scheinlich, daß äußere Bedingungen, z. B. Lichtmangel, das Auftreten dieser eigenartigen Gebilde begünstigen. Wenigstens ist es auffallend, daß diese „rhizomorphen Ausläufer" zwar bei ge ophilen Teilen verschiedener monokotyler Pflanzen (Liliaceen, Orchideen), aber — soweit mir bekannt niemals an oberirdischen Teilen auftreten.

Man kann hier ron einer „direkten Anpassung" derzeit nicht sprechen; ebenso kann man ja auch bei den Wurzelhauben eine solche verneinen,

1) Als Ausnahme wären zu nennen die geophilen Sprosse von Psilotum und Tmesipteris. Indes wachsen diese nicht in festem Boden, sondern in einem lockeren, mulmigem Substrat (z. B. als Epiphyten auf Raumfarnen nsw.) und breiten sich nicht sehr weit aus. Auch ist die Regenerationsfäbigkeit der Spitzen eine große.

Goebel, Organographie der Pflanzen. 2. Aufl. Allgem. Teil. 
obwohl, wie erwähnt, hier eine direkte Beeinflußung wahrsclieinlicher erscheint.

Jedenfalls aber zeigen uns auch diese Beispiele, daß die Pflanze, bildlich gesprochen, das Gute nimmt, wo sie es findet, nicht aber, wie man auch schon angenommen hat, es sucht.

\section{§ 6. Ranken.}

Eine auffallende Beziehung zwischen Bau und Funktion findet sich anscheinend bei rielen Ranken. Bekanntlich verkümmern vielfach die Ranken, welche keine Stiitze gefaßt haben, während solche, bei denen dies der Fall war, sich auffallend verändern, namentlich verholzen und so für die dauernde Anheftung der Rankenpflanze besonders geeignet werden. Auch in diesem Falle ist es aber - wenigstens der Hauptsache nach nicht die mechanische Beanspruchung der Ranke durch Zug, welche zur
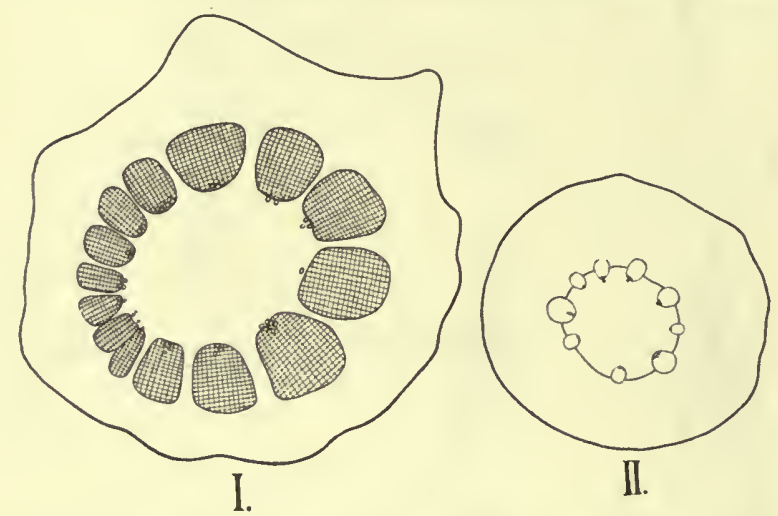

Fig. 16. Psedera (Ampelopsis) himalayensis. Querschnitt durch die Basis einer Ranke, die noch keine Stütze gefalt hat (II) und eine, die vor längerer Zeit eine Stütze erreicht hatte $(I)$. Bei $I I$ ist ein Kreis wenig entwickelter Leitbiindel vorhanden; sie bestehen abgesehen vom Protoxylem aus zartwandigen Zelleu. Bei $I I$ ist die Bildung von Holz eingetreten, das hauptsächlich ans mechanisch wirksamen Zellen besteht. hat, ein beträchtliches sekundäres Dickenwachstum aufweisen, welches mechanisch sehr leistungsfähiges Gewebe geliefert hat. Daß Zug die Erhöhung der Zugfestigkeit begiinstigt, ist möglich, und wird ron mehreren Autoren angegeben. Indes kommt auch die neueste Untersuchung (betreffs der Ranken von Passiflora) zu dem Resultate, daß "Kontakt" für die Ausbildung des mechanischen Gewebes bei weitem die wichtigste Rolle spielt (er veranlaßt die Zunahme der Holzzellen an Zahl und Dicke). Die Zugfestigkeit der Ranke könne aber durch Zug noch erhöht werden, wobei die Markzellen verdickt werden ${ }^{1}$ ). Es ist also der Hauptsache nach auch hier ein indirekter Reiz, der die Weiterentwicklung des Rankengewebes auslöst, und es ist fraglich, ob die Erhöhung der Zug-

1) W. D. Bruch, The formation of mechanical tissue in the tendrils of Passiflora coerulea as induced by traction and contact, Botanical Gazette 1912 vol. LIII p. 453. Es mag dahingestellt bleiben, ob die Resultate des Verf. wirklich unanfechtbar sind, d. h. ob bei seinen Zugversuchen nicht eine Verstärkıng der Reibungsreize oder hei Verstärkung der Einkrümmung ein kamptotropher Reiz mitwirkte. 
festigkeit durch Zug, welche angegeben wird, für die Pflanze selbst von Bedeutung ist, d. h. ob die durch Reibungsreiz bedingte Erhöhung der Zugfestigkeit nicht schon ausreichend ist, um die normale Belastung der Ranke zu tragen. $\mathrm{Ob}$ es sich bei dem kümmerlichen Gedeihen ganzer Rankenpflanzen, deren Ranken keine Stütze gefaßt haben, um eine indirekte Folge (ungünstige Lage der Assimilationsorgane usw.) oder um das Unterbleiben eines von den normal funktionierenden Ranken auf die ganze Pflanze fortgeleiteten Reizes handelt, ist meines Wissens nicht näher untersucht.

Ebenso wie die Verstärkung der Ranken ist das Verhalten der Ranken aufzufassen, welche Haftscheiben bilden, d. h. Verbreiterungen, welche teils an der Spitze, teils auch seitlich (z. B. Trichosanthes Fig. 17) auftreten können. Es handelt sich dabei um Zellwucherungen, (Fig. 18) deren Auftreten bei den genannten Pflanzen durch Reibungsr ei z bedingt wird, also auch hier nicht durch einen funktionellen Reiz.

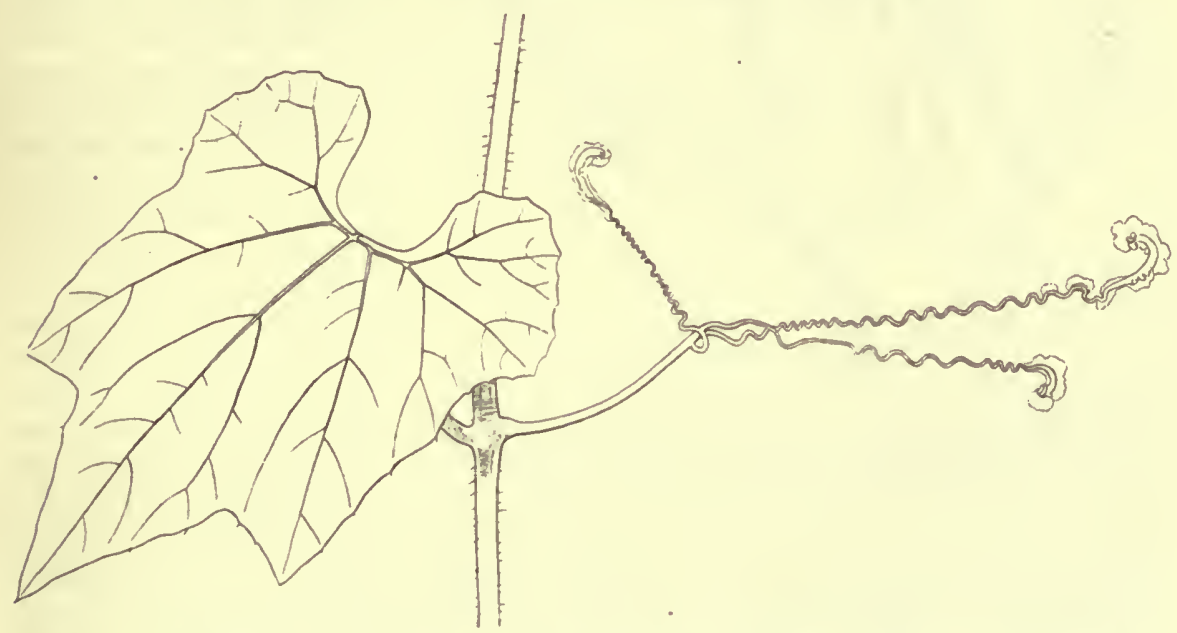

Fig. 17. Sproßstiick von Trichosanthes cucumerina. Die Rankenarme hatten sich an einer Glasscheibe festgeheftet und sondern eine Klebesubstanz aus, die als Hof an der Haftscheibe erscheint.

Andere Rankenpflanzen mit Haftscheiben sind dadurch ausgezeichnet, daß sie die letzteren auch ohne Reibungsreiz ausbilden; es findet, wenn die Haftscheibe mit einem festen Körper in Berührung kommt, nur eine Vergrößerung statt.

Ein Beispiel dafuir bietet Fig. 19. Sie stellt die Knospe am Ende eines Zweiges der Bignoniacee Glaziova bignonioides dar. Die Enden der beiden unteren noch nicht ganz entfalteten Blätter haben große Haftscheiben $(H)$ entwickelt, die hier also ohne äußeren Reiz aụftreten, sich aber, wenn dieser einwirkt, noch erheblich vergrößern. Ähnlich 
ist es bei einigen anderen Bignoniaceen, bei der Cucurbitacee Peponopsis adhaerens, bei „Vitis heterophylla" [Ampelopsis Veitchi].u. a.). Man wird in diesen Fällen geneigt sein $\mathrm{zu}$ 'sagen, die Bildung der Haftscheiben sei „erblich geworden", $d$. h: die Bildung der Haftscheiben infolge des Kontaktreizes sei das Ursprüngliche, die Bildung ohne Kontaktreiz das Sekundäre; die Pflanzen hätten die Haftscheibenbildung sozusagen auswendig gelernt.

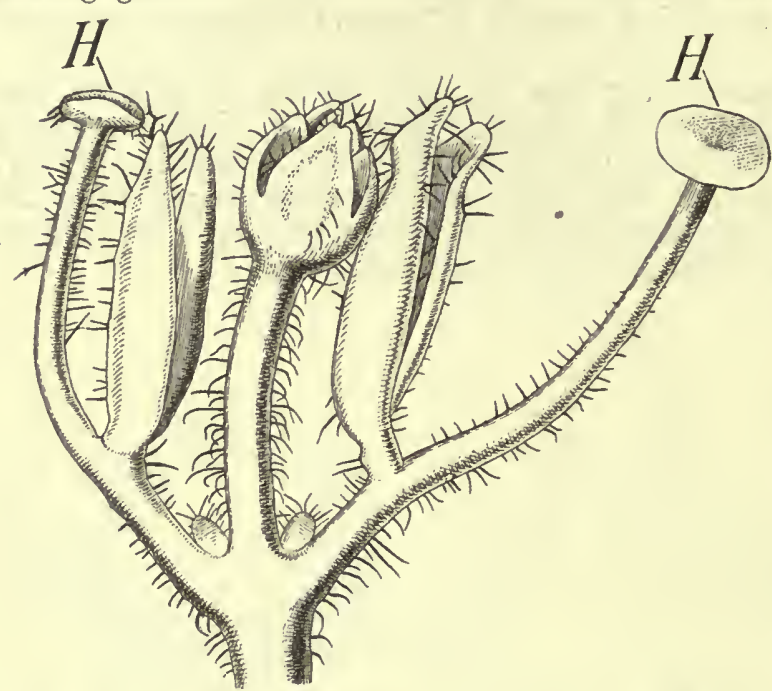

Fig. 19. Sproßende von Glaziova bignonioides. An dem Ende der mit einem Fiederpaar versehenen Blätter entstehen Haftscheiben $(H)$ ohne jeden Kontaktreiz.

Diese Auffassung wird dann an Gewicht gewinnen, wenn es gelingt, sie experimentell zu stiitzen, also Fälle ausfindig $\mathrm{zu}$ machen, in welchen ein durch einen äußeren Reiz induziertes Gestaltungsverhältnis bei Aufhören des Reizes noch auftritt, also der Reiz nachwirkt. Das ist nun, wie bei Besprechung der Wurzelsymmetrie gezeigt werden wird, tatsächlich der Fall bei den stark abgeflachten merkwürdigen Wurzeln ron Phalaenopsis Schilleriana. Die Abflachung ist durch das Licht induziert, findet aber auch bei monatelangem Wachsen im Finstern noch statt. Auf die Nachkommen übertragen wird in diesem Falle allerdings nur die Fähigkeit auf einen äußeren Reiz in bestimmter Weise durch Gestaltveränderung zu reagieren. Aber der Vegetationspunkt, welchem auch die Gameten - entstammen, hat hier doch schon eine bestimmte ron Reiz nicht mehr direkt abhängige Induktion erfahren, welche dazu führen kann, dabs auch die Gameten derselben Induktion unterliegen. Jedenfalls sind Fälle wie der von Phalaenopsis sehr wichtig und fordern $\mathrm{zu}$ weiterer Untersuchung auf.

Beispiele dafür, daß die Entwicklung eines Organs bei einer Pflanze von einem von außen kommenden Reiz ablängig ist, bei anderen nicht. finden sich auch sonst.

Bei den meisten Pflanzen findet die Entwicklung der Samenanlagen ohne äußere Reize statt. Bei Quercus und Fagus aber erfolgt sie nur durch den Reiz der Pollenschläuche. der bei den Orchideen zwar nicht die Anlegung, wohl aber die Weiterentwicklung der Samenanlagen bedingt. Ohne Zweifel ist dieses Verhalten ein abgeleitetes. Ähnlich könnte es auch bei den Ranken-Haftscheiben sein. Nur liegen die Verhältnisse in beiden Fällen insofern etwas verschieden, als bei den Samenanlagen das Entwickeln ohne äußeren Reiz das Normale, bei den Haftscheiben dagegen das seltenere Vorkommnis ist.

Von anderen ähnlichen Fällen sei nur auf die Kéeimung der Orchideen hingewiesen. Wir wissen aus den Untersuchungen ron Bersard und 
Burgeff, daß die Samen mancher Orchideen nur bei Gegenwart eines Pilzes sich weiter entwickeln (daß es möglich ist, dessen Einwirkung durch Zufuhr organischer Substanzen zu ersetzen, kommt hier nicht Betracht). Auch hier liegt die Annahme nahe, daß eine Gewöhnung an den Pilz eingetreten ist, so daß beim Fehlen des Pilzes die Entwicklung unterbleibt.

Inwieweit die (autonome) Bildung von Haftscheiben ohne äußeren Reiz etwa vorteilhafter ist, als die auf Reiz erfolgende (incluzierte), könnte nur durch sehr genaue Beobachtung der Lebensverhältnisse einigermaßen ermittelt werden. Ersteres könnte ein rascheres Anhaften ermöglichen, letzteres vermeidet den Materialverlust, der durch Bildung solcher Haftscheiben eintritt, welche mit keiner Unterlage in Berührung kommen, ein Verlust, der bei Pflanzen tropischer und subtropischer Gebiete iibrigens kaum in Betracht kommen wird. Auf etwas mehr oder weniger an Assimilaten - die sich leicht vermehren lassen - kommt es hier wohl kaum an.

Die oben angefiihrten Beispiele zeigen, daß die Ausbildung pflanzlicher Gestaltungsverhältnisse zwar vielfach von äußeren Reizen abhängig ist, daß aber eine direkte Beeinflussung der Gestaltung durch die Funktion bei ihnen nicht erwiesen ist, was selbstverständlich nicht ausschließt, daß ein solcher Nachweis anderweitig gelingt.

\section{§ 7. Indirekte Beeinflussung.}

Eine solche läge z. B. vor, wenn Hartig's Annahme, daß die Vermehrung der Gefäße in dem auf die Freistellung von Buchen (Fagus silvatica) folgenden Jahre durch die vermehrte Transpiration bedingt sei. Diese niußte dann auf das Cambium, aus welchem der neue Jahresring hervorgeht, so einwirken, daß in dem letzteren mehr Wasserleitungsbahnen entstehen. Indes ist es meist schwierig festzustellen, welches der erste Anstoß bei einer Reaktion der Pflanze auf die Veränderung äußerer Bedingungen hin ist, und ob eine Änderung in der Beanspruchung oder Änderungen in der Baustoffrerteilung es sind, welche die Reaktion hervorrufen. Ein Waldbaum, den man freistellt, wird z. B. nicht nur stärkerer Transpiration ausgesetzt sein, sondern in Verbindung damit auch mehr Aschenbestandteile aufnehmen und infolge der intensiveren Beleuchtung auch seine Kohlenstoffassimilation verstärken. Es wird also die Zusammensetzung der dem Cambium zufließenden Baustoffe geändert. Welcher dieser Vorgänge dem Cambium Anstoß gibt zur Vermehrung der Gefäße ist unbekannt; jedenfalls wäre es auch hier nur eine pseudo-psychologische Verschleierung des Problems, wenn man sagen wollte, das Bedürfnis wirke als Reiz.

Ebenso ist es bei den Fällen indirekter Beeinflussung, welche durch Vermittlung des Vegetationspunktes stattfinden. Wenn ich z. B. eine Landform von Myriophyllum oder Hippuris unter Wasser versenke ${ }^{\mathbf{1}}$ ), so bildet sie nach einiger Zeit Wasserblätter, welche von den an der Luft sebildeten verschieden und namentlich direkt benetzbar, also für das Wasserleben geeignet sind. Es gelang sber später die charakteristischen Wasserblätter von Myr. proserpinacoides und selbst die "Schwimmblätter" von Polygonum amphibium auch an nicht untergetauchten Exemplaren, die in feuchter Luft wuchsen, und deren Wurzelsystem warm gehalten war, hervorzurufen.

1) Betr. der Einzelheiten s. Goeber, Einleitung in die experimentelle Morphologie, 1908. 
Es ist klar, daß die "Schwimmblätter" von Polygonum amphibium, (welche Spaltöffnungen fast nur auf der Oberseite haben), bei der Land. pflanze nicht durch einen funktionellen Reiz herrorgerufen sein können. Man kann in diesen Fällen freilich sagen: die Pflanzen sind mit einer, ursprüinglich im Zusammenhang mit dem Leben im Wasser oder auf den Lande entstandenen "labilen" Organisation versehen; das bedingt, daß die Organbildung auch auf andere Reize als den Wechsel des Mediums hin reagiert. ähnlich wie eine Ranke, welche eigentlich dazu bestimmt ist, sich infolge von Reibungsreizen zu krümmen, das auch infolge chemischer oder thermischer Einflüsse tun kann. Dieser Vergleich ist indes nur ein solcher zwischen zwei Dingen, deren Zustandekommen wir weder in dem einen noch dem anderen Falle kennen. Er enthält eine Voraussetzung, auf die erst weiter unten eingegangen werden kann.

Überblicken wir die angeführten Fälle, so ergibt sich daraus, daß Gestaltungsverhältnisse vielfach infolge äußerer Reize auftreten, daß aber diese Reize keine funktionellen zu sein brauchen.

In diesem Zusammenhang wäre auch die in der Einleitung aufgeworfene Frage zu erörtern, inwieweit Gründe vorliegen für die Annahme, daß funktionslos gewordene Organe verkümmern. Indes soll dies erst in dem Kapitel über Verkümmerung geschehen.

Hier sei nur angeführt, daß die Beobachtung, wonach Laubblätter, die normal der Kohlenstoffassimilation dienen, zugrunde gehen, wenn sie daran gehindert werden ${ }^{1}$ ), noch nicht beweist, daß es die Verhinderung der Assimilationstätigkeit dir e kt ist, welche dieses Resultat hervorruft. Denn zahllose Laubblätter assimilieren z. B. im Winter nicht, ohne dadurch geschädigt zu werden. Dann sind aber auch die übrigen Pflanzenteile in Ruhe. Ist dies nicht der Fall, so können in den der $\mathrm{CO}_{2}$-Assimilation entzogenen Blättern durch Abfuhr bestimmter Materialien nach anderen Organen, ferner durch ihren eigenen Atmungsvorgang usw. Störungen entstehen, die das angeführte Ergebnis haben. Sie würden wohl unterbleiben. wenn man dem Blatte Kohlenhydrate zuführen würde, obwohl das in der Natur nicht vorkommt.

\section{Zufälliges Auftreten von Gestaltungsverhältnissen, die bei anderen Pflanzen als Anpassungen erscheinen.}

Die rorstehenden Ausführungen beziehen sich meist auf Reaktionen, die wir an Pflanzen direkt beobachten könneı. Es ist rielfach angenommen worden, daß Gestaltungsverhältnisse, welche jetzt „autonom“, d. h. nicht mehr infolge direkter Anpassung an die Lebensbedingungen auftreten, doch ursprünglich so entstanden sein könnten. Die Zeiten der Vergangenheit sind uns ein "Buch mit sieben Siegeln“, und auf rein theoretische Erwägungen soll hier nicht eingegangen werden.

Wohl aber ist eine andere Art der Fragestellung möglich. Wir wissen, daß bei den Pflanzen der "normale" Entwicklungsgang keineswegs ein starr innegehaltener ist, daß vielmehr Abänderungen in ihm vorkommen. die im Extrem als Mißbildungen bezeichnet werden, vielfach aber auch ganz harmlos erscheinen. Er ist für unsere Zwecke nicht ron Belang, ob diese Abänderungen auf die Nachkommen übertragen werden oder nicht. Vielmehr handelt es sich nur darum: können bei diesen Abänderungen, die

1) Vgl. Vöcutıxg, Über die Abhängigkeit des Laubblattes ron seiner Assimilationstätigkeit. Botan. Zeitung 1891 . 
wir als ,.zufällige“" d. h. in keiner direkten Beziehung zu den Lebensrerhältnissen stehende bezeichnen wollen, auch Gestaltungsrerhältnisse auftreten, welche bei anderen Pflanzen konstant sich rorfinden und bei diesen als Anpassungscharaktere betrachtet werden (wie denn eine extreme Schule von Neodarwinisten alle Gestaltungsverhältnisse als adaptir auffaßt). Es sei wiederholt, daß die Bezeichnung ,zufällig“ nur bedeuten soll: nicht adaptiv. Die Ursachen für diese Abänderungen sind uns unbekannt, wir wissen aber, daß die Außenwelt auch hier nur auslösend einwirkt.

\section{§ 8. Blattbildung.}

a) Schildförmige und schlauchförmige Blätter.

Eine Anzahl ron Pflanzen aus den verschiedensten Verwandtschaftskreisen sind dadurch ausgezeichnet, daß ihre regulären Blätter Schildform haben, d. h. daß der Blattstiel nicht die Verlängerung der Blattspreite darstellt, sondern sich auf deren Unterseite ansetzt (Fig. 20, I). Die Fähigkeit,

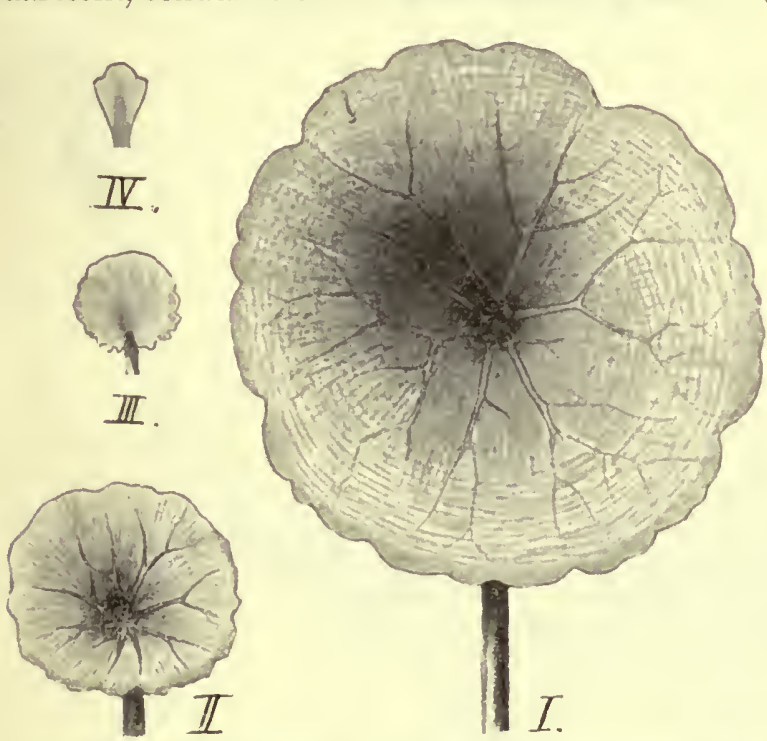

Fig. 20. Umbilicus pendulinus. $I$ und $I I$ schildförmige Lanbblätter, $I I I$ und $I V$ Hochblätter. solche Blätter ge legentli ch zubilden, ist bei einer großen Anzahl von Pflanzen vorhanden, deren Blätter normal nicht schildförmig sind (z. B.

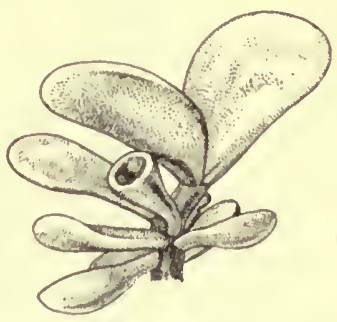

Fig. 21. Portulacaria afra, Steckling, an welchem ein Blattpaar ( $r o n$ dem nur ein Blatt zu sehen ist, das andere fällt anf die Rückseite) becherförmig ausgebildet ist.

Portulacaria afra Fig 21), sie tritt namentlich bei einer Änderung der -Ernährungsverhältnisse auf, wie sie z. B. bei Stockausschlägen stattfindet, kann aber in einzelnen Fällen, wie bei dem sonderbaren Ficus Krischnae auch auf alle Blätter einer Pflanze sich erstrecken ${ }^{1}$ ).

Ein merkwiirdiges Beispiel ist in Fig. 22 abgebildet. Sie stellt ein Blatt einer Primelpflanze (Primula Arendsii $=$ Pr. megasaefolia $\times$ Pr. obconica ${ }^{2}$ ) dar, welches zwei Eigentiimlichkeiten zeigt: einmal ist das Blatt nicht wie sonst bei Primula einfach, sondern gegliedert, indem es Seitenblättchen trägt,

1) C. de Candolze, Nouvelle étude des hypoascidies de Ficus, Bulletin de l'herbier Boissier Ileme sér. 1902, No. 9.

2) Gokbel, Annorme Blattbildnng bei Primula Arendsii. Flora 99 (1909), p. 370. 


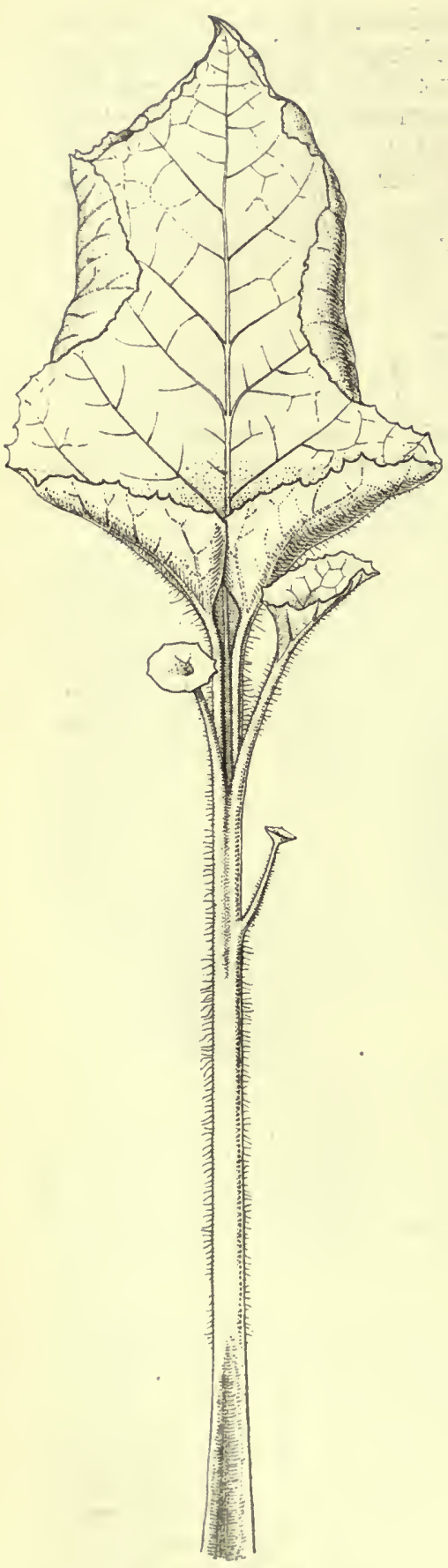

Fig. 22. Primula Arendsi

(Pr. megasaefolia $\times$ Pr. obconica). Abnormes Blatt. sodann sind diese schildförmig, zum Teil nach oben konkav vertieft. Die Schildform ist hier sicher eine für das Leben der Pflanze ganz gleichgültige Abweichung, die aber bei anderen Pflanzen regelmäßig auftritt. Es handelt sich bei dieser Primula wahrscheinlich um eine durch die Bastardierung bedingte, Eigentümlichkeit.

Noch auffallender ist ein anderes Beispiel. $\mathrm{Zu}$ den merkwürdigsten Blattformen gehören die Schlauchblätter mancher Insektivoren, z. B. die der Sarracenien, in Fig. 23 u. $24 C$ ist eines von S. psittacina abgebildet. Ganz ähnliche Schlauchblätter traten auf als gelegentliche "Variation" an den Hochblättern unterhalb der Blüten einer Kaktee, des Phyllocactus crenatus. Ein

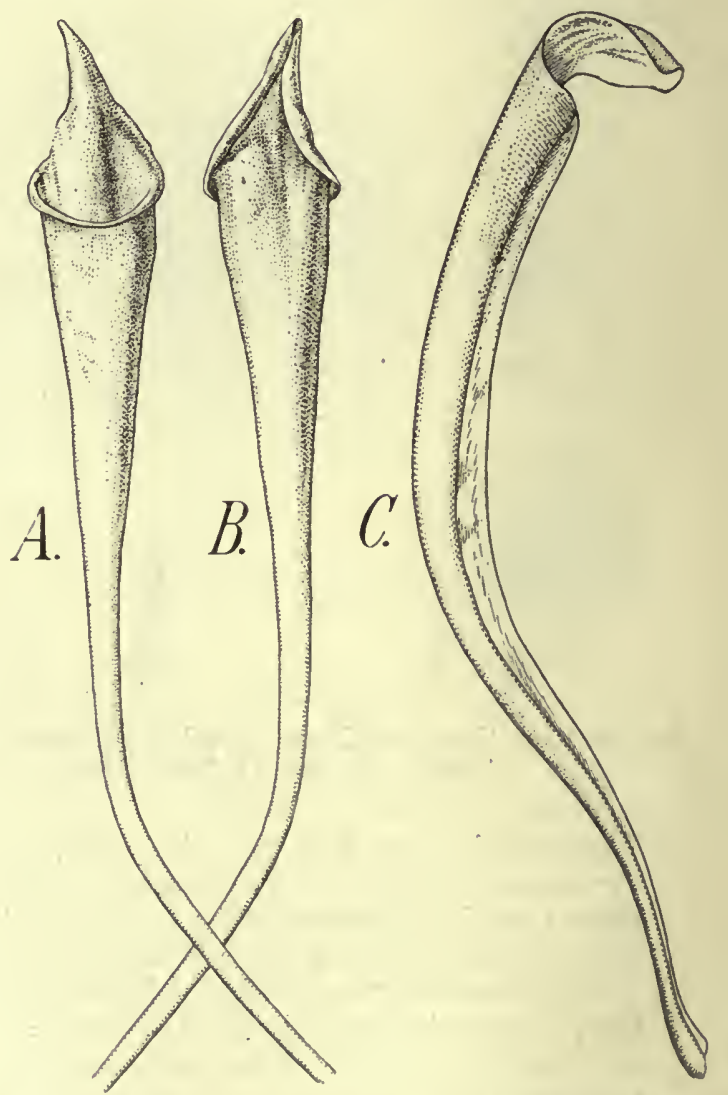

Fig. 23 und 24. Schlauchblatt von Phyllocactus crenatus, $A$ von vorne, $B$ von hinten, 2 fach. $C$ Schlauchblatt einer Keimpflanze von Sarracenia psittacina, von der Seite, ca. $1 \frac{1}{2}$ fach. 
derartiges Blatt ist in Fig. 23 u. $24 A$ und $B$ von rorn und von hinten abgebildet. Es zeigt eine überraschende Ähnlichkeit mit einem Sarraceniablatt - selbst der umgeschlagene Rand, welcher den Schlaucheingang aussteift, ist vorhanden. Selbstverständlich ist die Ähnlichkeit nur eine äußerliche, es fehlen die anatomischen Eigentïmlichkeiten, welche das Schlauchblatt von Sarracenia zu einer Tierfalle machen. Aber wir sehen doch, daß ,zufällig" eine Form zustandekommen kann, welche der bei Sarracenia "regulären entspricht; wenn sie sich mit den bei letzterer Gattung vorhandenen Struktureigentiumlichkeiten kombiniert, kann die merkwürdige Insektenfalle von Sarracenia zustandekommen.

\section{b) Wendeltreppenblätter.}

Manche Monokotylen zeigen die Blattform, welche ich Wendeltreppenblätter genannt habe ${ }^{1}$ ), d. h. die Basis der Blattspreite wächst längere

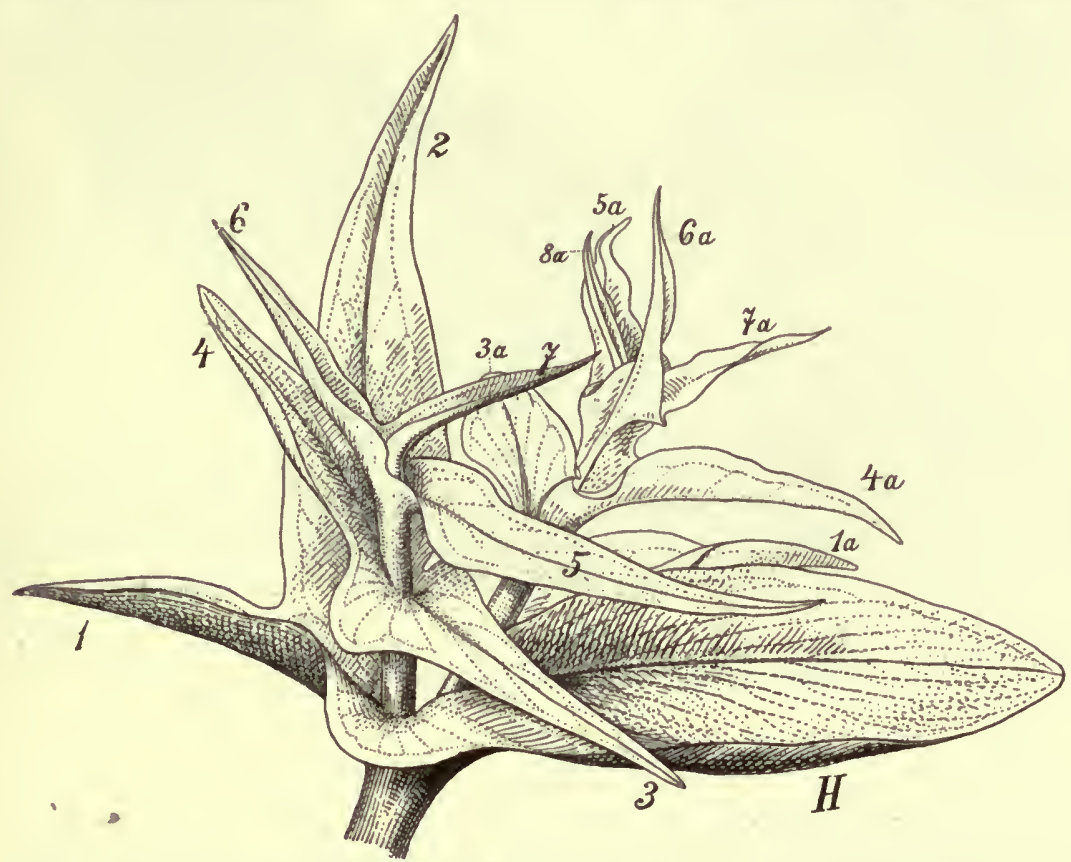

Fig. 25. Helicodiceros muscivorıs (Aroidee). Blatt anf die Hälfte verkleinert, schief von oben. $H$ die eigentliche Blattfläche, an deren Basis zwei Wendeltreppen mit den aufeinander folgenden Auszweigungen $1-7$, bzw. $1^{\mathrm{n}}-7^{\mathrm{n}}$.

Zeit fort und bildet rechts und links einen wendeltreppenartig gewundenen Auswuchs (Fig. 25). Auch diese Form tritt als ,zufällige" Variation bei anderen Pflanzen, zwei hybridogenen Begoniaformen (Begonia rex f. Comtesse Louise Erdödy und B. ricinifolia f. Wehlena) auf (Fig. 26). Die basalen Zipfel der Blattspreite gehen hier nicht in den Dauerzustand über, sondern wachsen lange Zeit weiter. Dies kommt am schönsten zur Geltung, wenn man diese Blätter als Stecklinge benutzt und alle Adventirsprosse entfernt. Es kann ein solches Blatt im Gegensatz zu den

1) Goeber, Über Wendeltreppenblätter. Naturw. Wochenschrift 1911. 
gewöhnlichen Begoniablättern monatelang wachsen - theoretisch vielleicht unbegrenzt; in praxi stirbt das Blatt schließlich ab, weil irreparable Schädigungen auftreten, doch gelang es, Blätter, deren Wendeltreppe 7 Umläufe zeigte, zu erzielen. Hier hat die Kreuzung offenbar eine Gestaltung in die Erscheinung treten lassen, welche bei den beiden Eitern nicht sichtbar war - eine Anpassungserscheinung liegt nicht vor.

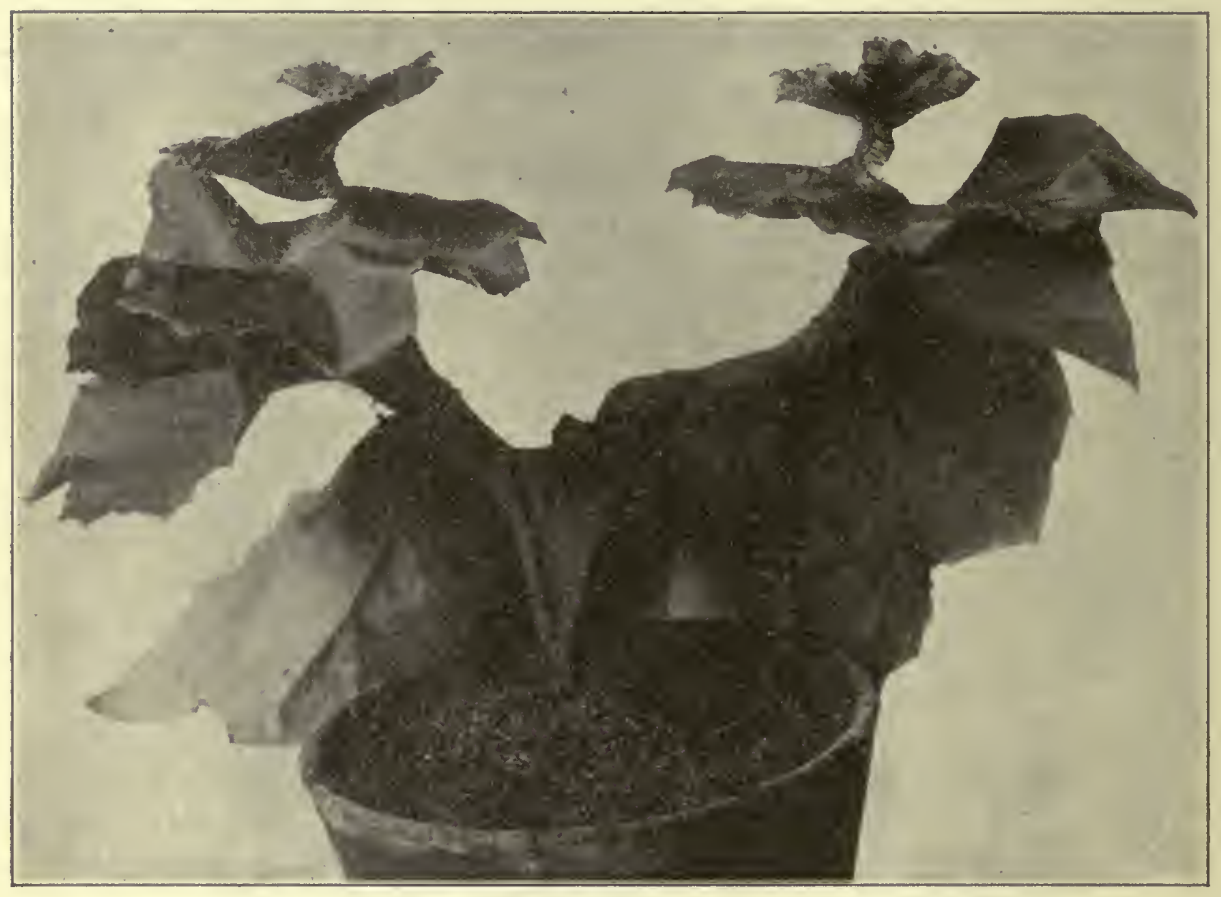

Fig. 26. Begonia ricinifolia f. Wehleana. Blattsteckling, an welchem die Zipfel der Blattspreite wendeltreppenartig ausgewachsen sind.

c) Gliederung des Blattes.

Schon bei Besprechung von Primula Arendsi wurde erwähnt, daß eine dem gewöhnlichen Verhalten gegenüber reichere Gliederung des Blattes als (wahrscheinlich hybridogene) Erscheinung „zufällig“" auftreten kann. Bei Pflanzen mit Blättern, deren Blattspreite reich gegliedert ist, kann das unter bestimmten Umständen von Vorteil sein. Allein diese reichere Gliederung kann auch als zufällige Variation auftreten.

Einige Farne, namentlich Nephrolepis-Arten bieten dafür auffallende Beispiele. Das Blatt ist hier typisch einfach gefiedert. Bei manchen, wahrscheinlich als Mutationen aufgetretenen Formen, wird die Fiederung aber eine doppelte, mit manchen Übergangsformen. Die Pflanzen zeigen dann diese Blattform meist an allen ihren Blättern. Aber es treten auch Rückschläge auf, Blätter, welche die "typische" einfach gefiederte Blattform ganz oder teilweise wieder annelmmen. So ist in Fig. 27 ein Blatt abgebildet, das in seiner oberen Hälfte die Normalform, in seiner unteren die Variationsform aufweist. Wie weit diese Blattvarianten bei Nephrolepis erblich sind, konnte 
bis jetzt nicht festgestellt werden, da sie keine Sporangien hervorbrachten. Wahrscheinlich ist Erblichkeit vorhanden, denn bei anderen Formen mit analogen Blattrarianten ist sie festgestellt ${ }^{1}$ ).

d) Blattfunktion durch die Nebenblätter übernommen.

Dies ist normal der Fall bei Lathyrus Aphaca, einer Pflanze, deren Blätter - abgesehen von den Primärblättern - zu fadenförmigen Ranken umgebildet sind, also für die Kohlenstoffassimilation so gut wie gar nicht in Betracht kommen. Dagegen sind die Nebenblätter stark rergrößert. Von einer anderen Papilionacee, Vicia Faba, ist ein Fall bekannt, in welchem die Blätter verkümmerten, die Nebenblätter aber dem gewöhnlichen Verhalten gegenüber stark vergrößert waren. Da, wie meine Versuche zeigten, eine Vergrößerung durch möglichst frühzeitige Entfernung der Blattspreiten liervorgerufen werden kann, so ist nicht daran zu zweifeln, daß dies auch bei jener Mißbildung der Fall war, zumal hier ja die Verkümmerung des Blattes viel frühzeitiger als beim Experiment und ohne Verletzung auftrat. Dasselbe ist auch für Lathyrus A phaca anzunehmen, bei welchem nur statt einer Verkiimmerung eine Umbildung des Blattes zur Ranke eingetreten ist.

e) Ranken. Tropaeolum aduncum gehört zu den Arten, welche "rankende" Blattstiele laben, die Blätter sind sonst aber als gewöhnliche Eaubblätter ausgebildet. Nor, ${ }^{2}$ ) beobachtete bei einer Keimpilanze an Stelle des fünften Blattes eine kleine, spreitenlose Ranke. Der Fall ist um so interessanter, als bei einer anderen (knollenbildenden) 'Tropaeolum-Art, T. tricolorum, an den Sprossen r e g e lmä Big zu Ranken umgebildete Primarblätter auftreten - verlängerte Blattanlagen, an denen eine Trennung in Stiel und Spreite noch nicht

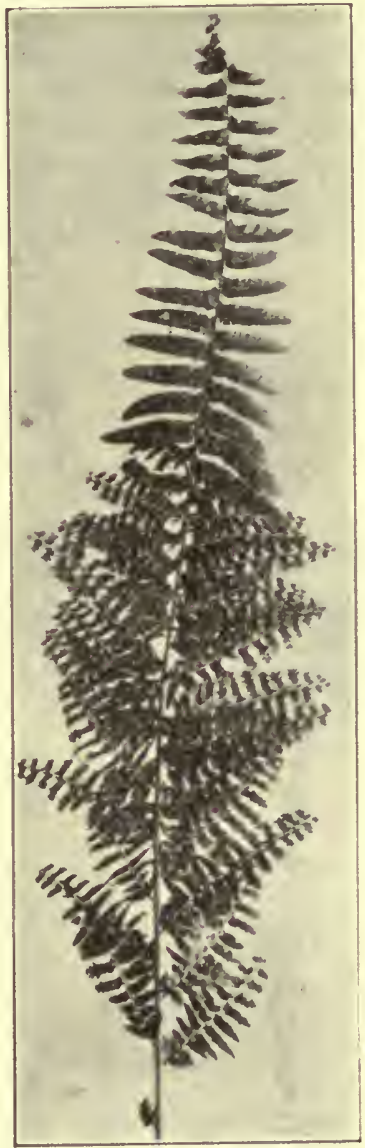

Fig. 27. Nephrolepis acuta f. Piersoni "elegantissima hort". Blatt oben "als Rückschlagsblatt ausgebildet. eingetreten ist.

\section{f) Gestaltung der Kotyledonen.}

Fiir die Ranunculacee Ficaria ranunculoïdes ist charakteristisch, daß die beiden Kotyledonen seitlich zu einem einzigen verwachsen. Genau dieselbe Erscheinung beobachtete ich als gelegentlich auftretende Variante bei Catha cassinoïdes.

1) Vgl. z. B. Heil.brosx, Apogamie Bastardierung und Erblichkeit bei einigen Faruen. Flora $101(1910)$, p. $1 \mathrm{ff}$.

2) F. Nour, Ċber das Auftreten einer typischen Ranke an einer sonst raukenlosen Pflanze. Sitz.-Ber. der niederrhein. Gesellsch. zu Bonı. 1895. 
g) Doppelnadeln. Ebenso treten die für Sciadopitys verticillata charakteristischen "Doppelnadeln" bei einigen Pinusarten als gelegentliches Vorkommnis auf.

h) Abweichende Stellung der Blattglieder. Für die Verzweigung der Blätter gilt die Regel, daß sie in der Ebene der Blattspreite erfolgt. Anders ist es bei den Ophioglosseen (Fig. 28). Hier steht der fertile Blattteil auf der Oberseite des sterilen Blattes (von welchem er in der Jugend schützend umhuillt wird). Man hat dies Verhalten aus dem gewöhnlichen abzuleiten gesucht, indem man annahm, der fertile Blatteil entspreche zwei rerwachsenen Fiedern und glaubte diese Annahme auch anatomisch stützen zu können. Doch beweist das nichts, denn es ist - nicht zu ver-

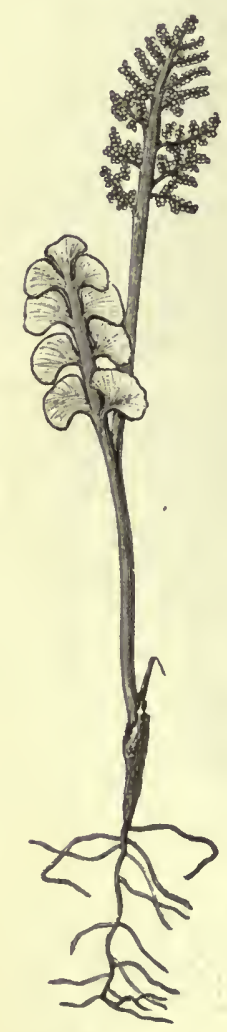

Fig. 28. Botrychium Lunaria und Ophioglossum vulgatum. Der fertile (sporangientragende) Blatteil entspringt anf der Oberseire des sterilen, nicht am Rande (Lehrb.).

wundern, daß ein median (namentlich ein den Blattrand nahe entstehender) - Auswuchs eine ähnliche Leit. bündelversorgung erhält, wie sonst zwei seitliche. Indes ist die laterale Auszweigung von Blättern auch nur ein zwar sehr verbreitetes, aber nicht aus. schließliches Vorkommen. Abnorm treten bei manchen Pflanzen auch auf der Blattfläche Blatteile auf. So in auffallender "IVeise bei dem in Fig. 29 abgebildeten Blatte von Brassica oleracea. Die mediane „Fieder" hat hier Becherform.

Was hier abnorm auftritt, ist bei den Ophioglosseen normal. Diese Ansicht wird dadurch gestützt, daß bei dem fertilen Blatteil einer Ophioglossee,

Fig. 29. Brassica oleracea Blatt (auf $1 / 4$ verkl.) mit becherförmigem Answuchs aus der Mittelrippe.

Helminthostachys eine Verzweigung auftritt, die (wenn man sich das junge Sporophyll flach denkt) nicht in der Fläche, sondern schief zu dieser stattfindet ${ }^{1}$ ) - im wesentlichen derselbe Modus wie der bei der Bildung des fertilen Blatteiles selbst, nur daß dieser nur in Einzahl und sehr frilhzeitig entsteht und deshalb mediane Stellung einnimmt.

1) Vgl. die 1. Auflage dieses Buches, p. 66 . 


\section{§ 9. Bliiten.}

a) Die Umwandlung ron Staubblättern in Blumenblätter tritt bei vielen Pflanzen (bei der Füllung der Blüten) als "Mißbildung“" auf. In den Blüten der Zingiberaceen, Marantaceen und Cannaceen ist dieser Vorgang normal vorhanden, so, daß von den ursprünglich in Sechszahl angelegten Staubblättern nur eines (Zingiberaceen) oder ein halbes (Marantaceen und Cannaceen) als pollenerzeugendes Organ übrig bleibt. Beiderlei Blütenänderungen (die anormale Variante und die reguläre) können als ,.zufällige " Formen aufgefaßt werden, wenngleich die aus den Staubblättern hervorgegangenen Blumenblätter im letzteren Falle für die Bestäubung der Bliiten von Bedeutung sind.

b) Auch wo es sich nicht um adaptiv zu deutende Verhältnisse in den Blüten handelt, sehen wir gleichfalls, daß ein für eine Gattung bestimmtes Zahlen- und Stellungsverhältnis innerhalb der Bliite in einer anderen als gleichgültige und zufällige Variante auftreten kann. So haben die Monokotylen typisch eine aus 53 zähligen alternierenden Kreisen aufgebaute Bluite. Potamogeton dagegen besitzt vier (resp. $2 \times 2$ )-zählige Bliiten, mit 4 diagonal gestellten Fruchtblättern. Bei Triglochin sehen wir normal dreizählige Blüten (Fig. $30)$. Es treten aber als Varianten zweizählige auf (Fig. 31), und obwohl selten - unter diesen auch solche mit 4 diagonal gestellten Fruchtblättern. Was bei dieser Pflanze als seltene Variation auftritt, kann bei Potamogeton ebenso zufällig normal geworden sein.

c) Besonders eigentümlich sind die Blü-

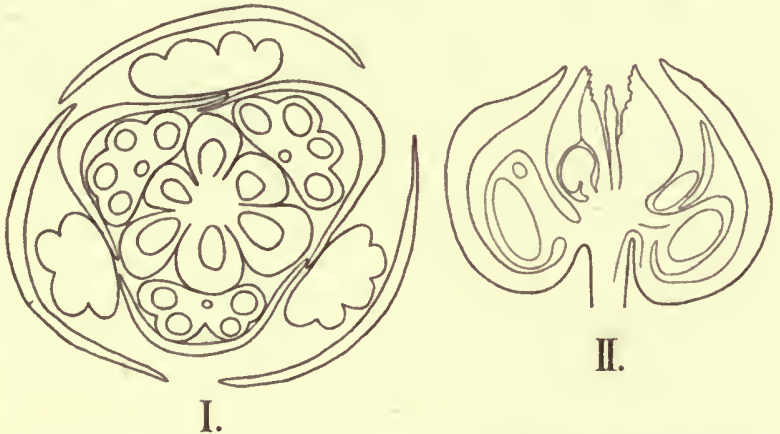

Fig. 30. Triglochin maritimum. 1 Querschnitt durch eine dreizählige Blüte (6 Perigon-, 6 Staub-, 6 Fruchtblätter, Stanbblätter den Perigonblättern opponiert. II Längsschnitt.
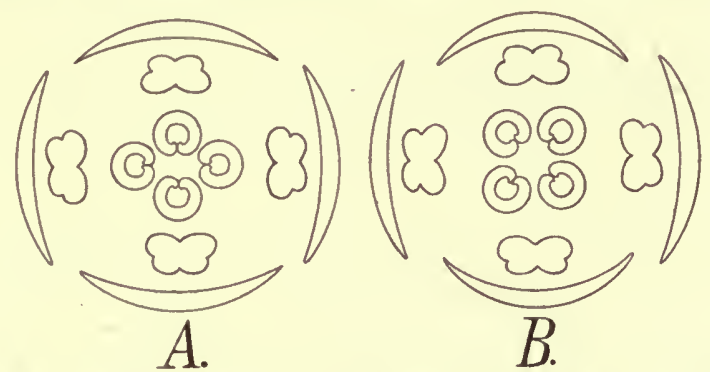

Fig. 31. Zwei Varianten von Triglochinblïten im Diagramm. Das in $B$ abgebildete entspricht einer Potamogetonblite.

ten, welche dorsiventral ausgebildet sind, weil sie vielfach ganz besondere Anpassungen an Insektenbestäubung zeigen. Man hat sie deshall als „durch Anpassung“ entstanden aufgefaßt. Es kommen aber auch Fälle vor, daß an einer Pflanze mit sonst radiären Blüten als Variante eine dorsiventrale auftritt. Dies hat z. B. HiLdebrand ${ }^{1}$ ) bei Fuchsia beobachtet. d) Systematisch (und auch für die Bestäubungsverhältnisse der Blüten) bedeutsam ist die "Verwachsung" der Blumenblätter bei den „Sympetalen".

\footnotetext{
1) Hildegbrand; Bot. Centralblatt 1899.
} 
Es sind sowohl bei Choripetalen (z. B. Papaver bracteatum f. monopetalım) ${ }^{1}$ ) Fälle bekannt, in denen Sympetalie „zufällig“ auftrat als solche bei Sympetalen, bei denen die Blüten choripetal ausgebildet waren, z. B. Rhododendron ponticum (vgl. DE VRIES a. a. O.).

\section{§ 10. Bliitenstände.}

Manche Blütenstände werden an ihrer Spitze wieder vegetativ, d. b. die Blütenbildung hört auf und statt der Blütendeckblätter treten Laubblätter auf. Diese Erscheinung findet sich konstant bei Ananas sativus ${ }^{2}$, Veltheimia viridiflora und einigen anderen Monokotylen, dagegen als "Mißbildung" unter (mehr oder weniger vollständiger) Verkümmerung der meisten (oder aller) Blüten an den Ährchenachsen mancher Gräser z. B. Poa alpina, P. bulbosa, Festuca ovina, die man als "vivipar" bezeichnet hat, obwohl dieser Ausdruck eigentlich ein unrichtiger ist. Diese "Viviparie" tritt teils nur gelegentlich, teils als Rassenmerkmal auf, d. h. die betreffenden Formen zeigen sie als erbliche Eigenschaft, wenn sie auch nicht unter allen äußeren Bedingungen zutage tritt. Auf trockenen und stickstoffarmen Substraten können bei der viviparen Poa alpina Rückschläge zur samentragenden Form eintreten ${ }^{3}$ ).

Da die aus den Ährchen entstandenen Sprosse sich leicht bewurzeln, stellen sie ein ausgiebiges Verbreitungsmittel der Pflanzen dar. Indes liegt die Sache keineswegs so, daß diese „viviparen" Sprosse dort auftreten, wo die Bedingungen für die Samenbildung ungünstige sind, wie schon die Angaben uiber das Auftreten der Rückschläge zeigen. Wohl aber kann unter bestimmten Umständen die Viviparie von besonderem Nutzen sein und dann den Eindruck einer „durch Anpassung erworbenen Eigenschaft" machen.

Besonders interessant ist das Verhalten von Deschampsia caespitosa ssp. litoralis var. rhenana am Bodensee. Sie findet sich dort an Standorten, welche nach und nach ganz überschwemmt werden, so daß die Pflanzen während der Sommermonate untergetaucht leben. Diese Pflanzen sind vivipar, was für sie zweifellos von großem Nutzen ist, da ein normaler Samenansatz unter diesen Verhältnissen nicht möglich ist. Sie köunen aber bei Wachstum auf trockenem Boden auch normale Bliiten und Früchte ausbilden. Wenn BaUMANN ${ }^{4}$ ) meint, die direkte Reizwirkung des umgebenden Mediums habe ein für die Pflanze vorteilhaftes ökologisches Merkmal "herausgebildet" (welches auch in der Kultur konstant bleibt!), so ist dies ein aus den Tatsachen keineswegs bewiesener Schluß. Diese zeigen vielmehr nur, daß das Gras unter den gegebenen Umständen vermöge der Viviparie (die bei anderen Gräsern auch da auftritt, wo sie keinen besonderen Vorteil bietet) vortrefflich gedeiht. Bewiesen wäre jener. Schluß nur, wenn es gelingen würde, eine nicht mit der Fähigkeit auf Überschwemmung mit Viviparie zu reagieren ausgerüstete Deschampsia durch Kultur an jenem Standort (oder unter denselben Bedingungen, wie dieser sie bietet) vivipar zu machen. Daß jetzt an jenem Standort keine „normale“ Form von Deschampsia mehr vorkommt, ist leicht verständlich, sie würde von der viviparen rasch ver-

1) Beobachtet von Vicyonrs, vgl. De Vries species and varieties, p. 661.

2) Hier werlen die "Schöpfe" bekanntlich mit zur künstlichen Vermehrung benutzt, da die Samen fehlschlagen. Sie haben auch schon Wurıeln angelegt. Was der Mensch hier kiinstlich tut, vollzieht die Natur selbst bej den viviparen Gräsern.

3) Vgl. Scirustek, Über die Morphologie der Grasbliite. Flora 100. Bd. (1910) p. 258.

4) E. Batmaxs, Die Vegetation des Untersees. Stuttgart 1911, p $21:$. 
drängt werden. Man könnte für die Annahme, daß eine direkte Anpassung vorliege, auch anführen: daß andere Gräser derselben Standorte (Agrostis alba, Poa alpina, Dactylis glomerata) gleichfalls Viviparie zeigen. Indes gilt auch für diese natürlich dasselbe. Solange nicht das oben genannte Experiment (bei welchem selbstverständlich keine Rückschlagsformen von viviparen Gräsern verwendet werden diirfen) gezeigt hat, daß äußere Einwirkungen Viviparie hervorrufen ${ }^{1}$ ) können, bleibt der Einwand bestehen, daß es sich an jenem Standort nur um ,zufällig" entstandene aber unter den dort herrschenden Bedingungen vortrefflich gedeihende Formen handle. Alles andere kann man allenfalls als eine Vermutung im Grunde des Herzens hegen - aber derzeit nicht beweisen!

Wie bei dem genannten Grase ein äußerer Umstand (das Überschwemmtwerden im See) Veranlassung gibt, daß eine - wahrscheinlich ganz unabhängig davon entstandene - Eigentümlichkeit der Pflanze als vorteilhafte Anpassung erscheint, so in anderen Fällen das Hinzutreten einer inneren, strukturellen Besonderlieit.

Sedum Stahlii ist eine Pflanze mit Bruchblättern ²), die sich leicht ablösen und da sie Adventivsprosse hervorbringen, ein ausgiebiges Vermehrungsmittel der Pflanze darstellen. Aber auch andere Sedumarten, deren Blätter sich nicht ablösen, z. B. Sedum album haben die Fähigkeit Adventivsprosse zu bilden. Sie bleibt aber für gewöhnlich - ohne Eingreifen des Menschen latent. Erst das Hinzukommen einer weiteren - auch zufälligen - Eigenschaft, der leichten Ablösbarkeit läßt die sonst nutzlose Eigenschaft der Blätter Adventivsprosse bilden zu können als eine nützliche erscheinen.

Ebenso könnten z. B. Zwerg- oder Trauerformen ron Bäumen, die in den verschiedensten Verwandtschaftskreisen als „,Mutationen“ aufgetreten sind, unter bestimmten Verhältnissen als zweckmäßige Anpassungen erscheinen.

In dieselbe Kategorie wie die oben angeführten Beispiele gehört auch die Erscheinung, daß vielfach Pflanzenteile, die weit verschiedenen Pflanzen angehören, einander sehr ähnlich sehen, ohne daß dabei etwa eine Anpassung an dieselben Lebensverhältnisse in Betracht käme.

Bei genauerer Betrachtung ist die Ähnlichkeit freilich meist weniger groß als man anfangs glauben mörhte. Einem geiibten Auge wird es z. B. nicht schwer fallen die Blätter der Composite Osmanthus ilicifolius ron denen der Aquifoliacee Ilex europaeus zu unterscheiden.

Es sei nur ein derartiger Fall erwähnt.
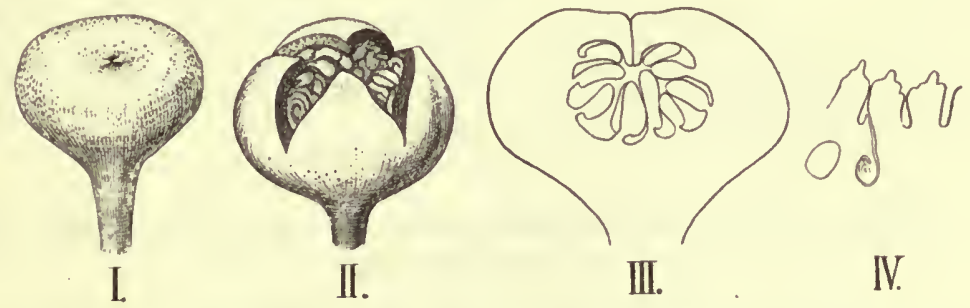

Fig. 22. Tambourissa quadrifida. I-III ınännliche Bliten. I Knospe, $I I$ geöffnet, III im Längsschnitt, $I V$ Stück aus dem Längsschnitt durch eine weibliche Blüte.

Die Bliitenknospen der Monimiacee Tambourissa sehen in ungeöffnetem Zustand einer kleinen Feige sehr ähnlich (Fig. 32 I), auch der Längs-

1) Was ich vergeblich versucht habe.

2) Abbildung bei Goeber, Einf. in die Exp. Morphol. p. 57. 
schnitt Fig. 32 III zeigt, daß in der hollen Bliitenachse der männlichen Blüten die Staubblätter ähnlich angeordnet sind wie die Blütenanlagen in einer jungen Feige.

Alle diese Ähnlichkeiten sind bloße Zufälle, ähnlich dem der bedingt, daß Kalksinterbildungen in Höhlen aussehen können wie Säulen, Vorhänge u. dgl.

Die angeführten Beispiele zeigen, daß Gestaltungsverhältnisse, die teilweise als auffallende Anpassungserscheinungen gelten, ,.ufällig" “ auftreten können. Nicht bewiesen ist damit natïrlich, daß sie dort, wo sie konstant vorkommen, auch zufällig aufgetreten sind.

Wenn wir über das Zustandekommen auffallender "Anpassungen" uns ein Bild zu machen suchen, so handelt es sich nicht um das Zustandekommen zweckmäßig gebauter Organismen überhaupt. Jeder Organismus, auch der einfachste, ist selbstverständlich „zweckmäßig“ gebaut, sonst wäre er nicht existenzfähig. Und außerdem sind, wie Verf. früher betonte ${ }^{1}$ ), nicht die Organismen die „Zweckmäßigsten“, die mit besonders auffallenden Apparaten einen bestimmten "Zweck" erreichen, sondern die, welche mit den einfachsten Mitteln arbeiten. Eine Orchideenblüte mit ihren oft wunderbaren Einrichtungen zur Bestäubung, speziell Fremdbestäubung, ist gewiß etwas sehr Merkwürdiges. Wer aber nur vom Nützlichkeitsstandpunkt ausgeht, wird mit Recht fragen: Wozu denn der ganze sinnreiche Apparat, während andere Pflanzen mit viel einfacheren Mitteln dasselbe erreichen? Offenbar ist das nur verständlich, wenn den Organismen das zukommt, was man früher "Gestaltungstrieb" genannt hat. Dessen Resultate, die je nach den Fähigkeiten der einzelnen Pflanzengruppen für den Áblauf bestimmter Funktionen nützlich, gleichgültig oder ungünstig sein werden, bedingen die in der Einleitung erwähnte Mannigfaltigkeit.

Mit schönen Worten hat GoETHE ${ }^{2}$ ) das so ausgedriickt. „Es ist ein großes Verdienst des alten Kant um die Welt, und ich darf sagen um mich, daß er, in seiner Kritik der Urteilskraft, Kunst und Natur nebeneinanderstellte und beiden das Recht zugesteht. z wecklos zu handeln. Natur und Kunst sind zu groß, um auf Zwecke auszugehen, und haben es auch nicht nötig, denn Beziige gibt's überall und Bezüge sind das Leben." Wenn diese "Bezüge" unvorteilhaft sind, wird ein Gestaltungsverhältnis sich nicht dauernd erhalten können. Aber auch an sich gleichgültige Gestaltungen können bestehen bleiben. Aufgabe der organographischen Forschung aber ist es, diesen "Beziigen" in den Richtungen, welche in der Einleitung angedeutet wurden, nachzugehen: die Erkenntnis, daß die Mannigfaltigkeit der Formen eine größere ist als die der "Anpassungen" an die Lebensbedingungen, kann uns von der Frage nach dem Zusammenhange beider durchaus nicht abschrecken.

\section{$\S 11$ Können die Lebensbedingungen die Reaktionsfähigkeit der Pflanzen ändern?}

Diese oben schon berührte Frage ist nach einer anderen Richtung hin hier noch kurz zu erörtern.

Wir wissen, daß die Bedingungen, unter welchen die Pflanzen leben, nicht immer dieselben waren, sondern gewechselt haben. und haben allen Grund, anzunehmen, daß auch die Pflanzen selbst im Verlauf ihrer Ent-

1) Gozber, Pflanzenbiolog. Schilderungen, p. 2 u. 3.

2) Govtue, Briefwechsel mit Zediter (18:30). 
wicklung sich geändert haben. Denn wir finden bei Pflanzen, welche unter extremen Lebensbedingungen $\mathrm{zu}$ wachsen vermögen, wie z. B. unter den Xerophyten und Wasserpflanzen Vertreter der verschiedensten Familien ror, die aber doch alle gemeinsame Züge in ihrem Verhalten zeigen. Bei den Xerophyten kommen z. B. die Einrichtungen, welche die Transpiration heruntersetzen, solche für Wasserspeicherung, Wasseraufnahme usw. in Betracht. Diese ermöglichen uns auch, an Stücken toter Pflanzen sofort zu erkennen, ob wir es mit einer „xerophilen“ oder "hygrophilen“ Pflanze zu tun haben: Wir können diese Übereinstimmung als das charakteristische Aussehen, die Fazies bezeichnen.

Wie ist diese gemeinsame "Fazies" zustande gekommen? Zwei Theorien stehen sich hier gegenüber: Die eine, die der indirekten Anpassung, sagt: eine wirkliche Anpassung im eigentlichen Sinne des Wortes, d. h. also eine direkt den Lebensverhältnissen zweckmäßig entsprechende Gestaltsregulierung gibt es nicht. Wohl sind manche Pflanzen befähigt auf verschiedene äußere Reize hin mit verschiedener Ausgestaltung ihrer Organe zu reagieren, also z. B. je nach den auf sie einwirkenden Bedingungen, entweder Luftblätter oder Wasserblätter, Dornen oder beblätterte Zweige, Kletterwurzeln oder Erdwurzeln, kleistogame oder chasmogame Blüten zu bilden, aber was sie auf ihre Nachkommen vererben, ist eben nur diese ihnen von vornherein eigentümliche und nicht etwa ad hoc erworbene Reaktionsfähigkeit, die ebenso wie andere Eigenschaften "zufällig* entstanden sein kann. Wenn ich eine Gesellschaft ron Pflanzen mit bestimmter Fazies antreffe, so besteht diese aus Pflanzen, die ihre Eigentïmlichkeiten z. B. die xerophilen ,zufällig“ erhalten haben, und sie nun an dem andere Pflanzen ausschließenden Standorte, auf den sie bei iliren Wanderungen gelangt sind, giinstig verwerten können, älnlich wie das oben an dem Beispiel der Viviparie bestimmter Gräser im Bodensee erörtert wurde. Einen derartigen Standpunkt vertritt z. B. DE VRres ${ }^{1}$ ) fiir die Wüstenpflanzen. Er meint, diese Pflanzen e rtragen ihren Standort, aber nur mit Miihe: "their life is nearer starvation than enjoyment": Eigentlich würden sie einen besseren, feuchteren Boden vorziehen, aber auf dem Wiistenboden seien sie frei vom Wettbewerb mit anderen Pflanzen und können sich rasch vermehren. Die Organisation dieser Pflanzen sei nicht das Produkt der Dürre des Standorts, sondern das Primäre, die Verteilung durch TVanderung das Sekundäre.

Unter den Wüstenpflanzen befinden sich ohne Zweifel manche, die auch an feuchteren Standorten ganz gut fortzukommen vermögen. Aber ob das für alle zutrifft, ist doch höchst fraglich. Man kann von kultivierten, d. h. unter unnatürlichen Verhältnissen erwachsenen Pflanzen aus keine bestimmten Schlüsse auf das Verhalten wildwachsender Pflanzen ziehen. Aber immerhin sei hier die jedem Kakteenliebhaber bekannte Erfahrung erwähnt, daß die Wurzeln mancher Formen sehr empfindlich sind gegen dauernde Befeuchtung des Bodens, namentlich in der Ruheperiode. Auch die oberirdischen Organe leiden leicht durch Fäulnis, wenn sie in sehr feuchter Luft kultiviert werden. Auch ohne Wettbewerb mit anderen Pflanzen würden also wohl manche xerophile Pflanzen bei dauernder Feuchtkultur nicht gedeihen. Aber auch wenn wir damit uns begnügten, alle xerophilen "Anpassungen" als ,zufällige" zu betrachten, so ist doch nicht einzusehen, weshalb die xerophilen Pflanzen ihre Eigenschaften fertig mitgebracht haben sollen. Sie könnten ja auch nur die

1) De Vries, plant breeding p. 347.

Goebel, Organog-aphie der Pflanzen. 2. Aufl. Allgem. Teil. 
Fähigkeit besessen haben, auf bestimmte Außeneinwirkungen in „xerophiler" Weise zu reagieren. Und daß die "Wandertheorie" nicht allg emein zutreffend sein kann, geht auch aus anderen Tatsachen hervor.

Unter den Wasserpflanzen z. B. befindet sich eine ganze Anzahl, welche auf dem Lande gar nicht existenzfähig sind, selbst wenn man sie gegen Austrocknung schützt, weil ihre Leitungsbabnen stark rückgebildet sind und Wurzeln ganz fehlen. So z. B. Ceratophyllum, Wolffiaarten, viele Podostemaceen (von letzteren gehen manche - vielleicht alle schon zugrunde, wenn sie aus dem fließenden in ruhiges Wasser gelangen). Andererseits ist nicht zu bezweifeln, daß die monokotylen und dikotylen Wasserpflanzen von Landbewohnern sich ableiten. Die genannten auf dem Lande jetzt nicht mehr lebensfähigen Pflanzen können also nicht in ihrer jetzigen Beschaffenheit vom Lande her eingewandert sein, sie müssen ihre Eigenschaften erst im Wasser erlangt haben ${ }^{1}$ ). Nun ist es möglich, daß auch hier die Abänderungen ,zufällig“ vor sich gingen, und daß in TVasser eben auch solche Abänderungen bestehen blieben, welche bei Landpflanzen nicht oder nur unter ganz besonderen Lebensbedingungen sich erhalten konnten. Es handelt sich, wie anderswärts ausgeführt ${ }^{2}$ ), bei den Wasserpflanzen einerseits um das Auftreten von Hemmungserscheinungen (z. B. geringere Gewebedifferenzierung, Unterbleiben der Bildung von Spaltöffnungen, Verkümmerung von Wurzeln), andererseits aber auch um Steigerung gewisser Eigentümlichkeiten (Ausbildung lufthaltiger Interzellularen, drüsiger Anhängsel) gegenüber den Landpflanzen.

In ersterer Beziehung ist stets im. Auge zu behalten, daß tatsächlich Verkümmerung und Hemmung außerordentlich häufig vorkommen. Welnn z. B. bei der Podostemacee Rhyncholacis die Wurzelbildung ganz fehlt - was möglich ist, weil die Pflanze durch andere Haftorgane, die sog. "Hapteren“ am Gesteine befestigt ist, - während andere Podostemaceen, welche in denselben Flüssen wachsen, Wurzeln haben, so wird man den Wurzelverlust im ersteren Falle nicht als eine "Anpassung" an das Wasserleben betrachten, sondern nur sagen können: die Pflanze konnte ihn ertragen, weil sie Hapteren besitzt, ähnlich wie wir in der Einleitung den Wurzelverlust von Genlisea durch die Übernahme der Wurzelfunktion seitens anderer Organe ermöglicht sahen. Und auch jene Rückbildungen der Leitungsbahnen usw. brauchen durchaus keine direkt zweckmäßigen Anpassungen an das Wasserleben zu sein, sondern nur Eigentümlichkeiten, welche im Wasser - nicht aber auf dem Lande - die Existenzfähigkeit nicht beeinträchtigen. Aber die gleiche "Fazies" der Wasserpflanzen würde dann voraussetzen, daß „zufällig" bei einer größeren Anzahl von Pflanzen verschiedener Verwandtschaftskreise dieselben Abänderungen vor sich gingen. Auch das ist möglich, aber es müßte erst entschieden werden, ob nicht noch eine andere Erklärung für diese Konvergenz gegeben werden kann. Nehmen wir z. B. die Verteilung der Spaltöffnungen auf den Blättern der Wasserpflanzen. Sie ist zwar keineswegs so „zweckmäßig“, wie man sie oft hingestellt hat und (wie früher gezeigt), durchaus nicht dire kt vom Medium abhängig - namentlich ist auch die oft wiederholte Angabe, daß bei Stratiotes die Blätter, soweit sie aus dem Wasser hervorragen, Spaltöffnungen besäßen, an ihren untergetauchten 'Teilen aber nicht, unrichtig ${ }^{3}$ ) -

1) Dasselbe gilt z. B. von Schmarotzern wie Orobanche. Lathraea, Balanophoreen, die keine Laubblätter mehr entwickeln und als autotrophe Pflanzen nicht mehr existenzfäbig wären.

2) Gozbra, Einleitung in die experimentelle Morphologie (1908) p. $36 \mathrm{ff}$.

3) Mostesantos, Beitr. zur Kenntnis der Hydrocharideen, Flora 105 (1912, p. 1 ff.). 
aber es ist doch sehr merkwürdig, daß die Schwimmblätter von Pflanzen aus den verschiedensten Familien Spaltöffnungen $\mathrm{nur}$ (oder fast nur) auf der Oberseite besitzen. So die der Nymphaeaceen, die der Gentianee Limnanthemum, die Polygonee Polygonum amphibium, der Hydrocharideen Hydrocharis morsus ranae und Limnobium Bosci, der Lemnaceen (soweit sie nicht submers wachsen), der Hydropteridee Marsilia quadrifolia. (Die am Rand der Unterseite bei letzteren rorkommenden meist übersehenen Spaltöffnungen sind offenbar Wasserspalten).

Es wurde oben (p. 21) schon mitgeteilt, daß Schwimmblätter von Polygonum amphibium auch bei Landpflanzen erzielt wurden. Dasselbe gelang bei Marsilia quadrifolia (an eben nach der Winterruhe austreibenden Pflanzen). Es ist dies eine Pflanze, welche normal an überschwemmten Standorten keimt. Sie bildet zuerst untergetauchte Primärblätter (welche aber noch Spaltöffnungen besitzen), dann Schwimmblätter, welche einen Blattstiel besitzen, der sehr lang werden kann und eine auf dem Wasser schwimmende Blattspreite, welche Spaltöffnungen nur auf der Oberseite hat im Gegensatz zu den Luftblättern. Später entwickeln sich Luftblätter, deren Blattstiele mit Sklerenchym versehen sind, iiber den Wasserspiegel hervorwachsen und Blattspreiten haben, die auf der Oberund Unterseite, auf letzterer aber viel mehr Spaltöffnungen besitzen. Man kann die Schwimmblätter auch später wieder hervorrufen, wenn man die Pflanzen, nachdem sie schon Luftblätter gebildet haben, in tieferes Wasser bringt. Es ist dies, wie schon A. Braun mit Recht hervorhob, eine Wiederhervorrufung der Jugendform. Diese kann aber auch auftreten, wenn man Marsilia quadrifolia mit Bodenwärme und unter möglichster Verhinderung der Transpiration kultiviert, dann also wenn die Pflanze sehr wasserreich ist. Die Verteilung der Spaltöffnungen steht hier in Korrelation mit anderen Eigenschaften des Blattes, und das Auftreten derartiger Blätter ist an besondere innere Zustände der Pflanze gebunden, die auf verschiedene Weise von der Außenwelt herrorgerufen werden können. Man sagt nur etwas Selbstrerständliches aus, oder vielnehr es ist nur ein Wortspiel, wenn man sagt, nur solche Pflanzen könnten Schwimmblätter bilden, welche vermöge ihrer spezifischen Struktur dazu befähigt seien. Gewiß wirkt die Außenwelt nur auslösend, nicht gestaltend, und eine Pflanze muß, um sich "anpassen" zu können, dazu sonst "latente" Fühigkeiten besitzen. Aber die Frage ist die, ob nicht die Reaktionsfähigkeit auf äußere Einflüsse durch diese selbst geändert werden kann? Nehmen wir ein anderes Beispiel von Wasserpflanzen: Manche Monokotylen besitzen bandförmige ungegliederte Primärblätter, so z. B. die SagittariaArten. Sie treten bei den einen z. B. Sag. chinensis als rasch vorübergehende Jugendstadien auf, bei anderen bilden sie die Hauptblattform, neben der die Blätter mit Stiel und Spreite mehr nebensächlich erscheinen. So bei S. natans u. a. Es sind dies Arten, welche mehr dem submersen Leben angepaßt sind; tatsächlich finden auch die Bandblätter das Optimum ihrer Entwicklung im Wasser, obwohl sie auf dem Lande gleichfalls auftreten können. Ihr Auftreten hängt von bestimmten Ernährungsbedingungen der Pflanze ab, aber die Reaktionsfähigkeit ist bei den verschiedenen Arten eine verschiedene. Nehmen wir nun zwei Pflanzen derselben Sagittaria-Art; die eine fruktifiziert (was z. B. bei S. sagittifolia auch vorkommt) auf dem Stadium, in welchem sie nur Bandblätter produziert hat, die andere (wie das hier das Normale ist) auf dem, welches Luftblätter besitzt, so ist denkbar, daß in den reifenden Samen im ersteren Fall quantitativ oder qualitativ anders zusammengesetzte Baumaterialien 
gelangen; als im letzteren. Damit aber wird auch die Gestaltung der Keimpflanze eine andere, sie würde im ersteren Falle mehr Bandblätter bilden als im letzteren, auch unter sonst gleichen Bedingungen. Sollte auf diese Weise sich nicht schließlich die Reaktionsfähigkeit überhaupt ändern, die Fähigkeit die „höhere“ Blattform zu bilden latent werden und schließlich ganz verloren gehen können?

Die moderne Vererbungslehre wird diese Frage rerneinen, und tatsächlich liegt in der Botanik auch kein Beweis für ihre Berechtigung vor. Wohl aber legen zahlreiche Tatsachen die Annahme einer zweiten Theorie (betr. der ersten vgl. p. 33) nahe, daß auch eine auf die Nachkommen überlieferte Beeinflussung der Gestaltungsverhältnisse durch die Außenwelt stattfindet. Nicht in der Art, daß die Pflanze ein "Bedürfnis" empfindet und dies als Reiz wirkt ${ }^{1}$, sondern so, da $\boldsymbol{B}$ ein bestimmtes Gestaltungsverhältnis sei es "zweckmäßig" oder gleichgültig ursprünglich in seinem Auftreten an äußere Bedingungen gebunden war, aber jetzt auch ohne direkte äußere Einwirkung auftreten kann. Mit anderen Worten es würde ein Erblichwerden erworbener Eigenschaften anzunehmen sein, wobei für unsere Zwecke nicht in Betracht kommt, wie das zu denken wäre. Diese Annahme beruht hauptsächlich auf folgenden Gründen:

1. Der oben erwähnten gleichartigen „Fazies" in Gebieten mit extremen Bedingungen.

2. Der Tatsache, daß die Gestaltungsverhältnisse, welche bei manchen Pflanzen auftreten infolge bestimmter äußerer Einwirkung, bei anderen ohne diese auftreten, als nach dieser Annahme „erblich fixiert" sind. Ein Beispiel dafür wurde oben schon für die Haftscheibenbildung an manchen Ranken angefïhrt, hier sei namentlich noch das Verhalten mancher Alpenpflanzen erwähnt, welches in letzter Zeit sehr häufig erörtert wurde.

a) Es kommen hier vor allem die Versuche G. Bonsien's in Betracht, von denen es wünschenswert wäre, $d a ß$ sie nachgeprüft würden. Viele Alpenpflanzen und auch solche des arktischen Nordens sind ausgezeichnet durch niedrigen Wuchs, durch Zusammendrängung der Blätter und verhältnismäßig starke Entwicklung der unterirdischen Teile (Wurzeln, Rhizome). (Vgl. Fig. 33.)

In Bonsick's Versuchen wurden stets zwei demselbem Exemplare entstammende Talpflanzen in verschiedener Höhe kultiviert.

Von 203 Pflanzen gingen zunächst $80 \mathrm{am}$ alpinen Standorte (in ca. $2000 \mathrm{~m}$ Höhe) zugrunde, sie waren nicht imstande, diesem sich anzupassen. Es blieben durch natürliche Auslese nur die übrig, die sich in entsprechender Weise verändern konnten, wie hier kurz an einigen Beispielen geschildert sei. Helianthus tuberosus war auf dem alpinen Standort ganz unkenntlich geworden: er bildete eine Rosette sehr behaarter, dicht dem Boden anliegender Blätter, während er in der Ebene einen hohen beblätterten Sproß trieb. Weniger auffallend, aber gleichfalls sehr charakteristisch sind die Veränderungen von Lotus corniculatus und Alchemilla vulgaris, die auf hochalpinem Standort dem Boden anliegende Teile bilden, was ihnen in verschiedener Beziehung von Vorteil ist: sie sind gegen zu starke Austrocknung durch den Wind besser geschützt und liegen dem Boden an, dessen obere Schicht vielfach wärmer ist, als die Luft. Jedenfalls haben sich diese Pflanzen in der TVeise rerändert, daß sie sich dem

1) Bei den Schwimmblättern würde es sich also darum handeln, daß die Spaltoffnungen nicht deshalb auf der Unterseite fehlen, weil sie dort nutzlos wären, sondern deshalb, weil das Fehlen in Beziehung zu anderen Eigenschaften des Blattes steht. 


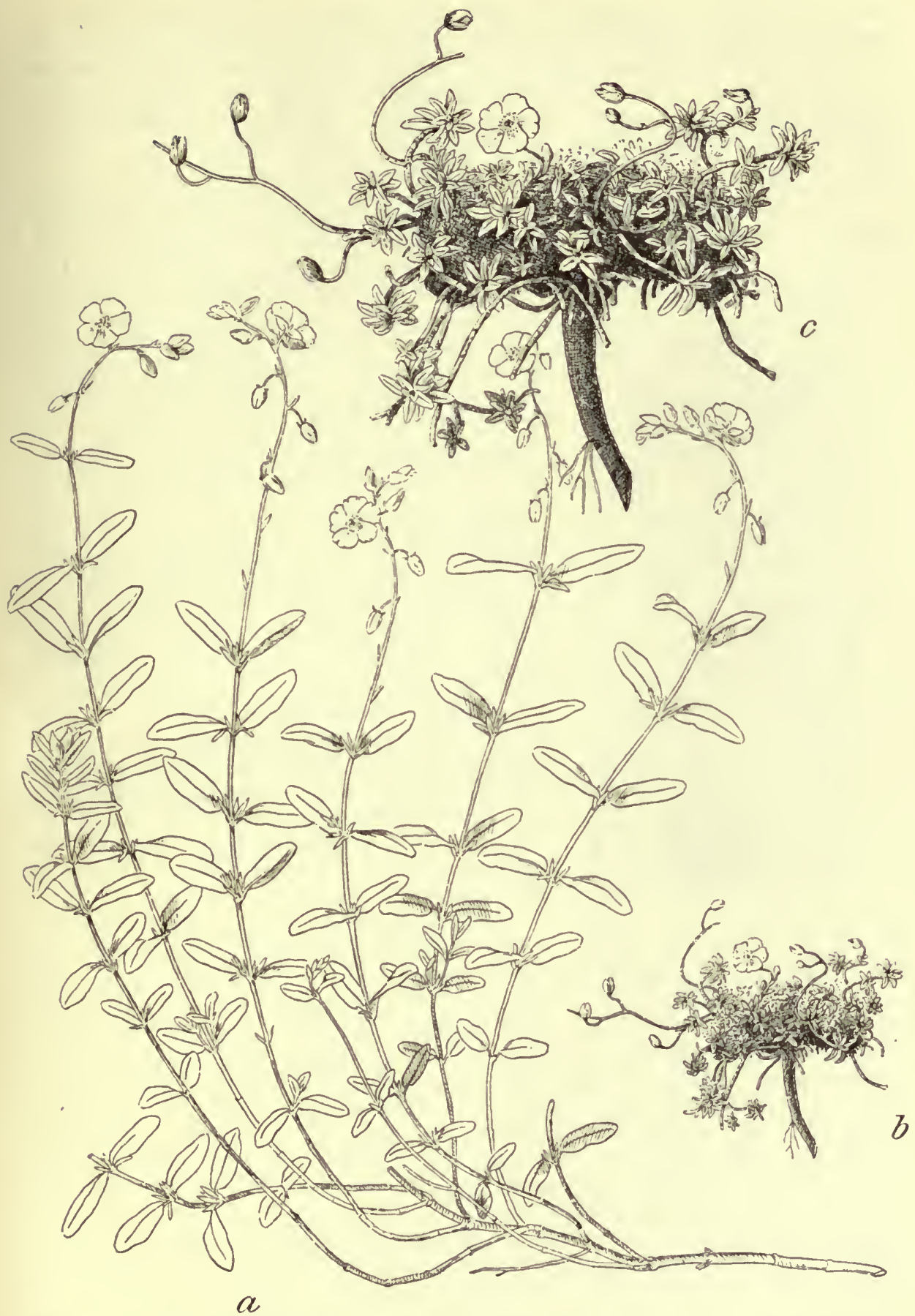

Fig. 33. Helianthemum vulgare. $a$ im Tieflande, $b$ im Höhenklima ( $1 / 2$ nat. Größe), $c$ dasselbe wie $b$, aber nat. Größe. Nach G. Bonsier ans Schimper, Pflanzengeographie. 
Habitus vieler eigentlicher Alpenpflanzen nähern, d. h. solcher, welche diese Gestaltungsverhältnisse auch an nicht alpinen Standorten zeigen.

$\mathrm{Da} ß$ die Reaktionsfähigkeit der Pflanzen eine größere ist, als sie beim normalen Verlauf der Vegetation hervortritt, zeigen uns nicht nur viele "Mißbildungen", sondern namentlich auch die höchst merkwürdigen Reaktionen auf Einwirkung von parasitischen Organismen.

b) Bilaterale resp. „amphitrophe" Coniferenäste.

Bei manchen Coniferen, z. B. Araucaria excelsa, sind die Seitenäste dadurch ausgezeichnet, daß sie trotz allseitiger Beblätterung nur auf den

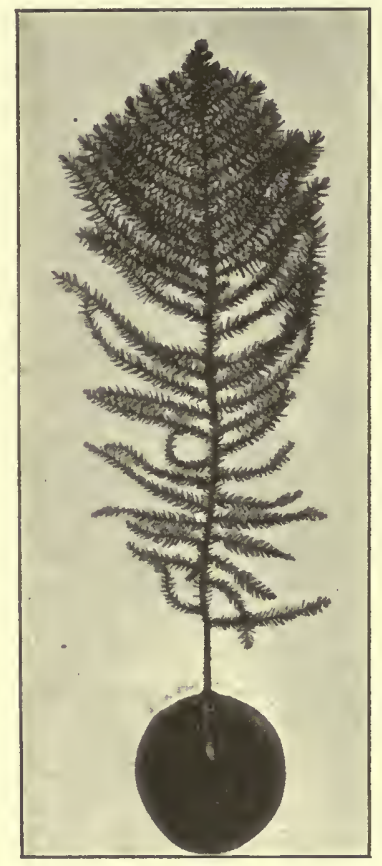

Fig. 34. Arancaria excelsa. 7 Jahre alter Steckling eines Seitensprosses, der seine bilaterale Beschaffenheit beibehält. Flanken Zweige tragen (,amphitroph" sind). Sie behalten diese Eigenschaft (wie lange Zeit bekannt ist) auch bei, wenn sie aus dem Verbande mit der übrigen Pflanze gelöst sind. So ist in Fig. 34 ein derartiger Ast abgebildet, der seit 7 Jahren als Steckling weiter wuchs. Es können, namentlich wenn die Spitze verletzt wird, auch nicht flankenständige Sprosse auftreten, aber auch diese ergeben amphitrophe Sprosse.

Bei anderen Coniferen, z. B. Ar. Cookii und Picea excelsa, aber sehen wir, daß die Amphitrophie der Seitenäste anfangs nicht vorhanden ist, sondern aus allseitiger Verzweigung durch die Unterdrückung der nicht flankenständigen Sprosse zustande kommt. Es ist mindestens wahrscheinlich, daß derselbe Vorgang nur nicht ontogenetisch, sondern phylogenetisch bei den anderen Formen stattgefunden hat. Ganz analoge Verhältnisse treffen wir bei den Laubmoosen. Der spontan amphitrophe Ast ron Araucaria excelsa entspricht einem Sproß von Hypnum (Ptilea) crista castrensis. Bei anderen Laubmoosen aber ist diese Gestalt wesentlich eine induzierte.

c) Dasselbe gilt für den dorsiventralen Bau vieler Laubblätter. Unzweifelhaft ist die verschiedene Ausgestaltung von Licht- und Schattenseite bei vielen Blättern jetzt nicht mehr (oder doch nur in quantitativer, nicht in qualitativer Beziehung) von äußeren Faktoren bedingt. Die Erörterung der Fälle aber, in denen die sonst als "Unterseite" ausgebildete abaxiale Blattseite den Bau der "Oberseite" "annimmt, wird dartun, daß dies unter dem Einfluß äußerer Faktoren, vor allem des Lichtes erfolgt ${ }^{1}$ ). Das läßt sich bei manchen Fällen auch noch experimentell nachweisen. Bezeichnenderweise sind das solche, für welche wir allen Grund zu der Annahme haben, daß es sich um verhältnismäßig noch nicht seit langem erfolgte Änderungen handelt. So bei einer blattähnlichen Ausbildung ganzer Sproßsysteme (Lycopod. complanatum, Cupressineen). Hier ist die Lage der Assimilationsfläche jedenfalls eine

2) Wobei allerdings zu betonen ist, daß uber die Frage nach der "Erblichkeit" dieser Struktur (also ihr Auftreten auch ohne direkte Lichtwirkung) nur sehr spärliche Untersuchungen rorliegen. 
nachträglich gewordene, derartige Pflanzenteile erscheinen noch plastischer als andere, z. B. die gewöhnlichen bifazialen Blätter, welche seit unendlicher Zeit ihre adaxiale Seite dem Lichte zugekehrt haben, und jetzt in ihrer Ausbildung sozusagen stereotypiert sind.

GewiB ist es schwer und in manchen Fällen wohl auch unmöglich zwischen spontan und induziert entstandenen Gestaltungsverhältnissen zu unterscheiden. Aber der Vergleich einerseits, die Auffindung plastischer Formen und planmäßige Versuche andererseits ermöglichen doch einen Fortschritt auch auf diesem schwierigen und viel umstrittenen Gebiete.

Das Resultat der obigen Ausführungen läßt sich kurz dahin zusammenfassen: Die "Teile" der Organismen sind Organe, ebenso wie dies bei einer Maschine der Fall ist. Ihre Gestalt hängt mit ihrer Funktion zusammen. Aber nicht alle Gestaltverschiedenheiten innerhalb einer natiirlichen Gruppe brauchen einen ganz bestimmten "Nutzen" zu laben. Die Mannigfaltigkeit der Formen ist vielmehr größer als die Mannigfaltigkeit der Lebensbedingungen. Viele auffallende "Anpassungen" sind wahrscheinlich ,.zufällig“, d. h. indirekt, entstanden. Die gleichartige „Fazies" bestimmter Gruppen sowie die Tatsache, daß dieselben Gestaltungsverhältnisse in einem Fall "spontan", im anderen induziert auftreten, machen es aber außerordentlich wahrscheinlich, daß auch die Art der Reaktionsfähigkeit auf äußere Faktoren sich unter dem Einflusse der letzteren geändert hat. Dabei gewährt es, wie Verf. schon früher betont hat ${ }^{1}$, keinen tieferen Einblick in die Verkettung von äußerem Anstoß und schließlicher Reaktion der Pflanze, wenn wir dieser ein „Bedliirfnis“ oder eine Art zielbewußter Reaktion zuschreiben.

Die nun folgenden Ausführungen sollen Materialien zum Studium der berïhrten Probleme darbieten.

1) GokBEL, Über Studium und Auffassung der Anpassungserscheinungen bei Pflanzen, München, Verlag der k. b. Akaremie, 1898. Ferner: Die kleistogamen Blüten und die Anpassungstheorien, Botan. Centralblatt, XXIV (1904). 
Zweiter Abschnitt.

\section{Die 0rganbildung anf den verschiedenen Stufen des Pflanzenreichs.}

\section{Einleitung: Organbildung und Arbeitsteilnng bei niederen Pflanzen (Thallophyten).}

Ein Vegetationskörper, welcher nicht in Sproßachse und Blatt gegliedert ist und auch nicht die für die Gefäßpflanzen charakteristischen IVurzeln besitzt, wird als Thallus bezeichnet. Einen flach, blattähnlich ausgebildeten Thallus hat man früher auch als "frons" beschrieben, eine iuberflüssige Benennung, die glücklicherweise im Aussterben begriffen ist. Der Ausdruck Thallus, der auch nichts anderes bedeutet als Sproß, ist von ACHarios ${ }^{1}$ ) zuerst auf die Flechten angewendet, nachher von anderen auf Algen, Pilze und die thallosen Lebermoose übertragen worden. Daß eine scharfe Grenze zwischen einem Thallus und einem beblätterten Sproß nicht zu ziehen ist, zeigen schon die unten anzuführenden Beispiele, besonders klar tritt dies auch bei den Lebermoosen hervor.

Es ist auch versucht worden, neben dem Begriff Thallus noch den des "Phytoms" aufzustellen. Darunter versteht NüGELI den Vegetationskörper der einzelligen Pflanzen, ferner den aus gleichwertigen Zellen bestehenden und den zwar mit Verzweigungen, aber nur mit unter sich und dem Mutterorgan gleichwertigen, versehenen Vegetationskörper. Das Phytom soll sich vom Thallus resp. Thallom dadurch unterscheiden, daß der Thallus "Trichome" hervorbringt. Diese Unterscheidung erscheint durchaus entbehrlich. Die mehrzelligen "Phytome" fallen teils unter den später zu erörternden Begriff der Kolonien resp. Coenobien, und von "Trichomen" in dem Sinne wie bei den höheren Pflanzen kann man bei den Thallophyten überhaupt nicht sprechen. Die Organe, die man bei ihnen als haarartige bezeichnen kann, haben den verschiedensten Ursprung und die verschiedenste Funktion ${ }^{2}$ ), es sind darunter Haftorgane, Schutzorgane der verschiedensten Art, solche, die Schleim absondern, und viele, deren Bedeutung wir nicht kennen. Sie haben nur das gemeinsam, daß sie klein bleibende Anhängsel des Thallus darstellen und mit den Haaren höherer Pflanzen vielfach eine

1) Vgl. Acuanius, Lichenographia universalis. Gottingae 1810 (p. 3: „In omni Licheno completo duae. . . sese offerunt partes, quarum nna corpus ipsius "Lichenis constituens thallus a me dicitur" ${ }^{\prime}$...).

2) Vgl. u. a. Moesius, Morphologie der haarartigen Organe bei den Algen. Biolog. Centralblatt XII S. $71 \mathrm{ff}$. 
gewisse-äußere Ähnlichkeit haben, aber es fehlt ihnen (da keine Epidermis vorhanden $\mathrm{zu}$ sein pflegt) natürlich auch das formale Merkmal, das man für jene als das ausschlaggebende betrachtet.

Gerade die niederen ${ }^{1}$ ) Pflanzen bieten Anhaltspunkte dafür, wie, ron einfachen Formen ausgehend, eine Reihe mit einer höheren (mit Arbeitsteilung verknüpften) Gliederung endigen kann, ein Vorgang, der sich nicht nur einmal vollzogen, sondern in verschiedenen Reihen wiederholt hat. Diejenige Gliederung, welche bei den höheren Pflanzen sich findet, erscheint dabei nur als ein Einzelfall der iberhaupt aufgetretenen.

\section{§ 1. Ein- und mehrzellige Pflanzen.}

Die äußeren Gestaltungsverhältnisse des Pflanzenkörpers sind bedingt durch die Eigenschaften der lebendigen Substanz, des Protoplasmas, das bei den höheren Pflanzen eingeschlossen ist in den zallreichen Zellen, die den Pflanzenkörper zusammensetzen. Nur unter den niederen Pflanzen finden wir einzellige vor. WVie SACHŚ gezeigt hat ${ }^{2}$ ), ist indes der Zellbegriff, wie er historisch sich entwickelt hat, ungenügend geworden, er führt zu offenbar unrichtigen Vergleichen. Wenn man eine Caulerpa und eine Diatomee oder Desmidiee alle als einzellig bezeichnet, so ist damit offenbar nur ein äußerer Umstand hervorgehoben: der, daß alle diese Pflanzen, von einer Zellhaut umgeben, einen nicht gekammerten mit einheitlicher Hautschicht versehenen ${ }^{3}$ ) Protoplasmakörper einschließen ${ }^{4}$ ). Der innere Bau dieser Plasmakörper ist indes ein verschiedener. Es zeigt sich dies dadurch, daß der eine (bei Desmidieen und Diatomeen) nur einen, der andere viele Zellkerne hat. Darin spricht sich aber eine verschiedene Organisationshöhe aus.

Nehmen wir ein Beispiel. $A$ sei eine einkernige, $B$ eine mehrkernige Zelle. Beide sollen sich vermehren durch Schwärmsporen. Dies kann bei $B$ einfach dadurch geschehen, daß jeder der vorhandenen Zellkerne sich mit Protoplasma umgibt, resp. daß der Plasmakörper sich in einzelne Teile sondert. Bei $A$ muß erst ein wiederholter Teilungsvorgang eintreten. Die ,vielkernige Zelle" ist also der einkernigen in diesem Beispiel zeitlich voraus, und außerdem zeigt sie in ihrem vegetativen Leben ein Verhalten, das bei der anderen erst zurzeit der Fortpflanzung eintritt - nämlich eben das, daßs sie vielkernig ist. Sie entspricht also nicht dem vegetativen, sondern dem vor der Fortpflanzung erreichten Zustand der einkernigen Zellen. Von einer mit vielen einkernigen Zellen aufgebauten unterscheidet sich eine Caulerpa nur durch das Fehlen der Zellwände.

Diese Erwägung veranlaßt uns, den Sachsschen Energidenbegriff anzuwenden. "Unter einer Energide," sagt. SAcHs, "denke ich mir einen

1) Dabei ist freilich nicht obne weiteres die einfachere Form als die primitive zu bezeichnen, vielfach lassen sich auch Rückbildungen feststellen; ein einzelliger Plenrococcus 2. B. ist offenbar nicht primitiv, sondern aus einer höher gegliederten Form rïckgebildet.

2) Vgl. namentlich dessen Physiologische Notizen II. Beiträge zur Zellentheorie. Flora 75. Bd. 1892 S. 57 and IX. Weitere Betrachtungen über Energiden und Zellen ibid. 81. Bd. (Ergbd. z. Jahrg. 1895).

3) Daranf legte z. B. Strasburger besonderes Gewicht.

4) So sagt z. B. L. Kr.EIN (vgl. Untersuch. über Morphologie nnd Biologie bei der Gattung Volvox; Ber. d. naturforsch. Ges. za Freiburg i. B. Bd. V Heft 1 S. 43): „Die böchste Ansbildungsstufe erweist das einzellige Individuum bei den Siphoneen - bei welchen die Natur einmal zeigen wollte, welche Entwicklungshöhe sich mit einer einzigen Zelle erreichen läßt. denn als solche müissen wir den Thallus trotz Größe und weitgehender Arbeitsteilung bezeichnen." 
einzelnen Zellkern mit dem von ihm beherrschten Protoplasma.". Diese Energiden können dann in Ein- oder Mehrzahl in einer Zellkammer eingeschlossen sein. Es ist dabei nicht notwendig, daß die von einem Zellkern „beherrschte“ Protoplasmamasse immer dieselbe sei ${ }^{1}$ ); aber gerade das Verhalten der Kerne bei der Bildung der Fortpflanzungsorgane der Siphoneen spricht deutlich für die Rolle, die ihnen der Begriff "Energide" zuweist, und ebenso das Verhalten bei der Regeneration. Bei der Fortpflanzung, sowohl der geschlechtlichen als der ungeschlechtlichen, treten in den genauer untersuchten Fällen einzelne Energiden auf, oder, wo dies nicht der Fall ist, wie bei den Schwärmsporen von Vaucheria ${ }^{2}$, zeigt das Verhalten der Cilien sehr deutlich, daß kein einfaches, sondern ein aus vielen Energiden zusammengesetztes Gebilde vorliegt.

Demnach unterscheiden wir auf Grund der neueren Zellenlehre zunächst nicht mehr ein- und mehrzellige, sondern monergide (abgekürzt aus monenergide) und polyergide Pflanzen; die polyergiden lassen sich dann in zelluläre (die gewöhnliche Form) und nichtzelluläre gruppieren, je nachdem die Energiden in Zellkammern eingeschlossen sind oder nicht.

Polyergide nichtzelluläre Pflanzen sind z. B. die Myxomyceten (falls man diese überhaupt zu den Pflanzen rechnen will) und die nur gegen außen durch eine Membran abgegrenzten Siphoneen, Organismen, die beide nur als Bewohner des Wassers oder ständig feuchter Standorte denkbar sind, in denen die Myxomyceten bis zum Fortpflanzungsstadium verborgen leben. Bei Landpflanzen dagegen tritt allgemein der zelluläre Bau auf, wobei die einzelnen Zellkammern durch feste Wände voneinander getrennt sind.

Die Schilderung des inneren Baues der Pflanzen gehört indes nicht hierher, dagegen konnte die oben kurz gegebene Auseinandersetzung auch vom organographischen Standpunkt aus nicht übergangen werden. Daß es auch zwischen den einzelnen oben aufgestellten Kategorien Übergänge gibt, braucht kaum hervorgehoben zu werden, als solche können z. B. die Siphonocladiaceen aufgefaßt werden, deren fadenförmiger, verzweigter Thallus aus polyergiden Zellen besteht.

Die Gestaltungsverhältnisse monergider Pflanzenkörper zu schildern, liegt nicht in der Aufgabe dieses Buches. In einer Anzahl von Fällen ist es gelungen, deren Form mit den Lebensverhältnissen in Beziehung zu setzen, so bei manchen Diatomeen, bei denen die festsitzenden anders gestaltete monergide Zellen haben, als die beweglichen oder schwebenden; ebenso ist klar, daß die birnförmige Gestalt dẹ meisten Schwärmsporen für ihre Bewegung besonders geeignet ist. In anderen Fällen kennen wir die speziellen Lebensverhältnisse noch zu wenig, um sagen zu können, ob z. B. die stabförmigen oder sichelförmigen Desmidieen anderen Verhältnissen angepaßt sind, als die platten, aber es ist wohl nicht zu bezweifeln, daß gerade bei diesen Formen die Mannigfaltigkeit der Gestaltung größer ist, als die der Lebensbedingungen.

1) Roß und Reiter bilden in einem Kavallerieregiment eine "Einheit", auch wenn die Pferde gewechselt werden!

$\left.{ }^{2}\right)$ Wie Scirsitz nachgewiesen hat, entsprechen jedem Zellkern, oder, wie wir jetzt sagen können, jeder Energide zwei Cilien, die ganze vielwimperige Schwärmspore also einen Komplex zahlreicher zweiwimperiger. - Die Verschiedenheit monergider und poly. ergider "Lellen spricht sich namentlich auch durch ihr Verhalten bei der "Regeneration" aus; kleine Stiucke des Inhalts polyergider Zellen könmen (sofern sie eine oder mehrere Energiden enthalten) zu neuen Zellen auswachsen, bei monergiden Zellen ist eine solche Teilbarkeit nicht vorhanden. 
Der Übergang von monergiden zu polyergiden Formen hat offenbar in den verschiedensten Verwandtschaftskreisen stattgefunden und zwar dadurch, daß die bei der Teilung entstandenen Energiden sich nicht vereinzelten, sondern im Verbande miteinander blieben. NÄGELI ${ }^{1}$ ) hat das schon vor längerer Zeit folgendermaßen geschildert: „Die Zellen, die bei der einfacheren Pflanze sich als Keime lostrennen und die Anfänge neuer Individuen darstellen, werden bei der nächsthöheren Pflanze Teil des individuellen Organismus und verlängern die Ontogenie um einen entsprechenden Schritt."

\section{§ 2. Zellkolonien und Zellstaaten.}

Der Verband, in welchem die einzelnen Energiden miteinander stehen, kann ein mehr oder minder inniger sein. Eine polyergide Pflanze ist entweder eine (zelluläre oder nichtzelluläre) Energiden-Kolonie (oder Coenobium = Energiden- "Horde"), bei der eine Arbeitsteilung zwischen den einzelnen Energiden noch nicht aufgetreten ist und jede Energide auch für sich zu leben rermag, oder die Energiden zeigen eine Arbeitsteilung und werden in Verbindung damit verschieden voneinander, sie gestalten sich zum Energiden-,Sta at"; dies ist der Fall, welcher bei der Mehrzahl der..polyergiden Pflanzen verwirklicht ist. Zwischen beiden gibt es natürlich Übergänge, schon weil die Abtrennung eine künstliche, auf die extremen Verhältnisse begründete ist.

\section{$\S 3$. Kolonien.}

Die äußere Form der Kolonien ist eine sehr verschiedene; ich möchte im folgenden lediglich einige Beispiele herausgreifen, um zu zeigen, worauf es hier ankoinmt.

\section{A. Nicht festsitzende Kolonien.}

\section{Kolonien nackter Energiden (nichtzelluläre Energidenkolonien)}

finden wir in den Plasmodien der Myxomyceten (Fig. 34 A). Die Vorteile der Koloniebildung hängen hier offenbar mit der Sporenbildung und namentlich der Sporenverbreitung zusammen. Eine Energidenkolonie kann größere, für die Verbreitung der Sporen besser ausgerüstete Fruchtkörper aufbauen. Besonders lehrreich ist, daß bei einer niederen Entwicklungsreihe, der der Acrasieen, die vegetativen Energiden noch vereinzelt leben, kein Plasmodium bilden, und erst wenn die Sporenbildung herannaht, zusammenkriechen. Ein Fruchtkörper kommt dabei bei Guttulina z. B. noch nicht zur Ausbildung, und ein besonderer Vorteil des Zusammenkriechens der Energiden oder des Zusammenlagerns der Sporen ist nicht abzusehen, wenn man nicht etwa annehmen will, daß ein solches Sporenhäufchen für die Verbreitung der Sporen günstigere Aussichten biete, als eine einzelne Spore sie hat. Nehmen wir aber als einmal gegebeu an (ohne daß wir uns um den Nutzen weiter kümmern), daß die ursprünglich freilebenden (hier als Amöben zu bezeichnenden) Energiden eine Anziehung aufeinander ausüben (wahrscheinlich eine chemotaktische), so läßt sich, von den

1) NäGRLI, Systematische Übersicht der Erscheinungen im Pflanzenreich. Freiburg i. B. 185̄3. Ferner: Mechanisch-physiol. Theorie der Abstammungslehre S. 332. 
Acrasieen ausgehend, eine fortschreitende Reihe zusammenstellen, bei der die Sporenbildung in einen imm er späteren Zeitpunkt nach der Koloniebildung verlegt wird, also zwischen der letzteren und der Sporenbildung ein vegetatives Stadium eingeschaltet wird, das ermöglicht, viel mehr Sporen zu bilden, als Energiden sich zur Kolonie vereinigt hatten, während ursprünglich
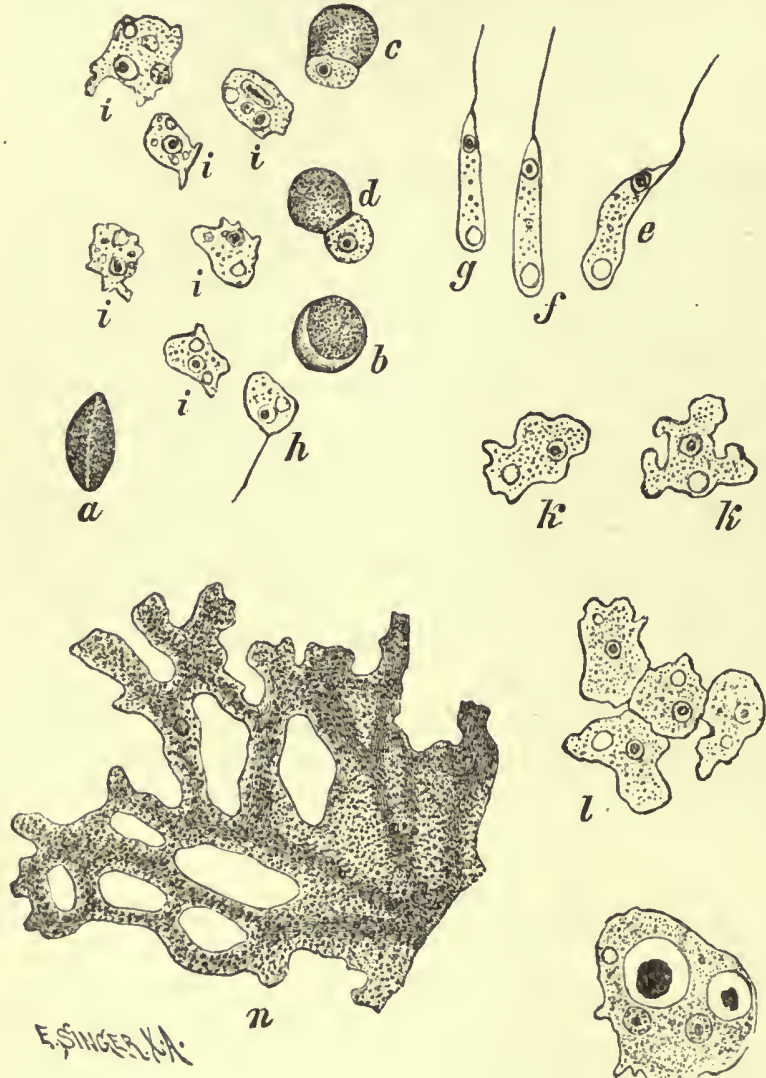

Fig. 34 A. Keimung und Plasmodienbildung des Myxomyceten Chondrioderma difforme; ans den Sporen schwärmen nackte, bewimperte Energiden aus $(a-g)$, die zu Amöben $(i, k)$ werden; aus diesen geht später eine Energidenkolonie hervor; $n$ ältere Energidenkolonie (= Plasmodium). (Lehrb.)

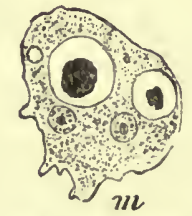
(bei Guttulina) die Zahl der Sporen und der Energiden gleich war. In den höchst entwickelten Fällen findet schon bei den Acrasieen eine Arbeitsteilung unter den Energiden statt, es bilden sich Fruchtkörper, bei denen nicht mehr alle Energiden zu Sporen werden, sondern nur ein Teil - allerdings der größere -, während andere zum Aufbau des Stieles Verwendung finden.

Lehrreich sind die von BREFELD näher untersuchten Arten Polysphondylium violaceum (Fig. 35) und Dictyostelium mucoroides ${ }^{1}$ ). Aus den keimenden Sporen gehen hier nackte, amöboide Energiden hervor, die sich durch Zweiteilung vermehren, aber nicht, wie bei anderen Schleimpilzen, zu einem Plasmodium sich vereinigen. Erst zur Bildung eines Fruchtkörpers kriechen sie (nach Potrs veranlaßt durch Nahrungsmangel) in ungemein großer Zahl zu einer dichten Masse zusammen, wobei offenbar chemotaktische Richtungsbewegungen mit im Spiel sind. Nun tritt zwischen den sich offenbar beeinflussenden Amöben eine "Arbeitsteilung" ein. Nicht alle werden, wie bei den niederen Formen dieser Reihe noch geschieht, zu Sporen. Eine mittlere Partie der Amöbenmasse wird zur Bildung eines zelligen Stieles verwendet. Die hier gelegenen Amöben nehmen Wasser auf, welches sie anderen entziehen, umgeben sich mit einer Membran und werden zu polyedrischen Zellen. Der Stiel (dessen

1) Brefeld, Untersuchungen ans dem Gesamtgebiete der Mykologie 6. Heft. Potrs, Zur Physiologie des Dictyostelium mucoroides. Flora 91, p. 281. 
Bildung im Wasser unterbleibt) wächst an seiner Spitze, indem die hier gelegenen Amöben zu Stielzellen umgebildet werden. An dem Stiel kriechen die Amöbenmassen in die Höhe, und wenn er fertig ist, werden alle nicht zur Stielbildung verwendeten Amöben zu Sporen. Offenbar sind die Amöben ursprünglich alle gleich. Es hängt von ihrer Lage im Amöbenhaufen und von ibrer gegenseitigen Beeinflussung ab, ob eine Amöbe zur Stielzelle oder zur Spore wird. Daß die Stielbildung für die Sporenverbreitung vorteilhaft ịst,

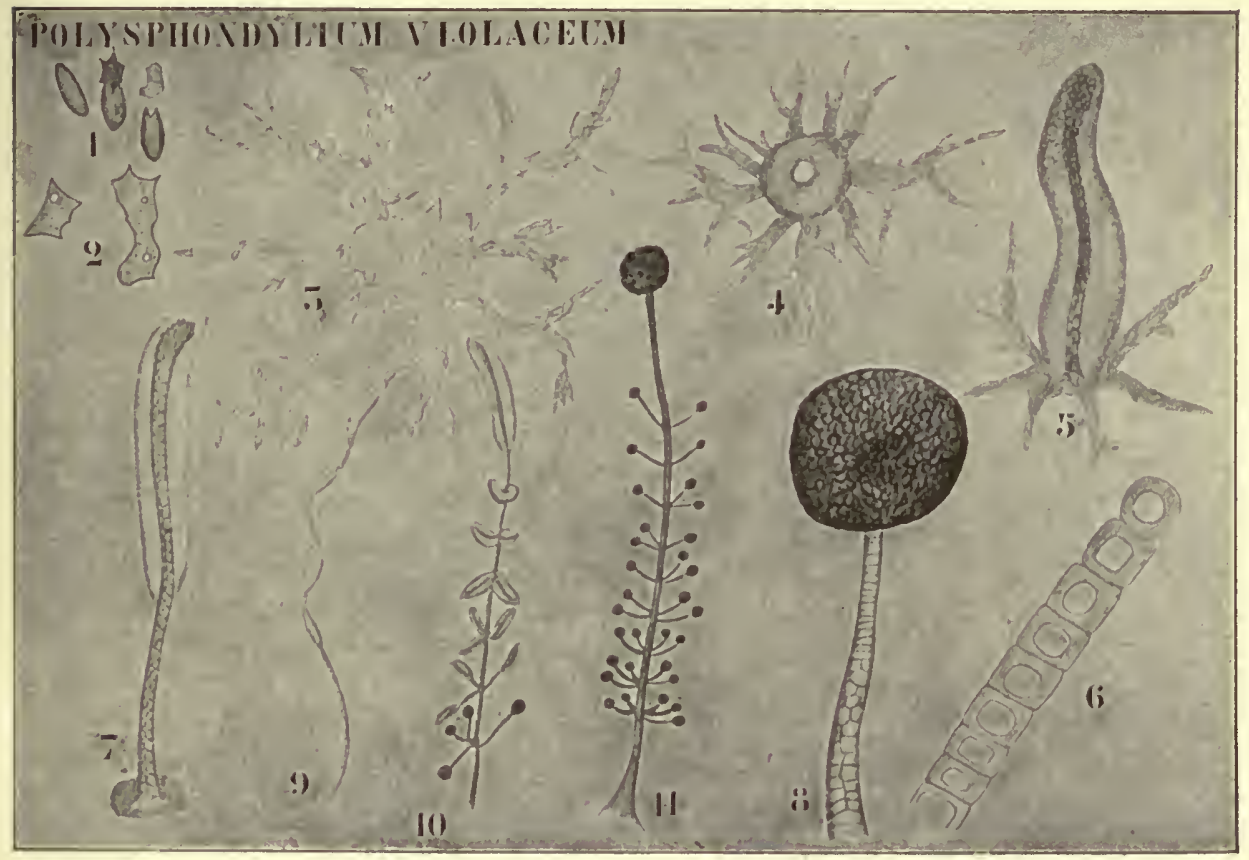

Fig. 35. Polysphondylium riolaceum (nach Brefeld). 1. Sporen links und aus diesen ausschlüpfende Amöben rechts; 2. Amöben (rechts in Teilung begriffen); 3 . Pseudoplasmodiun; 4. Anfang der Fruchtkörperentwicklung; ら. älteres Stadium, zentraler Strang, steril bleibender Amöben: 6. Teil des Zentralstrangs stärker vergröl'lert; 7., 8. Plasmodium kriecht an dem Stiele hinauf; 9.-11. verzweigte Fruchtkörper. Ans Lo'ss, Vorlesungen über Stammesgeschichte.

ist klar; sie hat dieselbe Funktion wie bei den Moossporogonien usw. Ein an seiner Spitze durch neu heraufkriechende Energiden wachsender Polysphondyliumfruchtkörper stellt ein sonderbares Gegenstück zu einem Sproß einer höheren Pflanze dar, der auch an seiner Spitze - am Vegetationspunkt embryonale, weiter unten fertig ausgebildete Energiden besitzt.

\section{Kolonien behäuteter Energiden ${ }^{1}$ ) (zelluläre Energidenkolonien).}

Angeführt werden sollen nur einige Beispiele, welche für allgemein organographische Fragen lehrreich sind.

a) Protococcaceen. In Fig. 36 abgebildet ist eine größtenteils aus entleerten Zellen bestehende Kolonie von Pediastrum granulatum, einer häufigen Süß.

1) Betr. der Literatur sei auf das Outmanss'sche Algenbuch verwiesen. 
wasseralge. Wir benterken, daß die den Rand der tafelförmigen Kolonie einnehmenden Zellen andere Gestalt haben als die inneren, sie sind mit zwei hornförmigen Fortsätzen versehen, oder, kurz gesagt, zweiarmig. Bei den inneren Zellen tritt dies nicht hervor. Aber die Durchmusterung einer Anzahl von Formen (auch das in Fig. $36 C$ abgebildete Jugendstadium) zeigt uns, daß eigentlich alle Zellen die Fähigkeit haben, zweiarmig zu werden, daß aber die inneren durch ihre dichte Zusammenlagerung daran verhindert werden, diese Form anzunehınen. Würde man die regelmäßige Anordnung der Zellkolonie bei ihrer Geburt stören, so würden gewiß alle Zellen zweiarmig werden. Wir sehen also, daß hier schon eine, wenn auch nicht sehr tiefgreifende gegenseitige Beoinflussung der Zellen eintritt. Die einzelnen Zellen der Pediastrumkolonie werden übrigens nach CHODAT frühzeitig polyergid, und

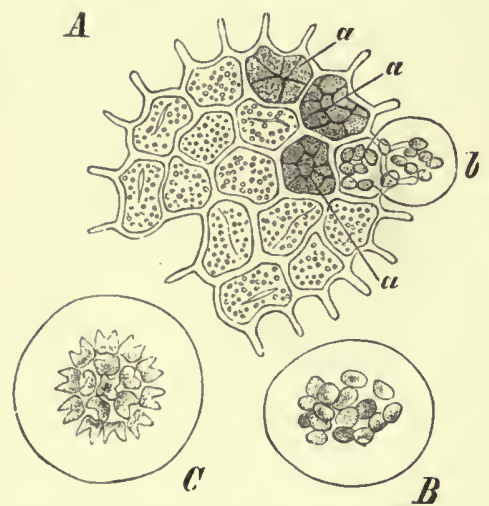

Fig. 36. Pediastrum granulatum (nach A. Braun). A Kolonie, deren Zellen bis auf vier entleert sind; der Inhalt der letzteren wird zur Bildung von Tochterkolonien verweudet. $B$ Junge Kolonie, deren Zellen noch regellos angeordnet sind. $C$ Etwas ältere $\mathrm{K}_{0}$ lonie, deren Zellen sich in eine Ebene angeordnet haben; die änßeren sind deutlich zweispitzig, die inneren zeigen uur eine Andeutung davon. (Lehrb.)

sich durch eine Längswand, der

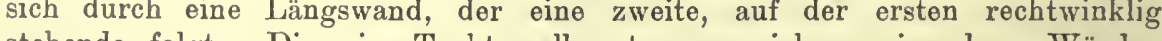
stehende folgt. Die vier Tochterzellen trennen sich voneinander. Würden sie - in einer Ebene liegend - vereinigt bleiben, so würden sie eine vierzellige Kolonie bilden, wie sie bei der Gattung Gonium (Fig. 37) vorkommt. Hier sind 4 bis 16 einander ganz gleiche Zellen von einer gemeinsamen Schleimhülle umgeben, sie bilden eine flache, tafelförmige Kolonie, deren Zellen nicht, wie man früher annahm, durch Protoplasmafortsätze miteinander in Verbindung stehen. Wie wenig innig die Zellen miteinander verbunden sind, zeigt auch die Tatsache, daß bei Gonium pectorale (wie BüTSCHLI angibt) häufig einzelne Zellen die Kolonie verlassen und als chlamydomonasartige Wesen frei umberschwärmen; manchmal lösen sich auch die Kolonien ganz in einzelne Zellen auf. Jede der Zellen kann zum Ausgangspunkt einer neuen Kolonie werden, eine vegetative Vermehrung der Zellen aber findet, nachdem die Kolonie einmal gebildet ist, nicht mehr statt. Denken wir uns die flache Goniumkolonie zu einer Hohlkugel eingestülpt, so erhalten wir Eudorinakolonien (Fig. 38) (ebenso entstehen in etwas abgeänderter Weise auch die Pandorinakolonien). Auch hier 
sind die Zellen noch sämtlich gleichwertig und nicht miteinander in Verbindung. Anders bei der Gattung Volvox selbst. Zunächst ist hervorzuheben, daß hier schon die Zahl der Zellen, sowie die Größe der ganzen Kolonie eine bedeutendere ist, als bei den oben angeführten Gattungen. Erstere schwankt bei Volvox aureus zwischen 200 und 3000, bei Volvox globator zwischen 1500 und 16400 (bei den hier allein, in Betracht kommenden ungeschlechtlichen Kolonien).

Der merkwürdige feinere Bau der Kolonien kann hier nicht geschildert werden, es genügt, zu erwähnen, daß sie zwei Pole besitzen, die sich sowohl entwicklungsgeschichtlich als ihrem Baue nach unterscheiden. Der eine, bei der Bewegung nach vorn gerichtete trophis che Pol ist der, an welchem das Zusammenschließen der Zellen aus einer konkaven Platte zur Kugel stattfand; zuweilen bleibt hier noch eine Öffnung erhalten. Die Zellen, welche

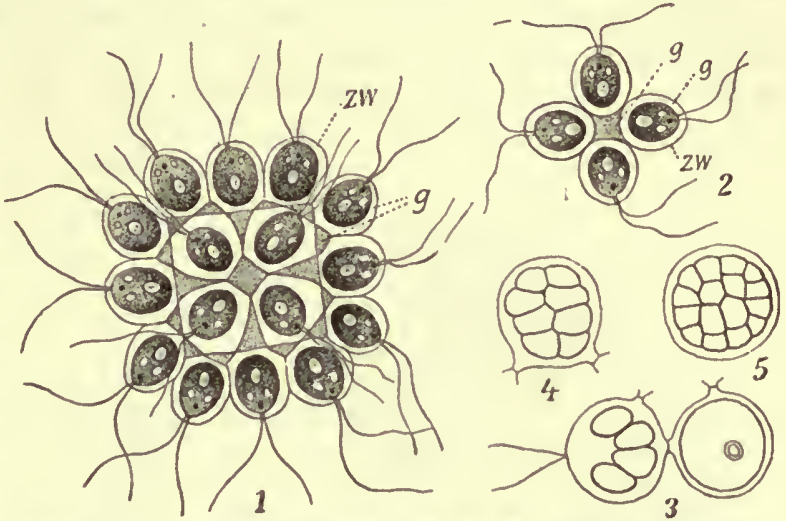

Fig. 37. 1. Goninm pectorale nach Migula; 2. Gonium pectorale; desgl. 3.-5. Teilungsstufen ron G. pectorale nach Outmanss. $g$ Gallert, sw Zellwand (ans Ottmasss, Algen).

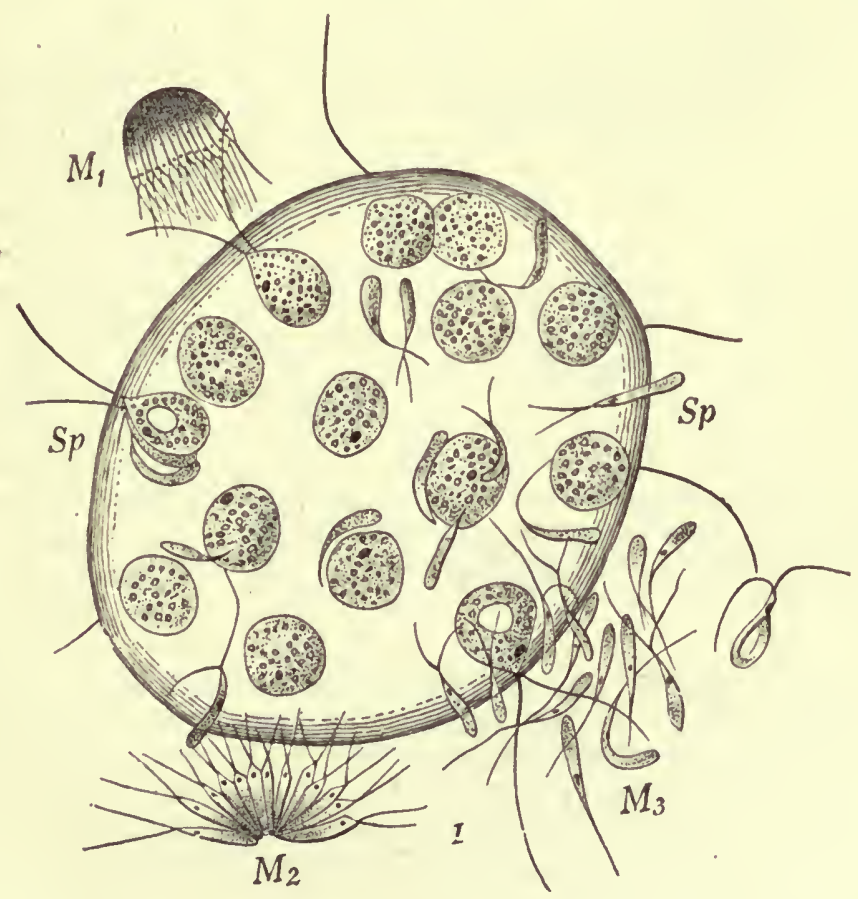

Fig. 38. Eudorina elegans, weibliche Kolonie umgeben von Spermatozoïden. 
dem trophischen Pole genähert liegen, sind die Ernährungszellen, während in der hinteren Hälfte der Kolonie diejenigen sich finden, welche die Fortpflanzung übernehmen (die Kolonien sind hier immer entweder mit geschlechtlichen oder ungeschlechtlichen Fortpflanzungszellen versehen); die im vorderen Pol befindlichen Zellen haben einen besonders großen, roten Augfleck (Stigma), der bei der Orientierung der Bewegung wahrscheinlich eine Rolle spielt. Gegen den Äquator der Kolonie zu wird er kleiner und verschwindet nach hinten ganz oder wird durch ein farbloses Öltröpfchen ersetzt. Auch in der hinteren Koloniehälfte werden aber nicht alle Zellen zu Fortpflanzungszellen; bei V. globator sind es deren meist nur acht (vgl. auch Fig. 39). Die übrigen haben lediglich

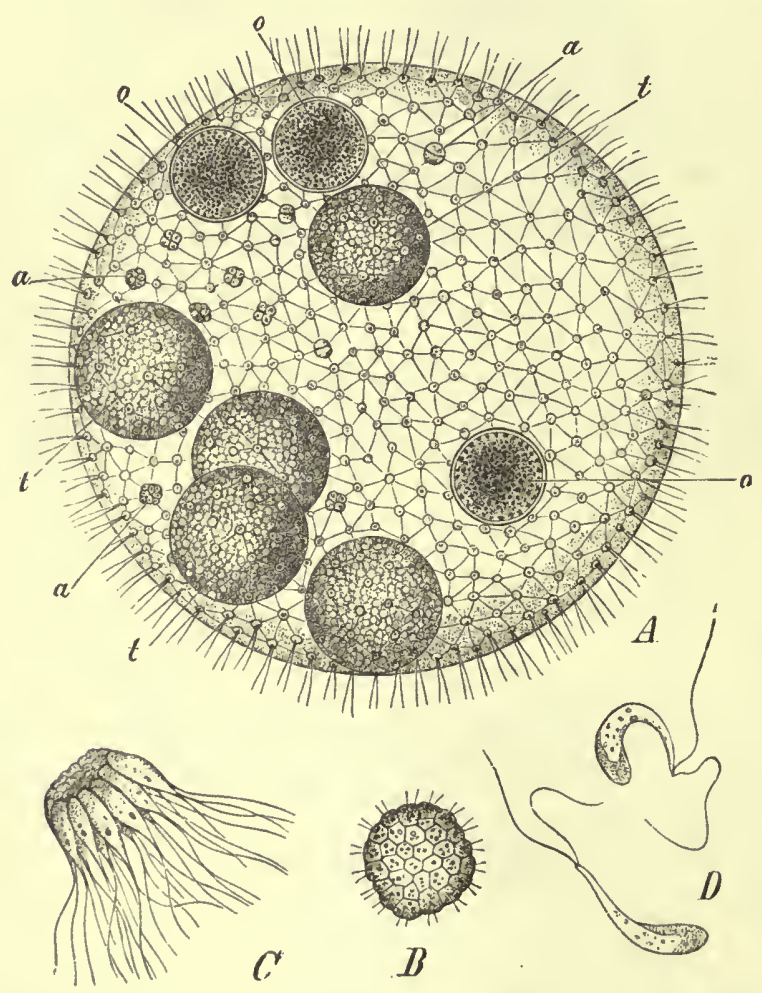

Fig. 39. Volvox aureus (nach L. KLEIN). A Alte, mit Tochterkolonien $(t)$, Eizellen $(o)$ und Antheridien $(a)$ versehene Kolonie. Die Zellen treten nur als kleine Kreise auf der Kugeloberfläche hervor. $B$ Junge Kolonie. (Lehrb.)
Ernährungsfunktion. Sie gehen später zugrunde. Offenbar werden sie von den Fortpflanzungszellen ausgesogen. Ihre Protoplasmakörper wachsen dementsprechend auch während der Entwicklung der Fortpflanzungszellen nicht mehr und werden substanzärmer. Eine solche weitgehende Beeinflussung der Zellen wird dadurch erleichtert, daßsie miteinander durch Plasmafortsätze in Verbindung stehen, Verbindungen, die in der hinteren generativen Hemisphäre zahlreicher sind, als in der vorderen, trophischen.

So sehen wir also bei Volvox schon eine Arbeitsteilung eingetreten 1. innerhalb der vegetativen Zellen insofern, als die vorderen etwas anders organisiert sind, als die hinteren, 2. zwischen vegetativen und generativen Zellen. Die vegetativen Zellen gehen zugrunde, sie arbeiten für die generativen.

Es wird dadurch der Kolonie ermöglicht, unter günstigen Umständen rasch sich zu vermehren und sogleich kräftige Tochterkolonien in die Welt zu senden. Tatsächlich findet unter solchen Umständen auch eine ungemein ergiebige Vermehrung statt. Daß übrigens auch bei den anderen Volvocineenkolonien eine, wenngleich viel weniger tiefgreifende, gegenseitige Beeinflussung der Zellen stattfindet, ergibt sich schon aus ihrer gemeinschaftlichen Schwimmbewegung, welche offenbar eine Regulierung der Cilientätigkeit der einzelnen Zellen voraussetzt. 
Daß wir auch Volvox selbst noch als Kolonie bezeichnen, hat eigentlich nur dadurch Berechtigung, daß die Beziehungen zu den Kolonien der anderen Volvocineen so klar zutage liegen; rein für sich betrachtet könnte man Volvox auch eine echte vielzellige Pflanze, einen Zellenstaat nennen.

Einer experimentellen Behandlung ist bis jetzt die Frage nicht unterworfen worden, ob etwa bei einer Zerstörung der generativen Zellen beliebige andere sich zu solchen ausbilden können; wenn die Zerstörung ohne tiefgreifende Schädigung der Kolonie und frübzeitig genug möglich wäre, ist die Frage wahrscheinlich zu bejahen.

Daß auch betreffs der hier nicht zu erörternden Fortpflanzungsorgane bei den Volvocineen eine sehr lehrreiche Stufenfolge von Isogamie zu Oogamie sich findet, daran sei hier nur erinnert. Die Spermatozoiden von Volvox stellen eine Parallelbildung zu den Spermatozoiden der Archegoniaten dar; ihre langgestreckte Gestalt steht, meiner Ansicht nach wie bei diesen, damit in Verbindung, daß sie, um zu den Eizellen zu gelangen, sich in gallertige Substanzen einzubohren haben.

\section{B. Die festsitzenden Kolonien}

haften am Substrate entweder durch Ausscheidung einer haftenden Substanz oder durch Ausbildung besonderer Haftorgane, die vielfach infolge äußerer Reize (namentlich sog. Kontaktreize) auftreten. Durch das Vorhandensein einer angebefteten Basis ist eine weitere Differenzierung der Kolonie gegeben, welche zu der eines Zellenstaates namentlich dann über-geht, wenn das der Basis entgegengesetzte Ende der Kolonie sich zum Vegetationspunkt gestaltet. Dieser Schritt hat offenbar mehrfach stattgefunden. Zunächst seien aber einige Beispiele geschildert, in denen er nicht getan wurde. Die von einer gemeinsamen Gallerthülle umgebenen Kolonien von Apiocystis scheiden an der Basis eine Haftsubstanz in Gestalt einer Art Haftscheibe aus. Die eigentümlichen "Pseudocilien" dieser Alge, welche aus der Gallerthülle hervorragen, möchte ich für Organe halten, welche für den Stoffaustausch (namentlich auch den Gaswechsel), welcher durch die derbe Gallerthülle erschwert ist, in Betracht kommen.

Sehr mannigfaltige, sowohl frei flottierende als festsitzende Koloniebildungen kommen bei den $\mathrm{Di}$ atomeen vor, wobei die einzelnen Zellen meist durch Gallertausscheidung zusammengehalten sind; solche Ausscheidungen dienen bei den festsitzenden Kolonien auch zur Anheftung. Eine Arbeitsteilung unter den Zellen der Kolonien ist nicht bekannt, abgesehen davon, daß bei manchen, wie bei der Gattung Achnantus, bei der die Kolonien fadenförmig und an einem Ende des Fadens angeheftet sind, nur diese Basalzelle den Schleimfaden ausscheidet. Sie verhält sich also anders als die übrigen Zellen der Kolonie, von denen aber jede wohl imstande wäre, die Bildung des Schleimfadens zu übernehmen.

Auch bei der in Fig. 40 abgebildeten Licmophora flabellata (L. radians K.) ist nur scheinbar eine verschiedene Ausbildung der einzelnen Glieder der Kolonie vorhanden. Die Zellen sitzen hier in fächerförmiger Anordnung auf den etwas verbreiterten Enden verzweigter Gallertstiele, die Äste sind aber von verschiedener Stärke. Einige sind kurz und dünn und tragen nur wenige Zellen, andere sind viel dicker und länger und mit zahlreichen Zellen am Ende versehen. Diese Erscheinung erklärt sich dadurch, daß die Gallerte am unteren Ende der Zellen ausgeschieden wird, und daß dann einzelne Zellen sich von den anderen abtrennen. Sie fahren mit der Gallertausscheidung fort 
und bilden so einen neuen Stiel, der notwendig dünner und kürzer sein muß als der, welcher von einer größeren Zahl von Zellen hervorgebracht wird. Es komint so ein Bíld zustande, welches dem eines monopodialen Verzweigungssystemes ähnlich sehen kann. Aber die Ähnlichkeit ist nur eine äußerliche, die Zellen sind alle gleich, die Abtrennung

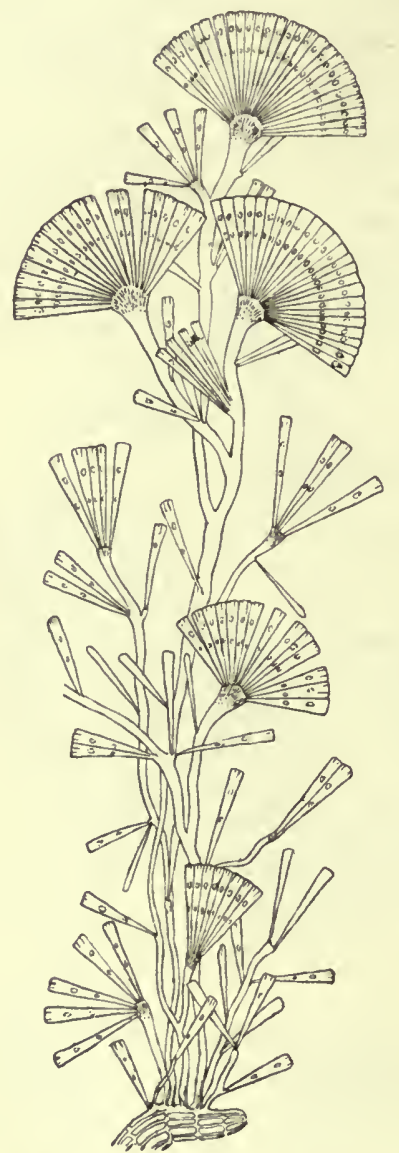

Fig. 40. Licmophora flabellata (nach Surтu). Diatomeen-Ko. c lonie mit verzweigten Gallertstielen. einzelner kein regelmäßiger Vorgang. Etwas anderes würde es sein, wenn die Zellen der "Seitenäste" nach einiger Zeit ihre Wachs. tums- und Teilungsfähigkeit einstellen würden, während die an der Spitze der Hauptachse gelegenen' sie beibehielten. Dazu liegt bei diesen nur durch Gallerte verbundenen Zellen aber weder ein äußerer noch ein innerer Grund vor ${ }^{1}$ ).
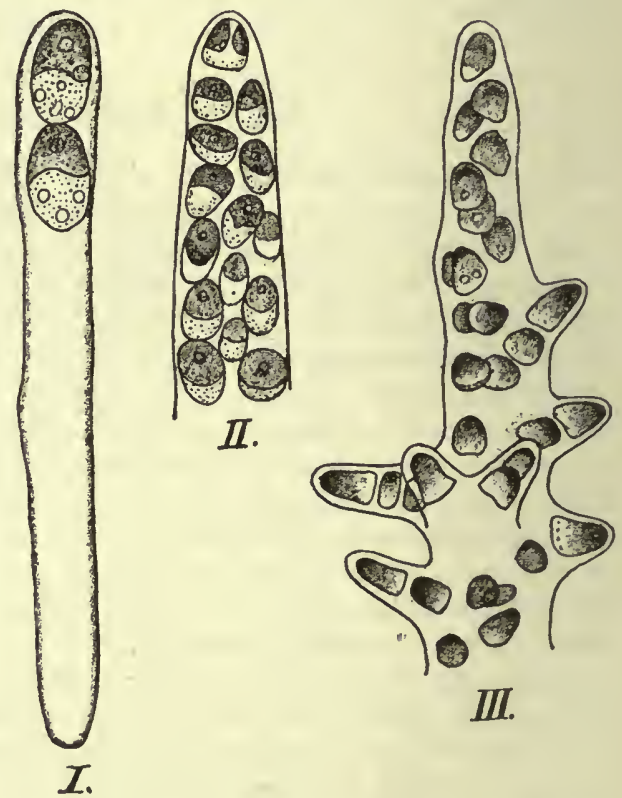

III.

Fig. 41. Hydrurus foetidus. I Junge Pflanze. II Spitze einer Pflanze; Chromatophor der endständigen Zelle schon längs geteilt. III Verzweigung. ( $I$ u. $I I$ nach KLEBS, $I I I$ nach Berthold.)

Eine besondere Hervorhebung verdient hier die Gattung Hydrurus, eine Alge, die in Gestalt reich verzweigter, unter Umständen mehrere Meter langer Gallertstränge in Süßwasserbächen und Flüssen nicht selten vorkommt. Es liegt hier eine hochentwickelte Kolonie brauner Flagellaten vor, wie sich schon daraus schließen läßt, daß jede Zelle 5 bis 6 pulsierende Vakuolen hat, wie

1) Ganz ähnliche Verzweigungen finden sich bei den Kolonien des sonderbaren Spaltpilzes Nerskya ramosa. (Vgl. Famintzin, Mélanges biolog. Acad. de St. Pétersbourg t. XIII liv. 2.) Über die interessanten Koloniebildungen bei Myxobakterien s. Trraxter, Myxobacteria. Botanical gazette 1892. Es scheint hier eine Arbeitsteilung vorzukommen, indem nicht alle Zellen der Kolonie gleich entwicklungsfähig sind. 
sie sonst nur schwärmenden Zellen zukommen. Die einzelnen Energiden sind in einer gallertigen Substanz eingebettet, und zwar ist schon bei der Keimung der Fortpflanzungszellen die Schleimabsonderung in dem dem Substrate zugewandten Teile eine stärkere, es bildet sich hier also ein Haftorgan aus (Fig. 41 I). Die Energiden der Kolonie verhalten sich ursprünglich alle gleich, alle können auch zu Ästen auswachsen, so daß also eine ganz regellose Verzweigung eintritt (Fig. 41 III). Aber zwischen den Ästen. und dem Hauptstamm besteht eine Verschiedenheit. Nur die Energiden der Äste können zu Fortpflanzungszellen werden. Der Hauptstamm dient offenbar nur noch als mechanische Grundlage des Ganzen, er geht später zugrunde. Die Entwicklungsfähigkeit der an seiner Basis gelegenen Energiden ist gestört worden - ob durch äußere Faktoren (schwächere Beleuchtung, stärkere mechanische Inanspruch. nahme) oder aus, ,inneren Gründen" muß dahingestellt bleiben -.

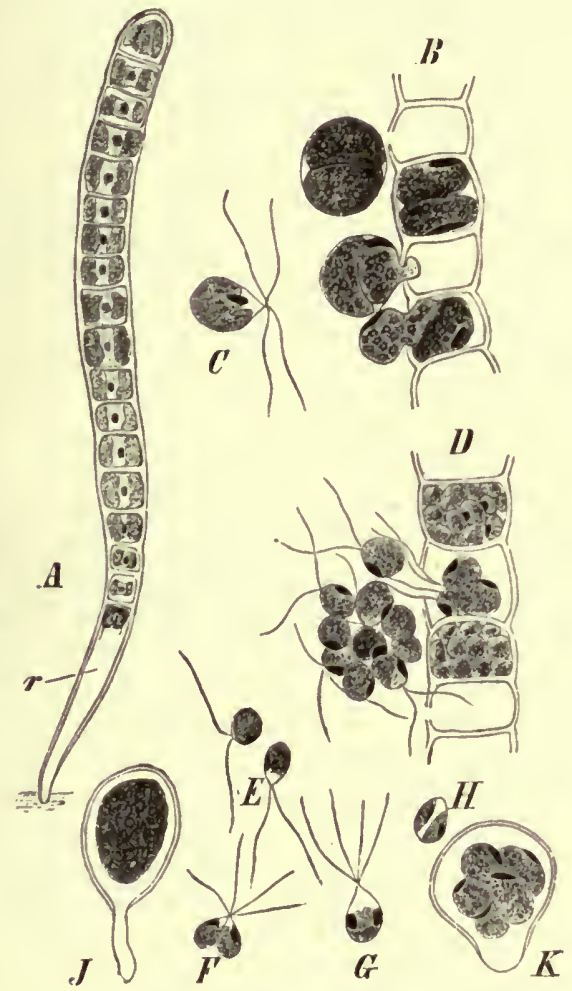

Fig. 42 .

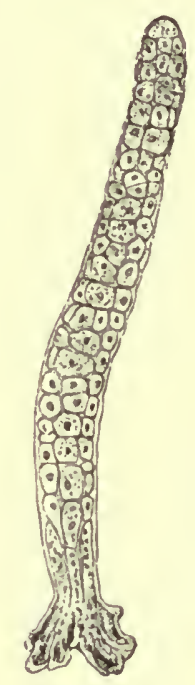

Fig. 43.

Fig. 42. Ulothrix zonata, $A$ Keimpflanze; $r$ Haftorgan, welches chlorophyllarm ist oder den Chlorophyllgehalt ganz verliert. (Lehrb.)

Fig. 43. Keimptlanze von Ulva Lactnca. An der Basis haben sich Haftorgane gebildet. (Lehrb.)

Ferner ist auch das Wachstum der Äste bemerkenswert. Am Scheitel ist die Gallerte dünner, und hier liegt eine Energide, die sich (nach KLEBS) durch eine Längswand teilt. Dann findet eine Verschiebung statt, indem eine Energide wieder an den Scheitel rückt: Obwohl die einzelnen Energiden einander im weșentlichen gleich sind, zeigt also immerhin der Scheitel einen anderen Bau, als die hinter ihm liegenden Teile. Es ist wenigstens eine Annäherung an das Vorhandensein eines Vegetationspunktes gegeben.

Wahrscheinlich sind auch die Fäden vieler Fadenalgen (Oedogoniaceen, Confervaceen u. a.) nichts anderes als Kolonien von zeitweilig mit einer Membran 
umgebenen Schwärmsporen. Die basalen Zellen dieser Fäden, welche zu Haftorganen ausgewachsen sind, verhalten sich vielfach ähnlich wie der basale Teil des Hydrurus-Hauptstammes, d. h. sie haben ihre Entwicklungsfähigkeit ein. gebüßt. So stirbt z. B. bei Ulothrix zonata (Fig. 42 A) (deren Zellen sonst alle gleichmäßig sich teilen) in der basalen Zelle das Protoplasma nicht selten ab, so daß hier die Teilungen aufhören. Der Grund dieser Erscheinung ist ebensowenig für Hydrurus bekannt.

Es läßt sich iiber die etwaigen Vorteile der Koloniebildung derzeit nichts Allgemeines aussagen; vermutlich sind sie in den einzelnen Fällen auch sehr verschieden, und auch nicht in allen merklich vorhanden. SENN ${ }^{1}$ ), welcher für Coelastrum-Arten gefunden hat, daß sie in luftreicher Flüssigkeit freie Zellen, in luftarmer dagegen Kolonien (Coenobien) bilden, meint, daß der Vorteil der Koloniebildung darin liege, daß sie die sofortige Wegführung des bei der Assimilation abgegebenen Sauerstoffs und der bei der Atmung abgegebenen Kohlensäure verhindern ${ }^{2}$ ); er gibt auch einen Überblick darüber, wie Koloniebildung zustandekommt. Bei den durch Gallerthüllen vereinigten Kolonien wird es wesentlich auf die Eigenschaften der Gallerthüllen ankommen.

Die angeführten Beispiele zeigen uns, daß, ausgehend von Kolonien gleichartiger Zellen resp. Energiden, die alle sich weiter entwickeln könnnen, nach verschiedenen Richtungen hin gewissermaßen der Versuch gemacht wird, zu höherer Gliederung zu gelangen, wie sie sich in der Arbeitsteilung zwischen den Koloniebewohnern ausspricht.

Das Wort Arbeitsteilung erklärt natürlich noch gar nichts, es ist lediglich ein zusammenfassender Ausdruck für die Tatsachen. Bedingt wird die Arbeitsteilung und die damit verbundene Verschiedenheit einmal durch die gegenseitige Beeinflussung der Energiden einer Kolonie, sodann durch ihre verschiedenen Beziehungen zu äußeren Faktoren. Vielfach werden Energiden schon durch ihre Lage in der Kolonie von anderen Energiden beeinflußt (z. B. Pediastrum, Polysphondylium, auch Volvox), und dadurch in ihrer Gestalt und Funktion bestimmt, sie werden ferner auch durch diese Lage von äußeren Faktoren anders beeinflußt, werden auf äußere Reize anders reagieren als die anderen Energiden, wie dies für Hydrurus u. a. hervorgehoben wurde.

Eine weitergehende Arbeitsteilung aber ist nur bei verzweigten Vegetationskörpern zu erwarten. Verzweigung kommt, wie wir sahen, schon bei Kolonien vor. Sie wird aber eine geregelte, erst beim Vorhandensein eines Vegetationspunktes, der Besitz eines solchen ist charakteristisch für die Zellenstaaten und damit für die "typischen" Pflanzen überhaupt.

\section{§ 4. Zellenstaaten mit Vegetationspunkten.}

Die sonderbare Bezeichnung Vegetationspunkt rührt her von dem Begründer der Entwicklungsgeschichte, K. FR. WoLFF ${ }^{3}$ ), welcher gegenüber den zu seiner Zeit herrschenden Spekulationen der Evolutionstheorie die Entstehung der Organe, ihre "generatio", durch Beobachtung zu ermitteln suchte, wobei er zu dem Schlusse kam, daß bei der Ent-

1) SENN, Über einige koloniebildende einzellige Algen. Botan. Zeitung 57 (1899) p. 37.

2) Das wird bei flachen Kolonien, wie denen von Pediastrum, nur wenig in Betracht kommen.

3) Kaspar Friedrich Wolfe, Theoria generationis. Halle, 1759. 
wicklung eine wirkliche $\mathrm{Neubildung}$ ron Teilen stattfinde, eine Neuanlage ron Organen an dem ursprïnglich ungegliederten Keime.

Dies Resultat ergab sich schon aus seinen Untersuchungen über die Entwicklung des Blattes (welche er an der Bohne verfolgte) und der Blüte. Er erkennt, daß das Vorhandensein von Blattanlagen in der Knospe, auf welche die Erolutionslehre sich stiitzte, denn doch nur ein eng begrenztes ist. Untersucht man nämlich die Knospe genauer: „donec tandem hoc modo introrsum et deorsum simul penetrando ad substantiam plantae interiorem pervenias, humidam, succis gravidam et nulla anılius folia tenentem", so gelangt man damit an die "extremitas axeos trunci", in der noch keine Gewebedifferenzierung vorhanden ist. Diese Endigung der Stamm- oder Zweigachse nennt er Vegetationspunkt, und an ihm entspringen Blattanlagen und Seitenzweige als "propulsiones trunci“.

Damit war eine der fundamentalen Tatsachen in der Entwicklung der Pflanze klargelegt, die, daß im Gegensatz gegen die höheren Tiere der Pflanzenkörper Stellen besitzt, wo (nach der Bezeichnung von SAcrs) noch "embryonales" Gewebe vorhanden ist, das neue Zellen und neue Organe liefert. Die letzteren entstehen gewöhnlich so, daß die jüngsten dem Vegetationspunkt am nächsten sind - in progressiver Reihenfolge. Die Betrachtung niederer Pflanzen zeigt in dieser Beziehung weniger konstante Verhältnisse, auch der Besitz eines von den übrigen Teilen verschiedenen Vegetationspunktes ist nur ein Spezialfall der möglichen Konstruktionen des Pflanzenkörpers, allerdings der verbreitetste.

\section{A. Organbildung bei einigen Algen.}

Wir haben schon bei Hydrurus eine Andeutung eines Vegetationspunktes getroffen. $\mathrm{Zu}$ einem wirklichen Vegetationspunkte aber gehört, daß die an ihm liegenden Zellen sich anders verhalten, als die weiter rückwärts befindlichen, und daß die Anlegung der seitlichen Bildungen in ganz bestimmter, rom Vegetationspunkt aus geregelter Reihenfolge geschieht.

Innerhalb der Arten der Gattung Cladophora läßt sich in dieser Hinsicht ein Fortschritt verfolgen; es ist dies eine sehr verbreitete, aus verzweigten Zellreihen bestehende Fadenalge. Daß die einzelnen Zellen polyergid sind, ist für unsere Betrachtung nicht von Belang.

Bei Cladophora fracta ${ }^{1}$ ) findet die Zellvermehrung zunächst durch TTeilung der an der Spitze gelegenen Zelle (Scheitelzelle) statt, und die Äste (welche ebenso ausgebildet sind, wie die Hauptachse) entstehen an den von der Spitzenzelle abgegliederten Zellen in progressiver Reihenfolge. Später aber treten auch an den Gliederzellen Teilungen auf, und es bilden sich aus den neuentstandenen Zellen Äste, die zwischen die alten eingeschaltet sind. Denken wir uns diese interkalare Astbildung unterbleibend, wie dies bei anderen Cladophoraarten, z. B. Cladophora prolifera, der Fall ist (vgl. auch Fig. 44), so erhalten wir das Schema der Bildung seitlicher Organe, welches bei den Pflanzen am meisten verbreitet ist, $d . h$. das der progressiven Entstehung von Neubildungen.

Mit der Verzweigung ist, wie schon bei Hydrurus hervorgehoben wurde, vielfach eine verschiedene Ausbildung von Hauptachse und Seiten-

1) Vgl. Berthold, Untersuchungen über Verzweigung von Süßwasseralgen. Nova acta acad. Leop. Carol. Bd. XV, 1878. 
zweigen verbunden. Ganz wie dort hat die Hauptachse einmal eine andere mechanische Funktion als die Seitenachsen, und sodann steht sie zu diesen in bestimmten Stoffwechselbeziehungen, sie erhält von den Seitenachsen Stoffe und umgekehrt. Wo die Seitenachsen dicht gedrängt eine Hauptachse umschließen, werden sie diese für die Assimilationsarbeit weniger geeignet machen, weil die Seitenachsen jetzt das Licht wegnehmen. So kann es denn nicht befremden, wenn wir auch hier Verschiedenheiten von Haupt- und Seitenachsen antreffen, wenn z. B. bei Algen, die wie Draparnaldia und Chaetophora reich verzweigt sind, die Zellen des Haupt-

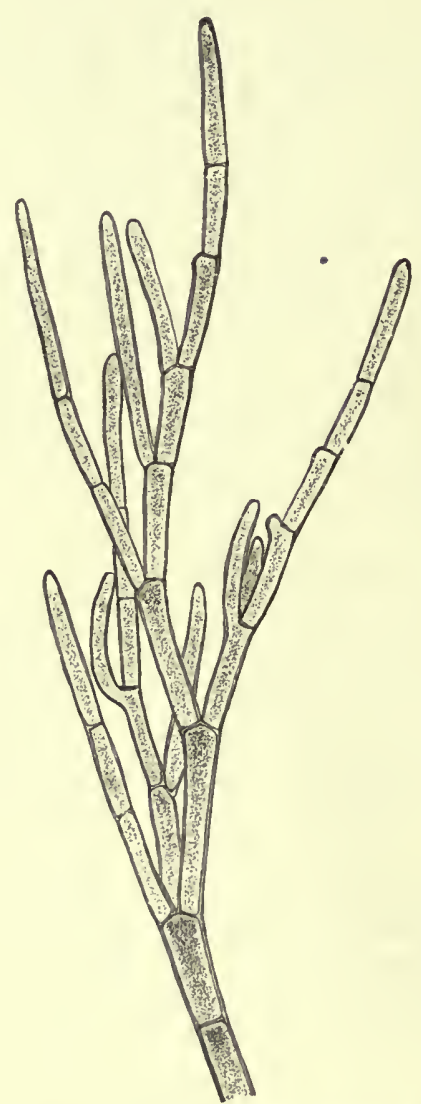

Fig. 44. Clarlophora glomerata, Stück des Thallus. Die Verzweigung findet in regelmäßig gegen die Spitze der Fäden hin fortschreitender (progressiver) Reihenfolge statt. (Lehrb.)

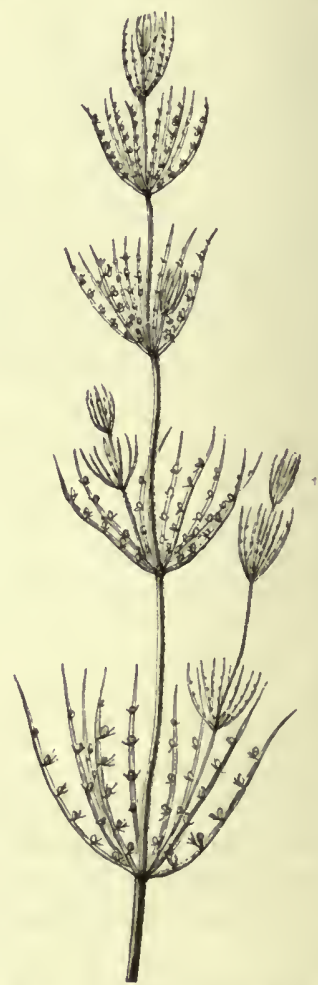

Fig. 45. Chara fragilis, Sproßstïck. Die wirtelig gestellten Blätter, welche die Geschlechtsorgane tragen, sind Kurztriebe. (Lehrb.)

stammes bei einem gewissen Alter der Pflanze, wo die Zellen der Seitenachsen noch ungestört weiter wachsen, schon unfähig sind, sich zu teilen, Schwärmsporen zu erzeugen oder in umfassender Weise zu assimilieren. Dieselbe Erscheinung kann sich natürlich zwischen den Seitenachsen wiederholen, es wird, wie Herbert Spencer (a. a. O. I § 214) sehr gut ausgeführt hat, besonders mit der Vergrößerung des Vegetationskörpers 
ein Ungleichwerden seiner Glieder Hand in Hand gehen, namentlich eine Verschiedenheit von Hauptachsen und Seitenachsen.

Außerdem läßt sich bei Algen nicht selten beobachten, daß die Zelle, welche einen Ast bildet, im Wachstum zeitweilig oder dauernd gegenüber den anderen zurückbleibt. Geschieht dies regelmäßig, so wird dadurch die Hauptachse selbst eine Gliederung erfahren, die Stellen derselben, wo seitliche Organe entspringen, die $\mathrm{Kn}$ oten, verhalten sich anders als die Internodien, und diese Verschiedenheit ist bei manchen (wie den Charen) eine ungemein scharfe (Fig. 45). Entstanden sein dürfte sie dadurch, daß die Bildung eines seitlichen Organes ursprünglich direkt eine Hemmung der betreffenden Zone der Hauptachse herbeiführte.

Wir haben dann also erreicht eine Pflanze mit Vegetationspunkt und regelmäßiger Ausgliederung seitlicher Organe; wir haben ferner gesehen, wie vielfach schon durch die Tatsache der Verzweigung eine mehr oder minder ausgeprägte Verschiedenheit zwischen Hauptachse und Seitenachsen herbeigeführt wird, und haben nun die verschiedene Ausbildung der Seitenachsen selbst zu prüfen.

Eine ungemein häufige Erscheinung ist es, daß die Seitenachsen sich in Langtriebe und Kurztriebe trennen. Die äußere Verschiedenheit beider liegt darin, daß die Kurztriebe begrenztes, die Langtriebe unbegrenztes Wachstum haben, erstere erscheinen als Hemmungsbildungen der letzteren. Mit dieser äußeren Verschiedenheit geht aber auch eine solche der Funktion Hand in Hand: die Langtriebe ermöglichen die eigentliche Verzweigung, die Kurztriebe sind meist Assimilationsorgane. So sind bei Chara z. B. die wirtelförmig gestellten „Blätter" nichts anderes als Kurztriebe, welche gegenüber den Langtrieben einen etwas einfacheren Bau aufweisen. Dieselbe Verschiedenheit kehrt uibrigens bei höheren Pflanzen wieder, es genüge, an die bekannten Gestaltungsverhältnisse der Pinusarten, mancher Kakteen $\mathrm{u}$. a. zu erinnern.

Wie bei diesen Pflanzen sind auch bei den niederen Kurztriebe und Langtriebe ursprïnglich nur quantitativ, nicht qualitativ verschieden; dieselbe Seitenachse, die unter günstigen Vegetationsbedingungen zu einem Langtriebe geworden wäre, wird unter ungünstigen zu einem Kurztrieb. In den Fällen, in denen Langtriebe und Kurztriebe schärfer getrennt sind, die Induktion also statt einer labilen eine stabile geworden ist, ist auch der Ort ihrer Entstehung ein verschiedener, auch die Verschiedenheit der Struktur nimmt zu.

Dafür seien einige Beispiele angeführt. Einen lehrreichen Fall für die verschiedenartige Abstufung der einzelnen Organe bieten unter den Phaeophyceen die Sphacelarien von denen aber nur einzelne Beispiele hervorgehoben werden sollen, wir wollen uns dabei auf die Astbildung beschränken.

Die Gattung Sphacelaria selbst besteht aus Achsen, die aus mehreren Zellreihen aufgebaut sind. Sie verzweigen sich, indem sie seitlich entspringende Äste hervorbringen, die bei manchen Arten sich gleich verhalten, bei andern in Kurz- und Langtriebe gegliedert sind. Außerdem besitzen sie "Haare", d. h. Auszweigungen begrenzten Wachstums, die einfache, plasmaarme Zellreihen bleiben und auch anders angelegt werden, als die gewöhnlichen Zweige, nämlich sehr nahe am Scheitel, so daß bei ihrer Entstehung die Scheitelzelle seitlich abgelenkt wird. Bei Halopteris filicina (Fig. 46 und 47) fehlen die "Haare". Der reichverzweigte Thallus besteht lediglich aus Langtrieben und Kurztrieben verschiedener Ordnung. Sie werden alle in gleicher Weise an- 
gelegt, und zwar, wie Fig. 47 zeigt, sehr nahe am Scheitel. Jeder Sproß endigt mit einer Scheitelzelle und ist gewöhnlich zweizeilig verzweigt, so daß ein fiederiges Gesamtverzweigungssystem zustande kommt. Dabei unterscheiden sich die Zweige verschiedener Ordnung schon dadurch, daß die Scheitelzelle um so kleiner wird, je höher die Verzweigungsordnung ist, und um so früher stellt der betreffende Sproß dann auch sein Wachstum ein und geht in den Dauerzustand über ${ }^{1}$ ). Während bei der Achse 1. Ordnung in Fig. 47 die sämtlichen Zellen wiederholt durch Längswände geteilt sind, unterbleibt bei den Achsen höherer Ordnung diese Gliederung mehr und mehr, und manche bleiben einfache Zellreihen, sie stellen den anderen gegenüber $\mathrm{H}$ em mungs bildungen dar, wobei die Hemmung auf verschiedenen Stadien der Entwicklung eintreten kann. Zugleich geht aus der Fig. 47 weiter hervor, daß

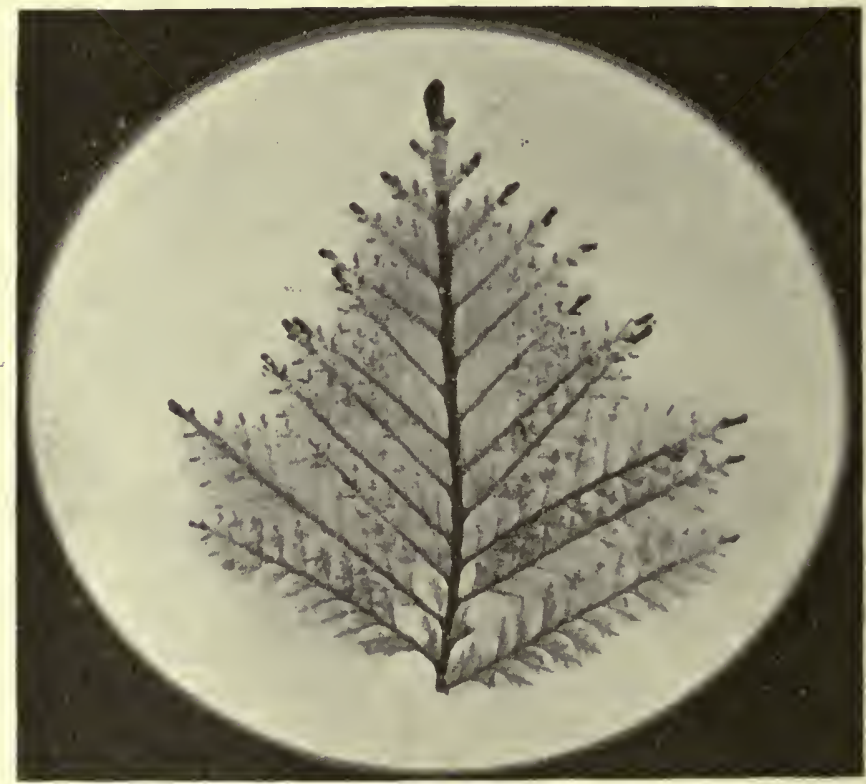

Fig. 46. Halopteris filicina. Sproßsystem, schwach vergrïßert (nach einer Mikrophotographie). Man erkennt an den Sproßendungen die Scheitelzellen als dunklen Flecke.

bei allen Seitensprossen der erste Zweig dem Muttersproß zugekehrt ist; und daß die beiden ersten Seitenzweige immer auf einer Seite stehen - eine An. ordnung, die ermöglicht, daß die Sprosse alle Platz haben, ohne sich zu decken; es kommt eine Deckung zwar auch sonst gelegentlich vor, aber wenn die Äste gleich anfangs regelmäßig zweizeilig stünden, müßte hier ständig eine Deckung eintreten.

1) Ganz ähnliche Verschiedenheiten finden sich auch bei den Sproßsystemen höherer Pflanzen. Bei der Tanne z. B. sind die Vegetationspunkte der verschiedenen Sproßformen verschieden. Die Knospe des Hauptstammes zeichnet sich aus durch kurze, gedrungene Form, massige Anlage usw. und unterscheidet sich dadurch von den Langtriebknospen und Kurztriebknospen; Kurztriebknospen können aber zur Ausbildung als Langtriebe veranlaßt werlen und Langtriebe zu Hauptsprossen werden. Vgl. betr. der Gestalt der verschiedenen Vegetationspunkte: Busse, Beiträge zur Kenntnis der Morphologie und Jahresperiode der Weißtanne. Flora 77. Bd., Jahrg. 1893, S. $113 \mathrm{ff}$. 
Die untersten Äste sind oft in ihrer Entwicklung gehemmt. Die Verschiedenheiten zwischen Kurztrieben und Langtrieben sind hier also nur quantitativ, nicht qualitativ. Eine höhere Gliederung - die sich aber von der von Halopteris nicht phylogenetisch ableiten läßt - zeigt Cladostephus (Fig. 48), der auch eine höhere anatomische Ausbildung besitzt. Es sind hier folgende Glieder vorhanden :

1. Langtriebe. Neue Langtriebe entstehen durch eine eigentümliche Gabelung des Scheitels.

2. Kurztriebe, die wirtelig gestellt aus den ältesten Rindenzellen des Stengels hervorgehen. Sie werden von Prixgsheim als "Blätter" bezeichnet und werden also von Anfang an anders angelegt als die Langtriebe (vgl. Fig. 48).

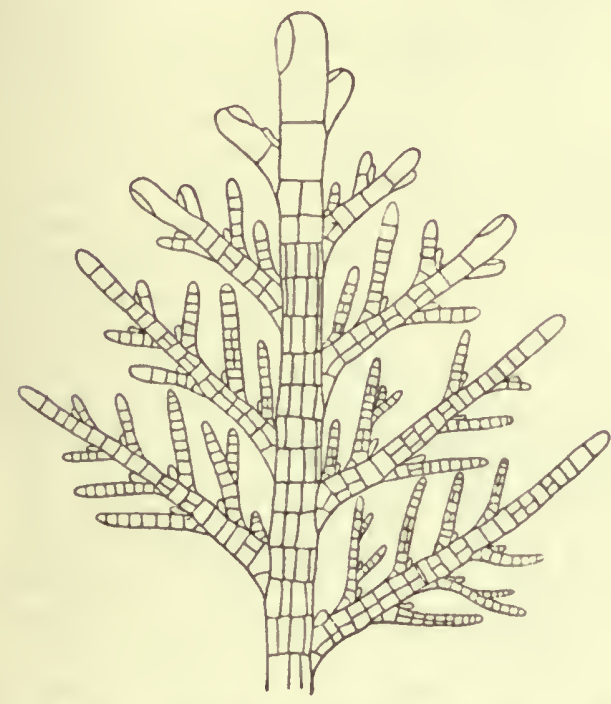

Fig. 47. Halopteris filicina. Ende eines Langtriebes. Vnn der großen Scheitelzelle werden durch uhrglasförmig gebogene Wände Segmente herausgeschnitten, die zu Ästen erster Ordnung auswachsen; diese verzweigen sich ihrerseits in derselben Weise. Die Seitensprosse höherer Ordnung entwickeln sich aber immer weniger kräftig.

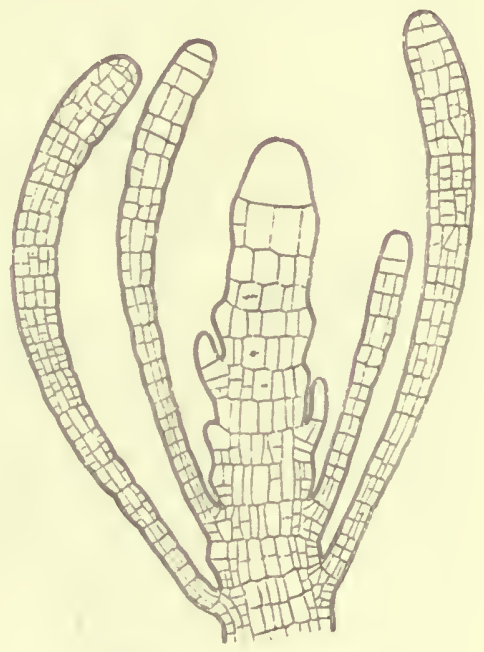

Fig. 48. Cladostephus verticillatus (nach Pringsherm), Längsschnitt durch eineı Langtrieb mit Kurztrieben. Die Kurztriebe sind begrenzten Wachstums; ihre Scheitelzelle verwandelt sich durch Teilungen in einen Zellkörper. (Lehrb.)

3. Die „Fruchtblätter", d. h. Kurztriebe, welche die Fortpflanzungsorgane tragen. Sie stimmen im allgemeinen mit den Blättern überein, unterscheiden sich aber von ihnen durch eine einfachere anatomische Ausbildung und durch ihre Stellung, sie bilden sich nämlich am Ende dẹ Vegetationsperiode in regelloser Stellung an den alten Stengelgliedern.

4. "Haare", Zellreihen, die an den Blättern sich ausbilden.

5. Adventivsprosse, ausgehend von den Zentralzellen der Achse. - Von den Wurzelfäden kann hier abgesehen werden.

Charakteristisch ist hier also namentlich, daß die verschiedenen Glieder hier schon ihrem Ursprung nach verschieden sind, was bei Halopteris nicht der Fall ist. 
Eine ganz analoge Gliederung in Langtriebe und Kurztriebe finden wir auch bei vielen Florideen, von denen einige Vertreter, die namentlich auch die Arbeitsteilung unter den Kurztrieben erläutern sollen, hier kurz geschildert sein mögen. Ich wähle dazu zunächst einige an den Flußmündungen Guianas auf Mangroven usw. wachsende Süßwasserflorideen ${ }^{1}$ ).

Bostrychia Moritziana ist eine Floridee, die fiederige Verzweigungssysteme trägt. Diejenigen Achsen, die als Träger der Verzweigungssysteme ausgebildet sind, haben einen komplizierteren Bau als die Zweigendigungen. Während letztere Zellreihen sind, sind erstere Zellkörper. Aber auch die Hauptachse endigt in eine Zellreihe.

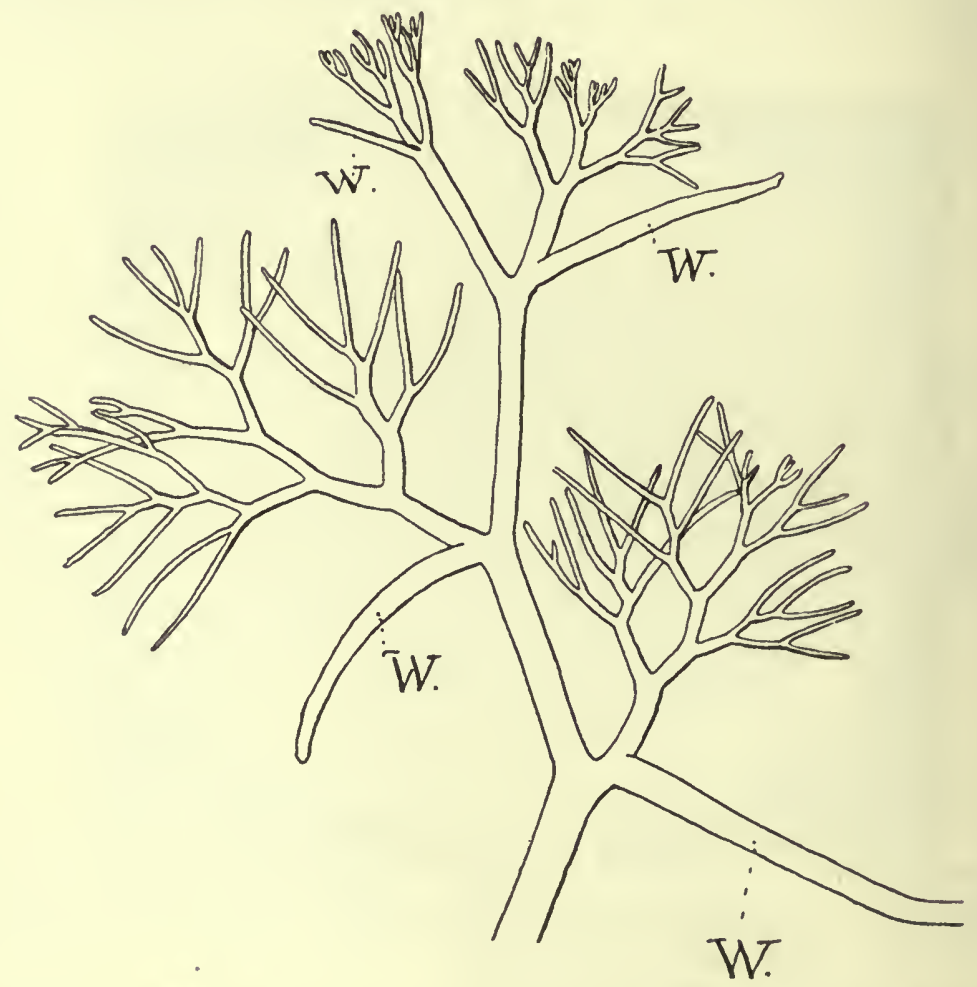

Fig. 49. Bostrychia Moritziana. Habitusbild eines Sprosses (vergr.). Die Sproßachse trägt als Assimilationsorgane funktionierende verzweigte Kurztriebe und solche, die unverzweigt bleibend, sich zum Substrate wenden und die Pflanze an demselben befestigen $(W)$.

Die Fiederzweige haben ein begrenztes Wachstum, sie stellen Kurztriebe verschiedener Ordnung dar, die auf einem früheren oder späteren Entwicklungsstadium stehen bleiben. Untersucht man die Verzweigung am Scheitel, so erscheint sie als eine gabelige. Indes ist sie in Wirklichkeit doch eine monopodiale, nur entsteht der Seitenzweig in der Scheitelzelle dadurch, daß durch eine weit hinaufreichende Wand ein Stück abgeschnitten wird, das zum Zweig auswächst und sich zunächst ebenso kräftig entwickelt, als die Fortsetzung des Hauptsprosses, welche zur Seite gedrängt wird. Derselbe

1) Vgl. Goesen, Über einige Süßwasserflorideen aus Britisch Guiana. Flora 83. Bd., S. 436.1897. 
Vorgang wiederholt sich bei der Verzweigung der einzelnen Glieder, abgesehen von denen, die zur Bildung von Haft- oder Fortpflanzungsorganen bestimmt sind. Die Pflanzen sind an dem Substrate fest gewurzelt durch besondere, unverzweigt bleibende Thallusglieder, die an ihrem Scheitel die Haftorgane (gewöbnlich als Rhizoiden bezeichnet) hervorbringen. Diese in der Fig. 49 mit $W$ bezeichneten Zweige haben einen anderen Bau und eine andere Wachstumsrichtung, als die vegetativen $Z$ weige, sie sind nämlich im fertigen Zustand bis zum Scheitel Zellkörper (angelegt werden auch sie als Zellreihen) und wenden sich dem Substrate zu. Sie erscheinen früh schon anf der Unterseite der Zweige inseriert, der ganze Vegetationskörper gewinnt dadurch den Charakter eines dorsiventralen Sproßsystems, auf dessen Unterseite Wurzeln sich befinden. Diese stellen meist den basalen Ast eines der Assimilationskurztriebe dar. Übrigens ist zu bemerken, daß die'Verzweigungsebenen der Assimilationssprosse nicht immer zusammenfallen. Außer dieser Sproßumbildung kommt noch eine andere vor: einzelne, gleichfalls unverzweigt bleibende Sprosse werden zu keulenförmigen Zellkörpern (Stichidien), welche die Tetrasporen hervorbringen.

Von Interesse ist, daß drei andere an demselben Standorte wachsende Pflanzen eine ganz ähnliche Organdifferenzierung zeigen. Haftsprosse, die ebenso wie die von Bostr. Moritziana entstehen, bat Bostrychia callipteris, bei Lomentaria impudica stehen sie auf der Unterseite der Verzweigungssysteme zwischen zwei Seitensprossen, die Haftsprosse sind hier nicht selten mit Auswüchsen versehen. Delesseria Leprieurii hat zwar keine Zweige zu Haftsprossen 'umgebildet, aber Rhizoidenbüschel unmittelbar unter jeder (scheinbaren) Thallusgabelung. Diese leisten hier dieselben Dienste; sie fehlen bei den Sprossen, welche Tetrasporen tragen. In allen diesen Fällen entstehen die Haftorgane ohne Einwirkung eines äußeren Reizes. Bei Plocamium (Fig. 50) dagegen entscheidet offenbar die Berührung mit einem festen Körper darüber, ob die Spitze eines beliebigen Sprosses zum Haftorgan sich umbildet oder nicht, während bei den obengenannten drei Pflanzen von vornherein bestimmte Sprosse als solche angelegt werden.

Wir sehen hier also, daß schon auf dieser einfachen Stufe der Organbildung eine Gliederung zustande kommen kann, welche Wurzel (bei Bostrychia Moritziana sind die abwärts wachsenden Zweige Wurzeln analog) und beblätterten Sproß der höheren Pflanzen repräsentiert. Diese Ähnlichkeit wird noch auffallender, wenn die Kurztriebe auch äußerlich blattähnlich ausgebildet sind. Polyzonia jungermannoides z. B. gleicht (Fig. 52), wie der Artnamen sagt, durchaus einem beblätterten Lebermoose, auch die Schiefstellung der Blätter stimmt mit der der Lebermoose überein. $\mathrm{Daß}$ diese Blätter verbreiterte Kurztriebe sind, zeigt z. B. der Vergleich mit der in dieselbe Florideengruppe gehörigen Cliftonaea pectinata (Fig. 51), bei der in der Abbildung links zwei Reihen von einfacher gebauten und weniger blattähnlichen Kurztrieben sichtbar sind; auf der Unterseite der Pflanze (die in der Knospe konvex gekrümmt ist) ist eine flügelartige Verbreiterung vorhanden.

Auch die bei höheren Pflanzen die Regel bildende axilläre Stellung der Seitensprosse finden wir schon bei Polyzonia. Die Seitensprosse entspringen an der Basis eines Blattes; eine ähnliche Beziehung zwischen Kurz- und Langtrieben findet auch bei anderen Florideen statt ${ }^{1}$ ).

Die Haftorgane (Hapteren) sind bei Polyzonia Zellkörper, die wir uns aus einer "kongenitalen Verwachsung" von — sonst einzelligen - Rhizoiden zustandegekommen denken können.

1) Vgl. z. B. KNy, Über Axillarknospen bei Florideen. Berlin 1873 
$\mathrm{Daß}$ das nicht für alle Haftorgane anderer Meeresalgen zutrifft, ist unzweifelhaft. Indes ist hier nicht der Ort, auf diese Frage näher einzugehen. Es sei nur erwähnt, daß die Bildung nach abwärts wachsenden Thallus z w $\theta$ ig $e$, wie wir sie bei Bostrychia erwähnten, auch bei anderen Thallophyten vorhanden ist (ebenso bei einigen thallosen Lebermoosen, vgl. Fig. 53). Da dieser Fall für die Frage nach der Entstehung der Wurzeln von besonderem Interesse ist, so sei ein bisher, wie es scheint, verkanntes Beispiel von den Phaeophyceen angeführt.

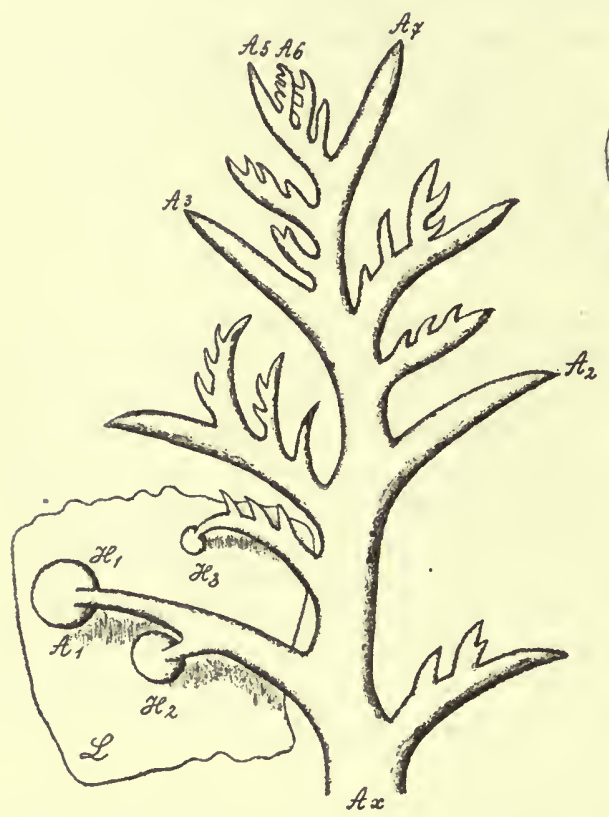

Fig. 50. Plocamium coccineum. Die Zweigspitzen haben sich bei $H_{1}, H_{2}, H_{3}$ zu Haftscheiben entwickelt.

Fig. 51. Cliftonaea pectinata. Ende eines Sprosses. Die Kurztriebe, den Blättern von Polyzonia entsprechend, stehen der Oberseite genähert (links). Vergr.
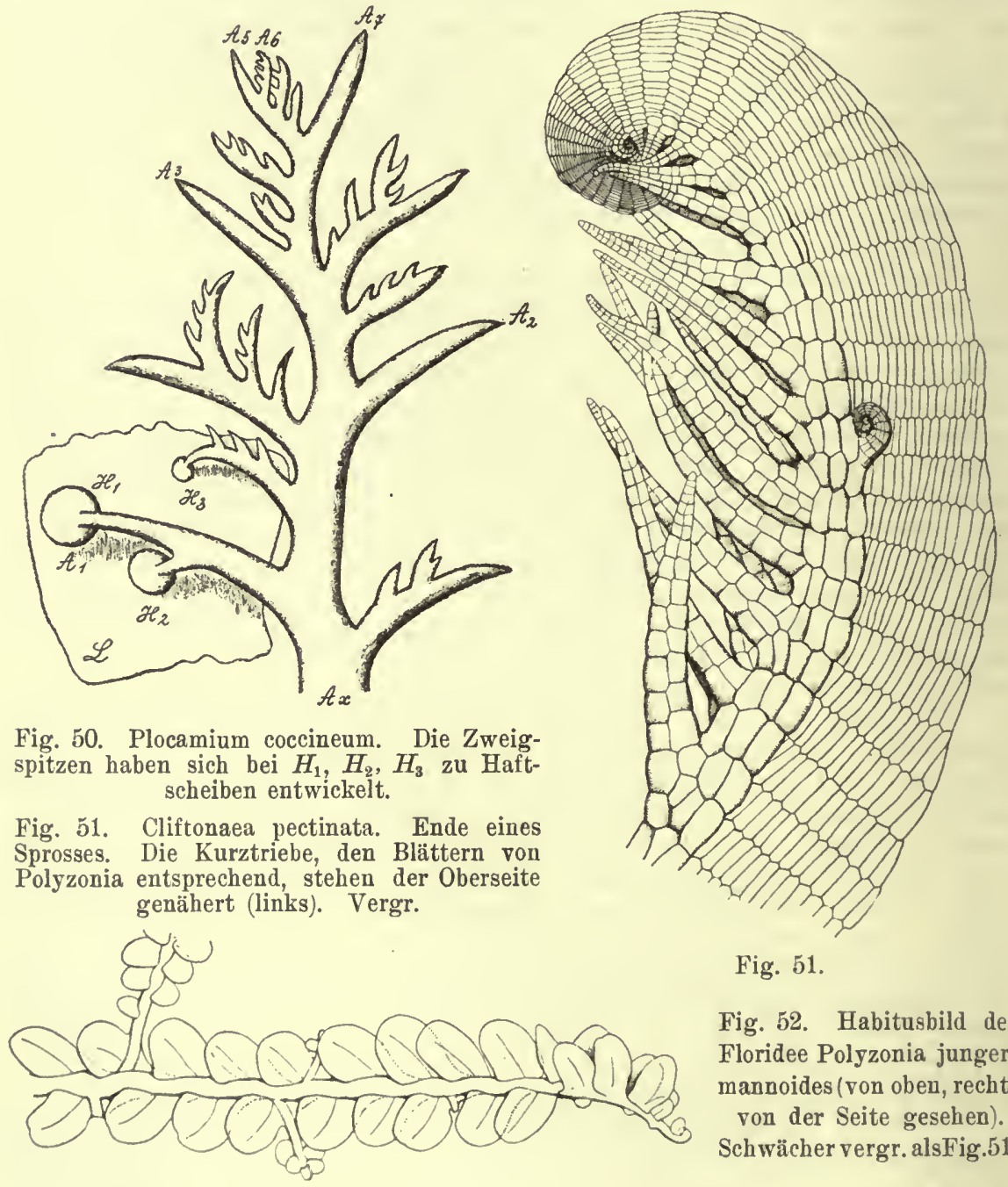

Fig. 51 .

Fig. 52. Habitusbild der Floridee Polyzonia jungermannoides (von oben, rechts von der Seite gesehen). Schwächer vergr. alsFig.51.

Dictyota Mertensii (Fig. 54) zeigt an der Basis des Thallus, aus der Fläche der Unterseite entspringend, eine Anzahl Hapteren, dünne Stränge, die nach abwärts wachsend sich am Substrate anheften. Sie sind aber keine "Rhizoiden " ${ }^{1}$ ), 
sondern entsprechen durchaus den übrigen Thallusgliedern; sie wachsen wie diese mit der für Dictyota charakteristischen Scheitelzelle. Sie können auch an ihrer Spitze sich verbreitern und zu vegetativen Thallnszweigen werden. Sie sind also offenbar "adventiv" entstandene Zweige, die sich anders verhalten, als die gewöhnlichen Assimilationsorgane, 1. indem sie nicht als seitliche Auszweigungen - Dichotomieäste - entstehen, sondern auf der Fläche; 2. indem sie sich dem Substrate zuwenden. Sie sind den Wurzeln höherer Pflanzen ebenso analog, wie die oben angeführten Bostrychia-Sprosse oder die Hapteren von Aneura eriocaulis (Fig. 53).

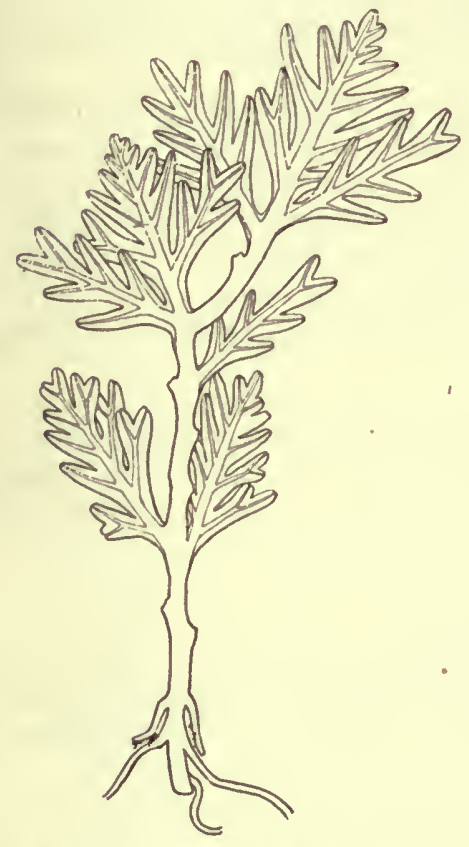

Fig. 53. Aneura eriocaulis. Habitusbila $3 \times$ vergr. Die an der Basis des Thallus entspringenden (nicht ganz gezeichneten) wurzelähnlichen Organe oder Hapteren sind Thallusäste, deren Gestalt und Wachstumsrichtung von der der als Assimilationsorgane dienenden $\ddot{A}$ ste ab weicht.

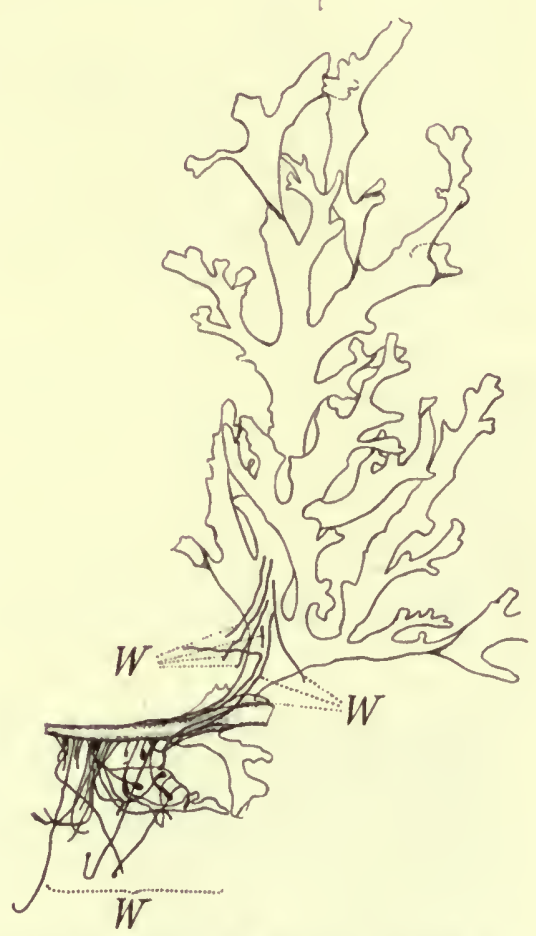

Fig. 54 . Dictyota Mertensii. Stück eines Thallus mit Hapteren ( $W$ ).

Wir sehen also, daß eine "Anisotropie" sonst gleichartiger Thalluszweige bei verschiedenen Gruppen der Thallophyten vorkommt, und daß wir solche aus "Umbildung" bestimmter Thallusglieder entstandene Organe von einfachen Auswüchsen, wie sie z. B. bei den Hapteren von Polyzonia vorliegen, zu unterscheiden haben - die ersteren sind letzteren analog, nicht homolog.

Die Besprechung der Organbildung bei Pilzen kann hier unterbleiben, da sie den Pflanzen, welche den Hauptgegenstand dieses Buches bilden, ferne stehen.

Dagegen sei kurz erwähnt die 


\section{B. Organbildung am vegetativen Thallus der Flechten ${ }^{1}$ ).}

Verglichen mit der Mannigfaltigkeit der Gliederung des Vegetationskörpers, wie sie die Algen zeigen, ist die derjenigen der Fle chten eine verhältnismäßig ärmliche. Sie bietet aber einige merkwürdige Probleme dar. Daß der Thallus dieser symbiontischen Organismen dem Lichte eine große Fläche bieten muß, ist klar. Der Gegensatz, den die Vegetationskörper der Flechten gegenüber denen der Pilze bilden, ist namentlich von SACHS (Vorlesungen über Pflanzenphysiologie) scharf hervorgehoben worden.

Es kann die Oberflächenvergrößerung auf sehr verschiedene Weise geschehen - ebenso wie bei den Algen kommen teils flache, teils zylindrische Thallusformen vor.

Alle Autoren sind wohl darin einig, daß sie denFlechtenthallus vom Pilzthallus ableiten. Denn abgesehen von einigen wenigen Fällen (Ephebe, Coenogonium, Collema) ist es ja der Pilz, welcher - eventuell beeinflußt durch die mit ihm zusammenlebenden Algenzellen - die Gestalt des Flechtenthallus -bestimmt. Wenn man bedenkt, daß der gewöhnliche Pilzthallus an das Substrat gebunden ist (in dem or meist verborgen ist), so wird man als den höchst entwickelten Flechtenthallus den betrachten, welcher mit dem Substrat nur an seiner Basis in Verbindung stebt.

Gegenüber den Krustenflechten sind schon diø Laubflechten vom Substrate mehr losgelöst. Es wird bei Besprechung der Symmetrieverhältnisse zu erörtern sein, wie aus einem dorsiventralen Flechtenthallus ein radiärer oder bilateraler werden kann. Als gestaltlich am böchsten entwickelt werden wir Flechten betrachten können, wie die in Fig. 55 abgebildete Cladonia verticillaris, die eine radiäre Achse mit dorsiventralen Anhängseln besitzt, also einigermaßen an eine beblätterte Pflanze erinnert.

Eine Arbeitsteilung innerhalb der Vegetationsorgane scheint (abgesehen von den der Befestigung dienenden Hyphensträngen, der Bildung von Ästen begrenzten Wachstums, Soredialen u. dgl.) nur in unbedeutendem Maße vorzukommen. Eines der auffallendsten mir in dieser Hinsicht bekannt gewordenen Beispiele ist das von Anaptychia leucomelaena (Fig. 56). Diese Pflanze besitzt am Rande ihres weißlichen Thallus (dessen Spitze eine Einkrümmung zeigt, wie sie auch sonst beim Vegetationspunkt dorsiventraler Sprosse höherer Pflanzen sich findet) lange dünne, nur aus Hyphen gebildete Auszweigungen, welche der auf Baumrinden epiphytisch zwischen Moosen lebenden Flechte als Haftorgane (und jedenfalls auch zum Festhalten und zur Aufnahme von Wassertropfen) dienen. Sie können an ihrer Spitze wie die Ranken mancher Ampelopsisarten zu Haftscheiben ( $H$, Fig. 56) anschwellen.

Diese Flechte ist auch deshalb lehrreich, weil ihre „Hapteren" zeigen, daß die Hyphen allein in geschlossenen, verzweigten Strängen wachsen können, ohne von den Algen direkt beeinflußt zu sein (eine indirekte Beeinflussung ist natürlich schon insofern vorhanden, als sie auf Kosten der Assimilate der Algen wachsen). Es ist also auch in anderen Fällen möglich, daß der Pilz von vornherein die Fähigkeit, geschlossene, mit großer Oberfläche versehene Hyphenkomplexe zu bilden, besaß, obne daß ibnen diese Fähigkeit erst durch das Zusammenleben mit den"Algen induziert wurde, wohl aber kann sie dadurch erst auffallend in die Erscheinung treten. Andererseits ist ebenso denk-

1) Vgl. z. B. Reinke, Abhandlungen über Flechten in Jahrb. für wissensch. Botanik XXVI-XXIX. 
bar, daß die Oberflächenvergrößerung durch den Besitz der Algenzellen erst veranlaßt wurde. Indes haben manche Pilze, auch ohne die Algen, die Fähigkeit, am Lichte große Oberflächenentwicklung aufzuweisen.

Fig. 57 zeigt z. B. die Fruchtkörper einer Thelephora, welche in der Gestaltung ihres vegetativen Thallus manchen Meeresalgen durchaus gleichen. Die

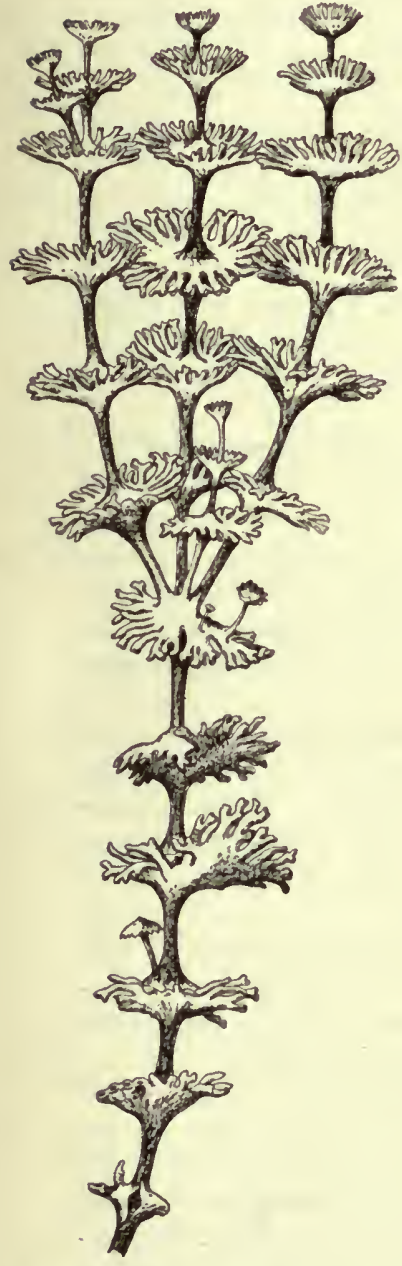

Fig. 55. Cladonia verticillaris in natürl. Größe.

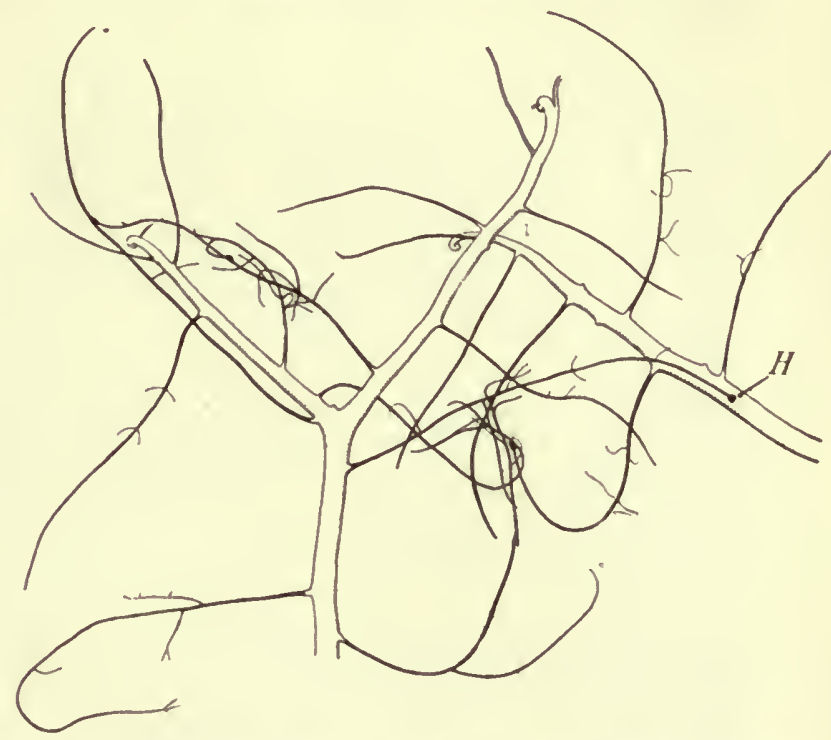

Fig. 56. Anaptychia lencomelaena. Thallusspitzen nach unten eingebogen, am Rande lange "Hapteren" (eine hat bei $H$ eine Haftscheibe entwickelt). Die Flechte wuchs epiphytisch zwischen Moosen. Die Hapteren besitzen keine Algenzellen.

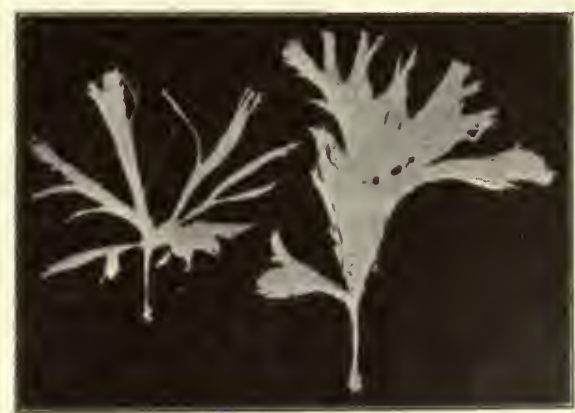

Fig. 57. Thelephora sp. (aus Südindien) Fruchtkörper verkleinert: sie gleichen dem (an der Basis festsitzenden) Vegetationskörper mancher Algen.

große Oberflächenentwicklung kommt hier natürlich nicht für die Kohlenstoffassimilation, sondern für die Hervorbringung und Ausstreuung der Sporen in Betracht.

Die erwähnte Frage kann hier um so weniger eingehend erörtert werden, 
als es an experimentell ermittelten Tatsachen noch sehr fehlt ${ }^{1}$ ). Es sei nur erwähnt, daß mir die Ableitung des Flechtenthallus von einem Pilz. thallus keineswegs - wenigstens nicht für alle - sichergestellt zu sein scheint. Wir wissen wenigstens für die Hymenolichenen, daß es sich bei ihnen um eine in dem Fruchtkörper des Pilzes eingetretene Symbiose handelt. Die Alge findet also eine für ihre Assimilationstätigkeit geeignete Gestalt des Pilzes schon vor, der Flechtenthallus geht hier aus dem Fruchtkörper des abgebildeten Pilzes hervor.

A. MöLLER ${ }^{2}$ ) hebt indes hervor, daß die Thelephora, welche mit der Alge Chroococcus zusammen die Flechte Cora bildet, ohne diese viel kleiner bleibe, also eine geringere Oberflächenentwicklung habe. Der Pilzfruchtkörper bezieht ja seine Nahrung allein vom Substrat, während ihm die Alge an beliebigen Stellen Nahrung liefert. Ebenso kann auch bei Ascolichenen die Flechtenbildung von den Fruchtkörpern ausgegangen sein, bei denen infolge der durch den Besitz der Algen erfolgten Ernährungsänderung die Apothecienbildung in einen späteren Zeitpunkt verlegt wurde. Ein solcher Ausgangspunkt (der ja nicht für alle Flechten zuzutreffen braucht) ist insofern auch wahrscheinlich, als die Fruchtkörper der meisten Ascomyceten ohnehin sich am Licht - auf welches ja auch die Algen angewiesen sind - entwickeln, während die Mycelien der meisten Pilze im Substrate verborgen sind. Von den Fruchtkörpern aus konnten Algen dann auch ins Mycel gelangen und diesem eine oberirdische Lebensweise ermöglichen.

Die Ansicht von KrabBE, wonach bei Cladonia der Flechtenkörper aus einer Entwicklung des Stieles (Podetiums) der Fruchtkörper hervorgegangen sein soll, ist neuerdings von $\mathrm{BAUR}^{3}$ ) und G. WOLFF u. a. bekämpft worden. Die Entwicklungsgeschichte zeigt nämlich, daß das Podetium rein thalloser Natur ist. Es entsteht als Hyphenauswuchs (ist also ursprünglich algenlos) und erst an ihm entwickeln sich die Apothecien. Das Podetium sei also eine vegetative, rechtwinklig zum horizontalen Thallus gerichtete vegetative Sprossung des ersteren.

Mir scheint das nicht auszuschließen, daß der Ausgangspunkt ein Apothecienstiel war, der mit Algen besiedelt wurde, während die Bildung der Karpogonien in einen späteren Zeitpunkt verlegt wurde. Entwicklungsgeschichtlich kann man auch eine Vitisranke an einer nicht blühbaren Pflanze nicht als steril gewordenen Blütenstand erkennen, obwohl sie das zweifellos ist (vgl. den Abschnitt über Umbildung).

Daß der Flechtenkörper dem Thallus der Meeresalgen gegenüber so sehr an Mannigfaltigkeit der Gestaltung nachsteht, dürfte auch damit zusammenhängen, daß die Flechten fast ausschließlich Landpflanzen sind, deren Gestaltung bei Nichtvorhandensein höher entwickelter Leitungsbahnen eine beschränktere ist als die der Wasserpflanzen. Sie besitzen z. B. keine besonderen Wasserleitungsbahnen und lösen die Wasserfrage einfach dadurch, daß sie bei Wassermangel in einen zeitweiligen Ruhezustand übergehen und Trockenperioden mehr oder minder lange ohne Schädigung im Zustand des "latenten Lebens" ertragen können. Organographisch gehören die Flechten zu den mehr stumpfsinnig sich verhaltenden Pflanzen, wenn man sie vergleicht mit den Meeresalgen und den Lebermoosen.

1) Vgl. die ron H. Winkler gegebene Diskussion (H. Winkler, Untersuchungen über Pfropfbastarde I $102 \mathrm{ff}$.). Daselbst ist auch die Literatur angegeben.

2) A. Möbler, Über die eine Thelephoree, welche die Hymenelichenen: Cora, Dictyonema und Laudatea bildet. Flora 77 (1893), p. 276.

$\left.{ }^{3}\right)$ BaUr, Untersuchungen iber die Entwicklungsgesch. der Flechtenapothecien.

Bot. Zeit. 1901, G. WolfF, Flora 95. Bd., p. 44. 


\section{§ 4. Organanlegung und Verzweigung.}

Aus den oben angeführten Beispielen geht herror, daß schon bei Thallophyten am Vegetationspunkt sowohl Verzweigung (d. h. die Anlage von mit den vorhandenen gleichartigen) als Anlegung ungleichartiger Organe (z. B. von "Blättern" an einem Vegetationspunkt von Polyzonia jungermannoides) stattfindet.

\section{Reihenfolge.}

Wir können uns zunächst fragen, in welcher Reihenfolge die Neubildungen am Vegetationspunkt auftreten, und sodann wie die Verzweigung stattfindet. Die Erscheinungen der Regeneration, Adrentirbildungen usw. müssen hier außer Betracht bleiben, unter Verweisung auf die rom Verfasser an einem anderen Orte gegebene Darstellung ${ }^{1}$ ).

Bezüglich der Reihenfolge bei der Organanlegung seien nur folgende Hauptpunkte herrorgehoben:

1. An Vegetationspunkten, die eine unbegrenzte Tätigkeit haben, entstehen die Anlagen gewöhnlich in progressiver Reihenfolge, d. h. die jüngsteı Anlagen sind die dem Vegetationspunkt nächsten, mag dieser nun terminal oder interkalar liegen, und zwar erscheinen sie als seitliche Aussprossungen, exogen oder endogen. In manchen Fällen (monokotyle Embryonen, Lemnaceen) ist ein deutlich abgegrenzter Vegetationspunkt überhaupt nicht vorhanden.

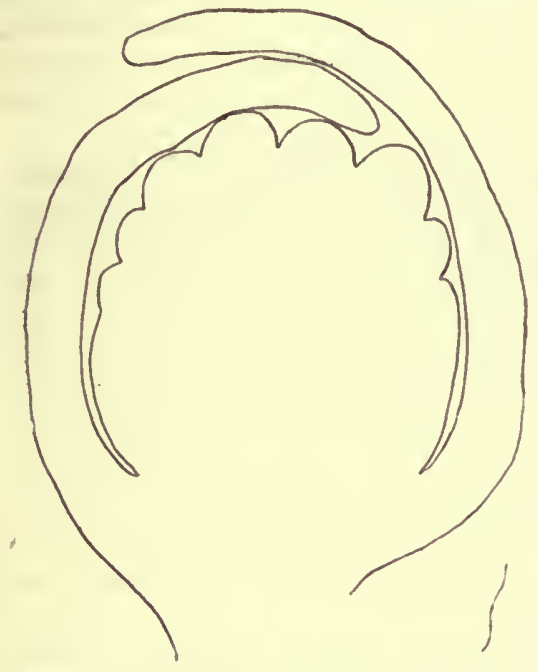

Fig. 58. Vallisneria (Lagarosiphon) alternifolia, Längsschnitt einer ganz jungen männlichen Inflorescenz; die Blüten werden in absteigender Reihenfolge angelegt.

2. In der Bliitenregion (auch bei einigen Kurztrieben z. B. Sciadopitys, Pinus monophylla) wird der Vegetationspunkt von den zuletzt entstandenen Blattorganen oft ganz aufgebraucht; es findet also eine t e r m inale Ausgliederung statt. Dasselbe ist der Fall bei den Antheridien und Archegonien vieler Moose usw.

3. Bei Sproßachsen begrenzten Wachstums und Blättern richtet sich die Reihenfolge des Auftretens der Organanlagen danach, welcher Teil des Vegetationspunktes am längsten den embryonalen Charakter behält. Ist dies der basale Teil, so kann die Reihenfolge der Entwicklung nach unten hin fortschreiten ${ }^{2}$ ) (vgl. Fig. 58) oder (wie bei manchen Blättern die Anlegung der Seitenblättchen, bei Placenten die der Samenanlagen) von der Mitte aus nach zwei Seiten. Einschaltung neuer Organanlagen zwischen schon vorhandene findet bei höheren Pflanzen nur in der Bliitenregion und bei „unterbrochen gefiederten" Blättern statt.

1) Goener, Einleitung in die experimentelle Morphologie der Pflanzen. 1906.

2) Derartige Fälle sind oft schwer zu unterscheiden von denen, in welchen ein sympodialer Aufbau vorliegt, und leiten sich wohl teilweise von diesen ab.

Goebel, Organographie der Pflanzen. 2. Aufl. Allgem. Teil. 
4. Die Vegetationspunkte wirken wie Anziehungszentren für Baustoffe, je nach ihrer Lage stärker oder schwächer. Wird z. B. der Vegetationspunkt eines Farnprothalliums verletzt oder weggeschnitten, so bilden sich zahlreiche "Adventivsprosse" an dem Prothallium, die, so lange der Vegetationspunkt in voller Tätigkeit war, nicht auftreten konnten. Bei einer Pflanze mit zahlreichen Vegetationspunkten entsteht so vielfach eine Art Wettbewerb der Vegetationspunkte, ein Verhalten, das bei den "Correlationen" zu besprechen sein wird.

Die Samenpflanzen, bei denen ein Vegetationspunkt fehlt, sollen bei Besprechung der Organunterscheidung erwähnt werden.

\section{Allgemeines iiber Verzweigung.}

Von "Verzweigung" sprechen wir, wenn am Vegetationspunkt eines Organes ihm gleichartige Organe sich bilden, also am Vegetationspunkt eines Sprosses Seitensprosse, an dem eines Blattes Blattglieder, dem einer Wurzel Seitenwurzeln usw. So wenig wie andere Definitionen, welche die Gestaltungsverhältnisse der Lebewesen in bestimmte Kategorien einordnen wollen, ist - namentlich für manche Thallophyten - auch diese eine überall und ausnahmslos passende; es sei hier nur hingewiesen auf Fälle, in denen zwischen den am Vegetationspunkt entstehenden Organen eine scharfe Arbeitsteilung nicht vorhanden ist.

Für die Organographie ist die Betrachtung der Verzweigung in zweierlei Hinsicht wichtig. Die Verzweigung ist eine Wachstumserscheinung. Nun sehen wir, daß in manchen Fällen das Wachstum selbst dann, wenn es sehr lange fortdauert eine nicht mit Verzweigung verbundene Oberflächenvergrößerung zur Folge hat. So z. B. bei den jahrzehntelange fortwachsenden unverzweigtbleibenden Blättern von Welwitschia. Wir brauchen uns nur zu denken, eine Pilzhyphe, eine Erdwurzel oder ein kleinblätteriger Sproß wachse in derselben Weise wie ein Welwitschiablatt weiter. um ohne weiteres einzusehen, wie sehr viel zweckmäßiger es ist, daß bei ihnen die Oberflächenvergrößerung mit Verzweigung verbunden ist. Es braucht ja kaum daran erinnert zu werden, daß dadurch erst einer Pilzhyphe oder einer Erdwurzel eine günstige Ausnutzung des Substrates oder einem oberirdischen Sproß die richtige Anordnung der chlorophyllhaltigen Organe zum Lichte ermöglicht wird.

Außerdem bietet die Verzweigung die Möglichkeit einer Arbeitsteilung, bei Sprossen auch die der vegetativen Vermehrung usw.

$\mathrm{Da} ß$ übrigens bei den verschiedenen Pflanzen die Verzweigung eine verschiedene Bedeutung hat, ist nicht $\mathrm{zu}$ verwundern. Es sei das unten näher zu erörternde Beispiel erwähnt, das uns die radiären Farnstämme im Vergleich mit den radiären Equisetenstämmen darbieten. Letztere, bei denen die Sproß a c h s e n die Organe der Kohlenstoffassimilation sind, sind reich verzweigt, bei ersteren tritt - z. B. bei den Baumfarnen die Verzweigung sehr zurück, was, wenn wir auch die inneren Gründe dafür nicht kennen, wenigstens biologisch begreiflich erscheint, da die Blätter hier eine große Oberflächenentwicklung besitzen.

Andrerseits kann die Verzweigung direkt abhängig sein von äußeren Faktoren: dieselbe Luftwurzel, die gänzlich unverzweigt dem Substrate entgegenwächst, bildet reichlich Seitenwurzeln, sobald sie dieses erreicht hat; ebenso kann bei Moossprossen, welche im Finstern sich ent- 
wickeln, das Auftreten der Verzweigung ganz unterdrückt werden. Es wird in diesen Fällen (teleologisch gesprochen), alles verfügbare Material verwendet, um entweder die Luftwurzel in den Boden oder den Hauptsproß an das Licht zu bringen. Es sind also einerseits die Beziehungen der Verzweigung $\mathrm{zu}$ den Lebensverhältnissen ron Bedeutung, andererseits ist aber auch die Art und Weise wie die Verzweigung erfolgt für bestimmte Organe und auch für große Pflanzengruppen eigentümlich. Hat doch z. B. J. Sachs die Lycopodinen seinerzeit als "Dichotomen" bezeichnet, um hervorzuheben, daß für sie die gabelige Verzweigung ein wichtiges systematisches Merkmal darstelle. Wir werden uns also auch fragen müssen, in welcher Beziehung die einzelnen Verzweigungsarten zueinander stehen, ob sie sich innerhalb einer systematischen Gruppe auf ein einheitliches Schema zurückfuihren lassen und wie die einzelnen Gruppen sich in dieser Beziehung zweinander verhalten.

\section{Yersehiedene Arten der Verzweigung.}

Zunächst wird es erforderlich sein, einige in verschiedenem Sinne gebrauchte Bezeichnungen etwas näher zu begrenzen. Die normale Verzweigung ist stets gebunden an Vegetationspunkte. Die Fïlle von „falscher Verzweigung", wie wir sie bei fadenbildenden Cyanophyceen und einigen Bakterien finden, sind solche, bei denen ein Vegetationspunkt nicht vorhanden ist, und Seitenzweige durch seitliches Auswachsen von Fadenzellen entstehen, die unter sich (ron den Heterocysten abgesehen) offenbar gleichartig sind. Nur bei den höchstentwickelten Cyanophyceen kommt es zur Ausbildung eines Vegetationspunktes.

Bei mit Vegetationspunkten versehenen Pflanzen finden sich aber vielfach auch "Adventiv"-Bildungen. Diesen Begriff hat man in dem verschiedensten Sinne gebraucht, man bezeichnete z. B. Sprosse und Wurzeln als adventive, wenn sie an anderen Stellen als aus einem Sproß-oder Wurzelvegetationspunkt entstehen, ja sogar auch Seitensprosse die nicht, (wie das sonst bei den Samenpflanzen die Regel ist), in den Blattachseln stehen. Andererseits aber wurden mit demselben Namen auch Neubildungen an abgetrennten Pflanzenteilen bezeichnet. Wie friiher ${ }^{1}$ ) hervorgehoben wurde, lassen sich weder bei der weiteren noch bei der engeren Fassung des Begriffs normale und adventiv entstehende Neubildungen scharf voneinander unterscheiden. Indes wird eine Bezeichnung um so weniger zweckmäßig je unbestimmter sie ist. Wir werden deshalb im folgenden den Begriff "adventiv" wegen seiner Vieldeutigkeit ganz ausschalten und als Verzweigung die Bildung gleichnamiger Organe aus dem embryonalen Gewebe eines Thallus, einer Sproßachse, einer Wurzel oder eines Blattes bezeichnen. Die ungleichnamigen Organe aber benennen wir nach ihrem Entstehungsorte, reden also von sproßbürtigen Wurzeln, blattbürtigen Sprossen, wobei jeweils hervorgehoben wird, ob solche im ungestörten Verlauf der Vegetation oder regenerativ, nach Verletzungen auftreten.

Kehren wir zu den am Vegetationspunkt angelegten Organen zurück, so fragt sich, wie weit ihr weiteres Schicksal von der Art ihrer Anlegung am Vegetationspunkt abhängt. Es kann gleich von vornherein fest bestimmt, - stabil - oder noch nachträglich veränderlich, labil sein.

1) Über Regeneration im Pflanzenreich. Biol. Zentralbl. 22, 1902. 
Außer dieser Frage ist aber noch die andere zu erörtern, wie überhaupt eine Abgliederung seitlicher Organe zustande kommt.

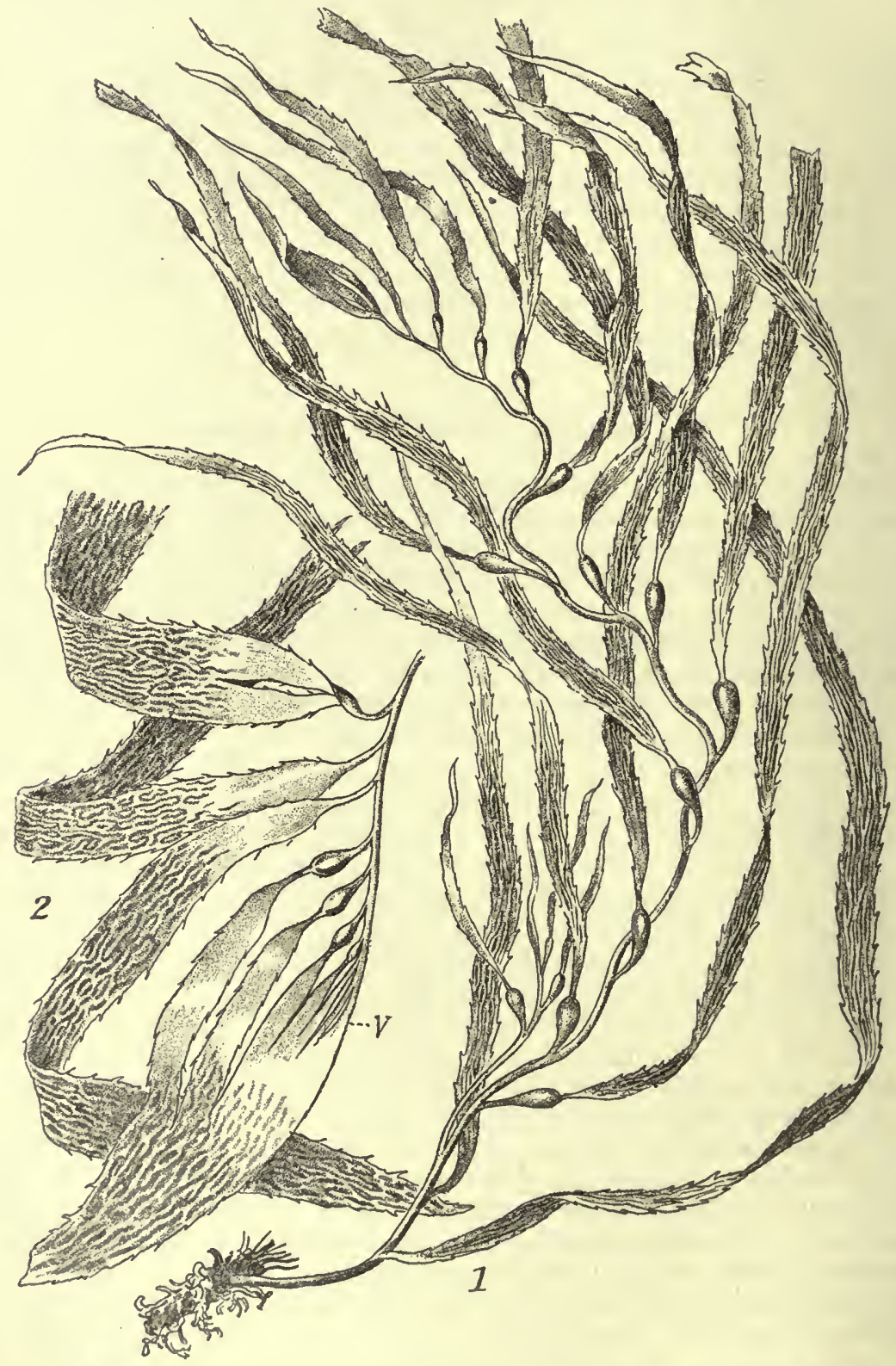

Fig. 59. 1. Macrocystis angustifolia, nach Postels und Ruprecht, ganze Pflanze. 2. Endstiuck von Macrocystis pyrifera; $v$ Interkalarer Vegetationspunkt (Aus OLtmanss, Algen).

Zwei Wege sind es, welche dabei die Natur eingeschlagen hat, der eine (a), nur wenig begangen, weil offenbar nur für bestimmte Gestaltungsverhältnisse gangbar, findet sich merkwürdigerweise bei Gruppen, die 
weit voneinander entfernt stehen, der andere (b) ist der übliche und weit verbreitete.

a) Eine Gliederung kommt zustande durch nachträgliche Zerteilung einer ursprünglich zusammenhängenden, aus embryonalem Gewebe herrorgegangenen Fläche. Dies geschieht einerseits bei den Thallusflächen mancher Laminariaceen - also einer den Phaeophyceen angehörigen Gruppe von Meeresalgen - andererseits bei den Blättern einiger Monokotylen, besonders denen der Palmen.

Von den ersteren seien hier angeführt die merkwürdigen Vorgänge, wie wir sie bei Macrocystis finden.

Diese Gattung besitzt an einer im Wasser flutenden strickartigen Hauptachse eine Anzahl blattartiger Organe. Wie Fig. 59 zeigt, werden diese durch Spaltenbildung aus einer ursprünglich einheitlichen Fläche herausgeschnitten, und wachsen unter Gestaltveränderung noch bedeutend heran. In primitiverer Weise findet sich derselbe Vorgang auch bei anderen Laminariaceen.

Auch die Blätter der Palmen (Fig. 60) besitzen ursprünglich eine zusammenhängende Blattfläche, von der dann einzelne Stuicke abgegliedert werden. Bei den Fächerpalmen bleiben die Blattflächen der Hauptsache nach einheitlich und lösen sich nur am Rande in einzelne Strahlen auf, bei den „Fiederpalmen" ist die ganze Blattfläche in einzelne, an einer starken Mittelrippe aneinandergereihte Abschnitte zerteilt. $\mathrm{Da} B$ ein derartiges Blatt durch seine Gliederung ebenso wie der MacrocystisThallus mechanischen Insulten leichter ausweichen kann, als wenn die 'Teilung unterbliebe, ist klar. Indes sind auch

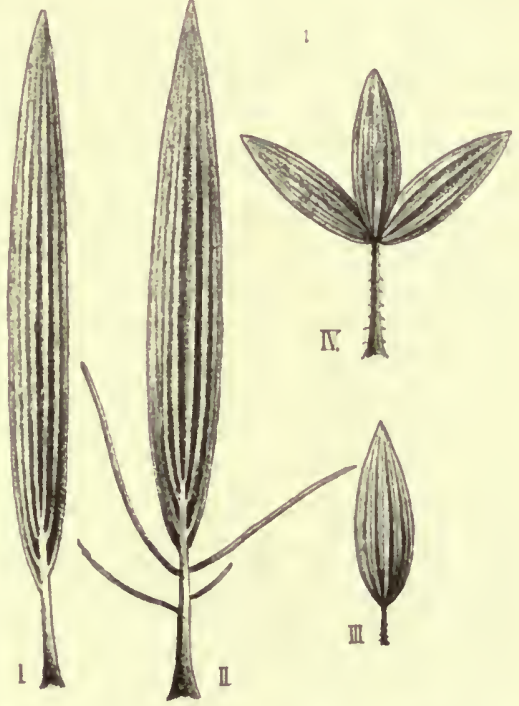

Fig. 60. I und II Phoenix canariensis, Blätter von Keimpflanzen. Das Primärblatt $I$ ist noch ganz, bei $I I$ haben sich unten von der Blattfläche 4 Eiedern abgespalien; III und IV Primärblätter der Fächerpalme Chamaerops excelsa. Fälle bekannt, in denen eine Zerteilung der Blattspreite von keinem derzeit ersichtlichen Nutzen ist. So die Lochbildung und Lappenbildung der Blätter einiger Arö̈deen. Was man zur „Erklärung" dieser Bildungen als Anpassungserscheinungen gesagt hat, ist nicht überzeugend.

b) Die soeben angeführten Fälle treten, wie schon bemerkt, an Zahl weit zurück gegen die, in denen eine wirkliche Verzweigung stattfindet. Das Bemühen, die Art und Weise dieses Vorganges näher zu präzisieren, hat zur. Aufstellung verschiedener "Typen" geführt. Es handelt sich dabei einmal um die Art und Weise der Anlegung seitlicher Organe am Vegetationspunkt und sodann um die Beziehung zwischen Stärke und Wachstumsrichtung des neuen Vegetationspunktes zum alten. In ersterer Hinsicht sind die Typen die der exogenen und der endogenen Verzweigung, in letzterer die der dichotomen und der seitlichen. 


\section{Exogene und endogene Verzweigung.}

An Vegetationspunkten, welche aus einem Zellkörper bestehen, beteiligen sich bei der Entstehung seitlicher Organe in weitaus den meisten Fällen auch die äußersten Zellschichten. Die Entstehung ist dann eine „exogene". Es ist klar, daß dabei geringere Widerstände $\mathrm{zu}$ überwinden sind, als wenn die äußerste Zellschicht (oder Zellschichten) durchwachsen oder durchbrochen werden müßten. Außerdem hängt diese Art der Verzweigung auch damit zusammen, daß an massigeren Vegetationspunkten die inneren Zellen ihren embryonalen Charakter früher verlieren als die äußeren, oft schon ganz nahe dem Ende des Vegetationspunktes.

Die endogene Entstehung ist umgekehrt dadurch ausgezeichnet, daß hier äußere Zellschichten ihren embryonalen Charakter früher verlieren als innere, die dann zum Ausgangspunkt der Verzweigung werden. Im Zusammenhang damit treten die endogen entstehenden Anlagen den exogen gebildeten gegenüber meist später auf; es muß erst die angeführte Differenzierung am Vegetationspunkt vollzogen sein, ehe sie sich bilden können. Sehr auffallend zeigt sich dies bei den Wurzeln, die (abgesehen von den gabelig sich verzweigenden und einigen exogen entstehenden sproßbürtigen Wurzeln) ihre endogenen Seitenwurzeln erst in beträchtlicher Entfernung rom Vegetationspunkte anlegen.

Die endogene Entstehung der Wurzeln läßt sich ohne Zweifel als eine vorteilhafte betrachten. Es fällt bei den Wurzeln der Schutz der Vegetationspunkte durch Blätter ja weg, und die endogene Entwicklung läßt die jungen Wurzeln zunächst unter dem schützenden älteren Gewebe ihre Wurzelhaube ausbilden und erstarken; es ist eine ganz ähnliche Erscheinung wie die Überlagerung des embryonalen Gewebes des Wurzelregetationspunktes durch die Wurzelhaube. Wie hier die peripherischen Zellen in den Dauerzustand übergehen, weiter nach innen gelegene embryonal bleiben, so bleiben auch im Innern der Wurzeln bestimmte Zellschichten länger embryonal (bei den Samenpflanzen der Perizykel, bei den Pteridophyten die innerste Rindenschicht) und werden zum Ausgangspunkt der Wurzelbildung.

Damit ist die endogene Entstehung der Wurzeln natürlich nicht „erklärt", sondern nur in Beziehung zu ihren Lebensverhältnissen gesetzt.

Solche Beziehungen sind derzeit nicht erkennbar bei anderen Fïllen endogener Verzweigung, wie sie sich bei einigen Algen und Lebermoosen finden.

So unter den Florideen bei einer Anzahl Rhodomeleen ${ }^{1}$ ). Hier ist der typische Bau der, daß eine zentrale Zellreihe im Thallus umgeben ist von Perizentralzellen. Viele haben eine exogene Verzweigung, dic am Vegetationspunkt vor sich geht, ehe die angedeutete Gliederung eintritt, andere (Euzoniella, Polyzonia, Leveillea) legen die Kurztriebe exogen, die Langtriebe (die dementsprechend später auftreten) endogen an, wieder andere, wie z. B. Amansia, Rytiphloea, Vidalia, Halopitys, Ctenosiphon bilden sämtliche Sprosse endogen. Dabei findet beim Durchwachsen der Sproßanlagen zwischen den Perizentralzellen keine Zerstörung oder Schädigung der letzteren statt. Eine Beziehung der endogenen Entstehung zu den Lebensverhältnissen oder eine Nützlichkeit dieses Vorgangs ist nicht bekannt, er scheint „zufällig" aufgetreten zu sein.

1) Vgl. Falkenberg, Die Rhodomeleen des Golfes von Neapel, Leipzig 1901. 
Unter den beblätterten Lebermoosen fand Leitger Formen, die bestimmte Äste aus den unmittelbar unter der äußersten Zellschicht des Vegetationspunktes gelegenen Zellen anlegen, während sonst die Verzweigung stets exogen erfolgt. Endogen aber entstehen die merkwürdigen Flagellenäste bei Mastigobryum, die Fruchtäste derselben Gattung und die von Lepidozia und Calypogeia,..sowie die Äste von Jungermannia bicuspidata. Es handelt sich dabei um Aste, welche auf der Unterseite der dorsiventralen Sprosse entstehen. Es mag also mit der Lage die Tatsache zusammenhängen, daß die dem Substrate zugekehrte äußerste Zellschicht hier frühzeitig in den Dauerzustand uibergeht und die Fähigkeit zur Hervorbringung einer Astanlage verliert. Jedenfalls werden wir dieses Verhalten als ein von der gewöhnlichen exogenen Entstehung der Zweige abgeleitetes betrachten dürfen. Eine analoge Erscheinung (ein Verlegen von Neubildungen nach innen) finden wir auch sonst z. B. bei der Bildung der Antheridien von Anthoceros, vgl. speziellen Teil).

Bei höheren Pflanzen sind Fïlle normal endogen erfolgender Verzweigung nicht bekannt.

Was man dafür gehalten hatte, hat sich bisher regelmäßig als eine durch friihzeitige Umwallung der Seitenknospe hervorgerufene Täuschung entpuppt. So bei Equisetum und ebenso bei Dracaena, der ein neuerer Schriftsteller auf Grund unzureichender Beobachtungen eine endogene Knospenbildung zugeschrieben hat.

Sproßbildung bei Regeneration kann endogen erfolgen; indes ist dies keineswegs (wie früher teilweise angenommen wurde) immer der Fall.

\section{Dichotome und seitliche Verzweigung.}

Fanden wir bei endogener und exogener Verzweigung keine absolute Gesetzmäßigkeit - etwa in der Art, daß man sagen könnte, alle Wurzeln entstehen endogen, alle Sprosse exogen, so wird sich in diesem Abschnitt zeigen, da $B$ auch $z$ wischen dichotomer und seitlicher Verzweigung sich keine festen Grenzen ziehen lassen, nur die extremen Fälle lassen eine scharfe Abgrenzung zu.

Bei der dichotomen Verzweigung - (ebensogut ist natuirlich theoretisch eine polytome möglich) - hört das Wachstum des Scheitels in der bisherigen Richtung auf, dieser wird ersetzt durch zwei gleich starke in divergenter Richtung wachsende Äste, zu deren Bildung meist der ganze bisherige Scheitel aufgebraucht wird. Bei der seitlichen Verzweigung dagegen treten die Auszweigungen unterhalb des in seiner bisherigen Richtung zunächst weiter wachsenden Vegetationspunktes auf.

Für eine „echte" dichotome Verzweigung ist seit NäGELI's Untersuchungen Dictyota ein klassisches Beispiel geworden (Fig. 61, 62, 63 A). Es ist hier am bandförmigen Thallus eine von zwei flachgewölbten Wänden begrenzte Scheitelzelle vorhanden, von welcher durch Antiklinen Segmente abgeschnitten werden. Bei der Verzweigung tritt eine Aenderung des Verhaltens der Scheitelzelle ein. Leider sind die Vorgänge cytologisch noch nicht untersucht (wir wissen nicht, ob eine Drehung der Kernteilungsfigur stattfindet, nicht einmal, ob die Scheitelzelle vor der zur Verzweigung führenden Teilung eine Änderung ihrer bisherigen Gestalt erfährt), nur rein äußerlich ist die Anordnung der Zellwände bekannt. Wir sehen, $d a ß$ in der Scheitelzelle eine Halbierungswand ( $a, a$ Fig. $63 \mathrm{~A}$ ) auftritt. Dadurch sind zwei neue Scheitelzellen angelegt, welche in der in Fig. $63 \mathrm{~A}$ durch Punktierung angedeuteten Weise auswachsen. 
die Verzweigung an den Scheitel rückt. In Fig. $63 \mathrm{D}$ ist dies auch der Fall, aber das mit 1 bezeichnete Segment der Scheitelzelle ist so viel kleiner als der Rest des Vegetationspunktes, daß damit auch das Beibehalten der seitherigen Wachstumsrichtung gegeben ist; die Verzweigung verhält sich dann ebenso, wie wenn der Seitenzweig weiter vom Scheitel entfernt angelegt würde. Nahe dem Scheitel angelegt wird auch der Ast des Thallus von Caloglossa Lepriearii (Fig. 1, Flora 1894, p. 439), indes bleibt hier doch der Seitenast seiner ersten Anlage entsprechend weniger kräftig ausgebildet als die Hauptäste, welche durch die Verzweigung dichotomieähnlich geknickt erscheint.
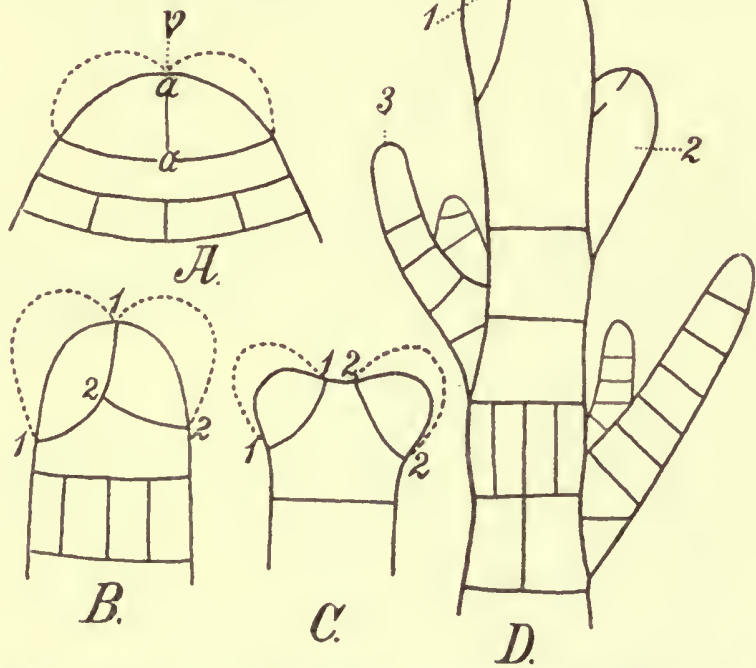

Fig. 63. $A-C$ Schema für verschiedene Arten der Dichotomie z. B. $A$ Dictyota, $B$ Cladostephus, $D$ Halopteris filicina, SproBscheitel. Die Äste werden in der Scheitelzelle selbst angelegt, die die Astanlage herausscheidende Wand reicht bis zum Scheitel selbst ( $B$ und $C$ nach Pringsireis).

Es wird unten zu erwähnen sein, daß die einmal angelegten Äste auch nachträgliche Veränderungen erfahren können.

Die angeführten Beispiele genügen wohl, um zu erläutern, daß zwischen echter Dichotomie und seitlicher Verzweigung es schon bei Thallophyten Übergänge gibt. Eine gabelige Verzweigung kann um so leichter zustandekommen, je näher am Scheitel sie erfolgt. Das Extrem stellt die genaue Spaltung eines Scheitels in zwei dar, ebenso aber kann auch ein ursprünlich seitlich angelegter Zweig als Gabelzweig sich entwickeln. In einem einzelnen Falle darüber zu streiten, ob eine "echte Dichotomie" vorliege, ist also überflüssig; vielmehr besteht die Aufgabe der morphologischen Untersuchung nur darin, $z u$ ermitteln, wieweit ein bestimmter Verzweigungsmodus innerhalb einer natürlichen Gruppe konstant ist und wenn nicht, wie die einzelnen Verzweigungsarten miteinander zusammenhängen. 


\section{VI. Änderungen in dem Verhältnis der Zweige zueinauder oder zur Hauptachse.}

Die Betrachtung eines Verzweigungssystems in fertigen Zustand gibt bekanntlich nicht immer ohne weiteres Aufschluß über sein Zustandekommen. Ein dichotom angelegtes Verzweigungssystem kann durchaus das Aussehen eines durch seitliche Verzweigung entstandenen annehmen (Fig. $64 C$ ). Bei letzterem besteht eine gemeinsame Hauptachse oder, wie man es mit einem nicht gerade gliicklichen Namen bezeichnet hat, e in Fußstück oder Podium, also ein Mo n o podium (Fig. 65). Hier ist also der Vegetationspunkt der Hauptachse dauernd der kräftigst wachsende. Es kann aber auch die Hauptachse jeweils zur Seite gedrängt werden durch einen Seitensproß (Fig. 65 C), dessen unteres Stück sich dann in die

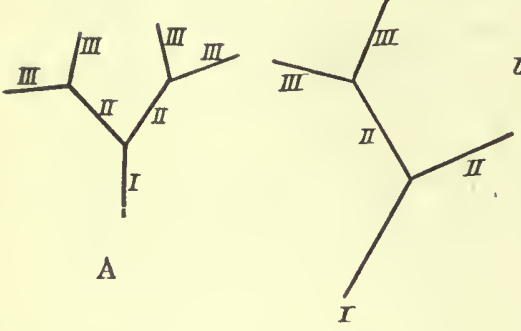

B

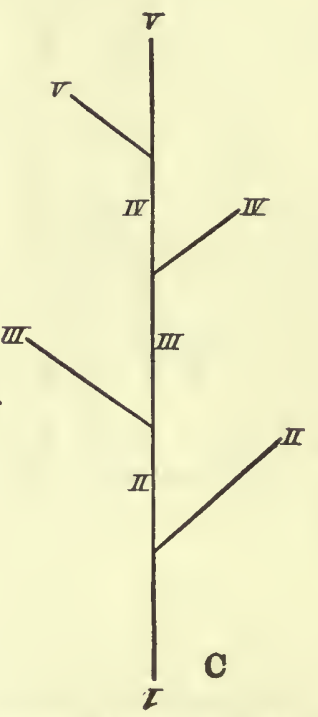

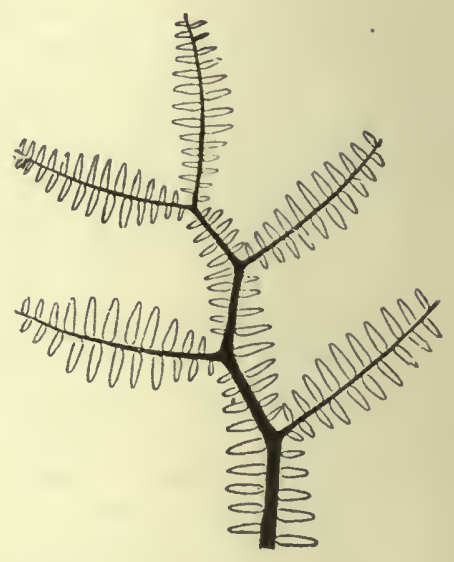

D

Fig. 64 (nach Poтомı́́). A Schema einer gabeligen Verzweigung. $B$ Übergang von Gabelungen zu sympodialer Verzweigung; die einzelnen Fußstiicke des Sympodiums $(I$, $I I, I I I, I V)$ noch deutlich erkenubar. $C$ 'Sympodium mit gestreckter Achse. $D$ Callipodium. Rest aus dem oberen Palaeozoicum entsprechend dem Schema $B$.

Verlängerung der frïheren Hauptachse stellt so daß eine Verkettung von Fußstiicken verschiedener Sproßgenerationen (s. Fig. 65 C), ein ,Sympodium" zustande kommt.

Dieser Vorgang kann entweder entwicklungsgeschichtlich nachweisbar sein, oder es findet die Übergipfelung schon von vornherein statt. In diesem Falle ist das Sympodium dann ontogenetisch wieder $\mathrm{zu}$ einem Monopodium geworden und der Vorgang selbst nur vergleichend-historisch als aus Sympodialbildung entstanden erkennbar. Die Verkennung dieser Tatsache, z. B. bei dem Aufbau von Vitis, ferner manche Infloreszenzen (von welchen unten noch ein Beispiel erwähnt werden soll), hat früher zu Erörterungen Veranlassung gegeben, die jetzt nur noch geschichtliches Interesse haben.

Ganz ähnliche Übergipfelung kann auch bei Gabelverzweigung eintreten (Fig. 64). Wir erhalten dann hier ein Sympodium dessen Zustandekommen aus Gabelverzweigung nicht mehr ohne weiteres klar ist. Auch 
hier tritt derselbe Vorgang auf, wie bei den aus seitlicher Verzweigung entstandenen Sympodien, d. h. die Übergipfelung kann eine „kongenitale" sein, es kann der Gabelzweig, welcher das Sympodium fortsetzt, (Fig. 64 C) von vornherein kräftiger sein als der andere; so ist es z. B. bei den Blättern und Sproßachsen mancher Farne. Auch schon innerhalb der Gruppe der "Dichotomen" treten, wie wir sehen werden, dieselben Erscheinungen auf. An diese Tatsachen war kurz zu erinnern, weil sie für den Zusammenhang der Organbildung innerhalb einer Gruppe ron Bedeutung sind.
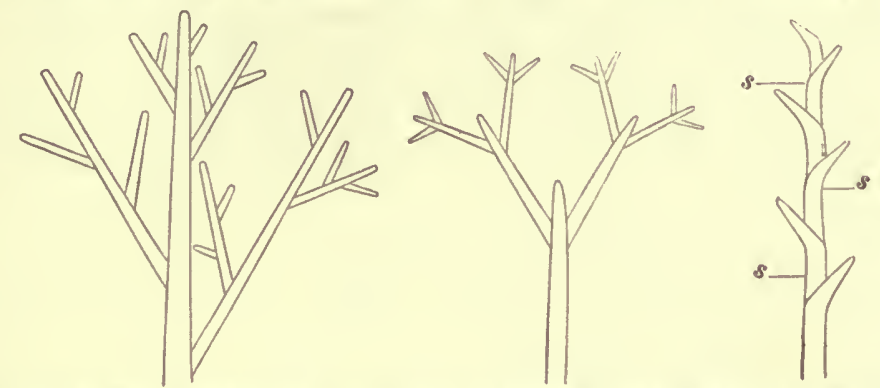

Fig. 65. Schematische Darstellung der monopadiolen Verzweigung $A$ Typisches Monopodinm, $B$,Falsche" Dichotomie, $C$ Seitliche Verzweigung mit Förderung eines Seitenzweiges and Sympodienbildung ( $s$, $s$, die Podien), der Gipfel der jeweiligen Hauptachse wird durch das Podium zur Seite gedrängt (Lehrb.).

\section{Axlllăre Verzweigung.}

Bei der seitlichen Verzweigung sehen wir da, wo es sich um beblätterte Pflanzen handelt, vielfach eine konstante räumliche Beziehung auftreten zwischen einem Blatt und einem Seitenzweig, der in dessen Achsel anftritt. Es fragt sich, wie weit diese Erscheinung verbreitet ist, und ob ihr eine besondere biologische Bedeutung zukommt.

Ehe diese Frage für die einzelnen Gruppen der beblätterten Pflanzen näher erörtert wird, sei zunächst noch darauf hingewiesen, daß eine konstante räumliche Beziehung zwischen verschiedenartigen Auszweigungen für Lang- und Kurztriebe schon bei Thallophyten sich finden kann (p. 59), Beziehungen, die wir als Parallelbildungen zur axillären Verzweigung betrachten können.

Da die Morphologie ausging von der Untersuchung der Samenpflanzen und bei diesen die "axilläre" Verzweigung eine weite - freilich, wie wir im speziellen Teile sehen werden, nicht allgemeine - Verbreitung besitzt, so ist leicht verständlich, daß man auch bei anderen Pflanzengruppen eine gesetzmäßige Beziehung zwischen Blatt und Achselsproß nachzuweisen suchte. Indes ist eine Übertragung der Regeln, die man bei höheren Pflanzen findet, auf niedere unstatthaft. Vielmehr sind die Gestaltungsverbältnisse jeder Gruppe für sich zu betrachten, and nicht von vornherein in ein Schema zu zwängen.

Wenn im folgenden die Verzweigung innerhalb einzelner Gruppen besprochen wird, so kann es sich dabei nur um allgemeinere Beziehungen, nicht um Eingehen in Einzelheiten handeln.

\section{$\S 5$. Verzweigung bei Bryophyten.}

Die thallosen Formen sind alle dorsiventral. Sie haben teils laterale, teils ventrale Verzweigung. Bei ersterer entstehen die Seitensprosse so nahe am Scheitel, daß die Bedingungen für gabelige Aus- 
bildung gegeben sind. Die ventralen Sprosse treten nicht bei allen auf, wo sie sich finden, sind (wie ja schon durch ihre Lage bedingt ist) ihre Funktionen meist von denen der seitlichen Zweige verschieden, namentlich werden sie bei manchen Arten als Träger der Sexualorgane benutzt ${ }^{1}$ ). So zeigt z. B. Fig. 66 ein Thallusstück ron Hymenophytum flabellatum von der Unterseite. Der fächerförmig geteilte Assimilationsthallus ist durch wiederholte "Gabelung" entstanden; die ventralen Sprosse auf seiner Unterseite tragen Archegonien und sind normal begrenzten Wachstums. Indes können sie, wenn man einen Assimilationssproß frïhzeitig abschneidet, auch zu vegetativer Entwicklung veranlaßt werden. Daß bei der mit Hymenophytum verwandten Metzgeria die ventralen Sprosse (nach LEITGEB) endogen anstehen, hängt wohl, wie in den p. 71 angeführten Fällen mit ihrer - den seitlichen gegenüber - verzögerten Entstehung zusammen.
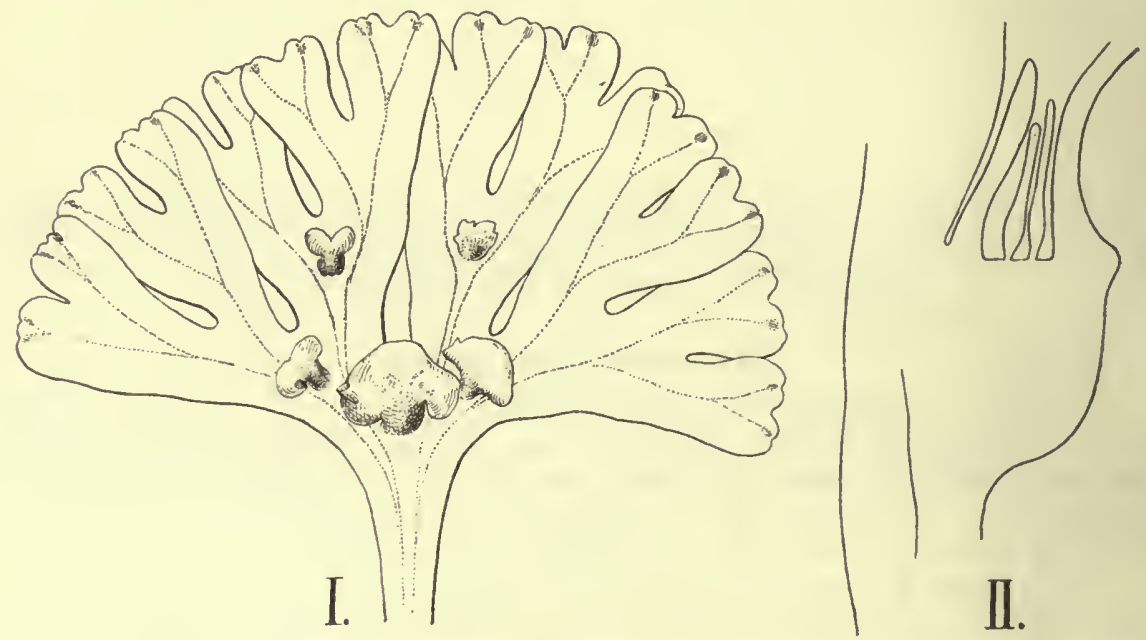

Fig. 66. I Hymenophytum flabellatum. Stïck eines oberirdischen Thallus von der Unterseite betrachtet. Er ist gabelig verzweigt. Die schuppenartigen Auswüchse der Unterseite sind ventrale Sprosse, welche die Archegonien tragen, wie der in $I I$ abgebildete Längsschnitt zeigt.

Bei den beblätterten Bryophyten wächst das Stämmchen mit einer dreioder zweischneidigen Scheitelzelle. Da - von hier nicht zu erörternden Ausnahmen abgesehen - all e Segmente zu Blättern auswachsen, so müssen zwischen Blättern und Seitensprossen räumliche Beziehungen vorhanden sein. Thre Feststellung verdanken wir den Untersuchungen von LeITGEB, welche neuerdings für die foliosen Lebermoose durch Evass ${ }^{2}$ ) ergänzt worden sind.

Es fragt sich $1.0 \mathrm{~b}$ die Verzweigung bei allen beblätterten Bryophyten gleichartig ist, 2. wie weit eine Arbeitsteilung zwischen den einzelnen Zweigen vorkommt. Letztere Frage soll im speziellen Teile erörtert werden, also kommt hier nur die erste in Betracht.

1) Merkwürdig ist, daß bei keinem bis jetzt - wenigstens mir - bekannten thallosen Lebermoose die ventralen Sprosse als dauernd wurzelähnliche Organe entwickelt sind, wie bei der oben erwähnten Dictyota Mertensii. Die Haftorgane mancher Aneuraarten sind Seitenzweige (Fig. 53).

2) A. E. Evans, Branching in the leafy Hepaticae. Annals of botany. Vol. XXV (1912), p. $1 \mathrm{ff}$. 
Eine Übereinstimmung sämtlicher beblätterter Bryophyten findet zunächst insofern statt, als überall keine (oder eine nur scheinbare) axilläre Verzweigung auftritt.

Bei den Laubmoosen entwickeln sich an den Vegetationspunkten zunächst die Blattanlagen und unter diesen (aber nicht aus jedem Segment) die Seitenzweige.

Der neuerdings unternommene Versuch, den Laubmoosen eine axilläre Verzweigung anzudichten, beruht, wie v. Schoevad ${ }^{1}$ ) gezeigt hat, auf Irrtümern. Es sei hier nur das Wesentliche kurz angeführt.

Die Anlage des Seitensprosses kann entweder in der mittleren Höhe des blattbildenden Segmentes erfolgen (Fontinalis, Fig. 67) oder an dessen Basis (Fig. 68). Im letzteren Falle können die Sproßanlagen scheinbar axillär zu einem unter ihnen stehenden Blatte stehen. So befindet sich in

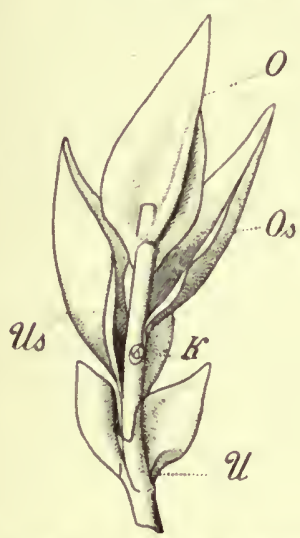

Fig. 67. Fontinalis antipyretica (nach v. SchozNAU). Sproßsück, an welchem ein Blatt $(U)$ teilweise abgeschnitten ist, um die Stellung der Knospe $K \quad$ zu zeigen. Schematisiert nnd schwach vergr.
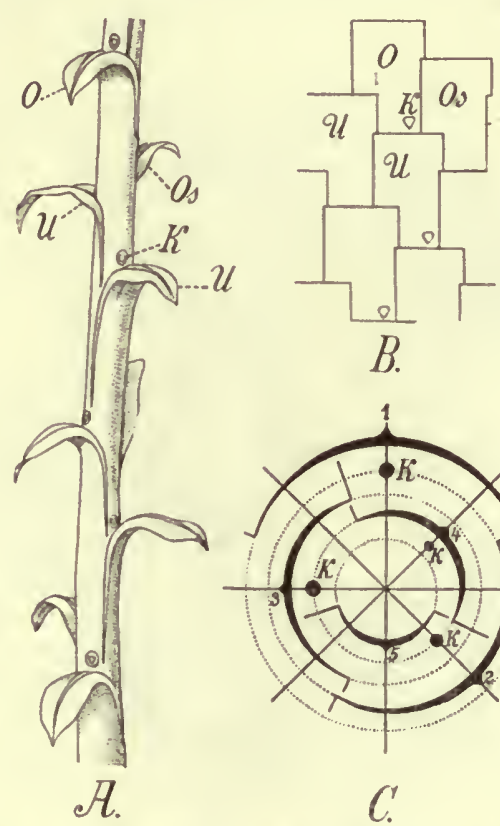

Fig. 68. Blatt und Knospenstellung von Mnium nach v. Schoenad, schematisiert. A Stämmchen von außen betrachtet. Blatt $O$ und Knospe $K$ gehören miteinander zu einem Segmente der Scheitelzelle; bei oberflächlicher Betrachtung könnte man das Blatt $U$ für das Deckblatt der Knospe halten. $B$. Schema für die Anordnung der Segmente. C. Diagramm der Blatt- und Knospenstellung.

Fig. 68 die Knospe $\mathrm{K}$ in der Achsel des Blattes U. Angelegt ist sie aber an der Basis des Segmentes, aus welchem Blatt $O$ hervorging. Sie entstand hier aber nicht in der Mitte des Segmentes, sondern seitlich anı kathodischen Teile, was mit der hier stattfindenden, später zu besprechenden "Scheiteltorsion“ zusammenhängt. Es kann also aus der geschilderten Art der Astbildung eine ,axilläre" Stellung sich ergeben, aber $\mathrm{da} ß$ dies sozusagen nur ein Zufall ist, zeigt die Tatsache, daß bei anderen

1) K. $\nabla$. Schoevad, Zur Verzweigung der Laubmoose. Dissert. München 1910, und Hedwigia 1910. 
Moosen mit schwächerer Scheiteltorsion, z. B. Sphagnum, ein median unter der Knospe stehendes Blatt nicht vorhanden ist.

Die hier erörterte Beziehung gilt, wie die Besprechung der beblätterten Lebermoose zeigen wird für alle beblätterten Bryophyten.

Für die Laubmoose sei noch erwähnt, daß ruhende Astanlagen bei ihnen häufig vorkommen.

Eine Arbeitsteilung der einzelnen Sprosse in einem Sproßsystem kommt namentlich durch den früheren oder späteren Abschluß des Wachstums zustande (so sind z. B. die fiederig angeordneten Seitensprosse von Hypnum splendens begrenzten Wachstums). Auch Bildung von A usläufern, Laubknospen usw. wird im speziellen Teile zu erwähnen sein.

Die beblätterten L e ber -

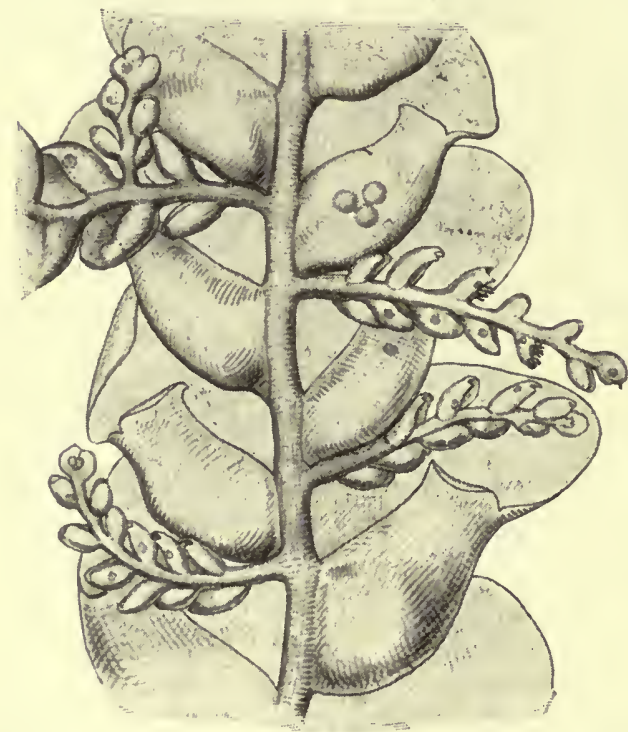

Fig. 69. Sproßstück von Radula uvifera von unten. Unterhalb von drei Seitenblättern sind kleinblätterige Seitenäste aufgetreten (vergr.). moose sind, mit Ausnahme von Haplomitrium und Calobryum, alle dorsiventral. Damit hängt es offenbar zusammen, da $B$ die $Z_{\text {weige, }}$ wie bei den thallosen Formen entweder seitlich oder ventral stehen. Allerdings ist die Verzweigungsart eine etwas mannigfaltigere, als Leitgeb angenommen hatte. LeItgeb unterschied Endverzweigung und interkalare; bei ersterer gehen die Äste aus sehr jungen, bei letzterer aus älteren Segmenten hervor. Indes möchte ich auch hier die Einteilung in ventrale und seitliche Z Zweige vorziehen. Erstere sind (wenn sie normal, nicht nach Verletzung entstehen) wie bei den thallosen Formen, oft anderen Funktionen als der Assimilation angepaßt, teils Träger von Sexualorganen teils "Flagellen".

Die laterale Verzweigung ist in verschiedenen Typen ausgebildet.

Fig. 69 zeigt den Radulatypus. Dieser entspricht der Verzweigung bei den Laubmoosen, d. h. unterhalb eines Blattes tritt - aus demselben Segment wie dieses - ein Seitenzweig hervor, der also die Ausbildung des Blattes nicht stört, bei manchen Radula-Arten (z. B. R. foliicola) hängen Blatt und hypophyller Sproß eine Strecke weit zusammen. Der Seitensproß entsteht hier meist aus der ventralen Hälfte des blattbildenden Segmentes, bei Anomoclada (wo keine entwicklungsgeschichtliche Untersuchung vorliegt) aus der dorsalen. Beim Frullaniatypus dagegen ist die Zweigbildung mehr an den Scheitel herangerückt, und zwar so, daß dadurch die Blattbildung gestört ist: man sieht, daß eine Hälfte des Segmentes, die sonst zur Blattbildung verwendet worden wäre, hier zur Zweigbildung benutzt wird; das Blatt, unterhalb dessen der Achselsproß steht, ist dann nur halb entwickelt. Solche nahe dem Scheitel angelegten Sprosse können dann leicht sich ebenso stark wie der Hauptsproß entwickeln und so eine "Gabelverzweigung" bedingen. 
In den meisten Fällen gehen derartige Seitensprosse aus der ventralen Hälfte des Blattsegmentes hervor, wie Evass (auf dessen $\mathbf{A b}$ handlung betreffs der Einzelheiten verwiesen werden muß) nachwies, beim Microlepidoziatypus aus der dorsalen.

Wie hängen nun diese Typen zusammen? LeITGEB war der Ansicht, daß der Frullaniatypus der ursprïngliche sei, da er sich zweifellos mehr dem der thallosen Formen anschließt, und daß von ihm der Radulatypus und die interkalare Zweigbildung sich ableite. Dieser Anschauung kann man sich dann anschließen, wenn man die thallosen Lebermoosformen für die primitiveren hält. Die auffallende Störung der Blattbildung durch die Verzweigung hängt dann damit zusammen, daß erstere jiinger ist als letztere. Allein auch für die umgekehrte Auffassung lassen sich Grïnde anführen, namentlich der, daß der Radulatypus sich dem der Laubmoosverzweigung am nächsten anschließt. Da kein Grund vorliegt, bei den Laubmoosen diese Verzweigungsart als eine abgeleitete anzusehen, so kann man sie auch als die für beblätterte Bryophyten typische ansehen und den Frullaniatypus aus einem Vorrücken der Verzweigung nach dem Scheitel zu ableiten.

Die Erörterung dieser Frage muß auf den speziellen Teil verschoben werden. Hier geniigt es hervorzuheben, daß die Beziehungen zwischen Blattbildung und Verzweigung bei den beblätterten Bryophyten nichts mit axillärer Verzweigung $\mathrm{zu}$ tun haben, und daß sie in der Gesamtgruppe sich in eine Reihe anordnen lassen, von der, wie so oft, nicht sicher ist, was als Anfang und was als Ende zu betrachten ist.

Lehrreich aber ist jedenfalls, daß hier, ebenso wie bei der exogenen oder endogenen, der gabeligen oder seitlichen Verzweigung die verschiedenen Verzweigungstypen namentlich damit zusammenhängen, ob die Verzweigung näher oder ferner am Scheitel eintritt.

Endlich sei erwähnt, daß wie die Bildung eines beblätterten Sprosses bei den Bryophyten nur eine phylogenetisch bedeutungslose Parallelbildung zu der der anderen Archegoniaten ist, auch die Verzweigung mit der bei diesen auftretenden nicht iibereinstimmt. Der Versuch, eine solche Übereinstimmung zu konstruieren, ist, wie aus dem obigen hervorgeht ganz mißlungen.

\section{§ 6. Verzweigung der Lycopodinen.}

Sachs hat, wie erwähnt, seinerzeit die Lycopodinen als "Dichotomen" bezeichnet. Damit ist ausgesprochen, daß die Verzweigung bei ihnen deutlich durch Gabelung erfolgt. Tatsächlich kann man oft eine "echte" Gabelung, d. h. die Teilung des Vegetationspunktes in zwei gleich starke Tochtersprosse oder Tochterwurzeln beobachten. Bei den Sprossen, die mit zahlreichen kleinen Blättern versehen sind, ist dabei ohne weiteres klar, daß die Verzweigung der Sproßachsen ohne jede Beziehung zu den Blättern erfolgt. Aber die Gabelung tritt keineswegs immer auf. Wir finden vielmehr schon hier Übergänge zur monopodialen Verzweigung.

Besonders klar und einfach tritt dies bei den Wurzeln hervor, von denen ich L. annotinum untersuchte. Wir sehen hier die einzelnen Wurzeln keineswegs, wie man bei einer wirklichen Gabelung erwarten sollte, einander anatomisch gleich gebaut.

Eine als Beispiel gewählte stammbürtige Wurzel hatte in ihrem oberen Teile 8 GefäB- (und Siebröhrein)teile in ihrem Zentralzylinder - die feinsten Auszweigungen besaßen aber nur je einen; erstere waren also oktarch, letztere monarch. 
Die feinen Endwurzeln zeigten die Gabelung sehr deutlich (Fig. 70 II), bei den stärkeren aber trat die Verzweigung zwar auch am Scheitel ein, aber einer der Wurzeläste erschien als Seitenzweig, der andere als Fortsetzung der sich verzweigenden Wurzel (Fig. 70 III $S$ und $H$ ). Die Ungleichwertigkeit beider Wurzeläste tritt auch anatomisch deutlich hervor. Fig. I zeigt einen Querschnitt einer Wurzel unterhalb der Verzweigungsstelle, die (relative) Hauptwurzel ist tetrarch, die Seitenwurzel diarch. Dies ist bedingt dadurch, daß die Seitenwurzel schon bei der ersten Anlage mit weniger Material an embryonalen Zellen ausgestattet wird, als die Hauptwurzel.

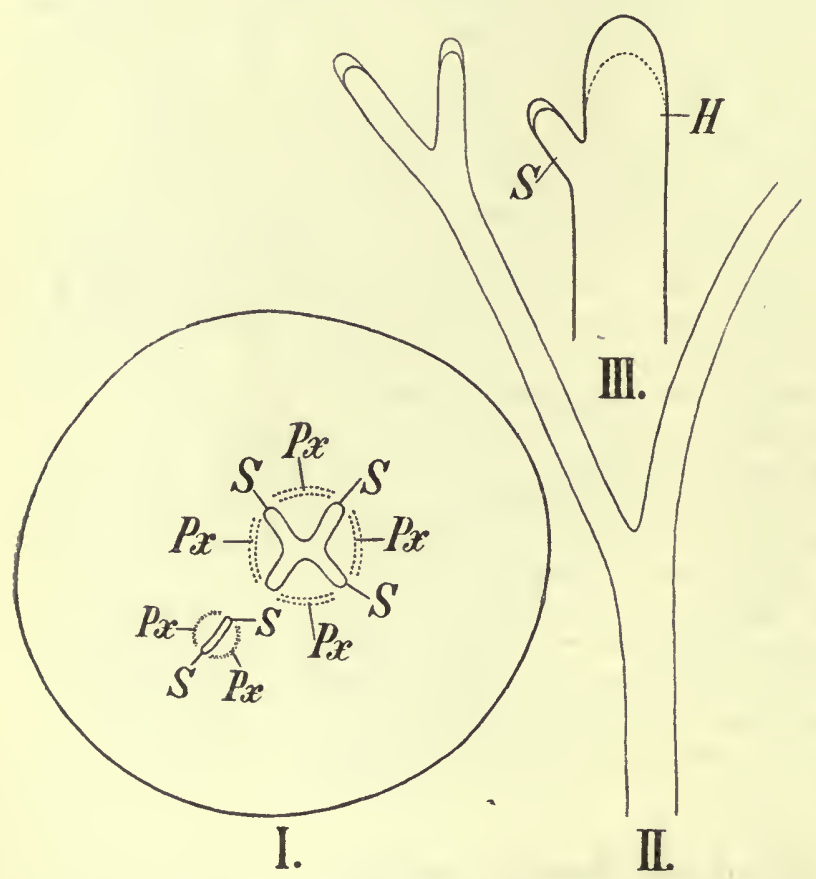

Fig. 70. Lycopodium annotinum. I. Wurzelquerschnitt oberhalb einer Verzweigungsstelle. Rechts oben Zentralzylinder des stärkeren Astes ( $H$ in Fig. IIII.) links unten des schwächeren ( $S$ in Fig. III). Ersterer hat 4 Protoxylem und Protophloëmgruppen ( $P x$ und $S$ ) letzterer 2. II. Gabelige Verzweigung einer schwachen Wurzel. III. Seitliche Verzweigung einer stärkeren Wurzel ( $H$ Hauptachse, $S$ Seitenachse.
Ein solches Wurzelsystem ist, wie mir scheint, nur für einen lockeren, wenig $\mathrm{W}$ iderstand bietenden Boden geeignet. In einem festeren Boden wird eine monopodial rerzweigte Wurzel, die unverzweigt vordringt und erst weiter hinten ihre Seitenwurzeln herrortreten läßt, der "dichotomen" überlegen sein. Letztere hat größere Widerstände zu überwinden, da die Wurzelspitze bei ihrer Verzweigung

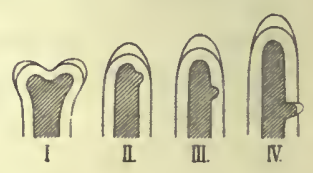

Fig. 71. Erläuterung einer Hypothese über die $\mathrm{Ab}$ leitung der endogenen Wurzelverzweigung von der Gabelung. Der Zentralzylinder ("Plerom") der Wurzel schraffiert.

anschwillt, und die Seitenwurzeln unmittelbar hinter ihr auftreten.

Über die Verteilung des Längenwachstums an derartigen Wurzeln ist nichts bekannt. Es ist wohl anzunehmen, daß es während der Verzweigung unterbrochen ist, also sozusagen stoßweise erfolgt.

Es läßt sich die endogene Entstehung der Wurzeln ableiten von der gabeligen. Charakteristisch für die endogene Entstehung ist, daß die neue Wurzel aus dem Zentralzylinder entspringt. Sie besteht aus embryonalem Gewebe, an welchem die peripherischen Gewebeschichten erst später ausdifferenziert werden. Denken wir uns nun 1. daß bei der Gabelung einer Wurzel (Fig. 71) die Verzweigung eingeleitet wird durch eine Verbreiterung 
des Zentralzylinders (resp. Pleroms), welcher dann die der peripherischen Schichten folgt; 2. daß diese "Verbreiterung" ähnlich, wie wir dies für die Verzweigung sahen, zu einer unterhalb des Scheitels des Zentralzylinders auftretenden also seitlichen wird (Fig. 71,II und $I I I$ ), während die peripherischen Schichten keinen Impuls zum Wachstum empfangen, so erhalten wir einen Auswuchs des Zentralzylinders, der aus embryonalem Gewebe besteht, das ebenso eine Wurzelhaube usw. erzeugen kann, wie dies bei der Regeneration einer verletzten Wurzelspitze der Fall ist.

Das ist selbstverständlich nur eine Konstruktion, gegen die sich mancherlei einwenden läßt. Indes kommt als wichtiger Stützpunkt in Betracht eine Angabe Bruchmans's ${ }^{1}$ ) die ich erst auffand, nachdem obige Zeilen schon niedergeschrieben waren. Bruchmans fand nämlich, daß die Gabelung der Wurzeln von Lycopodium und Isoëtes vom "Plerom" eingeleitet wird, "die übrigen Gewebe verhalten sich mehr passiv." Das stimmt ganz zu der oben gemachten Annahme 1. Die anderen Annahmen aber sind gleichfalls keine willkürlichen, sondern durch Analogie gestützt.

Auch bei der Verzweigung der Lycopodiumsprosse findet sich häufig schon am Vegetationspunkt eine ungleiche Stärke der beiden "Gabelsprosse".

Besonders deutlich tritt bei der Anlage der "Brutknospen" von Lycop. Selago hervor, daß sie von vornherein ein viel kleineres Areal einnehmen, also viel weniger Zellenmaterial mitbekommen als der Hauptsproß, an dem sie seitlich stehen (Fig. 72).

Das ist ein extremer Fall von ungleichem Verhalten der beiden „Gabelsprosse", bei den gewöhnlichen vegetativen Sprossen

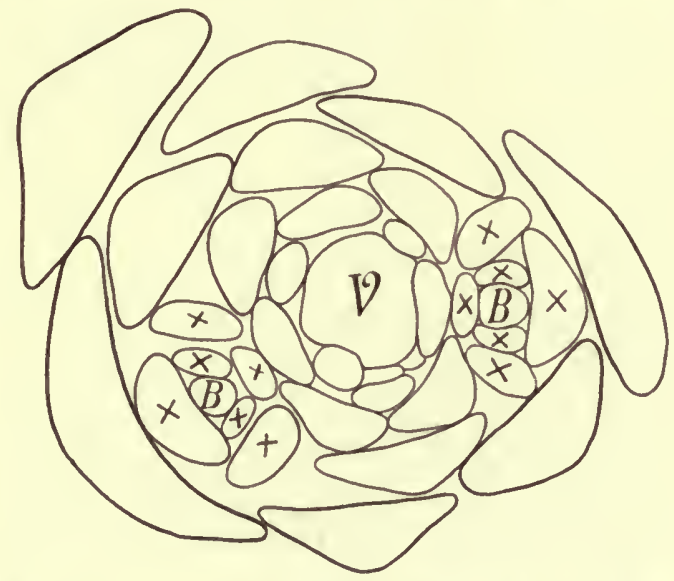

Fig. 72. Lycopodium Selago. Querschnitt durch eine Sproßspitze $V$ Hauptachse $B$ zwei Brutknospen. Die $\mathbf{z n}$ diesen gehörigen Blätter sind mit $X$ bezeichnet. ist die Ungleichheit weniger auffallend.

Die letzten Auszweigungen dagegen zeigen auch bei den Sprossen, ebenso wie bei den Wurzeln die Dichotomie deutlicher ausgeprägt. DaB diese verschiedenen Sprosse auch physiologisch verschieden wachstumsfähig sind, wird im Kapitel über Symmetrie zu schildern sein: die starken Sprosse von Lycop. Chamaecyparissus werden am Licht nur schwach, die schwachen stark dorsiventral. Die Sprosse aber, welche Sporophyllstände bilden, werden radiär; sie sind gegenüber der Lichtwirkung offenbar "blind".

Das allgemeine Interesse der Verzweigung bei Lycopodium liegt für uns darin, daß die - überall jedenfalls vorhandene - Fähigkeit der Gabelung unter bestimmten Umständen latent bleiben kann, und zwar offenbar bedingt durch Ernährungsverhältnisse. Schwach ernährte Sprosse

1) H. BRuchuans, Über Anlage und Wachstum der Wurzeln von Lycopodium und Isoëtes. Jenaische Zeitschrift, Bd. VIII (1874). 
und Wurzeln gabeln sich. Fließt aber in der Richtung der vorhandenen Längsachse (bildlich gesprochen) ein kräftiger Nahrungsstrom, so bleibt von den beiden einen der eine, kräftigere in der Richtung der alten
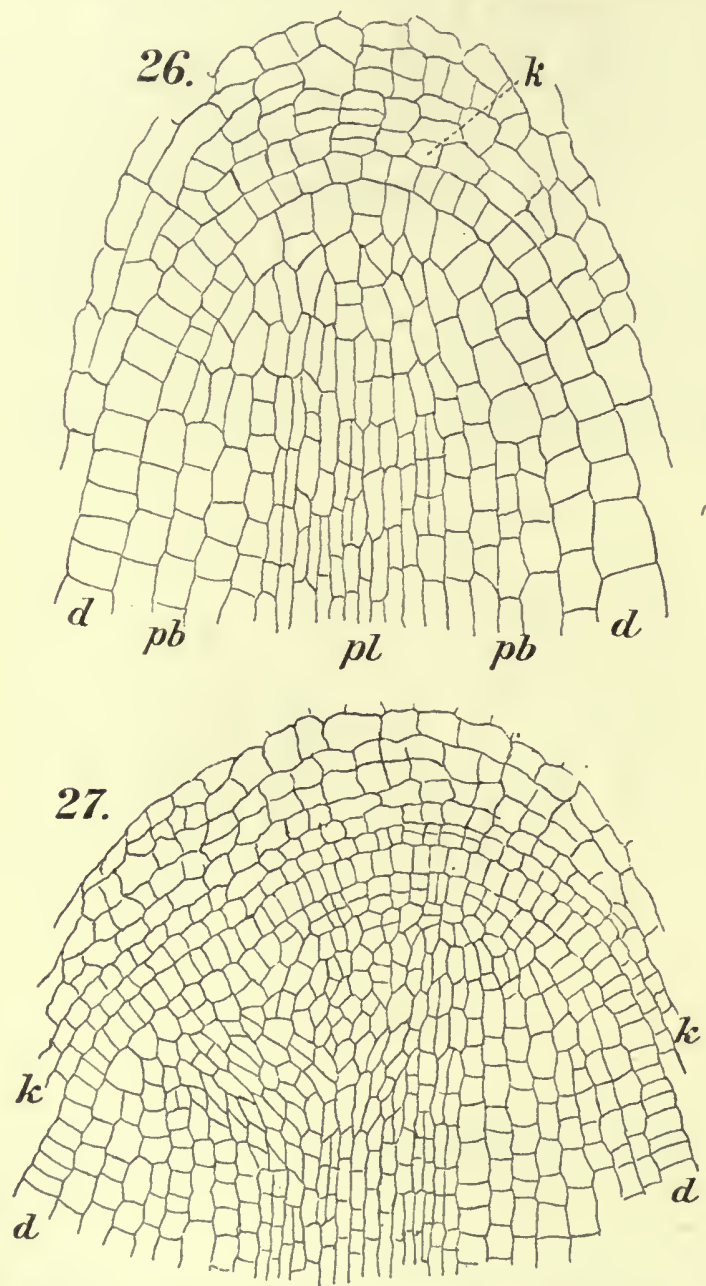

Fig. 73. Selaginella Lyallii (nach Brochmans). Oben Längsschnitt durch eine Wurzelspitze ( $k$ Kalyptrogen, $d$ Dermatogen, $p b$ Periblem, $p l$ Plerom) $(440 X)$. Unten Längsschnitt durch die Spitze einer sich verzweigenden Wurzel $(280 \times)$. Man sieht, daß wie in Fig. $72 I I I$ der Wurzelzweig rechts von Anfang an kräftiger ist und in der Richtung der alten Wurzel weiter wächst.
A chse (Fig. $70 I I I)$, der schwächere erscheint dann als Seitensproß. Es ist das ein, für die Analyse des Verzweigungsvorganges offenbar wichtiges Verhalten.

Ebenso wie die TVirzeln von Lycopodium verhalten sich auch die der Selaginellen (vgl. Fig. 73) und deren Sprosse. Wir sehen, $\mathrm{da} B$ auch hier die schwächer ausgebildeten Organe eine Gabelung zeigen, die stärkeren dagegen eine Teilung des embryonalen Gewebes am Scheitel in ungleich große Stücke, so daß eine fortwachsende "Hauptachse" mit Seitenachsen zustande kommt ${ }^{1}$ ).

Die Keimpflanzen vieler Selaginellen, z. B. S. spinulosa, Martensii, Lyallii zeigen zunächst eine Gabelung; wenn die Sproßachse erstarkt, Teilung in ungleiche Stïcke. Wenn man den letzteren Verzweigungsmodus teilweise als einen „pseudomonopodialen" bezeichnet hat, so ist das nur insoferm berechtigt, als es sich dabei 1. um eine wahrscheinlich von der Dichotomie abgeleitete Verzweigungsart handelt, und 2. die betreffenden Pflanzen wie wir sahen, die Fähigkeit haben, den dichotomen Verzwei-

gungsmodus wieder aufzunehmen. Es ist das Verhalten ähnlich dem der Blattbildung mancher amphibischer Pflanzen, die je nach den Wachstums-

1) Gewöhnlich setzt dabei der stårkere Zweig die bisherige Wachstumsrichtung fort, indes kann dies auch der schwächere tun. So nach Bruchmans an den Rhizomen von Selaginella Lyallii, an denen der stärkere Ast der ans Licht tretende ist, der schwächere das Rhizom fortsetzt. Vgl. H. Brucimass, von den Vegetationsorganen der Selaginella Lyallii Spr. Flora 99 (1909) p. 430. 
bedingungen Wasser- oder Luftblätter entwickeln können. Es wäre also besser statt von einer „pseudomonopodialen“ Verzweigung von einer fakultativen Dichotomie zu sprechen.

Der Zusammenhang zwischen Ernährung und Verzweigungsart tritt dabei deutlich hervor: wo eine kräftige Ernährung einsetzt, sehen wir den Vegetationspunkt (beeinflußt wohl durch das unter der Gabelungsstelle liegende Stïck) in monopodiale Verzweigung eintreten, also ein einheitlich fortwachsendes Stück zustande kommen. Man kann sich dies bildlich als eine gleich von vornherein erfolgende Sympodienbildung vorstellen oder auch sagen bei kräftigem embryonalem Wachstum ist ein Aufgehen der Wachstumsrichtung in zwei neue weniger leicht, als bei schwachem. Aber es ist dies nur ein Bild, während die oben angeführtẹn Sätze die Tatsachen unmittelbar wiedergeben. In Wirklichkeit sind Wurzeln, welche "latent" die Fähigkeit zur dichotomen Verzweigung haben, imstande zur monopodialen überzugehen, wenn es sich - teleologisch gesprochen - darum handelt, ein kräftig fortwachsendes, beträchtliche Länge erreichendes Orgạn herzustellen. Dies dient dann als Träger der schwächer entwickelten Äste und als Leitungsbahn für die von diesen abgelieferten Assimilate. Ganz dasselbe werden wir auch bei den Blättern der Farne sehen. Es handelt sich also um eine weit verbreitete Erscheinung.

Die dichotome Verzweigung ist bei höheren Pflanzen, wie aus dem folgenden hervorgehen wird, verhältnismäßig selten, viel verbreiteter ist die monopodiale resp. axilläre. Es mag daher schon hier die Frage berechtigt sein, ob die letztere der Pflanze größere Vorteile bietet, als die erstere. Sie ist für die Wurzeln oben schon bejaht worden, und mir scheint, daß dasselbe für die Sprosse gilt. Die Pflanzen mit monopodialer Verzweigung haben im allgemeinen eine viel reichlichere Bildung seitlicher Anlagen, als die mit dichotomer - man braucht nur daran zu denken, wie viele Achselknospen ein Lycopodium besitzen würde, wenn auch nur ein Teil der Blätter solche bilden könnte. Die dichotome dagegen liefert viel weniger Zweige, sie müßte sich unverhältnismäßig oft wiederholen, wenn sie ebensoviele Seitenzweiganlagen liefern sollte, als solche bei der axillären Verzweigung auftreten.

Auch bei gabeliger Verzweigung kommt es zwar vor, daß einzelne Vegetationspunkte zunächst sich nicht entfalten, sondern als Ruheknospen verharren, so bei einigen Lycopodien und Selaginellen an der Basis der Pflanze. Aber auch diese „Organreserven", die meist nur unter bestimmten Umständen - wenn die anderen Teile beschädigt werden oder ihr Wachstum einstellen - zur Entwicklung gelangen, sind doch sehr spärlich gegenüber den bei Pflanzen mit axillärer Verzweigung reichlich vorhandenen ruhenden Knospen ${ }^{1}$ ). Diese können verloren gegangene Teile leicht ersetzen. Schneidet man bei einem Lycopodium (ich benutzte L. Selago) die Vegetationspunkte $a b$, so kann die Pflanze keine neuen entrickeln. Nur an jungen aus Brutknospen entwickelten Pflanzen von L. Selago erhielt ich Regeneration von entgipfelten Pflanzen - es bildeten sich teils an

1) Daß auch bei Wurzeln ruhende Seitenwurzeln vorkommen, geht aus der Exp. Morphologie p. 165 angeführten Tatsachen hervor. Die an der Basis mancher Lycopodien vorkommenden ruhenden Knospen die Strasburger (Einige Bemerkungen über Lycopodiaceen Bot. Zeit. 1873) für ,Adventivknospen “ hielt, können wir wohl unbedenklich als zurückgebliebene Gabeläste betrachten, wie sie z. B. auch bei Selaginella Preissiana nnd anderen Selaginellen vorkommen. Derartige basale Astanlagen sind fïr das Weiterbestehen der Pflanze besonders dann wichtig, wenn das Wachstum der sämtlichen anderen Sprosse durch Bildung von Blüten (Sporangienständen) seinen Abschluß findet. 
der Schnittfläche teils unter dieser Zellhöcker, welche zu neuen Sprossen wurden (Fig. $74 \mathrm{~A}$ ).

Auch an isolierten, stark mit Reservestoffen gefüllten Blättern dieser Brutknospen traten Sprosse gelegentlich auf. Aber abgesehen davon sind gabelig verzweigte Sprosse für den Ersatz verloren gegangener Teile im Nachteil gegeniiber den anderen - was weniger ins Gewicht fallen wird bei Pflanzen, bei denen wie z. B. bei Selaginella spinulosa, die Vermehrung durch Sporen eine sehr ausgiebige ist.

Außerdem ist die Bildung gleichstarker Gabelzweige für den Aufbau eines größeren Baumgerüstes auch mechanisch weniger günstig als der monopodiale Typus. Man kann sich in jedem Obstgarten leicht davon überzeugen, daß Bäume, deren Hauptstamm sich (infolge bestimmter Störungen im jugendlichen Zustand der Pflanze) in zwei annähernd gleich starke Aste teilt, leicht „schlitzen“, man sucht dies durch Anbringung von Klammern zu verhindern.

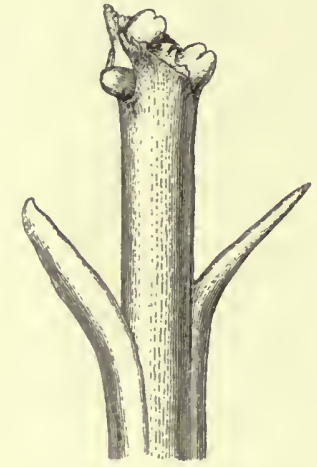

Fig. 74 A. Lycopodinm Selgo. Oberes Stück einer geköpften aus einer Brntknospe erwachsenen jungen Pflanze. Es haben sich nahe der Schnittfläche drei neue Sprosse gebildet.

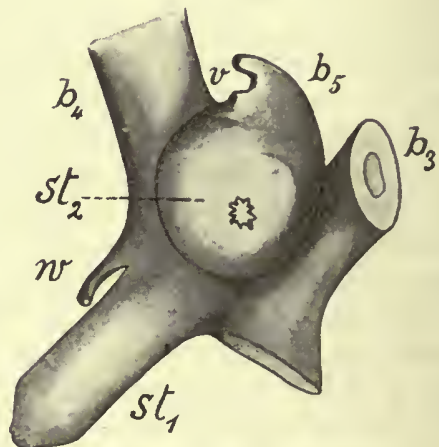

Fig. 74 B (nach Sperlich).

Nephrolepis tuberosa Presl subsp. etuberosa Heinr. Ende einer jungen Pflanze $b_{3}-b_{5}$ Blätter $\left(b_{3}\right.$ u. $b_{4}$ abgeschnitten) $v$ Vegetationspunkt des Sprosses $w$ Wurzel $s t_{1}$ junger blattloser Ausläufer $s t_{2}$ Anlage eines jungen Ausläufers.

Damit mag es immerhin zusammenhängen, daß die gabelige Verzweigungsart nach oben hin im System stark zurücktritt und uns derzeit einen gewissen archaistischen Eindruck macht ${ }^{1}$ ).

Blattbiirtige Sprosse sind bei den Lycopodinen - abgesehen von denen die an abgetrennten Blättern von Keimpflanzen und, wie oben erwähnt, Brutknospenblättern von L. Selago auftreten können, nur bei einer Rasse von Isoetes lacustris bekannt, also als ausnahmsweises Vorkommnis. Bei Farnen und Angiospermen werden wir dagegen "phyllogener" Sproßbildung rielfach begegnen, eine Tatsache, welche mit anderen auf die Verwandtschaf tdieser Gruppen hindeutet, und uns auch einen Hinweis auf das Verhalten hölierer Pflanzen geben wird.

1) Vgl. auch Porosie, Grundlinien der Pflanzen-Morphologie p. 138. Daß die dort p. 135 gemachte Angabe, ${ }_{n}$ die Verzweigungen werden zwar noch dichotomisch angelegt., sind aber bei der fertigen Pflanze meist nicht mehr als solche zu erkennen", nicht einmal für die Lycopodinen allgemein zutrifft - geschweige denn fïr andere Pteridophyten - geht ans dem Obigen hervor. 
Bei Isoetes tritt eine Verzweigung des Stammscheitels (eine Gabelung) nur selten ein ${ }^{1}$ ). Die Blätter sind hier im Verhältnis zu anderen Lycopodinen groß; an dem knolligen mit sekundärem Dickenwachstum begabten Stamme kann eine'Vergrößerung der assimilierenden Oberfläche durch Steigerung der Blattzahl eintreten, auch ohne daß Verzweigung erfolgt. Bei den kleinblätterigen Lycopodinen dagegen ist die Verzweigung das einfachste Mittel $\mathrm{um}$ eine Vermehrung der assimilierenden Oberfläche herbeizuführen.

\section{$\S 7$. Verzweigung der Farne.}

Bei den Lycopodinen fanden wir einen einheitlichen Typus der Verzweigung, wenn er auch in verschiedenen Modifikationen auftritt.

Wie ist es bei den Farnen? Diese Frage ist oft erörtert worden, und zwar nicht immer objektiv. Dogmatisch veranlagte Schriftsteller haben die Verzweigung teils in das Schema der Dichotomie, teils in das der axillären Verzweigung höherer Pflanzen hineinpressen wollen.

Ehe darauf näher eingegangen wird, sei zunächst erwähnt, daß die Verzweigung des Stammes bei den Farnen im allgemeinen eine weniger reiche ist, als bei den Lycopodinen (rgl. p. 66). Es gilt dies namentlich für solche mit radiären orthotropen Sprossen. Viele Baumfarne z. B. bleiben ganz unverzweigt oder zeigen doch nur gelegentlich mehrköpfige Stänme (z. B. Balantium antarcticum). Ausgiebiger ist die Verzweigung bei Farnen mit kriechenden, dorsiventralen Rhizomen.

Eine Arbeitsteilung zwischen den verschiedenen Sprossen einer Pflanze tritt indes nur bei verhältnismäßig wenigen auf. Sehen wir ab davon, daß auch hier wie so oft einzelne Kinospen im Wachstum zuriickbleiben können, sowie davon, daß die blattbürtigen „Brutknospen“ bei einigen als zwiebeloder knollenähnliche Gebilde auftreten, so sind mir keine eigentlichen Kurztriebe u. dgl. bei Farnen bekannt. Bei einigen Farnen treten „Ausläufer" auf (so bei Onoclea Struthiopteris, wo an den Ausläufern zunächst Niederblätter sich finden; Blechnum occidentale u. a.). Nephrolepis ") besitzt, wie im speziellen T'eile näher erläutert werden soll, blattlose Ausläufer, welche teils als Wurzelträiger, teils zur Vermehrung, teils als Speicherorgane niitzlich sind.

Betrachten wir zunächst die Verzweigung bei Farnen mit kriechendem, dorsiventralem Stamme, so finden sich hier Fälle, die sich der dichotomen Verzweigung der Lycopodinen anschließen, oder sich davon ableiten lassen.

Es ist dies dadurch erklärlich, daß zwar die Scheitelzelle (Fig. 75) ${ }^{3}$ ) des Stammes sich nicht in zwei gleiche Hälften teilt, wie die von Dictyotas, aber (wie namentlich aus den Untersuchungen von L. KLEIN und SperLich hervorgeht) die Seitenknospen sehr nahe am Scheitel angelegt werden (Fig. 74 B). Dadurch ist die Ausbildung einer gabeligen Verzweigung zwar nicht gefordert aber erleichtert.

Daß bei vielen Farnen eine von den Blättern unabhängige "Gabelung:" auftritt, ist längst bekannt und bei Lygodium, Polypodium vulgare u. a. leicht zu sehen.

1) Vgl. Solms-Lavbarch. Isoetes lusteis Bot. Zeitung 1902.

2) Vgl. A. Spenuich, Zur Entwicklnngsgeschichte der Stolonen von Nephrolepis. Flora 98 (1908), p. 340. Daselbst weitere Literatur.

3) Die sich aber auf einen radiären Sproß bezieht! 


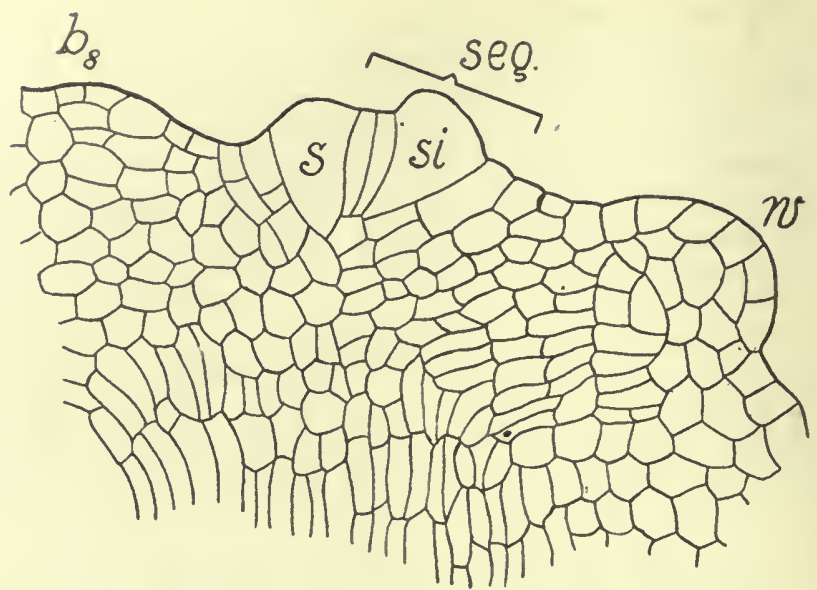

Fig. 75. Nephrolepis cordifolia ssp. etuberosa (nach Speruich) Längsschnitt durch den Scheitel eines Rhizoms ( $250 \times) s$ Sproßscheitelzelle $s i$ Scheitelzelle eines Seitensprosses $w$ (nicht gauz median getroffene) Wurzel.

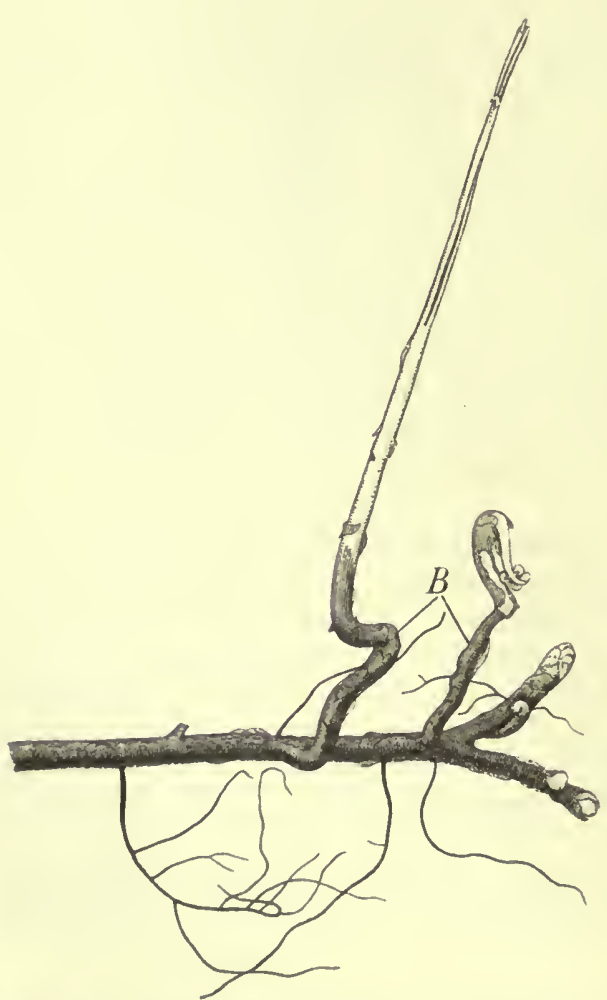

Fig. 76. Phegopteris Dryopteris. Gabelig verzwejgtes Rhizom, $B$ Blätter, das jüngere davon noch unentfaltet, vom älteren nur der Blattstiel gezeichnet. Nat. Gr.

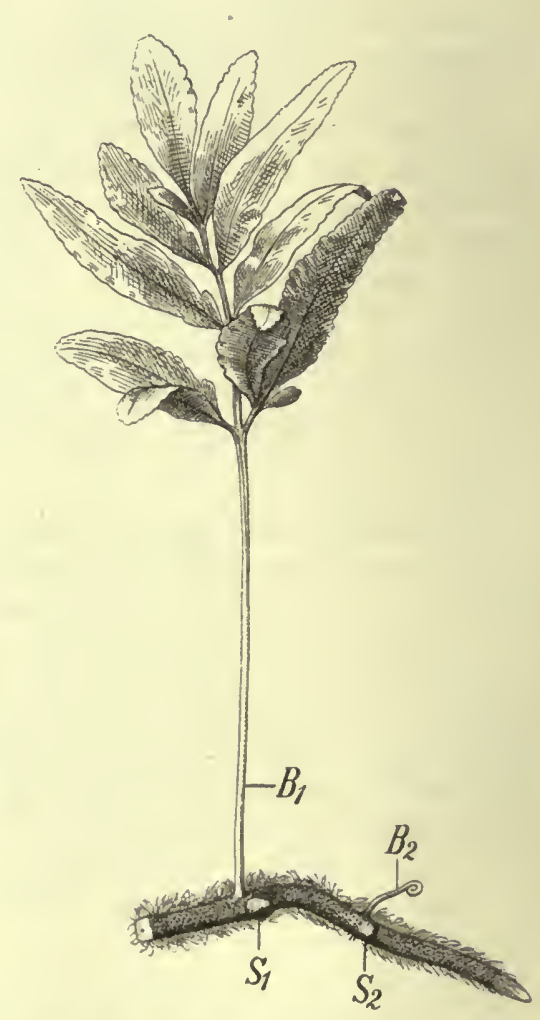

Fig. 77. Davallia pentaphylla. Vorderes Stück des Rhizoms ron der Seite, $S_{1} S_{2}$ Seitenzweige, $B_{1} B_{2}$ Blätter. 
Fig. 76 zeigt ein Rhizom von Phegopteris Dryopteris, welches gabelig verzweigt ist, wobei beide Gabelsprosse annähernd gleich stark entwickelt sind. Dagegen tritt uns bei Darallia pentaphylla (Fig. 77) ein monopodial wachsendes Rhizom entgegen, bei welchem die Seitensprosse $\left(S_{1} S_{2}\right)$ viel schmächtiger sind als der Hauptsproß. Zugleich tritt hier eine räumliche Beziehung zu den Blättern hervor. Man sieht, daß die Seitenknospen $S_{1}$ und $S_{2}$ jeweils unterhalb eines Blattes gegen die Rhizomspitze hin stehen. Nicht selten bleiben sie unentwickelt. Kein Zweifel, $\mathrm{da} B$ sich dieser Typus von dem in Fig. 76 abgebildeten ableiten läßt. Denkt man sich hier den rechten Gabelast klein, den linken in seiner Entwicklung dagegen nicht gehemmt, so wird dieser zuriickgebliebene Gabelast zu dem jüngeren der beiden mit $B$ bezeichneten Blätter wesentlich dieselbe Stellung einnehmen wie die Sprosse $S_{1}$ und $S_{2}$ in Fig. $77 \mathrm{zu}$ $B_{1}$ und $B_{2}$. Es kann also ausgehend von der Gabelung zu einer konstanten räumlichen Beziehung zwischen Blatt und Seitensproß kommen. Eine "axilläre" Stellung nimmt der letztere nicht ein, das hängt mit der dorsiventralen Struktur zusammen, bei der wir häufig sehen, daß die Seitensprosse auf den Flanken, die Blätter auf der Oberseite stehen. Ganz analoges zeigen z. B. die dorsiventralen Rhizome am Marsilia und Pilularia.

Auch Polypodium vacciniaefolium (Fig. 78) zeigt einen regelmäßigen Rhythmus von Blatt- und Zweigbildung, nur stehen hier die Blätter ebenso wie die Knospen seitlich von der kriechenden Sproßachse, annähernd einander gegenüber. Das wesentliche der Erscheinung ist für uns nicht die Stellung der Blätter und Seitensprosse, sondern der Rhythmus ihres Auftretens, weil dieser uns e ine der Möglichkeiten zur Ableitung der axillären Verzweigung bietet. Bei Samenpflanzen wïrde man ein solches Rhizom entweder als ein "Sympodium" gedeutet haben, - ähnlich dem ron VItis! - oder man hätte angenommen, die Knospe $K$ gehöre zu dem darunter stehenden Blatt und sei nur an der Hauptachse angewachsen. Indes kann das von anderen Pflanzen entnommene Schema der axillären Verzweigung auf die Farne ïberhaupt keine Anwendung finden, vielmehr suchen wir bei Farnen gerade nach Vorgängen, aus denen eine axilläre Verzweigung sich ableitet.

Ein anderes Beispiel für die Anlegung von Blättern und Seitensprossen in regelmäßigem Rhythmus bietet die Gattung Niphobolus ${ }^{1}$ ). Die kriechenden Rhizome tragen auf ihrer Oberseite zwei Reihen von Blättern. Diese sind in der schematischen Abbildung mit $I-I V$ bezeichnet. Nach jedem Blatte wird - abwechselnd nach rechts und nach links - ein (oft unentwickelt bleibender) Seitensproß ( $a-d$ Fig. 79) angelegt. Das Blatt ist von dem nächststehenden Seitensproß durch ein Stiick der Sproßachse getrennt. Denken wir uns dieses verkürzt, so erhalten wir Seitensprosse, die nahe der Basis eines Blattes entspringen ähnlich wie dies bei Davallia pentaphylla geschildert wurde.

Bei radiären Sprossen sind bei den Farnen dagegen solche räumlichen und zeitlichen Beziehungen zwischen Blatt und Seitensproß nicht bekannt, so entstehen z. B. die Ausläufer von Nephrolepis - welche von Anfang an viel schmächtiger sind als die radiären beblätterten Sprosse, an denen sie entstehen, ganz unabhängig von den Blättern (vgl. Fig. 74 B).

Für die Frage nach dem Zustandekommen der axillären Verzweigung bei den Angiospermen ist es aber von Wichtigkeit, zu untersuchen, ob dafür bei

1) Giesenhagen, Die Farngattung Niphobolus. Jena 1901, p. 24. 


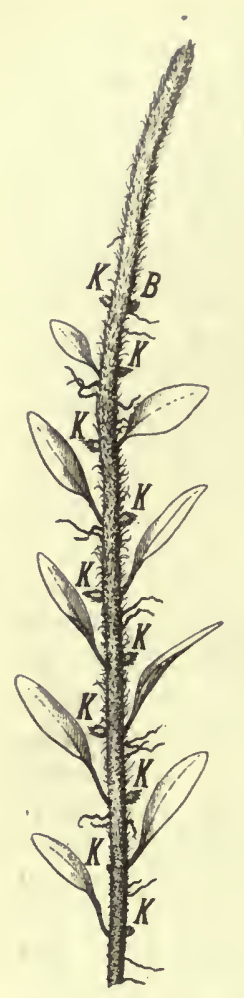

Fig. 78. Polypodium vacciniaefolium.

Rhizom mit Seitenknospen u. Blättern. $B$ ein junges Blatt, $K$ Knospen ( $1 / 2$ nat.Gr.).

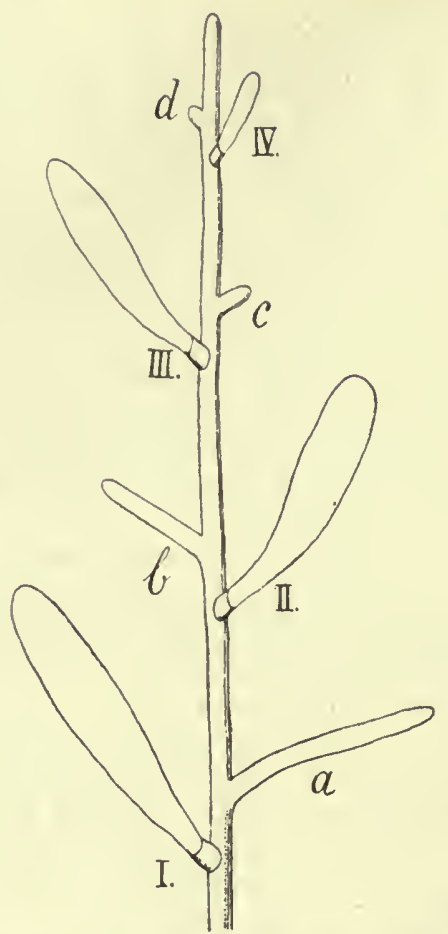

Fig. 79. Schema der Blatt- und Zweigstellung bei NiphobolusArten mit gestreckten Internodien (nach GirsenhaGeN). Die Blätter $I-I V$ entspringen in zwei Zeilen der Oberseite der Sprossenachse, $a-d$ Seitensprosse.
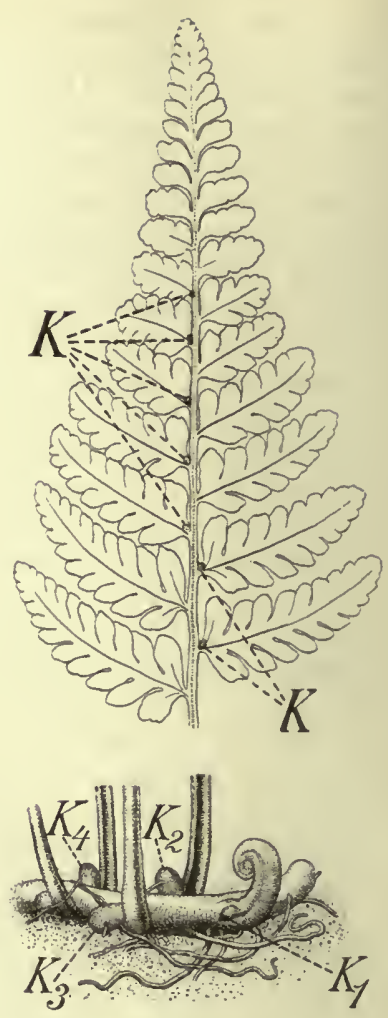

Fig. 80. Dennstaedtia rubiginosa, oben Stück eines Blattes mit Knospen $(K)$, unten Rhizom mit "axillären" Knospen $\left(K_{1}-K_{4}\right)$. $1 / 2$ nat. Gr.

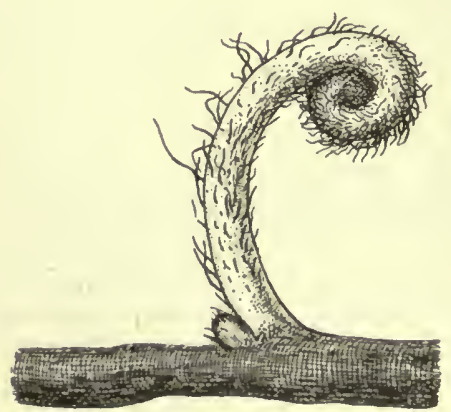

Fig. 81. Trichomanes radicans. Stück eines Rhizoms, von welchem die gegliederten Haare abpräpariert sind. Die Spitze wiirde nach links liegen. In der Achsel des jungen Blattes die Knospe eines Seitenzweiges.

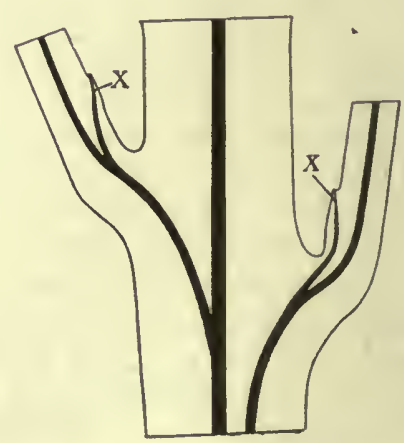

Fig. 82. Trichomanes javanicum (nach Chambers). Schema für den Leitbündelverlauf. $x$ die für den ,Achselsproß $ß^{6}$ bestimmte "Stele", sie zweigt von der Blattstele ab. 
den Farnen irgendwelche Ausgangspunkte gegeben sind. Es sind hier drei Möglichkeiten vorhanden:

1. Es treten zwischen einem Blatt der Hauptachse und einem Seitensproß konstante Beziehungen derart auf, daß die Seitensprosse in regelmäßigem Rhythmus mit den Blättern und diesen benachbart angelegt werden (Fig. 78).

2. Das Blatt bringt scheinbar einen Achselsproß herror, in Wirklichkeit ist dieser aber blattbürtig, phyllogen, angelegt.

3. Eine scheinbar axilläre Verzweigung kommt dadurch zustande, daß das Blatt, in dessen "Achsel" eine Knospe steht, eigentlich der letzteren, nicht der Hauptachse angehört.

Welche von den zwei letztgenannten Möglichkeiten jeweils zutrifft, kann nur durch eingehende entwicklungsgeschichtliche Untersuchungen, welche sehr erwünscht wären, aufgeklärt werden. Hier seien die Möglichkeiten nur durch zwei Beispiele erläutert.

Zunächst ist zu erwälnnen, daß blattbürtige Knospen bei den Farnen eine ungemein häufige Erscheinung sind, wie aus einer von KUPPER ${ }^{1}$ ) gegebenen Liste (die sich leicht noch erweitern ließe) hervorgeht (vgl. Fig. $80 \mathrm{~K}$ ). In allen näher untersuchten Fällen werden diese blattbürtigen Knospen an dem embryonalen Gewebe der Blattanlagen exogen angelegt. Bei Ceratopteris thalictroides sind sie sogar, da der Stamm, soweit bekannt, unverzweigt bleibt, die einzigen Seitenknospen, sie dienen der vegetativen Vermehrung.

Hier sind nur die zu besprechen, welche (soweit dies ohne Kenntnis der Entwicklungsgeschichte erkennbar ist) an der Blattbas is auftreten. Dennstaedtia rubiginosa (Fig. 80) besitzt eine kriechende Sproßachse. An den Blättern treten in den Winkeln, welche die Blattfiedern mit der Blattspindel machen, Knospen auf, die sich aber, so lange das Blatt festsitzt, nicht weiter entwickeln.

Auch an der Basis jedes Blattes entsteht eine Knospe. Der blattbürtige Ursprung der Knospe ist hier deutlich, weil sie dem hinteren (abaxialen) Rande der Blattbasis genähert entspringt. Sie erscheint aber bei weniger eingehender Beobachtung um so mehr als ein Seitensproß des Rhizoms, als sie sofort weiterwächst und Wurzeln entwickelt - im Gegensatz zu den weiter oben stehenden blattbürtigen Knospen. Der Unterschied im Verhalten darf wohl der erleichterten Wasserzufuhr zu dẹ basalen Knospen zugeschrieben werden. Es ist klar, daß eine geringe Änderung in der Ansatzstelle diese Basalknospen als axilläre erscheinen lassen wïrde. Jedenfalls kann man sich auf diesem Wege die Entstehung von Axillarknospen vorstellen. Mit anderen Worten läßt sich auch sagen, die phyllogene Sproßbildung, welche bei den meisten Farnen nur in den Dienst der ungeschlechtlichen Vermehrung tritt, kann dann, wenn sie an der Basis der Blätter eintritt, zu einer „axillären" führen.

Solche „axillären" Knospen finden sich bei manchen Hymenophylleen, z. B. Trichomanes radicans (Fig. 81) und auch bei Arten mit radiärer Sproßachse, wobei die Achselknospen häufig nicht zur vollen Entwicklung gelangen, z. B. bei Trichomanes javanicum ${ }^{2}$ ). Die anatomische Untersuchung ergab in diesem Falle, daß vom Stamm eine Stele für Blatt und Achselsproß abgegeben wird, die sich dann in die Blattstele und die für die Achselknospe $x$ (Fig. 82) teilt. Dieses Verhalten gibt aber über die

1) W. KUPPER, Über Knospenbildung an Farnblättern. Flora 96 (1906), p. 337.

2) Vgl. H. S. Chanbers, The vestigial axillary Strands of Trichomanes javanicum Bl. Annals of botany. Vol. XXV, 1911, p. $1037 \mathrm{ff}$. Daselbst weitere Literatur. 
genetischen Beziehungen zwischen Blatt und Achselsproß keinen Aufschluß; dies kann nur die Entwicklungsgeschichte tun. Es ist z. B. möglich, daß die Knospen (entsprechend der oben unter 3 angeführten Möglichkeit) durch Endverzweigung der Hauptachse entstehen und aus ihnen das scheinbare Tragblatt hervorgeht. Aber wahrscheinlicher erscheint, daß sie blattbürtig sind. Dagegen spricht auch nicht, daß der untere Teil der gemeinsamen Stele in ihrer Struktur mit derjenigen der Sproßachse ïbereinstimmt.

Das Resultat unserer kurzen Erörterung über die Verzweigung der Farne kann dem jetzigen Stand unseres Wissens entsprechend kein abschließendes sein. Sie zeigt nur, 1. daß manche Farne eine gabelige Verzweigung ihrer Sproßachsen besitzen, von der sich die monopodiale ableiten läßt, 2. daß bei den Farnen eine Annäherung an die axilläre Verzweigung zustandekommen $\mathrm{kann}$, einerseits in Ableitung aus einer dichotomen Verzweigung mit regelmäßigem Rhythmus von Blatt- und Sproßbildung, andererseits aus "phyllogener" Sproßbildung.

Wir werden dasselbe Verhalten auch bei Angiospermen antreffen; manche Tatsachen deuten darauf hin, daß die axilläre Verzweigung hier sich ableitet von einer akrogenen und einer phyllogenen, wie beides ja auch für die Farne oben wahrscheinlich gemacht wurde.

\section{§ 8. Equisetum.}

Die Farne zeigten uns Verzweigungen, welche teils sich der dichotomen anschließen, teils monopodialen Charakter tragen. Letzterer ist bei Equisetum allein vorhanden. Zugleich sehen wir wieder, daß mit dem Zurüicktreten der Blattbildung die Verzweigung der Sproßachse eine reichlichere und für den Gesamtbau wichtigere wird, als bei den Farnen.

In den typischen Fällen bilden sich an einer kräftig fortwachsenden Hauptachse Wirtel von Seitensprossen, welche zwischen den Zähnen der Blattscheiden stehend letztere durchbrechen. Da sie fruihzeitig umwallt werden, hat man sie früher für endogen gehalten ${ }^{1}$ ).

Auf die Einzelheiten einzugehen, ist hier nicht erforderlich, es ist nur hervorzuheben, inwiefern eine Arbeitsteilung und eine innere Verschiedenheit der verschiedenen Sprosse eintritt. Daß wir die erstere zu erwarten

1) Wenn neuerdings die Verzweigung der Equiseten als „eine modifizierte Dichotomie“ aufgefaßt wurde, so könnte das höchstens im historischen Sinne verstanden werden, ähnlich wie bei den Farnblättern, bei denen aber für eine solche Annahme viel mehr Anhaltspunkte vorliegen. $\mathrm{Da} B$ von einer Dichotomie jetzt bei Equisetum nicht die Rede sein kann, spricht sich schon darin aus, daß die Seitensprosse relativ weit vom Scheitel entfernt angelegt werden. JANCzEwski gibt an, gelegentlich Gabelungen der Sprosse beobachtet zu haben. Dies ist aber wahrscheinlich auf durch Verletzung der Spitze herbeigeführte frühzeitige Entwicklung von Seitensprossen zurückzuführen. (Vgl. K. Ludwias Untersuchungen zur Biologie der Equiseten, Flora 103 (1911), p. 385 ff.) Vidal (La croissance terminale etc. chez l'Equis-palustre. Ann. d. sc. bot. Tl. X Sér. Vol. XV, 1912, p. 1ff.) hebt nenerdings hervor, daß die Blattscheiden und die mit den Blättern alternierenden Sprosse zu demselben Knoten gehören, also nicht etwa die Seitensprosse zu dem weiter oben stehenden Knoten sind. So ist das Verhalten wohl auch bisher aufgefaßt worden. Ein Rhythmus zwischen Blattbildung und Seitenknospenbildung besteht hier insofern, als die Zahl der Seitenknospen mit der der Zipfel der Blattscheiden übereinstimmt. $\mathrm{Ob}$ - wie das wahrscheinlich ist, namentlich auch nach dem Verhalten der Keimpflanzen - die Dreizahl der Blätter die ursprüngliche ist, von der sich die übrigen Zahlen durch "kongenitale Spaltung“ ableiten, sei bier nicht erörtert. Die anatomischen Verhältnisse können gegen diese Annahme nicht ins Feld geführt werden. Denn sobald einmal mehr als drei Blattanlagen da waren, kann auch von jeder auf das Gewebe des Vegetationspunktes der Reiz ausgeübt werden, der zur Bildung eines besonderen Leitbündels führt. 
haben, geht daraus schon hervor, daß einerseits alle Equiseten unterirdisch und oberirdisch lebende Sprosse besitzen, andererseits die oberirdischen Sproßachsen in den Dienst der Kohlenstoffassimilation treten; die Blätter kommen wesentlich nur als Schutzorgane für die Vegetationspunkte in Betracht. Dabei ist von Interesse, daß an den unterirdischen Sprossen die über den Vegetationspunkt weit herrorragenden Blätter anders ausgebildet zu sein pflegen als an den oberirdischen; sie bilden eine scharf zulaufende "Bohrspitze". die durch Absonderung ron Schleim ebenso schlüpfrig wird (und sich dadurch das Vordringen im Boden erleichtert), wie dies bei den Wurzelspitzen der Fall ist - eine interessante Parallelbildung. Es wäre zu untersuchen, ob die Verschiedenheit zwischen dem Verhalten der Rhizomspitzen und dem der oberirdischen Sprosse nicht mit dem begrenzten Wachstum der letzteren zusammenhängt, denn das Wachstum der Rhizome ist ein sympodiales.

Im iibrigen sind die Knospen nicht bei allen Equiseten ron vornherein zur Bildung von Rhizom- und oberirdischen Sprossen „determiniert", bei einigen Knospen ist die Induktion eine labile ( $\mathrm{rgl}$. die angeführte $\mathrm{Ab}$ handlung von K. Ludwigs). Da bei der Keimung und bei der Regeneration zunächst nur Luftsprosse auftreten, ist wohl anzunehmen, daß die Rhizome erst entstehen können, wenn Assimilate in größeres Menge sich angehäuft haben. Merkwürdig ist, $d a ß$ an jeder Seitenknospe eine Wurzel angelegt wird, auch dort, wo sie - wie bei den oberirdischen Sprossen - normal sich niemals entfaltet, wie denn auch ruhende Sproßanlagen außerordentlich zahlreich vorkommen.

Da die Sprosse begrenzten Wachstums sich physiologisch wie Blätter verhalten, so ist nicht $\mathrm{zu}$ verwundern, daß die kräftigsten Sproßanlagen sich an der Basis der Hauptsprosse finden, wie denn auch bei der Keimpflanze die Verzweigung an der Basis, nicht an der Spitze auftritt, obwohl nahe der letzteren sicher Sproßanlagen vorlaanden sind.

Die oberirdischen Haupt- und Seitensprosse stimmen darin überein, daß sie alle begrenzten Wachstums sind, mögen auch die Hauptsprosse bei Equisetum giganteum, das ich bei Caracas in stinkendem Schlamme wachsend antraf, üiber $3 \mathrm{~m}$ Höhe erreichen '). Sie unterscheiden sich nicht nur dadurch, daß die Wachstumsgrenze hei den Seitensprossen um so friiher erreicht wird, je höherer Ordnung sie sind, sondern auch durch ihren Bau. Die Seitensprosse haben eine kleinere Zahl von Blättern in ihren Wirteln und mehr Assimilationsgewebe als die Hauptsprosse. Doch kommt es, soweit meine Erfahrungen reichen, nirgends zur Ausbildung dorsiventraler Struktur dieser Seitensprosse, wenngleich bei horizontal gerichteten Seitensprossen von Eq. silvaticum der Chlorophyllgehalt auf der Oberseite größer sein mag als auf der Unterseite.

Besonders sei betont, daß die Verschiedenheit von Haupt- und Seitensprossen eine quantitative, nicht eine qualitative ist. Dies ergibt sich nicht nur daraus, daß die Hauptsprosse der Keimlinge (Fig. 83) im wesentlichen die Gestalt und den Bau haben, der später den Seitensprossen zukommt, sondern namentlich auch daraus, daß die Hauptachse kräftiger vegetativer Triebe von Equisetum arvense u. a. an ihrem Ende die Beschaffenheit annehmen, welche den Seitensprossen zukommt. Da diese theoretisch wichtige Erscheinung bis jetzt wenig beachtet wurde, sei sie an einem Beispiel geschildert.

1) Wenn neuerdings für diese Art $12 \mathrm{~m}$ angegeben werden, so ist das wohl ein Irrtum, es sind offenbar ‘ and $m$ verwechselt. 
Ein steriler Sproß von E. arvense zeigte in seinem mittleren Teile 12 Blattanlagen in jedem Wirtel, demgemäß 12 Rippen, Leitbuindel, Karinalhöhlen usw. (vgl. Fig. 85 1). An seinem Ende verschmälerte er sich sehr bedeutend (Fig. 84). Die Zahl der Blätter in jedem Wirtel sank auf 5, dann 4 (Fig. $\left.85 I I)^{1}\right)$. Zugleich traten die chlorophyllhaltigen Flügel der Internodien (eigentlich die vorspringenden, herablaufenden Blattbasen) stark hervor, die lufthaltigen Räume aber sehr zurück (vgl. Fig. $85 I I I$ ). Schon äußerlich war damit eine so große Ähnlichkeit mit den Seitensprossen erreicht, daß es aussah, als ob ein solcher Seitensproß dem Hauptsproß aufgepfropft sei (Fig. 84). Daß die Übereinstimmung sich auch auf den Bau bezieht, zeigt Fig. $85 \mathrm{IV}$. Die Seitensprosse sind relativ

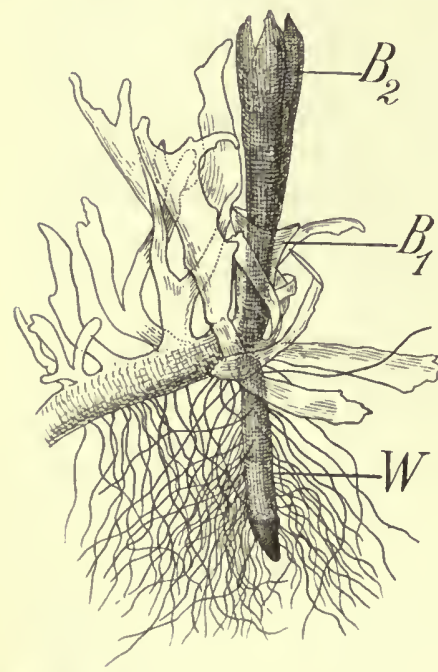

Fig. 83. Prothallium von Equisetum Telmateja mit (dunkler gehaltener) Keimpflanze. $\quad B_{1}$ deren erster, $B_{2}$ deren zweiter (die Endknospe überragender) Blattwirtel. $W$ erste Wurzel der Keimpflanze.

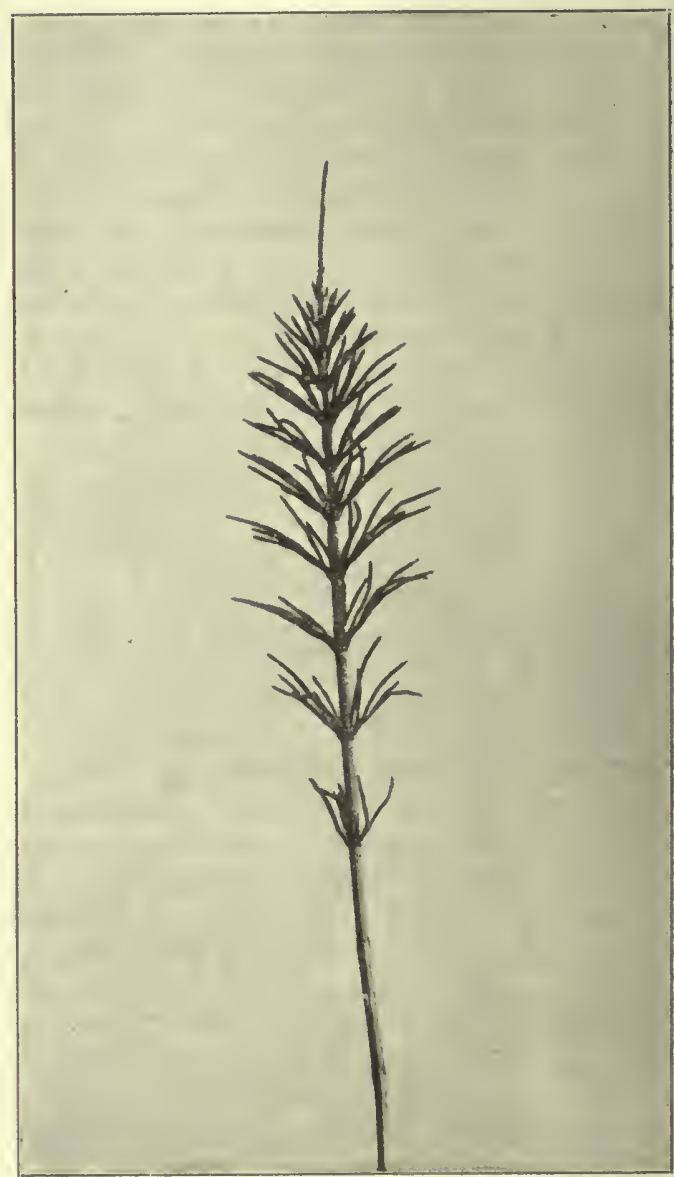

Fig. 84. Equisetum arvense. Die Hauptachse verschmälert sich nach oben, bleibt hier astlos und nimmt den Bau der Seitensprosse an (verkleinert).

viel reicher an Assimilationsgewebe als der Hauptsproß, sie haben 5, 4 oder meist 3 Rippen. Ihr Leitbündelkörper ist zwar ärmer an tracheidalem Gewebe als der des Hauptsproßendes, aber' das ist auch nur graduell. Der Vegetationspunkt am Ende dieses Sprosses war bedeutend wenig

1) Churci (On the relations of phyllotaxis to mechanical laws part II, 1902) gibt für Equisetum Telmateja an einem schwachen Laubtrieb folgende Zahlen für die Blätter der aufeinanderfolgenden Wirtel an: $11,13,14,14,17,20,20,22,24,27,28,29,30$, $29,30,26,26,26,23,23,21,19,16,14,12,9,8,6,6,4,3$. 
massiger entwickelt als der kräftig entwickelter Triebe. Die Kräftigkeit des Vegetationspunktes aber entscheidet offenbar darüber, ob viele oder wenige Blattanlagen auftreten.

Aehnlich wie dieser als Beispiel herausgegriffene Sproß verhalten sich auch auch die anderen sterilen Triebe ron E. arvense, sowie Tealmateja u. a. Offenbar besteht zwischen der Entwicklung des chlorophyllhaltigen Assimilationsgewebes und der der übrigen Gewebe eine Korrelation: Je kräftiger letztere (namentlich das Festigungsgewebe) entwickelt sind, desto stärker tritt verhältnismäßig das erstere zurück und umgekehrt. Da nach Analogie

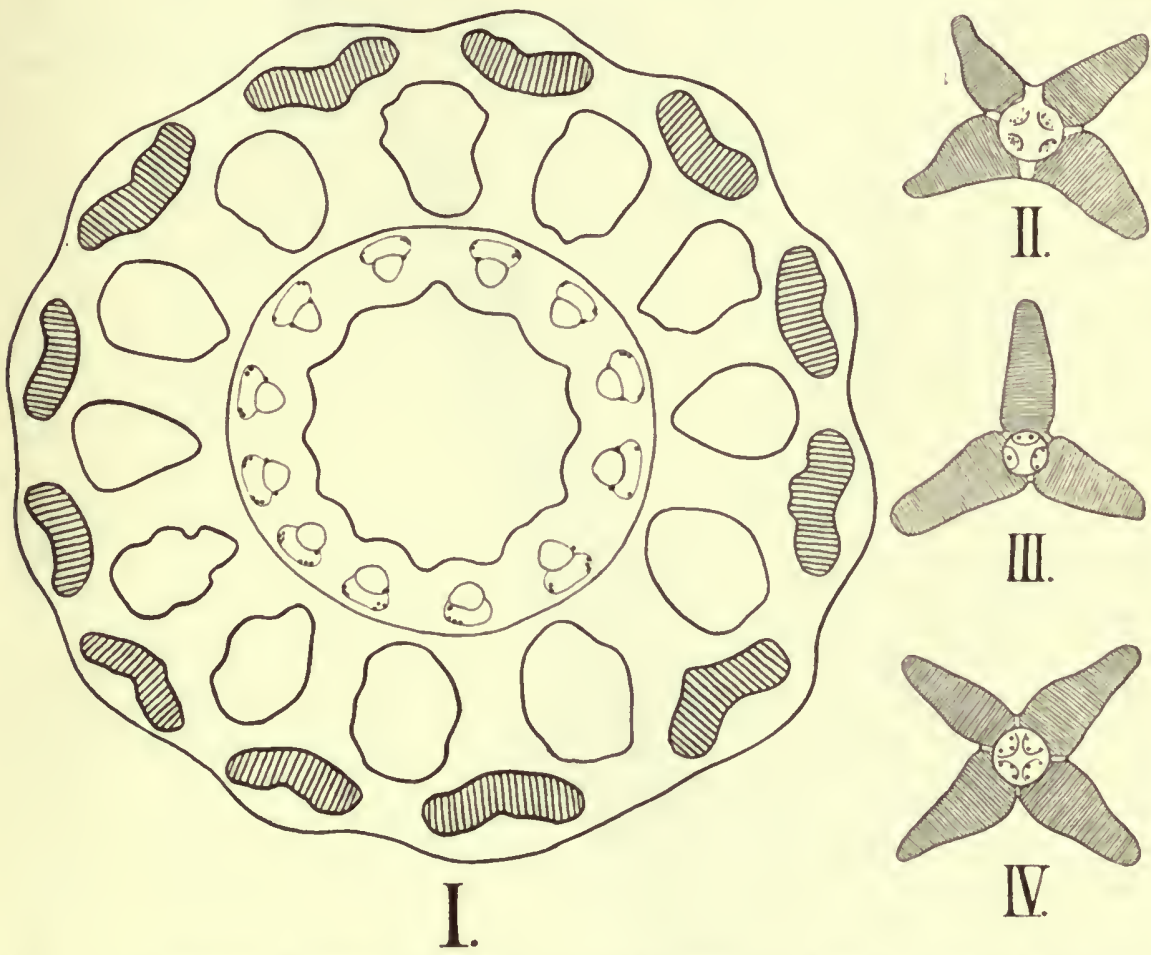

Fig. 85. Equisetum arvense. 1 Querschnitt einer Hauptachse (vergr.). Das Assimilationsparenchym ist hier, wie in den anderen Figuren $(I I-I V)$ durch Schraffierung angedentet. Es sind 12 Blätter im Wirtel (und ebenso viele Leitbündel und Luftränme in der Rinde) vorbanden. II Derselbe Sproßs weiter oben, er trägt hier vier Blätter im Wirtel, ist vierflügelig und hat vier Leitbündel. III Noch weiter oben mit drei Blättern etc. $I V$ Querschnitt eines Seitensprosses derselben Pflanze ca. 21 fach vergr.

anderer Pflanzen anzunehmen ist, daß die Entwicklung des Assimilationsgewebes rom Lichte abhängig ist, könnten wir auch sagen: die Sprosse werden um so reaktionsfähiger auf die Lichteinwirkung, je schwächer sie sind. Dies würde übereinstimmen mit dem Verhalten mancher anderen Pflanzen.

Aus der Tatsache, daß der Hauptsproß, wenn er abgeschwächt, d. h. schlechter ernährt wird, sich in seiner Struktur den Seitensprossen nähert, können wir den Schluß ziehen, daß die Differenz beider auf Ernährungsverschiedenheiten beruht, die sich schon in der geringeren Größe der 
Scheitelzellen, welche zu Seitensprossen werden, gegenüber der des Hauptsprosses aussprechen ${ }^{1}$ ).

Die Übereinstimmung der beiden in ihren Extremen so sehr verschiedenen Sproßformen spricht sich auch darin aus, daß bei den Formen, bei welchen die Sporangienstände an den Enden der Hauptsprosse auftreten, gelegentlich auch die Seitensprosse mit Sporangienständen (Blüten)

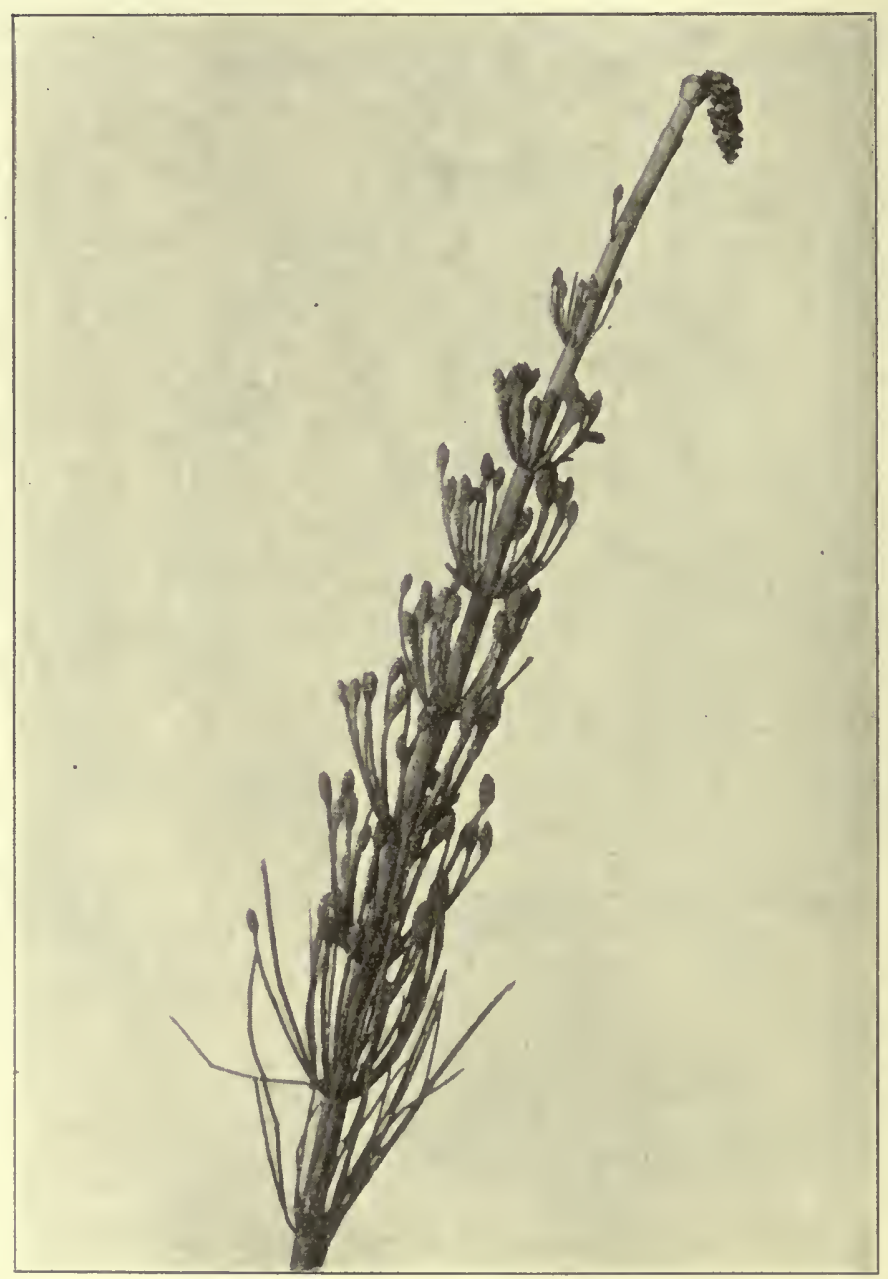

Fig. 86. Equisetum limosum. Sproß, an welchem nicht nur die Hauptachse, sondern auch fast alle Seitenachsen erster Ordnung mit Blïten (Sporangienständen) abschließen.

abschließen können (Fig. 86). So erläutert uns die Natur selbst, daß Hauptund Seitensprosse der Equiseten nur $\mathrm{s} \mathrm{ch}$ e in bar, d. h. äußerlich voneinander verschieden sind.

1) Auch experimentell ließ sich zeigen, daß bei ungünstigen Ernährungsbedingungen die Reduktion im Bau der Hauptsprosse frủher eintritt (vgl. K. Lodwias a. a. O.). 
Die Sprosse von Equisetum zeigen also was trotz einer wenig umbildungsfähigen Beschaffenheit durch Variation eines und desselben Organes geleistet werden kann.

\section{§ 9. Allgemeines über die Verzweigung der Samenpflanzen.}

a) Verschiedenes Verhalten von Blatt und AchselsproB.

Bei den Samenpflanzen ist bekanntlich die axilläre Verzweigung die Regel. Die Abweichungen, wie wir sie z. B. an dorsiventralen Sprossen finden und die verschiedenen Modifikationen im Verhältnis von Deckblatt und Achselsproß sollen an dieser Stelle nicht näher besprochen werden.
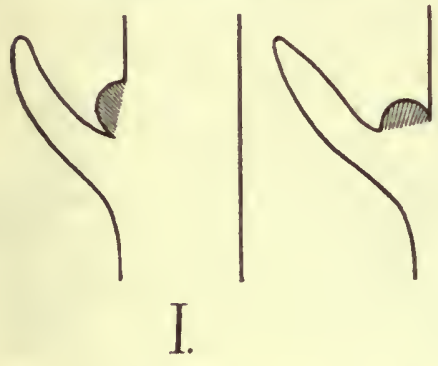

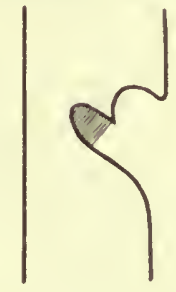

II.

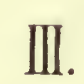

Fig. 87.

Schema für die entwicklungsgeschichtlichen Beziehungen von Blatt und Achselsproß bei Samenpflanzen, im Längsschnitt gedacht.

Es sei nur -erwähnt, daß Blatt und Achselsproß normal als "gepaarte" Anlagen entstehen, daß aber ihr örtliches und zeitliches Verhalten zueinander ein verschiedenes sein kann. Einige der beobachteten Fälle sind in Fig. 87 dargestellt, wobei jeweils die später entstehende Anlage schraffiert ist. In Fig. $87 I$ entsteht der Achselsproß nach dem Deckblatt und unabhängig von ihm an der Sproßachse. Es findet hier also eine akrogene Verzweigung statt, die man, wenn man will, von der ableiten kann, die sich bei den Farnen findet. In Fig. 87 II entsteht der Achselsproß auf der Basis des Deckblattes. Wenn man das als "Verschiebung" aus dem bei Fig. $87 I$ angefïhrten Verhalten ableiten will, was berechtigt erscheint, weil es Übergänge zwischen beiden Formen gibt, so ist doch zu bemerken, daß es auch Fälle gibt, in denen das nicht gut möglich ist, Fälle die darauf hinweisen, daß es auch bei den Samenpflanzen phyllogene Verzweigung gibt wie bei den Farnen.

Es sei nur ein Beipiel angeführt. Drosera pygmaea Fig. 88, 89, 90 hat merkwürdige Brutknospen - linsenförmige mit Reservestoffen gefüllte Körper, an deren Basis eine Knospe sitzt, die sich später zu einer neuen Pflanze enfwickelt.

Die Entwicklungsgeschichte zeigt, daß die Brutknospen umgebildete Blätter darstellen, die an ihrer Basis aber deutlich auf ihrer Fläche eine Knospe bilden (Fig. 89), während der untere Teil des Blattes zu einem Știele (St, Fig. 90) auswächst, von welchem sich die Brutknospen ablösen. Ähnliche Knospenentstehung zeigen eine Anzahl von Pflanzen mit „epiphyllen" Infloreszenzen, und nicht wesentlich davon verschieden sind die Pflanzen, deren Blätter im embryonalen Zustand Knospen erzeugen wie die von Bryophyllum, Pinellia tuberifera $u$. a.

In der Blütenregion tritt vielfach die Entwicklung des Deckblattes zurïck. Dies prägt sich auch darin aus, daß es nach dem Sproß entstehen, und wie Fig. $87 I I I$ zeigt, aus ihm hervorwachsen kann. 


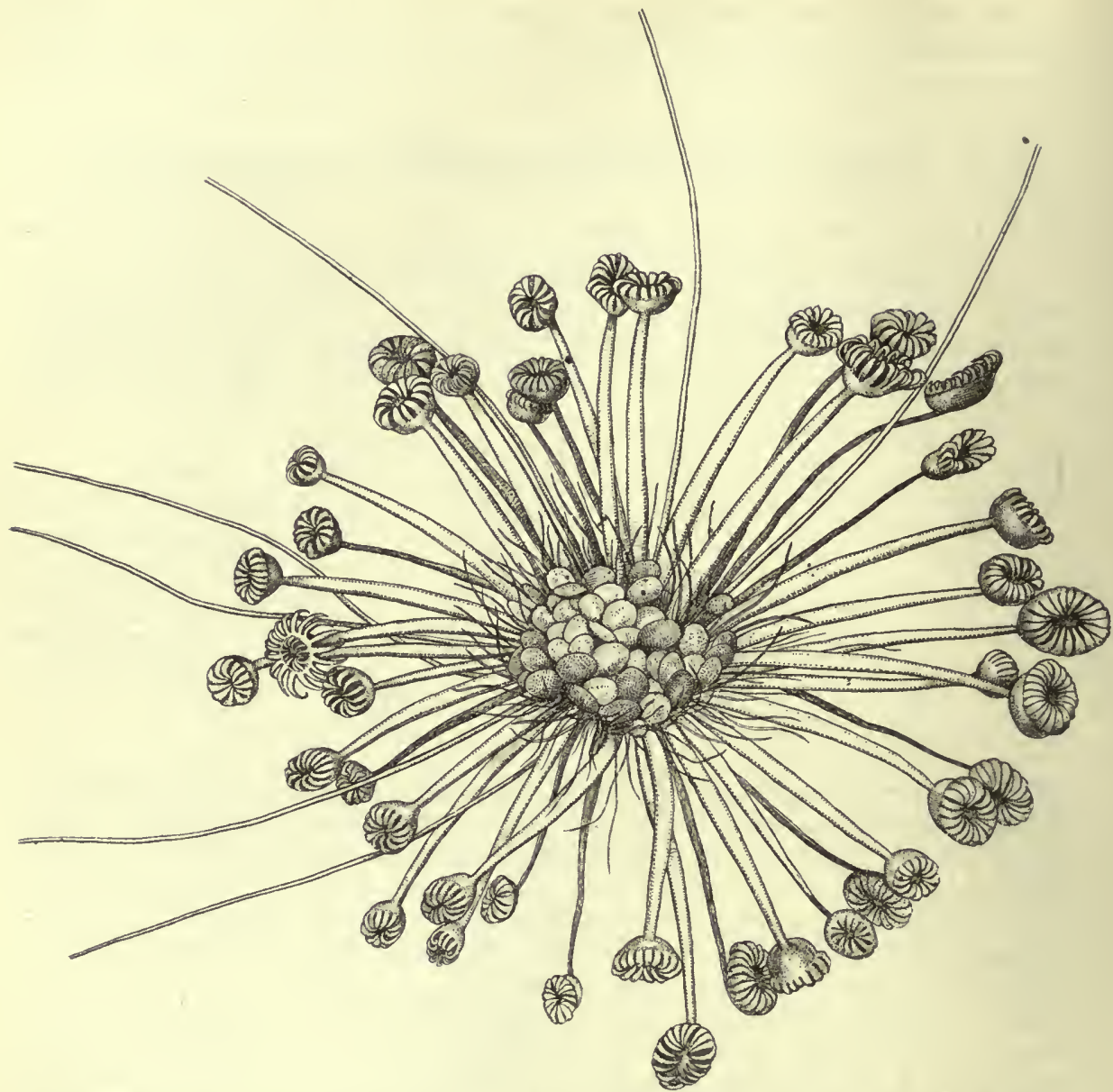

Fig. 88. Drosera pygmaea, etwa $6 \times$. Pflanze in der Ruheperiode, die Blattspreiten der schildförmigen Blätter sind braun und abgestorben. In der Mitte der Pflanze liegen zahlreiche Brutknospen, die wie grüne Blattläuse aussehen.

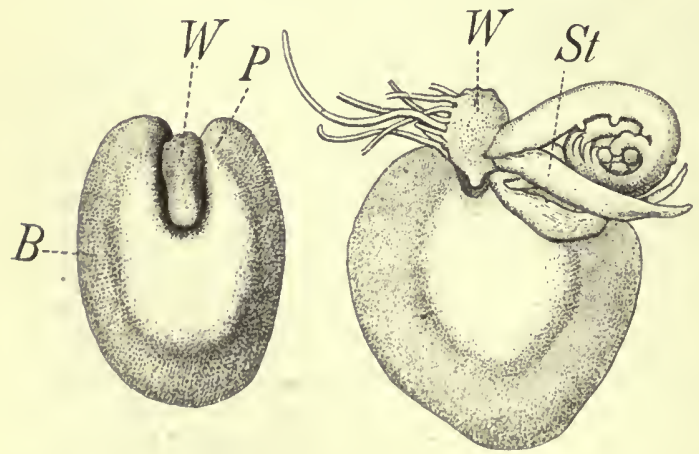

Fig. 89. Links Brutknospe von der Oberseite. $B$ Reservestoffbehälter der Brutknospe; $W$ Knospe an der Basis. Rechts eine Brutknospe, deren Sproßanlage sich zu einer jungen Pflanze entwickelt hat.

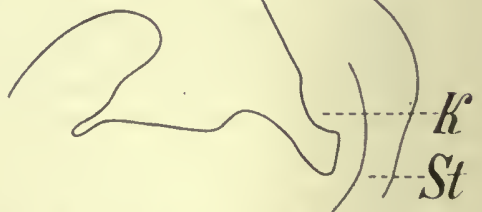

Fig. 90. Längsschnitt durch einen Vegetationspunkt ron Drosera pygmaea. Links junges Blatt; die Anschwellung nahe seiner Basis ist der Vegetationspunkt der Sproßanlage. Rechts älteres Blatt mit Knospe $(K)$ und Stiel. 
b) Die Bedeutung der axillären Verzweigung.

Die weite Verbreitung der axillären Verzweigung legt die Frage nahe, welche Bedeutung ihr zukommt.

$\mathrm{DaB}$ die Bildung zahlreicher seitlicher Vegetationspunkte schon dadurch von Bedeutung ist, daß eine Anzahl davon als "Organreserven" dienen können, wurde schon hervorgehoben. Außerdem ist der seitliche Vegetationspunkt in der Blattachsel in einer gut geschïtzten Lage, vielfach sehen wir auch den unteren Teil des Deckblattes noch besonders durch scheidenförmige Ausbildung, Nebenblätter usw. als Schutzorgan besonders ausgebildet.

Außerdem ist klar, daß in den Fällen, in welchen die Achselknospe sich $\mathrm{nach}$ dem als Laubblatt ausgebildeten Deckblatt entwickelt, ihr die Assimilate des letzteren auf kürzestem Wege zufließen können. Bei Fortnahme oder Inaktivierung des Laubblattes wird deshalb die Acliselknospe beeinträchtigt werden. BERThoLd ${ }^{1}$ ) hat z. B. bei einem Ahornpflänzchen, an dem je ein Quirlblatt möglichst früllzeitig entfernt wurde, beobachtet, daß die Achselknospe des fortgenommenen Blattes in ihrer Entwicklung weit hinter der des gegenüberstehenden zuriickblieb. Andererseits kann in solchen Fällen, in denen Achselknospen sehr frühzeitig sich entwickeln, Deckblatt und Achselsproß also gewissermaßen ron derselben Quelle gespeist werden, eine Entfernung der Aclıselknospe eine Vergrößerung des Deckblattes bedingen ${ }^{2}$ ).

Indes ist diese Wechselwirkung aus leicht ersichtlichen Gründen viel weniger verbreitet als eine andere, die darin besteht, daß bei manchen Pflanzen ${ }^{3}$ ) das Austreiben resp. Nichtaustreiben der Achselknospe durch das Vorhandensein des Stützblattes bedingt wird. So wurde z. B. gezeigt ${ }^{4}$, daß, wenn man einen Jahrestrieb von Prunus Padus im Anfang der Vegetationsperiode entspitzt und entblättert, dann die Achselknospen, welche sonst erst in der nächsten Vegetationsperiode sich entwickelt hätten, austreiben, und darauf hingewiesen, da $B$ uns dadurch verständlich wird, weshalb die Achselknospen von Blättern, welche wie die der Langtriebe von Berberis verdornt, oder wie die der Langtriebe ron Pinus als Knospenschuppen entwickelt sind, ihre Achselknospen schon im Jahre ihrer Entfaltung austreiben lassen - sie verhalten sich physiologisch wie die entblätterten Triebe von Prunus Padus. Selbstrerständlich kann dies Austreiben nur erfolgen an Knospen, welche noch nicht in den vollständigen Ruhezustand übergegangen sind, welcher die Knospen unserer Holzgewächse später befällt.

In der angeführten Abhandlung wurde unentschieden gelassen, worauf die Korrelation zwischen Blatt und Achselknospe beruht. Neuerdings ist DostáL den Korrelationsbeziehungen zwischen Blatt und Achsel-

1) Bertrold, Untersuchungen zar Physiologie der pflanzlichen Organisation

(1901)

Bd. II, 1 p. 106.

2) H. WinkLER, Über korrelative Beziehungen zwischen Blatt und Achselknospe. (Ann. du jardin bot. de Buitenzorg. 2. sèr. Vol. V, p. 41).

3) Die Erscheinung ist keineswegs eine allgemeine. Bei nicht wenigen Pflanzen mit krantartigen Sprossen entwickeln sich die Achselsprosse (anch abgesehen von der Blütenregion) im Jahre ihrer Anlegung. So bei Hypericum, Androsaemum, Salvia-Arten u. a. Auferdem kommen noch andere Beziehungen in Betracht. Wo keine Achselknospen angelegt sind, wio in den Achseln von Knospenschuppen, können die ersteren natürlich auch nicht austreiben. 1880 , p. 803.

) Goener, Beitr. zur Morphologie und Physiologie des Blattes. Botan. Zeitung

Goebel, Organographie der Pflanzen. 2. Auff. Allgem. Teil. 
knospen näher getreten ${ }^{1}$ ). Schneidet man z. B. ein Blattpaar von Sambucus nigra mit einem Stiick Sproßachse ab und kultiviert es in feuchtem Sand, so werden die Achselknospen (durch Trennung von der Endknospe des Triebes) zur Entfaltung angeregt; nimmt man von beiden Blättern aber eins weg, so ist dessen Achselknospe gefördert und hemmt die Entfaltung der Achselknospe der anderen; selbst bei Vorhandensein der Gipfelknospe führt die Entfernung eines Blattes, z. B. bei Calamintha Clinopodium zur Entfaltung von dessen Achselknospe. Das entspricht also ganz dem von Prunus Padus u. a. bekannten Verhalten. Auch die Verhinderung der Assimilationstätigkeit des Blattes führt zu demselben Resultate. Man kann sich denken, daß im assimilierenden Blatt "Hemmungsstoffe" entstehen, bei deren Wegfall das Austreiben der Knospen erfolgt.

Vielleicht handelt es sich aber auch nur um die Konzentrationsverhältnisse der vom Blatte abgeleiteten Stoffe. Man kann sich vorstellen, daß eine von relativ stark konzentrierten organischen Stoffen umspülte Achselknospe dadurch am Austreiben verhindert wird, oder daß diese Verhinderung bedingt wird durch einen relativen Mangel an Aschenbestandteilen. Damit würde übereinstimmen, daß bei stark wachsenden Pflanzen, bei denen eine rasche Ableitung der Assimilate des Blattes stattfindet, ein Austreiben der Achselknospen auch ohne Entfernung ihrer Deckblätter stattfindet. Namentlich war mir in dieser Beziehung das Verhalten von "Stockausschlägen" von Interesse. So bezeichnet man die an dem stehengebliebenen Stumpf eines gefällten Baumes entwickelten Sprosse, seien es nun solche, die sich aus "schlafenden Augen" (ruhenden Seitenknospen) oder solche, die aus dem Cambial-Kallus des Stumpfes entstanden sind. Diese Sprosse haben ein unverhältnismäßig großes Wurzelsystem - das des gefällten Baumes - zur Verfiigung und weichen infolgedessen in ihrem Verbalten mehrfach von dem "normalen" ab. Nicht nur haben sie vielfach größere und teilweise auch anders gestaltete Blätter als die anderen, auch ihre Entwicklungsdauer und Verzweigung ist eine andere. Stockausschläge von Aesculus Hippocastanum und Alnus glutinosa waren im September 1911 noch im lebhaftesten Wachstum und in Entwicklung begriffen (während diese bei den normalen Sprossen längst abgeschlossen war) und entwickelten zahlreiche axilläre Seitensprosse, die an den anderen erst im nächsten Jahre auftraten. Das zeigt also, daß auch am intakten Sprosse die Hemmung der Achselknospen aufgehoben werden kann.

Eine eigentümliche Korrelation von Blatt und Achselsproß fand Nordhausen bei einigen Salixarten ${ }^{2}$ ). Bei S. Lapponum haben die Blüten, in deren Achsel die Infloreszenzen stehen, einen anderen Blattstiel als die, welche regetative Knospen schützen. Die Basis des Stieles ist scheidenartig erweitert, verdickt und vergrößert. Wenn man die Infloreszenzknospe in der Achsel eines möglichst jungen Blattes entfernt, so unterbleibt diese abweichende Ausbildung des Blattgrundes. Sie ist offenbar bedingt dadurch, daß von den in die Infloreszenz strömenden Baumaterialien auch das Deckblatt der Infloreszenz beeinflußt wird - eine Beeinflussung, welche mit der Entfernung der Infloreszenzknospe selbstverständlich wegfällt.

1) R. DostáL, Die Korrelationsbeziehungen zwischen dem Blatt und seiner Achselknospe. Ber. der dentschen bot. Gesellsch. 27 (1909, p. 546).

2) M. Nordhuusen, Über die Wechselbeziehung zwischen Infloreszenzknospe und Gestalt des Stützblattes bei einigen Weidenarten. Ber. der dentschen bot. Gesellsch. XXVIII (1910), p. 207. 
Diese Tatsachen zeigen, daß zwischen Blatt und Achselknospe nicht nur örtliche, sondern auch ernährungs- (resp. reiz-)physiologische Beziehungen bestehen. Dies wird besonders deutlich auch durch Versuche mit Circaea lutetiana erläutert ${ }^{1}$ ) (vgl. Fig. 91). Nimmt man von der Pflanze mit
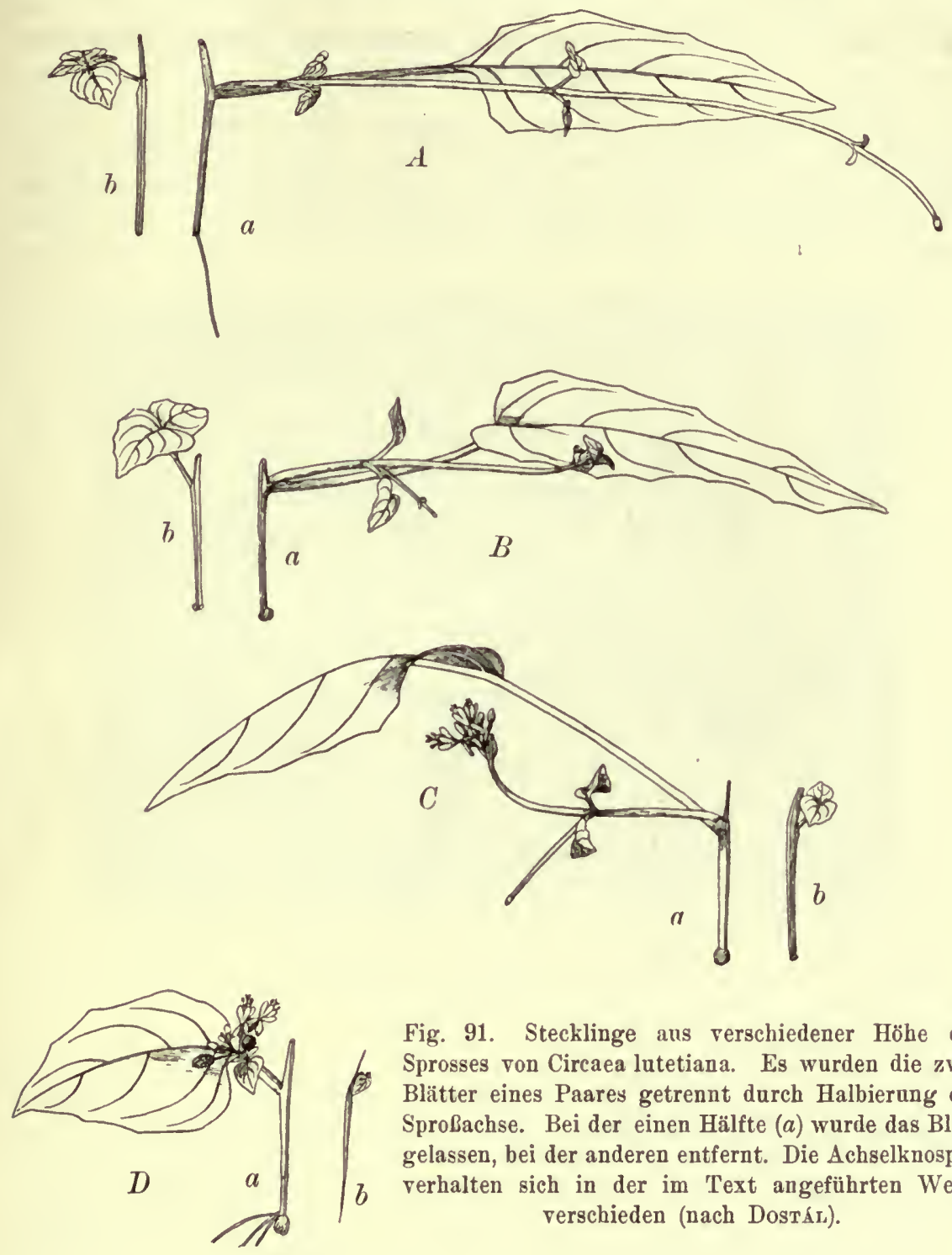

Fig. 91. Stecklinge ans verschiedener Höhe dee Sprosses von Circaea lutetiana. Es wurden die zwei Blätter eines Paares getrennt durch Halbierung der Sproßachse. Bei der einen Hälfte $(a)$ wurde das Blatt gelassen, bei der anderen entfernt. Die Achselknospen verhalten sich in der im Text angeführten Weise verschieden (nach DostÁL).

Blättern versehene Stecklinge aus verschiedener Höhe, so wachsen die Knospen der unteren zu Ausläufern aus (Fig. 91 $A, a$ ), die der mittleren zu zunächst horizontalen Zweigen (Fig. 91 B,a), die der oberen (Fig. $91 D, a$ )

1) Goeber a. a. 0.; R. Dostát, Zur experimentellen Morphogenesis bei Circaea und einigen anderen Pflanzen, Flora 103, p. 1. 
zu blühenden Sprossen. Nimmt man aber blattlose Stecklinge aus denselben Regionen, so wachsen die austreibenden Achselknospen alle zunächst zu aufrechten Laubtrieben aus (Fig. $91 A, B, C, D, b$ ).

\section{$\S 10$. Dichotome Verzweigung und kongenitale Sympodienbildung bei Samenpfianzen.}

a) Sproßachsen. Daß in der Gruppe der Samenpflanzen dichotome Verzweigung vorkomme, haben einige Autoren ganz in Abrede gestellt. Tatsächlich läßt sich auch nachweisen, daß in einigen Fällen, in denen sie dem Augenschein nach vorliegt, der wirkliche Vorgang ein anderer ist; in andern dagegen ist sie zweifellos vorhanden.

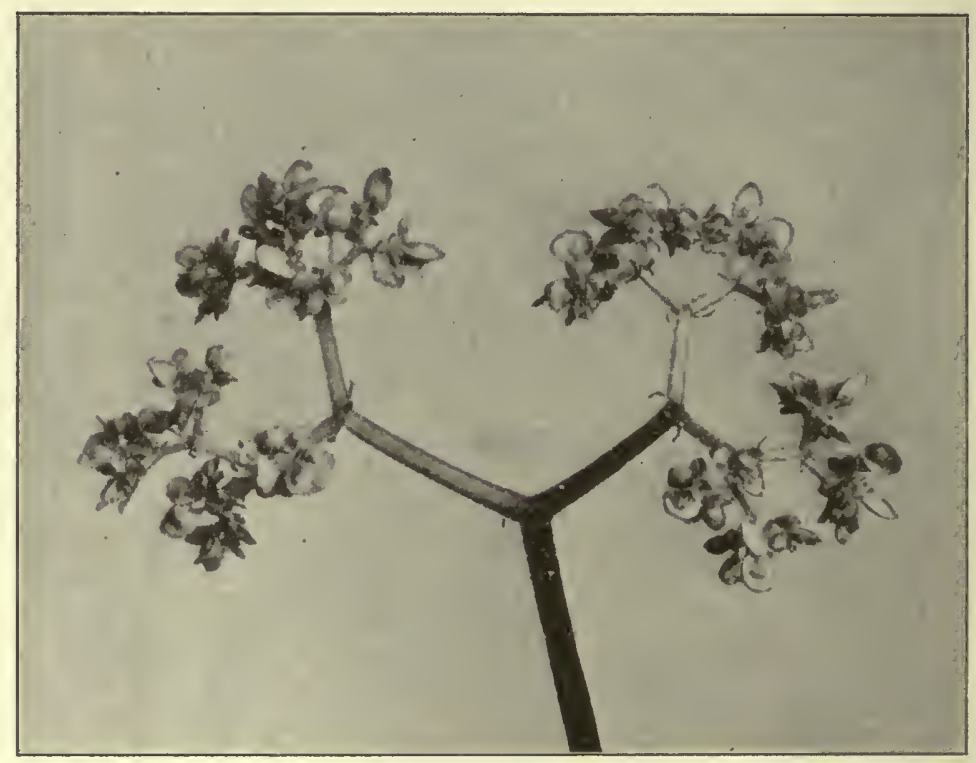

Fig. 92. Begonia vitifolia. Scheinbar gabelig verzweigt. Infloreszenz mit noch unentfalteten Blüten.

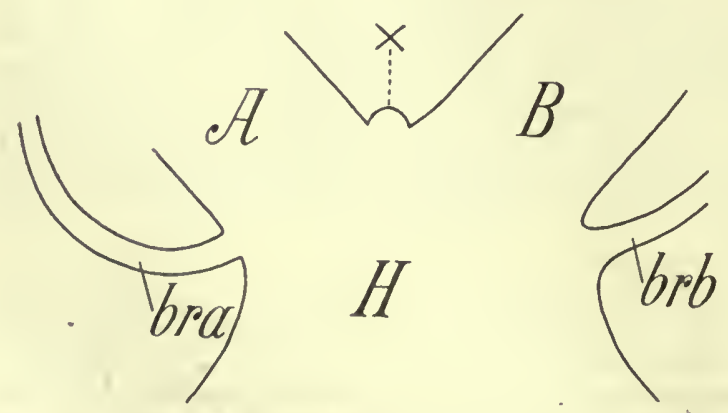

Fig. 93. Begonia vitifolia, unterer Teil einer jungen Infloreszenz im optischen Längsschnitt $H$ Hauptachse, deren verkïmmerndes Ende bei X liegt. $A B$ die beiden Gabeläste in den Achseln der Deckblätter bra und brb vergr.
Fig. 92 stellt einen Blütenstand ron Begonia vitifolia dar. Die Verzweigung bietet den Anschein einer echten Gabelung dar. Aber einerseits finden wir unter denGabelsprossen je ein kleines, hinfälliges Deckblatt (was zeigt, daß sie Acliselsprosse darstellen), andererseits sehen wir bei den weiter oben stehenden Verzweigungen zwischen 
zwei (mit je einer Blüte endigenden) Gabelästen eine Endblïte und werden also schließen, daß diese zwischen den unteren Infloreszenzästen nur verkümmert ist. Tatsächlich zeigt auch die entwicklungsgeschichtliche Untersuchung (Fig. 93) zwischen den beiden ersten Gabelästen der Infloreszenz einen kleinen Höcker $(X)$ - das Ende der massigen ersten Achse $H$, unterhalb dessen die beiden gleich starken Seitenzweige $A$ und $B$ entspringen. Würde dieser Höcker ganz aufgehen in die Bildung der beiden Gabeläste, so würde eine "Dichotomie" vorliegen, die wir nur deshalb als "echte" nicht bezeichnen würden, weil ihre Ableitung aus der axillären Verzweigung klar liegt. Es ist wahrscheinlich, daß die Verkümmerung der Primärblüten in korrelativer Beziehung bedingt ist durch die frühzeitige und starke Entwicklung der Seitenäste. Bildlich gesprochen würde das so viel heißen: Es kommt der Pflanze zunächt darauf: an, das Ger üste der Infloreszenz aufzubauen. Der Vorgang läßt sich vergleichen mit dem, welchen wir bei der dichotomen Verzweigung früher angeführt haben: Wie an den schwächeren Enden des Wurzelsystems vion Lycopodium rein gabelige Verzweigung auftritt, so an den oberen Teilen der Infloreszenz die dichasiale, während in den kräftigen entwickelten Teilen der erwähnte "Geriistban" stattfindet.

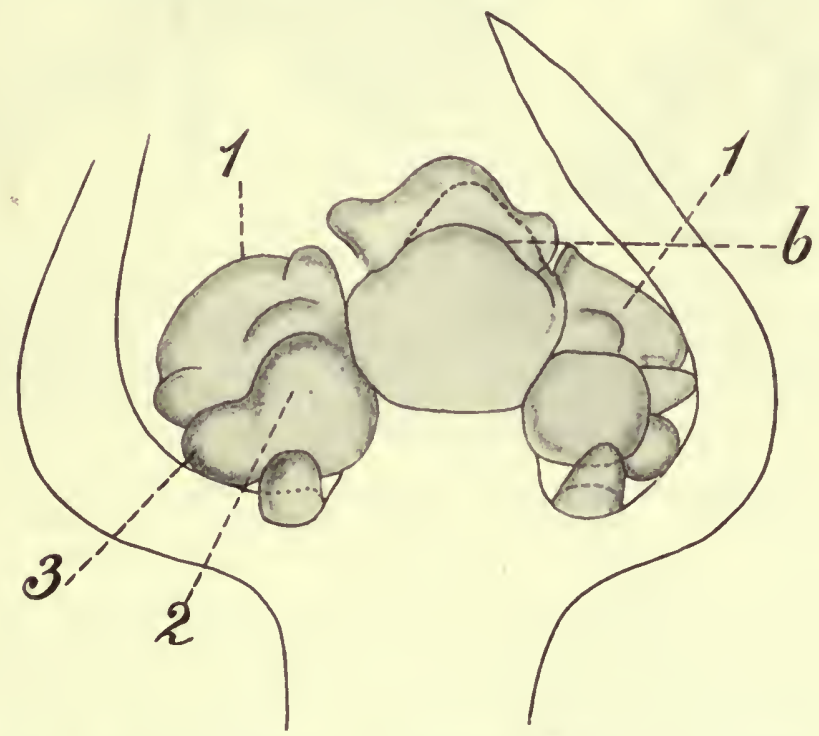

Fig. 94. Lamium album. Gipfel einer blühenden Pflanze in Seitenansicht. In der Achsel der Blätter stehen "Doppelwickel". 1 erste, 2 zweite, 3 dritte Blüte, $b$ Blattanlage.

In anderer Weise führt ein Weg von der axillären zur gabeligen Verzweigung bei manchen als "Boragoide" bezeichneten Infloreszenzen. In Fig. 95 ist eine junge Infloreszenz von Omphalodes linifolia abgebildet. $\mathrm{Tb}$ ist die Terminalbliite, unterhalb dieser gelangen zwei axilläre Inflorenszenzen zur Ausbildung. Die links hat eine Blütenanlage I und einen Vegetationspunkt abgegliedert, welcher sich durch eine Furche in zwei Stïcke embryonalen Gewebes parzelliert, ein oberes zur Blüte II werdendes und ein unteres, welches die Teilung wiederholt. Wir können sagen, dies Verhalten ist aus einem solchen entstanden, wie er es bei den in Fig. 94 abgebildeten Labiatenbliutenständen vorhanden ist. Unterhalb 
der Mittelbliite 1 bilden sich zwei "Wickel" aus, von denen einer sichtbar ist. An dessen erster Blüte (2) wird ein später ebenfalls zu Blïte werdender Vegetationspunkt 3 ausgegliedert, der aber kleiner als 2 ist und erst allmählich zur Größe des letzteren (unterdes schon zur Blitenbildung übergegangenen) heranwächst. Wenn nun die Bildung von 3 beschleunigt wird, so erhält es von vornherein ein größeres Areal am Vegetationspunkt zugeteilt, es entsteht dann eine "Dichotomie“ (Fig. 95). Ja der so eingeleitete Prozeß geht vielfach noch weiter, und führt sozusagen zur Umkehrung des ursprünglichen Vorgangs. Es entsteht nicht mehr $b$ aus $a$, $c$ aus $b$ usw. in der Reihenfolge, die einem "Wickel" entspricht, sondern es bildet sich ein Vegetationspunkt, an welchem $a, b, c$ als seitliche Sprossungen erscheinen. So kann es schon bei der als Beispiel angeführten Pflanze sein, noch auffallender bei anderen wie Symphytum (Fig. 96). Tiaridium indicum (Fig. $97 \mathrm{~A} \mathrm{u}$. B), es tritt dann ein dorsirentrales Monopodium auf. Dessen Ableitung von einer sympodialen

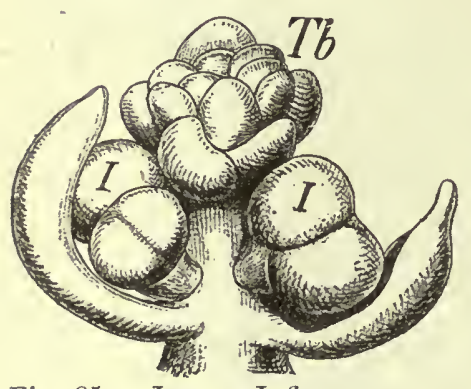

Fig. 95. Junge Infloreszenz von Omphalodes linifolia nach W. MLüLLER. Tb Terminalblüte, unterhalb dieser zwei axilläre Boragoide, welche sich gabelig verzweigen.

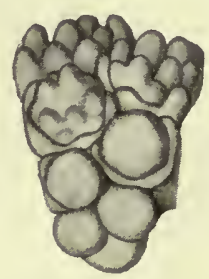

Fig. 96. Symphytum asperrimum.

Junger Blütenstand von oben, die Blütenhöcker treten als seitliche Anssprossungen (kleiner als der terminale Vegetationspunkt) auf.

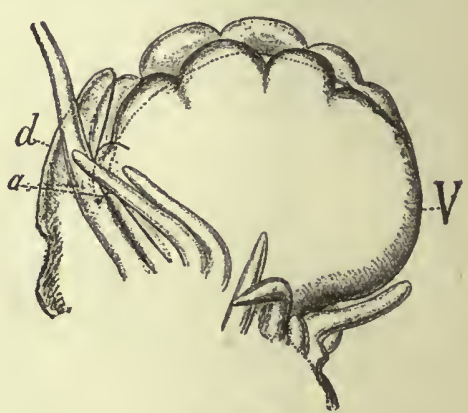

Fig. $97 \mathrm{~A}$ (nach W. MÜLLER). Junge Infloreszenz von Tiaridium indicum von der Seite. $V$ Infloreszenzregetationspunkt, auf dessen Oberseite zwei Reihen von Blïtenanlagen entstehen.

Verzweigung läßt sich, wie oben ausgeführt wurde, noch erkennen - es ist, im wesentlichen derselbe Vorgang den wir auch bei Lycopodium u. a. erwähnten. Dabei ist bemerkenswert, daß offenbar Ernährungseinflüsse dafür maßgebend sind, ob mehr die gabelige oder die monopodiale Anlage hervortritt; ersteres ist bei ungünstigen Bedingungen der Fall, d. h. wahrscheinlich dann, wenn Material zur Blütenbildung in geringerer Menge oder langsamer den jungen Blïtenständen zugeführt wird ${ }^{1}$ ).

Ganz ähnliche Erscheinungen wie bei den Blütenständen der Boragineen treffen wir auch im Sproßaufbau die Ampelideen an, welche gleichfalls zu vielen Diskussionen Veranlassung gegeben hat. Die Sproßranken stehen hier ohne Deckblatt im entwickelten Zustand seitlich an der Hauptachse. Phylogenetisch sind diese Ranken von terminalen Inflorenszenzen abzuleiten, die durch Bildung vegetativer Seitensprosse zur Seite gedrängt

1) Literatur: GoEner, Über die Verzweigung dorsiventraler Sprosse, Arb. der botan. Inst. in Würzburg, heransgeg. von J. SAcHS II. Bd. (1880). Derselbe, Zur Entwicklungsgesch. des Boragoids (Flor. 91. Bd. (1902) p. 255). W. MüLlER, Beitr. zur Entwicklnngsgesch. der Infloreszenzen der Boragineen und Solaneen (Flor. 94. Bd. (1905) p. 385). In diesen Arbeiten ist weitere Literatur zitiert. Anf die mannigfache Diskussion einzngehen, die sich an die Auffassung der Boragoide geknüpft hat, liegt kein Grund vor. Meiner Ansicht nach ist die Frage nach dem Zustandekommen der Boragoide aufgeklärt, wünschenswert wäre dagegen eine experimentelle Behandlung. 
wurden; der Aufbau war also ein ursprïnglich sympodialer. Es gibt sogar Ampelideen, bei welchen die Infloreszenz deutlich terminal ist, und dann von einem unter ihr entstehenden Achselsproß zur Seite gedrängt wird. So bei Cissus alnifolia ${ }^{\mathbf{1}}$ ). Die Entwicklnngsgeschichte der Rankenbildnng bei Vitis und Ampelopsis, die ron zahlreichen Forschern untersucht ist, zeigt, daß die Ranke nicht (wie es nach der oben angeführten Theorie zu erwarten stünde), bei ihrem Sichtbarwerden die Fortsetzung

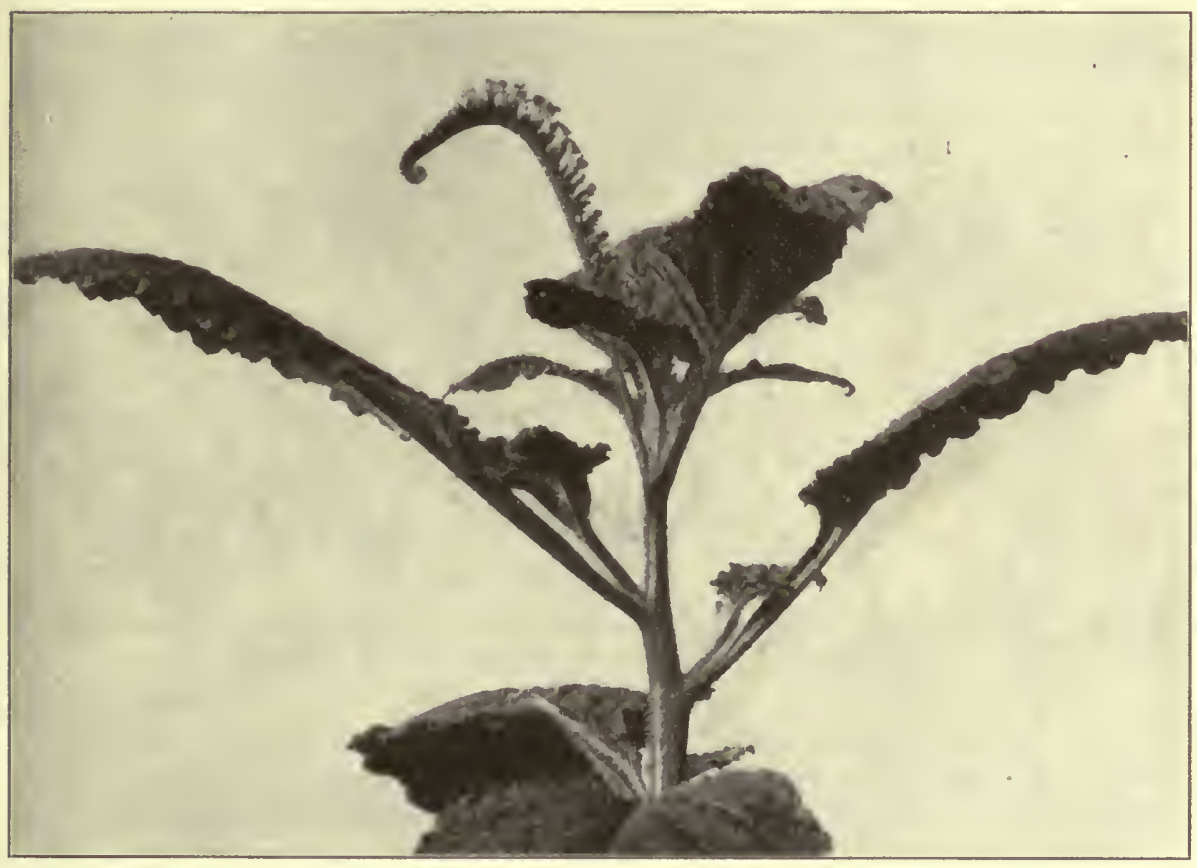

Fig. 97 B. Tiaridium (Heliotropium) indicum mit dorsiventraler (sekundär-) monopodialer Infloreszenz.

des darunter befindlichen Internodiums bildet, und erst nachträglich durch kräftigere Ausbildung des obersten Axillarsprosses (durch Übergipfelung) zur Seite geworfen wird, sondern daß sie entweder gleich anfangs die blattgegenständige Stellung des fertigen Zustandes hat (N̈̈GELI und Schwendener, auch Warming für Ampelopsis) oder aber aus dem Achsenscheitel selbst durch ungleiche Teilung hervorgeht, wobei der andere Teil die Rebe fortbildet (Prillieux, WARming für Vitis vulpina). So sehen wir auch in Fig. 98 die Ranke $R$ von Anfang an seitlich auftreten und kleiner als den Sproßregetationspunkt. Es kommt (bildlich gesprochen), der Pflanze auf eine rasche Fortsetzung des regetativen Gerüstes an, die sich schon durch das Verhalten des Vegetationspunktes ausspricht. $\mathrm{Ob}$ man von einem Sympodium oder einem Monopodium sprechen will, konmt auf den Sinn an, den man mit diesen Worten verbinden will. Es liegt eben ein Monopodium vor, welches phylogenetisch

1) Vgl. M. BRandt, Untersuchungen über den Sproßaufbau der Vitaceen. Diss. Berlin 1911 . 
von einem Sympodium abzuleiten ist. Weder das eine noch das andere kann - wie dies wiederholt versucht wurde - ex cathedra wegdisputiert werden. Ein Streit darüber ist also ganz überflüssig.

b) Wurzeln. Ebensowenig wie die Sprosse folgen auch die Wurzeln der Angiospermen in ihrer Verzweigung streng einem Schema. Wir können hier zwei Fälle unterscheiden:

Eine Abweichung von der gewöhnlichen monopodialen Verzweigung der Wurzeln tritt entweder $\alpha$ ) spontan oder $\beta$ ) veranlaßt durch symbiontisch in der Wurzel lebende Organismen auf, die dann eine "latente" Fähigkeit der Wurzelverzweigung in die Erscheinung treten lassen.
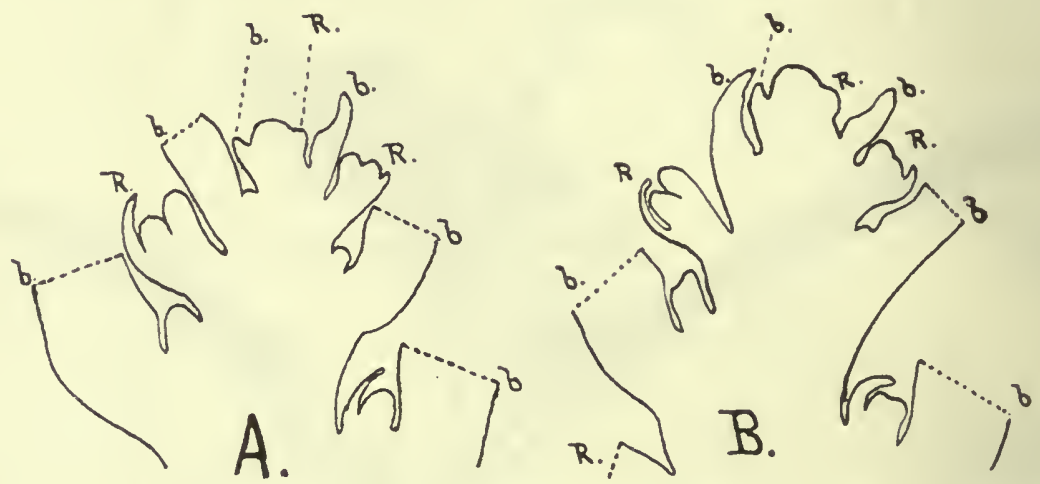

Fig. 98. Längsschnitte durcb die Sproßspitzen von A) Vitis vulpina (nodoratissima"), $B$ ) V. cinerea. $R$ Ranke, $b$ Blätter (nach A. Mans).

a) Spontan zeigen die Knollenwurzeln mancher Erdorchideen eine Dichoresp. Polytomie ihrer Vegetationspunkte. Es sei bezüglich dieser vielfach irrig als durch "Verwachsung" von Wurzeln entstanden betrachteten Organe auf den speziellen Teil verwiesen.

$\beta$ ) Eine Gabelung tritt auf an den Mykorrhizen von Coniferen und den "Luftwurzeln" einiger Cycadeen, auch den durch Bakterien hervorgerufenen Almus-"Mykorrhizen“. Daß eine Dichotomie stattfindet, ist wenigstens für die Coniferen sicher festgestellt ${ }^{1}$ ).

Diese Erscheinung als "Atavismus" zu betrachten liegt kein zwingender Grund vor, da ja auch latente Eigenschaften, die bei den Vorfahren nicht sichtbar waren, durch Gallentiere, Pilze usw. zur Entwicklung gebracht werden können. Immerhin wird man diese Wurzelgabelungen als Stütze für die auf S. 80 versuchte Ableitung der Wurzelverzweigung benutzen können.

c) Blätter. Auch die Blätter einiger Dikotylen zeigen gabelige Verzweigung, welche teilweise wohl ebenso wie in den unter a) und b) betrachteten Fällen von der seitlichen abzuleiten ist, teilweise aber auch als zufällige Variante selbständig aufgetreten sein mag. So bei Drosera dichotoma und Dr. binata - Formen, bei denen die Dichotomie offenbar durch das Spitzenwachstum des Blattes ermöglicht wird. Eine Ableitung von seitlicher Verzweigung liegt auch bei Utricularia nahe. Die ersten

${ }^{1}$ ) Strasburarr, Die Coniferen und die Gnetaceen, p. 359; Bruchuans, Über Anlage und Wachstum der Wurzeln von Lycopodium und Isoetes, Diss. Jena 1874. 
Auszweigungen der Blätter der Wasser-Utricularien sind gabelig verzweigt, (Fig. 99) und gelegentlich tritt eine Gabelung auch bei den Blättern von Land-Utricularien ein ${ }^{1}$ ).

Namentlich finden sich Erscheinungen, die an Gabelung erinnern, auch an den Kotyledonen mancher Pflanzen, entwicklungsgeschichtliche Untersuchungen liegen hier freilich nicht vor; und so ist zunächst nicht zu entscheiden, ob eine „echte Gabelung“ durch Teilung der Spitze im embryonalen Zustand, oder ein Auswachsen der seitlichen Teile unterhalb der in der Entwicklung gehemmten Blattspitze vorliegt. Ein solcher Fall könnte z. B. bei Argyreia speciosa (Fig. 100 II) vorliegen, während der Kotyledon von Kigelia africana (Fig. $100 \mathrm{I}$ ) den Eindruck einer Gabelung macht. Die Frage ist auch insofern nicht ohne Interesse, weil (wie im speziellen Teile näher zu erörtern sein wird), eine vollständige, kongenitale Teilung der Kotyledonen nicht selten vorkommt. Ein solcher Fall liegt z. B. in Fig. 100 III für Tacsonia Van Volxemii vor. Für gewöhnlich hat diese Pflanze einfache, ungeteilte Kotyledonen (Fig. 100 IV),

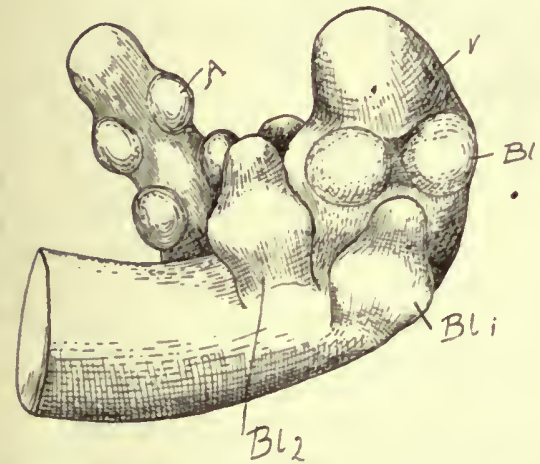

Fig. 99. Vegetationspunkt $(v)$ eines Sprosses $^{4}$ einer Wasser-Utricularia (Utr. Elephas) nach LuETzenbura. Die an den Flanken des Vegetationspunktes $V$ entstehenden Blattanlagen $B l$ gabeln sich sehr frühzeitig, so daß $B l_{1}$ und $\mathrm{Bl}_{2}$ später scheinbar selbständig an der Sproßacbse stehen. Sie verzweigen sich dann seitlich (so bei $A$ ).
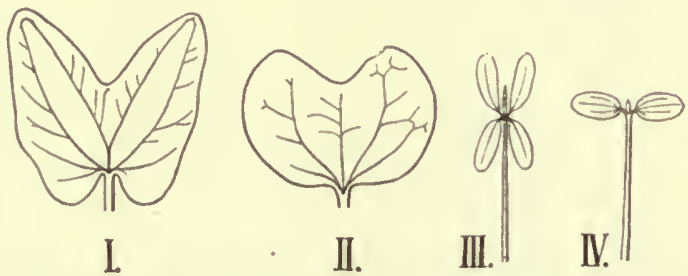

Fig. 100. Kotyledonen. I von Kigelia africana, II von Argyreia speciosa, III und IV Tacsonia Van Volxemii.

die aber, wie Fig. 100 III zeigt, sich so tief spalten können, daß scheinbar vier vorhanden sind. Das wäre dann die (hier nur ausnahmsweise eintretende) Steigerung eines Verhaltens wie es bei Kigelia africana und anderen normal vorhanden ist.

\section{$\S 11$. Weitere Beispiele für eigenartige Verzweignngen.}

Daß auch bei der Verzweigung der Angiospermen das Prinzip der Mannigfaltigkeit herrscht, dafür seien hier nur wenige Beispiele angeführt.

a) Eine allgemeine Regel ist, daß der Seitensproß sich zunächst in derselben Richtung entwickelt wie der Hauptsproß, also die beiden Vegetationspunkte gleich gerichtet sind, auch dann, wenn spüter die Sprosse "anisotrop" werden.

1) Vgl. z. B. Utr. bifida, Abbildung in GoebeL, Pflanzenbiol. Schilderungen, p. 153. 
Anders bei den männlichen Blütenständen der Composite Ambrosia (Fig. 101). An dem Vegetationspunkt $V$ entstehen seitliche, zu Blütenköpfen werdende Vegetationspunkte. An deren adaxialer Seite sproßt das erste Blatt hervor (a Fig. 101), der Vegetationspunkt des Seitensprosses aber (b) entwickelt sich auf der abaxialen Seite. Es ist hier nicht zu erörtern ${ }^{1}$ ), ob das Blatt $a$ als Deckblatt des Seitensprosses oder dessen erstes Blatt zu betrachten ist. Man könnte auch sagen der Vegetationspunkt des Seitensprosses erfahre eine "kongenitale Drehung" um $180^{\circ}$. Jedenfalls kommen die männlichen Blüten, deren. Pollen sich durch den Wind verbreitet, hier von vornherein in dieselbe (für die Pollenausschüttelung günstige) Lage, wie sie die männlichen Blüten von Juglans und Corylus durch die hängende Lage des Blütenstandes erhalten - eine "zufällig" entstandene Abweichung kann bestehen bleiben, weil sie zum mindesten eher nützlich als schädlich ist. Für eine insektenblütige Pflanze wäre die Lage der Blüten nach unten eine ungünstige.

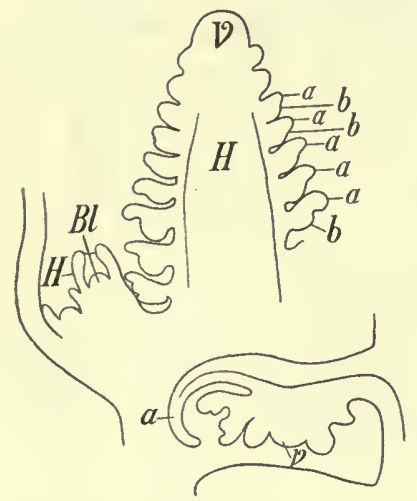

Fig. 101. Ambrosia tripartita. Oben Längsschnitt durch eine männliche Infloreszenz ( $B l$ eine weibliche), die männlichen Teilinfloreszenzen $(b)$ entwickeln sich auf der abaxialen Seite. $a$ deren erstes Blatt. Darunter eine ältere männliche Teilinfloreszenz, $v$ deren Vegetationspunkt.
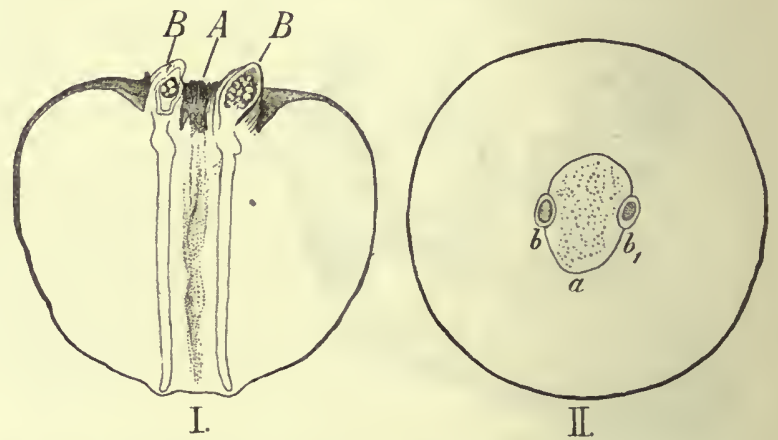

Fig. 102. Corydalis solida. I Längsschnitt durch eine Kuolle im November 1902. A Stelle, wo der alte Sproß des vorigen Jahres saß. $B B$ Seitensprosse, welche im Jahre 1903 geblüht haben würden. II Querschnitt einer Knolle, a Kambiumring der alten Knolle, $b, b_{1}$ neue Kambiumringe.

b) Gewöhnlich stehen die Seitenknospen mit der relativen Hauptachse, von der sie entstanden sind, in der Weise in Verbindung, daß die Leitbündel der ersteren sich an die der letzteren ansetzen. Es kann aber auch die Seitenknospe sich ganz selbständig machen und den Zusammenhang mit der Hauptachse lösen. Dies geschieht in sehr eigenartiger Weise bei Corydalis solida ${ }^{2}$ ), einer Pflanze, deren Knolle bei der Keimung aus dem Hypokotyl hervorgeht. Die Knolle besitzt einen Kambiumring. Jede solche Knolle lebt nur ein Jahr; sie wird ersetzt durch eine oder zwei neve Knollen. Gehen wir aus von einer blühbaren Pflanze, so entstehen an der Basis des blühenden Sprosses (der bei $A$ in Fig. 102 stand) eine oder zwei axilläre Seitenknospen (B B Fig. 102).

Die Infloreszenz (nebst den an ihrer Basis stehenden Blättern) stirbt nach dem Verblühen ab, und das bedingt offenbar, daß auch das zum alten Sproß ge- 
börige, in der Knolle befindliche Kambium seine Tätigkeit einstellt. Nur unterhalb der beiden Achselknospen ist dies nicht der Fall. Hier entstehen zwei neue Kambiumringe ( $b$ und $b_{1}$ Fig. $102 \mathrm{II}$ ), welche neues Knollengewebe hervorbringen. Das geschieht wesentlich auf Kosten der Reservestoffe, die in der alten Knolle abgelagert waren. Die alte Knolle wird dabei allmählich aufgesogen und das entleerte Gewebe zusammengedrückt - schließlich erscheint es nur noch in Gestalt dünner Häute.

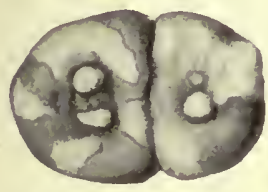

I.

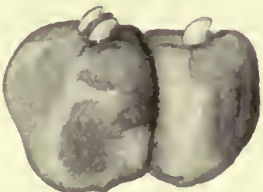

II.

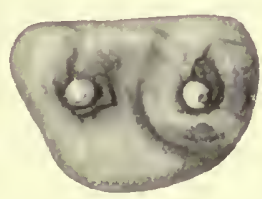

III.

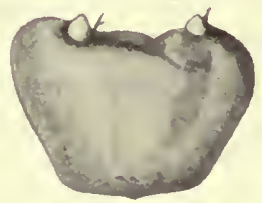

IV.

Fig. 103. Corydalis solida. Teilung der Knollen $I$ and $I I, I I I$ und $I V$, je eine Knolle in Ober- und in Seitenansicht. Bei $I$ und $I I$ ist die Teilung rollständig, bei $I I I$ und $I V$ unvollständig. Die dunkleren Häute sind Reste der vorjährigen Knolle.

Die Mittelpunkte der beiden neuen Knollen aber entfernen sich immer mehr voneinander und schließlich sind statt einer alten Knolle zwei neue entstanden (Fig. 103 I, II). Hier ist es offenbar ein von den axillären Vegetationspunkten ausgehender Reiz, welcher bedingt, daß aus einem Teile des alten Kambiumrings ein neuer sozusagen regeneriert wird. Das Eigentümliche des Vorgangs ist also das: Die Seitenknospen stehen in keiner Leitbündelverbindung mit ihrer Mutterachse. Während letztere samt ihrer Knolle abstirbt, bedingt ein von den Vegetationspunkten der Seitenknospen ausgehender Reiz, daß ein Teil des embryonalen Gewebes der alten Knolle in den Dienst der Seitenachsen tritt und zu einer neuen (kambiogenen) Knolle wird, und zwar auf Kosten des in der alten Knolle angehäuften Baumateriales. Auch eine Wurzel wird an der Basis der neuen Knolle regeneriert. Das Absterben der alten Knolle und die Beeinflussung des Kambiums durch die Vegetationspunkte der Achselsprosse wirken hier also zu dem merkwürdigen Vorgang der Knollenneubildung zusammen.

\section{$\S 12$. Einteilung der Vegetationsorgane bei den Samenpflanzen.}

Die Unterscheidung und Benennung der Pflanzenorgane ging selbstverständlich aus von den höheren Pflanzen, da man diese zuerst kennen lernte. Da der „Metamorphosenlehre" der wichtige Nachweis gelungen war, daß die scheinbar große Zahl der Organe sich zurückführen läßt auf wenige "Grundformen", so handelte es sich darum, diese voneinander abzugrenzen und sie zu charakterisieren. Unwillkürlich ging man dabei aus von den Vegetationsorganen, zumal man auch die Sporophylle der Bliite lediglich für „Blatt"organe hielt, während die Bedeutung der Sporangien erst durch Vergleich mit den Gefäßkryptogamen erkannt werden konnte.

Daß die wichtigsten Vegetationsorgane der höheren Pflanzen Wurzel, Stengel und Blatt (Laubblatt) sind, zeigt die unmittelbare Beobachtung. Man fügte diesen Organen später noch die Haargebilde oder Trichome hinzu, die Anhängsel der Oberhaut darstellen, welche aus 
Epidermiszellen entspringen. Und als sich zeigte, daß zur Bildung mancher Stacheln, Drüsen usw. auch tiefer liegende Gewebeschichten verwendet werden, schuf man für diese Gebilde die Kategorie der „Emergenzen", deren Charaktere eigentlich wesentlich negativer Natur waren, d. h. sie sind weder Blätter noch Sprosse noch Wurzeln und entstehen nicht endogen. Bei den Sprossen, Blättern und Haaren abstrahierte man von all den verschiedenen Ausbildungsformen und faßte sie als Caulome, Phyllome und Trichome zusammen.

Hier ist zunächst hervorzuheben, daß es der Morphologie nicht gelungen ist, diese Organkategorien durch scharfe, allgemein gültige Definitionen voneinander abzugrenzen, trotzdem gibt es nur selten Fälle, in denen man zweifelhaft sein könnte, in welche Organkategorie ein bestimmtes Organ gehört, oder mit anderen Worten, was seine morphologische Bedeutung, oder kïrzer gesagt, seine $\mathrm{Homologie} \mathrm{ist.}$

Ebensowenig nämlich wie in der Systematik ein einzelnes Merkmal als ausschlaggebend für die Verwandtschaft betrachtet wird, ebensowenig kann auch ein einzelnes Merkmal ausschlaggebend für die Homologie eines Organes sein, vielmehr ist das die Gruppe von Eigenschaften, die man als die morphologischen $\mathrm{zu}$ bezeichnen pflegt. Es handelt sich darum festzustellen, welche Stellung es in der Gesamtentwicklung einnimmt, welchem Organe einer verwandten Form es entspricht, durch welchen Umbildungsvorgang es zustande kam, oder mit anderen Worten, welcher Funktionswechsel eingetreten ist.

Eine der großen Schwierigkeiten, die uns bei der Definition der ve getativen Organe entgegentreten, fällt bei den Fortpflanzungsorganen weg. Die eigentlichen Fortpflanzungsorgane (Sporangien, Oogonien usw.) haben der Natur der Sache nach keinen Funktionswechsel, sie behalten ihre Funktion und Form, und darin beruht ja auch ihre Wichtigkeit für die Systematik.

$\mathrm{DaB}$ die Unterscheidung der Vegetationsorgane ursprünglich ausging von äußeren Formverschiedenheiten, ist selbstverständlich. In dem Namen "Blatt" liegt schon, daß man darunter ein flaches, plattes Organ verstand, das man dadurch von dem meist zylindrischen Stengel unterschied, während man zu den Wurzeln alle unterirdischen Organe rechnete. Es ist jetzt eine allgemein bekannte Tatsache, daß es Blätter gibt, die ganz wie Sprosse aussehen, und umgekehrt; wurden doch vielfach Blätter der Juncusarten als blattlose Sproßachsen bezeichnet, nur deshalb, weil sie in der Tat wie zylindrische, blattlose Sprosse aussehen; oft werden die Rhizoiden der Moose als "Haare" bezeichnet, anch nur, weil sie wie Haare höherer Pflanzen a ussehen, obwohl sie mit diesen sonst gar nichts zu tun haben.

Daß für eine genauere Betrachtung äußere oder Habitusähnlichkeiten nicht in Betracht kommen können, ist ohne weiteres klar. Vielmehr handelt es sich um den Gesamtaufbau der Organe, wie er sich ausspricht in ihrer ersten Anlegung, ihrer Entwicklung, ihrem anatomischen Bau und der mit diesen Eigenschaften aufs engste zusammenhängenden Funktion.

Aber auch wenn wir diese alle eingehend berücksichtigen, fragt es sich, ob wir zı einer scharfen Unterscheidung gelangen können.

Zunächst sei wiederholt, daß die genannten Organe nicht nur durch ein einzelnes Merkmal sich auszeichnen, sondern durch eine ganze Anzahl von Eigenschaften. Diese stimmen aber nicht bei allen einzelnen Blättern iiberein. Weder die Abflachung (von der die Blätter ursprünglich ihren 
Namen haben) noch der Chlorophyllgehalt noch der anatomische Bau kommen allen Blättern in gleicher Weise zu. Vielleicht aber gibt es einzelne wesentliche Merkmale, welche nicht variieren, also einen sicheren Maßstab für die Beurteilung an die Hand geben? Das soll bei Besprechung der einzelnen Organkategorien erläutert werden. Hier sei zunächst erwähnt, daß der Fortfall einzelner Eigenschaften ein Organ der Beschaffenheit eines anderen, sonst von ihm verschiedenen, annähern kann.

Das sei erörtert an Organen, welche Eigenschaften besitzen, die sonst teils Wurzeln, teils Sprossen zukommen.

\section{§ 13. Wurzel und Sproß.}

Eine Wurzel ist ron einem Sproß in den ,typischen "Fällen unterschieden durch folgenden Komplex von Eigenschaften:

1. durch Blattlosigkeit,

2. durch den Besitz einer Wurzelhaube,

3. durch endogene Entsteliung und Verzweigung,

4. durch den anatomischen Bau (radiale Struktur des Leitbiindelkörpers),

5. durch ihre kurze Streckungszone,

6. durch den Besitz der Wurzelhaare.

Dazu könnte man noch als weniger ,wesentlich" Chlorophyllmangel, Wachstum in der Erde, Unfähigkeit zu etiolieren usw. fügen.

Aber auch keines der unter 1-6 aufgezzählten Merkmale ist ein konstantes, allgemein zutreffendes Unterscheidungsmerkmal. Es gibt zwar keine blattbildenden Wurzeln ${ }^{1}$ ), aber blattlose Sprosse; wir lernten ferner schon p. 15 Sprosse mit wenigstens temporärer "Haube" kennen und ebenso gibt es auch haubenlose Wurzeln; die endogene Entstehung der Wurzeln ist keine allgemeine und die endogene Verzweigung fehlt bei den Lycopodinen; bei diesen ist auch der anatomische Bau von Wurzel und Sproß im wesentlichen ein iibereinstimmender. Die kurze Streckungszone fehlt bei Luftwurzeln und findet sich bei unterirdischen Sprossen (p. 16), und sowohl Sproßachsen wie Blätter können „Wurzelhaare" entwickeln.

Wenn ich also bei irgendeiner Pflanze ein haubenloses, blattloses und wie eine Wurzel wachsendes Organ antreffe, so kann das entweder ein stark umgebildeter Sproß oder eine abnorme Wurzel sein. Eine Entscheidung darüber ist möglich, wenn es möglich ist, das betreffende Gebilde wenigstens phylogenetisch von einem Sproß oder einer Wurzel abzuleiten. Ist dies aber nicht der Fall, so liegt eine dritte Möglichkeit vor, nämlich die, daß das in Rede stehende Organ Eigenschaften von Wurzeln und solche von Sprossen besitzt, ohne sich historisch von einem von beiden abzuleiten.

Die dogmatische Morphologie allerdings leugnet diese Möglichkeit. Sie glaubt an feste, sozusagen stereotype Organkategorien und geht so "durch die sichere Pforte zum Tempel der Gewißheit ein". - Aber nur in Gedanken!

Beispiele: Die blattlosen Sprosse von Nephrolepis wurden von manchem Botaniker für Wurzeln gehalten. Sie gehören aber zweifellos zu den Sprossen, sie stimmen in der Mehrzahl der Merkmale mit diesen überein,

1) Was man gelegentlich als solche beschrieben hat, bleibt am besten unerörtert! 
haben wie sie Spreuschuppen, ihre Seitensprosse gehen leicht in beblätterte Sprosse über. Auch die Hauptachsen der Ausläufer lassen sich (wie Sperlich nachwies) in beblätterte Sprosse iiberführen und letztere in Ausläufer (Heinricher). Sie unterscheiden sich also von Ausläufern anderèr Farne nur durch das Merkmal der Blattlosigkeit, das auch nicht unabänderlich ist.

Die blattlosen Sprosse bringen zahlreiche Wurzeln hervor und dienen so - abgesehen von ihrer Bedeutung für die ungeschlechtliche Vermehrung - als Wurzelträger. Analoge Organe treffen wir bei den Selaginellen und bei den Samenpflanzen bei den Dioscoreen. Sehen wir, ob wir auch bei ihnen die Möglichkeit der Einordnung in die Organkategorien Wurzel und Sproß haben.

\section{Wurzelträger der Selaginellen ${ }^{1}$ ).}

Alle Arten der umfangreichen Gattung Selaginella besitzen Wurzelträger, freilich in sehr verschiedener Ausbildung. Betrachten wir z. B. die in den Gärten weit verbreitete Sel. Martensii, so finden wir an ihren

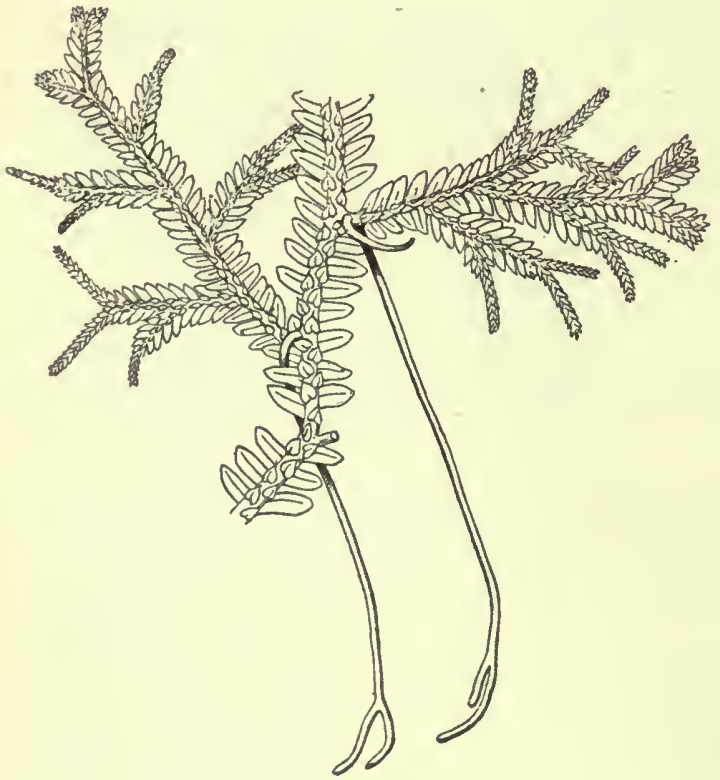

Fig. 104.

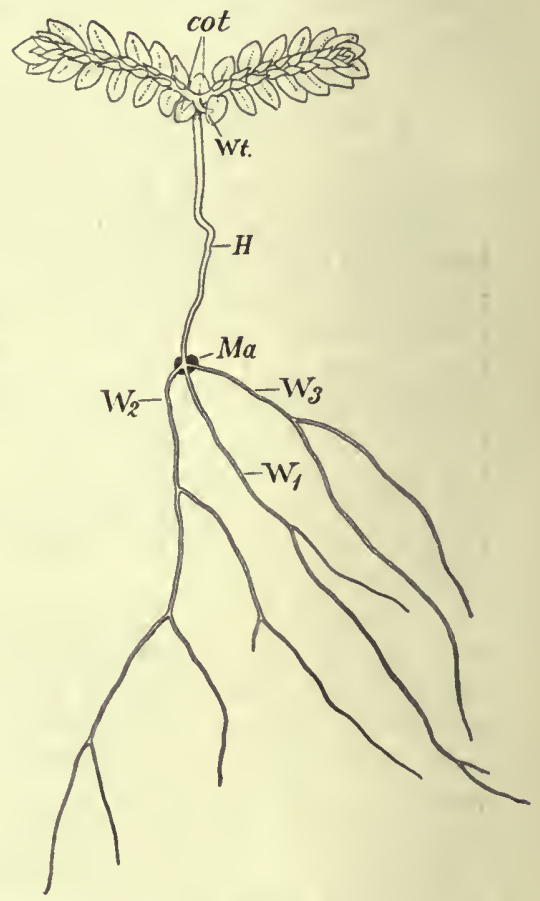

Fig. 105.

Fig. 10٪. Sproßstück von Selaginella Martensii mit Wurzelträgern.

Fig. 105. Keimpflanze von Selaginella ( ${ }_{\text {hortensis }}{ }^{4}$ ), 2 fach vergr. $\cot$ Kotyledonen, Wt junger Wurzelträger, $H$ Hypokotyl, $M a$ Makrospore, $W_{1}$ Hauptwurzel (aus dem ersten Wurzelträger entstanden), $W_{2}, W_{3}$ aus den folgenden Wurzelträgern entspringende Wurzeln.

1) Vgl. Goeber, Morphol. u. biol. Bemerkungen 16 (Flora, 95. Bd. [1905], p. 167), Bruchmans, Von den Wurzelträgern der Selaginella Kraussiana, daselbst p. 150. In diesen Abhandlungen ist auch die ältere Literatur zitiert. 
Haube, 3. dadurch, daß sie endogen Wurzeln bilden, 4. dadurch, daß sie leicht in beblätterte Sprosse übergehen können. Das kann spontan geschehen oder auch künstlich hervorgerufen werden (so durch Abschneiden der Sprosse oberhalb der Wurzelträger, oder wenn man abgeschnittene Sproßsysteme in Wasser bringt, oder wenn man im Freien kultivierte Pflanzen, deren Sprosse mit Blühen abgeschlossen haben, durch Wärme zu neuem Wachstum anregt). Regelmäßig ohne äußere Eingriffe erfolgt diese UmwandJung bei Sel. grandis (Fig. 106, 107), bei der die beblätterten Sprosse, die aus Wurzelträgern hervorgehen, die Mittelsprosse, isophyll sind wie die Bliiten; sie können sich auch als Blüten ausbilden, bleiben aber gewöhnlich klein und entwickeln sich nur bei Verletzung der Sproßsysteme-zu anisophyllen Trieben weiter. Bei den aus Umbildung der Wurzelträger entstandenen anisophyllen Sprossen ist die Oberseite (die jeweils mit kleineren Blättern versehene) der Sprosse der Sproßgabel zugekehrt ${ }^{1}$ ). Auf den anatomischen Bau soll hier nicht näher eingegangen werden.
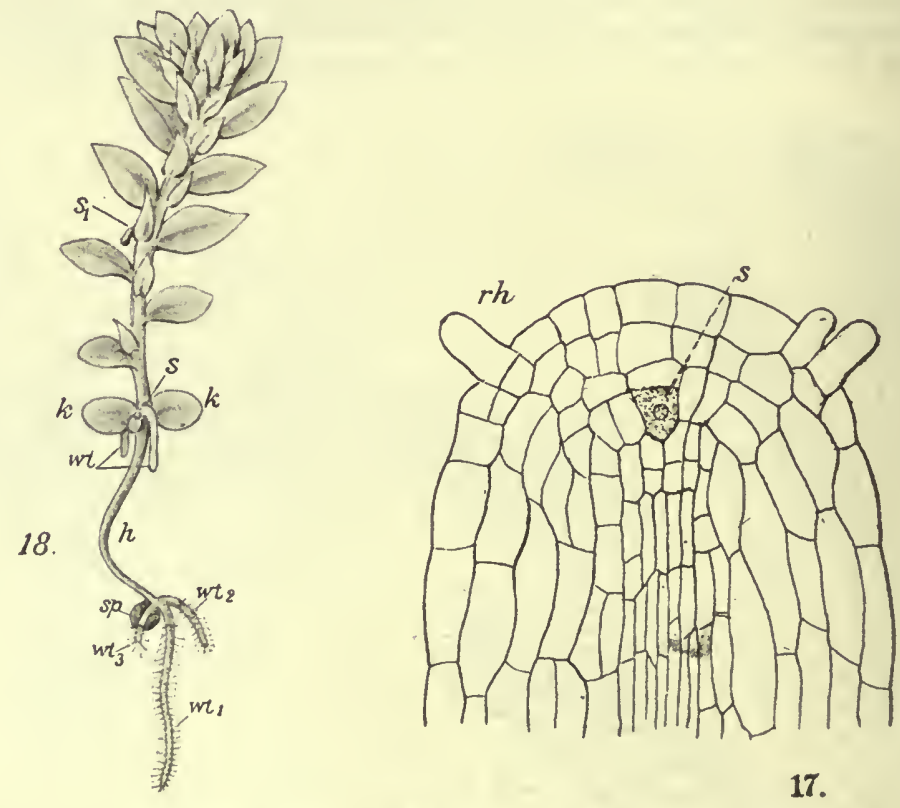

Fig. 108. Links Keimpflanze von Sel. Martensii. $s$ Makrospore, $w t_{1}, w t_{2}, w t_{3}$ Wurzelträger des Hypokotyls $h$, an denen je eine Wurzel entstanden ist, wt weiterer Wurzelträger, $s$ zurückgebliebener Gabelast oberhalb der Kotyledonen $k$. bei $S_{1}$ ein zweiter schlummernder Gabelast, unterhalb dessen sich ein Wurzelträger entwickelt hat $(6 X)$. Rechts Längsschnitt durch den ersten Keimwurzelträger, endogen hat sich eine Wurzelscheitelzelle $s$ gebildet $(340 \mathrm{X})$. Beides nach Bruchmasn.

Nun entstehen die Wurzelträger schon am (blattlosen) Hypokotyl der Keimpflanzen (Fig. 108, 109), welche abgesehen davon, daß sie sehr kurz bleiben, mit den später entstehenden ganz übereinstimmen.

Ein zwingender Grund, anzunehmen, es seien phylogenetisch die Wurzelträger der Selaginellen aus beblätterten Sprossen entstanden, liegt

1) Boshart, Beitr. zur Kenntnis der Blattasymmetrie und Exotrophie, Flora 103, (1911), p. 103. R. E. FrIEs, Et bidrag til kännedomen om Selaginella-Rotbärarna, Svensk boternisk tidskrift, Bd. 5 (1912), p. 252. 
derzeit nicht vor. Wir kennen keine Selaginellen, deren beblätterte Sprosse an ihrer Spitze Wurzeln anlegen oder an deren Hypokotylen normal (ohne Verletzung) beblätterte Sprosse entstehen. Wäre das der Fall, so würde es sehr für die Ableitung der Wurzelträger aus Sprossen sprechen. Der Verf. kam deshalb zu der Ansicht, daß die Selaginellawurzelträger betreffs der einzelnen Merkmale, die sie charakterisieren, den Sprossen näher stehen als den Wurzeln, aber phylogenetisch nicht als blattlos gewordene Sprosse aufgefaßt zu werden brauchen. Sie treten, wie Fig. 109 zeigt, am Hypokotyl schon sehr friih auf, und dieses embryonale Gestaltungsverhältnis wird auch später wiederholt. Es sind also nach unserer jetzigen Kenntnis Organe, die sowohl Eigenschaften von Sprossen haben (diese in überwiegender Zahl) als von Wurzeln (von letzteren z. B. Blattlosigkeit, Gestalt und Aufsuchen des Substrats). In diesem Sinne können wir sie als Organe bezeichnen, welche zwischen Wurzeln und Sprossen stehen. Als umgebildete Sprosse würden wir sie nur dann bezeichnen, wenn wir dafür auch in ontogenetischer oder phylogenetischer Beziehung Anhaltspunkte hätten.

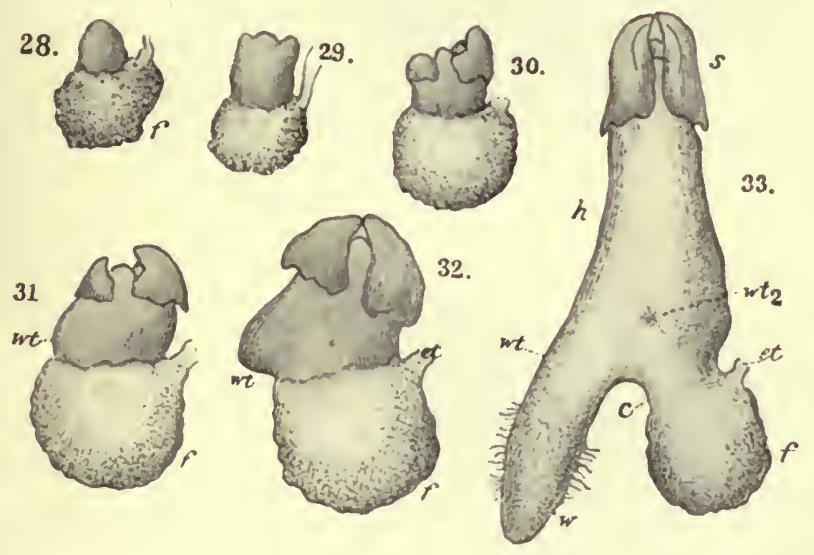

Fig. 109. Keimpflanze ron Selaginella Poulteri (nach Brochmaxn). $s$ Stammknospe mit den beiden Kotyledonen, $h$ Hypokotyl, wt erster am Hypokotyl entstandener Wurzeltrïger, an dem eine, scheinbar seine direkte Fortsetzung bildende Wurzel $w$ entstanden ist, $w t_{2}$ zweiter Wurzelträger,

$f$ Fuß, et Embryoträger.

\section{Die Knollen der Dioscoreen.}

Die Dioscoreen haben teils Arten, welche im Aufbau ihrer Vegetationsorgane dem gewöhnlichen Schema folgen, teils solche, bei welchen Abweichungen davon vorkommen. So besitzen z. B. Dioscorea quinqueloba, D. villosa, Trichopus ceylanicus kriechende, sympodial gebaute Rhizome, von denen Wurzeln nach unten und beblätterte Sprosse nach oben ausgehen. Die Organbildung ist bei ihnen also die uibliche. Andere aber sind mit sehr merkwürdigen Knollenbildungen ausgeriistet. Diese Knollen sind entweder radiär oder dorsiventral gebaut. Sie dienen einerseits als Wurzelträger, andererseits als Reservestoffbehälter und können, da sie (im Gegensatz zu den beblätterten Sprossen) sekundäres Dickenwachstum besitzen, bedeutende Größe erreichen. Von den dorsiventralen Knollen gibt Fig. 110 eine Vorstellung: Sie liegen als flache Gewebemassen auf dem Boden. Auf der Unterseite entstehen Wurzeln, das Kambium befindet sich auf der chlorophyllhaltigen Oberseite.

Die radiären Knollen mancher Formen sind äußerlich, namentlich solange sie noch jung sind, Wurzeln außerordentlich ähnlich. Sie besitzen Wurzelhaare und eine kurze Streckungszone wie die Wurzeln (Fig. 111),

Goebel, Organographie der Pflanzen. 2. Aufl. Allgem. Teil. 
unterscheiden sich von diesen aber schon durch ihren anatomischen Bau, der dem der Sprosse gleicht. Verfolgen wir das Verhalten der Keimpflanzen, z. B. bei Tamus communis Fig. 112,113, so zeigt sich, daß diese an der dem Kotyledon gegenüberliegenden Seite der Sproßachse eine Anschwellung bilden, die sich in ihrem inneren Teile rasch mit Stärke füllt, die Hauptwurzel zur Seite drängt und, nachdem sie zuerst etwa erbsenförmig war, später einer dicken Wurzel ähnlich in den Boden dringt. Der Vegetationspunkt wird durch einen Mantel von Dauergewebe geschützt, der dem Periderm entspricht. Bei der gleichfalls zu den Dioscoreen gehörigen Testudinaria elephantipes ist eine riesige oberirdische Knolle vorhanden, die man als eine allseitige (nicht wie in den anderen Fällen als eine einseitige) Anschwellung der Keimpflanzenachse betrachten kann.

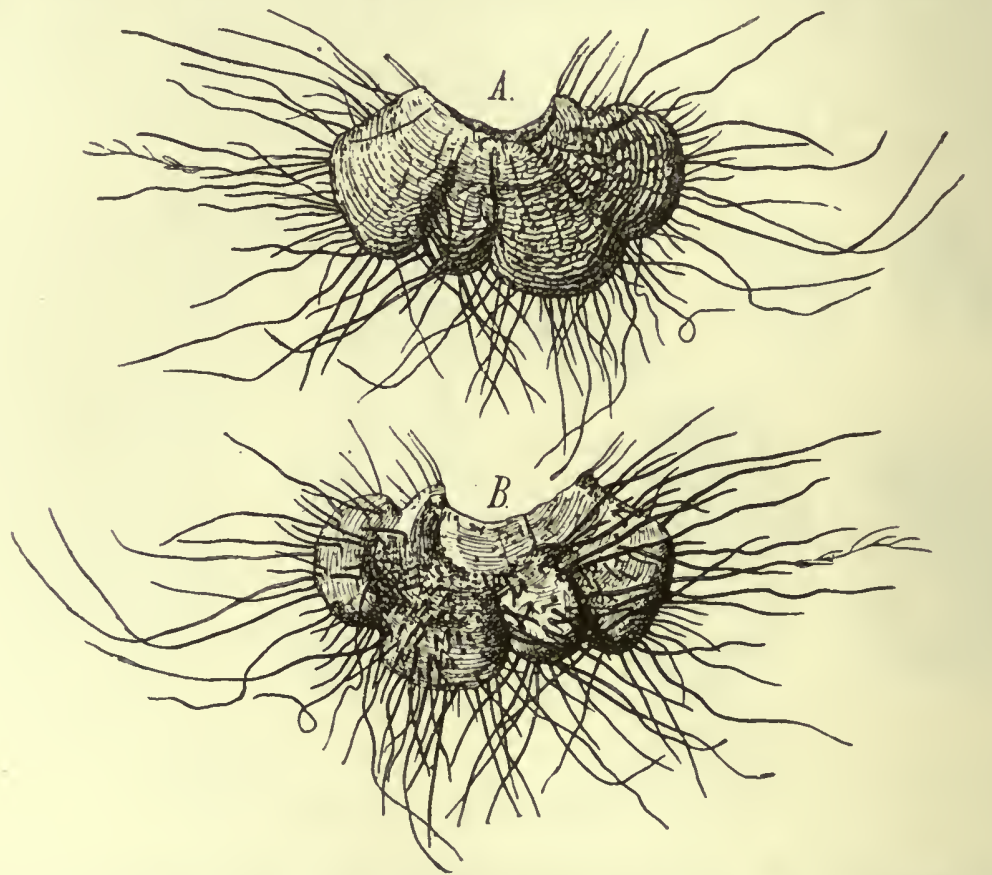

Fig. 110. Dioscorea sinuata. Von der Sproßachse abgetrenntes Knollenstiuck. $A$ von oben, $B$ von unten, $1 / 3$ nat. Gr. Die Knolle stellt eine flache, am Rande fortwachsende, kuchenförmige Masse dar, die dorsiventral ausgebildet ist.

Außerdem besitzen manche Dioscoreen oberirdische Knöllchen, die als Anschwellungen von Seitenachsen entstehen (Fig. 114) und der ungeschlechtlichen Vermehrung dienen. Sie sind, wie a. a. O. gezeigt wurde, nichts als hauptsächlich durch mangelnde Wasserzufuhr bedingte zeitweilige Hemmungsbildungen der Erdknollen. Diese Dioscoreaknollen haben also ähnlich den Wurzelträgern der Selaginellen Sproßcharaktere (überwiegend) und Eigenschaften, in welchen sie Wurzeln gleichen. Eine Umbildung in beblätterte Sprosse ist bis jetzt bei ihnen nicht gelungen, dagegen bilden selbst Teilstücke bei manchen, z. B. D. batatas leicht Adventivsprosse.

Bei einigen Dioscoreen findet die Knollenbildung an der Spitze bestimmter Wurzeln statt (z. B. Diosc. eburnea). Es tritt hier eine mit einer Strukturveränderung verbundene knollenförmige Anschwellung auf. An der Knolle entstehen später endogen Sprosse. Sehen wir von diesen 
Formen ab (vgl. Anmerkung $\left.{ }^{1}\right)$ ), so läßt sich sagen: die Knollenbildung der Dioscoreen ist ermöglicht durch das Auftreten eines Kambiums an be-
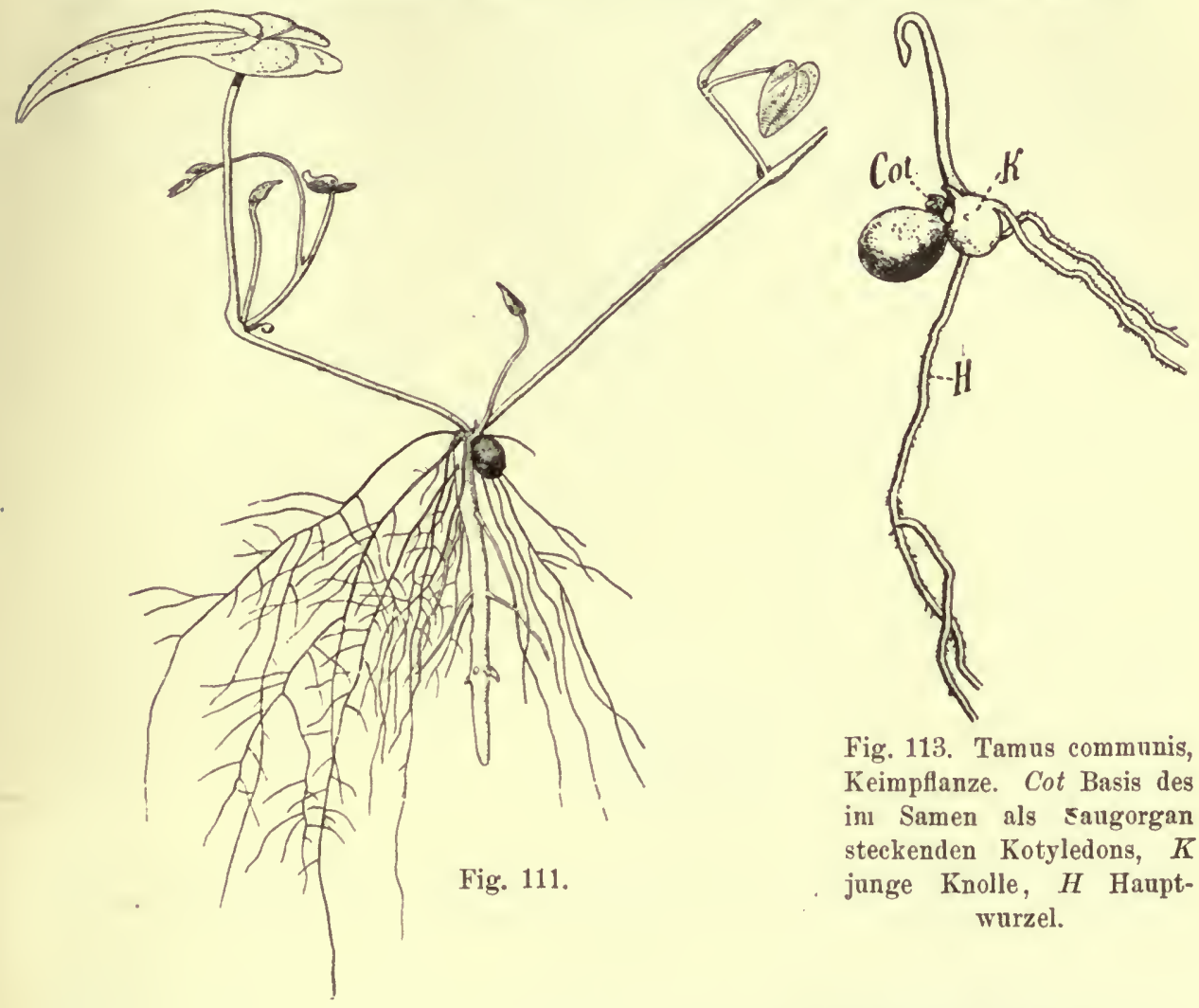

Fig. 113. Tamus communis, Keimpflanze. Cot Basis des inı Samen als saugorgan steckenden Kotyledons, $K$ junge Knolle, $H$ Hauptwurzel.

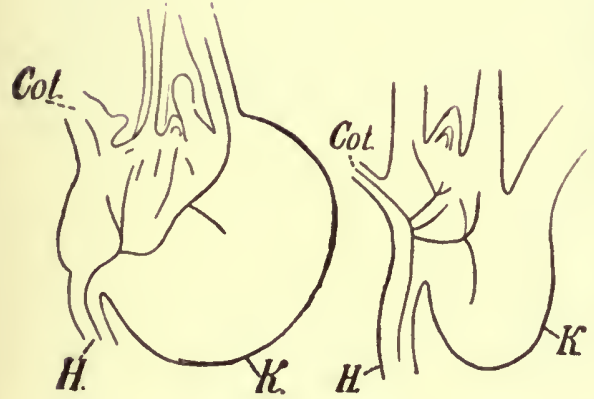

Fig. 112 .

Fig. 111. Dioscorea alata. Junge Pflanze, die sich aus einem Luftknöllchen (dunkel gehalten, rechts) entwickelt hat. Am Knöllchen sind einige W'nrzeln entstanden. Die Mehrzahl der Wurzeln aber entspringt aus der neuen, wurzelähnlichen Knolle (hell gehalten), die an der Stammbasis entstanden ist ( $1 / 2$ nat. Größe).

Fig. 112. Links Längsschnitt durch eine Keimpflanze von Tamus communis, rechts durch eine solche von Dioscorea sinuata. Cot Basis des Kotyledons, $K$ Knöllchen, $H$ erste Wurzel.

1) S. Linninger (Über den morphologischen Wert der an Wurzeln entstehenden Knollen einiger Dioscoreenarten. Beih. z. botan. Zentralblatt, Bd. XXI, 1907) ist der Meinung, bei der an den Wurzelspitzen entstehenden Knollenbildung (welche durch eine sehr starke primäre Zellvermehrung im Vegetationspunkt zustande kommt) sei nicht der morphologische, sondern der physiologische Wert geändert. Die Knolle sei eine Wurzelknolle. Es handelt sich dabei wesentlich um die Frage, wieweit die anatomischen Veränderungen, die mit der Knollenbildung verknüpft sind, sich dem Sproßbau nähern. Von dem oben vertretenen Standpnnkt ans ist die Frage nicht von besonderer Bedeutung, es ist auch ganz gat möglich, dab bei den Dioscoreen Knollenbildung anf zwei verschiedenen Wegen erfolgt. 
stimmten Stellen der Sproßachsen. Die Knollen nehmen die verschiedenste Form an, ihre physiologische Funktion ist aber überall im wesentlichen dieselbe, sie sind einerseits Reservestoffbehälter, andererseits Wurzelträger. Sie treten, wie die Selaginellawurzelträger schon früh an der Keimpflanze auf, haben wie diese eine überwiegende Mehrzahl von Sproßmerkmalen (jedoch können sie, soweit bis jetzt bekannt, nicht direkt in Sprosse übergeführt werden), aber auch solche Wurzelmerkmale, daß botanische Autoritäten (z. B. J. Sachs) sie ohne weiteres als Wurzeln betrachtet haben. Gelingt

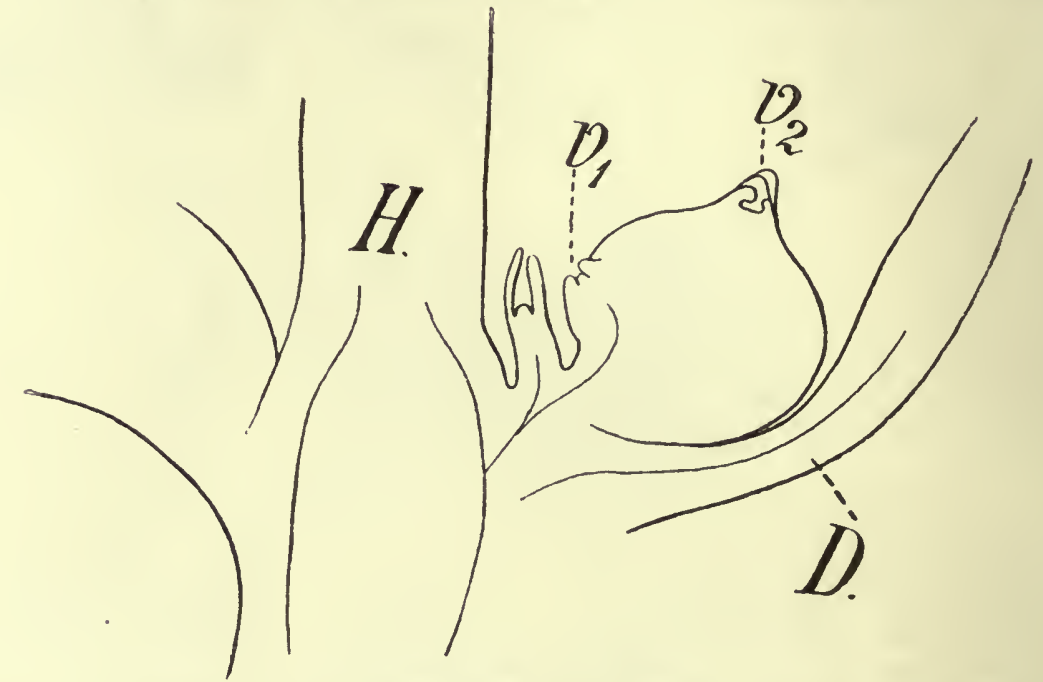

Fig. 114. Längsschnitt durch einen Sproß von Dioscorea japonica. $H$ erste Achse, $D$ Blatt, in dessen Achsel sich ein Luftknöllchen mit zwei Vegetationspunkten, $\nabla_{1}$ und $V_{2}$, gebildet hat.

es, ihre Ableitung von Sprossen darzutun, so kann man sie als stark umgebildete, ganz blattlos gewordene Sprosse bezeichnen. Solange dies nicht möglich ist, und solange nicht bewiesen ist, daß ein Organ, das kein Blatt und für die "Emergenzen" zu vornehm ist, entweder ein Sproß oder eine Wurzel sein " mu B, werden wir gut tun, wie bei den Selaginellawurzelträgern zu sagen: die Dioscoreenknollen haben von Sprossen die Eigenschaften $a, b, c, d \ldots$ ron Wurzeln $k, m \ldots$

\section{§ 14. Blatt und Sproß.}

Sehen wir von der äußeren Gestalt und dem anatomischen Bau (der bei den Symmetrieverhältnissen zu erwähnen sein wird) ab, so kommt hier zunächst in Betracht die verschiedene Entwicklungsdauer. Die Blätter sind meist Gebilde begrenzten Wachstums, die Sprosse nicht. Nun giebt es freilich viele Sprosse, die normal gleichfalls begrenztes Wachstum besitzen wie die Kurztriebe mancher Nadel- und Laubhölzer, aber diese können veranlaßt werden, sich $\mathrm{zu}$ unbegrenzt wachsenden Trieben, zu Langtrieben umzubilden. Sie sind von denselben nicht spezifisch verschieden; die Begrenztheit der Entwicklungsfähigkeit wird ihnen nur durch ihre Stellung im Gesamtbau aufgeprägt. Freilich wissen wir nicht, $o b$ dies für alle Kurztriebe gilt. Es ist wahrscheinlich, daß z. B. die nadelförmigen, blattlosen, als Assimilationsorgane dienenden Kurztriebe von Asparagus von vornherein als Sprosse begrenzter Entwicklung ange- 
legt werden, daß also auch hier sich dieselbe Abstufung in der Organbildung findet, der wir noch oft begegnen werden.

Sie findet sich auch bei niederen Pflanzen. Die „Blätter" von Chara z. B. sind nichts anderes als Kurztriebe, aber es ist, soweit wir bis jetzt wissen, unmöglich sie zu Langtrieben umzubilden und unwahrscheinlich,

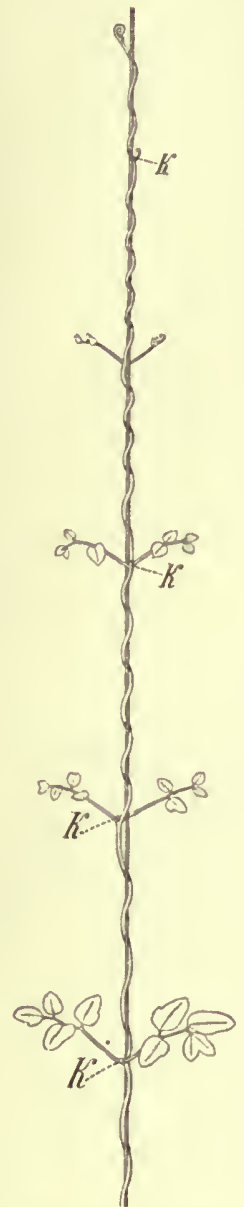

Fig. 115. Lygodium polymorphum.

Spitze eines an einem Bindfaden emporkletternden Blattes. $K$ ruhende Spitzen der Fiedern (verkleinert).

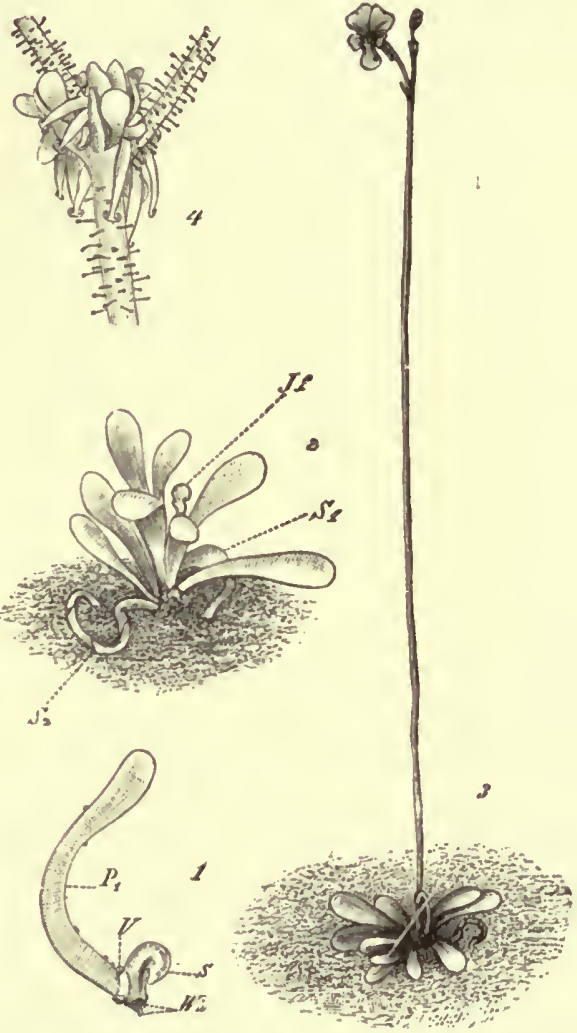

Fig. 116. Genlisea violacea. 1 Keimpflanze mit 3 Blättern, vergr., $P_{1}$ erstes Laubblatt, $S$ Schlanchblattanlage, $V$ Vegetationspunkt, $W h$ Wurzelhaare. 2 Altere Keimpflanze etwa 3 mal vergr. Sie hat anßer einer Anzabl Laubblätter 2 Schlauchblätter $S_{1}$, aus $S_{2}$ gebildet, die in den Boden eingedrungen sind. $J f^{\prime}$ terminale Infloreszenz. 3 Dieselbe Pflanze (nat. Größe) später, an der Basis der ersten Infloreszenz hat sich eine zweite gebildet. 4 Stück einer Infloreszenz mit regetativem Sproß, die zweiarmigen jungen Schlauchblätter nach unten gerichtet.

daß dies je gelingen wird. Ebenso ist es bei den Samenpflanzen niemals gelungen, ein Blatt künstlich zu unbegrønzter Entwicklung zu veranlassen. Wohl aber macht die Natur selbst dies Experiment. Sie zeigt uns bei einigen Farnen Blätter, die mehrere Vegetationsperioden hindurch an ihrer Spitze weiter wachsen, und in viel auffallenderem Maße ist dies der Fall bei der zu den merkwürdigsten Pflanzen der Erde gehörenden Gattung Utricularia. 
Es sei zunächst auf die merkwürdige Blattbildung des Farnkrautes Lygodium hingewiesen. Aus dem kriechenden Rhizom erheben sich hier Blätter, die an ihrer Spitze sehr lange fortwachsen, und wie Schlingpflanzen an Stützen emporwindend eine Länge von mehreren Metern erreichen können.

Der obere Teil eines solchen Blattes ist in Fig. 115 abgebildet. Das Blatt bringt Seitenfiedern hervor, an denen sich zunächst nur die abstehenden Basalfiedern zweiter Ordnung entwickeln, die dem Blatt ermöglichen, auch ohne "Stütze eine Strecke weit als "Spreizklimmer" emporzuklettern. Der Vegetationspunkt dieser Seitenfiedern geht dagegen zunächst in einen Ruhezustand über ( $K$ Fig. 115). Dieses Blatt verhält sich wie ein Sproß nicht nur durch sein lange andauerndes Spitzenwachstum, sondern auch dadurch, daß die „Knospen" der Seitenfiedern sich zur „Endknospe" des Blattes (der wachsenden Blattspitze) ganz ähnlich verhalten wie die Seitenknospen eines Sprosses zu dessen Endknospe. Schneide ich nämlich die wachsende Endknospe des Blattes ab, so werden dadurch die obersten "Seitenknospen" zum Austreiben angeregt und entwickeln sich zu kräftigen schlingenden Blatteilen. Bei Lyg. japonicum trieben an Blättern, die den Winter über braun, vertrocknet und abgestorben schienen, die „Seitenknospen" der Blätter wieder aus ganz wie ruhende Knospen eines überwinternden blattlos gewordenen Sprosses. Ohne Zweifel haben also diese Blätter einzelne Sproßeigenschaften.

In anderer Art - durch interkalares Wachstum - zeigen die Blätter von Welwitschia mirabilis, daß Begrenztheit des Wachstums nicht allen Blättern eigentümlich ist.

Ein noch viel auffallenderes Beispiel findet sich bei den Dikotylen, und zwar bei der Gattung Utricularia. Die Gattung besitzt teils auf dem Lande, teils im Wasser lebende Arten. Alle sind wurzellos wie die in der Einleitung behandelte in dieselbe Familie gehörige Genlisea. Wie bei dieser sind bei den Landformen die Blätter teils noch als Laubblätter ausgebildet, teils zu ganz abweichender Gestaltung und Funktion gelangt.

Utricularia gehört zu der Familie der Lentibulariaceen, deren sämtliche Gattungen Insektivorie betreiben. Pinguicula zeigt die "normale" Gliederung des Vegetationskörpers der Samenpflanzen, Wurzel und beblätterten Sproß. Die anderen Gattungen sind wurzellos. Die Funktion der Wurzeln wird bei Genlisea ${ }^{1}$ ) durch die zugleich als Insektenfallen dienenden, höchst merkwürdigen Schläuche ersetzt, welche wie sonst die Wurzeln in das Substrat eindringen (vgl. Fig. 116, 1); es kann keinem Zweifel unterliegen, daß diese Schläuche umgebildete Blätter sind (vgl. S. 2).

Bei Polypompholyx und einigen (aber offenbar nur der Minderzahl) der auf dem Lande lebenden Utriculariaarten finden wir folgende Organbildung. Als Beispiel diene die in Westaustralien gesammelte Utricularia Hookeri $^{2}$ ) (Fig. 117). Aus dem Samen geht ein an seiner Spitze in einen Blütenstand übergehender radiärer Sproß hervor, der, abgesehen von den Blïten und den Hochblättern folgende Organe trägt: 1. Laubblätter, 2. Schläuche, die als Tierfallen dienen, 3. langgestreckte, aber

1) Vgl. Einleitung, ferner S. II und zur Biologie von Genlisea, Flora, 1893, 77. Bd., p. 208.

$\left.{ }^{2}\right)$ Derartige einfach organisierte Utricularien waren mir bei meinen früheren Untersuchungen nicht bekannt, sie wurden zuerst in der 1. Aufl. dieses Buches beschrieben. Ganz ähnlich verhält sich Polypompholyx (vgl. LANG in Flora 88 (1901), p. 149). Die Gestaltungsverhältnisse von Utricalaria wurden geschildert in Flora, 1889 (der Aufbau von Utricularia) und "Morpholog. und biolog. Studien" (Annales du jardin botanique de Buitenzorg, Vol. IX and S. II). Vgl. ferner v. LoEtzelBung, Beitr. zur Kenntnis der Utricularien, Flora 100 (1909). Daselbst weitere Literatur. 
unverzweigte und schlauchlose, dünnen Wurzeln gleichende Bildungen, wir wollen sie "Blattwurzeln" nennen. Diese stecken wie die Schläuche im Substrat (feuchtem Boden), die Laubblätter erheben sich an das Licht.

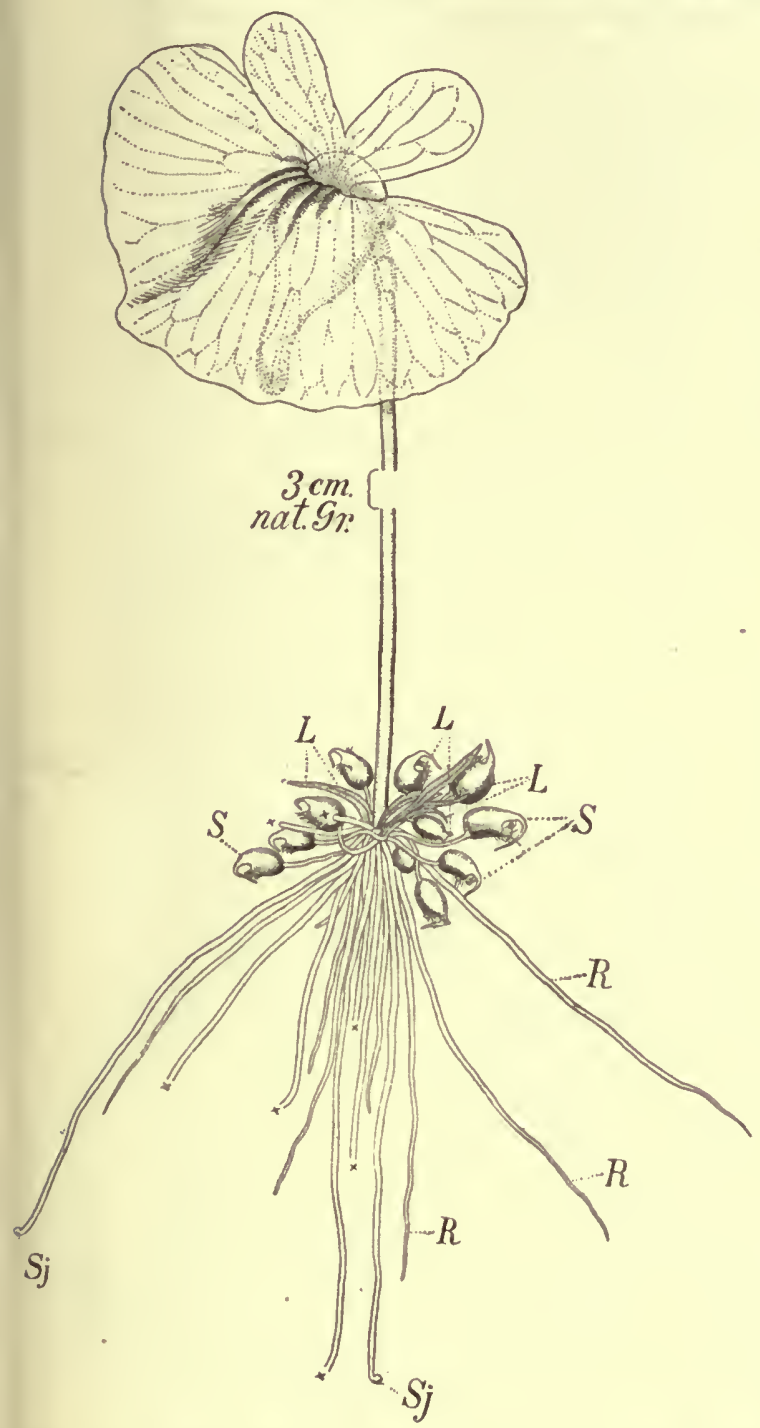

Fig. 117. Utricularia Hookeri, blühende Pflanze 3 mal vergr. (Im Schaft ein $3 \mathrm{~cm}$ langes Stïck ausgelassen.) $L$ schmale Laubblätter, $S$ Schläuche, $R$ Blattwurzeln (Rhizophylle), Sj junge Schläuche am Ende ron Blattwurzeln (bei $X$ abgebrochene Enden).

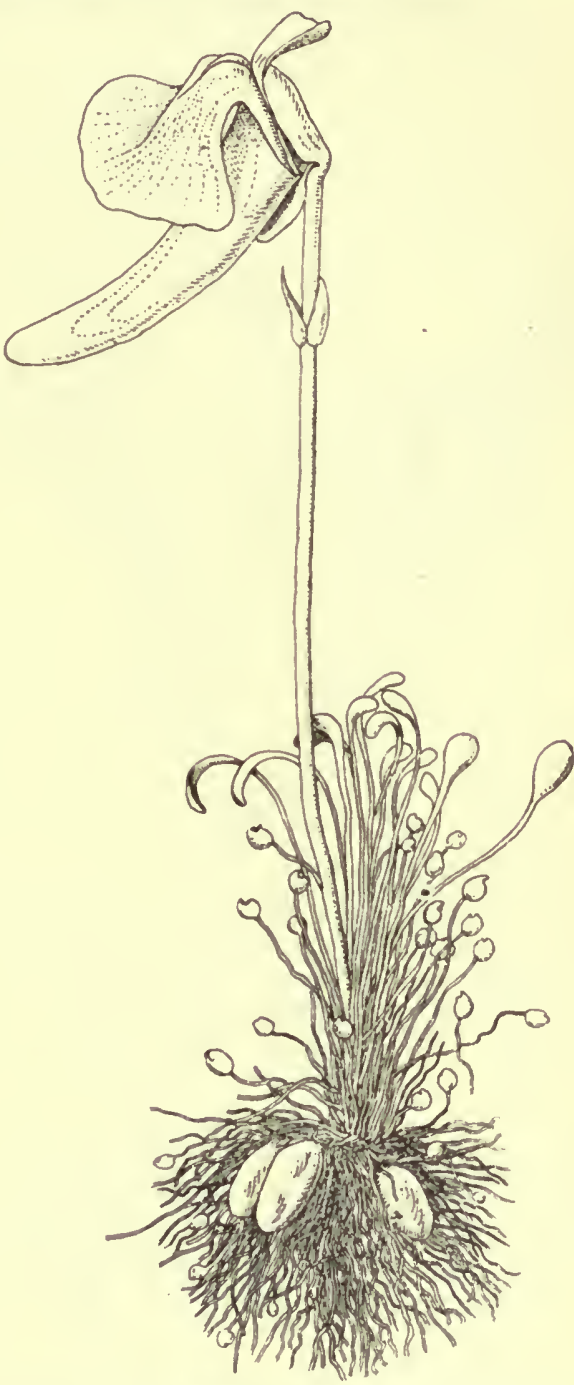

Fig. 118. Utr. Menziesii, aus dem Substrat freipräparierte Pflanze mit spatelförmigen uber das Substrat hervortretenden Blättern, langgestielten Blasen und meist an der Spitze abgerissenen Blattwurzeln, von denen drei zu Knollen angeschwollen sind.

Hier ist also die bei Genlisea ron den Schlauchblättern geleistete Doppelfunktion (Tierfallen und Haftorgane resp. Wasseraufnahme) auf zwei Organe verteilt: die Schlauchblätter und die Blattwurzeln. Beide stehen einander aber noch sehr nahe, beide sind umgebildete Blätter, die Stiele der Schläuche gleichen sehr den Blattwurzeln und nicht selten findet am 
Ende langgestreckter Blattgebilde, die man zunächst für Blattwurzeln zu halten geneigt war, noch Schlauchbildung statt (siehe Fig. 117).

Umbildung von Blättern zu Schläuchen finden wir auch sonst vielfach, sie ist also nichts Besonderes. Die „Blattwurzeln" (die nur für einige

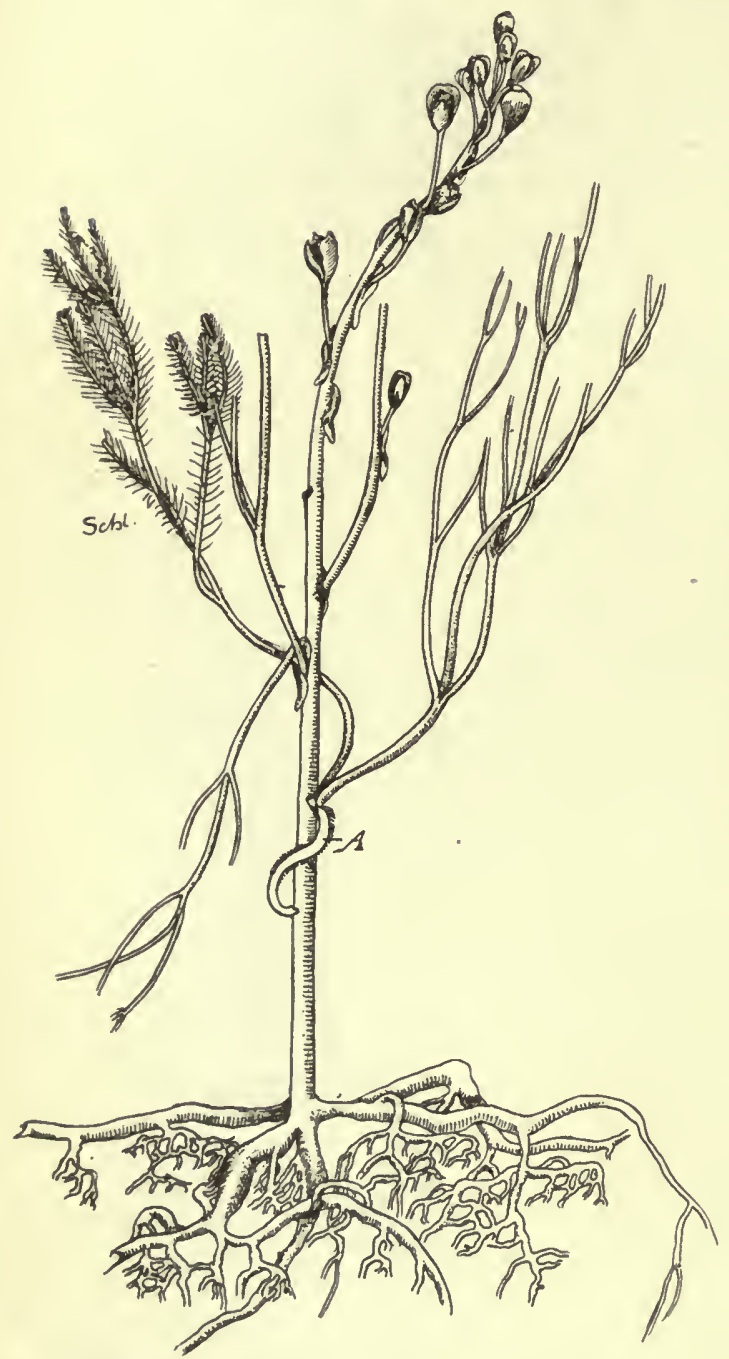

Fig. 119. Utricularia neottioides (nach Loetzelburg, vergr.). Blühende Pflanze, die an ihrer Basis dnrch netzartig verwachsene Haftorgane am Substrat festsitzt. Die Pflanze wächst in fließendem Wasser, damit steht Droseraceen bekannt ${ }^{1}$ ) sind) unterscheiden sich immerhin nicht sehr auffallend von den Blättern der Utric. Hookeri: sie behalten das auch bei diesen zunächst (wenngleich nur ganz kurz) vorhandene Spitzenwachstum länger bei und bleiben - wie dies bei nicht an das Licht tretenden Organen ja auch sonst bekannt ist schmäler als die Laubblätter. Bei Utric. Menziesii - einer anderen australischen Art - sind einzelne „Blattwurzeln“ zu Knollen angeschwollen, die als Reservestoffbehälter (für Wasser u. a.) dienen, was bei den unten zu erwähnenden "Ausläufern" einiger epiphytischer Arten wiederkehrt.

Der Unterschied gegenüber Genlisea ist also hier kein großer. $\mathrm{Ob}$ man die Blattwurzeln von Schlauchblättern, die keine Sçhläuche mehr ausbilden oder direkt von den Blättern ableiten soll, mag hier unerörtert

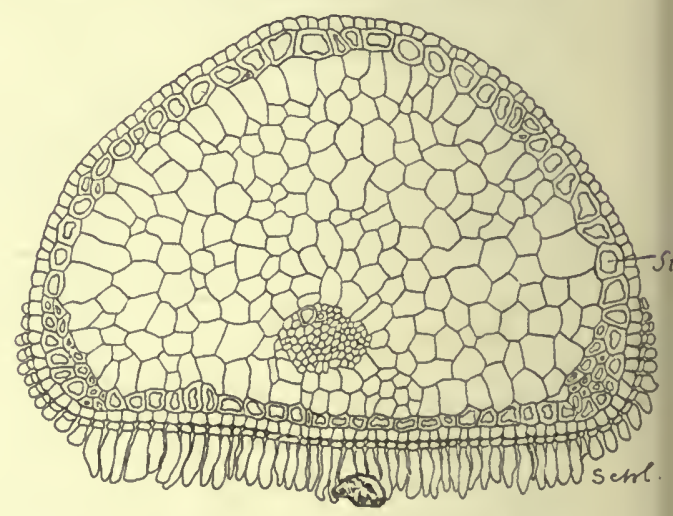

Fig. 120. Querschnitt eines Rhizomrastes ron U neottioides. Man sieht, daß er dorsiventral gebaut uı mit Schleimhaaren auf der Unterseite befestigt i: (Nach Luetzelburg.) ihre Organbildnng in Beziehung.

bleiben, zumal die verschiedenen Utricularien sich in dieser Beziehung vielleicht verschieden verhalten haben.

Diese Utricularien sind für ihre Verbreitung (soweit wir derzeit wissen) ausschließlich auf die Samen angewiesen. Wahrscheinlich stellen sie ver-

1) Vgl. L. Diels, Droseraceae in Engler, das Pflanzenreich (IV. 112) Heft 26. 1906. 
hältnismäßig kurzlebige Formen dar, welche nur in der feuchteren Jahreszeit vegetieren. Als "primitiv" erscheinen sie uns einerseits wegen des Vergleichs mit Genlisea, andererseits wegen der Übereinstimmung mit dem Jugendstadium anderer Utricularien, bei welchen die den Blattwurzeln entsprechenden Organe zu unbegrenzt wachsenden Ausläufern geworden sind, welche Blasen, Laubblätter, Blütenstände und andere Seitensprosse entwickeln. Sie verlieren so den Blattcharakter vollständig.

Sehen wir z. B. die in Fig. 121 abgebildete Utr. affinis an, so finden wir an der Basis der Infloreszenz keine Laubblätter mehr vor (bei der Keimpflanze waren sie auch hier sicher vorhanden), sondern nur den Blattwurzeln entsprechende Organe $(K)$, sowie Ausläufer, die Blätter $(b)$ entwickelt, und sich verzweigt haben. Die Blattwurzeln können in Ausläufer

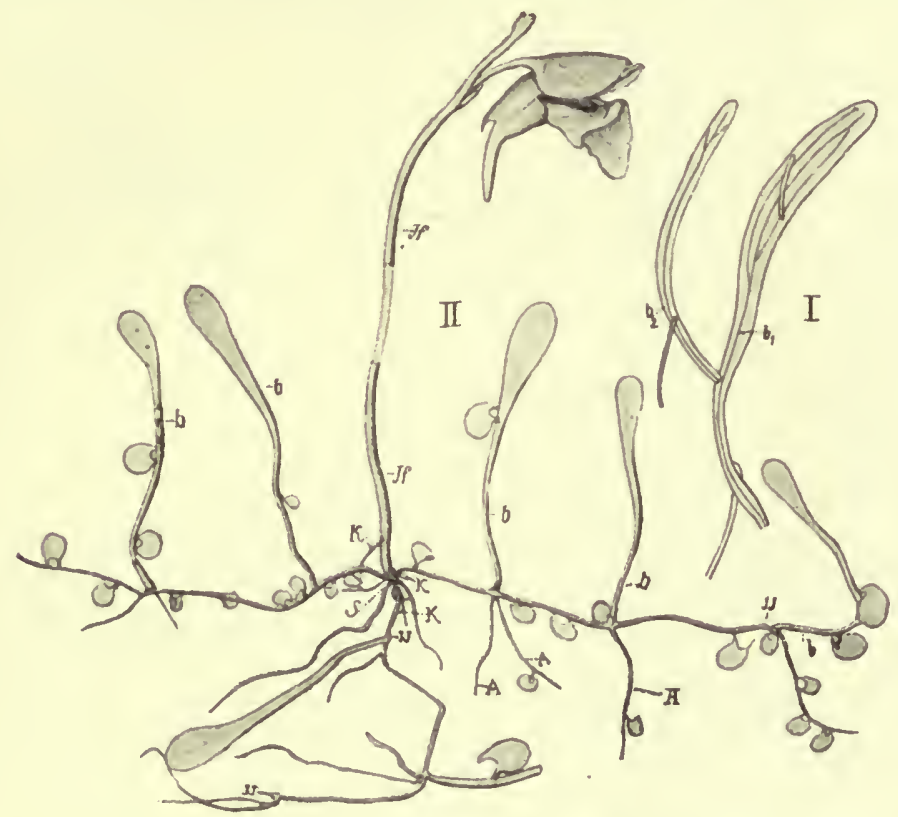

Fig. 121. I Utric. coeruca (vergr.). Blatt $\left(b_{1}\right)$, aus dem ein Ausläufer und ein zweites Blatt $\left(b_{2}\right)$ hervorgesproßt ist. II Habitusbild von Utr. affinis (vergr.), blühende Pflanze (die Blüte etwas verbogen), der unten die Samenschale noch ansitzt ( $S$ ), Laubblätter sind an der Basis der Infloreszenz nicht mehr vorhanden, sondern nur beblätterte Ausläufer und Blattwurzeln $K$.

übergehen und zwischen diesen und den Laubblättern gibt es bei manchen Arten alle Übergänge, wofür a. a. O. zahlreiche Beispiele angeführt wurden. Die Blätter sind überhaupt durch ein staunenswertes Reproduktionsvermögen bei manchen Arten ausgezeichnet, Ausläufer, ja selbst neue Blätter können aus den Blättern entspringen (Fig. 121 I), die Ausläufer ihrerseits können sich zu krallenähnlichen, der Substanz angeschmiegten Haftorganen, z. B. Utr. neottioides (Fig. 119, 120), und zu knöllchenförmigen Wasserspeichern gestalten, kurz es ist das gewöhnliche Schema der Organbildung hier ganz über den Haufen geworfen. Die Betrachtung der Keimung aber und der entwicklungsgeschichtliche Vergleich haben den Ausgangspunkt aller dieser wunderbar mannigfaltigen Verhältnisse erkennen lassen. Die Keimpflanzen haben auch bei den meisten untersuchten Arten 
das Verhalten beibehalten, das z. B. Utr. Hookeri zeitlebens zeigt, d. h. hier stehen die Schläuche als umgebildete ganze Blätter an der Hauptachse, während wir sie bei vielen anderen Arten auch an den Blättern antreffen. Auch die an den Keimpflanzen entstehenden Ausläufer gleichen zunächst den „Blattwurzeln", später verzweigen sie sich dann in der oben erwähnten Weise.

Die Gründe, welche uns die so verschieden gestalteten, oben besprochenen Organe der Landutricularien als „Blätter" erscheinen lassen, mögen hier kurz zusammengefaßt werden, um so mehr, als sie in der neueren Literatur mehrfach unrichtig ${ }^{1}$ ) dargestellt wurden.

1. Keinem Zweifel kann unterliegen, daß die "Blätter" und „Ausläufer" einander gleichwertig sind.

Denn: a) Sie stimmen in der Stellung überein; bei manchen Landutricularien z. B. entstehen am Embryo ein Blatt und ein Ausläufer, letztere beide in derselben Stellung.

b) Ein Blatt kann an seiner Spitze in einen Ausläufer übergehen, ein Ausläufer in ein Blatt.

c) Sie können sich gegenseitig vertreten. Die Keimpflanze von Utr. exoleta bringt normal zwei Blätter hervor -- statt deren können auch Ausläufer auftreten. Ebenso können Ausläufer statt der Deck- und der Vorblätter. von Blüten vorhanden sein.

d) Auch in der anatomischen Struktur findet sich keine Differenz.

2. Es handelt sich also nur darum, ob die ..Blätter" von Utricularia Phyllokladien oder die Ausläufer eigenartig reränderte Blätter sind. Da nun die Blattnatur der Deck- und Vorblätter zweifellos ist, da ferner die Ausläufer nicht wie Phyllokladien in der Achsel von Blättern auftreten, so ergibt sich die oben gezogene Schlußfolgerung, wonach hier die aus Blättern hervorgegangenen Ausläufer so viel Sproßcharakter angenommen haben, daß die Unterscheidung von Sproß und Blatt überhaupt aufhört.

3. Die einfachen Utricularien wie Utr. Hookeri, Utr. Menziesii sowie (die von Utricularia wohl kaum abtrennbare Gattung) Polypompholyx zeigen eine Organbildung, die im wesentlichen mit der bei Keimpflanzen anderer Landformen auftretenden übereinstimmt, ebenso im wesentlichen mit der von Genlisea. Es ist unschwer vorzustellen, wie von hier aus die Weiterentwicklung stattfand, die wir bei anderen Utricularien finden. Ebenso ist der Unterschied zwischen den einfachen Blättern der Landpflanzen und den geteilten der Wasserpflanzen ein fließender: Utricularia Humboldti und Utr. reniformis zeigen, wie aus einem "ganzen" Blatt ein geteiltes Wasserblatt entstehen kann und durch das Weiterwachsen eines Zipfels des letzteren ein WassersproB. Indes kann auf diese Fragen hier nicht eingegangen werden. Erwähnt sei nur, daß auch im anatomischen Bau der Sproßachsen Utricularia sich als eine Pflanze zeigt, die sozusagen ihre eigenen Wege geht. Die normale Ausbildung des Leitbündelsystemes ist in der Sproßachse der Landutricularien aufgegeben. Auch die Samenentwicklung hat ihre Besonderheiten. Die Gattung hebt sich so als eine eigenartige von all den vielen anderen Dikotylen ab, welche in ihrer Organbildung das übliche Verhalten zeigen. Es wurde in der 1. Auflage dieses Buches darauf hingewiesen, daß der Tierfang, welcher Utricularia von dem Kampf um die Nahrung zwischen autotrophen Pflanzen unabhängiger macht, ihr wahrscheinlich erlaubt hat, sich ihrem "Gestaltungstrieb" freier hinzugeben, als dies sonst möglich wäre.

1) So von Baumanx (vgl. die Berichtigung in Flora 101. Bd.). 
Sahen wir so an zwei Beispielen, daß die "begrenzte" und „unbegrenzte" Entwicklung kein allgemeines Unterscheidungsmerkmal zwischen Blättern und Sprossen abgibt, so gilt dasselbe auch für die erste Anlegung der Blätter. Denn der Satz, daß Blätter als seitliche Auswïchse an einem Vegetationspunkt angelegt werden, gilt zwar für die Mehrzahl der untersuchten, aber keineswegs für alle Pflanzen.

Sehen wir ab von den Kotyledonen, welche unabhängig vom Sproßvegetationspunkt entstehen, so seien hier folgende Beispiele angeführt:

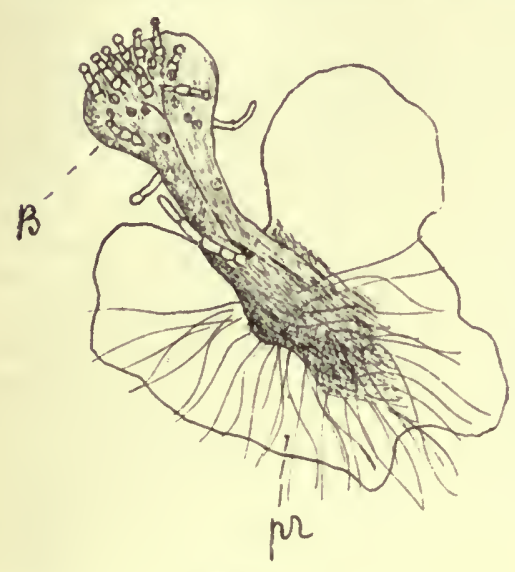

Fig. 122.

Fig. 122. Notochlaena sinuata. Prothallium $p r$, an dem apogam ein Blatt $B$ ohne Sproßregetationspunkt entstanden ist (nach HeL. Worosis).

Fig. 123. Notochlaena sinuata. Am Prothallium ist ein verkümmertes Blatt $v k$ entstandelı, an diesem ein zweites Blatt $B$ (nach H. Woronis).

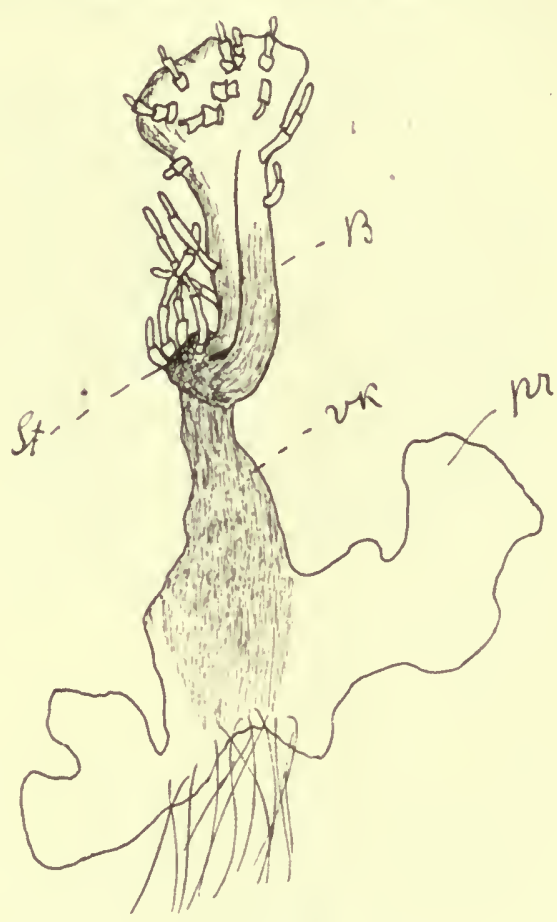

Fig. 123.

1. Farne. a) An den Prothallien, welche „apogame“ Sproßbildung zeigen, entsteht das erste Blatt vor und unabhängig von dem Sproßvegetationspunkt, an dem die späteren Blätter sich entwickeln. Bei Notochlaena sinuata $^{1}$ ) kann sogar auf dem ersten verkümmerten Blatt ein zweites sich bilden, aus welchem dann erst der Stammscheitel entspringt.

b) Eine Anzahl von Farnen haben Blätter, deren Spitze in eine beblätterte Knospe übergeht. Die ersten Blätter der letzteren entstehen ehe der Sproßvegetationspunkt differenziert ist, unabhängig von letzterem, ebenso ist es, wie Doposcheg gezeigt hat, auch an den Adventivsprossen einiger Farne.

2. Sam enpflanzen. a) Lassen wir das Verhalten von Utricularia und das Auftreten von Blättern an den der Sproßvegetationspunkten beraubten Hypokotylen von Cyclamen ${ }^{2}$ ) beiseite, so sind namentlich folgende Pflanzen zu erwähnen.

2) Goeber, Über Regeneration im Pflanzenreich, Biolog. Centralblatt 22 (1902), p. 483. 
a) An Embryonen von Monokotylen, z. B. Triticum ${ }^{1}$ ), ist bei der Entstehung der ersten Blätter ein Sproßvegetationspunkt nicht wahrnehmbar. Ältere Pflanzen dagegen zeigen einen solchen wohl entwickelt. Dies ist ron Interesse, weil, was hier nur im Jugendstadium auftritt, zum dauernden Verhalten geworden ist bei

b) den Lemnaceen. Deren Verhalten soll bei Besprechung der Jugendformen Erwähnung finden.

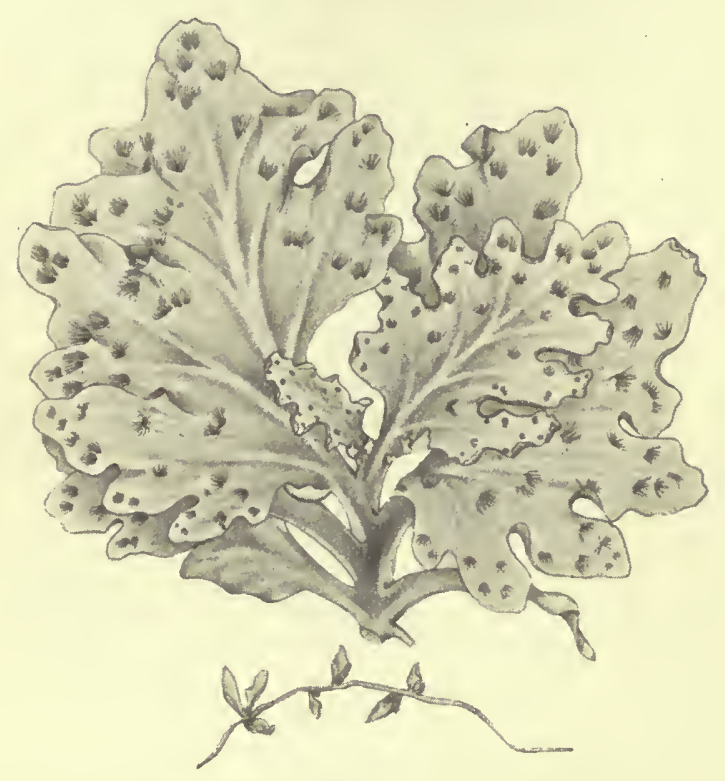

Fig. 124. Oben: Oenone latifolia (verkl.). Unten: Wurzel mit Adventivsprossen (auf die Hälfte verkleinert). c) Handelt es sich bei den Lemnaceen um verhältnismäßig kleine Wasserpflanzen, so läßt sich doch der Mangel eines Vegetationspunktes nicht mit der geringen Körpergröße in Verbindung bringen. Denn dasselbe Verhalten findet sich auch bei einer Anzahl stattliche Größe erreichender Podostemaceen, z. B. der in Fig. 124 abgebildeten Oenone latifolia. Diese in rasch strömendem Wasser an Felsen festsitzende Pflanze hat breite, zweizeilig gestellte Blätter, die mit ihrer Unterseite dem Substrate aufliegen. Aber weder eine ron den Blättern abgegliederte Sproßachse noch ein Sproßvegetationspunkt

sind rorhanden. Die Entwicklungsgeschichte zeigt ${ }^{2}$, daß das jüngste Blatt jeweils aus der Basis des nächstälteren hervorsproßt.

Da andere Podostemaceen, wie z. B. die Tristichaarten (welche einen kleinen, moosähnlichen Vegetationskörper besitzen), auch am v e g e ta ti v e n Sproß einen Vegetationspunkt haben, so liegt es nahe, das Fehlen eines solchen bei Formen wie Oenone u. a. als auf Rückbildung beruhend $\mathrm{zu}$ betrachten. Wohl aber finden sich bei den Lemnaceen ebenso wie bei den erwähnten Podostemaceen Vegetationspunkte, dann, wenn die Pflanze Blütenstände bildet. Es ist auch sonst vielfach zu beobachten, daß bei der Blïtenregion Gestaltungsverhältnisse noch bestehenbleiben, die in der vegetativen Region verwischt sind.

Wir sehen also, daß auch in dem Auftreten eines so wichtigen Organs wie der Vegetationspunkt es ist, Schwankungen auftreten und daß auch die Ausbildung einer Sproßachse bei manchen Pflanzen unterbleiben kann.

Man kann aber solche Fälle nicht benützen, um - wie dies von einigen Autoren geschehen ist - die Sproßachse als etwas durch Ver-

\footnotetext{
1) Vgl. Hrgecmaler, Zur Entwicklungsgeschichte monokotyler Keime etc. Bot. Zeit. 32 (1874). p. $631 \mathrm{ff}$.

$\left.{ }^{2}\right)$ Wie für andere Formen Warming nachwies, für Oenone vgl. Matthirsex, Beitr. zur Kenntnis der Podostemaceen. Biblioth. botanica, 88 (1908).
} 
kettung der unteren Teile von Blättern entstandenes $\mathrm{zu}$ betrachten ${ }^{\mathbf{1}}$ ), wenigstens nicht, wenn man sich auf die jetzt lebenden Pflanzen stützt. Deren ungeheure Mehrzahl zeigt eine selbständige Sproßachse, an deren Vegetationspunkten die Blätter als seitliche Gebilde entstehen. Außerdem gibt es auch Sproßachsen, an denen jede Blattbildung unterdriickt ist, an deren selbständiger, von den Blättern unabhängiger Existenz also nicht zu zweifeln ist. So die erwähnten Ausläufer des Farnkrauts Nephrolepis, die "Nadelzweige" von Asparagus officinalis und Bowiea volubilis die "Borsten" an den Infloreszenzen ron Setaria und Cenchrus. Gewiß sind das Sproßformen, die sich von ursprünglich beblätterten Sprossen ableiten lassen. Aber Tatsache ist nichtsdestoweniger, daß Sproßachsen ohne alle Blattbildung vorhanden sind, und es wäre eine starke Zumutung, wenn man sich bei solchen blattlosen Achsen etwa noch die "spirits" längst verschwundener Blätter (der "Idee" nach) beteiligt denken sollte.

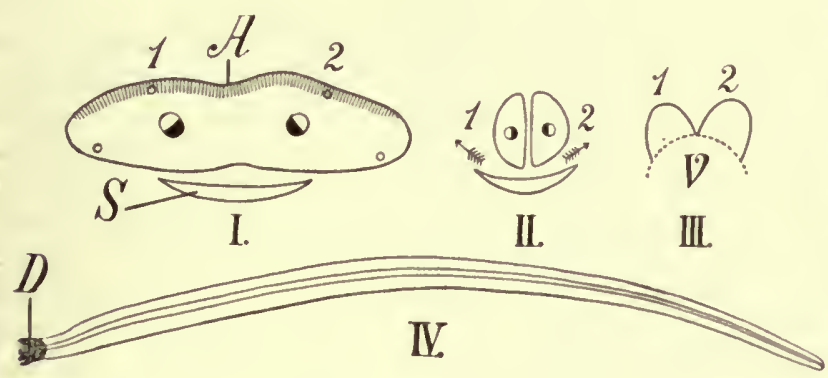

Fig. 125 .
Fig. 125. Sciadopitys verticillata. $I V$ Doppelnadel in der Achsel eines Deckblattes $D$. I Querschnitt durch einen

Kurztrieb (schematisch), SDeckblatt, $\boldsymbol{A}$ Lichtseite init Assimilationsparenchy m. Xylem der beiden Leitbündel schwarz. II Schema für die Drehung der beiden miteinander "verwachsenen"Nadeln. III Schema: die beiden Blattanlagen brauchen den Vegetationspunkt des Kurztriebes auf.

c) Term in ale Blätter. Das Auseinanderhervorsprossen der Blätter an einem Embryo von Triticum könnte man sich auch so vorstellen, daß zwar jeweils ein Sproßvegetutionspunlit angelegt, dieser aber sofort von einem Blatte ganz aufgebraucht werde. Das wäre indes nur ein Bild, da sich ein derartiger Vorgang nicht direkt nachweisen läßt. Aber tatsächlich findet er sich bei Sprossen begrenzten Wachstums durchaus nicht selten. Der Blütenvegetationspunkt z. B. kann von mehreren oder auch von einem Blatte so beansprucht werden, daß kein freies Stück mehr daron uibrig bleibt, was für die Auffassung gewisser Gestaltungsverhältnisse in den Blüten von großer Wichtigkeit ist. Ein einziges Staubblatt verbraucht den Bliitenvegetationspunkt z. B. bei Najas, Callitriche, Scirpodendron. Auch bei Kurztrieben kommt dasselbe vor.

In den Kurztrieben von Sciadopitys verbrauchen zwei Blattanlagen, die vereint wachsen, den Vegetationspunkt rollständig; nur in seltenen Ausnahmefällen wird er noch entwickelt. Und ebenso ist es mit dem einzigen Nadelblatt in den Kurztrieben von Pinus monophylla.

Sciadopitys sei hier etwas eingehender erörtert, weil sich daran noch eine weitere Eigentümlichkeit anschließen läßt.

Diese Kurztriebe werden gewöhnlich als „Doppelnadeln" bezeichnet. Tatsächlich sieht man auch namentlich an jungen, eben austreibenden

1) Vgl. die Darstellung solcher Hypothesen bei Potonié, Grundlinien der Pflanzenmorphologie, Jena 1911. 
Sprossen die Zusammensetzung aus zwei miteinander „verwachsenen" Nadeln, zwischen denen eine Längsfurche sehr deutlich verläuft. Sie stehen in den Achseln kleiner Schuppen am Stamme (Fig. 125 I S, IV D), nehmen also dieselbe Stellung ein wie die Kurztriebe von Pinus. Auf die Tatsache gestiitzt, daß die Nadeln von zwei vollkommen voneinander getrennten Gefäßbündeln durchzogen sind, welche von dem für die Coniferenblätter eigentümlichen "Transfusionsgewebe" umschlossen sind, sprach Монц die Ansicht aus, es seien diese Nadeln aus der Verwachsung der beiden ersten Blätter eines im übrigen verkümmernden Achselsprosses der Schuppe entstanden. Die von Strasburger mitgeteilte Entwicklungsgeschichte dieser Gebilde ist sehr eigentümlich, bedarf aber, wie ich glaube, noch erneuter Prüfung. Es entsteht in der Achsel der Schuppen eine Achselknospenanlage, welche früh schon einen deutlichen medianen Einschnitt am Scheitel zeigt, der auch an der fertigen "Doppelnadel" noch erkennbar ist (Fig. 125 II). Nach Strasburger's Darstellung ist dieses ganze Gebilde als Anlage der Doppelnadel zu betrachten: es wächst, nachdem das Scheitelwachstum frühe aufgehört hat, wie andere Nadeln an seiner Basis. Es ginge also der Scheitel des Achselsprosses hier in der Bildung der Nadeln auf, die letzteren aber wachsen nicht gesondert, sondern durch interkalares Wachstum ihrer gemeinsamen Basis. Kein Zweifel, daß das Gebilde einer Kurztriebanlage von Pinus entspricht, an der nur zwei Blattanlagen angelegt werden. Wenn diese Blattanlagen den Vegetationspunkt rollständig aufbrauchen und wenn ihre Basalstücke die Sproßachse außen berinden, so kann man sich vorstellen, wie durch interkalares Wachstum der unterhalb der Furche zwischen 1 und 2 gelegenen Partie der Fig. 125 III die „Doppelnadel" zustandekommt. Es hört eben hier die Differenzierung von Blatt und Sproß auf, die Sproßachse ist ganz zur Blattbildung in Anspruch genommen worden, man könnte die Doppelnadel auch ein "Phyllocladium" nennen "), aber am Namen liegt nicht viel. Merkwürdig ist, daß der Vegetationspunkt in seltenen Fällen nicht ganz zur Blattbildung verwendet wird, sondern die Fähigkeit besitzt, zwischen den Nadelblättern durchzuwachsen ${ }^{2}$ ). Hier sind aber die Doppelnadeln von Interesse als Beispiele terminaler Blätter und eines vollständigen anatomischen Verschwindens der Sproßachse.

Hierher dürften auch die eigentümlichen zwiebeltragenden "Blätter" gehören, welche sich bei einigen Monokotylen, z. B. Allium magicum und nigrum befinden ${ }^{3}$ ). Man findet hier an der Spitze gewöhnlicher Blätter (teils Laubblätter, teils Niederblätter) einen rinnenartig verschmälerten Fortsatz und auf diesem an der kapuzenförmig umgebogenen Spitze eine Zwiebel. Diese wird dadurch von der alten Pflanze entfernt und man kann derartige Blätter als "Ausläuferblätter" bezeichnen. Nun wäre natürlich die einfachste Annahme die, es handle sich um ein Blatt, das an seiner Spitze eine Zwiebel trage, wie z. B. an der Spitze der Blätter der Orchidee Malaxis paludosa der vegetativen Vermehrung dienende Knospen

1) Wie ich schon in der „Vergl. Entwicklungsgeschichte nommen ist) hervorgehoben habe. Nach Bower (GARD. Chronicle, 15. März 1884, p. 346) hat schon Dickson die Doppelnadeln als Phyllocladien betrachtet. Betr. der Anatomie vgl. auch Bertrand, Anatomie comparée des tiges et des feuilles chez les Gnétacées et des Conifères, Ann. d. sc. nat. 5. Ser. Bot. t. XX

2) Vgl. die Abbildung von Carriere in Gardener's Chronicle, 1. März 1884.

3) Goeber, Morphol. und biolog. Bemerkungen 18. Flora 98 p. 331. - Gute Habitusbilder bei Germain de Saint Pierre. Archives de Biologie végétale, Livr. 1 u. 2 Paris 1850. 
vorkommen. Dies ist aber hier nicht möglich, denn die Ausläuferblätter entwickeln sich - soweit bekannt - teils an Stelle axillärer Sprosse, teils aus der Spitze der Pflanze selbst. Vielmehr stellt, wie es scheint, die Zwiebel das Ende eines Sprosses dar, dessen unterer Teil sich ganz als Blatt entwickelt hat, also mit Unterdruickung der anatomischen Sproßcharaktere. Es sei auf diesen Fall namentlich deshalb aufmerksam gemacht, weil eine entwicklungsgeschichtliche Untersuchung (welche mir wegen Mangels an Material nicht möglich war) außerordentlich erwünscht wäre. Man könnte auch sagen, wir erhalten ein solches Ausläuferblatt, wenn man sich die von Tulipa praecoxerwähntenAusläufer hinter der Endknospe (Fig. 15) der Länge nach anfgeschlitzt und den aufgeschlitzten Teil flach ausgebreitet, auch anatomisch als Blatt entwickelt denkt.

Ebensowenig konstant sind andere Merkmale, die man als für Blätter wesentlich betrachtet hat. So die flache Gestalt - die zylindrischen Blätter mancher Juncusarten gleichen so sehr den Sproßachsen, daß man sie lange als „culmi steriles" bezeichnet hat -, die Art der Entstehung am Vegetationspunkt und der

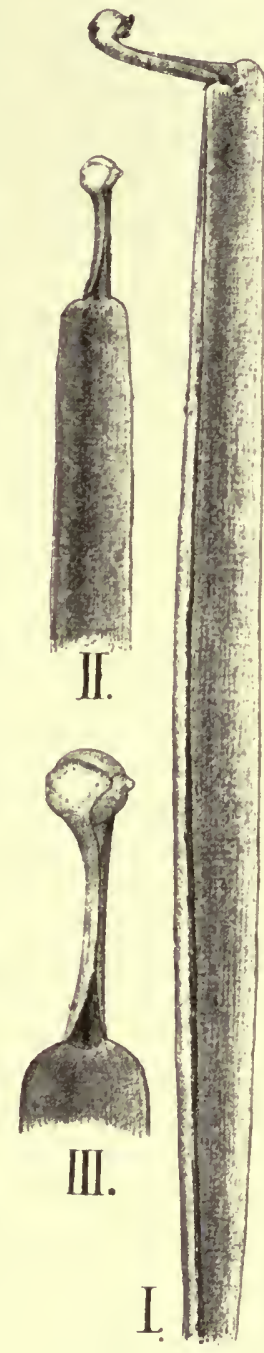

Fig. 126.

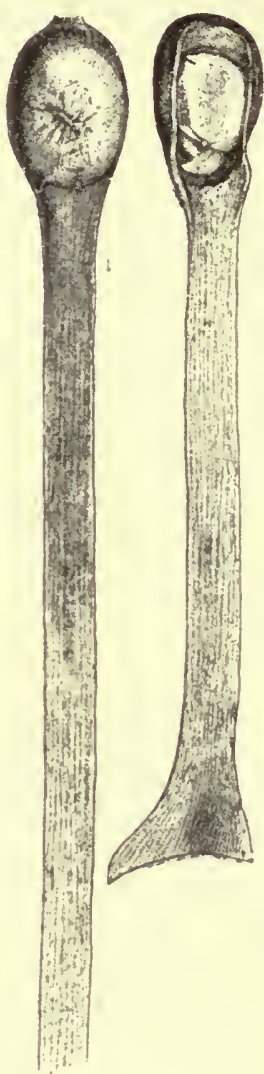

Fig. 127.

Fig. 126. Allium magicum. Lanbblatt mit brutknospentragendem Endteil.

Fig. 127. Ausläuferblätter von Alliun nigrum. Besitz von Leitbündeln.

Gewöhnlich beteiligen sich an der Bildung eines Blatthöckers außer der äußersten Zellschicht des Vegetationspunktes auch tiefer gelegene, wie es ja der massigeren Ausbildung der Blattanlagen entspricht. Es gibt aber auch Blätter, die teilweise oder ganz nur aus der äußersten Zellschicht entstehen. So bilden sich die Seitenteile des kleinen Blattes von Elodea canadensis nur aus dem "Dermatogen", ganz entstehen aus diesem das „Perigon" von Ephedra. 
Letzteres ist auch ganz ohne Leitbündel. Das gilt auch für einige andere Wasserpflanzen. Die Blätter der Podostemacee Tristicha hypnoides z. B. sind ganz ohne Leitbündel. Sie haben aber wenigstens noch die regelmäßige Stellung, welche den Blättern sonst zukommt. Bei Weddelina squamulosa ${ }^{1}$ ) sind die leitbündellosen Blätter teils zu gezähnten Schuppen, teils (an den Sproßenden und kleinen Zweigchen) zu schmalen langgestreckten Gebilden reduziert, die keine bestimmte Anordnung erkennen lassen, auch die axilläre Verzweigung fehlt hier. Die Pflanze hat sich also - nur in anderer Weise, als dies für Utricularia angeführt wurde - von dem sonst geltenden Schema der Organbildung emanzipiert. Die an den Blütensprossen stehenden Blätter zeigen noch das gewöhnliche Verhalten, ein weiteres Beispiel für die oben angeführte Erscheinung, daß die Bluitenregion nicht selten konservativer ist als die vegetative.

Derartige Fälle abnormer Organbildung lassen die meisten Botaniker lieber auf sich beruhen. Sie stören unser Bedürfnis, zu schematisieren und uns dadurch leichter in der Mannigfaltigkeit zurechtzufinden, sind also unbequem. Um so mehr sind sie aber hier hervorzuheben.

Wir könnten ihnen anschließen die Besprechung der Rückbildung der Vegetationsorgane vieler Parasiten. Indes ist deren Ableitung noch eine rielfach unsichere, sie mag deshalb dem speziellen Teile rorbehalten bleiben.

\section{Als Fortpflanzungsorgane}

im engeren Sinne des Wortes kommen für uns nur die Gametangien und die Sporangien in Betracht. Die mancherlei Einrichtung, welche die "Brutknospenbildung" (die Ablösung einzelner Teile des Vegetationskörpers) aufweist, sind zur Besprechung im allgemeinen Teile nicht geeignet.

\section{§ 15. Die Gametangien.}

\section{Ihre verschiedene Ausbildung.} stehen.

Als Geschlechtsorgane bezeichnen wir solche, in denen Gameten ent-

Bei einzelligen Pflanzen, wie z. B. den Conjugaten, ist ein Unterschied zwischen vegetativen Zellen und Gameten noch nicht oder doch nur zeitweilig ausgeprägt. Gewöhnliche chlorophyllhaltige Zellen werden zu Gameten, die miteinander verschmelzen.

In der "Hauptreihe" des Pflanzenreiches, welche hier allein besprochen werden soll (also mit AusschluB der Pilze und vieler anderer Thallophyten), sehen wir die Gameten, in einfachsten Fällen beide gleich gestaltet, und zwar als Schwärmsporen oder "Planogameten" entwickelt. Von hier aus läßt sich folgende Reihe aufstellen, die aber keineswegs bei allen Gruppen vollständig vorhanden ist:

1. Beide Sexualzellen sind noch Planogameten, aber die eine („weibliche") ist größer als die andere (z. B. Phyllobium unter den Grünalgen).

1) Gokber, Pflanzenbiol. Schilderungen. WÄchter, Beiträge zur Kenntnis einiger Wasserpflanzen. Flora 83. Bd. (1897), p. $367 \mathrm{ff}$. 
2. Die größere weibliche Sexualzelle verliert nach einiger Zeit ihre Cilien und wird als ruhendes Ei befruchtet (Cutleria).

3. Die weibliche Sexualzelle bildet keine Cilien mehr, wird aber vor der Befruchtung noch aus ihrer Bildungsstätte entleert, die Befruchtung findet also außerhalb des Pflanzenkörpers statt (Fucus).

4. Die unbeweglich gewordene Eizelle wird innerhalb des Pflanzenkörpers von dem beweglichen männlichen Gameten befruchtet; die schon bei 2 hervorgetretene Verschiedenheit von Spermatozoid und Eizelle ist nunmehr eine scharf hervortretende geworden (zahlreiche Grünalgen, wie Oedogonium, Coleochaete und sämtliche Archegoniaten).

Wieweit dieser Reihenfolge auch eine zeitliche (bzw. phylogenetische) entspricht, ist nicht mit Sicherheit zu sagen - denn wenn wir die einfachere Form (Isogameten usw.) an den Anfang stellen, so entspricht das zunächst nur einer Gewohnheit unseres Verstandes. Ebensowenig läßt sich ein Zweckmäßigkeitsgrund für die Arbeitsteilung der Gameten anführen. Es erscheint uns zwar einleuchtend, daß eine daron hauptsächlich das Material für die erste Entwicklung der Zygote liefert, und man kann sich denken, daß eine relative Verkleinerung der männlichen Gamete ihre Beweglichkeit erleichtert, während die Vergrößerung der weiblichen Gamete deren Beweglichkeit erschwert. Aber ein Einblick in den Vorgang selbst ist damit nicht gewonnen.

Hand in Hand mit der Verschiedenheit der Gameten geht auch die ihrer Bildungsstätten, der Gametangien.

\section{Homologie der beiderlei Gametangien.}

Wo die Sexualzellen gleich sind, sind auch beiderlei Gametangien gleich, wo sie ungleich sind, treten charakteristische Unterschiede hervor, die auch bei den höheren Pflanzen im Prinzip in gleicher Weise wiederkehren. Selbst dann, wenn die Sexualorgane äußerlich voneinander sehr verschieden sind, läßt sich doch ihre Homologie nachweisen ${ }^{1}$ ). Entsprechend ihrem Ursprung aus ursprünglich gleichen Gametangien zeigen sie noch gemeinsame Zïge in ihrem Aufbau, gelegentlich treten auch Mittelbildungen auf.

A. Differenzierung der männlichen und weiblichen Gametangien bei Thallophyten:

Wenige Beispiele genügen, um auf das Wesentliche hinzuweisen; sie mögen den Phaeophyceen entnommen werden. Dabei kommen natürlich nur die in Betracht, deren Gameten. - und dementsprechend auch die Gametangien - verschieden sind. Dies ist der Fall bei Cutleria (Fig. 128).

Betrachtet man die männlichen und die weiblichen Gametangien, so sieht man ohne weiteres, daß sie beide im wesentlichen gleich gebaut sind. Sie gehen auch beide aus einer einzigen Zelle hervor, die sich

1) Dies geschah zuerst in des Verf. Vgl. Entwicklungsgeschichte (Schenk's Handbuch der Botanik II, $413 \mathrm{ff}$, 1883) wurde aber nicht beachtet. Eingehender ist die Frage erörtert in Goenes, Über die Homologien in der Entwicklung männlicher und weiblicher Geschlechtsorgane, Flora 90, 1902 (p. 279). Zu ganz übereinstimmenden, aber mit phylogenetischen Hypothesen verknüpften Resultaten gelangten später: B. M. DAvis, The origin of the Archegonium, Annals of botany XVII, (1903) und H. Schenck, Über die Phylogenie der Archegoniaten und der Characeen, Exalers botan. Jahrb. Bd. XLII. (1908). - Die von Holferty (Bot. Gazette 37, 1904) beschriebenen (unten teilweise zu erwähnenden) Mittelbildungen zwischen Antheridien und Archegonien lassen sich aus den früher erörterten Homologien leicht verstehen und beinahe voraussagen.

Goebel, Organographie der Pflanzen. 2. Auf. Allgem. Tell. 
wiederholt teilt, ein Unterschied besteht nur in zweifacher Hinsicht: 1. sind die männlichen Gametangien (Antheridien) kleiner und zahlreicher als die weiblichen (Oogonien), wir wollen sie als Mikrogametangien bezeichnen, die weiblichen als Makrogametangien ${ }^{1}$ ); 2 . treten in ihnen mehr Zellteilungen auf. Die Makrogametangien bleiben also auf einer Stufe der Entwicklung stehen, welche von den männlichen überschritten wird. Es braucht kaum betont zu werden, daß dadurch die Hervorbringung einer viel größeren Zahl männlicher Gameten ermöglicht wird.
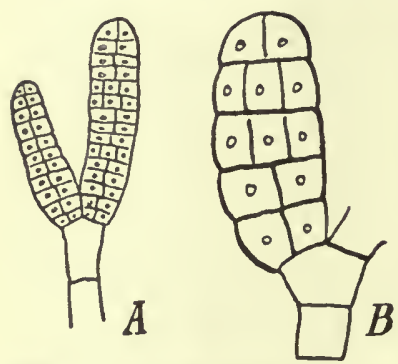

Fig. 128. Gametangien von Cutleria multifida. A Antheridien, $B$ Oogonien.

(Nach ReInke, Lehrb.)

Ganz dasselbe gilt für Fucus, wo die Verschiedenheit in der Zahl, der Größe und dem Verhalten der Gameten noch beträchtlicher ist. Dabei zeigen die einzelnen Fucaceengattungen interessante Unterschiede im Verhalten der Makrogametangien. Fucus hat noch acht weibliche Gameten, andere Gattungen haben nur vier, zwei und schließlich nur ein $\mathrm{Ei}$. Indes tritt hier, wie Oltmanss zeigte, noch eine Achtteilung der Gametangienkerue auf, aber nur einer wird zur Gametenbildung verwendet, die anderen gehen zugrunde. Wir sehen hier also außer dem Auftreten von wenigen Zellteilungen im Makrogametangium noch einen zweiten Vorgang: es werden eine Anzahl (potentieller) Gameten steril, d. h. gelangen nicht zur vollen Entwicklung.

Bei den Makrogametangien von Dictyota unterbleibt selbst diese Teilung, es bildet sich nur ein einziges Ei. Selbst in den Fällen, wo die Sexualorgane so verschieden sind wie bei Chara, hat sich in den ersten Stadien der Entwicklung noch eine Homologie nachweisen lassen.

B. Die Gametangien der Archegoniaten, welche hier zunächst allgemein, bezüglich ihrer Homologie, besprochen werden sollen (unter Verweisung auf den speziellen Teil betreffs der Einzelheiten), unterscheiden sich von denen der Thallophyten dadurch, daß sie eine aus sterilen Zellen bestehende Wandung besitzen (vgl. z. B. Fig. 137, 3 mit Fig. 137, 1). Diese kommt in Betracht nicht nur als Schutz während des Heranreifens ein Schutz, welcher vielfach durch eine Versenkung der Gametangien in Gruben, oder durch haarähnliche Bildungen u. dgl. noch erhöht wird -, sondern namentlich auch für die Öfnung der Gametangien, welche in ganz bestimmter Weise durch die Wandschicht bedingt wird.

Man kann das Vorhandensein einer Hülle aus sterilen Zellen mit der Tatsache in Verbindung setzen, daß die Archegoniaten schon typische Landpflanzen sind, auch in ihren Gametophyten, noch mehr ja in den Sporophyten. Selbst die im Wasser lebenden Formen sind jedenfalls nur sekundär dort eingewandert. Jedenfalls aber liegt hier eine Verschiedenheit gegenüber den Thallophytengametangien vor, die funktionell verständlich ist; es entspricht ihr übrigens auch die Struktur der Sporangien verglichen mit der der sporenbildenden Organe bei den Thallophyten.

Gemeinsam ist den sämtlichen Archegoniaten ferner, daß im Makro-

1) Im Interesse einer einheitlichen Terminologie wäre es sehr erwünscht, wenn diese Ausdrücke sich einbürgern könnten. Dann kann man sagen: der Gametophyt hat Gametangien, die zu Mikro- und Makrogametangien sich differenzieren können. Der Sporophyt hat Sporangien, die ebenso in Mikro- und Makrosporangien sich scheiden können. 
gametangium e in e Eizelle (十 „Bauchkanalzelle“) und eine oder mehrere "Halskanalzellen" erzeugt werden, in den Antheridien dagegen zahlreiche Spermatozoiden.

I. Pteridophyten. Es sei (wie in der Vergl. Entwicklungsgeschichte) ausgegangen von dem Verhalten der eusporangiaten Farne,weil diese besonders klar die Homologie von Antheridium und Archegonium erkennen läßt.

Archegonien wie Antheridien sind hier dem Gametophyten eingesenkt. Sie gehen hervor aus einer Zelle, welche sich durch eine Perikline $\times \times$ Fig. $129 B$ teilt in eine äußere (Deckel-) Zelle $h$ und eine innere (in Fig. 129 nebst ihren Abkömmlingen

außen punktiert). Aus ersterer geht am Antheridium der Deckel mit seinem Öffnungsmechanismus hervor; beim Archegonium die Hülle des Halses der sich mehr oder weniger weit über die Oberfläche hervorwölbt; aus letzterer beim Antheridium durch oft wiederholte Teilung der Komplex von Spermatozoidmutterzellen. Beim Archegonium finden in dieser Zelle, die sich stark streckt, nur wenig Querteilungen statt, es bildet sich die 1. Halskanalzelle $\left(h_{1}\right.$, Fig. $\left.129 C^{\prime}\right)$ (bei Lycopodium [Fig. 130] statt deren eine ganze Reihe). 2. Die Bauchkanalzelle $b$, Fig. $129 \mathrm{D}$, und die Eizelle $(e)$. Halskanalzellen, Bauchkanalzelle und Eizelle entsprechen also zusammen dem Komplex der
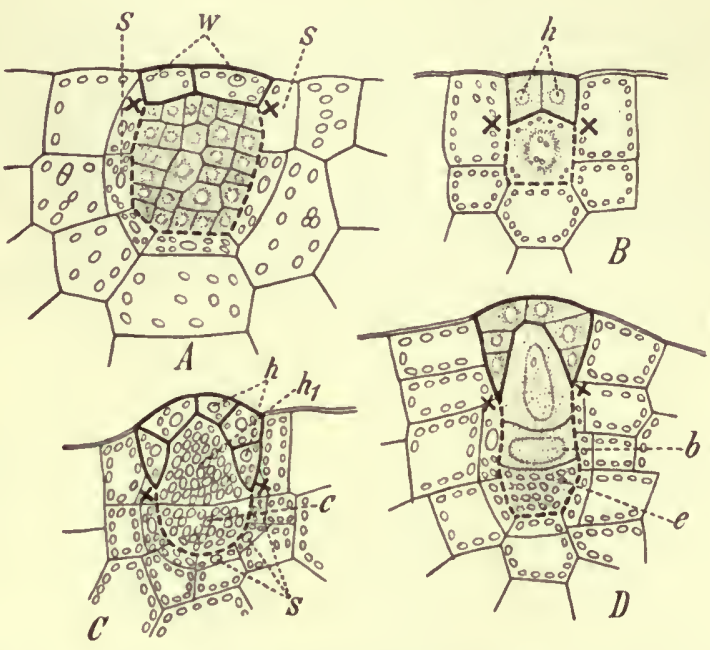

Fig. 129. Antheridien $(A$ n. $B)$ und Archegonien $(C$ u. $D)$ ron Marattiaceen im Längsschnitt (schematisiert nach $A b-$ bildungen Jonкмan's), die Deckelzelle und die durch Teilung aus ihr hervorgegangenen Zellen stärker ausgezogen, die untere Grenze mit $\times X$ bezeichnet. Die Innenzelle ist gestrichelt. $B$ ist junges Entwicklungsstadium für beiderlei Organe.

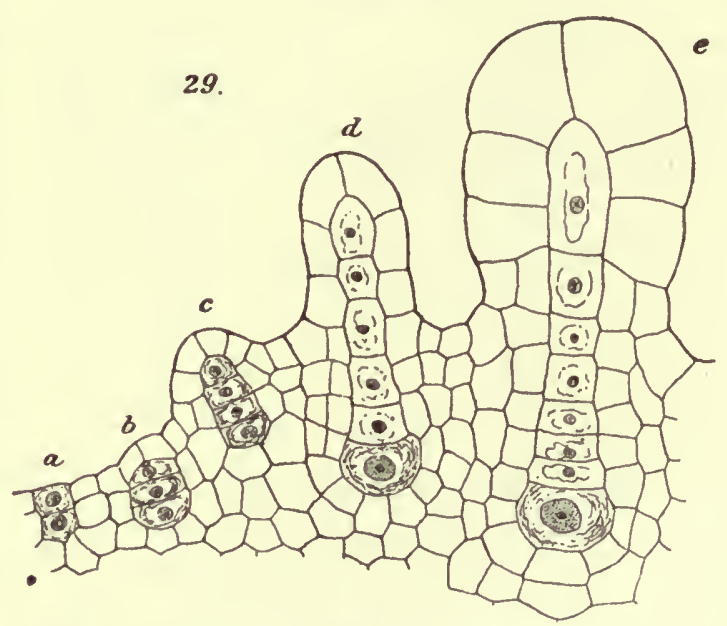

Fig. 130. Lycopodium Selago. Archegonien verschiedener Entwicklnngsstadien im Längsschnitt (nach BRUCHMANN). Es ist eine ganze Reihe von Halskanalzellen vorhanden.

Spermatozoidmutterzellen. Nur sind ebenso wie in den oben angeführten Fällen im weiblichen Gametangium bedeutend weniger Teilungen erfolgt und von den wenigen dadurch entstandenen Zellen ist nur eine einzige fertil; die 
sterilen sind aber indirekt in den Dienst der Befruchtung getreten durch Schleimbildung, bei der Bauchkanalzelle vielleicht auch durch Absonderung einer chemotaktisch wirkenden Substanz.

Im Grunde verhalten sich auch alle anderen Antheridien und Archegonien wie in der 1 . Auflage dieses Buches dargetan wurde und im speziellen Teil zu erörtern sein wird, ganz ähnlich wie die der Marattiaceen.

II. Etwas weniger einfach liegen die Verhältnisse bei den Bryophyten.

1. Lebermoose. Die Antheridien stellen keulen- oder kugelförmige, mit einer Wandschicht und einem Innenkomplex von Spermatozoidmutterzellen versehene Körper dar, die auf einem kürzeren oder längeren Stiele sitzen können.

In ihrem Aufbau lassen sich zwei Typen unterscheiden, welche durch Übergänge miteinander verbunden sind.

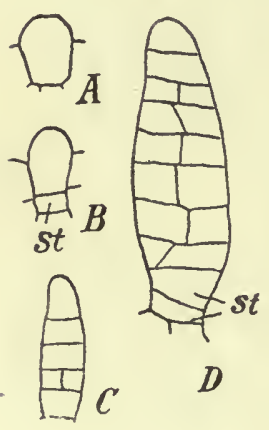

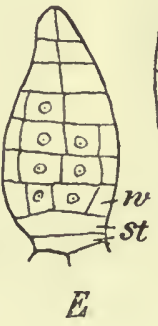

Fig. 131

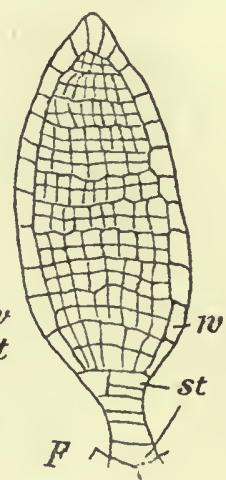

Fig. 131.

Antheridienentwicklung von Fegatella. Nach Bolleter.

Fig. 132.

Schematische Querschnitte. I durch ein Marchantiaceen-, II durch ein Jungermanniaceenantheridium, III durch ein Lebermoosarchegonium. Fertile Zellen punktiert, wo sterile (Wand-) Quadranten.
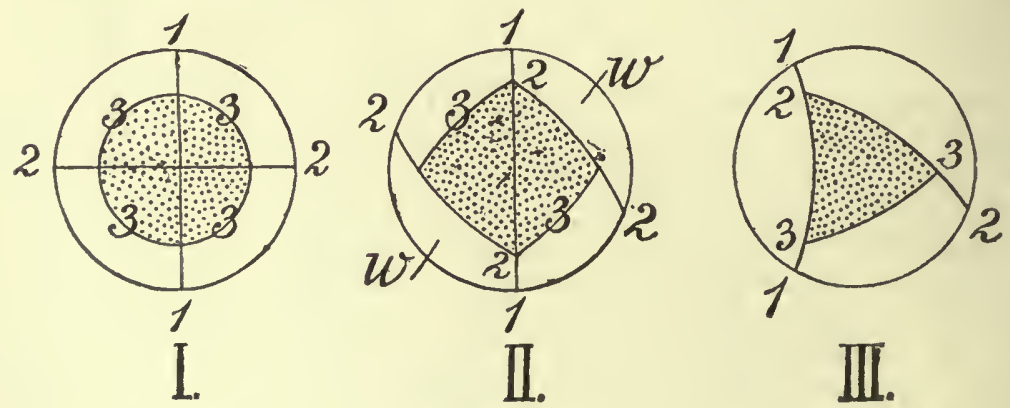

Fig. 132.

a) Ein primitiver Typus ist der, welcher sich in der Marchantiaceenreihe findet. Hier kommen die Antheridien zustande aus mehreren Stockwerken von Zellen (Fig. 131), in welchen verhältnismäßig spät sich die Wandschicht $(w)$ von dem Inhalt sondert, nämlich erst dann, wenn jede Zelle durch zwei Längsteilungen in vier Quadranten zerlegt ist, innerhalb deren, wie Fig. 132 I zeigt, nun (meist durch Periklinen) die Wandzellen abgetrennt werden.

b) In den Antheridien der meisten Jungermanniaceen ist gegenüber denen der Marchantiaceen eine doppelte Reduktion eingetreten:

1. Wird der Antheridienkörper aus viel weniger Querscheiben aufgebaut, meist nur aus einer. 
2. Treten in diesen andere Zellteilungen ein. Zwar tritt noch die Halbierungswand 1, Fig. 132 II, auf, aber darauf folgen keine Quadrantenwände, sondern die mit 22 bezeichneten Teilungswände setzen sich der Wand 1 unter einem Winkel von etwa $45^{\circ}$ an. Dadurch wird statt zweier Quadranten eine kleinere äußere Zelle, die zur Wandbildung verwendet wird, abgeschnitten und eine größere innere, welche durch die Periklinie 3 sich in eine Wandzelle und eine fertile (in Fig. 132 II punktiert) teilt. Diese eigenartige Teihng leitet sich, wie a. a. O. ausgeführt wurde, offenbar von einer Quadrantenteilung ab, bei der in jeder Antheridienhälfte ein Quadrant steril bleibt, d. h. nicht zur Spermatozoidenbildung verwendet wird; es entstehen zwei physiologisch ungleichartige Zellen, von denen die eine zur Wandbildung verwendet wird, die andere aber dieselben Teilungen erfährt, wie die Quadranten im Marchantiaceenantheridium.
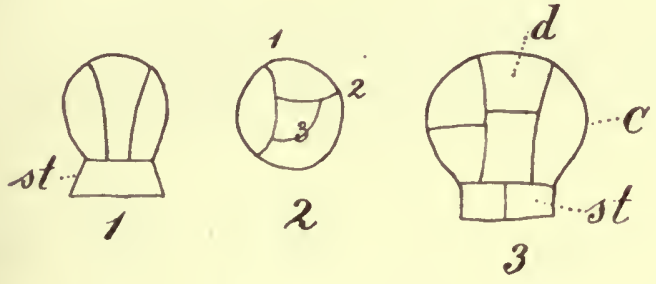

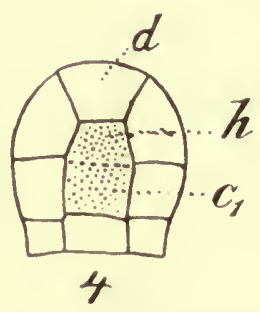

Fig. 133. Schema der Archegonienentwicklung der Lebermoose 1, 3, 4 im Längsschnitt, $2 \mathrm{im}$ Querschnitt, entsprechend Fig. 132 III. In 3 die Innenzelle von der Deckelzelle getrennt, in 4 die fertilen Zellen ( $h$ und $c$ ) punktiert, st Stiel.

Diese Auffassung wird gestützt $\alpha$. dadurch, daß bei manchen Jungermanniaceenantheridien normal noch Quadrantenbildung wie bei den Marchantiaceen auftritt (z. B. Fossombrōnia longiseta nacli HuMrHrey).

$\beta$. Dadurch, daß Quadrantenteilung als Variante auch bei solchen Jungermanniaceen vorkommt, die sonst die oben geschilderte Anordnung der Zellwände zeigen (z. B. Scapania nach LeitgeB).

$\gamma$. Dadurch, daß eine solche Variante sogar bei Marchantiaceen sich findet (Monoselenium) ${ }^{1}$ ).

Der in den Antheridien nachweisbare Reduktionsvorgang wird nun bei den Archegonien gesteigert. Ein Archegonium entspricht einem halben Antheridium, d. h. einem solchen, dessen eine Längshälfte ganz steril geworden und zur Wandbildung verwendet ist.

Dies ergibt sich ohne weiteres aus Fig. 131 3. Im jungen Archegonium treten drei Längswände auf, die eine mittlere fertile Zelle herausschneiden (von der sich oben eine Deckelzelle abtrennt) (Fig. 133 $4 d$ ) und drei sterile. Die Wand 1 entspricht der ersten Medianwand im Antheridium. Diese tritt exzentrisch auf, entsprechend der Tatsache, daß sie zwei physiologisch ungleichartige Zellen trennt. Die kleinere Längshälfte (in der Fig. 132 III die linke) bleibt steril, die andere erfährt genau dieselben Teilungen wie eine fertile Antheridienhälfte. Mithin entsprechen einander die Innenzellen von Antheridium und Archegonium genau wie bei den Farnen, und die Homologie von Antheridium und Archegonium tritt auch hier klar zutage.

1) Vgl. Gorber, Monoselenium tenerum, Flora 101 p. 68. 
Die hier mitgeteilte Auffassung wird, wie mir scheint, gestützt durch Beobachtungen, welche ich an Archegonien von Makinoa crispata $^{1}$ ) $\mathrm{zu}$ machen Gelegenheit hatte. Die Archegonien stehen in großer Zahl auf der Oberseite der Thallus in einer Gruppe, hinter welcher sich eine schuppenförmige Wucherung erhebt (Fig. 134). Die Mündung der dadurch gebildeten Grube bleibt aber weit offen, so daß die jungen Archegonien frei zutage treten. Etwas ältere Archegonien sind so massig, daß sie mit der Lupe leicht sichtbar sind; vielleicht steht ihr massiger Bau damit in Zusammenhang, daß sie längere Zeit ganz frei liegen.

Als ich junge Archegonien untersuchte, glaubte ich zunächst Antheridien, oder Mittelbildungen zwischen Antheridien und Archegonien vor mir zu haben. Dies wird bei Betrachtung der Figur 13 johne weiteres einleuchten: es findet sich im Inneren der Archegonien nicht eine fertile Zelle (welche durch Querteilungen dann eine Zellreihe liefern würde), sondern vorhanden sind 2-4. Diese fertilen Zellen sind meist nicht alle gleichmäßig entwickelt, reichen auch nicht immer alle gleich weit zur Basis des Archegoniums hinab. Aber sie verhalten sich sonst gleich, teilen sich also durch Querwände und unterscheiden sich von den Wandzellen sowohl durch ihren Inhalt, als ihre Zellwände, welch letztere sich mit Kongorot intensiver färben als die der Wandzellen.

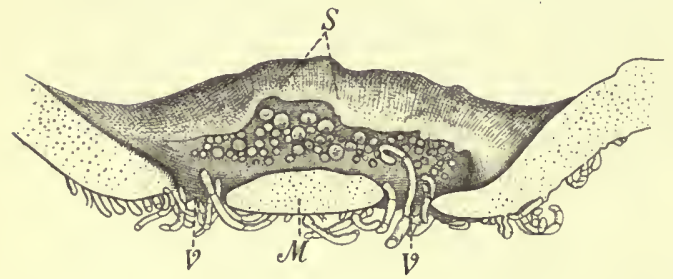

Fig. 134. Makinoa crispata. Scheitel einer weiblichen Pflanze von oben $V V$ zwei Vegetationspunkte. $M$ Mittellappen, darüber die Archegonien. $S$ Perichaetial-Schuppe.
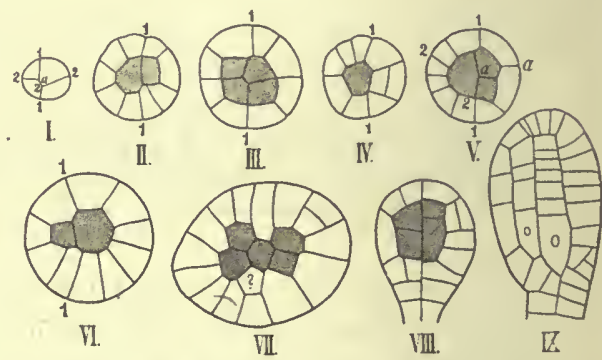

Fig. 135. Makinoa crispata. I-VII Querschnitte, VIII und $I X$ Längsschnitte durch abnorme Archegonien.

Es fragt sich, wie diese Mehrzahl von fertilen Zellen entsteht und wie sie sich bei der Weiterentwicklung der Archegonien verhalten.

Die erste Frage kann in doppelter Weise beantwortet werden. Entweder wird wie gewöhnlich ein e fertile Zelle angelegt und diese teilt sich dann durch Längswände, oder es werden unabhängig voneinander mehrere fertile Zellen angelegt. In letzterem Falle liegt dann die Annahme nahe, daß mehr als ein Quadrant fertil wird.

Dies ist nun in der Tat der Fall, obwohl auch der erstgenannte Vorgang eintreten kann.

Schon ganz junge Archegonienanlagen zeigen von oben betrachtet eine große Annäherung an die Quadrantenbildung (Fig. 135 I, III).

Die Wand 11 in Fig. $135 I$ tritt dort in anderen Fällen (IID) beinahe vollständig als Halbierungswand auf, ebenso ist die Wand 22 als Quadrantenwand noch deutlich erkennbar. Aus den größeren Quadranten kann die fertile Zelle wie üblich durch eine Perikline herausgeschnitten werden, aber wie Fig. $132 V$ zeigt, kann auch zunächst eine Antiklina

1) Schönes lebendes Material verdanke ich der Güte des Herrn Prof. FuJI in Tokio. 
a a auftreten, und dieser erst sich eine Perikline ansetzen. Tritt schon in diesem Verhalten eine Annäherung an die Antheridienbildung (vom Marchantiaceentypus) deutlich hervor, so ist das noch mehr der Fall dadurch, daß auch andere Quadranten fertil werden. Die Querschnittsbilder, Fig. $135 I I I, V, V I, V I I$, sind kaum anders aufzufassen, als daß in Fig. $135 V, 3$, in Fig. $135 I I I, 4$ Quadranten eine fertile Innenzelle gebildet haben - im letzteren Falle ist die Übereinstimmung mit den Antheridien eine vollständige. Jedenfalls zeigen diese abnormen Archegonien, daß auch andere Quadranten ,fertile“" Zellen liefern können. Ob diese abnormen Archegonien (welche in großer Zahl auftraten) befruchtungsfähig sind, vermag ich nicht zu sagen, da mir keine männlichen Pflanzen zu Gebote standen.

Merkwürdige Mittelbildungen verschiedener Art zwischen Antheridien und Archegonien hat K. MEYER ${ }^{1}$ ) bei.Corsinia marchantioides beschrieben, sie reihen sich den oben erwähnten und den für Laubmoosen anzuführenden an.

2. La ubmo ose. Bei diesen stimmen die Antheridien mit denen des Marchantiaceentypus unter den Lebermoosen ïberein, nur daß der Aufbau nicht durchQuerwände, sonderndurch eine "zwcischneidige" Scheitelzelle erfolgt, eine Variante, welche gelegentlich auch bei Marchantiaceen - Antheridien (z. B. bei Monoselenium) sich findet. Die Teilungen innerlıalb der einzelnen Zellen des Antheridienkörpers erfolgen aber nach dem Jungermanniaceentypus, so daß das Laubmoosantheridium gewissermaßen eine Kombination des Marchantiaceen- mit den Jungermanniaceen-Antheridium darstellt.

Die Archegonien (vgl. über deren Aufbau den speziellen Teil) zeigen auch hier die Homologie ihrer "fertilen" (aber mit Ausnahme der Eizelle steril gewordenen) Innenzellen mit denen der Antheridien. Wenn man diese Übereinstimmung im
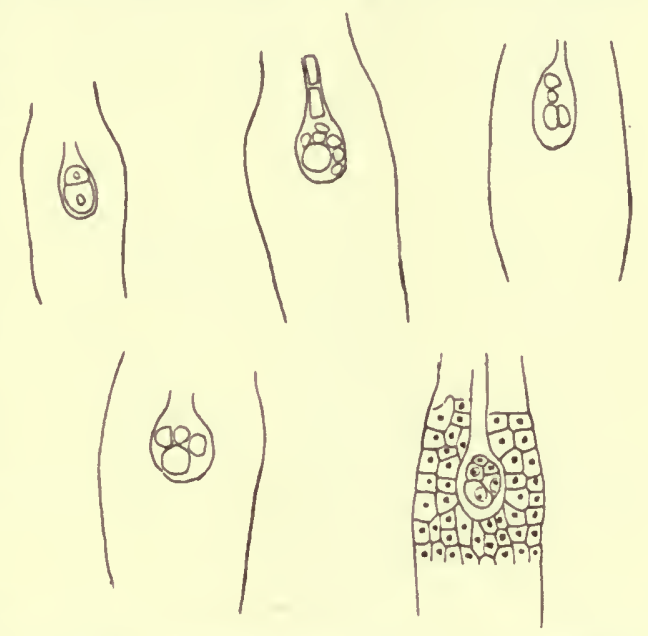

Fig. 136. Basalteile abnormer unbefruchteter Archegonien von Inium cuspidatum (nach ZIELINSKI). Statt einer Eizelle sind im Archegonienbauch mehrere Zellen vorhanden.

Auge behält, so sind auch die Mittelbildungen zwischen Archegonien und Antheridien, die bei Laubmoosen öfters beobachtet worden sind (zuerst wohl von JANCZEwski bei Catharinea) verständlich.

Zunächst ist nach dem obigen nicht verwunderlich, wenn statt einer wirklich fertilen Zelle im Archegonium zuweilen mehrere auftreten. Dies ist z. B. der Fall in den in Fig. 136 abgebildeten Archegonien 2). Coker hat bei Mnium cuspidatum gleichfalls zwei Eizellen (und zwei Bauch-

1) K. Meyer, Zur Frage von der Homologie der Geschlechtsorgane und der Phylogenie des Archegoniums. Biolog. Zeitschrift (Moskau II, 1912).

2) Zieuinski, Beitr. zur Biologie des Archegoniums usw. Flora 100, p. 1. Vgl. anch Hofeneder, Zwei Eizellen in einem Archegonium von Bryum caespiticium (Ber. des naturw.-med. Vereins. Innsbruck, XXII (1911).) 
kanalzellen, hier könnten also zwei Embryonen entstehen) beobachtet, außerdem wie Fig. 13711 zeigt Längsteilungen in den Zellen des Halskanales und Teilungen unterhalb der Eizelle. Hier liegt zweifellos schon eine Mittelbildung zwischen Archegonium und Antheridium vor, die noch dentlicher in Fig. 13712 zutage tritt, wo im "Stiel" des Archegoniums sich ein Nest von Spermatozoidmutterzellen befindet. Dem entsprechen offenbar die von JANCZEWSKI bei Catharinea beobachteten Zwitterbildungen welche in der unteren Hälfte ein normal ausgebildetes Antheridium vorstellten, aber oben in einem typischen Archegonienhals mit seinem centralen Kanalzellstrang ausgezogen sind. $\mathrm{Ob}$ hier ein analoger Entwicklungsvorgang vorlag, wie etwa in dem Fig. 13711 abgebildeten Fall

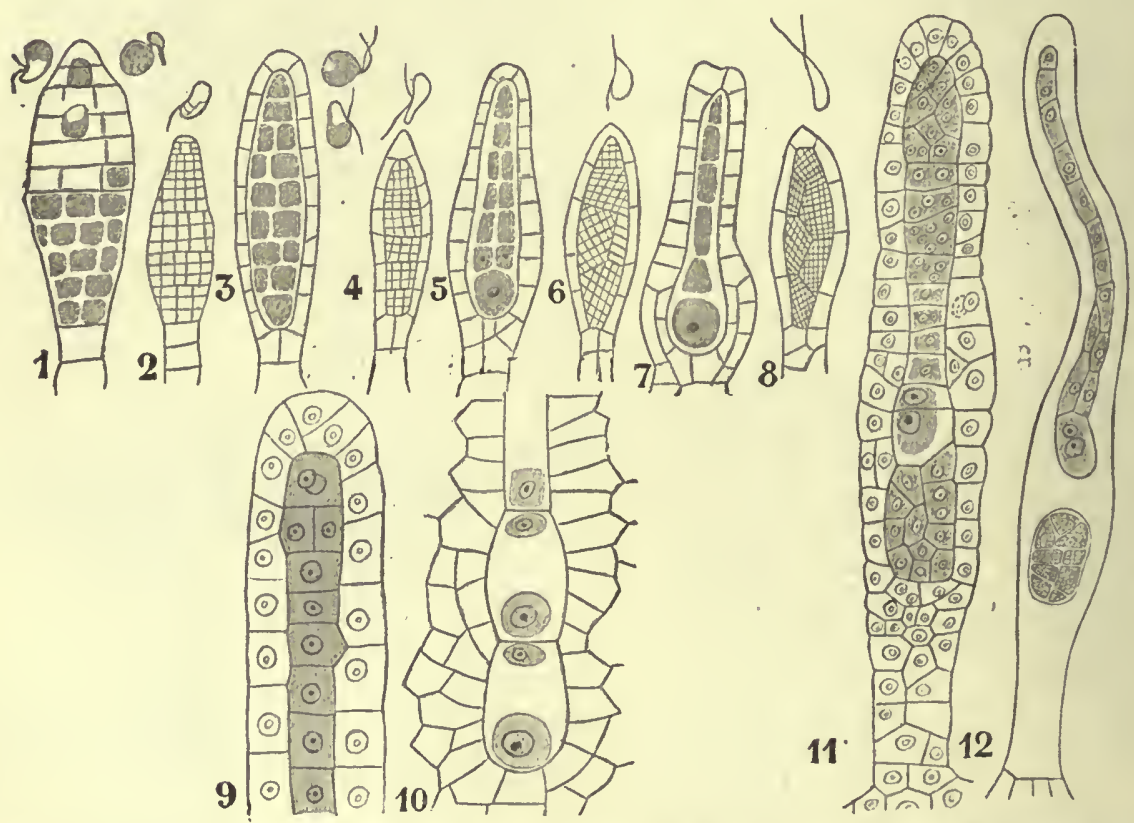

Fig. 137. 1-8 Gametangien nnd konstruierte Übergänge von solchen zu Archegonien und Antheridien nach DAvis. 9-12 abnorme Archegonien (bzw. in 9 ein Halsteil eines Archegons) von Mnium cuspidatum. 10 nach CoKER, die tibrigen Abbildungen nach Holferty. (Aus Lotsy, Vortr. über bot. Stammesgeschichte.)

oder ob - was ja auch möglich ist - die Antheridienmutterzellen im Archegonstiel nicht aus dessen Innenzellen hervorgingen, sondern gewissermaßen verirrte Bildungen darstellten, läßt sich ohne Kenntnis der Entwicklung nicht entscheiden.

\section{§16. Sporangien.}

Während die Gestaltung der Mikrogametangien der Archegoniaten nur in einem Punkte abweicht von der, welche wir an Gametangien von Thallophyten finden, kennen wir Organe, die den Bau der Sporangien oder Sporogonien der Archegoniaten besitzen, bei den Thallophyten nicht. Dann auch die Zellkörper, welche aus der Zygote von Coleochaete hervorgehen. sehen nur äußerlich einem Archegoniatenembryo ähnlich. Gleichen würden sie ihm nur dann, wenn sie aus diploiden Zellen bestehen würden, 
die erst später - vor der Sporenbildung - die Reduktionsteilung erfahren. Das ist aber nach den vorliegenden Untersuchungen nicht der Fall. Es bleibt also, wie Schexck hervorgehoben hat, nur die Übereinstimmung der Sporenmutterzellen der Archegoniaten mit denen der Thallophyten iubrig. Ob zwischen den Sporophyten der Bryophyten und denen der Pteridophyten Beziehungen bestehen, derart, da $B$ die letzteren von einer den ersteren entsprechenden Gestaltung aus sich weiter entwickelt haben, ist unbekannt und nach des Verf. früher dargelegten Ansichten nicht wahrscheinlich. Die verschiedenen phylogenetischen Theorien zu besprechen liegt außerhalb des Planes dieses Buches.

Die Gestaltung der Sporangien ist für die einzelnen Gruppen eine so charakteristische, daß sie im speziellen Teile eingehender zu erörtern sein wird. Hier kann nur auf die wichtige Tatsache hingewiesen werden, daß wir bei den Sporangien der Pteridophyten ganz dieselbe Erscheinung wahrnehmen können, wie bei den Gametangien.

Wie bei diesen die Reihe begann mit Formen die keine Verschiedenheit von männlich und weiblich erkennen ließen, so beginnt auch bei den Sporangien die Reihe mit den isosporen Pteridophyten. Wie die weiblichen Gametangien einerseits weniger Zellteilungen, andererseits Sterilwerden mancher Zellen zeigten, so auch die Makrosporangien gegenüber den Mikrosporangien: die Zahl der Makrosporenmutterzellen ist bei den Makrosporangien von Azolla, Salvinia, Pilularia und Marsilia eine geringere, als die der Sporenmutterzellen in den Mikrosporangien und bei Selaginella sind in den Makrosporangien gewöhnlich alle sonst sporogenen Zellen steril bis auf eine einzige. Ebenso tritt eine Übereinstimmung darin hervor, daß die Mikrosporangien wie die Mikrogametangien eine weniger starke Umbildung gegenuiber dem primitiveren Sporangienbau erfahren als die Makrosporangien und Makrogametangien.

Dem sei angeschlossen die Besprechung der Frage, in welcher Weise auch in der Stellung der Gametangien und der verschiedenen Sporangien eine Verschiedenheit hervortritt und wieweit auch die Teile der Pflanze, welche die rerschiedenen Fortpflanzungsorgane tragen, rerschieden sind. Ist dies der Fall, so können wir von einem sexuellen Dimorphismus sprechen.

\section{$\S 17$. Unter sexuellem Dimorphismus ${ }^{1}$ )}

verstehen wir die Tatsache, daß die sexuelle Differenz sich nicht nur erstreckt auf die Sexualorgane selbst, sondern auch auf die Pflanzenteile an welchen die Sexualorgane sich befinden, ja unter Umständen (bei „diözischer" Verteilung der Sexualorgane) auf die ganze Pflanze.

\section{Allgemeines, Verschiedenheit ganzer männlicher und weiblicher Pflanzen.}

Dabei sei zweierlei von vornherein bemerkt: Einmal: bei Tieren ist der sexuelle Dimorphismus viel häufiger, weil Zwitter hier (wenigstens bei den höheren Gruppen) verhältnismäßig selten sind. Bei den Pflanzen dagegen ist (namentlich bei den höheren Gruppen) Zwitterbildung rorherrschend, und wo eine Trennung der Geschlechter eingetreten ist, ist sie z. B. bei den Samenpflanzen häufig eine sekundäre und nicht immer konstante. Wir werden also schon aus diesem Grunde einen weniger

1) Das folgende ist eine etwas veränderte Wiedergabe der Abhandlung des Verf. „Über sexuellen Dimorphismus bei Pflanzen“. (Biolog. Zentralblatt XXX, 1910.) 
scharf ausgesprochenen Sexualdimorphismus erwarten dürfen $\left.{ }^{1}\right)$. Zweitens sei erwähnt, daß wir als sexuell differenziert auch die Blüten der höheren Pflanzen betrachten wollen. Streng genommen gehören sie ja der ungeschlechtlichen (diploiden) Generation an; wo aber Mikrosporen und Makrosporen ausgebildet werden, also schon in der Sporangienbildung ein Dimorphismus hervortritt, sind auch die Organe, welche die Mikro- und Makrosporangien hervorbringen, meist verschieden; es greift also die Sexualdifferenz auch auf die "ungeschlechtliche" Generation über.

Gerade an den Blüten lassen sich die hier zu erörternden Fragen am leichtesten darlegen. Männliche und weibliche Blüten (und Bluitenstände) unterscheiden sich oft durch Zahl, Stellung und Ausstattung. Sind diese Verschiedenheiten verständilich als im Zusammenhang stehend mit der verschiedenen Funktion der beiderlei Blüten (oder Blütenstände)?

Vielfach ist diese Frage leicht $\mathrm{zu}$ beantworten, namentlich dann, wenn die weiblichen Blüten Einrichtungen zum Schutz der heranreifenden oder zur Verbreitung der fertigen Früchte aufweisen. So ist z. B. bei Friocaulon nautiliforme ${ }^{2}$ ) das liintere Perigonblatt der weiblichen Blüten nautilusförmig aufgeblasen und klebt der Frucht an, für die es einen Schwimmapparat darstellt. Ebenso ist die Verschiedenheit der männlichen und der weiblichen Blütenstände des Hopfens (Humulus Lupulus) teleologisch ohne weiteres ausdeutbar. Aber in nicht wenigen Fällen versagt die teleologische Auffassung; namentlich die oft geäußerte Formel, daß nutzlos gewordene Organe verkümmern. Es wird unten z. B. zu erwähnen sein, daß auch männliche Blüten von Kompositen einen "Pappus" anlegen, obwohl hier ein Flugapparat natürlich nicht von Bedeutung sein kann. Auch die Verschiedenheit in den Zahlenverhältnissen der Blütenhülle männlicher und weiblicher Begoniablüten u. a. ist nicht als Anpassungsmerkmal $\mathrm{zu}$ betrachten.

$\mathrm{Ob}$ nun solche Merkmale sich nachweisen lassen oder nicht, jedenfalls knüpft sich an den sexuellen Dimorphismus von Blüten die weitere Frage: welche Veränderungen sind dem ursprünglichen zwitterigen $\mathrm{Zu}$ stand gegenüber vor sich gegangen?

Haben sich beide Blütenformen verändert oder nur eine, und, falls ersteres der Fall ist, ging die Veränderung bei männlichen und weiblichen Blüten in gleicher oder verschiedener Richtung vor sich?

Eine dritte Kategorie von Fragen bezieht sich auf die Ursachen der Verschiedenheit. Diese ist naturgemäß am schwierigsten zu beantworten. Man wird sich bei dem jetzigen Stand unserer Kenntnisse schon begnügen müssen, wenn man für die beiden ersten Fragen Anhaltspunkte findet, welche dann auch für die Versuche die dritte zu erforschen von Bedeutung sein können. Bei diözischen Pflanzen kann es sich dabei handeln um Verschiedenheiten der ganzen Pflanzen, bei monözischen um solche in der Anordnung und Ausbildung der beiden Geschlechtsformen.

Was die Verschiedenheit von Männchen und Weibchen bei diözischen Pflanzen anbelangt, so sei hier nur weniges angeführt, zumal eingehende eigene Untersuchungen darüber mir nicht zu Gebote stehen, Keine wesentliche Differenz zwischen männlichen und weiblichen Pflanzen besteht z. B. bei den diözischen („heterothallischen“) Mucorineen - man

1) Selbstverständlich fehlen bei den festgewurzelten Pflanzen auch alle Einrichtungen zum Erreichen der Weibchen (und zum Kampf um sie), wie sie bei Tieren in so reicher Mannigfaltigkeit auftreten.

2) Vgl. Lecoste, Journal de botanique Juni 1908. 
kann dem Myzel nicht ansehen, ob es „männlich" oder ,weiblich“ ist, zumal auch die Sexualorgane selbst ganz gleich sind. Nach BlakesteE's Vorschlag spricht man deshalb von + und - Myzelien.

In anderen Verwandtschaftskreisen läßt sich wohlim allgemeinen sagen, daß, woVerschiedenheiten vorkommen, die weiblichen Pflanzen die kräftigeren und langlebigeren sind ${ }^{1}$ ). Indes ist hervorzuheben, daß der Vergleich natürlich nur ror der Befruchtung (also präfloral) und zwischen unter denselben äußeren Bedingungen gewachsenen Pflanzen stattfinden darf, denn nach der Befruchtung (postfloral) entwickeln sich (bei, hapaxanthischen" Pflanzen resp. Sprossen) die weiblichen Pflanzen bzw. Bliitenstände weiter, während die männlichen zugrunde gehen. Als Beispiel möge Petasites niveus dienen (Fig. 135).

Tiefgreifende präflorale Verschiedenheiten zwischen Männchen und Weibchen sind bei Samenpflanzen nur selten anzutreffen.

DARWIN ${ }^{2}$ ) erwähnt einen solchen Fall. "Es ist eine gegenwärtig unerklärliche Tatsache, daß bei einigen diözischen Pflanzen, von denen die Restiaceae von Australien und dem Kap der guten Hoffnung das auffallendste Beispiel darbieten, die Ver-

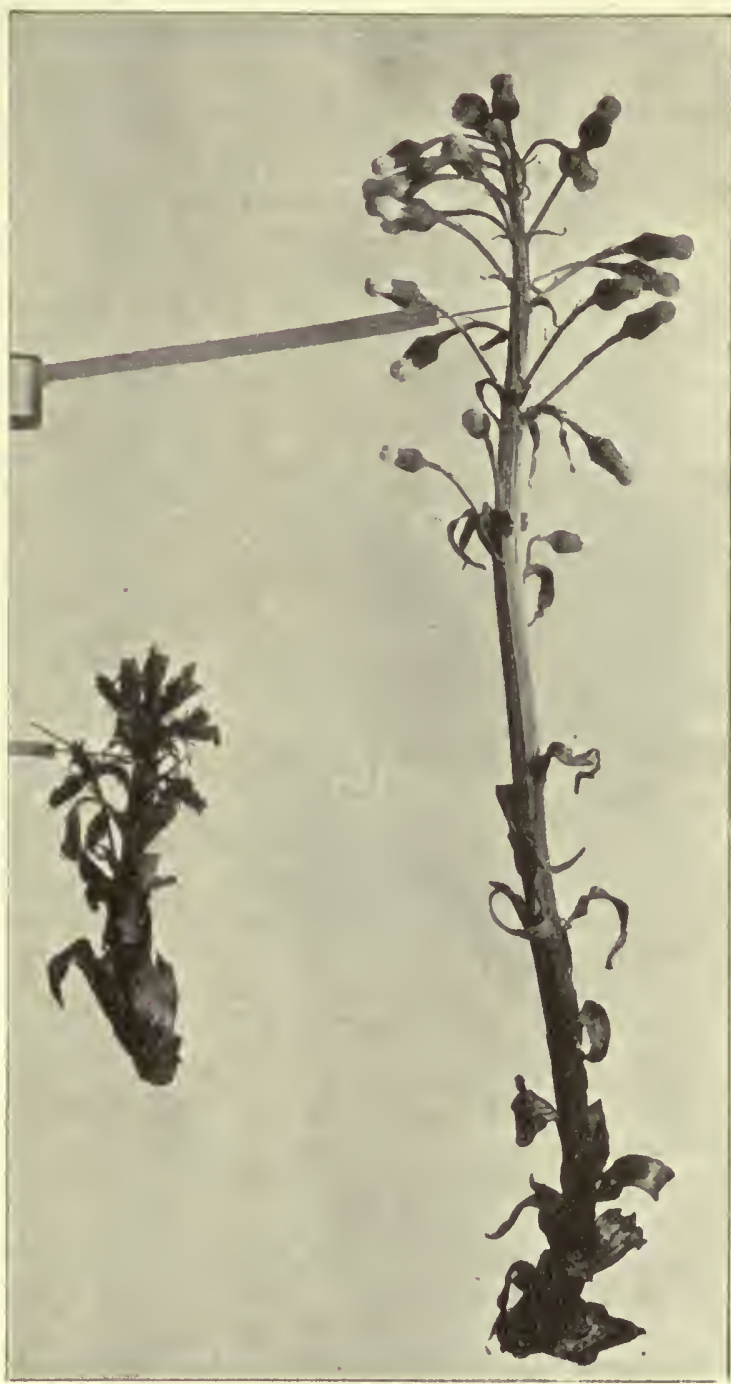

Fig. 135. Petasites niveus. Links männlicher, rechts weiblicher (in Fruchtbildung begriffener) Blütenstand, beide gleichstark verkleinert.

1) Marian North sagt, daß auf den Seychellen die männlichen Exemplare der bekannten Palme Lodoicea Seychellarum größer seien als die weiblichen. Derartige allgemeine Angaben lassen sich indes nicht verwenden. Es wäre z. B. möglich, daß die weiblichen Exemplare in ihrem Wachstum erst infolge der Fruchtbildung zurückbleiben. Man müBte also männliche und weibliche, nnter denselben Ernährungsverhältnissen gewachsene Exemplare zur Zeit der ersten Blütenbildung vergleichen (M. Noнтн, recollections of a happy life, p. 289).

2) CH. DARwis, Die verschiedenen Blittenformen an Pflanzen der nämlichen Art (Übers. von J. V. CARUs), 1877, p. 9. 
schiedenartigkeit der Geschlechter die ganze Pflanze in einer solchen Ausdehnung affiziert hat (wie ich von Mr. Thiselton Dyer höre), daß Mr. Bentham und Professor OLIVER es häufig unmöglich gefunden haben, die männlichen udn weiblichen Exemplare einer und derselben Spezies zusammenzubringen". Es wäre um so interessanter, über diesen Fall Näheres zu erfahren ${ }^{1}$ ), als er offenbar ein ziemlich vereinzelter ist. Denn es ist mir zweifelhaft, ob die für andere diözische Pflanzen angegebenen Verschiedenheiten wirklich allge $\mathrm{me}$ in zutreffende sind.

Eines der am öftesten erörterten Beispiele bietet der Hanf, Cannabis sativa. Bekannt ist ja, daß man im Mittelalter die männlichen Pflanzen, weil sie oft zarter und kleiner ${ }^{2}$ ) sind als die weiblichen, für letztere hielt (aus mißverstandener Analogie mit tierischen Verhältnissen), daher die Bezeichnung "femeln" für das Ausjäten der männlichen Pflanzen. Diese schließen ihr Wachstum oft früher durch Blütenbildung ab als die weiblichen und bleiben demgemäß meist kleiner, haben auch durchschnittlich schmalere und weniger reich gegliederte Blätter als die weiblichen.

Heyer $^{3}$ ) findet, daß die männlichen Pflanzen schlanker sind als die weiblichen (mit längeren Internodien), daß ihre Blätter im Beginn deı Blütezeit eine dunklere Farbe haben als die weiblichen, während es am Ende der Blütezeit umgekehrt sei.

Indes scheint es fraglich, ob es konstante präflorale Verschiedenheiten zwischen männlichen und weiblichen Hanfpflanzen gibt oder nur quantitative, speziell eine verschiedene Reaktionsfähigkeit den äußeren Wachstumsbedingungen gegenüber. Mir selbst liegen darüber keine eingehenden Beobachtungen vor; ich kann nur sagen, daß einzelne Pflanzen, die ich vor der Blütezeit für weibliche hielt, männlich waren (daß also gut ernährte männliche Pflanzen eine bedeutende Höhe [fast $2 \mathrm{~m}$ ] erreichen können). Es wäre zu untersuchen, ob derartige Pflanzen vielleicht (wie dies gelegentlich vorkommt) auch weibliche Blüten hervorbringen. Einen stets deutlichen präfloralen Dimorphismus konnte ich also nicht wahrnehmen. Ich gebe aber gerne $\mathrm{zu}$, daß eine genaue Prüfung vielleicht sichere Trennungsmerkmale ergeben wird. Einstweilen scheint mir das Vorhandensein von solchen auch bei diözischen Holzpflanzen noch unsicher.

Wenn z. B. BlakesLeE ${ }^{4}$ ) meint, bei "Populus pyramidalis" sei eine auffallende Sexualdifferenz vorhanden, da die männlichen Exemplare pyramidal, die weiblichen dagegen mit einer flacheren Krone versehen seien, so ist dies ein Irrtum; die Pyramidenpappel ist zweifellos nicht einfach die männliche, sondern eine Mutationsform von P. nigra, die meist nur in der männlichen Form vorhanden ist. Es kommen aber auch weibliche Pyramidenpappeln vor, und jedenfalls hat die Wuchsform nichts mit der Geschlechtsdifferenz zu tun. Auch sonst scheinen mir die Angaben über weibliche und männliche Holzpflanzen ziemlich fraglich. Ich habe bis jetzt wenigstens niemand getroffen, der mir bei einem nicht blühenden (resp. fruchtenden) Taxus ${ }^{5}$ ), Juniperus, Cycas das Geschlecht angeben konnte. Und wenn gesagt wird,

1) Namentlich darüber, ob sich die Verschiedenheit nur auf die Blütenstände oder die ganzen Pflanzen bezieht. Ersteres erscheint zunächst wahrscheinlicher.

$\left.{ }^{2}\right)$ Wobei präflorales und postflorales Verhalten nicht unterschieden wurden.

3) HEYER, Untersuchungen über das Verhalten der Geschlechter usw. Dissert. Halle 1884.

4) Blakesles, Differentiation of sex in Thallus, Gametophyte und Sporophyte, Botanical gazette vol. XLII (1906).

5) Taxus ist bekanntlich nicht selten auch monözisch, was auch bei Juniperus aber nur ausnahmsweise - vorkommt. Vgl. RENNER, Über Zwitterblüten bei Juniperus communis. Flora, 93 (1904), p. 297. 
daß bei Ailanthus glandulosa der männliche Stamm schlanker und reichlicher verzweigt sei als der weibliche, daß er bei Ginkgo eine länger gestreckte Krone und weiter abstehende Zweige habe ${ }^{1}$ ), während die weiblichen Pflanzen dichter gedrungen und schattiger seien, so wird sich fragen, ob diese Angaben all $g$ em $\theta$ in $\theta$ Gültigkeit haben.

Bei Bryophyten und Thallophyten sind Fälle von sexuellem Dimorphismus häufiger.

Bekannt sind z. B. die „Zwergmännchen" mancher Moose. Darunter versteht man winzige Pflanzen, die nur Antheridien hervorbringen und dann absterben ${ }^{2}$ ).

So stellt z. B. Fig. 139 ein in einem Sporgon von Dicnemom calycinum entwickeltes Pflänzchen dar, dessen Länge $1 / 3 \mathrm{~mm}$ betrug. Es ist nach Bildung einiger Blätter zur Antheridienbildung geschritten. Solche winzigen männlichen Pflanzen sind auch bei anderen Moosen bekannt. Es gibt alle Abstufungen von Formen, bei denen die männlichen Pflanzen etwas kleiner sind als die weiblichen, bis zu solchen, bei denen sehr bedeutende Größenverschiedenheiten zwischen beiden vorkommen.

Zwergmännchen sind z. B. beobachtet bei Dicranaceen, Leucobryum, Fissidens anomalus. Indes fragt es sich, ob die geringe Größe schon durch die Beschaffenheit der Sporen oder durch äußere Verhältnisse bedingt ist. Auf letzteres deutet z. B. die Tatsache hin, daß bei Dicranum scoparium die männlichen Pflanzen teils als Zwergmännchen im Wurzelfilze, teils in 3 und mehr cm hohem Rasen vorkommen. Bei anderen diözischen Dicranumarten sind die männlichen Pflanzen teils nur als Zwergmännchen, teils als wohlentwickelte Pflanzen bekannt - es ist also

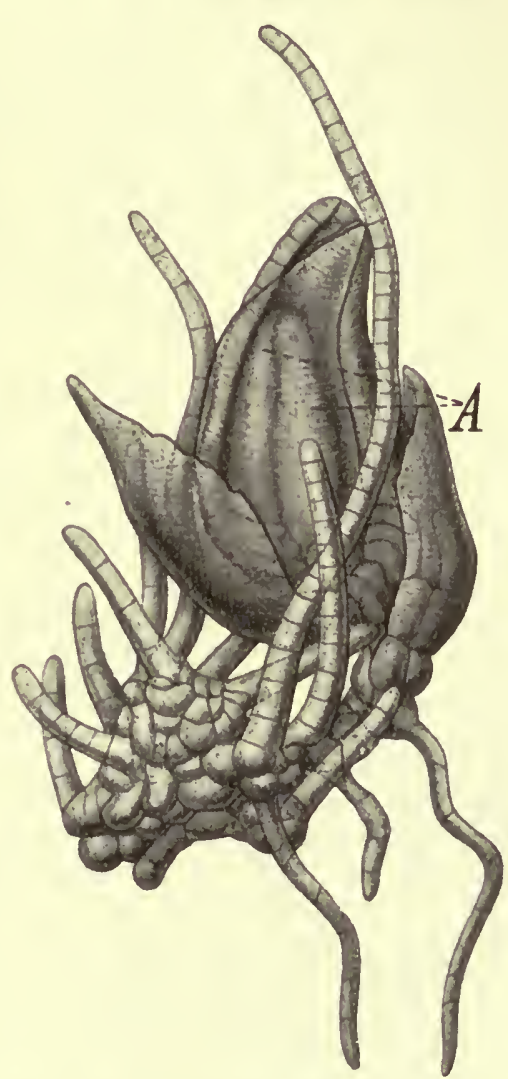

Fig. 139. Dicnemon calycinum. Der mehrzellige Sporenkörper hat eineAnzahl Protonemafäden entwickelt, an einem von diesem ein wenigblätteriges Pflänzchen, welches einige Antheridien $(A)$ (als Abschluß seiner Entwicklung) hervorgebracht hat. wahrscheinlich, daß hier das Auftreten

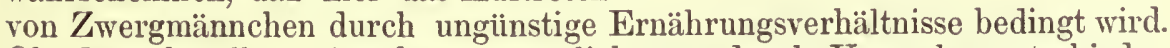
$\mathrm{Ob}$ das überall so ist, kann natiirlich nur durch Versuche entschieden werden.

Fleischer ${ }^{3}$ ) beobachtete bei Macromitriumarten Zwergmännchen, welche auf den Blättern weiblicher Pflanzen aus Sporen entstanden waren,

1) Heyer a. a. O. Nach Fuji haben die männlichen Exemplare stärker aufsteigende Zweige als die weiblichen. (Zitiert bei Lotsy, Vortr. über botan. Stammesgeschichte II, p. 779 .

2) Vgl. Goemel, Archegoniatenstudien X Flora 96 (1906) p. $55 \mathrm{ff}$.

3) R. Fleischer, Die Musci der Flora von Buitenzorg. Bd. II (Leiden 1902-1909 p. 402,427$)$. 
andere männliche Pflanzen sind bei dieser Gattung und bei Schlotheimia nicht bekannt. Es ist möglich, daß hier schon in den Sporen (die von auffallend verschiedener Größe sind) die geringere Größe der männlichen Pflanzen bestimmt ist - es wäre das ein Parallelfall zu der Bildung ron Mikro- und Makrosporen bei Pteridophyten. Allein auch hier ist unbekannt, wie die Sporen unter gleich günstigen Ernährungsbedingungen sich entwickeln, ob sie auch dann männliche und weibliche Pflanzen verschiedener Größe ergeben. Die Sexualdifferenz selbst dürfte schon in den Sporen bestimmt sein, damit ist aber noch nicht notwendig auch der sexuelle Dimorphismus gegeben. Jedenfalls kann bei den Moosen, ähnlich wie dies unten für die Farnprothallien zu erwähnen sein wird, die Antheridienbildung unter Umständen erfolgen, welche eine Archegonienbildung nicht gestatten. Damit bängt offenbar auch die bei manchen wahrnehmbare Verschiedenheit zwischen männlichen und weiblichen Pflanzen zusammen.

Auch bei den diözischen Characeen wird angegeben ${ }^{1}$ ), daß die weiblichen Pflanzen oft größer und stärker entwickelt seien als die männlichen und bei den einjährigen länger am Leben bleiben.

Ganz besonders bezeichnend sind ja die bei manchen Oedogonien vorkommenden "Zwergmännchen" und ebenso die ungemein stark rückgebildeten männlichen Prothallien der heterosporen Pteridophyten.

Zusammenfassend läßt sich alsó sagen, daß äußerlich sichtbare ${ }^{2}$ ) sekundäre Geschlechtsdifferenzen bei diözischen Pflanzen vorhanden sein können, aber nicht vorhanden sein müssen. Sie sprechen sich dann vielfach darin aus, daß die männlichen Pflanzen kleiner, weniger kräftig entwickelt sind als die weiblichen (während der umgekehrte Fall, von zufälligen Erscheinungen abgesehen, nie auftritt), und das um so mehr, in einem je früheren Stadium der Entwicklung die Bildung der Sexualorgane eintritt. Dies ist aber bei den männlichen Pflanzen deshalb möglich, weil die männlichen Sexualorgane an das Vorhandensein von Baustoffen - wie wenigstens in einigen Fällen nachgewiesen ist - geringere Ansprüche stellen als die weiblichen (vgl. unten iiber Farnprothallien). Dasselbe Prinzip tritt vielfach auch zutage, wenn wir die Beschaffenheit nicht der ganzen Pflanze, sondern der Teile, welche die Sexualorgane hervorbringen, betrachten, namentlich auch bei monözischen Pflanzen.

\section{Einzelfälle; Verschiedenheit in der Ausbildung einzelner Teile.}

Aus der großen Gruppe der Thallophyten möchte ich hier zunäclıst die Characeen herausgreifen. Sie können als Beispiel dafür dienen, daß männliche und weibliche Organe sich durch ilıre Stellung am Vegetationskörper unterscheiden in der Art, daß die weiblichen an den Stellen stehen, welche für die Zufuhr von Baustoffen die günstigsten sind.

Früher folgerte man aus der verschiedenen Stellung der Antheridien und der Oogonien der Characeen sogar eine verschiedene „morphologische Bedentung" beider Organe. Man hielt die Antheridien für umgebildete Blättchen, die Oogonien für umgebildete Sprosse. Zweifellos sind indes

1) Mrgula, Die Characeen. Leipzig 1897, p. 51. anbekannt. 
beiderlei Organe auch hier homolog ${ }^{1}$ ). In ihrer Stellung unterscheiden sie sich vor allem dadurch, daß die Oogonien stets unmittelbar aus einem Knoten entspringen (so das Oogonium 0 in Fig. 137 an dem Knoten des "Blattes" $b$ ), während die Antheridien das Ende am Blättchen einzunehmen pflegen, wenn also die abgebildete Nitella tenuissima nicht diözisch wäre, würde ein Antheridium am Ende von $b$ stehen können.

Nun sind die Knoten der Characeen die Stellen, an denen die Neubildungen stattfinden (Bildung von „Blättchen“, Seitenzweigen usw.), die Stellen also, wo eine Anhäufung von Baustoffen eintritt. Diese können, da die Oogonien an den Knoten stehen, auf kuirzestem Weg in die Eizellen geschafft werden; tatsächlich zeichnen sich ja auch die befruchteten Eizellen der Characeen durch eine sehr starke Anhäufung an Reservestoffen aus.

Obwohl mehrere Beispiele für dasselbe Verhalten - verschiedene Stellung männlicher und weiblicher Organe - bei höheren Pflanzen im Verlaufe der Darstellung noch hervortreten werden, mag doch hier schon auf ihre weite Verbreitung hingewiesen werden ${ }^{2}$ ).

Bei Pinus stehen die weiblichen Blütenzapfen an Stelle der Langtriebe, die männlichen an Stelle der Kurztriebe (daß die Langtriebe die besser ernährten sind, ist unzweifelhaft).

Ähnlich ist es bei Quercus, wo die weiblichen Blütenstände im oberen, die männlichen im unteren Teil des Jahrestriebes entspringen, entsprechend

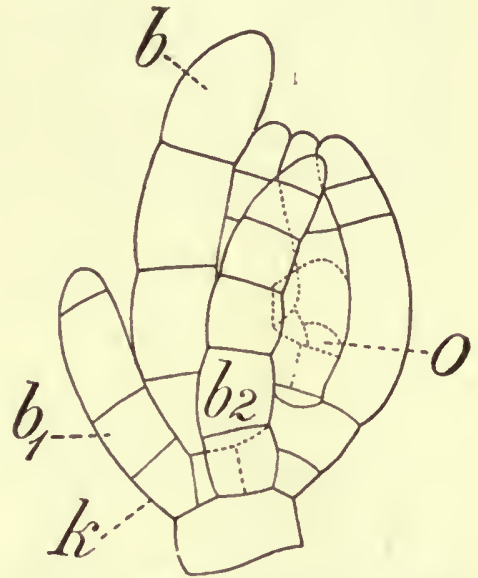

Fig. 140. Nitella tenuissima. Blättchen $b$, an dessen Basalknoten ein Oogonium $O$ (Wendungszellen punktiert) und die Blättchen $b_{1}$ und $b_{2}$ entspringen.

der Tatsache, daß die vegetativen Knospen um so kräftiger sind, je näher sie der Spitze des Jahrestriebes liegen. Dementsprechend können an schwächlichen Trieben die männlichen Blütenstände auch allein auftreten. Ganz entsprechend verhält sich auch Juglans regia. Die weiblichen Blütenstände treten hier als Abschluß der Jahrestriebe, die männlichen seitlich am vorjälırigen Trieb auf. MeEHAN ${ }^{3}$ ) gibt für Juglans nigra dreierlei Knospen an. Die größten liefern die Sprosse, welche zur Fortsetzung des holzigen Gerüstes des Baumes dienen; andere weniger kräftige ${ }^{4}$ ) schließen mit weiblichen Blütenständen $a b$, noch schwächere blühen gar nicht oder männlich.

Von diesen klar liegenden Fällen aus werden auch andere zu beurteilen sein, nur muß man im Auge behalten, daß es bei der Verschiedenheit in der Stellung männlicher und weiblicher Blüten (oder Blïtenstände) nicht bloß auf örtliche Verschiedenheiten, sondern auf Ernährungsdifferenzen ankommt. Nicht immer ist z. B. die Spitze eines Sprosses der in der Nahrungszufuhr begünstigte Teil, wie in den soeben angeführten Beispielen.

1) Gozber, Vergl. Entwicklungsgeschichte p. 418 und die dort angeführte Literatar.

2) Vgl. Goeber, Organographie, 1. Aufl., p. 654.

3) Th. Meenan, Law of sex in Juglans nigra. Proceed. of the academy of nat. Science, Philadelphia 1873, p. 291.

4) Es ist nicht zu bezweifeln, daß auch der Gehalt an Banstoffen bei diesen verschiedenen Knospen ein verschiedener ist. 
Namentlich bei Sprossen von begrenztem Wachstum können Seitenknospen infolge der Erstarkung der Pflanze unter günstigeren Ernährungsbedingungen als die Endknospen stehen. Solche Fälle werden z. B. für Funaria, Zea Mais u. a. anzuführen sein.

Auch ist die Stellungsverschiedenheit zwischen männlichen und weiblichen Blüten nicht bei allen Pflanzen eine konstante. Wie Wiтtrock ${ }^{1}$ ) gezeigt hat, kommen bei Acer platonoïdes fünf verschiedenartige Inflorescenzen vor: 1. solche, welche nur weibliche Blüten haben, 2. solche, bei denen die zuerst entwickelten Blüten weiblich und die später entwickelten männlich sind (der häufigste Fall), 3. solche, bei denen die zuerst entwickelte Blüte (die Gipfelblüte) männlich ist, die folgenden sind teils männlich, teils weiblich, die zuletzt auftretenden meist männlich, 4. solche, bei welchen die zuerst entwickelten Blüten männlich und die später entwickelten weiblich sind, 5 . solche, die nur männliche Blüten zeigen. $\mathrm{Da}$ im allgemeinen ein Baum nur einen und denselben Inflorescenztypus zeigt,

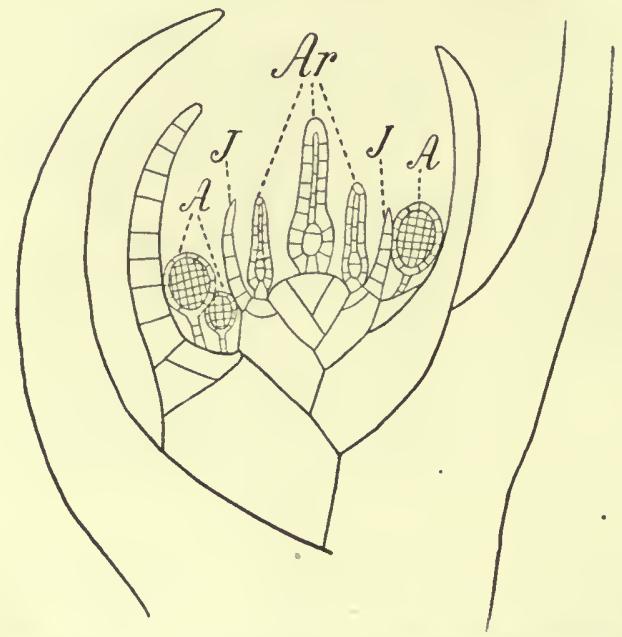

Fig. 141. Schema für die Verteilung der Sexualorgane bei einem monözischen foliosen Lebermoose. Das Stämmchen ist im Längsschnitt gedacht. A Antheridium, Ar Archegonium, $J$ die zunächst in der Entwicklnng stark gehemmten, miteinander seitlich vereinigten Blätter, welche später das Perianth bilden. Scheitelzelle und Segmente sind angedeutet. so wäre es von Interesse $\mathrm{zu}$ wissen, wie weit die Verschiedenheiten hier erblich bedingt oder durch äußere Faktoren beeinflußt sind. Im übrigen dürfte aus den obigen Mitteilungen hervorgehen, daß die weiblichen Blüten in geringerer Zahl auftreten als die männlichen, eine Erscheinung, die uns auch bei anderen Pflanzen begegnet.

Mo ose. Die Verteilung der Sexualorgane ist hier eine sehr verschiedene, teils eine monözische - in verschiedenen Modifikationen - teils eine diözische. Auf Einzelheiten kann hier nicht eingegangen werden. Es sei nur erwähnt, daß meiner Ansicht nach hier wahrscheinlich die Verteilung die ursprünglichste war, daß Archegonien und Antheridien zusammen an einem Sproß auftraten und zwar die Archegonien nach resp. über den Antheridien. Das kommt jetzt noch bei Laub- wie bei Lebermoosen vor, teils normal, teils ausnahmsweise bei solchen, die normal eine andere Verteilung haben.

Bei Funaria z. B. stehen gewöhnlich die Antheridienstände terminal am ersten Sproß, die Archegonienstände am Ende von (seitlichen) Erstarkungssprossen. Gelegentlich traf ich aber auch Antheridienstände, in deren Mitte ein Archegonium zur Ausbildung kam. Normal finden wir diese Verteilung unter den Lebermoosen z. B. bei Pellia calycina und Radula complanata, ${ }^{2}$ ) in Fig. 141 ist ein Schema für diese Verteilungsart dargestellt.

1) V. B. Wiтtrock, Über die Geschlechterverteilung bei Acer platanoïdes und einigen anderen Acer-Arten (Botan. Centralblatt III [1885]).

2) DaB ein Archegonium hier aus der Sproßspitze selbst hervorgeht, ist ein für nnsere jetzige Betrachtung nicht sehr wichtiger Spezialfall. 
Es ist klar, daß den Archegonien eine bessere Ernährung ermöglicht wird, wenn die regetative Weiterentwicklung des Sprosses entweder zeitweilig oder ganz ausgeschaltet ist; dies wird um so leichter möglich sein, je näher an der Sproßspitze die Archegonien stehen. Dasselbe Prinzip ist es, wenn die Archegonien am (kräftiger ausgebildeten) Hauptsproß, die Antheridien an kurzlebigen Seitensprossen stehen, wie dies z. B. bei Targionia der Fall ist.

Wir nehmen also an, daß beiderlei Sexualorgane ursprünglich die gleiche Stellung hatten, nur eine verschiedene zeitliche Reihenfolge, und $\mathrm{da}$ die getrennte Verteilung ebenso wie in den Blüten der Phanerogamen durch Ausfall des einen Geschlechtes zustande kam. ${ }^{1}$ ) Die Moose verhalten sich dann ebenso wie die Prothallien der isosporen Farne, und die immer zahlreicher werdenden Fälle, in denen z. B. bei normal getrenntgeschlechtigen Lebermoosen eine zwitterige Verteilung der Sexualorgane auftritt, erscheinen historisch betrachtet als Rückschläge. Eingehender kann diese Hypothese hier nicht begründet werden, da unsere eigentliche Aufgabe vielmehr die ist, die Verschiedenheiten in der Ausbildung der Träger der männlichen und der weiblichen Sexualorgane zu besprechen.

Diese seien an einigen Beispielen hier erörtert.

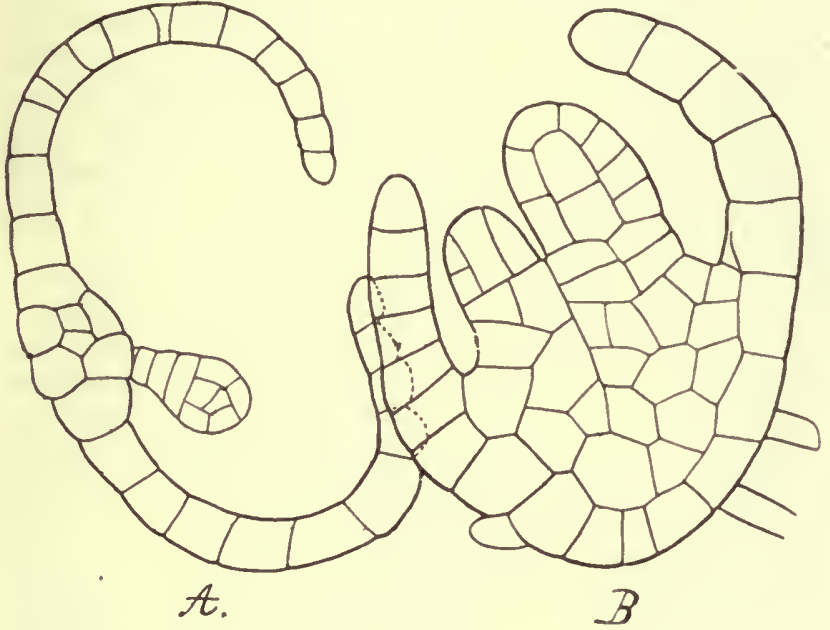

Fig. 142.

Metzgeria furcata. A Querschnitt durch einen männlichen Sproß. Die Mittelrippe ist diinn, ein junges Antheridium ist getroffen. $B$ Querschnitt durch einen weiblichen Spro\&. Die Mittelrippe ist dick, zwei junge Archegonien entspringen ibr.

Thallose Lebermoose.

Die Übereinstimmung von männlichen und weiblichen Sprossen (wenn wir zur Abkürzung diesen Ausdruck gebrauchen wollen) tritt meist ohne weiteres hervor. Doch finden sich auch in einigen Fällen Verschiedenheiten.

Ein, wie mir scheint, besonders lehrreiches Beispiel bietet die Gattung Metzgeria, eine thallose Form, bei welcher die männlichen und die weiblichen Sprosse als kurze Seitenzweige auf der Unterseite des Thallus entspringen. Sie haben eine verschiedene Gestalt und einen verschiedenen Bau. Die männlichen sind blasenförmig eingerollt, sie tragen auf ihrer Oberseite die Antheridien. Die weiblichen sind meist nur eingefaltet; an

1) $\mathrm{DaB}$ bei den Lavbmoosen in den mänulichen Blüten der Sproßscheitel zur Antheridienentwicklung verwendet wird, wird dann also ebenso eine nachträglich entstandene Eigentïmlichkeit sein, wie die Tatsache, daß bei den akrogynen Lebermoosen ein Archegoninm ans der Sproßspitze entspringt.

Goebel, Organographie der Pflanzen. 2. Aufl. Allgem. Teil. 
derselben Stelle, an der die männlichen Sprosse Antheridien tragen, bringen sie Archegonien hervor. Aber während die männlichen Sprosse eine dünne Mittelrippe und einen verhältnismäßig großen flügelförmigen Teil des Thallus haben (Fig. 142), zeigen die weiblichen eine dicke Rippe und einen weniger entwickelten Flügel, was offenbar auch die verschiedene Gestalt beider Sprosse bedingt. Die starke Entwicklung des Gewebes unterhalb der Archegonien ermöglicht die Aufspeicherung von Reservestoffen für die Embryoentwicklung. Offenbar sind also auch hier die Archegonien

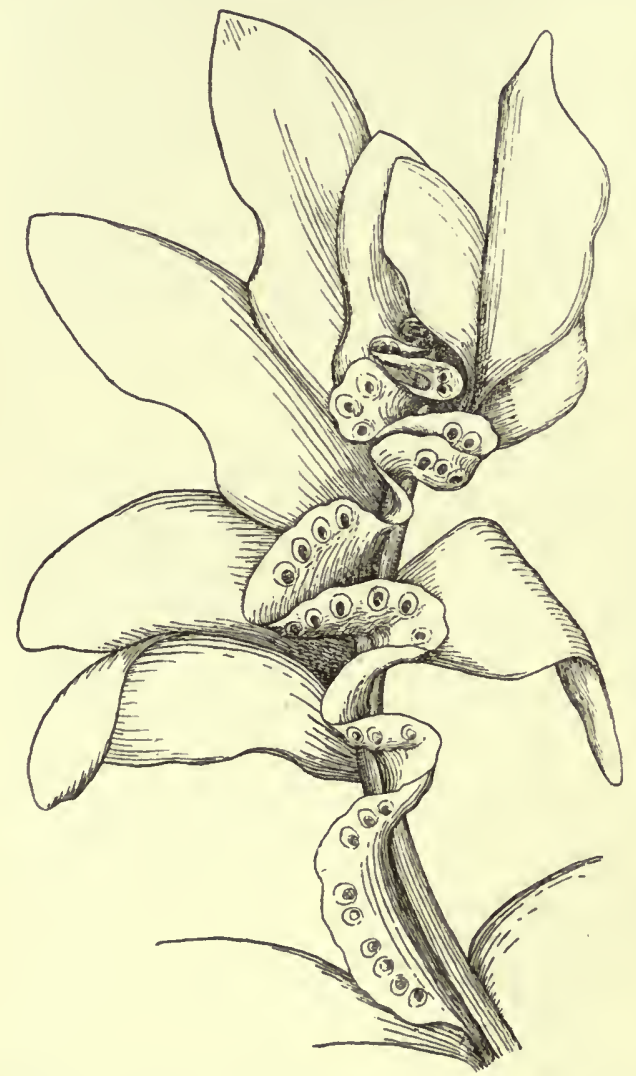

Fig. 143. Riella Clausonis mit Antheridien, welche dem Flïgel eingesenkt sind. an den besser ernährten Sprossen angelegt. Die männlichen stellen ephemere, nach der Entleerung der Antheridien zugrunde gehende Gebilde dar.

Dasselbe Prinzip kann auch ähnlich wie bei den erwähnten Characeen eine andere räumliche Anordnung von Antheridien und Archegonien bedingen.

Die merkwürdige Gattung Riella z. B. besitzt einen Thallus bestehend aus einer mehrschichtigen, als Leitungs- und Speichergewebe dienende Rippe („Stämmchen“) und einem (vertikal stehenden) Flügel, welcher einschichtig ist. An ihm entstehen dieAntheridien(Fig.143), die Archegonien dagegen an den Stämmchen (Fig. 144) was sich in ganz ähnlicher Weise auch bei den Prothallien vieler Farne wiederholt.

Eine andere Art sexueller Verschiedenheit findet sich bei den Gattungen Blyttia, Symphyogyne u. a.

Symphyogyne leptothele zeigt eine diözische Verteilung. Fig. 145 zeigt das Ende einer männlichen, Figur 147 den Längsschnitt einer weiblichen Pflanze. An den männlichen Pflanzen sehen wir die Antheridien (bedeckt von schuppenförmigen Thalluswucherungen) längs der Mittelrippe in großer Zahl auftreten. Bei den weiblichen (Fig. 146) sitzen die Archegonien in Gruppen, welche ron einer einzigen Schuppe bedeckt sind; sie stehen hier auf einer Vorwölbung, die embryonalen Charakter behaltend nach der Befruchtung, die sog. Calyptra bildet (indem sich der Embryo in das weiter wachsende Gewebe einbohrt). Ich habe früher die Ansicht ausgesprochen ${ }^{1}$ ), daß die Verschiedenheit in der Anordnung von Antheridien und Archegonien dazu in Beziehung stehe, 


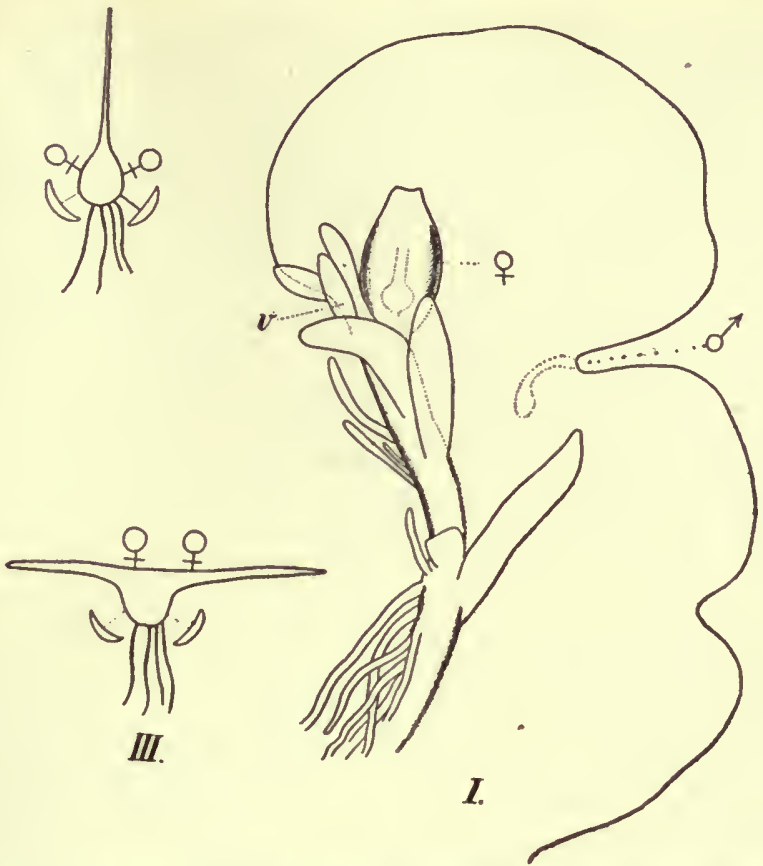

Fig. 144. Riella Battandieri mit einem von einer Hülle umgebenen Archegonium $\$$, welches am "Stämmchen" steht.

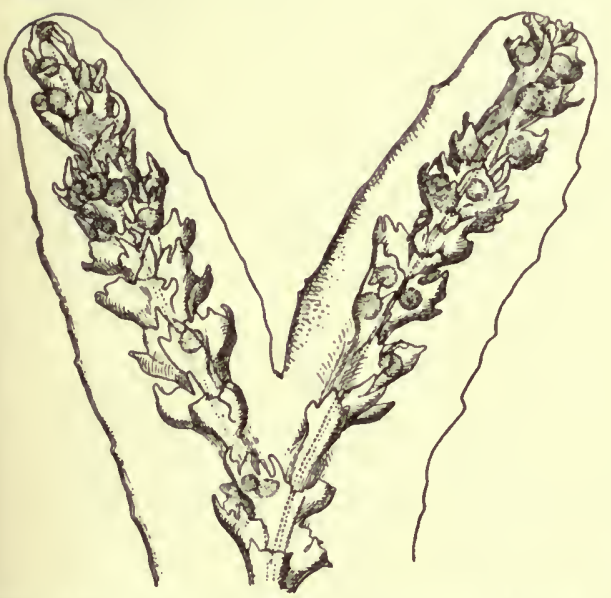

Fig. 145. Symphyogyne leptothele. Endstïck einer männlichen Pflanze. Nahe der Mittelrippe entspringen 2-4 Reihen von Schuppen, nnter welchen je ein Antheridium sich befindet (etwa 10 fach vergr.).

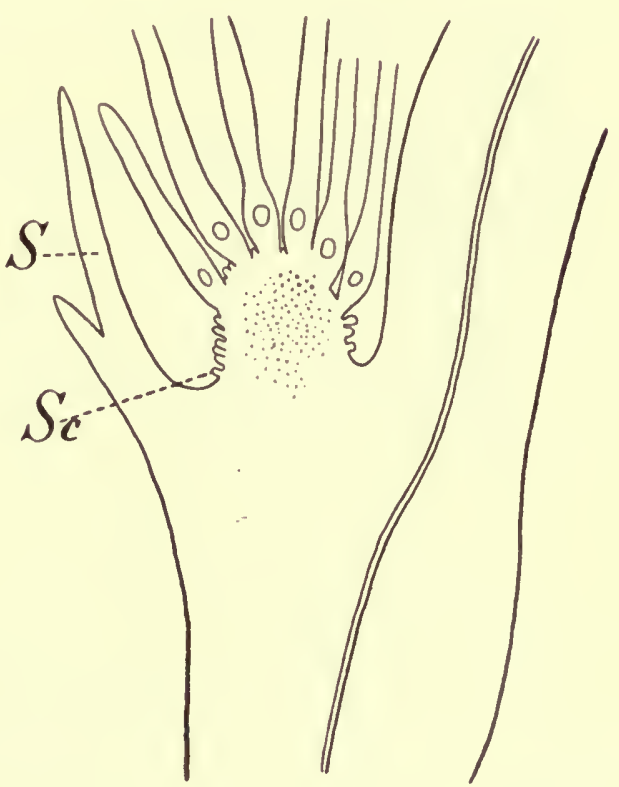

Fig. 146. Symphyogyne lepthothele. Längsschnitt durch eine weibliche Pflanze (vergr.). $S$ eine Schuppe, unter welcher die Archegoniengruppe sich befindet, Sc Schleimbazillen. 
da $\beta$ es bei den Antheridien auf die der Altersfolge nach vor sich gehende Entleerung der Spermatozoiden nach außen ankomme, während von den zahlreichen Archegonien nur eines einen Embryo entwickelt. Wenn also eine größere Anzahl von Archegonien verschiedener Entwicklung sich beisammen befinden, wird die Wahrscheinlichkeit der Befruchtung durch Spermatozoiden, welche in den kapillar in den Hohlraum unter der Schuppe eingesogenen Wassertropfen sich befinden, erhöht.

Besonders oft erörtert sind die männlichen und weiblichen Sprosse bei den Marchantiaceen. Sie sind schon deshalb von Interesse, weil sie auffallend verschieden gestaltet sind, dadurch, daß scheinbar die Antheridien auf der Oberseite, die Archegonien auf der Unterseite stehen. Die entwicklungsgeschichtliche Untersuchung ${ }^{1}$ ) hat aber schon längst ergeben, daß in Wirklichkeit auch die Archegonien auf der Oberseite entstehen und auf die Unterseite erst im Verlaufe der Entwicklung verschoben werden, eine Stellung, welche sie nicht nur in eine besonders geschützte, sondern auch in eine für die Befruchtung günstige Lage bringt.

Es wurde ${ }^{2}$ ) versucht darzulegen, daß die männlichen Sprosse der Marchantiaceen, wenn wir den Zusammenhang der einzelnen Formen dieser Gruppe betrachten, plastischer sind als die weiblichen. Diese erfahren schließlich ganz ähnliche Rückbildungen wie die männlichen. Darauf kann hier nicht näher eingegangen werden, es sei nur auf die Verschiedenheit zwischen einem männlichen und einem weiblichen "Träger" von Preissia commutata hingewiesen. Der männliche ist kleiner als der weibliche und sein scheibenförmiger Teil (der oben die Antheridien trägt) zeigt keine Gliederung mehr, während diese bei den weiblichen Ständen (namentlich in den jüngeren Stadien) noch deutlich hervortritt.

Auch bei den Jungermanniaceen kommen ähnliche Verhältnisse vor. Bei Hymenophytum (Umbraculum) flabellatum sind die männlichen Sprosse zu kleinen, dem Thallus aufsitzenden Scheiben reduziert, die weiblichen viel weniger ${ }^{3}$ ).

Wir können also, wenn wir damit das oben gesagte vergleichen, sagen, daß bei den thallosen Lebermoosen allgemein die Träger der männlichen Sexualorgane stärkere Um- und Rückbildungen aufweisen als die der weiblichen.

Foliose Lebermoose und Laubmoose.

Auch bei ihnen sind die Antheridienstände plastischer als die Archegonienstände, das zeigt sich darin, daß

1. bei den foliosen (akrogynen) Lebermoosen die Antheridienstände (entsprechend der Gestaltung des Vegetationskörpers) wohl nur dorsiventral sind, während bei den Archegonienständen radiäre Ausbildung sehr häufig ist,

2. daß sie leicht regetativ auswachsen (was bei den Archegonienständen aus dem p. 145 Anm. erwähnten Grunde nicht möglich ist),

3. daß die ganzen männlichen Pflanzen oft einer stärkeren Reduktion unterliegen als die weiblichen. Es ist dies aber keineswegs immer der Fall, bei Monoclea z. B. sind männliche und weibliche Pflanzen oft anscheinend ganz gleich. Die antheridientragenden Zweige der Laubmoose zeigen nicht selten (so bei Mnium, Politrychum) ein vollständiges Fehlen der Blattbildung, was bei den archegonientragenden Zweigen nicht vor-

3) Vgl. Goerel, Über die Verzweigung dorsiventraler Sprosse (Arb. a. d. bot. Institut Würzburg II, 1880, p. 371 und LeITGEB, Unters. über die Lebermoose, Hft. Vl).

2) Flora, 101 (1910), p. 8 jf.

3) Vgl. Goebel, Archegoniatenstudien X. Flora, 96 (1906), p. 175. 
kommt, ja bei Sphagnum ist (nach Leitgeb's Auffassung) der ganze antheridientragende Seitensproß auf ein Antheridium reduziert.

Das Verhalten stimmt also mit dem für die Antheridienstände der Machantiaceen oben angenommenen überein, und ebenso mit dem für die männlichen Pflanzen mancher Laubmoose oben erwähnten. Als Erläuterung dafür sei auf die Abbildung von Ephemerum (Fig. 147) verwiesen. Ebenso stimmt damit überein das Verhalten der männlichen Pflanzen mancher diözischen Iaubmoose (vgl. S. 141). Ein noch auffallenderes Beispiel dafür bietet die Laubmoosgattung Buxbaumia, bei welcher es in den männlichen Pflanzen (welche nur ein Antheridium besitzen) gar nicht melır zur Ausbildung eines Stämmchens kommt und nur ein rudimentäres Blatt als Hülle des Antheridiums vorhanden ist, während die. weiblichen Pflanzen ein Stämmchen mit mehreren Blättern (und bei B. aphylla auch mehrere Archegonien) besitzen. Es tretell also uiberall gemeinsame Züge hervor,

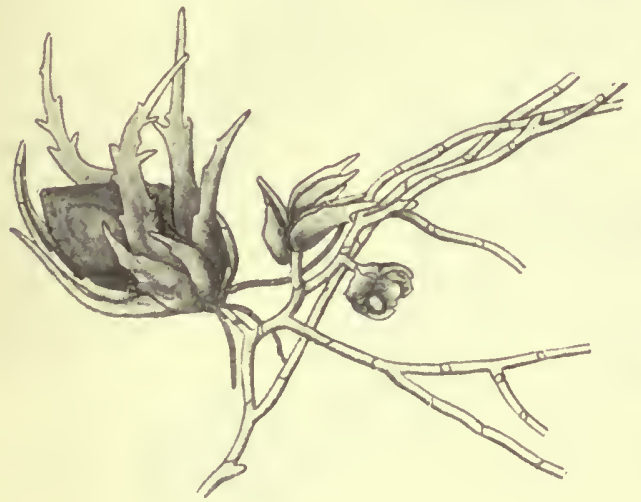

Fig. 147. Ephemerum serratum. An dem fadenförmigen Protonema haben sich mehrere männliche Pflanzen und zwei weibliche gebildet. Die, welche ein Sporogon entwickelt hat, besitzt viel größere Blätter als die männlichen Pfänzchen nnd hat aus ihrer Basis Rhizoiden getrieben, was bei den männlichen Pflanzen nicht der Fall ist. (Vergr. etwas über 40 fach )

die kausal offenbar bedingt sind dadurch, „daß die Entstehung männlicher Geschlechtsorgane erfolgt unter Bedingungen, welche zur Bildung der weiblichen nicht hinreichen" "), biologisch dadurch, "daß die weiblichen Pflanzen, welche später den Embryo auszubilden haben, besser ausgerüstet sein müssen, als die männlichen" "2). Letzteres ist ebenso wie die Tatsache, daß die weiblichen Sproßteile bei beblätterten Moosen in der Nähe der Archegonien vielfach besonders große Blätter hervorbringen, eine Folge der reichlichen Nährstoffzufuhr zu den Bildungstätten der weiblichen Organe.

\section{Pteridophyten. A. Geschlechtsgeneration.}

Unter den isosporen Pteridophyten sind die Verhältnisse der Geschlechtsverteilung am bekanntesten bei den Farnen. Das gewöhnliche Verhalten ist hier das, daß am Prothallium zunächst die Antheridien, und erst dann, wenn die Assimilate in größerer Menge angehäuft sind, die Archegonien auftreten. Der instruktivste Fall ist vielleicht der in Fig. 148 abgebildete: bei Trichomanes treten die Antheridien an Zellfäden auf, die Archegonien erst dann, wenn sich ein Zellkörper. (das Archegoniophor) gebildet hat

1) Goeber, Organographie der Pflanzen, 1. Aufl. p. 371.

2) Ebendaselbst. 
(was nur unter günstigen Ernährungsverhältnissen möglich ist). Dem entspricht die bekannte Tatsache, daß unter ungünstigen Ernährungsverhältnissen - falls es überhaupt zur Bildung von Sexualorganen kommt nur Antheridien auftreten ${ }^{1}$ ). Es stimmt das, wie schon oben bemerkt, mit zahlreichen Fällen bei anderen Pflanzen überein. Dabei kommt es offenbar an auf die Produktion kompliziert gebauter organischer Verbindungen. Denn die Verhinderung der Archegonienbildung erfolgt offenbar sowohl bei mangelhafter $\mathrm{C}$ - als $\mathrm{N}$ - und P-Assimilation.

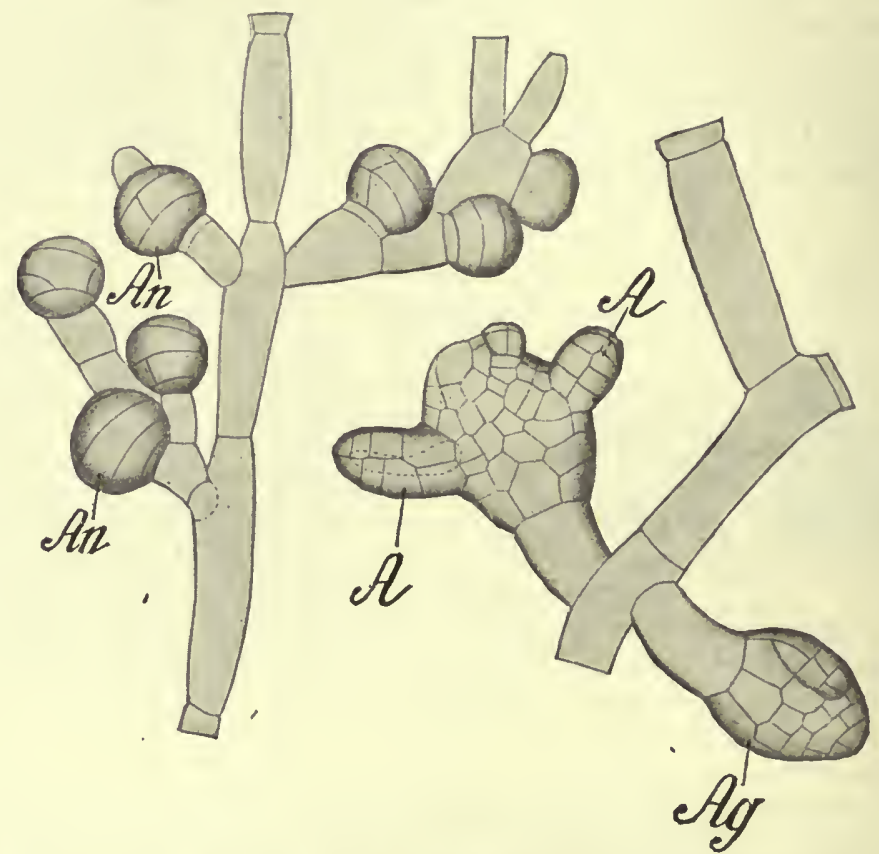

Fig. 148. Trichomanes rigidum. Diese Hymenophyllace besitzt Prothallien in Gestalt verzweigter Fäden. Links Stück eines Fadenprothalliums mit Antheridien $A n$ (unmittelbar an den Fäden), rechts Prothalliumfaden, an welchem „Archegoniophore“ $(A g)$ sitzen, d. h. massive Zellkörper, an welchen erst die Archegonien $(A)$ entstehen.

Auch bei Equisetum, wo normal nur ,.diözische" Prothallien auftreten, können (wie die vor Jahren auf meine Veranlassung ron BuchtieN ausgeführten Untersuchungen gezeigt haben) die weiblichen Prothallien ${ }^{2}$ ) durch schlechte Ernährung in männliche übergeführt werden. Die männlichen Prothallien stellen sich den weiblichen gegenüber deutlich als Hemmungsbildungen dar, und ebenso ist es auch bei den heterosporen Pteridophyten, nur daß die „Hemmung“ hier aus „inneren“ Gründen auf-

1) Bei einzelnen Farnen (z. B. wie schon Prantl bei Ceratopteris fand) genügen schon die in der Spore vorhandenen Reservestoffe, um nach der Keimung die Bildung der Antheridien zu ermöglichen. Das aus der Spore entwickelte Prothallium kann deshalb in solchen Fällen sehr kleil sein, zuweilen nur aus einer oder zwei Zellen bestehen. Dagegen tritt die Entwicklung der Archegonien stets erst nach ausgiebiger Ernährung des Prothalliums ein.

2) Wie früher hervorgehoben wurde, ist die Eigentümlichkeit hier die, daß an den weiblichen Prothallien normal die Antheridienbildung, obwobl sie "potentiell “ ist, ganz unterbleibt, was auch bei Farnen vorkommt. 
tritt und schon bei der Sporenbildung erfolgt, wozu sich Übergänge vielleicht auch schon bei den isosporen Formen finden.

Es wird sich weiter fragen, ob sich in der ungeschlechtlichen Generation der heterosporen Formen Einrichtungen finden, welche auf eine Verschiedenheit in den Bedingungen für die Bildung von Mikro- und Makrosporangien hinweisen, und welche Sporangienformen der ursprünglichen (isosporen) Sporangienform näher steht.

\section{B. Ungeschlechtliche Generation.}

Wenn wir oben (S. 150) die letzte Frage dahin beantworteten, daß die Mikrosporangien der ursprünglichen Sporangiumsform noch näher stehen als die Makrosporangien, so soll damit nicht gesagt sein, daß sie gar keine, sondern nur, daß sie weniger starke Veränderungen erfahren haben, als jene. Es spricht sich das ja schon darin aus, daß in den Mikrosporangien normal noch alle Sporenmutterzellen zur Sporenbildung gelangen (wie bei den isosporen Formen), in den Makrosporangien bei den meisten Formen nur eine. Es ist aber kaum zu bezweifeln, daß z. B. bei Selaginella die vier Makrosporen eines Makrosporangiums nicht ebensoviel Baumaterial beanspruchen wie die 256 Mikrosporen eines Mikrosporangiums, sondern mehr. Das ist freilich zunächst nur eine auf den Augenschein gegründete Vermutung. da weder Gewichtsbestimmungen noch chemische Analysen vorliegen. Daß mit der Verschiedenheit der Sporenbildung auch eine solche in der Gestalt und im Bau der Sporangien verbunden sein kann, wurde früher für Selaginella ${ }^{1}$ ) gezeigt; die Beziehungen dieser Verschiedenheiten zu der Verbreitung der Sporen traten dabei deutlich hervor.

Ferner ist die Frage zu erörtern, ob Mikro- oder Makrosporangien in ihrer Stellung verschieden sind, und ob, falls dies der Fall ist, die Verschiedenheit der entspricht, welche für männliche und weibliche Organe oben (S. 149) erörtert wurde.

In der Anordnung der Sporangien lassen sich zwei Fälle unterscheiden: Bei den heternsporen Farnen sind (wenigstens ursprünglich) Makro- und Mikrosporangien in "Sori" vereinigt und zwar so, daß die Makrosporangien iiber den Mikrosporangien stehen. Bei den heterosporen Lycopodinen stehen die Sporangien einzeln in den Blattachseln und zwar bei den radiären Sporangienständen (welche wir als die ursprünglicheren betrachten) meist so, daß Makrosporangien an der Basis stehen.

Heterospore Farne. Unter diesen zeigen Azolla und die Marsiliaceen meiner Ansicht nach das ursprüngliche, Salvinia ein abgeleitetes Verhalten.

Bei den Marsiliaceen befindet sich im Sorus oben eine Reihe von Makrosporangien, unterhalb dieser stehen die Mikrosporangien. Analog ist es bei Azolla, nur verkümmern hier in den Makrosoris die Mikro-, in den Mikrosoris die Makrosporangien, die ,zwitterige“ Anlage der Sori tritt aber noch deutlich hervor.

In allen diesen Fällen entstehen die Makrosporangien zuerst; sie sind durch ihre Stellung, durch ihren massigeren Stiel, ihre bedeutendere Größe den Mikrosporangien gegenüber dentlich als dis besser ernährten kenntlich.

Damit stimmen auch die experimentellen Untersuchungen von SнатTUCK überein ${ }^{2}$ ).

1) Goeber, Sporangien, Sporangienverbreitung und Blütenbildung bei Selaginella. Flora 88 (1901), p. 207.

${ }^{2}$ ) Shatruck, The origin of heterospory in Marsilia (The botanical gazette Vol. XLII [1910], p. 19). 
Es gelang ihm in den Mikrosporangien einzelne Sporen von bedeutend größerem Volumen zu erzielen. Es geschah dies in Kulturen, die sehr gut ernährt waren und denen nur wenige Sporokarpien gelassen worden waren. Andererseits zeigten sich die Makrosporangien im jugendlichen Stadium empfindlicher gegen ungünstige Ernährungsbedingungen als die Mikrosporangien.

Salvinia zeigt insofern abweichende Verhältnisse, als Mikro- und Makrosori hier sich ontogenetisch nicht mehr wie bei Azolla von einer „Zwitterigen" Anlage ableiten lassen. Indes haben sowohl Metrenius ${ }^{1}$ ) als HeINRıCHER ${ }^{2}$ ) gelegentlich Sori mit Mikro- und Makrosporangien gefunden, und man wird letzterem nur beistimmen können, wenn er diese Erscheinung als Atavismus betrachtet. Es werden also in den Makrosoris die Mikro-, in den Mikrosoris die Makrosporangien für gewöhnlich spurlos unterdriickt, wie denn auch in anderen Beziehungen (Entwicklungsfolge der Sporangien im Sorus, Verschiedenheit der Wasser- und Luftblätter, Wurzellosigkeit) Salvinia sich Azolla gegenüber als der stärker veränderte Typus zeigt.

Für die hier erörterte Frage ist es auch von Interesse, daß bei Salvinia natans an schwächlichen Seitenzweigen und am Ende der Vegetationsperiode (diese Art ist bekanntlich „einjährig") nur Mikrosori auftreten - ein deutlicher Hinweis darauf, daß diese weniger Ansprüche an die Ernährung machen als die Makrosori.

Is o ëtes. Die Isoëtesarten sind Pflanzen mit ausschließlich radiären Sprossen. Die Makrosporangien tragenden Blätter (Makrosporophylle) gehen normal den Mikrosporangientragenden voraus; sie treten in etwas kleinerer Zahl als letztere auf ${ }^{3}$ ). TVenn wir bedenken, daß auf die Mikrosporophylle später sterile Blätter folgen, daß bei $\mathrm{schwächlichen} \mathrm{Exem-}$ plaren von I. tegulensis die Zahl der Makrosporophylle auf eines reduziert sein kann, ferner daß bei dieser Art (und wohl auch bei anderen) junge Exemplare vorkommen, welche $\mathrm{n}$ ur Mikrosporophylle tragen ${ }^{4}$ ), so ist nicht zu bezweifeln, daß die Bildung der beiderlei Sporangien, resp. Sporophylle von Ernährungsbedingungen abhängig ist, in der Art, daß die Makrosporophylle größere Ansprïche an die Ernährungstätigkeit stellen, als die Mikrosporophylle.

Es wird also bei jungen Exemplaren, in welchen die Ablagerung von Reservestoffen im Stamme noch eine geringere ist, ohne Zweifel möglich sein, experimentell die Bildung von Mikrosporophyllen allein hervorzurufen.

Selaginella. Wenn man Abbildungen, wie die oft kopierte SACHs'sche von S. inaequalifolia ${ }^{5}$ ) ansieht, so könnte man glauben, daß bei dieser Gattung Mikro- und Makrosporangien sich in ihrer Stellung innerhalb der "Blüte" nicht unterscheiden. Man sieht nämlich an dieser Figur links in den Achseln der Sporophylle Mikro-, rechts Makrosporangien. In Wirklichkeit aber liegt die Sache anders. Die Sachs'sche Abbildung ist vollständig richtig. Aber sie bezieht 'sich auf eine Selaginella mit annähernd horizontal stehenden „Bliiten“. In diesen sind (gleichgültig ob

1) Metreanios, Bciträge zur Kenntnis der Rhizocarpeen. Frankfurt 1846.

2) Heinricher, Die näheren Vorgänge der Sporenbildung der Salvinia natans. Sitznngsber. d. Kais. Akad. der Wissensch. LXXXV, Wien 1882.

3) A. Braun, Über die Isoëtesarten der Insel Sardinien. Sitzungsber, d. phys.math. Klasse der Berliner Akademie, 7. Dez. 1863, p. 563.

4) Analog der Tatsache, daß bei manchen monözischen Pflanzen in der Jugend nur männliche Blitten anftreten.

B) GoEBEL, Grundzüge der Systematik usw. Fig. 253, p. 326. 
die Blüten gleich große Sporophylle haben oder invers dorsiventral sind) normal die Mikrosporangien auf der Ober-, die Makrosporangien auf der Unterseite angeordnet ${ }^{1}$ ). Die SACHs'sche Abbildung stellt also einen vertikalen Längsschnitt dar.

Man hat die Anordnungsverhältnisse verschieden in Gruppen zu gliedern versucht. SPRING ${ }^{2}$ ) hatte vier Typen der Verteilung unterschieden:

1. Blüten (épis) mit einem Makrosporangium an der Basis (größer als die Mikrosporangien).

2. 4-6 Makrosporangien, welche kaum größer sind als die Mikrosporangien.

3. Makrosporangien in unbestimmter Zahl gemischt mit den Mikrosporangien.

4. Eingeschlechtige Blüten, die aber nicht konstant bei den betreffenden Arten sind.

Eingehender hat Hierovyuus die Verteilung der Sporangien besprochen. Er unterscheidet drei hauptsächliche Blütentypen: 1. die aufrechten, radiären haben meist an der Basis, bisweilen auch in der ganzen unteren Hälfte, selten darüber hinaus, Makrosporangien, dann Mikrosporangien. Ein Spezialfall wird durch die Oligomakrosporangiaten dargestellt, bei denen nur ein sehr großes Makrosporangium sich an der Basis der Blüten befindet. 2. Horizontal liegende Blüten zeigen meist die Makrosporangien auf der dem Boden zugekehrten Seite, die Mikrosporangien auf der Lichtseite. 3. Hängende Blüten oder solche mit nach unten umgekehrten Spitzen zeigen nicht selten an der Spitze Makrosporangien. Hieronymus hält einen Einfluß der Schwerkraft auf die Sporangienverteilung für wahrscheinlich. Indes könnte dieser doch nur ein ganz indirekter sein, denn die Entwicklung der Makrosporangien beginnt zu einer Zeit, in welcher diese wohl kaum "schwerer" sind als die Mikrosporangien.

Es möge an einigen Beispielen erörtert werden, welche Verschiedenheiten hier auftreten. Selaginellen des dritten Hreronysus'schen Typus zu untersuchen hatte ich keine Gelegenheit, es mögen also nur die zwei ersten Typen erörtert werden.

Für die orthotropen Blïten gelten wohl die für Isoëtes geltend gemachten Gesichtspunkte. Sie würden zu Versuchen besonders geeignet sein, indes sind gerade diese Arten wohl kaum in den Gewächshäusern vertreten; auch die einheimische hierhergehörige S. spinulosa gehört nicht zu den leicht zu kultivierenden Pflanzen.

Indem bezüglich einiger abweichende Einzelfälle, wie Sel. rupestris auf die Ausführungen a. a. $\mathrm{O}^{3}$ ) verwiesen wird. sei hier nur erörtert, inwiefern die Stellungsverschiedenheiten der Makro- und Mikrosporangien kausal verständlich sind.

Die plagiotropen Blïten haben, wie Hierovymus zuerst hervorhob, die Makrosporangien auf der Unterseite.

Die Unterseite, auf welcher die Sporangien stehen, ist diejenige, welche am vegetativen Sproß die geförderte ist, was sich schon dadurch ausspricht, daß hier die größeren Blätter stehen (vgl. die analogen unten für Pocris zu schildernden Verhältnisse). Wenn bei den invers dorsiventralen Blüten hier die kleinen Blätter auftreten, so könnte man vermuten, daß hier eine Korrelation zur Bildung der Makrosporangien

1) Vgl. auch Neokr, Die Sporenansstreuung bei Selaginella helvetica und S. spinulosa. Flora 103 (1911) p. 74.

2) Monographie des Lycopodiacées.

3) Biol. Zentralblatt XXX p. $675 \mathrm{ff}$. 
vorliege, d. h. daß das Auftreten der ernährungsphysiologisch anspruchsvollen Makrosporangien ein Kleinerwerden, das der anspruchslosen Mikrosporangien umgekehrt ein Größerwerden der zugehörigen Blätter bedinge. Diese Annahme wird, wie mir scheint, dadurch gestritzt, daß -- wie ich a. a. O. nachgewiesen habe -, die Umkehrung der Anisophyllie sofort verschwindet, wenn man die Blüten nötigt, unter Aufgabe der Sporangienbildung vegetativ weiter zu wachsen. Es wäre demnach die gewöhnliche Anisophyllie auch bei den Blüten latent vorhanden, nur verdeckt durch Korrelationsverhältnisse.

Indes möchte ich nicht verschweigen, daß ich bei $\mathrm{S}$. rubricaulis und minima ${ }^{1}$ ), welche invers dorsiventrale Blüten haben, auch in den Achseln der oberen (größeren) Sporophylle Makrosporangien fand, ein Fall, auf welchen die soeben vorgetragene Hypothese nicht paßt. Sie mag trotzdem nicht unerwähnt bleiben, denn es können ja noch andere Faktoren mitwirken, welche das Resultat ändern.

Im übrigen sind die Verhältnisse recht mannigfaltig. Einige Beispiele mögen angeführt werden.

Bei S. Pouzolziana var. obtusifolia fanden sich bei einer ziemlich kümmerlich wachsenden Pflanze nur Mikrosporangien in den Blüten (sowohl auf der Ober-als der Unterseite), ohne daß sich darunter - wie dies sonst nicht selten vorkommt - verkümmerte Sporangien gefunden hätten, so z. B. bei einer gleichfalls kränklichen S. viticulosa, welche in ihren Blüten nebén vielen verkümmernden nur Mikrosporangien besaß, nur eine Blüte hatte ein einziges Makrosporangium. Bei S. erythropus fanden sich an der Spitze der Blüten nur Mikrosporangien, im unteren Teil der Blüte auf der Unterseite bei

1. 2 Mikrospor. 3 Makrospor. (dann Mikrospor.).

2. 1 " 2

3. $2 " 1$

4.4

5. 2

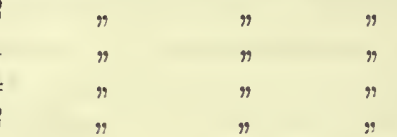

Analoge Verhältnisse wären von anderen Selaginellen zu berichten. Indes würden die Zahlen kein weiteres Interesse haben. Sie zeigen jedenfalls, daß die Verteilungsverhältnisse bei manchen Arten nicht konstant sind, daß zwar die Makrosporangien sich fast ausschließlich auf der Unterseite ausbilden, ihre Zahl aber offenbar von Ernährungsrerhältnissen abhängig ist und daß die Makrosporangienbildung durch ungünstige Ernährungsverhältnisse leichter unterdrückt werden kann als die Mikrosporangienbildung.

Von Monokotylen sei zunächst erwähnt das merkwürdige Verhalten der (gewöhnlich diözischen) Orchideengattung Catasetum, bei welcher männliche und weibliche Blüten so verschieden sind, daß man sie früher als verschiedene Gattungen beschrieb. Das gelegentliche Vorkommen ron männlichen und weiblichen Blüten in einer Inflorescenz oder an einem Exemplar der sonst diözischen Pflanzen hat den wirklichen Sachverhalt klargestellt. Die seinerzeit von DARwrN ${ }^{2}$ ) vertretene Annahme, daß außer männlichen und weiblichen Blüten auch noch Zwitterblïten vorkommen,

1) Ob die von Sadeneck als S. minima bestimmte Pflanze des Münchener Herbars (gesammelt von Disklage in Gabun, Westafrika) mit $S$. minima Spr. übereinstimmt, kann ich wegen Mangel an Vergleichsmaterial nicht feststellen.

$\left.{ }^{2}\right)$ CH. DanwiN, UUber die Einrichtungen zur Befruchtung heimischer und ausländischer Orchideen, Übers. p. 185. 
hat sich nach den Untersuchungen von RoLFE ${ }^{1}$ ) nicht als zutreffend erwiesen. DARwix hebt hervor, daß die verschiedenen Blütenformen von Catasetum in viel höherem Grade voneinander verschieden seien, als z. B. Pfauhahn und Pfauhenne. Dabei ist noch bemerkenswert, daß die weiblichen Blüten verschiedener Arten, wie RoLFe anführt, einander sehr gleichen, während die männlichen untereinander rerschieden sind. Die Verschiedenheiten sind teils primäre, d. h. auf die Sexualorgane selbst bezügliche, teils sekundäre. $\mathrm{Da}$ in den weiblichen Blüten die Pollinien und die merkwürdigen "Antennen" des Rostellums, in den männlichen der Fruchtknoten und die Narbe rückgebildet sind, entspricht den auch sonst vielfach auftretenden Verschiedenheiten zwischen männlichen und weiblichen Blüten.

Aber besonders merkwürdig sind die sekundären Verschiedenheiten. Nicht nur ist z. B. bei Cat. barbatum (Fig. 149) in den männlichen Bluiten das Labellum nach unten gekehrt (eine Lagenveränderung um $180^{\circ}$, welche bei den meisten Orchideen und auch bei den weiblichen Blüten einiger Catasetumarten [rgl. ROLFe, a. a. O., p. 222] eintritt), in den weiblichen nach oben, auch das Perigon ist sehr verschieden geformt, wie das aus Fig. 149 hervorgeht.

CRÜGER ${ }^{2}$ ) gibt an, daß bei Cat. tridentatum die Pollinien in den weiblichen Blitten kleiner sind als in .. den männlichen und unmittelbar nach dem Öffnen der Blüten abfallen. Ihre Pollenzellen können, auf die Narbe gebracht, nur wenige und rudimentär bleibende Pollenschläuche treiben. In den Fruchtknoten der männlichen Blüten fand ich Samenanlagen ohne Integumente. Sie sind nicht entwicklungsfähig, trotzdem bewirkt eine Bestäubung der männlichen Blüten (nach CrüG ER) eine Vergrößerung des Fruchtknotens und ein Abwelken des Labellums usw., nach kurzer Zeit aber fällt die Blüte ab. Es scheint, daß die männlichen Blüten variabel sind. Denn die „Übergangsformen“, welche CrüGEr (leider nur ganz kurz) erwähnt, sind, da sie steril bleiben, jedenfalls männlich.

Fragen wir uns, welche von den beiden Blütenformen der ursprünglichen Z witterblüte am nächsten steht, so scheint mir dafür maßgebend der Vergleich mit der Sektion Pseudocatasetum der Gattung Catasetum, welche Zwitterblïten besitzt. Bei diesen gleicht die Gestalt der Bliiten, namentlich des Labellums, mehr den weiblichen Blüten der diözischen Formen, die Lippe ist nach unten gekehrt, die Antennen sind nicht vorhanden. Wir werden also wohl die männlichen Catasetumblïten als die abgeleiteten, am meisten veränderten zu betrachten haben, die Antennen als - vielleicht in Korrelation zur Hemmung des Gynaeceums entstandene

2) R. A. Rolfe, On the sexual forms of Catasetum etc. Jonrnal of the Linnean society, botans vol. XXVII (1895), p. 206.

z) H. CrÜGER, Few notes on the fecundation of Orchids and their morphology (Linnean societys journal vol. VIII, p. 127. 
- Neubildungen, wie sie denn auch ontogenetisch erst spät auftreten. In den weiblichen Blüten ist nur insofern eine anderung eingetreten, als bei manchen die Drehung, durch welche die Lippe nach unten gekehrt wird, unterblieb. Das ist hier auch offenbar ohne Schädigung der Bestäubung möglich ${ }^{1}$ ), während bei den männlichen Blüten das Ausschleudern der Pollinien wahrscheinlich besser vor sich geht, wenn das Labellum nach unten gerichtet ist.

Wie die Verschiedenheit des Perigons mit der Geschlechtsdifferenz zusammenhängt, bleibt gänzlich dunkel; es wäre von großem Interesse, wenn die von CrÜGER erwähnten Mittelformen näher untersucht würden. Mit der Annahme, daß bei den diözischen Catasetumarten die weiblichen Bliiten die konservativeren, die männlichen die fortschrittlichen sind, stimmt auch die oben erwähnte Tatsache, daß die weiblichen Blüten bei den verschiedenen Arten sich mehr gleichen als die männlichen. Nach der hier vorgetragenen Anschauung würde also eine stärkere Hemmung in der Ausbildung des Gynaeceums in den männlichen Blüten als in der des Androeceums in den weiblichen Blüten eingetreten sein; die abweichende Ausbildung der männlichen Blüten hingegen steht nicht mit einer Steigerung der "Männlichkeit" (gegenüber den Zwitterbliiten), sondern mit einer Abnahme der "Weiblichkeit" in Zusammenhang.

Immerhin wäre der Versuch erwünscht, in männlichen Blüten mechanisch eine Hemmung oder Schädigung der Staubblattbildung herbeizuführen, und dadurch - falls dies frühzeitig genug möglich ist - eine Annäherung der Blütengestaltung an die der weiblichen Blüten herbeizuführen. Aussichtsreicher würde freilich (wenn die oben entwickelte Anschauung richtig ist) der sein, die Entwicklung des Gynaeceums in den männlichen Blüten zu steigern und dadurch die Ausbildung der spezifisch-männlichen Charaktere der Blüten $\mathrm{zu}$ hemmen. Leider sind die Catasetumarten in der Kultur meist wenig reichliche Blüher. In den Tropen liegen natürlich die Verhältnisse wesentlich günstiger.

Catasetum diurfte das auffallendste Beispiel von Blütendimorphismus darstellen.

Zea Mais. Zunächst sei bemerkt, daß hier zwar männliche und weibliche Blïten örtlich scharf getrennt sind (von „abnormen" Vorkommnissen abgesehen), daß aber die zwitterige Anlegung der Blüten noch sehr deutlich hervortritt.

Fig. 150 zeigt z. B. ein weibliches Ährchen, in dessen Endblüte die Staubblätter $(S t)$, ehe sie verkümmern, weit entwickelt sind, sie weisen deutlich die Gliederung in Anthere und Filament auf.

Bekanntlich ist der männliche Blütenstand endständig an der ganzen Pflanze und rispig verzweigt. Die weiblichen Blütenstände dagegen stehen seitlich von großen Hüllblättern umgeben und sind unverzweigt. $\mathrm{Da}$ sie erst angelegt werden, wenn der Vorrat der Pflanze von organischem Baumaterial ein beträchtlicherer ist als zu der Zeit, in der die männlichen Blütenstände auftreten, läßt sich auch experimentell erweisen. Die Sachlage ist also ganz ähnlich wie bei Funaria und den Farnprothallien, den Begoniablütenständen u. a. Schlecht ernährte Pflanzen bleiben auf dem männlichen Stadium stehen ${ }^{2}$ ).

1) Die Hummeln drängen sich, durch den Gernch nnd das „Futtergewebe“ auf dem Labellum angezogen, in dies hinein.

$\left.{ }^{2}\right)$ Vgl. z. B. GokBes, Einleitung in die experimentelle Morphologie (1908), p. 119. Ebenso erzeugt Ambrosia artemisifolia nach Meenan (Bot. Jahresber. 1880, I) bei dichtem 
Es kann keinem Zweifel unterliegen, daß die Trennung der Blütenstände beim Mais eine später aufgetretene ist. Sie leitet sich ab ron Blütenständen, welche an ihrer Basis weibliche, an ihrer Spitze männliche Blüten besaßen, und diese wieder von rein zwitterigen Infloreszenzen. Bei CoIx ${ }^{1}$ ) läßt sich der Vorgang, der zur Bildung von rein weiblichen Infloreszenzen führt, auch ontogenetisch noch nachweisen, der ganze männliche Endteil der Infloreszenzen verkümmert. Die Frage ist nur, wie dieser Vorgang bei Zea sich abgespielt hat?

Man wird wohl geneigt sein, die männliche Infloreszenz von Zea als der ursprünglichen Form noch näher stehend zu betrachten, weil sie mit anderen Grasinfloreszenzen mehr übereinstimmt als der weibliche Bliitenkolben, dessen fleischige dicke Achse die Ablagerung von Baustoffen ermöglicht, welche später zur Samenbildung verwendet werden.

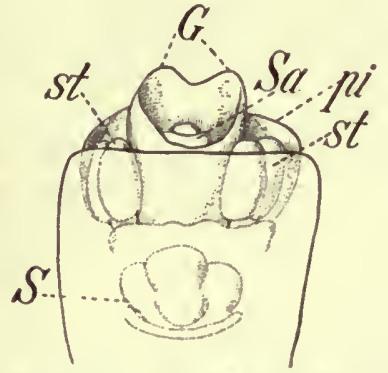

Fig. 150. Zea Mais. Weib. liches Ährchen mit Endblüte und (viel weniger weit entwickelter) Seitenblüte $S$, $G$ Griffel, $S a$ Samenanlage, st zwei der drei Staubblätter, pi palea inferior.
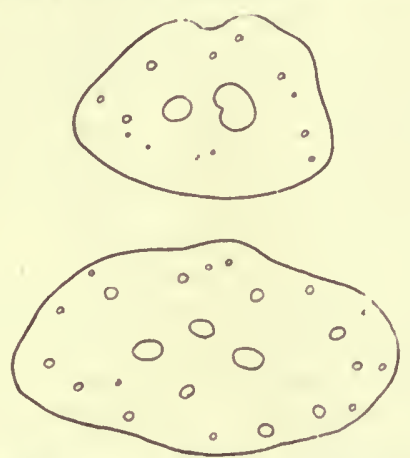

Fig. 151. Sagittaria pugioniformis. Oben Querschnitt durch den Stiel einer männlichen, unten durch den einer weiblichen Blüte. Das Stranggewebe (teils aus Leitbündeln, teils aus mechanischen Zellen bestehend) angedeutet.

HARshberger ${ }^{2}$ ) z. B. meint, der weibliche Blütenkolben sei zustande gekommen durch die Vereinigung mehrerer getrennter Äste (spikes) und sucht die Annahme durch die Beobachtung zu stützen, daß gelegentlich verzweigte Maiskolben auftreten. Das erscheint indes sehr wenig wahr-

Stand fast ausschließlich männliche Blütenköpfe, bei vereinzelter Stellung auf gutem Boden vorwiegend weibliche.

1) Im Sommer 1908 traten bei Coix Lacrymae im Mïnchener Garten in den ,mänılichen " Blütenständen viele Zwitterblïten auf; angelegt werden sowohl bei Zea als bei Coix alle Blüten zwitterig. Vgl. hierüber und betreffs der Infloreszenzen GoenEL, Beiträge zur Entwicklungsgeschichte einiger Infloreszenzen, Jahrb. f. wiss. Botanik XIV. Die männlichen und weiblichen Infloreszenzen sind bei Coix sehr verschieden: die weiblichen sind auf ein Ährchen mit einer Blüte reduziert, während die männlichen zahlreiche Ährchen haben. Es wurde aber a. a. O. nachgewiesen, daß gegen das Ende der Vegetationsperiode hin männliche Infloreszenzen auftreten können, welche genau so gestaltet sind wie die weiblichen, d. h. aus einem einzigen Ährchen bestehen, an welchem zwei Borsten stehen. Sie sind von besonderem Interesse deshalb, weil sie zeigen, wie durch bloße Ernährungsänderungen aus dem reich ausgestatteten Sproßsystem der männlichen Infloreszen\% ein Gebilde entstehen kann, wie wir es bei der weiblichen konstant vor uns haben.

\&) Harshberger, On Mais (Contributions form the Pensylvania botanical laboratory I (1897), p. 77. Vgl, namentlich H. ILrrs, Über einige bei Zea Mays Is beobachtete Atavismen etc. Zeitschr. für Abstammungslehre, Bd. V (1911). (Daselbst weitere Literatur). 
scheinlich. Es ist viel einfacher anzunehmen, daß im weiblichen Blüteukolben die Bildung der Seitenäste ${ }^{1}$ ) im Zusammenhang mit der starken Entwicklung der Hauptachse und der sie umgebenden Hüllblätter unterdrückt wurde. Die Ausbildung der Blütenstandachse ermöglichte dabei die Bildung einer viel größeren Zahl weiblicher Blüten und größerer Früchte als sie bei der Urform vorhanden war.

Zea weicht von den meisten anderen Gräsern auch dadurch ab, daß die Ährchen an der.. Spindel nicht zwei- sondern mehrreihig stehen; dies ist auch mit den Ästen an der Basis der männlichen Infloreszenz der Fall; an ganz ärmlichen weiblichen Blütenständen fand ich aber an der Spitze auch zweizeilige Stellung. Normal aber zeichnet sich die weibliche Infloreszenz dadurch aus, daß sie schon vor dem Auftreten der Ährchen relativ dick und drehrund ist ${ }^{2}$ ).

Wir leiten also Zea ab von einem Grase, das zunächst zweizeilig verzweigte end- und seitenständige Infloreszenzen mit Zwitterbliiten besitzt. Mit dem Dickerwerden der Infloreszenzachse trat mehrreihige Verzweigung ein. Das kann gelegentlich auch bei verwandten Formen (Enchlaena) eintreten. Ferner wurde die Basis der Inflorenszenzen weiblich, der obere Teil männlich. Sodann erfolgte eine stärkere räumliche Trennung der Infloreszenzen als bei den übrigen Maydeen. In den seitenständigen Infloreszenzen verkümmerte der männliche Endteil, in den männlichen unterblieb im Zusammenhang mit ihrer frühzeitigen Anlegung die Bildung weiblicher Blüten an der Basis.

Ein analoger, hier aber nicht näher zu schildernder Vorgang, hat offenbar bei Carex stattgefunden.

Bei Cocos nucifera finden sich die weiblichen Bliiten an der Basis der Aste des Blütenstandes. Sie zeichnen sich schon im Knospenzustande durch eine bedeutendere Größe gegenüber den viel zahlreicheren männlichen aus. Auch das Perigon ist größer als das der letzteren, während sonst bei vielen weiblichen Blüten das Entgegengesetzte der Fall ist. Ebenso macht DruDE ${ }^{3}$ ) aufmerksam auf die ,enorme weibliche Blüte von Borassus, mit der im Vergleich dazu winzigen männlichen". Es scheint, daß diese Verschiedenheit sich namentlich bei solchen Palmen findet, bei denen die Früchte (und Samen) sich durch Größe auszeichnell. Diese bedeutende Entwicklung des Gynaeceums spricht sich dann von vornherein in der Gestaltung der weiblichen Blüten aus, von denen anzunehmen ist, daß schon ihr Vegetationspunkt massiger ist als der der männlichen Blüten. Der ursprünglichen Zwitterblüte gegenüber dürften bei den genannten Formen sowohl die weiblichen Blüten (durch Größenzunahme) als die männlichen (durch Größenabnahme) verändert sein.

Hier mag auch Sagittaria pugioniformis erwähnt werden. Die weiblichen Bliuten stehen hier an der Basis der Infloreszenz. Sie blühen auf und sind befruchtungsfähig zu einer Zeit, in welcher das die männlichen Blüten bergende Ende der Infloreszenz noch geschlossene Knospen zeigt. Daß hier ein ähnliches Verhältnis wie bei Zea vorliegt, zeigt die Tatsache, daß die Stiele der weiblichen Bliiten (Fig. 151) beinahe doppelt so breit und dicker sind als die der männlichen; letztere haben eine größere Blumenkrone als erstere.

Dikotylen. Männliche und weibliche Blüten zeigen hier entweder

1) Natürlich mit Ausnahme der zu Ährchen werdenden.

2) Vgl. Gozber, a. a. 0., p. 7.

3) Drude, Palmae in Engler-Prantl, Nat. Pflanzenfamilien II, 3 (1889). 
keine auffälligen sekundären Verschiedenheiten, oder es treten solche in der Bliitenhülle, in dem Bau der Blütenstiele, der Anordnung und der Zahl der beiderlei Bliiten auf.

Melandryum album ${ }^{\mathbf{1}}$. Männliche und weibliche Blüten dieser diözischen Pflanze sind auffallend unterschieden durch die Kelchbildung. Der Kelch der weiblichen Blïten ist derber und bauchiger als der der männlichen, letzteren fand ich öfters rötlich gefärbt (speziell über den Nerven) ersteren grünlich, doch ist dies nicht konstant.

Namentlich ist die Nervatur beider Kelche verschieden. Fig. 152 zeigt links den Querschnitt einer weiblichen, rechts den einer etwas jüngeren männlichen Blüte. Bei der weiblichen Blüte liegen zwischen den fünf Hauptnerven (welche in die fünf Spitzen der Kelchblätter gehen) je drei weitere Nerven („Kommissuralnerven"), bei der männlichen Blüte jeweils nur einer. Es kommt zwar bei männlichen Blüten in einzelnen Längsstreifen des Kelches gelegentlich eine Annäherung an die reichere Nervatur des Kelches der weiblichen Bliiten vor, aber eine Übereinstimmung fand ich in den untersuchten Fällen nicht, vielmehr konnte ich männliche und weibliche Kelche stets unterscheiden ${ }^{2}$ ).
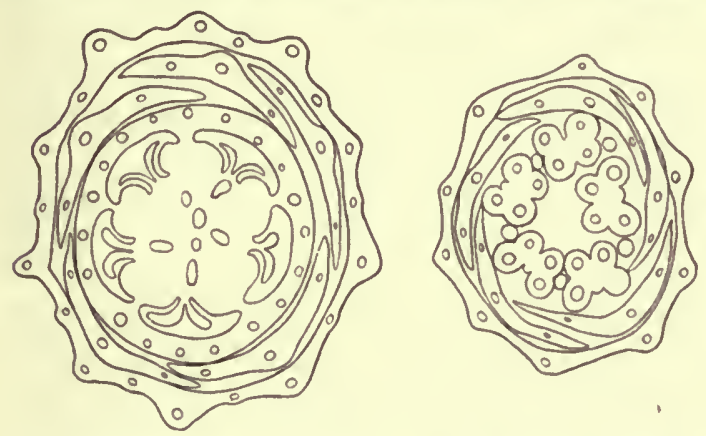

Fig. 152. Melandryum album. Links Querschnitt durch eine weibliche, rechts durch eine (etwas jüngere) männliche Blüte.

Der Kelch ist bei beiden verschieden.

Es fragt sich, welches Verhalten man als das ursprïngliche ansehen soll, oder mit anderen Worten: hat im Kelch der männlichen Bliiten eine Verminderung oder im Kelch der weiblichen Blüten eine Verstärkung der Nervatur stattgefunden? Wenn man bedenkt, daß im Kelch der männlichen Blïten noch Anzeichen einer reicheren Nervatur vorkommen, so wird man wohl die Reduktion des Kelches in den männlichen Blüten für wahrscheinlich halten dürfen ${ }^{3}$ ), also als Ausgangspunkt eine Zwitterbliite mit dem Kelch der weiblichen Bliite annehmen. Solche Zwitterblüten finden sich z. B. bei Silene corsica.

Man kann die Annahme, daß die Zwitterbliiten von Mel. album eine solche Kelchgestaltung besessen haben, selbstverständlich nur als eine aus p. $657 \mathrm{ff}$.

1) Vgl. Strasburger, Versuche mit diözischen Pflanzen. Biol. Centralbl. 20 (1900),

$\left.{ }^{2}\right)$ An anderen Standorten ist das Verhalten des Kelches der weiblichen Blüten weniger von dem der männlichen Blüten verschieden. So fanden sich bei Ambach weibliche Blüten mit Kelchen, deren Kommissuralnerven an drei Kelchbuchten einfach waren, bei zweien waren zwei Nerven vorbanden. $0 b$ es sich um durch den Standort bedingte oder um erbliche Verschiedenheiten handelt, vermag ich nicht zu sagen.

${ }^{3}$ ) Dafür spricht anch, daß bei Melandryum rubrum die an fruchtenden Pflanzen zuletzt auftretenden Blüten (welche kleiner sind als die früheren) einen Kelch mit zehn Nerven haben, während er bei den früheren Blüten mehr Nerven hat, wenngleich nicht so viele wie bei Mel. album. 
den angeführten Gründen wahrscheinliche bezeichnen, und wenn jemand die Kelchbildung der männlichen Bluiten für die ursprünglichere halten will, so bleibt ihm das unbenommen. Am einfachsten wäre es, das Verhalten der Zwitterblüten von Melandryum selbst in Betracht zu ziehen. Wirkliche Zwitterblüten, d. h. solche, bei denen die Entwicklung der Antherenrudimente weiblicher Blüte nicht durch den Brandpilz Ustilago violacea veranlaßt worden ist, sind aber sehr selten ${ }^{1}$ ). Mir sind keine zu Gesicht gekommen.

Jedenfalls aber ist eine Korrelation zwischen Kelch und Fruchtknotenausbildung hier vorhanden, die ja ernährungsphysiologisch unschwer verständlich ist.

Eine Betrachtung der beiden Blütenquerschnitte könnte auch auf eine Verschiedenheit in der Deckung der Blumenkrone schließen lassen; es sei deshalb bemerkt, daß die bei der abgebildeten männlichen Blüte vorhandene gedrehte Knospenlage nicht immer sich findet. In der Größe der Blumenkrone konnte ich zwischen männlichen und weiblichen Blüten keine konstanten Verschiedenheiten wahrnehmen. A. Schulz ${ }^{2}$ ) gibt an, daß die Blütenblätter der weiblichen Pflanzen kleiner seien als die der männlichen, wie dies auch sonst bei Sileneen der Fall zu sein pflegt. Vielleicht würde diese Verschiedenheit deutlicher hervortreten, wenn man nicht eine "Population" (welche vielleicht aus einer Anzahl in der Größe der Blumenkrone verschiedenen Linien besteht), sondern die (unter gleichen Verhältnissen erwachsenen) Nachkommen einer Pflanze vergleicht. Bei Silene Otites $^{3}$ ) fand A. Schulz die männlichen Blüten (von der Ausbildung des Gynaeceums abgesehen) mit den Zwitterblüten übereinstimmend, die weiblichen mit kleineren Blumenblättern und viel dickeren Stielen versehen (deren anatomische Beschaffenheit nicht untersucht wurde).

Urticaceen. 1. Pilea Spruceana. Die männlichen und die weiblichen Blüten finden sich hier in monözischer Verteilung. Meist ist ein basaler Ast des Blütenstandes männlich, der Rest weiblich. Entgegen der sonst geltenden Regel sind hier die männlichen Blïten den weiblichen gegenuiber bedeutend in der Minderzahl, was auch bei einigen anderen monözischen Urticaceen wiederkehrt, z. B. bei Urtica urens und der nachher zu schildernden Procris. Es mag dies damit zusammenhängen, daß die weiblichen Blüten nur eine Samenanlage führen, also jeweils eine geringe Pollenmenge zur Bestäubung erfordern. Außerdem sind die Antheren verhältnismäßig groß und durch die monözische Verteilung der Blïten ist zudem die Bestäubung gesicherter als bei diözischer. Wir werden auch sehen, daß bei diözischen Urticaceen meist ein anderes Zahlenverhältnis zwischen männlichen und weiblichen Blüten besteht.

Bei Pilea Spruceana (vgl. Fig. 153) sind die männlichen Bliuten von den weiblichen unterschieden auch dadurch, $\mathrm{da}$ 乃 sie viel länger gestielt sind als letztere (was natürlich die Verbreitung des Pollens erleichtert) und ein bedeutend größeres Perigon besitzen (die Länge der Perigonblätter der männ-

1) Neuerdings hat ShoLr (Inheritance of sex in Lychnis, Botanical gazette XL [1910], p. 110) solche beschrieben, ohne indes über die Blütengestaltung Näheres mitzuteilen, er faßt die hermaphrodite Form als "a modified male" auf.

2) A. Schuzz, Beiträge zur Kenntnis der Bestäubungseinrichtungen und Geschlechtsverteilung bei den Pflanzen II, Bibl. Bot. 17 (1890), p. 182. - Die Verschiedenheit im Kelch hat SCHOLz nicht berïcksichtigt. GäRTNER hatte dagegen die männlichen Blüten „etwas kleiner und von zarterem Bau" als die weiblichen gefunden (GÄrTnER, Versuche und Beobachtungen [1849], p. 44).

3) A. Schulz, Beitr. I (Bibl. Bot. Heft 10, 1888), p. 8 u. 9. 
lichen Blüten betrug 2-2,4 mm, die Breite durchschnittlich $1,1 \mathrm{~mm}$; bei den weiblichen Blüten betrug die Länge des größeren Blütenhülllblattes 0,7 bis $0,9 \mathrm{~mm}$, die des kleineren $0,04 \mathrm{~mm}$, ihre Breite $0,25 \mathrm{~mm}$ ), das sich bei der Streckung der Filamente ausbreitet, während das kleine Perigon der weiblichen Blüten dem Fruchtknoten anliegt. Teleologisch könnte man die bedeutendere Größe des Perigons der männlichen Blïten damit zu „erklären" versuchen, daß sie durch das "Bedürfnis" die großen Staubblätter im Knospenstadium zu schützen bedingt sei. Wie bei anderen Urticaceen sind auch hier die Filamente in der Knospenlage eingebogen. Die Perigonblätter, deren Spitzen aufrecht bleiben, haben vor jedem Stanbblatt einen Auswuchs. Die vier Auswüchse (welche den Axillarstipeln der Laubblätter entsprechen), bilden ein Dach über .den Staubblättern. Bei den weiblichen Blüten könnte man die Kleinheit des Perigons in Beziehung bringen $\mathrm{zu}$ der Kleinheit des Fruchtknotens und der gedrängten Stellung der weiblichen Bliiten. Jedenfalls kann man in ihnen von einer Rückbildung des Perigons sprechen.

Diese macht sich auch darin geltend, daß die Perigonblätter nicht mehr in Vierzahl wie bei den männlichen Blüten, sondern (meist) in Dreizahl auftreten. Eines daron ist derber und hat auf seiner Vorderseite einen Vorsprung, welcher dem der Perigonblätter der männlichen Blüten entspricht. Es sei auf diese Perigonverschiedenheit bei diesen windblütigen Pflanzen um so mehr hingewiesen, als man analoge Erscheinungen bei Pflanzen mit gefärbter Blütenhülle als mit der $\mathrm{Be}$ stäubung durch Insekten im Zusammenhang stehend hat "erklären" wollen.

Procris. Diese Gattung gehört zu den Urticaceen mit ausgegrägt dorsiventralem Sproßbau: die Blätter stehen in vier Reihen, und zwar sind die auf der dem Lichte zuge-

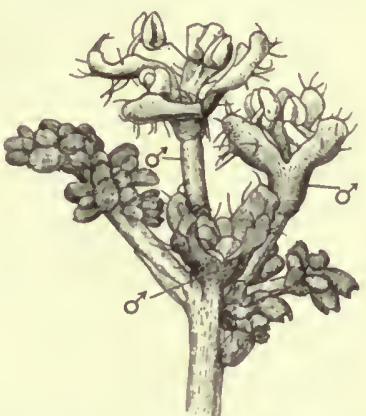

Fig. 153. Infloreszenz einer brasilianischen Pilea. Die männlichen Blïten $\left(\sigma^{7}\right)$ sind größer und weniger zahlreich als die weiblichen.

kehrten Seite stehenden riel kleiner als die anderen; außerdem sind die Blätter jeweils mit ungleich großen Hälften versehen.

Der sexuelle Dimorphismus ist hier ein besonders interessanter. Einmal nämlich sind männliche und weibliche Infloreszenzen in ihrer Gestalt sehr verschieden, auch die Blüten in diesen Infloreszenzen sehen recht verschieden aus; sodann haben die beiderlei Infloreszenzen eine verschiedene Stellung.

Wie Fig. 154 u. 155 zeigen, stehen nämlich normal die männlichen

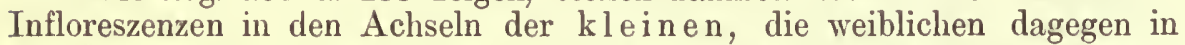
den Achseln der großen Blätter. Nun kann es keinem Zweifel unterliegen, daß die verschiedene Blattgröße bedingt ist durch Ernährungdifferenzen. Die kleineren stehen auf der schlechter, die größeren auf der besser ernährten Sproßseite. Demzufolge stehen also auch die männlichen Infloreszenzen an Stellen, wo sie weniger gut ernährt sind als die weiblichen ${ }^{1}$ ). Bei diesen wird außerdem die Assimilationstätigkeit des großen Blattes, in dessen Achsel sie stehen, den heranreifenden Früchten zugute

1) Andere anisophylle Pflanzen zeigen vielfach, daß nur die größeren Blätter noch Achselsprosse hervorbringen. So z. B. stehen bei Columnea purpurea die Blüten nur in der Achsel der größeren Blätter.

Goebel, Organographie der Pflanzen. 2. Aufl. Allgem. Teil. 
kommen können. Außerdem unterscheiden sich die männlichen Blütenstände von den weiblichen noch durch die verschiedene Ausbildung der Blütenhülle und dadurch, daß sie viel weniger, aber ziemlich langgestielte Bliiten haben, daß diese Blüten eine lockere cymöse Infloreszenz bilden, während die weiblichen Blïten einer fleischig verdickten Infloreszenzachse dicht gedrängt aufsitzen. Namentlich ist auch auffallend, $\mathrm{da} \mathrm{B}$ die weiblichen Blïtenknäuel alle nach der Schattenseite hin gewendet sind, also von den männlichen Blütenständen abgewendet. Es ist dies

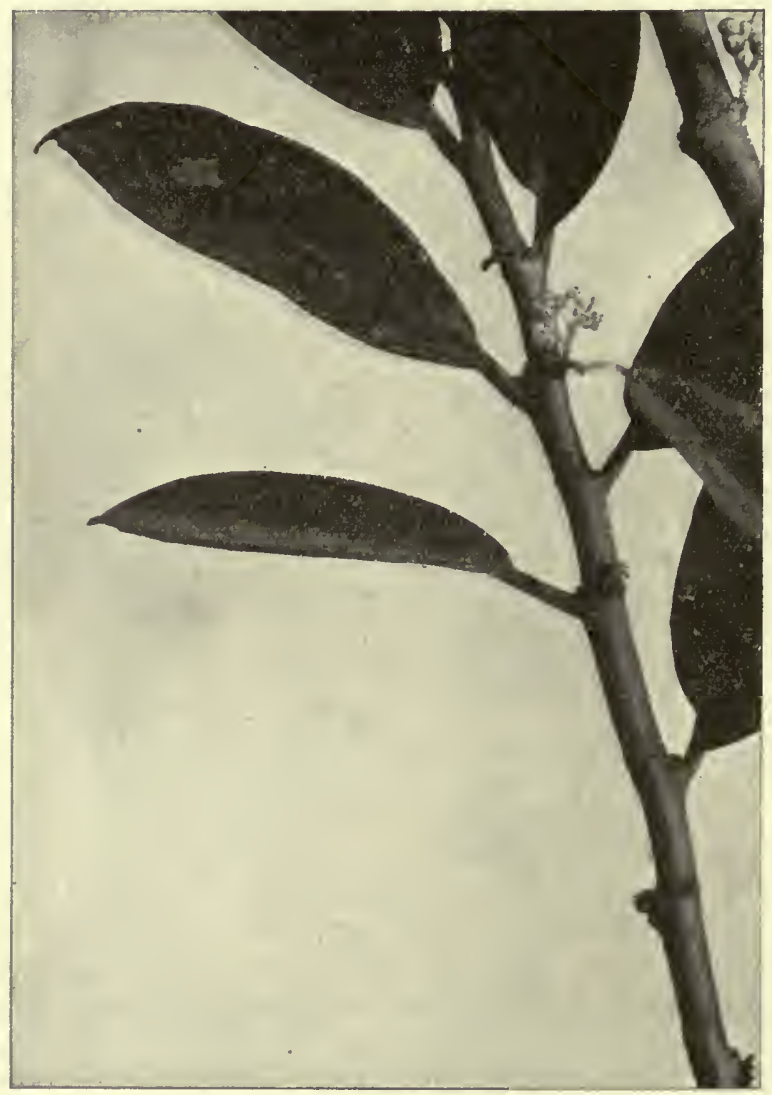

Fig. 154. Procris laevigata mit männlichen Infloreszenzen (von oben). Diese stehen in den Achseln der kleinen Blätter und sind locker verzweigt. eine Erscheinung, welche mir biologisch bis jetzt nicht recht verständlich ist (wenn man sie nicht etwa als eine Einrichtung zurFremdbestäubung betrachten will). Es ist ja doch anzunehmen, daß Procris wie andere Urticaceen windblïtig ist; man sollte also denken, daß eine nach oben gerichtete Lage der weiblichen Blütenknäuel bessere Aussicht auf Bestäubung bieten wiirde. Nun wachsen die Procris-Arten (wie ich mich von Java her erinnere), meist als Epiphyten; es ist also wohl möglich, daß auch von unten her kommende Luftströme ihnen Pollen zuführen. Auch von oben kann dieser übrigens auf sie gelangen, da oberhalb der Blütenknäuel an dem asymmetrischen Deckblatte sozusagen ein Stuick der Blattspreite fehlt und Sproßachse wie Blattstiel glatt sind. Jedenfalls bieten die weiblichen Infloreszenzen durch die zahlreichen Narbenhaare, welche sie wollig erscheinen lassen, einen vortrefflichen Auffangeapparat für die Pollenkörner dar. Selbstbestäubung dürfte durch diese verschiedene Stellung männlicher und weiblicher Infloreszenzen immerhin erschwert werden.

Trotz ihres verschiedenen Aussehens stimmen männliche und weibliche Infloreszenzen in ihrer Entwicklung überein. Die starke Anschwellung der weiblichen Infloreszenzachse (vgl. Zea!) erlaubt (wie bei den Kompositen) die vorläufige Ablagerung von Reservestoffen für die Samenbildung. Die fleischige (wenn man will eigentlich sympodiale) Infloreszenzachse schwillt 
außerdem nach der Befruchtung zu einem fadsüßlich (einigermaßen wie eine Maulbeere) schmeckenden Körper an, auf welchem die zahlreichen kleinen Nüßchen sitzen, deren Perigon gleichfalls etwas angeschwollen ist. Es ist wohl nicht zweifelhaft, daß diese Blütenkuchen von Tieren gefressen und so die Früchte verbreitet werden. Man könnte diese Fruchtstände mit denen der Feigen vergleichen, nur daß bei diesen die weiblichen Blüten in einem konkav vertieften, bei Procris auf einem konvex gewölbten, fleischig gewordenen Achsengebilde sitzen.

Für die auffallende Minderzahl der männlichen Blüten gelten natürlich dieselben Erwägungen wie bei Pilea.

Was die Umhüllung der Blüten anbetrifft, so haben die männlichen ein fünfteiliges, unten glockenförmig verwachsenes Perigon. Das der weiblichen Bliiten ist viel kleiner, unscheinbarer, und besteht aus nicht verwachsenen Blättern. Ich traf deren teils 5, teils 4, teils 3 an. Es dïrfte die Reduktion des Perigons mit der dichten Stellung der weiblichen Bliiten im Zusammenhang stehen. Die männlichen Bluiten sind, was die

Zahlenverhältnisse anbelangt, offenbar dem ursprünglichen Zustand der Bliiten näher.

Dies gilt auch von anderen Urticaceen,

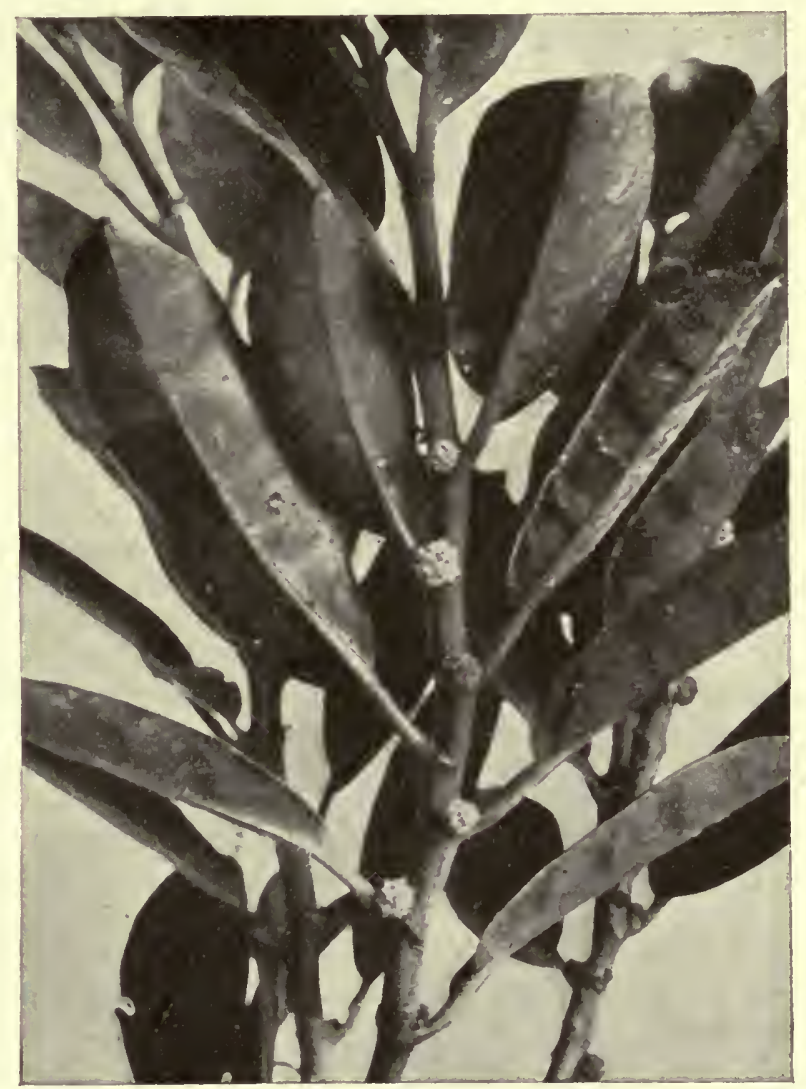

Fig. 1ōō. Procris laevigata mit weibl. Infloreszenzen (von unten). Diese stehen in den Achseln der großen Blätter, die Blüten sind sitzend und bedecken dicht die fleischige Infloreszenz. die aber nicht im einzelnen besprochen werden sollen. Erwähnt sei nur, daß bei Cannabis die münnlichen Blüten ein fünfzähliges Perigon haben, während bei den weiblichen bei einigen Formen ${ }^{1}$ ) (so bei der als $\mathrm{C}$. gigantea und C. himalayana bezeichneten) zwei Perigonblätter zwar noch angelegt werden, aber nur eine kiimmerliche Ausbildung erfahren. Bei C. sativa fand Zinger, daß auch von diesen beiden Blattanlagen eine in der Entwicklung ganz zurückblieb, ja daß die Entwicklung des Perigons sogar bis auf kaum wahrnehmbare

') Vgl. Zinger, Beiträge zur Kenntnis der weiblichen Blüten und Infloreszenzen bei Cannabineen, Flora, 85 (1898), p. 207. 
Reste gehemmt werden kann. Offenbar steht diese Hemmung hier in Beziehung zu der Umhüllung der weiblichen Blüten durch ihr stark entwickeltes Deckblatt, eine Erscheinung, welche - mutatis mutandis auch sonst wahrnehmbar ist. So haben die männlichen Blüten von Casuarina eine Blütenhülle, die weiblichen nicht; bei ihnen..wachsen aber die Vorblätter nach der Befruchtung noch stark heran. Ähnlich ist es bei Batis, bei welcher die weiblichen Blüten in Höhlungen des Blütenstandes eingeschlossen sind.

Bei Cannabis und Humulus sind die männlichen Blütenstände sehr viel reichblütiger als die weiblichen, und das dürfte auch für andere diözische Urticaceen, wenngleich in geringerem Grade, gelten. Die bei Procris angeführte. Verschiedenheit der männlichen und weiblichen Infloreszenzen, welche darin besteht, daß erstere durch Streckung der Achsen und der Blütenstiele viel lockerer sind als letztere, tritt auch bei anderen Urticaceenformen, z. B. U. pilulifera, auffallend hervor. Das sind verhältnismäßig kleine Verschiedenheiten, die sich leicht biologisch ausdeuten lassen.

Aber auch in den Fällen, in welchen männliche und weibliche Blütenstände äußerlich sehr verschieden sind, hat sich doch die Übereinstimmung im Aufbau ergeben ${ }^{1}$ ). Betreffs der anatomischen Verschiedenheiten möchte ich auf die Untersuchungen von Greviluius ${ }^{2}$ ) verweisen. Erwähnt sei nur, daß ich bei Urtica dioica in den untersuchten Fällen die weiblichen Infloreszenzachsen ursprünglich schwächlicher gebaut fand als die männlichen, welche zahlreichere, größere und schwerere Blüten zu tragen haben. Postfloral tritt aber in den Leitbündeln der weiblichen Blütenstandsachsen ein sekundäres Dickenwachstum ein, welches namentlich auch mechanisches Gewebe liefert. Auch die mechanischen Zellen des Grundgewebes werden verstärkt, wie denn auch sonst eine mechanisch stärkere Ausbildung von weiblichen Infloreszenz- resp. Blütenachsen vielfach wahrnehmbar ist. Sie wird ermöglicht durch den infolge der Befruchtung eintretenden $\mathrm{Zu}$ strom von Baumaterialien. Daß dabei nicht etwa die durch das Schwererwerden der heranreifenden Blüten eintretende stärkere Belastung als Reiz wirkt - wie teilweise angenommen wurde - ist zweifellos ${ }^{3}$ ).

Euphorbiaceen. Mercurialis perennis, eine diözische Pflanze, sei hier erwähnt, weil, wie die Abbildungen Fig. 156 u. 157 zeigen, hier besonders deutlich die Tatsache hervortritt, daß die weiblichen Infloreszenzen viel ärmer an Blüten sind als die männlichen; oft ist bei ersteren sogar nur eine Blüte vorhanden, während bei den männlichen Blütenständen die Zahl wohl selten unter 12 heruntergeht. Erhebliche Unterschiede im anatomischen Bau der männlichen und weiblichen Infloreszenzachsen (wobei letztere, wie das bei Begonia u. a. der Fall ist, die besser ausgestatteten wären) konnte ich nicht feststellen, im Gegenteil, es scheinen die Leitbündel in den männlichen stärker entwickelt, was mit der größeren Zahl der Blüten zusammenhängen $\mathrm{mag}^{4}$ ). Übrigens ist ja klar, daß die

1) Vgl. GoLenkin, Beitrag zur Entwicklungsgeschichte der Infloreszenzen der Urticaceen und Moraceen (Flora 18) (1894), p. 97.

$\left.{ }^{2}\right)$ Grevirisus, Anatomiska studier ofver de florala axlarna hos diklina fanerogamer (Bihang till K. Srenska Vet. Akad. Handlingar, Bd. 16, Afd. III, Nr. 2, Stockholm 1890.

3) Vgl. z. B. FraSKÄMPER, Unters. iiber die Abhängigkeit der Gefäß- und Sklerenchymbildung von äußeren Faktoren etc. Flora 101 (1910), p. 181.

4) Auf die Veränderungen im Bau der weiblichen Infloreszenzachsen während der Fruchtreife soll nicht näher eingegangen werden, es sei nur erwähnt, daß die Leitbündel sich noch weiter entwickeln (vgl. GRevillius, a. a. 0., p. 52). 
weiblichen Bliiten schon durch ihre geringe Zahl in verhältnismäßig günstige Ernährungsbedingungen gelangen.

Weibliche Pflanzen zeichnen sich oft durch besonders dunkelgriine Färbung und große Blätter aus. $\mathrm{Ob}$ das (unter sonst gleichen Wachstumsbedindungen) immer der Fall ist, bleibt näher zu untersuchen.

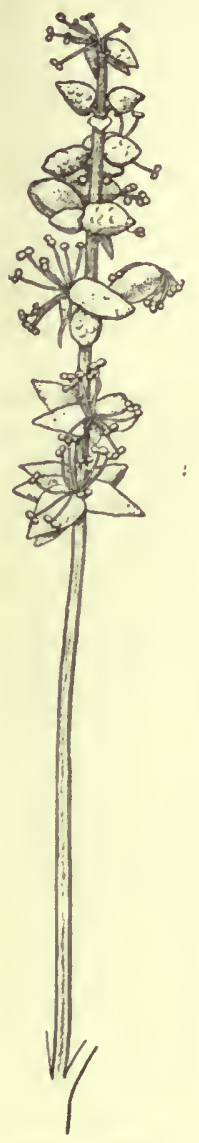

Fig. 156.

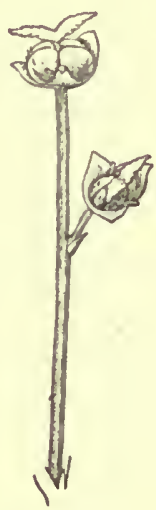

Fig. 15 7.

Fig. 156 männliche, Fig. 157 weibliche Infloreszenz ron Mercurialis perennis. Je $2 \mathrm{mal}$ vergr.

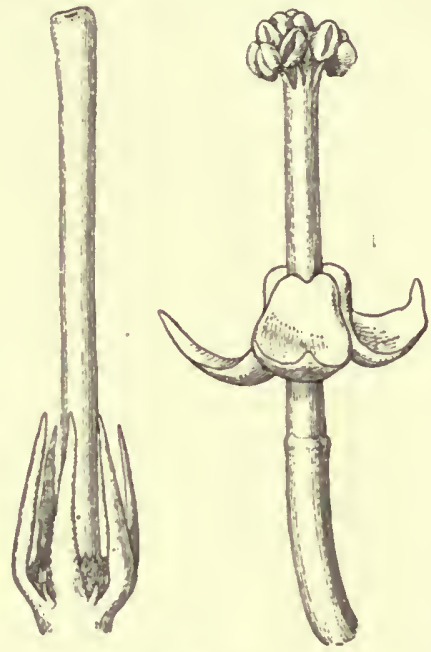

Fig. 158.

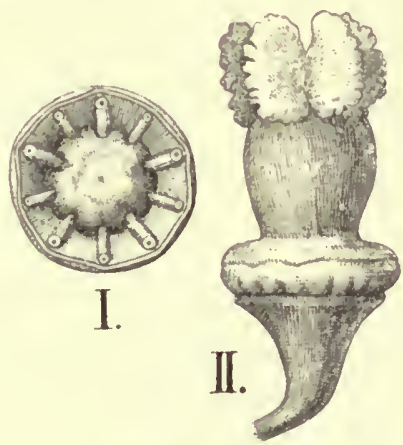

Fig. 159.

Fig. 158. Dalechampia Roezliana. Links weibliche, rechts männliche Blüte. Je 5 fach vergr.

Fig. 159. Manihot palmata 3 fach vergr. 1 Männliche Blinte (nach Entfernung des Perigons) von oben. Das Nektarium stark gelappt. II Weibl. Blitte in Seitenansicht, das Nektarium (unterhalb des Gynäceums) kaum gelappt.

Noch sei erwähnt, daß die nach F. E. Werss ${ }^{1}$ ) als Nektarien funktionierenden zwei Staminodien der weiblichen Blüten gelegentlich Antheren tragen, also auch hier wie in so vielen anderen Fällen die Geschlechtertrennung in den Blüten keine ganz konstante ist.

Dalechampia Roezliana. Diese merkwürdige Euphorbiacee hat

1) F. E. WeIss, Die Bliitenbiologie von Mercurialis (Ber. d. Deutsch. Bot. Gesellsch. Bd. XXIV (1906), p. 501). 
männliche und weibliche Blüten in demselben Bluitenstande vereinigt. Die weiblichen Bluiten sind sitzend, die männlichen gestielt, wobei hier wie bei anderen Euphorbiaceen (und Urticaceen) die Gliederung des Blütenstieles $\mathrm{zu}$ beachten ist, welche die spätere Abbruchstelle schon frühzeitig erkennen läßt. Der Gegensatz zwischen den männlichen kurzlebigen, nach der Pollenreife abfallenden und den langlebigen weiblichen Blüten tritt also schon früh hervor. Die Blütenhülle ist bei den männlichen Blüten bedeutend größer als bei den weiblichen. Ich fand sie aus 3-4 Blättchen bestehend, die der weiblichen aus 5-6 ${ }^{1}$ ). Vermutlich ist die ursprüngliche Zahl 5, eine Verminderung kann durch Verwachsung bedingt werden, die 6-Zahl in den weiblichen Blüten dürfte mit der Dreikantigkeit des Fruchtknotens in Beziehung stehen.

Manihot palmata. Den Vergleich der männlichen Blätter (Fig. 159 I) und der weiblichen (Fig. 159 II) ist insofern ron Interesse, als er die Verschiedenheit in der Ausbildung des kragenförmigen Nektariums in beiden Blüten kausal verständlich erscheinen läßt.

In den männlichen Blüten ist das nektarabsondernde Gewebe tief ausgebuchtet: offenbar weil die Filamente der Staubblätter als Hemmungskörper dienen. Der Nektarring an der Basis des Fruchtknotens der weiblichen Bliiten dagegen ist kaum gelappt, in Ermanglung der Staubblätter konnte es sich gleichmäßiger ausdehnen.

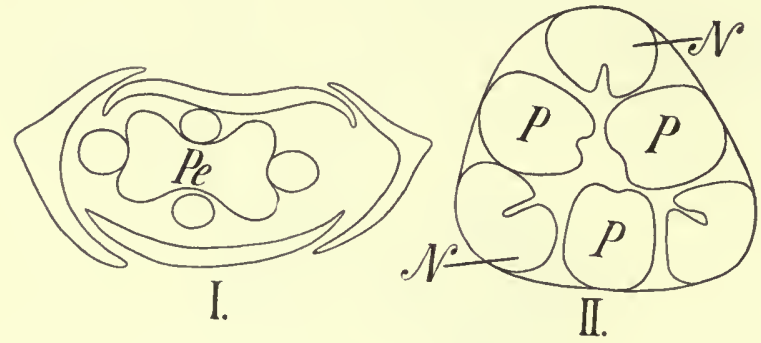

Fig. 160 .

Buxus sempervirens. $I$ Querschnitt einer männlichen Blüte mit 4 Perigonblättern u. 4 Staubblättern und einem vierlappigen Nektarkörper Pe. II Querschnitt einer weiblichen Blüte (ohne die umhüllenden Schuppen). $N$ Narben. $P$ Nektardrüsen.

Bei Herea ${ }^{2}$ ) sind an den rispenförmigen Blütenständen die Endblüten weiblich, die .Seitenblüten (mit kürzerem, gegliedertem Blütenstiel) männlich - und Ähnliches wiederholt sich auch in den sonderbaren "Cyathien" der Gattung Euphorbia selbst, welche hier nicht näher erörtert werden sollen.

Die Blüten von Buxus sempervirens mögen hier angeführt werden, weil sie rerschiedene Deutungen erfahren haben. Die Blïten sind in monözischen Infloreszenzen angeordnet, die weiblichen terminal, also in viel geringerer Zahl als die männlichen. Die Blütenhülle der letzteren (Fig. 160 1) besteht aus 4 Blättern, die weiblichen haben eine größere Anzahl (nach VAN TIEGHEM ${ }^{3}$ ) 6) Hüllblätter. Im Zentrum der männlichen Blüten befindet sich ein gelappter Drüsenkörper, $(P e$ Fig. $160 I)$, welchen man (aber ohne Grund) oft für ein Fruchtknotenrudiment gehalten hat. Die weiblichen Blüten haben drei Fruchtblätter und mit ihnen alternierend drei nektarabsondernde Protuberanzen ( $P$ Fig. 160 II). Es ist

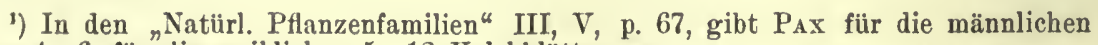
Blüten 4-6, für die weiblichen 5-12 Kelchblätter an.

2) Vgl. Leconte, Sur le dimorphisme des fleurs chez les Hevea. Bull. de la société botanique de France, t. 57 (1910), p. 134.

3) Van Tigahex, Sur les Buxacées Ann. d. scienc. nat. VIII, Sér. 15, 1897. 
mir unverständlich, wenn Van TIEgheM sagt, daß die Nektarien in männlichen und weiblichen Bliiten einen verschiedenen morphologischen Wert haben sollen. Sie sind doch in beiden Fällen mit den Sporophyllen abwechselnde Protuberanzen, die in den männlichen Blïten wegen der vollständigen Unterdrückung des Gynaeceums zu einem vierlappigen Körper verschmelzen können, in den weiblichen Bliiten sind sie auf den Fruchtknoten emporgehoben und stehen zwischen den Narben. Die Förderung der Nektarien in den männlichen Blüten spricht sich auch darin aus, da $B$ bei einigen Buxusarten (z. B. B. acuminata) nur die männlichen Blüten Nektarien haben, die weiblichen nicht, bei anderen (z. B. Buxus MacOwani) fehlen sie auch in den männlichen. Wie in den mutmaßlich zuerst vorhanden gewesenen Zwitterblüten die Nektarien angeordnet waren ist fraglich und eine Aufstellung von Hypothesen würde nicht weiter führen.

Umbelliferen ${ }^{1}$ ). Eine vollständige Trennung der Geschlechter ist hier verhältnismäßig selten; dagegen finden sich männliche Blüten neben Zwitterblüten bei sehr vielen. Untersucht wurden Scandix grandiflora (in Dalmatien), Myrrhis odorata (im Münchener Botan. Garten), Astrantia major.

Die zwei erstgenannten bilden scheinbar männliche und weibliche Blüten, in Wirklichkeit Zwitterbliiten und männliche Bliuten aus (Fig. 161). Doch fallen in den Zwitterblüten die (übrigens normal entwickelten) Staubblätter frühzeitig $a b$, so dab die Blüten dann weiblich erscheinen. Bei Scandix scheinen in den Zwitter-

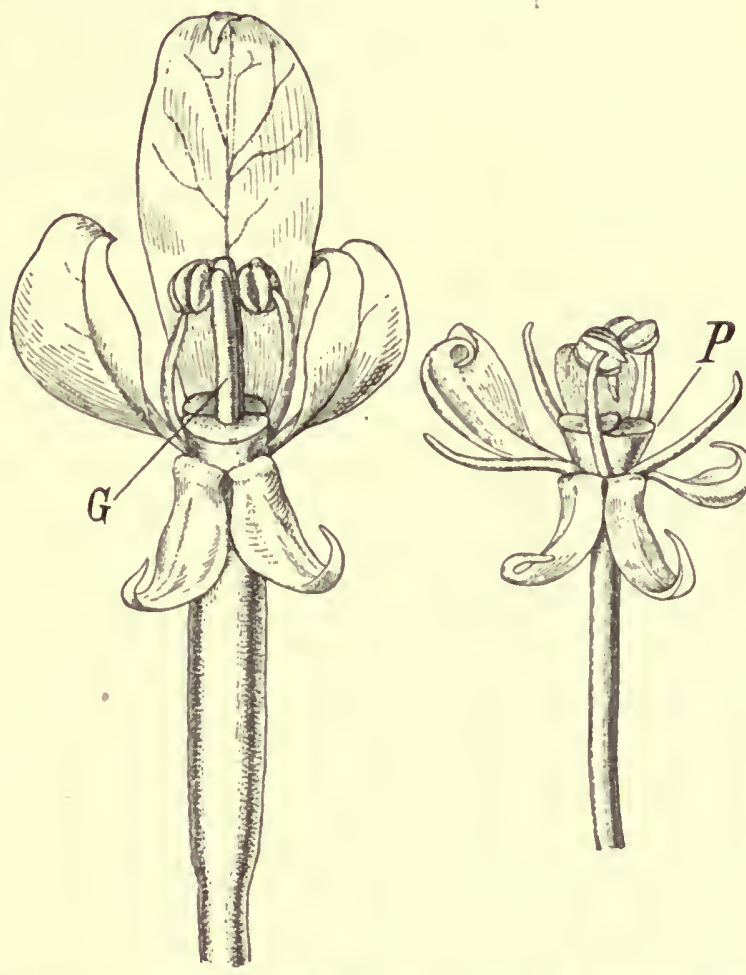

Fig. 161. Scandix grandiflora. Links Zwitterblüte (an der nur noch 2 Staubblätter erhalten sind). $G$ Griffel, darunter das Griffelpolster. Rechts männliche Blüte (gegen die weibliche um $90^{\circ}$ gedreht), an dem Griffelpolster $P$ scheinbar keine Griffel vorhanden. Je 10 fach vergr. blüten nicht immer alle

fünf Staubblätter zur Ausbildung zu gelangen, so daß die Blüten vielleicht dazu hinneigen, weiblich zu werden.

Zwischen den beiden Blütenformen bestehen erbebliche Verschiedenheiten. Die Zwitterblüten haben viel größere Blütenkronen, ferner

1) Vgl. W. Burck, On plants which in the natural state have the character of eversporting varieties in the sense of the mutation theory (Kon. Ak. van Wetensch. te Amsterdam May 25, 1906). Daselbst weitere Literatur. 
derbere (und auch anatomisch anders gebaute) Stiele als die männlichen. In den letzteren sind die beiden langen Griffel der Zwitterblüten scheinbar ganz verschwunden, was um so auffallender wäre, als die (als Nektarien dienenden) Griffelpolster ( $P$ Fig. 161) - welche basale Anschwellungen der Griffel darstellen -, auch in den männlichen Blüten stark entwickelt sind ${ }^{1}$ ). In Wirklichkeit sind aber auch die Griffel vorhanden, nur bleiben sie sehr klein ${ }^{2}$ ) und sind, da sie auf der Innenseite des Griffelpolsters stehen, äußerlich nicht sichtbar. Auch die Fruchtknotenhöhle wird angelegt, bleibt aber bald stehen. Auffallend ist jedenfalls, daß die Hemmung der Fruchtknotenentwicklung die Griffelpolster nicht trifft, also gerade den Teil des Gynäceums, welcher als Nektarium auch für die männlichen Blüten von Wichtigkeit ist.

Was den Blütenstiel anbetrifft, so ist er bei den männlichen Blüten bedeutend kleiner und schmächtiger als bei den Zwitterblüten und zeigt nur drei kümmerlich ausgebildete Leitbündel, während der der Zwitterblüten sechs aufweist (Fig. 162, oben). Andere Verschiedenheiten seien hier nicht erwähnt, da sie für unsere Fragestellung nicht von größerer Bedeutung sind.

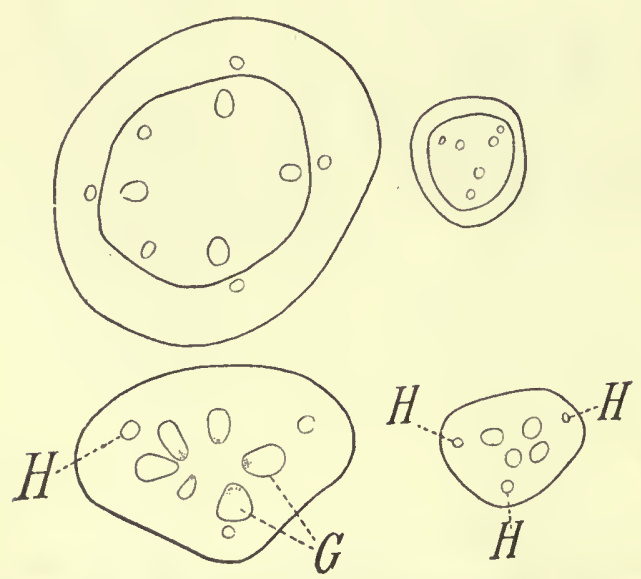

Fig. 162. Querschnitt durch die Stiele von Zwitterblïten (links) und männliche Blüten (rechts), oben von Scandix grandiflora (außer den Leitbündeln sind noch 3 Harzgänge vorhanden), unten von Myrrhis odorata. $G$ Leitbündel, $H$ ' Harzgänge.
Dagegen ist der Stellungsverhältnisse zu gedenken. Die Zwitterblüten finden sich an den zuerst auftretenden, am kräftigsten ausgebildeten Dolden ${ }^{3}$ ), namentlich auch als deren Randblüten. Indes kann die Verschiedenheit zwischen Zwitterbliiten und männlichen nicht etwa auf die zurïckgeführt werden, welche zwischen den (mit größerer einseitig geförderter Blumenkrone versehenen) Randblüten und den inneren Blüten bei manchen Doldenpflanzen besteht. Denn die Verschiedenheit ist bei Myrrhis vorhanden, auch wenn eine Zwitterblüte und eine männliche auf gleicher Höhe nebeneinander stehen und in den oberen, rein männlichen Dolden sind die Randblüten nicht größer als die männlichen Blüten, welche in der Mitte einer Dolde mit zwittrigen Randblüten stehen.

Von anderen Umbelliferen mit getrenntgeschlechtigen Blüten sei zunächst auf die Ferula-Arten hingewiesen, die selbst $\mathrm{zu}$ untersuchen ich

1) Sie sind etwas kleiner und flacher als die in den Zwitterblüten; hier haben die Griffelpolster einen etwas wulstig verdickten Rand, was an die unten $\mathrm{zu}$ erwähnende Eigentümlichkeit bei Ferula erinnert.

2) Wenn A. Schulz (Beitr. I, p. 61) von Scandix Pecten veneris angibt, die männlichen Blüten hätten „keine Spur von Griffel und Fruchtknoten ", so hat er erstere wohl nur übersehen.

3) Diese haben nicht nur, einen kräftigeren Stiel, sondern anch größere Hüllblätter als die männlichen Dolden. 
nicht in der Lage war. Nach den Angaben von Berg und Schмrmt ${ }^{1}$ ) sind die weiblichen Dolden, z. B. von Ferula rubricaulis, endständig, umgeben von den männlichen. Die männlichen Blitten haben ein bedeutend kleineres Perigon als die weiblichen (1,5: $2,0-2,5 \mathrm{~mm}$ Länge). Es ist klar, daß die „weiblichen" Blüten den Zwitterblüten von Myrrhis und Scandix entsprechen. Sonderbar ist die Verschiedenheit in der Gestaltung des Griffelpolsters: es ist bei den weiblichen Blüten schüsselförmig vertieft und am Rande gezähnelt, bei den männlichen flach kegelförmig, am Rande gewellt. Vermutlich ist letztere Form eine Hemmungsbildung verglichen mit der ersteren.

Astrantia major. Es finden sich bei dieser Pflanze Zwitterbliiten und männliche, vielfach auch Übergangsformen zwischen beiden, d. h. Bliiten, bei welchen der unterständige Fruchtknoten, welcher den männlichen fehlt, in geringerer Ausbildung als bei den Zwitterblüten vorhanden ist.

Von Interesse ist die Verteilung der beiderlei Blütenformen. Dolden, welche nur Zwitterblüten enthielten, traf ich nicht an, stets waren wenigstens einige männliche vorhanden. Aber ihre Zahl ist eine wechselnde und offenbar von Ernährungsverhältnissen abhängige ${ }^{2}$ ). Die besternährten haben am wenigsten, die schlechtesternährten Dolden am meisten männliche Blüten. Ein Beispiel diene zur Erläuterung.

Die Enddolde der ganzen Pflanze hat der Hauptsache nach Zwitterblïten. Am Rande und im Zentrum der Dolde aber auch männliche. Diese haben längere und etwas dünnere Stiele als die Zwitterbliiten; es wird gewissermaßen das bei letzteren auf den (unterständigen) Fruchtknoten fallende Stück zum Stiel geschlagen.

Daß die Seitendolden 1. Ordnung weniger gut ernährt sind als die Hauptdolde, spricht sich schon in ihrem diinneren und schwächer gebauten Stiele aus, auch darin, daß sie eine kleinere Hülle haben als die Enddolden. Die Zahl der Zwitterbliiten ist hier eine bedeutend geringere, die der männlichen Blüten eine größere als in der Enddolde; bei einer an der Basis der Pflanze stehenden Seitendolde 1. Ordnung war nur eine Zwitterbliite (nebst verschiedenen Zwischenformen) außer den männlichen vorhanden. Die Seitendolden 2. Ordnung endlich pflegen rein männlich zu sein. Bei kräftigen Pflanzen aber können auch sie noch Zwitterblüten führen.

Kelch und Blumenkrone der männlichen Bliiten sind nicht größer, sondern eher kleiner als bei clen Zwitterbliiten. Erstere sind zweifellos aus letzteren durch Reduktion entstanden. Daß diese mit den Ernährungsverhältnissen im Zusammenhang steht, zeigt die soeben erwähnte Verteilung. Für die Annahme, daß auch innerhalb der Dolden einerseits die Peripherie, andererseits das Zentrum die Stellen sind, welche für die Ausbildung der Blüten weniger günstige Ernährungsverhältnisse darbieten als ein mittlerer Gürtel der Dolde, spricht die Beobachtung, daß in einer männlichen Dolde die peripherischen Blüten ganz verkümmerten (sie waren nur als kleine Stiele mit einer verkümmerten Knospe wahrnehmbar). Eine solche Verkümmerung geht am leichtesten bei den weniger widerstandsfähigen Teilen vor sich.

Die genannten Umbelliferen stimmen also alle darin iiberein, daß die

1) A tlas der offizinellen Pflanzen. 2. Aufl. Bearbeitet von A. Mryer und K. Schumann.

2) H. MüLLer (Alpenblumen und ihre Befruchtung etc., p. 542) sagt von A. minor: „Je schwächlicher die Pflänzchen sind, um so geringer ist die Zahl der zweigeschlechtigen Blïten, die schwächlichsten Exemplare produzieren ausschließlich männliche." 
männlichen Blüten den Zwitterblüten gegenüber als unterernährt erscheinen. Dies tritt sehr deutlich auch an den prachtvollen Blütenständen von Heracleum Mantegazzianum hervor (die Pflanze erreicht eine Höhe von über $3 \mathrm{~m}$ ). Die letzten Dolden sind auch hier männlich; die wenigen darin befindlichen Zwitterblüten setzten keinen Samen an, obwohl sie gut entwickelte Griffel hatten, was dadurch bedingt sein dürfte, daß alle Assimilate zur Reifung der Früchte in den ersten Dolden verwendet werden. Ähnlich, nur weniger auffallend, ist die Blütenausbildung auch bei unseren einheimischen Heracleum Sphondylium ${ }^{1}$ ), bei Angelica silvestris u. a. Wie die letzten Mikrosporangien von Azolla werden diese am Ende der Blütezeit auftretenden männlichen Blüten vielfach ganz nutzlos sein. - Burck (a. a. O. p. 809) fand (entsprechend der Beobachtung von H. MüLLER), daß bei Anthriscus silvestris und Chaerophyllum temulum auf gutem Boden die Zahl der Zwitterblüten bedeutend größer war als auf schlechtem.

Es liegen die Verhältnisse also ganz ähnlich wie bei den Pflanzen mit kleistogamen Bliuten ${ }^{2}$ ). Letztere entsprechen in den Bedingungen ihres Auftretens den männlichen Blüten der Umbelliferen, und ganz analog verhalten sich die weiblichen Blüten der von ConRENs untersuchten gynodiözischen Pflanzen. Wenn A. Schulz ${ }^{3}$ ) sagt, daß kräftige Ernährung bei manchen Umbelliferen das Entstehen männlicher Blüten begünstige, so ist dazu zu bemerken, daß eine kräftige Ernährung der Vegetationsorgane nicht zusammenzufallen braucht mit der der einzelnen Blüten, wofür z. B. die Violaarten ${ }^{4}$ ) mit kleistogamen Blüten einen Parallelfall darbieten. Wenn also auch z. B. ein größeres und vieldoldigeriges Exemplar von Peucedanum Cervaria weniger Zwitterblüten hervorbringen kann als ein kleineres, so beweist das nichts gegen die oben dargelegte auch von Burck vertretene Auffassung.

Begonia. Herkunft und Verwandtschaft der in vielen Beziehungen merkwürdigen Familie der Begoniaceen sind dunkel. Es ist deshalb auch nicht möglich, mit einiger Sicherheit die Gestaltungsverhältnisse der Blüten von anderwärts bekannten abzuleiten. Immerhin nähert sich noch am meisten dem gewöhnlichen Dikotylentypus, bei welchem eine doppelte Bliitenhülle vorhanden ist, die Gattung Hillebrandia ${ }^{5}$ ), welche auf den Sandwichinseln vorkommt. Wie bei allen Begoniaceen, sind auch hier die Blüten getrenntgeschlechtig. Aber männliche und weibliche Blüten stimmen in ihrer Blütenhülle der Hauptsache nach üb e r e in, während sie sonst meist auffallende Verschiedenheiten aufweisen. Bei beiden sind nämlich fünf weiße oder blaßrote Kelchblätter und fünf sehr schmale Blumenblätter vorhanden, welche in den männlichen Blüten teilweise durch Staubblätter ersetzt sein können. Die weiblichen Blüten können (der Gattung Begonia gegenüber) als primitive angesehen werden auch deshalb, weil der Fruchtknoten, wie es scheint, nur halb unterständig ist, während er bei Begonia selbst unterständig ist.

1) Diese Pflanze scheint sich in verschiedenen Gegenden verschieden zu verhalten. Schulz (Beitr. II, p. 90) führt sie unter denen an, die neben hermaphroditischen Blüten $k$ ein e eingeschlechtigen haben.

2) Vgl. Gokвes, Die kleistogamen Blüten und die Anpassungstheorien, Biol. Centralbl. Bd. XXIV. - Betreffs anderer Fälle s. DüsING, Die Regulierung des Geschlechtsverhältnisses. Jen. Zeitschr. f. Naturwissensch. 17 (1884), p. $803 \mathrm{ff}$.

3) A. Scrulz, Beitr. II, p. 47.

4) Vgl. GokBer, Chasmogame und kleistogame Blüten bei Viola, Flora 95 (1905), p. 234 und .Einleitung in die experimentelle Morphologie (1908), p. 134.

5) Abbildung in Gardener's Chronicle. Dez. 12. 1908. 
Sehen wir uns bei Begonia zunächst die Stellung der männlichen und weiblichen Blüten in den Blütenständen an, so kann hier auf Einzelheiten von nur morphologischem Interesse natürlich nicht eingegangen werden ${ }^{\mathbf{1}}$ ). Von Interesse sind für die hier erörterten Fragen nur drei Tatsachen.

1. Die Blütenstände (welche zu den „cymösen" gehören) beginnen mit männlichen Blüten, welche die relativen Hauptachsen abschließen.

2. Unter den weiblichen Blüten geht gewöhnlich die Verzweigung des Blütenstandes nicht weiter (vgl. das Schema Fig. 163). Dieser Satz ist zwar kein ansnahmsloser ${ }^{2}$ ), gibt aber wohl bei weitem das häufigste Vorkommen wieder; d. h. also, wenn einmal eine weibliche Blüte gebildet ist, so findet von ihr aus keine weitere, ja stets mit Verbrauch ron Baumaterialien verbundene Bildung seitlicher Organe statt; es können den heranreifenden Früchten also mehr Baumaterialien zufließen, als wenn die Verzweigung weiter gehen würde.

Fig. 163. Begonia hirsuta. Schema. des Blütenstandes im Querschnitt. Die Hauptachse $(H)$, an welcher die Infloreszenz steht, ist dorsiventral, sie hat eine Plus- $(+)$ und eine Minusseite. Nach ersterer hin stehen die größeren Blatthälften der unsymmetrischen Blätter und die größeren Nebenblätter. Die Infloreszenz steht nach der Minusseite hin. Sie bringt nach drei männlichen Blüten eine weibliche (punktiert) $I V$ hervor.

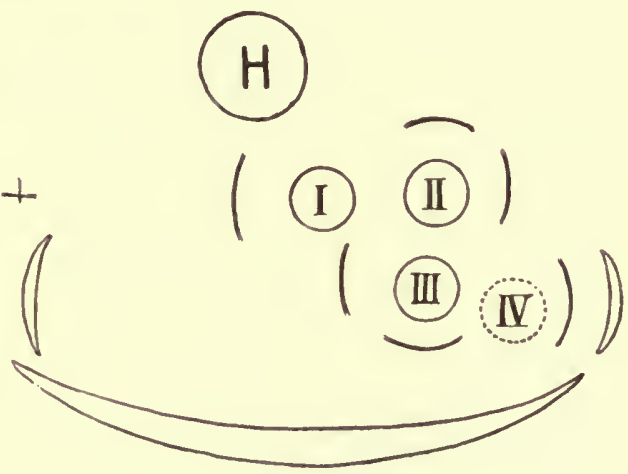

Fig. 163.

Fig. 164. Begonia Eng'eri. Querschnitte des Blütenstiels, $a$ ron einer männlichen, $b$ von einer weiblichen Blüte.
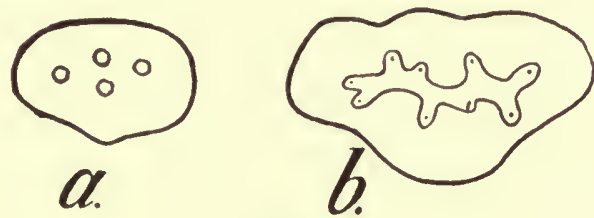

Fig. 164 .

3. Die Stiele der weiblichen Blïten, welche ja selbstverständlich nach dem Verblühen (falls Befruchtung eingetreten ist) an der Infloreszenzachse sitzen bleiben, während die männlichen Blïten abgeworfen werden ${ }^{3}$ ), haben einen anderen Bau als die der männlichen Blüten - wenigstens bei den Arten, welche ich aufs Geratewohl herausgriff und untersuchte ${ }^{4}$ ).

Für Begonia Engleri z. B. zeigt Fig. 164 a den Querschnitt eines männlichen, b den eines weiblichen Blütenstiels bei derselben Vergrößerung. Es tritt ohne weiteres die größere Leistungsfähigkeit des letzteren hervor.

1) Vgl. diesbeziiglich Fr. Benecke, Beitrag zur Kenntnis der Begoniaceen. (Engler, Botan. Jahrbücher III [1882].)

2) Wenn in den Achseln der Vorblätter weiblicher Blïten weitere Blüten anftreten, sind sie weiblich. Wir. können also selbst dann sagen, daß die Infloreszenzen resp. Infloreszenzäste erst männlich, dann weiblich sind.

$\left.{ }^{3}\right)$ Es ist eine besondere Ablösungszone vorhanden.

4) Vgl. auch Grevillius a. a. 0. p. $59 \mathrm{ff}$. 
Er enthält einen deutlichen, wenn auch abgeplatteten Zentralzylinder mit neun Leitbündeln; er ist ferner bedeutend massiger als der männliche Bliitenstiel, der nur vier Leitbündel hat, keinen deutlich abgegrenzten Zentralzylinder besitzt und kein Anthocyan, welches dem weiblichen Blütenstiel eine rote Färbung verleiht. Daß diese Differenz „zweckmäßig“ ist, ist klar, hat doch der weibliche Blïtenstiel der heranreifenden Frucht die nötigen Baumaterialien zuzuführen, während die männliche Blüte nur den Blütenstaub hervorbringt und dann abgeworfen wird.

Besonders auffallend tritt dies hervor bei einigen brasilianischen Begoniaarten, deren Sprosse mehrere Meter Höhe erreichen und die Blütenstände mit Hunderten von männlichen und (weniger) weiblichen Blüten hervorbringen. Bei B. valida (n. sp.) geht ein Regen weißer männlicher Blüten von den Infloreszenzen nieder. Dann treten die weiblichen $1 \mathrm{~m}$ so auffallender hervor, als jede mit einem weißen Flügel am Fruchtknoten versehen ist, der größer ist als dieser selbst. Das bleibende Gerüst des Blütenstandes tritt nach dem Verschwinden der kurzlebigen männlichen Blüten nun erst auffallend hervor, jeder Zweig endigt mit einer weiblichen Blüte. Offenbar sind anch hier, wie bei den oben erwähnten Fällen, für die Ausbildung der weiblichen Blüten größere Mengen ron Baumaterialien notwendig als für die männlichen, was sich dann auch im Bau der Blütenstiele ausspricht ${ }^{1}$ ).

Es erscheint wahrscheinlich, daß die weiblichen Blütenstiele in ihrem Bau dem der ursprünglichen Zwitterblüten näher stehen als die männlichen, die sich dann analog wie bei den oben besprochenen Umbelliferen als eine "Minusvariante" betrachten ließen.

Bei einigen Begoniaarten (z. B. Beg. rhizocarpa und B. attenuata) ist eine Trennung der männlichen und weiblichen Blüten eingetreten. Die männlichen Blütenstände der ersteren sind mèhrblïtig und langgestielt, die weiblichen einblütig, fast sitzend. Hier tritt das oben erwähnte Prinzip besonders dentlich hervor, daß mit der Bildung der weiblichen Blüte das weitere WVachstum der Infloreszenzäste abgeschlossen ist ${ }^{2}$ ). Ebenso ist klar, daß die Zahl der männlichen Blüten die der weiblichen erheblich übertrifft.

Die männlichen Blütenstände sind nicht nur viel zahlreicher, sondern anch reichblütiger; ich zählte in ihnen bis zu 12 Blüten, oft sind diese aber weniger zahlreich. Beide Blütenstände stehen an den kriechenden Rhizomen, offenbar in derselben Stellung. Die männlichen stehen, wie die Achselsprosse vieler dorsiventraler Sprosse, unterhalb der Mediane ihres Deckblattes; ob dies bei den weiblichen auch zutrifft, konnte nicht festgestellt werden, da ich die seltene Pflanze der Untersuchung nicht opfern wollte. Der Fruchtknoten der weiblichen Blüte ist im Verhältnis zu ihrer sonstigen Gestaltung groß. Er hat oben einen Griffel entwickelt, der die Narben emporhebt und so trotz der "sitzenden" Stellung der weiblichen Bliite die Bestäubung erleichtert. Diese dürfte durch Insekten vor sich gehen; die Blüten besitzen, von ihrem Schauapparat abgesehen, auch einen deutlich wahrnelombaren Geruch.

Auch bei anderen Begonien dürfte die Zahl der weiblichen Blüten

1) Bei einer gelb blühenden Knollenbegonia waren die Stiele der großen männlichen Blüten dicker als die der weiblichen, auch ihr Leitbïndelsystem stand binter dem der letzteren nicht zurück. Doch dürfte dies ein Ansnahmefall sein.

2) $\mathrm{Ob}$ die einzige weibliche Blüte hier den Abschluß eines Achselsprosses 1. Ordnung bildet, konnte wegen Mangel an Material nicht untersucht werden, indes ist dies wahrscheinlich. 
hinter der der männlichen zurückbleiben, wenngleich nicht in so hohem Grade wie bei B. rhizocarpa. So zeigt z. B. Fig. 163 eine Infloreszenz von $B$. hirsuta, in welcher auf drei männliche Blüten eine weibliche kommt.

Männliche und weibliche Blüten von Begonia unterscheiden sich namentlich auch durch ihre Blütenhülle.

Der - wenigstens bei den von mir untersuchten lebenden Pflanzen - gewöhnlichste Fall ist der, daß die männlichen Blüten eine weiß oder rot (seltener gelb) gefärbte einfache, aus vie r Blättern bestehende Blütenhülle haben, die weibliche eine aus fünf Blättern bestehende. Vielfach, z. B. bei den Knollenbegonien, tritt dabei hervor, daß die männlichen Blüten durch ihre größere Bluitenhüille viel mehr in die Augen fallen als die weiblichen, eine Erscheinung, welche ja auch sonst wiederkehrt. Indes ist sie auch bei Begonia keine ganz allgemeine. Bei B. heracleifolia z. B. sind die Hüllblätter der männlichen Blüten zwar länger aber schmäler als die der weiblichen.

Welche Gestaltung der Blüten ist nun die ursprünglichere, die der männlichen oder die der weiblichen? Meiner Ansicht nach die der letzteren. Sie zeigen die größte Annäherung an die von uns als verhältnismäßig primitiv betrachtete Hillebrandia. Es sind bei Begonia offenbar die inneren Blätter der Blütenhülle nicht zur Ausbildung gekommen, sondern nur die äußeren, dem Kelch anderer Pflanzen entsprechenden.

Das braucht nicht auf eine Verkümmerung zurückgeführt zu werden, da die Begoniaceen ja auch ,.typisch" apetal sein könnten. Hillebrandia hätte dann eine Anzahl der Staubblätter zu Blumenblättern entwickelt, wie das etwa bei manchen Ranunculaceen vorkommt. Es ist auch nicht notwendig anzunehmen, daß die 5-Zahl der Blütenhülle die ursprïngliche sei. Wie der korollinische Kelch bei den Ranunculaceen bald in 5-, bald in einer höheren Zalıl ausgebildet ist (letzteres z. B. bei Trollius), so kann dies auch bei Begonia eingetreten sein. Wir können also ausgehen von einer azyklischen Blüte mit einfachem Perianth, wozu bei Hillebrandia noch eine Umbildung einer Anzahl äußerer Staubblätter zu Blumenblättern gekommen ist. Indes berïhrt das die hier behandelte Frage nicht näher. Für uns ist jedenfalls die Annahme berechtigt, daß männliche und weibliche Bluiten ursprünglich gleich gestaltet waren. Die oben aufgestellte Meinung, daß die weiblichen Blüten bei Begonia weniger weit fortgeschritten sind als die männlichen beruht ferner auf folgenden Gründen :

1. Es gibt Übergänge in der Ausbildung der Blïtenhïlle zwischen männlichen und weiblichen Bliiten.

2. Bei manchen Begoniaarten sind die männlichen Bliten noch weiter verändert worden, indem die Zahl der Blütenhüllblätter bis auf zwei sinkt. Dies ist offenbar nur ein weiterer Fortschritt in der Verringerung der Perigonblattzahl; es gibt Begoniaarten, bei denen auch die weiblichen Bliiten dieselbe Veränderung erfahren haben. Es ist also eine "Tendenz" zur Verringerung der Perigonblätter vorhanden, welche von den männlichen Blüten früher durchgeführt wird als von den weiblichen. Beziiglich der Einzelheiten sei auf die a. a. O. gegebene Begriindung verwiesen; es sei nur erwähnt, daßs die Verminderung der 5-Zahl auf die 4-Zahl bei den Bliitenhüllblättern der männlichen Blüten offenbar dadurch zustande kam, daß zwei Blätter durch eins ersetzt wurden.

Valerianeen. In der Gattung Valeriana kommen neben Arten mit Zwitterblïten (z. B. V. officinalis) auch solche mit getrenntgeschlechtigen Blüten vor, allerdings mit "labiler" Trennung. Hier soll auf die Einzel- 
heiten der Geschlechtsverteilung nicht eingegangen, sondern nur erwähnt werden, daß die männlichen. Bliiten bei allen derartigen Arten (bei vielen anderen Sympetalen auch die Zwitterblïte, z. B. Salvia pratensis, Fig. 165 B, 166 links) bedeutend größere Blumenkronen haben als die weiblichen (Fig. $165 \mathrm{~A}, 166 \mathrm{rechts)}$ und daß die männlichen einen gut entwickelten Griffel, die weiblichen deutlich sichtbare Staubblätter haben, die aber in der Entwicklung zurückbleiben.

Welche der beiden Blütenformen ist die der Zwitterbliite näher stehende? Es kann meiner Ansicht nach nicht zweifelhaft sein, daß die Blumenkrone der weiblichen Blüten gegenüber der der Zwitterblüten eine Verringerung erfahren hat. Möglich ist es, daß die der männlichen Bliiten

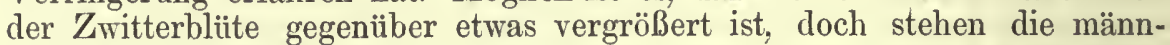
lichen Blüten meiner Ansicht nach den Zwitterblüten näher als die weiblichen.

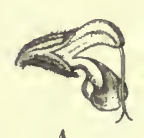

A.

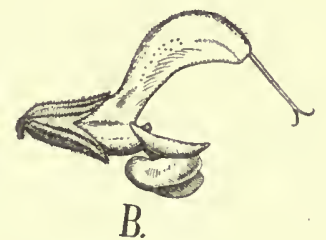

Fig. 165. Salvia pratensis. $A$ weibliche, $B \mathrm{Z}$ witterblüte.

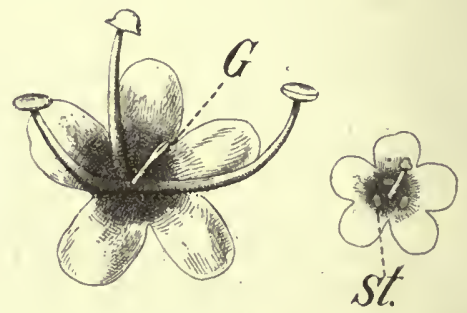

Fig. 166. Links männliche, rechts weibliche Blüte von Valeriana montana. G Griffel, st Staminodien.

Die Gründe für diese Ansicht sind:

1. Gelegentlich fand ich in männlichen Blïtenständen von V. montana Fruchtansatz, es waren hier also Zwitterblitten rorhanden, die in ihrer Gestalt von den sonst männlichen nicht abwichen.

2. Bei V.dioica fand H. MüLleri ${ }^{1}$ ) männliche Blüten ohne Stempel, mit sehr großen Kronen und solche mit Stempelrest und etwas kleineren Kronen (in seltenen Fällen auch Zwitterblüten) und weibliche Blïten mit „kleinerem Pistill und größeren Kronen" und solche mit größerem Pistill und sehr kleinen Kronen. Diese Beobachtungen beziehen sich nur auf die fertigen Bliiten, sie sollten durch die Untersuchung der Frage, wie die verschiedenen Blütenformen sich im Knospenstadium verhalten, ergänzt werden. Aber auch aus ihnen scheint mir die Rïckbildung der Krone in den weiblichen Blüten hervorzugehen. Auf die Ansicht MǗLLER's iiber die biologische Bedeutung der größeren Auffälligkeit der männlichen Blüten wird unten kurz einzugehen sein. Hier sei nur erwähnt, daß, wie offenbar zwischen der Ausbildung der Blumenkrone und der der Staubblätter eine Korrelation besteht, wenn sie auch nicht überall. hervortritt.

Ein schönes Beispiel für diese Beziehung hat Correxs ${ }^{2}$ ) bei Geranium pratense gefunden. Hier sind die Zwitterblüten durchschnittlich $40 \mathrm{~mm}$ breit, die rein weiblichen etwa $30 \mathrm{~mm}$. Bei den Übergangsformen, bei welchen einzelne Staubblätter rückgebildet waren, waren auch die unter, 
ihnen stehenden Blumenblätter kleiner als die unter den normalen Staubblättern stehenden.

Kompositen. In dieser großen Familie treten in den Blüten sehr mannigfache Verteilungsverhältnisse der Sexualorgane auf, es finden sich neben Z witterblüten vielfach weibliche und männliche. Es ist klar, daß durch die große Anzahl der Blüten, welche in einem Köpfchen zusammenstehen, die Möglichkeit, verschiedene Blïtenformen zu entwickeln, eine. größere ist als bei den Pflanzen mit einzelstehenden Blüten.

Hier sollen zunächst zwei Beispiele besprochen werden, bei welchen die männlichen und die weiblichen Bliten auf rerschiedene Infloreszenzen verteilt sind; daran wird sich die Besprechung der Gestaltrerschiedenheit zwischen männlichen und weiblichen Bliiten anschließen.

1. Petasites niveus. Die Trennung ist hier insofern keine ganz scharfe, als in den weiblichen Blütenköpfen auch (sterile) männliche Bliiten vorkommen; indes können diese zunächst außer Betracht bleiben. Männliche und weibliche Infloreszenzen zeigen nach dem Abbliihen, wie Fig. 135 zeigt, ein auffallend verschiedenes Verhalten: die Hauptachse der männlichen Infloreszenz und die Stiele der Blütenköpfe entwickeln sich nicht weiter, während bei der weiblichen Infloreszenz eine Streckung und Verdickung eintritt. Es beruht dies auf einer Vergrößerung der Zellen; auch scheint der weibliche Infloreszenzschaft mehr Zellen auf dem Querschnitt aufzuweisen als der männliche. Indes war die Zahl der Messungen zu klein als daß diese Angabe verallsemeinert werden könnte. Jedenfalls tritt schon beim Durchschneiden hervor, daß der weibliche Infloreszenzschaft eine größere Härte erreicht als der männliche. Die Collenchymbüindel vor und hinter den Leitbündeln verholzen nämlich, ebenso das Grundgewebe zwischen den Leitbïndeln. Auch ohne Versuche ist es kaum zweifelhaft, daß der weibliche Infloreszenzschaft biegungsfester wird als der männliche. Ein Interfaszikularkambium bildet sich nicht, auch in den Leitbiindeln selbst ist nur ein unbedeutendes Dickenwachstum vorhanden. Die Fruchtreife findet rasch statt, dann stirbt auch der weibliche Bliitenstand ab.

Hier sind also die Verschiedenheiten zwischen weiblichen und männlichen (zusammengesetzten) Infloreszenzen hauptsächlich durch eine postflorale stärkere Entwicklnng der weiblichen bedingt. Es wurde nicht untersucht, ob diese ron der Befruchtung abhängig ist, wie das ja kaum zu bezweifeln ist.

Das nächste Beispiel betrifft einen Fall, bei welchem weibliche und männliche Infloreszenzen von vornherein stark verschieden sind.

2. Xanthium. Die Kompositengattung Xanthium zeigt männliche und weibliche Blïtenköpfe in monözischer Verteilung. Sie unterscheiden sich schon bei oberflächlicher Betrachtung sehr bedeutend. Die männlichen Blütenköpfe haben den ursprünglichen Charakter am meisten gewahrt. Sie zeigen in der Achsel von Deckblättern (Fig. $167 I$ ) eine Anzahl von Blüten, welche sich von den gewöhnlichen Kompositenblüten hauptsächlich dadurch unterscheiden, daß die Fruchtknoten frühzeitig verkümmern (eine eigentliche Fruchtknotenhöhle fand ich bei $\mathrm{X}$. spinosum nicht mehr angelegt).

Die weiblichen Blütenköpfe haben nur zwei Blüten, und die Blumenkrone ist sehr stark reduziert, sie scheint als verspätete Bildung $\mathrm{nach}$ Anlage des Fruchtknotens noch aufzutreten. Später ist sie als kurzer, schief abgeschnittener Saum sichtbar, von Staubblattanlagen war nichts 
mehr nachweisbar. Die Früchte sind in eine mit Widerhaken versehene harte, feste, mit zwei Fortsätzen versehene Hülle eingeschlossen.

Diese kommt durch „Verwachsung" der beiden Deckblätter der weiblichen Blüten zustande ( $\mathrm{vgl}$. die a. a. O. angeführte Literatur). In den männlichen Infloreszenzen stehen in den Achseln aller Hochblätter Blüten, in den weiblichen nur in den Achseln von zweien (Fig. $167 I, I I$ ). Diese aber greifen um die Blüten so herum, dảß die Ränder jedes Deckblatts untereinander sich zusammenhängen. Der mit $S a_{1}, S b_{1}$ bezeichnete zweiteilige Körper gehört dieser Auffassung nach nur teilweise, in seiner zwischen der Punktierung liegenden Partie zur Blütenstandsachse der weiblichen Infloreszenz. Die beiden Stïcke $a$ und $b$ gehen seitlich in die Ränder der Hüllblätter über. Es liegt also ein ähnlicher Vorgang vor wie etwa bei der Bildung eines apokarpen aus zwei Fruchtblättern bestehenden Fruchtknotens, die beiden Deckblätter der Blüten haben ihre Ränder so weit nach innen geschlagen, daß sie sich berühren. Dies tritt bei einer Oberflächenansicht (Fig. 167 IV) deutlich hervor. Eine „Einsenkung" tritt dann dadurch ein, daß der peripherische Teil der" Infloreszenzachse interkalar emporwächst; dadurch werden auch die obersten Anlagen der Haken mit emporgehoben. Ebenso findet in der Mittelregion,
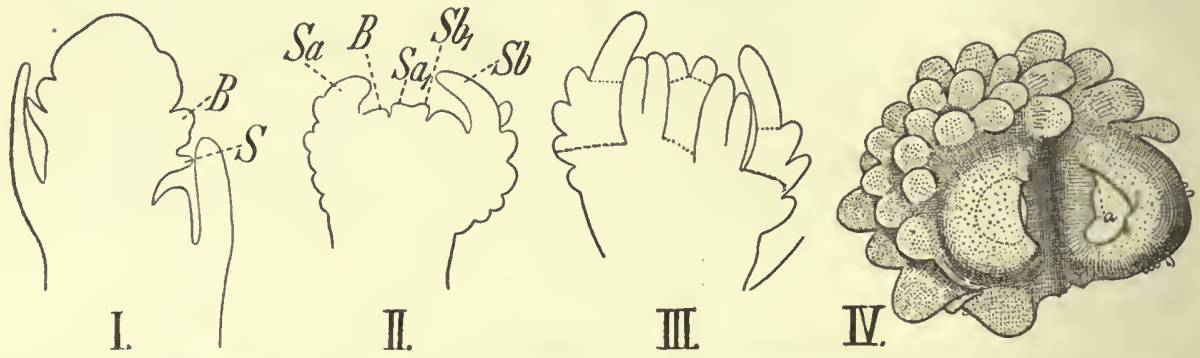

Fig. 167. Xanthium (I-III X. spinosum, IV X. Strumaria). I Längsschnitt durch eine junge männliche Infloreszenz. S Deckblatt, $B$ Blütenanlage. II Längsschnitt durch eine junge weibliche Infloreszenz. $S a, S b$ die zwei Deckblätter der zwei Blütenanlagen. $S a_{1}, S b_{1}$ die nach innen geschlagenen Ränder dieser Deckblätter. III Längsschnitt durch eine ältere weibliche Infloreszenz. Die weiblichen Blüten (bis jetzt nur aus dem Fruchtknoten mit zwei Griffeln bestehend) sind durch interkalares Wachstum der zwischen den gestrichelten Linien liegenden Gewebe "versenkt". IV Weibliche Infloreszenz sehief von oben. Man sieht anßer den Borsten" die zwei Deckblätter der (nicht sichtbaren) Blüten. a Die Seitenteile des mit den Rändern eingeschlagenen Deckblattes der rechts liegenden Blüte.

wo die beiden Blütendeckblätter zusammenstoßen, ein interkalares Wachstum statt. Die Haken stehen dann teilweise an der Infloreszenzachse, teilweise an den Hüllen. Wenn man also annimmt, daß der Teil der Hiullen, welcher die Haken trägt, eigentlich ein emporgewölbter Teil der Infloreszenzachse sei, so kann man den einheitlichen Ursprung der Haken retten und diese als umgebildete äußere Hüllblätter betrachten. Dann müßten sie den Deckblättern der Blïten der männlichen Infloreszenz entsprechen, und die schnabelförmigen Bildungen, in welche die weiblichen Blüten eingeschlossen sind, wären die obersten Deckblätter. Sind aber die Haken den männlichen Infloreszenzen gegenüber Neubildungen (Emergenzen), so wären die untersten Deckblätter die, welche in der weiblichen Infloreszenz die Umbildung erfahren.

Welche der beiden Ansichten über die Natur der Haken zutrifft, wird sich wohl nur durch ein vergleichendes Studium der Infloreszenz- 
bildung der mit Xanthium verwandten Formen - wozu ich keine Gelegenheit hatte - ermitteln lassen. Jedenfalls ist so viel klar, daß männliche und weibliche Infloreszenzen auch bei Xanthium ursprünglich gleich gewesen sein müssen und daß die weiblichen viel stärker umgebildet sind als die männlichen. Der Ausgangspunkt wird der dem Verhalten anderer Kompositen entsprechende sein mit Köpfchen, in denen außen weibliche, innen männliche Blüten waren. Solche finden sich bei der Kompositengruppe, zu welcher Xanthium gehört, noch bei rerschiedenen Gattungen, Ira, Oxytenia w. a. Bei Dicoria wird angegeben, daß die Blïtenköpfe 1-2 weibliche Blüten in den Achseln großer Deckblätter haben. Denken wir uns in den Blütenköpfen den oberen, männlichen Teil unterdrückt, so würde eine bedeutende Annäherung an Xanthium sich ergeben.

Diese Erwägung weist, wie mir scheint, darauf hin, daß die Deckblätter der Xanthiumblüten dem untersten Teil der Infloreszenz angehören, nicht dem oberen, und folglich die Haken Neubildungen darstellen.

Blüten. Über den sexuellen Dimorphismus der Blïten von Kompositen liegt eine sorgfältige Untersuchung von M. r. UEXKÜLL-GYLI_ENBAND vor ${ }^{1}$ ).

In der uns hier speziell interessierenden Frage kommt die Verfasserin zunächst zu folgenden Schlüssen:

1. Sämtliche bei den Kompositen gefundenen 14 Blütenformen lassen sich von einer gemeinsamen Urform, der röhrenförmigen Zwitterblüte ableiten.

2. In einem jugendlichen Zustand lassen sich zwitterige Anlagen auch bei in erwachsenem Zustand rein weiblichen Blüten nachweisen.

3. Die weiblichen Blüten zeigen eine starke Modifikationsfähigkeit, sowohl in bezug auf die Korolle als auf den Stempel.

4. Bei den männlichen Blüten finden keine weiteren Modifikationen statt.

Der erste Satz ist unbestreitbar und gibt wohl auch die allgemeine Annahme wieder ${ }^{2}$ ).

Der zweite würde der normalen Entwicklungsfolge entsprechen, wenn die Ontogenie die Phylogenie wiederholt; es findet das vielfach, aber nicht immer statt. Es ist diese Frage von Interesse, weil sie sich bezieht auf das allgemeine Problem, inwieweit bei der Einzelentwicklung der phylogenetischen gegenüber Abkürzungen vorkommen. Es sei deshalb hervorgehoben, daß - im Gegensatz zu der oben angeführten Angabe - bei den weiblichen Blüten von Cotula coronopifolia, Calendula, Filago arvensis und von Xanthium keine Spur der Anlage von Staubblättern nachzuweisen war ${ }^{3}$ ).

1) M. v. UexkülL-Gyllenband, Phylogenie der Blütenformen und der Geschlechterverteilung bei den Kompositen (Bibliotheca botanica herausgeg. von Lùrssen, Heft 52, 1901).

$\left.{ }^{2}\right)$ GoEBEL, Vgl. Entwicklungsgeschichte der Pflanzenorgane 1883 (Schenk's Handbuch der Botanik II, p. 290). Aum. 3. Als die phylogenetisch älteren dürfen wir wohl die Röhrenblüten betrachten, aus denen sich ja, wie die ,gefüllten' Gartenformen vieler Kompositen zeigen, auch durch Kultur Zungenblüten erzielen lassen."

$\left.{ }^{8}\right)$ p. 49 ihrer Abhandlung gibt UexkÜLl-Grulenband an, daß sie bei Leontopodinm alpinum keine Spur von Antherenanlagen in den schmalen röhrenförmigen Blüten gefunden habe. - Ebenso wie die Antherenentwicklung kann auch die Kelchanlage bei den Kompositen vollständig ausgeschaltet (übersprungen) werden. So bei Xanthium. Übrigens kommen analoge Fälle (des „Überspringens") auch sonst vor. So werden in den unterirdisch entwickelten kleistogamen Bliten von Cardamine chenopodifolia die Blumenblätter ganz unterdrückt (GoEBEL, Die kleistogamen Blüten und die Anpassungstheorien, Biolog. Centralblatt XXIV, p. 746).

Goebel, Organographie der Pflanzen. 2. Aufl. Allgem. Teil. 
Für Xanthium wurde die Tatsache, daß die Staubblätter ganz fehlgeschlagen sind, oben schon hervorgehoben.

Bei Calendula sind die zungenförmigen Randblüten weiblich und fruchtbar, die Scheibenblüten männlich und deshalb unfruchtbar. Zunächst sei erwähnt, daß die Randblüten bei zwei untersuchten Calendulaarten (C. officinalis und C. malacitana) keine Spur von Staubblättern aufwiesen, während Arctotis breviscapa, welche sich sonst ähnlich verhält wie Calendula, deutlich Staubblattrudimente in den weiblichen Blüten zeigt $\left.{ }^{1}\right)$. Auffallend ist, daß die Randblüten, welche später durch ihre große leuchtende Korolle die Scheibenblüten weit übertreffen, in der Entwicklung lange Zeit hinter den Scheibenblüten zurückbleiben, selbst zur Zeit der Pollenreife sind sie kaum halb so groß als jene. Die Vergrößerung der Korolle erfolgt also erst verhältnismäßig spät im Streckungsstadium.

Die Verschiedenheit des Griffels und der Narben ist in den Blütenformen eine sehr auffallende: in den männlichen Blüten sind die Narben außerordentlich kurz und breiten sich nicht aus, so daß über den Fegehaaren der Griffel scheinbar eine einheitliche Spitze besitzt (Fig. 168 IV). In den weiblichen Blüten ist der Griffel (Fig. $168 \mathrm{II}$ ) viel kürzer, die Narben sind viel länger, von Fegehaaren fand ich keine Spur, höchstens könnte man die nicht sehr auffallende Zellwandvorwölbung der Epidermiszellen an der betreffenden Stelle für einen letzten Rest der Fegehaare halten.

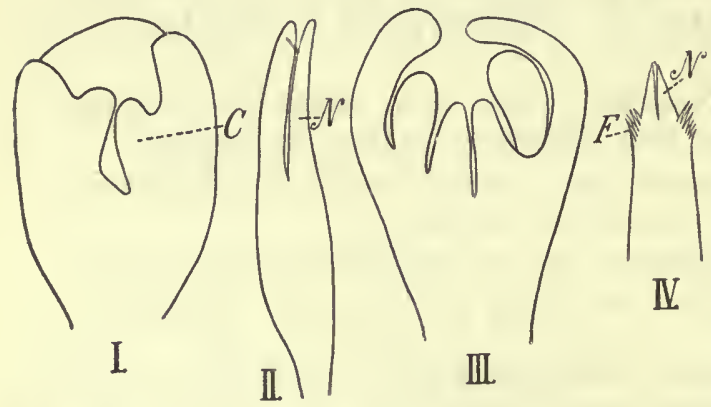

Fig. 168. Calendula officinalis. I Längsschnitt durch eine junge weibliche Blüte. Obwohl die zwei Fruchtblätter (C) vorhanden sind, ist keine Spur von Staubblattanlagen sichtbar. II Griffel einer weiblichen Blüte. $N$ Narbe. III Längsschnitt durch eine junge männliche Blüte. IV Oberer Teil des Griffels einer männlichen Blüte, $F$ Fegehaare.

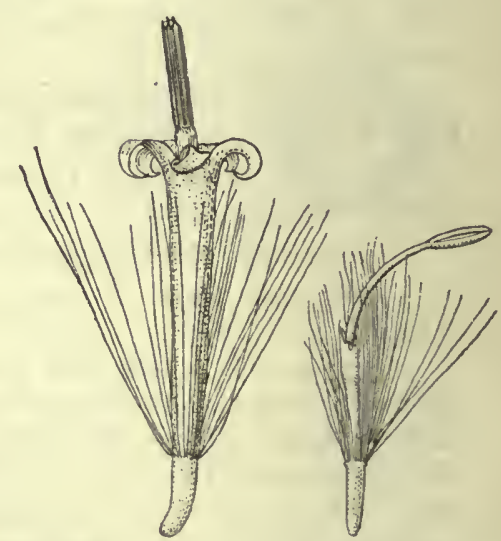

Fig. 169. Homogyne alpina. Links Zwitterblüte, rechts weibliche Blüte.

Für diese Verschiedenheit gibt auch die Entwicklungsgeschichte keine Aufklärung. Sie zeigt nur, $d a ß$ in den männlichen Blüten die beiden Fruchtblätter früh miteinander verschmelzen und die Bildung einer eigentlichen Fruchtknotenhöhle unterbleibt, während der Griffel dem starken Wachstum der Korolle entsprechend sich verlängert. Wenn nun weiter gesagt würde, daß in den männlichen Blïten eine Hemmung der Narben - in den weiblichen eine Hemmung des Griffels und der Fegehaarbildung eintritt, so wäre das nur eine Umschreibung der Tatsachen, keine „Erklärung". Ebensowenig liegt eine solche natürlich auch in der Annahme, $\mathrm{da} B$ die 'Teile gehemmt werden, welche nicht mehr gebraucht werden. Die männlichen Blüten der untersuchten Arctotisarten haben z. B. einen (aus Spreublättern bestehenden) „Pappus“, obwohl sie ihn gewiß nicht brauchen!

1) Es sind indes hier einzelne den Randblüten benachbarte Scheibenblüten fertil. 
Es soll unten versucht werden eine Hypothese aufzustellen, welche hier in Betracht kommen könnte.

Leichter verständlich ist eine andere Tatsache: Die weiblichen Bluiten von Calendula sind ausgiebiger mit Leitbündeln versorgt als die männlichen. Letztere erhalten nämlich vom „Bluitenboden nur 2-3, erstere gewöhnlich 4 Leitbündel" "1). - Es entspricht dies den oben für Begonia und anderen Pflanzen angeführten Tatsachen. Dafür, daß die Leitbündelversorgung der männlichen Blüten als eine Minusvariante anzusehen ist, spricht, daß z. B. bei Silphium, Lindheimera, Melampodium die Leitbuindel, welche in die fruchtbaren Randbliiten eintreten, zwar nicht an Zahl, aber in ihrem Aufbau die in die Röhrenblüten tretenden übertreffen.

Calendula ist ein Beispiel für die bei vielen, aber keineswegs allen Kompositen sich findende Eigentiimlichkeit, daß die Blumenkrone der weiblichen Randblüten größer ist als die der männlichen oder zwitterigen Röhrenblüten im inneren Teil des Blütenkopfes. Das steht im Widerspruch mit der sonst allgemeinen, oben z. B. bei Valeriana erörterten Regel. Indes hat die Größe der Randblütenkrone mit der Geschlechtsverteilung bei den Kompositen überhaupt nichts $\mathrm{zu}$ tun, sondern hängt mit ihrer Stellung zusammen.

Die äußeren Blüten einer Blütengenossenschaft sind auch bei Dipsaceen, einigen Umbelliferen und Cruciferen (z. B. Iberis umbellata) die am meisten modifizierten. Es findet bei ihnen eine Vergrößerung der Blumenkrone statt, die man bei den Kompositen vielfach als mit der Hemmung der Staubblattentwicklung korrelativ verknüpft betrachtet hat. Man wird indes UexkÜLL-GYLLENBAND beistimmen müssen, wenn sie eine solche Korrelation als nicht erwiesen betrachtet. Denn in zahlreichen Fällen haben die weiblichen Blüten kleinere Korollen als die männlichen oder die Zwitterblüten. So bei Homogyne alpina (Fig. 169) und den oben beschriebenen Beispielen von Xanthium und Cotula. Wenn man auch derartige Fälle wenigstens teilweise als sekundär eingetretene gegenüber den mit großen strahlenden Korollen bei den Tubulifloren wird betrachten dürfen, sprechen sie doch gegen eine kausale Verknüpfung von Staubblattverkümmerung und Blumenkronenvergrößerung.

Auch sonst dürften bei den Kompositen die Anschauungen, welche der Pflanze eine ängstliche Sparsamkeit in der Verwendung von Baumaterialien zuschreiben, kaum zutreffen.

Zum Beleg dafür seien die Blütenverhältnisse von Petasites niveus, deren Infloreszenzen oben erwähnt wurden, kurz geschildert ${ }^{2}$ ). Die untersuchten Blütenstände waren diözisch. die weiblichen viel unansehnlicher als die männlichen, was für die Einzelköpfchen durch die Vergleichung der unscheinbaren weiblichen Blüten (Fig. 170 I) mit den viel stattlicheren männlichen (Fig. $170 I I$ ) leicht ersichtlich ist. Es haben aber auch die männlichen Blüten noch einen Pappus, obwohl dieser hier gäuzlich ïberflüssig ist. In den weiblichen Blüten sind die Fegehaare des Griffels,

1) Vgl. J. Nissen, Untersuchungen über den Blütenboden der Kompositen. Dissert. Kiel 1897, p. 18. Der Verf. spricht dort von ${ }^{2} z$ witterigen Randblüten“, was anf einem Irrtum beruhen dürfte. Bei Helianthns, Cryptostemma u. a. konnte eine Verschiedenheit in der Leitbündelversorgung der unfruchtbaren (aber mit großer Blumenkrone versehenen) Randblüten und der fruchtbaren Röhrenblüten nicht festgestellt werden. Diese kann anch nicht für die ursprüngliche (vor der Leitbündelansbildung erfolgende) Anlage der Blüten, sondern nur für deren spätere Entwicklnng in Betracht kommen.

2) Vgl. UexküLl-Gyllenband a. a. 0. und die dort angeführte Literatur, 
welche in den männlichen den Pollen herausfegen, nur noch als kleine Papillen angedeutet, es fehlt auch die Anschwellung des Griffels unterhalb der Narben, welche beim Herausfegen des Pollens gleichfalls eine Rolle spielt (Fig. 170 III).

Diese Verschiedenheiten sind also im Gegensatz zu dem Verhalten des Pappus teleologisch verständlich, ebenso wie die Tatsache, daB in den männlichen Blüten die Griffeläste sich meist nicht ausbreiten.

Fig. 170.

Petasites niveus.

1 Weibliche Blüte (aus einem weiblichen Blütenkopf).

II Männliche Blüte, bei welcher der Griffel die Staubblattröhre gerade durchwächst.

III Ältere männliche Bluite.

IV „Honigblüte" aus einem männlichen Blütenkopf.
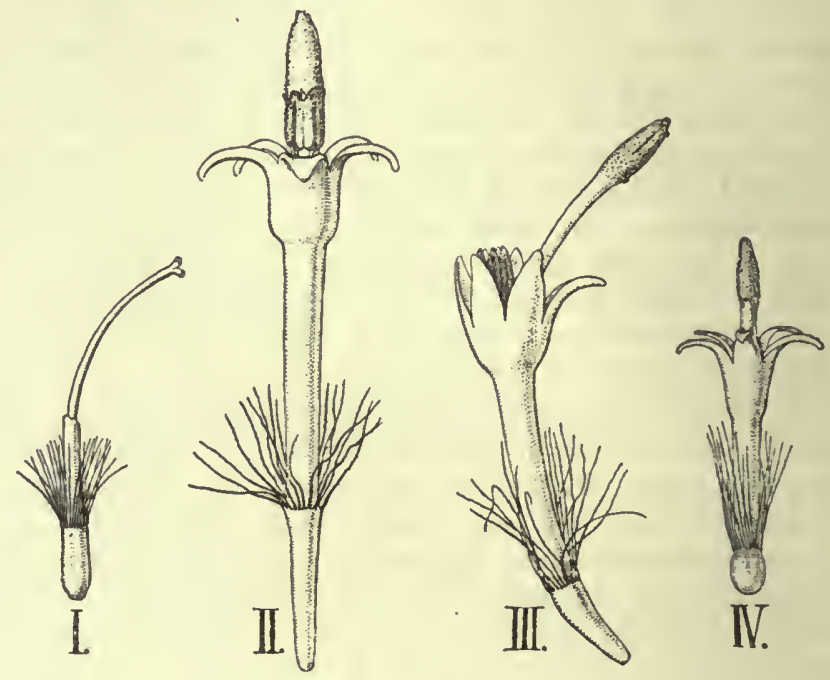

In den weiblichen Blütenköpfen finden sich im Zentrum noch einige wenige "Honigblüten" (Fig. $170 I V$ ) mit tauben Antheren, aber verhältnismäßig großen Honigdrüsen. Sie haben größere Korollen als die weiblichen Blüten und, obwohl sie steril sind, einen Pappus. Es ist also klar, daß alle diese Blüten sich von einer mit Pappus versehenen Zwitterblüte ableiten, daß die weiblichen Blüten wie sonst an der Peripherie der Köpfchen auftraten, bei den einen aber (mit Ausnahme der Honigbluiten) eine Verweiblichung eintrat, während bei den anderen die Ausbildung weiblicher Randblüten ebenso unterdrückt wurde, wie dies z. B. bei Senecio vulgaris der Fall ist, zu dessen Verhalten die Blütenköpfe. von S. silvaticus mit wenig auffallenden, eingerollten Randblüten einen Übergang bilden. Bei Matricaria inodora finden sich Stöcke mit wohl entwickelten und solche mit rückgebildeten Randblüten. Wir werden also zweierlei Kompositen mit ausschließlicher Röhrenblütenbildung $\mathrm{zu}$ unterscheiden haben: solche, bei denen dies Verhalten primitiv ist und solche, bei denen es auf Verkümmerung ron Randblüten beruht.

Filago arvensis. Die kleinen Blütenköpfchen dieser Komposite haben im Zentrum einige Zwitterblüten, die umgeben sind von einer größeren Anzahl weiblicher Blüten, die hier also nicht nur als Randblüten auftreten, sondern gegen die Mitte des Blütenstandes hin vorgedrungen sind. Sie sind mit einer sehr unscheinbaren, röhrenförmigen Blumenkrone versehen, welche meist drei-, zuweilen vierzipfelig ist.

Die Pflanze ist dadurch von Interesse, daß schon die Anlagen der beiderlei Blüten auffällig voneinander unterschieden sind. 
Ein junges Blütenköpfchen, dessen Blütenanlagen noch ganz ungegliedert sind, zeigt nämlich, daß in der Oberflächenansicht (vgl. die Fig. 171 links), die annähernd halbkugeligen Höcker, welche zu weiblichen Blüten werden, von Anfang an viel kleiner sind als die, welche sich zu $Z_{\text {witterbliten entwickeln. Es }}$ ist also von vornherein die sexuelle Ausbildung bestimmt; der geringere Materialaufwand, welchen eine weibliche Blüte gegenüber einer Zwitterblüte erfordert, spricht sich schon in der ersten Aniage der Bliiten aus. Kein Wunder, daß dann auch die Anlegung der Staubblätter in den weiblichen Blüten vollständig unterbleibt. Sie sind auch in späteren Entwicklungsstadien bedeutend schwächer als die Zwitterblüten; ihre Fruchtknotenwand z. B. ist schmächtiger als die der letzteren. Die ersten weiblichen Blüten stehen noch in den Achseln von Deckblättern, die späteren sind, ebenso wie die Zwitterblüten, ganz deckblattlos. Ihren Griffeln fehlen (von kleineren Papillen abgesehen) die Fegehaare, welche in den Zwitterbliiten gut entwickelt sind. Die Haare entstehen verhältnismäßig spät.
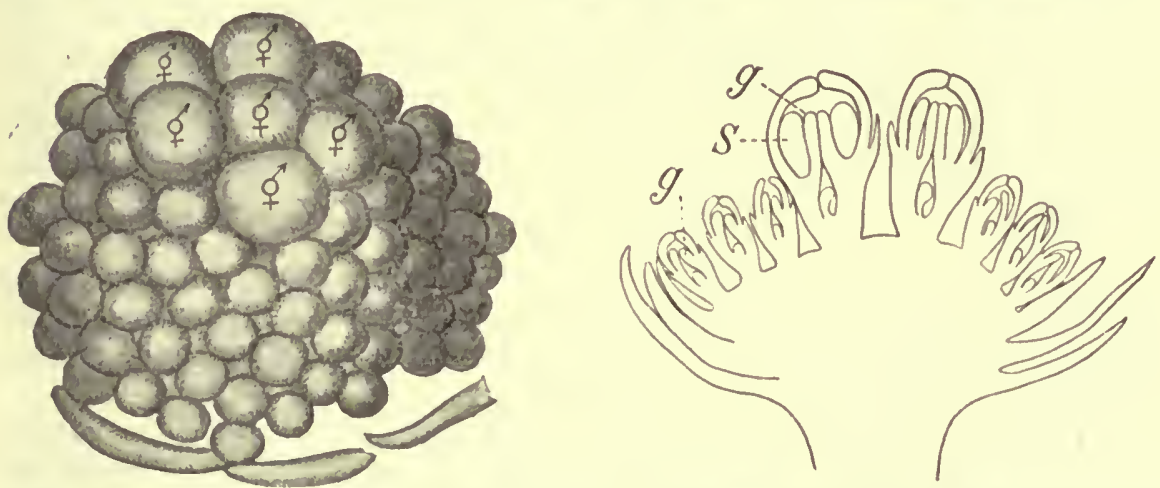

Fig. 171. Filago arvensis. Links junger Bliutenstand schief von außen gesehen. Die kleinen Höcker werden zu weiblichen, die größeren zu Zwitterblüten ( $\left.\sigma^{\top}\right)$. Rechts Längsschnitt durch einen älteren Blütenkopf. In der Mitte zwei Zwitterbliiten ( $g$ Griffel, $s$ Staubblätter). Außen weibliche Bliiten. Die Stanbblattanlagen sind ganz unterdriickt.

Thre Entwicklung ist wahrscheinlich bedingt durch Vorgänge, die sich in den Staubblättern abspielen, vielleicht durch bestimmte Stoffwechselprodukte („Hormone"), welche als Reiz wirken. Diese Annahme einer kausalen Beziehung zwischen Staubblattausbildung und Griffelgestaltung kann an anderen Kompositen als an der wegen der Kleinheit der Blüten dazu sehr wenig geeigneten Filago vielleicht auch experimentell geprïft werden. Sie wiirde verständlich erscheinen lassen, weshalb die Bildung der Fegehaare an den weiblichen Bliiten unterbleibt.

Im übrigen dürfte aus dem oben Mitgeteilten hervorgehen, daß der Ort in der Infloreszenz nur dadurch iiber die Natur der Bliite entscheidet, daß er die Entwicklungsbedingungen günstiger oder ungünstiger gestaltet, und zwar entstehen bei giinstiger Ernährung die zwitterigen, bei ungünstiger die eingeschlechtigen, männlichen oder weiblichen Blüten. ${ }^{1}$ ) Daß bei männlichen Blüten dieser Umstand sich nicht wie bei den soeben geschilderten weiblichen von Filago von vornherein in der Größe des Blüten-

1) Vgl. auch Conrexs, Zur Kenntnis der Geschlechtsformen polygamer Blütenpflanzen und ihrer Beeinflußbarkeit (Jahrb. f. wiss. Botanik Bd. XLIV (1907), p. 142. 
höckers geltend macht, liegt darin begründet, daß für die Bildung der fünf Staubblätter ein beträchtliches Zellenmaterial erforderlich ist und daß in den männlichen Blüten ja auch die beiden Fruchtblätter noch angelegt werden.

Ein geeignetes Material für die Vergleichung von männlichen und Zwitterbliuten bietet z. B. Dimorphotheca pluvialis. Bei dieser mit Calendula verwandten Pflanze sind die Randblüten weiblich (haben aber im Gegensatz zu Calendula noch deutliche Staubblattrudimente), dann kommen Zwitter- und schließlich männliche Blïten. Eine erhebliche Größenverschiedenheit zwischen den ersten Anlagen der beiden letzteren war nicht festzustellen, was aus den oben angeführten Gründen auch nicht verwunderlich ist. Die männlichen Blüten zeigen sogar noch die Anlage der Fruchtknotenhöhle und (wenigstens in manchen Fällen) die ersten Andeutungen einer Samenanlage. Sie stehen also den Zwitterblüten noch recht nahe; "erspart" wird bei ihnen eigentlich nur die bei den Kompositen verhältnismäßig kleine Samenanlage, eine wesentliche Verschiedenheit in der Größe der Blütenanlage ist also nicht zu erwarten. Übrigens wird man zu unterscheiden haben zwischen den Faktoren, welche die erste Anlage, und denen, welche die weiteren Schicksale der Blüte bedingen. Wie oben erwähnt wurde, ist z. B. die (erst verhältnismäßig spät eintretende) Leitbündelversorgung der weiblichen Blüten von Calendula eine ausgiebigere als die der männlichen, obwohl letztere massiger angelegt werden als erstere.

Wenn wir die Ausbildung der Blumenkrone bei den weiblichen Kompositenblüten ins Auge fassen, so können wir die Verschiedenheit, welche sich dabei geltend macht, bildlich auf den Kampf zweier "Tendenzen" zurückführen.

Die eine sucht (wie bei vielen anderen Pflanzen) die Blumenkrone zu hemmen gegenüber der der Zwitterblüten resp. der der männlichen. Diese (mit der Hemmung der Staubblattbildung im Zusammenhang stehende) Verminderung der Korollengröße kann bis zum fast vollständigen Verschwinden der Korolle gehen. Die andere sucht sie zu vergrößern. Letztere Tendenz ist in der Stellung der weiblichen Blüten am Rande begründet, sie war bei den betreffenden Formen wahrscheinlich schon vorhanden, als die Randblïten noch zwitterig waren, hängt also mit dem Weiblichwerden nicht direkt zusammen und iš demgemäß auch nicht immer mit ihm verbunden.

Daß zwei solcher "Tendenzen" vorhanden sind, konnten wir auch entwicklungsgeschichtlich nachweisen. Wir sahen, daß z. B. bei Calendula die weiblichen Bliiten zunächst in der Entwicklung ihrer Blumenkrone gegenüber den männlichen auffällig zurückbleiben, während später dann ein ausgiebiges Wachstum der ersteren einsetzt.

Andere Kompositen mit "strahlenden" Randbliiten verhalten sich, soweit meine Untersuchungen reichen, ebenso. Z. B. Helianthus, dessen Randbliiten später so auffallend große Korollen haben. Auch die sterilen Randbliuten von Centaurea Jacea bleiben den fertilen gegenüber zunächst erheblich zurück. Man könnte auch hierin eine Ähnlichkeit der Blïtenköpfe der Kompositen mit Einzelbluiten sehen. Auch bei diesen ist ja die Entwicklung der Blumenkrone in den ersten Stadien gegenüber der der Staub- und Fruchtblätter oft (z. B. bei den Cruciferen) auffallend gehemmt.

Auch bei den Kompositen bleiben, wenn der "Randfaktor" wegfällt, 
die Blumenkronen der weiblichen Blüten erheblich kleiner als die der Zwitterblüten.

Worin das $X$, welches wir als Randfaktor bezeichnet haben, besteht, bedarf selbstverständlich einer eingehenden Untersuchung, auch wenn wir es als "Exotrophie“ bezeichnen würden, wäre damit nur ein anderer Name für die in ihrer Bedingtheit derzeit unbekannte Erscheinung gewonnen.

Immerhin liegen auch jetzt schon Anhaltspunkte für die Annahme vor, daß die Ernährungsverhältnisse am Rande des Blütenkopfes der tubulifloren Kompositen andere sind als weiter innen. Bei den ligulifloren Kompositen ist dies offenbar nicht der Fall. Wenigstens fand ich weder bei Sonchus oleraceus noch bei Crepis succisifolia (den einzigen daraufhin untersuchten Ligulifloren) eine Verschiedenheit zwischen der 'Entwicklung der Rand- und der inneren Blüten. Daß bei "gefüllten" Blütenköpfen von tubulifloren Compositen auch weiter nach innen liegende Blüten die Ausbildung der Randblüten annehmen können, ist kein Grund gegen die Annahme, daß diese durch ihre Stellung $\mathrm{zu}$ der für sie eigentümlichen Ausbildung gelangt seien; es handelt sich bei der Füllung um eine Vermehrung einer schon vorhandenen Blütenform, nicht um ihre Entstehung.

\section{Zusammenfassung der Ausführungen über sekundäre Sexualcharaktere.}

1. Bei diözischen Pflanzen sind sekundäre Sexualcharaktere in der Gesamtgestaltung männlicher und weiblicher Pflanzen nicht immer wahrnehmbar. Wo dies der Fall ist, sind die männlichen Pflanzen meist kleiner und schwächlicher als die weiblichen, um so mehr, je früher die Anlegung der männlichen Sexualorgane erfolgt. Diese ist dadurch möglich, daß die männlichen Organe geringere Ansprüche an Baustoffe machen als die weiblichen.

2. Dasselbe Prinzip zeigt sich bei monözischen Pflanzen. Die Pflanzenteile, welche die männlichen Organe tragen, sind die weniger kräftig ernährten. Dies tritt z. B. deutlich hervor bei den männlichen Blütenständen der Umbelliferen (die außer männlichen auch Zwitterblüten haben), namentlich aber auch bei Pflanzen, die männliche und weibliche Bliiten besitzen.

Dabei wird eine anatomische Differenzierung am ehesten dort zu erwarten sein, wo postfloral eine Weiterbildung in den die weiblichen Organe tragenden Pflanzenteilen nicht eintritt (Farnprothallien, Zea Mais und andere Monokotylen, Begonia). Bei dikotylen Pflanzen ist dementsprechend der Bau der männlichen und weiblichen Infloreszenzachsen präfloral oft nicht verschieden. Eine ausgiebigere Ernährung der weiblichen Bluiten wird nicht nur durch die postflorale Weiterentwicklung der tragenden Achsen, sondern in manchen Fällen auch durch die geringere Anzahl der weiblichen Blüten ermöglicht (z. B. Mercurialis perennis). Dasselbe gilt für die Makrosporangien heterosporer Pteridophyten.

3. Den Zwitterblüten gegenüber sind sowohl die männlichen als die weiblichen als die mit geringerem Aufwand von Baumaterialien zustande gekommenen zu betrachten. Am auffälligsten spricht sich dies aus bei einigen Kompositen, bei denen schon von vornherein die Vegetationspunkte, aus denen weibliche Blüten hervorgehen, beträchtlich kleiner sind 
als die, welche Zwitterblüten werden. Bei solchen Blüten sind die Anlagen der Staubblätter ganz unterdrückt, während sie bei verwandten Formen noch auftreten können, eine Tatsache, welche die Annahme unterstïtzt, daß auch in anderen Fällen, in welchen die Verkümmerung des einen Geschlechtes in diklinen Blüten eine vollständige ist, doch diese Blüten sich von $Z$ witterblüten ableiten. In anatomischer Beziehung spricht sich im Bau des Blütenstiels bei manchen Umbelliferen an den männlichen Blüten eine „Unterernährung“ gegenüber den Zwitterblüten aus.

4. Bei getrenntgeschlechtigen Blüten kann ein Dimorphismus auftreten im Bau des Blütenstiels (vgl. unter 2) und in der Gestaltung der Blütenhülle. Es handelt sich hier verhältnismäßig selten um qualitative Verschiedenheiten (so z. B. bei Catasetum), meist um eine GröBenverschiedenheit in der Ausbildung der Blütenhüllen.

So haben die weiblichen Blüten von Melandryum album einen kräftiger entwickelten Kelch als die männlichen, und bei den weiblichen Blüten der Kokospalme ist die ganze Blütenhülle größer als die der männlichen. Sehr häufig aber zeigen die weiblichen Blïten eine geringere Ausbildung der Blütenhülle als die männlichen. So bei den Urticaceen und vielen sympetalen Dikotylen, unter denen viele Kompositen nur scheinbar eine Ausnahme machen. Schon die Tatsache, daß diese Verschiedenheit der Blütenhülle auch bei windblütigen Pflanzen vorkommt, bei denen es sich nicht um einen "Schauapparat" handelt, macht für die Formen, bei denen die männliche Blüte eine größere Blumenkrone als die weibliche hat, die Annahme von H. MülleER, daß dadurch Sicherung der Kreuzbefruchtung bewirkt werde, unwahrscheinlich. Eine Korrelation besteht offenbar nicht nur zwischen der Entwicklung der Staubblätter und der Blütenhülle, sondern auch zwischen Staubblattentwicklıng und Griffelgestaltung.

5. Was die Frage anbetrifft, ob die männlichen oder die weiblichen Blüten sich stärker von dem ursprünglichen Typus (der Zwitterblüte) entfernt haben, so war sie verschieden zu beantworten. Bei den Urticaceen, Valerianaceen und Kompositen erschienen die weiblichen Blüten stärker verändert als die männlichen, bei den Begoniaceen sind sie als die konservativeren zu betrachten. Dasselbe ergab sich für die Archegonienstände der Marchantiaceen und mancher Laubmoose.

Die kürzere Lebensdauer der männlichen Blüten gegenüber den weiblichen spricht sich in manchen Fällen (Urticaceen, Euphorbiaceen) von vornherein schon darin aus, daß der Blütenstiel mit einer Abbruchstelle ausgestattet ist. Die Ausstattung weiblicher Blüten mit besonderen Schutzapparaten und Einrichtungen zur Fruchtverbreitung (vgl. den merkwürdigen Fall von Xanthium) wird ermöglicht durch die (den mänulichen Blüten gegenüber) reichere Ausstattung mit Baumaterialien, welche den weiblichen Blüten und Blütenständen in verschiedener Weise zuteil wird. Eine große Anzahl von Gestaltungsverhältnissen bei verschiedenen Pflanzen läßt sich so unter einen einheitlichen Gesichtspunkt bringen. 


\section{Dritter Abschnitt. Symmetrieverhältnisse. $\left.{ }^{1}\right)$}

\section{§ 1. Einleitung.}

Unter den Symmetrieverhältnissen verstehen wir hier ganz allgemein die räumlichen Beziehungen der Pflanzengestaltung.

Nur selten sind die Pflanzenkörper nach allen Richtungen des Raumes hin annähernd gleichmäßig entwickelt, wie dies z. B. bei den monergiden, kugeligen Zellen von Eremosphaera der Fall zu sein scheint; gewöhnlich ist die Ausbildung nach verschiedenen Richtungen hin eine verschiedene.

Die Untersuchung der Symmetrieverhältnisse ist von großer Wichtigkeit. Einerseits hat man versucht, bestimmte Kategorien von Organen durch ihre Symmetrieverhältnisse zu schematisieren. So glaubte VAN TIEghEM ${ }^{2}$ ), daß Sproßachsen und Wurzeln allgemein radiär, Blätter dagegen dorsiventral seien. Andererseits stehen die Symmetrieverhältnisse in engster Beziehung zu den Lebensverhältnissen und sind auch für die Beurteilung des Gesamtaufbaues von erheblichster Bedeutung. Gründete sich doch die "Spiraltheorie“, welche lange die Morphologie beherrscht und vielfach gehemmt hat, wesentlich auf eine unrichtige Verallgemeinerung der Symmetrieverhältnisse orthotroper Sprosse der höheren Pflanzen.

Zunächst sei daran erinnert, daß, wie im vorhergehenden Abschnitte dargetan wurde, die meisten Pflanzen und Pflanzenteile eine polare Ausbildung zeigen, einen Gegensatz zwischen "Spitze und Basis", ein Gegensatz, den wir schon bei manchen Zellkolonien antrafen, der aber scharf hervortritt, sobald ein Vegetationspunkt vorhanden ist, mit dessen Auftreten schon von vornherein die Polarität gegeben ist.

Es tritt uns diese ferner namentlich bei der Regeneration mancher Pflanzenteile entgegen. Aber auch in normalen Leben ist die verschiedene Ausbildung einer basalen und einer apikalen Region, namentlich bei Holzgewächsen, ausgeprägt genug. Wir sehen, daß die Seitenzweige um so mehr gefördert sind, je näher sie der Spitze des Jahrestriebes liegen,

1) Literatur: MонL, Über Symmetrieverhältnisse der Pflanzen (Verm. Schriften 1845); Herb. Spencer, Prinzipien der Biologie; Sacus, Lehrbuch der Botanik I.-IV. Aufl.; SACHS, Über orthotrope und plagiotrope PHanzenteile (Ges. Abhandl. Band II); Goeber, Über die Verzweigung dorsiventraler Sprosse (Arb. a d. botan. Institut in Würzburg); Wiesner, Biologie der Pflanzen, 3. Auflage.

$\left.{ }^{2}\right)$ Annales des sciences nat. botanique 5. série, t. XIII (1872). 
eine Einrichtung, welche besonders geeignet erscheint, eine geregelte Ausbreitung des Holzgerüstes eines Baumes herbeizuführen ${ }^{1}$ ).

So hat der Jahrestrieb von Pinus in seinem basalen Teile keine Seitensprosse, weiter hinauf folgen Kurztriebe, und erst an der Spitze stehen in scheinbar wirteliger Stellung die Langtriebe; dadurch kommt am Hauptsproß selbst ein stockwerkartiger Aufbau zustande, ohne daß die Äste sich decken, während bei den Seitenzweigen die Äste höherer Ordnung immer mehr vom Hauptstamm abruicken und so die Assimilationsorgane ständig nach der Peripherie hin rücken, wo sie die günstigsten Beleuchtungsverhältnisse finden. Analog verhalten sich viele Laubhölzer. nur daß hier eine mehr allmähliche Abstufung eintritt und die Knospen im Basalteil des Jahrestriebes vielfach als Ruheknospen ausgebildet sind, die sich nur bei Beschädigungen entfalten.

Spitze und Basis eines Pflanzenteils können wir uns durch eine Linie verbunden denken, die wir als seine Längsachse bezeichnen.

Sehen wir ab von seltenen Ausnahmefällen, so lassen sich betreffs der Anordnung der seitlichen Organe und der Ausbildung der Organe selbst dreierlei Fälle unterscheiden:

1. Radiäre Ausbildung ist vorhanden, wenn ein Organ keine vordere und hintere, keine rechte und linke Seite unterscheiden läßt, sondern rings um die Längsachse nach allen Radien des Querschnitts annähernd gleichartig organisiert ist.

Anmerkung. Diese Ausbildungsform wurde ursprünglich von E. MEYER als die konzentrische bezeichnet, ein Name, der wobl mit Recht keinen Eingang gefunden hat. Namentlich paßt die Mexer'sche Bezeichnung nicht auf die radiäre Verteilung seitlicher Organe. Leider hat sich für die Blüten durch A. BRAUN eine besondere Terminologie eingebürgert. Radiäre Blüten werden auch als aktinomorph, dorsiventrale als zygomorph bezeichnet. Diese Benennungen sind überfüssig und werden deshalb in diesem Buche nicht angewandt.

2. Unter bisymmetrischen oder bilateralen Organen verstehen wir solche, welche eine vordere und eine hintere, eine rechte und eine linke unter sich jeweils gleiche Seite haben. Bilateral ist also z. B. ein zweizeilig beblätterter Sproß von Schistostega (Fig. 173) und Fissidens, (dessen Sprosse freilich meist schon schwach dorsiventral ausgebildet sind) der gefiederte Bryopsisthallus usw. Bei Schistostega ist die bilaterale Gestaltung übrigens im Verlauf der Entwicklung aus einer radiären hervorgegangen. Die später der Länge nach angehefteten zweizeilig stehenden Blätter waren nämlich im Vegetationspunkt quer inseriert (Fig. 174) und rings um die Sproßachse verteilt.

Noch einfacher gestaltet sich bei Opuntia der Übergang: die radiäre Sproßachse wird auf zwei einander gegenüberliegenden Seiten abgeflacht und so $\mathrm{zu}$ einem bilateralen Gebilde. Wie nahe sich radiäre und bilaterale Struktur stehen, sehen wir auch bei dem frei im Wasser flutenden, nur an der Basis festgewurzelten Thallus vieler Meeresalgen, der bald flach (bilateral), bald zylindrisch ist. Manche Blätter, die schwertförmigen von Iris und anderen Pflanzen, könnte man - wenigstens im Spreitenteil - als bilaterale bezeichnen. In Wirklichkeit liegt, wie unten erörtert werden

1) Abweichende Fälle seien hier nicht weiter erwähnt. $\mathrm{Zu}$ ihnen gehört z. B. das Verhalten mancher Palmen, stammbildender Agaven u. a., die an der Basis des Stammes Seitenknospen entwickeln. 
soll, hier die eigentümliche Modifikation eines dorsiventralen Blattes vor, die wir als "unifazial" bezeichnen.

Zur Vermeidung von Mißrerständnissen sei übrigens bemerkt, daß man die Bezeichnung bilateral teilweise auch in demselben Sinne wie dorsiventral verwendet hat.

3. Dorsiventrale Organe lassen stets, wie dies im Namen liegt, eine Rücken- und eine Bauchseite unterscheiden, die voneinander verschieden sind. Die beiden Seitenflächen, die Flanken, sind entweder einander gleich, oder sie sind verschieden; letzteres ist z. B. der Fall bei den nur auf einer Seite mit Bliiten besetzten Infloreszenzen ron Vicia Cracca (Fig. 172), auf der blïtentragenden Seite stehen die Blüten in Schrägzeilen.

Mit diesen Kategorien sind nur die häufigsten Fälle charakterisiert; daß sie ineinander übergehen können, wurde schon für den Fall von Schistostega erwähnt. Ebenso wie ein radiär angelegtes Organ bilateral. kann ein bilaterales oder radiäres dorsi-
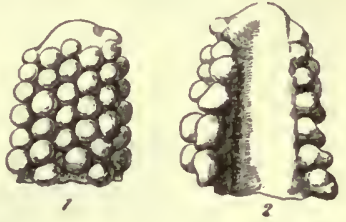

Fig. 172. Vicia Cracea. Blütenstand links von der abaxialen, rechts von der adaxialen Seite. ventral werden: Beispiele dafür werden sich im Verlaufe der Darstellung ergeben; zunächst ist kurz zu erwähnen, welche Beziehungen zwischen Symmetrie und Richtung der Organe bestehen.

SAchs hat (a. a. O.) die Pflanzenorgane eingeteilt in orthotrope und plagiotrope.

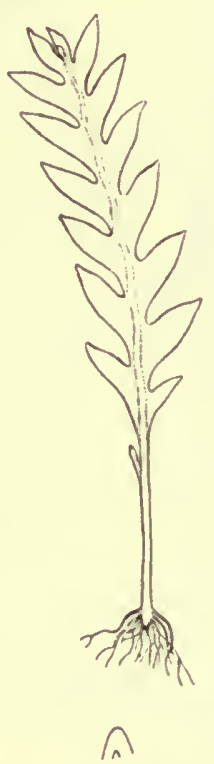

Fig. 173. Zweizeilig beblättertes Pflänzchen von Schistostega osmundacea (vergr.), als Beispiel für bilaterale Ausbildung.
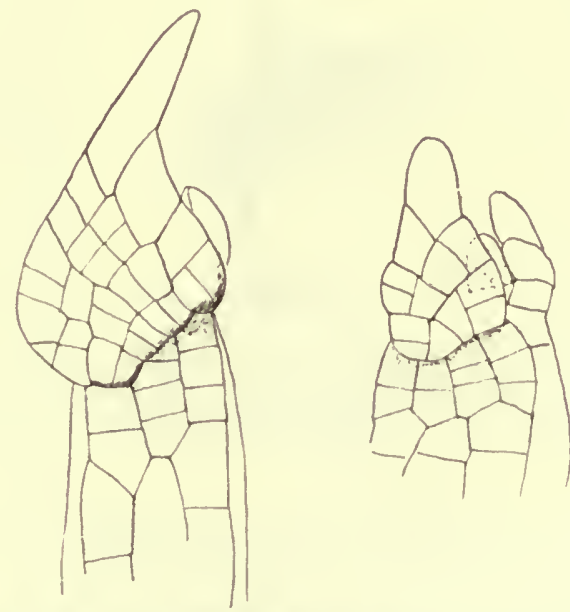

Fig. 174. Schistostega osmnndacea. Zwei Sproßspitzen von außen. Die ursprünglich quere Blattinsertion wird in die Längslinie der Sproßachse verschoben.

Orthotrop ist ein Organ, wenn es unter gewöhnlichen Lebensverhältnissen auf horizontaler Erdoberfläche bei allseitig gleicher Beleuchtung senkrecht aufwärts oder senkrecht abwärts wächst, plagiotrop, wenn es 
schiefe Richtung zum Horizont oder horizontale Lage annimmt. Die äußeren und inneren Einwirkungen, welche dabei beteiligt sind, bleiben hier außer Betracht; dagegen ist auch für die organographische Betrachtung wichtig der Satz, daß orthotrope Organe sehr oft radiär oder bilateral, plagiotrope dagegen häufig dorsiventral sind, seltener bilateral, z. B. die Sprosse von Schistostega und Fissidens. Es genügt, auf die orthotropen Hauptachsen der krautigen Gewächse, deren radiäre Gestaltung ohne weiteres erkenntlich ist, und auf die gewöhnlich plagiotropen Blätter hinzuweisen, deren dorsiventraler Bau an der Verschiedenheit von

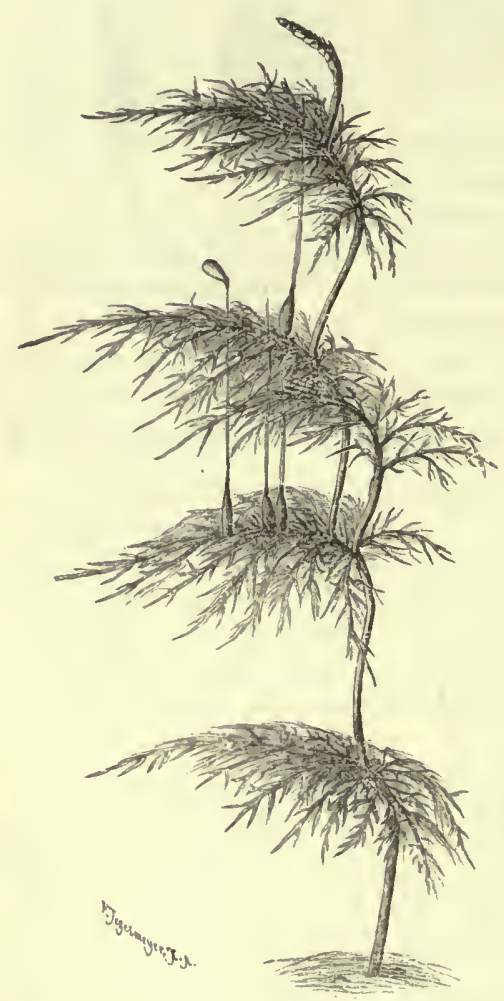

Fig. 175. Hypnum (Hylocomium) splendens. Etagenwuchs: in jedem Jahre bildet sich ein erst orthotroper, dann plagiotroper, in einer Ebene verzweigter Sproß aus.

Ober- und Unterseite sofort hervortritt, während die radiär gebauten (aber unifazialen) Blätter von Juncus orthotrop sind, ebenso wie die "bilateralen" Blätter von Iris u. a.

Daß plagiotrope-Organe so selten bilateral sind (vgl. die oben angeführten Beispiele), hängt wohl damit zusammen, daß die meisten unter dem Einfluß der Außenbedingungen dorsiventral geworden (oder geblieben) sind. Die Frage soll im siebenten besonderen Abschnitt erörtert werden. Jedenfalls kann man aber aus radiärer Struktur nicht ohne weiteres auf orthotropen Wuchs schließen, wie uns manche plagiotropen radiär gebauten Wurzeln und Rhizome, auch die plagiotropen Seitenäste der Equiseten zeigen (p. 92). Ihre plagiotrope Stellung ist durch die Beziehungen $\mathrm{zu}$ anderen Organen bestimmt und die Anschauung berechtigt, daß wenigstens in manchen Fällen die plagiotrope (durch äußere und innere Faktoren veranlaßte) Richtung das Primäre, die dorsiventrale Ausbildung das, Sekundare sei.

Damit, daß speziell das Licht eine große Bedeutung für die Ausbildung der Dorsiventralität hat, hängt es vielleicht auch zusammen, daß unterirdische plagiotrope Organe fast immer radiär gebaut sind. Die dorsiventralen Wurzeln, von Orchideen und Podostemaceen wachsen alle am Lichte. Ist einem Organe einmal der dorsiventrale Charakter aufgeprägt, so reagiert es dann gegen äußere Einflüsse auch anders als ein radiäres.

Im einzelnen gestalten sich die Verhältnisse ziemlich mannigfaltig. Ein und dasselbe Organ kann in den verschiedenen Stadien seiner Entwicklung erst orthotrop und dann plagiotrop sein oder infolge der verschiedenen Einwirkung äußerer Reize entweder orthotrop oder plagiotrop sich verhalten, namentlich auch infolge von Korrelations verhältnissen aus der plagiotropen in die orthotrope Stellung übergehen. Nicht selten 
finden wir auch, daß die regetativen Sprosse plagiotrop, die der Fortpflanzung dienenden orthotrop sind.

Ein schönes Beispiel für den erstgenannten Fall bietet das Wachstum von Hylocomium splendens. Dieses im Schatten der Wälder wachsende Moos besitzt (vgl. Fig. 175) einem gefiederten Blatte gleichende, zweizeilig verzweigte Sprosse, die sich rechtwinklig zum Lichteinfall stellen. Jedes dieser plagiotropen, mit kleinen Blättchen besetzten Sproßsysteme ist nur eine Vegetationsperiode tätig. Im Beginn der nächsten entwickelt sich nahe seiner Basis ein starker, zunächst orthotroper und unverzweigt bleibender Seitensproß, der aber bald plagiotrop wird und sich zweizeilig in einer zum Lichteinfall rechtwinklig stehenden Ebene verzweigt. Da die alten, absterbenden Sproßgenerationen noch einige Zeit erhalten bleiben, so kommt dadurch ein stockwerkartiger Aufbau zustande, der die neue Sproßgeneration vor dem Begrabenwerden in dem Detritus des Waldbodens schützt.

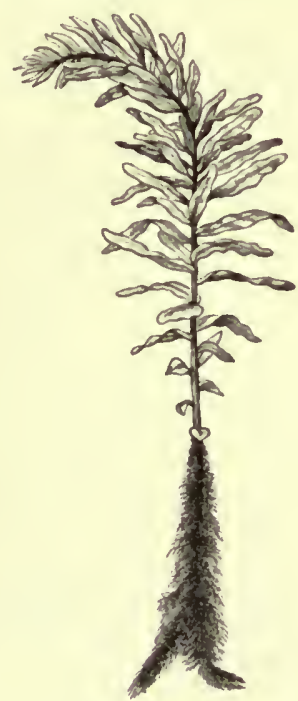

Fig. 176 .

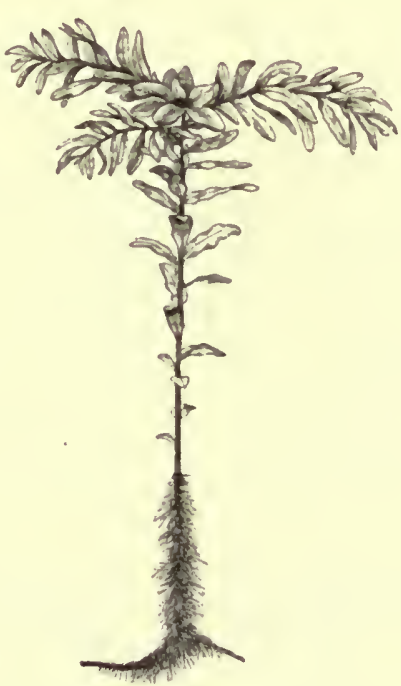

Fig. 177.

Fig. 176. Mnium undulatum. Vegetativer SproB. Er ist erst orthotrop und wird dann plagiotrop. Natürl. Größe.

Fig. 177. Mnium undulatum. Orthotroper Sproß, welcher mit einem rosettenförmigen Antheridienstand abgeschlossen hat. Unterhalb desselben sind drei vegetative, von Anfang an plagiotrope Seitensprosse entstanden. Natürl. Größe.

Bei Mnium undulatum (Fig. 176 u. 177) tritt besonders deutlich hervor, daß die Sprosse, solange sie kräftig wachsen und gut ernährt sind, orthotrop sind und plagiotrop erst werden, wenn sie sich dem Abschluß ihrer Entwicklung nähern, was bei den unterhalb der Antheridienstände entspringenden Seitensprossen viel früher der Fall ist, als bei den relativen Hauptsprossen.

Auch bei Bäumen findet sich ein analoger Wechsel. So bei Pinusarten, welche mit einem orthotropen Hauptsproß und plagiotropen Seitenästen ausgerüstet sind. Die im Frühjahr neu austreibenden Spitzen der Seitentriebe aber sind zunächst orthotrop und werden erst später - offenbar unter dem Einfluß des Hauptsprosses - plagiotrop. 
Manche Bäume besitzen - wenigstens im späteren Lebensalter ausschließlich dorsiventrale Sprosse. Trotzdem komm es zur Ausgestaltung eines orthotropen Hauptstammest, der aber erst nachträglich aus einer Verkettung dorsiventraler Sproßgenerationen entsteht. So ist es bei der Buche, Linde, Ulme. Nur in der Jugend, bei der Keimung, bilden diese Bäume orthotrope Sprosse, die dann auch in ihrer Gestaltung von den später auftretenden plagiotropen abweichen. Die letzteren sind zweizeilig beblättert und dorsiventral. Die Keimpflanzen der Buche sind orthotrop, die ersten Blätter mit den Kotyledonen gekreuzt, meist schließen die Keimpflanzen damit ihr Wachstum ab; nicht selten tritt aber noch ein drittes, über einen der Kotyledonen fallendes Blatt auf. Die Endknospe des ersten Jahrestriebes aber wird schon dorsiventral. Ähnlich ist die Gestaltung der Keimsprosse bei Tilia und Ulmus, letztere wird in dem Abschnitt über Entwicklung besprochen.

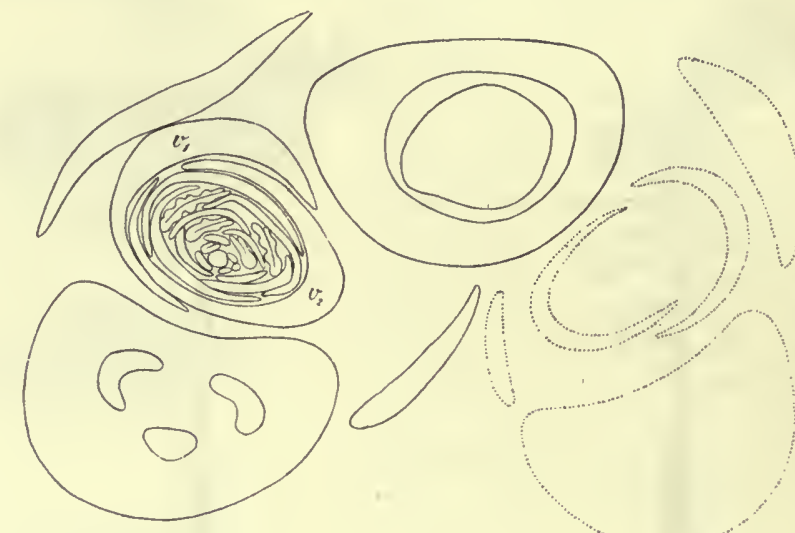

Fig. 178. Querschnitt durch einen Lindenzweig. Eine Seitenknospe ist getroffen; dieselbe ist zweizeilig beblättert. Ihre Symmetrieebene fällt mit der ihres Iuttersprosses nicht zusammen. Ungleiche Größe der Mitte.

Trotzdem nun diese Pflanzen späterhin nur dorsiventrale, zweizeilig beblätterte, meist plagiotrope Sprosse bilden, kommt ein mit radiärer Krone versehener Stamm zustande, wie sie bei anderen Bäumen von Anfang an vorhanden ist. Es geschieht dies dadurch, daß die Symmetrieebenen der aufeinander folgenden Sproßgenerationen nicht miteinander zusammenfallen (vgl. Fig. 178). Bei den am meisten aufrecht wachsenden Sprossen muß also, da der Stamm aus verschiedenen Sproßgenerationen sich zusammensetzt, notwendig ein radiäres Gebilde zustande kommen, während bei den mehr horizontal wachsenden Sprossen durch Internodiendrehung die Symmetrieebene der zweizeilig beblätterten Seitensprosse vertikal gestellt wird, und so diese horizontalen Seitenzweige zu Gebilden sich gestalten, die, einem mehrfach gefiederten Blatte gleichend einen dorsiventralen Gesamtbau aufweisen.

Bei der Richtungsverschiedenheit der einzelnen Sproßsysteme solcher aus nur plagiotropen Sprossen aufgebauten Bäume spielen wohl einerseits die Intensität und Richtung des Lichtes, andererseits Korrelationsverhältnisse eine Rolle. Die Hauptsprosse von Fagus silvatica z. B. sind bei freiem Wuchs steil aufgerichtet, bei schwacher Beleuchtung (im dichten 
Walde) wachsend, können sie fast horizontal werden. Auch bei Tilia platyphyllos wachsen die dorsiventralen Sprosse von der Spitze der Krone hell beleuchteter Bäume oft vertikal nach oben.

Wollte man die Sproßgestaltung als eine durch Anpassung entstandene betrachten, so müßte man annehmen, daß derartige Bäume ursprünglich als Bewohner schattiger Standorte entstanden seien. Als solche besitzen sie die Blattanordnung, die an mehrreihig beblätterten plagiotropen Sprossen erst durch Drehung erreicht wird (Anordnung der Blätter in einer Ebene). Die orthotrope Stellung kräftig wachsender Triebe wäre dann eine nachträglich zustande gekommene. Indes finden wir Analoges auch bei anderen Pflanzen.

Vicia Faba z. B. ist eine nach ihrer Verzweigungsart, wie viele andere Papilionaceen, als dorsiventral zu bezeichnende Pflanze ${ }^{1}$, ihre Sprosse sind aber orthotrop. Für die große Mehrzahl der Fälle aber gilt die oben aufgestellte Regel.

Es wird von Interesse sein, auch von niederen Pflanzen einige Beispiele für die Beziehungen zwischen Symmetrie und Richtung anzuführen.

Bei den Flechten tritt die Differenz zwischen den dorsiventral gebauten, meist dem Substrat angeschmiegten "Laubflechten" und den radiär gebauten, aufrecht wachsenden oder herabhängenden "Strauchflechten" besonders deutlicb hervor. Von besonderem Interesse ist der Übergang von dorsiventralen in radiäre Organe, der sich bei den Flechten mehrfach findet ${ }^{2}$ ). Zunächst sei erwähnt, daß ein solcher Übergang in dreifacher Weise stattfinden kann: 1. durch Zusammenrollung eines dorsiventralen Thallus resp. Thallusteiles, 2. durch Bildung orthotroper vegetativer Auswüchse am dorsiventralen Thallus, 3. durch Entwicklung der Stiele der Fruchtkörper, die namentlich dann eine auffallende wird und zur Bildung eigenartiger vegetativer Organe führt, wenn die Bildung der Fruchtkörper selbst in eine spätere Entwicklungsperiode verlegt oder ganz und gar unterdrückt wird. Für diese drei Fälle seien einige wenige Beispiele angeführt.

1. Cetraria islandica besitzt einen dorsiventralen, flachen oder oben rinnigkonkaven Thallus, der schräg aufsteigend wächst. Bei manchen, mehr aufwärts gerichteten Ästen verwachsen die Thallusränder miteinander zu einer Röhre. Das letztere wird die Regel bei der als var. crispa bezeichneten Form, und derartige Thallusäste nehmen dann meist einen radiären Bau an, indem die grünen Algenzellen gleichmäßig verteilt sind, während sie an den dorsiventralen Ästen der Oberseite genähert liegen; daß übrigens die Einrollung des Thallus namentlich auch in mechanischer Beziehung von Vorteil ist, braucht kaum hervorgehoben zu werden; ein flacher Thallus kann sich, wenn er eingerollt ist, viel leichter aufrecht halten, als wenn er ausgebreitet bliebe.

2. Bei Thalloidima vesiculare zeigt der Thallus keulenförmige Auswüchse, die an manche niederen, strauchförmigen Algen erinnern, und bei den Bartflechten entwickelt sich der Thallus offenbar von Anfang an in dieser Weise ${ }^{3}$ ). Die Algenzellen sind in diesen Fällen radiär verteilt.

3. Bei einigen Flechten sind die Stiele der Askusfruchtkörper, die Podetien, stark entwickelt und als Assimilationsorgen von Bedeutung (z. B.

1) Die Infloreszenzen sind - ähnlicb wie bei Vicia Craca - alle nach einer Seite hin gerichtet, die vegetativen Knospen nach der anderen.

2) Vgl. darüber Reinke, Abhandl. über Flechten IV. Pringsh. Jahrb. XXVIII p. 191.

$\left.{ }^{3}\right)$ Vgl. Reinke, Abhandl. über Flechten III. Pringsh. Jahrb. XXVIII p. 105. 
Pycnothelia, Glossodium u. a.; Abbildungen bei REINKE). Denken wir uns diese "Podetien" verzweigt, so gelangt man zu den. eigenartigen Formen, wie sie bei manchen Stereocaulonarten sich finden. Hier tritt ein aus Körnern und Schuppen gebildeter primärer Thallus auf, dem bei manchen Arten strauchige,. reich verzweigte Gebilde entspringen, welche an den Enden der stärkeren Äste die Fruchtkörper tragen, während die schwächeren steril bleiben, begrenztes Wachstum haben und lediglich als Assimilationsorgane dienen.

Bei Cladonia treffen wir zwei Hauptformen, die Strauchform und die Becherform, die miteinander durch Übergänge verbunden sind. Bei den Becherformen tritt in der becherförmigen Erweiterung (welche eine Vergrößerung der assimilierenden Oberfläche bedingt) schon wieder der dorsiventrale Bau auf, während die zylindrischen Becherstiele radiär sind. In besonders auffallendem $\mathrm{Maße}$ ist dies der Fall bei Cl. verticillaris (Fig. $179 \mathrm{II}$ ), bei der die gestielten Becher stockwerkartig auseinander hervorsprossen und der Becherrand in blattartige Zipfel zerschlitzt ist, so daß der Gesamthabitus dem einer Pflanze mit wirtelständigen Blättern, etwa einer Chara, ähnlich wird, eine $\mathrm{Ge}$ staltung, die wieder zeigt, daß von ganz verschiedenen Ausgangspunkten aus ähnliche Formen erreicht werden können.

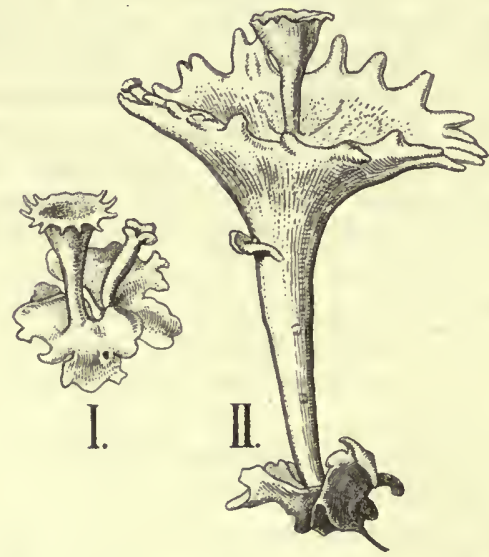

Fig. 179. Junge Exemplare von Cladonia verticillaris: bei $I$ horizontaler Thallus mit 2 Podetien, bei II Podetium in der Mitte sprossend, 2 fach .vergr.

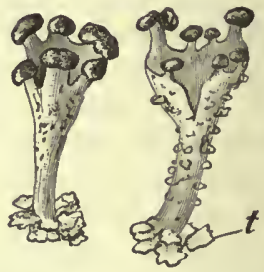

Fig. 180. Cladonia coccifera. Aus dem horizontalen Thallus $(t)$ hat sich ein becherförmiges Podetium entwickelt, aus dessen Rand gestielte Apothecien entspringen (Lehrb.)

Wenn wir junge Pflanzen von Cladonia verticillaris ansehen (Fig. $179 \mathrm{I}$ ), so finden wir hier noch den horizontalen (und dorsiventralen) Thallus, der aber nur als rasch vorübergehendes Jugendstadium auftritt. An ihm finden sich zunächst einfache, becherförmige Aussprossungen, die dann in der Mitte weitere neue hervorbringen und sich verzweigen. Diese Jugendstadien stimmen überein mit der Gestaltung, welche andere Cladonien, z. B. Cladonia coccifera (Fig. 180) zeitlebens behalten - eine Erscheinung, für die auch bei anderen Pflanzen Beispiele anzuführen sein werden. An älteren Pflanzen (vgl. Fig. 55) ist von dem horizontalen Thallus nichts mehr zu sehen.

Nach dieser allgemeinen Orientierung über die Beziehungen von Lage und Gestaltung sollen im folgenden die Symmetrieverhältnisse der einzelnen Organe besprochen werden, und zwar in folgender Einteilung: 
I. Vegetationsorgane.

A. Sproß.

1. Radiäre und bilaterale Sprosse;

2. dorsiventrale Sprosse.

B. Blatt.

II. Blüten und Blïtenstände.

\section{§ 2. Allgemeines über Stellnngsverhältnisse der Organe an radiären Achsen.}

Einer der wichtigsten Fortschritte der Pflanzenmorphologie war ohne Zweifel die Erkenntnis, daß die Anordnung seitlicher Organe an radiären Achsen bestimmten Regeln folgt.

Für die Anordnung der Seitenwurzeln an Hauptwurzeln ergab sich, daß. sie normal in Längsreihen stattfindet und durch die anatomische Struktur der Hauptwurzel bedingt ist, also in letzter Linie durch Vorgänge, die innerhalb des Vegetationspunktes der Wurzeln sich abspielen, ohne daß dabei irgendwelche mechanische Beeinflussungen in Betracht kommen können.

Bei den Sproßachsen war es die Anordnung der Blätter (die bei axillärer Verzweigung ja meist auch die Anordnung der Seitenzweige bedingt) welche zu zahlreichen Untersuchungen Veranlassung gegeben hat.

Die tatsächlichen Verhältnisse - wenigstens die häufigsten - werden in jedem Lehrbuche behandelt, sie können hier also als bekannt vorausgesetzt werden.

Die Frage, welche uns interessiert, ist vielmehr eine doppelte:

1. Haben wir einen Einblick in die Ursachen, welche die Anordnung der Blätter am Vegetationspunkt bedingen?

2. Steht die Blattanordnung mit den Lebensverhältnissen der Pflanzen in Beziehung?

Die Ursachen der Gesetzmäßigkeit in der Anordnung der Blätter hat man in verschiedener Art aufzufinden gesucht.

Die Spiraltheorie zog aus den Anordnungsverhältnissen im fertigen Zustand den Schluß, daß das Wachstum in einer Schraubenlinie vor sich gehe, und die Stellen, an denen Blätter auftreten, solchen gesteigerten Wachstums entsprechen.

Auch später hat man die Beobachtung der Vorgänge am Vegetationspunkt selbst vielfach zuriicktreten lassen gegenüber dem Studium von Modellen (Delopino's Kugelpyramide, Schwendener's Pappschachteln usw.) oder graphischen und mathematischen Konstruktionen, Hilfsmittel, die an sich selbstverständlich berechtigt und notwendig sind. Selbst Vertreter der entwicklungsgeschichtlichen Forschung haben dem Vegetationspunkt nur insofern eine Bedeutung zugeschrieben, als er den Raum darstellt, der mit Blattanlagen besetzt werden soll.

Eine vergleichende Betrachtung zeigt aber, daß es nicht nur auf die Raumverhältnisse ankommt. Diese werden erst durch das Wachstum des Vegetationspunktes geschaffen, und die Blattanlagen treten dort auf, wo eine Anhäufung embryonalen Protoplasmas stattfindet. Dies zeigen besonders deutlich die dorsiventralen Sprosse, bei welchen die Blattanlagen auf bestimmte Seiten der Sproßachse beschränkt sind oder hier zuerst auftreten, obwohl auch an anderen Stellen Platz vorhanden wäre.

Goebel, Organographie der Pflanzen. 2. Anfl. Allgem. Teil. 
Schon daraus geht für uns hervor, daß - im Gegensatz zu den mechanischen Blattstellungstheorien - die inneren (durch Struktur und Ernährung bedingten) Verhältnisse des Vegetationspunktes es sind, welche für die Anordnung der seitlichen Organe maßgebend sind.

Eine Darstellung der Blattstellungstheorien ist hier nicht möglich. Es sei nur Weniges erwähnt.

HofMeister (Allgemeine Morphologie der Gewächse 1868) war der erste, welcher ein kausales Verständnis der Blattanordnung zu gewinnen suchte. Er stellte zunächst den Satz auf, der als die "HOFMEISTERsche Regel" bezeichnet werden kann, wonach die Blattanlagen sich in den meisten Fällen in (über oder unter) die größten Lücken gleichartiger früher entstandener Anlagen einschalten. Das ist noch keine Theorie, sondern ein Erfahrungssatz, dem eine weite aber nicht allgemeine ${ }^{1}$ ) Gültigkeit zukommt. HOFMEISTER suchte ihn kausal verständlich zu machen durch die Annahme, daß die Stelle der Neuanlage zugleich die sei, wo die Zellmembranen am wenigsten (durch die bei der Entstehung früherer Anlagen geübte Spannung) in Anspruch genommen seien. Das war eine von vornherein nicht sehr wahrscheinliche Hypothese. Sehen wir doch, daß z. B. bei der Entstehung der Adventivsprosse an B goniablättern alte Epidermiszellen mit starren Außenwandungen unter dem Einfluß des Protoplasmas diese Wände wieder in wachstumsfähigen Zustand versetzen. Wir werden also nicht geneigt sein, die Eigenschaften der Membran gegenüber denen des Protoplasmas als maßgebend zu betrachten: wo dieses einen Impuls gibt, ist die Beschaffenheit der Zellmembran ron sekundärer Bedeutung.

Bei SCHWENDENER's mechanischer Theorie der Blattstellungen ${ }^{2}$ ) handelt es sich um drei "Grundtatsachen", die als maßgebend für die Anordnung betrachtet wurden, nämlich um

1. die relative Größe der Blattanlagen,

2. den Kontakt der neuen Anlagen mit den vorhergehenden,

3. geringe Schwankungen in der Querschnittsgröße zugunsten der Raumausfüllung.

Außerdem wird angenommen, daß die einmal angelegten Organe Verschiebungen erfahren, bei denen Druckverhältnisse eine große Rolle spielen. Diese sollten auch maßgebend sein für die Anordnung der Blätter blattachselständiger Knospen. Deren Vegetationspunkt solle in seitlicher Richtung in allgemeinen einem geringeren Drucke ausgesetzt sein, als in medianer Richtung. Daraus wird abgeleitet, daß die häufigste Stellung der beiden ersten Blätter eine laterale sei (Fig. 181, 0 und 1). Diese Druckverhältnisse sind aber nur angenommen, in keinem einzigen Fall wirklich nachgewiesen worden, während wir zahlreiche Fälle kennen, in denen die - sicher nicht auf Druckverhältnissen beruhende - Gestalt des Vegetationspunktes für die Anordnung maßgebend ist.

Besonders wichtig für die Theorie war der zweite Punkt. Falls die Blattanlagen bestimmte gesetzmäßige Stellungen haben $\mathrm{schon}$ ehe sie miteinander in Kontakt treten, kann dieser letztere für die primären Stellungsverhältnisse (um die es sich hier handelt) nicht maßgebend, sondern nur allenfalls bei sekundären Änderungen (welche organographisch viel weniger ins Gewicht fallen) beteiligt sein. Die Untersuchungen von RACIBORSKI ${ }^{3}$ ),

1) Diese Regel trifft, wie unten gezeigt werden soll, nur bei symmetrischem Wachstum des Vegetationspunktes, also bei Wirtelbildung ganz zu. Bei asymmetrischem nur mit einer Beschränkung.

2) Schwendener, Mechanische Theorie der Blattstellungen, Leipzig 1878.

3) M. RAciborski, Die Morphologie der Nymphaeaceen und Cabombeen, Flora 78 (1894) p. 244. Beitr. zur Kenntnis der Cabombeen und Nymphaeaceen Flora 79 (1894) p. 92; Über die Verzweigung (Ann. du jard bot. de Buitenzorg 2. Sér. Bd. 2 (1900). 
Jost ${ }^{1}$ ), H. WINkLeR ${ }^{2}$ ), A. H. ChurCh ${ }^{3}$ ) u. a. haben nun gezeigt, daß „die an der Sproßspitze hervortretenden Primordien gar. nicht in dem Kontakte mit den schon früher angelegten entstehen, sondern in gewissen Abständen davon" (RACIBORSKI 1894). Der Autor der Theorie selbst hat dann zugegeben, daß jeder Anlage ein bestimmtes "Entwicklungsfeld" entspricht. Da diese "Entwicklungsfelder aber selbst schon eine gesetzmäßige Stellung haben, so kommt die "mechanische Blattstellungstheorie" für das Verständnis dieser GesetzmäBigkeit - die.sie voraussetzt - nicht in Betracht.

Eine kurze Darstellung der (historisch interessanten) ScHwexdenerschen Theorie findet sich in der 1. Auflage dieses Buches (aus der Feder A. WeIsses), auf welche hier verwiesen sei.

Hier sei nur erwähnt, daß wir bei manchen Vegetationspunkten ohne weiteres deutlich sehen, daß die Blattanordnung durch die Eigenschaften der embryonalen Substanz des Vegetationspunktes selbst bedingt wird. So bei manchen Vegetationspunkten mit Scheitelzellen. Tritt bei einem Vegetationspunkt mit "dreischneidiger"

Scheitelzelle, welche drei Reihen von Segmenten abgliedert, die Blattbildung in den Segmenten sehr früh ein ${ }^{4}$ ) (wie bei Moosen undLebermoosen), so erbalten wir (an radiären Sprossen) drei Reiben von Blättern - deren Anordnung durch Wachs-

tumsverhältnisse der

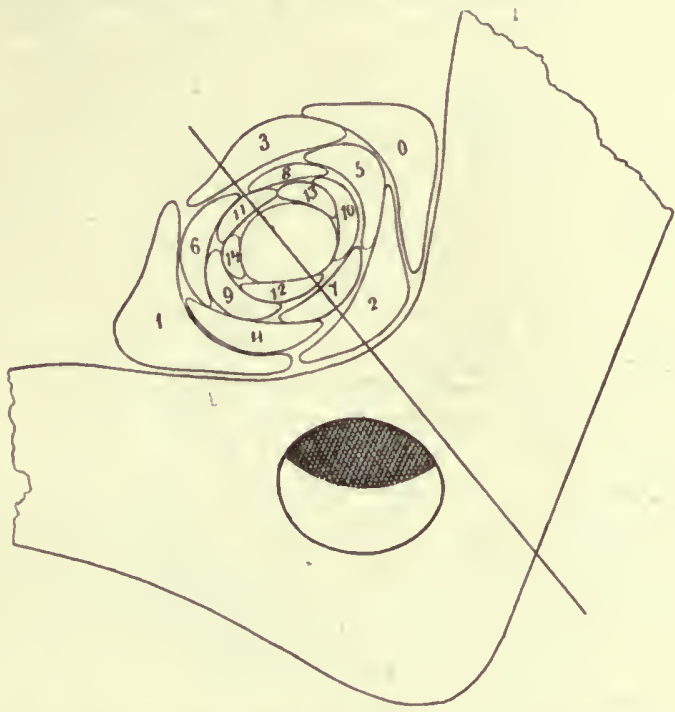

Fig. 181. Querschnitt durch eine Axillarknospe von Solidago canadensis nebst Tragblatt. Vergr. 45 fach. (Nach Scriwendener.) Die beiden ersten Blätter 0 uud 1 seitlich der Knospe.

Sproßachse verändert werden kann, aber ohne daß dabei irgendwelche Druckverhältnisse in Betracht zu kommen brauchen.

Ebenso sehen wir bei Florideen die Anordnungsverhältnisse durch die Eigenschaften des Scheitels bedingt. Es sei nur ein Beispiel angeführt.

Die Hauptsprosse von Asparagopsis armata ${ }^{5}$ ) haben eine Scheitelzelle, welche sich durch Querwände teilt. Diese stehen aber nicht rechtwinklig zur Sproßachse, sondern schneiden ein Segment ab, das auf einer (der Plus-) Seite

1) Jost, Die Theorie der Verschiebung seitlicher Organe durch ihren gegenseitigen Druck (Bot. Zeit. 57 (1899).

2) H. Winkiser, Untersuch. zur Theorie der Blattstellungen I und II (Jahrb. für wissensch. Botanik Bd. 36 (1901) nnd 38 (1903).

3) A. H. Church, On the relation of Phyllotaxis to mechanical laws I-III Oxford 1901-1903. VAn Itrrson. Mathemat. und mikroskop. anatomische Studien über Blattstellung, Jena 1907. In diesen Abhandlnngen ist weitere Literatur erwähnt.

4) Erfolgt die Blattbildung später, nachdem die Segmente schon vielzellig geworden sind, wie bei Farnen, so steht die Blattbildung in keiner direkten Beziehung zur Scheitelzellsegmentierung.

$\left.{ }^{5}\right)$ Connolty, Beitr. zur Kenntnis einiger Florideen. Flora 103 (1911) p. 135. 
höher ist als auf der anderen (der Minusseite) (Fig. 182). Die Mittellinie der Plusseite jedes Segmentes hat von der des folgenden und des vorhergehenden einen Abstand von $90^{\circ}$, die fünfte Wand also hat wieder dieselbe Richtung wie die erste. Die Volumzunahme der Segmente schreitet also asymmetrisch fort, in einer Schraubenlinie. Asparagopsis ist ein Beispiel eines "spirotrophen" Wachstums. Auf der Plusseite jedes Segments entsteht ein Ast, der sich als Kurztrieb entwickelt, später ihm gegenüber ein Langtrieb. Es ergibt sich daraus die in dem Diagramm Fig. 183 dargestellte Anordnung.

Wie in diesen Fällen, so ist auch in allen anderen nach der Ansicht des Verfasers die Anordnung seitlicher Sprossungen bedingt durch Struktur- und Wachstums- resp. Ernährungsverhältnisse des Vegetationspunktes, werde er nun von einer Scheitelzelle oder einem Zellkomplex eingenommen.
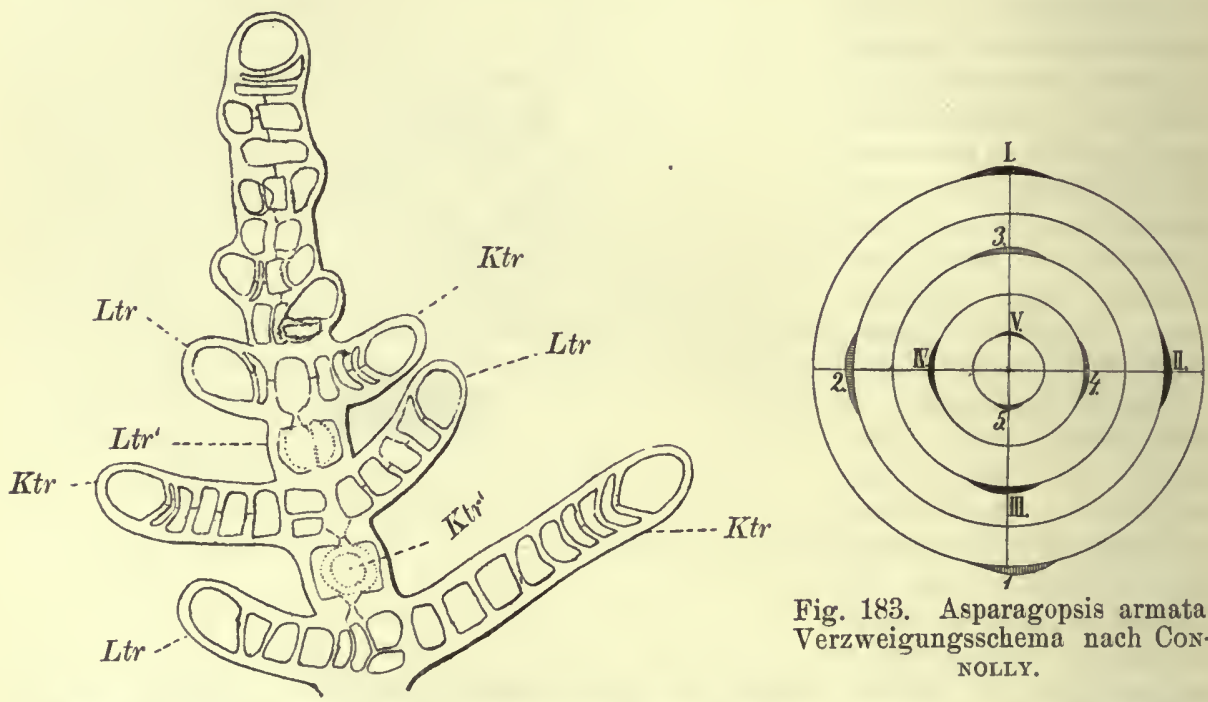

Fig. 183. Asparagopsis armata. Verzweigungsschema nach CoNNOLLY.

Fig. 182. Sproßspitze von Asparagopsis armata (nach ConsouLy). Ktr Kurztriebe, Ltr Langtriebe, $L t r^{\prime}$, und $K \boldsymbol{H}^{\prime}$, Insertionsstellen eines Langtriebes und eines Kurztriebes, welche senkrecht zur Papierebene stehen und nicht gezeichnet sind.

Fig. 183 (nach Connoluy). Diagramm für die Stellung der Lang- und der Kurztriebe. Erstere sind schwarz und mit römischen Zahlen, letztere schraffiert und mit arabischen Zahlen beziffert.

Äußere Faktoren können nur insofern auf die erste Anordnung seitlicher Organe einwirken, als sie das embryonale Gewebe des Vegetationspunktes beeinflussen.

Da wir einen Einblick in den Zusammenhang zwischen der Beschaffenheit des embryonalen Gewebes und dem Auftreten seitlicher Sprossungen derzeit nicht besitzen, so kann es sich hier nur darum handeln, einige allgemeine Regeln anzuführen, welche organographisch von Bedeutung sind.

Es handelt sich darum, 1. die Mannigfaltigkeit der Erscheinungen unter bestimmte Gesichtspunkte zu bringen, 2. zu fragen, wie sie zustande kommt, 3. ihre etwaige biologische Bedeutung zu ermitteln. Erst wenn diese Dinge klar erkannt sind, ist ein Fortschritt zu erhoffen. Die mathematischen Beziehungen, die bisher die Aufmerksamkeit in so hohem Maße fesselten, werden sich dann wahrscheinlich als selbstverständliche und an sich unwichtige Folgen bestimmter Wachstumsgesetze ergeben. 


\section{§ 3. Regel der Äquidistanz, Quirlbillung.}

Eine sehr allgemeine Regel ist die, daß wenn an einer radiären Achse ${ }^{1}$ ) einzelne Partien sich von den anderen verschieden ausbilden, jene sich gleichmäßig verteilen: Regel der Aquidistanz. Diese Regel kommt sowohl bei inneren (anatomischen) als äußeren (morphologischen) Differenzierungen zur Geltung.

Sehen wir uns z. B. eine diarche Wurzel an, so stehen die Gefäßteile einander gegenüber, haben also eine "Divergenz" von $180^{\circ}$, bei triarchen eine von $120^{\circ}$ usw. Man kann dafür wohl auch Zweckmäßigkeitsgründe anführen (bei Äquidistanz der Gefäßteile z. B. wird die Zuleitung des Wassers von auBen in diese am einfachsten erfolgen) aber es liegt offenbar doch ein innerer Grund für diese gleichmäßige Verteilung vor; sei es, daß man diesen sucht in den unbekannten Eigenschaften des Protoplasmas oder anschaulich $\mathrm{zu}$ machen sucht durch Bilder wie das einer gegenseitigen $\mathrm{Ab}$ stoßung der betreffenden Differenzierungen, das einer Baustoffverteilung nsw.

Dieselbe Regel der Äquidistanz treffen wir auch in der großen Mehrzahl der Blattstellungsverhältnisse an, am übersichtlichsten bei den Wirteln, deren einzelne Blätter sich äquidistant in den Stammumfang teilen. Die Wirtelstellung ist der vollkommenste Ausdruck gleichmäßig radiärer Ausbildung. Sie tritt dann ein, wenn das embryonale Gewebe dauernd eine symmetrische Beschaffenheit beibehält, während "spiralige" Blattstellung stets durch asymmetrisches Verhalten des embryonalen Gewebes bedingt ist. Die Zahl der Blätter in einem Wirtel hängt, wie namentlich Equisetum am deutlichsten zeigt, ab einerseits von der relativen Größe des Vegetationspunktes ${ }^{2}$ ) und der Blattanlagen, außerdem aber von dem Vegetationspunkt zugeführten zur Blattbildung geeignetem Material. Es ist gewiß kein Zufall, daß bei Dikotylen die dekussierte Blattstellung sehr verbreitet ist; sie schließt sich der Stellung der Kotyledomen unmittelbar an. Auch bei Pflanzen mit dekussierter Stellung sind besonders krïftige Sprosse oft mit dreizähligen Wirteln ausgestattet (Weigelia, Forsythia) ebenso wie bei kräftigen Kakteentrieben (mit zerstreuter Blattstellung) die Zahl der Orthostichen steigt.

Wirtel mit größeren Blattzahlen treten nur bei Pflanzen mit schmalen Blattansätzen auf (z. B. Hippuris, das an schmächtigen Sprossen 4 zählige, an kräftigen bis 12 zählige Wirtel trägt ${ }^{3}$ ). Die Regel der Äquidistanz

1) Für dorsiventrale Achsen gilt die Regel nicht!

2) H. Winkler (a. a. O. I) findet, daß die Schwankungen der absoluten wie der relativen Größenverhältnisse des Sproßscheitels und der Blattanlagen ohne Einfluß auf das Zustandekommen bestimmter Blattstellungen ist. Das dürfte eine zu weitgehende Verallgemeinerung von Beobachtungen an einzelnen Pflanzen sein. Indes erachte auch ich die Raumverhältnisse nicht als absolut ausschlaggebend, es muß ein ernährungsphysiologischer Faktor hinzukommen.

3) Man kann ohne Zweifel durch Kultur unter relativ ungünstigen Bedingungen die Verminderung der Blattzahl in einem Wirtel auch experimentell hervorrufen. In dieser Beziehnng ist von Interesse, daß wie Moliscr jüngst mitteilte (H. Molisch, Über den Einfluß der Radiumemanation auf die höheren Pflanzen, Sitz.-Ber. der Wiener Akademie Math.-naturw. Klasse 1912). Sedum Sieboldi (eine Pflanze, welche sonst dreizählige Blattwirtel besitzt) an einem der Radiumemanation ausgesetzten Exemplare mit Ausnahme eines einzigen Sprosses nur Triebe mit zweizähligen Blattwirbeln hervorbrachte. Dazu ist $\mathrm{zu}$ bemerken, daß wohl alle Sedumarten mit dreizähligen Blattwirteln auch Sprosse mit zweizähligen hervorbringen; solche.traten z. B. bei Sedum terratum in meinen absichtlich feucht gehaltenen Kulturen in großer Zahl auf. Sicher handelt es sich auch bei Sedum Sieboldi nicht um eine Mutation, sondern um eine an Pflanzen, die weniger gïnstigen Bedingungen ausgesetzt sind, auch sonst auftretende Eigentümlichkeit. 
und der Einfluß des relativen Größenverhältnisses zwischen Blättern und Vegetationspunkt, treten also in allen diesen Fällen deutlich hervor.

Daß die aufeinanderfolgenden Wirtel miteinander alternieren aber wird wahrscheinlich durch die Verteilung der Baumaterialien bedingt. Die Ausbildung eines Blatthöckers erfordert einen bestimmten Aufwand an Baumaterial. Die Vegetationspunkte lebten sozusagen parasitisch auf den assimilierenden Organen, von denen aus ihnen die Baumaterialien zugeleitet werden. Es ist wahrscheinlich, daß oberhalb jedes Blattes eines WVirtels eine Verminderung von Baustoffen eintritt, während dies an den zwischenliegenden Stellen nicht der Fall ist. Diese sind dementsprechend dann für die Neubildungen am geeignetsten. Diese Erwägungen lassen uns, wenn sie zutreffen, auch verständlich erscheinen, weshalb in Blüten häufig opponierte Wirtel vorkommen. Man hat dies historisch durch die Annahme von Verkümmerungen („Schwindekreisen") zu "erklären" gesucht. Das mag auch in manchen Fällen durchaus zutreffen, aber schwerlich in allen.

So namentlich nicht bei denen, bei welchen es sich um "gepaarte" Blattanlagen handelt ${ }^{1}$ ), d. h. um solche, die konstante räumliche Beziehungen in diesem Falle die Opposition - festhalten, auch wenn sonst die Zahlenverhältnisse der Wirtel sich ändern. Solche Paarungen kommen sowohl bei Monokotylen (bei diesen auch, wie unten an Beispielen erläutert wird, an vegetativen Sprossen) wie bei Dikotylen vor; sie sind wichtig für die Ableitung

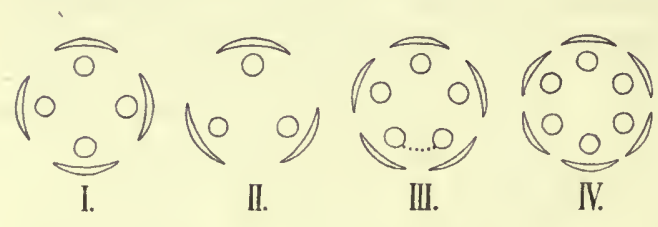

Fig. 184. Diagramm rerschiedener Blüten von Alnus viridis. I vierzählig, $I I$ dreizählig, $I I I$ fünfzählig, $I V$ sechszählig. In allen bleibt die "Paarung" von je einem Perigonblatt und einem Staubblatt gewahrt. Ganz ähnliche Erscheinungen finden sich bei Chenopodiaceen, Urticaceen, Loranthaceen.

verschiedener Blütenformen voneinander und die Deutung der einzelnen Blütenteile. Hier können nur wenige Beispiele angeführt werden.

Gepaart sind z. B. Staubblätter und Perigonblätter bei Triglochin, Fig. 30, Potamogeton unter den Monokotylen, unter den Dikotylen, bei Alnus (Fig. 184), ebenso bei den Urticifloren, Loranthaceen und anderen. Es ist eine solche Erscheinung um so eher auf Grund der oben angefübrten Hypothese verständlich, als die nur engbegrenzter Entwicklung fähigen Blütenvegetationspunkte frübzeitig schon die Baumaterialien, welche zur Anlegung der einzelnen Organe erforderlich sind, mitbekommen, also "geschlossene" Systeme vorstellen, während die vegetativen Sprosse (von Kurztrieben abgesehen) "offen" sind, d. b. unter ständiger Weiterentwicklung auch ständig neue Baustoffe zugeführt erhalten.

Gehen wir noch auf die teleologischen Gesichtspunkte bei der Wirtelbildung ein, so ist folgendes zu bemerken.

1. Die Anordnung der Blätter in Wirtel gestattet eine günstige Verteilung der Blätter nach allen Seiten hin an orthotropen vegetativen Sprossen nur dann, wenn die Wirtel durch Internodienstreckung, auseinandergerückt sind, sonst würden sie sich ja beschatten. Daß das Alternieren der successiven Wirtel gleichfalls für die Belichtung von großer Bedeutung ist, braucht kaum bemerkt zu werden. Tatsächlich sind, wenn bei Pflanzen mit dekussierter Blattstellung an der Basis (infolge unent-

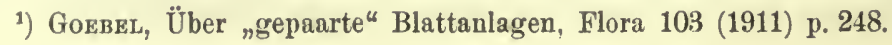


wickelt gebliebener Internodien) die Bildung von Blattrosetten vorkommt, nur wenige Blattpaare daran beteiligt. So bei Arnica montana gewöhnlich zwei, wenn mehr, so vergilben die untersten bald. Dagegen sind mehr Blätter in der Rosette vorhanden, wenn Torsionen eintreten (z. B. bei Horminum pyrenaicum), welche den unten zu erwähnenden entsprechen.

2. Für plagiotrope Sprosse ist die Wirtelstellung an sich für die Lichtausnützung ungünstig. Es finden bei solchen Sprossen oft Drehungen statt - entweder der Internodien oder der Blattstiele - welche alle Blattoberseiten nach oben, alle Blattunterseiten nach unten wenden. So bei sonst orthotropen Hauptsprossen von Gentiana asclepiadea, Veronica urticaefolia u. a., wenn sie im Waldesschatten wachsen. Sie werden dann plagiotrop (sei es passiv durch Überhängen infolge schwächerer Gewebeausbildung, sei es aktiv) und drehen ihre Blattflächen alle nach oben. Dasselbe erfolgt normal an vielen Seitensprossen mit dekussierter Blattstellung.

Wie Frank ${ }^{1}$ ) fand, geht die Internodiendrehung bei Lonicera, Deutzia, Philadelphus auch bei Lichtabschluß vor sich, sie kann nach ihm durch die Schwerkraft allein verursacht werden, das Licht aber kann sich unter „gewöhnlichen" Verhältnissen in gleichsinniger Weise beteiligen. Indes ist die Bedeutung der Schwerkraft einer weiteren Priifung bedürftig. Jedenfalls handelt es sich dabei um Seitenknospen, denen Dorsiventralität schon induziert war. Wie diese Induktion zustande kommit, ist näher zu untersuchen. Auch ist sie bei den einzelnen Pflanzen eine verschieden feste. Bei Coffea arabica ${ }^{2}$ ) z. B. sind die, wie die Hauptsprosse dekussiert beblätterten Seitensprosse nicht imstande, den entfernten Hauptsproß zu ersetzen, also orthotrop zu werden, während die unter ihnen stehenden „Beiknospen" dies tun können.

\section{$\S 4$. Pflanzen mit Wirtelstellung, welche Übergänge zu dorsiven- traler, spirotropher oder bilateraler Ausbildung zeigen.}

Die Pflanzen mit Blattwirteln wurden oben als solche bezeichnet, deren Sproßachse gleichmäßig symmetrisch weiter wächst.

Wie überall, läßt sich aber auch hier keine scharfe Grenze zwischen den Gestaltungsverhältnissen ziehen.

Schon die Begründer der Blattstellungslehre K. Schimper und A. Braun ${ }^{3}$ ) kannten Pflanzen mit Blattwirteln, welche in der Ausbildung ihrer Achselsprosse ein von der symmetrischen Gestaltung abweichendes Verhalten zeigen. Bei der letzteren verhalten sich die Achselsprosse aller Blätter gleich, bei den hier zu erwähnenden Fällen ungleich. Und zwar unterscheiden wir drei Kategorien: 1. Wirtelpflanzen mit Übergang zur dorsiventralen, 2. solche mit Übergang zur spirotrophen Gestaltung und 3. solche die Wirtel mit bilateraler Ausbildung verknüpft zeigen. Erstere können als zum Acanthaceen-, letztere als zum Caryophylleentypus gehörig bezeichnet werden (womit nicht etwa gesagt sein soll, daß alle Pflanzen innerhalb dieser Familien sich gleich verhalten). Die dritte Gruppe stellt den Rocheatypus dar. p. 93 .

1) Frank, Die natürl. wagrechte Richtung von Pflanzenteilen, Leipzig 1870.

2) Vgl. Gozbel, Einleitung in die experimentelle Morphologie der Pflanzen (1908)

s) Vgl. auch Wichưra, Beiträge zur Lehre von der Blatt- und Knospenstellung, Flora 29 (1846) p. $225 \mathrm{ff}$.; ferner BacıBonski, Über die Verzweigung, Ann. du jard. bot. de Buitenzorg 2. sér. Bd. 2 (1900). 
1. Scheinbar ganz radiäre Sprosse können eine Annäherung an dorsiventrale Ausbildung zeigen, die namentlich dadurch von Interesse ist, daß sie vielfach sich vorfindet in Familien, in denen Formen mit ausgeprägt dorsiventralen Sprossen vorkommen. Die Dorsiventralität der letzteren erscheint also als eine Steigerung der schon bei den radiären Formen in schwachem Grade vorhandenen ${ }^{1}$ ) - eine Tatsache, die sehr zu berücksichtigen ist, wenn man die Entstehung dorsiventraler Sprosse sei es durch "Mutation" - sei es als Anpassungserscheinung zu ermitteln sucht.

Eine solche „Kryptodorsiventralität" ${ }^{2}$ ) radiärer Sprosse tritt in allen möglichen Abstufungen bei manchen Acanthaceen auf (vgl. Fig. 185 A). Hier sind die Achselsprosse innerhalb eines Blattpaares nicht gleichartig. Der eine ist entweder kräftiger als der gegenüberliegende (Fig. 186, in Fig. $185 \mathrm{~A}$ ist der geförderte mit + der gegenuiberstehende mit - bezeichnet) oder der geförderte ist ein Langtrieb, der geminderte ein Kurztrieb (bei Barleria buxifolia z. B. ein Dorn, bei Ruellia formosa ist der $+Z$ weig oft
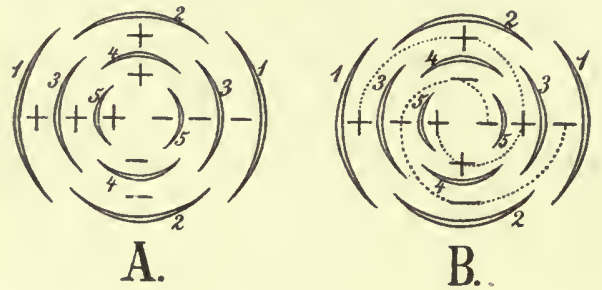

Fig. 185.

Schema für die Verzweigung. $A$ Acanthaceen $-B$ Caryophylleentypus.

eine Blüte, der -Zweig vegetativ). Es liegen, wie das Schema, Fig. $185 \mathrm{~A}$, zeigt, alle + und alle - Sprosse in zwei Reihen übereinander, der ganze Sproß hat also eine aus zwei Orthostichen bestehende Plusseite und eine aus zwei Orthostichen gebildete Minusseite. Ganz ebenso verhalten sich auch die Melastomacee Monochaetum hirtum u. a.

Auch einige Lythraceen zeigen dasselbe. So die in den Gärten vielfach kultivierte Gattung Cuphea, an der man besonders leicht die dorsiventrale Ausbildung der orthotropen Sprosse sehen kann.

Fig. 187 gibt ein Diagramm von Cuphea platycentra (ganz analog verhalten sich andere "alterniflore" Cuphea-Arten, "wie C. viscosa u. a.). Das Diagramm ist insofern nicht ganz richtig, als die Blattquirle sich nicht rechtwinklig, sondern etwas schief kreuzen. Die Blüten $(B)$ fallen alle nach Einer Seite, sie sind in zwei um $90^{\circ}$ divergierende Reihen angeordnet (daß sie am Stengel - bis zum nächsten Knoten "hinaufwachsen", bleibt hier außer Betracht), ebenso die vegetativen Seitensprosse. Diese haben verschieden große Blätter, die mit + und - bezeichnet sind. Man sieht, daß sie so angeordnet sind, daß ein symmetrisches Ganzes entsteht. Die Größendifferenz zwischen den beiden transversalen Blättern ist geringer als die zwischen den medianen, erstere gleicht sich später mehr aus, letztere nicht.

Auch dieser Fall zeigt also, daß dem ganzen Sproß eine bestimmte Symmetrie aufgeprägt ist, die offenbar schon im Vegetationspunkt vorhanden ist.

1) Wenn man nicht einem in der Botanik oft geübten Brauche entsprechend die Reihe umkehren will!

$\left.{ }^{2}\right)$ Die alte Morphologie drückte das, um die geliebte "Spirale" auch hier anwenden zu können so aus, daß die stärkeren und die schwächeren Knospen sich jeweils durch zwei "gebrochene Spiralen" miteinander verbinden lassen! (Vgl. Wichona a. a. 0. p. 235.) 
Die Verschiedenheit der Axillarsprosse, wie sie bei den Acanthaceen erwähnt wurde, dürfte durch Ernährungsdifferenzen bedingt sein (welche ihrerseits durch den inneren Aufbau veranlaßt werden).

Die geförderte Seite dürfte die besser ernährte sein. Dafür spricht der in Fig. 188 abgebildete Regenerationsversuch. In dem Blattwirtel von Blechum Brownii war nur Ein Seitensproß in der Achsel des geförderten Blattes entstanden. Der Steckling zeigt, daß unterhalb dieses Blattes auch die ersten Adventivwurzeln auftreten. Man könnte hier allerdings auch einen von dem Achselsproß auf die Wurzelbildung ausgehenden Reiz annehmen, indes machen analoge Erfahrungen an anderen Stecklingen ohne Vegetationspunkte die erstgenannte Annabme wahrscheinlicher (vgl. auch die S. 98 erläuterten Beziehungen von Blatt und Achselsproß).

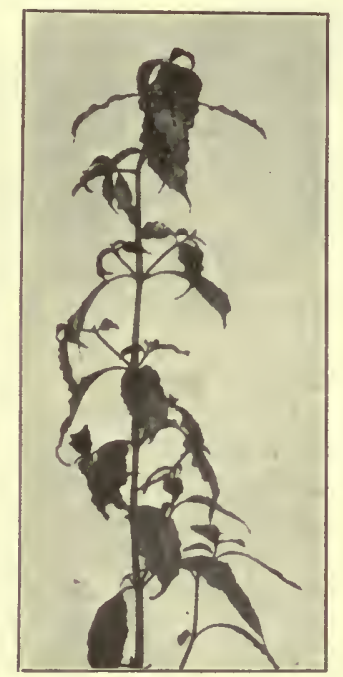

Fig. 186. Asystasia bella (Verkl.) Habitusbild einer Pflanze. Die Achselsprosse jedes Blattpaares sind ungleich groß. Die Pflanze neigt auch zur Anisophyllie, die hier aber keine konstante ist.

Fig. 187. Cuphea platycentra. Schema der SproBanordnung. Die regetativen Sprosse sind schraffiert (durch + und sind die Größenverhältnisse ihrer Blätter bezeichnet) die Bliten $B$ weiß gelassen.

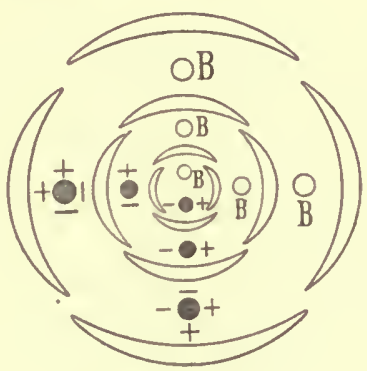

Fig. 187.

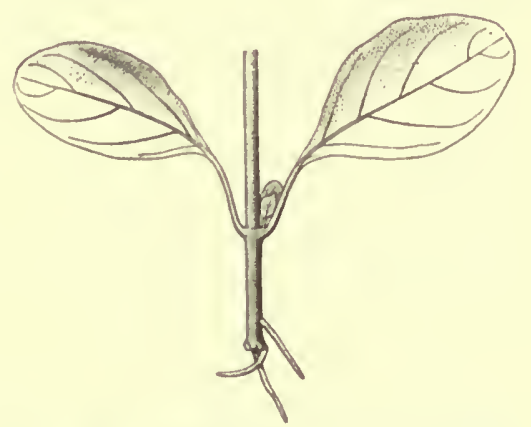

Fig. 188. Blechum Brownii Steckling. Die ersten Wurzeln treten unter dem Blatte anf, welches einen Achselsproß besitzt.

Wieweit die Verschiedenheit der Plus- und Minusseite in einem Wirtel sich ausspricht auch bei der ersten Anlegung der Blätter und der Achselsprosse am Vegetationspunkt, ist näher zu untersuchen. Vielleicht wird sich ergeben, daß bei manchen hierher gehörigen Pflanzen das Blatt, in dessen Achsel der + Sproß entsteht, friher angelegt wird, als das ihm gegeniiberliegende. So ist es nach HofMerster bei Fraxinus excelsior, Syringa vulgaris u. a., bei denen aber in der Entwicklung der Seitensprosse keine nennenswerte Verschiedenheit angegeben wird.

Es ist klar, daß eine Verringerung der Blätter der Minusseite zur 
Anisophyllie führen würde, und dies ist tatsächlich bei manchen Acanthaceen eingetreten.

2. Vergleichen wir damit das Verhalten anderer spirotropher Pflanzen mit dekussierten Blättern, z. B. das der Caryophylleen, so finden wir betreffs der Achselsprosse auch einen geförderten und einen geminderten. Aber in anderer Verteilung als bei dem Acanthaceen-Typus. Bei dem Caryophylleentypus lassen sich die geförderten und die geminderten Sprosse in je einer gleichsinnig verlaufenden Schraubenlinie anordnen (Fig. 182 B). Nach Hofmeister soll auch die Entstehungsfolge der Blätter dem entsprechen: die mit + bezeichneten Blätter entstehen jeweils früher als die betreffenden - Blätter. Indes konnte ich bei Dianthus caesius keine solche Verschiedenheit finden. Die Orthostichen sind nicht, wie in dem Schema angenommen, gerade, sondern etwas gedreht. Wir haben hier eine spirotrophe Änderung des radiären Baues. Sie ist bei den Caryophylleen biologisch offenbar bedeutungslos.

Ein im wesentlichen übereinstimmendes Verhalten zeigt die p. 196 erörterte Floridee Asparagopsis, nur handelt es sich bei ihr nicht um axilläre Sprosse. Aber auch bei ihr lassen sich die t- und - Sprosse in je eine Schraubenlinie anordnen.

Diese Fälle sind von besonderem Interesse, weil sie zeigen, daß eine "spiralige" Anordnung lediglich durch innere Eigenschaften des Vegetationspunktes zustandekommt und daß dazu keine Drehung notwendig ist, es genügt, wenn eine Förderung der Baustoffzufuhr in der Richtung einer Schraubenlinie stattfindet (Spirotrophie).

3. Bei der zerstreuten Anordnung der Blätter handelt es sich, wie oben bemerkt, um ein asymmetrisches Wachstum des Vegetationspunktes. Dies kann in seltenen Fällen noch mit der Wirtelstellung verbunden sein. So bei den sich schief kreuzenden Blattpaaren einiger Sukkulenten, wie Rochea falcata und (in geringerem Grade) R. odorata. Diese mit "dekussierter" Blattstellung versehenen Pflanzen machen einen höchst sonderbaren und zunächst unverständlichen Eindruck, namentlich Rochea falcata. Die sichelförmigen aufgerichteten Blätter (Fig. 189) sind stark asymmetrisch, sie haben eine konvex gekrümmte größere und dünnere und eine kleinere dickere konkave Seite. Erstere pflegt schief nach oben gerichtet zu sein. Die Blätter stehen in schief gekreuzten Paaren, die größeren Blattseiten jeden Paares stehen einander abgekehrt (vgl. Fig. 190 und das Schema Fig. 191).

Wir können das Verhalten, wie mir scheint, auf einen verhältnismäßig einfachen Ausdruck zurückführen. Der Vegetationspunkt ist hier nicht radiär, sondern bilateral entwickelt, d. h. er besitzt den stumpfen Winkeln, unter denen sich die Medianebenen der Blattpaare schneiden entsprechend zwei "Plusseiten" (Pl Fig. 191) (geförderte) und zwei „Minusseiten" ( $M$ Fig. 191). Alle größeren Blatthälften sind einer Plus-, alle kleineren einer Minusseite zugekehrt, wir können den ganzen Sproß durch zwei die Minus- und die Plusseiten halbierenden Teilungsebenen annähernd ${ }^{1}$ ) symmetrisch teilen.

Was den Vegetationspunkt veranlaßt hat bilateral zu werden, ist unbekannt, und ebenso auch die eventuelle biologische Bedeutung dieser Erscheinung, von der man vermuten könnte, daß sie mit der Profilstellung

1) Von einer wirklich symmetrischen Teilung kann natïrlich keine Rede sein, schon deshalb, weil die + Seiten der Blätter erst im $\mathrm{nächsten} \mathrm{Wirtel} \mathrm{wieder} \mathrm{auf} \mathrm{dieselbe}$ Seite fallen, wie im vorhergehenden. - Auch bei anderen Crassulaceen findet sich eine schiefe Kreuzung der Wirtel. So bei Cotyledon macrantha, wo aber die Asymmetrie der Blätter viel weniger ausgebildet ist, als bei Rochea falcata. 
der Blätter in Beziehung steht, indes trifft dies z. B. für Cotyledon macrantha nicht zu. Sicher aber sind zwei Dinge, und auch deren Erkennung ist schon ein Gewinn; einmal: daß es auch hier das Verhalten des Vegetationspunktes ist, das die Blattanordnung und Blattsymmetrie bestimmt, und sodann, daß sich diese Ausbildung ron der gewöhnlichen dekussierten ableitet. Das ergibt sich nicht nur aus dem Verhalten der Keimpflanzen, die mit gewöhnlicher dekussierter Stellung beginnen; auch für die Seitensprosse trifft dasselbe $\mathrm{zu}$, und unterhalb der Blütenregion der Sprosse tritt wieder fast radiäre Ausbildung ein. Hier haben wir also eine

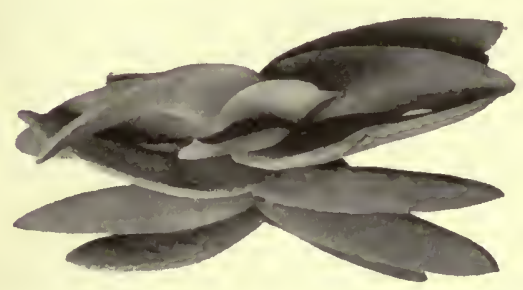

Fig. 189. Rochea falcata. Spitze einer Pflanze von oben (verkl.)

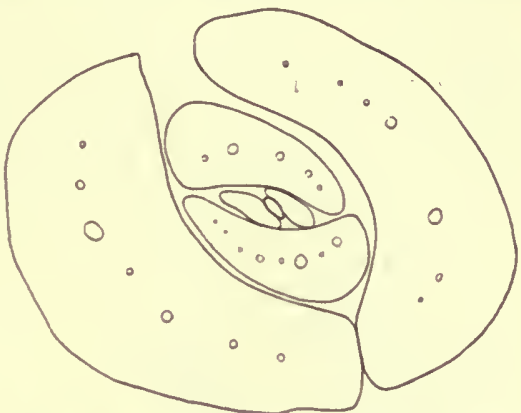

Fig. 190. Querschnitt durch die Endkuospe einer jungen Pflanze von Rochea falcata. Die Blattpaare schief gekreuzt, die Blätter asymmetrisch. (Vergr.)

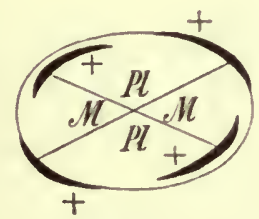

Fig. 191. Schema der Sproßsymmetrie von Rochea falcata. Die Plusseiten der Blätter mit + , die der Sproßachse mit $P l$ bezeichnet. $M$ Minusseiten der Sproßachse.

Fig. 191.

bilaterale Veränderung der Wirtelstellung. Die Beschaffenheit des Vegetationspunktes bedingt es auch, daß die Regel der Äquidistanz hier nicht eingehalten wird $^{1}$ ).

\section{$\S 5$. Die zerstreute (spiralige) Blattstellung der Dikotylen.}

Hier ist zu besprechen die Veränderung, welche bei den Dikotylen eintritt, welche zur zerstreuten Blattstellung übergehen.

Die Kotyledonen bilden einen zweigliedrigen Wirtel, dessen Glieder nur selten auseinanderrücken. Bei sehr vielen Dikotylen wird auch von den folgenden Blättern die dekussierte Stellung beibehalten. So bei Labiaten, Rubiaceen, Valerianeen. Bei anderen Familien haben wenigstens einzelne Gattungen dekussierte Stellung, andere zerstreute. So bei Crassulaceen,

1) Die mechanische Blattstellungslehre würde das Verhalten von Rochea falcata wohl darauf zurïckführen, daß durch die nnsymmetrische Ausbildnng der Blattbasen der Vegetationspunkt einen ,Druck ${ }^{\alpha}$ erfahre, der anders gerichtet ist als bei gewöhnlicher dekussierter Blattstellung. Nach unserer Auffassung dagegen wird die Gestaltang der Blattanlagen bestimmt durch die Eigenschaften des Vegetationspunktes, nicht umgekehrt. 
Scrophularineen u. a. Oder es behält die Pflanze im Verlauf der Einzelentwicklung zunächst die dekussierte Stellung und geht dann früher oder später zur zerstreuten ïber. Dieser Übergang findet bei Cabomba, Veronica, Beccabunga, Helianthus strumarius u. a. erst in der Blütenregion, bei anderen viel früher statt - vielfach verhalten sich auch einzelne Árten innerhalb einer Gattung verschieden. Es sei hier nur an einem Beispiel erörtert, wie nach des Verf.s Ansicht der Übergang zur 2/5 Stellung zustandekommen kann.

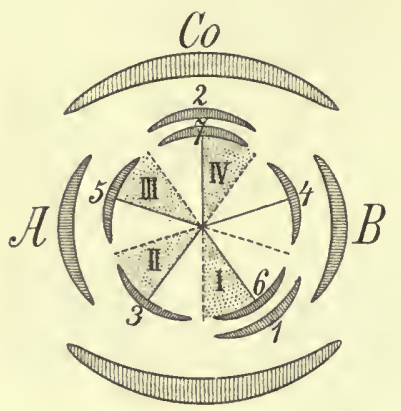

Fig. 192. Schema für den Übergang von dekussierter in $2 / 5$ Stellung.

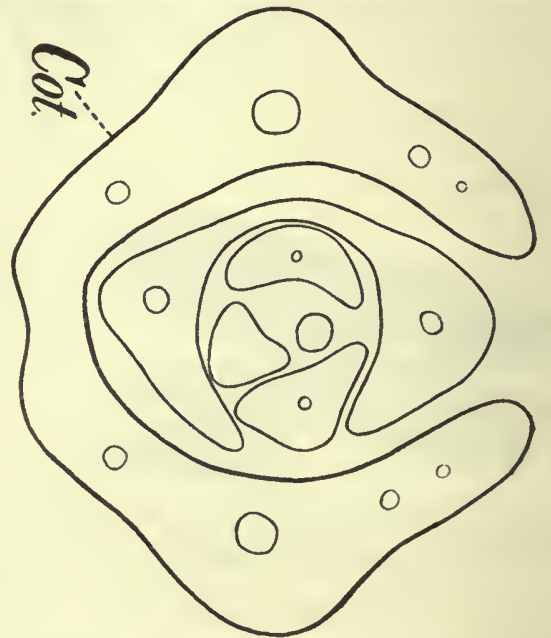

Fig. 193. Helianthus annuus. Querschnitt durch die Knospe einer Keimpflanze. Cot. Die beiden miteinander an der Basis verwachsenen Keimblätter, darauf folgt ein dekussiert stehendes Blattpaar, dann beginnt die zerstreute Blattstellung.

Bei Helianthus annuus folgen auf die zwei Kotyledonen eine variable Anzahl zweizähliger Wirtel, ehe die "spiralige" Stellung beginnt. In dem Schema Fig. 192 ist angenommen, daß mit den Kotyledonen gekreuzt nur Ein Blattpaar, $A$ und $B$, auftritt. Das erste Blatt des nächsten Paares fällt aber nicht in den Zwischenraum zwischen $A$ und $B$, weil der Vegetationspunkt auf der nach $A$ hingekehrten Seite kräftiger ernährt wurde und (wio wir annehmen wollen) stärker wuchs, als auf der nach $B$ zuliegenden. Infolgedessen ist das Blatt 1 nach $B$ hin abgelenkt und entsteht früher als das Blatt 2, das seine Stellung in der Mitte zwischen $A$ und $B$ beibebalten hat. Ebenso steht das Blatt 3 nicht über $A$, sondern ist in derselben Richtung verschoben wie 1, 4 aber fällt, der Äquidistanzregel entsprechend zwischen 1 und 2, steht also nicht mehr über $B$ direkt usw. Zugleich sehen wir, daß die HOFMEISTER'sche Regel nicht wörtlich zutrifft, Blatt 3 steht in der größten Lücke, aber nicht in deren Mitte, sondern nach 1 hin "verschoben". Wir können schematisch annehmen, es finde vor der Anlegung der Blätter 1, 3, 5, 7 usw. an dem Vegetationspunkt die Hinzufügung einer Zone statt, die in der Figur punktiert ist, und auf deren Einschaltung das asymmetrische Wachstum beruhe. Diese Zonen sind, wie ersichtlich, in einer der "Blattspirale" gegenläufigen Richtung angeordnet. Selbstverständlich geht das asymmetrische Wachstum nicht in so grob abgeteilter Weise vor sich, es sollte nur bildlich veranschaulicht, werden. Die Abbildung des Mikrotomschnittes eine Helianthuskeimpflanze (Fig. 193) zeigt, daß das Schema mit der Wirklichkeit übereinstimmt. 
In dem oben gegebenen Schema wurde die Asymmetrie in dem Auftreten neuer Blattanlagen auf eine periodische Asymmetrie des Wachstums des Vegetationspunktes zurückgeführt, für welche man auch den Ausdruck "Scheiteltorsion" gebrauchen könnte. Wieweit eine solche bei Dikotylen stattfindet, bedarf eingehender Untersuchung. Es kann dasselbe Resultat auch durch "eine Asymmetrie in der Zufuhr von Baustoffen zum Vegetationspunkt erreicht werden.

Auf deren Bedeutung weist namentlich auch die zweizeilige Blattstellung hin, die sowohl bei Dikotylen (z. B. bei Anona-Arten und solchen mit dorsiventralen Sprossen, wie Tilia, Fagus, Ulmus) als namentlich bei Monokotylen auftritt.

Wenn auf die Kotyledonen bei Dikotylen zweizeilige Stellung eintritt, beruht dies der hier vertretenen Anschauung nach darauf, daß schon die erste Blattanlage so viel Material in Anspruch nimmt, daß nicht ihr unmittelbar gegenuiber, sondern erst weiter oben an dem Vegetationspunkt eine zweite auftreten kann (Fig. 194).

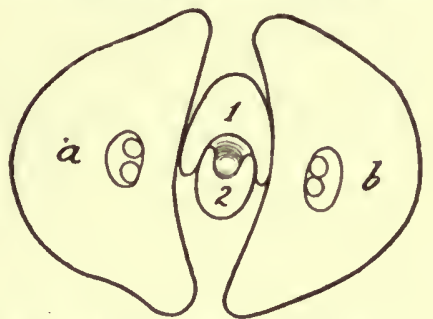

Fig. 194. Querschnitt der Hauptknospe einer Keimpflanze von Asarum europaenm. $a$ nnd $b$ Kotyledonen, 1 und 2 die ersten Lanbblätter. Vergr. $\times 5$ nach vaN ITERSON.

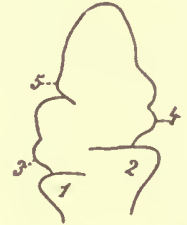

Fig. 195. Junges Ährchen von Poa annua. $1,2,3,4,5$ zweizeilig gestellte Blätter ( 1 nnd $\ddot{z}$ glumae, $3-5$ paleae inferiores).

Hofmeister und nach ihm Schumanx und van Iterson haben dagegen der Gestalt der Blattanlagen einen maßgebenden Einfluß für das Zustandekommen der zweizeiligen Blattstellung eingeräumt.

15i. Diese sollte dann eintreten, wenn eine Blattanlage vor dem Auftreten der nächst jüngeren mehr als die Hälfte des Stengelvegetationspunktes umfaßt. Dies mag auch vielfach richtig sein (vgl. Fig. 194), obwohl, wenn man auf die jüngsten Stadien zurückgeht, selbst in der vegetativen Region die Allgemeinheit des "Gesetzes" mir fraglich ist. Betrachtet man aber die Entwicklung der Infloreszenzen der Gräser, so sieht man, daß die erwähnte Anschauung nicht zutrifft. Hier ist eine zweizeilige Blattstellung vorhanden, obwohl beim Auftreten des jüngsten Blattes sicher nicht das nächstälteste den Sproßvegetationspunkt zur Hälfte um greift (Fig. 195). Nun könnte man sagen: "Die Infloreszenz setze eben die zweizeilige Stellung der vegetativen Region auch dann fort, wenn die Blattanlagen sich anders verhalten, es sei aber auch hier für jede Blattanlage eigentlich ein bestimmtes Areal des Vegetationspunktes bestimmt, das sie nur entweder später oder unvollständig in Anspruch nehme." Das wäre aber nur ein schön eingewickeltes Zugeständnis dafür, daß nicht die Form der Blattanlagen, sondern die Beschaffenheit des Vegetationspunktes es ist, welche die Blattstellung bestimmt, und gerade das sollte hier ja gezeigt werden!

Wenn die Blattanlagen später einen beträchtlichen Teil des Vegetationspunktes in Anspruch nehmen können, so ist das eine Folge ihrer zweizeiligen An- 
ordnung ${ }^{1}$ ), nicht aber deren Ursache, demgemäß kann erstere auch ausbleiben. Mit anderen Worten können wir auch sagen: Die zweizeilige Blattstellung beruht ebenso auf der Verteilung des embryonalen Materials am Vegetationspunkt, wie dies z. B. bei dem Laubmoose Fissidens der Fall ist (Fig. 196). Hier wissen wir, daß die Zweizeiligkeit in der Art der Segmentierung der Scheitelzelle begründet ist: $d . h$. diese verteilt das embryonale Material von Anfang an in zwei Reihen, die Blätter stehen zweizeilig und umfassen später auch mehr als die Hälfte des Umfanges der Sproßachse. Nicht das aber, sondern die Verteilung der embryonalen Substanz am Scheitel ist maßgebend.

Dasselbe gilt unserer Auffassung nach auch für Scheitel ohne Scheitelzelle. Jede Neuanlage braucht eine bestimmte Menge embryonalen Plasmas, also eine bestimmte Menge Baumaterial. Zweizeiligkeit tritt ein, wenn die Bildung einer Blattanlage das auf einer Längshälfte des Vegetationspunktes vorhandene Material ganz erschöpft, so daß erst auf der gegenüberliegenden Seite weiter oben eine Neubildung auftreten kann. Für die Infloreszenzen gilt dasselbe.

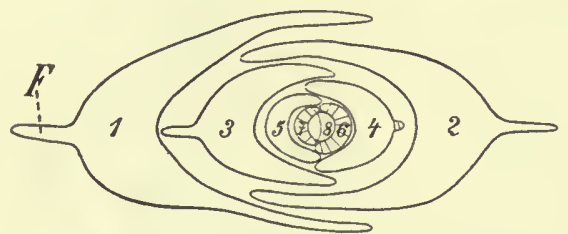

Fig. 196. Fissidens taxifolius. Knospenquerschnitt, etwas schematisiert. $F$ Fln̈gel. Dort ist das Blattbildungsmaterial überhaupt verringert, die Stellung bleibt aber dieselbe, obwohl die neue Anlage ganz gut auch $90^{\circ}$ von der alten divergierend Platz hätten. Wird das Material stark gesteigert, so tritt das auch ein: gut ernährte Infloreszenzen des Grases Euchlaena mexicana können statt 2-, 4 zeilig verzweigt sein, und bei Zea Mais, deren Infloreszenzen normal mehrzeilig sind, tritt an schwächlich ausgebildeten weiblichen Blütenkolben gegelentlich Zweizeiligkeit ein.

\section{§ 6. Scheiteltorsion bei Laubmoosen und anderen Pflanzen.}

Fissidens war ein Moos mit zweischneidiger Scheitelzelle und zweizeiliger Blattstellung. Die meisten Laubmoose verhalten sich anders und bieten ein auch für die Untersuchung der höheren Pflanzen lehrreiches Beispiel für Scheiteltorsion. Der Vegetationspunkt hat eine dreiseitigpyramidale Scheitelzelle. Diese scheidet 3 Reihen von Segmenten ab, aus deren jedem ein Blatt hervorgeht. Im einfachsten Falle ist die Blattstellung $1 / 3$ - es sind also drei Reihen jeweils übereinander fallender Segmente und Blätter vorhanden, so bei Fontinalis, Hypopterygium, Cyathophorum (abgesehen von nachträglichen Torsionen der Sproßachse).

Bei anderen Moosen finden sich dagegen andere Divergenzen. Bei einem orthotropen Sprosse mit wenig entwickelten Internodien wird eine solche Verteilung der Blätter eine günstigere Lichtausnutzung ermöglichen, als die $1 / \mathrm{g}^{-}$-Stellung.

Die Verschiebung läßt sich besonders deutlich bei Moosen mit "Blattspuren" in der Sproßachse verfolgen. Fig. 197 I zeigt bei Dawsonia superba die Blattspuren im unteren Teil der Sproßachse noch in 3 geraden Reihen, in Fig. 197 III dagegen sind die Reihen stark gedreht. Da diese

1) Namentlich des beträchtlichen Materialaufwandes für jede Blattanlage, der ihr eine entsprechende Ansdehnung erlaubt. Selbstverständlich brauchen zweizeilig gestellte Blätter deshalb noch nicht auch eine bedeutende absolute Größe zu erreichen. Es kommt vielmehr an auf das rela ti ve Verbältnis zwischen Blatt und Vegetationspunkt. 
Torsion nahe am Scheitel eintritt, an einer Stelle, an der die eigentliche Sproßachse noch kaum sichtbar ist, kann man sie mit Correns ${ }^{1}$ ) als Scheiteltorsion bezeichnen. Sie kommt durch nąchträgliche seitliche Verschiebungen in den Segmenten zustande, wobei das Segment in seinem anodischen Teile (dem in der Richtung der Blattspirale gelegenen) breiter wird, als in seinem kathodischen (vgl. auch Fig. 68). Früher hatte man angenommen, daß diese Verschiebung gleich Anfangs beim Auftreten der Segmentwand vor sich gehe (vgl. Fig. 198). Nach Correxs und Seck' werden aber die Segmentwände zunächst parallel der Außenwand angelegt und dann erst tritt die Verschiebung ein. Ob das immer so ist, wird sich fragen, es diirften wohl beide Fälle vorkommen. Jedenfalls erfolgt die "Torsion" lediglich durch das Wachstum der Sproßachse, nicht durch irgendwelche hypothetische Druckverhältnisse zwischen den Blättern untereinander oder mit der Sproßachse, sie würde genau so eintreten, wenn die Blätter nur als Punkte vorhanden wären. Der Verf. muß trotz des Widerspruchs von Seckт auf der in der 1. Auflage dieses Buches ausgesprochenen Behauptung stehen

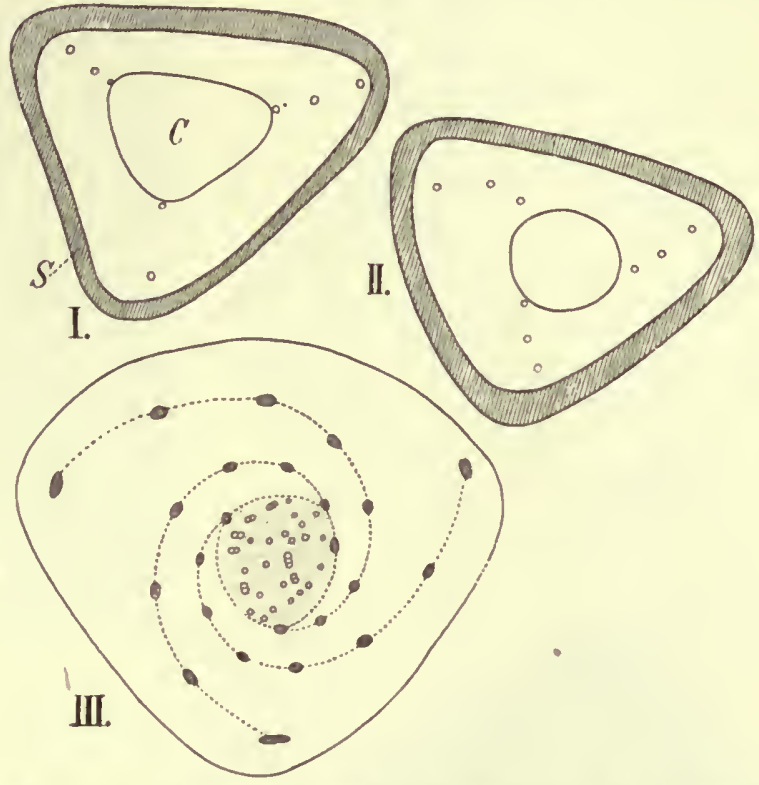

Fig. 197. Dawsonia superba. Querschnitte durch einen Sproß auf rerschiedener Höhe $I$ weit unten, die Blattspuren bilden noch 3 annähernd gerade Reihen. II etwas weiter oben: man beinerkt schon eine schwache Torsion, III noch weiter oben die 3 Reihen von Blattspuren stark tordiert. bleiben, daß die

Schwendexer'sche mechanische Blattstellungstheorie auf die Moose keine Anwendung finden kann.

Auch bei höheren Pflanzen kommen solche spirotrophen Stengeltorsionen vor, so in dem bekannten Fall von Pandanus, bei Cyperaceen u. a.

Nach Sachs und Schumans liegen die Blätter zunächst in drei geraden Zeilen, später findet eine Torsion der Sproßachse statt, welche bedingt, daß die Blätter in drei gewundenen Zeilen stehen. Analoge Erscheinungen finden sich bei einigen sukkulenten Monokotylen, namentlich Aloë resp. Gasteriaarten (Gasteria obliqua, carinata u. a.). Die Blattstellung ist bei den Keimpflanzen ursprünglich eine zweizeilige (Fig. 200) und bleibt bei manchen Arten z. B. A. plicatilis (Fig. 199) auch zeitlebens so. Bei anderen sind später die Blätter in zwei mehr oder minder stark gewundenen Zeilen angeordnet, und asymmetrisch ausgebildet, eine Erschei-

1) C. Correns, Über Scheitelwachstum, Blattstellung und Astanbeginn des Laubmoosstämmehens, Festschrift für ScHweNdeNer 1899. H. SECKT, Beiträge zur mechan. Theorie der Blattstellungen bei Zellenpflanzen. Botan. Centralblatt Beihefte Bd. X (1901). 
nung welche zur Torsion der Sproßachse ohne Zweifel in derselben kausalen Beziehung steht, die oben für die Asymmetrie der Blätter von Rochea falcata angenommen wurde.

Wenn man bei Pandanus in biologischer Beziehung für die Torsion ähnlicher Erwägungen, wie bei den Moosen, wird aufstellen können, so sind solche bei einer ohnedies an sehr stark beleuchteten Standorten wachsenden Sukkulente wie Gasteria sehr zweifelhaft ${ }^{1}$ ).

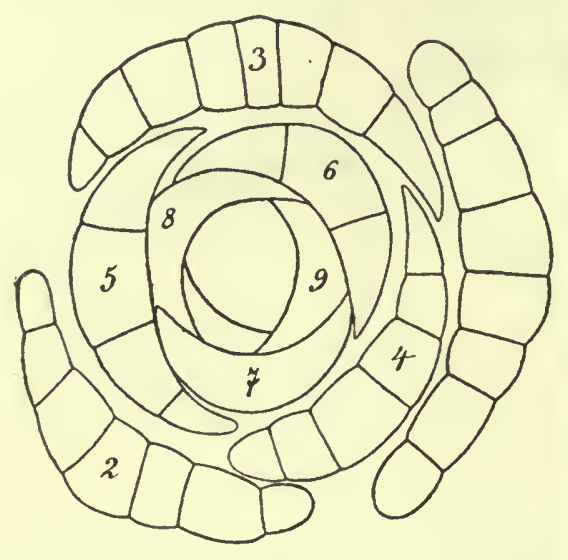

Fig. 198.

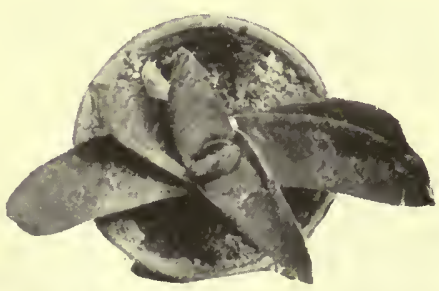

Fig. 200. Gasteria cheilophylla. Junge Pflanze von oben.

\section{§ 7. Die Blattstellung der Monokotylen.}

Sie leitet sich nach des Verf. Auffassung ${ }^{2}$ ) von der $1 /{ }_{2}$-Stellung ab.

Diese wird von vielen dauernd beibehalten. Sie ist wohl in fast allen Familien der Monokotylen vertreten, in manchen ausschließlich lierrschend (z. B. Gramineen, Irideen s. str.). Selten ist von der zweizeiligen Stellung aus Wirtelbildung eingetreten, also ein Zusammenrücken von zwei oder mehr Blättern auf einen Knoten.

Ein Beispiel dafür bietet Polygonatum verticillatum. Die rerwandten Arten sind mit zweizeiliger Blattanordnung versehen. So ist es auch bei P. verticillatum im Jugendzustand und bei dem mit Niederblättern ausgerïsteten ersten geophilen Entwicklungsstadium jedes Sprosses. Später treten statt eines breiten Blattes an jedem Knoten mehrere schmäler inserierte auf (Fig. 201, IV), die sich gleichmäßig in den Umfang teilen. Die

1) Schöne Abbildungen bei Снurch a. a. 0 .

2) Vgl. Goebel, Scheinwirtel, Flora 105 (1912) p; 71. 
einzelnen Wirtel alternieren miteinander, aber zeigen manche Unregelmäßigkeiten ( $\mathrm{rgl}$. die Angaben a. a. O.).

10 Bei den Monokotylen, welche zu anderen Divergenzen als 1/2 übergegangen sind, finden wir ein rerschiedenes Verhalten, welches hier nicht näher geschildert werden kann. Es sei nur erwähnt, daß wir zwei Fälle unterscheiden können: in dem einen findet ein Zusammenhalten je zweier (,gepaarter") Blätter statt ${ }^{1}$ ), die einander noch annähernd gegenüberstehen, im anderen ist jedes Blatt für sich.

Bei den Monokotylen mit gepaarten Blättern verhalten sich die beiden Glieder eines Paares oft dadurch verschieden, daß jeweils nur eines einen Achselsproß hervorbringt.

Erwähnt sei zunächst Najas ${ }^{2}$ ), deren Verhalten nach Untersuchung ron Najas microdon geschildert sei. Die Blätter stehen (Fig. 202) in schief gekreuzten Paaren. Jedes Paar besteht, wie die Entwicklungsgeschichte (Fig. 203) zeigt, aus zwei ungleich alten Blättern, zwischen denen das Internodium sich nicht streckt. Sie stehen einander nicht genau gegenüber. $\mathrm{Je}$ weils das erste Blatt jedes Paares (in Fig. 203 mit + bezeichnet) hat einen Achselsproß, das zweite (in Fig. 203 mit - bezeichnet) nicht. Der zweizeiligen Stellung gegen-

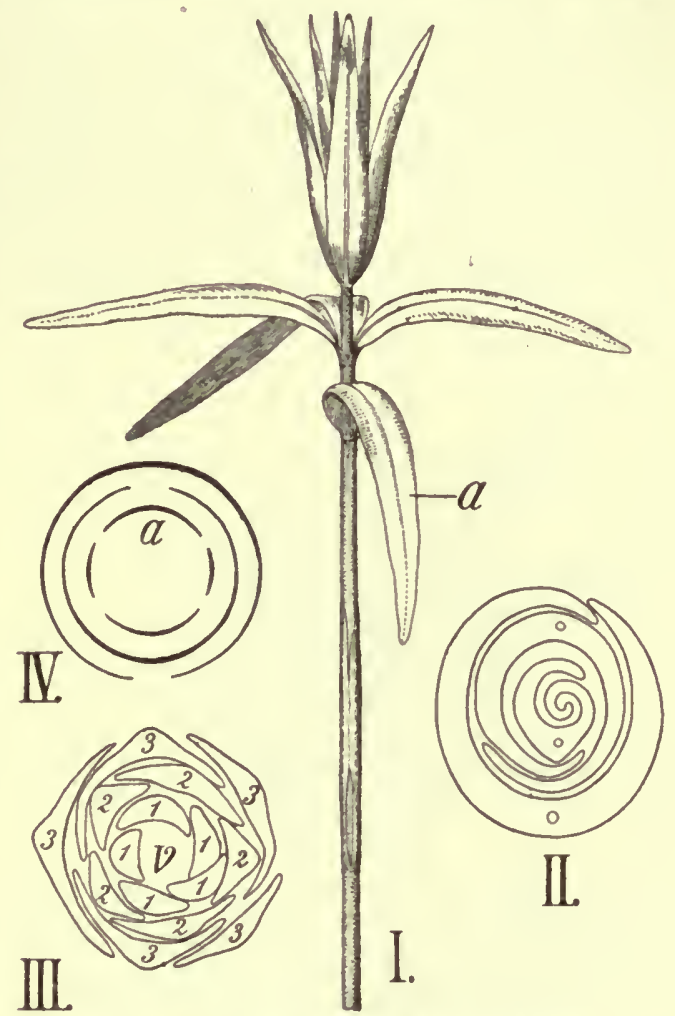

Fig. 201. Polygonatum verticillatum.

$I$ Junger Sprol, Blatt $a$ breiter als die anderen, II Querschnitt der Knospe einer Keimpflanze, III einer älteren Pflanze, IV Diagramm zu $I$.

Fig. 202. Najas microdon. I Querschnitt durch ein Blatt mit Achselsproß ( weibl. Blüte) $M$ Deckblatt des vegetativen Seitensprosses der weibl. Blüte, st sterileBlätter. o männl. Blüte. $I I$ Querschnitt einer Endknospe, die ungeraden Blätter fertil, die geraden steril.
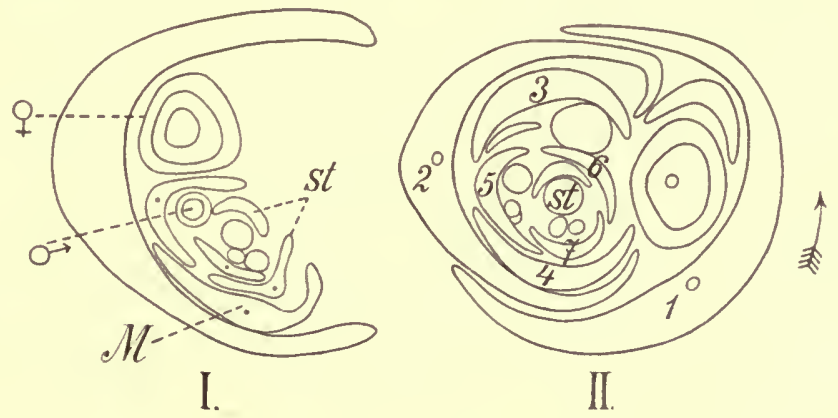

1) So bei Potamogeton pectinatus auch schon bei $1 / 2$-Stellung.

2) Vgl. P. Magnus, Beiträge zur Kenntnis der Gattung Najas; Berlin 1870.

Goebel, Organographie der Pflanzen. 2. Aufl. Allgem. Teil. 
über ist, speziell zwischen den einzelnen „Paaren" eine Drehung in der Richtung des Pfeiles (Fig. $202 I I$ ) eingetreten.

Ebenso verhält sich Ottelia, nur daß hier die Drehung eine stärkere ist, als bei Najas. Betrachten wir Fig. 204, so sehen wir den Querschnitt einer Knospe mit Blattpaaren, deren ungerade bezifferte Blätter einen Achselsproß haben, während die mit $X$ bezeichneten (geraden) steril sind. Man sieht ohne weiteres, daß die "fertilen" Blätter und. die sterilen je eine wendeltreppenartige Anordnung haben. Früher suchte man auch in derartigen Fällen vor allem die „Divergenz" zu bestimmen ${ }^{1}$ ). Diese aber erscheint uns unwesentlich gegenüber der Erkenntnis, daß eine solche Anordnung aus der $1 / 2$-Stellung durch „Drehung" sich ableitet.

Da damit scheinbar ganz heterogene Erscheinungen unter einen Gesichtspunkt gebracht werden, so sei noch das Verhalten einer Monokotyle mit "gepaarten" fertilen und sterilen Blättern erwähnt, welche dorsiventrale Sprosse entwickelt hat.

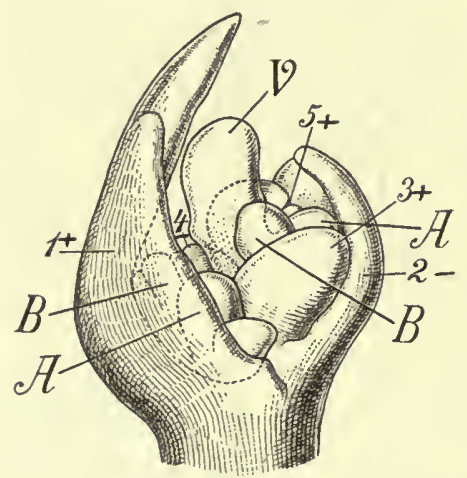

Fig. 203. Najas microdon. Frei präparierter Vegetationspunkt $(V)$ von der Seite. Die fertilen Blätter $1+, 3+$, $5+$ deutlich eine Wendeltreppe bildend, $B$ Blüte, $A$ vegetativer Achselsproß. Der Vegetationspunkt $V$ ist nicht gerade, sondern nach rechts gebogen.

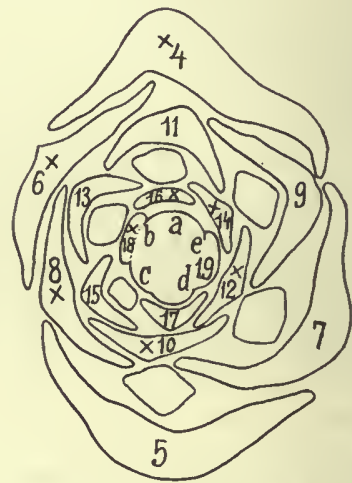

Fig. 204. (Nach MonteSANTos). Querschnitt einer Knospe von Ottelia alismoides; die geraden $(X)$ (sterilen) und die ungeraden (fertilen) Blätter in je einer Schraubenlinie angeordnet.

Es ist dies die Gattung Halophila, eine sehr merkwürdige marine Hydrocharidee ${ }^{2}$ ). Auch hier leitet sich die Blattstellung ab von einer mit gepaarten Blättern (vgl. Fig. 20j I). Aber die Blattpaare sind hier nicht wie bei Najas und Ottelia gleichsinnig, sondern jeweils in entgegengesetzter Richtung "verschoben" worden, was hier wie in den anderen Fällen schon im embryonalen Gewebe erfolgt.

In Fig. 203 ist die asymmetrische Gestalt des Vegetationspunktes von Najas deutlich zu erkennen. Wenn wir an das p. 196 für Asparagospis angeführte Verhalten denken, so ist ohne weiteres klar, daß ein solches Verhalten nicht durch eine wirkliche „Drehung“, sondern durch asymmetrische Wachstum- resp. asymmetrische Baustoffverteilung der Scheitelregion zustande kommen kann. Die Anordnungsverhältnisse im fertigen

1) So auch Mostresaxtos, Morph. und biolog. Untersuch. über einige Hydrocharideen, Flora 105 (1912) p. 1.

2) J. B. Balfour, The genus Halophila, Transactions of the botanical Society Edinburgh Vol. XIII (1879). 
Zustand sind ja auch in beiden Fällen analog, wenn wir die Kurztriebe mit den fertilen, die Langtriebe mit den sterilen Blättern von Najas vergleichen.

Hier handelte es sich um Monokotylen, deren Blätter paarweise zusammenhalten und verschiedene Eigenschaften haben. Vergleichen wir damit andere Fälle, bei denen die Blätter alle gleich sind, so zeigen die Figuren 206 für Aloë und 200 für Gasteria wie aus einer zweizeiligen Blattstellung eine mehrreihige zustande kommt. Bei den rosettenförmig angeordneten Blättern älterer Aloëpflanzen (z. B. A. arborescens) ist das Zustandekommen aus ursprünglich zweireihiger Stellung nicht mehr $\mathrm{zu}$ erkennen, bei Gasteria tritt es auch im späteren Alter meist noch deutlich hervor, offenbar tritt ontogenetisch die "Drehung" hier auf einem späteren Stadium ein, als bei Aloë.

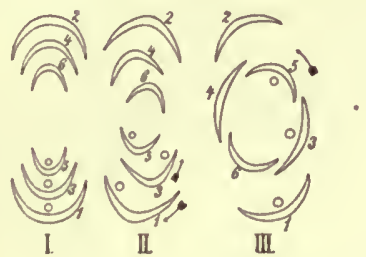

Fig. 20j. Schema $I$ einer monokotylen Pflanze mit einseitig gestellten Achselsprossen. II Halophila-Typus; Achselsprosse (und in geringerem Grade auch deren Deckblätter) jeweils nach entgegengesetzter Richtung "verschoben". III Najastypus (Gleichsinnige "Verschiebung").

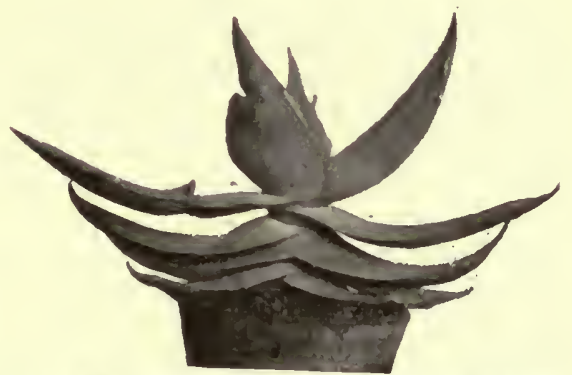

Fig. 206. Aloe striata. Die ersten Blätter der jungen Pflanze zweizeilig, dann "Drehung".

Es kann hier nicht weiter ausgeführt werden, wie diese und andere Monokotylen sich verhalten, erwähnt sei nur, daß auch ohne „Drehung“ (in dem verschiedenen oben erläuterten Sinne) manche Monokotylen ihre Blätter so (durch ,laterale Nutation") biegen, daß man von oben betrachtet den Sproß für einen spiralig beblätterten halten würde. So bei Ophiopogon muscaroïdes ${ }^{1}$, Crinum-Ârten u. a. Es gibt also verschiedene Wege um die zweizeilig angeordneten Blattflächen sich sozusagen ausweichen zu lassen.

Es dürften aber die oben angeführten Beispiele genügen, um zu zeigen, daß die genetisch-vergleichende Betrachtung auch hier eine ergiebigere ist, als die nur Divergenzen registrierende. Übrigens dürfte es sich bei derartigen Monokotylen um solche mit aphotometrischen Blättern handeln.

SchUManx ${ }^{2}$ ) glaubte die Verhältnisse bei Najas anders auffassen zu müssen. Da gerade dies Beispiel besonders deutlich die Unfruchtbarkeit der von Schumans in seinem "Blütenanschluß" und seinen "morphol. Studien" vertretenen Richtung zeigt (eine Unfruchtbarkeit, die in der Fragestellung - Kontakt! - begründet war und sich auf die allgemeinen Resultate bezieht, dankenswerte Einzeltatsachen hat der eifrige Forscher gewiß eine Menge ermittelt), so sei hier kurz darauf eingegangen. Nach Schumans soll das frühe und mächtige Auftreten des Seitensprosses bei Najas störend auf das Zustandekommen der Distichie wirken, indem für jede Neuanlage eines fertilen Blattes

1) Vgl. K. Lrssbader, Über einen Fall von sekundärer Radiärstellung der Laubblätter, Österr. botan. Zeitschrift 1905 Nr. 7 u. 8.

2) K. Schumann, Morpholog. Studien Heft I 1892 p. 174. 
das Primordium aus der Achsel des nächst älteren Blattes und das diesem entsprechende sterile Blatt als "Kontaktkörper" fungieren. Ich finde, da $\beta$ bei der von mir untersuchten Najas dies nicht zutrifft, vielmehr das fertile Blatt zunächst obne Kontakt auftritt, und zwar auf einer schwach konvexen Seite des Vegetationskegels. Die Konvexseite ist (soweit meine nicht zahlreichen Beobachtungen reichen) abwechselnd immer eine andere, sie entspricht der Reihenfolge der fertilen Blätter. Ebensowenig treffen meiner Ansicht nach SchumanN's andere Scheinerklärungen zu. Wenn er sagt, daß die Annahme einer sekundären Drehung zur Erzeugung des eigentümlichen Blattstellungsverhältnisses von Najas nicht herbeigezogen werden könne, so bestätigt er damit nur die schon durch Magnus bekannten Tatsachen. Aber er übersieht, daß es auch eine "primäre Drehung" geben kann, welche, wie mir scheint, gerade bei Najas besonders klar hervortritt, und zudem braucht ja eine spirotrophe Entwicklung, wie wir sie z. B. bei den Achselsprossen der Caryophyllaceen fanden, nicht mit einer wirklichen "Drehung " verbunden zu sein.

Bei Najas tritt die Ableitung der spirotrophen Ausbildung aus der Zweizeiligkeit besonders in folgenden Erscheinungen deutlich hervor: 1. Das sterile und fertile Blatt stehen sich unter einer Divergenz gegenüber, die zwar kleiner ist als $180^{\circ}$ aber doch bedeutend größer als die zwischen dem sterilen Blatt und dem nächsthöheren (oder -niederen) fertilen, welche fast $90^{\circ}$ betragen kann. Die "Verschiebung:" des sterilen Blattes aus der Divergenz $180^{\circ}$, erfolgt in derselben Richtung wie die (nur viel stärkere) des nächsten fertilen Blattes. 2. Die Seitensproßanlagen sind (wenigstens bei N. microdon) von Anfang an in der Richtung der spirotrophen Entwicklung "verschoben", d. h. stehen nicht genau in der Blattmediane. Dem entspricht auch, daß der sterile Seitensproß neben der Blüte in derselben Richtung liegt. 3. Das asymmetrische, spirotrophe Wachstum des Najasvegetationspunktes läßt sich, wie es scheint, direkt beobachten. 4. Die verwandten Formen sind mit distich gestalteten Blättern ausgestattet.

\section{§ 8. Biologische Bedentung der häufigsten وspiraligen“6 Blattstellungsverhältnisse an radiären Sprossen.}

Bekanntlich gibt es unter den Divergenzen eine Hauptreihe, die am öftesten $\mathrm{zu}$ beobachten ist - es ist dies die Reihe $1 / 2,1 / 3,2 / 5,3 / 8,8 / 13 \ldots$ Es handelt sich dabei übrigens überall nur um Annäherungswerte, nicht um mathematische Genauigkeit, auch kommen alle möglichen Übergänge vor. Die Frage, weshalb gerade diese Divergenzen am häufigsten auftreten, ist öfters aufgeworfen worden. Diese Frage ist von WRIGHT, C. Decandolle, Hanstein und namentlich von Wiesser ${ }^{1}$ ) dahin beantwortet worden, da $\beta$ die in die Hauptreihe fallenden Divergenzen besonders zweckmäßig seien, weil durch sie mit der kleinsten Zahl von Blättern eine möglichst gleichmäßige Verteilung der Blätter an der Achse errẹicht werde. Dies bedinge dann auch eine gleichmäßige Belastung und günstige Beleuchtung. Gewiß sind das sehr beachtenswerte Gesichtspunkte. Indes ist zu bemerken, daß z. B. ein Tannenzapfen oder ein Cycadeenblütenkolben $^{2}$ ) mit andern Divergenzzahlen ebenso zweckmäßig konstruiert wäre,

1) Vgl. Wiesser, Zur Biologie der Blattstellung, Biolog. Centralblatt Bd. XXIII (1903) daselbst weitere Literatur.

2) Man kann diese Gebilde als Abkömmlinge der vegetativen Sprosse betrachten und sagen, ihre Blattstellungsverhältnisse schließen sich denen der letzteren an. Indes dürfte damit nicht viel gewonneu sein. 
wie mit denen der Hauptreihe, daß die (sehr häufige) $1 / 2$-Stellung für orthotrope Sprosse, die keine sehr langen Internodien haben, für die Beleuchtung relativ ungiinstig ist, und $\mathrm{da} B$ die an sich relativ ungünstigeren niederen Divergenzen der Hauptreihe $(1 / 2,1 / 3,2 / 5,3 / 8,5 / 13)$ in der vegetativen Region offenbar viel verbreiteter sind, als die für die Lichtausnützung an sich günstigeren, sịch dem Grenzwert nähernden. Auch kann man den oben erwähnten Übergang von der dekussierten Blattstellung zur zerstreuten wohl kaum als eine Anpassungserscheinung betrachten, denn auch die dekussierte Stellung ist, sobald Internodien vor handen sind, eine sehr vorteilhafte.

Das Primäre sind also auch hier wohl die Gestaltungsverhältnisse am Vegetationspunkt, welche eine für die Funktion der Anhangsorgane günstige oder auch gleichgültige Anordnung bedingen, denn ungiinstige können sich ja ohnedies nicht auf die Dauer halten.

Es wird noch vieler Arbeit bedürfen, bis wir die Mannigfaltigkeit in der Blattanordnung einigermaßen kausal verstehen können. In den obigen Ausführungen ist nur kurz angedeutet, nach welchen Richtungen hin sich des Verfassers Ansicht nach zunächst die weitere Fragestellung betätigen kann.

\section{§ 9. Allgemeines über dorsirentrale Sprosse.}

1. Verschiedener Bau von Ober-und Unterseite.

Die Verschiedenheit von Riicken- und Bauchseite dorsirentraler Sprosse kann sich ebenso wie bei einem dorsiventralen Blatt oder einem Marchantiatlıallus im anatomischen Bau äußern.

Am längsten bekannt ist die Erscheinung, daß an plagiotropen Ästen von Holzpflanzen der Holzkörper vielfach auf der nach oben oder der nach unten gekehrten Seite stärker in die Dicke wächst, so daß das Mark eine excentrische Lage erhält.

Diese Erscheinung wurde von C. Schimper ${ }^{1}$ ) als Epinastie und Hyponastie bezeichnet.

Diese Ausdrücke sind später auch in anderem Sinne verwendet worden. Es erscheint deshalb zweckmäßiger, sie durch andere zu ersetzen.

Wir nennen also mit Wresner ${ }^{2}$ ) dorsiventrale Organe epitroph hypotroph oder amphitroph je nachdem die Oberseite, die Unterseite oder die Flanken in ihrer Ausbildung gefördert sind, eine Förderung, die teils in der Organbildung, teils im anatomischen Bau zutage tritt. Daß diese Förderung beruht auf stärkerer Baustoffzufuhr zu den betreffenden Partien, erscheint unzweifelhaft. Aber es ist damit noch nicht gesagt, welche Reize die Ernährungsdifferenzen bedingen.

Es werden unten einige Belege für die Annahme, daß es sich um Ernährungsdifferenzen handle, anzuführen sein. Hier sei zunächst auf Fälle hingewiesen, bei denen bei plagiotropen Sprossen eine Verschiedenheit im Bau von Licht- und Schattenseite hervortritt.

Diese kann schon eine äußerlich wahrnehmbare sein. So sind die Achsen der blattähnlichen Sprosse von Phyllanthusarten (vgl. Fig. 221, 222)

1) C. Schimper, Amtlicher Bericht der Naturforscherversammlung in Göttingen 1854.

2) J. Wiesner, Über Trophieen nebst Bemerkung iiber Anisophyllie, Ber. der deutschen botan. Gesellsch. XIII (1895). 
oben abgeflacht wie die Blattstiele, ebenso die dorsiventralen Sproßachsen von Hypnum (Hylocomium) splendens, und manche dorsiventralen Infloreszenzen.

Auch an den kriechenden Rhizomen von Nuphar luteum erkennt man (abgesehen von der Bewurzelung). die Unterseite daran, daß die Blattansätze auseinander gerückt sind, die Sprosse sind hypotroph.

Ähnlich ..(nur in weniger auffallendem Maße) verhalten sich die plagiotropen Äste mancher Coniferen (z. B. Picea excelsa, Taxus u. a.) auch die unten zu erwähnenden Sprosse von Elatostemma und Goldfussia glomerata.

Was den anatomischen Bau betrifft, so haben, wie erwähnt, einzelne Schriftsteller versucht, die Sprosse und Wurzeln nach ihrem Bau als radiär gegenüber den dorsiventralen Blättern dazustellen. Die zahlreichen Fälle hypotropher und epitropher Sprosse zeigen schon, daß diese Gegenüberstellung nicht zutrifft. Hier seien indes zunächst nicht die vegetativen Achsen besprochen, sondern Infloreszenzachsen, weil bei diesen die Verhältnisse insofern besonders klar liegen, als man hier nicht (wie etwa bei den Phyllocladien) die dorsiventrale Struktur auf die Übernahme der sonst den Blättern zukommenden Funktion zurückführen kann.

Der Querschnitt durch die Achse einer männlichen Infloreszenz von Urtica dioïca $^{1}$ ) ist auf der Oberseite abgeflacht, auf der Unterseite (der Außenseite) gewölbt. Der Parenchym ist auf der Unterseite viel stärker entwickelt, als auf der Oberseite, ebenso der Leitbündelring. Bei schwachen Infloreszenzachsen bleibt er oben offen, wie bei vielen Blattstielen, bei stärkeren kann er zwar geschlossen sein, ist aber auf der Oberseite viel weniger entwickelt, als auf der Unterseite. Die Infloreszenz ist als $\rho$ hypotroph. Ähnlich ist es bei Heliotropium indicum, wo namentlich auch das Sklerenchym auf der Unterseite stärker entwickelt ist, als auf der Oberseite. Auch der Querschnitt durch einen Infloreszenzstiel von Trifolium lupinaster (Fig. 312 III) zeigt deutlich Abflachung und Hypotrophie. An eine direkte Beeinflussung dieser dorsiventralen Struktur durch Schwerkraft und Licht ist hier nicht zu denken, die Infloreszenzen von Heliotr. indicum z. B. sind in der Jugend schneckenförmig eingerollt, die Seite, welche später nach unten sieht, ist eine Zeitlang nach oben gerichtet. Wohl aber ist überall der Zusammenhang zwischen Bau und Lage sichtbar, alle diese Infloreszenzen sind plagiotrop, nicht orthotrop.

Dies tritt auch hervor, wenn wir den Bau der Infloreszenzstiele bei Doldenpflanzen vergleichen, bei denen zahlreiche Infloreszenzstiele mehr beieinander aber in verschiedener Lage entspringen. Sehen wir uns z. B. die Dolden von Heracleum sphondylium an. Die Stiele der Einzeldolden des zusammengesetzten Blütenstandes sind von verschiedener Richtung: die inneren sind fast orthotrop, die äußeren fast horizontal, die ersteren tragen radiäre Dolden, welche auf der Außenseite stärker entwickelt sind, als auf der Innenseite, die letzteren solche; dem entspricht auch der anatomische Bau: die geneigten Stiele sind stark dorsiventral, die anderen radiär gebaut. Es tritt das schon bei Betrachtung mit bloßem Auge hervor. Die dorsiventralen Stiele sind auf der Oberseite dunkler grün, als auf der Unterseite und haben auf der ersteren Furchen, während sio unten glatt sind; diese Verschiedenheiten werden im sechsten Abschnitt zu besprechen sein.

1) Gokbel, Über die Verzweigung dorsiventraler Sprosse (SACHs, Arbeiten aus dem bot. Institut in Würzburg, herausg. von SAcHS II Bd. (1890) p. 431). Die hier gemachten Angaben sind übersehen in der Abhandlung von H. RIcose ,recherches experimentales sur la symétrie des rameaux floraux. Ann. d. Sc. nat. 8 Sér. Bot. T. 7 (1898). 
Kurz seien hier die Symmetrieverhältnisse des Dickenwachstums seitlicher Äste erwähnt. Wie namentlich aus den Untersuchungen von KNY und WIESNER hervorgeht, ist bei horizontalen Ästen der vertikale Durchmesser in der Regel größer als der horizontale. Bei einigen Pflanzen, z. B. Coniferenästen, ist das Dickenwachstum auf der Unterseite gefördert, sie sind hypotroph, bei anderen auf der Oberseite, so namentlich bei Laubhölzern, deren Äste also meist epitroph sind. Indes sind die Verhältnisse bei einer und derselben Pflanze nicht konstant, Urspruxg ${ }^{1}$ ) fand z. B. bei $18 \%$ der untersuchten Pinusäste Epitrophie. Eine kausale Erklärung der Anisotrophie der Äste ist bis jetzt nicht gelungen (man vgl. das später für die Wurzeln anzuführende), URSPRUNG hat eine teleogische Deutung versucht. Der Ast mit elliptischem Querschnitt ist biegungsfester als der runde. Die Oberseite muß zugfest, die Unterseite druckfest gebaut sein, und zwar so, daß die Zugfestigkeit der Oberseite gleich ist der Druckfestigkeit der Unterseite. Die Anisotrophie wird eintreten, wenn das Gewebe der Unterseite Druckfestigkeit hat, welche geringer ist, als die Zugfestigkeit der Oberseite. Es muß dann sozusagen mehr davon gebildet werden, der Ast wird hypotroph (und vice versa).

\section{Symmetrie und Ernährung.}

Hier ist noch anzugeben, inwieweit die oben gemachte Annahme, daß ungleiche Ernährung eine verschiedene Ausbildung hervorrufen könne, experimentell gestüzt ist. Es sind zwei Gruppen von Belegen dafür vorhanden. Die eine (A) bezieht sich auf künstliche Herstellung von Asymmetrie infolge der Unterbrechung ron Leitungsbahnen, die andere (B) auf Regenerationsvorgänge.

A) Hierzu eignen sich besonders Blätter, die normal beide Hälften gleich ausbilden, die aber asymmetrisch gemacht werden können, indem an dem noch jungen Blatte die Leitbündel auf einer Seite unterbrochen werden. Fig. 207 gibt nach den Untersuchungen GENTser's ${ }^{2}$ ) einige Beispiele dafür, wobei $\mathbf{x}$ die Stelle bezeichnet, an der der Blattstiel des jungen Blattes verletzt wurde: auf dieser Seite blieb die Blattspreite in ihrer Entwicklung zurück. Dasselbe Resultat kann man auch erhalten durch eine 'Torsion des jungen Blattstiels, wobei die Seite des Blattes (von Boehmeria platyphyllos) eine stärkere Entwicklung aufwies, welche auf der Seite des Blattstiels lag, die eine Zugspannung erfahren hatte. Ebenso läßt sich die Blattgestaltung durch Einschnitte in die Sproßachse beeinflussen. Klugia zeylanica z. B. besitzt sehr stark asymmetrische Blätter, die beiden Hälften der Blattspreite verhalten sich wie 1:3 (oder $1: 2,5)$ durch Einschnitte in die Sproßachse, auf der Seite der großen Blatthälften konnte BosHaRT das Verhältnis auf 1:1,2 oder 1:1,5 herabmindern.

Es ist dabei zu beachten, $d a ß$ es sich um rohe und verhältnismäßig spät erfolgende Eingriffe handelt. Würden diese den Vegetationspunkt ohne tiefgreifende Schädigung schon frïher treffen, so würde ohne Zweifel das Ergebnis ein noch größeres sein. Indes genügen auch die erwähnten

..) Unsprung, Untersuchungen über das exzentrische Dickenwachstum an Stämmen und Ästen, Beih. Bot. Centralblatt XIX 1905. Derselbe; Die Erklärungsversuche des exzentrischen Dickenwachstums (sic!) Biol. Centralbl. XXVI (1906). Über das exzentrische Dickenwachstum an Wurzelkrümmungen und über die Erklärungsversuche des exzentrischen Dickenwachstums Beih. zum Bot. Centralblatt 29 (1912).

$\left.{ }^{2}\right)$ G. Gentner, Untersuchungen über Anisophyllie und Blattasymmetrie, Flora Bd 99 (1909) p. 289; L. Boshart, Beitr. zur Kenntnis der Blattasymmetrie und Exotrophie, Flora 103 p. 101. 
Versuche schon um zu zeigen, daß Asymmetrie künstlich hervorgerufen und die schon vorhandene aufgehoben oder doch stark gemindert werden kann.

Auch an Blüten gelangen derartige Beeinflussungen, obwohl die Blüten wegen ihres meist zarten Baues weniger zu solchen Versuchen geeignet sind. Dagegen gelang es nicht, Vegetationspunkte radiärer Sprosse durch möglichst frühzeitige Entfernung der Blätter auf einer Seite dorsiventral zu machen.

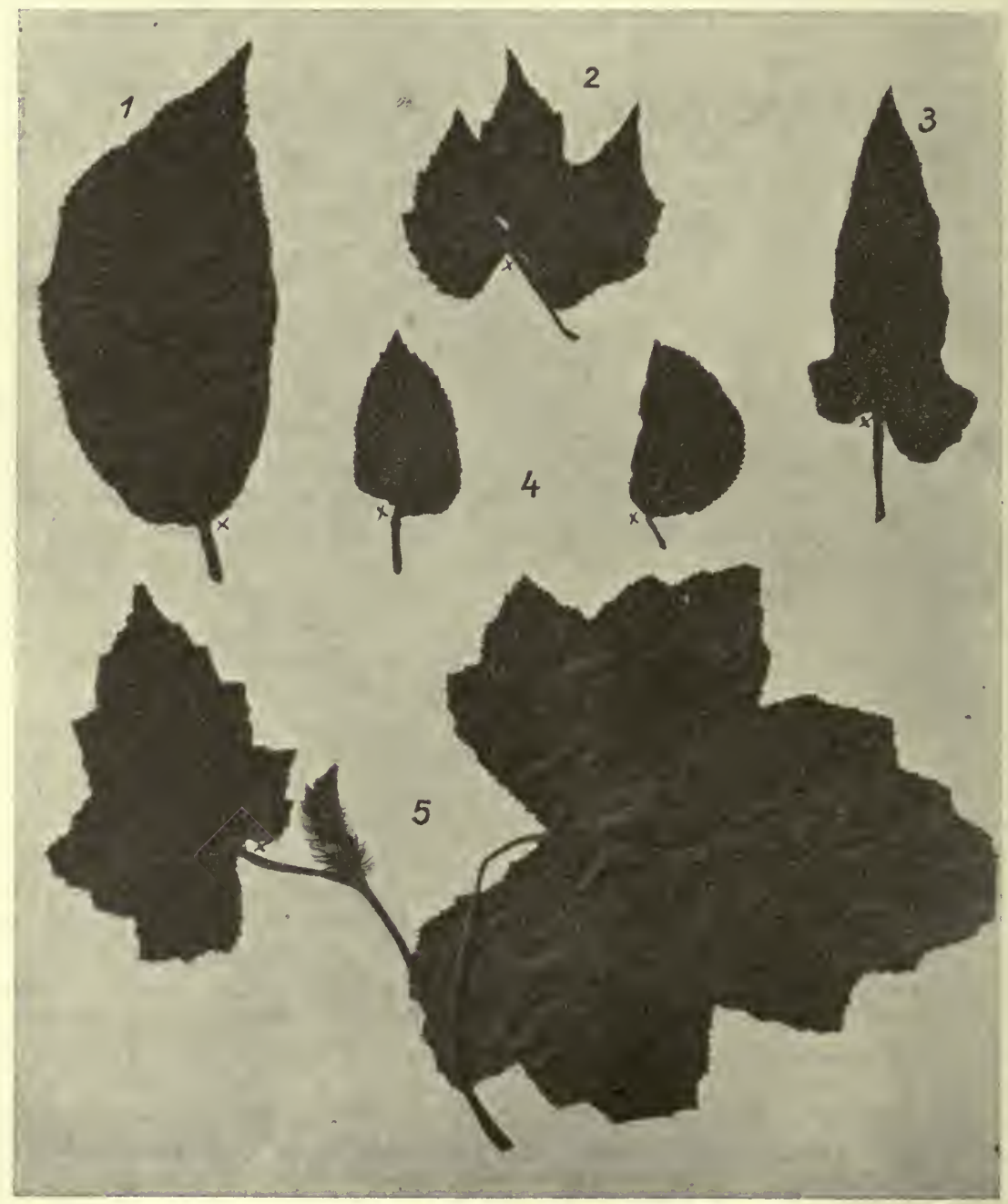

Fig. 207. (Nach GENTner) Blätter, welche künstlich durch einseitige Verletzung (bei $X$ ) asymmetrisch gemacht. 1 Boehmeria platyphyllos, 2 Vitis vinifera, 3 Rubus moluccanus, 4 Eupatorium macrophyllum, 5 Rubus alcaefolius.

B) Wenn wir einen dorsiventralen Sproß als Steckling benutzen, so sehen wir, daß die ersten Wurzeln auf der geförderten'Seite auftreten (vgl. auch p. 201), ebenso bei den ungleichhälftigen Blättern auf der der größeren Blatthälfte entsprechenden Seite. So entstanden z. B. bei 
Strobilanthus glomeratus auf der Plusseite (unterhalb eines der größeren Blätter) drei große Wurzeln, auf der Minusseite erst später sechs kleinere. Bei den Begoniaarten ist, wie unten zu schildern sein wird, 'bald die Rücken- bald die Bauchseite der Sprosse die Plusseite. In beiden Fällen entstehen an dieser zuerst die Wurzeln.

Diese Erfahrungen deuten somit darauf hin, daß es bei der Verschiedenheit zwischen Rücken- und Bauchseite dorsiventraler Sprosse Verschiedenheiten im Gehalt an Baustoffen beteiligt sind.

Die Verschiedenheit beider Seiten spricht sich auch aus in einem Verhalten des Vegetationspunktes, welches wir in den verschiedensten Abteilungen des Pflanzenreichs antreffen, nämlich in seiner starken Einkrümmung oder Einrollung, eine Eigentiimlichkeit, die zum Schutze des embryonalen Gewebes dient. Sie findet sich in derselben Weise bei den Blättern der Farne, Droseraceen usw.

Fig. 208 gibt ein Beispiel eines solchen eingerollten Vegetationspunktes einer Alge (in noch stärkerem Maße eingerollt ist der von Polyzonia junger mannoïdes); unter den Muscineen bieten Mastigobryum und Hypnum crista castrensis, unter den Gefäßkryptogamen Azolla, unter den Samenpflanzen Utricularia (die wasserbewohnenden Arten) Beispiele dafür.

Die Einrollung erfolgt in allen diesen Fällen nach der $\mathrm{O}$ b e r seite hin.

Die Organbildung ist an solchen Vegetationspunkten keineswegs, wie man nach den p. 9 angeführten Tatsachen vermuten könnte, auf der konvexen Seite des Vegetationspunktes gefördert. Z Zwar findet sich hier bei Cliftonaea ein flügelförmiger Fortsatz und bei Utricularia vulgaris

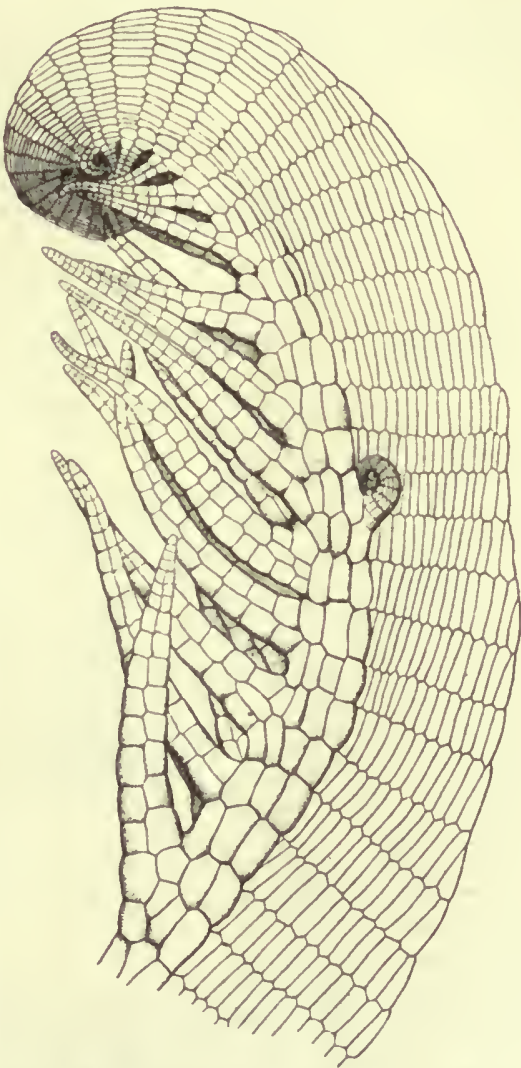

Fig. 208. Cliftonaea pectinata. Spitze eines der dorsiventralen Sprosse. sind die Schleimhaare hier früher entwickelt als auf der konkaven Seite. Aber die Kurztriebe von Cliftonaea stehen auf der Konkarseite (wo auch bei Utricularia die Luftsprosse angelegt werden) und die Blätter stehen bei letzterer auf den Flanken des Vegetationspunktes.

Bei Seitensprossen (und seitlichen Gliedern überhaupt) tritt sehr häufig eine dorsiventrale Ausbildung auf, die in bestimmter Beziehung zum Hauptsprosse steht, ohne daß es bis jetzt möglich wäre, diese Beziehung anders als rein äußerlich - räumlich - festzustellen. Fig. 209 zeigt ein einem Einzelfall nachgebildetes Schema der Verzweigung eines Sprosses von Thuya occidentalis. Es erhellt, daß jeder Seitensproß zunächst dorsiventral ist, insofern seine ersten $3-5$ Auszweigungen nur auf 
der dem Muttersproß zugekehrten Seite auftreten, später stehen sie abwechselnd an den beiden Kanten, und zwar ist bei dieser anfänglich einseitigen Stellung weder an eine Beeinflussung durch Schwerkraft, noch durch Licht zu denken.

Ganz ähnliches findet sich bei manchen Algen (vgl. z. B. Fig. 211 von Halopteris filicina ${ }^{1}$ ), die untersten Seitenäste jedes primären Astes sind der Hauptachse zugekehrt, die folgenden alternieren; ferner Fig. 213 von Euptilota (wo die äußere Seite bevorzugt ist), und vielen Blättern.

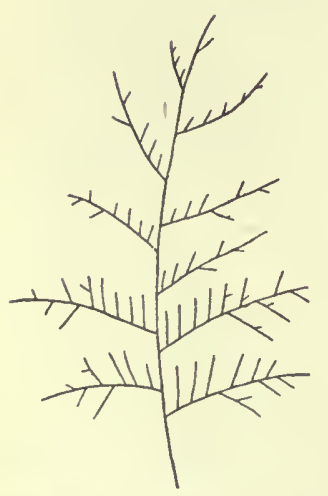

Fig. 209. Thuya occidentalis. Schema der Zweig. stellung an einem Seitensproß: die ersten Äste dritter Ordnung stehen auf der der Hauptachse zugewandten Seite der Äste zweiter Ordnung.

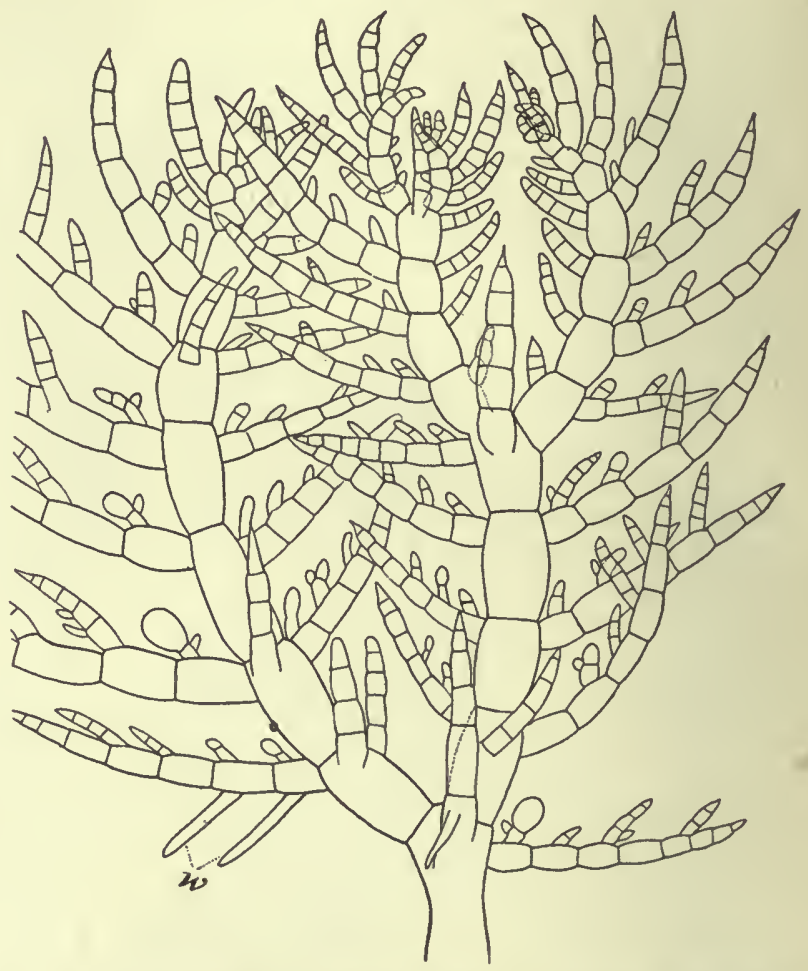

Fig. 210. Antithamnion (Pterothamnion) Plumula. Thallusstück, stark vergr. (Erklärung im Text.) Die kleinen, eigentümliche Inhaltskörper einschließenden Zellchen sind absichtlich weggelassen. $w$ Rhizoiden.

Ein Nutzen dieser Stellung ist insofern vorhanden, als bei Entwicklung der Zweige auf beiden Seiten eine Deckung und somit eine Beeinträchtigung ihrer Funktion stattfinden würde; über das ursprüngliche Zustandekommen ist damit aber noch nichts ausgesagt.

Besonders auffallend ist der in Fig. 210 abgebildete Fall von Anti-

1) Bei Stypocaulon fand Geycer (Zur Kenntnis der Sphacelarien. Jahrbücher für wissensch. Botanik IV, 2) bei den Ästen erster Ordnung den ersten Ast zweiter Ordnung in 44 Fällen $8 \mathrm{mal}$ nach außen, $36 \mathrm{mal}$ nach innen gerichtet, so daß hier zwar eine bedeutende Bevorzngung der inneren Seite, aber keine absolute Konstanz.in der Stellung des ersten Astes ersichtlich ist. - Vgl. auch Berthold, Beitr. zur Morphologie und Physiologie der Meeresalgen. Jahrb. für wissensch. Botanik XIII. 
thamnion Plumula. Wir sehen hier Langtriebe und Kurztriebe; die Kurztriebe stehen einerseits in der Ebene des Papiers (und diese bilden das eigentliche Gerüst der Pflanze), andererseits auch oben und unten. Die letzteren sind aber in viel geringerer Anzahl vorhanden und dienen, wie es scheint, nur noch zum Schutze der jugendlichen Teile, da sie namentlich an der Stelle sich finden, wo ein seitlicher Langtrieb sich bildet. Die Langtriebe zeigen nun zunächst, daß die Auszweigungen auf der Außenseite gefördert sind, auf den Innenseiten dagegen zurückbleiben, während jeder Kurztrieb nur auf der der Hauptachse zugekehrten Seite Auszweigungen herrorbringt. Auch die in Fig. 213 abgebildete Alge zeigt an dem Langtrieb unten rechts deutlich eine Förderung der Außenseite.

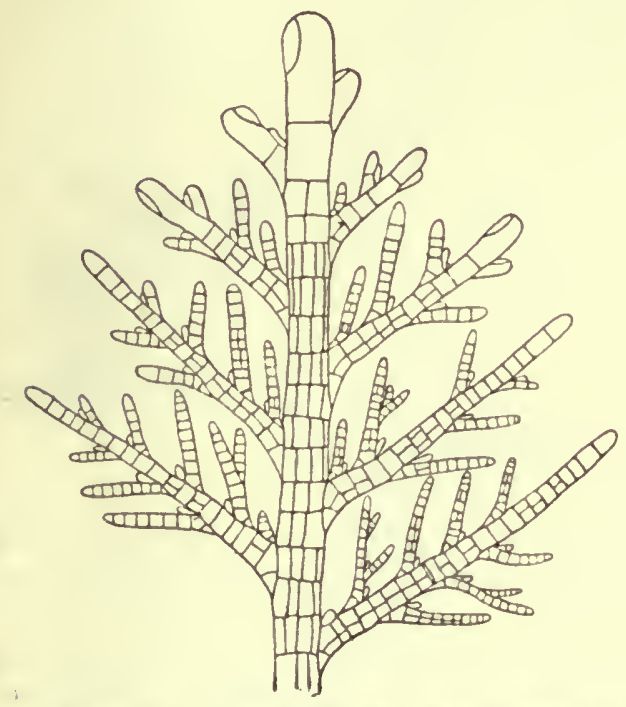

Fig. 211. Spitze eines Langtriebes von Halopteris filicina. Vergr.

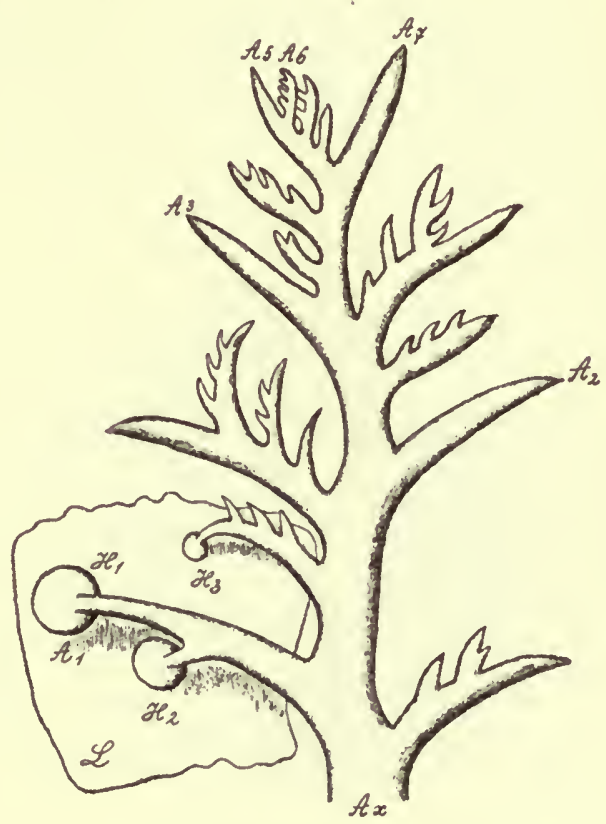

Fig. 212.

Fig. 212. Plocamium coccineum (vergr.). Die Seitenäste stehen immer nur auf einer Seite, der Wuchs ist sympodial. Bei $H_{1}, H_{2}, H_{3}$ Haftscheiben, mittelst deren die Pflanze sich an einer anderen Alge $(L)$ festgeheftet hat.

Diese können wir als (mit WIESNER) „Exotrophie“ bezeichnen, weil die Außenseite gefördert ist. Es wird eine Aufgabe der Zukunft sein, diese Erscheinung unserem Verständnis kausal näher zu bringen. Einstweilen kann nur auf ihre weite Verbreitung in verschiedenen Gruppen des Pflanzenreichs und auf die Ausführungen im VI. Abschnitt hingewiesen werden.

Im folgenden sollen die wichtigeren Formen dorsiventraler Ausbildung besprochen werden. Eine strenge Trennung nach Kategorien ist kaum durchführbar, die folgende Einteilung soll also lediglich von äußerlicher Bedeutung sein.

1. Kriechende und kletternde Sprosse;

2. dorsiventrale Seitensprosse;

3. Anisophyllie. 
Die letztere Gruppe wird nur wegen ihrer weiten Verbreitung getrennt behandelt, denn Anisophyllie findet sich einerseits bei dorsiventralen Zweigen, andererseits auch bei kriechenden und kletternden Hauptsprossen. Eine andere Eigentümlichkeit mancher dorsiventraler Sprosse, das Auftreten asymmetrischer Blätter, wird bei Besprechung der Symmetrieverhältnisse der Blätter zı behandeln sein.

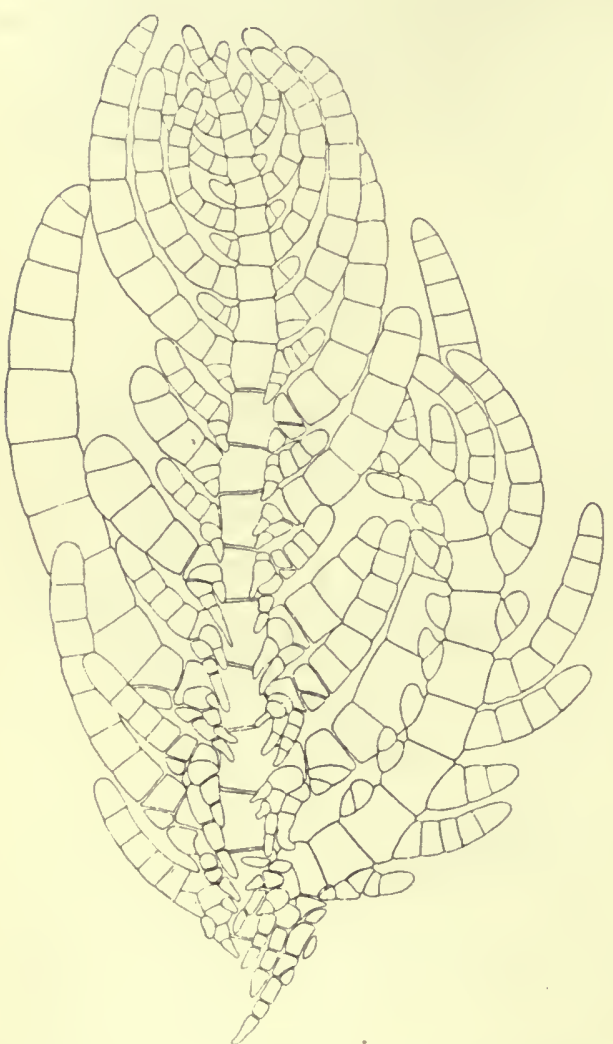

Fig. 213.

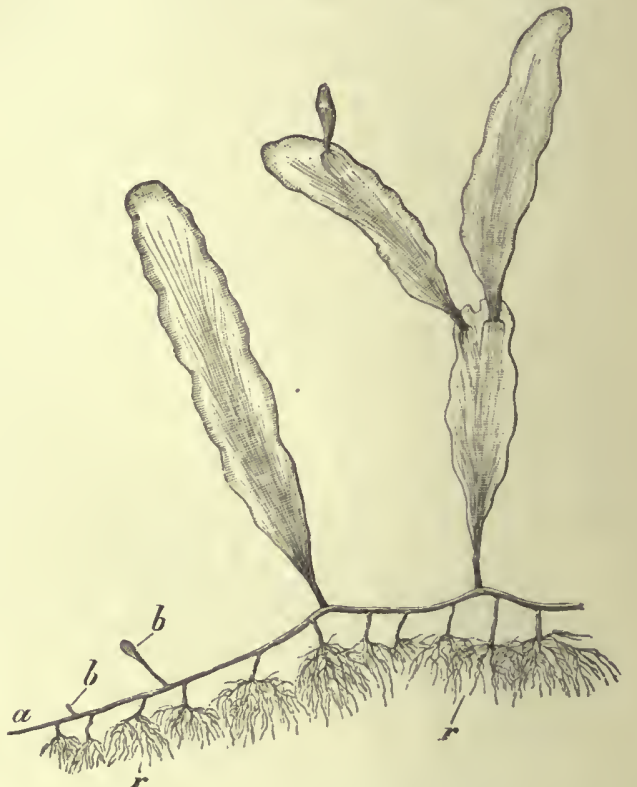

Fig. 214. Caulerpa prolifera. Habitusbild. Die kriechende Sproßachse $(a)$ trägt oben die Blätter (b), unten die Wurzeln $(r)$. Lehrb.

Fig. 213. Euptilota Harveyi nach Cramer. Spitze eines Langtriebes. An jedem Gliede stehen zwei (ungleich große) Kurztriebe. Unten rechts hat sich ein Langtrieb entwickelt, dessen Seitenäste auf der der Hauptachse zugewendeten Seite im Wachstum zurückbleiben.

\section{$\S 10$. Kletternde und kriechende Sprosse.}

Die Dorsiventralität äußert sich zunächst darin, daß die Wurzeln sich auf der Bauchseite (der dem Lichte abgekehrten) finden, wie dies schon an einem Lebermoosthallus oder einem Farnprothallium deutlich hervortritt und ebenso bei vielen höheren Pflanzen. Die Beziehung dieser Erscheinung zum Lichte wird später zu erörtern sein. Hier sei nur erwähnt, daß manche in der Erde kriechenden Rhizome wie z. B. die von Polygonatum, Majanthenum bifolium u. a. Wurzeln auch auf der Oberseite haben, wahrscheinlich werden diese auch in ihrer Wachstumsrichtung durch die Schwerkraft nicht beeinflußt, sie erreichen keine bedeutende Länge und werden später durch andere weiter nach der Rhizomspitze zu entstandene ersetzt.

Eine zweite Stufe spricht sich darin aus, daß bei dorsiventralen 
Sprossen die „Tendenz" herrscht, die Blätter auf die Oberseite zu rücken, während die Seitensprosse auf den Flanken bleiben. Dies tritt in merkwürdiger Übereinstimmung bei Pflanzen der rerschiedensten Verwandtschaftskreise auf. Wie so oft können wir auch hier zwei Fälle unterscheiden: entweder es erfolgt diese Organstellung wirklich im Verlauf der Einzelentwicklung, oder sie geschieht schon von vornherein am Vegetationspunkt.

Für den ersten Fall seien zwei Beispiele ron Sprossen mit zweizeiliger Blattstellung angeführt.

Monstera deliciosa (eine Aroïdee) besitzt kletternde Sprosse. Die Blätter werden (hauptsächlich durch Torsion der Sproßinternodien) so nach der Ruickenseite hingeschoben, daß sie oft scheinbar nur eine Blattzeile bilden.

Ähnlich ist es bei den kriechenden Sprossen von Acorus und Butomus. Der von Butomus umbellatus hat eine aufrechte Endknospe, in welcher die Blätter zweizeilig, die Anlagen der Seitenknospen vor der Blattmitte stehen. Am niederliegenden Teile des Rhizomes aber stehen die Blätter auf der Rückenseite in zwei einander sehr genäherten Reihen, die Bauchseite

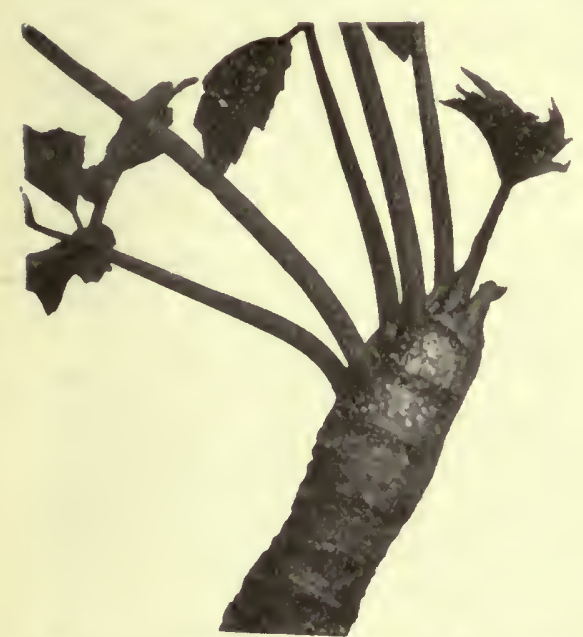

Fig. 215. Begonia caroliniaefolia. Oberer Teil des dorsiventralen Rhizoms von der Seite. Man sieht, daß die beiden Blattreihen nach oben hin konvergieren. (Verkl.) Die Seitensprosse stehen hier in den Blattachsen (also nit auf der Oberseite).

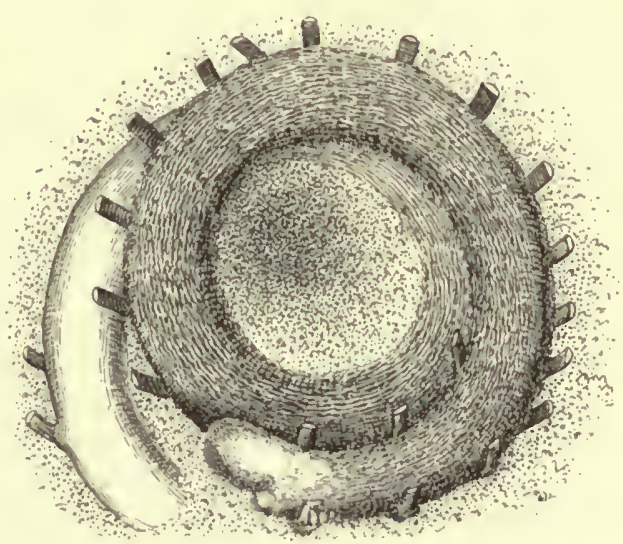

Fig. 216. Polypodium Heracleum. Stamm einer auf Erde kultivierten Pflanze, stark verkleinert. Die Blätter stehen in einer Reihe, sie sind abgeschnitten. Man sieht, daß der Stamm auf seiner Außenseite stärker wächst und sich deshalb spiralig ,einrollt.

scheint von Blattinsertionen fast ganz entblößt, sie trägt nur Wurzeln, und die Seitenknospen stehen am unteren Blattende auf den Flanken. Ganz ähnlich ist die Organstellung in der zweiten Kategorie von Fällen. Die Siphonee Caulerpa prolifera (Fig. 214) besitzt einen kriechenden Stamm, der auf seiner Unterseite Wurzeln, auf seinen Flanken Zweige, auf seiner Rückenseite Blätter trägt. Ebenso verhält sich die Floridee Herposiphonia, bei welcher auf der Rückenseite zwei Reihen Blätter, auf den Flanken Seitensprosse, auf der Bauchseite Wurzeln stehen; damit vollständig übereinstimmend sind die Stellungsverhältnisse bei den kriechenden Stämmen der Farne Marsilia und Pilularia und manchen Begoniaarten, so zeigt Fig. 215 sehr deutlich, wie die beiden Blattreihen der hypotrophen Sproßachse nach oben hin zusammengeschoben erscheinen. 
Andere kriechende Farnstämme, wie die von Lygodium palmatum, Polypodium Heracleum (Fig. 216), P. quercifolium ${ }^{1}$ ), haben die rückenständigen Blattzeilen so genähert, daß sie wie eine einzige aussehen, während bei Polypod. taeniosum auf der Rückenseite allein die in Parastichen geordneten Blätter dicht gedrängt stehen.

Die von KLEIN untersuchten Keimpflanzen von Polyp. Heracleum zeigten zweizeilige Blattstellung (mit einer Divergenz der Blattzeilen von etwa $45^{\circ}$ auf der Rückenseite), so daß also an ihnen die Dorsiventralität weniger scharf ausgeprägt ist als an den älteren Pflanzen, welche einzeilige oder nahezu einzeilige Blattstellung haben. Bei allen diesen Farnen ist die Dorsiventralität schon im Vegetationspunkt bestimmt, be. ruht also nicht auf nachträglicher Verschiebung.

Die Stämme von Polypodium Heracleum wachsen auf Baumstämmen so, daß die Unterseite der Baumrinde angeschmiegt ist. Sie haben dabei noch die merkwürdige Eigenschaft, daß sie auf der blattragenden Außenseite stärker wachsen, als auf der Innenseite. Kultiviert man sie auf dem Boden, so wachsen sie in eigentümlicher Weise eingerollt. Als Epiphyt umwächst der Farn Baumstämme meist in einer wenig steilen Schraubenlinie und kann so mit den dicht gestellten Blättern große Mengen von Humus sammeln ${ }^{2}$ ). Ob dabei irgendeine Art von geotropischer Reaktion mit im Spiele ist, ist fraglich. Sollte negativer Geotropismus vorhanden sein, so würde er jedenfalls nicht genügen, um beim Wachsen auf der Erde die Rhizomspitze über den Boden zu erheben. Wahrscheinlich ist die epitrophe Sproßachse aber ageotropisch.

Die Seitensprosse dieser Farne stehen den Flanken genähert.

Auch die dem Substrat angeschmiegten Podostemaceen zeigen vielfach dorsiventrale Ausbildung ${ }^{3}$ ), und andere Beispiele werden sonst noch gelegentlich im Verlaufe der Darstellung zu erwähnen sein (z. B. das von Nuphar luteum oben Angeführte). Indes genügen die erwähnten Tatsachen, um zu zeigen, wieweit verbreitet dorsiventrale Ausbildung bei kriechenden resp. kletternden Sprossen von Pflanzen aus den verschiedensten Verwandtschaftskreisen ist. Daß das erörterte Stellungsverhältnis dasjenige ist, welches als das vorteilhafteste zu bezeichnen ist, ist klar. Die Blätter werden am einfachsten, ohne Drehungen usw., an das Licht gelangen, wenn sie der Oberseite der kriechenden oder kletternden Sprosse genähert sind, für die Wurzeln ist die Stellung auf der Unterseite die beste, und da die sämtlichen Sprosse dem Substrat ausgedriickt sind, ist auch die Flankenstellung der Z weige teleologisch ohne weiteres verständlich.

Manche kriechenden und kletternden Sproßachsen zeigen eine mehr oder minder große Abflachung. Deren Ursachen sind meist nicht untersucht; in manchen Fällen erfolgt sie autonom, in anderen ist vielleicht das Licht dabei beteiligt; es sei besonders auf die unten anzuführenden Beispiele hingewiesen, wo bei $\mathrm{W}$ urzeln eine Abflachung unter dem Einfluß des Lichtes erfolgt, und dadurch dorsiventrale Struktur bedingt wird.

Wenn die Abflachung nicht eine erbliche ist, erfolgt sie bei Sproßachsen und Wurzeln auf der dem Substrate anliegenden Seite offenbar dadurch, daß die betreffenden Teile schon in jugendlichem plastischem Zustande sich dem Substrate anlegen (sei es infolge ron negativem Helio-

1) L. KLEIN, Bau und Verzweigung einiger dorsiventral gebauter Polypodiaceen. Nova acta Leop.-Carol. XLII (1881).

$\left.{ }^{2}\right)$ GozBri, Über epiphytische Farne und Muscineen, Annales du jardin botanique de Buitenzorg VII (1889).

$\left.{ }^{3}\right) \mathrm{Vgl}$. darüber die Angaben von Warming und siehe S. II p. $331 \mathrm{ff}$. 
tropismus oder von anderen Ursachen). Es wurde auf diese Erscheinung bei manchen Orchideenluftwurzeln hingewiesen ${ }^{1}$ ); sie ist aber auch z. B. bei Farnstämmen vielleicht vorhanden. So bei Acrostichum scandens (wo aber auch die Lichtseite abgeflacht ist, Fig. 217); vielleicht ist aber auch hier wie bei dem mit flach krustenförmigen Sproßachsen ausgerüsteten Polypodium Schomburgkianum (Fig. 217, II), die Abflachung eine autonome. Die krustenförmigen Sproßachsen bieten hier den Wurzeln Schutz.

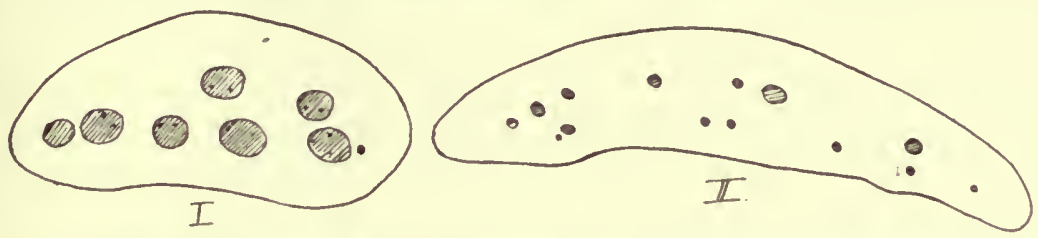

Pig. 217. Querschnitte zweier flacher, dorsiventraler, auf Baumrinden kriechender Farnstämme. I Acrostichum scandens. II Polypodium Schomburgkianum.

\section{$\S 11$. Dorsiventrale Ausbildung der Seitensprosse.}

Wenn an einem orthotropen radiüren Hauptsproß sich Seitensprosse ausbilden, so erlangen diese sehr häufig statt der radiären eine dorsiventrale Ausbildung. Es kann dies in sehr verschiedenem Grade und auf verschiedenem Wege erfolgen. Der Vorgang läßt sich unter folgende Gesichtspunkte bringen:

1. Veränderung der Stellung der Blätter; diese erfolgt

a) durch Anderung der Blattinsertion,

b) durch Drehung der Internodien oder der Blattbasis,

c) von vornherein im Vegetationspunkt;

2. verschiedene Ausbildung der Blätter auf Ober- und Unterseite des Sprosses (Anisophyllie) (läufig mit den unter 1. angeführten Vorgängen zusammen vorkommend);

3. Ausbildung der Seitenzweige nur oder doch vorzugsweise auf den Flanken der Sprosse (Amphitrophie).

Es genïgt, einige Beispiele anzufülıren.

1.a. Die sämtlichen Sprosse unserer Eichenarten ${ }^{2}$ ) (Quercus pedunculata und Qu. sessiliflora) sind radiär nach $2 / 5$ beblättert; die Seitensprosse sind dorsiventral, die Insertion der Blätter nämlich ist bei ihnen nicht quer, sondern geneigt zur Längsachse des Sprosses, ähnlich, nur nicht so stark wie bei den zweizeiligen Sprossen ron Tilia, Fagus usw. (Fig. 218). Betrachtet man einen Zweig von oben, so steht an den Blättern auf der linken Seite der linke, auf denen der rechten der rechte Rand tiefer als der andere. Blätter, die genau oben inseriert sind, zeigen vielfach quere Einfügung (der Grad der schiefen Einfügung variiert übrigens auch bei den Seitenblättern sehr). Diese oberen Blätter sind auch mit fast gleichen Blatthälften versehen, während die anderen verschieden ausgebildete Blatthälften haben; auch die unten näher zu besprechende Erscheinung der Anisophyllie ist bei den Seitensprossen der Eiche schon bemerkbar, die also von vollständig radiärer Anlage im Verlaufe der Entwicklung zur (freilich nicht stark hervortretenden) dorsiventralen Ausbildung übergehen.

2) Vgl. Möhl, Unters. über die Eiche; Wigand, Der Baum p. 45. 
1b. Bei Seitensprossen werden vielfach die Blattinsertionen in eine (annähernd horizontale) Ebene gebracht durch Internodiendrehung. Sämtliche Blattoberseiten sind dabei dem Lichte zugekehrt. So besonders auffallend bei Sträuchern, deren Blätter in zweizähligen gekreuzten Quirlen stehen (Arten von Lonicera, Philadelphus, Deutzia), aber auch bei solchen mit zerstreuter Blattstellung z. B. Spiraeaarten. Es wurde schon p. 199 darauf hingewiesen, daß, wenn sonst orthotrope Sprosse bei schwacher einseitiger Beleuchtung plagiotrop werden. sie dieselbe Erscheinung aufweisen, d. h. also durch Drehung der Internodien eine Blattfläche rechtwinklig zum Lichteinfall herstellen; dies zeigt Gentiana asclepiadea, wenn sie an Waldrändern wächst, besonders deutlich; aber auch bei vielen anderen Pflanzen läßt sich dieselbe Erscheinung beobachten. Daß in anderen Fällen die Drehung, welche die Blattflächen annähernd in eine Ebene bringt, durch die Blattbasen selbst ausgeführt wird (wie bei der „Scheitelung" der Tannennadeln), ist für das schließliche Resultat ohne Bedeutung.

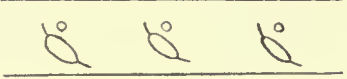

Fig. 218. Schema der Blattund Seitensproßinsertion an dorsiventralen Zweigen von Tilia, Fagus etc.

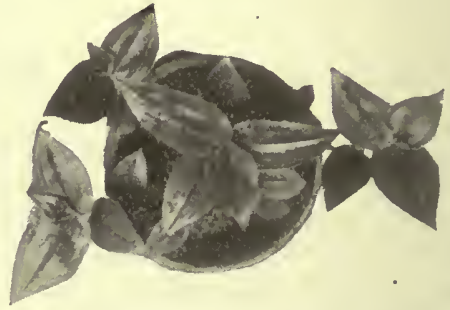

Fig. 219. Keimpflanze von Tradescantia geniculata ron oben (rerkl.). Die Hauptachse mehrzeilig, die Seitenachsen nach $1 / 2$ beblättert.

Bei den Nadelhölzern, welche diese mit der Nichtausbildung von Internodien im Zusammenhang stehende Erscheinung zeigen, tritt mit besonderer Deutlichkeit auch in der Verzweigung der amphitrophe Charakter der Seitensprosse hervor. Die Zweige höherer Ordnung entspringen ausschließlich oder doch vorzugsweise den Flanken der Seitensprosse, und dadurch kommen die flachen Verzweigungssysteme zustande, wie jedermann sie von den Ästen der Araucaria excelsa (Fig. 34), Abies pectinata u. a. kennt. Obwohl die Beeinflussung der Gestaltung durch äußere Faktoren erst in einem anderen Kapitel zu besprechen sein wird, so möchte ich hier doch auf den lehrreichen Unterschied in dem Verhalten der Fichte und der Tanne hinweisen. Bei der Tanne werden die Seitenknospen an den horizontalen Ästen alle von vornherein nur auf den Flanken angelegt (gelegentlich treten bei A. pectinata und anderen Abiesarten solche auch auf der Zweig unterseite auf). Bei der Fichte zeigen bei kräftigen, frei stehenden, also allseitig beleuchteten Exemplaren die oberen Seitensprosse des Hauptstammes eine radiäre Anordnung der Zweige, die unteren nur die flankenständigen und teilweise die auf der Außenseite entwickelt. Daß dies durch Verkümmerung der beschatteten (auf der Zweigoberseite entstandenen) Zweige geschehen ist, zeigt die Tatsache, daß, soweit ich gesehen habe, bei im Schluß stehenden Fichten auch an den ob e r en Seitenzweigen nur flankenständige Verzweigung eintritt. Auch hier also sehen wir wieder, daß bei der einen Pflanze (der Fichte) durch äußere Einflüsse ein Gestaltungs- 
verhältnis zustande kommt, das bei anderen von vornherein vorhanden, erblich ist.

Vielfach ist zu beobachten, daß die Seitensprosse bei zerstreuter Blattstellung weniger zahlreiche Blattreihen tragen, als die Hauptsprosse, was mit der verschiedenen Kräftigkeit der beiderlei Vegetationspunkte zusammenhängt.

Das bildet einen Übergang zu der Erscheinung, daß am Vegetationspunkt der Seitensprosse von vornherein eine andere Blattanordnung auftritt als am Hauptsproß.

Ehe auf Einzelbeispiele eingegangen wird, sei nur herrorgehoben, daß bei Seitensprossen zweierlei in Betracht kommt: einerseits ihre plagiotrope Stellung, andererseits ihre unter dem Einfluß des Hauptsprosses und ihrer Lage zum Erdradius erfolgende schwächere Ausbildung überhaupt, die an und für sich schon, ganz abgesehen von der Dorsiventralität, zu einer Verminderung der Blattzeilen führen kann. Es tritt dies deutlich hervor z. B. bei vielen Coniferen. Ein besonders auffallendes Beispiel zeigen auch die als "Brutknospen" ausgebildeten Seitensprosse von Lycopodium Selago, wenn wir die Blattanordnung mit der an den Hauptsprossen vorhandenen vergleichen (Fig. 72).

Von hier aus ist dann nur noch ein Schritt zu dem Verhalten, bei welchem die Seitensprosse nur zwei Blattreihen zeigen (die, ihre Oberseiten nach oben kehrend, für den Lichteinfall besonders geeignet sind), die Hauptsprosse dagegen eine größere Anzahl.

Von hierher gehörigen Beispielen seien genannt: bei Castanea vesca stehen die Blätter an den Keimsprossen (der Hauptachse) und kräftigen Stockausschlägen nach $2 / 5$, bei den Seitensprossen nach $1 / 2$. Bei den Keim pflanzen von Corylus Avellana nach $1 / \mathrm{s}$, schon die Seitenknospen dieser Achsen zeigen zweizeilig angeordnete Blattstellung. Kräftige Triebe der Haselnuß (wie sie an der Basis der Sträucher sich nicht selten bilden) werden orthotrop und zeigen dann radiäre Blattstellung (nach $1 / 3$ ).

Arten einer und derselben Gattung können sich übrigens verschieden verhalten. Bei unseren einheimischen Birken sind alle Sprosse mit spiralig gestellten Blättern besetzt, bei Betula lenta und B. nigra dagegen nur der orthotrope Hauptsproß, die Seitensprosse sind zweizeilig beblättert; ebenso verhält sich Alnus viridis. (Über Alnus glauca vgl. Hofmerster, Allg. Morph. S. 609 u. 610). Analoge Fälle von sukkulenten Pflanzen hat Verf. anderwärts besprochen ${ }^{1}$ ).

Daß auch bei krautartigen Pflanzen dasselbe vorkommt zeigen namentlich einige Commelynaceen. So zeigt z. B. Fig. 219 eine junge Pflanze von 'Tradescantia geniculata, der Hauptsproß ist "spiralig", die Seitensprosse sind zweizeilig beblättert. Die radiäre Hauptachse (die bei anderen Commelynaceen, z. B. Campbellia zanonia stark entwickelt ist) ist hier aber auf das Keimlingsstadium beschränkt; ein solcher Sproß tritt bei dieser Art im späteren Leben nur selten noch auf und ist bei den meisten Tradescantiaarten rollständig — auch bei den Keimpflanzen verschwwunden ${ }^{2}$ ).

Ähnlich verhalten sich auch die Bäume, welche wie Carpinus, UTlmus, Tilia u. a., späterhin nur noch aus zweizeilig beblätterten Seitensprossen bestehen.

1) GozBes, Einleitung in die experimentelle Morphologie.

2) Nach der p. 208 für die Blattanordnung bei den Monokotylen vertretenen Anschauung wären diese Pflanzen nachträglich wieder zur 1/2 Stellung (durch Ausfall der mehrreihig beblätterten Sprosse) zurückgekehrt.

Goebel, Organographie der Pflanzen. 2. Aufl. Allgem. Teil. 
Wenn man das Verhalten einer Anzahl verwandter Pflanzen vergleicht, so liegt es nahe, die radiäre Blattstellung bei ihnen als die primäre, die zweizeilige als die unter dem Einfluß der seitlichen Stellung bei manchen Pflanzen zustande gekommene zu betrachten; sehen wir doch innerhalb einer und derselben Gattung (Betula) die Seitenäste bei den einen Arten zweizeilig, bei anderen radiär beblättert, und in der Gattung Corylus läßt sich gleichfalls eine Steigerung wahrnehmen, wenn wir Corylus Colurna mit radiärem orthotropem Hauptstamm vergleichen mit Cor. Avellana, wo die zweizeiligen plagiotropen Sprosse überwiegen. Das Extrem bilden dann, wie schon erwähnt, Formen, bei denen die radiäre Ausbildung auf den Keimsproß beschränkt ist, alle anderen aber ausgeprägt dorsiventralen Charakter zeigen. Dieser tritt bei Corylus, Carpinus, Fagus, Ulmus, Tilia ${ }^{1}$ ) hervor, auch in der Stellung der Blätter und Seitenknospen. Die beiden Blattreihen stehen einander nicht gegenüber, sondern sind (bei Tilia) auf der Unterseite der Sproßachse einander genähert. Die Blattinsertionen verlaufen ferner nicht quer zur Längsachse der Sprosse, sondern schief (Fig. 218), und zwar so, daß dadurch die Blattoberseite schon schief nach oben gerichtet ist, so daß es nur noch einer Drehung von etwa $45^{\circ}$ an der Blattstielbasis bedarf, um die Blattfläche horizontal (resp. parallel der Längsachse des Zweiges) zu stellen.

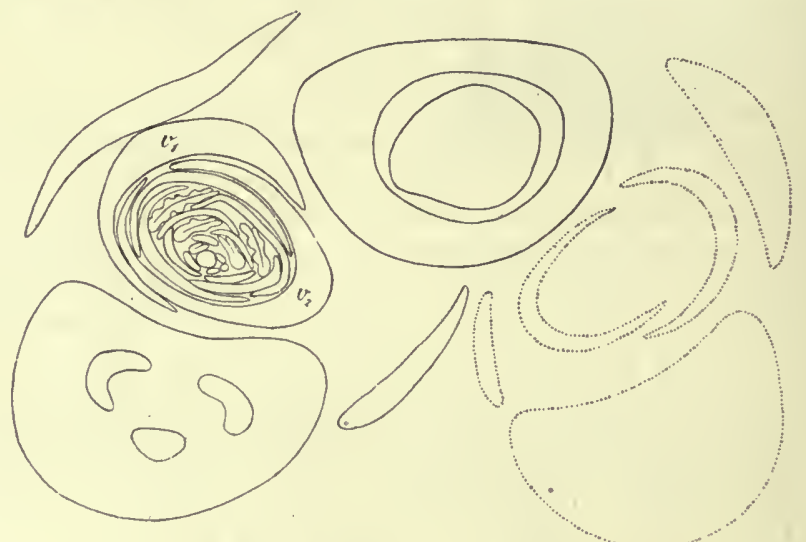

Fig. 220. Querschnitt durch eine Sproßachse von Tilia parvifolia. Links ein Blatt mit Achselsproß getroffen, $v_{1}, v_{2}$ dessen Vorblätter; rechts (punktiert) der Qnerschnitt eines weiteren Blattes mit Achselsproß angedeutet. Die Blätter konvergieren aber nicht so stark, wie dies hier in übertriebener Weise angenommen worden ist.

Die Seitenknospen aber sind nicht vor der Blattmitte, sondern oberhalb dieser, dem oberen Nebenblatt des Tragblattes genähert, eingefügt, ganz wie bei so vielen anderen dorsiventralen Sprossen.

Nicht selten nehmen die Seitensprosse blattähnlichen Habitus an und stimmen mit den Blättern namentlich aucl darin überein, daß sie begrenztes

1) Auch Aristolochia Clematitis führt Hofmeister (a. a. 0. p. 609) unter den Pflanzen an, bei denen die Blätter lotrecht wachsender Achsen nach der Divergenz $2 / 5$, an den von der Vertikale abgelenkten Sprossen aber zweizeilig angeordnet sind. Ich kenne die Keimpflanzen von Ar. Clematitis nicht. Bei den adventiv an den Wurzeln entstebenden orthotropen Sprossen aber finde ich von Anfang an die Blattstellung 1/2. Dasselbe war der Fall bei den von mir nntersuchten Keimpflanzen von Ampelopsis und Vitis vinifera, während nach anderen Angaben die Keimsprosse der letzteren spiralig (meist nach $2 / 5$ beblättert) sind. Offenbar kommen hier also Verschiedenheiten ror. 
Wachstum besitzen und wie Blätter von der Hauptachse abgegliedert werden. Sehen wir $a b$ von den im speziellen Teile zu besprechenden Phyllocladien, so ist hier als Beispiel anzuführen das Verhalten einiger Phyllanthusarten ${ }^{1}$ ). Wie die in Fig. 221 gebildete Art, $\mathrm{Ph}$. mimosoides zeigt, sind hier scheinbar doppelt gefiederte Blätter vorhanden, ähnlich wie bei manchen Leguminosen, worauf auch die Artbenennung (ebenso bei Phyll. lathyroides u. a.) hindeutet. In Wirklichkeit haben wir aber

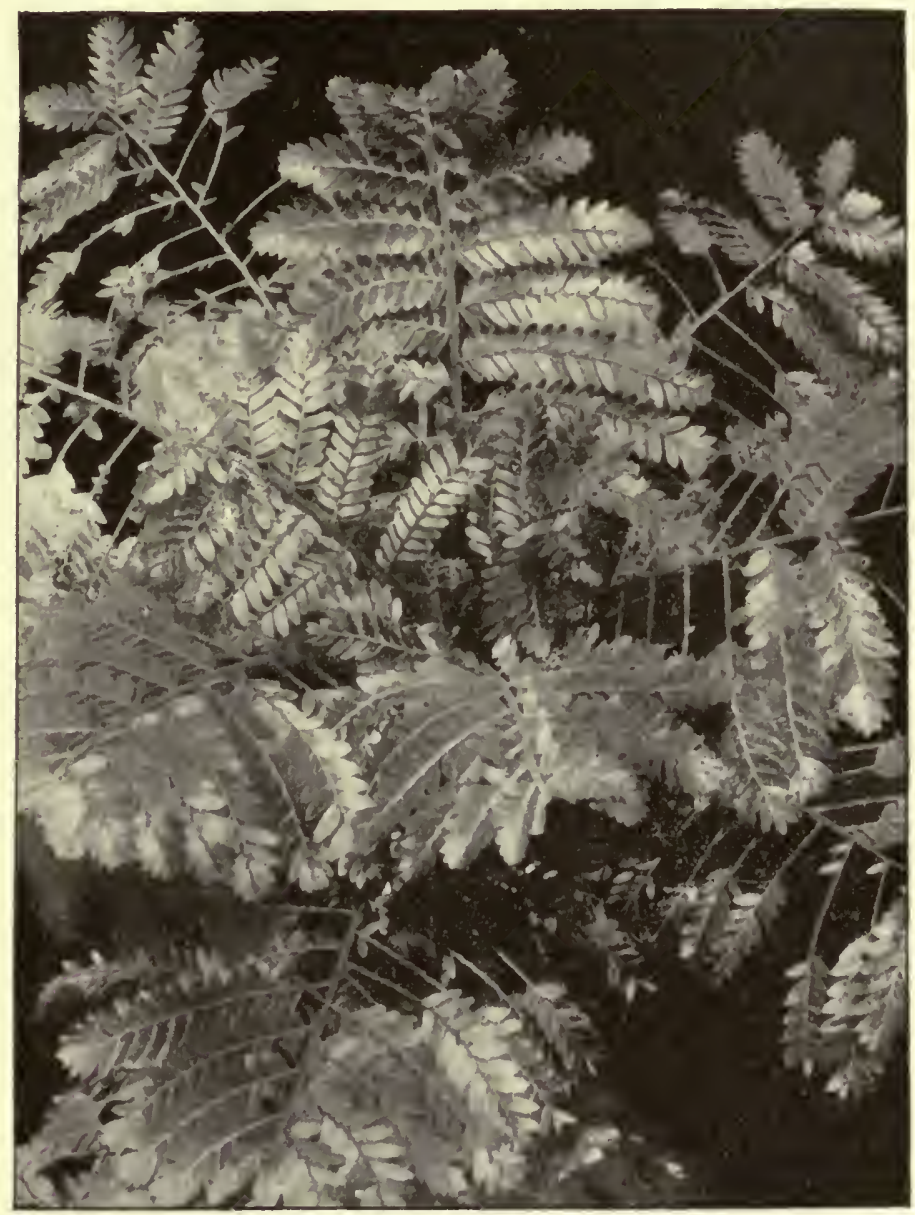

Fig. 221. Gipfel einer Pflanze von Phyllanthus mimosoides, schief ron oben gesehen. Die radiäre Hauptachse der Pflanze ist scheinbar besetzt mit doppelt gefiederten Blättern. In Wirklichkeit sind diese zweizeilig verzweigte, blattähnliche Sproßsysteme; die Blätter sind einfach.

(ebenso wie bei Flüggea microcarpa Fig. 222) Zweige mit zweizeilig gestellten Blättern vor uns, wie schon die Tatsache zeigt, da $\beta$ an ihnen die Blïten stehen. Die Hauptachse und die stärkeren Seitenachsen sind

1) Vgl. Dingler, Die Flachsprosse der Phanerogamen. I. Heft: Phyllanthus. München 1885. 
spiralig beblättert, tragen aber keine Laubblätter, sondern nur Schuppen, in deren Achseln dann die Seitensprosse stehen, deren Spitzen das Wachstum einstellen und vertrocknen. Hier wie in anderen Fällen ist die Verschiedenheit von Haupt- und Seitensprossen teils eine - wenigstens nach unseren jetzigen Erfahrungen - unabänderliche, teils eine veränderliche, labile. Im letzteren Fall kann man selbst zweizeilig beblätterte Seitensprosse dadurch, daß man die anderen Vegetationspunkte entfernt, zu „spiralig" beblätterten umbilden. Dies gelang zuerst ${ }^{1}$ ) bei jungen Pflanzen

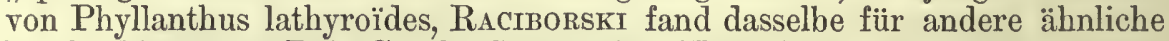
Euphorbiaceen. Bei Corylus ${ }^{2}$ ) ist die Umbildung auch bei älteren Sprossen möglich: der zweizeilig beblätterte Sproß mit unsymmetrischen Blättern geht in einen dreizeilig beblätterten mit symmetrischen Blättern über. Dagegen gelang diese Umbildung gar nicht bei Ulmus und höchst selten (wenn überhaupt) bei Tilia ${ }^{3}$ ). Im allgemeinen handelt es sich ja bei diesen Umänderungen um eine Rückkehr zur Jugendform. Diese wird

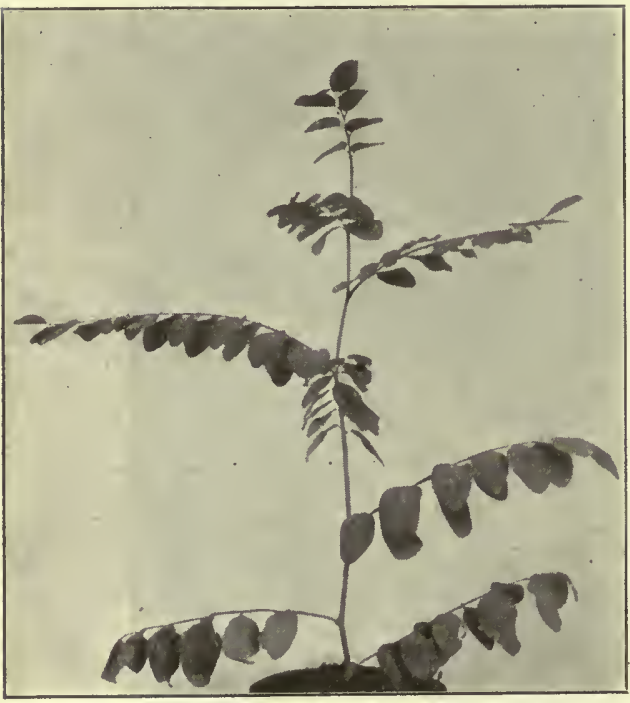

Fig. 222.

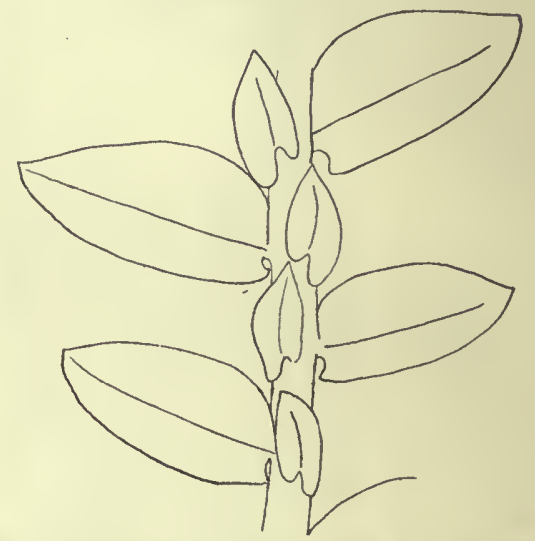

Fig. 223. Sproßstück von Selaginella Galeottii von oben gesehen, vergr.

Fig. 222. Flüggea microcarpa. Langtriebe (die nur Niederblätter hervorbringen) nach $\%$, Kurztriebe (wie Fiederblätter aussehend) nach $1 / 2$ beblättert.

um so leichter vor sich gehen, je weniger sie sich von der Folgeform unterscheidet (Corylus). Bei Ulmus ist aber der Unterschied ein sehr beträchtlicher (vgl. V. Abschnitt). Allerdings können bei Sprossen infolge der Korrelationsänderungen auch andere Abweichungen der Blattanordnung als die Rückkehr zur Jugendform auftreten (z. B. dreizählige Wirtel bei Fraxinus, Auseinanderrücken der Blätter eines Wirtels), indes kann hier nicht näher darauf eingegangen werden.

Die angeführten Beispiele zeigen, daß Seitensprosse radiär dorsiventral

1) Goeser, Über Jugendformen von Pflanzen usw. (Sitzungsber. der math.-physik. Klasse der K. Bayer. Ak. d. W. 1896 S 492).

2) KNY, Ein Versuch zur Blattstellungslehre (Ber, der D. bot. Ges. XVI (1898) S. (60)-(64); A. WEIsse, Über Veränderung der Blattstellung an aufstrebenden Axillarzweigen, Ibid. XVII (1899) p. 343. WeIsse wies nach, daß - wie zu erwarten war der Vegetationspunkt sich beim Übergang zur Spiralstellung verbreitert.

s) $\mathrm{Ob}$ bei Keimpflanzen, bleibt zu untersuchen. 
sein können, und daß ganze Bäume ohne radiäre Hauptachse nur aus sympodial verketteten dorsiventralen Sprossen aufgebaut sein können. Bei Besprechung der Keimungserscheinungen wird zu erwähnen sein, daß auch die Keimachsen mancher Pflanzen schon dorsiventrale Ausbildung annehmen können. So bei Hedera helix, wo die radiäre Ausbildung erst bei den blühbaren Sprossen auftritt. Offenbar handelt es sich aber hier um eine sekundär entstandene "Anpassung".

\section{§ 12. Allgemeine Bemerkungen über Anisophyllie ${ }^{1}$ ).}

Unter Anisophyllie verstehen wir die Tatsache, daß an dorsiventralen (meist plagiotropen, selten orthotropen) Sprossen die Blätter auf der Lichtund der Schattenseite voneinander an Größe und Gewicht, 'vielfach auch im anatomischen Bau und in der Lebensdauer verschieden sind.

Diese Erscheinung tritt in verschiedener Ausbildung auf, steht aber stets mit der Gesamtsymmetrie der Sprosse in unmittelbarem Zusammenhang, was lange Zeit nicht beachtet wurde. Meist sind die auf der Oberseite (der Lichtseite) stehenden Blätter kleiner als die auf der Unterseite stehenden (vgl. z. B. Columnea sanguinea Fig. 224). Die Sprosse sind alsdann hypotroph. Aber auch das umgekehrte Verhalten ist sehr häufig (Fig. 225). Es findet sich bei epitrophen Sprossen. Endlich können bei amphitrophen Sprossen die Blätter auf den Flanken größer sein als die auf der Ober- und der Unterseite.

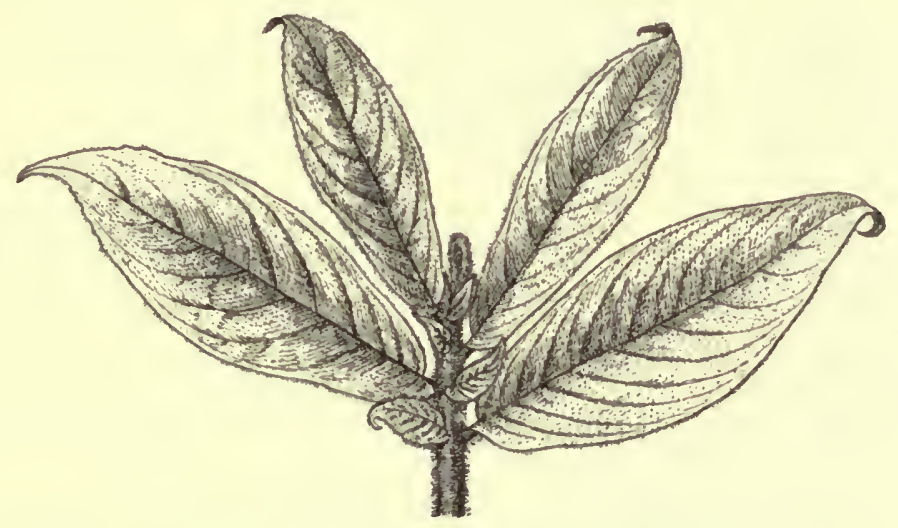

Fig. 224. Columnea sanguinea. Sproß in Oberansicht, 1/4 nat. Gr.

Die Anisophyllie tritt in den verschiedensten Verwandtschaftskreisen gleichartig, zuweilen (z. B. bei den Lycopodinen) auch innerhalb eines Verwandtschaftskreises in ungleichartiger Weise auf.

So stimmen bezüglich der Beblätterungsverhältnisse miteinander überein die hypotrophen Sprosse von Selaginella (Fig. 223) - also einer Lycopodine - mit denen von Columnea sanguinea, einer Gesneracee (Fig. 224). In Fig. 225 sind (annähernd auf dieselbe Größe gebracht) gezeichnet die epitrophen Sprosse von einer Podostemacee (I), von einem Lebermoos $(I I)$ und einem Laubmoos $(I I I)$. Hier sind iberall die auf der Unterseite (Schattenseite) stehenden Blätter die kleineren.

1) Die Literatur ist angeführt in FIGDOR, Die Erscheinung der Anisophyllie, Leipzig und Wien 1909. 
Mit der Anisophyllie ist häufig auch eine asymmetrische Ausbildung entweder aller oder nur bestimmt angeordneter Blätter verbunden, und zwar tritt auch diese Erscheinung bei Pflanzen aus den verschiedensten Verwandtschaftskreisen auf.

Zunächst ist (wie in der 1. Auflage betont wurde) hervorzuheben, daß ebenso wie die Größe auch die Symmetrie der Blätter der Gesamtsymmetrie des Sprosses untergeordnet ist, $d$. h. trotzdem die Blätter asymmetrisch sind, bildet der ganze Sproß ein - wenigstens annähernd - symmetrisch teilbares Ganzes. So sind z. B. bei Hypopterygium (und ebenso bei Cyathophorum) (Fig. 225 III) die auf der Sproßunterseite stehenden Blätter annähernd symmetrisch, die beiden oberen Blattreilıen dagegen bestehen aus asymmetrischen Blättern, deren größere Hälften einander zugekehrt sind. Ähnlich ist es - mutatis mutandis - bei Selaginella und Columnea.

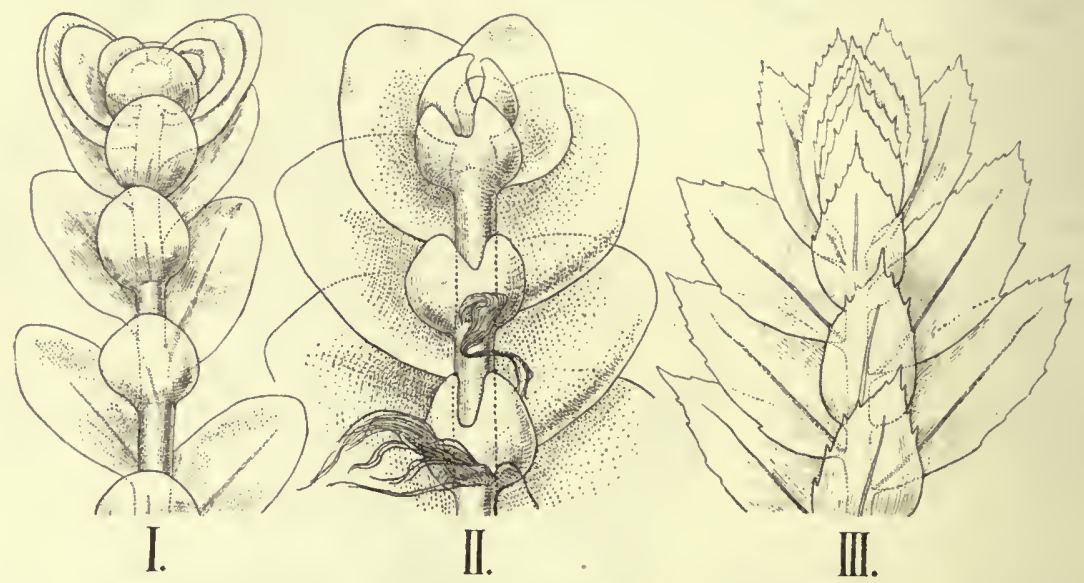

Fig. 225. Anisophyllie (mit kleineren Blättern auf der dem Beschauer zugekehrten Schattenseite) als Parallelbildung in verschiedenen Verwandtschaftskreisen: I Tristicha hypnoides (Dikotyl.). II Kantia (Calpogeia) Trichomanes (Lebermoos). III Hypopterygium Douini (Laubmoos).

Vergleichen wir aber diese beiden Pflanzen näher, so sehen wir, daß die asymmetrischen Blätter in verschiedener Weise zur Gesamtsymmetrie des Sprosses in Beziehung stehen. Ein Diagramm (Fig. 226) wird dies ohne weiteres erläutern. Bezeichnen wir die größeren Blatthälften als + , die kleineren als - Hälften, so sind bei Selaginella (Fig. 226 I) die + Hälften in jedem Blattpaar gleichsinnig einander zu und nach der Sproßunterseite hingerichtet. Bei Columnea sanguinea und Goldfussia glomerata dagegen sind die + Hälften nach der Sproßoberseite gerichtet (Fig. 226 II).

Die Asymmetrie kann in beiden Fällen entweder bedingt sein dadurch, $\mathrm{da} ß$ auf jedes einzelne ursprünglich symmetrisch angelegte Blatt eine Einwirkung ausgeübt wird, welche es zur asymmetrischen Weiterentwicklung veranlaßt (was, wie p. 215 erwähnt wurde, auch durch experimentelle Einwirkung erfolgen kann). Oder sie ist bedingt durch die Beschaffenheit der Sproßachse; der Teil des Blattes, der auf der geförderten Partie der Sproßachse steht, wurde der geförderte, besser ernährte und erhielt ein größeres Areal des Vegetationspunktes als Insertionsstelle zugeteilt. Der Verfasser $\operatorname{kam}^{1}$ ) zu der Auffassung, daß die zweite Alternative - wenigstens für

\footnotetext{
1) Archegoniatenstudien X (Flora 96, Bd. 1906).
} 
eine große Anzahl von Fällen - zutrifft. Es ist dies ohne weiteres einleuchtend für die Fälle, in denen die + Seiten der geförderten Sproßseite zugekehrt sind, so bei epitrophen Moosen wie Hypopterygium und Cyathophorum (Fig. 230), bei der hypotrophen Selaginella u. a. In dem Schema Fig. $226 I I$ sind aber die + Seiten der O b e r seite der hypotrophen Sprosse zugekehrt. Hier findet vielleicht, wie BosHant ${ }^{1}$ ) ausgeführt hat, eine Korrelation zwischen den Blättern statt: ursprünglich entspricht, wenn wir uns die Blätter auf einer Höhe stehend denken, jedem Blatt ein Quadrant der Sproßachse (vgl. Fig. 227). Die größeren Blätter beeinflussen noch den nächstoberen Quadranten, entnehmen ihm für ihre Entwicklung Baumaterialien und entziehen diese den kleinen Blättern, deren entsprechende Hälfte dann zur Minusseite wird. Es wird diese Annahme dadurch gestützt, daß durch eine Entfernung der größeren Blätter tatsächlich die kleineren bedeutend größer werden als sonst und auch ihre Asymmetrie etwas verringert wird.

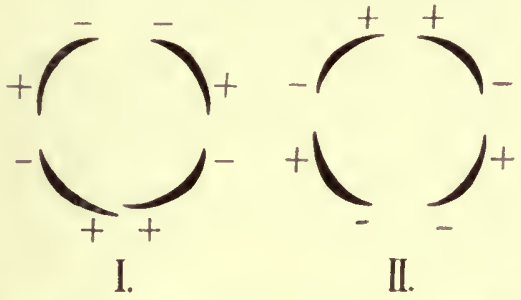

Eig. 226. Verschiedene Typen der Blattasymmetrie.

Fig. 227. Diagramm von Goldfussia glomerata. Hypotropher Sprob, $a, b$ die ursprüngliche Quadrantenteilung. Die beiden unteren Quadranten werden größer als die beiden oberen.

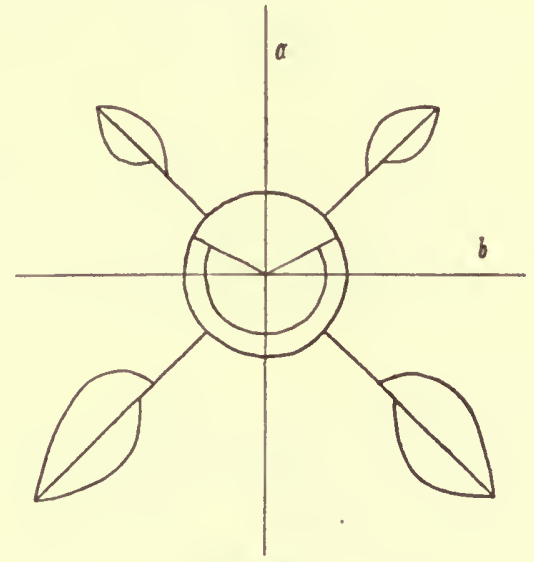

Fig. 227.

Wenn an derartigen Pflanzen isophylle Sprosse auftreten, so haben sie symmetrische Blätter. Auch das spricht für die Abhängigkeit der Blattsymmetrie von dem Zustand der Sproßachse.

\section{§ 13. Anisophyllie bei Laubmoosen.}

Die meisten Laubmoossprosse sind orthotrop und isophyll; von den plagiotropen sind einige isophyll, z. B. die plagiotropen Hypnumarten. Die plagiotropen Laubsprosse (die Blütensprosse sind orthotrop) von Mnium undulatum (Fig. 176 u. 177) zeigen meist eine Andeutung von Anisophyllie insofern, als die auf der Unterseite stehenden Blätter etwas kleiner sind als die anderen. Indes tritt dies Verhältnis bei frei wachsenden Sprossen nur wenig ausgeprägt auf. Dagegen läßt sich, wenn die plagiotropen Sprosse einer Unterlage entlang wachsen, deutlich erkennen, daß die auf der Schattenseite stehenden Blätter kle in e r sind als die auf der Lichtseite stehenden (Fig. 228), was zweifellos auf die Einwirkung des Lichtes zurückzuführen ist. Bei gänzlichem Lichtmangel bleiben alle Blätter von Mnium (Fig. $228 \mathrm{~A}$ ) (und anderen Laubmoosen) klein. Bei einseitiger Beleuchtung

1) Boshart, Studien über Blattasymmetrie usw. Flora 103. 
werden also die auf der Schattenseite ausgebildeten Blätter kleiner als die auf der Lichtseite stehenden, wie denn auch bei zweizeilig verzweigten Moosen die Astbildung auf einer Seite ganz unterbleiben kann, wenn diese dem Substrat anliegt (Fig. 229), weil auch die Entwicklung der Seitensprosse vom Licht abhängig ist - sie unterbleibt bei etiolierten Sprossen.

Diese Tatsachen waren hier anzuführen zum Vergleich mit anderen Laubmoosen, bei welchen die Anisophyllie nicht direkt durch äußere Faktoren bedingt, sondern gewohnheitsmäßig geworden, habitu ell ist. In Fig. 230 ist abgebildet ein prachtvolles, in den Farnschluchten Australiens und Neuseelands auf Baumfarnstämmen (aber auch auf Erde) häufig wachsendes Moos, Cyathophorum bulbosum ${ }^{1}$ ). Seine Sprosse sind ausgesprochen epitroph; die auf der Oberseite stehenden Blätter sind größer

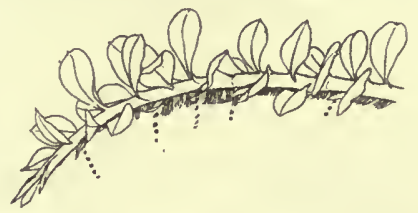

Fig. 228. Mnium undulatum. Plagiotroper mit der Unterseite einem Baumfarnstamm angeschmiegter Sproß. Die auf der Unterseite stehenden mit punktierten linien bezeichneten Blätter sind viel kleiner als die anderen.

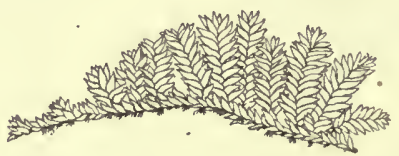

Fig. 229. Plagiothecium undulatum. Zweizeilig verzweigtes Sproßsystem. Die Zweige auf der einen Seite sind nicht entwickelt, es ist dies die dem Substrat anliegende. Sprosse, welche frei sich entwickelten, haben auf beiden SeitenZ $Z$ weige.

Fig. $228 \mathrm{~A}$. Sproß von Mnium serratum, der oben etioliert ist, die Blätter sind klein geblieben (vergr.).

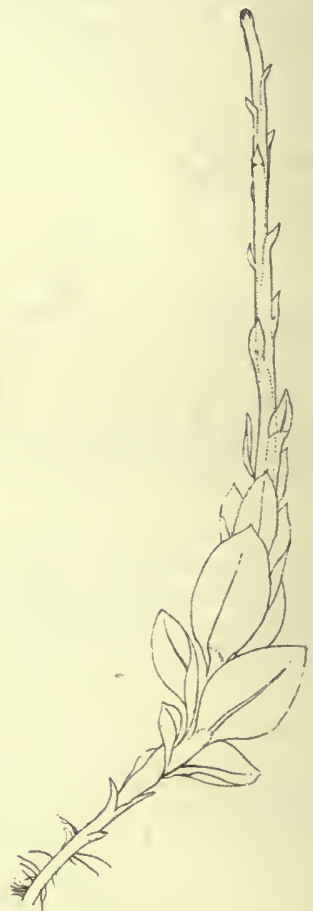

Fig. $228 \mathrm{~A}$.

als die auf der Unterseite (Schattenseite) stehenden. Erstere kehren ihre (morphologische) Unterseite nach oben, letztere die Oberseite; jene sind asymmetrisch, diese symmetrisch. Die ganze Gestaltung ist eine auffallende Parallelbildung zu der der meisten foliosen Lebermoose. Wie bei diesen (Fig. 232) kehrt die dreiseitig-pyramidale Scheitelzelle eine Kante nach oben, eine Fläche nach unten; die Seitenblätter werden so verschoben, daß sie schief zur Längsachse orientiert sind, dabei wird die eine Hälfte der Blattinsertion größer als die andere; der dieser entsprechende Blatteil wächst nun auch stärker und wird der größere. Aus Brutknospen erzogene Pflänzchen zeigten, daß die Dorsiventralität und die durch sie bedingte

1) Vgl. darliber und ïber ähnliche Moose Goeber, Archegoniatenstudien X (Flora 96 (1906), p. 771). 
Anisophyllie nicht von Anfang an vorhanden sind, sondern erst allmählich sich ausbilden: die ersten Seitenblätter sind noch ganz symmetrisch und annähernd quer zur Längsachse des Stämmchens eingefügt, erst die späteren werden schief gestellt und asymmetrisch ${ }^{1}$ ). Es ist nicht zu bezweifeln, daß Cyathophorum sich von einer isophyllen Moosform ableitet. Die Sexualsprosse sind auch noch isophyll, aber die Anisophyllie ist hier offenbar nicht mehr unmittelbar vom Lichte bedingt, sondern dem 'Vegetationspunkt eingeprägt.

Ahnlich verhält sich die Gattung Hypopterygium (Fig. 225 III), nur daß hier die Sprosse reich verzweigt zu sein pflegen (wobei aber nur unterhalb der Seitenblätter Zweige auftreten). Sie bilden Sproßsysteme begrenzten Wachstums, welche einem zierlichen Farnblatte gleichen.

Betreffs der amphitrophen Laubmoose muß auf den speziellen Teil verwiesen werden. Hier sei nur erwähnt, daß bei ihnen ebenso wie bei den oben erwähnten anisophyllen hervortritt, daß sie ihre Blätter so ausbilden, daß die ganze Pflanze eine einheitliche Assimilationsfläche darstellt, an deren Herstellung sich aber nicht alle Blätter beteiligen. Derartige Moose wachsen an Standorten mit geminderter Lichtintensität, deren Ausnutzung auf diese Weise ermöglicht wird. Biologisch denselben "Zweck" erreichen auf einfachere Weise die S. 186 erwähnte Schistostega (durch Drehung) sowie Formen mit zweizeiliger Beblätterung wie Fissidens, Rhizogonium distichum u. a. (Fig. 231).

\section{$\S 14$. Anisophylle Lebermoose.}

Sehr auffallend tritt die Anisophyllie und ihre Beziehung zur Dorsiventralität und zum plagiotropen Wuchs bei den beblätterten Jungermannieen hervor, weil sie hier nicht als eine vereinzelte Erscheinung (wie bei den Laubmoosen), sondern bei alle n "akrogynen" Formen vorhanden ist. Die Stämmchen wachsen dem Substrat angeschmiegt (bei sehr

1) Betr. der Möglichkeit einer Umkehrung der Dorsiventralität vgl. BosHART. in Flora 103 (1911).

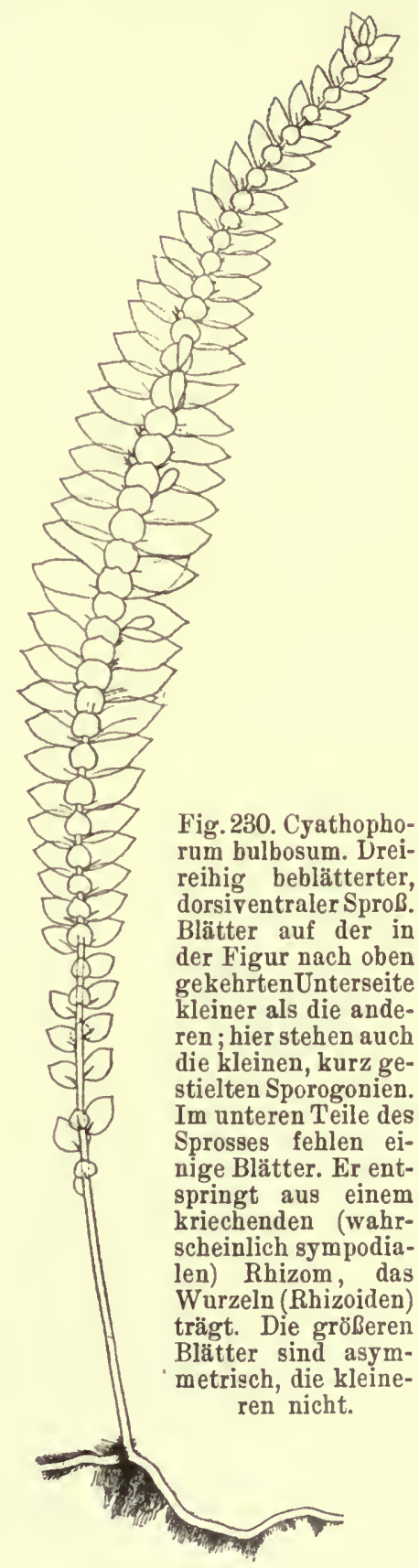

Fig. 230. Cyathophorum bulbosum. Dreireihig beblätterter, dorsiventraler Sproß. Blätter auf der in der Figur nach oben gekehrtenUnterseite kleiner als die anderen; hier stehen auch die kleinen, kurz gestielten Sporogonien. Im unteren Teile des prosses fehlen einige Blätter. Er entspringt aus einem kriechenden (wahrscheinlich sympodialen) Rhizom, das Wurzeln (Rhizoiden) trägt. Die größeren Blätter sind asymmetrisch, die kleineren nicht. 
schwachem Lichte werden sie positiv heliotropisch), seltener sind schief aufsteigende Formen, wie Mastigobryum.
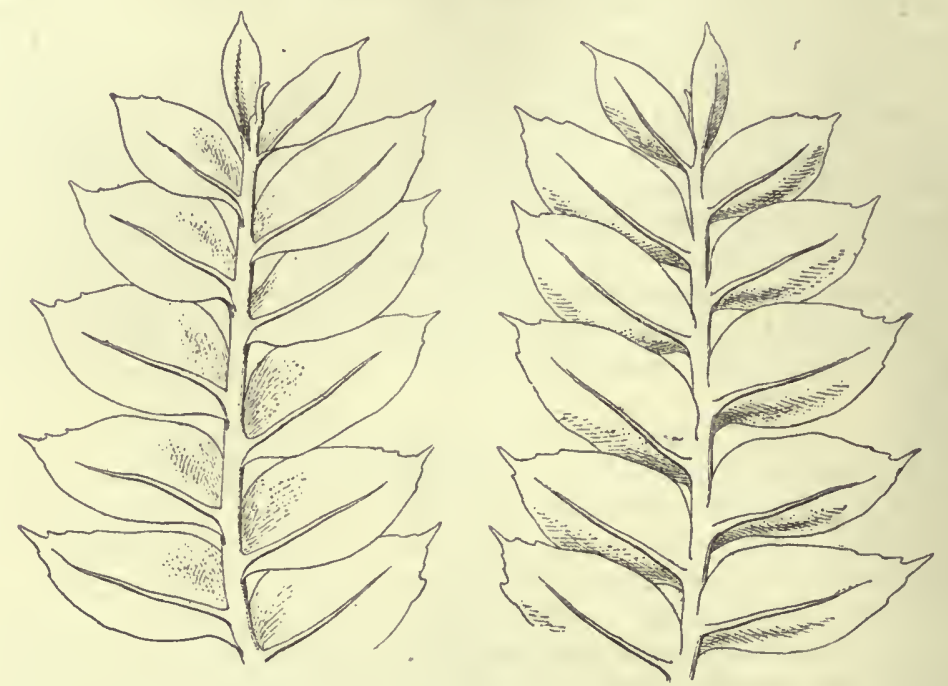

Fig. 231. Rhizogonium distichum. Habitusbild eines sterilen Sprosses. Die zweizeilig gestellten Blätter sind asymmetrisch und stehen nicht quer, sondern fast parallel zu der Längsachse des Stämmchens. Dieses ist schwach dorsiventral ausgebildet.

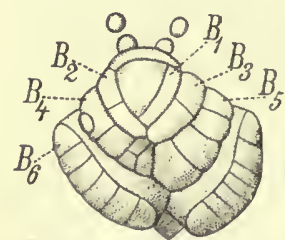

Fig. 232. Jungermannia bicuspidata. Stämmchen schief von oben. $B_{1}-B_{6}$ die Segmente, welche zu den seitlichen Blättern auswachsen.

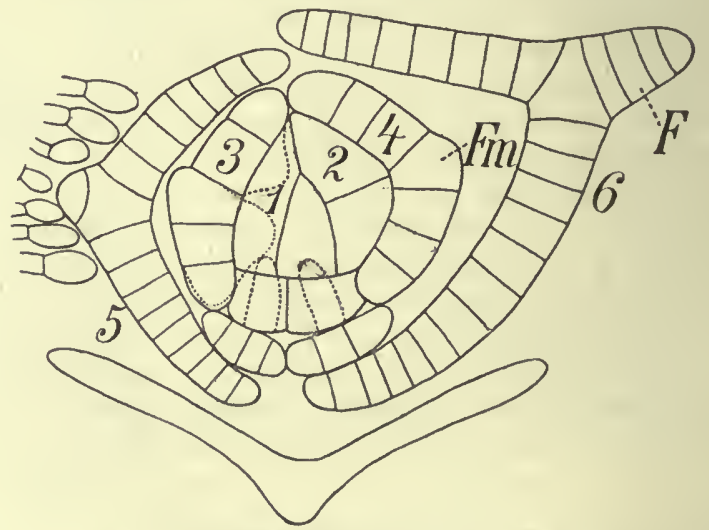

Fig. 233.

Fig. 233. Gottschea appendiculata. Querschnitt durch die Knospe. Die Scheitelzelle ist dreiseitig pyramidal, die seitlichen Segmente (mit $1-6$ bezeichnet) sind von Anfang an größer als die nach unten hin abgeschnittenen aus denen die Amphigastrien hervorgehen. $F$ Flügel der Seitenblätter.

Die Sprosse haben drei Reihen von Blättern, zwei seitliche und eine, aus viel kleineren (bei manchen Formen äußerst reduzierten) Blättern bestehende untere, die der Amphigastrien. Diese Blätter gehen hervor aus den Segmenten einer „dreiseitig pyramidalen" Scheitelzelle, welche die eine ihrer Flächen dem Substrate zukehrt (Fig. 232). Dabei ist charakteristisch, daß bei denjenigen Formen, welche entwickelte Unterblätter (Amphigastrien) besitzen, die Projektion der Scheitelzelle ein gleich- 
seitiges Dreieck darstellt; bei denjenigen, welche reduzierte oder gar keine Amphigastrien haben, ist die Grundlinie des Dreiecks kleiner als dessen Seiten (Fig. 233). Die ausgeprägtere Dorsiventralität kommt hier also schon im Bau des Vegetationspunktes zum Ausdruck; je mehr das der Fall ist, desto weniger werden wir erwarten dürfen, daß sie direkt von äußeren Faktoren beeinflußbar ist. Die Stämmchen sind hier alle epitroph; die seitlichen Segmente können sich verschieden verhalten. Sie zerfallen frühzeitig in zwei Hälften, von denen jede je einen Blattlappen produziert. Ist die obere Hälfte gefördert, so ist der obere Blattlappen größer als der untere, und umgekehrt. Es können also auch die Flanken epioder hypotroph sein.

Die Seitenblätter sind ursprünglich quer zur Längsachse der Stämmchen inseriert. Sie behalten diese Stellung entweder bei (was ${ }^{3}$ der seltenere Fall ist), oder erfahren eine Verschiebung. Ersteres ist der Fall bei einigen mehr aufrecht wachsenden Formen, z. B. Marsupielea, ferner bei den Arten, deren Blätter nicht als Zellflächen ausgebildet sind, sondern (ganz oder teilweise) aus Zellreihen bestehen (Trichocolla, Jungerm. trichophylla, Arachniopsis. Bei den anderen ist von Interesse, wie rerschieden die Mittel sind, um die Assimilationsflächen der Blätter in schiefe oder annähernd horizontale Lage $\mathrm{zu}$ bringen. Es lassen sich diese in zwei Gruppen bringen: entweder wird das ganze Blatt verschoben, so daß es nach wie vor eine einheitliche Fläche bildet, oder es wird gefaltet, meist so, daß die Faltungsstelle an der Grenze am Ober- und Unterlappen liegt.

Fig. 234. Schema für die Blattinsertion einiger folioser Lebermoose in Seitenansicht des Stämmchens. Die Lichtseite (Oberseite des letzteren) ist bei $1-4$ die links liegende, bei 5 die rechts liegende. 1 u. 2 Verschiebung der ganzen Blattinsertion aus der Querstellıng (meist geht sie noch viel weiter als hier angenommen). 1 oberschlächtig, 2 unterschlächtig, 3-5 mit Faltung der Blätter, 4 und 5 mit stärker entwickelten Unterlappen.

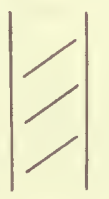

1. 2

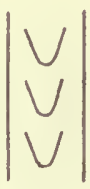

3.

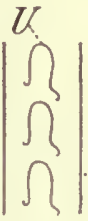

5.

In Fig. 234 sind schematisch die einzelnen Fälle dargestellt. Wir sehen, daß entweder die Ober- oder die Unterseite der Blätter dem Lichte zugekehrt sein kann und daß bei Balantiopsis (Fig. 234, 5), wo der (den Oberlappen an Größe weit übertreffende) Unterlappen sehr entwickelt ist, dieser eine Faltung aufweist, während der Oberlappen quer inseriert bleibt. Über die Blattgestaltung der vegetativen Sprosse im einzelnen und die Blattbildung an den Sexualsprossen, bei denen die Anisophyllie häufig verschwindet, ist der spezielle Teil zu vergleichen.

Daß die dorsiventrale Ausbildung der vegetativen Sprosse als eine zu dem Lichte in direkter Beziehung stehende zu betrachten ist, zeigt schon eine vergleichende Betrachtung. Die von der Lichtquelle hinwegwachsenden (also nicht plagiotropen), als "Wurzelträger" funktionierenden Sprosse von Mastigobryum trilobatum haben drei Reihen gleich großer quer inserierter Blätter. Schneidet man diese "Wurzelträger" ab und läßt sie im Lichte weiter wachsen, so gehen sie in die gewöhnlichen, stark anisophyllen Sprosse über.

Auch andere Beispiele zeigen, daß die Anisophyllie bei den dorsiventralen Lebermoosen offenbar eine sekundäre Erscheinung ist, welche aber jetzt als Gruppencharakter auftritt, was auch für die phylogenetische 
Betrachtung dieser Gruppe von Bedeutung ist. Es sei nur eines noch genannt. Calypogeia Trichomanes besitzt dorsiventrale, dem Boden angeschmiegte Sprosse mit sehr kleinen, öfters auch verkümmerten Amphigastrien. Diese Sprosse werden orthotrop, wenn sie Brutknospen erzeugen. Sofort werden die Amphigastrien größer, sie bleiben hinter den Seitenblättern kaum mehr zurück, während sie vorher von diesen um ein Vielfaches übertroffen wurden.

Die wenigen isophyllen (anakrogynen) Jungermannieen (Calobryum, Haplomitrium) sind orthotrop; es scheint aber, nach früher von mir gemachten Wahrnehmungen, daß Calobryum unter Umständen plagiotrop und im Zusammenhang damit auch anisophyll werden kann, ähnlich wie dies für eine Selaginellaart unten anzuführen sein wird.

Auch bei Haplomitrium scheint dies zuzutreffen ${ }^{1}$ ). Es ist nicht unwichtig, hervorzuheben, daß diese orthotropen beblätterten Lebermoose mit wurzelähnlichen unterirdischen Sprossen versehen sind, welche ihnen offenbar ihre Wachstumsrichtung allein ermöglichen. Denn ein nur mit den kleinen Rhizoiden der übrigen foliosen Lebermoose ausgestattetes Stämmchen kann zwar, wenn es dem Substrate angeschmiegt oder in dichtem Rasen wächst, genügend Halt (und Wasserversorgung) finden, aber nicht ein aufrecht wachsendes. Dagegen sind die Rhizoiden sowie die (durch Kapillarität erfolgende) äußere Wasserleitung (bei manchen Formen auch die innere), der Laubmoose weit entwickelter und dementsprechend finden sich hier auch orthotrope Formen in überwiegender Menge.

\section{$\S 15$. Anisophylle Lycopodinen.}

Bei den Filicinen und Equisetinen sind Beispiele von Anisophyllie nicht bekannt, was bei den Equisetinen nicht wundernehmen kann, da bei ihnen die Blätter als Assimilationsorgane nicht in Betracht kommen. Bei den Farnen wäre es sehr wohl möglich, daß Beispiele von Anisophyllie noch entdeckt würden. Es scheint übrigens, daß bei kleinblätterigen Pflanzen Anisophyllie (in dem Sinne wie bei den oben erörterten Bryophyten) leichter eintritt als bei großblätterigen.

Die Erscheinung der Heterophyllie, wie sie bei manchen Farnen sich findet und später näher zu besprechen sein wird, gehört nicht hierher, da es sich dabei um eine qualitative, nicht um eine quantitative Verschiedenheit der Blattbildung handelt ${ }^{2}$ ). Wohl aber zeigen einige Lycopodinen ein merkwürdiges Verhalten.

A) Die Gattung Lycopodium selbst hat einerseits Arten, welche nur orthotrope, radiär ausgebildete Sprosse besitzen, wie L. Selago, L. Hippuris u. a. (Fig. 235), andererseits solche, deren plagiotrope Sprosse mehr oder minder stark dorsiventral sind, die extremen Formen haben eine stark ausgesprochene Anisophyllie.

Die einzelnen Arten zeigen dabei ein verschiedenes, außerordentlich lehrreiches Verhalten, das deshalb kurz geschildert sei.

1. Arten mit wenig auffallender Dorsiventralität. Hierher gehören die kriechenden Sproßachsen z. B. von L. clavatum, annotinum, inundatum.

1) Solche - nur unter besonderen Bedingungen auftretenden - anisophyllen Sprosse sind von einem neueren Autor irrig für die normalen gehalten worden.

$\left.{ }^{2}\right)$ Dies ist wenigstens in den typischen Fällen so; auch die Anisophyllie kann aber, wie die nnten zu erwähnenden Urticaceen zeigen werden, sich bis zu qualitativen Verschiedenheiten der Blätter steigern. 
Diese zeigen einerseits, daß die auf der Schattenseite stehenden Blätter etwas kleiner sind als die auf der Lichtseite stehenden. Bei L. annotinum finde ich an den kriechenden Sproßachsen die seitlichen Blätter größer, breiter und dunkler grün als die unteren, aber diese nur bei genauerer Beobachtung hervortretende Verschiedenheit kann biologisch wohl kaum in Betracht kommen. Bei L. inundatum sind die Blätter der. Schattenseite oft chlorophyllos, andererseits sind die Blattpolster ${ }^{1}$ ) auf der Lichtseite stärker entwickelt als auf der Schattenseite. Die Sprosse sind also, wenngleich nicht sehr auffallend, epitroph, eine Erscheinung, die sich, wie unten gezeigt werden soll, bei anderen Arten erheblich steigert.
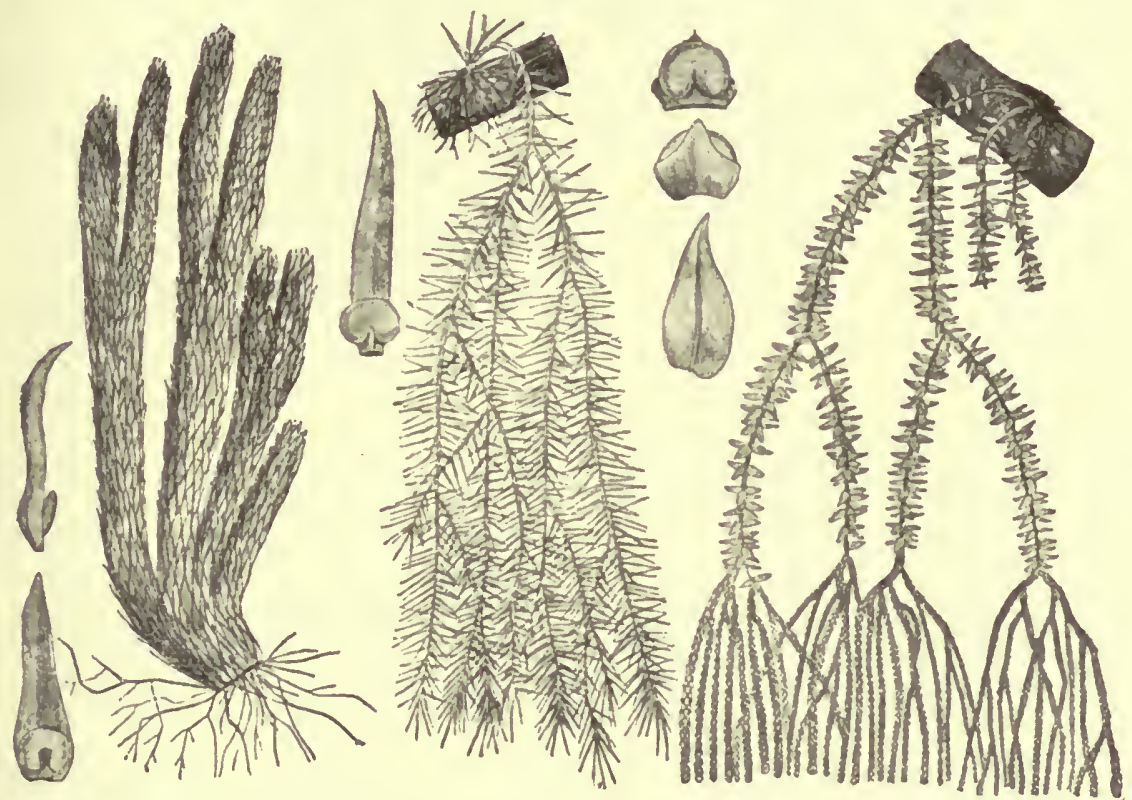

Fig. 235. Habitusbilder ron Lycopodien mit nur radiären Sprossen (nach PritzeL). 1 Lyc. Saururus, 2 L. linifolium, 3 L. Phlegmania. (Aus Lorsy, Vortr. über bot. Stammesgesch. II.)

2. Auffallende Anisophyllie tritt dagegen auf im Verwandtschaftskreis von L. complanatum (L. complanatum, alpinum). Es seien zuerst die Symmetrieverhältnisse, wie ich sie bei L. complanatum fand, geschildert. Die Pflanze besitzt eine unterirdisch kriechende Hauptachse, von der aus Seitensprosse begrenzten Wachstums an das Licht treten. Die unterirdischen Teile sind - was zu betonen bei Gefäßkryptogamen nicht überflüssig ist - chlorophyllos. Die oberirdischen Sprosse - namentlich die Auszweigungen höherer Ordnung — sind stark abgeflacht, ausgeprägt

1) Vgl. Hegelmaier (Botan. Zeitg. 1872, p. 776): Der Rindenkörper entwickelt sich auf der Lichtseite $z u$ abgerundeten, aber doch deutlichen, von den Blattinsertionen herablaufenden Leisten (d. h. die Blattpolster sind hier entwickelt), während er auf der Schattenseite glatt ist, die Blattpolster also nicht hervortreten. Dasselbe, nur in viel ausgesprochenerem Maße, ist auch bei den ausgeprägt dorsiventralen Sprossen von L. Chamaecyparissus, wie weiterhin gezeigt werden soll, der Fall. Die Lycopodiumarten bieten ein sehr lehrreiches Beispiel dafür, daß verwandte Formen verschieden stark auf äußere Gestaltungsreize reagieren können. $\mathrm{Da}$ in der Tat solche hier in Betracht kommen, ergibt sich aus meinen später anzuführenden Untersuchungen für L. complanatum. 
dorsiventral und anisophyll. Es sind an ihnen vier Blattreihen vorhanden (an stärkeren Ästen mehr, vgl. unten), eine obere, zwei seitliche und eine untere. Die seitlichen Blätter, denen zusammen mit ihrem Blattpolster (dem mit der Sproßachse "verwachsenen" Teile der Blattbasis) die Assimilationsarbeit fast allein zukommt, sind nicht nur größer als die oberen und unteren Blätter, sondern a ch anders geformt. In ihrem oberen Teile wie die Blätter der beiden anderen Reihen flach, werden sie nämlich

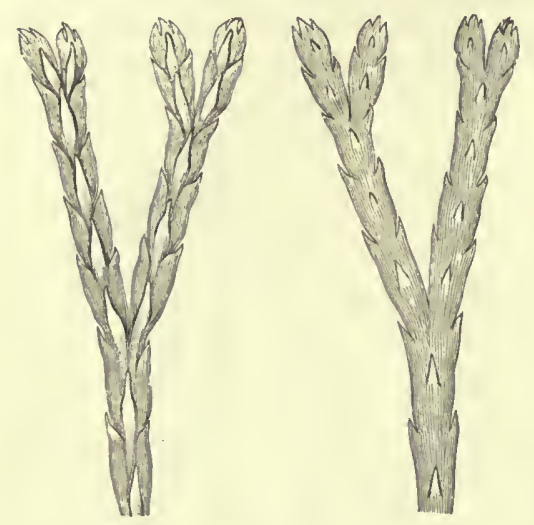

Fig. 236. Lycopodium complanatum. Dorsiventraler Sproß, links von der Licht-, rechts von der Schattenseite. Etwas $\left(1 \frac{1}{2}\right.$ fach) vergrößert. in ihrem unteren Teile kielförmig (Fig. 236, I), mit anderen Worten, sie zeigen in ihrer Gestaltung eine Annäherung an die Ausbildungsform der Blätter, welche als "unifaziale" bezeichnet wurden. Dabei ist der in das Blattpolster sich fortsetzende Kiel auf der Oberseite viel chlorophyllreicher als auf der Unterseite. Spaltöffnungen fehlen auf der Lichtseite, sind dagegen auf der Schattenseite vorhanden. Es ist hier also die dorsiventrale Ausbildung des Blattes gleichzeitig mit seiner Lage geändert, um $90^{\circ}$ verschoben worden, ein auffallendes Beispiel direkter Beeinflussung der Struktur durch die Lage, wie sie bei manchen Coniferen als Parallelbildung wiederkehrt ( $\mathrm{vgl}$. das unten über Thuyopsis Gesagte). Daß diese Gestaltung der Seitenblätter geeignet ist, ohne Drehung derselben den Sproß zu einem flachen, blattähnlichen Assimilationsorgan zu machen, braucht kaum hervorgehoben $\mathrm{zu}$ werden. Die Blätter der Ober- und der Unterseite sind gleichfalls unter sich verschieden. Die letzteren sind kleiner, sie spielen bei der Assimilation keine Rolle, sie sind bleich und ohne hervortretende Blattpolster,

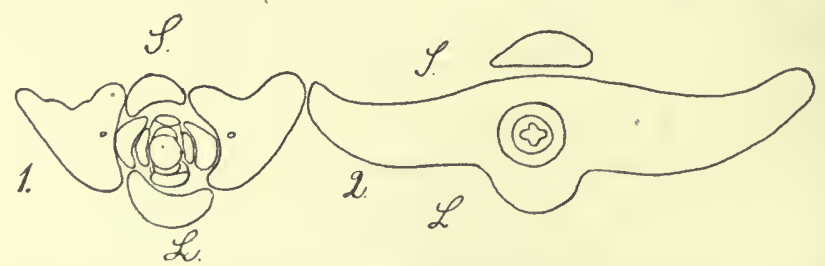

Fig. 237. Lycopodium complanatum. Querschnitte durch einen dorsiventralen Sproß höherer Ordnung: 1 an der Spitze, 2 weiter unten. $S$ Schattenseite, $L$ Lichtseite.

die ersteren dagegen chlorophyllreich und mit hervortretendem Blattpolster versehen, so da $\mathrm{B}$ durch diese hervortretenden Blattpolster eine, wenn auch nicht beträchtliche Vergrößerung der assimilierenden Fläche herbeigeführt wird. Am Vegetationspunkt tritt die Verschiedenheit in der Ausbildung der Blätter übrigens noch nicht hervor, doch macht sich die Ungleichheit von Ober- und Unterblättern schon frühzeitig geltend (Fig. 237, 1).

Weit verschieden von der Gestaltung dieser Assimilationssprosse ist. die der unterirdischen. Diese sind radiär, mit spiraliger Blattstellung versehen, von (annähernd) zylindrischem Querschnitt, mit Blättern, die alle 
gleich ausgebildet sind, und einem Gefäßbiindelkörper, der gleichfalls radiär ist, während der der dorsiventralen Sprosse bilateral symmetrisch ist (vgl. Fig. 237, 2). Auch die Verzweigung erfolgt an den unterirdischen Sprossen im Gegensatz zu den oberirdischen nicht in einer Ebene. Zwischen den beiden Sproßformen gibt es indes alle Übergänge. Die über den Boden sich erhebenden Sprosse gewinnen nämlich ihre Dorsiventralität nnd Anisophyllie erst allmählich. Ursprünglich sind sie radiär, mit vielzeiliger Blattstellung. Sie flachen sich dann auf der Lichtseite ab, bleiben aber auf der Schattenseite noch gewölbt, und die am Rande stehenden Blätter nehmen jetzt schon Kielform an. Die Dorsiventralität spricht sich auch darin aus, daß die Verzweigung nur in einer Ebene erfolgt. An diesen in ihrem oberen Teile schon dorsiventralen Sprossen stehen dann als Seitensprosse höherer Ordnung die oben geschilderten, ${ }^{\circledR}$ stark dorsiventralen, deren Blattanordnung auch eine andere ist. Die Dorsiventralität ist hier, wie meine Untersuchungen gezeigt haben, bedingt durch das Licht und ebenso die Anisophyllie. Lehrreich ist das allmähliche Zustandekommen beider Erscheinungen und die Tatsache, daß Sprosse höherer Ordnung auf den bedingenden äußeren Faktor stärker reagieren als die direkten Seitenzweige des „Rhizoms"“.

Zugleich liefern die verschiedenen Lycopodiumarten ein Beispiel dafür, wie verschieden selbst innerhalb einer Gattung die Empfänglichkeit
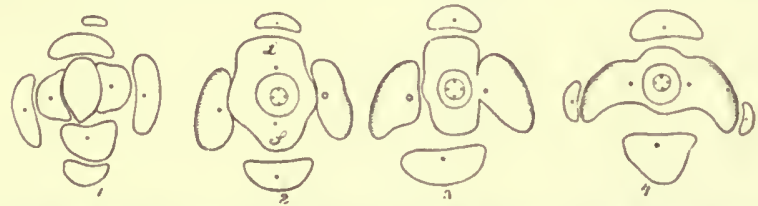

Fig. 238. Lycopodium alpinum. Querschnitte durch einen Sproß anf verschiedener Höhe (1 am höchsten, 4 am tiefsten). Die Lichtseite $L$ ist nach oben, die Schattenseite $S$ nach untel gekehrt (also umgekehrt wie in Fig. 231); bei $2-4$ ist die Stelle der Blattpolster, welche am chlorophyllreichsten ist, durch Schraffierung angedeutet.

für die Einwirkung äußerer Faktoren sein kann. Die plagiotropen Sprosse ron L. annotinum u. a. sind nur schwach dorsiventral in bezug auf die Entwicklung der Rinde und des Leitbündelkörpers. Bei L. alpinum steigert sich die Dorsiventralität und nähert sich schon

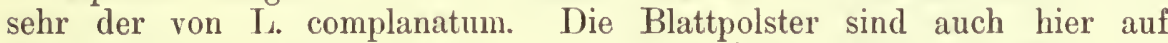
der Lichtseite stärker entwickelt als auf der Schattenseite (vgl. Fig. 238) und die Blattpolster der Seitenblätter stark abgeflacht und dorsiventral. Der Einfluß der Lage auf die Ausbildung ist also ebenso deutlich wie bei L. complanatum. Die Seitenblätter selbst aber sind noch nicht so verändert wie bei L. complanatum; sie sind der Hauptsache nach flach und erfahren nur in ilirem unteren, in das Blattpolster übergehenden Teile eine Drehung (wobei die morphologische Unterseite nach oben gekehrt wird, die eine Hälfte der (morphologischen) Blattoberseite nach unten) (vgl. Fig. 238) und werden hier auch schwach kielförmig. Die auf der Schattenseite stehenden Blätter sind hier kräftiger entwickelt als bei L. complanatum.

3. Stark amphitrophe Formen. Bei den genannten Arten waren die Seitenblätter am stärksten entwickelt, die auf der Lichtseite stehenden Blätter kleiner, die Lichtseite aber, namentlich was die Blattpolster betrifft, gefördert gegenüber der Schattenseite. Die Sprosse sind also amphitroph und epitroph. Es ist wahrscheinlich, daß das Zurïckbleiben der Blätter auf der Lichtseite mit durch Korrelation bedingt wird. Daß bei 
der gegebenen Stellung die Herstellung einer Fläche am leichtesten durch Förderung der flankenständigen Blätter erreicht wird, ist klar.

In viel auffallenderem Maße findet sich dieselbe Erscheinung bei L. volubile (Fig. 239). Hier sind an den sich abflachenden Zweigen (die Hauptsprosse sind annähernd zylindrisch und zeigen keine auffallende Anisophyllie) meist mehr als vier Blattreihen vorhanden. Die auf der Oberseite stehenden Blätter sind sehr viel kleiner als die flankenständigen, noch mehr an Zahl und Größe verringert sind die Blätter auf der Schattenseite. Diese Sprosse sind also besonders deutlich amphitroph. Zugleich tritt der. Unterschied zwischen kräftig ernährten (fast oder ganz) radiären Hauptsprossen und den stark dorsiventralen Sprossen höherer Ordnung auch hier auffallend hervor.

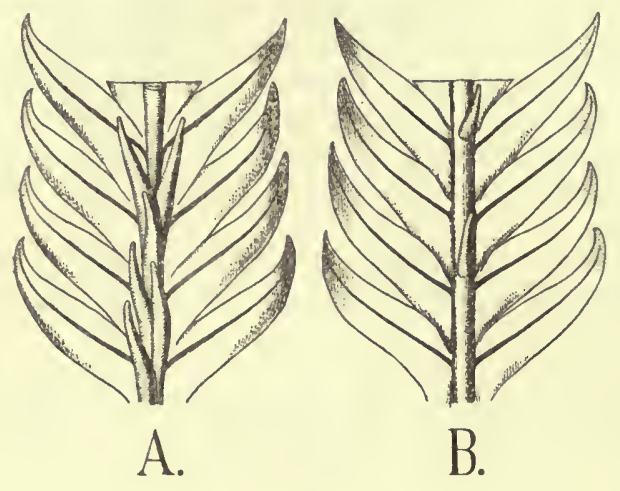

Fig. 239.

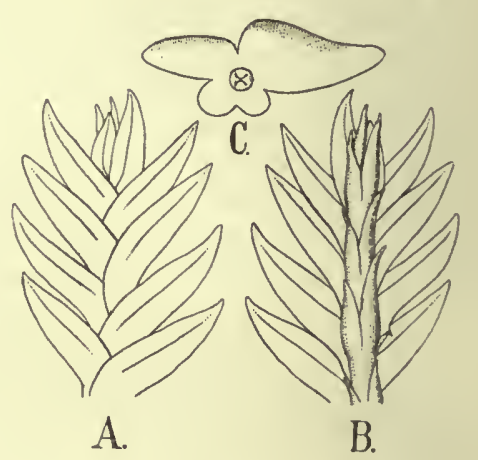

Fig. 241.

Fig. 239. Lycopodium volubile. Sproßstück $A$ Fig. 241. Lycopodium scariosum. von oben, $B$ von unten $(5 X)$. $A$ Ober-, $B$ Unteransicht 5 fach vergr. $C$ (stärker vergr.) Querschnitt.
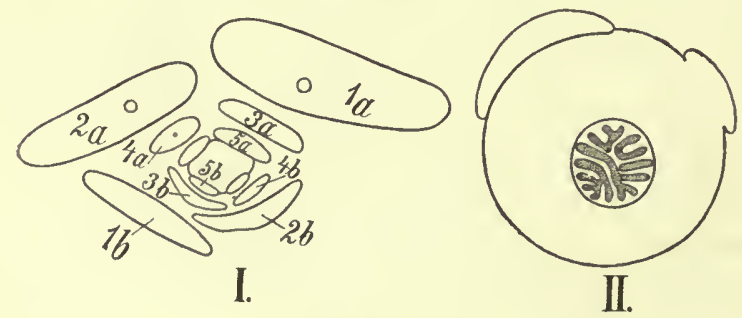

Fig. 240. Lycopodium scariosum. I Querschnitt durch eine Knospe; die zu einem Paar gehörenden Blätter mit $1 a, 1 b, 2 a, 2 b$ usw. bezeichnet.

II Stammquerschnitt.

Fig. 240.

4. Auf andere Weise als L. complanatum erreicht Lycopodium scariosum (das Verf. in Neuseeland beobachtete) dasselbe "Ziel", d. h. den Übergang von radiärer in dorsiventrale Ausbildung ${ }^{1}$ ).

Betrachten wir die Sprosse höherer Ordnung, so sehen wir sie wie bei L. complanatum auf der Lichtseite (Fig. 241, A) abgeflacht. Aber es sind hier nicht die seiılichen Blätter, welche stark entwickelt sind,

1) Ganz ähnlich verhält sich L. Iussiaei nach Untersuchung eines aus Peru stammenden Herbar-Exemplares. In einem neueren botanischen Werke behauptet der Verfasser: "Die kleinen Blätter stünden auf der Oberseite, die großen auf der Unterseite wie bei Selaginella." Die anatomische Struktur zeigt sofort die Unrichtigkeit dieser Angabe. 
sondern die nach oben gekehrten, die nach unten gekehrten dagegen sind klein und unscheinbar (Fig. 240,241 B). Bei den auf der Lichtseite stehenden Blättern ist die Unterseite (die abaxiale) die dem Licht zugekehrte und dementsprechend wird sie auch anatomisch als „Ober"seite ausgebildet.

Ein Schnitt durch den Vegetationspunkt (Fig. 240) zeigt, daß schon frühzeitig eine Förderung der nach oben gekehrten Blätter eintritt: Die kräftigeren Sprosse zeigen eine mehrreihige Beblätterung (nicht nur eine annähernd vierreihige wie die Sprosse höherer Ordnung). Eine Verschiedenheit der Blätter auf der Licht- und Schattenseite ist auch hier vorhanden, aber lange nicht so auffallend wie bei den anderen Sprossen. $\mathrm{Da} B$ auch diese Sprosse dorsiventral sind, zeigt die exzentrische Lage des Zentralzylinders, welcher der Schattenseite genähert liegt (Fig. 240 II). Wir sehen hier also eine stärkere Entwicklung der Lichtseite, die auf andere Weise erfolgt als bei L. complanatum. Bei dieser Art waren es die seitlichen Blätter, welche die Erscheinung der "Phototrophie". am stärksten zeigen, hier sind es die oberen; die Sprosse ron L. scariosum sind gegenüber denen von L. complanatum um $45^{\circ}$ gedreht, d. h. sie kehren dem Lichte nicht eine, sondern zwei Blattreihen $\mathrm{zu}$, und diese sind nun stärker entwickelt als die auf der Schattenseite. Die Sprosse sind hier also nur epitroph. Bei beiden Arten handelt es sich, teleologisch gesprochen, darum, eine möglichst breite chlorophyllhaltige Fläche aus einem mehrzeilig beblätterten Sproß zu schaffen. Das geschieht, wenn eine Blattzeile nach oben gewendet ist, vor allem durch starke Entwicklung der Seitenblätter (L. complanatum), wenn zwei Blattreihen nach oben gekehrt sind durch starke Entwicklung dieser unter entsprechender Lagenveränderung, wobei diese Blätter auch etwas asymmetrisch werden.

Es liegt also vor: einerseits Förderung der dem Lichte zugewandten Sproßseite gegenüber der Schattenseite (Epitrophie), andererseits Herstellung einer Assimilationsfläche, wobei die Pflanze sich um den anato-
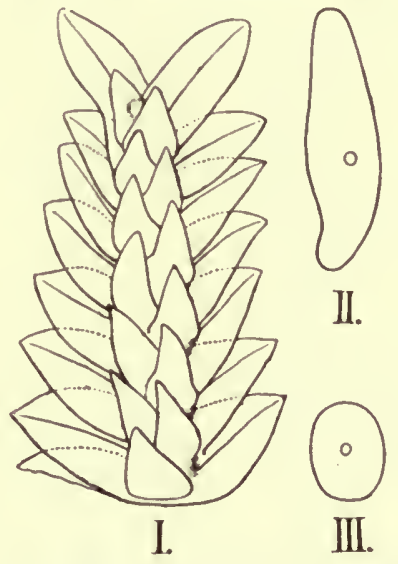

Fig. 242. I Lycopodium paradoxum, SproB $(5 X)$ von oben. II Lycop. carolinianum, Querschnitt eines randständigen. III (bei derselben Vergröß.), Querschnitt eines auf der Oberseite stehenden Blattes. mischen Gegensatz der sonst zwischen Oberund Unterseite der Blätter herrscht, nicht kümmert, sondern die Lichtseite als (anatomische) Oberseite ausbildet und umgekehrt.

4. Als letzten Typus können wir den von I. paradoxum bezeichnen. Auch hier sind an den kriechenden Sprossen vier Blattreihen vorhanden deren Stellung der bei L. scariosum erwähnten entspricht. Es sind aber nicht die oberen sondern die unteren Blattreihen die größeren, die Sprosse sind hypotroph (Fig. 242 I), ähnlich wie dies bei.zahllosen Arten der umfangreichen Gattung Selaginella der Fall ist ${ }^{1}$ ). Ähnlich verhält sich auch L. carolinianum (in Ceylon gesammelt). Hier stehen auf der Oberseite zahlreiche schmale, fast nadelförmige aufgerichtete Blätter (vgl. den

1) Es ist nicht überflüssig, darauf hinzuweisen, daB L. paradoxum an besonders $\mathrm{schattigen} \mathrm{Standorten} \mathrm{wächst} \mathrm{(}{ }^{\text {ad }}$ abrupta viarum umbrosarum" Martius, Icones plant. cryptog., p. 28).

Goebel, Organographie der Pflanzen. 2. Aufl. Allgem. Teil. 
Querschnitt Fig. 242 III). Die auf der Unterseite stehenden Blätter breiten sich dagegen flach aus und sind viel breiter und länger (Fig. 242 II).

Wenn wir, wie die angeführten Beispiele zeigen, innerhalb einer Gattung bei plagiotropen Sprossen ein so verschiedenes Verhalten finden, so ist dies kaum anders verständlich, als durch folgende Annahmen:

1. Die Verbreiterung plagiotroper, mehrreihig beblätterter Lycopodiumsprosse erfolgte unter dem Einfluß eines äußeren Faktors, und zwar dem des Lichtes.

2. Die einzelnen Arten waren für dessen Einwirkung sehr verschieden empfänglich (vgl. z. B. L. annotinum mit L. complanatum), ebenso ist die Empfänglichkeit bei den verschiedenen Sproßgenerationen einer Pflanze eine verschiedene.

3. Auch bei den empfänglichen Arten waren die für die Lichtwirkung empfindlichen Teile nicht überall dieselben. Die am stärksten geförderten Blätter sind bald die oberen (L. scariosum), bald die seitlichen, bald die unteren. Dabei wird die anatomische Ausbildung ohne Rücksicht auf die ursprüngliche Stellung der Blattflächen zum Vegetationspunkt nach der Lichtlage geregelt, und so schließlich überall ein physiologisch übereinstimmendes Verhalten erreicht.

Übrigens kommt noch eine andere Art der Flächenbildung vor, die nur beiläufig erwähnt sei. Bei Lycop. nummulariaefolium sind die Blätter „komplanat" wie bei manchen Moosen, $d$. h. sie liegen dem dünnen Stamme annähernd in einer Ebene an. Da sie aber alle annähernd gleich groß sind, gehört dieser Fall im Grunde nicht hierher.

Schließlich mag noch betont sein, daß die Keimpflanzen der Lycopodiumarten mit anisophyllen, dorsiventralen Sprossen zunächst radiär und isophyll sind. Die Heterophyllie bei L. volubile z. B. macht sich erst geltend bei Pflanzen, die über $8 \mathrm{~cm}$ lang sind, bei jungen Pflanzen sind die Blätter an Größe gleich und in einer irregulären Spirale angeordnet ${ }^{1}$ ). Ahnlich ist es bei L. scariosum, nur daß die Heterophyllie hier früher einsetzt.

Es spricht dieses Verhalten gleichfalls dafür, daß die Anisophyllie von der radiären Struktur abgeleitet ist. Daß bei einigen Lycopodiumarten wie L. inundatum, cernuum, laterale, welche einen "Protokorm" besitzen, dieser dorsiventral ist, kann gegen die soeben angeführte Anschauung nicht geltend gemacht werden, denn dabei handelt es sich um eine sekundär entstandene Anpassung, wie sie auch sonst noch vielfach sich vorfindet (Beispiele in dem Abschnitt über Entwicklung).

B) Selaginella. In dieser umfangreichen Gattung finden sich isophylle und anisophylle Arten - letztere sind an Zahl bei weitem überwiegend ${ }^{2}$ ), bei Lycopodium dürfte das Umgekehrte stattfinden. Die isophyllen Arten sind teils vierreihig beblättert, wie die in Fig. 243 abgebildete Selag. Preissiana, teils mehrreihig („spiralig“), wie z. B. S. spinulosa, S. rupestris. Wenn man bedenkt, daß etiolierte Sprosse der letzteren vierreihige $\mathrm{Be}$ blätterung aufweisen, sowie daß die Blüten bei S. rupestris und spinulosa gleichfalls vierzeilig beblättert sind, so dürfen wir diese Blattanordnung (mit Blattpaaren gleicher Größe, die sich unter einem annähernd rechten Winkel kreuzen) wohl als ursprünglich („typisch") für die Selaginellen ansehen, und von ihr auch die anisophyllen Selaginellen ableiten.

Dafür spricht auch, daß es eine Form gibt, die - offenbar je nach äußeren Umständen - bald isophyll, bald anisophyll vorkommen kann.

1) J. E. Holloway, A comparative Study of the anatomy of six New Zealand species of Lycopodium. (Transactions of the New Zealand institute, vol. XLII, 1909, p. 360.)

$\left.{ }^{2}\right)$ BAKER, Handbook of the Fern-Allies zählt 334 Arten auf, von denen 8 isophyll sind. 
S. sanguinolenta, eine an steinigen und, der Blattanatomie nach $\mathrm{zu}$ schließen, wenigstens zeitweilig trockenen Standorten ${ }^{1}$ ) wachsende Art hat aufrecht wachsende Sprosse mit vier Reihen anliegender, derber Blätter, die alle von gleicher Größe und quer zur Längsachse der Sprosse inseriert sind (Fig. 244). Außer diesen kommen aber auch Sprosse vor, bei denen Anisophyllie eingetreten ist, wenn auch nicht in so hohem Grade wie bei anderen Selaginellaarten. Immerhin kann man, wie Fig. 245 zeigt, sehen, daß auf der Oberseite der Sprosse Blätter stehen, die kleiner

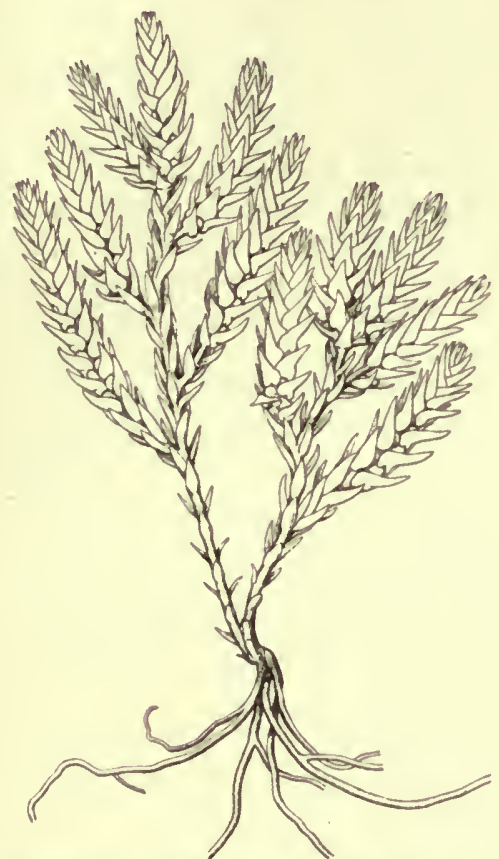

Fig. 243. Selaginella Preissiana. Habitusbild, etwas mehr als doppelte Naturgr. An der Basis Astanlagen (zurückgebliebene Gabelsprosse). Die entwickelten Äste enden in Blüten.

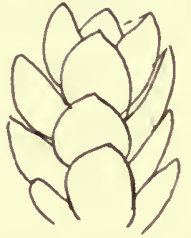

Fig. 244. Selaginella sanguinolenta. Spitze eines gewöhnlichen, isophyllen Sprosses. Vier Blattreiben vorhanden ans gleichgroßen and gleichgestalteten Blättern.

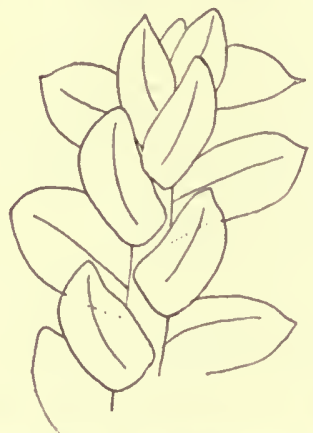

Fig. 245. Selaginella sanguinolenta. Dorsiventraler, anisophyller Sproß von oben.

Etwas stärker vergr. als Fig. 244.

sind als die Seitenblätter. Außerdem haben die Blätter hier eine schiefe Insertion, was ihnen eine günstige Ausnutzung des einfallenden Lichtes, ohne sich gegenseitig stark zu decken, ermöglicht. Diese Sprosse sind offenbar solche, die an beschatteten und zugleich feuchteren Standorten gewachsen sind, was sich auch darin ausspricht, daß die Blätter größer sind als an den isophyllen Sprossen. Die ersteren sind plagiotrop und schwach dorsiventral geworden unter dem Einfluß schwacher, einseitiger Beleuchtung.

1) Überhaupt wachsen die isophyllen Selaginellen (soweit sie mir aus eigener Anschanung bekannt sind, S. spinulosa, rupestris) an trockneren und helleren Standorten als die anisophyllen. Daß auch unter letzteren Formen sich finden, die an besonderen Standorten wachsend sich periodischer Austrocknung angepaßt haben (S. lepidophylla), ist wohl als eine seknndäre Erscheinnng za betrachten. Leider ist es mir bis jetzt nicht gelungen, Sel. sanguinolenta lebend $\mathrm{zu}$ erhalten und ihr Verhalten experimentell zu prüfen. 
Was hier offenbar direkt infolge äußerer Einwirkungen eintritt, die dorsiventrale Struktur, ist bei den anderen Selaginellen, soweit wir wissen,

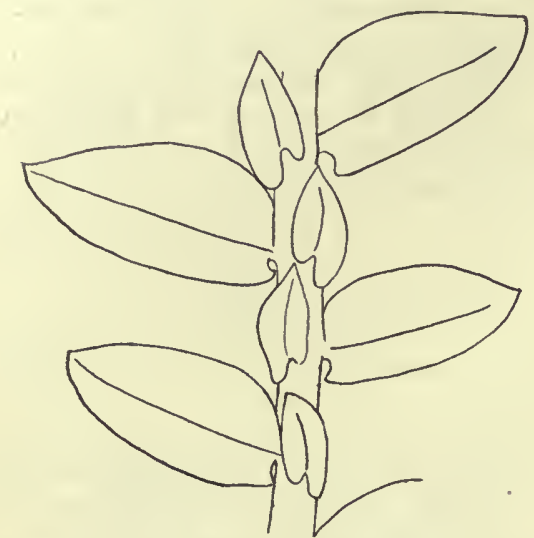

Fig. 246. Selaginella Galeottii. Sproßstiick von oben (vergr.). Die auf der Oberseite stehenden Blätter kleiner als die auf der Unterseite; außerdem die Blätter ungleichhälftig. erblich, d. h. von äußeren Faktoren unabhängig. Bei manchen, z. B. Sel: caulescens, wachsen die Sprosse zunächst orthotrop und sind dann vollständig isophyll, werden dann aber später plagiotrop und anisophyll. Bei anderen tritt schon von vornherein Anisophyllie auf. Die seitlich inserierten Blätter kehren ihre Oberseite, die auf der Oberseite stehenden ihre (morphologische) Unterseite dem Lichte zu (Fig. 246). Dabei ist charakteristisch, daß die vier Blattzeilen einander nicht mehr unter rechtem Winkel schneiden (vgl. Fig. 246a). Dies kehrt bei anderen anisophyllen Pflanzen, wie wir sehen werden, wieder und ist eine Einrichtung, welche die die Assimilation hauptsächlich besorgenden Blätter in die günstige seitliche Lage bringt. Die Dorsiventralität ist schon im Vegetationspunkt ausgeprägt, dessen Querschnitt nicht kreisförmig, sondern elliptisch ist, indem die Licht- und die Schattenseite abgeplattet sind. Bei vielen Selaginellen tritt auch Asymmetrie der einzelnen Blätter auf, gleichfalls eine bei dorsiventralen Sprossen weit verbreitete Erscheinung. Während also bei

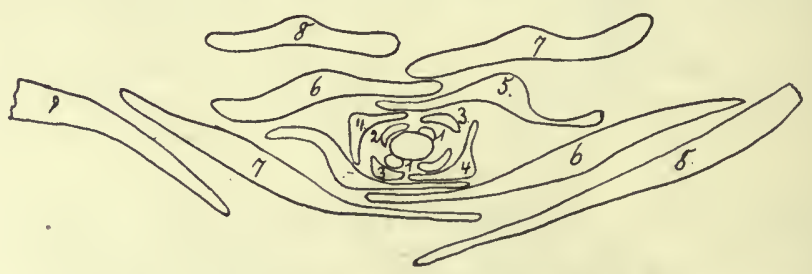

Fig. 246a. Querschnitt durch eine Sproßspitze von Selaginella haematodes. Die schief sich kreuzenden Blattpaare der Altersfolge nach beziffert; die auf der Oberseite stehenden Blätter kleiner als die auf der Unterseite stehenden (Blatt 8 und 9 nicht ganz gezeichnet, im zweiten und fünften Blattpaar ist bei dem unteren Blatt die Nummer weggeblieben).

Lyc. complanatum von den vier Blattreihen zwei einander gegenüberliegende sich an der Herstellung der Assimilationsfläche beteiligen, bei Lyc. scariosum die beiden óberen, sind es bei Selaginella die zwei einander angrenzenden Blattreihen der Sproßunterseite, die dieselbe Rolle spielen. Dort trat eine auffallende Veränderung der Blattform ein, es fielen die auf der Schattenseite liegenden Blattreihen fast der Verkümmerung anheim; hier werden die großen Blätter schon bei ihrer Anlage am Vegetationspunkt nach der Lichtseite hin gerückt, und nehmen auch die beiden Reihen kleinerer Blätter, welche der Sproßachse anliegen, an der Assimilation noch Anteil. Die oben angeführten Erfahrungen, $\mathrm{da} ß$ es 1. eine Selaginellaart gibt (S. sanguinolenta), bei der die Anisophyllie nicht konstant, sondern offenbar unter dem Einfluß äußerer Faktoren 
auftritt, und daß 2. bei manchen starkwüchsigen Selaginellaarten die Sprosse in ihrem unteren Teile noch isophyll sind, und 3. die Tatsache, daß bei etiolierten Sprossen von Sel. helvetica die Anisophyllie zwar nicht ganz verschwunden, aber doch vermindert ist, sprechen dafür, daß auch bei den "habituell" anisophyllen Selaginellen eine ursprünglich durch das Licht bedingte Veränderung des Symmetrieverhältnisses des Vegetationspunktes vorliegt.

Daß diese keine unabänderliche ist, obwohl experimentell nicht einmal eine Vertauschung der beiden Seiten durch Änderung des Lichteinfalls gelingt, zeigt einerseits die später zu erwähnende merkwürdige Gallenbildung bei S. pentagona, andererseits das Verhalten der Blüten (Sporangienstände) bei manchen Selaginella-Arten. Es soll hier nur das Verhalten der Sporophylle - der Blätter, in deren Achseln die Sporangien stehen - berücksichtigt werden, nicht die Verteilung der beiderlei Sporangien (Mikro- und Makrosporangien). Die meisten Selaginellen haben Blïten, deren Sporophylle alle (wenigstens annähernd) gleich groß sind. Außerdem gibt es auch dorsiventrale Blïten. Nur selten setzt sich bei ihnen das Größenverhältnis der Blätter direkt in die Blüten fort, so also, daß auch in diesen die nach oben (dem Lichte) zugekehrten Blätter die kleineren sind. Meist sind diese Bliiten invers dorsiventral ${ }^{1}$ ), d. h. die oberen Sporophylle sind größer als die unteren. Die Ursache dieser Ausbildung ist unbekannt. Ersichtlich ist nur, daß sie mit der Sporangienbildung korrelativ zusammenhüngen muß. Denn wenn man die letztere unterdriickt dadurch, daß man eine Bliite abschneidet und als Steckling benutzt, so wächst sie in einen vegetativen Sproß aus, bei welchem (der Blüte gegenüber) die Blätter auf der Unterseite vergrößert, auf der Oberseite verkleinert werden.

Wir nehmen also an, daß die Dorsiventralität der Selaginellen eine nur scheinbar, d. h. nur für die bis jetzt angewandten groben Methoden, fest induzierte ist. Sie sitzt nur nicht so locker wie bei anderen Formen; die Pflanze selbst kann sie beseitigen. Das müßte auch dem Experimentator gelingen, wenn er über die richtigen Mittel verfügen wïrde, $d . h$. über die, welche geeignet sind, die Beschaffenheit des Vegetationspunktes zu beeinflussen, z. B. durch Zufuhr organischer Substanzen.

Wie (nach des Verf.s Ansicht) der Bau der Sproßachse mit der Anordnung und der Symmetrie der Blätter zusammenhängt, mag das Schema Fig. 247 erläutern.

Wir denken uns die abgeflachte Sproßachse in vier Quadranten (einen dorsalen $D$, einen ventralen $V$ und zwei laterale $F_{1}$ und $F_{2}$ ) geteilt, die Grenzlinien der Quadranten bezeichnen zugleich die Blattinsertionen. Gemäß der hypotrophen Ausbildung ist der ventrale Quadrant größer als der dorsale ${ }^{2}$ ). Es ergibt sich nun ohne weiteres, daß bei jedem Blatte die + Seite einer + Hälfte der SproBachse, die - Seite einer - Hälfte der letzteren zugekehrt ist (z. B. $a$ und $b$ sind ein Paar, die + Seite von $a$ ist der aus $V+F_{2}$, die - Seite der aus $D+F_{1}$ gebildeten Sproßachsenhälfte zugekehrt, ebenso bei $b$ usw.).

Ferner ist durch das Verhalten der Sproßachse auch die Tatsache bedingt, daß bei der Verzweigung unmittelbar unter der Verzweigungsstelle ein (mehr oder minder) symmetrisches Blatt auftritt (wenn die beiden

1) GоввEL, Sporangien, Sporenverbreitung und Blütenbildung bei Selaginella, Flora 68 (1901), p. 207.

$\left.{ }^{2}\right)$ Selbstverständlich handelt es sich dabei nicht um eine räumliche Abgrenzung, es sollen nur die "Potenzen" der verschiedenen Sproßachsenteile versinnlicht werden. 
„Gabeläste" an Kräftigkeit stark voneinander abweichen, ist indes das Blatt asymmetrisch, derart, daß die größere Hälfte auf der Seite des stärkeren Gabelastes liegt, mit dessen Blattsymmetrie es auch übereinstimmt). Die Teilung erfolgt nämlich in der durch die punktierte Linie der Fig. 247 angedeuteten Symmetrieebene. .Dabei wird der Quadrant $V$ halbiert und nun annähernd so groß wie $F_{1}$ oder $F_{2}$, demgemäß wird das unter der Gabelungsstelle stehende Blatt symmetrisch werden, während es, wenn bei der Teilung $V$ größer bleibt als $F$, asymmetrisch wird (Fig. 248).

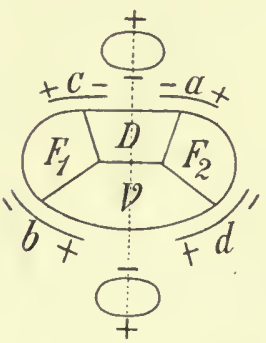

Fig. 247. Schema für die Blattbildung und das Verhalten der Wurzelträger (diese stehen oben und unten, sie kehren ihre Minusseite der Sproßachse $\mathrm{zu}$ ).

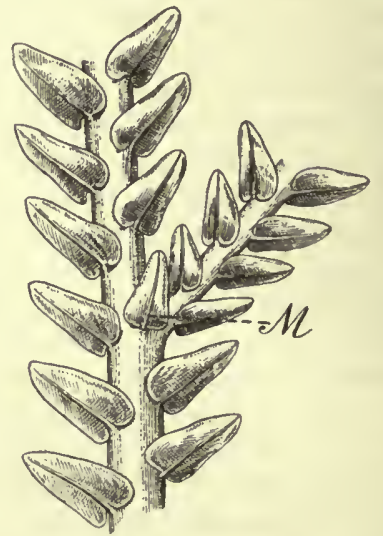

Fig. 248. Selaginella Martensii $(2 \times)$ von unten. Das "Mittelblatt" $M$ an der Verzweigungsstelle ist fast symmetrisch, seine linke Hälfte ist etwas größer als seine rechte.

Ferner: Die "Wurzelträger" ron Selaginella (vgl. p. 110) entstehen dorsal und ventral; daß meist nur der unten zur Entwicklung gelangt hängt mit der starken Ausbildung des Ventralquadranten zusammen. Sie können zu beblätterten Sprossen auswachsen. Der obere kehrt seine Plusseite nach oben ${ }^{1}$ ) (kann also erst durch eine Überkrümmung die normale Lichtlage erreichen). Der untere kehrt seine - Seite nach oben. Die Wurzelträger entstehen stets unterhalb einer Gabelung. Die aus Wurzelträgern hervorgegangenen Sprosse sind also stets in gesetzmäßiger Weise zum Hauptsproß orientiert (exotroph), sowohl auf dessen Plus- als auf dessen Minusseite.

\section{$\S 15$. Anisophyllie bei Coniferen.}

Zwischen Lycopodinen und Coniferen besteht bekanntlich vielfach eine Habitusähnnlichkeit, bedingt durch Gestalt und Anordnung der Blätter. Eine solche Ähnlichkeit tritt auch auf hinsichtlich der Anisophyllie, die bei den Coniferen allerdings nicht in so mannigfaltiger Ausbildung vorkommt, wie wir sie bei Lycopodinen kennen lernten.

Die Ausbildung der Seitenzweige mancher Cupressineen gleicht ganz

1) Boshart a. a. 0.; R. Fries, Et Bidrag till kaennedomen om SelaginellaRotbaerarna. Svensk botanisk tidskrift 1911. 
der der plagiotropen Sprosse von Lycopodium complanatum. Sie sind vierreihig beblättert, die freien Blatteile sind nur wenig entwickelt gegenüber den Blattpolstern, welche mit der Sproßoberfläche verschmolzen sind.

An den orthotropen Sprossen von Thuyopsis bestehen alle vier Blattreihen aus gleichgestalteten Blättern, welche auch alle Achselsprosse hervorbringen können. Die abaxiale Seite dieser Blätter (resp. Blattpolster) ist als Unterseite ausgebildet und mit zwei Wachsstreifen versehen, die adaxiale kommt für die $C$-Assimilation kaum in Betracht. Dagegen ist bei den plagiotropen Sprossen (Fig. 249) die abaxiale Seite sämtlicher auf der Lichtseite befindlicher Blätter als "Oberseite" entwickelt, was sich schon in dem dunkleren Grün und dem Verschwinden der Wachsstreifen zeigt. Die ersten "Oberblätter" zeigen sie bei kräftigen plagiotropen Sprossen auch.

Fig. 249. Thuyopsis dolabrata. $A$ Zweig ron unten, $B$ ron oben, $C$ Querschnitt des freien Teiles eines seitlichen Blattes, $O$ Oberseite, $U$ Unterseite, $H$ Harzgang, $G$ Leitbiindel, Assimilationsgewebe auf der Lichtseite schraffiert.

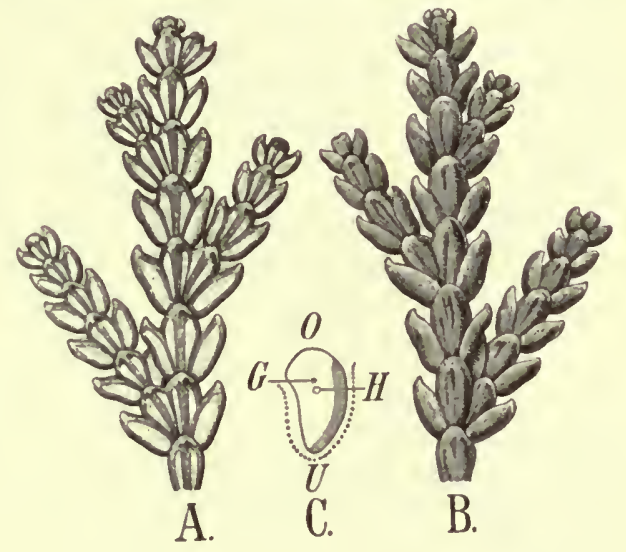

Man findet auch Übergangsformen mit einem Wachsstreifen und Zweige, an denen die Ausbildung der Ober- und Unterseite wechselt, derart, daß dieselbe Seite eine Strecke weit als „Oberseite“, dann als Unterseite entwickelt ist, was offenbar mit Beleuchtungsdifferenzen zusammenhängt. Der ganze plagiotrope Sproß hat also blattähnliche Gestalt und blattähnlichen Bau angenommen.

Das ist namentlich auch bedingt durch die Seitenblätter, welche gegenüber den Ober- und Unterblättern gefördert sind (wie die Amphitrophie auch in der Beschränkung der Verzweigung auf die Flanken hervortritt) und einen merkwürdigen Bau zeigen. Die abaxiale Seite (also die Unterseiten, Fig. 249, C) ist stark kielförmig entwickelt. Sie hat auf ihrer Lichtseite einen anderen anatomischen Bau als auf ihrer Schattenseite; ersterer nimmt teil am Bau der Sproßoberseite, letzterer an dem der Unterseite. Hier ist also ein Blatt auf seiner abaxialen (sonst als Unterseite ausgebildeten) Seite anatomisch teils als Ober-, teils als Unterseite entwickelt, und die Abflachung des $Z$ weiges ist wesentlich mit bedingt durch die Kielbildung der Seitenblätter, welche - ebenso wie die von Lycopodium complanatum - sich den „unifażialen" Blättern nähern und beträchtlich stärker entwickelt sind als die auf der Ober- und die auf der Unterseite stehenden Blätter. Ähnliche, nur weniger scharf ausgeprägte Bauverhältnisse zeigt z. B. auch die bekannte Thuya occidentalis.

Bei den mit zerstreuter Blattstellung versehenen Coniferen tritt an den plagiotropen Sprossen Anisophyllie namentlich dann deutlich hervor, wenn die Nadeln "gescheitelt" sind. Dabei sind die auf der Oberseite 
stehenden Nadeln kürzer als die auf der Unterseite stehenden, so besonders auffallend bei Tsuga canadensis und Abies pectinata. Diese Formen sind also hypotroph. Es wird bei Besprechung des Zustandekommens der Anisophyllie auf diese Fälle zurückzukommen sein.

\section{$\S 16$. Anisophyllie bei Angiospermen.}

Wie bei den niederen Pflanzen, so tritt auch bei den höheren Anisophyllie in den verschiedensten Verwandtschaftskreisen und oft innerhalb einer und derselben Gattung in verschiedenem Grade auf. Die Blätter der einen Seite (der Oberseite) unterscheiden sich zunächst nur durch geringere Größe von denen der anderen, aber bei hochgradiger Anisophyllie, wie sie namentlich bei manchen Urticaceen, Elatostemma, Pellionia u. a. vorhanden ist, finden wir die beiden Blätter nicht nur durch ihre Größe, sondern auch durch ihren Bau und ihre Funktion voneinander sehr verschieden. Es lassen sich zunächst zwei, freilich nicht scharf trennbare Fälle unterscheiden. In dem einen sind nur die Seitensprosse radiärer isophyller Hauptsprosse anisophyll; wir können diesen Fall als laterale Anisophyllie ${ }^{1}$ ) bezeichnen, im zweiten ist das ganze Sproßsystem anisophyll: habituelle Anisophyllie.

\section{A. Die laterale Anisophyllie}

tritt am auffallendsten auf an den seitlichen Ästen von Holzpflanzen mit großen dekussierten Blättern (z. B. Aesculusarten (Fig. 250), Sambucus nigra, Acer campestre, platanoides, Pseudoplatanus u. a. Fraxinus, Staphylea pinnata) aber auch z. B. bei Catalpa syringaefolia, welche dreigliederige Blattwirtel besitzt. Minder auffallend sind die Differenzen bei zerstreuter Blattstellung (vgl. das oben von Quercus und das unten von Abies Angeführte).

Die Anisophyllie ist übrigens auf Holzgewächse nicht beschränkt, sie findet sich auch bei krautigen Pflanzen, z. B. bei Urtica, Scrophulariaarten u. a.; namentlich bieten die Tropen dafür eine reiche Anzahl von Beispielen. Bei unseren Sträuchern fehlt sie gewöhnlich denen, die, wie oben erwähnt, ihre Blätter an den Seitensprossen durch Drehung in eine Ebene verschieben, oder tritt doch nur an den letzten, ihre Stellung beibehaltenden Blättern eines Jahrestriebes hervor.

An Eschen- und Ahornarten (auch bei dem in Fig. 250 abgebildeten Aesculuszweig) ist nicht selten das oberste, unmittelbar an die Terminalknospe angrenzende Blatt als Knospenschuppe, das untere als Laubblatt ausgebildet, was gleichfalls zeigt, daß die Blattbildung auf der Unterseite gefördert ist.

Bei Pflanzen mit dekussierten Blättern, bei welchen die Blattpaare nicht durch Internodiendrehung in eine Ebene gebracht werden, bleiben die Blätter entweder in ihrer normalen Lage, d. h. zwei Blattreihen seitlich, eine oben, eine unten, oder es findet eine Drehung statt, so daß die Blattreihen diagonal stehen. Im ersteren Fall, der bei der lateralen Anisophyllie der gewöhnliche ist, sind an den seitlichen Blattreihen die beiden einander gegenüberstehenden Blätter von gleicher Größe. Im zweiten, der

1) WiEsner hat diesen Ausdruck in anderem Sinne gebraucht, vgl. die Bemerkung in FIGDor, Die Erscheinung der Anisophyllie p. 27 (daselbst auch die Literatur angeführt). 
bei der habituellen Anisophyllie stets eintritt, sind die zwei oberen Blattreihen aus kleineren Blättern gebildet als die beiden unteren. Auch bei lateraler Anisophyllie kann aber (z. B. bei Aesculus Hippocastanum Fig. 250) eine solche Drehung eintreten. Die größeren Blätter haben auch größere Achselknospen als die kleineren. Es sind also die dem Muttersproß abgekehrten Teile gefördert, eine Förderung, die wir bei Bäumen als eine vorteilhafte bezeichnen können, weil die assimilierende Blattfläche dadurch an die Außenseite der Baumkrone verlegt wird, wo die Beleuchtungsverhältnisse günstigere sind.

Fig. 250. Aesculus Hippocastanum nach NordHAUSEN. Zum Horizont geneigter Zweig. Vorhanden sind 3 Blattpaare: $a-, a+; b-, b+;(c-$ als Knospenschuppe ausgebildet und desbalb in der verkleinerten $\mathrm{Ab}$ bildung nicht sichtbar) $c+$ Das geförderte Teilblättchen ist mit + , das geminderte mit - be. zeichnet.

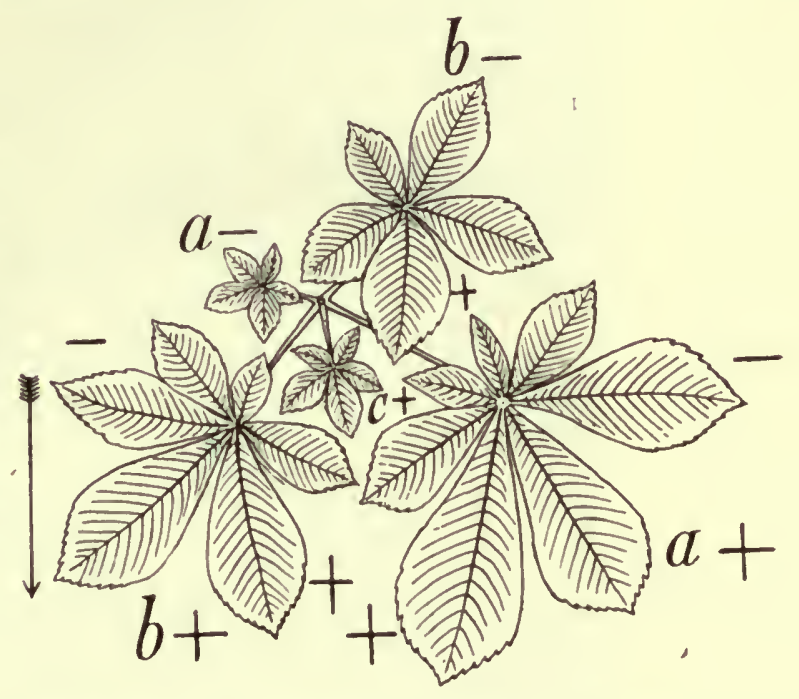

Bei den Pflanzen mit habitueller Anisophyllie bringen entweder auch die größeren Blätter allein oder doch kräftigere Achselsprosse hervor (Procris, Elatostemma), oder die kleineren (Pilea muscosa, Schlechtendali u. a. Wie es scheint, findet sich der letztgenannte Fall nur bei kleinblätterigen Pflanzen, er wird wohl auf einer Korrelation zwischen Blatt- und Achsels̄proßgröße beruhen (vgl. S. 97).

B. Habituelle Anisophyllie.

Es sind dies Fälle, die sich an das bei Selaginella besprochene anschließen, nur daß sie teilweise noch weiter - bis zum Verkümmern der auf der Oberseite stehenden Blätter - geführt werden.

I. Urticaceen. Hier sind besonders zahlreiche Formen durch Anisophyllie ausgezeichnet. Manche davon werden auch in Gewächshäusern kultiviert. Die meisten sind Schattenpflanzen der Tropenwälder. In Fig. 251 ist Procris laevigata abgebildet; die größeren Blätter tragen gewöhnlich allein regetative Seitensprosse ${ }^{1}$ ). In ihren Achseln entstehen auch die weiblichen Infloreszenzen (Fig. 251A), während die männlichen auf der Oberseite in der Achsel der kleineren Blätter

1) Man kann aber durch Entgipfeln oberbalb eines der kleineren Blätter auch bei ihnen vegetative Achselsprosse hervorrufen. Die Achselknospen haben ihr größeres Blatt auf der Seite, auf der die größere Hälfte der Deckblätter liegt. 


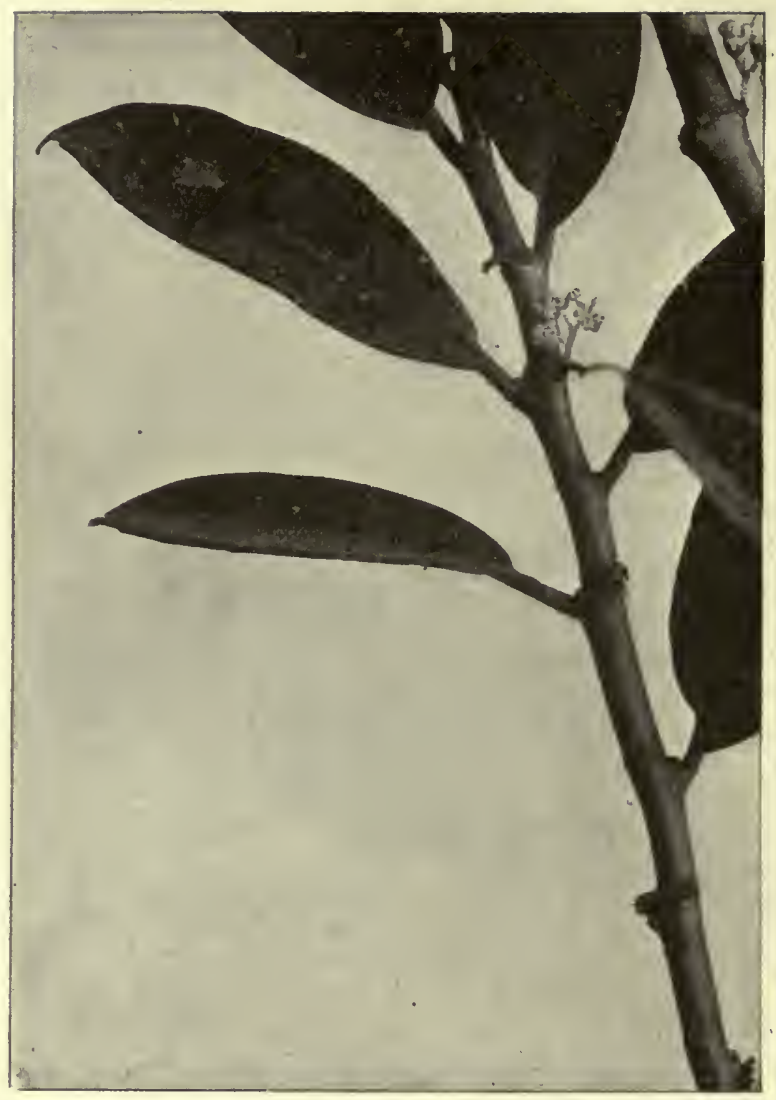

Fig. 251. Procris laevigata. (Von oben) männliche Infloreszenzen in den Achseln der kleinen schuppenförmigen Blätter.

stehen (Fig. 251), ein höchst interessanter weiterer Ausdruck der Dorsiventralität $\left.{ }^{1}\right)$.

(1) Die Verfolgung der Keimungsgeschichte zeigt, daß die Anisophyllie schon an der Hauptachse der Keimpflanze auftritt (Fig. 252), aber zunächst in viel geringerem Maße als später, so daß die allmähliche Herausbildung an der Keimpflanze noch deutlich zutage tritt. Dabei finden Schwankungen statt: die ersten, mit den Kotyledonen gekreuzten Blätter sind bei den einen Keimpflanzen (Fig. $252 I$ und $I V$ ) gleich groß, bei anderen (Fig. $252 I I$ ) schon verschieden, was sich dann bei den folgenden Blättern steigert.

Weiter vorgeschritten ist die Anisophyllie bei der in Fig. 253 abgebildeten Pellionia. Hier sind die Blätter der Oberseite zu kleinen, bald abfallenden Schuppen verkümmert, die in Fig. 253 nicht sichtbar sind.

Scheinbar ist der Sproß zweizeilig beblättert, in Wirklichkeit sind vier Blattzeilen -vorhanden, aus gekreuzten Blattpaaren bestehend. Die einander gegenüberstehenden Blätter aber sind in jedem Paare von sehr ungleicher Größe und Gestalt: die oberen, in Fig. 254 mit deutschen

1) Vgl. S. 161. Übrigens ist auch diese Regel nicht ohne Ausnabme. Gelegentlich können weibliche Infloreszenzen auch in den Achseln der kleineren Blätter stehen. 


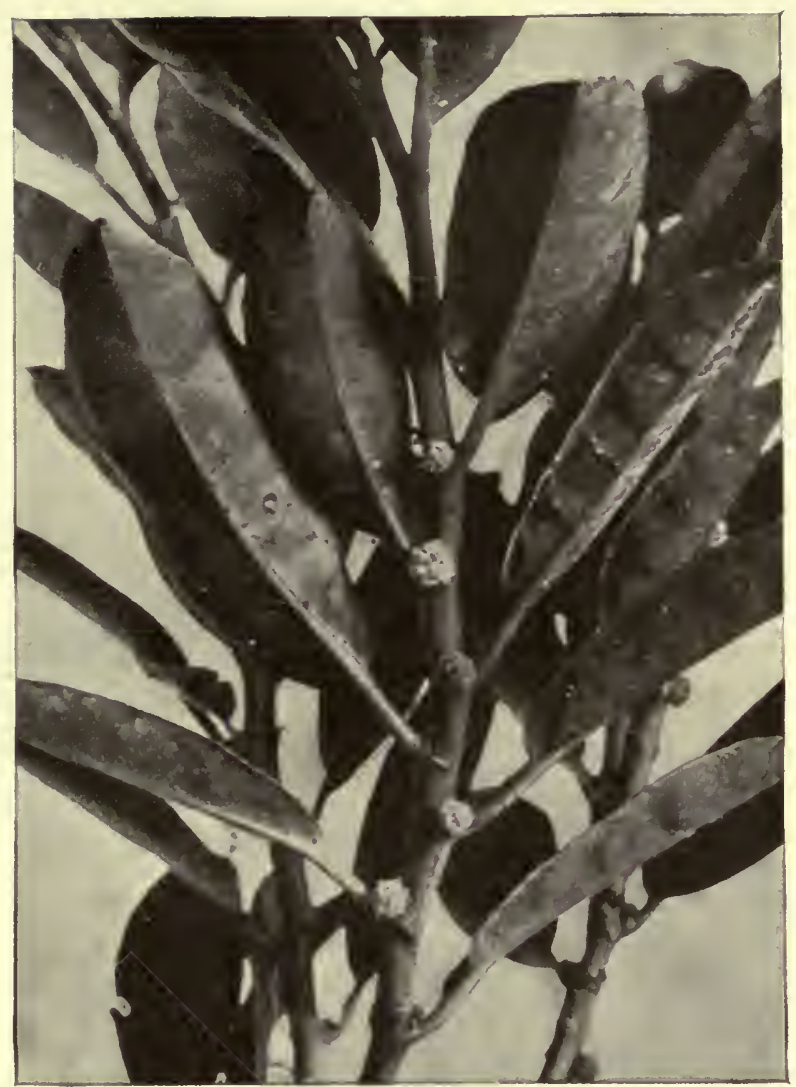

Fig. 251 A. Procris laevigata. (Von unten) weibliche Infloreszenzen in den Achseln der großen Blätter.
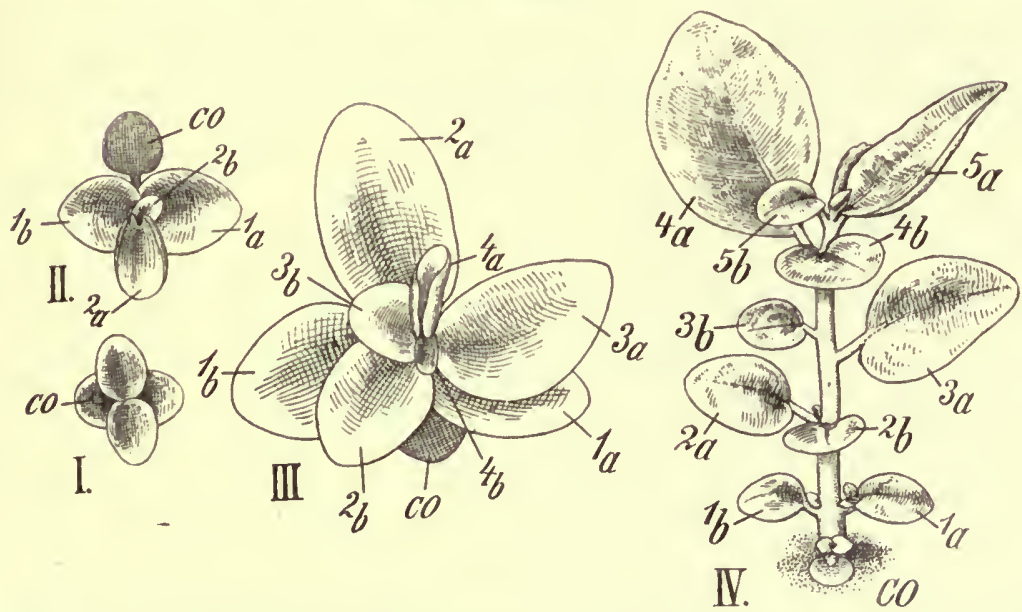

Fig. 252. Procris laevigata. Keimpflanzen. I Junge Keimpflanze von oben gesehen. Die mit den Kotyledonen gekreuzten Blätter sind gleich groß. II Etwas ältere Keimpflanze $1 a, 1 b, 2 a, 2 b$ die beiden ersten Blattpaare. Der eine Kotyledon ist verdeckt. III Keimpflanze mit 4 Blattpaaren, die kleineren Blätter immer mit $b$ bezeichnet. IV Noch ältere Keimpflanze in Seitenansicht. 
Ziffern bezeichneten sind viel kleiner als die unteren, sie haben aber wie diese hier noch ihre Axillarstipeln ${ }^{1}$.

Mehr reduziert sind die oberen Blätter bei Elatostemma sessile (Fig. 255). Es kommt bei ihnen nicht mehr zur Ausgliederung von Blatt und Nebenblatt (Axillarstipel), und man kann die oberen Blätter leicht mit Nebenblättern verwechseln. Die unteren sind als Laubblätter ausgebildet, die eine "Axillarstipel" (ein häutiges Schutzorgan der Knospe) entwickeln.

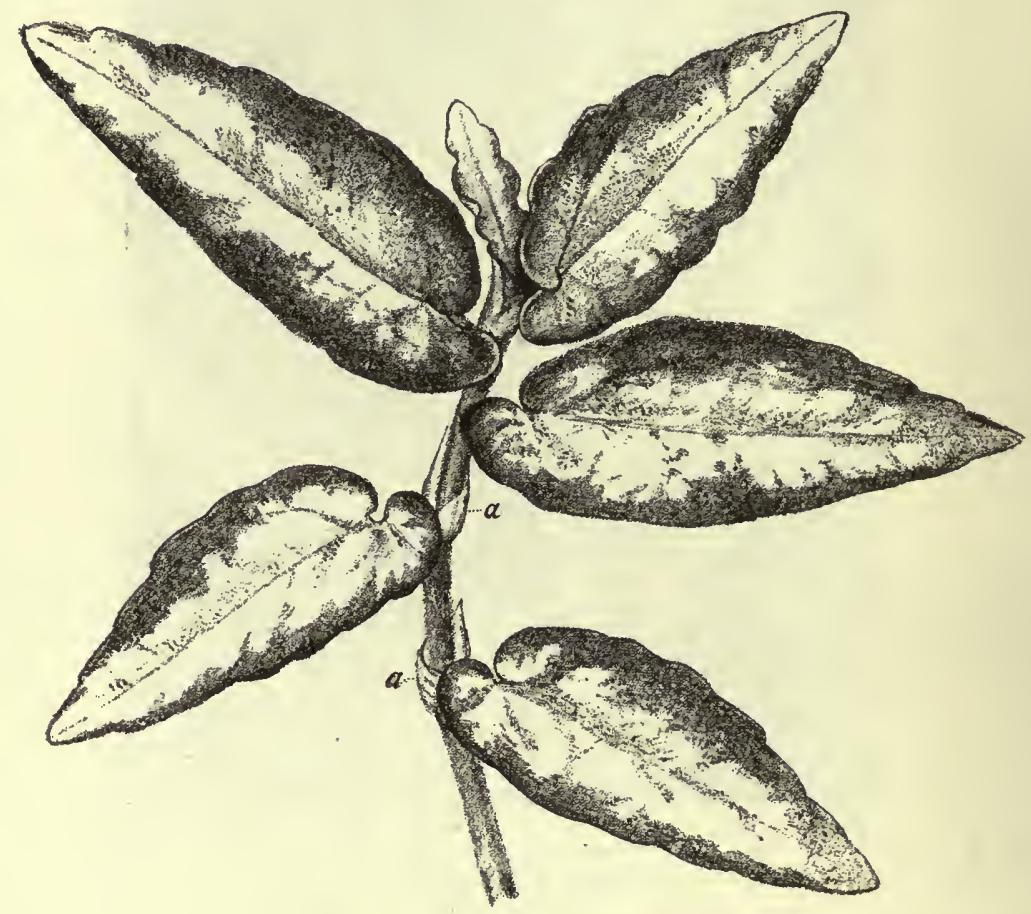

Fig. 25ॅ3. Pellionia Daveauana. Sproßstïck mit asymmetrischen Blättern. a Axillarstipeln der verkümmerten, auf der Oberseite stehenden, schon abgefallenen Blätter, die Axillarstipel der Laubblätter steht mehr nach unten; es sieht aus, als ob jedes Blatt zwei Stipulae hätte!

Fig. 255 zeigt einen Querschnitt der Knospe, die Laubblätter sind mit römischen Zahlen bezeichnet, die kleinen, ihnen gegenüberstehenden

1) Es ist ein Irrtum, wenn Figdor sagt (a. a. 0. p. 50) ich habe in der 1. Auflage die an der Oberseite der Achse stehenden kleinen Blätter gar nicht beobachtet. Ich habe sie in der ersten Auflage mit denselben Worten wie oben angegeben und in der Fig. 63 a. a. 0. gezeichnet ( $\mathrm{vgl}$. anch die Berichtigung im Vorwort zum speziellen Teile der 1. Aufl.). In dem Habitusbild sind sie nicht $z a$ seben, weil sie weggefallen waren, vorhanden sind sie hier stets. Die Vermutung Figdons, dasselbe sei anch bei Elatostemma sessile der Fall, trifft nicht zu. Erneute entwicklungsgeschichtliche Untersuchung zeigte vielmehr, daß, wie schon in der ersten Auflage angegeben, das kleinere Blatt die Axillarstipel bei El. sessile nicht mehr anlegt. Es ist dies aus Fig. 256 deutlich sichtbar. Dagegen verhält sich El. repens wie Pellionia und die Keimptlanzen von EI. sessile (Fig. 257) zeigen an dem ersten kleinen Blatt noch eine Gliederung in ein winziges grünes Blättchen und eine Axillarstipel. Bei schwächlich entwickelten Keimpflanzen war auch am ersten Blatt die Gliederung in ein kleines Blättchen und eine Axillarstipel nicht mehr zu erkennen - ob sie ganz unterbleibt (wie bei den folgenden) oder das kleine Blättchen zwar noch angelegt wird, aber sehr frühzeitig stehen bleibt, habe ich nicht untersucht. 
Schuppenblätter mit Buchstaben. Blatt $I$ ist nicht gezeichnet, nur seine Axillarstipel $s t_{1}$ ist in der Figur vorhanden. Ihm steht das Schuppen-

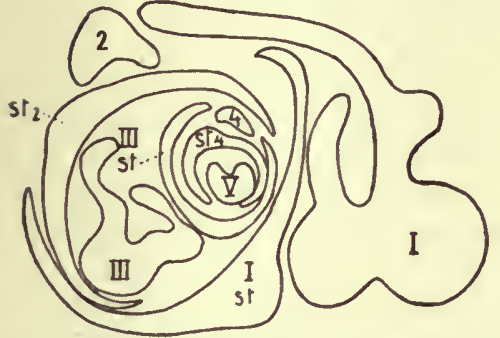

Fig. 254. Pellionia Daveauana. Querschnitt einer Sproßknospe. Die größeren Blätter jedes Blattpaares sind mit lateinischen, die kleineren, dazu gehörenden, mit dentschen Nummern versehen, $\mathrm{zu}$ jedem Blatte eine Axillarstipel (also z. B. stI gehört zu $I$, st 4 zu 4). Die Ziffern sind versehentlich in verkehrter Lage angebracht.

Fig. 255. Elatostemma sessile. Querschnitt durch eine Knospe. $I I-I V$ die Laubblätter (von dem Lanbblatt $I$ ist nur die zugehörige Axillarstipel $s_{1}$ getroffen); $a, b, c$ die $I, I I, I I I$ gegenüberstehenden und mit denselben Blattpaare bildenden, zn Schuppen verkümmerten Blätter (sie haben keine Axillarstipeln).

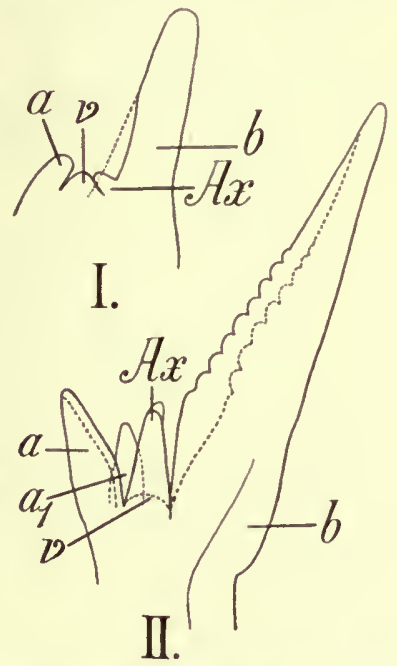

Fig. 256. Elatostemma sessile. $I$ Vegetationspunkt $(V)$ mit zwei Blattanlagen in Seitenansicht, $a$ kleines $b$ großes Blatt, $A x$ Anlage der Axillarstipel. II Anderer Vegetationspunkt von außen. Man sieht, daß $a_{1}$ in der Lücke zwischen $a$ und $b$ steht.

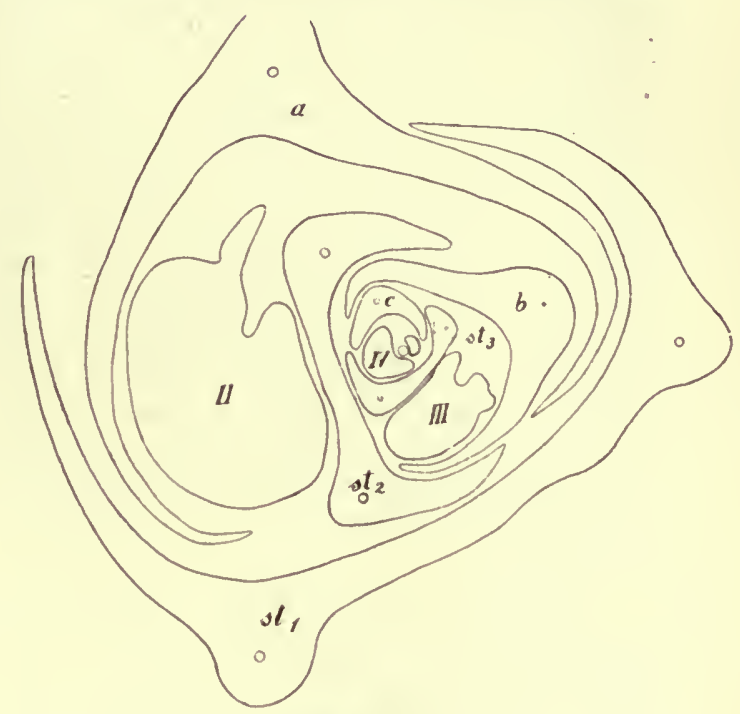

Fig. 25う̄.

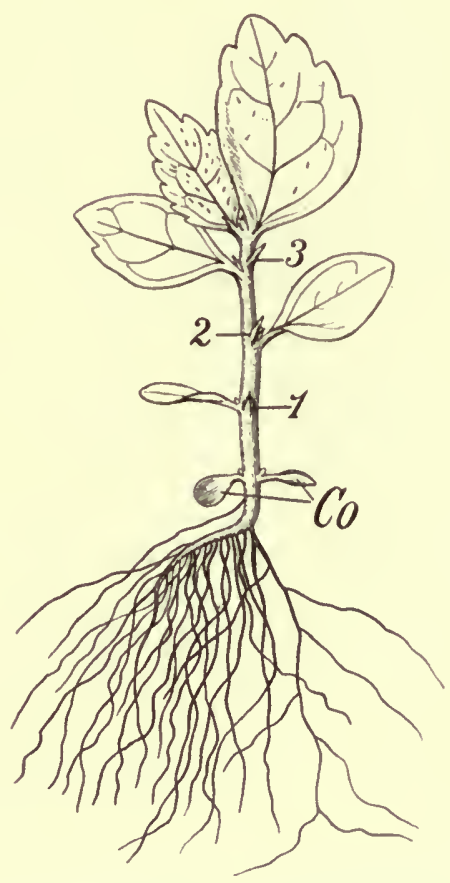

Fig. 257. Elatostemma sessile.

Keimpflanze $(11 / 2 \times), 1,2,3$ die 3 ersten kleinen Blätter, 1 noch mit Differenzierung einer Axillarstipel. 
blatt $a$ gegeniiber, das keine Rolle mehr bei der Assimilation spielt, nur noch als Schutzorgan dient ${ }^{\mathbf{1}}$ ). Bei manchen Elatostemmaarten sollen diese rudimentären Blätter ganz verkümmern, dann würde eine ähnliche Blattstellung sich ergeben, wie sie bei Ulmus z. B. sich vorfindet. In ihrem Gesamtaufbau scheinen die Elatostemmaarten sich verschieden zu verhalten. Bei zwei Elatostemmaarten (E. sessile, Fig. 257 und einer unbestimmten Form) beobachtete ich, daß schon der Keimsproß plagiotrop und anisophyll sich ausbildete; von anderen javanischen Arten finde ich in meinen Notizen, daß sie einen kriechenden Stamm besitzen, von dem plagiotrope Sprosse ausgehen, deren Blätter, solange sie noch im Boden sind, von gleicher Größe sind. Es scheinen sich also ähnliche Differenzen zu finden wie bei Selaginella. Bei Elat. sessile ist die Anisophyllie iibrigens auch an etiolierten Sprossen vorhanden, wie sie denn offenbar in allen diesen Fällen durch äußere Faktoren nicht direkt veranlaßt ist. Vegetative Sprosse entstehen nur in den Achseln der größeren Blätter

$\mathrm{DaB}$ von der Blattgestaltung von Elatostemma nur noch ein kleiner Schritt notwendig ist, um zu der zu gelangen, welche die nur mit zwei Blattzeilen versehenen Urticifloren zeigen, ist oben schon erwähnt worden.

Als Beispiel sei Ul m u s angeführt. Die Sprosse sind hier alle dorsiventral mit zweizeilig gestellten asymmetrischen Blättern. Die Keimungsgeschichte zeigt uns, daß dies Verhalten ein von der anisophyll vierzeiligen $\mathrm{Be}$ blätterung abgeleitetes ist. In Fig. 258 ist eine Keimpflanze von Ulmus effusa abgebildet. Auf die schon abgefallenen Kotyledonen $(\mathrm{Co})$ folgen zunächst zwei dekussierte Blattpaare (zuweilen auch nur eines) mit gleich großen, symmetrischen Blättern. Das nächste Blattpaar ist stark auseinander gedruickt und von sehr ungleicher Größe. $R$ ist klein und schuppenIörmig, $S$ ein großes, etwas asymmetrisches Laubblatt. Doch kann auch $R$ noch als Laubblatt entwickelt oder auch ganz unterdruickt sein. Weiterhin sind die zunächst nur reduzierten $R$-Blätter ganz unterdriickt, die Blattstellung geht, wie in dem Diagramme der Fig. 258 erläutert ist, ganz in die zweizeilige iiber. Die Stammknospe, welche ursprünglich aufrecht stand, hängt dann einseitig uiber.

Die Verhältnisse bei den Keimpflanzen sind, wie schon die oben mitgeteilten Beobachtungen zeigen, ziemlich variabel, und auch wohl durch Internodiendrehung zum Teil verwickelt. So kann das kleine Blatt auch erst $\mathbf{n}$ ach dem großen kommen, welchem es annähernd gegenübersteht, darauf wieder ein kleines und sodann ein großes. Oder es kommen nach dem letzten Blattwirtel auseinander gerückt, aber mit größerer Divergenz als $1 / 4$, zwei rudimentäre Blättchen, dann die zweizeilig gestellten Laubblätter. Trotz dieser Schwankungen, welchen sich leicht noch andere anreihen ließen, glaube ich an der in dem Diagramm in Fig. 258 gegebenen Deutung festhalten zu sollen. - Bei Ulmus glabra behalten die Keimpflanzen die radiäre Gestaltung länger bei.

So sahen wir bei dem Verwandtschaftskreis der Urticifloren schon an den wenigen angeführten Beispielen, daß wir folgende Reihe aufstellen

1) WedpecL (Monographie des Urticacées 1856) hat dies Blatt als Stipula betrachtet. Dies ist nicht richtig; es ist kein Rudiment einer Blattspreite nachzuweisen, und das stipelähnliche Blatt ist ein $\mathrm{g}$ anzes, frühe stehen gebliebenes Blatt. Es bedeckt sich früh mit Haaren, was auch die Blattanlagen der großen Blätter, nicht aber die Axillarstipeln tun. 
können, welche durch die Anisophyllie schließlich zur Ausbildung dorsiventraler zweizeilig beblätterter Sprosse führt:

1. Die Sprosse sind mit gekreuzten isophyllen Blattpaaren versehen (an den Seitensprossen kann laterale Anisophyllie auftreten), z. B. Urticaarten.

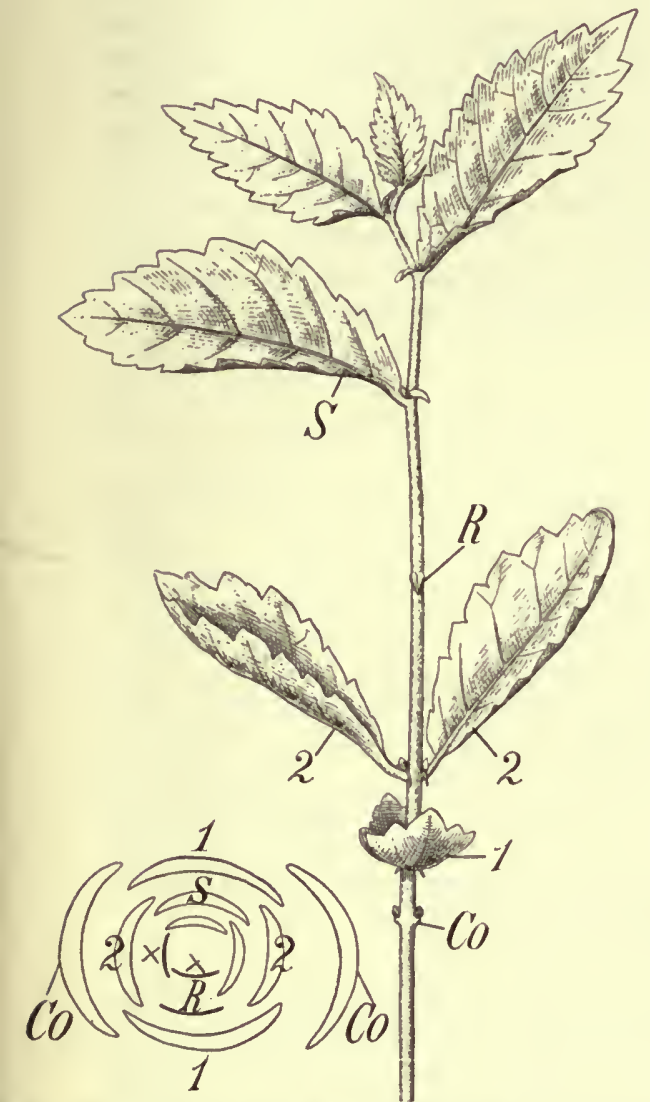

Fig. 258. Ulmus effusa. Keimpflanze. Co Ansatzstelle der Kotyledonen, 1 und 2 gekreuzte isophylle Blattpaare. $R$ Schuppenblatt, welches eigentlich mit $S$ zu einem Paare zusammengehört. Die Endknospe der Keimpflanze ist nicht mehr gerade, sondern übergeneigt. Daneben Diagramm. Die mit $X$ bezeichneten Blätter sind verkümmert.

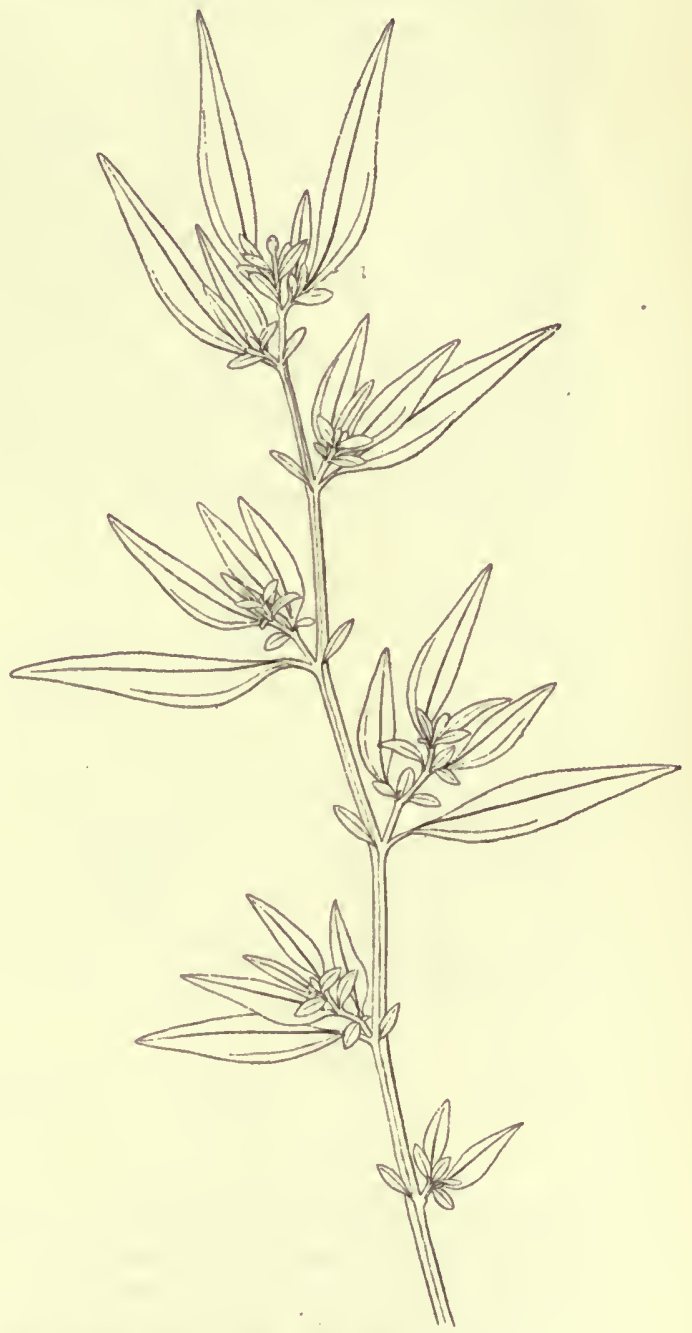

Fig. 259. Centradenia inaequilateralis. Die Blätter stehen in gekreuzten Paaren; sie sind sehr unsymmetrisch. In jedem Blattpaare ist außerdem ein Blatt viel größer als das andere; nur das größere Blatt hat einen Achselsproß.

2. Der Keimsproß geht nach kurzem dem Verhalten von 1 entsprechenden Stadium zur habituellen Anisophyllie über, die kleineren Blätter sind aber noch Laubblätter (Procris laevigata, in verringertem Maße Elatostemma repens).

3. Diese verlieren den Laubblattcharakter und werden zu kleinen 
Schuppen, nur am Keimsproß tritt noch e in Blatt der Oberseite als Laubblatt auf (Elat. sessile).

4. Die "Oberblätter" sind ganz verschwunden, nur am Keimsproß treten sie noch in Rudimenten auf: Ulmus.

II. Die Melastomaceengattung Centradenia enthält Arten, die verschieden stark anisophyll sind. In ausgeprägtem Maße ist die Verschiedenheit der Blätter sichtbar bei der in Fig. 259 abgebildeten Centradenia inaequilateralis, deren plagiotrope Sproßsysteme sich auch durch die sichelförmig gestalteten Blätter auszeichnen. Die Ausbildung der Laubsprosse deutet auf schattige Standorte hin, an denen sie sich rechtwinklig zum Lichteinfalle stellen. Sehr viel weniger ausgeprägt (namentlich an den orthotropen Sprossen) ist die Anisophyllie bei C. floribunda; z. B. größeres Blatt Länge $6 \mathrm{~cm}$, größte Breite $1,4 \mathrm{~cm}$, kleineres Blatt Länge 5 , größte Breite 1,1 cm. Auch die sichelförmige Krümmung des Blattes ist hier nur schwach angedeutet; die Pflanze bildet keine flachen Verzweigungssysteme, da auch die kleineren Blätter Axillarsprosse haben. So wenigstens bei Gewächshauspflanzen; bei im Schatten des Waldes wachsenden dürfte der plagiotrope und anisophylle Charakter ausgeprägter sein ${ }^{1}$ ); jedenfalls aber ist er hier noch weniger fixiert als bei $\mathrm{C}$. inaequilateralis.

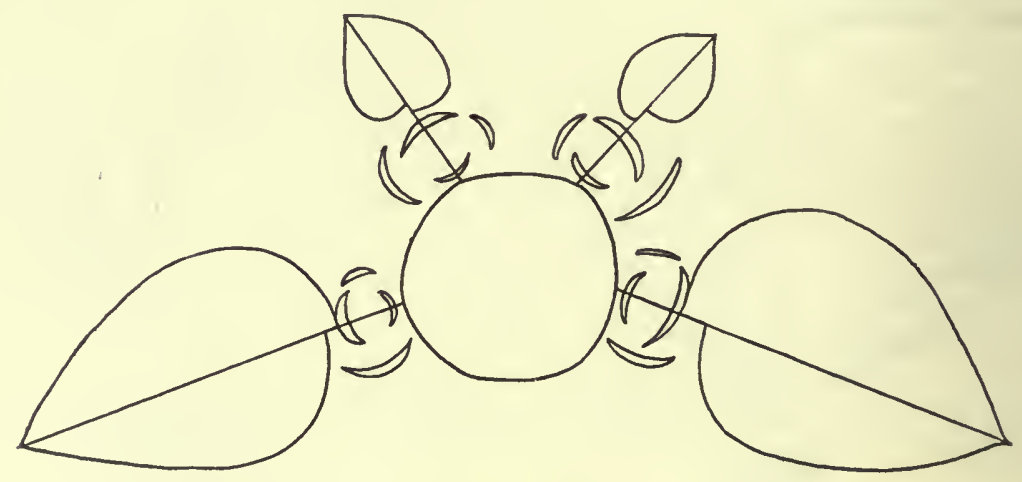

Fig. 260. Goldfussia glomerata. Diagramm. Die Blätter des Hauptsprosses in Flächenansicht, die der Achselsprosse im Durchschnitt.

III. Als letztes Beispiel sei eine Acanthaceengattung, Goldfussia, hier angeführt. Fig. 260 gibt ein Diagramm der Stellungsverhältnisse von Goldfussia glomerata. Es kommen bei dieser (neuerdings zur Gattung Strobilanthes gezogenen) Art auch isophylle Sprosse vor, die wahrscheinlich Rückschläge zur isophyllen Keimsproßausbildung darstellen. Für Goldfussia (Strobilanthes) anisophylla fand FIGDOR neuerdings, daß die Keimsprosse isophyll sind, wie dies ja auch sonst öfters der Fall ist (W. FIGDoR, Das Anisophylliephänomen bei Vertretern der Gattung Strobilanthes Bl., Ber. der deutschen botan. Gesellsch. 29 (1912), p. 54 f.). Es ist nur der Zeitpunkt rerschieden, in welchem das Plagiotropwerden (mit Anisophyllie) eintritt. Die Blätter sind auch hier dekussiert, aber es fällt sofort auf, daß die Blattpaare später sich nicht rechwinklig kreuzen, der Abstand zwischen den großen Blättern ist größer als $90^{\circ}$, sie erscheinen nach den Seiten hin verschoben,

1) Oft sind nämlich die Verschiedenheiten größer, bei Herbarptlanzen fand ich die kleinen Blätter oft nur $1-2 \mathrm{~cm}$, die großen $4-6 \mathrm{~cm}$ lang. 
der der kleinen ist $\angle 90^{\circ}$. Die Achselknospen sind im Querschnitt eingetragen. Sie beginnen mit zwei lateral gestellten Blättern, von denen eins gewöhnlich kleiner ist als das andere, darauf kommt ein zweites Blattpaar, bei welchem stets das der Mutterachse zugekehrte Blatt das kleinere ist. Diese Stellung ist, wie a. a. O. betont wurde, deshalb von Wichtigkeit, weil sie zeigt, daß hier nicht, wie man früher annahm, die Anisophyllie zur Schwerkraft in direkter kausaler Beziehung stehen kann. Zwar ist bei den beiden ersten Blättern, wenn man sich den Hauptsproß in geneigter Richtung oder horizontal liegend denkt, stets das nach unten gekehrte das größere, nicht aber bei dem folgenden Blattpaar, bei welchem die Orientierung zum Muttersproß ausschlaggebend ist: stets wird das dem Muttersproß abgekehrte Blatt das größere, gleichgiiltig, ob es nach oben oder nach unten liegt $\left.{ }^{1}\right)$. Später kommen die Blattreihen durch Drehung in die Diagonalstellung zu liegen.

Weitere Beispiele von Anisophyllie bieten in derselben Familie Strobilanthusarten, bei den Gesneriaceen Columnea (schwach bei C. Schiedeana, sehr stark bei Col. Kalbreyeri und C. purpurata (Fig. 224)). Es ist wahrscheinlich, daß bei manchen Gesneriaceen die beiden Reihen kleiner Blätter auf der Oberseite ganz verkümmert sind (Klugia, Rhynchoglossum u. a.). Bei Klugia fand ich in der Tat gelegentlich auf der Sproßoberseite ein Blatt, meist kleiner als die seitlichen Blätter. offenbar ist dies ein Rest der oben stehenden Blätter, während das ganze Verhalten liegt wie bei Ulmus.

Anisophyllie kann auch an sympodial verketteten Sproßsystemen auftreten, die plagiotrop wachsend sich ebenso verhalten wie monopodiale Sprosse. Eines der schönsten Beispiele dafür bilden die blühenden, ausgeprägt plagiotropen Sprosse von Atropa Belladonna, bei denen die auf der Oberseite stehenden Blätter viel kleiner sind als die am Rande stehenden, während der orthotrope Hauptsproß isophyll ist. Die Ausbildung dieser Sprosse stimmt also ganz mit der von Selaginella, Elatostemma u. a. überein, abgesehen eben von ihrem Zustandekommen. Die plagiotropen, anisophyllen Sprosse von Atropa Belladonna bẻhalten ihre Eigenschaft, auch wenn sie als Stecklinge von der Mutterpflanze getrennt wachsen, bei. Es können aber radiäre Adventivsprosse an ihrer Basis auftreten ${ }^{2}$ ).

\section{$\S$ 17. Allgemeines über asymmetrische Blätter.}

Die Blätter radiärer Sprosse sind gewöhnlich symmetrisch ausgebildet, asymmetrische Blätter sind, wie oben angeführt wurde, bei dorsiventralen Sprossen häufig, ohne auf diese beschrïnkt zu sein.

Die Asymmetrie kann bedingt sein A) durch die Eigenschaften der Sproßachse, an denen die betreffenden Blätter stehen, oder B) durch Ein-

1) Dasselbe Verhalten beobachtete ich auch an den zwei ersten Blättern der Achselsprosse von Goldf. isophylla, welche später Blattpaare von gleicher Größe haben. Bei dem medianen Blattpaare ist die Größendifferenz insofern verständlich, als das der Mutterachse zugewendete Blatt das schwächer beleuchtete ist. Es war in einem Falle $6,5 \mathrm{~cm}$ lang, das ihm gegenuiber stehende $11,5 \mathrm{~cm}$, auch ist das obere schmäler als das untere. Das folgende, in die Vertikalebene fallende Blattpaar zeigt die Erscheinung zuweilen auch noch, aber weniger stark.

2) Macht man die Stecklinge im Herbst, so wachsen sie im Winter im Gewächshaus weiter, während die Pflanzen im Freien längst bis auf ihre Basalteile abgestorben sind, und \%war wahrscheinlich nicht infolge des Sinkens der Temperatur, sondern durch Korrelationsverhältnisse. Indes bedarf das experimenteller Prüfung.

Goebel, Organographie der Pflanzen. 2. Aufl. Allgem. Teil. 
wirkungen auf die jungen Blattanlagen selbst, ohne Vermittlung der Sproßachse.

A) Hierher gehören folgende Fälle:

1. Die oben angeführten dorsiventralen Sprosse mit asymmetrischen Blättern.

2. Rochea falcata (p. 202).

3. Gasteriaarten (p. 211).

4. Vielleicht sind hier anzuschließen auch einige Blätter mit „gedrehter" Knospenanlage, bei denen die innen liegende stärker gerollte Blatthälfte größer wird als die andere. So besonders auffallend bei den Blïten von Vinca und anderen Asclepiadeen, deren Blumenkronengipfel asymmetrisch sind. Da dies bei allen in derselben Richtung erfolgt, liegt aber wahrscheinlich eine von der Sproßachse ausgehende Beeinflussung vor.

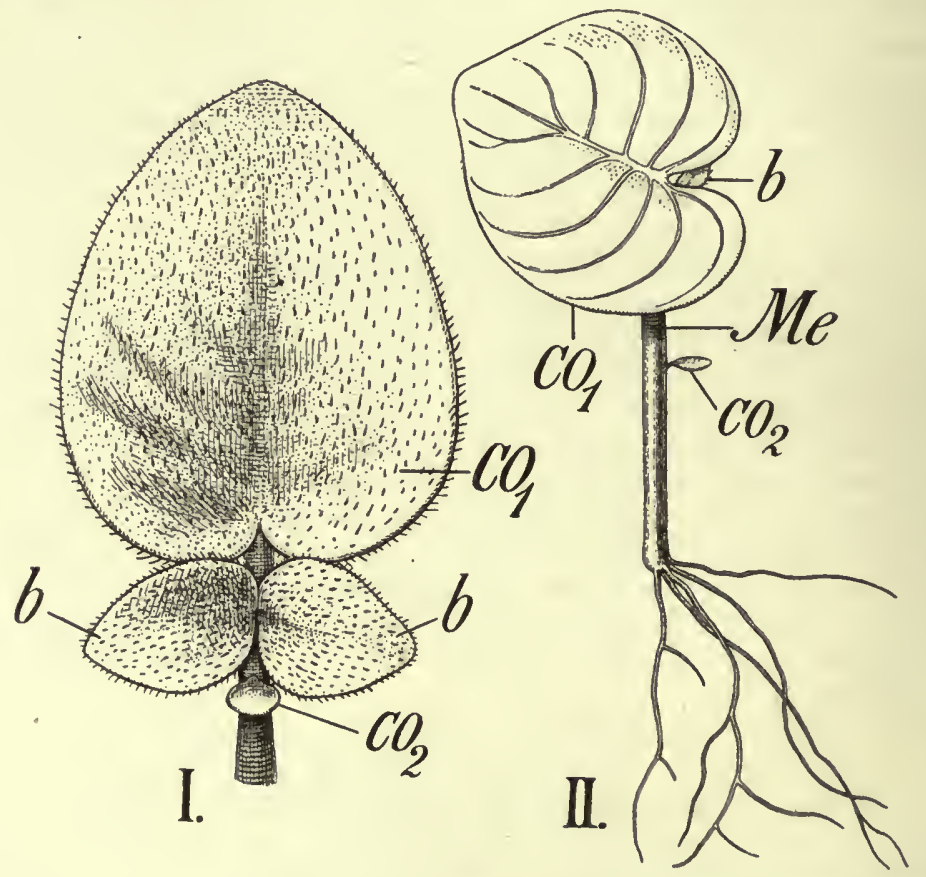

Fig. 261. 1 Streptocarpus Holstii. Keimpflanze schief von oben gesehen, $\mathrm{CO}_{1}$ großer, $C O_{2}$ kleiner Kotyledon. $b b$ die ersten (Primär-)Blätter. Ihre gröBere Hälfte ist dem größeren Kotyledon zugekehrt. 3 fach vergr. II Klugia Notoniana. Me Mesokotyl, $b$ erstes Laubblatt, $\mathrm{CO}_{1}$ and $\mathrm{CO}_{2}$ die beiden Kotyledonen (durch das Mesokotyl voneinander getrennt).

Auch bei den Laubblättern einiger Marantaceen mit gerollter Knospenlage dürfte dasselbe zutreffen. Man wird ScHuManN ${ }^{1}$ ) nicht zustimmen können, der meint, diese Erscheinung sei dadurch bedingt, daß die äußere Hälfte in der Umfassung durch das nächstältere Blatt ein Hemmnis für sein weiteres Wachstum erfahre. Denn solche mechanischen Hemmungen kommen gestaltbeeinflussend nur in ganz untergeordnetem Maße in Betracht. Lehrreich ist das Verhalten der in Fig. 261 abgebildeten Keim-

1) Schumann, Marantaceae in Engleli, Das Pflanzenreich, p. 6. 
pflanzen. $I$ zeigt eine solche von Streptocarpus Holstii, einer der mit gestreckten Sproßachsen versehenen Streptocarpusarten. Die beiden Kotyledonen sind sehr ungleich, der eine auf der (+ Seite) der Sprossachse stehende wird viel größer als der andere. Die Blätter des mit den Kotyledonen gekreuzten Wirtels sind auf der dem größeren Kotyledon $\left(\mathrm{CO}_{1}\right)$ zugekehrten Seite größer als auf der dem kleineren zugekehrten. Die beiden Kotyledonen sind aber symmetrisch, während bei Klugia Notoniana der größere Kotyledon stark asymmetrisch wird. Diese Pflanze besitzt später zweizeilige Blattstellung, die sich, wie erwähnt, ableitet von einer anisophyll vierzeiligen, mit verkümmernden (nur gelegentlich entwickelten) kleinen Oberblättern.

B) Für die Möglichkeit der Beeinflussung der Symmetrie des einzelnen Blattes wurden p. 215 experimentelle Belege gegeben. Selbstverständlich kann Asymmetrie auch durch andere Faktoren hervorgerufen werden. In Fig. 262 abgebildet ist ein Blatt einer "panachierten" Abutilonform, Ab. Sawitzii hort. Die Blätter sind gewöhnlich symmetrisch ausgebildet (Fig. 262 II). Ein Blatt, das großenteils zur grünen Stammform zurückgeschlagen war (Fig. 262 I), war dagegen stark asymmetrisch, weil der chlorophyllose Teil der Blattfläche im Wachstum stark zurückgeblieben war gegenüber dem chlorophyllhaltigen ${ }^{\mathbf{1}}$ ). Offenbar handelt es sich dabei um eine Lichtwirkung (die mit der Assimilationstätigkeit nicht in Zusammenhang zu stehen braucht). Die chlorophyllhaltigen Teile absorbieren jedenfalls viel mehr die für das Wachstum wichtigen Lichtstrahlen als die chlorophyllosen. Ebenso kann man z. B. bei Vitis an etiolierten Sprossen eine Asymmetrie der Blätter erzielen, wenn man eine Blatthälfte dem Lichte aussetzt, die andere verfinstert. Bei den Pflanzen mit teilweise oder ganz chlorophyllosen Blättern ist die Einwirkung des Lichtes auf das
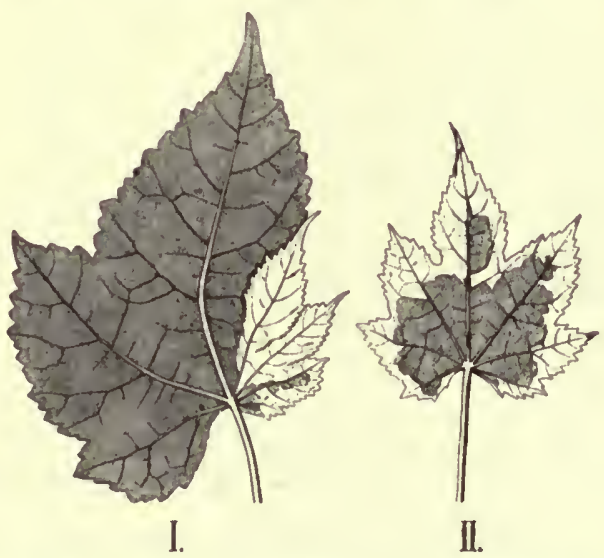

Fig. 262. Abutilon Sawitzii. II gewöhnliches, panachiertes Blatt, symmetrisch. I Blatt, dessen größere Hälfte rein grün ist, asymmetrisch $(1 / 4)$.

Wachstum zum großen Teile verhindert, die betreffenden Blattteile sind sozusagen blind - eine Erscheinung, die nach des Verf. Ansicht auch an chlorophyllhaltigen Organen auftreten kann.

Dieses Verhalten könnte für die Anschauung herangezogen werden, welche die Asymmetrie als eine (erblich gewordene) schwächere Entwicklung der schwächer beleuchteten Blatthälfte auffaßt. Indes läßt sich diese Annahme derzeit experimentell weiter nicht stiitzen.

Was die asymmetrischen Teilblättchen anbetrifft, so ist unbekannt, weshalb in den meisten Fällen die adaxiale, in manchen die abaxiale Seite

1) Ein ähnliches Beispiel führt Teononesc (Revue genérale de botanique t. XI, p. 374, von Solanum tuberosum an. - Sehr schön war dasselbe zu sehen auch bei Sprossen von Glechoma hederacea mit „panachierten " Blättern. Es kommen hier wie bei anderen „panachierten Pflanzen“ gelegentlich Blätter vor, welche ganz chlorophyllos sind. Diese sind die kleinsten. Ist an einem Blatte annähernd eine Hälfte grün, die andere nicht, so wird es schief wie ein Begoniablatt. 
die geförderte ist. Wahrscheinlich hängt die Asymmetrie mit der Art des Ansatzes der Teilblättchen an die Blattspindel zusammen, teilweise kommen auch Beziehungen $\mathrm{zu}$ anderen Blatteilen in Betracht. So sind bei einigen gefiederten Blättern, z. B. denen von Roupala Pohlii, Juglans regia, Fraxinus excelsior die Endblättchen entweder symmetrisch oder (seltener) asymmetrisch. Letzteres geschieht dann, wenn nahe der Endfieder eine Seitenfieder abgegliedert worden ist, die letzten Seitenfiedern also auf ungleicher Höhe stehen (Fig. 263). Das hat offenbar zu einer geringeren Ausbildung der einen Hälfte der Endfieder geführt.

$\mathrm{Da} ß$ aber asymmetrische Ausbildung der Blätter nicht, wie HoFMEISTER seinerzeit annahm (und mit ihm einzelne Autoren auch jetzt), durch die Lage zum Erdradius bedingt sein kann, geht schon aus einer vergleichenden Betrachtung hervor. Bezüglich der induzierten Blattasymmetrie von Bäumen sei auf $\S 19$ rerwiesen.

Fig. 263.

Schema für das verschiedene Verhalten des Endblättchens gefiederter Blätter von Fraxinus u. Juglans usw.(nach BosharT). Links ist das Endblättchen asymmetrisch, die beiden nächsten Fiedern stehen auf ungleicher Höhe; rechts ist es symmetrisch; die beiden nächsten Fiedern stehen einander gegenüber.
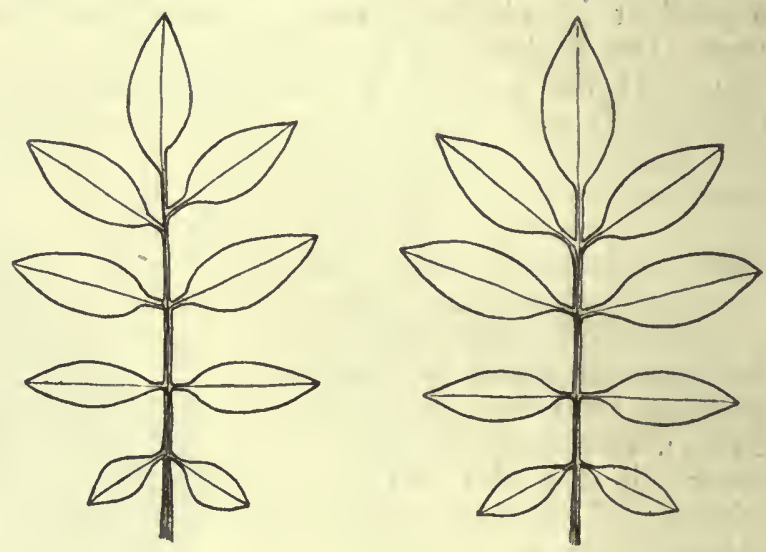

\section{$\S$ 18. Blattasymmetrie bei Begonia ${ }^{1}$ ).}

Es wurde mehrfach betont, daß die Asymmetrie der Blätter mit der Gesamtsymmetrie des Sprosses in ganz bestimmter Beziehung steht. Stets sind alle großen Blatthälften (die Plusseiten) nach einer Sproßseite, die kleineren (Minusseiten) nach der entgegengesetzten hin gerichtet.

Dies soll am Beispiel von $\mathrm{B}$ eg o nia erläutert werden.

Diese Gattung ist dadurch ausgezeichnet, daß sie ausschließlich dorsiventrale Sprosse in der vegetativen Region hervorbringt. Die Dorsiventralität äußert sich in der Gestalt der Blätter, der Nebenblätter und (bei manchen Arten) in der Stellung der Blätter und Seitensprosse.

Alle Begonien sind ausgezeichnet durch zweizeilige Blattstellung und mehr oder minder asymmetrische Blätter; Asymmetrie ist kaum merklich bei B. rhizocarpa und B. herbacea, Formen mit kriechendem Rhizom und fast aufrechten Blättern; sehr stark ausgeprägt ist sie z. B. bei B. incarnata (Fig. 264). Die Asymmetrie findet sich auch bei Arten mit orthotropen, bedeutende Höhe (uiber $6 \mathrm{~m}$ ) erreichenden Sprossen, z. B. B. vitifolia. Auch sonst kommen mancherlei Abweichungen vor. Denken wir uns einen geneigt wachsenden Begoniasproß horizontal gestellt, so daß seine Unter-

1) Vgl. Korderup-Rosenvixae, Influence des agents exterienrs etc. Revue de botanique I (1889) p. 244. Daselbst weitere Literatur. 
seite genau nach unten, seine Oberseite nach oben steht, und von vorn betrachtet, so kommen betreffs der Orientierung der beiden ungleichen Blatthälften zwei Fälle vor ${ }^{1}$ ).

1. Bei dünnstämmigen Arten, wie z. B. Begonia scandens, B. maculata, incarnata (Fig. 264), sind, wie bei Pellionia, die größeren Blatthälften nach oben gewendet.

2. Bei anderen, namentlich dickstengligen Arten, wie bei B. manicata, B. Rex u. a., ist die kleinere Blatthälfte nach oben gewendet, also umgekehrt wie bei 1. Das Blatt wendet sich aber bei der Entfaltung so, daß die Blattspitze und damit die kleinere Blatthälfte nach unten sieht. Bei den aufrecht oder schief aufsteigend wachsenden Arten stehen die Blätter in zwei Zeilen, die etwa $180^{\circ}$ voneinander divergieren, die Seitenknospen noch in den Blattachseln. Bei den mit kriechendem Stamm versehenen sind die beiden Blattzeilen einander auf der Oberseite genähert, wie das Diagramm Fig. 265 zeigt, während die Seitenknospen bei B. Rex auf den Flanken, in der Achsel eines der Nebenblätter stehen, eine Einrichtung, deren Vorteil ohne weiteres einleuchtet, und die bei vielen dorsiventralen Sprossen wiederkehrt.
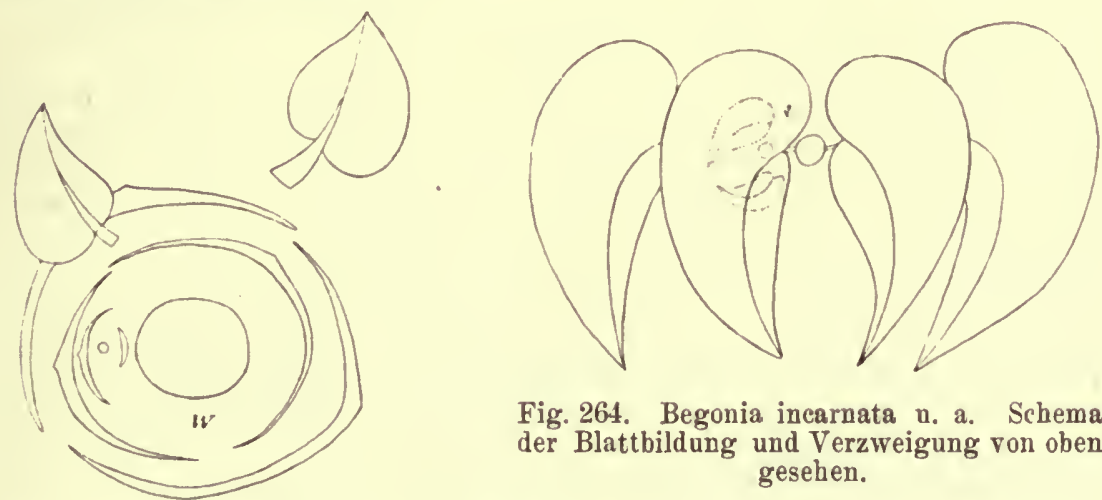

Fig. 264. Begonia incarnata n, a. Schema der Blattbildung und Verzweigung von oben gesehen.

Fig. 265. Begonia Rex. Sehema der Blattstellung und Verzweigung von vorn gesehen. $W$ Wurzelseite der Sproßachse, die oberhalb $W$ im Querschnitt zu sehen ist. Vor jedem Blatt zwei Stipulae, diese im Querschnitt gedacht, während die Blätter selbst in Flächenansicht gezeichnet sind. In der Achsel des zweiten Blattes (scheinbar in der der unteren Stipel) ein Achselsproß.

Die Orientierung der Symmetrieebene der Seitensprosse zu der der Hauptsprosse ist eine sehr verschiedene. In manchen Fällen steht sie rechtwinklig zur ersteren, und dies scheint mir der "typische" Fall zu sein, er ist bei den dünnstengligen Arten der herrschende; in anderen macht sie mit ihr einen Winkel oder fällt gar mit ihr zusammen (vgl. KOLDERUPRosenvinge a. a. O.).

Es knüpfen sich an die Erörterung der Asymmetrie von Begonia zwei Fragen an: 1. wodurch ist sie kausal bedingt?, 2. hat sie eine biologische Bedeutung?

Die erste Frage ist zunächst dahin zu beantworten, daß die Asymmetrie

1) Ich finde bei Untersuchung einer Anzahl von Arten die Verhältnisse so, wie Sacrs (Lehrbnch, 4. Aufl., p. $213 \mathrm{ff}$.) sie angegeben hat; die Angaben von Hofmeister sind in mehr als einem Punkte irrig, auch darin, daß bei orthotropeu Begoniasprossen die, Spitzen übergeneigt seien. 
zusammenhängt mit der Dorsiventralität der Sproßachse, welche bewirkt, daß eine Blatthälfte stärker ernährt wird als die andere. Die Begonien, welche dem Rexschema folgen, haben eine hypotrophe Sproßachse. Das spricht sich aus in der stärkeren Entwicklung dieser Seite, wie sie sehr auffallend bei dem in Fig. 215 abgebildeten Rhizom von B. caroliniaefolia hervortritt. Dieser stärker entwickelten Hälfte sind auch die größeren Blatthälften zugekehrt. Die oben unter 2 aufgezählten Begonien dagegen besitzen epitrophe Sproßachsen.

Die Begoniablätter sind mit Nebenblättern versehen. Die zwei Nebenblätter eines Blattes verhalten sich bei den einzelnen Arten verschieden, d.h. sie können entweder (annähernd) gleich groß sein, z. B. bei B. sanguinea, maculata oder ungleich groß, z. B. bei B. dichroa, B. caroliniaefolia ${ }^{1}$ ). In diesem Falle ist die größere Stipel auf der der größeren Blatthälfte entsprechenden Blattseite, wie dies (mit Ausnahme von Ulmus und Tilia) auch sonst der Fall ist, wenn ungleichseitige Blätter mit ungleich großen Nebenblättern versehen sind.

Hat die Blattasymmetrie eine biologische Bedeutung? Diese Frage kann jedenfalls nicht für alle mit der Blattasymmetrie in Beziehung stehenden Eigentümlichkeiten bejaht werden. Die verschiedene Größe der Nebenblätter z. B. kann nicht teleologisch gedeutet werden.

Herbert Spencer ${ }^{2}$ ) war der Meinung, daß bei Begonia wie in anderen Fällen von Blattasymmetrie die eine Hälfte des Blattes mehr Licht erhalte, als die andere "the species profits by a large development of the exposed halves; and by survival of the fittest acting along with the direct effect of extra exposure, this modification becomes established". $\mathrm{Da}$ eine Blatthälfte günstiger beleuchtet ist als die andere, trifft aber keineswegs bei allen Begonien zu; eigentlich nur bei Arten mit kurzen Internodien, und auch bei diesen nicht überall. Auch die von H. Spencer als Stütze seiner Ansicht angeführten auf langen Blattstielen einzeln stehenden Blätter von B. nelumbifolia (die nach ihm kaum asymmetrisch sein sollen) sind in Wirklichkeit ziemlich stark asymmetrisch, nur tritt das an dem schildförmigen Blatte nicht sehr hervor. Würde die Spencer'sche Ansicht zutreffen, so müßte man annehmen, daß die Dorsiventralität der Sproßachsen erst sekundär durch die-Asymmetrie der Blätter entstanden und erblich geworden sei, denn daß jetzt die Blattasymmetrie nicht mehr direkt von äußeren Faktoren abhängig ist, ist zweifellos. Bei der SPENCER'schen Auffassung läge also eine "Anpassung" in der Richtung vor, daß die Assimilationsfläche an der günstig beleuchteten Seite auch besser entwickelt ist, eine Art Phototrophie. Eine solche Auffassung kommt unserem Kausalbedürfnis ohne Zweifel besser entgegen, als die einer "zufälligen" Entstehung der Sproßdorsiventralität und der dadurch bedingten Blattasymmetrie. Aber eine experimentelle Stütze liegt nicht dafür vor.

Es ist also derzeit nicht mit Sicherheit möglich, die Asymmetrie von Begonia als einen nützlichen Anpassungscharakter zu betrachten. Das

1) VAN TIEgham hatte in einer (bekannte Dinge ohne Literaturangabe wiederholenden) Abhandlung (Sur la dissymétrie des feuilles distiques, Ann. des scienc. nat. IX. sér., t. 3, p. 375) angegeben, die Nebenblätter seien bei den Begoniablättern gleich, was, wie aus dem oben Mitgeteilten hervorgeht, keineswegs allgemein zutrifft. Übrigens wird schon in der 1. Auflage dieses Buches z. B. die Ungleichheit für Beg. maculata erwähnt. Dort wurde auch auf den Zusammenhang der Blattsymmetrie mit der Sproßdorsiventralität (den VAN TIEGHEM, wie es scheint, als etwas Neues betrachtet) nachdrücklich hingewiesen.

2) Herbert Spencer, Principles of biology, Sec. Ed., Vol. II, p. 158. 
schließt natürlich nicht aus, daß Gestalt und Lage der Blätter unter bestimmten Standortsverhältnissen von Bedeutung sein können.

Begoniaarten mit aufrecht wachsenden nicht kletternden Sprossen sind, soweit meine Erfahrungen reichen, solche, die ein buschiges, durch reiche Verzweigung bedingtes Wachstum haben. Betrachten wir einen Sproß von oben (Fig. 264), so zeigt sich, daß die horizontal stehenden Blattflächen der Hauptsache nach nach einer Seite hin, die als die Außenseite zu betrachten ist, rerlegt sind. Die Blattspitzen stehen nicht, wie dies sonst bei zweizeilig beblätterten Sprossen der Fall ist, dem Anheftungspunkt des Blattes gegenüber, sondern haben diesem gegenüber eine Drehung bis zu 90" ausgeführt. Der dorsiventrale Charakter auch der aufrecht wachsenden Formen tritt dadurch hervor; jeder Sproß hat eine Außenseite mit viel, eine Innenseite mit wenig Blattfläche (in Fig. 264 nach oben gekehrt). Da nun die einzelnen Sprosse einander ihre Innenseite zukehren, so wird dadurch eine nach auBen gerichtete Beblätterung des ganzen Sproßsystems erzielt, während gleichzeitig die einzelnen Blätter so gelagert sind, daß die beschattete Seite weniger entwickelt ist als die unbeschattete. Es liegt hier also ein Fall ron „Exotrophie" vor.

Diese kann, wenn die Pflanze z. B. am Waldesrand wächst, eine günstige Lagerung der Blattfläche bedingen, wie dies bei der gleichfalls mit sehr stark asymmetrischen Blättern versehenen Klugia ceylanica auf Ceylon leicht zu beobachten ist. Aber es ist das doch nur eine sekundäre Wirkung der durch den Gesamtbau der Sprosse bedingten Dorsiventralität.

Diese tritt frïhe an der Keimpflanze auf, (nur das erste Laubblatt ist symmetrisch) und ist nach den bis jetzt vorliegenden Erfahrungen nicht umkehrbar. Wohl aber läßt sich die Asymmetrie der Blätter durch Einschneiden des Blattstiels junger Blätter an der normal geförderten Seite, also durch eine Ernährungsstörung in giinstigen Fällen direkt umkehren ${ }^{1}$ ), es wird dadurch die von der Sproßachse auf die Blätter ausgeibte Induktion in ihrer Wirkung verhindert.

\section{$\S$ 19. Blattasymmetrie bei Holzpflanzen.}

Die oben schon mehrfach erwähnte Blattasymmetrie bei Holzpflanzen soll hier nochmals besprochen werden, weil sich besonders an sie die Versuche kausaler und teleólogischer Erklärung kniipfen. Wie so oft, treffen wir auch hier auf zwei Kategorien: die "induzierte" und die habituelle.

a) Induzierte Blattasymmetrie findet sich an solchen plagiotropen Sprossen, welche laterale Anisophyllie zeigen (p. 248). So bei Aesculus Hippocastanum ${ }^{2}$ ) (Fig. 250). An orthotropen Sprossen ist das Mittelblïttchen des "gefingerten" Blattes das längste, die anderen nehmen nach der Basis der Blattspreite zu, an Größe ab. Das Blatt ist symmetrisch, also sind die beiden rechts und links rom mittleren Blatteil stehenden Teilblättchen gleich groß. Anders an den anisophyllen plagiotropen Sprossen: die in Fig. 250 mit + bezeichneten Blättchen sind größer als die mit bezeichneten und übertreffen sogar teilweise das Mittelblättchen. Ähnliches trifft für Acer u. a. zu. p. 290 .

1) G. Gentner, Unters. über Anisophyllie und Blattasymmetrie, Flora 99 (1909),

2) Vgl. Nordhausen, Untersuchungen über Asymmetrie an Laubblättern höherer Pflanzen. Jahrb. für wissensch. Bot. 37 (1901). 
Ohne Zweifel hängt die Asymmetrie hier mit der Lage des Blattes zum Horizont zusammen. Aber nach des Verf. Ansicht handelt es sich nicht um eine direkte Beeinflussung des einzelnen Blattes durch die Schwerkraft, sondern um eine solche des ganzen Sprosses. In der Blattasymmetrie prägt sich hier wie in der Anisophyllie ${ }^{1}$ ) die Dorsiventralität (Hypotrophie) aus, die dem Vegetationspunkt der Sproßachse aufgeprägt worden ist.

b) Habituelle Anisophyllie. Sie ist von der induzierten nicht scharf zu trennen, da auch sie - wenngleich in geringerem Grade - beeinflußbar ist.

Es handelt sich dabei um Holzpflanzen mit zweizeilig angeordneten Blättern. Diese zeigen ein Verhalten, welches durch das Schema Fig. 266 erläutert werden mag.

Beim Ulmustypus ist die untere ${ }^{2}$ ) Blatthälfte die geförderte, wie der schematische Querschnitt Fig. 266 III zeigt. Am entfalteten, seine adaxiale Fläche nach oben kehrenden Blatte ist demgemäß die innere (der Sproßachse zugekehrte) Blatthälfte die größere (Fig. 266 II). Das Schema entspricht dem der Fig. $226 \mathrm{I}$, wenn man sich die beiden oberen Blätter wegdenkt.

Fig. 266. Schema für die Ansbildung der Blattasymmetrie zweizeilig gestellter Blätter. $I I$ und III Ulmus und Tilia (untere Blatthälfte größer). $I$ nnd $I V$ Fagus silvatica, Begonia fagifolia u. a. Obere Blatthältte größer.

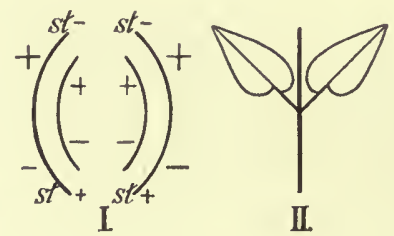

II III

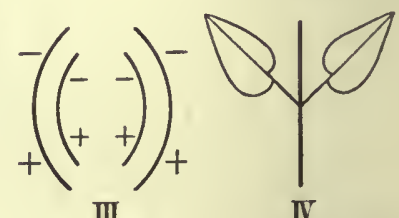

I.

Beim Fagustypus (Fig. 266 IV) ist das Verhalten das umgekehrte (er entspricht mutatis mutandis dem Schema Fig. $226 \mathrm{II}$ ); es ist also die größere Blatthälfte die obere (Fig. 266 III), nach der Drehung des Blattes die äußere. Gegen das Ende der Jahrestriebe hin pflegt die Asymmetrie abzunehmen, auch an orthotropen Stockausschlägen von Ulmus und Tilia trifft man fast symmetrische Blätter an. An schwach beleuchteten Sprossen von Ulmus fand NordHausen die Blattasymmetrie um so weniger ausgebildet, je geringer die Lichtmenge war, die sie erhielten. In diesen Fällen ist also die Beschaffenheit des Sproßvegetationspunktes (von der die Asymmetrie abhängt) eine modifizierte.

Eigentümlich ist das Verhalten der Nebenblätter. Die zwei zu einem Blatte gehörigen Nebenblätter sind vielfach voneinander verschieden. Dabei fällt bei Ulmus und Tilia das größere Nebenblatt auf die kleinere Blatthälfte bei Fagus, Castanea, Carpinus (wo die Verschiedenheit meist eine wenig auffallende ist) auf die größere. Der letztere Fall ist leicht verständlich. Die Nebenblätter nehmen an der Gesamtsymmetrie der Sprosse teil. Der erstere beruht vielleicht auf einem Korrelationsverhältnis, wie solche vielfach vorkommen.

Als Anpassungscharakter hat H. Spencer die Blattasymmetrie in ähnlicher Weise wie für Begonia u. a. aufgefaßt und sie auf die ungleiche Belichtung der beiden Blatthälften zuriickzuführen gesucht. Es sei auf das über Begonia Gesagte verwiesen.

1) Vgl. betr. deren Zustandekommen den Abschnitt VI.

2) Am nnentfalteten $Z$ weig. 


\section{§ 20. Asymmetrie bei „zusammengesetzten“ Blättern.}

Ungleiche Entwicklung der beiden Blatthälften kommt auch bei zu sammengesetzten Blättern vor, durch ungleiche Größe der Teilblättchen, die so weit gehen kann, daß auf einer Seite einige der Teilblättchen verkümmern. Zunächst sei erwähnt, daß die Nebenblätter bei manchen dorsiventralen Papilionaceen auf der Lichtseite (der Infloreszenzseite) größer sind als auf der Unterseite (Fig. 278 S. 271). Viel beträchtlicher ist aber die Ungleichheit der Fiederblättchen selbst bei einer Anzahl von Arten, die, soweit ich sie lebend untersuchen konnte, alle ausgezeichnet sind durch den Besitz ausgesprochen plagiotroper, niederliegender Sprosse. Diese sind zweizeilig beblättert, die eine Blatthälfte ist nach oben, die andere nach unten gekehrt. Die Verschiedenheit ist zuweilen so auffallend, da sie selbst in der systematischen Benennung Ausdruck gefunden hat. Die Blätter von Indigofera diphylla (Fig. 267 II), Hosackia subpinnata, Anthyllis tetraphylla(Fig. $267 I I I$ ) sind, "einseitig gefiedert". Bei Indig. diphylla (Fig. 267 II) ist auf der Oberseite nur Ein Fiederblättchen vorhanden. Anthyllis tetraphylla (Fig. 267 III) hat auf der nach oben gewendeten Seite 2-3 größere, auf der nach unten gekehrten nur ein Fiederblättchen. Die Blätter sind an dem niederliegenden Sproß schief inseriert, so daß ihre Oberseiten schief nach der Sproßoberseite gerichtet sind. Es ist klar, daß diese Sprosse eine epitrophe Dorsiventralität zeigen. und

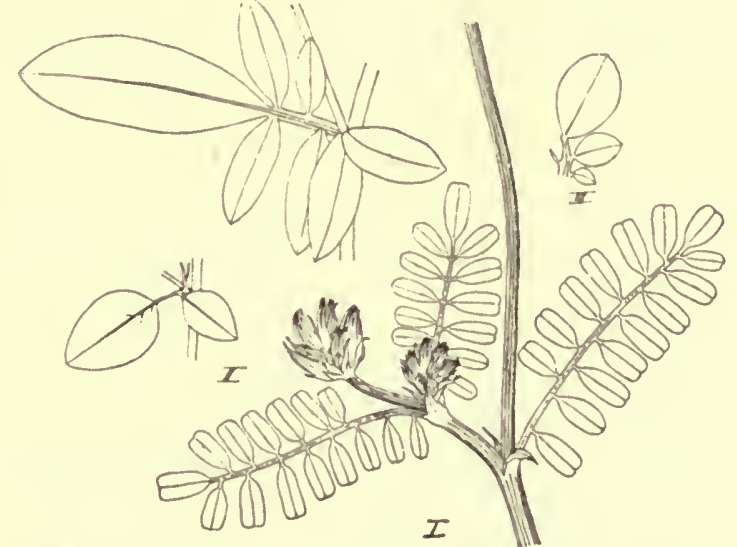

Fig. 267. Ungleichseitig ausgebildete Blätter verschiedener Papilionaceen. I Hedysarum capitatum; II Indigofera diphylla; III Anthyllis tetraphylla; $I V$ (Nummer ans Versehen weggeblieben) Hymenocarpns circinnatus.

daß die Blatthälften reduziert erscheinen, welche die schwächer beleuchteten sind.

Dabei ist bemerkenswert, daß diese Erscheinung innerhalb des Verwandtschaftskreises der Leguminosen unabhängig bei verschiedenen Gattungen aufgetreten ist. Es fiel mir dies besonders auf bei einigen sizilianischen Papilionaceen. Lehrreich ist Hedysarum capitatum (Fig. 267 I). Die Blätter der radiären orthotropen Grundrosette sind symmetrisch, d. h. es sind rechts und links gleichviel Fiederblättchen vorhanden; bei den weiterhin sich entwickelnden niederliegenden (plagiotropen) Sprossen dagegen fehlen auf der einen (dem Boden zuliegenden) Blatthälfte ein oder zwei Fiederblättchen. Dasselbe beobachtete ich bei Vicia Cracca, bei der auch die auf der Sproßoberseite stehenden Nebenblätter größer sind als die der Unterseite. Auch Hymenocarpus (Fig. 267 IV) hat solche asymmetrischen Blätter, und es ließe sich noch eine Reihe von Fällen anführen. Die weniger ausgebildete Hälfte des Blattes ist, wenn Seitensprosse oder Infloreszenzen in der Blattachsel vorhanden sind, von diesen 
teilweise bedeckt. So fand sich denn bei Anth. tetraphylla, daß die kleinen, dem Verkïmmern zuneigenden Fiederblättchen auch anatomisch anders beschaffen sind als z. B. die großen Endblättchen. Die ersteren sind nur halb so dick als die letzteren; während diese zwei Reihen von Palisadenzellen besitzen, haben jene entweder keine deutlichen Palisaden oder doch nur eine Reihe ganz kurzer palisadenähnlicher Zellen. Mit anderen Worten, ihr Bau erinnert an den der Schattenblätter; es ist auch dies ein Grund, der wahrscheinlich macht, daß die Reduktion oder gänzliche Verkümmerung bedingt war durch die Lage der hinteren Blatthälfte, die schon durch ihre Stellung, namentlich aber auch durch die Verdeckung von seiten der Achselsprosse weniger Licht erhält als die vordere. Damit ist aber noch nicht gesagt, daß die Lichtwirkung eine das einzelne Blatt dir ekt treffende sei, es kann der ganze Sproß "phototroph" beeinflußt sein, derart, daß die beleuchtete Seite die geförderte ist, wie dies ja auch durch Stellung und Ausbildung der Infloreszenzen hervortritt. Auch wird die Gestaltung der Blätter der Hauptsache nach bedingt durch den Vegetationspunkt der Sproßachse, dessen Beschaffenheit wird also in erster Linie maßgebend sein. Es liegt somit bei diesen Pflanzen dasselbe Problem vor, wie bei den in $\S 19$ behandelten.

\section{§ 21. Asymmetrische Teilblättchen.}

Es ist eine ungemein häufige Erscheinung, daß bei einem zusammengesetzten Blatte das Endblättchen symmetrisch, die Seitenblättchen asymmetrisch sind; aus der großen Anzahl von Beispielen seien nur einige genannt: Rubusarten, Papilionaceen (z. B. Tetragonolobus, Phaseolus), Juglans, Chelidonium, Fraxinus, Heracleum, also Pflanzen aus den verschiedensten Verwandtschaftskreisen.

Indes wurde p. 260 ausgeführt, daß auch bei solchen Pflanzen unter bestimmten Umständen das Endblättchen asymmetrisch werden kann (vgl. Fig.: 263 links) - ein Beispiel, das insofern besonders lehrreich ist, als es von vornherein eine teleologische Deutung ausschließt.

Das Endblättchen hat in diesem Fall einseitig eine Schwächung erfahren und ist auf dieser Seite asymmetrisch.

Ganz dasselbe, nur in entgegengesetzter Anordnung, läßt sich auch bei Seitenblättchen zusammengesetzter Blätter beobachten.

Bei Vitis Voineriana ist das Blatt meist dreiteilig, wobei die seitlichen Blatteile stark asymmetrisch mit geförderter Außenseite sind. Gliedert aber ein solches Teilblättchen seinerseits ein weiteres Teilblatt ab, so wird es symmetrisch. Es hat in beiden Fällen, bei dem Endblatt von Juglans wie bei den Teilblättchen von Vitis, also eine Änderung der Symmetrie durch Abgliederung eines Seitenblättchens stattgefunden, diese äußert sich bei einem gewöhnlich symmetrischen Blatteil im Asymmetrisch-, bei einem asymmetrischen im Symmetrischwerden. Nennen wir die der Blattspitze zugekehrte Hälfte eines Fiederblättchens seine obere oder abaxiale, so ist gewöhnlich die untere (adaxiale) Hälfte die größere (Fig. 269, 270), selten die obere, so z. B. bei Cedrela amara, Caesalpinina Sappan, Tamarindus indica und Roupala Pohlii (Fig. 268), Pflanzen, die, weil sie mir lebend vorlagen, hier genannt seien. DECANDOLLE hat ausdrücklich betont, daß bei asymmetrischen Blättchen stets die untere Hälfte die größere sei was dem eben Angeführten zufolge nicht allgemein zutrifft, wenigstens für den ausgewachsenen Zustand, denn wenigstens bei Tamarindus indica zeigt 
nach Boshart die Entwicklungsgeschichte, daß auch hier ursprünglich die adaxiale Hälfte der Fiederblättchen die größere ist, und daß sie erst später in der Entwicklung zurückbleibt.

Daß auch hier nicht, wie zuerst HofMeISTER annahm, die Einwirkung der Schwerkraft die Asymmetrie bedingt, wurde in der ersten Auflage dieses Buches betont. Vielmehr handelt es sich, wie bei der gelegentlich auftretenden Asymmetrie der Endblättchen um Förderungen und Hemmungen des Wachstums, welche durch die Insertion am Blatte und die Bezieliungen zu anderen Teilen bedingt sind, also ebenso wie beim ganzen Blatt durch Ernährungsverhältnisse.

So zeigt die in Fig. 269 abgebildete Bauhinia, daß die zwei Teilblättchen sehr stark asymmetrisch sind. Die Asymmetrie macht sich schon friih geltend, sie ist entgegengesetzt HoFMEISTER's Angabe schon lange vor der Entfaltung vorhanden. Der

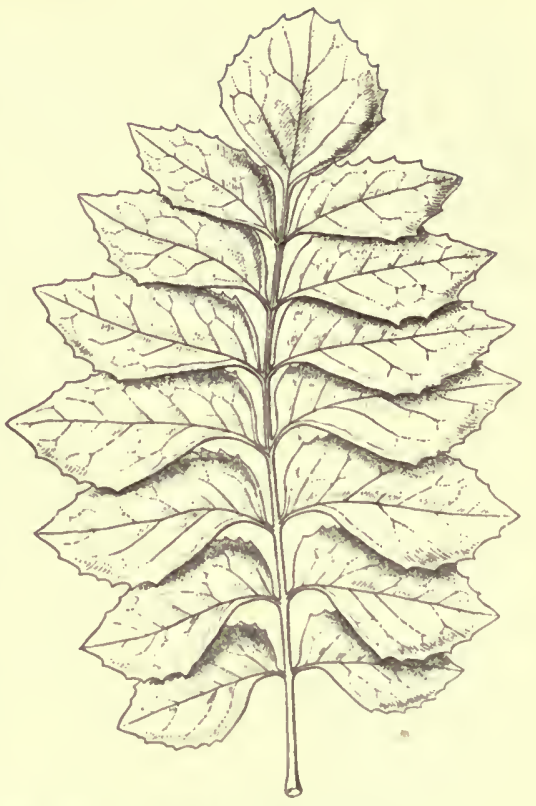

Fig. 268. Roupala Pohlii. Blatt auf $1 / 4$ verkleinert. obere Rand des Blattes ist hier

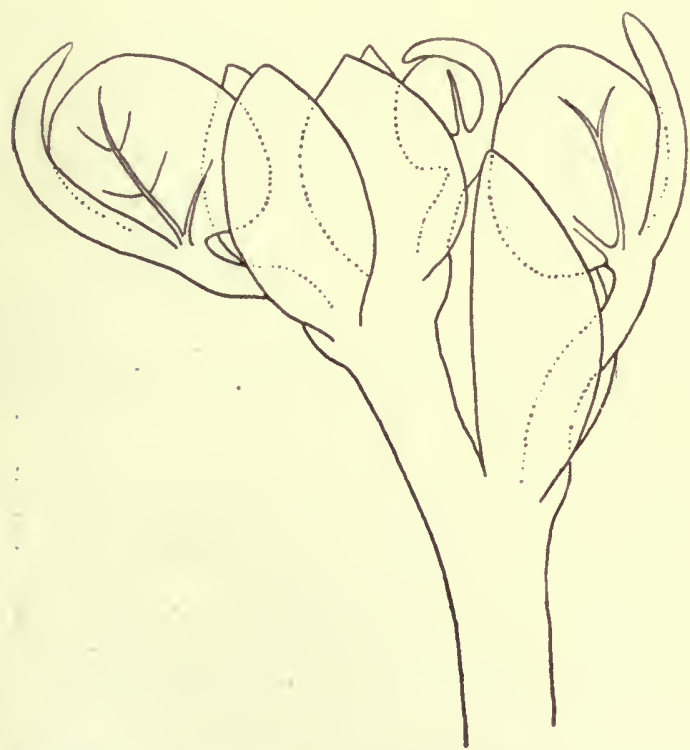

Fig. 269. Bauhinia sp. Sproßspitze. Die Blätter haben zwei frühzeitig stark asymmetrisch werdende Teilblättchen, an der Basis jedes Blattes zwei Nebenblätter.

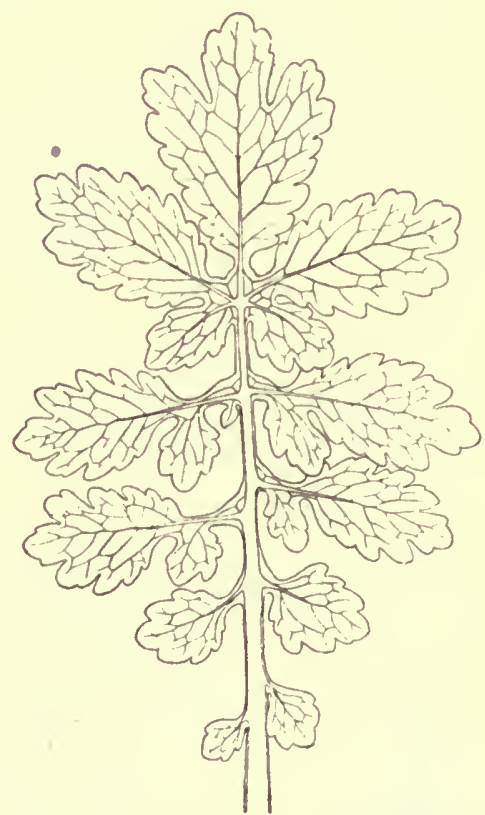

Fig. 270. Blatt von Chelidonium majus (um die Hälfte verkleinert). Asymmetrische Gestalt der Blattfiedern. 
von dem verkümmernden Blattende gedeckt und geschützt, das untere Ende liegt frei zwischen den muschelförmig zusammenschließenden Nebenblättern. Daß in anderen Fällen die kleinere Hälfte die ist, welche eine günstige Lichtausnutzung ermöglicht, indem Beschattung vermieden wird, hat H. Spencer hervorgehoben. Indes ist dies eine sekundäre Folge der durch die Organisationsverhältnisse gegebenen Asymmetrie und abgesehen von den bei lateraler Anisophyllie auftretenden Gestaltungsverhältnissen ist bis jetzt kein Fall bekannt, in welchem es gelungen wäre, die Asymmetrie experimentell $\mathrm{zu}$ verhindern oder hervorzurufen.

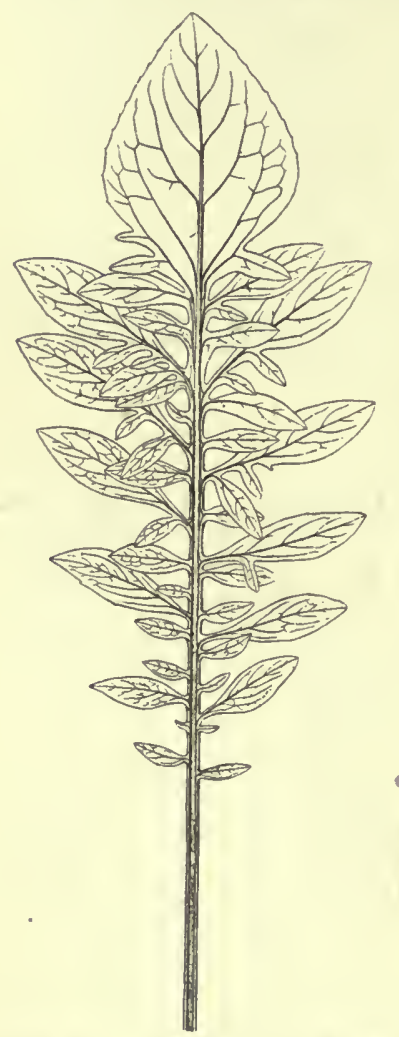

Fig. 271. Centaurea Kotschyii. Blatt stark verkleinert.

Die Blattbildung von Chelidonium majus möchte ich, weil sie besonders lehrreich ist, hier kurz besprechen (vgl. Fig. 270). Das Endblättchen und die untersten Seitenblättchen sind annähernd symmetrisch, die untersten Seitenblättchen stehen aber in einem Winkel von annähernd $45^{\circ}$ von der Blattspindel ab. Die oberen Seitenblättchen sind stark asymmetrisch, namentlich dadurch, daß ihr unterster Seitenlappen stark vorspringt. Ihm entspricht an dem weiter nach unten stehenden Fiederblatt ein Ausschnitt, entsprechend der Stelle, auf welche bei Beleuchtung von oben der Schatten des Lappens fallen wïrde ${ }^{1}$ ). Die einzelnen Teilblättchen sind übrigens nicht in der Fläche der Endblättchen ausgebreitet,

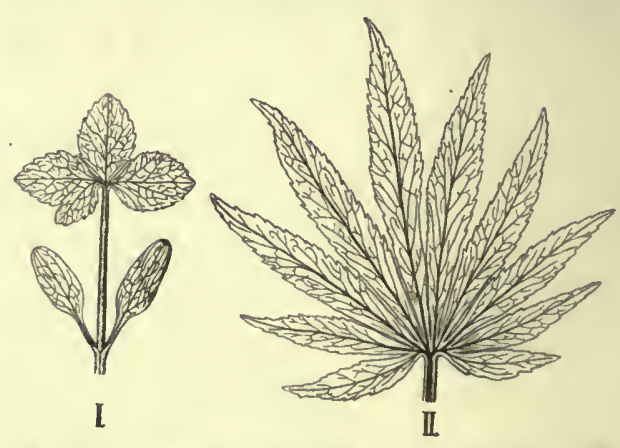

Fig. 272. Helleborus foetidus. I Keimpflanze. II Blatt einer älteren Pflanze (verkleinert).

sondern machen mit ihr einen Winkel; die untersten Seitenblättchen weichen durch ihre schiefe Stellung der Beschattung durch die oberen aus. Wenn dieser Fall, wie andere, sich also teleologisch zurechtlegen läßt, so ist das doch in zahlreichen anderen Fällen nicht möglich.

Noch auffälliger als bei Chelidonium tritt die Förderung der adaxialen Hälfte der Blattfiedern bei dem auch sonst eigentümlichen Blatte von Centaurea Kotschyii (Fig. 271) hervor. Wir sehen hier zunächst wie bei Chelidonium die Fiedern von oben nach unten an Größe abnehmen. Die größeren Fiedern zeigen besonders deutlich, daß die Fiedern zweiter

1) Es sei bemerkt, daß die Teilblättchen gefiederter Blätter auch dann asymmetrisch sind, wenn sie mit der Endfieder im Zusammenhang stehen. Hier kann aber die kleinere Hälfte nicht die schwächer beleuchtete sein! 
Ordnung einseitig (auf der der Blattbasis zugekehrten Seite) stehen. (Auf die kleinen zwischen den größeren stehenden Fiederblättchen wird S. 272 bei Besprechung der „unterbrochen gefiederten" Blätter einzugehen sein.)

In etwas abgeänderter Gestalt tritt dieselbe Erscheinung hervor bei den "fußförmigen" Blättern, wie sie sich z. B. bei Helleborus foetidus finden (Fig. 272 II). Auch hier handelt es sich um eine Förderung der dem Blattstiel näheren Partie des Blattes. Das Primärblatt ist dreiteilig, seltener tritt hier schon wie in Fig. $272 l$ an der Basis eines oder beider seitlicher Teilblättchen eine Auszweigung auf. Indem nun auch diese nur wieder an ihrem dem Blattstiel zugekehrten Rande sich rerzweigt und dieser Vorgang weiter sich wiederholt, entsteht das eigentümliche "fußförmige" Blatt.

Ein Beispiel dafür, daß von den Teilblättchen eines Blattes die einen symmetrisch, die anderen asymmetrisch sein können, bietet das Blatt von Mimosa sensitiva, welches in Fig. 273 abgebildet ist. Das Blatt ist doppelt gefiedert, der Endteil verkümmert. Die Fiederblättchen sind von sehr ungleicher Größe, die größeren Fiederblättchen sind stark asymmetrisch, die kleineren annähernd symmetrisch. Teleologisch sind die Symmetrieverhältnisse hier leicht verständlich. Wäre bei den asymmetrischen Fiedern die kleinere Hälfte so groß wie die größere, so würden Deckungen stattfinden; bei den inneren Blättchen, die viel kleiner sind, liegt nur eine Ausfüllung des Zwischenraumes zwischen den größeren vor.

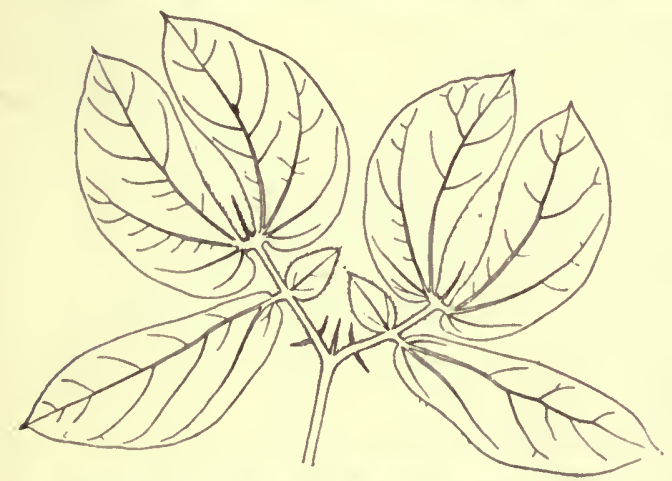

Fig. 273. Blatt von Mimosa sensitiva (natürl. Größe). An der Basis jeder der beiden Hauptfiedern zwei "Stipellen " (verkümmerte Fiedern zweiter Ordnuag).

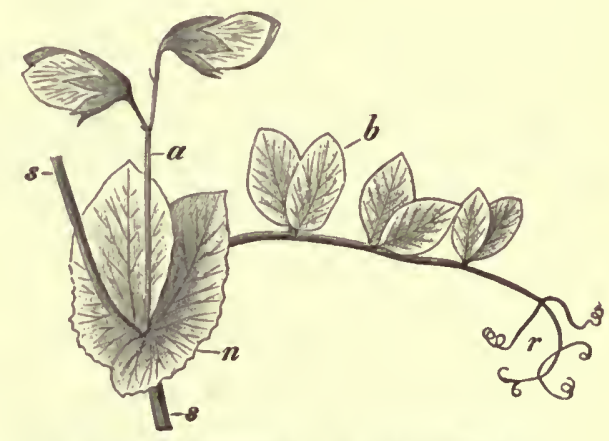

Fig. 274. Sproßstück von Pisum sativum. Die Nebenblätter $(n)$ des gefiederten Blattes sind stark asymmetrisch. (Lehrb.)

\section{§ 22. Asymmetrische Nebenblätter.}

An die Pflanzen mit ungleichseitigen Teilblättern schließen sich die an, welche ungleichseitige Nebenblätter haben, was bei vielen Leguminosen (z. B. Arten von Vicia, Pisum [Fig. 274], Orobus, Lathyrus), ferner Rosaceen (Spiraea Ulmaria, Agrimonia u. a.) der Fall ist. In besonders hohem Maße tritt diese Erscheinung bei den in Fig. $275 \mathrm{I}$ abgebildeten Nebenblättern von Passiflora Raddiana hervor, die nur auf einer Seite eine wohlentwickelte Spreite haben. Überall ist der dem Blatte abgekehrte Teil des Nebenblattes derjenige, welcher das stärkere Wachstum aufweist und dadurch wohl auch zum Knospenschutz geeigneter wird. Besonders interessant in dieser Beziehung ist Lathyrus Aphaca 
(Fig. 276, 277); hier sind nämlich die Nebenblätter, die an den ausgebildeten Blättern stehen, asymmetrisch, die an den verkümmerten oder zu Ranken umgebildeten symmetrisch. Zweifellos wirkt hier das Laubblatt (wo es wohlentwickelt ist) hindernd auf die Ausbildung der Nebenblätter, speziell auf deren innere Seite. Experimentell hat sich dies freilich nicht erweisen lassen, da die Nebenblätter sehr frühzeitig sich entwickeln. Indes kann das Verhalten der Pflanze selbst als ein Experiment betrachtet werden.

$\mathrm{Da}$ in teleologischer Beziehung die einseitig geförderte Ausbildung der Nebenblätter in manchen Fällen verständlich ist, zeigt ein Blick auf Fig. 278, welche einen Querschnitt durch die Knospe einer blühenden Pflanze von Vicia Cracca darstellt. Die Blätter sind hier wie bei den anderen Papilionaceen zweizeilig gestellt und der Länge nach eingefaltet,

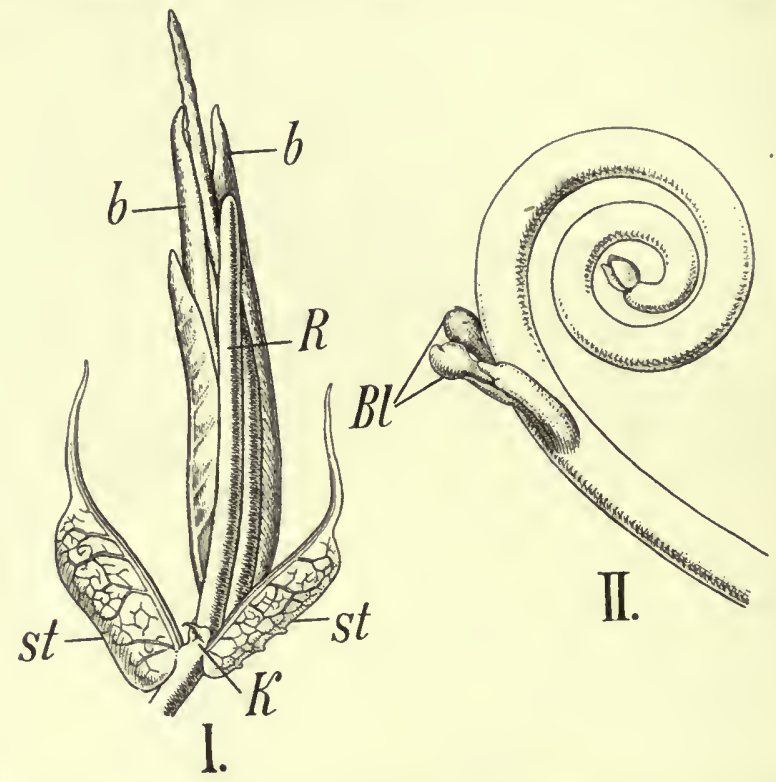

Fig. 275. $I$ Passiflora Raddiana. Die beiden Nebenblätter st des Blattes $b$ stark einseitig (exotroph) entwickelt.

ebenso jedes einzelne Fiederblättchen. Da die Blätter auf der Außenseite stark behaart sind, so ist die Knospe gut geschützt. Oben und unten aber finden sich zwei breite Längsstreifen, welche durch die Stipeln $\left(s t_{1}-s t_{6}\right)$ bedeckt werden. Es ist klar, daß der Schutz, den sie der Knospe verleihen, ein um so besserer sein wird, je mehr sie nach der dem Blatte abgekehrten Seite sich ausdehnen, weil hier die nicht vom Blatt selbst gedeckten Stellen sich finden. Indes ist die Asymmetrie der Nebenblätter nur ein Einzelfall der stärkeren Entwicklung adaxialer Blatteile. Wenn bei Lathyrus Aphaca das Blatt selbst am Knospenschutz so gut wie unbeteiligt ist (Fig. 277), so wird die Vergrößerung und das Symmetrischwerden der Nebenblätter nicht durch das "Bedürfnis" nach einem stärkeren Knospenschutz, sondern durch korrelative Beziehungen zur Verkümmerung des Blattes bedingt sein.

Entwicklungsgeschichtlich ${ }^{1}$ ) tritt die Asymmetrie der Nebenblätter

1) Vgl. Boshart, Flora 103, p. 101. 
der Papilionaceen schon sehr früh auf, und nimmt mit dem weiteren Wachstum zu.

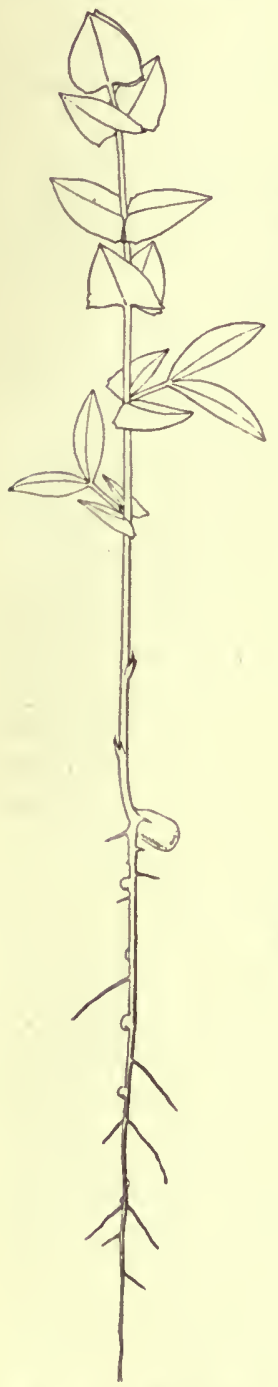

Fig. 276. Lathyrus Aphaca. Keimpflanze. Die Nebenblätter sind an den beiden unteren Blättern, bei denen die Blattspreite ausgebildet ist asymmetrisch, bei den oberen, wo die Blattspreite verkümmert ist, symmetrisch.

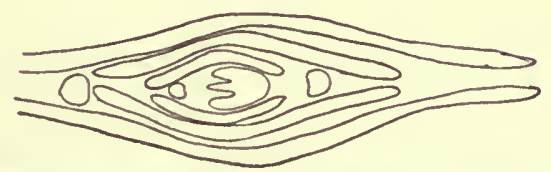

Fig. 277. Querschnitt durch die Sproßspitze von Lathyrus Aphaca. Die großen Nebenblätter übernehmen allein den Schutz der Stammknospe.

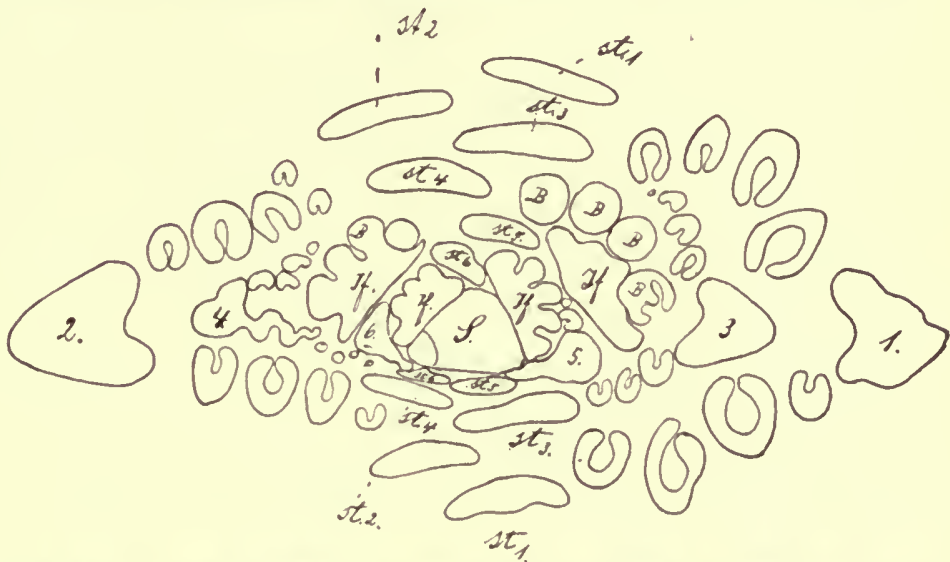

Fig. 278. Vicia Cracca. Querschnitt durch eine SproBspitze. 1-6 Blä̈tter (mit Fiederblättchen), die zugehörigen Nebenblätter $s t_{1}-s t_{6}$ füllen oben und unten die Räume zwischen den Blättern aus und tragen so zum Schutze der Knospen bei.

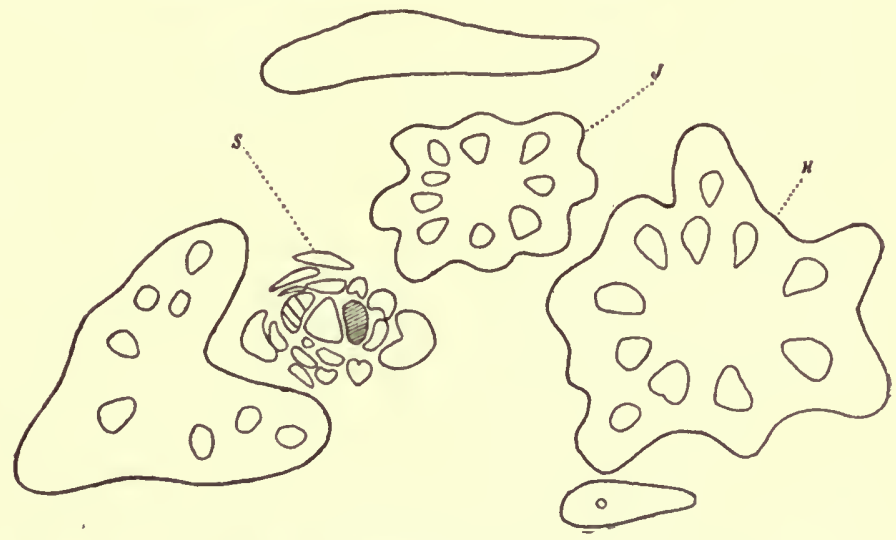

Fig. 279. Vicia Cracca. Querschnitt durch eine Hauptachse $(\boldsymbol{H})$. In der Achsel des Blattes links steht die Infloreszenz $J$, unterbalb dieser der ${ }_{n}$ Beisproß $S$, der auch schon axilläre Infloreszenzen hervorgebracht hat, die durch Schraffierung angedeutet sind. Die Symmetrieebene des Sprosses $S$ steht nahezu parallel mit der des Hauptsprosses; die Infloreszenzen sind in beiden nach der Lichtseite hin gerückt. 


\section{§ 23. Größenverschiedenheit der Blatteile nntereinander.}

Der Fall von Mimosa sensitiva (Fig. 273) bietet zugleich ein Beispiel für die verschiedene Entwicklung der Fiederblättchen eines und desselben Blattes. Die inneren Blattfiedern zweiter Ordnung sind hier viel kleiner als die nach außen gerichteten, zuweilen sind sie nur als kleine Zäpfchen oder gar nicht entwickelt. Die Fiedern erster Ordnung sind also stark exotroph. a Blattes ausgebildet bei Pflanzen verschiedener Verwandtschaftskreise. So bei denen, welche die Terminologie als "unterbrochen gefiedert" bezeichnet, so z. B. Solanum tuberosum, Geumarten (vgl. Fig. 280), Centaurea Kotschyii (Fig. 271), Potentilla anserina, Spiraea filipendula u. a.

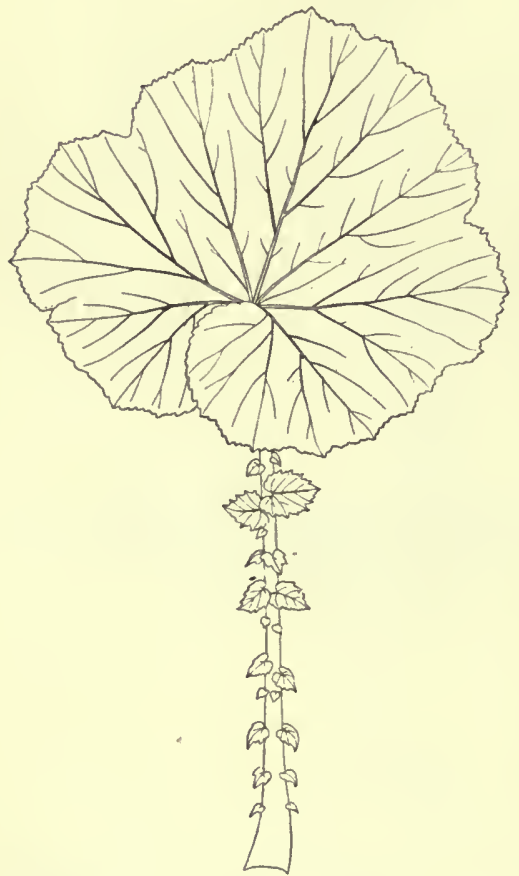

Fig. 280. Geum bulgaricum. Blatt (verkleinert). Die Endtieder ungemein stark vergrößert, die Seitenfiedern von ungleicher Größe, meist abwechselnd kleinere und größere Paare.

In allen diesen Fällen bleiben im Verlauf der Entwicklung einzelne Fiederblättchen im Wachstum gegenüber den anderen zurück, ein Zurückbleiben, das sich schon in einer verspäteten Anlage (den anderen Fiederblättern gegenüber) aussprechen kann. Die klein bleibenden Blättchen füllen die Zwischenräume zwischen den größeren aus. Auch hier können wir wieder von niederen Pflanzen ein ganz entsprechendes Gestaltungsverhältnis anführen: Wir sehen bei der in Fig. 213 abgebildeten Alge, daß abwechselnd rechts und links ein Kurztrieb in der Entwicklung zurückbleibt, der Langtrieb ist „unterbrochen gefiedert". Die Regulierung geschieht wahrscheinlich durch Korrelation der einzelnen Blatteile unter sich: die Vergrößerung einiger bedingt das Kleinbleiben anderer, an sich ebenso entwicklungsfähiger. Wenigstens scheint bei den Blättern höherer Pflanzen keine bestimmte Regel dafür vorhanden $\mathrm{zu}$ sein, welches Teilblättchen klein bleibt. Außerdem sehen wir bei Centaurea Kotschyii (Fig. 271) und Geum bulgaricum den Endteil des Blattes stark gefördert. Das kehrt auch sonst vielfach wieder. Die der Achse zugekehrten Teilblättchen der Kastanie, von Lupinus und vielen anderen bleiben kleiner als die ihr abgekehrten und bewirken so eine Verlegung der Blattfläche nach außen. Die kleiner bleibenden Blättchen sind in diesen Fällen wohl immer die zuletzt angelegten.

Bei Geum bulgaricum (Fig. 280) ist das Blatt gewissermaßen im Begriff, aus einem gefiederten, und zwar einem unterbrochen gefiederten, wieder zu einem einfachen zu werden. Das Endblättchen hat sich bedeutend vergrößert, es stellt sich so, daß der Anschein eines schildförmigen Blattes zustande kommt. Die Seitenfiedern werden dadurch fast ganz verdeckt und sind sehr reduziert. Immerhin kann man ihre Größen. 
verschiedenheiten noch erkennen. Bei anderen Geumarten ist die Verschiedenheit des Endblättchens von den Seitenfiedern nicht so groß wie bei G. bulgaricum.

\section{$\S 24$. Terminologisches über die Symmetrie im anatomischen Bau des Blattes.}

Wenn wir hier auch auf die im anatomischen Bau zutage tretenden Symmetrieverhältnisse eingehen (auf die schon oben teilweise hingedeutet wurde), so kann das nur in aller Kürze und nur insofern, als dabei allgemeinere organographische Probleme in Betracht kommen, geschehen.

Die Terminologie des Blattbaues (nach seinen Symmetriererhältnissen) befindet sich derzeit in einem sehr üblen Zustande. Einmal in sprachlicher Hinsicht, indem man "hybride" (aus zwei Sprachen zusammengemengte) Worte, wie „isolateral", „monofazial" usw. verwendet. Dann auch sachlich, indem man Flächen (facies) und Seiten (latera) als gleichbedeutend betrachtet, was offenbar sinnlos ist. Im folgenden sollen die Flächen - und zwar die ursprünglich am Blatt vorhandenen bzw. die bei "normalen" Blättern vorhandenen - stets als "facies" bezeichnet werden. Sind sie - betreffs des Assimilationsgewebes - verschieden gebaut, so nennen wir ein solches Blatt dorsiventral, sind sie gleich gebaut äquifazial. Diese Blätter haben alle zwei Flächen, eine adaxiale und eine abaxiale, sie sind also im eigentlichen Sinn des Wortes bifazial (ein Ausdruck, der aber auch in anderem Sinne gebraucht wird). Außerdem gibt es noch un ifaziale Blätter, bei denen e in e Fläche stark entwickelt ist, während die andere oft kaum mehr zu erkennen ist.

\section{$\S 25$. Bifaziale Blätter mit dorsiventralem oder invers-dorsiventralem Bal.}

Die Kenntnis der Blattgestaltung hat sich entwickelt durch die Untersuchung der Blätter mitteleuropäischer Pflanzen. Hier sind die Blätter fast alle deutlich dorsiventral gebaut. Das entspricht ja auch der Tatsache, daß die meisten Blätter eine Fläche nach oben, die andere nach unten kehren, also eine Licht- und eine Schattenseite haben. Die Dorsiventralität spricht sich aus:

1. in der Ausbildung der Leitbündel, welche das Blatt durchziehen. Die Gefäßteile sind nach oben, die Siebteile nach unten gekehrt, entsprechend der Lagerung in den Sproßachsen;

2. in der Ausbildung des Assimilationsgewebes. Bekanntlich ist dies bei den Blättern europäischer Pflanzen meist als Palisadenparenchym auf der Oberseite, als Schwammparenchym auf der Unterseite entwickelt.

Dies ist a) die „normale" dorsiventrale Struktur der Pflanzen der mitteleuropäischen Flora. Diese wird in den anatomischen Handbüchern, auf die hier verwiesen wird, näher erörtert $\left.{ }^{1}\right)$. Indes kommt auch bei europäischen Pflanzen schon invers-dorsiventrale Ausbildung vor.

b) Als invers-dorsiventrale Blätter bezeichnen wir die, bei welchen die Unterseite (abaxiale, Außenseite) diejenige Struktur des Assimilationsparenchyms hat, welche sonst der Oberseite (adaxialer oder Innenseite)

l) Vgl. z. B. Haberlandt, Physiol. Pflanzenanatomie.

Goebel, Organographie der Pflanzen. 2. Aufl. Allgem. Teil. 
zukommt. Dabei kann die Oberseite als Assimilationsfläche entweder ganz ausgeschaltet sein, oder sie kann die Struktur annehmen, die sonst der Unterseite zukommt. Invers-dorsiventrale Blätter mit vertauschten Assimilationsflächen lassen sich in zwei - nicht scharf getrennte - Gruppen einteilen: $\alpha$ ) solche ohne und $\beta$ ) solche mit Orientierungsbewegungen.

$\alpha)$ Wir finden hierbei zunächst Pflanzen, deren Blätter schuppenförmig und der Sproßachse genähert (nicht flach ausgebreitet) sind. So z. B. bei Salicornia, wo der freie Teil des Blattes zurücktritt gegenüber dem unteren, welcher die Sproßachse berindet: das chlorophyllreiche Gewebe findet sich hier auf der abaxialen Blattseite, die ja auch die stärker beleuchtete ist. Ähnlich verhalten sich wie p. 247 berichtet, die Blätter einiger Cupressineen ${ }^{1}$ ). Auch bei anderen Nadelhölzern, bei denen die Blätter von der Sproßachse abstehen, kommt inversdorsiventrale Ausbildung vor. So bei Picea ormorica, P. ajanensis u. a. Die Nadeln von P. ajanensis, die schief rom Zweige abstehen, haben zwei Wachsstreifen und die Spaltöffnungen oberseits, das chlorophyllreiche Gewebe auf der spaltöffnungsfreien abaxialen Seite; letztere ist auch hier die dem Lichte dargebotene. Die auf der Zweigunterseite stehenden Blätter drehen sich so, daß ihre abaxiale Seite dem von oben einfallenden Lichte (bei dickeren Zweigen wenigstens der Außenseite) zugekehrt ist, wodurch die $Z$ weigunterseite auf den ersten Blick wie von Nadeln entblößt aussieht. Der Zweig erscheint infolgedessen von oben betrachtet dunkelgrün, von unten hell, ähnlich wie ein solcher von Abies pectinata (bei der die Nadelblätter den normalen dorsiventralen Bau haben). Übrigens fallen bei dickeren Zweigen die untersten Nadeln auch früher ab als die anderen. Sie sind trotz der erwähnten Drehung in ungünstigeren Beleuchtungsverhältnissen. Hier führt also ein Teil der Blätter schon Orientierungsbewegungen aus, andere nicht, während an den vertikalen Sprossen alle Blätter ihre Lage beibehalten.

Auch bei Dikotylen finden sich solche invers-dorsiventrale der Sproßachse im entfalteten Zustand nicht anliegende Blätter. So besitzt die xerophile Komposite Phoenocoma prolifera ${ }^{2}$ ) nadelförmige Blätter, die steil aufgerichtet sind. Die Oberseite ist hier mit einem dichten Haarfilz versehen, sie hat die Struktur, die sonst der abaxialen Seite zukommt. Daß bei derartigen Pflanzen wirklich eine "Vertauschung" der Blattflächen eingetreten ist, läßt sich daraus schließen, daß die Jugendform bei einigen noch Blätter mit normal orientierten Flächen besitzt. Wenigstens ist dies so bei Passerina, den "cupressoiden" Veronikaarten ${ }^{3}$ ) und den Cupressineen mit schuppenförmigen Folgeblättern, bei Salicornia sind die Blätter ron Anfang an schuppenförmig.

Die Annahme liegt nahe, die Vertauschung damit in Zusammenhang zu bringen, daß die späteren Blätter sich so stellen, daß die abaxiale Seite die stärker beleuchtete ist. Jedenfalls ist bei diesen Blättern ein Zusammenhang von Lage und Bau deutlich wahrnehmbar.

B) Mit Torsion. In Fig. 281 'sind die Kurztriebe einer Liliacee abgebildet, deren Blätter vertauschte Flächen haben, wie der Querschnitt (Fig. 282) deutlich zeigt. Sie drehen sich um $90^{\circ}$, so daß von den horizontal inserierten Kurztrieben die abaxialen Seiten alle nach oben zu liegen

1) Schon Thomas hat in seiner Arbeit znr vergleichenden Anatomie der Coniferenlaubblätter (Jahrb. für wiss. Botanik IV, 47 [1866]), auf diese Beziehungen hingewiesen.

2) Abbildung in Goeber, pflanzenbiolog. Schilderungen. Taf. XXIII, Fig. 12.

3) Vgl. Gozber, Einleitung in die experim. Morphologie p. 33. 
kommen ${ }^{1}$ ). Der Kurztrieb nimmt so eine habituelle Übereinstimmung mit dem von Medeola asparagoides an (Fig. $281 I I$, 283), welcher morphologisch freilich auf ganz andere Weise aufgebaut ist. Die blattähnlichen Phyllocladien (die normal dorsiventral gebaut sind) führen bei horizontal wachsenden Sprossen auch hier eine Drehung von $90^{\circ}$ aus, aber in entgegengesetzter Richtung gegenüber den Blättern von Geitonoplesium; in beiden Fällen kommt die mit dem chlorophyllreichen Assimilationsgewebe versehene Seite auf die Lichtseite.

Fig. 281. Links Kurztrieb von Geitonoplesium cymosum (verkl.). Die Blätter führen eine Drehung von $90^{\circ}$ ans. Daneben links die Basis eines Blattes in nat.Gr. II Kurztrieb ron Medeola asparagoides mit (dorsiventralen) Phyllocladien $(P h)$.
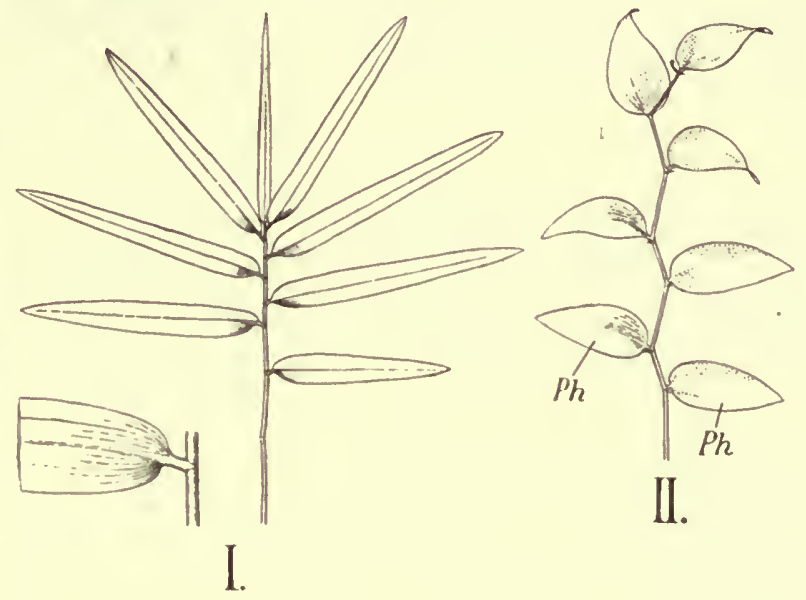

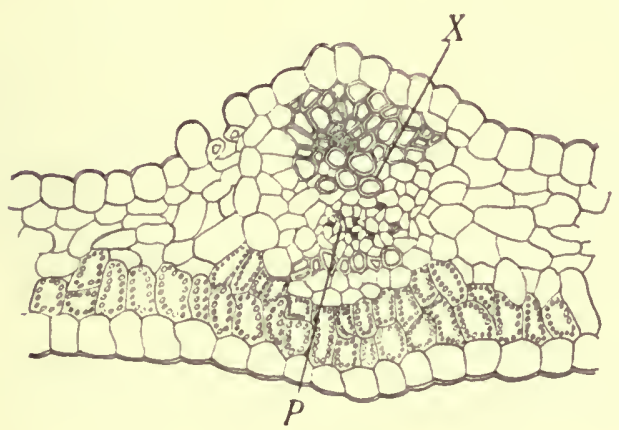

Fig. 282.

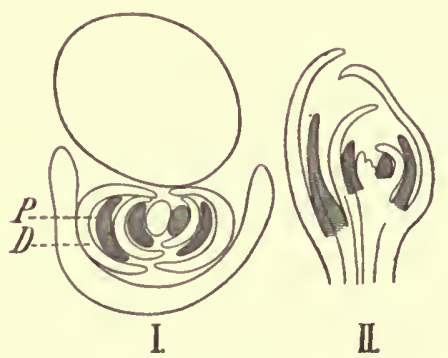

Fig. 283.

Fig. 282. Geitonoplesium cymosum. Blattquerschnitt $X$ Xylem (auf der $n$ Oberseite" ). $P$ Phloem auf der Unterseite. Daselbst Palisadenparenchym, in welches die in anderen Zellen weggelassenen Chlorophyllkörper eingezeichnet sind.

Fig. 283. Medeola asparagoides. I Querschnitt durch einen Kurztrieb, Phyllocladien schraffiert, 11 Längsschnitt.

Derartige Orientierungsbewegungen werden, so weit ich sehen kann, nur von solchen invers-dorsiventralen Blättern ausgeführt, welche eine wohl entwickelte Blattspreite besitzen. Sie treten besonders auffallend dann hervor, wenn eine Drehung um $180^{\circ}$, also eine "Resupination" stattfindet. Diese würde auch bei Geitonoplesium eintreten, wenn die ortho-

1) Das Blatt kehrt die Rinne des kurzen Blattstiels schief der Sproßspitze zu, es sieht aus, als ob es an der Basis asymmetrisch wäre. 
tropen (hier schlingenden) Achsen Laubblätter bilden würden; sie bringen aber - wenigstens im späteren Lebensalter - nur der Sproßachse anliegende und bei der Entfaltung abfallende Niederblätter ${ }^{1}$ ) hervor, in deren Achseln die erwähnten Kurztriebe stehen.

Resupinierende invers-dorsiventrale Blätter kommen namentlich bei einigen Monokotylen, seltener bei Dikotylen vor. Hier genügt (unter Verweisung auf den speziellen Teil) ein Beispiel, welches besonders auffallend ist, das einiger Alstroemeriaarten. Fig. 284 zeigt ein solches resupiniertes Blatt. Die Umdrehung geht, wie CzAPEK ${ }^{2}$ ) fand, auch im Finstern, wenngleich langsamer vor sich.

Fig. 284. Alstroemeria psittacina, Blatt (nat. Gr.). Durch Torsion des blattstielartigen unteren Teiles hat eine Drehung der Spreite um $180^{\circ}$ stattgefunden.

Fig. 285. Bomarea (spec.) Keimpflanze (verkl). Das Blatt 1 aufgerichtet mit wenig Chlorphyll. Blatt 2 kehrt seine abaxiale Seite $(A b)$ nach oben.

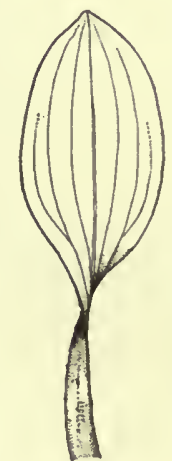

Fig. 284.

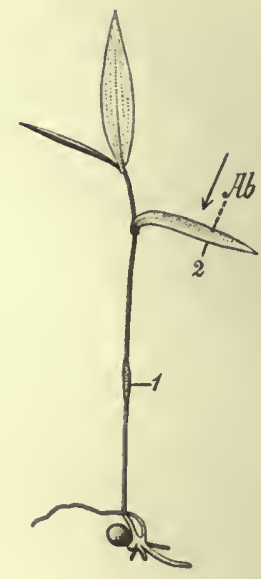

Fig. 285.

Derartige Blätter fordern natürlich zur Beantwortung der Frage auf, wie sie zustande kamen? Diese Frage wird später zu erörtern sein, hier sei nur kurz erwähnt, daß der Verf. in der 1. Auflage die Vermutung vertrat, daß solche Blätter aus usprünglich nicht flach ausgebreiteten aphotometrischen invers-dorsiventralen mit dem Lichte zugewandter abaxialer Seite (Rollblättern oder aphotometrisch aufgerichteten) hervorgegangen seien.

Dies wird auch für die Alstroemeriaceen gestützt durch folgende Beobachtung der Keimpflanzen einer brasilianischen Bomarea, welche vielleicht mit der von LINDMAN ${ }^{3}$ ) beobachteten übereinstimmt. Das erste Blatt nach dem Kotyledon war aufgerichtet, trägt aber mehr den Charakter eines Niederblattes als den eines Laubblattes und besitzt wenig Chlorophyll. Doch ist die inverse Dorsiventralität darin angedeutet, daß die Spaltöffnungen auf der Oberseite zahlreicher sind, als auf der Unterseite, auf der letzteren treten sie bei den folgenden Blättern noch mehr zurück. Das zweite Blatt führt schon eine

1) Diese stellen nur eine sekundäre Umbildung der Laubblätter dar, die ursprünglich wohl allein vorhanden und wahrscheinlich auch aufgerichtet waren.

2) Czaper, Studien über die Wirkung änßerer Richtkräfte auf die Pflanzengestalt. Flora 1898 p, 424. CzAPEK leitet die Alstroemeriablätter ab von "vertikalfächigen d. h. in Profilstellung befindlichen paratrophen Laubblättern“. Er führt zur Unterstützung an, daß die ersten Blätter der Keimpflanzen anf dem Klinostaten die dorsiventrale Ausbildung des Assimilationsapparates nicht zeigen. Das dürfte indes nur eine Folge geminderter Lichtintensität sein.

3) Lindman, Morphologie und Biologie einiger Blätter in Bihang till K. Svenska Vetensk. Akad. Handlingar, Bd. 25, Afd. II, 1899, p. 401. 
Drehung, wenn auch keine völlständige Resupination (um $180^{\circ}$ ) aus. Es gelangt durch stärkeres Wachstum der Unterseite nahe dem einen Blattrand die Unterseite nach oben; die Drehung wird durch eine einseitige Hyponastie bedingt.

Ob man berechtigt ist, aus der Tatsache, daß das erste Blatt der Sproßachse anliegt, zu schließen, dies sei die ursprünglich auch den anderen Blättern eigene Stellung und diese Stellung habe die invers dorsiventrale Ausbildung bedingt, ist indes sehr fraglich, so lange keine verwandten Pflanzen bekannt sind, bei denen ein solches Verhalten wirklich vorkommt. $\mathrm{Da} \beta$ die Resupination (bei Oberlicht) eine bessere Lichtausnutzung ermöglicht, ist klar, wenn sie aber Lindman auf ein "Bedürfnis" der Pflanze zurückfübrt, so ist dies doch auch nur eine Umschreibung dafür, daß eine uns zweckmäßig erscheinende Reaktion vorliegt ${ }^{1}$ ).

\section{§ 25. Äquifaziale Blätter.}

Von den äquifazialen Blättern seien nur die kurz erwähnt, die dadurch ausgezeichnet sind, daß sie auf beiden Seiten, der abaxialen und der adaxialen Palisadenparenchym haben. Sie sind für uns deshalb von Bedeutung, weil schon aus einem Vergleich der Standortsverhältnisse sich ergibt, daß sie besonders häufig an Pflanzen stark besonnter und verhältnismäßig trockener Standorte vorkommen.
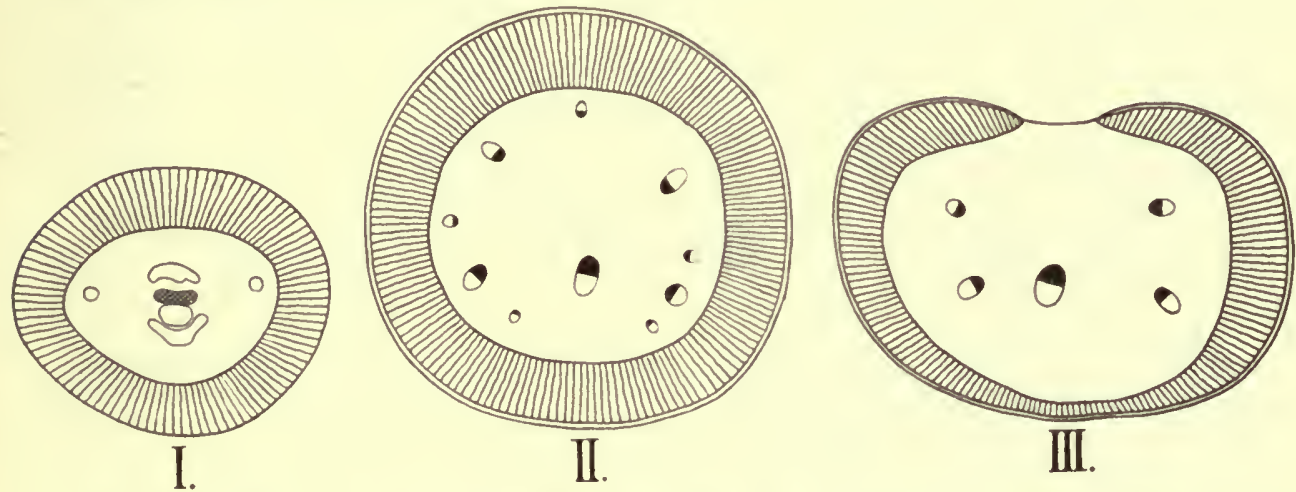

Fig. 286. Blattquerschnitte (adaxiale Seite nach oben gekehrt, Palisadenparenchym schraffiert). I von Calothamnus sanguinea. (Im Leitbündel, Xylem schraffiert.) II u. $I I I$ Hakea gibbosa. Das Batt ist bei $I I I$ nahe der Basis, bei $I I$ weiter oben getroffen, Xylem schwarz.

So sind in der australischen Flora derartige Blätter sehr häufig, eine Statistik der australischen Gehölzflora würde wahrscheinlich ergeben, daß Pflanzen mit äquifazialen Blättern dort in der Majorität sind.

Als Beispiele mögen die in Fig. 286 abgebildeten Blattquerschnitte einer australischen Myrtacee und einer australischen Proteacee dienen. Sehr bekannt ist auch das Verhalten von Eucalyptus, dessen Blätter bei der Jugendform horizontal und (mehr oder minder) dorsiventral, bei der Folgeform vertikal (durch Drehung!) und äquifazial ausgebildet sind. Ebenso sind die - von vornherein vertikal stehenden - Phyllodien vieler Acaciaarten äquifazial. In physiologischer Beziehung gibt es, wie es scheint,

$\left.{ }^{1}\right)$ Betr. das Verhalten anderer resupinierender Blätter namentlich der Grasblätter vgl. den speziellen Teil. 
zwei Arten äquifazialer Blätter: solche, welche in ihrer Stellung (entweder direkt oder indirekt) vom Lichte beeinflußt sind, also photometrische, und solche, bei denen das nicht der Fall ist, aphotometrische.

Zur ersteren gehören die Blätter älterer Pflanzen von Eucalyptus, welche sich durch Drehung in die Vertikalebene einstellen, ebenso die Kompaßpflanzen; zu letzteren, viele australische Pflanzen mit unbeweglichen Blättern wie Hakea gibbosa, pectinata u. a. (die freilich schon den unifazialen zuzuzählen sind). Diese Blätter stellen sich zwar annähernd quer zur Sproßachse ein, es ist aber nicht wahrscheinlich, daß hier eine photometrische Bewegung vorliegt, vielmehr ist anzunehmen, daß derartige Blätter ebenso aphotometrisch sind, wie z. B. die Blätter von Echeveria (nach WIESNER).

\section{§ 26. Unifaziale Blätter.}

Aphotometrisch sind ferner wohl alle unifazialen Blätter.

Bei diesen ist die abaxiale Seite (die "Unterseite") stark entwickelt während die Oberseite ganz und gar zurücktritt. Man kann auch sagen, es liege ein Fall starker "Exotrophie" der Blattspreite vor, wobei die Oberseite der Beobachtung äußerlich ganz entschwinden kann.
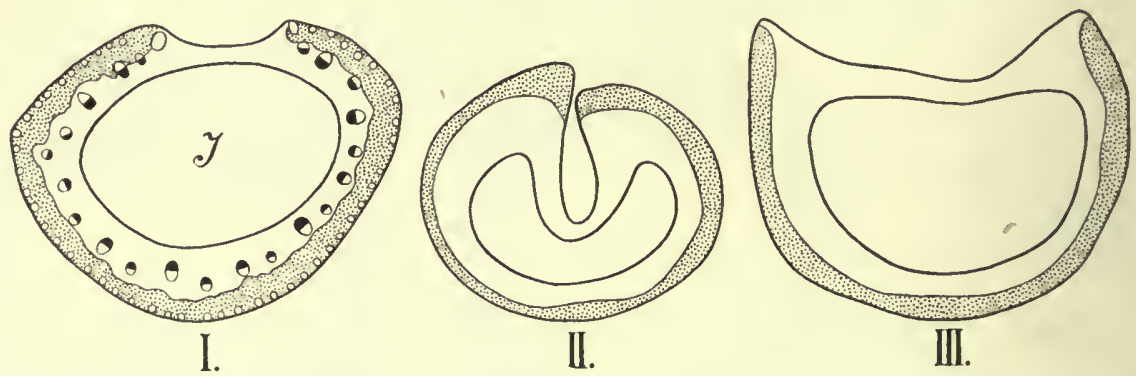

Fig. 287. Scirpus Holoschoenus. I Querschnitt eines Blattes unter der Infloreszenz. $J$ Luftraum, chlorophyllhaitiges Gewebe punktiert. II und III Querschnitt eines Laubblattes, $I I$ eingerollt, III ausgebreitet. Die Oberseite hat kein Assimilationsparenchym.

Runden sich derartige Blätter ab (z. B. bei Juncus), so erscheinen sie als radiär, was sie aber ihrer Entstehung nach eigentlich nicht sind. Diese scheinbar radiären Blätter können sich dann auch wieder abflachen (z. B. bei Allium Schoenoprasum u. a.) und sehen dann aus wie gewöhnliche, flache Blätter. Von diesen unterscheidet sie aber ihre innere Struktur, namentlich die Anordnung der Leitbündel.

Wir haben es hier mit einer sehr merkwürdigen, vielfach mißverstandenen Blattform zu tun, die einer etwas eingehenderen Besprechung bedarf.

Den bifazialen Blättern am nächsten stehen solche, bei denen die beiden Flächen zwar noch unterscheidbar sind, aber eine - die Oberseite - sehr zurücktritt.

So ist in Fig. 287, I abgebildet der Querschnitt eines unter der Infloreszenz von Scirpus Holoschoenus stehenden Blattes. Die Oberseite ist als eine seichte, kein chlorophyllbaltiges Gewebe führende, Rinne erkennbar. Viel mehr entwickelt, aber ohne Assimilationsgewebe und ohne Leitbündel, ist sie bei den gewöhnlichen Laubblättern derselben Pflanze. Die Ausbildung der Oberseite ermöglicht hier, daß das Blatt im trockenen $\mathrm{Zu}$ - 
stand als Rollblatt funktioniert (Fig. 287, II, III) und dann aussieht wie ein Juncusblatt, auch an Schnitten läßt sich die Einrollung durch Wasserentziehung leicht hervorrufen.

Auf eine noch engere Furche reduziert ist die Oberseite bei manchen Orchideen mit fleischigen, fast drehrunden Blättern. So bei Leptotes bicolor und Vanda teres (Fig. 289,0). Auch die dickfleischigen aufrechtstehenden Blätter der Liliacee Sanseviera cylindrica verhalten sich ähnlich.

Solche mit einer Furche auf der Oberseite versehenen Blätter haben Veranlassung gegeben zu einer unhaltbaren Auffassung über ihr Zustandekommen.

Das Vorherrschen der Unterseite bei ihnen hat man sich nämlich, ausgehend namentlich vom anatomischen Bau, dadurch zurechtgelegt, daß man annahm, es liege eine „Einfaltung" eines flachen Blattes nach oben, und eine "Verwachsung" der sich berührenden Teile der Oberseite vor.
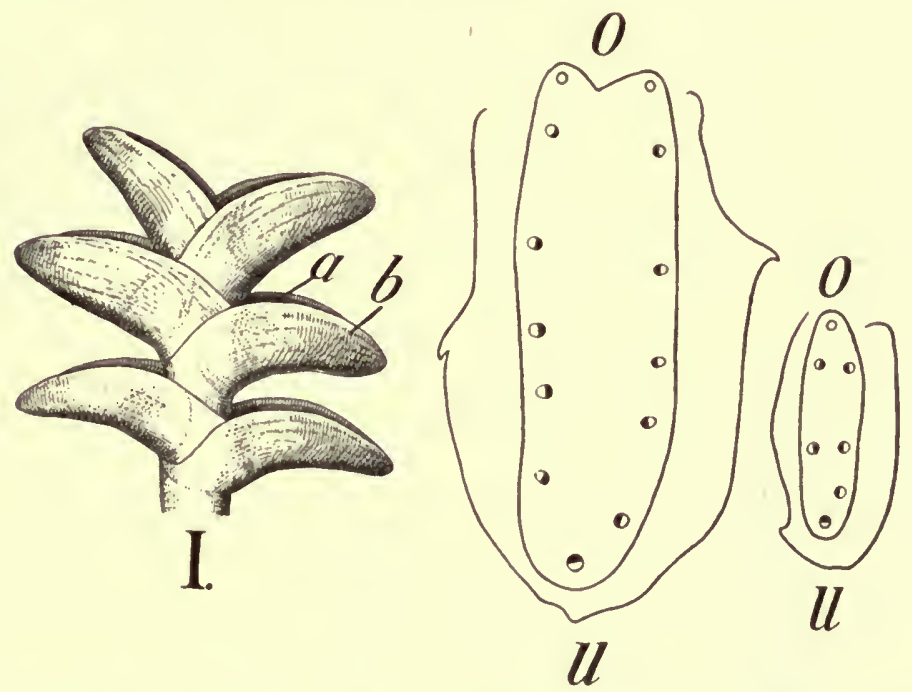

Fig. 288. Angraecum distichum. I Habitusbild eines Sprosses (nicht ganz 3 fach vergr.). Bei $a$ ist eine seichte Furche auf der Oberseite rorhanden. Die zweite Figur stellt einen Querschnitt bei $a$, die dritte einen solchen bei $b$ dar (vergr.). 0 adaxiale (Ober-), $u$ abaxiale (Unter)seite.

Diese Auffassung liegt bei oberflächlicher Betrachtung allerdings nahe. Sieht man z. B. die Blätter der Orchidee Angraecum distichum an, so findet man an ihnen von der Basis ausgehend auf etwa $2 / 3$ der Länge eine seichte Furche, deren Ränder denen eines flachen Blattes entsprechen (Fig. 288, I). Der Querschnitt (Fig. 288, II) zeigt, daß die Gefäßteile der Leitbündel alle nach innen gekehrt sind, also so liegen, wie es bei einer Einfaltung des (flach gedachten) Blattes der Fall sein müßte. Analoge Verhältnisse treffen wir bei der oben erwähnten Orchidee mit scheinbar drehrunden Blättern, Vanda teres an (Fig. 289). Auch hier ist auf der Oberseite eine Furche vorhanden, die Anordnung der Leitbündel ist eine ähnliche wie bei Angraecum, nur ist eine größere Anzahl vorhanden. Auch hier kann eine "Einfaltung" konstruiert werden. Aber das ist eben nur eine Zurechtlegung auf Grund des anatomischen Bildes. Dieses kann aber für die Frage nach dem Zustandekommen nicht ausschlaggebend sein. 


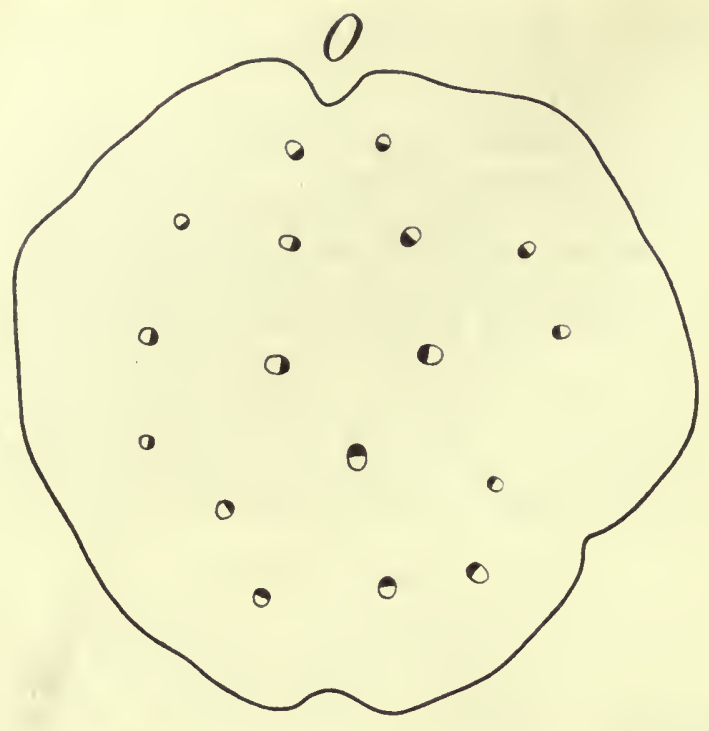

Fig. 289. Vanda teres. Blattquerschnitt vergr.

$O$ adaxiale Seite. Gefäßteile der Leitbündel dunkel gehalten.
Übrigens können auch an der Hauptsache nach bifazial ausgebildeten Blättern einzelne Teile unifazial entwickelt sein. So die Blattspitze bei einigen Monokotylen, deren Verhalten uns für die Auffassung der später $\mathrm{zu}$ besprechenden Fälle von Wert sein wird.

Die Blätter von Doryanthes Palmeri (und ähnlich verhält sich $\mathrm{z}$. B. die weitverbreitete Topfpflanze Ornithogalum caudatum) haben eine fast drehrunde Spitze ron einigen Zentimeter Länge, eine sog. "Vorläuferspitze" (Fig. 290, VS). An diese setzt sich nach unten der flache Teil des Blattes an in der

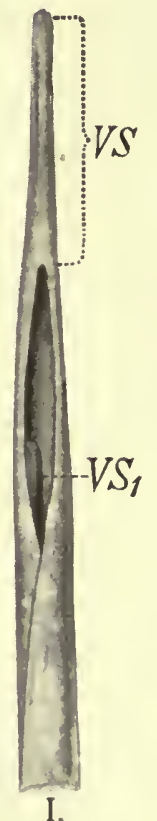

Fig. 290. Doryanthes Palmeri. I Junges, noch nicht entfaltetes Blatt von Do. ryanthes Palmeri. VS Vorlänferspitze, $\nabla S_{1}$ Vorlänferspitze des nächst jüngeren

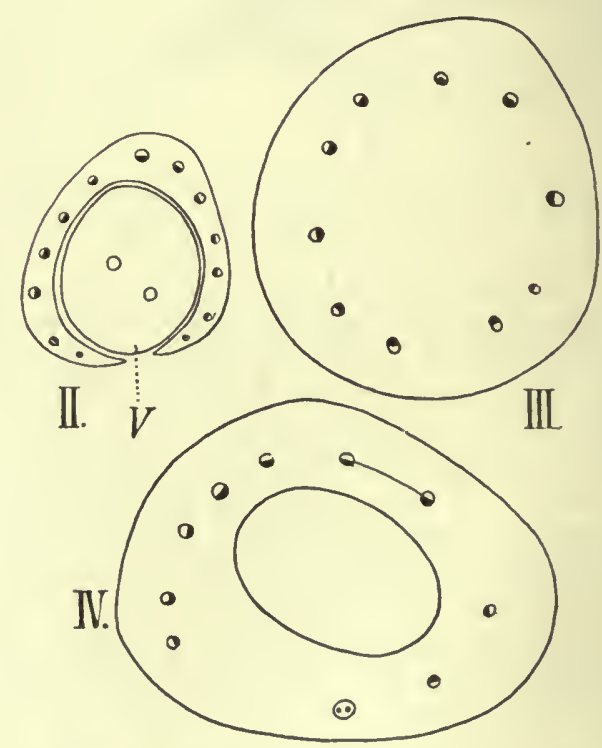

Fig. 291. Doryanthes Palmeri. III Querschnitt durch eine Vorläuferspitze, $I V$ und $I I$ weiter unten, die Gefäßteile der Leitbündel dunkel. 
Weise, daß das Blatt nach oben hin mit seinen Rändern eingebogen erscheint. Querschnitte (Fig. 291) durch die Vorläuferspitze zeigen einen annähernd radiären Bau; ein Kreis von Leitbiindeln mit nach außen gekehrten Siebteilen (Fig. 291, IIII) ist vorhanden, der sich nach unten hin sozusagen öffnet, das Blatt breitet sich seitlich aus, ist aber noch bedeutend dicker als weiter unten, wo es in die gewöhnliche, flache Form übergeht.

Wie sollen wir die Beziehungen der Spitze zum flachen Teil auffassen? Nichts ist einfacher als anzunehmen, die Spitze sei durch „Verwachsung" der beiden eingebogenen Ränder des Blattes zustandegekommen, ihre Außenseite entspreche also (mit Ausnahme eines schmalen Streifens, der die Oberseite darstellt) der Blattunterseite. Damit würde auch die Anordnung der Leitbündel stimmen. Und doch würde diese Auffassung der Wirklichkeit nicht entsprechen. Das Verhalten ist vielmehr das, daß die junge Blattanlage an ihrer Spitze von vornherein ziemlich massig entwickelt ist, und im embry onalen Zustand an Volumen zunehmend annähernd zylindrische Gestalt erreicht. Weiter unten flacht sich das (interkalar wachsende) Blatt ab und wird bedeutend breiter (vgl. das Schema Fig. 301). Von den zahlreichen Leitbündeln, welche in das Blatt eintreten, gehen nur wenige (die ältesten) bis in die Vorläuferspitze. Da unterhalb dieser das Blatt eingebogen ist, muß die oben geschilderte Anordnung der Leitbündel zustandekommen. In dem Schema (Fig. 301) sind fünf Leitbündel der Einfachheit halber angenommen, welche in dem flachen 'Teile des Blattes die übliche Orientierung zeigen. In dem dickeren Endteil des Blattes miissen sie mit Ausnahme des medianen eine kleine Drehung erfahren, welche dann die scheinbar radiäre Anordnung ergibt. Die Natur bringt also die abweichende Gestaltung der Vorläuferspitze nicht auf die sozusagen plumpe und langweilige Weise zustande, die man nach einer Betrachtung der fertigen Zustände annehmen könnte, sondern direkt und auf dem kürzesten Wege, den als eine "kongenitale Verwachsung" zu bezeichnen, nur eine Umschreibung folgenden Satzes sein würde: Die Spitzen der Blätter sehen ihrem anatomischen Baue nach so aus, als ob sie nach der Oberseite hin zusammengefaltet und hier verwachsen wären. Davon ist zwar in der Entwicklung durchaus nichts zu sehen. Aber ich kann mir den Vorgang wenigstens so denken, und bezeichne ihn als „kongenital", um mich mit einem Worte zu beruhigen ${ }^{1}$ ).

Wir haben uns bei diesem Falle etwas aufgehalten, weil er uns zu anderen überleitet, die oft erörtert und in verschiedener Weise aufgefaßt worden sind.

Sehen wir uns z. B. das Blatt von Allium Schoenoprasum an, so finden wir in der Blattspreite einen (mutatis mutandis) ganz ähnlichen Bau wie in der Vorläuferspitze der oben erwähnten Pflanzen; der Hohlraum im Innern (Fig. 292, I) ist erst sekundär entstanden durch Vertrocknen des (später auseinandergezerrten) inneren Gewebes der Blattspreite. Nur die Scheide ist hier flach und zeigt den gewöhnlichen dorsiventralen Ban. Es wird das Blatt vom Vegetationspunkt als ein den letzteren schon früh

1) Wie wenig man sich in der Botanik um eingehenderes Verständnis morphologischer Probleme kümmert, zeigt z. B. die Schilderung der Blätter von Tofieldia in der "Lebensgeschichte der Blïtenpflanzen Mitteleuropas" (Bd. I, 3. Abt. 14. Lief. (1911), Dort heißt es: „Längs der Mittellinie sind sie derart zusammengeklappt, daß sie eine rechte und eine linke Flanke, sowie eine Ober- und Unterkante darbieten, von denen erstere der Achse zugekehrt ist". Diese Darstellung mag für Elementarschulen geeignet sein, aber gehört nicht in ein wissenschaftliches Werk. 
umfassender Ringwall angelegt ${ }^{1}$ ), dessen basaler Teil sich dann später zu der (unten geschlossenen) Blattscheide gestaltet. Der obere Teil des Blattes aber gewinnt schon im embry onalen Stadium eine annähernd kegelförmige Gestalt mit kreisförmigem Querschnitt. Dabei ist es offenbar die dem Vegetationspunkt abgekehrte Seite der Blattanlage. (die Unterseite), welche sich stark entwickelt. Wir können das am Übergang der Blattscheide zur Blattspreite verfolgen, dort haben wir (auch bei Juncus, vgl. Figur 293, II) eine Ausbildung, welche an die erinnert, welche die Spreiten der oben erwähnten Orchideen haben. Die Leitbündel, welche

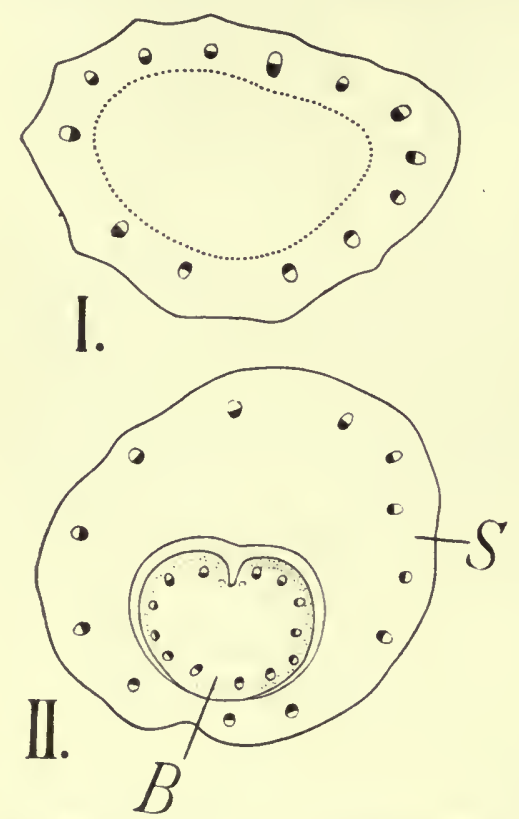

Fig. 292. Allium Schoenoprasum. 1 Blattquerschnitt (mit zentralem Luftranm). II Querschnitt durch eine Knospe, zwei Blätter sind getroffen, voll denen das jüngere in der Scheide des älteren steckt. Die Einsenkung, welche das jüngere zeigt, ist nicht immer vorhanden. die Scheide durchziehen, müssen in der Spreite also notwendig die Anordnung aufweisen, als ob dies Blatt nach oben umgebogen und mit seinen Rändern verwachsen wäre, was aber durchaus nicht der Fall ist. Vielmehr ist festzuhalten, daß die charakteristische Gestaltung schon im embryonalen Stadium zustande kommt; das ist ja allgemein das für Gestaltveränderungen empfindliche und ausschlaggebende. Die Gefäßbündelverteilung aber richtet sich nach den im embryonalen Zustand vollzogenen Gestaltungsverhältnissen, sie darf nicht, wie das noch vielfach geschieht, zum Ausgangspunkt der Auffassung gemacht werden.

$\mathrm{DaB}$ die Analogie der Alliumblätter mit der Vorläuferspitze der oben genannten Pflanzen zutreffend ist, zeigt auch die Tatsache, daß junge Pflanzen von Ornithogalum caudatum Blätter hervorbringen, welche (abgesehen von der Scheide) sozusagen nur aus der grüngefärbten Vorläuferspitze bestehen.

Ganz analoge Verhältnisse treffen wir bei Juncusarten. Einige Juncaceen wie z. B. Luzula, Juncus trifidus $u$. a. haben noch deutlich bifaziale Blätter. Bei den meisten Juncusarten treten aber Blätter mit scheinbar radï̈rer Spreite auf, welche man eben deshalb und infolge ihrer meist kurzen Blattscheiden oft auch für blattlose Sprosse gehalten hat. Tatsächlich gleichen sie auch sehr den Sproßachsen (aber nur an bestimmten Stellen). Indes kann an ihrer Blattnatur kein Zweifel sein.

In Fig. 293 sind Querschnitte auf verschiedener Höhe von dem Blatte, das unter der Infloreszenz von Juncus glaucus steht, wiedergegeben. Der basale Teil (Fig. 293, I) zeigt die Oberseite noch deutlich ausgebildet, aber ohne chlorophyllhaltiges Gewebe, ähnlich wie dies bei dem Laubblatt von Scirpus Holoschoenus der Fall ist. Weiter oben (Fig. 293, II) ist die Oberseite zu einer chlorophyllosen Rinne verkümmert, sie wird nicht von Leitbündeln versorgt; das Chlorophyll ist auf die stark entwickelte

1) Gozbel, Vergl. Entw. p. 216. (In Schenks Handbuch der Botanik II. Bd.) 
Unterseite beschränkt. Die Übereinstimmung mit dem in Fig. 287, $I \mathrm{ab}$ gebildeten Blatte von Scirpus Holoschoenus tritt ohne weiteres hervor. Endlich in Fig. 293, III ist die Oberseite ganz verschwunden, das Blatt hat einen scheinbar ganz radiären Bau angenommen.

Wir sprechen von scheinbar, weil wir das Zustandekommen aus der bifazialen Ausbildung verfolgen können. Es ist also nicht zutreffend, wenn teilweise gesagt wird, solche Blätter ließen sich in anatomischer $\mathrm{Be}$ ziehung von Sproßachsen nicht unterscheiden. Man sehe ihre Basis an, so. wird der Unterschied ohne weiteres hervortreten!

Wie erwähnt, können solche unifazialen Blätter sich auf der adaxialen (Ober-) und der abaxialen (Unter)seite abflachen und nehmen so die äußerliche Gestalt eines bifazialen Blattes an. So bei einigen Alliumarten, Asphodelus luteus u.a. Es dürfte dies ebenso eine sekundäre'Umgestaltung der unifazialen Blätter sein, wie wir sie bei den schwertförmigen, oder nach der älteren Terminologie „reitenden" Blättern finden.
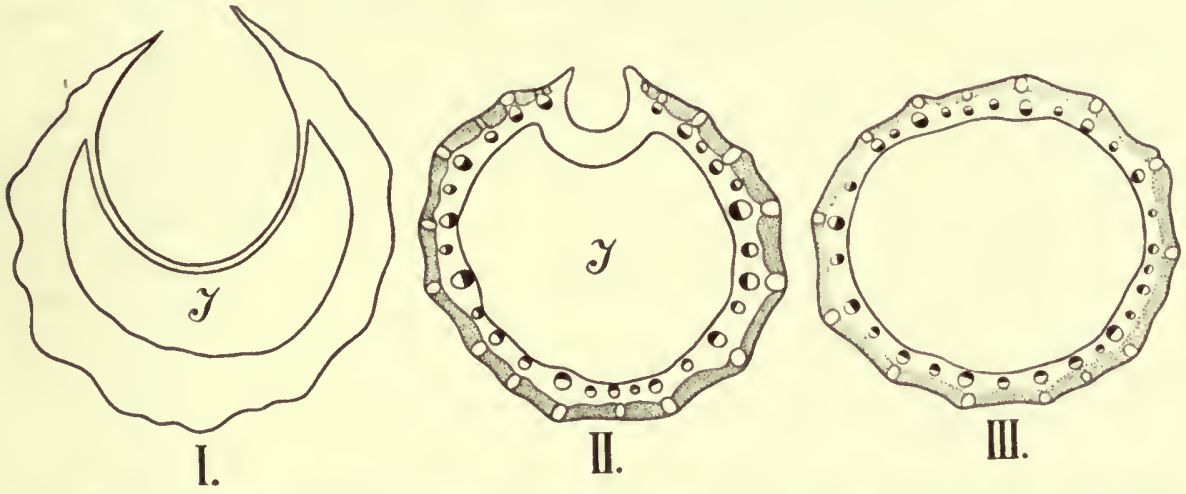

Fig. 293. Juncus glaucus. Querschnitte durch ein „Hochblatt" unter der Infloreszenz in verschiedener Höhe ( $I$ am tiefsten). $J$ großer Luftraum. Das Assimilationspareuchym bei $I I$ und $I I I$ punktiert. Xylem schwarz.

Denken wir uns ein Blatt von Allium Schoenoprasum oder die Vorläuferspitze von Doryanthes Palmeri aus weichem, plastischem Material aufgebaut und von den Flanken her flach gedrückt (was natürlich nur ein Bild, nicht die Bezeichnung des wirklichen Vorganges ist), so erhalten wir die "Schwertform" der Blätter, wie sie sich findet bei einer großen Anzahl von Irisarten, bei Acorus, Tofieldia, einigen Orchideen, Haemodoreen u. a. Jedenfalls also kehrt diese Blattform in verschiedenen Verwandtschaftskreisen der Monokotylen wieder.

Sehen wir uns die "typische" schwertförmige Blattform von Iris an, so finden wir bekanntlich die Blätter mit ihrer Spreite - welche unten in eine flache Scheide gewöhnlichen Baues übergeht - vertikal gestellt, beide Seiten gleich gebaut und die Gefäßbündel so orientiert, daß sie ihre Siebteile nach außen kehren.

Auch diese Blattform hat man so gedeutet, daß man annahm, die Blattfläche sei nach oben eingefaltet und mit den Rändern verwachsen, wofür die aufeinanderfolgenden Querschnitte durch ein Blatt von I. filifolia (Fig. 295) zu sprechen scheinen. Indes ist dies ebensowenig zutreffend, wie bei den oben erwähnten Fällen, mit denen die Gestaltung im wesentlichen ganz übereinstimmt. Denn auch hier entwickelt sich die Blattspreite von vornberein, im embryonalen Stadium, in der Vertikalebene, 
und zwar so, daß die Oberseite des Blattes ganz zurücktritt, die Unterseite demzufolge fast allein zur Ausbildung gelangt. Da sie sich an die flache Blattscheide ansetzt, so $\mathrm{m}$ üssen sich die Leitbündel so anordnen, wie sie auf dem Querschnitt erscheinen. Auch hier ist das Blatt hypotroph, d. h. die Blattfläche entspricht der stark entwickelten Unterseite. Wir sehen ja schon an den sukzessiven Querschnitten ganz deutlich, wie die Oberseite allmählich reduziert wird, die Unterseite an Dicke zunimmt. Genau dasselbe zeigt die Entwicklung der Blattspreite. Auf Einzelheiten einzugehen ist hier nicht der Ort. Wohl aber sind drei Punkte hier noch $\mathrm{zu}$ besprechen:

1. Die verschiedenen Irisarten mit Schwertblättern zeigen eine sehr verschiedene Ausbildung des "schwertförmigen" Teiles der Lamina. Bei I. filifolia sind z. B. die ersten Blätter, die beim Austreiben der Zwiebel entstehen, nur mit einem kurzen (ca. $3^{1} / 2 \mathrm{~cm}$ langen) oben schwertförmigen Teil und einem langen (ca. $12 \mathrm{~cm}$ langen) flachen, außen grünen versehen. Und das Blatt von Iris pyrenaica, welches in Fig. 294 von der Oberseite gesehen abgebildet ist, entspricht direkt einem mit einer zylindrischen Vorläuferspitze versehenen (Fig. 290). Erst später bringt die Pflanze Blätter hervor, welche eine längere Blattspreite im wesentlichen mit derselben Querschnittsform wie die von I. filifolia (Fig. 295 II) haben. Man könnte die erstauftretenden Blätter als die ursprünglicheren betrachten, da sie mit der typischen Blattform der meisten Monokotylen noch mehr übereinstimmen und daraus die anderen durch Verlängerung des oberen, Verkürzung des unteren (flachen) Teiles ableiten. Um so mehr als es auch Irisarten mit nur flachen, bifazialen Blättern gibt.

2. Es besteht offenbar ein Zusammenhang zwischen der Blattstellung und der Entwicklung von Blättern mit schwertförmiger Spreite. Alle mir bekannten Pflanzen mit schwertförmigen Blättern haben zweizeilige Blattstellung (Blattstellung -nach Divergenz 1/2) ${ }^{1}$ ) (umgekehrt gilt der Satz selbstverständlich nicht) und am vegetativen Sproß ungestreckte Internodien, also dicht über. einanderstehende Blätter. Eine solche Anordnung ermöglicht zunächst die charakteristische Knospenlage, wobei die Blätter ineinander geschachtelt sind. Ferner ist klar, daß die Blätter sich so nicht beschatten, während bei flacher Ausbildung der Lamina dies der Fall sein würde. Man könnte sich denken, daß solche Pflanzen zunächst steil aufgerichtete Blätter bildeten, welche nach oben eingefaltet waren und hier ihr Assimilationsgewebe einbüßten. Dann bildete sich die Lamina mehr und mehr in der Vertikalebene hypotroph aus und ersetzt so die ursprüngliche Form. Wir haben früher (p. 220 ff.) Beispiele kennen gelernt, welche zeigten, daß die Blattgestaltung mit Eigenschaften der Sproßachse zusammenhängt. Auch hier wird sich annehmen lassen, daß die Förderung der Außenseite der Blätter bedingt ist dadurch, daß sie zusammenfällt mit den Richtungen, in welchen die Sproßachse ihre organbildende Tätigkeit entfaltet. Ganz analoge Erscheinungen treffen wir bei Moosen. So bilden sich bei Fissidens die Flügel als Auswüchse der abaxialen Seite der Blätter in der Blattstellungsebene (Fig. 196). Der Flügel stellt bei Fissidens später den Hauptteil des Blattes dar, während die ursprüngliche - wie bei anderen Moosen flache - Blattanlage nur als seine Scheide erscheint. Auch hier ist das Blatt also hypotroph. Aber bei einem ursprünglich nur aus einer Zellschicht aufgebauten Blattanlage muß sich die Hypotrophie selbstverständlich etwas anders

1) So anßer Iris und anderen Irideen das oben angeführte Angraeecum und andere Orchideen wie z. B. Epidendrum equitans, die Haemodoree Xyphidium u. a., Xyrisarten, die Liliaceen Tofieldia, die Aracee Acorus Calamus. Ebenso z. B. Centrolepis aristata (Fig. 296), in dessen Blättern das Leitbïndelsystem entsprechend ihrer Kleinheit sehr vereinfacht ist. 
äußern als bei einer von vornherein einen Zellkörper darstellenden. Jedenfalls aber treffen wir hier eine der Irisblattbildung ganz analoge Erscheinung an und können bei der Keimpflanze von Fissidens noch ganz deutlich verfolgen, wie an dem ursprünglich bifazialen Blatte der hypotrophe, zuerst an der Spitze entstehende Flügel immer mehr die Überhand gewinnt. Einen solchen Vorgang kann man (mutatis mutandis) vermutungsweise auch für Iris annehmen.

3. Ist die Schwertform der Blätter eine "Anpassungserscheinung" ? Diese Frage ist ganz unabhängig von der, welche Faktoren die Entstehung der Schwertform bedingt haben, denn ganz gleicbgültig wie sie entstanden ist, kann eine bestimmte Blattform unter besonderen Lebensbedingungen von besonderer Bedeutung sein. Da die Blätter mit schwertförmiger Lamina bei den genannten Monokotylen "Profilstellung" haben, so wird man geneigt sein anzunehmen, daß sie - ähnlich wie die äquifazialen Eucalyptusblätter - für Pflanzen offener der Sonne ausgesetzter Standorte geeignet sind - Schattenpflanzen mit derartigen Blättern würden eine sehr ungünstige Lichtausnützung haben. Es scheinen auch tatsächlich die Pflanzen mit schwertförmigen Blättern alle an offenen Standorten vorzukommen. Wie es sich mit ihren Transpirationsverhältnissen verhält, wäre experimentell näher zu untersuchen.

Auch die sonstigen unifazialen Blätter bei Monokotylen scheinen Pflanzen, die an stark belichteten Standorten wachsen, anzugehören: die Orchideen Vanda teres, Leptotes bicolor, Angraecum distichum u. a. sind Epiphyten, auf stark besonnten Bäumen, Sanseviera cylindrica (ebenso S. Ebrenbergi) ist ein Xerophyt, Juncus (trotz des feuchten Standortes) ebenfalls.

$\mathrm{DaB}$ aber eine unifaziale Ausbildung recht verschiedenen "Zwecken " dienen kann (also nicht etwa als direkte Anpassung entstanden zu sein braucht), geht schon aus den unifazialen Vorläuferspitzen von Doryanthes Palmeri hervor, welche, wie ich früher nachzuweisen versucht habe, als Verschlußkörper dem Knospenschutz dienen ${ }^{1}$ ).

Da die bisher betrachteten Beispiele alle Monokotylen entnommen waren, so seien hier noch zwei für Dikotylen angeführt. Daß die äquifazialen sich in die Vertikalebene stellenden Folgeblätter von Eucalyptus nicht hierher gehören, ist klar. Dagegen sind unifaziale Blätter bei manchen Proteaceen vorhanden.

Vor Jahren fielen mir die sonderbaren, in ihren Umrissen mehr an eine Fucacee als ein dikotyles Blatt erinnernden Blätter von Stirlingia latifolia bei meinen Wanderungen am Swan-River auf. Diese Blätter sind wiederholt gabelig geteilt und (an aufrecht gedachten Sprossen) in der Vertikalebene abgeflacht. Fig. 297 zeigt einen Querschnitt oberhalb der Blattscheide (ein Stiel ist nicht vorhanden). Der unifaziale Bau tritt ohne weiteres hervor.

Hakea gibbosa, eine andere australische Proteacee hat annähernd zylindrische nach oben spitz zulaufende Blätter, die gegen die Basis zu oben und unten etwas abgeflacht sind. Die Abbildung (Fig. 286, II) zeigt, daß auch hier unifaziale Blätter mit weit überwiegender Entwicklung der Unterseite vorliegen.

Auch diese Pflanzen sind xerophile und Starklichtpflanzen. (Bei den oben erwähnten Moosen liegen die Verhältnisse ganz anders.) Es scheint mir unbestreitbar, daß unifaziale Blätter nur bei Pflanzen bestimmter Lebensbedingungen vorkommen, wenngleich manclie sich nachträglich verändert haben mögen.

1) GoEBEL, Flora 88 (1901) p. 470. 
Ganz ähnliche Verhältnisse, wie bei der Blattspreite finden sich bei manchen Pflanzen auch im Blattstiel, der ja nur ein unterer im Flächenwachstum gehemmter Teil der Blattspreite ist.

Strelitzia Reginae z. B. hat eine flache Blattscheide, in der die Leitbündel in der üblichen Orientierung (aber der Dicke der Spreite entsprechend in zwei Schichten) verlaufen. Der Blattstiel ist viel dicker und hat auf seiner Oberfläche eine Furche, die schmalen hier befindlichen Ränder (Fig. 298) gehen oben in die Blattfläche über. Die Leitbündel sind so orientiert, daß alle Siebenteile nach außen gekehrt sind, wir haben mutatis mutandis dasselbe Verhältnis wie es in Fig. 295, II für einen Teil der Blätter von Iris filifolia dargestellt ist. Wie sich die alte Verwachsungslehre das Zustandekommen dieses Blattstiels gedacht hätte, ist in Fig. 298 durch eine punktierte Linie angedeutet. In Wirklichkeit ist aber das Verhalten ganz dem oben angegebenen entsprechend. Der Blattstiel ist nach seiner Anlegung nicht gefaltet, sondern

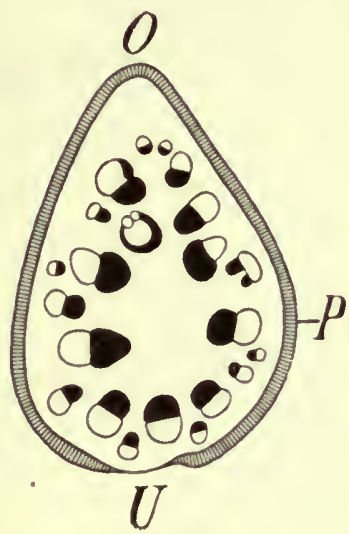

Fig. 297.

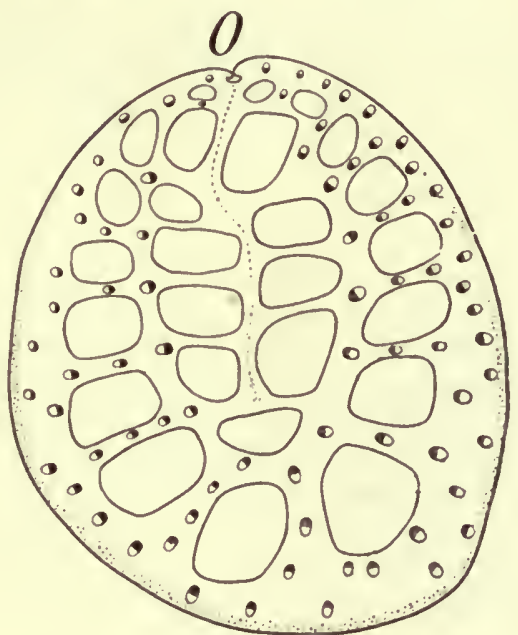

Fig. 298.

Fig. 297. Stirlingia latifolia. Stend. Querschnitt durch den unteren (oberhalb der Blattscheide liegenden noch ingeteilten) Teil des Blattes. $U$ abaxiale, $O$ adaxiale Seite. Das Palisadenparenchym durch Schraffierung angedeutet.

Fig. 298. Strelitzia reginae. Querschnitt durch den Blattstiel. Die kleineren Bündel nicht gezeichnet. Die punktierte Linie deutet an, wie sich die "Verwachsungshypothese" die Sache denken würde.

stark in die Dicke gewachsen, wobei vielfach namentlich die Oberseite sich durch lebhafte Zellteilungen auszeichnet. Daß die zylindrische, hier durch Hypotrophie zustandegekommene Ausbildung des Blattstiels mechanisch von Bedeutung ist, erfordert keine weitere Ausführung. Es kann sich eine Ausbildung wie die soeben erwähnte übrigens auch auf die Blattbasis erstrecken. Beispiele sollen dafür, um diesen Paragraphen nicht allzusehr anschwellen zu lassen, nicht angeführt werden.

Auch bei Dikotylen findet sich oft in den Blattstielen eine Annäherung an den radiären Bau. Während nämlich in dem Blattgrunde die Leitbündel typisch in einem nach der adaxialen Seite offenen Bogen angeordnet sind, trifft man im Blattstiel bei manchen einen vollständigen Leitbündelring, 
in welchem auch sekundäres Dickenwachstum eintreten kann ${ }^{1}$ ). Diese Anordnung ist indes im Blattstiel eine a bgeleitete. Sie kommt dadurch zustande, daß in dem jugendlichen Blattstiel an der Oberseite ein Teilungsgewebe tätig ist. Aus den durch dieses gebildeten Zellen differenzieren sich dann die Leitbündel, welche die auf der abaxialen Seite stehenden (an welche sie sich ansetzen) zu einem Ringe ganz oder teilweise ergänzen können. Dieser Leitbündelring besteht also aus zwei Teilen: einem ursprünglich zuerst vorhandenen (und bei manchen Pflanzen allein ausgebildeten) abaxialen und einem aus dem Teilungsgewebe hinzugefügten adaxialen. Ganz ähnliche Verhältnisse wurden oben für monokotyle Blätter erwähnt. In beiden Fällen handelt es sich also, wie schon betont um einen nachträglichen Zuwachs der Oberseite ${ }^{2}$ ), welcher diese verstärkt und die Ausbildung sekundärer Leitbündel ermöglicht. Die Betrachtung der Anordnung der Leitbündel im fertigen Zustand genügt also auch hier nicht zu einer richtigen Auffassung der Gestaltungsverhältnisse. Selbstverständlich ist es auch möglich, daß eine Verstärkung des Gewebes der Blattanlage wie wir sie im Blattstiel nachträglich haben eintreten sehen, schon im embryonalen Zustand der g an z en Blattanlage eintritt, und dann auch der Blattgrund an dem unifazialen Aufbau teilnimmt.

Fig. 299.

Acacia Melanoxylon. Querschnitt durch eine Zweigspitze. $a$ Sproßachse, o adaxiale Seite derPhyllodien $1-7$, st Nebenblätter.
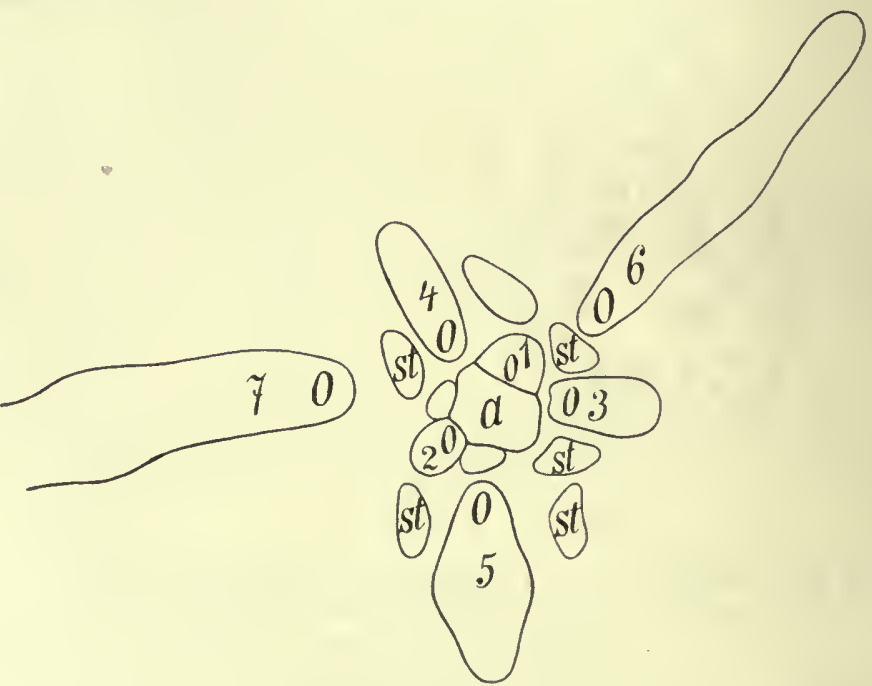

$\mathrm{Zu}$ den unifazialen Blättern gehören auch die bekannten Phyllodien vieler australischer Acaciaarten.

Sie entsprechen in ihrem Bau ganz den Irisblättern. Fig. 299 zeigt einen Querschnitt durch eine Knospe von Acacia Melanoxylon. $a$ ist die kurz unterhalb des Vegetationspunktes geschnittene Sproßachse, an welcher eine Anzahl von Phyllodien stehen, 0 ist deren - wenig entwickelte Oberseite, die mit Palisadenparenchym bekleideten Seitenflächen gehören der Unterseite an. Es hat sich die Blattanlage vertikal namentlich

1) Vgl. über diese, hier nicht näher zu erörternden Verhältnisse z. B. L. Pexit, Le pétiole des dicotylédones ?au point de vue de l'anatomie comparée et de la taxonomie (These), Bordeaux 1887.

2) Das hat schon Deinega (Flora 1898 p. 457) nachgewiesen. Vgl. auch H. BouYGuLs, Structure, origine et dévelopement de certaines formes vasculaires anormales du pétiole des Dicotyledones. Soc. Limécome de Bordeaux T. LVII. 
nach oben hin verbreitert. Dies tritt deutlich hervor namentlich auch in den Fällen, in welchen nicht nur der Blattstiel, sondern auch die Rhachis an der Phyllodienbildung teilnimmt (Fig. 300). Wer sich die oben geschilderten Entwicklungsvorgänge nicht vorstellen kann, mag auch hier sagen, das Phyllodium sei nach oben hin zusammengefaltet und verwachsen.
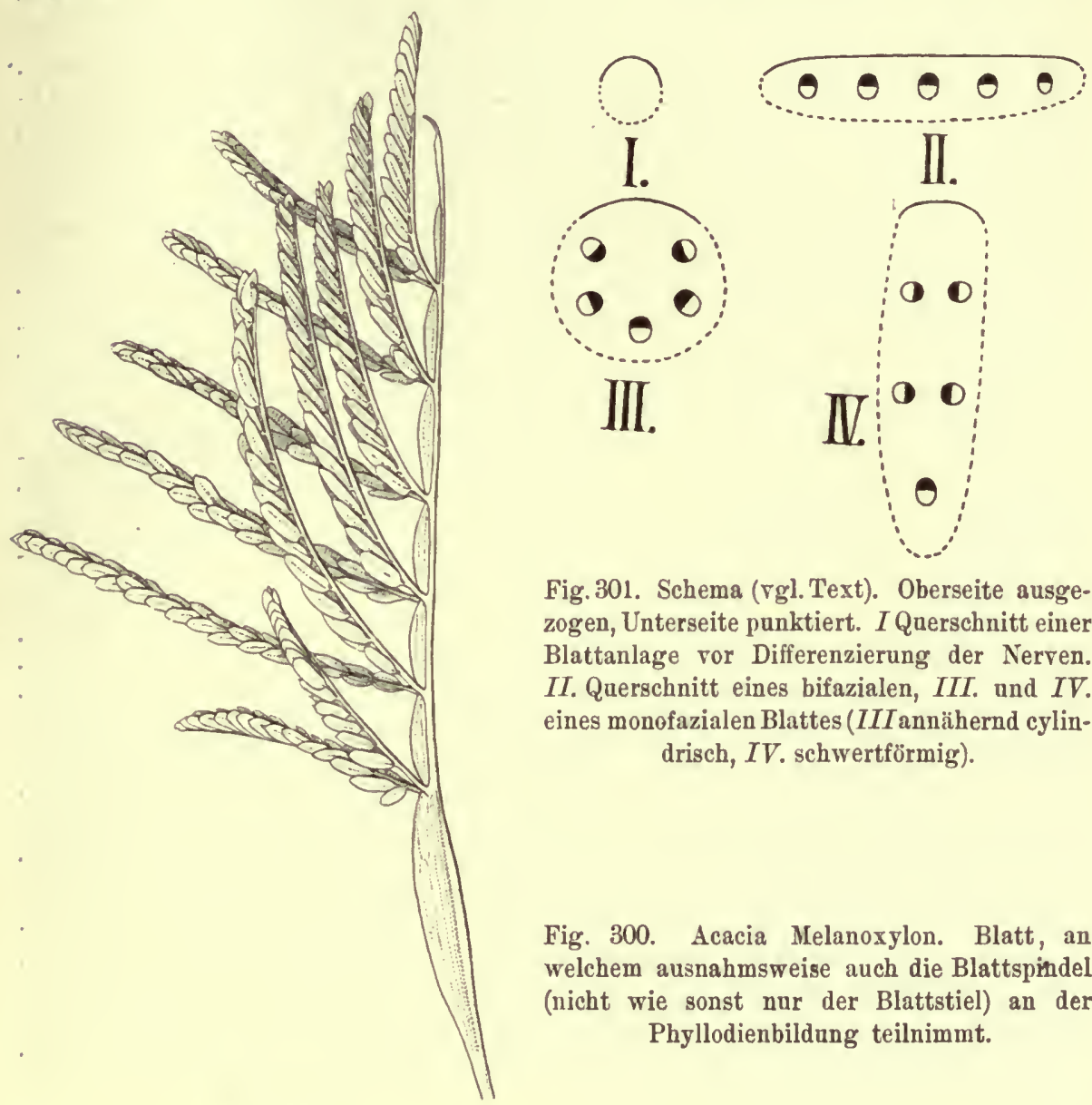

Fig. 300 .

Fig. 300. Acacia Melanoxylon. Blatt, an welchem ausnahmsweise auch die Blattspindel (nicht wie sonst nur der Blattstiel) an der Phyllodienbildung teilnimmt.

Die einfachste Form unifazialer Blätter findet sich wohl bei der Psilotacee Tmesipteris; deren von Anfang an in der Vertikalebene entwickelte Blätter besitzen nur ein Leitbündel. Vielleicht bringt trotzdem jemand das Kunststück fertig, sie aus zwei "zusammengeklappten" Hälften aufzubauen - man braucht ja nur anzunehmen die Leitbündel seien ursprünglich (was bei unifazialen Blättern vorkommt) annähernd in eine Ebene angeordnet gewesen, dann auf eines reduziert werden; es ergäbe sich dann ein Bild ähnlich dem von Centrolepis (Fig. 296).

Zum Überfluß sei das Verhalten von unifazialen und bifazialen Blättern noch an einem Schema (Fig. 301) erörtert. In $I$ ist der Querschnitt einer jungen Blattanlage dargestellt, ihre adaxiale Seite ist aus- 
gezogen, ihre abaxiale punktiert. In $I I$ ist ein daraus entstandenes, gewöhnliches bifaziales Blatt dargestellt; in $I I I$ und $I V$ je ein unifaziales; IV entspricht etwa einem schwertförmigen Blatt. Es ist ohne weiteres klar, daß ohne jede "Verwachsung" die Leitbündel die Anordnung haben, aus welcher man eine Verwachsung ableiten zu sollen glaubte.

Meine Auffassung der unifazialen Blätter, welche ich 1883 (in der "Vergleichenden Entwicklungsgeschichte") und 1900 in der ersten Auflage dieses Buches gegeben habe, ist angegriffen worden von CELAKOvSKY in dessen, mir nur im Referat des Botan. Centralblattes (Bd. 98, p. 343) zugänglicher Abhandlung "om listech monofaciálnich" in den Berichten (Rozpravy) der czechischen Franz-Josefsakademie 1903 Abh. VIII). ČELAKovsky hält sich, soweit aus dem Referat und den Figuren, welche der Abhandlung beigegeben sind, zu entnehmen ist, ausschließlich an den anatomischen Bau. Ich glaube oben gezeigt zu haben, daß dessen einseitige Berücksichtigung zu einer unhaltbaren Vorstellung über die Entwicklung führt, und habe keine Veranlassung an der früher geäußerten Auffassung etwas zu ändern. Vielmehr stimmt die Entwicklungsgeschichte und der anatomische Bau ganz überein; neu ist gegenüber der früher gegebenen Darstellung nur die Nomenklatur „unifazial“.. Wenn ich (a. a. O. p. 524) sagte, daß bei Iris an der Bildung der Spreite die beiden Seiten der Blattanlage beteiligt seien, so waren damit, wie aus dem Zusammenhange hervorgeht, nicht Ober- und Unterseite, sondern die rechte und linke Fläche der Unterseite der abgeflachten Blattanlage gemeint. Schon SCHLEIDEN hat übrigens mit Recht betont, daß bei der Entwicklung des Irisblattes keine Verwachsung stattfinde.

E. LAMPA (Untersuchungen über einige Blattformen der Liliaceen, Österr. botan. Zeitschrift 50. (1900) p. 421) möchte bei den Liliaceen die Rundblätter als die primäre Blattform betrachten und aus dieser die Flachblätter ableiten. $\mathrm{DaB}$ unifaziale Blätter mit ursprünglich annähernd kreisförmigem Querschnitt, sich abflachen können, ist richtig (so Allium fistulosum im oberen Teil der Blätter, auch bei Juncus glaucus führt die Verf. an, daß er „in sehr feuchten Gräben eine Abflachung der adaxialen Seite zeige"). Indes beweist diese Beobachtung ebensowenig wie die Tatsache, daß die Keimpflanzen mancher Monokotylen zunächst nur Rundblätter hervorbringen, den ursprünglicheren Charakter der letzteren. Mir scheint für die Entscheidung der Frage wesentlich, daß alle Teile des Blattes verglichen werden, nicht nur die Spreite. Tut man dies, so ergibt sich die oben dargelegte Anschauung. Auch Buchenau kam in seiner Monographie der Juncaceen für diese zu der Annahme, daß die Rundblätter aus Flachblättern entstanden seien durch Schmälerwerden der Oberseite.

\section{$\S 27$. Symmetrieverhältnisse von Blüten $\left.{ }^{1}\right)$.}

a) Die verschiedenen Formen der Blütensymmetrie.

$\mathrm{Da} B$ auch bei den $\mathrm{Blüten}$ die Unterscheidung zwischen radiärer und dorsiventraler Ausbildung hinreicht, wurde oben schon betont. Es erscheint unnötig, unter den radiären Blüten solche zu unterscheiden, welche sich

1) Vgl. E. v. FREYHoLd, Über Symmetrieverhältnisse und Zygomorphismus der Blüten. Eupen 1874. EICHLER's Blütendiagramme, GOEBEL, Über Symmetrieverhältnisse in Blüten (Festschrift für Wiesner) 1907. 
durch zwei oder mehr Symmetrieebenen teilen lassen, und solche, bei denen dies nicht der Fall ist.

Man hat zu viel Wert auf die (doch nur ideale) Möglichkeit, Blüten in symmetrische Hälften $\mathrm{zu}$ teilen, gelegt, namentlich auch bei den dorsiventralen Blüten. Bei einer acyklischen dorsiventralen Blüte ist eine Teilung in zwei symmetrische Hälften selbstverständlich unmöglich; so bei Aconitum und Delphinium. Sollen wir diese deshalb anders bezeichnen, als etwa die Blüte einer Papilionacee? Auch sind manche Blüten, die sonst radiär ausgebildet sind, wie z. B. die der Gentianeen, Asclepiaceen usw., wegen der Stellung des aus zwei Fruchtblättern aufgebauten Fruchtknotens tatsächlich nur durch eine Ebene symmetrisch teilbar. Sollen wir sie deshalb als "zygomorph" bezeichnen? Lassen wir doch die Teilerei auf sich beruhen! Sie ist ja doch nur eine künstliche Konstruktion.

Es kommt darauf an, ob irgendeine Seite in der Ausbildung von der anderen verschieden ist oder nicht. Wir werden sehen, daß es sogar Blüten gibt, bei denen nach $\mathrm{z}$ w ei verschiedenen Richtungen hin eine Förderung (resp. auf den entgegengesetzten Seiten eine Minderung) stattfindet, was der nur mit Teilungsebenen operierenden Morphologie besonders unbehaglich war, da hier "gänzlich asymmetrische" Bliiten entstehen).

Bei radiären Sprossen haben wir eine spirotrophe Ausbildung in einigen Fällen kennen gelernt. Spirotrophe Förderung (in manchen Fällen wie dem bekannten der Ausbildung der fünf Kelchblätter von Rosa, auch Hemmung) findet sich auch bei Bliiten und Bliitenständen. Als Beispiel sei Canna angeführt. An der Hauptachse der Infloreszenz stehen Bliitenpaare, je eine Blüte erster und zweiter Ordnung. Die letztere fällt stets auf dieselbe Seite der Bliite
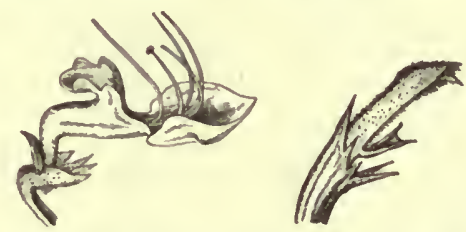

Fig. 302. Links Blüte von Coleus Penzigii. Blumenkrone mit geförderter Unterlippe, rechts Leonurus nepetifolia. Blüte mit geförderter Oberlippe. erster Ordnung, entsprechend einer "Spirale". Auch" in den Einzelbliiten tritt eine spirotrophe Förderung ein, die sich auch in der Ausbildung einzelner Bluitenteile ausspricht, so in der asymmetrischen Gestalt des Labellums, der Ausbildung eines einseitigen petaloiden Flügels am Staubblatt $u$. a. (vgl. die näheren Angaben bei Goebel a. a. O.).

Bei den dorsiventralen Blüten ist zunächst zu bemerken 1. daß die Förderung einer bestimmten Seite bei den einzelnen Organkomplexen, aus denen sich die Blüte zusammensetzt (Kelch, Blumenkrone, Androeceum, Gynoeceum), entweder gleichsinnig oder ungleichsinnig sein kann. In den meisten Fällen handelt es sich um eine Förderung der Außenseite, um eine Hypo- oder Exotrophie. Bei den Blüten vieler Labiaten ist zwar die Blumenkrone exotroph, also ihre Außenseite stark gefördert, der Kelch dagegen ist endotroph. Ebenso kann die Blumenkrone sich verschieden verhalten. Bei den meisten Labiaten ist die Unterlippe die geförderte (Fig. 302 links), bei der in Fig. 302 rechts abgebildeten Leonurusart dagegen die Oberlippe. Bei Echium ist umgekehrt der Kelch exotroph, die Blumenkrone endotroph, das Androeceum exotroph. Es darf wohl angenommen werden, daß hierbei Korrelationswirkungen zwischen den einzelnen Teilen der Blüte im Spiele sind, die das eigentümliche "Umschlagen" der geförderten Seite bedingen.

Hier wie in anderen Fällen hängt die Förderung mit stärkerer Ernährung zusammen. Es ist wahrscheinlich, daß in den genannten Fällen die Nähr- 
stoffzufuhr zu den Bliitenanlagen eine nicht gleichmäßig verlaufende ist und so z. B. eine stärkere Inanspruchnahme der Außenseite in dem einen Blatttkreis im nächsten auf der Innenseite mehr Material übrig läßt.

Die meisten dorsiventralen Blüten sind derart orientiert, daß die Förderung bzw. Minderung jeweils auf der abaxialen oder adaxialen Seite stattfindet, wie dies auch bei den oben als Beispiele benutzten Labiaten der Fall ist.

Es sind dies nach der Braus'schen Terminologie "medianzygomorphe" Blüten. Weniger häufig ist die Förderung in einer schief oder quer zum Deckblatt verlaufenden Ebene, solche Blüten sollen als klinotroph bezeichnet werden.

Eines der auffallendsten Beispiele bieten die Blüten mancher Fumariaceen, wie Corydalis und Fumaria. Betrachtet man die fertigen mit einem (als Nektarbehälter dienenden) Sporn versehenen Blitten, so sieht es so aus, als ob der Sporn auf der Außenseite (Unterseite) der Blüte stünde. Dies kommt aber nur daher, daß die Blüte eine Drehung um $90^{\circ}$ ausgeführt hat. Ursprünglich steht der Sporn seitlich; er stellt eine Ausbuchtung eines der beiden transversalen Blumenblätter dar. Es kann

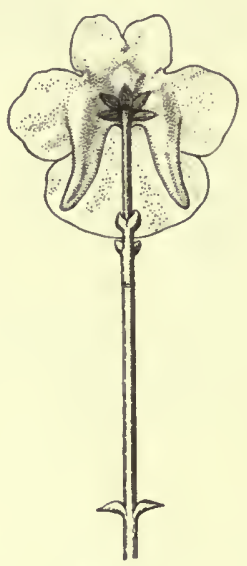

Fig. 303. Diacrium bicornutum. Blüte mit zwei Spornen von der Rückseite.

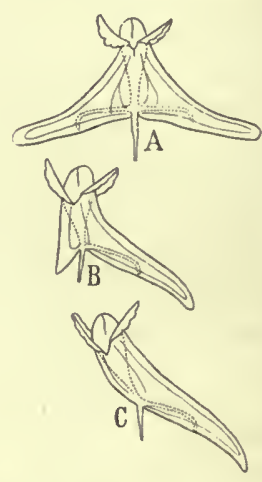

Fig. 304. Corydalis solida (nach MASSART). $A$ Blüte mit zwei Spornen, $B$ mit einem Sporn und einem Spornrudiment, $C$ mit e in e m Sporn.

keinem Zweifel unterliegen, daß die Blüte (wie dies noch jetzt der Fall ist bei denen von Dielytra und der in Fig. 303 abgebildeten Scrophulariacee Diacrium) ursprünglich zwei Sporne und $z$ wei Nektarien hatte. Nicht selten treten diese bei Corydalis noch auf (Fig. 304, A), zuweilen ist einer reduziert (Fig. 304, B), und dies ist bei C. ochroleuca regelmäßig der Fall ${ }^{1}$ ). Hier ist also die Bliite aus einer ursprïnglich bilateralen (resp. amphitrophen) zu einer klinotrophen (transversal-dorsiventralen) durch Reduktion auf einer Seite geworden. Dabei ist charakteristisch, daß der Sporn und das darin befindliche Nektarium stets gleichzeitig verkümmern, eine Korrelation, welche wohl dadurch bedingt ist, daß eine Hemmung des Blütenvegetationspunktes beide übereinander stehende Organe gleichmäßig beeinflußt. Godros (Ann. d. scienc. nat. V, 2) weist

1) Vgl. J. Massant, Sur des fleurs bicalcarées de Corydalis solida (Societé Belge de Microscopie 0. J.). 
darauf hin, daß bei einseitig gespornten Fumariaceenblüten der Sporn länger ist, als bei zweiseitig gespornten. In Fig. 304, $C$ tritt dies kaum hervor.

Bei klinotropher Ausbildung ist vielfach die Stellung des Fruchtknotens besonders auffallend. So bei Saxifraga granulata, wo sich zeigen läßt, daß die Stellung des Fruchtknotens in bestimmter Beziehung zum Gesamtaufbau der Infloreszenz steht (Goeber a. a. O.).

Es spricht sich die Spirotrophie auch aus in der ungleichseitigen aber in regelmäßiger Reihenfolge auftretenden Entwicklung der Staubblätter ${ }^{1}$ ) (Fig. 305).

Dieser Fall zeigt besonders deutlich, daß die Symmetrie der Bluite (soweit sie hier in der Stellung des Fruchtknotens zum Ausdruck kommt) abhängt von der Gesamtsymmetrie des Sproßsystemes, welchem sie zugehört, ohne daß dabei irgendwelche adaptative Erscheinungen wahrnehmbar wären.
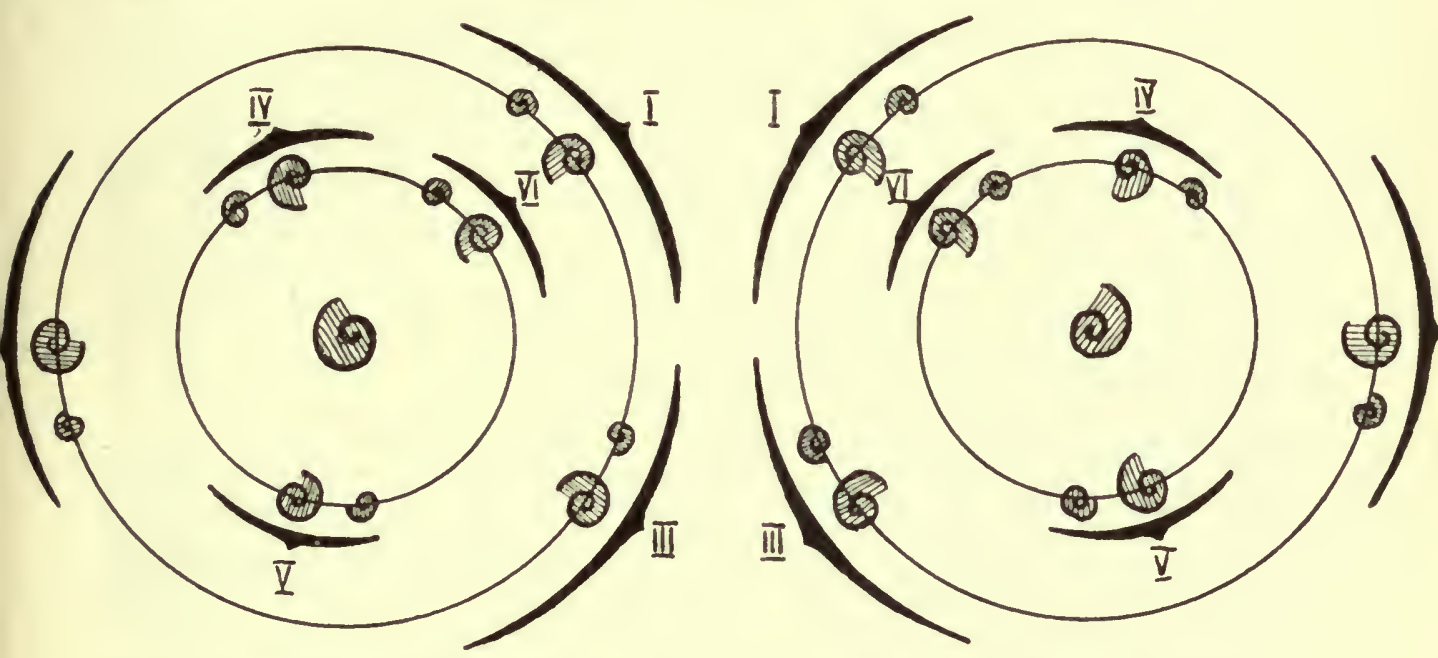

Fig. 305. (Nach Brenner.) Diagramm einer links und einer rechts „gewundenen “ Pflanze von Saxifraga granulata. Die Spiralen (von außen nach innen zu lesen) geben die Richtung der Anfblïhfolge der Staubblätter an. Die Blüten stehen nicht genau in der Mitte des Deckblattes, wie in dieser Figur gezeichnet ist.

Dem mag der Fall von Valeriana angeschlossen werden (Fig. 306). Die Blüten sind hier typisch 5 zählig. Es kombiniert sich bei ihnen Exotrophie und Klinotrophie. Erstere spricht sich darin aus, daß die Blumenkrone auf ihrer abaxialen Seite gespornt und annähernd zweilippig ist. Letzteres darin, daß die dem einen (dem $\beta$-) Vorblatt zugekehrte Seite gefördert ist. Hier allein erscheint eine Seitenblüte, und die $\operatorname{dem} \beta$-Vorblatt zugekehrten Staubblätter sind entwickelt, während auf der $\alpha$-Seite eins verkümmert ist. Auch von den drei Fruchtknotenfächern ist nur Eines fertil - wieder das nach der $\beta$-Seite hin liegende. Bei anderen Valerianeen (vgl. a. a. O.) findet eine Abnahme der Zahl der Staubblätter auf zwei und schließlich Eines statt (das in Fig. 306 mit 3 bezeichnete). Auch hier werden also die verschiedenen Blattkreise der Blite verschieden beeinflußt.

1) Vgl. W. Brenner, Beobachtungen an Saxifraga granulata, Flora (98 [1908], p. 250).

Die Stellung des Frachtknotens hat Br. nicht berücksichtigt. 
Namentlich bei cymösen Blütenständen tritt vielfach sehr deutlich hervor, daß der Gesamtblütenstand ein symmetrisches Ganzes bildet.

Sehen wir uns z. B. das Diagramm eines Blütenstandes von Commelyna coelestis an (Fig. 307), so sehen wir, daß die einzelnen Blüten alle „klinotroph" sind, daß sie aber dadurch die Seite, welche die unfruchtbaren Staubblätter enthält, alle schräg nach hinten (nach der Außenseite) des zickzackförmigen Blütenstandes kehren. Sie unterscheiden sich von denen von Valeriana dadurch, daß alle Blattkreise gleichmäßig klinotroph sind. Daraus ergibt sich eine Symmetriebeziehung der einzelnen Blüten zu einander; die Unterordnung der Symmetrie der Einzelblüte unter die Gesamtsymmetrie einer Infloreszenz, kommt selbst bei ganz unsymmetrischen Bluiten in Betracht. Bei Calathea sitzen die Blüten paarweise. Jede einzelne derselben ist so gebaut, daß sie nicht durch einen Schnitt symmetrisch geteilt werden kann, die beiden Blüten zusammen bilden ein symmetrisches Ganze ${ }^{\mathbf{1}}$ ).
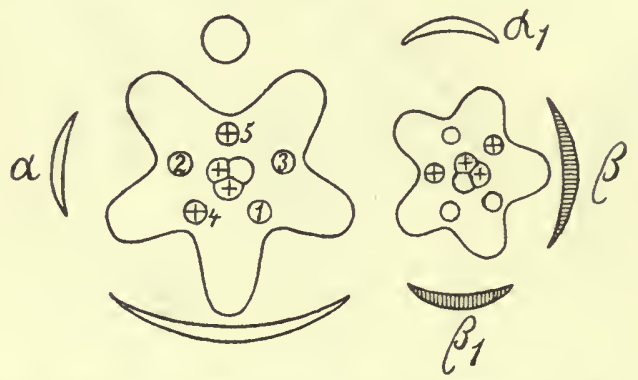

Fig. 306. Schema der Bluitensymmetrie ron Valeriana. Die mit + bezeichneten Staubblätter und Fruchtknotenfächer sind verkümmert. $\alpha$ und $\beta, \alpha_{1}$ und $\beta_{2}$ Vorblätter.

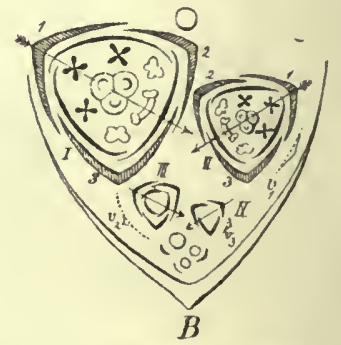

Fig. 307, Diagramm eines Blütenstandes von Commelyna coelestis (nach EichurR). Die Pfeile geben die Symmetrieebene der Bliten an; sie kehren alle dieselbe Seite schräg nach hinten, und zwar die, an der die unfruchtbaren (durch Kreuze bezeichneten) Staubblätter stehen.

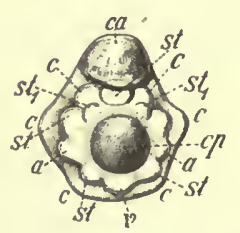

Fig. 308. Trifolium pratense. Junge Blüte von oben. $c a$ gefördertes abaxiales Kelchblatt, $c, c, c, c$ die übrigen Kelchblätter, $C C$ die beiden die carina bildenden Blumenblätter, $a, a$ die nalae", $v$ das Vexillum, st Stanbblätter.

Was die Entwicklung der dorsiventralen Blüten anbelangt, so sind zunächst zwei Fälle zu unterscheiden. Entweder sind nämlich die Blüten radiär angelegt und werden erst im Verlauf der Entfaltung dorsiventral, oder sie sind schon von Anfang an dorsiventral; es tritt die Dorsiventralität schon am Vegetationspunkt der Blüten in der Art und Weise der Anlegung der Blütenorgane auf ${ }^{2}$ ) (Reseda, Papilionaceen). In diesem Falle spricht sich die Dorsiventralität auch in der Reihenfolge der Organe aus. Bei den Papilionaceen z. B. wird das abaxiale in Fig. 308

1) Daranf hat - wie auf so vieles andere - schon HoFMEIsTer aufmerksam gemacht (Allgem. Morphol. p. 581). Betreffs der Symmetrie von Zingiberaceen vgl. F. MüLler, Schiefe Symmetrie bei Zingiberaceenblumen. Ber. der D. bot. Ges. V, p. 99 .

2) Vgl. die ausführliche Darstellung der Blütenentwicklung im speziellen Teile. 
ca bezeichnete Kelchblatt zuerst angelegt; auch zeigt diese Blütenknospe. daß von den fünf Staubblättern des inneren Kreises die abaxialen zuerst auftreten.

Diese Fälle sind aber in der Minderzahl; die meisten dorsiventralen Blüten sind radiär angelegt und werden erst dorsiventral. Der Zeitpunkt, in welchem dies geschieht, kann ein verschiedener sein. Der primitirste Fall ist der, wenn der Übergang während der Entfaltung der Blütenknospe erfolgt, wobei die Lage der Blütenteile sich so ändert, daß eine dorsiventrale Ausbildung sich ergibt.

Diese Lagenänderung erfolgt, wie für einige Beispiele nachgewiesen ist, als Reaktion auf äußere Einflüsse ${ }^{1}$ ). Dahin gehören z. B. Epilobium angustifolium und Epiphyllum truncatum, bei denen die dorsiventrale Ausbildung der Blüten nach der Entfaltung durch geotropische Reaktionen bedingt wird. Sie besteht hier in einer ungleichmäßigen Verteilung im Raume: die Blüte von Epilobium ist vierzählig. Das vordere und hintere Kelchblatt stehen median, die beiden seitlichen konvergieren nach hinten, auch die Blumenblätter richten sich nach der oberen Bliitenseite hin und die Staubblätter krümmen sich nach oben.

Focke betrachtet die Krümmung, welche der Griffel ron Lilium auratum und lancifolium ausführt, als eine heliotropische. Die Darstellung der Einzelheiten dieser Bewegungen gehört mehr in die Experimentalphysiologie. Hier sei zunächst noch hervorgehoben, daß in diese Kategorie auch die Pflanzen gehören, bei denen an einem und demselben Exemplar oder bei verschiedenen Exemplaren derselben Art radiäre und dorsiventrale Blüten vorkommen. An denselben Stock ron Saxifraga stellaris sind, wie H. MüLler ${ }^{2}$ ) angibt, die gerade nach oben gerichteten Bliiten radiär, die seitlich gerichteten zum Teil dorsiventral (indem die oberen Blumenblätter etwas schmäler sind und kleinere gelbe Flecke haben). Bei Soldanella pusilla finden sich Stöcke niit senkrecht herabhängenden Bliiten, die ringsum gleichgestaltet sind, und andere mit schräg abwärts geneigten, unten etwas weiter ausgebreiteten Blumenkronen ${ }^{3}$ ).

Für uns ist in den für Epilobium, Epiphyllum u. a. angeführten Fällen von Interesse, daß die Dorsiventralität durch äußere Faktoren induziert wird, und zwar geschieht das erst spät, nach dem Öffnen der Bliiten, während bei der zweiten Kategorie von Blüten die dorsiventrale Ausbildung schon vor der Entfaltung erfolgt.

In den meisten hierher gehörigen Beispielen werden derartige Blüten radiär angelegt, aber durch Förderung des äußeren Teiles der Blütenhülle dann dorsiventral, oder es geschieht dies dadurch, daß die inneren Bliitenteile in anderer Zahl angelegt oder ausgebildet werden als die äußeren; oft genug sind auch beide Vorgänge kombiniert, dann aber gewöhnlich in der Weise, daß daraus eine dorsiventrale Blüte resultiert. Mit anderen Worten, die Symmetrieverhältnisse der einzelnen Blütenkreise ändern sich nicht unabhängig von einander, sondern sind durch den Blütenvegetationspunkt bestimmt. Beispiele dafür bietet jedes systematische Werk, namentlich ErCHLERS Blütendiagramme.

Es sei an der Hand der Fig. 307 hier nur darauf hingewiesen, wie

1) Dufour, Sur l'inflnence de la gravitation sur les mouvements des quelques organes florissants (Arch. de scienc. phys. et nat. III, 14); Vöchtinc, Über Zygomorphie und deren Ursachen. Pringsh. Jahrb. XVI. Bả.

2) H. MǘlLer, Alpenpflanzen usw., p. 535.

3) Einen ähnlichen Fall bildet Herbert Spencer für Campanula ab (Prinzipien der Biologie II, p 160). 
eine radiär angelegte Blüte durch verschiedenartige Ausbildung des Androceums dorsiventral werden kann. Die Blüten von Commelyna bestehen wie die der meisten Monokotylen aus fünf dreizähligen Quirlen, sind also ursprünglich radiär. Es bilden sich aber von den sechs Staubblättern nur drei vollständig aus, die drei anderen (in der Figur durch schwarze Kreuze bezeichnet) sind steril und weichen auch durch die Form ihrer kreuzförmig-vierlappigen Antheren von den vorderen fruchtbaren ab. Also ist die Blüte dorsiventral geworden; in Verbindung damit zeigt das in die Symmetrieebene fallende Staubblatt eine andere Ausbildung als die beiden anderen, namentlich besitzt es ein breiteres Konnektiv. Es entspricht das ganz der Förderung der Blüte auf dieser Seite, auch hier ist diese Beziehung und nicht die (nur abstrakte) Symmetrieebene ausschlaggebend. Dieselbe Änderung der Symmetrie würde eingetreten sein, wenn die drei äußeren Staubblätter ganz verkümmert wären, wie denn solche Verkümmerungen sehr häufig eintreten. Namentlich ist aber, wie in der Morphologie der Blüte noch ausführlicher zu zeigen sein wird, die Zahl der Fruchtblätter häufig reduziert, wodurch die Gesamtsymmetrie der Blüte beeinflußt wird. Ihren augenfälligsten Ausdruck aber findet die letztere in der Ausbildung der Blütenhüille, speziell der Blumenkrone. Es braucht nur erinnert zu werden an die „lippenförmigen“, „zungenförmigen“" und "maskierten" Blüten, das Auftreten von Spornen usw.

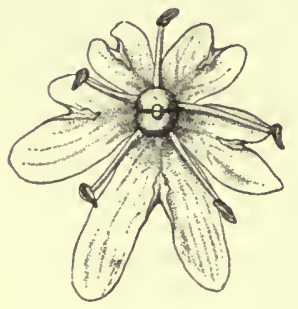

Fig. 309. Heracleum Mantegazzianum. Randblüte. Die Förderung der Außenseite spricht sich auch, abgesehen von der bedentenderen Größe der nach außen gekehrten Blumenblätter, aus in der asymmetrischen Gestaltung der beiden seitlichen Blumenblätter und in der größeren Länge der unteren Filamente.

Doppelte Naturgröße.

b) In physiologischer Beziehung sind, wie NoLL ${ }^{1}$ ) zuerst nachgewiesen hat, zweierlei Gruppen $z u$ unterscheiden.

Die, welche NoLL als "wesentlich" zygomorph bezeichnet, sind dadurch charakterisiert, daß sie sich stets in bestimmter Weise orientieren. Thre "Normalstellung" ist die, daß sich der Blüteneingang von der Infloreszenzachse abwendet, die Rückenseite nach oben, die Bauchseite nach unten gekehrt ist. Dabei kann der Insektenbesuch am günstigsten stattfinden. Wenn sie aus dieser Normalstellung gebracht werden, erreichen sie sie durch bestimmte Orientierungsbewegungen wieder, sie reagieren also auf Lagenveränderungen anders als radiäre Blüten.

„Unwesentlich" zygomorph sind dagegen die Blüten, die am Rande der Infloreszenzen von manchen Cruciferen (Iberis u. a.), Umbelliferen (Heracleum [Fig. 309], Coriandrum u. a.), Compositen, Dipsaceen usw. stehen. Sie werden dadurch im morphologischen Sinne dorsiventral, daß der nach außen gekehrte Teil der Blumenkrone sich stärker entwickelt, als der innere. Diese Blüten reagieren auf Lagenänderungen nicht anders als ihre radï̈r gebliebenen Schwesterblüten, sie dienen lediglich zur Verstärkung des Schauapparates der ganzen Infloreszenz. Zur Bestäubung der Einzelblüten steht die Dorsiventralität der Blumenkrone in keiner direkten Beziehung.

1) NoLL, Über die normale Stellung zygomorpher Blüten und ihre Orientierungsbewegungen zur Erreichung derselben. Arbeiten d. bot. Instituts in Würzburg, herausgeg. von SACHS, III. Bd. 
Dies zeigt sich namentlich auch dadurch, daß in manchen Fïllen dasselbe Resultat erzielt wird, ohne daß die Blumenkrone, das Androeceum und Gynoeceum eine dorsiventrale Ausbildung zeigen. So bei einigen Rubiaceen. Als ich vor Jahren einen Ausflug in die Bor Gaths in Indien machte, fielen mir Sträucher auf, auf deren leuchtend roten Blüten ich von weitem weiße Schmetterlinge sitzen zu sehen glaubte. Es war dies eine Mussaendaart, über deren Blüten ich damals folgendes notierte: „An einzelnen der äu $\mathrm{B}$ eren Blüten des Blütenstandes ist von den fünf Kelchblättern eines ungemein vergrößert und einem Laubblatt ähnlich geworden, nur daß es ganz und gar chlorotisch ist und keine Spur von Chlorophyll enthält. Durch diese weißen Blätter wird der Blïtenstand von weitem auffallend. .Die inneren Blüten haben fünf pfriemenförmigę kleine Kelchblätter." Ähnlich verhält sich auch Pogonopus Ottonis, eine andere Rubiacee. Hier werden also nur einzelne Kelchblätter der sonst radiär bleibenden Blüten stark gefördert.

\section{c) Bedeutung dorsiventraler Blüten.}

Die soeben kurz geschilderten Verhältnisse haben früh schon Veranlassung zu Versuchen einer teils teleologischen, teils kausalen Erklärung gegeben. Schon Christian Konrad Sprenger ${ }^{1}$ ) hat in ersterer Beziehung auf die Gesichtspunkte hingewiesen, welche auch heute noch (wenngleich teilweise in anderer Auffassung) als die wichtigsten zu betrachten sind. „Drey Umstände sind es, aus welchen man, wie so vieles andere, was die Struktur der Blumen betrifft, als auch, warum sie regulär ${ }^{2}$ ) oder irregulär ${ }^{3}$ ) sind, erklären kann. Der erste ist die Inflorescenz oder die Art und Weise, wie die Blumen an den Stengel oder an die Zweige einer Pflanze angefiigt sind. Der zweite ist, da $B$ die Regentropfen, wenigstens bei einer Windstille, perpendikulär auf die Blumen herabfallen. Der dritte ist die Absicht der Natur, daß die Insekten die Blumen befruchten sollen, wenn man dabey zugleich auf die natürliche Stellung der Insekten Rücksicht nimmt, welche im Fliegen allezeit und im Stehen und Gehen gewöhnlich die aufrechte ist." Bei einer gerade aufrecht stehenden oder gerade herabhängenden Blüte sei weder von seiten der Insekten, noch der des Regens die geringste Ursache gegeben, warum sie nicht radiär sein sollte, das Insekt müsse sie, wo es auch sich setze, befruchten können, während "horizontale" Blumen, weil sie eine obere und eine untere Seite haben, und das Insekt sich jedesmal auf die untere setzt und auf einer von beiden hineinkriecht, irregulär sein müssen .... (a. a. O. p. 42). Hier ist also die Gestalt der Bliiten teleologisch gedeutet.

Es lag auch nach Aufstellung des Selektionsprinzips nahe, das Auftreten der Dorsiventralität an Blüten dadurch zu ,.erklären“, daß man auf die Vorteile hinwies, welche daraus entspringen. „Der zygomorphe Bau der Blume lockt Kreuzungsvermittler an und schließt unnütze Honigräuber aus. Es werden mehr Samen durch Kreuzung erzeugt, und die daraus hervorgehenden Pflanzen zeigen sich widerstandsfähiger und lebenskräftiger als die durch Inzucht entstandenen. Je besser sich der Blütenbau den

1) Das entdeckte Geheimnis der Natur usw. Berlin 1793, p. 37. Vgl. auch Delpino zigomorfia florale e sue canse, Malpighia I, p. 245-262, RoBertson, zygomorphy and its causes, Bot. gazette 1888 .

$\left.{ }^{2}\right)=$ radiär.

$\left.{ }^{3}\right)=$ dorsiventral. 
Kreuzungsvermittlern anpaßt, um so kräftigerer Nachwuchs wird erzeugt, der die Eigenschaften der bestangepaßten Individuen auf die Nachkommen iibertragen wird" (FOCKE).

Wenn man indes die Dorsiventralität der Blüten lediglich als einen Anpassungscharakter betrachtet, so bleibt unerklärt, daß. dorsiventrale Blüten auch bei windblütigen Pflanzen rorkommen.

Daß dies der Fall sei, wurde von Darwin und DeLPLivo in Abrede gestellt, aber, wie in der 1 . Auflage dieses Buches hervorgehoben wird, mit Unrecht. Allerdings tritt die Dorsiventralität bei so unscheinbaren Blüten, wie die der windblütigen Pflanzen es meist sind, weniger auffallend hervor, als bei den mit auffälligen Blütenhüllen ausgerüsteten. Vorhanden ist sie dennoch bei mehreren. Man braucht, um dies zuzugeben, nur einen Blick zu werfen auf das Diagramm ron Heleocharis palustris oder das der .typischen Grasblüte (mit zwei Lodiculae) (Fig. 310 zeigt, daß das ganze Ährchen dorsiventral ist), der zweinarbigen weiblichen Carexblüten $u$. a.

Kein Zweifel, daß dorsiventrale Bliiten oft besonders geeignet sind zur Insektenbestäubung aber ihre En ts te hung ist nicht aus dem Nützlichkeitsprinzip abzuleiten. Dafür wurde bei Saxifr. granulata ${ }^{\mathbf{1}}$ ) ein Beispiel gegeben.

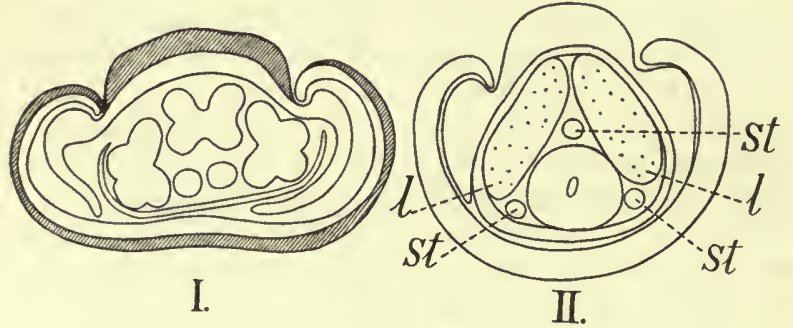

Fig. 310 .

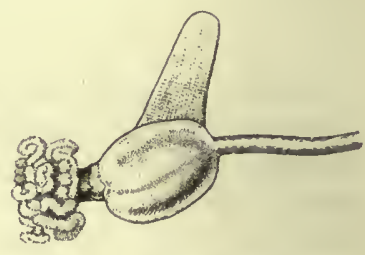

Fig. 311.

Fig. 310. Androscepia gigantea. Ährchenquerschnitt $I$ höher als $I I$, st Staubblätter, $l$ lodiculae.

Fig. 311. Begonia sp., weibliche Blüte, von welcher die Perigonblätter abgefallen sind. Der Fruchtknoten hat einen einseitigen Flügel.

Ganz abzuweisen sind meines Erachtens die rein mechanischen Erklärungsversuche, wie zuerst einer ron $\mathrm{A}$. P. DE CANDolue versucht wurde. Er erwähnt in seiner "Théorie élémentaire" (1819), daß die Stellung der Blüten von großem Einfluß auf ihre Symmetrieverhältnisse sei. Jede Blüte, die von Natur terminal, aufrecht und einzeln stehend sei, sei radiär, auch wenn sie einer Familie mit gewöhnlich dorsiventralen Blüten angehöre (z. B. Asarum unter den Aristolochieen); wenn aber unter einer Terminalblüte Seitenblüten entstehen, so werden diese unter dem Druck ihrer Nachbarn stehen und mehr nach außen wachsen, wo der Druck kleiner sei ${ }^{2}$ ). Auch andere Faktoren (Ungleichheit gegenüber der Ernährung, der Luft und dem Lichte) können eine Rolle spielen. Wo bei Pflanzen, die normal keine Terminal-, sondern nur stark dorsiventrale Seitenblüten haben, Endblüten auftreten (wie gelegentlich bei einigen Labiaten), sind diesse Terminalblüten radiär, auch weist er darauf hin, daß außerdem bei der Änderung der Blütensymmetrie Korrelationserscheinungen zwischen den einzelnen Blïtenteilen in Betracht kommen.

1) In der p. 290 Anm. zitierten Abhandlung.

2) Hypothesen, die in etwas geänderter Gestalt auch in der mechan. Blattstellungslehre auftauchten. 
Hofmeister nimmt auch bei den dorsiventralen Blïten (ähnlich wie bei den dorsiventralen Sprossen) eine kausale Beziehung zur Schwerkraft an (Allg. Morph. S. 581).

Endlich haben wir Versuche, wie Darwin hervorhebt ${ }^{1}$ ), welche die Insekten selbst dafür verantwortlich machen wollen, welche durch von ihnen ausgeübte Reize die Blütenform beinflussen sollen ${ }^{2}$ ). So sagt z. B. Hexslow ${ }^{3}$ ): "I regard this cause as issuing from the insect itself, namely the mechanical influence of its weight and pressures." Wie dies die Tatsache erklären soll, daß bei den Orchideen und anderen Pflanzen die richtige Orientierung der Blüte erst bei der Entfaltung erfolgt, ferner die oben erwähnten dorsiventralen Randblüten, vermag ich nicht einzusehen, die ganze Vorstellung ist eine subjektive Vermutung ohne irgend welchen tatsächlichen Beleg.

Im Grunde sind wir über die schon von Sprexger und De Candolue hervorgehobenen Gesichtspunkte: daß dorsiventrale Blüten namentlich als kurz gestielte Seitensprosse auftreten, nicht viel hinausgekommen ${ }^{4}$ ). Denn auch die Ausdrücke "Exotrophie" usw. bezeichnen nur bestimmte Beziehungen zur Lage. Immerhin aber werden wir die Lage als kausalen Faktor in erster Linie in Betracht ziehen müssen, wie dies ja auch bei exotrophen vegetativen Sprossen der Fall ist, von denen sich die Blüten nicht wesentlich unterscheiden. Daß bei den dorsiventral angelegten Bliuten eine wesentliche Beeinflussung durch äußere Kräfte in der Jetztzeit nicht stattfindet ist zweifellos, namentlich kommt (entgegen der Annahme HofMeisters) die Schwerkraft nicht in Betracht. Wenn man sie für die Vergangenheit annehmen will, begibt man sich auf das Gebiet der Hypothese. Wohl aber läßt sich erkennen, daß die Dorsiventralität der Blïten bei manchen Pflanzen im Zusammenhang steht mit der dorsiventralen Ausbildung des Vegetationskörpers. So, wie Wilurs ${ }^{5}$ ) betont hat bei einer Anzahl von Podostemaceen, bei welchen die dorsiventrale Ausblldung anscheinend von keiner biologischen Bedeutung ist. Ein ähnlicher Fall findet sich vielleicht bei einer Anzahl Begonia-Arten; die Dorsiventralität spricht sich hier aus darin, daß der Fruchtknoten auf einer Seite einen flügelförmigen Auswuchs hat(Fig. 311). Dieser steht zur Bestäubung in keiner Beziehung, wohl aber zur Lage der Blïte (worauf hier nicht näher eingegangen werden kann). Auch hier ist derzeit ein besonderer Nutzen dieser einseitigen Flügelbildung nicht zu erkennen, wenn man nicht etwa eine Steigerung der Transpiration als für die Fruchtreife nützlich betrachten will; bei einigen Arten ist der Flügel übrigens gefärbt und kann als Verstärkung des Schauapparates betrachtet werden. Wir sehen also einen dorsiventralen Bluitenbau auftreten teils ohne, teils mit deutlich erkennbarem Nutzen für die Funktion der Blüte.

Wir haben ferner (p. 29) ein Beispiel angeführt dafür, daß bei einer Pflanze mit normal radiären Blüten eine Blüte mit dorsiventraler Ausbildung als "zufällige" Abweichung auftreten kann. Ebenso sind bei Pflanzen mit

1) DARWIN, Diff. form of flowers, p. 147.

2) Vgl. NaEGeli, Mechanisch-physiologische Theorie der Abstammungslehre, wo der Einfluß des "Krabbelns" der Insekten in phantastischer Weise für die Gestaltung der Blumenkrone" herangezogen wird.

$\left.{ }^{3}\right)$ Hensuow, Floral structures, p. 103.

4) Allerdings verhalten sich die verschiedenen Familien hier sehr verschieden. Es gibt viele radiäre Seitenblüten (z. B. Anagallis, Lysimachia, Fuchsia) und dorsiventrale Endblüten (Solaneen).

5) Willis, Studies in the morphology and ecology of the Podostemaceae of Ceylon and India (Annuals of the Royal botanic gardens Peradeniga Vol. I, 1902). 
normal dorsiventralen Blüten radiäre als Abweichungen (Mutationen) beobachtet und als "Pelorien" bezeichnet worden. Auch Zwischenformen zwischen diesen und den dorsiventralen Blüten kommen vor ${ }^{1}$ ). Es ist wahrscheinlich, daß bei den Formen, welche zur Hervorbringung von Pelorien befähigt sind, das Auftreten der letzteren abhängt von Ernährungsbedingungen namentlich guter Beleuchtung. Dafür sprechen schon Versuche von Peyritsch ${ }^{2}$ ).

Ausgehend von im Freien gemachten Beobachtungen, fragte er sich; ob das Auftreten von Pelorien nicht vielleicht durch einen Wechsel der Lebensbedingungen veranlaßt sein könne? Versuche mit Galeobdolon luteum und Lamium maculatum weisen darauf hin, daß dies in der Tat der Fall ist. Zwar lassen diese Versuche manche wichtige Frage noch unbeantwortet, indes möchte ich doch um so mehr das Resultat derselben erwähnen, als eine ausgedehnte Wiederholung dieser Versuche außerordentlich erwünscht wäre.

Die genannten Labiaten wuchsen an ihren natürlichen Standorten im Schatten anderer Pflanzen. Werden diese (z. B. durch Abholzen von Waldstellen) entfernt, so trifft man vielfach Pelorien und in ihrer Begleitung andere Blütenanomalien. Die Annahme lag also nahe, daß die Steigerung der Lichtintensität, welche ihrerseits auf die Ernährung einwirkt, das Auftreten einer sonst "latent" bleibenden Gestaltung die Ursache des Auftretens dieser Blütenmißbildungen war. Der Versuch sprach deutlich für die Richtigkeit der Annahme, daß in der Tat die Änderung der Lebensbedingungen das Auftreten der Pelorien bei den Pflanzen veranlaßte.

Es wurden diese an Standorte mit starker Insolation gepflanzt (der Kontrollversuch, die Stöcke zu teilen und einen Teil der Pflanzen an normalen, schattigen Standorten weiter zu kultivieren, scheint leider nicht gemacht worden zu sein). Einige Exemplare entwickelten gar keine Blüten, eins änderte die Blütezeit, und die Blüten traten an Sprossen auf, die normal keine Blüten ansetzten. Drei Exemplare brachten gipfelständige Pelorien hervor. Zwei blieben vorwiegend normal, aber bei einem erschien doch eine in den Zahlenverhältnissen der Blütenblätter abnorme Blüte. Im folgenden Jahre waren die abnormen Erscheinungen geringer, es scheint eine Gewöhnung an die neuen Lebensbedingungen eingetreten zu sein, wie dies auch sonst vorkommt; daß dabei die Blütenbildung überhaupt eine verminderte war, erklärt sich wohl aus der ungïnstigen Beeinflussung des Gesamtwachstums. Bei Lamium maculatum ergaben sich ähnliche Anomalien, die aber ebenso wie bei Galeobdolon sich nie über die ganze Pflanze erstreckten. Auch in der regetativen Region traten gelegentlich Anomalien auf, aber nicht alle Pflanzen reagierten in gleicher Weise. Es handelt sich offenbar um das Vorhandensein bestimmter Formen, welche imstande sind unter bestimmten äußeren Bedingungen Pelorien $\mathrm{zu}$ bilden, während andere unter denselben äußeren Bedingungen nicht diese Fähigkeit besitzen, wie denn das Vorhandensein erblicher Disposition zur Pelorienbildung bei einer Anzahl von Pflanzen nachgewiesen ist, zuerst für Digitalis purpurea (durch VRoLIK) später auch für andere Pflanzen. Die Pelorien sind bei Linaria ${ }^{8}$ ) und Antirrhinum $^{\mathbf{3}}$ ) nicht auf das Ende der Infloreszenz beschränkt. Die

1) H. Frscrifr, Die Pelorien von Linaria vulgaris, Flora 98 (1908), p. 386.

2) Peyritsch, Ätiologie der Pelorienbildung, Denkschriften der k. k. Akadem. d. Wissensch. in Wien, 38. Bd., 1878.

3) Vgl. DE VRIEs, Die Mutationstheorie; BAUR, Einführung in die Vererbungslehre. 
Terminalstellung wirkt aber in manchen Fällen offenbar begünstigend für das Auftreten der Pelorien, wie wir auch sonst zuweilen Terminalblüten anders ausgebildet finden, als Seitenblüten (z. B. bei Ruta graveolens erstere meist fünf-, letztere vierzählig). - Die Terminalstellung bringt eben offenbar günstigere Ernährungsverhältnisse mit sich.

\section{§ 27. Dorsiventrale Infloreszenzen ${ }^{1}$ ).}

Wie bei den Blüten haben wir auch hier zwei Fälle: solche Infloreszenzen, die radiär angelegt sind und erst durch Drehung (sei es der Blütenstiele oder der Internodien der Infloreszenzachse) dorsiventral werden, und solche, bei denen schon von Anfang an Dorsiventralität verhanden ist. Die Blïten an dorsiventralen Infloreszenzen sind meist nur mit einem kurzen Stiele versehen, der Infloreszenzachse kommt die Aufgabe zu, sie für die Bestäubung usw. in die richtige Lage zu bringen. Was die Beziehungen zu den Lebensverhältnissen anbetrifft, so haben wir zwei Fälle zu unterscheiden. Dorsiventrale Infloreszenzen finden sich nämlich sowohl bei windblütigen, als bei insektenblütigen Pflanzen.

1. Windblütige Pflanzen. In den Infloreszenzen ron Urtica dioïca, Dorstenia, einiger Gramineen u. a. stehen die Bliiten (und bei Urtica dioïca u. a. auch die Infloreszenzäste) alle auf einer Seite der Infloreszenz und zwar auf der nach oben gekehrten. Ob diese Stellung eine "biologische Bedeutung: hat, ist sehr zweifelhaft. Vielleicht könnte man sie damit in Zusammenhang bringen, daB die Antheren explodieren. Der in Form kleiner Staubwölkchen zerstreute Pollen wird eher Aussicht haben, durch Luftströmungen transportiert $\mathrm{zu}$ werden, wenn er nach oben, als wenn er nach anderen Richtungen hin geschleudert wird. Urtica urens hat monözische Blütenverteilung und nicht dorsiventrale Infloreszenz.

Auffallend dorsiventrale Infloreszenzen, bei denen die ahrchen einseitig an dem Gesamtblütenstand inseriert sind, finden sich bei vielen Gräsern (Chloris, Dactylis u. a.). Für diese eine Beziehung zur Außenwelt zu finden, scheint kaum möglich. Doch mag folgendes wenigstens erwähnt werden. Wenn wir die Einrichtungen der Grasinfloreszenz vergleichend biologisch betrachten, so zeigt sich, daß ihre Gestaltung so eingerichtet ist, daß sie durch den Wind leicht bewegt werden kann. Die schlanken Halme, die Ährchen, die z. B. beim Zittergrase (Briza) auf langen, dünnen Stielen sitzen, die sparrig abspreizenden Aste dienen alle demselben „Zwecke", den auch die Gestaltung der Filamente verfolgt, dem, den Pollen leicht herausschütteln zu lassen. Einseitig entwickelte Infloreszenzen nun haben meines Wissens nur solche Gräser, bei denen die Ahrchen kurz gestielt sind. Rücken sie nach einer Seite hin (z. B. Dactylis), so wird dadurch dem Wind eine größere Fläche geboten, als wenn sie ringsum gleichmäßig verteilt wären. Aber auch wo wegen der geringen Zahl der Ährchen dieser Gesichtspunkt nicht in Betracht kommen kann, wird durch die einseitige Belastung ein öfteres Hin- und Herschwingen erfolgen, als wenn dies nicht der Fall wäre. Freilich bieten diese Erwägungen keine Erklärung der Dorsiventralität der Infloreszenz, und wahrscheinlich ist diese nur eine Steigerung der dorsiventralen Ausbildung, die auch an den Vegetationsorganen der Gräser sich mehr oder minder deutlich wahrnehmen läßt.

I) Vgl. Goeber, Über die Verzweigung dorsiventraler Sprosse (Arb. a. d. bot. Inst. in Würzb., heransgeg. von SACHS, II, 1880). 
Übrigens zeigen die mit radiären Infloreszenzen ausgestatteten Gräser, auf wie vielerlei Weise innerhalb einer Familie ein und dieselbe Aufgabe gelöst werden kann.

2. Insektenblütige Pflanzen. Bei Pflanzen, die an Standorten wachsen, an denen eine einseitige stärkere Beleuchtung herrscht, wie z. B. an Waldrändern, oder bei Infloreszenzen, die an dicht buschigen Pflanzen auftreten, wird der "Schauapparat" der Blüten (wie ich kurz angedeutet habe (a. a. O. p. 399) und durch URBAN ${ }^{1}$ ) weiter ausgeführt wurde), günstiger wirken, wenn er nach einer Seite und zwar nach der Lichtseite, hingekehrt ist. Am auffallendsten sind die schon der Anlage nach dorsiventralen Blütenstände, für die zunächst ein Beispiel angeführt sei.

Fig. 314 zeigt einen Querschnitt durch die Knospe einer blühenden Pflanze ron Vicia Cracca. Diese ist zweizeilig beblättert, es sind die mit 1-6 bezeichneten Blätter durch den Schnitt getroffen. Die Infloreszenzen (If) stehen in den Blattachseln. Aber sie erscheinen schon alle nach einer Seite (in der Figur nach der Oberseite) hingerïckt, weil jede einzelne Infloreszenz nicht vor der Mitte der Blattachsel, sondern nach der Stipula hingerückt erscheint ${ }^{2}$ ); auf der der Infloreszenz abgekehrten Seite der Blattachsel tritt dann später ein vegetativer Sproß auf (vgl. Fig. 279, p. 271).

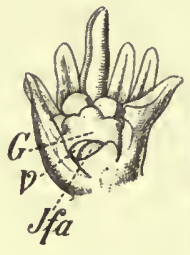

I.
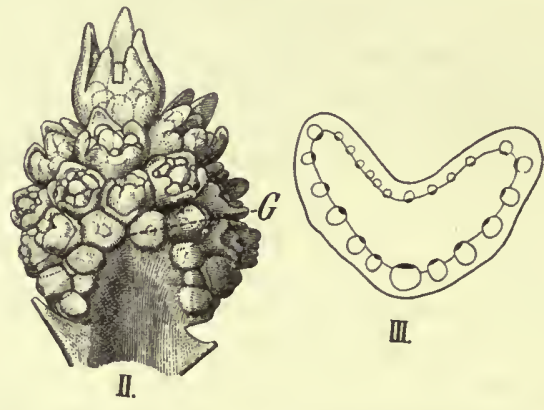

III.

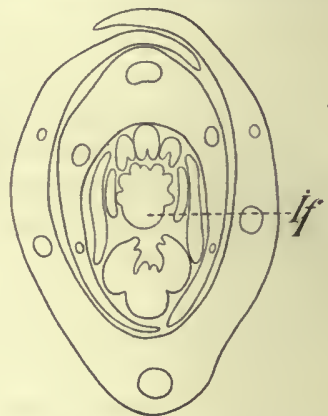

Fig. 312. Trifolium Lupinaster. I. Vegetationspunkt $(v)$ mit einer jungen Infloreszenz $(J f a)$ und einer älteren, bei welcher die ersten Blüten auf der abaxialen Seite stehen. $G$ Spitze dieser Infloreszenz. II. Ältere Infloreszenz frei präpariert. III. Querschnitt durch einen Infloreszenzstiel.

Fig. 313. Trifolium pratense. Querschnitt eines Sprosses. If junge Infloreszenz, welche auf ihrer abaxialen Seite Blütenanlagen zuerst entwickelt. Die Hauptachse ist nicht sichtbar.

In jeder einzelnen Infloreszenz stehen die Blüten auf der der Hauptachse (S) abgewendeten Seite, und dies spricht sich schon von Anfang an, also schon vor dem Auftreten der Bliiten, darin aus, daß die Infloreszenzachse auf dieser Seite stark abgeflacht ist und dementsprechend auch der Hauptachse dicht anliegt. Diese blütenleere Seite krümmt sich zunächst stark ein, was dem Schutze der jungen Blütenknospen zugute kommt. Später richten die Infloreszenzen sich negativ geotropisch auf, sie sind orthotrop, trotz ihrer Dorsiventralität. Sie kehren die blütenbesetzte Seite stets dem Lichte zu.

Auch hier scheint klar, daß die Dorsiventralität der Infloreszenz eine

1) Urban, Zur Biologie des einseitswendigen Blütenstände. Ber. der D. bot. Ges. Jahrg. 1885.

2) Dies ist aber gleich ron Anfang an der Fall, nicht etwa eine nachträgliche Verschiebung. 
Steigerung der Dorsiventralität des ganzen Sprosses ist, der Nutzen also nur sekundär in Betracht kommen kann.

Ein zweiter Fall mag an Trifolium Lupinaster erwähnt werden (Fig. 312). Auch hier ist es die abaxiale Seite der Infloreszenz, welche allein die Blüten hervorbringt, nur wächst hier der untere Teil der abaxialen Seite frühzeitig in die Höhe, während der adaxiale Teil kurz bleibt, und so kommt es, daß der Gipfel der Infloreszenz ( $G$ Fig. 312 II) nicht mehr den höchsten Punkt einnimmt - im übrigen liegen die Verhältnisse ähnlich wie bei V. Cracca. Der Querschnitt durch den Infloreszenzstièl (Fig. 312 III) gleicht dem durch manche Blattstiele, wie denn die Dorsiventralität der Infloreszenzen sich auch in ihrem Baue äußert (p. 214).

Einen Übergang zu den radiären Infloreszenzen anderer Papilionaceen bieten die von Trifolium pratense. Hier beginnt zwar die Blütenbildung auf der abaxialen Seite (Fig. 313), greift aber schließlich auf die adaxiale über; hier wie in anderen Fällen spricht sich die Förderung der abaxialen Seite in der Gestalt des Infloreszenzvegetationspunktes schon vor dem Auftreten von Blüten aus.

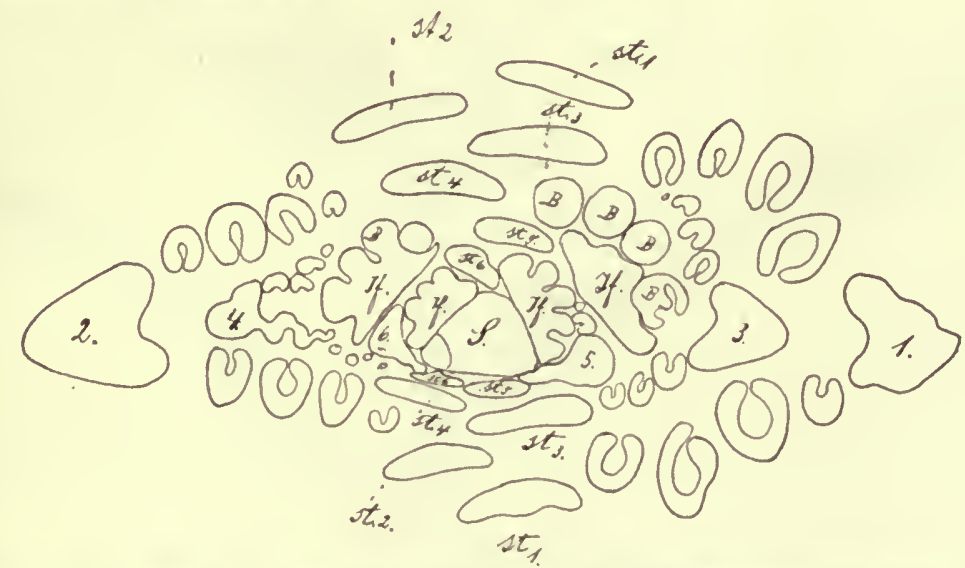

Fig. 314. Vicia Cracca. Querschnitt durch das Ende eines blühenden Sprosses. S Sproßachse. Es sind vier Infloreszenzen getroffen $(B$ die Blüten der älteren Infloreszenzen; alle Blüten stehen auf der der Hauptachse abgewendeten Seite) und sechs Blätter, von denen 3, 4, 5, 6 Infloreszenzen in ihren Achseln haben; die sämtlichen Infloreszenzen stehen aber nicht vor der Mitte der Deckblätter, sondern der nach oben gekehrten Seite der Hauptachse za. Die Fiederblättchen der älteren Blätter sind an ihrer Einkrümmung kenntlich; $s t_{1}-s t_{0}$ Stipulae (Nebenblätter); die, welche auf der Oberseite stehen, sind größer, als die auf der Unterseite.

Daran läßt sich anschließen die Besprechung der dorsiventralen schneckenförmig eingerollten Blütenstände, wie sie sich bei vielen (nicht allen) Boragineen, Hydrophylleen, Hyoscyamus u. a. finden. Phylogenetisch sind derartige Blütenstände wohl von Wickeln abzuleiten (vgl. p. 102). Für uns kommt hier nur in Betracht, daß sie ausgeprägt dorsiventral sind, sie tragen die Blüten auf der Oberseite (Fig. 96, 97), die Deckblätter (wo solche vorhanden sind) stehen auf den Flanken. Die Blütenstandachsen verlaufen meist schräg aufsteigend und entfalten sich in der Weise, daß die sich öffnenden Blüten auf dem höchsten Punkte der Infloreszenzachse stehen (Fig. 314), sie sind so nicht nur am besten sichtbar, sondern auch am besten beleuchtet, und daß das Licht nicht nur indirekt für die Bestäubung, sondern auch direkt in Betracht kommt, ist höchst wahrscheinlich. Die 
Gärtner z. B. sind allgemein der Meinung, daß eine künstliche Bestäubung bei Sonnenschein bessere Aussicht habe als bei trübem Wetter.

Als einseitswendig bezeichnen wir Infloreszenzen, deren Blüten sich durch Torsionen der Blütenstiele oder der Infloreszenzachse nach einer Seite hin wenden, während sie radiär angelegt waren. Solche finden sich unter den Papilionaceen, z. B. Hedysarum sibiricum u. a., aber auch in anderen Familien, namentlich bei Labiaten (Horminum pyrenaïcum, Scutellaria peregrina $u$. a.), Rhinanthaceen (namentlich Melampyrum), Scrophularineen (Digitalis purpurea), Pyrolaceen, auch bei manchen Monokotylen, wie Gladiolus, Freesia u. a. Besonders auffallend wird diese Einseitigkeit der Bliitenstände dann, wenn die Blätter, ursprünglich in gekreuzten Paaren stehend, durch Drehung der Infloreszenzachse in zwei Reihen zu liegen

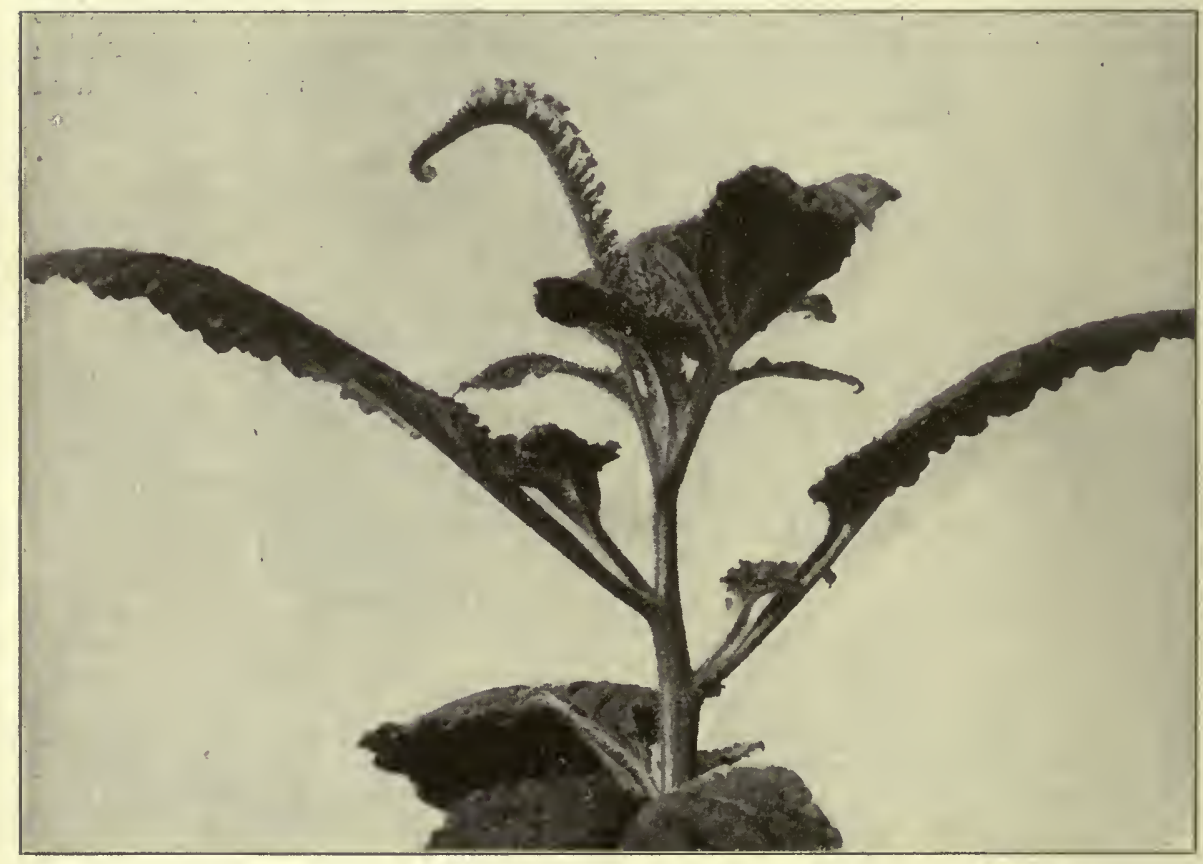

Fig. 315. Heliotropium (Tiaridium) indicum. Gipfel einer blühenden Pflanze. Man sieht deutlich, daß die Blïten auf der Oberseite der Infloreszenz stehen, deren Gipfel schneckenförmig eingerollt ist.

kommen (die bei manchen nach der blütenleeren Seite der Infloreszenz hin konvergieren), während die Blüten nach einer Seite hin sich biegen (Melampyrum pratense und silvaticum, Scutellaria peregr.), die Bliiten können so von den Deckblättern zur Blütezeit nicht mehr irgendwie verhüllt werden.

$\mathrm{Da} ß$ die Einseitswendigkeit der genannten Infloreszenzen in vielen Fällen durch äußere Faktoren bestimmt wird, scheint mir nicht zweifelhaft. Man wird zunächst mit VaUCHER annehmen ${ }^{\mathbf{1}}$ ) daß dabei vorzugs-

1) Histoire physiol. des plantes d'Europe Vol. III. Vgl. auch Wiesser, Die heliotrop. Erscheinungen im Pflanzenreich, p. 62-74. 
weise das Licht in Betracht kommt; er sagt (a. a. O. III 543) ron Melampyrum: "Cette direction des fleurs, du côté de la lumière, est si frappante, que dans le sylvaticum, qui ne croît guère qu'au milieu des bois, on peut juger par ce moyen quel est le côté le plus éclairé de la forêt; j'ai souvent remarqué dans la même plante les fleurs différemment tournées, selon la hauteur à laquelle elles étaient placés"... Daß indes keineswegs überall nur Lichtwirkung vorliegt, geht aus NoLL's Untersuchungen hervor (a. a. O. p. 235). An Waldrändern sieht man die DigitalisInfloreszenzen alle ihre bliitenbesetzte Seite nach dem Lichte hinwenden. Aber auch allseitig beleuchtete Infloreszenzen sind scharf einseitswendig. Die Infloreszenzachsen zeigen von einem gewissen Altersstadium ab eine Nutationskrümmung, hängen also über, die Blütenstiele sind positiv geotropisch, die Blüten muissen deshalb alle nach einer Seite hingekehrt sein, und zwar sind sie an seitlichen Infloreszenzen notwendig der Hauptachse abgekehrt. Bei einseitiger Beleuchtung aber krümmt sich die Infloreszenzachse positiv heliotropisch. Ähnlich dürfte es bei Convallaria, Polygonatum u. a. sein.

Auch an den auffallend einseitigen Infloreszenzen verschiedener Scutellariaarten sind die Bliiten - anch an stark einseitig beleuchteten Büschen - alle nach außen gewendet. Es findet eine Drehung der Internodien der Infloreszenz abwechselnd in entgegengesetztem Sinne statt, wodurch die Deckblätter der Blüten, die ursprünglich in gekreuzten Paaren standen, fast in zwei Reihen zu liegen kommen. Die Infloreszenzachsen hängen auch hier iiber (durch "spontane Nutation"), und die Richtung des Überhängens bestimmt die Richtung der Einseitswendigkeit (wie bei Digitalis), die Bluitenstiele aber sind positiv geotropisclı. Da die aus den Blattachseln der Hauptachsen entspringenden Seitensprosse plagiotrop sind und sich von der Hauptachse weg neigen, so müssen die Blüten alle nach außen gekehrt sein.

Das Gesamtresultat würde hier also von folgenden Faktoren abhängen: 1. Bei den Hauptachsen Annahme einer geneigten Stellung (ich würde sie einfach als plagiotrop bezeichnen). 2. Die schiefe Richtung der Seitenachsen wird beeinflußt von der Hauptachse, sie krümmen sich alle von der Hauptachse weg. 3. Internodiendrehung der Infloreszenzachsen (wie bei anderen plagiotropen Sprossen). 4. Positiver Geotropismus der Bliutenstiele.

Auch bei den dorsiventralen Infloreszenzen sehen wir also, um es kurz zu sagen, daß die Natur das Gute nimmt, wo sie es findet; wie es zustande kommt, ist ihr offenbar gleichgiiltig. Es ist unter bestimmten Umständen vorteilhaft, daß die Bliiten alle nach einer Seite hin gerichtet sind, und das kann teils durch Krümmungen (heliotropische, geotropische, plagiotrope Stellung der Infloreszenzachse), teils durch Anlegung auf einer Seite erfolgen; daß uibrigens auch allein durch einseitige Beleuchtung eine Internodiendrehung ausgelöst werden kann, welche die dekussiert stehenden Blätter in zwei Reihen bringt, zeigt unter bestimmten Umständen Urtica dioïca (Bot. Zeit. 1880 p. 843).

$\mathrm{DaB}$ die dorsiventralen Infloreszenzen aus radiären hervorgegangen sind, ist in dem Vorstehenden als wahrscheinlich angenommen; sehen wir doch, daß bei den einseits we ndigen Bliitenständen dieser Vorgang tatsächlich im Verlauf der Entwicklung eintritt. Die Ursache, welche die Entstehung der von vornherein dorsiventral angelegten Infloreszenzen bedingt hat (oder die Ursachen, da der Weg ein verschiedener gewesen sein kann), kennen wir nicht. 
Man ${ }^{1}$ ) hat, namentlich bei den Papilionaceen, die Nichtausbildung deı Blüten auf einer Seite dadurch erklären wollen, daß man annahm, sie werde hier durch den Druck der Hauptachse verhindert, welcher die Infloreszenzen, wie Fig. 314 zeigt, mit der blütenleeren Seite tatsächlich dicht anliegen. Dasselbe ist der Fall bei den Infloreszenzen von Trifolium rubens und Medicago sativa, die nur an der Basis eine blïtenleere Stelle haben. Indes dürfte das Kausalverhältnis gerade das umgekehrte sein: dies Anliegen findet statt, weil hier keine Blüten entstehen, und auch sonst keine Wachstumsvorgänge eintreten, welche ein frühzeitiges Abrücken der Infloreszenz bedingen würde. Nirgends läßt sich erweisen, $\mathrm{da} \mathrm{B}$ so grob mechanische Beziehungen, wie Druckverhältnisse, einen so weitgehenden Einfluß auf die Gestaltung ausüben. Auch gibt es bei den Papilionaceen Formen, wie das oben erwähnte Trifolium pratense, bei welchen die Bliitenanlegung einseitig beginnt, um dann allmählich die ganze Infloreszenzachse in Anspruch zu nehmen, ohne daß dafür Druckverhältnisse in Anspruch genommen werden könnten. Vielmehr prägt sich auch hier schon von vornherein die Eigentümlichkeit der Infloreszenz in der Gestalt ihres Vegetationspunktes aus.

Wir sahen bei Vicia Cracca, daß die Dorsiventralität der Infloreszenz in Beziehung steht zu der der ganzen Pflanze, die (eine dem Lichte zuwandte) geförderte und eine "Minusseite" hat; auch bei den Gräsern wurde oben auf eine solche Beziehung hingewiesen. Diese Dorsiventralität tritt in den Infloreszenzen in verschiedenem Grade gesteigert auf, sie kann auch biologisch von Bedeutung sein, notwendig ist das aber nicht.

Wir führten oben Beispiele dorsiventraler Infloreszenzen an, bei denen die Blüten auf der Lichtseite stehen, es gibt aber auch solche, bei denen sie sich auf der Schattenseite befinden. So bei Klugia ceylanica ${ }^{2}$ ). Diese Pflanze hat zweizeilig beblätterte Sprosse, die sich von vierzeiligen vom Typus der Goldfussia glomerata ableiten (p. 256). Sie sind also hypotroph. Dem entspricht auch die Tatsache, daß die Blüten auf der (Unter-), d. h. der Schattenseite stehen. Dies tut aber ihrer Sichtbarkeit keinen Eintrag, da sie gestielt sind und eine große, lebhaft gefärbte Unterlippe besitzen. Jedenfalls aber kann man hier die Einseitigkeit nicht als einen Anpassungscharakter betrachten, noch weniger als durch Druck veranlaßt (denn die Infloreszenzen sind terminal), vielmehr ist sie durch die Gesamtdorsiventralität der Sprosse bedingt.

Wir sehen also, daß dorsiventrale Infloreszenzen auf recht verschiedene Weise zustandekommen können: einmal an sonst radiären Sprossen, also gewissermaßen de novo, oder bedingt durch die Gesamtdorsiventralität der ganzen Pflanze.

\section{$\S 28$. Symmetrieverhältnisse der Wurzeln.}

Die Symmetrieverhältnisse der Wurzeln können kurz erledigt werden. Normale Erdwurzeln sind, wie oben schon bemerkt, meist radiär gebaut, auch die plagiotropen. Indes fehlt es nicht an Beispielen von Erd- und

1) Zuerst wohl Godron (Observations sur les bourgeons et sur l'inflorescence des Papilionacées, Nancy 1865).

2) Vgl. dariber Goeber, Über die Verzeigung dorsiventraler Sprosse. Die Hypotrophie von Klugia zeigt sich nicht nur dadurch, daß allein die beiden Blattreihen der Unterseite übrig bleiben, diese Seite wächst auch stärker in die Breite und bildet an Stecklingen zuerst Wurzeln (vgl. Bosнart a. a. 0. p. 118). 
Luftwurzeln, welche aus inneren oder aus äußeren Gründen dorsiventralen Bau angenommen haben. Sie sind von besonderem Interesse, weil hier am ehesten Aussicht vorhanden zu sein scheint, in das wichtige Problem der Entstehung der Dorsiventralität näher einzudringen.

1. Wurzeln, welche unabhängig von äußeren Einflüssen dorsiventral sind, scheinen nur bei einigen Pteridophyten vorzukommen. Dabei wollen wir als dorsiventral nicht etwa schon alle monarch gebauten Wurzeln bezeichnen (was an sich auch berechtigt wäre), sondern nur solche, bei denen die Dorsiventralität sich im Gesamtbau der Wurzeln ausspricht. Als Beispiel sei angeführt: Isoetes. Ein Querschnitt einer Isoeteswurzel z. B. I. lacustris (Fig. 316) zeigt, daß sie nicht zylindrisch, sondern abgeflacht ist. Die Dorsiventralität tritt hervor namentlich durch die Lage des großen Luftraums anf einer Seite des Leitbündelzylinders. Auch das Rindenparenchym ist auf dieser Seite etwas stärker entwickelt als auf der anderen, so daß auch abgesehen von der Lage des Luftraumes eine exzentrische Lagerung des Zentralzylinders zustandekommt. Die Dorsiventralität der Wurzeln steht mit ihrer Lage am Stämmchen in Beziehung. Die knolligen Isoetesstämme haben unten (im späteren Alter) eine Furche. Alle Wurzeln haben ihre Lufträume der Furche abgekehrt. Man könnte die stärkere Entwicklung der einen Seite damit in Beziehung setzen, daß diese ursprünglich konvex ist. Eine Beeinflussung durch Außenfaktoren erscheint sehr wenig wahrscheinlich, sie ließe sich durch Kultur der Pflanze in inverser Lage prüfen. Analoge Fälle von nicht durch äußere Faktoren induzierter Dorsiventralität mögen auch bei höheren Pflanzen vorkommen. L. KelLer ${ }^{1}$ ) gibt z. B. an, daß bei Piper nigrum der Leitbündelzylinder frei schwebender Luftwurzeln abgeplattet sei — was sich bei einseitiger Beruihrung mit einem Substrat verstärken, ohne diese vermindern soll. Wahrscheinlich war übrigens die Pflanze nicht Piper nigrum (viel-

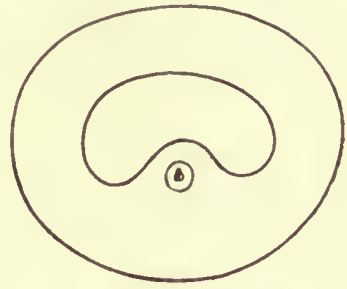

Fig. 316. Isoëtes lacustris. Querschnitt durch eine Wurzel mit großem Luftraum, unterhalb dessen das Leitbündel angedeutet ist. fach sind in Gärten andere Piperarten so bezeichnet) und der Fall miißte näher experimentell geprüft werden.

2. Viel häufiger findet sich Dorsiventralität an den dem Lichte ausgesetzten Wurzeln, wobei zu bemerken ist, daß auch unter diesen dorsiventrale nur bei verhältnismäßig wenigen Pflanzen vorkommen. Man kann hier mehrere Fälle unterscheiden, welche sich aber teilweise miteinander kombinieren können. bedingt

A. Dorsiventralität von Wurzeln ohne sekundäres Dickenwachstum

a) durch Verschiedenheit im anatomischen Bau der Ober- und Unterseite, und in manchen Fällen durch Abflachung der letzteren,

b) durch Abplattung und schwächere Entwicklung der (dem Substrate anliegenden) Unterseite,

c) durch Aërenchymbildung auf der Außenseite (Oberseite).

B. Wurzeln mit sekundärem Dickenwachstum, welches einseitig gefördert erfolgt.

1) L. KeLLER, Anatom. Studien über die Luftwarzeln einiger Dikotylen. Dissert. Heidelberg 1889. 
A. a) Hierher gehören die Luftwurzeln einiger Orchideen und die am Lichte wachsenden Wurzeln vieler Podostemaceen - bei ersteren handelt es sich um epiphytisch lebende Monokotylen, bei letzteren um in stark strömendem Wasser wachsende Dikotylen.

Viele epiphytische Orchideen besitzen Luftwurzeln, die außerhalb des Substrates entwickelt frei herabhängen oder einem Baumast angeschmiegt wachsen. Bei den meisten daraufhin untersuchten Arten sind sie radiär. Einige zeigen aber Differenzen im anatomischen Bau von Ober- und Unterseite, die namentlich darin bestehen, daß die Oberseite Zellen mit stärker verdickten Wänden aufweist, und die Luft festhaltenden Teile des Velamens nur auf der Unterseite ansgebildet sind (vgl. das unten über Phalaenopsis Anzuführende).

Bei einigen der untersuchten Orchideenluftwurzeln wird die dorsiventrale Struktur und die Abflachung durch die einseitige Beleuchtung bedingt, sie macht, wenn die Wurzel verdunkelt wird, einer radiären Platz. So, wie JANCzEWSKI ${ }^{1}$ ) zeigte, bei Epidendrum nocturnum. Dabei ist nicht näher untersucht, in welcher Teise das Licht einwirkt, ob durch Steigerung der Transpiration, durch Einwirkung auf die $\mathrm{CO}^{2}$-Zerlegung oder sonstwie.

Allein bei anderen macht sich die dorsiventrale Induktion, wenn sie einmal eingetreten ist, länger geltend, eine Erscheinung, welche von großem Interesse ist, zumal sie überleiten könnte zu den Fällen, in denen die dorsiventrale Ausbildung vom Lichte unabhängig eintritt.

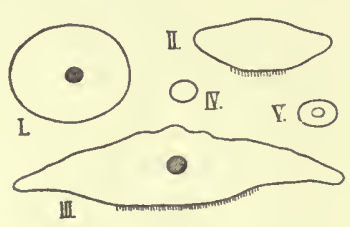

Fig. 317. Wurzelquerschnitte (alle bei derselbe $\mathbf{n}$ schwachen Vergr. gezeichnet). I Phalaenopsis Esmeralda; II Ph. Lïddemanniana; $I I I$ durch die ausgewachsene, $I V$ und $V$ durch die junge Wurzel (d, h. kurz hinter dem Vegetationspunkt) von $\mathrm{Ph}$. Schilleriana. Der zentrale Leitbündelzylinder der Wurzel in $I I$ und $I I I$ schraffiert.

Schon bei Sarcanthus rostratus verschwand (nach JANczewski) an dem im Finstern erfolgten Neuzuwachs nach mehreren Wochen die Dorsiventralität nicht ganz, es ist fraglich wieweit dies bei längerer Versuchsdauer etwà eingetreten sein würde, und noch fester ist die Induktion offenbar bei anderen Orchideen.

Zunächst sei indes betont, daß die Abflachung der Orchideenluftwurzeln auch biologisch in Betracht kommt, besonders dann, wenn chlorophyllhaltige Wurzeln, wie das bei einigen Orchideen der Fall ist, als e inzige Assimilationsorgane funktionieren. So bei Taeniophyllum, Angraecum fasciola u. a., bei denen die Blätter zu chlorophyllosen Schuppen verkümmert sind. Wie sehr die Wurzeln hier dem Leben am Lichte angepaßt sind, zeigt die Tatsache, daß sie bei Lichtabschluß (wie Wiesner bei Taeniophyllum feststellte) überhaupt nicht wachsen. Die Frage ist nun, wieweit die Abflachung durch äußere Faktoren bedingt wird. Es sei die Wurzelbildung bei der Gattung Phalaenopsis kurz besprochen. In Fig. $317 I-I I I$ sind Wurzelquerschnitte dreier Arten abgebildet. Ph. Esmeralda hat (auch außerhalb des Substrates) Wurzeln, die man als dorsiventral nicht bezeichnen kann, sie kommen auch als Assimilationsorgane wohl wenig in Betracht, werden aber, abgesehen ron

1) JANCZEwski, Organisation dorsiventrale dans les racines des Orchidées (Ann. des sciences nat. bot. VII Sér. T. 2 (1885). GoEber, Pflanzenbiol. Schilderungen I, p. 197 und 351. 
ihrer wasseraufnehmenden Tätigkeit, als Wasserspeicher in der trockenen Zeit (in welcher die Pflanze ihre Laubblätter verliert) von Bedeutung sein. Ausgesprochen abgeflacht und dorsiventral sind dagegen die Wurzeln bei $\mathrm{Ph}$. Luiddemanniana (Fig. $317 I I$ ). Die Wurzelhaare dieser den Baumästen anliegenden Wurzeln bilden sich nur auf der Unterseite, auch hier, wie in der Figur angedeutet ist, nur auf dem mittleren Teile ${ }^{1}$ ). Diese Abflachung wird noch bedeutend gesteigert bei Ph. Schilleriana (Fig. 317 III und Fig. 318), deren meterlange, den Baumästen angeschmiegte Wurzeln ein sehr sonderbares Aussehen haben. Es ist das Rindengewebe zu beiden Seiten des Leitbündelzylinders mächtig entwickelt: eine Einrichtung, die auch dadurch von Vorteil sein wird, daß Wasser auf der Unterseite der flachen Wurzel kapillar festgehalten wird. Die Abflachung beginnt schon
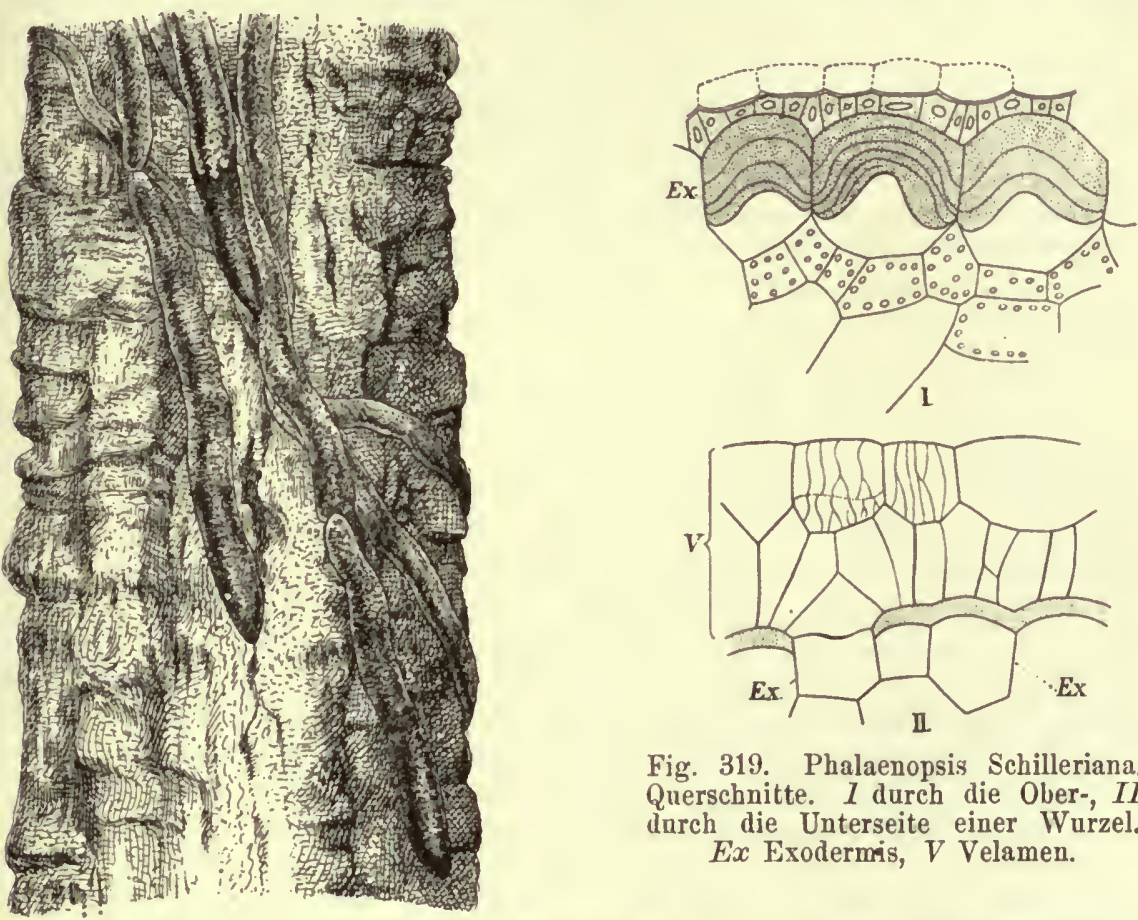

Fig. 319. Phalaenopsis Schilleriana, Querschnitte. I durch die Ober-, II durch die Unterseite einer Wurzel. Ex Exodermis, $V$ Velamen.

Fig. 318. Stïck einer Baumrinde, an welcher dicht angepreßt die stark abgeflachten Wurzeln von Phalaenopsis Schilleriana wachsen. Die an zwei Wurzeln sichtbaren Einschnürungen sind durch Wachstumsunterbrechungen veranlaßt ( $1 / 2$ nat. Gr.).

selır früh, schon der Querschnitt des Wurzelvegetationspunktes ist nicht mehr kreisrund, sondern elliptisch. Die Wasseraufnahme ist der Hauptsache nach auf die Unterseite verlegt, während die Oberseite zum Schutz gegen starke Transpiration ausgebildet ist. Dies spricht sich deutlich im anatomischen Bau aus (Fig. 319). Eigentlich ist auf beiden Seiten ein zweischichtiges "Velamen" vorhanden, unter welchem die "Exodermis" (Ex Fig. 319) liegt. Die Außenwände der letzteren sind auf der Oberseite mächtig, auf der Unterseite nur wenig verdickt. Das Velamen ist nur auf

1) Bei anderen Luftwurzeln, so denen von Oncidium Jonsèsi, fand ich frei in die 'Luft ragende Wurzelhaare anch auf der Lichtseite. 
der Unterseite als ein aus leeren, dünnwandigen, mit Faserverdickungen versehenen Zellen aufgebauter Wasseraufsaugeapparat entwickelt. Auf der Oberseite ist die äußere, dünnwandige Velamenschicht wohl ziemlich bedeutungslos, die innere hat sich $\mathrm{zu}$ dickwandigen Zellen umgebildet. Dem entspricht auch, daß die für das Velamen der Orchideenluftwurzeln charakteristischen „Durchlüftungsstreifen" sich nur auf der Unterseite finden.

Es zeigt also die Wurzelhülle auf der Ober- und der Unterseite eine bedeutende Verschiedenheit ihres Aufbaues.

Nun ist zu untersuchen, wieweit die Abflachung der Wurzel und ihre Dorsiventralität von äußeren Faktoren bedingt sind. In der ersten Auflage dieses Buches war Verf. zu der Ansicht gekommen, daß die Abflachung der Wurzeln von Phalaenopsis Schilleriana nicht durch das Licht bedingt sei. Es hatten nämlich Versuche ergeben, daß flache in eine undurchsichtige Röhre eingeführte Wurzeln in dieser mehrere $\mathrm{cm}$ weit ebenso abgeflacht wie am Lichte weiter wuchsen, nur die Zellwände der Wurzelhülle, namentlich die der Exodermis zeigten eine andere Ausbildung (a. a. O. p. 486).

Indes könnte das Verhalten auch darauf beruhen, daß der Vegetationspunkt der Wurzeln eine labile, aber noch einige Zeit $\mathrm{nach}$ wirkende Beeinflussung durch das Licht erfahren hat. Dafür spricht namentlich, daß die Pflanze außer den flachen Wurzeln, dann wenn sie auf einem lockeren Substrat wächst (nicht wie die früher von mir untersuchten Pflanzen auf nackten Baumrinden), auch zylindrische im Substrat wachsende Wurzeln bildet.

Weitere Versuche ergaben die Richtigkeit dieser Auffassung.

Eine in eine verdunkelte Glasröhre eingeführte Wurzel hatte in $3^{1} l_{2}$ Monaten in dieser ein neues Stück von $14 \mathrm{~cm}$ Länge gebildet. $6 \mathrm{~cm}$ lang war die Abflachung noch deutlich erkennbar, dann verlor sie sich, die Wurzel wurde fast zylindrisch. Auch die Verteilung der Durchlüftungsstreifen auf die Unterseite verlor sich. Noch rascher verlor sich die Induktion bei flachen Wurzeln, die an ihrer Spitze mit faserigem Material (Osmundafaser) umwickelt worden waren, namentlich dann, wenn die Wurzelspitze beschädigt war und Adventivwurzeln (die sich bei Verletzung der Wurzeln mitten auf der flachen Lichtseite bildeten $\left.{ }^{1}\right)$ ) auftraten. Wir haben hier also ein sehr wertvolles Beispiel einer scheinbar stabilen in Wirklichkeit labilen Induktion vor uns.

$\mathrm{Ob}$ diese Induktion direkt auf den Vegetationspunkt einwirkt oder von den älteren T'eilen her erfolgt, ist eine andere Frage, sie wird weiterhin geprüft werden. Jedenfalls kann auf die Phalaenopsiswurzeln Janczewski's Annahme (für Sarcanthus), daß es sich bei dem Zuwachs im Finstern um Teile handle, die schon vorher differenziert gewesen seien, nicht zutreffen. Ein mehrere cm langes Stück einer Wurzel kann sich nicht aus dem zur Zeit des Versuchsbeginnes vorhanden gewesenen Zellenmaterial des Vegetationspunktes entwickeln, es muß hier im Finstern ausgedehnte $\mathrm{Neubildung}$ eingetreten sein.

Bei Angraecum fasciola war (nach JANCZEwski) auch ein im Finstern neugebildetes Wurzelstiuck dorsiventral, auch hier fragt es sich nunmehr, $o b$ die Verhältnisse nicht ebenso liegen, wie bei Phalaenopsis ${ }^{2}$ ). Bei

1) Vielleicht liegt darin eine "Phototrophie“, ähnlich der im VI. Abschnitt für einige Kakteen zu schildernden.

$\left.{ }^{2}\right)$ Desgleichen bei Taeniophyllum, wo die Wurzeln so sehr dem Lichte „angepaßt sind, daß sie, wie WIESNER angibt, im Dunkeln überhaupt nicht wachsen. Wie früher bemerkt, fragt es sich, ob eine von vornherein im Dunkeln angelegte Wurzel sich nicht anders verhalten würde. Daruber soll später berichtet werden. 
dieser war bei den Dunkelwurzeln (die als Fortsetzung von Luftwurzeln sich entwickelt hatten) die Verschiedenheit der Wurzelhülle auf den verschiedenen Seiten verschwunden, offenbar infolge des feuchten Mediums, in welchem die Wurzeln wachsen. Der Bau stimmte im wesentlichen mit dem überein, den sonst die Unterseite der Wurzeln zeigt.

Wir dürfen wohl annehmen, daß bei allen Orchideen mit flachen Wurzeln eine Induktion vorliegt.

b) Hier handelt es sich darum, daß an einseitig dem Substrat aufliegenden Wurzeln die Schattenseite in ihrer Entwicklung zurückbleibt und abgeflacht ist, während freihängende Wurzeln zylindrisch sind. Verf. beobachtete dies bei einer Anzahl von Orchideen z. B. Cattleya Loddigesi, Epidendrumarten u. a. Die Beschaffenheit der Unterseite dürfte eine Substratwirkung sein: Die noch weiche, plastische Wurzel legt sich an das Substrat an, sei es infolge von negativem Heliotropisnus oder von Kontaktreiz. Auf welcher Wirkung aber die geringere Entwicklung der dem Substrat anliegenden Seite beruht, ist damit nicht gesagt. Es kann ein Fall von "Phototrophie" sein oder mit dem Gasaustausch (inkl. Transpiration), Druckwirkungen und dgl. zusammenhängen. Jedenfalls aber ist soviel klar, daß es sich um eine durch die Außenwelt bedingte Gestaltveränderung handelt. Die Außenzellen der Oberseite sind auch hier vielfach stärker rerdickt, als die der unteren.

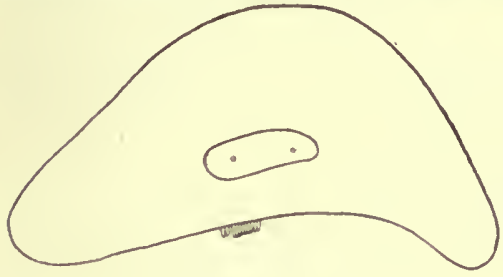

Fig. 320.
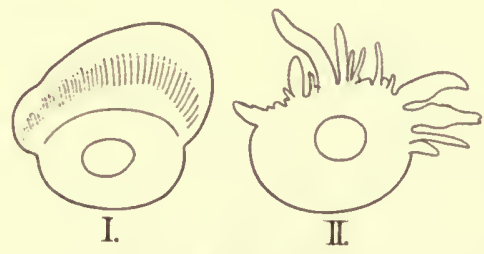

Fig. 321.

Fig. 320. Querschnitt durch die dorsiventrale, chlorophyllhaltige Wurzel der Podostemacee Oenone leptophylla. Sie ist auf der Unterseite, welche an dem Substrat durch zahlreiche Haare (einige derselben angedeutet) befestigt ist, abgeflacht, aber auch die Oberseite ist abgeflacht; der Leitbündelstrang liegt exzentrisch.

Fig. 321. Pothos celatocaulis. Querschnitt durch eine Luftwurzel mit einseitigem „Aërenchym ${ }^{\alpha}$. 1. weiter nach der Spitze als $I I$. Schwach vergr.

Sowohl Abflachung als stärkere Entwicklung der Oberseite kommt in Betracht bei den sich auf dem Gestein ausbreitenden Wurzeln der Podostemaceen. Die Fig. 320 gibt einen Querschnitt, der die dorsiventrale Gestaltung deutlich zeigt: auf beiden Seiten ist eine Abflachung eingetreten, eine Abflachung, die ungemein weit geht bei Dicraea algaeformis und Hydrobryum (vgl. im speziellen Teile das Kap. "Wurzel"). Experimentelle Untersuchungen liegen über diese Fälle bis jetzt nicht vor. Wir dürfen aber wohl annehmen, daß wenigstens bei manchen die Oberflächenvergrößerung eine direkte Lichtwirkung und bei anderen „erblich geworden“ ist.

c) Erwähnt werden mag ein eigenartiger Fall von Dorsiventralität bei den Luftwurzeln einer Aroidee. Die einem Farnstamm anliegenden Luftwurzeln von Pothos celatocaulis fielen mir dadurch auf, daß sie auf der freien Seite mit borstigen, dunkelgefärbten Auswïchsen besetzt waren (Fig. 321 II). Wurzelhaare konnten das - auch abgesehen ron der Länge - nicht sein, weil sie mehrzellig sind. Es zeigte sich, daß es sich um 
eine starke Streckung einiger Zellschichten der Außenrinde handelt, welche die Oberhaut sprengend nun in Gestalt jener Auswüchse frei zutage treten. Offenbar handelt es sich um eine durch starke. Wasserzufuhr bedingte "hyperhydrische" Zellwucherung, die hier in sehr eigentuimlicher Weise auftritt. Daß sie nur an der Oberseite sich findet, während die dem feuchten Substrat anliegende Unterseite sie nicht zeigt, kann entweder durch die stärkere Benetzung oder durch die Berührung mit der Luft (Sauerstoffzufuhr?) bedingt sein, falls nicht etwa bei diesen Luftwurzeln die Dorsiventralität ebenso inhärent ist, wie bei den Stämmen von Pothos celatocaulis. Es scheint übrigens auch bei den Haftwurzeln anderer Aroideen eine Dorsiventralität insofern vorzukommen, als die Bildung von Seitenwurzeln auf die Flanken und die Unterseite beschränkt ist, auf der Lichtseite aber unterbleibt. Doch bedarf dies noch genauerer Untersuchung.

B. Bei einer Anzahl von Pflanzen zeigen Wurzeln, welche ungleichartigen Bedingungen auf den verschiedenen Seiten ausgesetzt sind, ein verschieden starkes sekundäres Dickenwachstum auf den verschiedenen Seiten. Einige Beispiele mögen angeführt werden.

Ficus. Massart ${ }^{1}$ ) fand bei Ficus repens an den kletternden Sprossen auf der Lichtseite (auch wenn sie frei schweben) eine starke Verminderung, auf der Schattenseite eine korrelative Steigerung des Dickenwachstums. Ebenso bei den Luftwurzeln. Sie wird bedingt durch Beleuchtungsdifferenzen auf Licht- und Schattenseite. Bei Ficus Rumphii dagegen sollen die horizontalen Wurzeln, gleichgültig ob sie am Lichte oder unterirdisch wachsen, durch Schwerkraftswirkung auf der O ber seite stärker wachsen.

Es ist aber zu vermuten, daß die Verhältnisse hier ähnlich liegen wie bei den unten anzuführenden Beispielen.

Europäische Waldbäume. KNY ${ }^{2}$ ) fand an bloßgelegten Wurzeln von Pinus silvestris Hypotrophie, bei Fagus silvatica Epitrophie. Damit sind auch anatomische Veränderungen im Holze verbunden, der Bau nähert sich dem des Astholzes. Er führt diese Beeinflussung auf die Atmosphärilien (Licht, Wärme, Feuchtigkeit) zurück, während der Schwerkraft keine Bedeutung zukomme, Zug- und Druckkräfte aber ganz wegfallen.

Ein Nutzen der geschilderten Erscheinung für die betreffenden Bäume ist nicht ersichtlich. Und wenn auch die Erscheinung noch eingehender Untersuchung bedarf, so ist sie doch von erheblichem Interesse als Beispiel einer, wie es zunächst scheint, nutzlosen Reaktion der Pflanzengestaltung auf äußere Einflüsse.

1) Massart, Sur l'irritabilité des plantes supérieures (Mémoires couronnés, de l'académie royale de Belgique T. LXII, 1902. KELLER, Anat. Studien über die Luftwurzeln, Diss. Heidelberg, 1889, p. 26, gibt für die Lichtwurzeln von Ficus barbata Epitrophie an.

2) KNY, Über das Dickenwachstum des Holzkörpers der Wurzeln in seiner Beziehung zur Lotlinie (Ber. der deutschen botan. Gesellsch. Bd. XXVI (1907) p. 20). 
Vierter Abschnitt.

\section{Umbildung, Verkïmmerung, Verwachsung, Teilung.}

Die kurze in dem zweiten Abschnitt gegebene Übersicht über die Organbildung in verschiedenen Gruppen des Pflanzenreiches zeigt, daß die Mannigfaltigkeit zustande kommt dadurch, daß der "Gestaltungstrieb" in den einzelnen Gruppen in verschiedener Weise sich betätigt. Die im 3. Abschnitt erörterten Symmetriebeziehungen erläutern, welche Veränderungen der Organbildung durch Änderung der Symmetrie vor sich gehen können. Außerdem wird die Mannigfaltigkeit gesteigert dadurch, daß innerhalb der erreichten Stufe der Organbildung Umbildung, Verwachsung (oder Spaltung) und Verkümmelung von Organen stattfindet.

\section{Organumbildung.}

\section{A. Die normale Umbildung.}

\section{$\S 1$. Allgemeines über den Begriff Umbildung oder Metamorphose.}

Sowohl bei der Besprechung der Organbildung niederer Pflanzen als bei der der Verzweigung sind mehrfach Beispiele dafür angeführt worden, daß ursprünglich gleichartig angelegte Organe im weiteren Verlauf ihrer Entwicklung eine verschiedene Ausbildung erfahren können, welche sie wenn man nur den fertigen Zustand betrachtet - als ungleichartig erscheinen lassen. Es sei erinnert an die der Befestigung dienenden Sprosse von Bostrychia, Dictyota Mertensii (p. 58, 61), an die verschiedene Ausbildung von Kurz- und Langtrieben, an die Sproßbildung von Equisetum. In allen diesen Fällen zeigt die vergleichende Betrachtung, daß die Mannigfaltigkeit der Organbildung im Grunde keine so große ist, als es zunächst den Anschein hat, und zwar deshalb, weil man unterscheiden lernte zwischen der "morphologischen" und der "physiologischen" Bedeutung eines Organes. Mit anderen Worten: man erkannte, daß die Mannigfaltigkeit der Organbildung sich vielfach auf das Verschiedenwerden ursprünglich gleichartiger Teile des Pflanzenkörpers zurückführen läßt. Sahen wir doch schon in der Einleitung, daß die wurzelähnlichen Organe von Genlisea keine Wurzeln sind (obwohl sie in ihrer Funktion teilweise mit diesen übereinstimmen), sondern Blätter.

Einer der Fundamentalsätze der Morphologie lautet demgemäß dahin, daß die äußere Erscheinung und die damit in Zusammenhang stehende Funktion eines Organs über seine „morphologische Bedeutung " nichts aussage; oder anders ausgedruickt, daß dieselbe Funktion von Organen verschiedener morphologischer Bedeutung ïbernommen werden kann, daß "analoge" und „homologe" Organe unterschieden werden müssen. So sind 
die Ranken des Weinstocks, die von Passiflora u. a., Sproßachsen, deren Blätter ganz oder fast ganz unterdrückt sind; die Ranken der Papilionaceen und anderer Pflanzen aber, die jenen an Form und Funktion gleichen, sind umgebildete Blätter, sie sind jenen analog, nicht homolog.

Diese Erkenntnis ist eine der wichtigsten Errungenschaften der Morphologie. Sie war aber zugleich auch die Ursache einer unfruchtbaren Verallgemeinerung. Weil ein Organ gleicher morphologischer Bedeutung verschiedene Funktionen annehmen kann, wurde die Funktion als etwas ganz Nebensächliches betrachtet, als etwas, das für die Charakteristik der Organe gar nicht in Betracht kommen dürfe, von dem man also bei einer Einteilung der verschiedenen Glieder der Pflanze in allgemeine Kategorien von vornherein absehen müsse.

Diese Folgerung hat namentlich auch in einer mit ihr auf das Innigste zusammenhängenden Grundfrage der Morphologie zu einem unhaltbaren Standpunkt geführt. Das Problem, um welches es sich dabei handelt, wird seit GoEthe als die Lehre von der Metamorphose bezeichnet.

Wir verstehen darunter die Tatsache, daß die Mannigfaltigkeit der Pflanzenorgane sich bei genauerer Betrachtung auf wenige "Grundformen" zurückführen läßt, durch deren "Umbildung" die große "Zahl der verschiedenen Glieder des Pflanzenkörpers entsteht.

Wenn wir uns aber fragen, wie wir uns diese Grundformen und deren Umbildung vorzustellen haben, so geraten wir sofort auf verschiedene Auffassungen bei denen, die sich überhaupt die Mühe gegeben haben, über die Begriffe, mit denen sie operieren, nachzudenken.

In der idealistischen Morphologie, wie sie von Goethe, A. Braun und Hanstein vertreten war, handelte es sich bei der Metamorphosenlehre, wie ich anderwärts dargelegt habe ${ }^{1}$ ), wesentlich um eine Begriffskonstruktion. GOETHE selbst hat seine Anschauung treffend in den Worten bezeichnet, „daß nun das, was der I de e nach gleich ist, in der Erfahrung entweder als gleich oder als ähnlich, ja sogar als völlig ungleich und unähnlich erscheinen kann, darin besteht eigentlich das bewegliche Leben der Natur". Und in etwas anderer Form hat sich diese idealistische Auffassung auch erhalten, als durch K. F. WOLFF, R. BRown und Schlemen die Entwicklungsgeschichte $\mathrm{zu}$ einem der wichtigsten Hilfsmittel der Organographie erhoben wurde.

Die Anschauung, welche ich als die "Differenzierungstheorie" bezeichnet habe, hat sich, wie überhaupt die ganze Metamorphosenlehre, entwickelt an dem Studium der Umbildungen der Blätter, welche die größte Mannigfaltigkeit aufweisen. Hätte man statt dessen \%. B. die Umbildungen der Wurzeln als Ausgangspunkt genommen, so würde man wohl allgemein zu der Anschauung gekommen sein, welche die Metamorphose nicht als eine nur gedachte, sondern als eine wirkliche Umbildung auffaßt, eine Anschauung, die Verf. seit Jahren unter lebhaftem Widerspruche anderer eingehend zu begründen gesucht hat.

Die Differenzierungstheorie nimmt an, daß am Vegetationspunkte der Sprosse indifferente Anlagen entstehen, die sich in mannigfaltiger Weise je nach den Bedürfnissen der Pflanze weiter entwickeln können, unter sich aber das Gemeinsame haben, daß sie "Blätter" sind.

Die andere Auffassung nimmt eine reale Umbildung einer Anlage an, und zwar so, daß z. B. die Anlage eines Laubblattes, statt zu einem Laubblatt

1) Vergleichende Entwicklungsgeschichte der Pflanzenorgane. Schenks Handbuch der Botanik III, 1883, 1, S. $103 \mathrm{ff}$. 
sich wirklich auszubilden, zu einem im fertigen Zustand ganz anders aussehenden Schuppenblatt oder einem Sporophyll werden kann, oder eine Staubblattanlage zu einem Blumenblatt usw. Wir sehen in diesem Falle stets, daß ein mehr oder minder langer Weg der Entwicklungsgeschichte z. B. eines Laubblattes und eines Schuppenblattes übereinstimmt. Wir bezeichnen das letztere als eine Umbildung des ersteren schon deshalb, weil wir bei vielen (nicht allen) Schuppenblättern sehen, daß sie im jugendlichen Zustande Teile besitzen, die beim Laubblatt sich entfalten, beim Schuppenblatt aber verkümmern. Wir haben es sogar in der Hand, experimentell diese Umbildung zu verhindern.

$\mathrm{Da}$ gerade bei diesem Falle die Sache besonders klar liegt ${ }^{1}$ ), so sei kurz ein Beispiel dafür erörtert. Fig. 322 zeigt in $I$ die Umrisse eines Laubblattes, in $I I$ die einer Knospenschuppe ron Acer platanoïdes. Beide sind äußerlich recht verschiedene Gebilde. Das Laubblatt besteht aus der Spreite $(L)$, dem Stiel $S$ und dem nur wenig hervortretenden Blattgrund $G$; die Knospenschuppe ist ohne Gliederung.

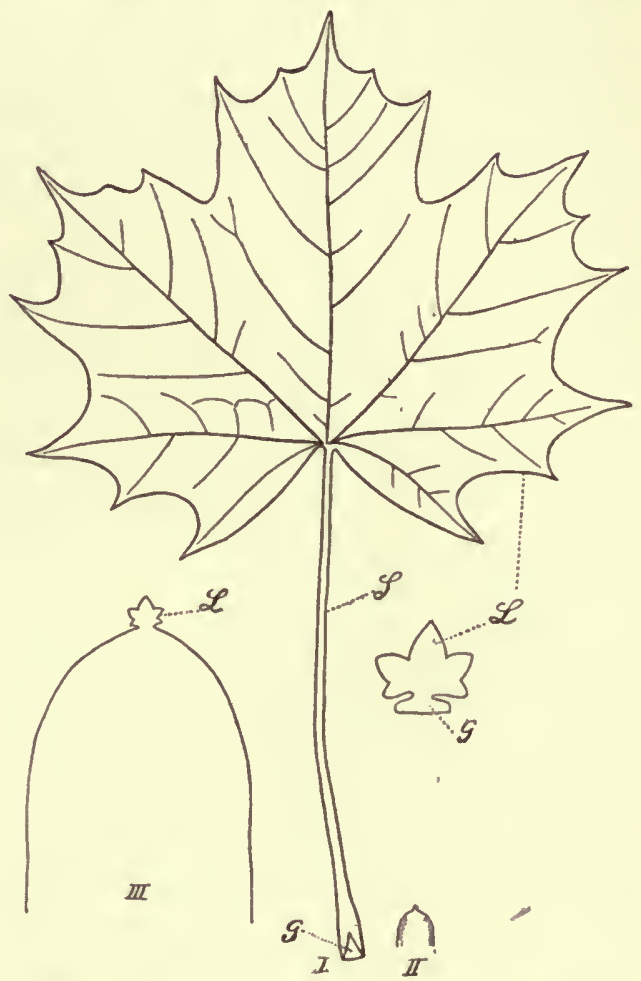

Fig. 322. Acer platanoïdes. I Laubblatt (verkl.), $G$ Blattgrund, S Blattstiel. II Knospenschuppe. III Junge Knospenschuppe (vergr.), $L$ Anlage der Blattspreite, welche später verkümmert, IV (Nr. weggeblieben) Laubblattanlage (vergr. u. schemat.). Trotzdem ist die Schuppe nichts anderes als eine umgewandelte Laubblattanlage. Wenn wir uns die kleine schwarze Spitze der Knospenschuppe näher ansehen (Fig. $322 I I I, L$ ), so finden wir, daß sie bei stärkerer Vergrößerung eine kleine Blattspreite aufweist, oder vielmehr die Anlage zu einer solchen, die aber sich nicht weiter entwickelt hat, sondern abgestorben ist.

Diese sonderbare Tatsache erklärt sich, wenn wir die Entwicklungsgeschichte des Laubblattes verfolgen, was hier nur in den gröbsten Ziugen zu geschehen braucht. Es zeigt sich, daß auf einer gewissen Entwicklungsstufe das Laubblatt etwa die in Fig. 322 IV abgebildete Gestalt besaß. Wir erkennen deutlich die Anlage der Blattspreite $(L)$, deren Gliederung schon sichtbar ist; der Blattstiel ist noch nicht vorhanden, er wird durch die Streckung der Zone entstehen, die zwischen der Blattspreite $(L)$ und dem Blattgrunde $(G)$ liegt.

1) Vgl. Goeber, Beitr. zur Morphologie und Physiologie des Blattes. Botan. Zeitung 1880 , p. $753 \mathrm{ff}$. 
Ganz dasselbe Entwicklungsștadium durchläuft nun auch eine Knospenschuppe. Aber jetzt tritt eine Anderung ein: Die Spreitenanlage $(L)$ vertrocknet, der Blattstiel bildet sich ïberhaupt nicht, der Blattgrund aber wächst bedeutend heran und gestaltet sich eben zu der Schuppe, von der wir ausgingen.

Wir können, wie erwähnt, eine ihrer Stellung nach zur Ausbildung als Schuppenblatt bestimmte Laubblattanlage auch experimentell verhindern, diese Umbildung zu erfahren und sie zwingen, als Laubblatt weiter zu wachsen. Es gibt ferner Fälle, in denen die Spreitenanlage auf

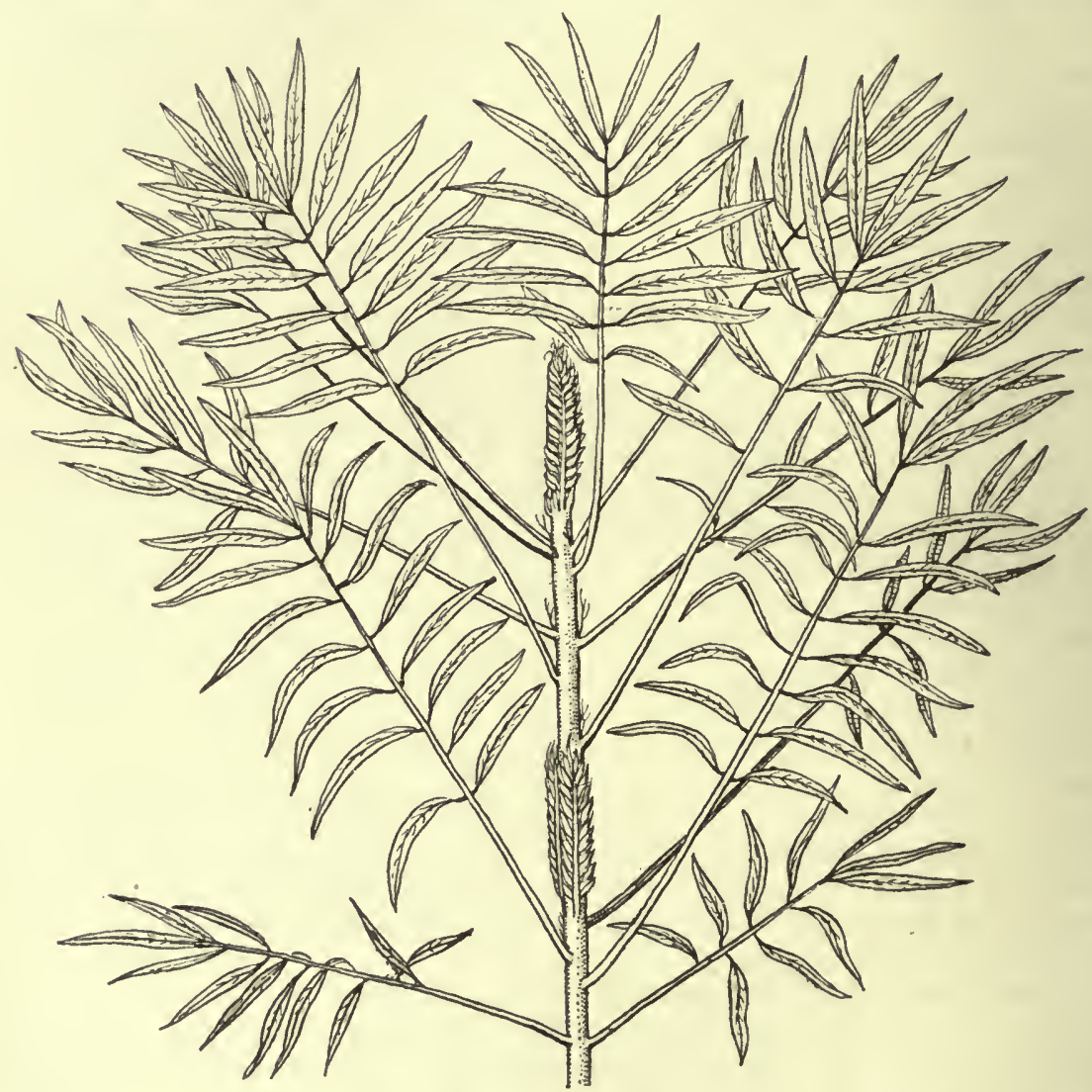

Fig. 323. Thalysia princeps. Ende eines Sprosses ${ }^{*}$ verkleinert. Die Knospen geschützt durch anfrecht stehende Niederblätter, welche ohne weiteres als Hemmungsbildungen von Laubblättern zu erkennen sind.

einem viel späteren Stadium vertrocknet; bei Thalysia princeps (Fig. 323) z. B. sind die Knospen geschützt durch aufrecht stehende, vertrocknete Laubblätter, an denen Blattfiedern usw. deutlich ausgebildet sind. Sie sind also deutlich als aus Laubblattanlagen entstanden erkennbar, die erst verhältnismäßig spät sich abweichend ausbilden; d. h. stehen blieben und vertrockneten. Vielfach freilich erfolgt die Umbildung auch schon früher, und ist dann natürlich nicht mehr direkt nachweisbar, sondern nur aus vergleichenden Gründen erschlossen.

Wenn nun die Differenzierungstheorie sagt: Die Anlagen eines 
Schuppenblattes und eines Laubblattes von Acer sind eben beide „Blattanlagen", die sich bald so, bald so ausbilden können, so iibersieht sie ganz, daß der Begriff „Blatt" lediglich eine Abstraktion, d. h. also nicht etwas Wahrgenommenes, sondern ein Wort, eine künstlich geschaffene Kategorie ist, die keine tatsächliche Existenz hat. Was wir durch Ans ch a u u ng wahrnehmen, sind Laubblätter, Schuppenblätter, Rankenblätter, Sporophylle usw. Das, was diese Organe gemeinsam haben, was uns gestattet, sie unter einen Allgemeinbegriff $\mathrm{zu}$ fassen, muß etwas anderes sein als das, daß sie alle aus "Blattanlagen" hervorgehen. Denn wenn es keine Blätter gibt, kann es auch keine Blattanlagen geben; es müssen entweder die Anlagen von Laubblättern, Schuppenblättern usw. von vornherein verschieden sein, oder sie sind eine Zeitlang gleich und werden dann verschieden, $d$. $h$. es muß eine wirkliche Umbildung, eine Änderung des Entwicklungsganges einer dieser Anlagen eintreten, aus der sich dann die anderen entwickeln können.

Daß nun schon die ersten Anlagen der Organe an den Vegetationspunkten nicht indifferenter Natur sind, $d . h$. nur aus embryonalem Gewebe bestehen, das in beliebiger Richtung sich entwickeln kann, das geht schon daraus hervor, daß z. B. die Anlagen von Blättern und von Seitensprossen innerlich voneinander verschieden sind schon zu einem Zeitpunkt, wo sie als ungegliederte Höcker über die Oberfläche des Vegetationspunktes hervortreten. Kein Fall ist bekannt, in welchem ein Höcker, der seiner Stellung nach eine Blattanlage liefern sollte, sich zu einem Sprosse entwickelt hätte und umgekehrt. Und doch sind Blatt und Sproß, wie das p. 118 erörterte merkwiirdige Beispiel von Utricularia zeigt, keine Organkategorien, die immer scharf voneinander getrennt sind. Man muß deshalb zugeben, daß Sproß- und Blattanlagen gewöhnlich von vornherein verschieden sind, und schon ein einfacher Analogieschluß führt uns dahin, daß wir auch für die .Blattanlagen" annehmen, daß sie von rornherein eine bestimmte, nicht eine indifferente stoffliche Beschaffenheit haben, die ihre weitere Entwicklung bedingt. Diese Beschaffenheit wird für alle „Blattanlagen" eine Zeitlang dieselbe sein (vgl. das oben angeführte Beispiel).

Die direkte Beobachtung zeigt nun weiter, daß in der Tat vielfach eine $\mathrm{Abänderung} \mathrm{des} \mathrm{Entwicklungsganges} \mathrm{rorkommt,} \mathrm{daß} \mathrm{eine} \mathrm{Organ-}$ anlage, an der man die Anlage der einzelnen Teile eines Laubblattes schon unterscheiden kann, nicht $\mathrm{zu}$ einem Laubblatt, sondern zu etwas anderem wird. Diese Entwicklungsänderung steht immer im Zusammenhang mit einer Funktionsänderung. Wenn eine Laubblattanlage zu einem Schuppenblatte wird, so hat sie allerdings nicht vorher als Laubblatt funktioniert, aber sie hat die Teile angelegt, die $\mathrm{zu}$ dieser Funktion geeignet und bei den Vorfahren auch wahrscheinlich bestimmt waren. Und viel deutlicher als dieser Fall zeigen andere, um was es sich eigentlich handelt, solche nämlich, wo wirklich ein und dasselbe Organ diesen Funktionswechsel in zeitlicher Aufeinanderfolge zeigt.

Einige Beispiele mögen dies erläutern.

\section{§ 2. Umbildungen von Blattorganen.}

Die Griffel in den Blüten von Pulsatilla und Dryas funktionieren während der Blütezeit nur als Griffel. Nach der Befruchtung aber verlängern sie sich und bilden mit ihren abstehenden Haaren Flugapparate fïr die Früchte. 
Auch bei manchen Laubblättern läßt sich eine mit Funktionsänderung verbundene Umbildung direkt beobachten.

Die basalen Laubblätter von Lilium candidum (und ebenso die einiger Arten von Dielytra) fungieren zunächst als gewöhnliche Laubblätter; später schwillt ihr unterer Teil $\mathrm{zu}$ einem schuppenförmigen Reservestoffbehälter an, während der obere Teil zugrunde geht, das Blatt hat sich umgebildet: es war erst Assimilationsorgan, und wurde dann in seinem unteren Teile Speicherorgan.

Ebenso ist es bei einer Kletterpflanze, Quisqualis indica, Fig. 324. Die Blatteile gewöhnlicher Laubblätter (die als solche funktionieren) ändern ihre Form und bilden sich zu harten, holzigen Hacken um, die der Pflanze als Kletterorgane dienen, während die Blattspreite abgeworfen wird.

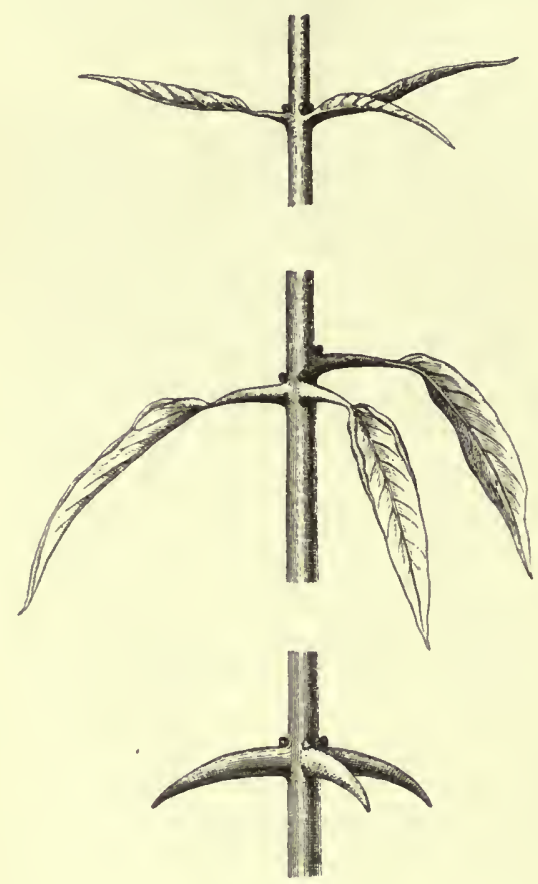

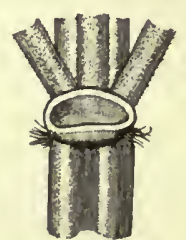

A

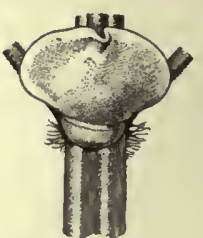

B.

Fig. 325. Ocimum carnosum. $A$ Schüsselförmige „Drüse“ unter einem Blütendichasium, $B$ früherer $\mathrm{Zn}$ stand.

Fig. 324. Quisqualis indica. Entstehung der Kletterhaken aus Blattstielen (die Blätter ausnahmsweise in 3 zähligen statt 2 zähligen Wirteln). Schon wenn die Blattspreite noch vorhanden ist, findet im Blattstiel Holzbildung statt.

Fig. 324.

Einigermaßen ähnlich verhalten sich die Deckblätter in den Bliitenständen der Labiate Ocimum carnosum. Unter den entfalteten Blüten findet man statt ihrer ein schïsselförmiges, Sekrettropfen absonderndes Organ, welches äußerlich manchen extrafloralen Nektarien gleicht (Fig. $325 \mathrm{~A})^{1}$ ). Betrachtet man aber jüngere Teile des Bliitenstandes, so sieht man, daß das drüsenförmige Organ nur den unteren Teil eines Deckblattes darstellt, dessen oberer schuppenförmiger Teil abgefallen ist (Fig. 325 B).

Bei einigen Arten von Astragalus und Caragana werden die Spindeln der gefiederten Blätter, nachdem die Fiederblättchen abgefallen sind, zu Dornen. Hier und in den oben beschriebenen Fällen wird doch niemand leugnen, daß eine wirkliche, reale Umbildung stattgefunden hat; ein

1) Es gelang nicht eine Zuckerreaktion nachzuweisen. 
Organ, das eine bestimmte Funktion ausgeübt hat, erhält eine andere Form und übernimmt eine andere Funktion.

Nehmen wir nun z. B. an, die Blattfiedern von Astragalus fielen ab, ehe sie sich entfalten, ehe sie also als Laubblatteile funktionieren können, während die Spindel sich zum Dorn entwickelt, wäre das nicht auch ein Fall von wirklicher Umbildung? Gewiß, sie hat sich nur um einen Schritt früher vollzogen. Was wir den "fertigen" Zustand nennen, ist ja nur das Endstadium einer Reihe aufeinander folgender Entwicklungsstufen. Diese aber sind nicht unabhängig voneinander, sondern gesetzmäßig miteinander verkettet, eine folgt aus der anderen. Wenn wir eine „Blatt"anlage auf irgendeinem Stadium als „indifferent" bezeichnen, so heißt das im Grunde nichts anderes, als die kausale Verknüpfung der Entwicklungsvorgänge leugnen. Ein Laubblatt wird zum Laubblatt nicht erst im letzten Stadium seiner Entwicklung, die Beschaffenheit der Anlagen - mögen wir diese nun im Vorhandensein bestimmter Stoffe oder einer bestimmten Struktur suchen - bedingt die Entwicklung. Diese besteht aus einer Aufeinanderfolge von Vorgängen, von denen immer der folgende von dem vorhergehenden abhängt. Innere oder äußere Einflüsse aber können diese Entwicklung in andere Bahnen lenken. Dann tritt eine Umbildung ein; je früher dies geschieht, um so weniger ist die Umbildung entwicklungsgeschichtlich nachweisbar, und um so verschiedener werden im allgemeinen die Organe auch im fertigen Zustand sein; aber gerade bei der Blattmetamorphose gibt es, wie früher gezeigt wurde, alle Abstufungen.

Dem entspricht auch, daß bei Umbildungen vielfach Mittelbildungen zwischen zwei Organen auftreten. Dies ist sehr hüufig bei „abnormen" Umbildungen, aber auch bei normalen durchaus nicht selten. So z. B. bei den Knospenschuppen, aber auch in zahlreichen anderen Fällen, ron denen ich nur wenige, leicht zu beobachtende hier nennen will.

Die Infloreszenzen von Nidularium splendens, einer Bromeliacee, sind umgeben von einer Anzahl prachtvoll rot gefärbter, als "Schauapparat" dienender "Hochblätter", die unter sich Verschiedenheiten aufweisen. Die untersten stimmen mit den gewöhnlichen Laubblättern iiberein, nur hat sich ihr Basalteil rot gefärbt. Bei den folgenden Blättern nimmt der rot gefärbte Teil immer mehr zu, bis bei den oberen das g an ze Blatt, von der Basis bis zur Spitze, rot gefärbt erscheint. Mit anderen Worten, die hier als Rotfärbung auftretende Umbildung tritt bald früher, bald später in der Entwicklung der Laubblattanlage ein. Der basale Teil ist nämlich der, welcher am spätesten bei der Blattentwicklung fertig wird; daraus ergibt sich, daß, wenn die Umbildung erst verhältnismäßig spät eintritt, n u r der basale Teil betroffen wird, die weiteren Stufen ergeben sich dann von selbst ${ }^{1}$ ). Bei anderen Bromeliaceen, wie z. B. Bilbergia, ist dagegen der Übergang von Laubblättern zu Hochblättern ein ganz unvermittelter, der Vorgang selbst bleibt aber offenbar derselbe.

Ebenso ist es z. B. bei vielen Rankenpflanzen. Bei manchen rankenden Fumariaceen, wie Corydalis claviculata, haben wir bei den aufeinander folgenden Blättern der Keimpflanze alle Übergänge von gewöhnlichen, nicht rankenden Laubblättern bis zu den mit Ranken ausgerüsteten. Wir sehen, wie die Stiele der oberen Teilblättchen sich allmählich verlängern, während die Spreite eine Verringerung erfährt, bis typische, fadenförmige Ranken entstanden sind. Bei einer anderen (nicht derselben Familie angehörigen) Rankenpflanze, der Cobaea scandens, ist dagegen der Übergang von nicht

1) Ein ganz analoges Beispiel bieten die Hochblätter der in botanischen Gärten viel kultivierten Dikotyle Eranthemum nervosum. 
rankenden zu rankenden Blättern meist ein ganz plötzlicher. Aber die Entwicklungsgeschichte der Ranken dieser Pflanze zeigte ${ }^{1}$ ), daß sie ganz auf dieselbe Weise entstehen, die wir bei Corydalis claviculata schon aus der einfachen Beobachtung der Keimpflanzen erschließen können; nämlich die Rankenfäden selbst sind stark verlängerte, mit Reizbarkeit ausgerïstete Blattstiele, und die Spreiten der Teilblättchen sind als kleine Haken an den Rankenenden noch nachweisbar.

Ähnlich verhält sich eine merkwürdige, neuseeländische Clematisart, Clematis afoliata. Wir treffen hier an den älteren Sprossen keine Laubblätter mehr an, sondern nur dünne, fadenförmige Ranken (Fig. 326 II).

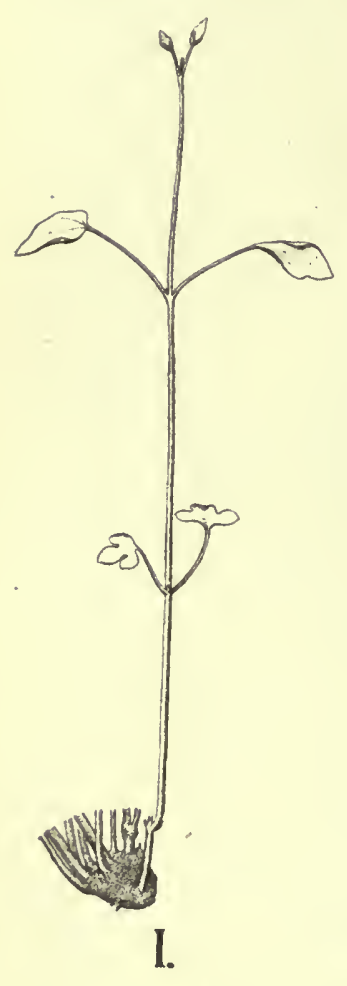

Fig. 326.

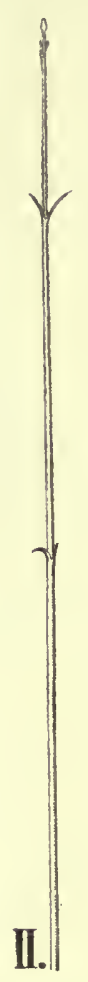

II.)

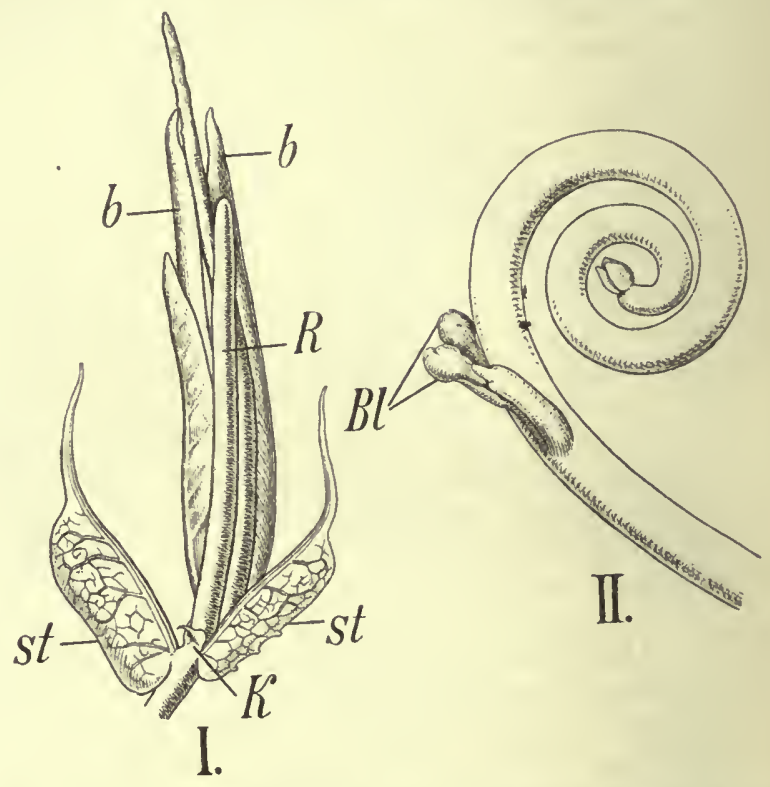

Fig. 327. I. Passiflora Raddiana. Blattlose Ranke $R$ in der Achsel eines Blattes (Hauptsprols weggeschnitten), $s t$ Stipulae, $b$ Blattspreite. II. Adenia palmata. Oberer Teil einer Ranke mit Blütenanlagen, welche verkümmern und Blattprimordien).

Fig. 326. Clematis afoliata (verkl.). I. Rückschlagssproß mit Blättern. II. Sproß mit zu Ranken umgebildeten Blättern.

Verfolgen wir aber die Keimung oder die Blattgestaltung an Rückschlagssprossen, wie in Fig. 326 I einer abgebildet ist, so treffen wir Blätter mit. zunächst dreiteiliger später einfacher Blattspreite an. Nach oben hin wird aber die Blattspreite immer mehr reduziert, es bleibt im wesentlichen nur der als Ranke funktionierende Blattstiel übrig.

Nicht bei allen Ranken findet die Umbildung der Laubblattanlage in der eben beschriebenen Weise statt. Es kann auch die ganze Blattanlage zur Bildung der fadenförmigen Ranke verwendet werden. Und wenn wir z. B. die Entwicklungsgeschichte der ersten Ranken von Benincasa cerifera, einer Cucurbitacee, untersuchen, so sehen wir, daß an ihnen noch deutlich eine Blattspreite angelegt wird, daß dann aber das ganze Blatt, statt in die Fläche zu wachsen, sich zu einer langen, fadenförmigen Ranke streckt.

1) Gokber, Vergl. Entwicklungsgesch. p. 431. Vgl. auch A. MaNN: „Was bedeutet Metamorphose in der Botanik ?" Dissertation. München 1894. 


\section{§ 3. Umbildungen von Sprossen und Wurzeln.}

Lehrreich ist auch das Verhalten mancher Sproßranken, weil es zeigt, daß die einzelnen Gattungen einer Familie (teilweise auch die Arten einer Gattung) sich in der Art der Umbildung verschieden verhalten können.

Die Ranken der Passifloreeen sind aus Blütenständen hervorgegangen. Untersucht man die Ranken ron Passiflora Raddiana (Fig. 327 I), so findet man an ihnen keine Spur ron Blüten mehr, auch nicht von Blattgebilden, nur an der Spitze der in Fig. $327 I$ abgebildeten Ranke $R$ befand sich eine kleine Einsenkung, an der eine kaum sichtbare Blattanlage entsteht. Dagegen fand ich an den Ranken nicht blühender Sprosse von Adenia palmata (in Ceylon) Schuppenblätter mit verkümmerten Blütenknospen (Bl.Fig. 327 II). Auch an der Rankenspitze sind deutlich Blattanlagen sichtbar. Die Umbildung tritt also bei Passiflora auf einem viel früheren Stadium ein als bei Adenia.

Ähnliches zeigen die Ampelideen. An jungen, nicht blühbaren Pflanzen ron Vitis ist keine Spur von Blütenbildung an den Ranken (welche aus einer Hauptachse und einem diese meist zur Seite drängenden Seitenast bestehen). Bei blühenden Sprossen aber lassen sich alle Ü̉bergänge beobachten. So besonders deutlich bei Vitis Labrusca ${ }^{1}$ ), wo häufig an $4-5$ übereinanderstehenden Knoten Blütenstände auftreten. Von diesen sind meist der unterste oder die beiden untersten $\mathrm{nur}$ Blütenstände. Weiter oben findet sich ein Bliutenstand, dessen Seitenast nur halb so viel Bluiten trägt als der Hauptast. Er ist gestreckt und für Reibungsreize empfindlicher. Noch weiter oben verliert er öfters ganz seine Bliiten und ist nur Ranke, und schließlich folgt ihm darin (mit den erwähnten Zwischenstufen) auch die Hauptachse der Ranke, womit die Gestalt der "typischen" Vitisranke erreicht ist.

In diesen Fällen liegt also eine entwicklungsgeschichtlich deutlich verfolgbare, bei rerschiedenen Pflanzen auf rerschiedenen Entwicklungsstadien einsetzende Umbildung vor.

Dasselbe gilt für manche $\mathrm{W}$ urzeln, welche, wie oben schon bemerkt, ein besonders klares Beispiel für den Vorgang einer wirklichen Umbildung darbieten.

Die Wurzeln sind nämlich (und zwar eben deshalb, weil bei ihnen eine Umbildung mit Funktionswechsel verhältnismäßig selten eintritt) leichter in ihrer Eigenart erkenn- und umgrenzbar, sowohl durch anatomischen Bau wie durch andere Eigenschaften.

Ein besonders einfaches Beispiel bieten die Haftwurzeln von Hedera Helix ${ }^{2}$ ) deshalb, weil sie einfache Hemmungsbildungen der Erdwurzeln darstellen. Wenn Hedera auf feuchtem Boden wächst, bildet sie nur reichlich verzweigte, nicht unbeträchtliche Größe erreichende Erdwurzeln. Wenn sie dagegen an einer Mauer oder einem Baumstamm emporklettert ${ }^{3}$ ), so bleiben die Wurzeln kurz, unverzweigt, dem Substrat fest angeschmiegt. Thre anatomische Ausbildung wird gleichfalls (den Erdwurzeln gegenüber) verfrüht fertig. Man kann aber auch eine Wurzelanlage, die normal zur Haftwurzel werden würde, sich wie eine Erdwurzel entwickeln lassen, wenn man ihr die nötige Feuchtigkeit darbietet (Fig. 328). Das muß aber selbstrer-

1) M. Brandt, Unters. über den Sproßaufbau der Vitaceen. Diss. Berlin 1911.

2) Vgl. W. Bruns, Beitr. zur exp. Morphologie, zur Biologie und Anatomie der Luftwurzeln. Flora 101 (1910), p. $98 \mathrm{ff}$.

$\left.{ }^{3}\right)$ Frei schwebende Triebe zeigen oft gar keine Wurzeln, weil auch zur Entwicklung der Haftwurzeln ein gewisses Maß von Feuchtigkeit notwendig ist, das sich an einer Mauer oder einem Baumstamm natürlich leichter findet. 
ständlich geschehen auf einem Entwicklungsstadium, welchem die Weiterentwicklung noch möglich ist (bis etwa $1 \mathrm{~cm}$ Länge). Ob auch die Enden der Erdwurzeln noch zu Haftwurzeln umgebildet werden können, ist nicht untersucht; möglicherweise ist die Empfindlichkeit gegen Austrocknung bei den in feuchtem Substrat gewachsenen Wurzeln eine viel größere als bei den in trockener Luft entwickelten und deshalb die Umbildung der Erd-

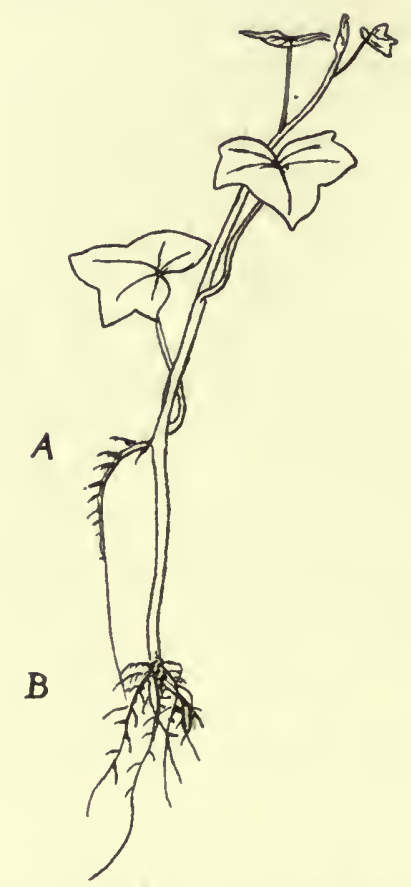

Fig. 328. Hedera Helix (nach Brunx). Steckling in Wasser kultiviert. Bei $A$ eine Wurzel, welche in mäßig feuchter Luft zu einer kurzen Haftwurzel geworden wäre, jetzt aber zu einer verzweigten "Erdwurzel" ansgewachsen ist. Bei $B$ an der Schnittfläche entstandene Wurzeln. Verkleinert.

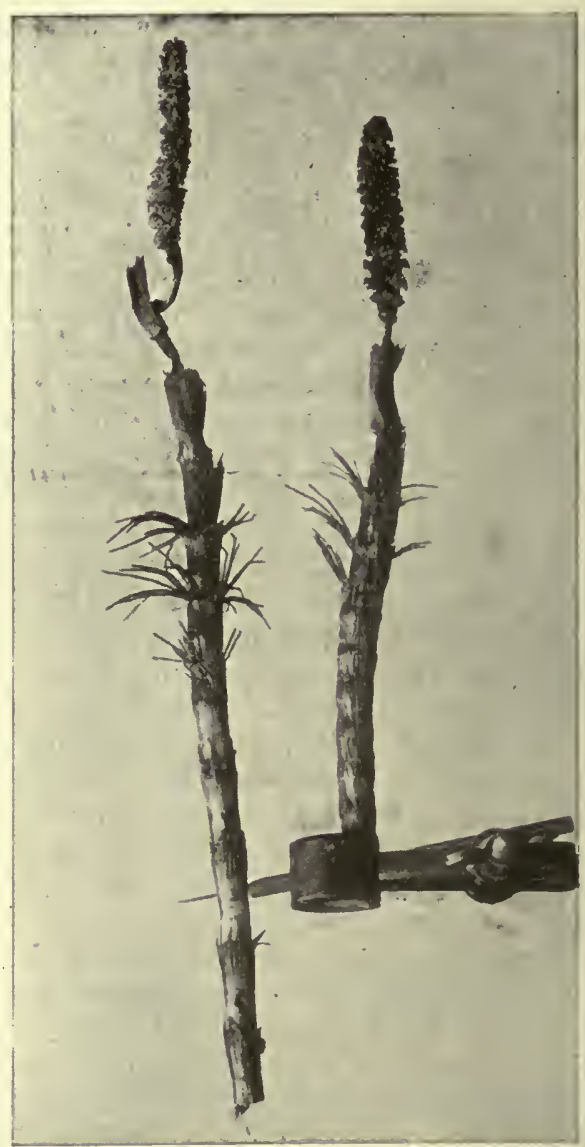

Fig. 329.

Fig. 329. (Nach LuDwigs.) Die sonst unverzweigten und chlorophyllosen fertilen Sprosse von Equisetum Telmateja haben sich (veranlaßt durch Wasserzufuhr) vegetativ verzweigt und sind ergrünt.

wurzeln zu Haftwurzeln schwieriger oder unmöglich. Wenn wir die Haftwurzeln von Hedera als umgebildete Erdwurzeln bezeichnen, so geschieht das, weil die letzteren zweifellos die ontogenetisch und phylogenetisch zuerst vorhandenen sind. Ihre Fähigkeit, unter bestimmten Umständen zu Kletterwurzeln zu werden, war die Voraussetzung für die Möglichkeit, daß der Efeu ein Wurzelkletterer werden konnte ${ }^{1}$ ). Betreffs tiefer greifender

1) Eine ähnliche einfache Hemmungsumbildung liegt bei den an den oberirdischen Sprossen mancher Dioscoreaarten entstehenden "Luftknöllchen" vor, die äußerlich sehr verschieden sind von den mächtigen Erdknollen (vgl. Goeber, Flora 95, p. 189). 
Wurzelumbildungen muß auf den speziellen Teil verwiesen werden. Wo solche vorhanden sind, sind auch Mittelbildungen zu erwarten, die bei einer einfachen Hemmungsbildung fehlen.

Schon bei den Hederahaftwurzeln ließ sich für die Umbildung ein experimenteller Beleg erbringen.

Solche liegen auch sonst vor.

\section{§ 4. Experimentell herrorgerufene Umbildungen.}

Die Experimente sind teils ron der Natur selbst, teils vom Menschen ausgeführt worden, sie fallen teilweise unter die später zu erörternden abnormen Umbildungen.

Wenn die Blütenknospen von Knautia arvensis von einem Pilze Peronospora violacea - befallen werden, so entwickeln sich häufig aus den Staubblattanlagen statt der Staubblätter Blumenblätter. Die Staubblattanlagen waren aber keine ,indifferenten" Anlagen. Die Reihe der Vorgänge, durch welche sie zu Staubblättern werden sollten, hatte schon begonnen, aber der Pilz lenkte die Entwicklung in andere Richtungen.

Es handelt sich dabei hauptsächlich um das Vegetativwerden eines Organes, das sonst Fortpflanzungsorgane (Mikrosporangien) trägt.

Ähnliche Erscheinungen lassen sich auch küinstlich hervorrufen.

So sind die fertilen Sprosse einiger Equisetumarten von den sterilen auffallend unterschieden durch ihre Farbe und den Mangel an vegetativen Zweigen. Indes lassen sie sich leicht zur vegetativen Entwicklung bringen ${ }^{1}$ ); es genügt, sie in Wasser zu legen (Fig. 329), es tritt dann (bei den uiberhaupt weiterlebenden Sprossen) Ergrünung und Verzweigung ein. Derselbe Vorgang findet sich nicht ganz selten auch in der freien Natur (ohne Abtrennung der fertilen Sprosse vom Rhizom). Es wird auf seine Bedeutung für die Beziehung zwischen "metabolen" und „ametabolen" Equiseten im speziellen Teile hinzuweisen sein.

Dasselbe gilt auch für die "Sporophylle“ der Farne.

Die Sporangien der Farne entstehen an Blïttern, die man als Sporophylle bezeichnet. Diese stimmen mit den Laubblättern entweder ganz überein, wie z. B. bei Aspidium filix mas, oder die Sporangienbildung bedingt mehr oder minder tief greifende Änderungen in Gestalt, Richtung und Bau der Sporophylle. Dieser Satz wird erläutert durch Fälle, bei denen die Sporophylle, wenn e in ig e Sporangien vorhanden sind, mit den Laubblättern übereinstimmen, während, wenn viele Sporangien da sind, die Sporophylle in ihrer Gestaltung von der der Laubblätter abweichen (Fig. 330) (Davallia heterophylla). Zu den Farnen, bei denen diese Verschiedenheiten am größten sind, gehört Onoclea Struthiopteris, deren Sporophylle in regelmäßigem Wechsel mit den Laubblättern gebildet werden. Sie stimmen aber mit den Laubblattanlagen ziemlich lange überein; erst mit der Bildung der Sporangien tritt eine Abänderung des Entwicklungsganges ein. Es läßt sich diese aber verhindern, wenn man die Laubblätter alle entfernt ${ }^{2}$ ). Dadurch werden die Sporophyllanlagen, die nichts anderes sind als Laubblattanlagen, genötigt, sich zu Laubblättern auszubilden; die Sporangienbildung wird unterdrückt, entweder ganz oder teilweise.

1) Goeser, Über die Fruchtsprosse der Equiseten, Ber. d. deutschen bot. Gesellsch. IV, 1886, p. 184. Lodwigs, Unters, zur Biologie der Equiseten, Flora 103 (1911).

2) GоввеL, Über künstliche Vergriinung von Farnsporophyllen, Ber. der deutschen botan. Gesellsch. V (1887), p. 69. 
Einen ähnlichen Fall zeigt Fig. 331 von einem Lycopodium. Die Sporophylle unterscheiden sich ron den Laubblättern durch ihre Gestalt und ihre Farbe. Sie haben eine breitere Basis und nehmen statt der grünen Färbung eine gelbliche an; außerdem finden sie sich an Sprossen begrenzten Wachstums. In dem in Fig. 331 abgebildeten SproB waren die Bedingungen für die Sporangienbildung ungünstige (die Pflanzen waren unter schlechten Ernährungsbedingungen kultiviert), es konnten sich nur sehr wenige ausbilden. Diese aber standen an der Basis gew öhnlicher Laubblätter, "und solche bildeten sich auch oberhalb der sporangientragenden Blätter (während sonst hier keine auftreten). Solche Erfahrungen sprechen mit dafür, daß es Ernährungsverhältnisse sind, welche die Umbildung bedingen. Die mit der Sporangienbildung verknüpften stofflichen Umänderungen im Sprosse waren hier also nicht stark genug,

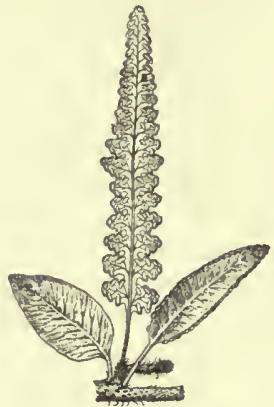

Fig. 330. Davallia heterophylla (verkl.). Links steriles, rechts fertiles einfaches, in der Mitte ein fertiles verzweigtes Blatt.

Fig. 331. Lycopodium inundatum. $(5 \times)$ Ein schlecht ernährter orthotroper Spro $B$ hatte, statt sein Ende ganz zur Blüte auszubilden, nur wenige Sporangien, und zwar in der Achsel gewöhnlicher Laubblätter hervorgebracht. Am Ende ist er ganz vegetativ.

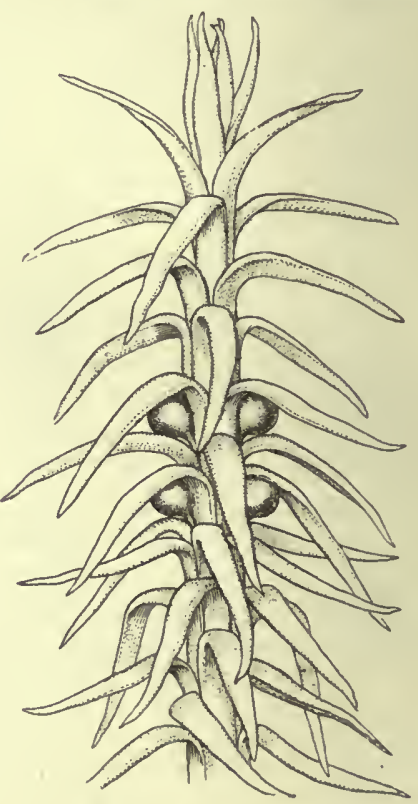

Fig. 331.

um eine Gestaltveränderung der Laubblattanlagen herbeizuführen - sie blieben Laubblätter, ebenso wie z. B. die Laubblattanlagen einer Knospe von Picea excelsa normale Laubblätter bleiben - , wenn sie nicht von der Fichtenblattlaus zu der eigentümlichen Gallenumbildung veranlaßt werden, die man so oft an Fichtenzweigen antrifft. Auch mit Rücksicht auf die Vererbung, d. h. die Tatsache, daß die Nachkommen, abgesehen von kleinen Abweichungen, die Entwicklung ihrer Eltern wiederholen, ist es von Wichtigkeit, daß nur bestimmte Organanlagen vererbt zu werden brauchen, aus deren Umbildung dann andere hervorgehen. Nur kommen die Ursachen der Umbildung nicht, wie in dem oben genannten Beispiele ron Knautia, von außen, sondern von innen, von der Tätigkeit der Pflanze selbst.

Unser Metamorphosenbegriff ist also zunächst ein ontogenetischer und darum ein experimentell faßbarer und beweisbarer. Phylogenetische Betrachtungen können hinzutreten, aber daß es nicht berechtigt ist, le dig lich in phylogenetischem Sinne ron einer Metamorphose zu sprechen, 
zeigt schon die einfache Tatsache, daß die Metamorphosenlehre älter ist als die Deszendenztheorie; sie würde auch bestehen bleiben, wenn die letztere in der Fassung, welche sie heute hat, aufgegeben würde. Außerdem ist $\mathrm{zu}$ beachten, daß ontogenetische und phylogenetische Umbildung sich nicht zu decken brauchen. Für unsere heute lebenden Farne zeigt die Beobachtung, daß die Sporophylle umgebildete Laubblätter sind. Das schließt die von manchen Botanikern vertretene Auffassung, daß phylogenetisch die Laubblätter aus Sporophyllen hervorgegangen seien, nicht aus. Sehen wir doch z. B., daß die Ranken der Ampelideen zweifellos als umgebildete, steril gewordene Blütenstände zu betrachten sind. Bei der Einzelentwicklung treten sie aber lange vor den Blütenständen auf, und es würde, wenn nur die Ontogenie berücksichtigt würde, ganz zutreffend sein, die Blütenstände als umgebildete Ranken zu bezeichnen. Zunächst aber werden wir uns an die Ontogenie halten müssen, die den großen Vorteil hat, daß sie auch experimentell beeinflußbar ist.

\section{§ 5. Umbildung oder Ersatz?}

Wir beschränken dabei den Begriff Umbildung auf die Fälle, wo der Funktionswechsel ein deutlich hervortretender ist. Auch die Laubblätter ein und derselben Pflanze sind voneinander an Gestalt vielfach verschieden. Wo aber damit nicht eine andere Funktion als die der Assimilation und Transpiration in den Vordergrund tritt, werden wir von einer Umbildung besser nicht reden, sondern nur von einer verschiedenen Ausbildung. Natürlich lassen sich - wie dies ja bei allen künstlichen $\mathrm{Ab}$ grenzungen, die sich auf Organismen beziehen, der Fall ist - scharfe Grenzen zwischen diesen Begriffen nicht ziehen, zumal die kleinen Abweichungen in der Funktion mit Gestaltrerschiedenheiten meist Hand in Hand gehen. In dem Wurzelsystem einer dikotylen Pflanze z. B. sind Hauptwurzel und Seitenwurzeln Organe, die im wesentlichen dieselbe Funktion und Gestaltung haben. Aber doch sind zwischen beiden Verschiedenheiten im physiologischen Verhalten und der Ausbildung vorhanden, die beruhen, einmal auf Korrelationsverhältnissen und dann auf der verschiedenen Reaktion äußeren Einflüssen gegenüber. Daß aber eine Nebenwurzel ihre Verschiedenheit gegenuiber der Hauptwurzel eben nur ihrer Lage im Wurzelsystem verdankt, sehen wir daran, daß sie unter bestimmten Umständen zur Ausbildung als Hauptwurzel veranlaßt werden kann. Die Verschiedenheiten zwischen Haupt- und Nebenwurzel sind aber zu wenig tiefgreifend, um von einer "Metamorphose“ zu reden.

Wie alle Begriffe ist also der der "Metamorphose" ein solcher, der keine absolute Geltung hat. Denn wenn eine Umbildung sehr früh eintritt, so ist sie, wie oben ausgeführt entwicklungsgeschichtlich nicht mehr nachweisbar. Man ist dann auf den Vergleich angewiesen, der naturgemäß nicht immer sichere Schlußfolgerungen ermöglicht.

Nicht selten ist es eine Frage der Zweckmäßigkeit, ob man von einer Umbildung reden soll oder von einem „Ersatz“. Bei einer Anzahl von Farnen z. B. geht aus der Blattspitze ein Sproß hervor (Fig. 332). Man könnte sagen, das Blatt habe sich in einen Sproß umgebildet, denn es geht das embryonale Gewebe der Blattspitze über in eine Sproßspitze. Bedenkt man aber, wie häufig bei anderen Farnen irgendwo am Blatte, solang dies noch embryonal ist, Sprosse auftreten (Fig. 333), so wird man auch jene Spitzenknospen nur als einen extremen Fall blattbürtiger 
Knospenbildung betrachten, als ein Vorrücken der Sproßbildung auf die Blattspitze.

Aber die Abgrenzung der Begriffe wird stets eine subjektive bleiben, es wird kaum möglich sein, "Ersatz" und Umbildung scharf abzugrenzen. Das ginge höchstens dann, wenn die geschichtliche Entwicklung der betreffenden Pflanzen schon sicher bekannt wäre. Aber auch die phylogenetische Betrachtung kann sich meist nur auf den Vergleich verwandter

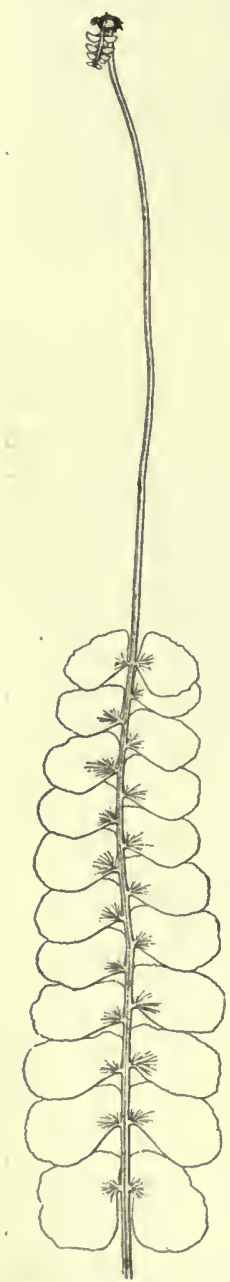

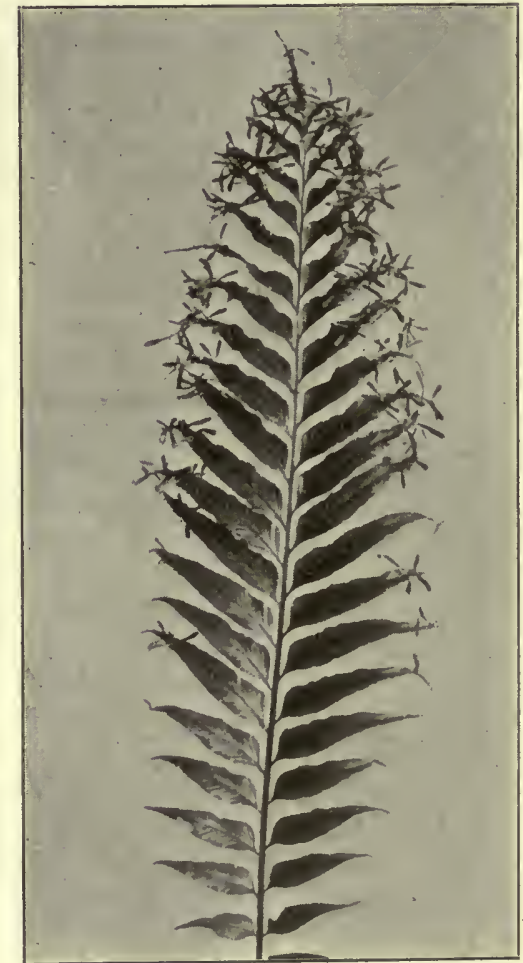

Fig. 333. Blatt von Asplenium lineare (verkl.). An den Fiederblättchen nahe der Spitze Adventivsprosse. Sie stehen auf der Oberseite und fallen leicht ab, stellen also Verbreitungsorgane dar.
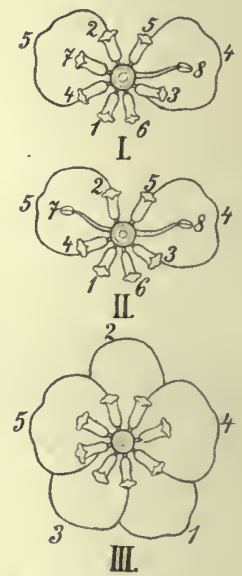

Fig. 334.

(Nach Bischoff.) Helleborus foetidus, Blüten. Die Blätter der Blütenhülle sind nur bei $I I I$ alle gezeichnet, hier

8 Honigblätter vorhanden, bei $I$ eins ( 8 ) durch ein Staubblatt ersetzt, bei $I I$ zwei

(7 und 8).

Fig. 332. Aneimia rotundifolia. Blatt (auf $1 / 4$ verkleinert) aus dessen Spitze eine junge Pflanze sich gebildet hat.

Formen stiutzen. Ein Beispiel: Wir haben allen Grund zu der Annahme, daß die "Honigblätter" der Ranunculaceen durch Umbildung von Staubblättern zustande gekommen ist, sehen wir doch z. B. bei Pulsatilla noch alle Zwischenformen zwischen Staubblättern und Honigblättern; auch stimmt die Anordnung der Honigblätter meist mit der der Staubblätter überein. Ontogenetisch ist die Umbildung aber nicht direkt zu erweisen (abgesehen von Pulsatilla). Vergleichende Gründe indes lassen die Annahme einer 
phylogenetischen Umbildung als berechtigt erscheinen. Nun finden sich bei Helleborus foetidus gelegentlich an Stelle der Honigblätter Staubblätter (Fig. 334). Aus diesem „Ersatz" allein könnten wir nicht auf eine Umbildung schließen, denn er kann in anderen Fällen auch ganz regellos stattfinden. Im Zusammenhang mit den anderen Gründen aber werden wir hier annehmen dürfen, daß die Umbildung einer oder zweier Staubblattanlagen zu Honigblättern unterblieben ist. Die alte Metamorphosenlehre dagegen drückte das Verhalten so aus, daß ein resp. zwei Blätter "des Blumenzyklus" schon zu der höheren Stufe der Staubgefäßbildung vorgeschritten sind ${ }^{1}$ ), d. h. sie faßten den Vorgang gerade umgekehrt auf. Und daß auch in unserer Zeit die Weiterentwicklung des Metamorphosenproblems nicht allzu bekannt geworden ist, zeigt ein im Jahre 1912 erschienenes Buch eines hervorragenden Pflanzenphysiologen ${ }^{2}$ ), welcher die Übergänge zwischen Laubblättern und Knospenschuppen erörtert, ohne auf das eigentliche Problem, um welches es sich dabei handelt, hinzuweisen.

B. Abnorme Umbildungen (MiBbildungen) und ihre Bedeutung für die Auffassung der normalen Organbildung.

\section{§ 6. Allgemeines über abnorme Umbildung.}

Der Metamorphosenbegriff ist ursprünglich entstanden durch die Betrachtung „abnormer" Umbildungen. Die gefüllten Blüten z. B. weisen vielfach alle Mittelstufen zwischen Staubblïttern und Blumenblättern auf und führten deshalb zur Erkenntnis der "Blatt"natur der Staubblätter. Zunächst ist $\mathrm{zu}$ bemerken, $\mathrm{da} B$ sich nicht fest bestimmen läßt, wo das Normale aufhört, das Abnorme anfängt. Denn das "Normale" selbst ist keine festbestimmte, sondern eine variable Größe. Nehmen wir ein bestimmtes Beispiel. Anemone Hepatica hat an ihren Blüten meist sechs Perigonblätter, aber die Zahl schwankt. Bei 75 aufs Geratewohl herausgegriffenen Bliiten fanden sich folgende Zahlen für die Perigonblätter: 35 hatten 6, $297,108,19$, und in vier der untersuchten Blüten waren Mittelbildungen zwischen Perigonblättern und Staubblättern vorhanden, welche darauf hindeuten, daß die Überzahl von Perigonblättern zustande kommt durch mehr oder minder frühzeitige Umwandlung ron Staubblattanlagen in Blumenblätter. $\mathrm{Da}$ die Zahl der Staubblätter hier aber eine sehr große ist, so ist die Funktion des Staubblattapparates noch nicht gestört. Von diesen Blüten sind die ganz gefüllten Formen, bei denen alle Staubblätter umgebildet sind, nur graduell verschieden. Dabei ist natiurlich fraglich, wie weit diese unter einer "Population" ermittelten Schwankungen bedingt sind durch das Vorhandensein von in den Zahlenverhältnissen der Blumenblätter sich verschieden verhaltender Formen, oder ob das Schwanken von äußeren Faktoren abhängig ist - ersteres ist das Wahrscheinlichere. Dabei ist zu berïcksichtigen, daß das Auftreten einer bestimmten Gestaltung oft nur unter bestimmten äußeren Bedingungen hervortritt. Es gibt also nahe verwandte Pflanzenformen, die auf äußere Einwirkungen verschieden reagieren, fehlen die letzteren (z. B. bestimmte Ernährungsbedingungen), so kann z. B. die Fähigkeit eine größere Anzahl von Blumenblätteru zu bilden, latent bleiben.

1) Bischoff, Lehrb. der Botanik I, 404.

$\left.{ }^{2}\right)$ Timiriazerf, The life of the plant, London 1912. 
Die abnormen Umbildungen sind nun vor allem in folgender Hinsicht ron Interesse:

1. Zeigen sie, daß die "normale" Gestaltung keineswegs die einzig mögliche ist, die Pflanze vielmehr Gestaltungsfähigkeiten besitzt, die gewöhnlich (normal) nicht zutage treten.

Dafür wurden im ersten Abschnitt einige Beispiele angeführt, auf die hier verwiesen werden kann.

2. Kann in den abnormen Umbildungen, die sonst nicht ohne weiteres kenntliche "morphologische Bedeutung" eines Organes hervortreten.

3. Das wird am klarsten der Fall sein, wenn eine abnorme Umbildung als Rückschlag auf die ursprüngliche Gestalt eines Organes betrachtet werden kann.

4. Können abnorme Umbildungen Schlüsse gestatten auf die Ursachen, welche der normalen Umbildung zugrunde liegen; sie sind Experimente, welche die Natur ausführt, und so das Vorbild für unsere eigenen Versuche, deren einige oben schon angeführt wurden.

Diese Gesichtspunkte sollen im folgenden kurz an der Hand einiger Beispiele erörtert werden.

\section{§ 7. Bedeutung der Mißbildungen für die Organographie.}

Wenn Mißbildungen ïberhaupt zu irgendwelchen morphologischen Schlüssen Verwendung finden sollen, so darf die abnorme Umbildung keine regellose sein. In der Tat sehen wir, daß niemals sich ein Blatt in einen Sproß oder eine Wurzel umwandelt (oder umgekehrt), obwohl bei der normalen Organbildung von Utricularia die Grenze zwischen Sproß und Blatt ganz verwischt wird. Diese Erscheinung ist deshalb von Wichtigkeit, weil sie uns zeigt, daß, sobald ein Organ einmal angelegt ist, seiner Entwicklung damit bestimmte Grenzen gezogen sind ${ }^{1}$ ). Der Höcker, der zu einem Seitensproß sich entwickelt, sieht äußerlich oft ganz so aus wie der, welcher eine Blattanlage darstellt; beide müssen aber innerlich verschieden sein, sonst wäre nicht verständlich, warum bei so gründlichen Störungen, wie sie bei manchen Blütenmißbildungen auftreten, nicht auch solche Umwandlungen vorkommen sollten.

Wenn wir die normale Entwicklungsgeschichte eines Pflanzenorganes kennen, so läßt sich vielfach schon aus dem fertigen Zustand erkennen, auf welchem Entwicklungsstadium die Ablenkung von der normalen Entwicklung auftrat. Überhaupt ist festzuhalten, daß eine Mißbildung nur auf Grund der Kenntnis der normalen Entwicklung verstanden werden kann. Bei den Sporophyllen in den Blüten, den Staubblättern und Fruchtblättern macht sich die Störung in einer Hemmung der Sporangien (der Pollensäcke und Samenanlagen) geltend, und vielfach kommen diese überhaupt nicht mehr zur Ausbildung. Derartige Fälle hat man häufig benutzt, um Aufschluß zu gewinnen über die „morphologische Natur" der Staubblätter, ein Bestreben, das um so verkehrter war, als diese Mißbildungen sich deutlich als krankhafte Störungen der normalen Entwicklung zu erkennen geben. Es findet nämlich dabei, je mehr die normale Entwicklung gestört ist, desto leichter ein Ersatz der Sporangien durch vegetative Organe statt. Eine Umwandlung der ersteren in letztere ist nicht vorhanden, und auch die Zwischenstufen zwischen dem normalen und dem abnormen Zustand beweisen eine solche Umwandlung nicht,

1) Vgl. p. 315 . 
sondern zeigen nur, daß die Störung in verschieden hohem Grade eintreten kann. Die morphologische Bedeutung der Staubblätter ergibt sich aus der Entwicklungsgeschichte und dem Vergleiche mit den Gefäßkryptogamen. Dieser zeigt, daß die Staubblätter Sporophylle sind, welche, ebenso wie die anderen Sporophylle, aus der Umbildung einer Laubblattanlage hervorgegangen sind ${ }^{\mathbf{1}}$ ).

Die vollständigst mißbildeten Staubblätter sind solche, bei denen die Pollensäcke (Mikrosporangien) gar nicht mehr zur Ausbildung gelangen, ähnlich wie dies auch bei vergrünten Sporophyllen von Farnen der Fall ist. Es erscheinen dann die Staubblätter entweder als Laubblätter oder als Blumenblätter, letzteres dann, wenn auf die Staubblattanlage vor Anlage der Pollensäcke die Faktoren einwirken, welche eine Laubblattanlage veranlassen, sich zum Blumenblatt auszubilden. In Mittelfällen erscheinen dann die Pollensäcke mehr oder minder vollständig ausgebildet, meist aber verzerrt.

Besonderes Gewicht hat man solchen Staubblattmißbildungen beigelègt, welche ein ,vierflügeliges" Blatt darstellen, d. h. ein solches, bei welchem längs des Mittelnervs je zwei Lamellen entspringen. Es unterliegt aber keiner Schwierigkeit, diese Erscheinung aus der normalen Entwicklungsgeschichte des Staubblattes zu erklären. Ein junges Staubblatt stellt vor dem Auftreten der Anlagen des sporenerzeugenden Gewebes einen vierkantigen Körper dar, in dessen vier Kanten sich dann die Anlage je eines Sporangiums (das Archespor) differenziert. Die vier Kanten wachsen nun in "vergrünten" Staubblättern zu kleinen Blättchen aus, eine Wachstumserscheinung, die dem gewöhnlichen Zustand gegeniiber eine durchaus abnorme ist, die sich aber in ähnlicher Weise gelegentlich auch bei vegetativen Blättern findet. Nichts wäre verfehlter, als jene Blättchen für Umwandlungsprodukte der Pollensäcke zu halten - diese haben sich entweder gar nicht ausgebildet, oder es findet sich ein sehr reduziertes pollenerzeugendes Gewebe. Was also hier zu einem Laubblatt oder Laubblatteil sich gestaltet, sind nicht die Pollensäcke, sondern Teile des Sporophylls. Daraus ergibt sich, daß wir es mit einer Rückschlagsbildung nicht zu tun haben können, ebensowenig als dann, wenn die Staubblattanlage zum einfachen Laub- oder Blumenblatt sich umbildet. Es hätte deshalb keinen Wert, die Hypothesen, die auf diese Abnormitäten gebaut wurden, anzuführen. Denn die Erfahrung zeigt, daß nicht diese Hypothesen, sondern die vergleichende Entwicklungsgeschichte uns über die Gestaltungsverhältnisse der Staubblätter Aufschluß gegeben haben. Dem unbefangenen Blicke kann nicht zweifelhaft sein, $\mathrm{daB}$ das Staubblatt einer Angiosperme homolog ist mit dem der Gymnospermen - die Mißbildungstheorien, die für die Angiospermen aufgestellt wurden, können aber, wie hier nicht weiter ausgeführt werden kann, auf die Gymnospermen keine Anwendung finden.

Hier sei mit Bezug auf die vergrünten Staubblätter nur noch darauf aufmerksam gemacht, daß selbstverständlich die Möglichkeit der Umwandlung der Staubblattanlage in eine einfache grüne oder blumenblattähnliche Blattspreite bei denjenigen Pflanzen länger vorhanden sein muß, bei welchen die Pollenmutterzellen sich erst auf einem relativ späten Entwicklungsstadium des Staubblattes ausbilden, als bei denjenigen, welche das Archespor schon relativ früh anlegen. Es kommt also bei der Umwandlung von Staubblattanlagen in Betracht erstens die Entwicklungsstufe,

1) Die folgenden Ausführungen entnehme ich der Hauptsache nach meiner "Vergl. Entwicklungsgeschichte", da ich sie auch jetzt noch für zutreffend halte. 
auf welcher die Staubblattanlage steht zur Zeit, wo sie den Antrieb zur Umwandlung - wenn dieser Ausdruck gestattet ist - erhält, und auf die Größe dieses Antriebs. Je nach dem Auftreten dieser Faktoren erhalten wir ein einfaches oder „vierflügeliges" Laub- oder Blumenblatt oder ein solches mit mehr oder weniger mißgebildeten, in ihrer Insertion verzerrten Pollensäcken.

In noch höherem Grade als die vergrünten Staubblätter haben die vergrünten Samenanlagen Anlaß zu morphologischen Hypothesen gegeben.

Ehe indes auf diese eingegangen wird, sei die abnorme Entwicklung der Sporangienanlagen von Athyrium filix femina f. clarisima besprochen ${ }^{1}$ ).

Ein junges Farnsporangium besteht aus einer fertilen (d. h. die Sporenmutterzellen durch wiederholte Teilung liefernden) Zelle, dem Archespor, und sterilen Zellen, welche teils das Archespor umbüllen, teils zur Bildung des Stieles Verwendung finden. Die abnormen Sporangien zeigen nun eine "Vergrünung", die sterilen Zellen werden zur Bildung eines Prothalliums verwendet, die fertile dagegen ( $A$ Fig. 335$)$ verkümmert.

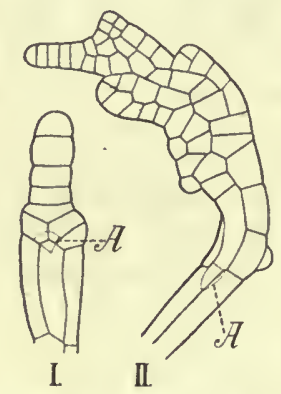

Fig. 335. Athyrium filix femina $f$. clarissima. Prothallienbildung aus Sporangien. $\boldsymbol{A}$ (punktiert) Archespor.

Daraus können keine anderen Schlüsse gezogen werden als der, daß die sterilen Zellen nicht fest „determiniert" sind. Prothallien können, wie das Experiment gezeigt hat, auch aus den Zellen ganz normaler Primärblätter von Farnen, wenn sie isoliert und unter günstige Wachstumsbedingungen gebracht werden, hervorgehen, in ,abnormen" Fällen auch aus den Zellen später auftretender Blätter. Mit anderen Worten, die Fähigkeit zur Prothallienbildung, die sonst aus Sporen erfolgt, ist latent auch in vegetativen Zellen vorhanden, nur das Archespor ist - soweit bis jetzt bekannt - davon ausgeschlosssen ${ }^{2}$ ).

Ähnlich sind die Erscheinungen bei den $a b-$ normen Umbildungen der Samenanlagen der höheren Pflanzen. Namentlich an kultivierten Pflanzen findet man nicht selten krankhaft veränderte Blüten, bei welchen ein Teil der Blattorgane der Blüte oder alle laubblattähnlich ausgebildet sind. So z. B. bei Aquilegia vulgaris, Reseda odorata, Alliaria officinalis u. a. Der Grund zu dieser "Vergrünung" ist meistens unbekannt, in einigen Fällen ist sie, wie Pexritsch experimentell nachgewiesen hat, durch Insekten veranlaßt, in anderen dürfen wir wohl annehmen, daß durch Ernährungsverhältnisse die sexuelle Potenz geschwächt, die vegetative gesteigert ist.

In diesen vergrünten Blïten sind nun namentlich auch die Fruchtknoten mehr oder weniger verändert, man findet sie entweder nur vergrößert, aufgeblasen oder an Stelle jedes Fruchtblattes ein Laubblatt, wie dies z. B. bei Trifolium repens und in anderen Fällen (z. B. bei gefüllten

1) Vgl. Bower, On Apospory and allied Phenomena. Trans. Linn. Soc. Ser. 2. Bot. Vol. II, 1887.

2) Indes ist $\mathrm{zu}$ erwähnen, $\mathrm{daß}$ der Unterschied zwischen vegetativen und sporenbildenden (bzw. zu Sporen werdenden) Zellen nicht immer ein fester ist. Rosenserg wies nach, daß bei einigen Hieraciumarten in bestimmten Samenanlagen das normale Archespor zugrunde geht und eine Makrospore (Embryosack) sich aus einer anderen Zelle entwickelt, bei H. flagellare z. B. aus einer Zelle des Integuments oder der Chalazaregion, bei H. aurantiacum aus einer Epidermiszelle des Nucellus. Rosensera, Cytological studies on the apogamy in Hieracium, Botanisk tidsskrift 29. Bind 1907. 
Kirschenblüten) nicht selten ist. An so vollständig "vergrünten" Fruchtblättern findet man meist gar keine Samenanlagen mehr, die Bildung derselben ist vollständig unterblieben. Bei Alliaria officinalis z. B. findet man auf der vollständigsten Vergrünungsstufe Kelchblätter, Staubblätter und Fruchtblätter vollständig in Laubblätter (mit Knospen und Sprossen in den Achseln) umgewandelt, an den Fruchtblättern keine Spur von Samenanlagen mehr. Es hat sich eben, schon ehe die letzteren angelegt waren, der Einfluß geltend gemacht, welcher die Blattanlagen der Blütenknospen zur Vergrünung veranlaßte. In anderen Fällen minder vollständiger Vergrünung aber findet 'man im Fruchtknoten Bildungen, die offenbar aus abnormer Entwicklung der Samenanlagen hervorgegangen sind. Und zwar treten eine ganze Anzahi verschiedener Mißbildungsformen der Samenanlagen auf. Die letzteren bestehen im normalen Zustand bekanntlich aus einem inneren Gewebekörper, dem Nucellus, welcher den wichtigsten Teil der Samenanlage, den Embryosack, enthält (und ron einer oder zwei Hüllen, den Integumenten, umgeben ist) und dem Stiele oder Funiculus, mittels dessen die Samenanlage der Plazenta aufsitzt.
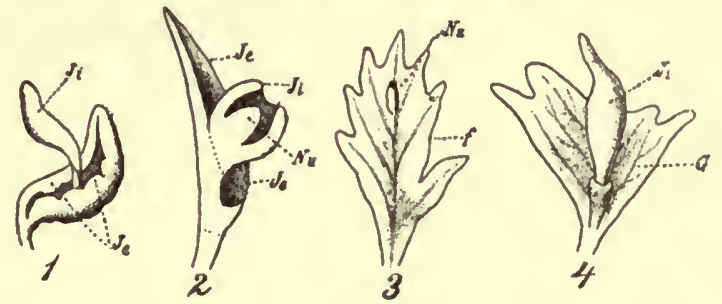

Fig. 336. Vergrünte Samenanlagen: $1-3$ von Hesperis matronalis nach CELAKovskY; 1 mit beiden Integumenten ( $J i$ inneres, $J e$ äußeres); 2 schematischer Längsschnitt eines ähnlichen Stadinms ( $N u$ Nucellus); 3 Samenanlage, die vor Anlage des äußeren Integuments vergrünt ist, $N u$ der verkümmerte Nucellus, $f$ „Ovularblättchen"; 4 vergrünte Samenanlage von Alliaria officinalis nach Velenovsky, äußeres und inneres Integument vorhanden; $G$ die „Funicularspreite".

Die wichtigste Frage ist die, wie verhalten sich die einzelnen Teile der Samenanlage in dem Vergrünungsprozeß? Hier ist zu betonen, daß in allen Fällen die Vergrünung begleitet wird von einer Verk ü m m er ung तes $\mathrm{Nucellus}$, also desjenigen Teiles, welcher überhaupt das Charakteristikum der Samenanlage ist, und das ausmacht, was sie von einer beliebigen ähnlichen Gestaltung unterscheidet. Dagegen erfahren die Integumente und oft auch der Funiculus eine vegetative Ausbildung, es können aus ihnen blättchenartige Gebilde hervorgehen.

Vor allem ist herrorzuheben, daß die Samenanlagen auf verschiedenen Stafen ihrer Entwicklung der Vergrünung unterliegen können, woraus dann natürlich auch verschiedene Vergrünungsstufen resultieren. In Fig. 3361 ist eine Samenanlage abgebildet, welche beide Integumente schon angelegt hatte. Das innere (Ji), welches den Nucellus umschließt, ist nur wenig verändert, dagegen entspringt es scheinbar auf einem Stiele aus dem kahnförmig gewordenen äußeren Integument, wie dies der schematische Längsschnitt (Fig. 336 2) einer weniger tief veränderten Vergrünung zeigt. Daß die Vergrünung hier das äußere Integument ergreift, erklärt sich daraus, daß es (wie bei der weit überwiegenden Mehrzahl der Fälle) später angelegt wird als das innere. Und daß der rom inneren Integument umschlossene Nucellus, welcher, wie die Entwicklung 
der normalen Samenanlage zeigt, stets terminal angelegt ist, zur Seite gedrängt erscheint und in der Fig. 3362 scheinbar aus der Fläche des geöffneten äußeren Integuments entspringt, kann uns ebenfalls nicht wundernehmen. Denn wir wissen, daß ein ähnlicher Vorgang vielfach auch in der normalen Samenanlagenentwicklung eintritt, indem auch hier bei Samenanlagen mit massig entwickeltem Integument die vom Nucellus gebildete Spitze zur Seite gedrängt wird, so daß der Nucellus seitlich außerhalb der von der Integumentanlage gebildeten Spitze der Samenanlage hervorzukommen scheint. In Fig. 3363 ist die Samenanlage $\mathrm{zu}$ einem Blättchen geworden, welches, wie oben erwähnt, den Nucellus auf einer Fläche trägt. Das äußere Integument war hier beim Eintreten der Vergrünung noch nicht angelegt, das innere vielleicht eben erst angedeutet. Der Funiculus hat sich ebenfalls blattartig ausgebildet, und der Nucellus ist, indem der darunter befindliche Teil der Samenanlage als Blättchen über ihn hinauswuchs, in seitliche Stellung geraten. In Fig. 3364 endlich ist ein Fall abgebildet, wo äußeres und inneres Integument bereits angelegt waren, der untere Teil der Samenanlage aber sich blattartig ausgebildet hat und über das äußere Integument hinausgewachsen ist.

Endlich finden wir häufig auch die Samenanlage ersetzt durch ein einfaches Blättchen, d. h. die Vergrünung ist eingetreten zu einer Zeit, wo weder Integumente noch Nucellus (resp. Archespor) angelegt waren.

Schon dies Endresultat hätte zeigen können, wie wenig berechtigt es war, die Vergrünungen als Rückschlagsbildungen aufzufassen: das 'Endresultat ist ein einfaches Blättchen, und es ist nicht möglich, dies als die primitivste phylogenetische Entwicklungsstufe aufzufassen, ebensowenig als man dies tun kann, wenn der charakteristisch gestaltete sporangientragende Blatteil einer Aneimia beim Unterbleiben der Sporangienbildung als vegetatives Blatt sich ausbildet; die Fortpflanzungsorgane, auf deren Entstehung und Entwicklung es uns in beiden Fällen ankommt, fehlen eben ganz, und in Verbindung und gewiß in kausaler Verknüpfung damit treten dann bestimmte regetative Erscheinungen auf.

Weil eine Integumentanlage $\mathrm{zu}$ einem Blättchen wird, braucht das Integument aber ebensowenig je ein solches gewesen zu sein, als die Zellgruppe in der Achsel dieses Integumentes, die sich bei Vergrünungen häufig zu einem Sproß entwickelt, jemals ein Sproß gewesen ist.

Der einzige Schluß, den man aus diesen Vergrünungen ziehen könnte, wäre der, daß die Integumente aus Fruchtblattsubstanz gebildet sind resp. Wucherungen des Fruchtblattes darstellen, die einer vegetativen Entwicklung um so mehr fähig sind, je mehr die Fortpflanzungsorgane (der Nucellus) in ihrer Entwicklung gehemmt sind.

Aus dem Gesagten ergibt sich nun ohne weiteres, daß wir in den vergrünten Samenanlagen krankhaft veränderte Bildungen zu sehen haben. Wir können es also nur als einen Irrtum betrachten, wenn man derartige Mißbildungen als Rückschlagsbildungen auffassen will und uns dariiber wundern, daß die Behauptung aufgestellt werden konnte, ein Blättchen, auf dem der verkümmerte Nucellus sitzt (unter welcher Form zuweilen die vergrünten Samenanlagen auftreten, so in Fig. 336), sei genau homolog mit einem ein Sporangium resp. einen Sorus tragenden Fiederblättchen eines Farn. Als ob ein verkümmertes, in den bis jetzt bekannten Fällen auch nicht einmal einen Embryosack zeigendes Höckerchen mit einem Sporangium auch im entferntesten etwas zu schaffen hätte!

Es ist von Interesse hervorzuheben, daß der Botaniker, welcher die phylogenetische Bedeutung der Vergrünungen am scharfsinnigsten verteidigt 
hatte, L. CelakovskÝ später seine Auffassung vollständig änderte ${ }^{1}$ ). Die Vergrünungen der Samenanlagen werden nicht mehr als Rïckschläge aufgefaßt, sondern sollen zeigen, wie ein ursprünglich reproduktives Organ vegetativ werden konnte.

Wenn damit gemeint ist, daß die Vergrünungen zeigen, daß eine bei den jetzigen Pflanzen latent vorhandene Umbildungsfähigkeit auch in der Stammesgeschichte sich geäußert haben $\mathrm{kann}$, so wird dagegen nicht viel einzuwenden sein, denn tatsächlich können wir die Vorgänge der Vergangenheit nur nach den in der Gegenwart stattfindenden beurteilen.

Indes sind wir dabei mehr oder minder auf Vermutungen angewiesen. Jedenfalls ist zunächst notwendig zu ermitteln, wi e die abnormen Umbildungen zustande kommen.

Als veranlassende Momente für solche Abweichungen ist die auf verschiedene Weise veranlaßte Störung der normalen Organkorrelationen zu betrachten (rgl. Abschnitt VI).

\section{§ 8. Bedingungen für das Auftreten abnormer Umbildungen.}

Hier seien einige Beispiele angeführt, in denen wir von der Kette, die zu solchen Abweichungen führt, wenigstens das erste Glied, wenngleich nicht die weiteren kennen. Wir sehen dabei ab von abnormen Gestaltungserscheinungen, wie sie im Etiolement usw. vorliegen. Da dieselben Tatsachen zum Teile im sechsten Abschnitt zu erörtern sein werden, so mögen sie hier nur kurz erwähnt werden.

Eine Korrelationsstörung liegt vor, wenn durch Entfernung des Hauptsprosses (oder einer Hauptwurzel) eine Verbäinderung (Fasziation) der Seitensprosse (bzw. Seitenwurzeln) reranlaßt wird, was z. B. bei Keimpflanzen von Phaseolus durch Abschneiden des Hauptsprosses iiber den Kotyledonen oft hervorgerufen werden kann. Ohne Zweifel handelt es sich dabei um eine Änderung in den Ernährungsverhältnissen der Seitensprosse. Diese erhalten vom Wurzelsystem her nun melr und anders zusammengesetzten "Saft" als sonst. Es ist nicht zu verwundern daß dieselbe Erscheinung auch eintreten kann ohne Entfernung des Hauptsprosses, wenn dieselben Ernährungsbedingungen gegeben sind. So z. B. bei "Wasserreisern" - üppig an älteren Holzpflanzen aufschießenden Sprossen.

Übrigens verhalten sich die einzelnen Pflanzenarten verschieden: Salix, Populus, Robinia, Tilia, Corylus geben an Stockausschlägen oder stark zurückgeschnittenen Pflanzen nach L. Blarixghem oft Fasziationen, während diese bei Quercus, Betula und Carpinus selten auftreten. Daß es bei Pflanzen mit periodisch unterbrochenem Wachstum auch auf die

1) L. Čnzakovskŕ, Unters. über die Homologien des generativen Produkts der Fruchtblätter bei den Phanerogamen und Gefäßkryptogamen. Jahrb. f. w. Botanik XIV (1884), p. 329. "Ich habe bisher die Umbildungen des Ovulums in der Vergrünung und insbesondere das Erscheinen des Nucellus auf der Oberseite des verlaubten Ovularblättchens für einen atavistischen Rückschlag gehalten.... Nachdem ich erkannt habe, $\mathrm{daB}$ auch dem Entwicklungsgang der Anaphytosenlehre zufolge das Ovulum vom Sporangium der Ophioglosseen hergeleitet werden muB, so kann ich allerdings in der Verlaubung des Ovulums keinen Rückschlag zur atavistischen Form mehr erblicken. Wohl aber erzeugt die Verlaubung aus dem Ovulum ähnliche Gestalten, wie sie einst die phylogenetische Verlaubung des ursprünglich wie bei den Ophioglosseen rein generativen Blattzipfels nnter den Farnen hervorgebracht hat, weil eben die morphologische Grundlage beiderseits, nämlich im Ovnlum das Ovularblättchen mit Nucellus, bei den Farnen das Sporophyllblättchen mit Sporangien, identisch ist." 
Zeit ankommt, in welcher der Eingriff erfolgt, ist selbstverständlich. Auch die Blattbildung an derartigen Sprossen ist häufig eine abnorme. Es finden sich an ihnen auch vielfach "Schlauchblätter" (vgl. p. 23).

Ferner treten bei derartigen Sprossen nicht selten "Doppelblätter" 1 ) auf. Es geschieht dies namentlich bei Pflanzen mit zweizähligen (dekussierten) Blattpaaren, wie z. B. Weigelia, Lonicera. Es ändert sich die Blattstellung, indem statt der zweizähligen dreizählige Quirle auftreten. Namentlich an der Grenze beider Stellungsverhältnisse findet man oft alle Übergangsstufen von einem mehr oder minder tief zweispaltigen zu getrennten, aber einander noch genäherten Blättern; auch bei ungeänderter Blattstellung können übrigens solche Blätter auftreten. Man hat diese Blattbildung auf doppelte Weise nach ihrem Zustandekommen aufgefaßt. Entweder entstehen sie durch Spaltung einer Blattanlage oder dadurch, daß am Vegetationspunkt unter dem Einfluß gesteigerter Ernährung statt zwei Blattanlagen deren drei auftreten, von denen zwei dicht zusammenliegen. Mir scheint, daß der Gegensatz beider Ansichten kein sehr tiefgreifender ist. Wir werden sehen, daß tatsächlich Übergänge von Spaltung eines Organs zum Auftreten von zwei oder mehr von Anfang an gesonderten vorkommen. Die Hauptfrage dürfte sein, welche Ursachen es bedingen, daß eine Änderung in der Blattgestalt und Blattanordnung eintritt - die zweispaltigen Blätter erscheinen als ein nicht vollständig geglückter Versuch statt eines Blattes deren zwei zu bilden ${ }^{2}$ ).

Diese Mißbildungen findet man einerseits an Sprossen, die nach dem Stutzen ihrer Hauptsprosse austreiben, andererseits sah ich sie auch an unverletzten, aber stark gedüngten Weigeliasträuchern. Üppig entwickelte Sprosse zeichnen sich auch sonst vielfach durch Abweichungen in ihrer Blattgestaltung - von der Blattgröße ganz abgesehen - aus, die man nicht gerade als Mißbildungen bezeichnen kann, die aber hier kurze Erwähnung finden mögen. Bei Symphoricarpus racemosus sind die Blätter gewöhnlich einfach und ganzrandig, an üppigen "Erneuerungssprossen" aber fiederschnittig. Bei Sambucus nigra zeigen die Stockausschläge die Nebenblätter, die sonst meist verkümmern, reichlich entwickelt und die Blattfläche weiter geteilt als sonst. Ähnliche Beispiele ließen sich noch vielfach anführen.

Ebenso konnten durch Entfernung des Hauptsprosses die einfachen Primärblätter an den basalen Seitensprossen von Vicia Faba veranlaßt werden, sich zu Laubblättern auszubilden (oder zu Mittelbildungen zwischen Laub- und Primärblättern, die jeder Teratologe als echte Mißbildungen anerkennen würde), und bei Versuchen, die A. Mavn auf meine Veranlassung anstellte, gelang es gleichfalls, die Ranken von Pisum sativum teilweise zur "Verlaubung:" zu bringen.

Eine sehr interessante Mißbildung an Wurzeln hat SACHS $^{3}$ ) bei Cucurbita dadurch hervorgerufen, daß er alle Sproßregetationspunkte entfernte. Dann wuchsen die rechts und links neben jedem Laubblattstiele im Stamm-

1) Vgl. J. KLEIN, Über Bildungsabweichungen an Blättern. Pringsh. Jahrb. XXIV S. $423 \mathrm{ff.}$; Cellakowsky, Über Doppelblätter bei Lonicera Periclymenum und deren Bedeutung. Ibid. XXVI S. 1 ff. PERCY Groom, Longitudinal Symmetry in Phanerogamia. Phil. trans. of the royal society Ser. B. Vol. 200. 1908.

$\left.{ }^{2}\right)$ Vgl. die schönen von Percy Groom a. a. O. angeführten Beispiele.

3) J. SACHS, Gesammelte Abhandlangen, p. 1172. Leider ist SACHs' interessanter Versuch später nicht mehr wiederholt und anatomisch nachgeprüft worden. Es ist ja sehr viel bequemer endlose anatomische Beschreibungen anzufertigen, als einen einzigen Versuch zu machen. 
gewebe sitzenden Wurzelanlagen zu hasel- bis walnußgroßen kurz gestielten Knollen aus, an denen die Wurzelhaube verschwindet, der Vegetationspunkt unkenntlich wird, während sich der axile Leitbündelkörper in einen Kreis von Leitbündeln auflöst, die durch chlorophyllhaltiges Gewebe von einander getrennt sind. Es entsteht so eine an die der Sproßachse erinnernde Gewebedifferenzierung.

Auch in den von L. Buaringhem ${ }^{1}$ ) ausgeführten Versuchen handelt es sich um Störung der Korrelationsverhältnisse, die Methode war also dieselbe, durch welche auch die Umbildung von Laubblattanlagen in Niederblätter oder Sporophylle verhindert oder Fasziationen und Bildung abnormer Blattgestalt und Blattanordnung an Stockausschlägen hervorgerufen wurden (vgl. p. 333). Durch Entfernung bestimmter Teile der Pflanzen konnten latente Anlagen zur Entwicklung gebracht werden (z. B. die Staubblattanlagen in den weiblichen und die Fruchtknotenanlagen in den männlichen Blüten von Zea Mais) oder eine Umänderung gegenüber dem „normalen" Blütenbau, die sich ausspricht in einer Umbildung von Staubblättern in Fruchtblätter bei Papaver bracteatum Lindl.; Änderungen in den Zahlenverhältnissen der Blüten usw.

Das Neue in diesen Versuchen liegt darin, daß Blarixghem angibt, die durch Verletzung hervorgerufenen Anomalien seien, wenigstens teilweise, erblich. Das ist eine Frage, welche noch sehr weiterer Prüfung bedarf, zumal BuARINGHEM Kulturpflanzen benutzte, von denen zahlreiche mit Fähigkeit zu Mißbildungen versehene Rassen existieren. Bei den Verletzungen handelte es sich also wohl darum, daß eine sonst nur gelegentlich zutage tretende Fähigkeit zu abnormer Ausbildung infolge der abnormen Ernährungsverhältnisse sich manifestierte, ähnlich wie dies bei den Perorien von Labiaten in Peyritsch's Versuchen der Fall war. Da auch die Samen der unter abnormen Verhältnissen ausgebildeten Blüten gleichfalls unter abnormen Verhältnissen sich ausbildeten, so ist es wolıl möglich, daß auch bei ihren Nachkommen die abnormen Gestaltungsverhältnisse mehr zutage traten. $\mathrm{Ob}$ aber die weiteren Generationen, falls sie unter "normalen" Verhältnissen sich entwickeln, die Disposition zu abnormer Ausbildung gleichfalls in verstärktem Maße zeigen, scheint mehr als fraglich - wahrscheinlicher ist es, daß sie die Eigenschaften der ursprüglichen Versuchspflanzen aufweisen werden!

Auch KLEBS benutzte bei seinen wichtigen Untersuchungen „Über künstliche Metamorphosen" 2) die Methode der Korrelationsänderung durch Entfernung der terminalen Infloreszenzen von Sempervivumarten, ohne sich indes auf diese zu beschränken. Es gelang an den seitlichen (neogenen) Blüten durch Änderung der Ernährungsbedingungen kurz vor oder während der ersten Anlage abnorme Gestaltungen der verschiedensten Art hervorzurufen. So z. B. Umbildungen der Kelchblätter in Blumenblätter oder Laubblätter, der Blumenblätter in Kelcl- oder Laubblätter, der Staubblätter in Kelchblätter, Blumenblätter in Fruchtblätter, der Fruchtblätter in Staubblätter oder Blumenblätter, Vegetativwerden von Blütenständen und Blüten, ebenso Änderungen der Zahlenverhältnisse, Verkümmerungen usw. Auch bei diesen Mißbildungen bedarf die Frage der Erblichkeit noch eingehender Prüfung.

1) L. Blaringhem, Mutation et tranmatisme. Lille 1907. Les transformations brusques des êtres vivants. Paris 1911. Chap. XXII.

$\left.{ }^{2}\right)$ Sonderabdruck aus den Abhandlungen der Naturforschenden Gesellschaft. zu Halle, Bd. XXV. Stuttgart 1906. 


\section{§ 9. Abnorme Umbildungen durch direkte Änderung der Außen- bedingungen.}

Besonders günstig für derartige Untersuchungen erwiesen sich niedere Pflanzen, namentlich Pilze; einige wenige Beispiele seien angeführt.

Dematium pullulans, ein Pilz, der sonst gewöhnliche Hyphen oder hefeartige Sprossung zeigt, bildet, wenn er andauernd bei einer Temperatur von $30-31^{\circ} \mathrm{C}$ kultiviert wird, eigentïmliche Gebilde; seine Zellen teilen sich jetzt nämlich nach allen Richtungen des Raumes; es gehen aus ihnen Zellkörper hervor, deren Zellen bei gewöhnlicher Zimmertemperatur dann wieder hefeartig aussprossen ${ }^{1}$ ).

Einigermaßen analog sind die interessanten Mißbildungen bei Basidiobolus ranarum, welche RACIBORSKI hervorgerufen hat ${ }^{2}$ ). Dieser Pilz besteht normal aus einkernigen, zylindrischen, zu Fäden aneinander gereihten Zellen; er läßt sich leicht kultivieren. Bei steigender Konzentration der Nährlösung werden die Zellen immer kürzer und nähern sich der Kugelform, ja die Wände erhalten statt eines queren immer häufiger einen schiefen Verlauf, was bei normalem Wachstum nie vorkommt.

Bringt man Kulturen in $10 \%$ ige Glyzerinlösung und kultiviert sie bei höherer Temperatur $\left(30^{\circ} \mathrm{C}\right)$, so entstehen vielfach — nicht alle Zellen reagieren gleich - Riesenzellen von $60 \mu$ Durchmesser mit zahlreichen Kernen; zwischen einzelnen derselben treten noch zarte Wände auf. Hier handelt es sich offenbar um tiefgreifende Störungen des Wachstums; die Riesenzellen sind nicht mehr entwicklungsfähig, sie gehen zugrunde. Andere Abnormitäten sollen hier nicht angeführt werden; erwähnt sei nur, daß man Basidiobolus durch Kultur in $1 \%$ igem Ammoniumsulfat oder $1 \%$ igem Chlorammonium dazu zwingen kann, ein "Palmellastadium" $\mathrm{zu}$ bilden, wie es sonst bei keinem anderen Pilze bekannt ist: er isoliert sie in kugelförmige Zellen mit dicker Wand, die sich aus der alten Zellhülle befreien. Hier ist die Hemmung der Entwicklung offenbar nicht eine so weit gehende wie in dem oben betreffs der "Riesenzellen" beschriebenen Falle.

Ähnliche Erfahrungen wurden bei einigen Algen gewonnen; auch bei ihnen können durch die Beschaffenheit der Nährlösung, namentlich die Konzentration derselben, Mißbildungen hervorgerufen werden, wenn dieselben auch nicht so weit gehen wie bei Basidiobolus.

So fanden Сhорat und Huber, daß bei Pediastrum Boryanum in konzentrierter Nährlösung die Bildung von Tochterkolonien unterbleibt, und die Zellen zuweilen zu großen „Hypnocysten" werden, und bei anderen Süßwasseralgen sah RichтеR bei Kultur in Salzlösung gleichfalls Abnormitäten auftreten.

Gehen wir zu den Phanerogamen über, so möchte ich rọr allem hier die Worte anführen, mit denen ein auf dem Gebiete der Ätiologie der Mißbildungẹn sehr verdienter Forscher, Pexritsch, seine Abhandlung über die Ätiologie pelorischer Blütenbildungen ${ }^{3}$ ) einleitet. „Bei der Erforschung der Ätiologie von Pelorienbildungen und überhaupt von Bildungsabweichungen dürfen zwei Momente nicht außer acht gelassen

1) Schostakowitsch, Über die Bedingungen der Konidienbildung bei Rußtaupilzen. Flora, 81. Bd. (Erg.-Bd. z. Jahrg. 1895), p. 376.

2) M. RAciborski, Über den Einfluß äußerer Bedingungen auf die Wachstumsweise des. Basidiobolus ranarum. Flora, 82. Bd., p. 107. 1896.

$\left.{ }^{3}\right)$ Denkschriften der k. k. Akademie der Wissenschaften in Wien, 38. Bd., 1878. 
werden. Es ist dies das veranlas sende Moment, das in vielen Fällen ein äußeres Agens sein dürfte, und dann ein inneres, nämlich die Prädisposition zur Entwicklung der Anomalie. Man kann sich durch vielfältige Erfahrung überzeugen, daß nicht alle Individuen derselben Art und auch zu allen Zeiten gegen dieselbe äußere Schädlichkeit in derselben Weise reagieren; nicht bei allen ist die Fähigkeit, abzuändern, in abnormen Formen aufzutreten, zu erkranken, in derselben Weise vorhanden." Es ist dies eine Erwägung. die im Grunde für die Einwirkung aller äußeren Faktoren auf die Gestaltungsverhältnisse gilt, nur daß es sich bei den Mißbildungen. um Prädispositionen handelt, die „normal“ nicht zutage treten.

Eine Aufzählung von Beispielen kann hier unterbleiben, da beziiglich der Abhängigkeit des Auftretens ron Mißbildungen von "Ernährungsbedingungen und der Erblichkeitsverhältnisse auf die grundlegenden Ausführungen von DE VRIES verwiesen werden kann $^{1}$ ).

\section{$\S 10$. Mibbildungen veranlabt durch Einwirkung parasitischer Organismen.}

Es ist klar, daß diese Einwirkungen um so tiefgreifender sein werden, je jünger die ihnen ausgesetzten Pflanzenteile sind. Am reaktionsfähigsten sind dementsprechend die embryonalen Gewebe, namentlich die Vegetationspunkte. Parasitische Pilze, Gallentiere usw. können auf diese leichter einwirken als dies in unseren Versuchen geschieht, bei denen es sich um eine indirekte Beeinflussung (von seiten der älteren Teile her) handelt.

Die Reaktion besteht entweder in einer örtlichen Verschiebung und Vermengung auch sonst auftretender Gestaltungsverhältnisse, einer Modifikation der normalen Gestaltung oder einem Auftreten sonst "latent" bleibender Charaktere.

\section{Durch Pilze veranlaßte Umbildungen ${ }^{2}$ ).}

Auf den Ästen der Weißtannen (Abies pectinata, aber auch anderer Abiesarten) findet man häufig „Hexenbesen“, negativ geotropische Sprosse, welche im Gegensatz zu den normalen Tannensprossen einjährige Nadeln tragen, die auch in Bau und Form von den normalen sich unterscheiden. Die Fähigkeit orthotrope Sprosse zu bilden ist also in den plagiotropen Seitensprossen von Abies vorhanden, sie kann auch durch andere Beeinflussungen zutage treten ${ }^{3}$ ). In diesem Falle aber wird sie durch die Einwanderung des Mycels eines Rostpilzes, der Melampsorella caryophyllacearum in eine Knospe hervorgerufen, die sich dadurch von der sonst ihr aufgeprägten Gestaltung emanzipiert. Die Hexenbesen sind stets steril, ebenso wie die von Uromyces Pisi befallenen Sprosse verschiedener Euphorbiaarten, die in ihrem ganzen Habitus sich auffallend ron den normalen unterscheiden ${ }^{4}$ ).

1) De Vries, Die Mutationstheorie, I. Bd., Leipzig 1901.

2) Diese Erscheinungen werden in der mykolog. Literatur ausfiuhrlich besprochen. Vgl. DE BarY, Morphologie und Physiologie der Pilze und die ausführliche Lusammenstellung bei $\nabla$. Tubeur, Pflanzenkrankheiten.

${ }^{3}$ ) Vgl. Gokber, Einleitung in die experimentelle Morphologie, 3. Abschnitt, wo auch angeführt ist, daß es sich in beiden Fällen offenbar um Änderungen der Ernährungsbedingungen handelt.

4) Vgl. Tischler, Untersuchungen ïber die Beeinflussung der Euphorbia cyparissias durch Uromyces Pisi. Flora 104 (1911).

Goebel, Organographie der Pflanzen. 2. Aufl. Allgem. Teil. 
Auch Exoascusarten rufen auf Kirschbäumen, Birken usw. abnorme, als Hexenbesen bezeichnete Verzweigungssysteme hervor (vgl. die zahlreichen Abbildungen in TuBeurs Buch).

In den Blüten von Knautia arvensis tritt, wenn sie von Peronospora violacea befallen sind, öfters eine Umwandlung der Staubblattanlagen in violette Blumenblätter, also eine „Füllung“ ein, in anderen Fällen nur eine Hemmung der Staubblattentwicklung oder das Aưftreten eines blumenblattartigen Flügels an Stelle eines Pollensackes. Ähnlich fand GIARD bei Saponaria officinalis in Blïten, die durch Ustilago antherarum (violacea) befallen waren, zuweilen die Staubblätter in Blumenblätter verwandelt, eine Umwandlung, die, wie wir sehen werden, auch infolge der Einwirkung von Tieren bäufig eintritt.

Dies sind Beispiele, in denen sonst anders sich entfaltende Organanlagen eine Ablenkung in ihrer Entwicklung erfahren. Aber auch normal verkümmernde Organe können durch die Einwirkung eines Schmarotzerpilzes zur Weiterentwicklung gebracht werden. Melandryum album ist eine gewöhnlich diözische Pflanze. Sie kommt zuweilen auch (aber meist nur scheinbar) mit Zwitterblüten vor. Dies ist in fast allen genauer untersuchten Fällen dadurch veranlaßt, daß weibliche Blïten von Ustilago violacea befallen wurden, einem Pilz, der die Ausbildung der sonst auf
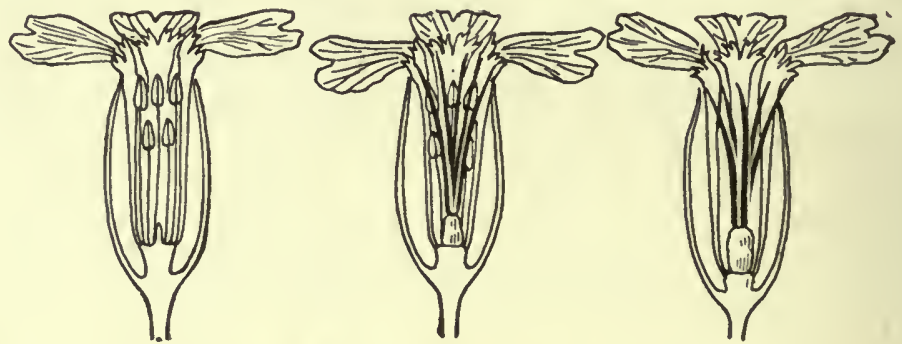

Fig. 337. Halbierte Blüten von Melandryum album nach Potonié. Links eine männliche, rechts eine weibliche, in der Mitte eine scheinbar zwitterige: Die in der Figur nicht sichtbaren, aber stets vorhandenen Antherenanlagen der weiblichen Blüte sind durch Ustilago violacea zur Weiterentwicklung angeregt worden.

einem frühen Entwicklungsstadium stehen bleibenden Staubblattanlagen veranlaßt (Fig. 327 Mitte); in den Antheren bilden sich aber statt der Pollenkörner Ustilagosporen aus, der weibliche Sexualapparat verkümmert großenteils.

Ein Beispiel von Neubildung von Organen an Stellen, an denen sie sonst nicht auftreten, haben wir an den sonderbaren "Hexenbesen", welche auf den Blättern von Pteris quadriaurita sich infolge der Einwirkung eines Pilzes, der Taphrina Laurencia, bilden ${ }^{1}$ ). Fs sind dies Adventivsprosse mit verbildeten Blättern, während normal Adventirsprosse auf den Blättern dieser Pflanze niemals auftreten; bei anderen Farnen gehört das Auftreten von blattbürtigen, der vegetativen Vermehrung dienenden Sprossen dagegen zu den normalen Erscheinungen. Die Blätter dieser Adventivsprosse weichen in Gestalt und Bau von den gewöhnlichen Pterisblättern ab. Ihre Gestalt wird aus der Abbildung hervorgehen (Fig. 338). Was den Bau anbelangt, so sei erwähnt, daß er ein viel einfacherer als der normaler Blätter ist; das Blattgewebe ist nur sehr wenig p. 130 .

1) K. Giesenhagen, Über Hexenbesen an tropischen Farnen. Flora 76 (1892), 
differenziert, die Epidermis besitzt keine Spaltöffnungen und die Blätter sind offenbar, teleologisch betrachtet, hier ebenso wie die Gewebewucherungen anderer "Pilzgallen" dazu bestimmt, aus dem Pflanzenkörper Baumaterialien an sich zu ziehen, die der Pilz dann zur Bildung seiner Sporen verwendet. Daß diese verbildeten Blätter aber trotzdem nichts anderes sind, als Umbildungen (resp. Hemmungsbildungen) gewöhnlicher Blattanlagen, ergibt sich schon daraus, daß sie ebenso wachsen und angelegt werden, wie normale Blätter, und daß man - obwohl sehr selten zwischen ihnen zuweilen ein normales Pterisblatt trifft; was wohl dadurch zustande kommt, daß hier ausnahmsweise in die Blattanlage keine

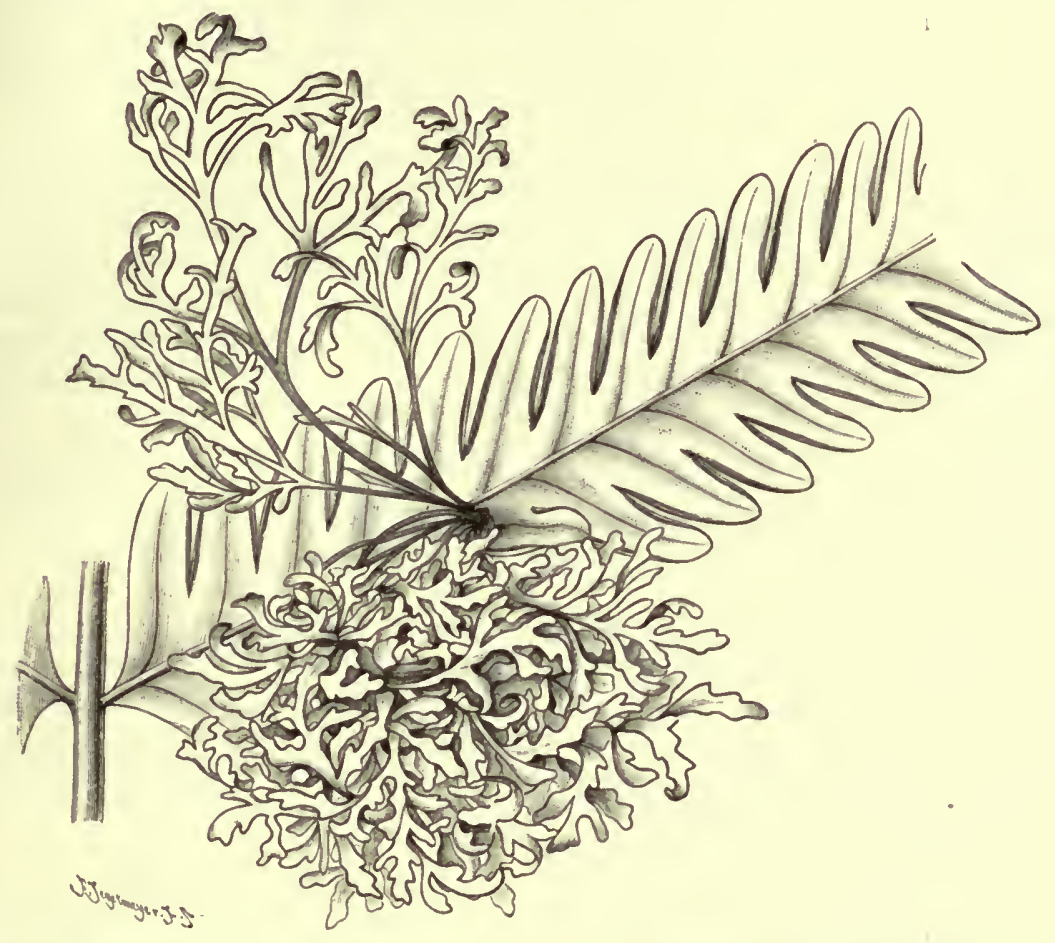

Fig. 338. Blattfieder von Pteris quadriaurita (nach GiesenHaGes), anf welcher sich"infolge der Einwirkung des parasitischen Pilzes Taphrina Laurencia ein "Hexenbesen gebildet hat, dessen Blätter abweichend ron den gewöhnlichen Blättern der Pflanze ausgebildet sind.

Pilzhyphen hineinwuchsen. Der Vorgang ist also offenbar der, daß infolge der Einwirkung des parasitischen Pilzes das Blattgewebe zur Bildung eines hier sonst nicht auftretenden Adventivsprosses veranlaßt wird, und daß der Pilz dann durch seine Einwirkung die Blattanlagen veründert. Das erstere Moment erinnert sehr an die unten von Selaginella pentagona angeführte Gallenbildung. (Betreffs der Pilzgallen von Aspidium aristatum vgl. Giesenhagen a. a. O.)

Bei Luzula flavescens und L. Forsteri, welche von einem „Brandpilze" befallen waren, fand Buchenau ${ }^{1}$ ) die Blüten durch dichte Büschel

1) Abhandl, d. naturw, Vereins zu Bremen II. 
von Hochblättern ersetzt, was uns zu den durch Tiere veranlaßten Vergrünungserscheinungen überleiten kann $^{1}$ ).

Von besonderem Interesse sind die Versuche „Über künstliche Erzeugung von gefüllten Blüten und anderen Bildungsabweichungen" von J. Peyritsch ${ }^{2}$ ). Leider hat der Tod diesen Forscher verhindert, die in Aussicht gestellte ausführlichere Darstellung seiner Versuchsresultate zu geben. So besitzen wir nur die genannte kurze Mitteilung, der früher schon eine andere ${ }^{3}$ ) vorhergegangen war, in der PeYrITSCH gezeigt hatte, daß man bei Arabisarten durch künstliche Infektion mit Aphisarten Vergrünungen von Blïten erzeugen kann, vorausgesetzt, daß die infizierten Blütenknospen noch nicht zu weit in ihrer Entwicklung rorangeschritten waren. Mit der Vergrünung war eine Störung der Ausbildung der Sporangien verbunden, namentlich war der Pollen rudimentär und offenbar funktionsunfähig.

Weitergehende Mißbildungen wurden durch Infektion mit Plytoptus bei Valerianeen und Cruciferen erzielt. Es stellten sich teils abnorme Blattformen, teils verschiedene Formen von Blütenfüllungen und sprossenden Bliiten ein. Die ersteren bestanden im allgemeinen darin, daß Blattzähne an einigen Stellen gleich den Zähnen eines Kammes aneinandergereiht auf Lappen standen, die meist über den übrigen Blattrand hervortraten; bei Centranthus calcitrapa zeigte sich öfters die Erscheinung, die Masters in seiner "Vegetable teratology" als "Enation von Blattorganen" bezeichnete. Bei Bättern von Fraxinus Ornus.die von Eriophyes Fraxini befallen waren, beobachtete Küster, daß aus den Seitennerren kleine Blattspreiten hervorwuchsen, auch sonst sind solche spreitenbürtigen Prolifikationen bekannt, welche der p. 28 angeführten Erscheinung entsprechen.

So hat H. Ross ${ }^{4}$ ) auf Melastomaceenblättern „Adventivblättchen" beobachtet, welche durch parasitisch lebende Tylenchusarten hervorgerufen waren. Wie es scheint kann diese Erscheinung auch ohne tierische Parasiten an anderen Melastomaceenblättern gelegentlich auftreten. Es zeigt sich also, daß Blattanlagen die Fähigkeit besitzen aus ihrer Fläche ohne Vorhandensein eines Vegetationspunktes neue „adventive" Blättchen hervorzubringen (vgl. auch p. 28).

In den Blütenständen der Cruciferen zeigte sich an wenigen oder an zahlreichen Blüten das Auftreten der sonst ganz verkümmerten Stützblätter. Diese glichen in Form und Textur kleinen Laubblättern.

Die Füllung der Blüten kam in den rerschiedensten Formen ror. Alle Zwischenstufen von der Petalodie einzelner Staub- und Fruchtblätter bis zur vollkommenen Füllung waren vertreten, und außerdem fanden sich Durchwachsungen der Blüten, doppelte und dreifache Corollen, Calycanthemie, Sprossungen innerhalb der Bliiten u. dgl.

Alle diese Erscheinungen wurden erzielt durch Übertragung eines Parasiten, und zwar eines Phytoptus, der sich in degenerierten Knospen von Valeriana tripteris fand. Der Grad der Umbildungen war dabei ein

1) Vgl. die interessante Zusammenstellung bei KüstrR, Die Gallen der Pflanzen. Leipzig 1911. Hier können, wie in der 1. Auflage, nur wenige Beispiele herausgegriffen werden.

$\left.{ }^{2}\right)$ Peyritsch, Zur Ätiologie der Chloranthien einiger Arabisarten. Pringsheims Jahrb. XIII, 1.

s) Sitznngsber. d. k. Akad. der Wissensch. in Wien, Bd. XCVII. 1888.

4) H. Ross, in Ber. der deutschen bot. Gesellschaft XXX (1912) p. 346. 
verschiedener, je nach der Größe der Infektion und der Empfindlichkeit der Pflanze.

Analog sind die Umbildungen, welche durch den Stich eines Insektes, der Livia juncorum, vielfach bei Juncusarten (J.lamprocarpus, supinus, acuminatus u. a.) hervorgerufen werden, sowohl an Bliiten, als an den Vegetationsorganen ${ }^{1}$ ). Die Erscheinungen bei Blüten sind verschieden, offenbar nach dem Zeitpunkt, in welchem die umbildende Einwirkung des Insektes stattfindet. Gemeinsam ist, daß eine Verkümmerung der Sexualorgane eintritt, außerdem bald nur eine Vergrößerung der Perigonblätter bis auf das Dreifache der normalen Länge, bald Knospenbildung in deren Achseln, wobei auch die Stellung der Perigonblätter verändert ist, bis schließlich statt der Blüten große Blattbuischel entstehen. Auch vegetative Sprosse können durch das Saugen des Insektes verändert werden. Dessen Einwirkung besteht darin, daß die Internodien ganz kurz bleiben und fast sämtliche Blattachseln Seitensprosse entwickeln, an denen die Blätter nach einem zwischen $1 / 2-1 / 8$ liegenden Dirergenzbruche stehen (aber nicht regelmäßig und unter mannigfachen Drehungen und Verschiebungen). Besonders eigentümlich aber ist die Veränderung, welche die Blätter erfahren; ihr Scheidenteil vergrößert sich ganz bedeutend, während der Spreitenteil klein bleibt oder ganz verkümmert, mit anderen Worten: das Insekt bringt hier dieselben Veränderungen hervor, wie sie sonst bei der normalen "Blatt. metamorphose" eintreten, wenn aus einer Laubblattanlage ein Niederblatt oder ein Hochblatt entsteht. Für das Insekt liegt der Vorteil offenbar darin, da $\mathrm{B}$ das weiche, in Streckung begriffene Gewebe der Blattscheide ihm leichter für die Ernährung zugänglich ist.

Kehren wir indes zu den Peyritsch'schen Versuchen zurück, so scheint mir zweierlei von besonderer Bedeutung zu sein. Einmal die Tatsache, daß, wie bei der Gallenbildung, eine stoffliche Einwirkung des Parasiten, d. h. eine Störung des normalen Ablaufes der Baustoffbildung und Verteilung, die Ursache der Mißbildung ist, und dann da $\beta$ bei den $M i \beta$ bildungen oft keine neue Organbildung auftritt, sondern nur eine

1) Vgl. Buchenau, a. a. 0. p. 390. Diese Mißbildung gehört offenbar zu den häufigsten; sie kommt anch in der Umgebung Münchens in zahlreichen Exemplaren vor.

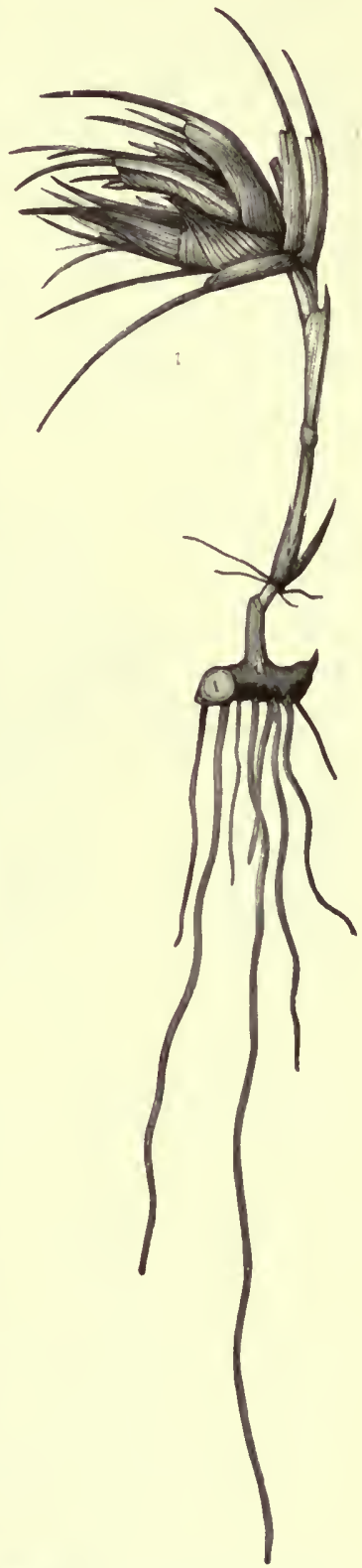

Fig. 339. Juncus lamprocarpus. Durch Livia jnncorum umgebildeter Sproß. Die Blätter haben eine mächtige Entwicklung der Scheiden unter Reduktion der Blattspreiten erfahren. 
Verschiebung der Organe. Andererseits zeigen schon die von Pilzen oben angeführten Fälle, daß bei Mißbildungen auch ne u e Gestältungsverhältnisse auftreten können.

Was zunächst die "Verschiebung" der Organbildung bedingt, so sei folgendes bemerkt. Wenn eine Blüte "vergrünt", so erhalten die statt der Blumenblätter, Staubblätter usw. auftretenden Laubblätter die Form der gewöhnlichen Laubblätter der betreffenden Pflanze, z. B. bei Drosera findet man in den vergrünten Blüten auf den Blättern die für die Droserablätter charakteristischen "Tentakeln". Es treten also nicht Rückschläge auf eine Stammform von Drosera auf, sondern die Laubblätter der Pflanze selbst, die hoch spezialisiert sind und jedenfalls eine lange Geschichte hinter sich haben. Freilich ist die Vergrünung nicht immer eine vollständige; dann ist die Form der bei der Vergrünung entstandenen Blätter natürlich eine einfachere, aber der extreme Fall ist

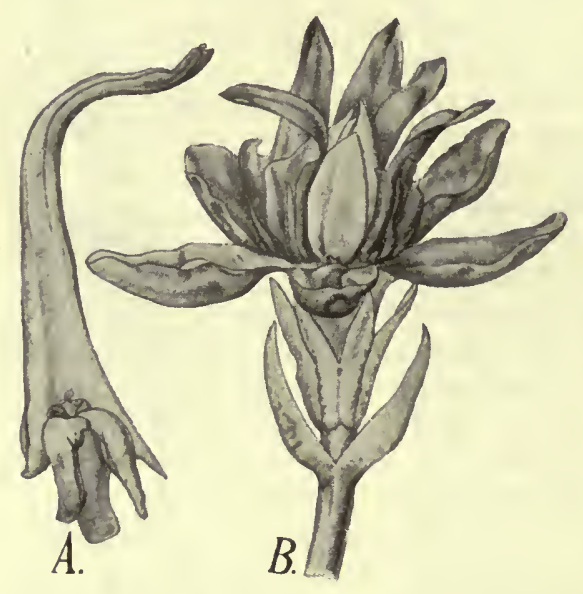

Fig. 340. Gentiana acaulis. $B$ durch Eriophyes Kerneri vergrünte Blüte, $A$ abnormes Staubblatt, an welchem Auswüchse entstanden sind. eben der klarste. Wenn ferner bei der Füllung der Blüten neue Petala erscheinen, so haben dieselben der Hauptsache nach die Form der gewöhnlich vorhandenen. Die Mißbildung bestand in einer abnormen Umbildung und gewissermaßen in einem Durcheinanderrütteln der verschiedenen Organe.

Eine derartige durch eine Milbe reranlaßte Blïtenangrünung ist in Fig. 340 für Gentiana acaulis abgebildet. $B$ zeigt eine Blüte, deren Vegetationspunkt nicht, wie dies sonst geschieht, nach der Bildung des Fruchtknotens sein Wachstum eingestellt hat; er hat neue Blätter gebildet und ist "durchgewachsen". Auch die Staubblätter sind abnorm verändert und bilden wie Fig. $340 \mathrm{~A}$ zeigt, eigentümliche (auch an anderen Stellen der Blüte vorkommende) Auswüchse, welche wohl den Milben zur Nahrung dienen.

Wir haben bei solchen Mißbildungen also einerseits eine neue Kombination des der Pflanze Möglichen. Die Eigenschaften, welche kombiniert werden, bleiben dieselben wie die Stïcke, welche die wechselnden Bilder des Kaleidoskops liefern. Mittelbildungen zwischen zwei Organen entstehen dabei sehr häufig, so hat Peyritsch bei Valeriana statt der Brakteen Mittelbildungen zwischen Brakteen und Pappusstrahlen beobachtet oder zwischen Brakteen und Blumenblättern.

Andererseits treten außer den neuen Kombinationen und den örtlichen Verschiebungen auch Eigenschaften hervor, die bei der normalen Entwicklung gar nicht sichtbar, und, soweit wir beurteilen können, auch bei den Vorfahren nicht vorhanden waren.

So haben A. Braun und Strasburger bei Selaginella pentagona merkwürdige Gallenbildungen beobachtet, die äußerlich Bulbillen ähnlich sind (Abb. in Abschnitt VI). Diese haben sechs Zeilen gleichartig ausgebildeter Blätter (während sonst bekanntlich - abgesehen von den wenigen isophyllen Formen - die Selaginellablätter in zweizähligen, schief gekreuzten Quirlen 
stehen und an den vegetativen Organen die beiden Blätter jedes Quirls von sehr ungleicher Größe sind). Eine derartige Blattstellung, wie sie diese Gallensprosse zeigen (die ron einer Dipterenlarve bewohnt sind), findet sich bei Selaginella sonst nie. Die „Bulbillen" wachsen mit einer dreiseitig pyramidalen Scheitelzelle. Thre ersten Entwicklungsstadien sind leider unbekannt, wir wissen nicht, ob sie als Neubildungen entstehen oder aus ohnedies vorhandenen Sproßanlagen, die ihre Beschaffenheit ändern. Wir haben keinen Grund, anzunehmen, daß die Vorfahren dieser Selaginella jemals sechsreihig beblätterte Sprosse gehabt haben, oder daß die Vorfahren von Pteris quadriaurita Adventivsprosse auf den Blättern entwickelten (vgl. p. 338), vielmehr sind diese Mißbildungen offenbar Neubildungen (deren Beschaffenheit abhängt von der des Protoplasmas der Pflanze einerseits und dem auf dieses ausgeïbten Reiz andererseits). Es scheint, daß niedere Pflanzen, namentlich Pilze, für Mißbildungen plastischer sind als höhere, bei denen, wie wir sahen, oft nur eine Verschiebung der Organbildung eintritt.

Die merkwürdigen Erscheinungen der Gallenbildung können hier - unter Verweisung auf Küster's angeführtes Buch — auch nur kurz berïhrt werden.

Der Reiz, welcher die Gallenbildung bedingt, ist leider immer noch nicht bekannt; es ist nicht gelungen Gallen ohne die Einwirkung des betreffenden Gallentiers zu erzeugen. Wir wissen nur, daß er ein direkter oder ein indirekter (von anderen Organen vermittelter) sein kann. Die Eigentiimlichkeit der Gallenbildung liegt bekanntlich darin, daß

1. infolge des durch ein Tier ausgeübten Reizes eine Neubildung entsteht, welche dem sich darin (oder daran) entwickelnden Tiere Wohnung, Nahrung und Schutz in oft iiberraschend zweckmäßiger Weise gewährt;

2. dabei Gewebe entstehen, die normal an dem betreffenden Orte nicht entstanden wären, deren Bildung also zeigt, daß die "Potenzen“ der Zellen beim normalen Entwicklungsgang nicht alle in die Erscheinung treten.

Es handelt sich also bei der Gallenbildung um eine Ausnutzung von Fähigkeiten des Pflanzenkörpers, die sonst nicht oder an anderer Stelle zutage treten. Wir wissen z. B., daß Zellen mit stark verdickten Wänden sich bilden, wenn Assimilate reichlich vorhanden sind (z. B. in den Blättern vieler xerophiler Pflanzen), es kann also nicht wundernehmen, daß auch in dem Gallengewebe, das reichlich ernährt ist die Bedingungen für das Entstehen sklerotischer Zellen vielfach gegeben sind.

Mit Recht hat man auch seit MALPIGHI auf die Ähnlichkeit zwischen der Gallenbildung und den Vorgängen, die nach der Befruchtung sich abspielen, hingewiesen.

Ein Embryo wie der in Fig. 405 abgebildete reranlaßt ganz ähnlich wie ein Gallentier ein Zuströmen von Baustoffen und damit in Verbindung Bildung von Organen, die ihm Nahrung, Wohnung und Schutz gewähren. Man kann z. B. die "Beutel" mancher "marsupiferen" Lebermoose mit Beutelgallen vergleichen. In beiden Fällen lösen Reize Gestaltungsverhältnisse aus, deren "Zweckmäßigkeit" ohne weiteres einleuchtet; die unzweckmäßigen (die gewiß auch vorkommen) werden ausgeschaltet.

Die Frage, ob in den Gallen etwas Neues entstehe oder nur Gewebeteile bzw. Organe, die an der betreffenden Pflanze auch sonst, aber an anderem Orte ausgebildet werden, ist verschieden beantwortet worden.

Daß eine "Verlagerung" bei der Gallenbildung rorkommt, ist unzweifelhaft. Es braucht nur erinnert zu werden an die merkwürdigen Larven- 
kammern, welche Mayetiola Poae an Poa nemoralis erzeugt, wobei infolge des Reizes der Larve sich Wurzeln bilden, die sich über die Larvenkammer herlegen und, miteinander verklebend, einen dichten lebendigen Mantel bilden ${ }^{1}$ ). Die Wurzeln entstehen hier an Stellen, wo sie normal sonst nie auftreten, sind also verlagert. Der zur Gallenbildung führende Reiz geht von der Larve aus, die sich mit der Oberfläche eines noch wachsenden Internodiums fest verklebt. Es bilden sich zunächst rechts und links, in beträchtlicher Entfernung von dem Tiere, leistenförmige Anschwellungen, aus denen dann die Wurzeln ihren Ursprung nehmen; man kann diese sogar veranlassen, sich zu normalen Wurzeln weiter zu entwickeln, wenn man die Galle als Steckling benützt. Ebenso wie hier ganze Organe (Wurzeln) können auch Gewebebestandteile, die an anderen Stellen des Pflanzenkörpers auftreten, sich in der Galle finden. Cosens ${ }^{2}$ ) z. B. führt an, daß bei der durch Neolasioptera perfoliatae auf Eupatoria perfoliata veranlaßten Galle „Drüsen“ an Stellen des Sprosses gebildet werden, an denen sie sich sonst nicht finden. Sie kommen nämlich sonst nur an der Basis der Sproßachse vor, in den anderen Teilen der Pflanze ist die Möglichkeit, sie zu bilden, wie die genannten Gallen zeigen, "latent" vorhanden.

Die einzelligen spitzen Haare der Galle, die durch Eriophyes querci auf Quercus macrocarpa hervorgerufen wird, sind sehr verschieden von den Sternhaaren des Blattes, also scheinbar etwas Neues. Sie finden sich aber auf den reproduktiven Achsen der Nährpflanze, sind also in der Galle nur verlagert. Ähnliche Erscheinungen ließen sich noch mehr aufzählen ${ }^{3}$ ). Sie sind übrigens nicht auf die Gallen beschränkt; so kommen im Wundholz mancher Pflanzen Sekretbehälter vor, auch wenn sie sonst im Holz der betreffenden Zweige nicht vorhanden sind ${ }^{4}$ ) oder Markstrahltracheiden, wo sie sonst fehlen ${ }^{5}$ ).

Es ist eine naheliegende und deshalb öfters ausgesprochene Vérmutung, daß alle abnormen Unmbildungen, seien sie wie immer veranlaßt, bedingt werden durch eine Änderung in der Zusammensetzung der den Organanlagen zufließenden Baumaterialien, sei es nun, daß man bestimmte organbildende Stoffe, "Wuchsenzyme", Hormone oder einen Wechsel in der Konzentration der einzelnen als Baumaterialien in Betracht kommenden Stoffe annimmt. Alle diese Anschauungen kommen bei dem jetzigen Stand unserér Kenntnisse nur als Arbeitshypothesen in Betracht. Es muß hier deshalb auf die Ausführungen von SACHS $^{6}$ ), KLEBS ${ }^{7}$ ) und dem Verfasser ${ }^{8}$ ) verwiesen werden. (43) 355 .

1) Beyerinck, Die Galle von Cecidomyia Poae an Poa nemoralis. Bot. Zeit. 1885

2) Cosens, A contribution to the morphology and biology of insect galls. Transactions of the Canadiainstitute, Vol. XV, 1912. (Der Verf. äußert über Gallenbildung im wesentlichen dieselben Anschaungen, wie sie in der 1. Auflage dieses Buches vorgetragen wurden.)

3) So gleichen z. B. die eigentümlichen gefransten Auswüchse auf den Gallen von Rhodites rosae sehr denen, die bei den "Moosrosen" sich vorfinden. Vgl. anch L. Drass, Der Formbildungsprozeß bei der Blütencecidie von Lonicera. Untergatt. Periclymenum. Flora 105 (1913).

4) Vgl. Tscinrch, Über den sog. Harzfluß. Flora 93 (1904), p. 179.

s) R. Holden, Ray tracheids in Coniferales. Bot. gazette 55 (1913).

6) J. SACHS, Stoff und Form, Ges. Abhandl. II, p. 1109.

7) G. KLEBS, Willkürl. Entwicklungsänderungen bei Pflanzen; Jena. Über künstliche Metamorphosen (s.o.) und andere Schriften.

8) Z. B. Goeber, Einleitung in die experim. Morphologie der Pflanzen. 1908. 


\section{Verkümmerung.}

\section{§ 11. Allgemeines über Verkümmerung.}

Von Verkümmerung oder Fehlschlagen sprechen wir hier zunächst mit Beziehung auf die Einzelentwicklung, die Ontogenie. In dieser beobachtet man sehr häufig, daß nicht alle begonnenen Entwicklungsvorgänge auch zu Ende geführt werden. Dafür wurden oben schon im Kapitel über Umbildung Beispiele angeführt, ist doch die Umbildung häufig mit Verkümmerung bestimmter Teile verbunden. So z. B. verkümmern die Spreitenanlagen vieler Niederblätter, die Blüten an Blütenstandsranken usw.

Man kann sagen, daß Verkümmerungen um so häufiger sind, je reicher die Gliederung einer Pflanze ist. Sie sind deshalb bei Thallophyten seltener als bei Samenpflanzen und treten bei diesen am meisten dort ein, wo die Organausbildung 'ihren Höhepunkt erreicht, in der Blütenregion.

Untersuchen wir die bei der Verkümmerung eintretenden Vorgänge etwas näher, so ist vor allem zu bemerken, daß wir die Fälle, in denen ein Organ durch ungünstige ä $u ß$ ere Einfliisse in seiner Entwicklung gehemmt wird, hier außer Betracht lassen, weil hier nur ein gelegentlich eintretender Vorgang vorhanden ist. Man kann ja auch eine Ranke, die nicht gefaßt hat (p. 18), oder ein unbefruchtet gebliebenes Archegonium als verkümmert betrachten, da auch hier die an bestimmte äußere Bedingungen geknüpfte Weiterentwicklung unterbleibt. Indes soll hier nur die durch „innere" Ursachen erfolgende Verkümmerung besprochen werdel, eine Verkümmerung also, die regelmäßig eintritt, wenngleich auch hierbei Schwankungen auftreten.

\section{$\S 12$. Art und Weise der Verkümmerung.}

Eine Verkümmerung erfolgt häufig dadurch, daß eine Organanlage ihren normalen Entwicklungsgang nicht vollständig durchläuft, sondern auf einem früheren oder späteren Stadium stehen bleibt. In diesen Fällen ist die Organanlage entwicklungsgeschichtlich noch nachweisbar; in zahlreichen anderen aber unterbleibt auch die erste Anlegung, und die Verkümmerung kann dann nur noch durch den Vergleich mit anderen Formen erschlossen werden.

Daß zwischen Verkümmerung und Nichtanlegung ("Abort und Ablast") keine scharfe Grenze zu ziehen ist, zeigt die Tatsache, daß bei einer und derselben Pflanze ein und dasselbe Organ bald in verkümmertem Zustand angetroffen wird, bald ganz fehlschlägt, und dies ist wieder nur ein Spezialfall der allgemeineren Tatsache, daß verkümmerte Organe in der Entwicklungshöhe, die sie erreichen, sehr schwanken. Zunächst seien jedoch für das erstere Beispiele angeführt.

Die Ährchen der Gräser Setaria, Pennisetum u. a. sind umgeben von einer aus Borsten bestehenden Hülle. Zweifelsohne sind, wie die Entwicklungsgeschichte zeigt ${ }^{1}$ ), diese Borsten Infloreszenzzweige, an denen man auch zuweilen Blütenrudimente wahrnimmt. Allein in den ..meisten der zahlreichen von mir untersuchten Borsten war keine Spur von Ährenbildung

1) GokBEL, Beiträge zur Entwicklungsgeschichte einiger Infloreszenzen. Jahrb. f. wiss. Bot. XI. 
an diesen Borsten wahrzunehmen. Es zeigt dieser Umstand, daß ein scharfer Unterschied zwischen dem Fehlschlagen (der Verkümmerung) und dem gänzlichen Unterbleiben der Entwicklung von Sprossungen nicht zu machen ist. Wenn an einer Setariaborste im einen Falle ein fast vollständiges Å̆hrchen, im anderen nur eine Andeutụng der Glumae, im dritten gar kein Ährchenrudiment angelegt wird, so sind diese drei Stadien doch offenbar nur dem Grade nach voneinander verschieden.

Ähnliche Fälle lassen sich auch von Blattbildungen anführen. So gibt $\mathrm{Schмiтz}^{1}$ ) an, daß sich bei Artanthe Jamaicensis, einer Piperacee, das median nach hinten stehende Staubblatt des zweiten Staubblattwirtels ausbildet, aber schmächtiger ist als die drei Staubblätter des äußeren Kreises. In einzelnen Bliiten war aber das genannte Staubblatt zwar als Höcker angelegt, kam aber nicht zur Ausbildung, schlug also fehl. Bisweilen aber unterblieb sogar die erste Anlegung eines solchen Höckers, ja sogar die ersten Zellteilungen, wodurch dessen Bildung sonst eingeleitet $\mathrm{zu}$ werden pflegte traten nicht ein.

Schмiтz hat das völlige Unterbleiben der Anlegung eines Organs als Ablast gegenüber dem Verkümmern, dem Abortus bezeichnet, aber, wie schon erwähnt, ist eine wesentliche Verschiedenheit zwischen beiden Vorgängen nicht vorhanden; die Annahme des Fehlschlagens eines Organs, sei dieses nun noch im rudimentären Zustand vorhanden oder nicht, wird immer durch V erg lei ch ung gestuitzt werden müssen. Der Umstand, da $ß$ mit solchen Vergleichungen zuweilen Mißbrauch getrieben worden ist, hindert daran nichts.

Es ist übrigens nicht immer möglich, verkümmernde Organe abzugrenzen gegenüber umgebildeten und gegenüber denen, die nur eine zeitweilige Hemmung ihrer Entwicklung erfahren.

So verharren z. B. die Blätter an den rasch wachsenden Sproßachsen mancher Schlingpflanzen zunächst in unentwickeltem Zustand, und werden in diesem entweder abgeworfen oder nehmen später ihre Entwicklung wieder auf.

Die „ruhenden Knospen“ vieler Bäume verkümmern schließlich (oft erst nach langer Zeit), wenn sie nicht durch Beschädigung des Baumes zum Austreiben veranlaßt werden.

Schon die oben kurz angeführten Beispiele zeigen, daß die Verkümmerung bei einem und demselben Organe früher oder später erfolgen kann; damit hängt es zusammen, daß die Ausbildung verkümmernder Organe außerordentlich schwankt, sowohl bei ein und derselben Pflanze als innerhalb eines Verwandtschaftskreises. Beispiele lassen sich sowohl aus der vegetativen Region, als aus den Blüten anführen.

Die unterste Gluma der Ährchen von Lolium ist bei den meisten Arten spurlos verkümmert. Bei L. temulentum dagegen ist sie entwicklungsgeschichtlich stets nachzuweisen und erreicht oft solche Größe, daß sie auch für das bloße Auge deutlich hervortritt. Die Deckblätter der Cruciferenblüten sind meist spurlos rerkümmert, treten aber gelegentlich auf.

Verkümmernde Staubblätter zeigen alle Übergangsstufen von dem normalen Bau der Anthere bis zu einem ungegliederten Höcker ${ }^{2}$ ).

1) Schmitz, Die Blütenentwicklung der Piperaceen, in Hasstein, Botan. Abhandl. II. Bd., p. 37.

2) Familier, Biogenet. Untersuchungen. Flora 1896, p. $133 \mathrm{ff}$. 


\section{§ 13. Reihenfolge bei der Verkümmerung.}

Am Vegetationspunkt der Sprosse werden normal die Organanlagen in progressiver Reihenfolge entwickelt (p. 65). Man könnte daraus schließen, daß auch bei Verkümmerung diese Reihenfolge eingehalten werde. Indes ist dies nicht immer der Fall.

Namentlich an dorsiventralen Sprossen tritt deutlich herror, daß, wenn eine Reduktion eintritt, diese die ohnedies schwächer ausgebildeten Teile stärker betrifft, als die geförderten.

In den Blüten von Viola z. B. ist die Unter-(Außen-)seite gefördert. Es spricht sich dies aus in der Ausbildung der Blütenhiulle (das größte Blumenblatt z. B. ist das median nach unten stehende) und der Staubblätter, von denen gleichfalls die beiden untersten gefördert sind. Bei den als Hemmungsbildungen zu betrachtenden kleistogamen Blüten sehen wir die oberen Staubblätter stets stärker reduziert, als die unteren, und ähnliche Erscheinungen sind in zahlreichen anderen Fällen $\mathrm{zu}$ beobachten. Das ist nicht weiter auffallend, weil ja in dorsiventralen Blüten auch die zeitliche Reihenfolge im Zusammenhang mit der Dorsiventralität von der gewöhnlichen progressiven abweichen kann (p. 294).

In radiären Blüten ist die normale zeitliche Reihenfolge: Kelch (1), Blumenkrone (2), Androeceum (3), Gynaeceum (4). Es können aber einzelne Organe dieser Reihenfolge vollständig ausgeschaltet werden und zwar nicht etwa nur am Ende, sondern auch am Anfang. Die weiblichen Blüten der Composite Xanthium z. B. haben keine Spur mehr von einem Kelch und einem Androeceum, sie besitzen außer dem Gynaeceum nur noch einen kleinen Rest der Blumenkrone. Die Reihenfolge der Anordnung ist hier also nicht $1,2,3,4$, sondern es ist nur 2 und 4 erhalten, wobei 2 verspätet und kümmerlich auftritt. Auch in anderen Fällen werden solche Reste häufig später sichtbar, als dies nach ihrer Stellung der Fall sein sollte. Wenn sie überhaupt nicht mehr angelegt werden, so kann dies so weit gehen, daß auch der Platz, an dem sie stehen sollten, verschwindet. So schon in den angeführten Compositenblüten, aber auch anderwärts z. B. in der Blüte der Labiaten. Sie ist eine "typisch" fünfzählige. Tatsächlich aber entwickelt sie sich ron der Bildung der Blumenkrone $a b$, als ob sie eine vierzählige wäre; die Stellung der vier Staubblätter läßt den Platz, an welchem das verkümmerte fünfte stehen sollte, nicht mehr erkennen.

Wir sehen also, daß zeitlich und räumlich die Verkümmerung bis zum vollständigen Verschwinden gehen kann, wenigstens was die für uns sichtbaren Vorgänge betrifft. Es kann aber trotzdem die betreffende Pflanze noch „latent" die Fähigkeit, das gewöhnlich verkümmernde Organ zu bilden besitzen.

\section{$\S 14$. Umänderung der Gestalt durch Verkümmerung.}

Durch Verkümmerung kann oft eine vollständige Verwischung der ursprünglichen Gestaltungsverhältnisse eintreten, welche an einigen Beispielen erläutert werden mag.

a) Ein ganzer Sproß kann auf ein einziges Blatt reduziert sein, wobei die Sproßachse nicht mehr gesondert hervortritt. Das ist in Bluten nicht selten. 
Fig. 341 zeigt links scheinbar eine monokotyle Blüte mit einem Deckblatt, einem Vorblatt und drei Staubblättern. In Wirklichkeit aber liegt, wie die schematische Abbildung rechts zeigt, hier ein Blütenstand (ein Ährchen) vor, bestehend aus drei sehr reduzierten Blüten $I, I I, I I I$, wobei II und III in den Achseln der beiden Vorblätter von $I$ stehen. In jeder der Blüten sind verkümmert: das ganze Perigon (bestehend aus 6 Blättern) 5 Staubblätter und das Gynaeceum. Es ist nichts übrig geblieben als ein Staubblatt, welches die ganze Blïtenanlage für sich in Anspruch nimmt. Diese Auffassung ist, da die verkümmerten Teile auch in Gestalt ron Resten nicht mehr nachweisbar sind, selbstrerständlich nur eine Deutung, die sich nicht direkt beweisen, aber durch Vergleich mit anderen verwandten Formen erschließen läßt. Diese zeigen uns, daß 1. tatsächlich bei den
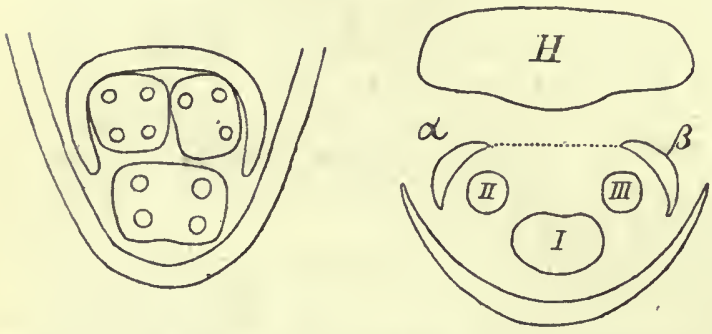

Fig. 341. Scirpodendrum costatum. Links Querschnitt eines dreibluitigen Ährchens, rechts Schema. I Primanblüte, $I I$ und $I I I$ Achselblüten in der Achsel der beiden Vorblätter $\alpha$ und $\beta$. H Infloreszenzachse, an der die Blüte $I$ als Achselsproß entsteht.

Fig. 342 (auf 1/4 verkl.). I Blatt von Filicium decipiens (Sapindacee), II von Phyllarthron comorense.

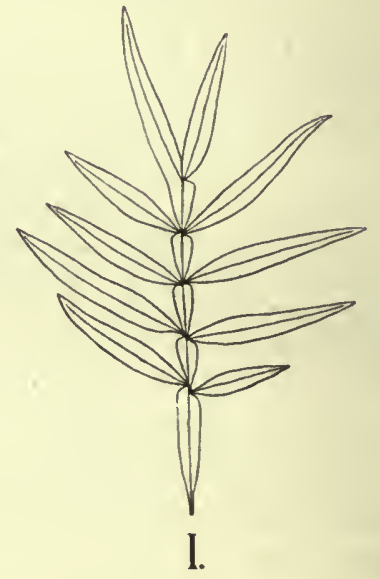

Fig. 342.

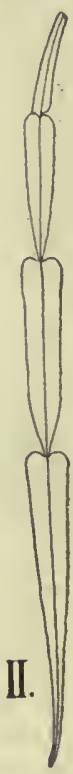

Cyperaceen Reduktionen oft vorkommen, speziell in der Blütenhịille und der Zahl der Staubblätter, 2. daß bei verwandten Formen die Ährchen bestehen aus einer weiblichen Endblüte und männlichen, aus nur einem Staubblatt bestehenden Seitenblüten. Derartige Ährchen gleichen oft sehr Einzelblüten, so z. B. bei Mapania, deren Ahrchen wir sicher für Blüten halten würden, wenn uns nicht verwandte Formen zeigen würden, daß es sich eigentlich um einen Blütenstand handelt.

Ahnliche Beispiele finden wir unter den Dikotylen, z. B. bei Euphorbia, und eine von Delpino und Wettstern aufgestellte Hypothese faßt sogar das Zustandekommen der Zwitterblüten bei Angiospermen allgemein in ähnlicher Weise auf, wie wir dies für die beiden oben angeführten Beispiele nachzuweisen versuchten.

b) Blätter. Verkümmerung ganzer Blätter tritt namentlich in der Bluitenregion in sehr verschiedenem Grade auf. Es gibt Blätter, die zwar noch deutlich als solche erkennbar, aber anatomisch außerordentlich vereinfacht sind (vgl. auch das Beispiel von Weddelina, p. 128), andere sind (wie z. B. die Deckblätter in den oberen Teilen der Grasinfloreszenzen) auf kleine, leitbündellose Wülste reduziert, bei den Cruciferen sind sie 
ganz verschwunden, können aber trotzdem in abnormen Fällen wieder auftreten. Wie ganze Blätter können auch einzelne Blatteile der Verkümmerung anheimfallen.

Es verkümmert z. B. die Blattspreite bei den sogenannten Phyllodien, und ein mit seitlicher Gliederung (Fiederblättern usw.) versehenes Blatt kann durch Verkümmerung wieder „einfach" werden. Fig. 342 gibt ein Beispiel, das wegen seines methodologischen Interesses hier angeführt sein mag. Es ist ungemein plausibel sich das Blatt von Phyllarthron (Fig. 342 II) aus einem ähnlichen, wie Filicium decipiens (Fig. 342 I) es zeigt, hervorgegangen zu denken. Allein beide Pflanzen gehören verschiedenen Familien an und dürfen also nicht direkt miteinander verglichen werden; wie das Phyllarthronblatt wirklich zustande gekommen ist, bleibt näher festzustellen.

In dieser Beziehung ist auch das Verhalten der Blätter, welche Sporangien tragen, der Sporophylle von Interesse. Namentlich ist das Verhalten der Cupressineen lehrreich (Fig. 343). Die männlichen Blïten bestehen aus einer größeren Anzahl von Sporophyllen. Die Zahl der Sporangien an jedem Sporophyll nimmt nach dem Blütenende hin ab, aber auch
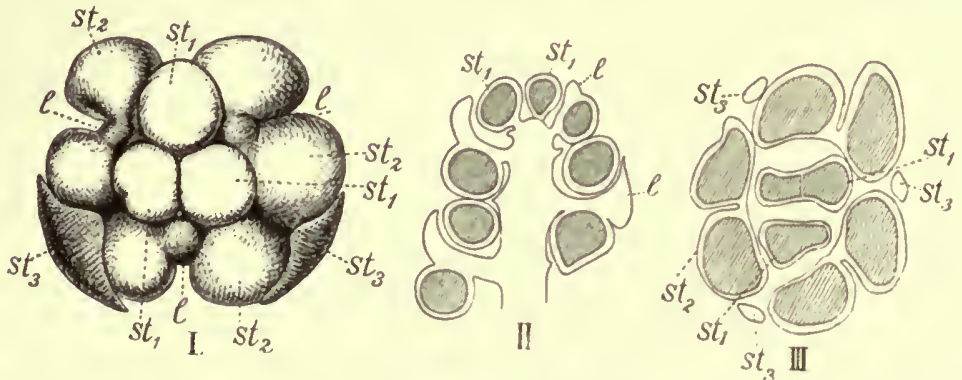

Fig. 343. Juniperus communis. I Oberansicht der Spitze einer männlichen Blüte. Der oberste Staubblattwirtel $\left(s t_{1}\right)$ ersetzt durch drei Sporangien. Der zweite Staubblattwirtel $\left(s t_{2}\right)$ zeigt an den Staubblättern je zwei Pollensäcke und die Andeutung einer Lamina (l). vom dritten Staubblattwirtel sind nur die Spitzen der Lamina zweier Staubblätter $\left(s t_{3}\right)$ gezeichnet. Sie haben je drei (nicht sichtbare) Pollensäcke. II Längsschnitt, III Querschuitt durch eine ähnliche männliche Blïte.

das Gewebe des Sporophylls verschwindet oft fast ganz, so daß an Stelle der Sporophylle einzelne Sporangien scheinbar direkt aus der Blütenachse entspringen. Auch können zwei Sporangien miteinander zusammenfließen, so daß nur unten noch eine unvollständige Trennungswand rorhanden ist.

Einige Najasarten bieten ein zweites Beispiel. Die männliche Blüte ist hier auf ein Staubblatt reduziert, das bei manchen Arten die Normalzahl der Sporangien (Pollensäcke) vier enthält. Bei anderen ist dies nicht der Fall, es verkümmert auch das Gewebe zwischen den einzelnen Pollensäcken, so daß diese (ähnlich wie das von Juniperus erwähnt wurde) teilweise „zusammenfließen“, ein Vorgang, der deutlich als eine Reduktion sich ausweist (Näheres im speziellen Teil).

Wir sehen hier Organe, die Mikrosporangien, die bei anderen Pflanzen scharf umgrenzt sind, ihre Selbständigkeit verlieren. Dasselbe gilt für die Sexualorgane. Die Archegonien z. B. sind bei den Moosen und Pteridophyten vielzellige Körper, mit Hals- und Bauchteil. Schon bei den Pteridophyten kann der Halsteil eine erhebliche Reduktion erfahren, bei den Gymnospermen geht diese noch weiter und schließlich bleibt nur die Eizelle vom ganzen Archegonium iibrig. 
Diese Beispiele werden genügen, um einerseits die weite Verbreitung, andererseits die Bedeutung der Verkümmerung als gestaltbeeinflussender Faktor zu exläutern.

\section{$\S 15$. Ursachen der Verkümmerung.}

Nur in rerhältnismäßig seltenen Fällen sind wir imstande, die Verkümmerungen einigermaßen kausal zu verstehen. Es ist dies namentlich dann der Fall, wenn sie unter der Einwirkung anderer Teile des Pflanzenkörpers, also durch Korrelation erfolgt. Hier seien nur einige Beispiele dafür angeführt.

Die Farnprothallien und Moosprotonemen (mit Ausnahme z. B. von Ephemerum) gehen zugrunde, wenn eine junge Pflanze entstanden ist, welche die Baustoffe an sich reißt.

In dem Fruchtknoten von Quercus entwickelt sich von sechs Samenanlagen, in dem der Linde von zehn nur eine, die alle anderen verdrängt.

Die oberen Blüten reichblütiger Infloreszenzen (z. B. Boragineen, Oenothera) verkümmern, wenn die unteren Samen ansetzen.

Die Knospen an der Basis der Jahrestriebe der meisten Holzpflanzen sind ebenso entwicklungsfähig wie die anderen, aber durch ihre Lage dazu verurteilt, "Ruheknospen" zu bleiben, die gewöhnlich ganz und gar verkümmern und nur unter bestimmten äußeren Umständen zum Austreiben gelangen. Zahlreiche andere Beispiele ließen sich anfiihren.

Als "Ursache" des "Verkümmerns" wird auch vielfach betrachtet das Funktionloswerden eines Organs. Daß dafür bei Pflanzen keine Beweise vorliegen, wurde in der Einleitung hervorgehoben.

Auch sehen wir, daß keineswegs unnötig gewordene Organe allgemein der Verkümmerung anheimfallen. Die Samen der Kulturformen von Ananas sativus, der kultivierten Bananen verkümmern regelmäßig, trotzdem bilden die Blüten immer wieder Samenanlagen. Die Samen können verkümmern, weil die Pflanzen sich durch vegetative Vermehrung erhalten.

Allerdings handelt es sich hier um Kulturpflanzen, welche künstlich dem Wettbewerb mit anderen entzogen sind. Ebenso wird aber in den männlichen Blüten von Petasites noch ein Flugapparat wie Pappus angelegt, obwohl sie keine Früchte bilden. Und die Blïten einer Anzahl kleiner Arten der Sammelart von Taraxacum officinale, bilden eine leuchtende Blumenkrone und Pollen, obwohl nie mehr eine Bestäubung und Befruchtung stattfindet, da die Früchte und Samen ohne Bestäubung (apogam) reifen.

\section{§ 16. Die morphologische Bedentung der verkümmernden Organe.}

Diese besteht namentlich darin, daß durch den Nachweis von Verkümmerungen vielfach eine Übereinstimmung einer Pflanzenform mit einer verwandten hergestellt wird, welche für den Zusammenhang dieser Formen von Bedeutung ist.

Dafür finden sich in den Blüten zahlreiche Beispiele. So haben z. B die Verbascumarten unter den Scrophulariaceen 5 Staubblätter, Pentastemon besitzt deren 4 und ein Staminodium an Stelle des fünften. Dieses ist bei Digitalis u. a. vollständig verschwunden. Bei Gratiola sind 2 Staubblätter und 2 Staminodien vorhanden. Das berechtigt uns zu der Annahme, daß ursprünglich alle Scrophulariaceenblüten 5 Staubblätter besaßen, von denen aber eins oder drei rerkümmerten.

Wir können eine Reihe aufstellen, welche beginnt mit den am 
vollständigsten ausgestatteten Blüten und endigt mit den am meisten rückgebildeten. Solche Reihen sind also Rückbildungsreihen, welche auf Verlust bestimmter Organe beruhen.

Die meisten phylogenetischen Reihen sind solche Rückbildungsreihen, wenigstens die, welche wir als die am besten begründeten betrachten können.

Es beruht dies auf zwei Gründen.

Einmal darauf, daß wir in der am vollständigsten ausgestatteten Form einen bestimmten Ausgangspunkt haben, auf den sich die anderen zurückführen lassen. Zweitens sind solche Rückbildungen zeitlich später eingetreten als die Entwicklung einer aufsteigenden Reihe von einfacher zu höher gegliederter Gestaltung. Sie sind deshalb oft vollständiger erhalten und so unserem Verständnis leichter zugänglich.

Freilich ist es oft sehr schwierig oder unmöglich, zu entscheiden, ob eine bestimmte Form primitiv oder ruickgebildet ist, ob sie also an den Anfang oder das Ende einer Reihe gehört. Es ist in solchen Fällen vor allem wichtig, daß die Zusammengehörigkeit einer Anzahl von Formen in eine Reihe erkannt wird. Wie man die Reihe lesen soll, ob von oben nach unten oder von unten nach oben, ließe sich nur dann mit Sicherheit entscheiden, wenn die paläontologischen Befunde uns vollständig vorliegen würden - was leider nicht der Fall ist.

Es wird sich im speziellen Teile Gelegenheit geben, an Einzelbeispielen auf diese Frage zurückzukommen.

Hier sei nur noch hervorgehoben, daß man keineswegs allgemein den Satz aufstellen kann, daß „funktionslose Gebilde immer nur Relikte nach vormals wohl ausgebildeten, normal funktionierenden Organen darstellen". Es ist vielmehr eine ganz allgemeine Regel, daß viel melrr Organanlagen gebildet werden, als zur Funktion gelangen.

Wir sehen dies z. B. bei der Bildung männlicher Gameten. Wenn jetzt viele Millionen von Farnspermatozoiden nicht zur Verschmelzung mit einer Eizelle gelangen, so berechtigt das nicht zu der Annahme, daß das bei den Vorfalıren der Farne anders war; selbst bei isogamer Befruchtung gehen sicher viele Gameten zugrunde. Die Überzahl der männlichen Grameten aber erhöht die Wahrscheinlichkeit der Befruchtung. Ebenso haben wir keinen Grund zu der Annahme, daß die Tausende von Knospen, die an jedem Baume normal verkümmern oder die vielen Blütenanlagen mancher Gräser, Oenotheraarten u. a., welche alljährlich verkümmern, je bei den Vorfahren dieser Pflanzen alle in Funktion traten. Sie sind, wie wir sahen, meist Organreserven, deren Verkiimmerung durch Korrelation bedingt wird.

\section{Verwachsung und spaltung.}

\section{$\S 17$. Verwachsung.}

Der Ausdruck Verwachsung wird teils im wörtlichen, teils im vergleichenden Sinne gebraucht, d. h. man versteht darunter sowohl die Tatsache, daß ursprünglich getrennte Organe sich mit ihren freien Teilen vereinigen, als die, daß man vielfach Organe, die bei gewissen Pflanzen frei, selbständig sind, bei anderen miteinander vereinigt findet, ohne daß diese Vereinigung durch eine im Verlaufe der Einzelentwicklung eintretende Verwachsung erfolgen würde.

Eines der bekanntesten Beispiele bietet die Blumenkrone der Sym- 
petalen, die gewöhnlich als verwachsenblätterig bezeichnet wird. In Wirklichkeit liegt die Sache so, daß eine Anzahl freier Blattanlagen gebildet, aber bald auf gemeinsamer ringförmiger Basis emporgehoben werden. Man kann diesen Ringwall betrachten als zustande gekommen aus den Basalteilen der betreffenden Blattanlagen, die aber von Anfang an oder „kongenital" miteinander vereinigt sind.

Darauf wird indes bei Besprechung der Blütenbildung zurïckzukommen sein, zunächst seien für das Eintreten wirklicher Verwachsung Beispiele angeführt. Dabei ist zu bemerken, daß von der Verwachsung im fertigen Zustand um so weniger zu bemerken ist, je früher sie erfolgt. Die Scheidewand des Fruchtknotens der Cruciferen z. B. ist aus zwei miteinander verwachsenen Stücken zusammengesetzt; die. Verschmelzung der Zellen geschieht aber so frühzeitig, daß sie im fertigen Zustand nicht mehr bemerkbar ist. Ähnlich ist es bei manchen Fruchtblättern', bei der Blumenkrone von Ceropegia usw.

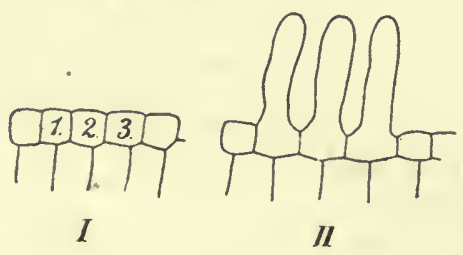

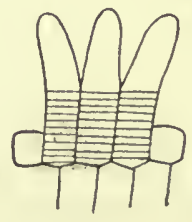

III

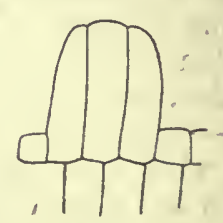

IV

Fig. 344. Schema für die freie Ansbildung (II), teilweise (III) oder vollständige (IV). "Verwachsung" dreier nebeneinander entstehender $(I)$ Haare.

Eine zeitweilige oder dauernde Verwachsung durch Nahtverbindungen tritt zwischen den Blättern der Blütenhülle, in manchen Fällen bei bestimmter („klappiger") Knospenlage ein ${ }^{1}$ ). Entweder wachsen die einander berührenden Epidermiszellen benachbarter Blätter zahnartig zwischeneinander ein, dann können wir von einer "Zellennaht" sprechen, oder die Verzahnung erfolgt nur durch Cuticularrippen und -zapfen, Cuticularnaht. In diesen Fällen erfolgte also im Gegensatz zu den oben erwähnten die Verwachsung erst nach Ausbildung der Cuticula. Indes kann diese auch nach der Verwachsung in manchen Fällen teilweise resorbiert werden (Staminaltubus von Lobelia nach ReICHE a. a. O.).

Die hier angeführten Fälle sind zwar biologisch von Interesse, treten aber an Wichtigkeit durchaus zurück gegenüber der kongenitalen Verwachsung, wobei es sich, wie schon oben erwähnt, um ganz andere Vorgänge handelt.

Nehmen wir einen einfachen Fall an (Fig. 344). Drei benachbarte Oberflächenzellen $(1,2,3$ Fig. $344 I)$ sollen zu Haaren auswachsen, jedes davon entwickle sich ohne Zusammenhang mit den anderen (Fig. $344 I I$ ). Bei einer verwandten Pflanze aber wachsen die Zellen von vornherein als einheitlicher Zellkörper. Diesen kann man als aus einzelnen Zellen „kongenital verwachsen" bezeichnen, was zunächst einen rein vergleichenden Sinn hat (d. h. nur ein anderer Ausdruck für die Tatsache ist, daß die Zellen bei der ersten Pflanze nicht miteinander rereint wachsen) und eigentlich erst dann.von Bedeutung wird, wenn sich wahrscheinlich machen

1) Vgl. ReIche, Über nachträgliche Verbindung frei angelegter Pflanzenorgane (Flora 1891 p. 435); RAciBonskr, Die Schutzvorrichțngen der Blütenknospen (Flora 81. Bd. 1895 p. 151 ff.). 
läßt, daß der kongenital verwachsene Körper phylogenetisch aus den freien Haaren hervorgegangen ist.

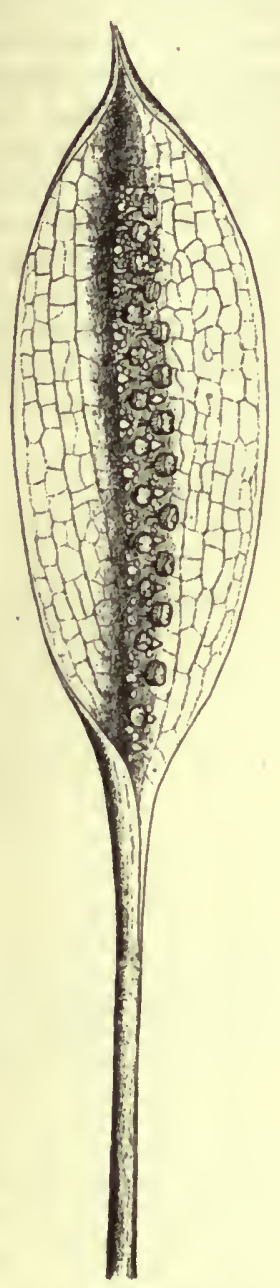

Fig. 345. Spathiphyllum platyspatha. Infloreszenz etwas schief von oben gesehen; die Infloreszenz ist einseitig, der Spadix mit der Spatha "verwachsen". Es sind zwei Reihen männlicher Blïten. vorhanden, dazwischen die weiblichen.

Eine Stïtze für diese Vorstellung würde es sein, wenn man eine Pflanze kennen würde, bei der die Haare, wie in Fig. 344 III, nur in ihrem unteren Teile (der schraffiert ist) zusammenhängen. Dieses Verhalten kann auf doppelte Weise erreicht werden. Entweder wachsen die Haare zunächst frei aus und werden dann durch die Streckung ihrer zusammenhängenden Basalteile emporgehoben, oder es entsteht zunächst ein Zellkörper (der schraffierte, ähnlich wie bei Fig. $344 I V)$ und es wachsen dann erst die drei Zellen an der Spitze weiter; für beide Modalitäten finden wir bei Entstehung der sympetalen Blumenkrone Beispiele. - Ein Vorgang, welcher der hier angenommenen Verwachsung von Haaren entspricht, findet sich in der Tat bei den "Haarwurzeln" mancher Florideen und einiger Lebermoose. Bei den meisten Arten beider Reihen sind einzelstehende Haarwurzeln vorhanden, bei einigen Zellkörper, die wir als aus Haarwurzelbüscheln „kongenital verwachsen" bezeichnen können (so bei Polyzonia jungermannoïdes unter den Florideen, betreffs der Lebermoose vgl. den speziellen Teil). In allen Fällen, wo eine kongenitale Verwachsung aus vergleichenden Gründen angenommen wird, muß eine entwicklungsgeschichtliche Prïfung ergeben, wie der Vorgang eigentlich ist. Beide Forschungsmethoden müssen sich gegenseitig ergänzen und berichtigen. Der unterständige Fruchtknoten z. B. wurde von der Entwicklungsgeschichte vielfach als von der becherförmig gewordenen Bliitenachse gebildet betrachtet, die Fruchtblätter sollten nur zur Griffelbildung verwendet werden. Die vergleichende Betrachtung hatte dagegen $\mathrm{zu}$ dem Resultate geführt, daß auch beim unterständigen Fruchtknoten die Fruchtblätter an der Bildung der Fruchtknotenhöhle beteiligt sein müßten, und $d a ß$ aus ihnen die Samenanlagen entspringen, ohne daß dadurch über den Vorgang selbst eine genauere Aufklärung gegeben wäre. Die genauere Verfolgung der Entwicklungsgeschichte zeigt nun in allen bis jetzt geprüften Fällen, daß beide Anschauungen in gewissem Sinne Recht haben, und daß sie sich rereinigen lassen, wofür auf den speziellen Teil verwiesen sei.

Hier möchte ich an der Hand der Figuren 345 und 346 ein anderes Beispiel kurz erörtern. Die Blütenkolben der Aroïdeen sind umhüllt von einem, als Spatha bezeichneten Hochblatt, welches unterhalb des Bluitenkolbens entspringt. Bei Spathiphyllum platyspatha liegt nun der eigentümliche Fall vor, daß der Blütenkolben ganz mit der Spatha verwächst, die Blüten entstehen nur auf dem freien, der "Verwachsungsstelle" gegen- 
überliegenden Teile des wenig hervortretenden Blütenkolbens. Ein Querschnitt durch den Blütenkolben (Fig. 346 III) erweckt den Anschein, als ob die Blüten aus der Oberseite der Spatha entsprängen, welche mit ihren eingeschlagenen Rändern den Blütenstand schützend umgibt. Die Entwicklungsgeschichte zeigt nun, daß unterhalb der Spitze des Blütenstandes auch hier die Spatha ganz normal angelegt wird (Fig. 346 I und II). Statt daß nun aber - wie gewöhnlich - der oberhalb der Ursprungsstelle der Spatha gelegene Teil stark wächst und sich mit Blüten bedeckt, erfolgt hier ein anderer Vorgang: es entwickelt sich die Zone der Infloreszenz, welcher die Spatha eingefügt ist, es ist dies der in der schematischen Fig. 346 IV schraffierte Teil. Dieser wächst heran, er besteht außen (in Fig. $346 I V$, rechts) aus der Infloreszenzachse, innen aus der Basis der Spatha, und so, durch Vereintwachsen von Blattinsertion und Sproßachse kommt das sonderbare Gebilde zustande, von dem wir ausgingen.
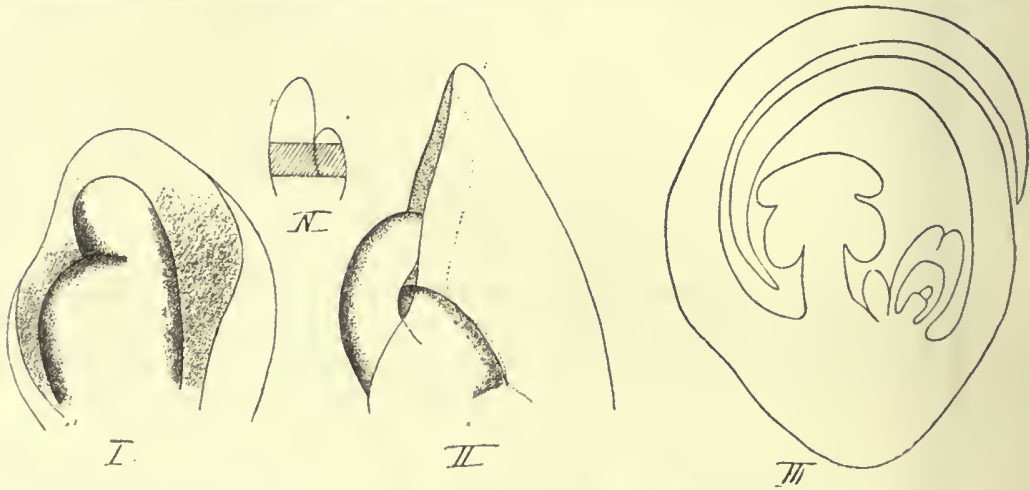

Fig. 346. Spathiphyllum platyspatba. Entwicklung der Infloreszenz. I und $I I$ junge Infloreszenzen, an denen man die Anlage des Spatha sieht, die seitlich unterhalb des Vegetationspunktes der Infloreszenz hervorsproßt. Das der Infloreszenz gegenüberstehende Blatt wird zu einem Niederblatt, in dessen Achsel sich ein Fortsetzungssproß entwickelt. III Querschnitt durch eine junge Infloreszenz. IV Schematische Figur zur Erläuterung der "Verwachsung“.

Andere Spathiphyllumarten zeigen diese Verwachsung in viel geringerem Grade, nur an der Basis der Infloreszenz. Mit welchen biologischen Beziehungen es etwa zusammenhängen mag, daß bei Sp. platyspatha der Entwicklungsgang in so eigentümlicher Weise abgeändert wurde, wissen wir nicht.

\section{$\S$ 18. Spaltung.}

Das Gegenstück der Verwachsung ist die Aufteilung einer Organanlage in mehrere, also eine Spaltung.

Eine Beeinflussung der Organbildung durch diesen Vorgang ist in der vegetativen Region verhältnismäßig selten, in der Blütenregion aber häufig. Hier kann es sich nur um einzelne Beispiele handeln, und zwar kommt hier vor allem die "kongenitale" Spaltung in Betracht.

Wir können zur Erläuterung dieselbe Abbildung (Fig. 344) wie für die kongenitale Verwachsung benutzen, nur daß wir sie in umgekehrter Reihenfolge lesen. Denken wir uns also, wir hätten in einem Verwandtschaftskreis ein einheitliches Organ wie in Fig. $345 \mathrm{IV}$. Aus diesem kann durch Getrenntwachsen $\mathrm{nach}$ der einheitlichen Anlage das Stadium Fig. $3451 I I$ hervorgehen, welches eine Spaltung in drei Teile zeigt. 
Oder es erfolgt die Spaltung kongenital, dann haben wir Fig. $345 I$. Manchmal wird es nicht ganz leicht sein, nachzuweisen ob III oder II vorliegt, da sanfte Abstufungen eintreten können. Wenn dann die "kongenital" gespaltenen Anlagen $(I I)$ auch noch ihren örtlichen Zusammenhalt aufgeben und einzeln entstehen, so ist es nur bei Vorhandensein von Übergangsformen möglich, den Zusammenhang zu erkennen.

Im Anschluß an das besprochene Schema

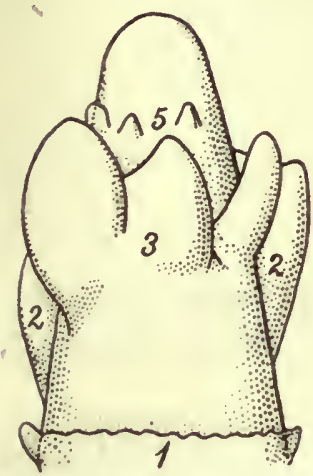

Hig. 347. Typha angustifolia. Oberes, noch blïtenleeres Ende einer Infloreszenzachse. 1 und 2 untere Teile zweier zweizeilig stehender Hochblätter, 3 ist in einzelne Teile gespalten, bei 5 treten die Teilstỉcke selbständig auf. mag erwähnt werden, daß Ersatz eines Organes durch mehrere auch sonst stattfindet. Die Besprechung des oft erörterten "Dedoublements" in den Blüten muß dem speziellen Teile vorbehalten bleiben; hier sei nur folgendes angeführt.

In den Infloreszenzen von Typha treten nach den zweizeilig gestellten Hochblättern in der oberen Region statt eines Blattes mehrere getrennte auf (Fig. 347), welche man, ohne nähere Prüfung als selbständige betrachten wiirde. Es tritt hier nur an einzelnen Punkten der Querzone der Sproßachse, die sonst einheitlich zur Entwicklung einer Blattanlage verwendet wird, ein Auswachsen ein.

Ganz ähnlich ist es bei den ersten Blättern der Seitenknospen einiger Moose, wie Mnium ${ }^{1}$ ).

Bei den Laubmoosen geht bekanntlich aus jedem Segment der Scheitelzelle ein Blatt hervor, dieses nimmt fast die ganze Segmentbreite ein. Die ersten Blätter der Seitensprosse von Mnium cuspidatum aber zeigen, daß eine "Spaltung" der Blattanlage eintritt, d. l. das Segment wächst nicht mehr im ganzen, sondern an einzelnen Stellen aus.

Dasselbe tritt ein bei der Brutknospenbildung von Aulacomnium androgynum. Die Brutknospen von Aulac. palustre sind umgebildete Blätter d. h. das ganze ausgewachsene Segment wird zur Brutknospenbildung verwendet. Bei Aulac. androgynum ${ }^{2}$ ) dagegen entstehen auf einer Segmentbreite mehrere Brutknospen, man kann sie, wenn man will, fiir Umbildungen kongenital gespaltener Blattanlagen halten.

Auch der Ersatz der fünf Kelchblätter der meisten Kompositen durch oft sehr zahlreiche Pappusstrahlen, der der Deckblätter der Blüten einer Anzahl von Kompositen durch zahlreiche Spreublätter mag auf dieselbe Weise zustandegekommen sein, wenn sich auch der Vorgang vielfach mehr durch Vergleich mit verwandten Formen erschließen als sicher nachweisen läßt.

Doch ist von Bedeutung, daß, wie Mißbildungen zeigen, tatsächlich auch solche Kompositen, die normal nur Pappusstrahlen bilden, latent die Fähigkeit fünf Kelchblätter auszubilden, besitzen. können.

Fälle wie den von Typha, Mnium, dem Kompositenkelch u. a. werden wir zu unterscheiden haben von denen, in welchen eine "Teilung" der Blätter bei Vermehrung der Blattzahl eintritt (vgl. p. 334). Erstere sind verbunden mit einer Reduktion der Blattbildung, letztere mit einer Steigerung.

1) v. SchöNAU (vgl..p. 77).

2) Vgl. Jongmans, Über Brutkörper bildende Laubmoose. Récneil des travaux bot. néerlandais. Vol. III. 1907. 


\section{Fünfter Abschnitt.}

\section{Verschiedenheit der Organbildung auf verschiedenen Entwicklungsstufen: Jugendformen und Folgeformen.}

Vorbemerkung. Eine Darstellung des in diesem Abschnitt behandelten Gegenstandes habe ich früher gegeben in Vergl. Entwicklungsgeschichte der Pflanzenorgane, p. $251 \mathrm{ff}$; f ferner: Über die Jugendzustände der Pflanzen, Flora 1889 p. 1-45; Über Jugendformen von Pflanzen und deren künstliche Wiederhervorrufung (Sitzungsberichte der kgl. bayer. Akademie der Wissenschaften math.-naturw. Klasse, 1896). Die Literatur ist, soweit sie Phanerogamen betrifft, aufgeführt in der Abhandlung von O. ScḦ̈FFER: Über die Verwendbarkeit des Laubblattes der heute lebenden Pflanzen zu phylogenetischen Untersuchungen (XIII. Band der Abhandlungen aus dem Gebiete der Naturwissenschaften. Herausgegeben vom naturwissenschaftlichen Verein Hamburg 1895.) Von neueren Abhandlungen nenne ich: Diels, Über Jugendformen und Blühreife im Pflanzenreich, Berlin 1906 (wo auch die interessanten Untersuchungen von L. Cockayne angeführt sind).

\section{$\S 1$. Einleitung.}

Alle Lebewesen befinden sich - von dem Zustande des ,latenten Lebens" abgesehen - fortdauernd in dem Zustand der Veränderung. Hier beschäftigt uns die mit dieser rerbundene äußere Gestaltveränderung.

Im allgemeinen ist diese um so mannigfaltiger, je höher organisiert eine Pflanze ist. Bei niederen Pflanzen, bei denen eine Trennung von generativem und regetativen Plasma noch nicht eingetreten ist (Bakterien, Konjugaten usw.), ist auch der Formwechsel bei der Entwicklung ein sehr einfacher.

Bei einem Mikrococcus z. B. besteht er nur darin, daß die kugelige Zelle sich teilt in zwei Halbkugeln, welche wieder zu Kugeln sich abrunden. Bezeichnen wir die.. Halbkugel als "Jugendstadium", so geht dieses rasch und ohne große Änderung in das darauf folgende ("Folge"-) Stadium, die Kugelform über, an der sich derselbe Vorgang wiederholt.

Je reicher gegliedert eine Pflanze ist, desto mannigfaltiger ist auch der Formwechsel von dem Jugendstadium bis zu dem, in welchem die Fortpflanzung eintritt, d. h. die Bildung neuer Keimzellen. 
Deren Auftreten bezeichnet stets einen Höhepunkt der Entwicklung, in vielen Fällen ihren Abschluß. Dieser Höhepunkt der Entwicklung wird nur allmählich erreicht.

Die ersten Stadien kann man als Jugendstadien bezeichnen. Es ist selbstverständlich unmöglich, sie scharf abzugrenzen. (Wir sehen dabei zunächst $\mathrm{ab}$ von den Anordnungsverhältnissen der Zellen und von der Gestaltung, die der Embryo höherer Pflanzen innerhalb des Samens erhält, und beschäftigen uns nur mit den Eigenschaften, die bei der Keimung auftreten.)

Die Abweichung dieser Jugendstadien ron der "Folgeform" kann mehr oder minder groß sein. Diese beiden Stufen bezeichnen ihrerseits wieder Reihen von Entwicklungsvorgängen, die meist ohne scharfe Grenzen ineinander übergehen. Die Verschiedenheit beider spricht sich in verschiedener Weise, sowohl in der Gestaltung als im physiologischen Verhalten aus.

Bei der Gestaltung kommt bei beblätterten Pflanzen in Betracht die Anordnung und Form der Blätter und die Ausbildung der Sproßachse.

\section{§ 2. Verschiedenheit in der Blattanordnung und im physiologischen Verhalten von Jugend- und Folgeformen.}

Wenn eine Verschiedenheit in der Blattanordnung vorhanden ist, so ist sie namentlich dann von Interesse, wenn sie uns einen Hinweis

Fig. 348.

Fissidens taxifolius. Junge Pflanze vergr. Die 3 ersten Blätter $1,2,3$ sind ${ }_{n}$ spiralig " gestellt nnd haben keinen Flügel. Von Blatt $4 \mathrm{ab}$ ist die Blattstellnng $1 / 2$. Der Flügel $F$ ist zunächst klein, später übertrifft er die übrige Blattfläche an Größe.

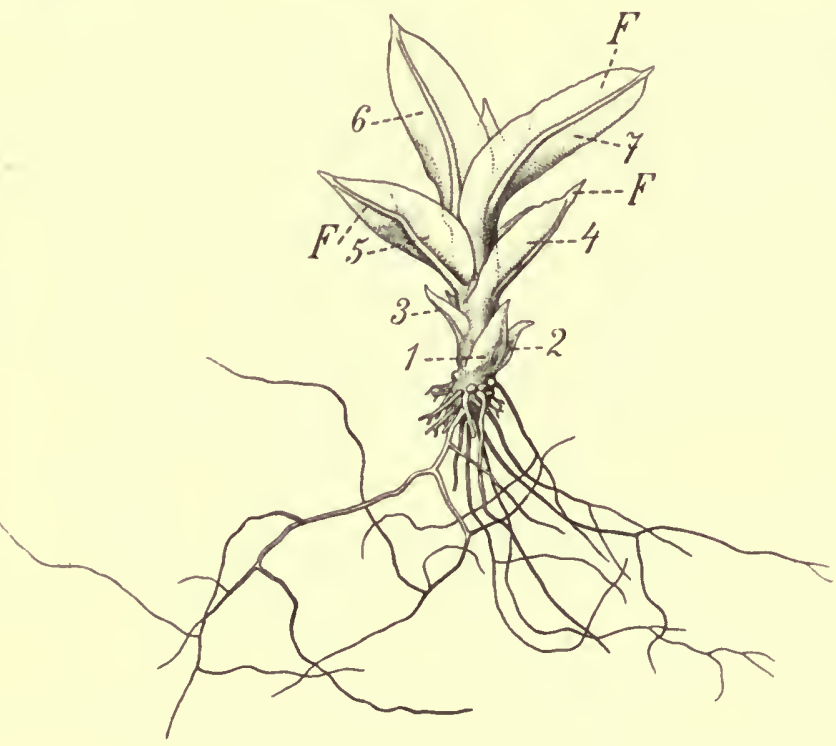

auf das Zustandekommen der Blattanordnung bei der Folgeform gibt. Beispiele dafür wurden früher schon mehrfach gegeben.

Es sei erinnert an das Verhalten von Polygonatum verticillatum (p. 208), Aloearten (p. 211), Helianthus (204), Ulmus (p. 254).

Weitere Beispiele:

Die Laubmoosgattung Fissidens hat zweizeilige Blattanordnung. Wie 
Hofmeister ${ }^{1}$ ) zuerst für Fissidens bryoïdes nachwies, haben die ersten Blätter der Keimpflanzen nicht nur noch nicht den für die späteren charakteristischen "Flügel", sondern sie stehen wie bei anderen Moosen, noch dreizeilig (Fig. 348).

Für Dawsonia wurde (p. 206) angeführt, daß die Keimpflanzen noch nicht die später einsetzende "Scheiteltorsion" zeigen. Vermutlich gilt das auch für andere Moose mit Scheiteltorsion, doch fehlt es dafür an Beobachtungen.

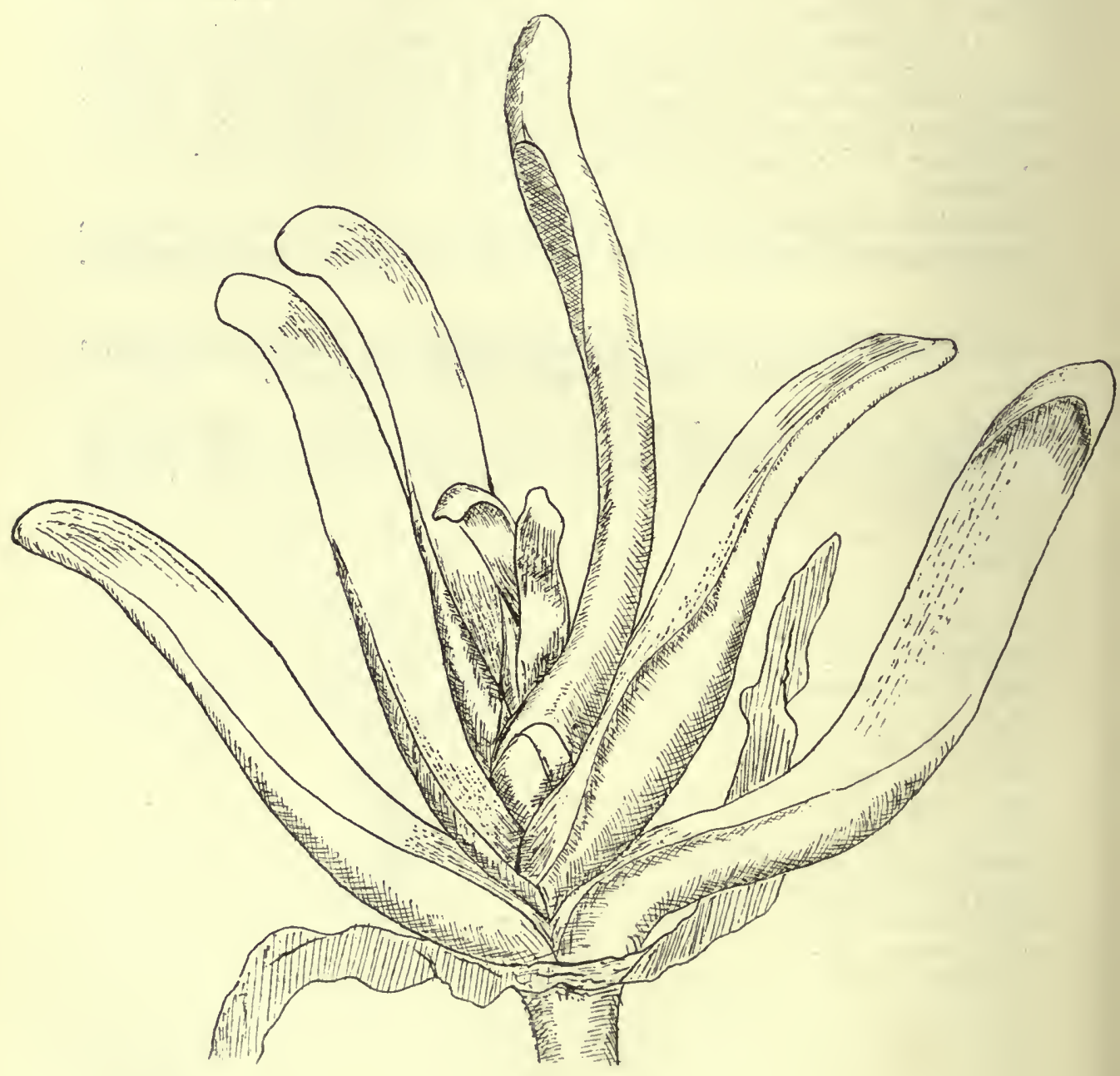

Fig. 349. Mesembryanthemum linguaeforme nach Gentwer, Sproß in nat. Größe.

Auch für die Dikotylen sei nur an wenige Beispiele erinnert (vgl. p. 204). Hier namentlich an solche, bei denen die Keimpflanze noch die dekussierte Blattstellung zeigt, die Folgeform nicht mehr. Den früher behandelten Fällen seien hier zwei hinzugefügt.

1) Hofmeister, Die Lehre von der Pflanzenzelle p. 140. 
Mesembryanthemum linguaeforme ${ }^{1}$ ) (Fig. 349), die Folgeform zeigt anscheinend zwieizeilige Blattstellung. Die Keimpflanze (Fig. 350) zeigt dagegen noch die normale dekussierte Blattstellung. Auch bei Vitis vinifera (Fig. 351) sind die ersten Blätter mit den Kotyledonen gekreuzt, worauf bei den von mir beobachteten Keimpflanzen (andere scheinen sich anders $\mathrm{zu}$ verhalten) zweizeilige Blattstellung eintrat.

Bei der Sproßachse handelt es sich namentlich um die Verschiedenheiten in der Entwicklung der Internodien, für welche Beispiele anzuführen kaum erforderlich sein wird.

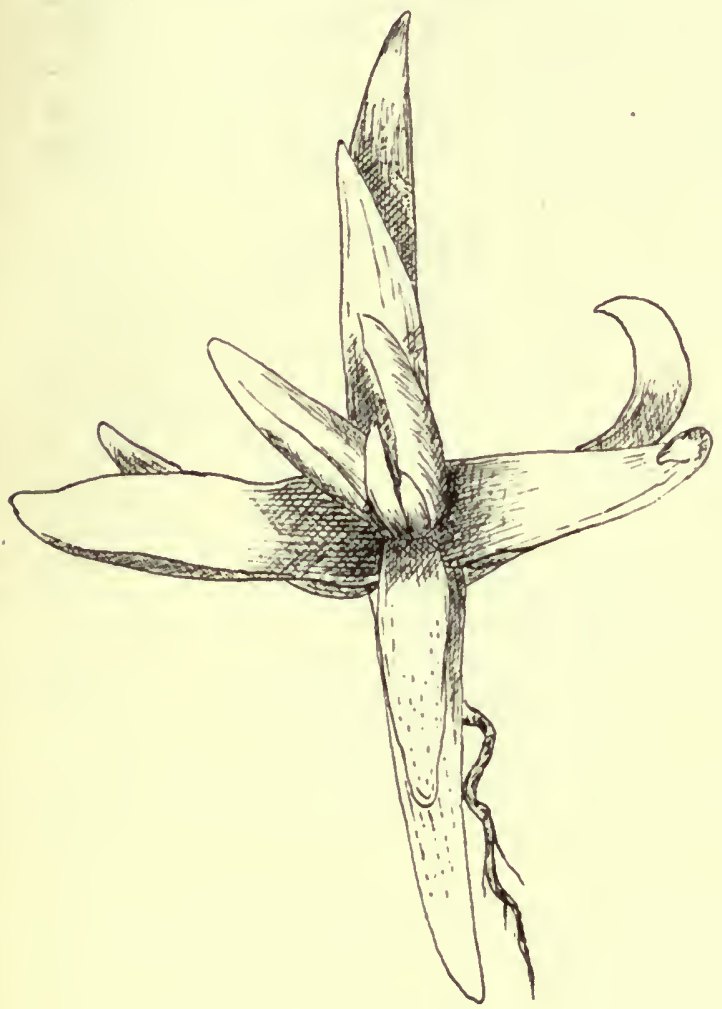

Fig. 350 .

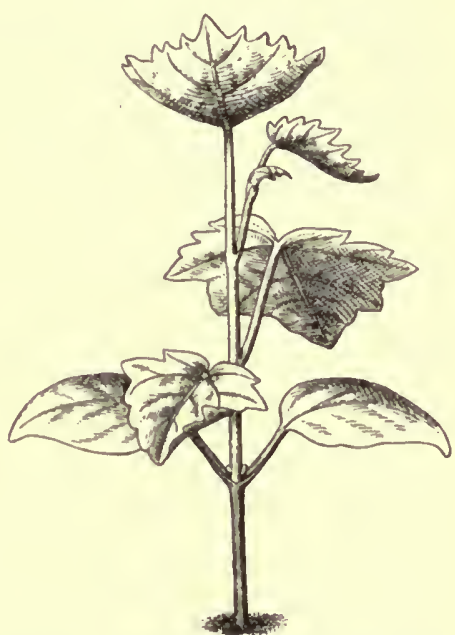

Fig. 351. Vitis vinifera, Keimpflanze. Erstes Blattpaar mit den Kotyledonen gekrenzt, darauf $1 / 2$ Stellung. Das dritte Blatt scheinbar terminal.

Fig. 350. Keimpflanze ron Mes linguaeforme.

In physiologischer Beziehung ist namentlich das Regenerationsvermögen der Jugendform vielfach ein anderes, als das der späteren. So haben die ersten Blätter der Keimpflanzen von Lycopodium inundatum die Fähigkeit, Adrentivsprosse zu erzeugen, die späteren nicht $\left.{ }^{2}\right)$. Analog verhalten sich diejenigen von Utricularia montana, und bei manchen Coniferen bewurzeln sich Stecklinge der Jugendform leicht, solche der Folgeform schwer oder gar nicht.

Wir sehen ferner die Richtungsverhältnisse der Jugendform oft abweichend: bei manchen Pflanzen, die später plagiotrope Sprosse bilden, ist der Keimling orthotrop (Tilia, Fagus, Carpinus, vgl. p. 190), bei

1) Gentwer, Unters. über Anisophyllie und Blattasymmetrie. Flora 99 (1909).

2) Vgl. auch das für Preissia commutata unten Angeführte und Goeber, Einleitung in die experimentelle Morphologie der Pflanzen (1908). 
anderen ist das Verhältnis umgekehrt, so bei den unten $\mathrm{zu}$ besprechenden Wurzelkletterern aus der Familie der Aroideen, Marcgraviaceen u. a.

\section{§ 3. Homoblastische und heteroblastische Entwicklung.}

Die angeführten Beispiele (denen sich zahlreiche andere anreihen ließen) erläutern, daB die Jugendform anders zur AuBenwelt in Beziehung tritt als die Folgeform, eine Tatsache, die bei den „Larvenformen" vieler Tiere noch viel auffallender sich zeigt.

Die Verschiedenheit beider Entwicklungsabschnitte tritt in sehr verschiedenem Grade hervor; wir haben Fälle, wo sie sehr gering ist, beide also ganz allmählich ineinander übergehen. Dies sei als homoblastische Entwicklung bezeichnet. Fälle, bei denen sie groß ist, zeigen heteroblastische Ausbildung. Zwischen beiden gibt es natürlich keine scharfe Grenze.

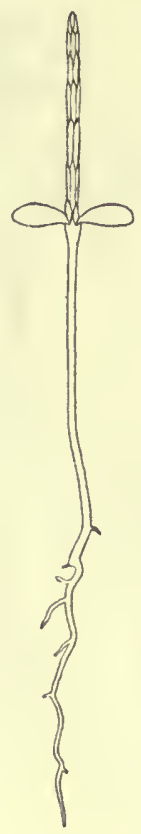

Fig. 352.

Keimptlanze von Casuarina torulosa. 2 mal vergr.

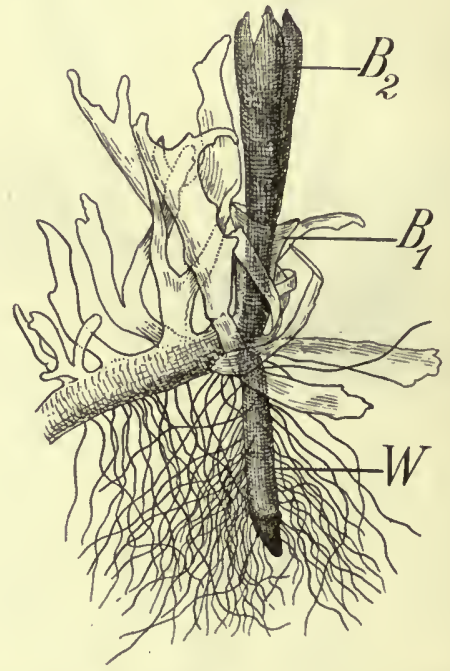

Fig. 353. Equisetum Telmateja, Prothallium mit Keimpflanze. Letztere (etwas dunkler gehalten) besteht aus einem mit zwei Blattwirteln $B_{1} B_{2}$ versehenen Sproß, der im wesentlichen ebenso gestaltet ist, wie die späteren Sprosse und einer Wurzel W.

Bei höheren Pflanzen können die Casuarinen als Beispiel für homoblastische Entwicklung dienen (Fig. 352). Die equisetumähnlichen, chlorophyllhaltigen Sproßachsen dieser Pflanzen haben rudimentäre, wirtelständige, zu Scheiden verwachsene Blätter. Schon die Keimpflanze verhält sich, abgesehen von den Kotyledonen, ebenso. Nur die Zahl der Blätter, welche einen Blattwirtel zusammensetzen, steigt später; auf die Kotyledonen folgt ein zweizähliger mit ihnen gekreuzter Blattwirtel, diesem ein zweiter gleichzähliger, der dritte ist vierzählig und mit dem zweiten diagonal gekreuzt ${ }^{1}$ ).

1) Vgl. Monısı, Contribnto all' anatomia del caule e della foglia delle Casuarinee. Mem. della R. Acc. delle science dell' istituto di Bologna Ser. V T. IV p. 692. 
Und ganz ähnlich ist es bei den den Casuarinen im Habitus ähnlichen Equiseten (vgl. p. 92 und Fig. 35̃3). Die Achse der Keimpflanze ist zwar viel schmächtiger und anatomisch einfacher gebaut als die Achse der späteren Sprosse, die Zahl der Blätter in einem Blattwirtel ist eine geringere, die unterirdischen Sprosse fehlen noch, es bilden sich aufeinanderfolgend immer kräftiger gebaute Sproßgenerationen aus, bis die definitive Ausbildung erreicht ist; aber die Grundzüge der Gestaltung sind doch bei allen Sprossen dieselben.

Dagegen sehen wir eine heteroblastische Entwicklung bei den australischen, Phyllodien besitzenden Akazien und in anderen Fïllen, namentlich bei Muscineen und manchen Algen.

Solche Beispiele haben namentlich dann die Aufmerksamkeit auf sich gezogen, wenn die Gestaltung der Keimpflanzen übereinstimmt mit derjenigen der Folgeform verwandter Pflanzen, wie dies bei den genannten Akazien der Fall ist. Viele Acaciaarten haben dauernd die Blattform, die bei den phyllodienbildenden nur bei der Keimung auftritt; die Gestaltung der Keimpflanzen führt uns direkt die Umbildung, welche vor sich gegangen ist, ror Augen. $\mathrm{Da} B$ sich bei diesen Keimpflanzen die ursprünglichere, phylogenetisch ältere Form der Vegetationsorgane erhalten hat, steht, wie unten noch auszuführen sein wird, auch hier damit im Zusammenhang, daß sie unter anderen Bedingungen leben als die Folgeform.

Denken wir uns, daß bei den phyllodienbildenden Akazien die Jugendformen der Blätter an der Keimpflanze wegfallen würden, so würde durch diese $\mathrm{Abkürzung} \mathrm{die} \mathrm{Entwicklung} \mathrm{aus} \mathrm{einer} \mathrm{heteroblastischen} \mathrm{zu}$ einer homoblastischen, ähnlich der für Casuarina angefuihrten. Bei den phyllodienbildenden Akazien stellen ebenso wie bei Tilia, Carpinus u. a. die Jugendformen ein phylogenetisch ursprünglicheres Gestaltungsverhältnis dar; eine homoblastische Entwicklung bei höheren Pflanzen ist meist ein Zeichen von Rückbildung, welche-bis auf das Jugendstadium sich erstreckt.

Aber in anderen Fällen béruht die Gestaltung der Keimpflanzen sicher nicht auf Erhaltung eines ursprünglichen Formverhältnisses, sondern auf einer später aufgetretenen „Anpassung". Die Keimpflanzen zeigen dann also nicht ein primitives, sondern ein abgeleitetes Verhalten. Die Anpassung an andere Verhältnisse gibt uns an und für sich noch keinen Aufschluß daruiber, sondern nur der Vergleich mit verwandten Formen. In manchen Fällen ist denn auch mit Sicherheit eine Entscheidung darüber nicht möglich, zumal innerhalb eines und desselben Verwandtschaftskreises, ja innerhalb einer und derselben Gattung die Gestaltung der Jugendform keineswegs immer eine übereinstimmende ist.

Außer dem abweichenden Verhalten der Jugendform zu den äußeren Bedingungen des Pflanzenlebens kommt vielfach noch ein weiterer Faktor in Betracht, der sich namentlich in der Gestaltung der Blätter (Primärblätter) der Jugendform ausspricht. Diese verdanken meist ihre von der der "Folgeblätter" abweichende Gestaltung der Tatsache, daß sie Hemmungsbildungen darstellen, d. h. ihre Entwicklung stimmt mit der der Folgeblätter überein, aber die Blattanlage bleibt auf einem gewissen Stadium stehen und erreicht dadurch eine scheinbar oft weit abweichende Gestaltung. Dieser Gesichtspunkt findet seine Anwendung iibrigens auch auf die Gestaltung derjenigen Jugendformen, welche oben als phylogenetisch primitiv gegenuiber der Folgeform bezeichnet wurden, da diese letztere ja ihren abweichenden Charakter dadurch erhält, daß sie zu einer weiteren Umbildung fortschreitet. 
Als eine solche „Hemmungsbildung" an Keimpflanzen erweist sich bei den Samenpflanzen die Gestaltung der Kotyledonen, welche in dem speziellen Teile zu besprechen sein wird. Hier sei nur erwähnt, daß diese von den Laubblättern oft so abweichend gestalteten Gebilde nichts anderes sind als Hemmungsbildungen; die Hemmung ist eine teils dauernde, teils vorübergehende.

Als Beispiel für letzteres Verhalten sei auf das' Verhalten der Kotyledonen von Ampelopsis hingewiesen, welche, ursprünglich klein und einfach, nach der Keimung zu verhältnismäßig großen Laubblättern auswachsen. Noch auffallender verhalten sich manche Oenothereen (Fig. 354), bei denen durch interkalares Wachstum an der Basis der Kotyledonen nach der Keimung ein Stück eingeschoben wird, das viel größer ist als der ursprüngliche Kotyledon.

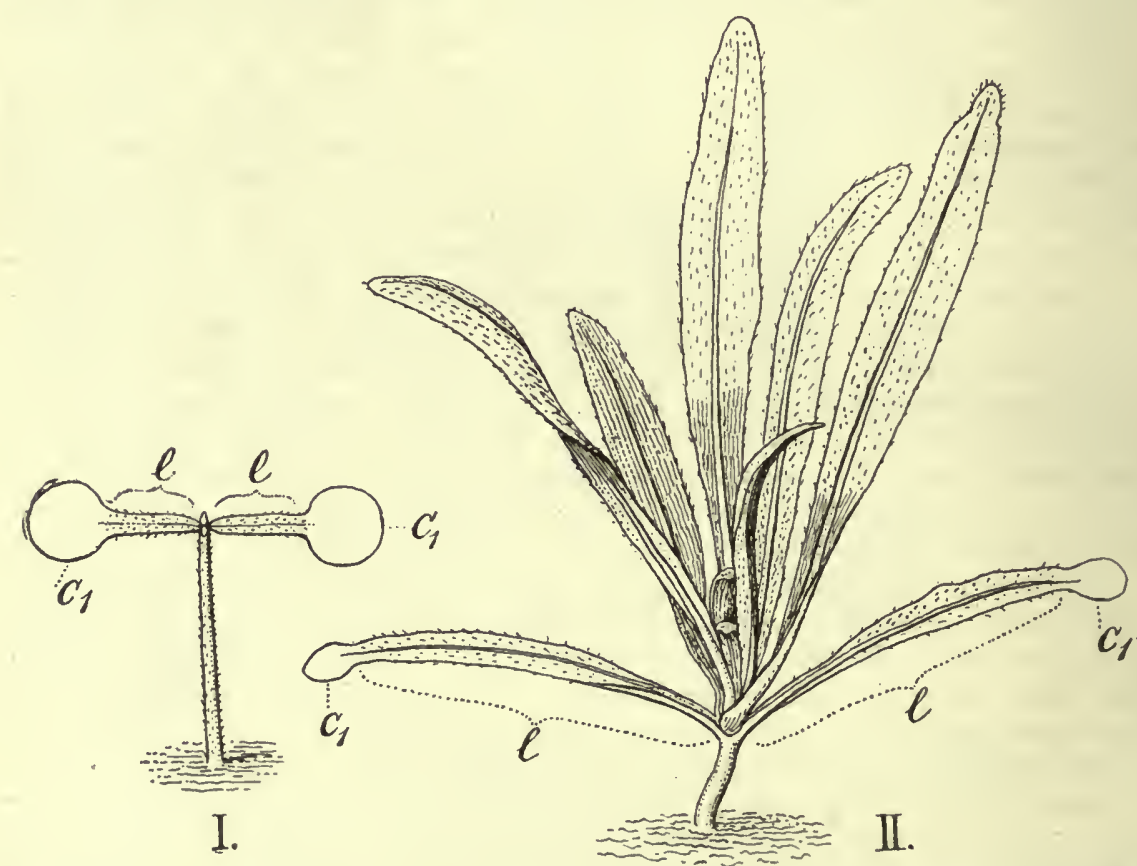

Fig. 354. Keimpflanzen von Oenothera bistorta (nach Luввоск), $c_{1}, c_{1}$ der ursprïngliche Kotyledon, $l l$ das später interkalar zugewachsene Stück.

Bei diesen Pflanzen hat also eine Hemmung in der Entwicklung der Kotyledonen nur für die Dauer der Samenruhe und die ersten Keimungsstadien stattgefunden, der Unterschied dem Verhalten der meisten anderen Kotyledonen gegenüber ist aber nur ein quantitativer, nicht ein qualitativer.

\section{$\S 4$. Verschiedene Dauer der Jugendform.}

Kaum minder verschieden als die äußere Gestaltung ist auch die Dauer der Jugendformen. Vielfach ist sie von äußeren Faktoren abhängig, namentlich bei niederen Pflanzen. Bei einigen stellt aber die 
Jugendform den eigentlichen Vegetationskörper dar, die Folgeform bringt der Hauptsache nach nur die Geschlechtsorgane hervor und erscheint als ein kurzlebiges Anhängsel der Jugendform. Dabei kann diese letztere auch dadurch an selbständigem Charakter gewinnen, daß sie besondere Vermehrungsorgane ausbildet, aus denen dann natürlich immer nur wieder die Jugendform sich ausbildet. Wenn dann die "Jugendform" auch zur Bildung von Geschlechtsorganen schreitet, so haben wir Pflanzen vor uns, bei denen ein Abschnitt der Entwicklung, der sonst als "Folgeform" auftritt und für den Artcharakter von großer Bedeutung ist, ganz ausgeschaltet erscheint.

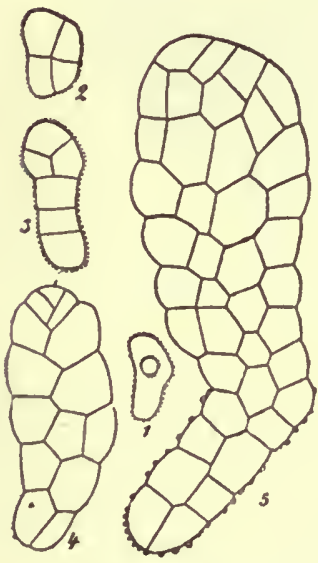

Fig. 3555 .

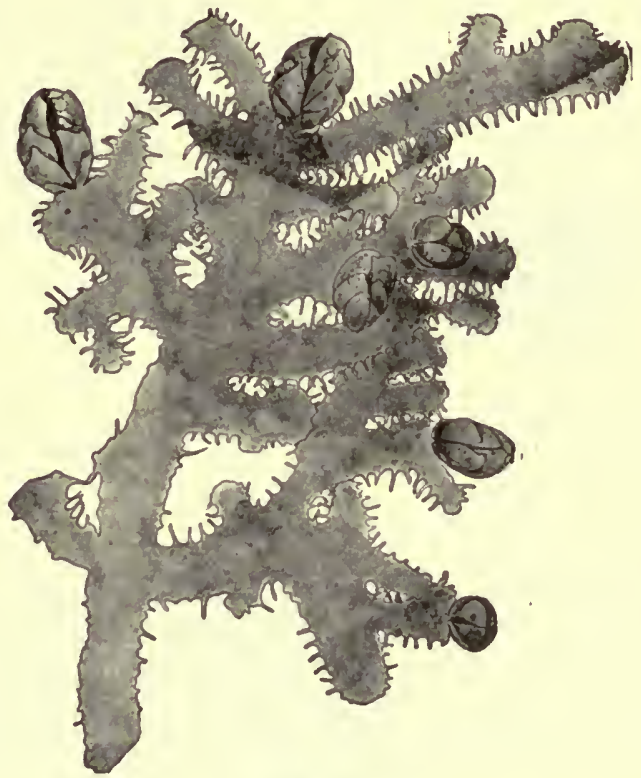

Fig. 356.

Fig. 35̌ zeigt die Keimung der Sporen einer Art des Lebermooses Lejeunia. Es bildet sich als "Vorkeim" eine mit zweischneidiger Scheitelzelle wachsende Zellfläche, die aber nur unbeträchtliche Größe erreicht und dann aus ihrer Scheitelzelle die beblätterte Pflanze entwickelt. Fig. 356 (viel schwächer vergrößert als Fig. 355). Lejeunia Metzgeriopsis. Der "Vorkeim" ist der eigentliche Vegetationskörper; an ihm treten, als kleine Anhängsel, die beblätterten Sprosse auf, die nur als Träger der Geschlechtsorgane (hier der Antheridien) funktionieren.

Als Beispiele für solche Pflanzen, bei denen die Jugendform eine sehr lange Dauer hat (während sie bei verwandten Pflanzen nur ein rasch vorïbergehendes Entwicklungsstadium darstellt), seien hier zunächst zwei Moose angeführt, bei denen dies Verhalten besonders einfach hervortritt. Lejeunia Metzgeriopsis (Fig. 356) besitzt einen reich verzweigten Thallus von bandförmiger Gestalt, der sich durch scheibenförmige Brutknospen sehr reichlich vermehrt. Trotzdem ist dies Lebermoos aber ein beblättertes, der Thallus ist nur eine Weiterentwicklung der bei der Keimung anderer Lejeuniaarten (Fig. 355) auftretenden Jugendform ${ }^{1}$ ). Die beblätterten

1) Goeberc, Morphol. und biolog. Studien, Ann. du jardin botanique de Buitenzorg VII (1887). Über die Jugendzustände der Pflanzen, Flora 1889, p. 14 und Flora 1893, p. 94 . 
Sprosse, die bei diesen die eigentlichen Vegetationsorgane darstellen, sind bei L. Metzgeriopsis nur noch als Träger der Geschlechtsorgane ausgebildet, die Jugendform stellt den eigentlichen. Vegetationskörper dar und besitzt selbständige Vermehrungsorgane, Brutknospen, die für die Verbreitung der Pflanze wahrscheinlich wichtiger sind als die Sporen. Da diese Pflanze als Epiphyt auf den Blättern höherer Pflanzen wächst, so ist der flache Thallus der Jugendform ganz besonders geeignet; sich dem Substrat fest anzuschmiegen und die Assimilate zu gewinnen, auf deren Kosten dann die kurzlebige "Folgeform" die Sexualorgane hervorbringt.

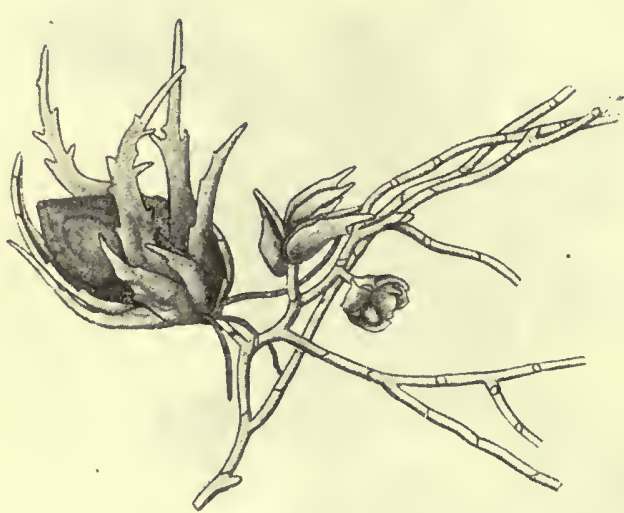

Fig. 35̌7. Ephemerum serratum. Protonema mit sieben (weiblichen und männlichen) Pflanzen. Eine der weiblichen Pflanzen (die größte links, welche die neben ihr stehende männliche Pflanze verdeckt) hat ein nahezu reifes Sporogon hervorgebracht. In der Mitte stehen ausnahmsweise drei beblätterte Pflänzchen zusammen, gewöhnlich sind es nur zwei.

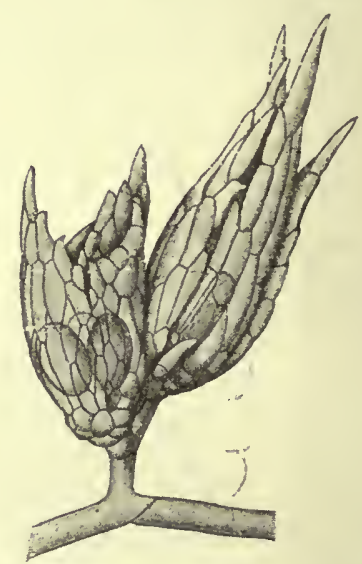

Fig. 358. Ephemerum serratum. Stỉck eines Protonemafadens mit $z$ wei jungen Pflanzen (stärker vergr. als Fig. 3577). In der Pflanze links schimmern drei Antheridien, in der' rechts ein Archegonium durch; das erste Blatt dieser Pflanze (nach vorn gekehrt) ist eine einfache Zellreihe.

Ähnlich verhält sich unter den Laubmoosen die Gattung Ephemerum. Die Jugendform der Laubmoose tritt typisch als ein aus verzweigten Zellfäden bestehendes Protonema auf, an welchem die beblätterten Pflanzen entstehen (Fig. 359). Nach deren Bildung verschwindet das Protonema. Bei Ephemerum (und einigen anderen Gattungen) aber perenniert es. An ihm entstehen winzige, beblätterte Pflänzchen, welche wesentlich nur der Hervorbringung der Sexualorgane dienen. Inwiefern dies mit den Lebensverhältnissen zusammenhängt, wird bei den Moosen zu erörtern sein. Bei diesen beiden Moosen ist die lange Dauer der Jugendform eine aus „inneren" Gründen erfolgende, d. h. sie ist nicht direkt durch die Außenwelt bedingt. Es mag aber auch hier schon an einem Beispiel gezeigt werden, daß äußere Faktoren die Dauer und Größenentwicklung der Jugendform weitgehend beeinflussen können. So zeigt Fig. 360 ein in Wasser gewachsenes Protonema von Philonotis fontana, das mächtige Dimensionen angenommen aber keine Moosknospen gebildet hat und statt als dïnner Überzug über das Substrat in Gestalt eines Polsters auftritt. Wie bei einer Samenpflanze, die Polster bildet, sind auch hier die chlorophyllhaltigen Teile nur in der Peripherie entwickelt, die inneren Protonema- 
fäden verlieren ihre grüne Farbe. Die beblätterten Sprosse dieses Mooses ${ }^{1}$ ) aber haben nicht die Reduktion erfahren, wie bei Metzgeriopsis und Ephemerum, vielmehr handelt es sich, wie erwähnt, nur um eine durch äußere Faktoren bedingte Verlängerung des Jugendstadiums.

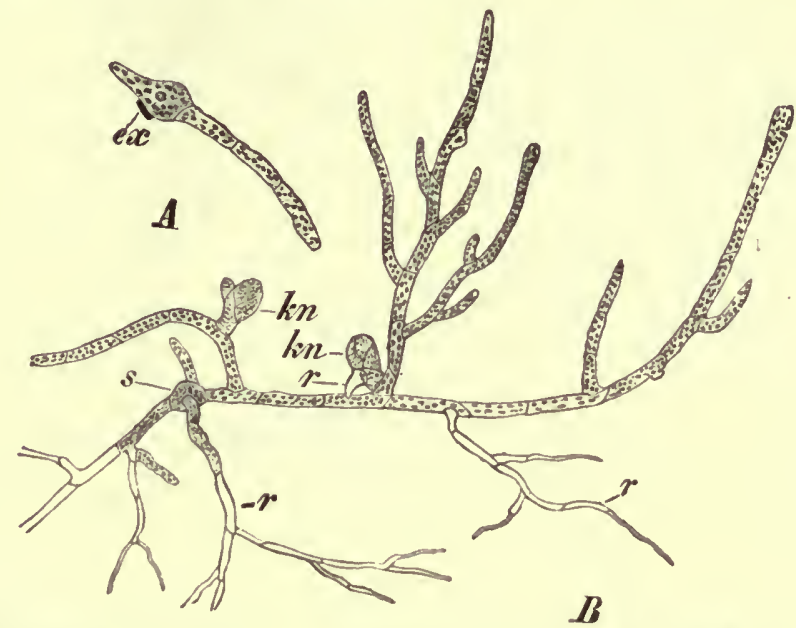

Fig. 359. Keimung der Sporen von Funaria hygrometrica (stark vergrößert). Bei $A$ Beginn der Keimung; $B$ ein Protonema mit zwei jungen Moosknospen $(k n)$, eine davon hat eine Wurzel $r$ getrieben. Nach Mǘlum-Thurgau. (Lehrb.)

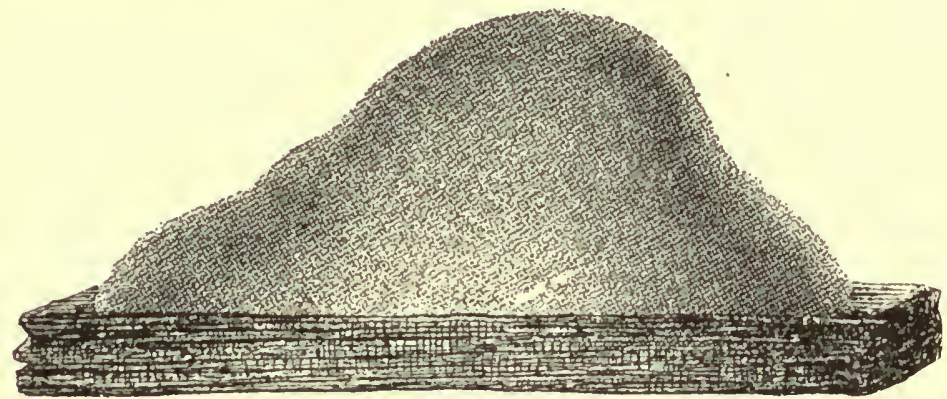

Fig. 360. Protonemapolster (natürl. Größe), von Philonotis fontana, einem Stück Holz aufsitzend. Diese nngewöhnlich massive Entwicklung hat unter Umständen stattgefunden, welche das Wachstum des Protonemas begünstigten, die Bildung von Moosknospen aber verhinderten.

Dafür, daß dieses auch bei den Moosen als Rückschlag im späteren Lebensalter wieder auftreten kann, liefert Fig. 361 ein auffallendes Beispiel. Die Gattung Tetraphis ist dadurch ausgezeichnet, daß an ihrem

1) Verf. hatte diesen Fall besprochen und abgebildet in der Abhandlung „Über Jugendformen von Pflanzen nsw., die Zugehörigkeit des Protonemas aber nicht bestimmen können. In einer Notiz in Potonié's Naturw. Wochenschrift 17, 1896 p. 444 wird von Zimmermann Philonotis fontana als das Moos genannt, welches in Bächen (mit Wasser, das reich ist an schwefelsauren Salzen und Eisen absetzt) die merkwürdigen Protonemapolster bildet. Es fragt sich, ob das Wasser als solches oder sein Gehalt an gelösten Substanzen die üppige Protonemabildnng bedingt; Moospflanzen scheinen sich da zu bilden, wo die Protonemapolster über den Wasserspiegel hervortreten. 
Fig. 361. Tetraphis pellucida (etwa 18 fach vergr.). Sproß, welcher geköpft und bei schwachem Lichte kultiviert war (was sich in der Kleinblättrigkeit ausspricht). In den Achseln zweier Blätter sind Protonemaflächen $(P)$ entstanden, welche viel größer als die Lanbblätter und offenbar der schwachen Beleuchtung besser angepaßt sind.

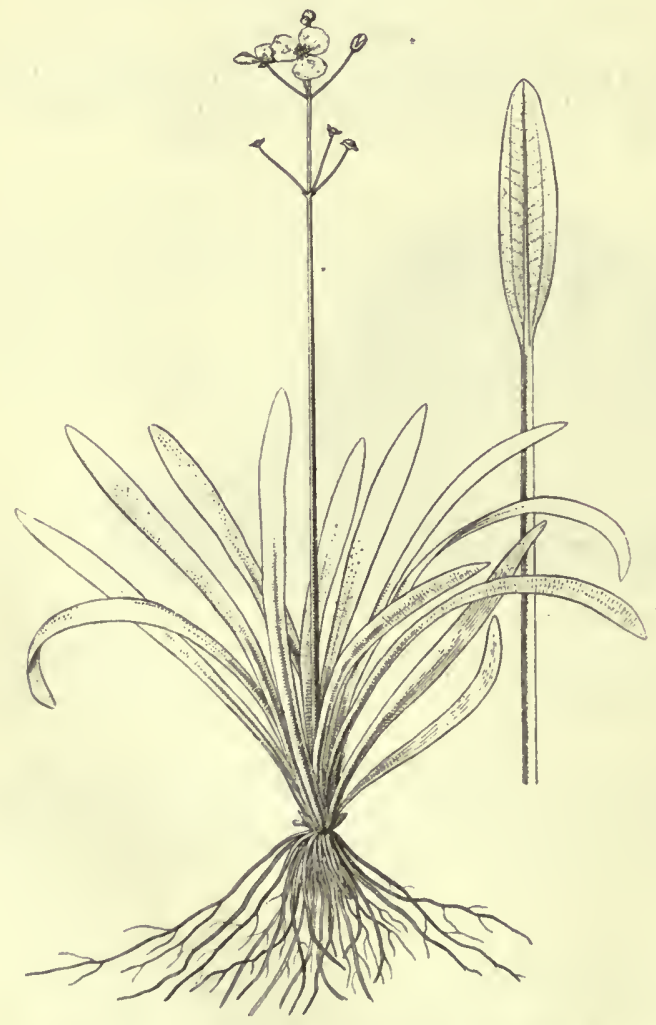

Fig. 362. Sagittaria Chapmani, Pflanze, welche im April im Jugendstadium (nur mit Bandblättern) blïht. Später im Juni blühten die Pflanzen mit Luftblättern, wie eins rechts abgebildet ist.
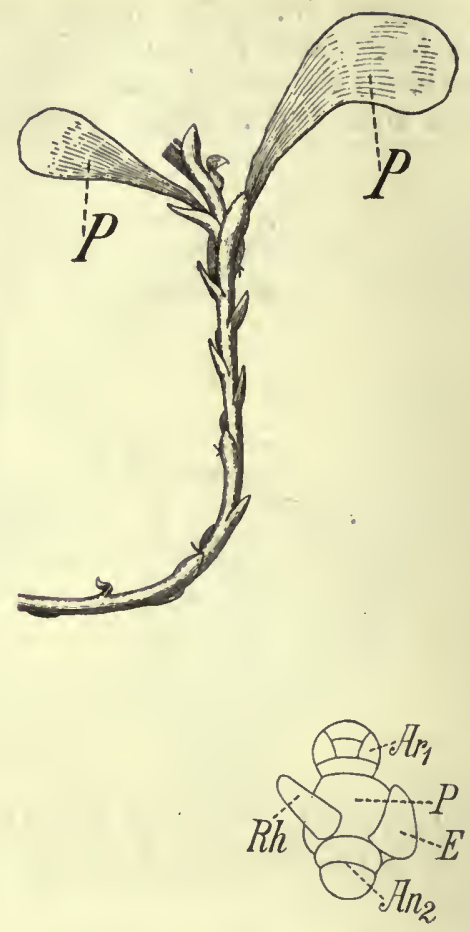

Fig. 363. Einzelliges Prothallium $(P)$ eines leptosporangiaten Farn mit zwei Antheridien $\left(A r_{1} A n_{\mathrm{g}}\right)$. $R h$ Rhizoid, $E$ Stück des Exospors.

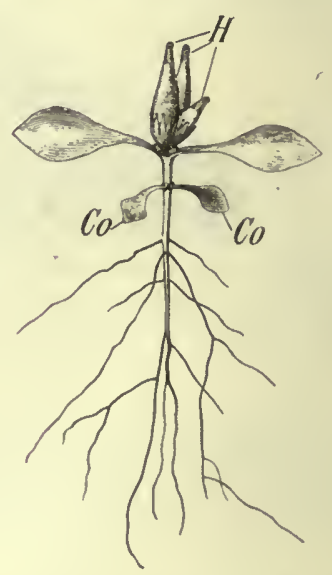

Fig. 364. Vandellia nummulariaefolia $(2 \times)$, Keimpflanze. Co Kotyledonen, sofort nach dem ersten Blattpaar treten die (kleistogamen) Blüten auf, womit die Entwicklung abgeschlossen ist. $H$ die als Haube abgehobene Blumenkrone. 
Protonema blattähnliche Zellflächen auftreten. Diese können, wie Fig. 361 zeigt, auch an der beblätterten Pflanze künstlich hervorgerufen werden.

Da es sich um eine für das Verständnis der Pflanzengestaltung wichtige Erscheinung handelt, so mögen auch von Pteridophyten und Samenpflanzen Beispiele gegeben werden.

Auch hier handelt es sich um zweierlei Erscheinungen: einmal um den Ausfall bestimmter Entwicklungsstadien und dann um die längere Dauer der den ausgefallenen vorausgegangenen Entwicklungsstufe.

Beide Erscheinungen können auch getrennt auftreten, und zwar finden sie sich bei den einen Pflanzen durch äußere, bei den anderen durch „innere" Ursachen bedingt.

Beispiele von Pflanzen mit Ausfall bestimmter Entwicklungsstadien ohne Verlängerung der Jugendform. Die tritt dann ein, wenn die Bildung von Bliiten und Früchten, die sonst den Abschluß der Entwicklung bildet (also an der Folgeform stattfindet), schon an der Jugendform eintritt.

Lehrreich sind manche Sagittarien. Diese zeigen an ihren Vegetationsorganen in den höchst entwickelten Fällen folgende (durch Übergangsformen verknüpfte) Blattformen, welche in der hier gegebenen Reihenfolge auftreten: 1. bandförmige Primärblätter ohne Gliederung in Blattstie] und Blattspreite, 2. Blätter mit ovaler Spreite, die einem Blattstiel aufsitzt, 3. Blätter mit pfeilförmiger Blattspreite (die nicht bei allen Arten auftreten).

In Fig. 362 ist Sagittaria Chapmani abgebildet. Diese blüht im Münchener bot. Garten im Friihjahr stets auf dem Jugendstadium (also mit $\mathrm{nur}$ bandförmigen Primärblättern). Im Juni dagegen haben die blühenden Pflanzen die in Fig. 362 rechts abgebildeten Folgeblätter. Man hat dieses Auftreten der Fortpflanzungsorgane auf dem Jugendstadium auch mit einem besonderen Namen als "Neotenie" bezeichnet.

Die Prothallien der Farne bringen normal Antheridien und Archegonien erst hervor, wenn sie mehrzellig geworden sind und eine gewisse Größe erreicht haben. Fig. 363 zeigt aber, daß schon an einem ein¿elligen Prothallium Antheridien auftreten können, ein Beispiel, das auch deshalb von Interesse ist, weil bei den heterosporen Farnen normal die männlichen Prothallien außerordentlich reduziert sind.

Von Dikotylen sei Vandellia nummulariaefolia als Beispiel angeführt. Diese Pflanze bildet bei kräftiger Entwicklung vegetative Sprosse mit zahlreichen gekreuzten Blattpaaren. Das in Fig. 364 abgebildete Pflänzchen hat nach den Kotyledonen nur ein Blattpaar gebildet und dann seine Entwicklung mit Bildung kleistogamer Blïten abgeschlossen. Es ist das zugleich ein Beispiel für "Nanismus" oder Verzwergung; diese tritt unter für das vegetative Wachstum ungünstigen Bedingungen bei manchen Pflanzen ein und kann sich bei ausdauernden Pflanzen unter Umständen lange erhalten.

Einen solchen früher ${ }^{1}$ ) angeführten Fall erläutert ein Farn (Fig. 365), Asplenium Ruta muraria. Bei kräftig entwickelten Pflanzen treten die Fortpflanzungsorgane auf reich gegliederten wiederholt geteilten Blättern auf. Das abgebildete Exemplar zeigt die Sporangien auf den Primärblättern, welche einfach, ungeteilt sind, eine Erscheinung, die dadurch er-

1) Einleitnng in die exp. Morphol. der Pflanzen p. 10. Vgl. betr. anderer Beispiele namentlich auch DIELs, Über Jugendformen und Blühreife. 
leichtert wird, daß auch bei normaler Entwicklung dieses Farns schon die Primärblätter fertil werden können ${ }^{1}$ ).
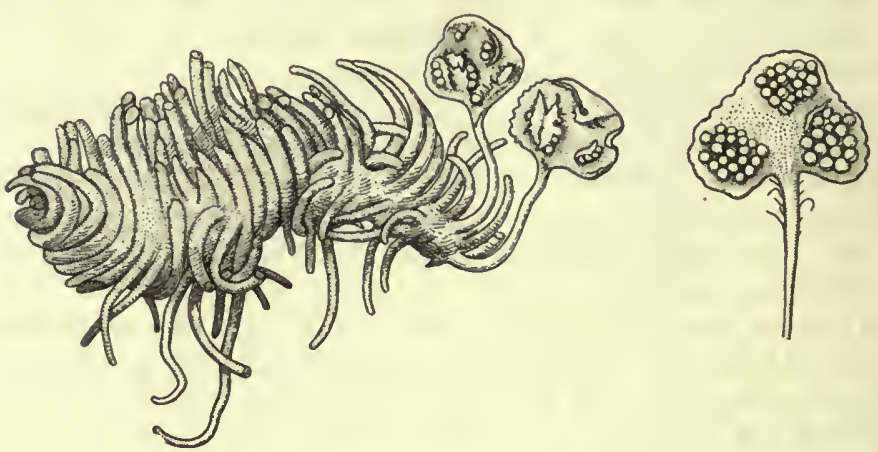

Fig. 365. Asplenium Ruta Muraria. Alte Pflanze aus den Felsritzen des Latemar (Siudtirol). Sie hat nur ein lebendiges Blatt, das, obwohl es über die Primärblattform nicht hinauskommt, trotzdem fertil ist. Das zweite Blatt, vom vorigen Jahre, ist vertrocknet, anßerdem zahlreiche Blattstiele früherer Blätter.

\section{$\S 5$. Ausfall von Folgestadien verkniipft mit starker Entwicklnng der Jugendstadien aus ,inneren" Gründen.}

Dies kann in verschiedener Weise stattfinden: Entweder es vergrößern Organe, die sonst rasch vorübergehen und in der Gesamtentwicklung nur eine untergeordnete Rolle spielen, ihre Existenzdauer und ihre Größe und treten so an Stelle eines bei verwandten Pflanzen später auftretenden, hier aber unterdrückten Organkomplexes oder es bleibt die Entwicklung auf einer bestimmten Stufe stehen, aber die betreffenden sonst als Jugendform auftretenden Organe werden nicht nur einmal, sondern oft wiederholt gebildet.

a) Als Beispiel sei die in Fig. 366 abgebildete Monophyllaea genannt. Der Namen ist eigentlich unrichtig gebildet, die Pflanze hat im blühbaren Alter allerdings scheinbar nur ein einziges großes Laubblatt ( $\mathrm{Co}_{1}$ Fig. 366), aber bei genauerer Betrachtung findet man ein zweites, viel kleineres $\left(\mathrm{Co}_{2}\right.$ Fig. 366), welches zuweilen (wie bei der abgebildeten Pflanze), auch recht stattliche Größe erreicht. Die Beobachtung der Entwicklung zeigt ohne weiteres, daß die beiden Blätter die Keimblätter (Kotyledonen) sind, von denen eins $\left(\mathrm{Co}_{1}\right.$ Fig. 366) sehr bedeutende Größe erreicht und an seiner Basis die Blütenstände hervorbringt, während das andere $\left(\mathrm{Co}_{2}\right)$ meist fruhzeitig im Wachstum stehen bleibt. Dabei kommt eine korrelative Beeinflussung durch den größer werdenden Kotyledon in Betracht, die um so weniger hervortreten wird, je kräftiger ernährt die ganze Pflanze ist.

Es kann keinem Zweifel unterliegen, daß das Verhalten von Monophyllaea (und der sich ganz ähnlich verhaltenden unifoliaten Streptocarpusarten z. B. Str. Wendlandi) sich ableitet ${ }^{2}$ ) von der gewöhnlichen Sproßform.

1) Interessante weitere Beispiele z. B. bei L. Cockayne, Some examples of precocius blooming in heteroblastic species of New Zealand plants. Australasian Ass. for the advancement of science Vol. XIII, 1912.

2) Vgl. auch K. Fritscn, Die Keimpflanzen der Gesneriaceen, Jena 1904 (daselbst weitere Literatnr). 
Bei anderen Gesneriaceen z. B. Chirita (Fig. 367) und Strept. Holsti hat die Keimpflanze auch ungleiche Kotyledonen, von denen einer größer und laubblattartig entwickelt wird. Aber auf die Kotyledonen folgen dann an einem gestreckten Stengel ( $H$ Fig. 367 ) stehende gekreuzte Blattpaare.
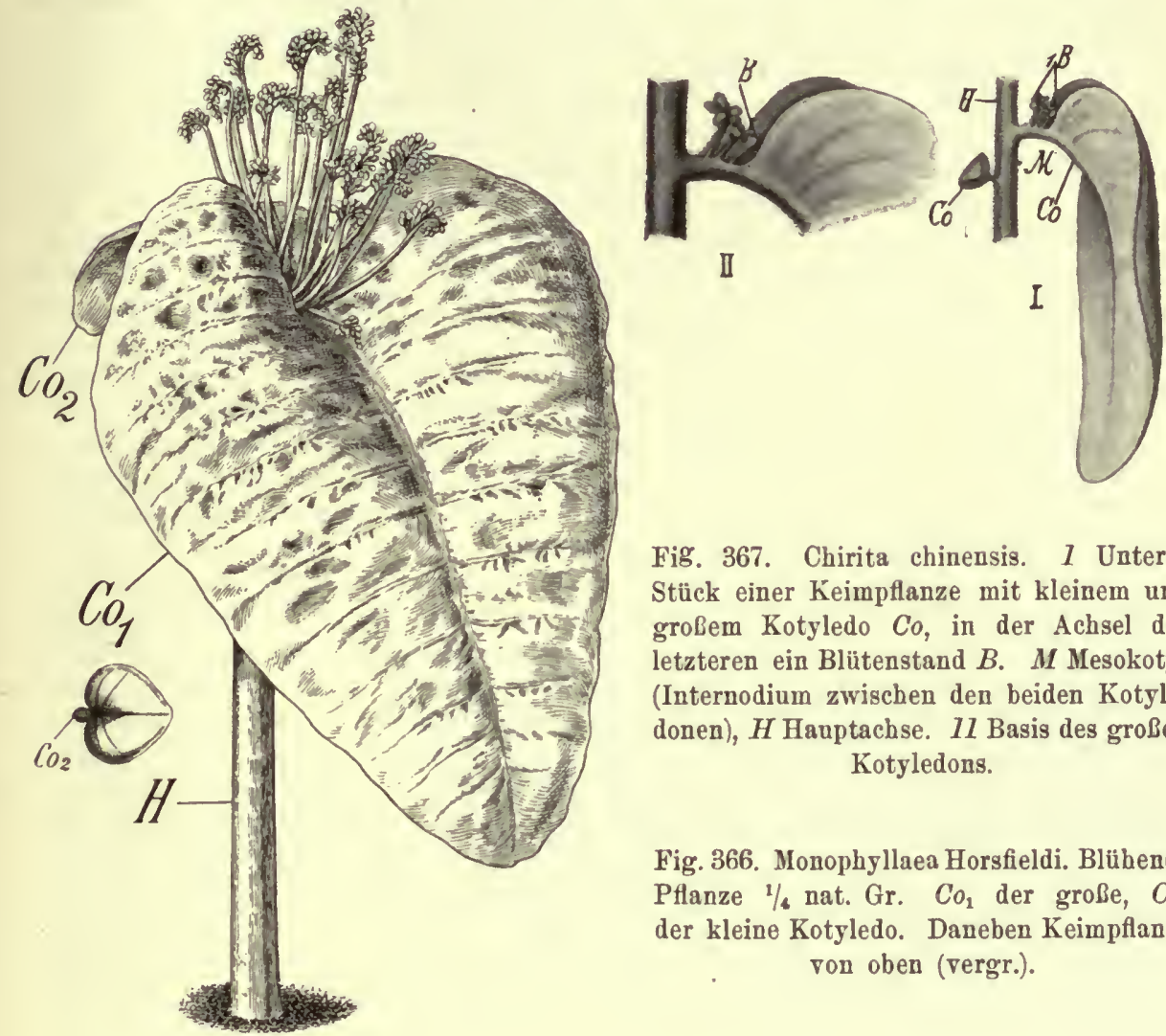

Fig. 367. Chirita chinensis. I Unteres Stïck einer Keimpflanze mit kleinem und großem Kotyledo Co, in der Achsel des letzteren ein Blütenstand $B . M$ Mesokotyl (Internodium zwischen den beiden Kotyledonen), $H$ Hauptachse. 11 Basis des großen Kotyledons.

Fig. 366.

Schon der größere Kotyledon der in Fig. 367 abgebildeten Pflanze hat eine axilläre (ganz auf das Blatt „verschobene") Infloreszenz entwickelt. Denkt man sich den Sproß $H$ ganz unterdriickt, so erhält man das Verhalten der Monophyllaea und der unifoliaten Streptocarpusarten. Die Voraussetzung zum Auftreten der sonderbaren Einblättrigkeit ist also folgende: 1. Fähigkeit eines Kotyledons (oder beider) zu länger andauerndem interkalarem Wachstum. 2. Fortfall der sonstigen vegetativen Entwicklung. Es ist möglich, daß dieser Fortfall korrelativ das Weiterwachsen des Kotyledons bedingt. Diese Annahme würde gestützt, wenn es gelingen würde, auch bei normal gestalteten Gesneriaceen (z. B. Streptoc. Holsti) durch künstliche Unterdrückung der Sproßbildung abnorm vergrößerte Kotyledonen $\mathrm{zu}$ erzielen. 3. Auftreten der Blïten schon in der Achsel eines Kotyledons, was wahrscheinlich durch zeitweilige (Chirita) oder dauernde Hemmung der vegetativen Sproßbildung begünstigt wird. Ob bei Monophyllaea der Vegetationspunkt der Keimpflanze einen terminalen Blütenstand liefert (die anderen stehen in der Achsel des großen Kotyledons) oder 
- was wahrscheinlicher ist - ganz unterdrückt wird, so daß also alle Infloreszenzen seitliche wären, ist derzeit nicht bekannt, auch für die hier erörterten Fragen nicht von besonderem Belang. Dagegen sei noch darauf hingewiesen, daß die Ungleichblättrigkeit auch im Bau des Hypokotyls sich äußert. Einmal in der Verteilung der Leitbündel und dann in der der Wurzeln. Letztere sah ich nämlich auf der unterhalb des großen Kotyledons stehenden Seite des Hypokotyls in größerer Anzahl auftreten als auf der anderen.

Die Frage, ob die eigentümliche Blattbildung der Pflanzen mit nur einem Laubblatt eine für sie vorteilhafte ist, würde sich nur bei genauer Kenntnis der Standortsverhältnisse lösen lassen. Monophyllaea Horsfieldi wächst auf nassem Kalkfelsen auf sehr schattigen Plätzen. Es scheint, wie RIDLEY ${ }^{1}$ ) anführt, daß auch andere an solchen Standorten vorkommende Pflanzen nur ein Blatt ausbilden, das aber nicht immer einer der Kotyledonen zu sein braucht. So z. B. die Rubiacee Argostemma unifolium King. Vielleicht ist es für die Pflanzen dieser schattigen Standorte ein Vorteil, daß sie möglichst bald eine große Assimilationsfläche ausbilden, was ja durch das lange andauernde interkalare Wachstum des Kotyledons ermöglicht wird. Indes würde auch in diesem Falle wohl nur eine, durch innere Gründe bedingte Eigentümlichkeit der Gestaltung sich als vorteilhaft erweisen, nicht eine direkte Beeinflussung der letzteren durch äußere Faktoren anzunehmen sein.

Einigermaßen ähnlich verhält sich eine an ganz anderen Standorten wachsende Pflanze, die beriihmte Welwitschia mirabilis, nur sind hier die Laubblätter, welche viele Jahrzehnte lang fortwachsen, nicht die Kòtyledonen, sondern die auf diese folgenden Blätter. Das Verhalten von Welwitschia kann mit den Standortsverhältnissen insofern in Beziehung gebracht werden, als es für diese extrem xerophile Pflanze wohl von Bedeutung sein wird, ihre transpirierenden Organe möglichst wenig dem Winde auszusetzen, was durch die Lage nahe am Boden erzielt wird. Bei Monophyllaea und den genannten Streptocarpusarten ist eine solche Beziehung derzeit nicht einzusehen; beide verhalten sich auch nicht ganz übereinstimmend; bei Monophyllaea ist das einzige Blatt auf dem Hypokotyl ziemlich hoch emporgehoben, bei Streptocarpus liegt es dem Boden an. Vielleicht bietet das insofern einen Vorteil, als andere Pflanzen dadurch unterdrückt werden, wie es z. B. bei den breitblättrigen PlantagoArten der Fall ist. Es kann aber auch die eigentümliche Gestaltung des Assimilationsapparates eine bloße "Konstruktionsvariation" sein, für deren Auftreten wir oben die Bedingungen kennen lernten.

B. Auf das eigenartige morphologische Verhalten der Lemnaarten (Fig. 368) wurde oben schon hingewiesen. Hier ist noch hervorzuheben, daß die Blattbildung auf dem Stadium bleibt, welches die Primärblätter verwandter schwimmender Wasserpflanzen zeigen. So zeigt z. B. Fig. 369 eine Keimpflanze von Pistia stratiotes von oben. Man sieht zwei. stiellose, mit der Unterseite dem Wasserspiegel aufliegende Primärblätter. Pistia aber bildet später andere, aufgerichtete, gestielte Blätter, während Lemna über das Stadium der kleinen, dem Wasserspiegel aufliegenden Blätter nicht hinauskommt. Man kann dies Verhalten auch bei Pistia einigermaßen nachahmen, wenn man an jungen Pflanzen die Wurzeln ständig entfernt. Sie kommen dann über das Primärblattstadium lange nicht hinaus (Fig. 370 unten). Die Wasseraufnahme durch die Unterseite der

1) H. N. RidLEY, Note on the foliar organ of Monophyllaea, Anuals of botany, Vol. XX (1906) p. 213. 
Blätter genügt nicht zu einer kräftigen Ernährung, wie sie beim Vorhandensein von Wurzeln erfolgt. Was die Art des Hervorsprossens neuer Blätter bei Lemna betrifft, so möchte ich annehmen, daß Wolffia, bei

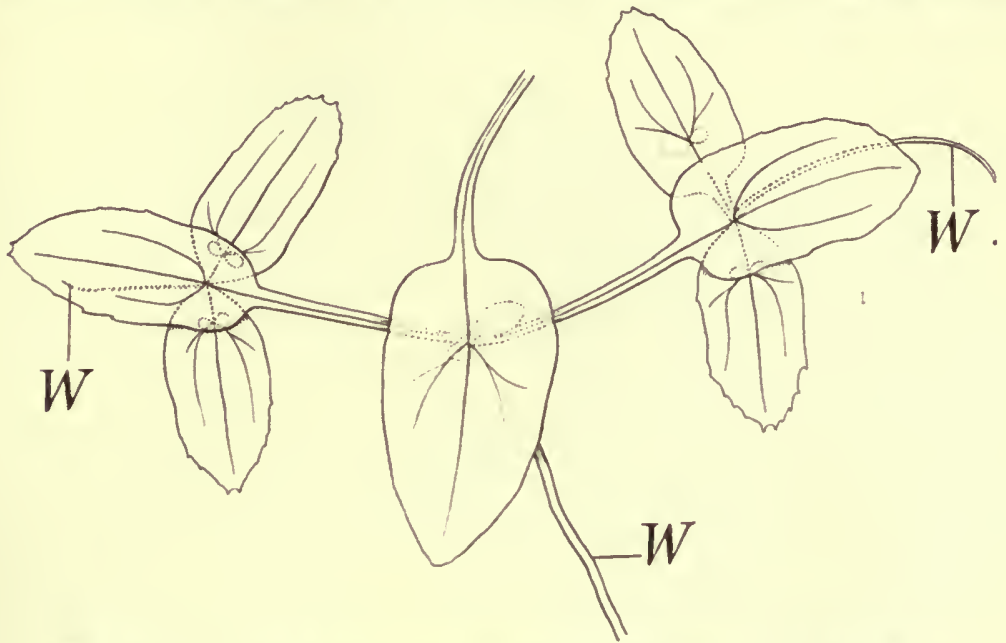

Fig. 368. Lemna trisulca, Habitusbild 4 fach vergr. W Wurzeln.

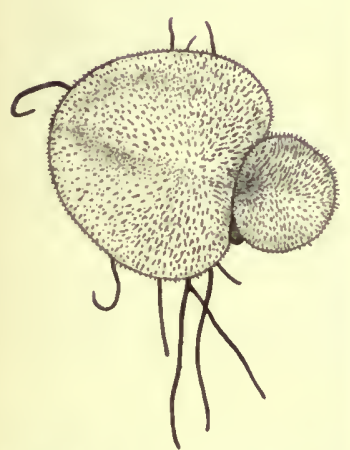

Fig. 369. Pistia Stratiotes. Keimpflanze ron oben $3 \mathrm{mal}$ vergr. Die beiden Blätter, welche sehr an die von Lemna erinnern, sind die beiden ungestielten Primärblätter (der Kotyledon bleibt im Samen stecken und ist nicht sichtbar).

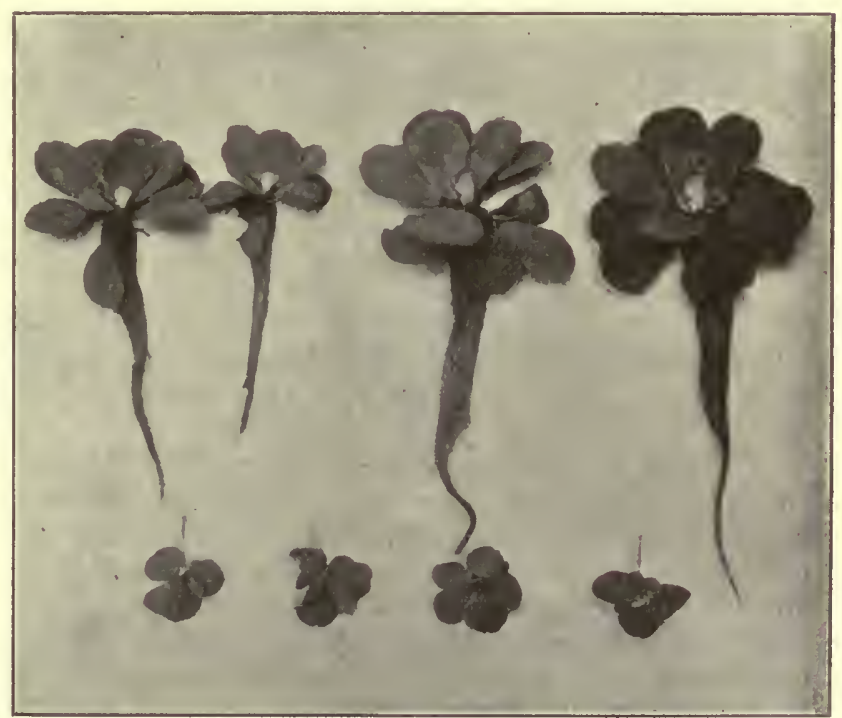

Fig. 370.

Fig. 370. Pistia Stratiotes (nach SNerd, verkleinert). Es waren je 4 junge nur mit ungestielten Primärblättern versehene Pflanzen kultiviert worden. Die oberen mit Wurzeln bildeten bald gestielte Blätter, die unteren, denen die Wurzeln immer entfernt wurden, blieben auf dem Primärblattstadium stehen.

welcher aus einem Blatt median ein neues (resp. mehrere) hervorsproßt, die primitivere Form ist. Denken wir uns, das Blatt rechts an der Keimpflanze von Pistia (Fig. 369) sprosse aus der Basis des Blattes links hervor, so würden wir im wesentlichen die Verhältnisse von Wolffia er- 
halten. Die Blüitenstände dagegen stehen bei den meisten Arten dieser Gattung rechts und links an der Blattbasis ${ }^{1}$ ). Bei Lemna ist an diese Stellen auch die Blattbildung rerlegt.

\section{$\S 6$. Wiederholung der Folgestadien.}

Wenn wir bei Lemna ein Beispiel dafür sahen, daß ein bei anderen Pflanzen nur in der Jugend auftretendes Gestaltungsverhältnis endlos wiederholt wird, so treffen wir bei anderen Pflanzen gewissermaßen das entgegengesetzte Verhalten, nämlich das, daß die Gestalt, welche dem blühbaren Stadium eigentümlich ist, in den Dienst des vegetativen Lebens tritt und in ihm selbst dann wiederholt wird, wenn es gar nicht zur Blütenbildung kommt. Es wird hier also auf die Jugendform in der Entwicklung der einzelnen Sprosse nicht mehr zurïckgegriffen.

Es seien dafür einige Arten der Gattung Scirpus angeführt. Die primitiveren Arten sind solche, welche wohl entwickelte Laubblätter besitzen und dann eine Infloreszenzachse bilden, welche mit chlorophyllhaltigem Gewebe versehen auch an der Kohlenstoffassimilation sich beteiligt. Statt nun aber nachher wieder Laubblätter und nach diesen neue Infloreszenzen zu bilden, wiederholen viele Scirpusarten (Sc. cicularis, prolifer u. a.) die Bildung der Infloreszenzachsen (an denen die Blütenstände vielfach verkümmert sind) und benutzen diese als Assimilationsorgane an Stelle der Laubblätter. Die Einzelheiten, wie die Bildung der Rhizome, die Verkettung der Sproßformen kommen hier nicht in Betracht. Es sollte nur gezeigt werden, daß hier die „Folgeform“ es ist, welche wiederholt wird. Die Fähigkeit, die Jugendform wieder hervorzubringen, schlummert freilich auch in diesen scheinbar starren Pflanzenformen. Aber in der Natur tritt sie z. B. bei Scirpus prolifer kaum je hervor. Wohl aber gelingt dies dem Experimentator. Darauf wird bei der Frage nach der Wiederhervorrufung der Jugendform einzugehen sein.

\section{§ 7. Auftreten von Jugendformen bei normalen Seitensprossen und bei Adventivsprossen.}

Wenn wir im vorstehenden von einer Jugendform gesprochen haben, so war damit zunächst das Verhalten der Keimpflanzen gemeint. Indes ist auch bei der Entwicklung von Zweigen das Auftreten der Jugendform oft $\mathrm{zu}$ beobachten. So fangen die aus Ausläufern entstandenen Pflanzen von Campanula rotundifolia ebenso wie die Keimpflanzen zunächst mit der Bildung von „Rundblättern" an, und die aus den Knollen von Sagittaria entstandenen Pflanzen mit „Bandblättern", auch die austreibenden knollenförmigen Rhizome von Nymphaea rubra beginnen wieder mit der Jugendblattform.

Dasselbe gilt auch für Adventivsprosse.

Als Beispiel wurde früher schon angefülırt ${ }^{2}$ ) das Verhalten der an

') Bei einigen Arten ist nur eine Infloreszenz auf dem Blatt vorhanden. Das dürfte eine Reduktion sein, zumal diese Infloreszenz z. B. bei Wolffia hyalina deutlich seitlich steht, d. h. wohl die eine von ursprünglich zweien darstellt.

2) GozBeL, Vergl. Entwicklungsgeschichte (1885), p. 260, R. T. JACKsoN, Localized stages in development in plants and animals. Memoirs of the Boston society of natural history. Vol. V (1899). C. Decandolce, Questions de morphologie et de biologie végétale. Archives des sciences physiques et naturelles XII. Genève 1903. 
isolierten Wurzelstöcken von Ailanthus glandulosa auftretenden Sprosse, die Blattfolge ist eine ähnliche wie bei den Keimpflanzen: zuerst bilden sich bleiche, ungegliederte Schuppen, die durch die folgenden Blätter allmählich in das reicher gegliederte Blatt übergehen. Es hängt offenbar von Ernährungsverhältnissen $a b$, welche Blattformen zuerst auftreten, ob die Primär- oder die Folgeblätter. So Haben die Adventivsprosse von Fraxinus americana bald einfache Primärblätter wie die Keimpflanzen, bald dreizählige oder fünfzählige.

Ein lehrreiches Beispiel bieten die an den Blättern von Begonia caroliniaefolia entstehenden Adventivsprosse, die Doposcheg ${ }^{1}$ ) untersucht hat. Die Blätter dieser Pflanze sind "geteilt"* in eine Anzahl von Teilblättern (Fig. 371). Die Adventivsprosse bringen zunächst einfache ganzrandige, die Asymmetrie noch nicht zeigende Primärblätter hervor, dann die in Fig. 372 abgebildeten Stadien, ron denen 1,2 und 3 Blattformen entsprechen, wie sie bei anderen Begoniaarten

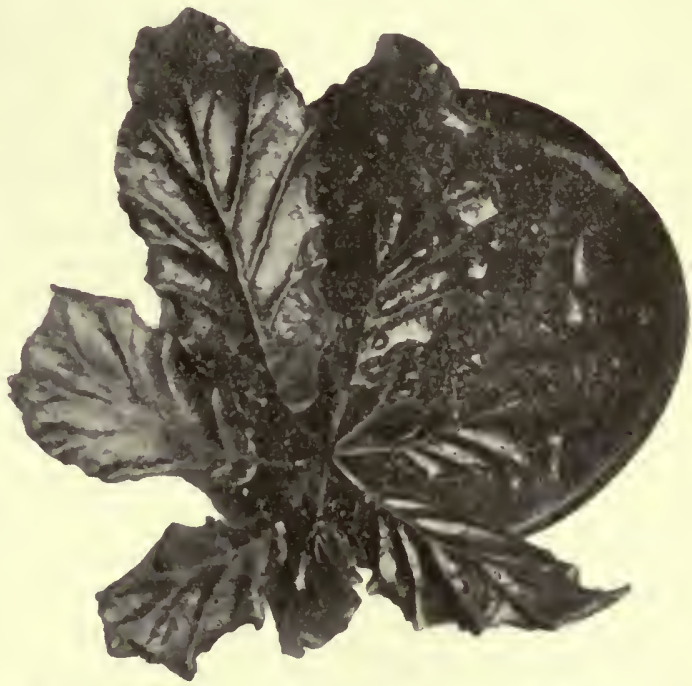

Fig. 371. Begonia caroliniaefolia. Folgeblatt von oben ( $1 / 2$ nat. Gr.). (Nach Doposcheg-Uhlár.) als höchstentwickelte Blatt-
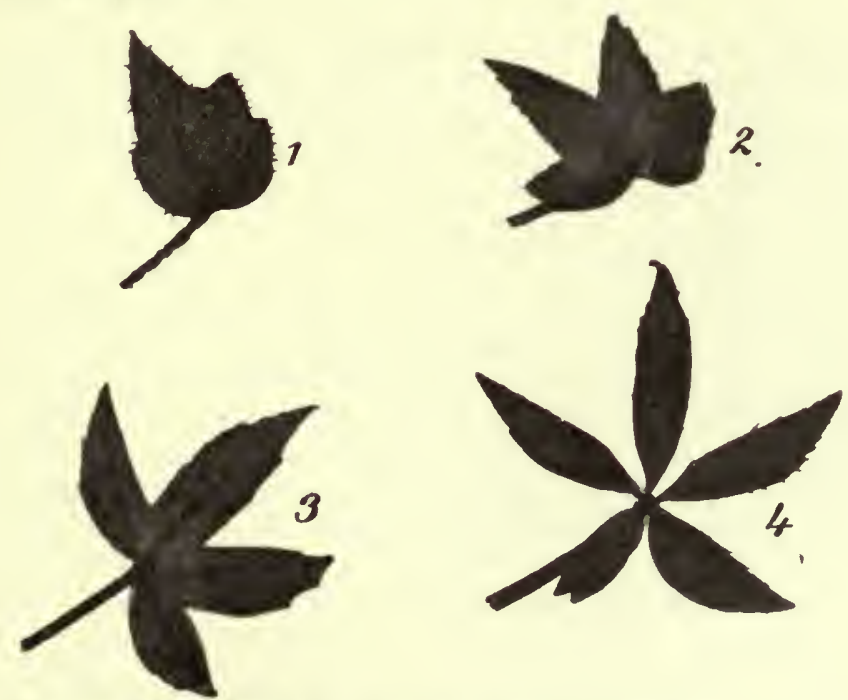

Fig. 372. Begonia caroliniaefolia. Übergang von Primärblättern zu Folgeblättern. Nat. Gr. Nach Doposcheg-Uhlár.

i) J. Doposcheg-Uníár, Studien zur Regeneration und Polarität der Pflanzen, Elora 102 (1911), p. 24. 
form auftreten. Dabei ist von besonderem Interesse, daß Adventivsprosse, welche an den abgetrennten Primärblättern sich bilden, ihre Blätter länger auf dem Primärblattstadium verharren lassen; erst das 5. oder 6. Blatt zeigt die Gestalt des in Fig. 372, 1 abgebildeten, das an Adventivsprossen von Folgeblättern schon als 2. oder 3. Blatt des Adventivsprosses auftritt.

Die Bedeutung dieser Tatšachen wird eine größere, wenn wir auch die anatomischen Verhältnisse in Betracht ziehen. Es zeigt sich ${ }^{1}$ ), daß die Primärblätter einer Anzahl daraufhin untersuchter Pflanzen (Fagus silvatica, Quercus pedunculata, Acer Pseudoplatanus u. a.) den Bau der "Schattenblätter" aufweisen (namentlich Reduktion der Palisadenschicht, lockerer Bau usw. Dieser Bau kann bei in hellster Sonne erwachsenen Keimpflanzen zwar etwas in der Richtung zum Sonnenblatt hin beeinflußt werden, aber ist doch deutlich wahrnehmbar. Die ersten Blätter jedes Jahrestriebes haben bei den daraufhin untersuchten Pflanzen selbst bei heller Beleuchtung mehr oder minder den Bau des Schattenblattes. Sie entsprechen also den Primärblättern in ihrem Baue. Wenn an einem Baume an schwach beleuchteten Sprossen im späteren Lebensalter nur Schattenblätter auftreten (wie dies zuerst STAHL nachgewiesen hat), so ist dies also dieselbe Erscheinung, wie wir sie unten auch sonst als künstliche Wiederhervorrufung der Jugendform anzuführen haben werden. Es ist demnach anzunehmen, daß Pflanzen, deren Primärblätter nicht den Bau der Schattenblätter haben, auch im späteren Lebensalter nicht imstande sein werden, Schattenblätter herrorzubringen.

Im folgenden soll eine Anzahl von Einzelbeispielen für heteroblastische Entwicklıng aufgeführt werden.

\section{§ 8. Thallophyten.}

Während die Sporen von Oedogonium, Vaucheria, Fucus u. a. ohne wesentliche Gestaltsveränderungen zur geschlechtsreifen Pflanze heranwachsen, ist dies bei anderen Algen nicht der Fall, sie bilden vielmehr einen mehr oder minder eigenartigen Vorkeim. Als Beispiele seien einige Florideen genannt, bei denen namentlich das Verhalten zweier Süßwasserformen, Lemanea und Batrachospermum, näher untersucht ist.

Lemanea besitzt einen aus zylindrischen Zellkörpern (die aber als aus verschmolzenen Zellfäden zustande gekommen zu betrachten sind) bestehenden Thallus, welcher die Geschlechtsorgane erzeugt. Die Sporen, die in ihm entstehen, wachsen zu einem viel einfacheren "Vorkeim " 2 ) aus (Fig. 373), der aus Zellfäden besteht, an denen dann die komplizierter gebauten Sexualsprosse auftreten. Hier wie in anderen Fällen (Protonema der Moose, Flächenvorkeim von Sphagnum) ist es charakteristisch, daß die Folgeform Wurzelfäden besitzt, die in ihrer Gestaltung mit der des Vorkeims übereinstimmen, und aus denen auch neue Pflanzen entspringen können. Sie kriechen auf der Unterlage und heften dadurch. den Thallus an. Solche Vorkeime können, wie Brand gezeigt

1) R. Sсндамм, Über die anatomischen Jugendformen der Blätter einheimischer -Holzpflanzen, Flora 104 (1912). M. Nordhauses, Über Sonnen- und Schattenblätter, 2. Mitt., Ber. der deutschen bot. Gesellsch. XXX (1912), p. 483.

2) Zuerst nachgewiesen von Tuwartes, On the early stages of development of Lemanea fluviatilis. Proc. of the Linnean Society of London Vol. I, p. 360. 1849. Vgl. ferner Wartsans, zit. bei Gokbel, Flora 1889. 
hat ${ }^{1}$ ), auch aus vegetativen Zellen der Sexualsprosse, die beim Austrocknen lebendig bleiben, hervorgehen. Lemanea verhält sich auch in dieser Beziebung ganz ebenso wie die Laubmoose.

Die "Vorkeime" von Lemanea sind teilweise als Formen der Algengattung Chantransia beschrieben worden, und dasselbe geschah mit denen von Batrachospermum ${ }^{2}$ ). Dessen Verhalten läßt sich folgendermaßen kurz zusammenfassen:

1. Aus den keimenden Sporen entsteht ein aus Zellfäden bestehender "Vorkeim", der sich zunächst der Unterlage anschmiegt und dadurch die Befestigung auf dieser vorbereitet.

2. Bei normalen Bedingungen, vor allem reichlichem Lichtzutritt, erreicht dieser Vorkeim meist nur geringe Größe; an ihm entstehen die eigentlichen Batrachospermumpflanzen.

3. Häufig aber, namentlich bei schwacher Beleuchtung, entwickelt sich der Vorkeim üppiger, es entstehen Räschen von aufrechten Zellreihen an ihm; diese sind als Chantransiaarten beschrieben worden. Auch an diesen können sich Batrachospermumpflanzen entwickeln; entsteht aber die Anlage zu weit vom Substrat entfernt, so verkümmert sie.

4. Die Vorkeime können sich selbständig durch Brutzellen (Gonidien) fortpflanzen.

5. Aus den Berindungsfäden der Batrachospermumpflanzen können sich sekundäre Vorkeime entwickeln.

Wir sehen also, daß die Vorkeime hier einer selbständigen Fortpflanzung fähig sind und daß sie unter Bedingungen zu wachsen vermögen, die nicht hinreichen, um die höhere Entwicklungsform der Pflanze hervorzurufen, Tatsachen, die ganz den von den Laubmoosen bekannten entsprechen.

Von marinen Florideen möchte ich nur zwei Fälle anführen.

Dumontia filiformis ${ }^{3}$ ) bildet bei der

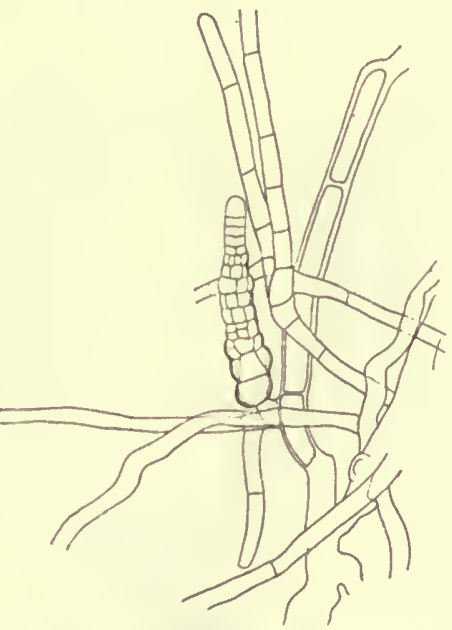

Fig. 373. Lemanea (wahrscheinlich torulosa). Fadenförmiger "Vorkeim", an welchem, ganz wie bei den meisten Laubmoosen, die Pflanze, an der später die Geschlechtsorgane entstehell, als Zellkörper auftritt. Keimung zunächst eine Haftscheibe, die dem Substrat dicht angeschmiegt ist. Sie besteht aus dicht gedrängten vertikalen Zellreihen und gleicht der Florideengattung Hildenbrandtia. An dieser entspringt ein verzweigter, aufrechter Thallus, der aber nach der Fruktifikation abstirbt, während die Haftscheibe perenniert und neve Dumontiasprosse erzeugen kann, im Grunde ein ähnliches Verhältnis wie bei Batrachospermum und Lemanea.

1) Fortpflanzung und Regeneration von Lemanea fluviatilis. Bericht d. D. bot. Ges. XIV. Bd., p. 185.

2) Vgl. Sinodot, Les Batrachospermes, Paris 1884, und die Kritik seiner Anschanungen in Flora 1889 , p. 5.

3) Reinke, Algenflora der westlichen Ostsee. Kiel 1889. Bresner, On the origin of the filamentous Thallus of Dumontia filiformis. Linnean Society's Journal Vol. XXX. Den von Brebser als öfters vorkommend beschriebenen endogenen Ursprung des Thallus an der Haftscheibe möchte ich auf frühzeitige Überwallıng zurückführen. 
Sehr eigentümlich ist das Verhalten von Polysiphonia ${ }^{1}$ ) Binderi (Fig. 374). Die Entwicklung der Pflanze beginnt mit der Bildung eines zylindrischen Keimsprosses, der in Bau und Gestaltung vollständig dem Typus der Gattung entspricht. An diesem (Fig. 374, 2) entstehen seitlich ein oder mehrere flache Gebilde, welche sich krustenförmig der Oberfläche anderer Algen, namentlich von Codiumarten, anlegen (Fig. 374, 1, 3). Diese Krusten kann man betrachten als bestehend aus einer Anzahl miteinander vereinigter, in einer Ebene liegender Polysiphoniafäden. Wenn es zur Bildung der Fortpflanzungsorgane geht, so treten nun wieder freie Polysiphoniafäden auf, welche Tetrasporen bilden. Dieser Fall ist besonders lehrreich. Daß die Krustenform des Thallus hier eine sekundäre Anpassung darstellt, welche das feste Anhaften am Substrate gestattet, ist klar. Sie greift hier aber noch nicht auf die ersten Keimungsstadien zurück; an sich wäre es ganz wohl möglich, daß die Kruste schon bei der Sporenkeimung auftreten würde, dann hätten wir einen Fall, dem ähnlich, welcher bei Dumontia geschildert wurde, (bei der aber der Bau der Scheibe auf ein primitiveres Verhalten hinweist).

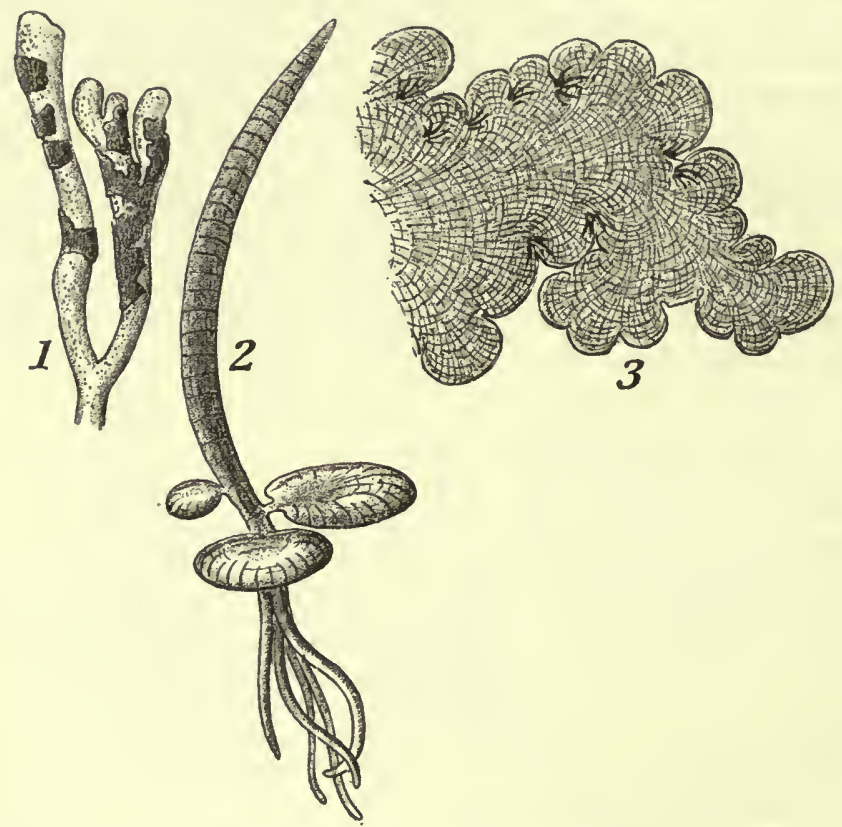

Fig. 374 .

1 Ein südafrikanisches Codinm mit dem krustenförmigen Thallus von Polysiphonia Binderi bedeckt.

2 Keimpflanze, an deren Basis krustenförmige

Thalli entstehen.

3 Älterer krustenförmiger Thallus im Querschnitt. (1 Orig. 2, 3 nach Falkenberg aus

OLtmanss, Algen).

Ähnliches wie für die genannten Florideen gilt nun auch für andere Algen, deren Verhalten aber nur kurz erwähnt werden kann. Die Vorkeime der Characeen werden in den größeren Lehrbüchern ausführlicher beschrieben ${ }^{2}$ ).

Bei den Sphacelariaceen ${ }^{\mathbf{3}}$ ) entsteht bei der Keimung gewöhnlich eine Haftscheibe, an der dann erst die zylindrischen, assimilierenden und fruktifi-

1) Man hat diese Form auf Grund von vegetativen, adaptativen Merkmalen als besondere Gattung Placophora anfgestellt, was gegen die systematischen Prinzipien ist. Vgl. Flora 1889, p. 3 und die dort angeführte Literatur.

2) Vgl. z. B. Goenes, Grundzlage der Systematik.

3) Vgl. Reinke, Übersicht der bisher bekannten Spbacelariaceen. Ber. d. D. bot. Gesellsch. VIII, p. 201 und Beiträge zur vergl. Anatomie und Morphologie der Sphacelariaceen. Bibl. botanica Heft 23, daselbst weitere Literatur. 
zierenden Sprosse sich bilden. Die Haftscheibe ist offenbar hervorgegangen aus kriechenden Zellfäden, die jetzt aber so miteinander verschmolzen sind, wie bei Polysiphonia Binderi und dabei auch weitere, nicht näher zu erörternde Differenzierungen erfahren haben. Von Interesse ist namentlich, daß es eine Gattung gibt (Battersia mirabilis), bei der die Haftscheibe, die ich als eine sekundär entstandene Anpassung betrachten móchte ${ }^{1}$ ), den eigentlichen Vegetationskörper darstellt, an welchem die fruktifizierenden Sprosse als kurze Anhängsel erscheinen, ebenso wie dies bei den oben erwähnten Muscineen Ephemerum, Lejeunia Metzgeriopsis u. a. der Fall ist.

So sehen wir also bei allen den genannten Algen die Jugendstadien die beiden Eigentïmlichkeiten entweder getrennt oder zusammen aufweisen: einerseits eine primitivere Gestaltung, die übereinstimmt mit der verwandter Formen (Polysiphonia Binderi) oder mutmaßlicher Vorfahren (Batrachospermum usw.), andererseits Anpassungen, welchen wir eine phylogenetische Bedeutung nicht beilegen können, und die bei diesen Thallophyten meist (aber nicht immer) mit der Befestigung am Substrat zusammenhängen.

Für das Verhalten der Muscineen mögen die wenigen oben kurz angeführten Beispiele genügen, da die interessanten Keimungserscheinungen dieser Gruppe im speziellen Teile eingehende Beriicksichtigung finden werden.

Erwähnt sei nur, daß, ganz abgesehen von dem Auftreten des Protonemas, dieser höchst eigentümlichen Jugendform, die Primärblätter der jungen Moospflanzen von Interesse sind, indem sie bei solchen Pflanzen, wo die Folge. blätter besondere Anpassungen zeigen, mit der einfacheren Gliederung anderer Moose übereinstimmen. So bei Sphagnum (die Primärblätter haben hier nicht die Verschiedenheit von chlorophyllhaltigen und leeren Zellen), Fissidens (die Primärblätter haben keine Flügel [Fig. 348] und sind noch nicht zweizeilig gestellt), Polytrichum (die Primärblätter haben noch keine Lamellen).

\section{§ 9. Gefäßkryptogamen.}

Die Entwicklung der Geschlechtsgeneration wird gleichfalls im speziellen Teile ausführlich besprochen werden; hier sei nur der Jugendstadien der ungeschlechtlichen Generation gedacht, weil sie für die hier behandelte Frage besonders lehrreich sind; das Verhalten der wenigen hierher gehörigen Wasserpflanzen wird mit den angiospermen Wassergewächsen zusammen zu erwähnen sein.

A. Die Farne sind bekanntlich ausgezeichnet durch eine große Formenmannigfaltigkeit in der Blattbildung. Die Primärblätter aber sind selbst bei Farnen, deren Folgeblätter sehr voneinander abweichen, übereinstimmend. So sind in Fig. 375 abgebildet Primärblätter von Asplenium Ruta Muraria und von Scolopendrium. Es sind dies zwei Farne, deren Folgeblätter so verschieden sind, wie nur irgend möglich. Scolopendrium besitzt eine langgestreckte, einfache, Aspl. Ruta Muraria eine reich zerteilte Blattfläche. Die Primärblätter aber gleichen sich sehr. Wir sehen sie von gabelig geteilten Nerven durchzogen, auch die Blattfläche selbst weist bei manchen Formen eine Gabelung auf, aber selbst wo dies nicht der Fall ist, ist die Wachstumsweise der Blätter

1) Solche Haftscheibenbildung findet sich auch bei Ectocarpeen, hier aber nicht allgemein. Vgl. die in S. I, p. 163 angeführten Fälle. 
eine übereinstimmende. In dem Blatte I von Scolopendrium ist schon ein aus den gabelig entstandenen Nerven sympodial entstandener Mittelnerv sichtbar, der später immer deutlicher hervortritt. Während man die Gabelteilung auch bei den folgenden, schon Fiederbildung zeigenden Blättern mancher Formen noch deutlich verfolgen kann, treten die Fiedern am Scheitel des erstarkten Blattes immer mehr als seitliche Bildungen auf.

Diese Bemerkungen beziehen sich auf die Farnblätter, bei denen frühzeitig das Scheitelzellwachstum durch Randzellenwachstum ersetzt wird (vgl. den speziellen Teil). Bei manchen, wie Ceratopteris thalictroides, ist die Scheitelzelle noch vorhanden, wenn schon einige Fiedern angelegt sind, die dann zweifellos seitliche Aussprossungen der Blattanlage darstellen. Auch in diesem Falle erscheinen übrigens die Primärblätter deutlich als Hemmungs bildungen, auch sie haben ursprünglich Scheitelzellwachstum, das nur viel frühzeitiger (vor dem Auftreten von Verzweigungen) in Randzellwachstum übergeht.

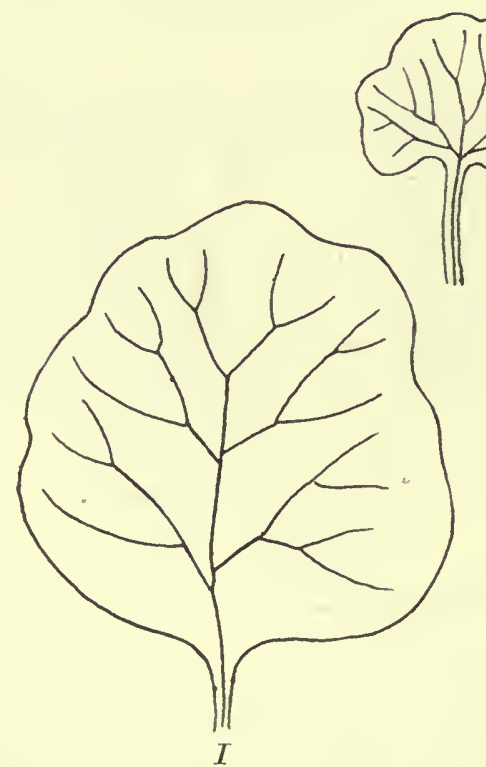

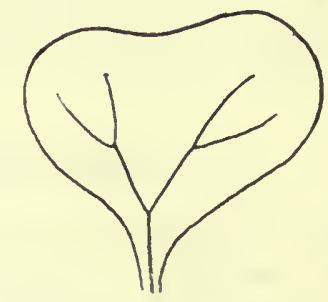

II

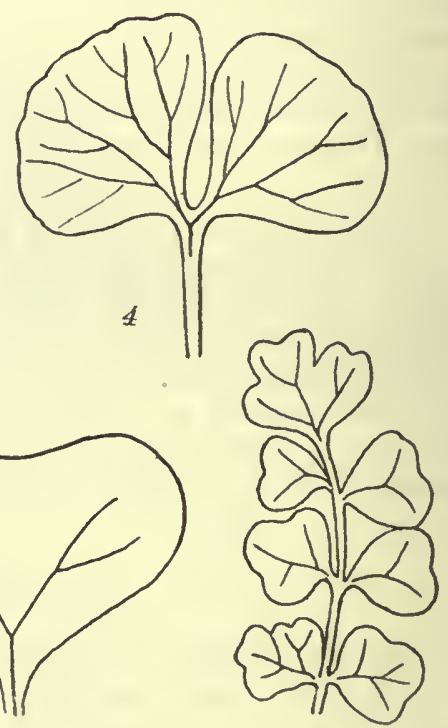

5

Fig. 375. Primärblätter von Farnen. I, II Scolopendrium officinarum; 3, 4 Asplenium Ruta Muraria; 5 älteres Blatt von Aspl. viride. (Vergr.)

Es würde keinen Zweck haben, den allmählichen Übergang zu den Folgeblättern hier ausführlich zu schildern.

Es sei nur folgendes hervorgehoben.

1. Die Farne zeigen besonders deutlich, daß Blattformen, welche bei den einen nur als Jugendblätter auftreten, bei anderen auch die Folgeform bilden. So ist - von kleineren Abweichungen abgesehen - das ungeteilte, mit wiederholt gabelig verzweigten Nerven versehene Blatt, das in Fig. 3753 abgebildet ist, auch Folgeform bei Adiantum reniforme, Scolopendrium nigripes $u$. a. das zweiteilige Blatt Fig. 375 II bzw. 4 Folgeform bei Regnellidium. Es wird nicht immer leicht sein, in diesen Fällen zu entscheiden, ob diese Farne solche sind, die auf der Bildung der Jugendblattform stehen geblieben sind, oder ob sie ursprünglich 
höher gegliederte Folgeblätter besaßen, die später unter Verlängerung der Jugendblattform fortfielen.

2. Der Entwicklungsgang der Primärblätter ist trotz aller äußeren Verschied enheit mit dem der folgenden übereinstimmend, sie sind Hemmungsbildungen.

3. Dies zeigt außer der morphologischen Betrachtung auch die Tatsache, daß die Ausbildung der Primärblätter schwankt, daß die höhere Blattform um so rascher erreicht wird, je kräftiger die Keimpflanze ist.

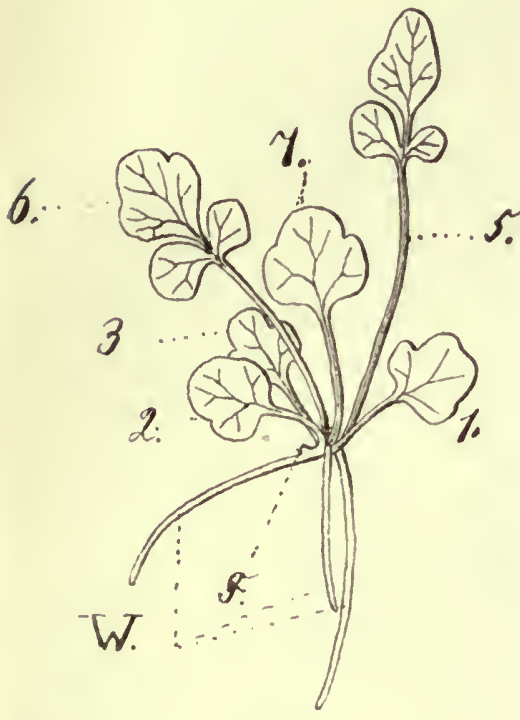

Fig. 376 .

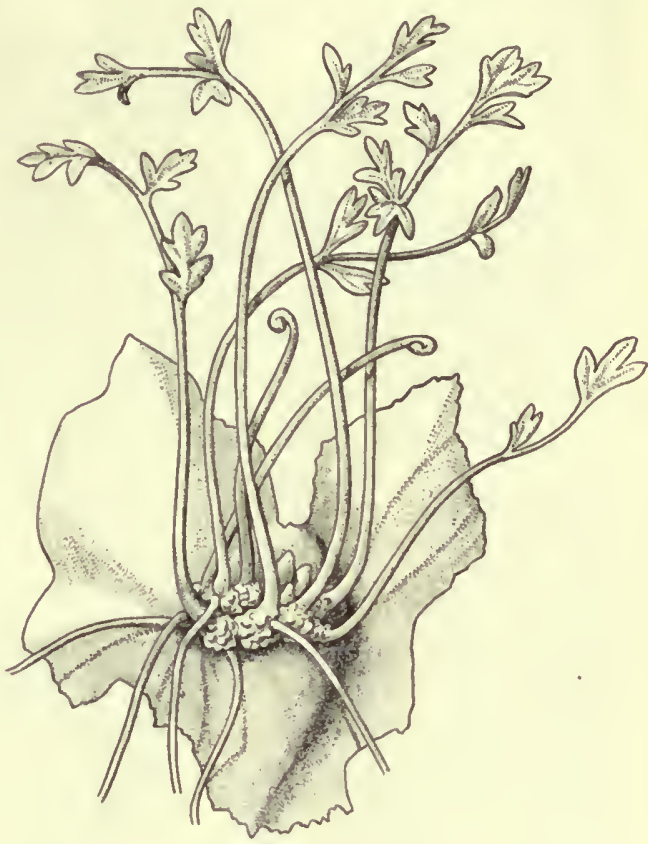

Fig. 377.

Fig. 376. Keimpflanze von Doodya caudata. Die Blätter der Reihenfolge nach beziffert. Während Blatt 5 nnd 6 schon die Gestalt gefiederter Blätter erreicht hatten, ist 7 infolge ungünstiger äußerer Einwirkungen wieder auf die Gestalt von 2 herabgesunken.

Fig. 377. Prothallium von Cystopteris fragilis f. polyapogama. An den Höckern anf der Unterseite sind hoch gegliederte Primärblätter entstanden. (Nach Heilbrons.)

Eine schöne Bestätigung dafür bildet ein von HeilbronN ${ }^{1}$ ) beobachteter Fall. Cystopteris fragilis besitzt an den sexuell entstandenen Keimpflanzen die gewöhnlichen einfachen Primärblätter. Eine Form (f. polyapogama) dagegen bildet apogam aus stärkereichen Höckern am Prothallium Keimpflanzen. Diese besitzen Primärblätter, die eine Organisationshöhe besitzen, wie sie die Normalform erst mit dem 6. bis 8 . Blatte zu erreichen pflegt (Fig. 377). Daśselbe zeigt das Experiment.

Man kann nämlich die Blattbildung einer Pflanze auch im späteren Alter wieder auf die Primärblattstufe herunterdrücken, wenn man sie unter ungünstige Bedingungen bringt. Dies zeigt Figur 376: Die Keimpflanze hat mit Blatt 5 schon den Typus eines gefiederten Blattes erreicht, wenngleich erst zwei Blattfiedern vorhanden waren; Blatt 7 aber hat wieder

1) Hellbrons, Apogamie bei einigen Farnen. Flora 101 (1910). 
ganz die Ausbildung der ersten Primärblätter, von Blatt 2, angenommen. Eine andere Pflanze sank von vier Fiederpaaren zunächst auf zwei herab, und würde, wenn sie unter den ungünstigen Verhältnissen

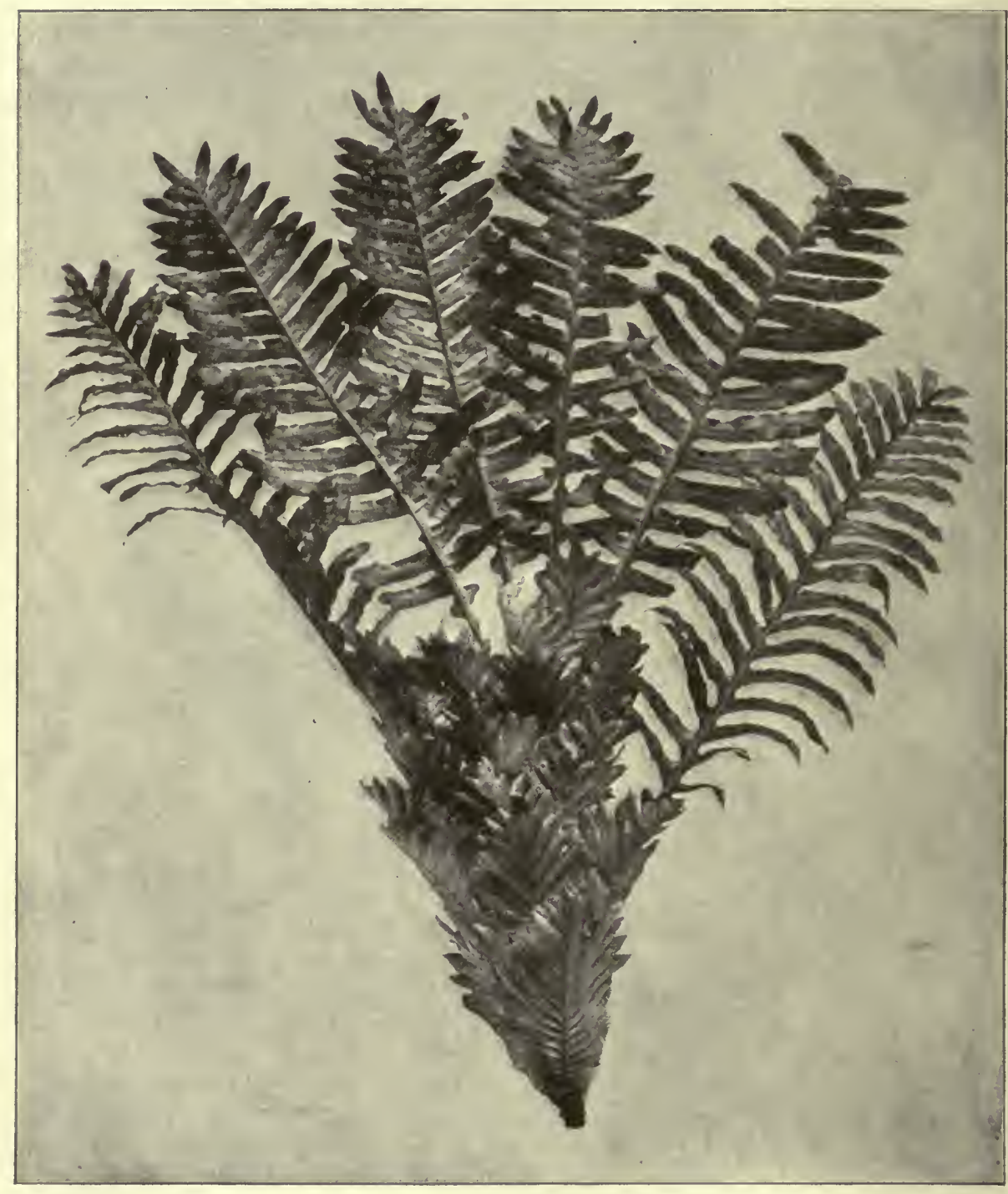

Fig. 378. Drynaria quercifolia (ca. $1 / 2$ nat. Gr.) nach einer in Buitenzorg aufgenommenen Photographie. Unten ungestielte Nischenblätter, oben Laubblätter (die man friiher als die "fertilen" bezeichnete, was sie aber wie schon die Keimungsgeschichte zeigt, durchaus nicht immer sind).

weiter vegetieren könnte, schließlich auch die Primärblattform wieder haben auftreten lassen. In weiteren Versuchen gelang es, bei Pflanzen, die schon Blätter mit mehr als vier Fiederpaaren entwickelt hatten, die Blattbildung auf die durch Blatt 6 und 7 in Fig. 376 dargestellte Stufe 
herunterzudrücken, ein weiterer Beweis für die oben dargelegte Anschauung. Bei älteren, mit stärkerer Sproßachse, vielen Reservestoffen usw. versehenen Pflanzen wird eine solche Reduktion vielfach unmöglich sein, namentlich auch deshalb, weil hier an

Vegetationspunkt schon mehr Blattanlagen vorhanden und in ihrer Gliederung bestimmt sind, und weil der Pflanze mehr Baustoffe zur Verfügung stehen, die eine ungünstige Beeinflussung zunächst äußerlich weniger hervortreten lassen.

4. Als ein besonders lehrreicher Fall sei der einiger heterophyllen Drynariaarten ${ }^{1}$ ) angeführt. Diese besitzen im ,erwachsenen" Zustand zweierlei Blätter : gestielte Laubblätter (die auch Sori hervolbringen können) und ungestielte, einfacher gegliederte "Nischenblätter", die ihr Chlorophyll bald verlieren und zum Humussammeln dienen (Fig. 378). So z. B. Drynaria quercifolia. Die Keimpflanze aber bringt nur Laubblätter hervor (Fig. 379), welche zunächst alle gleich sind (von der in Fig. 379 mit $a$ bezeichneten Form), später sich dadurch unterscheiden, da $\boldsymbol{B}$ die einen eine breitere Basis bekommen. Diese

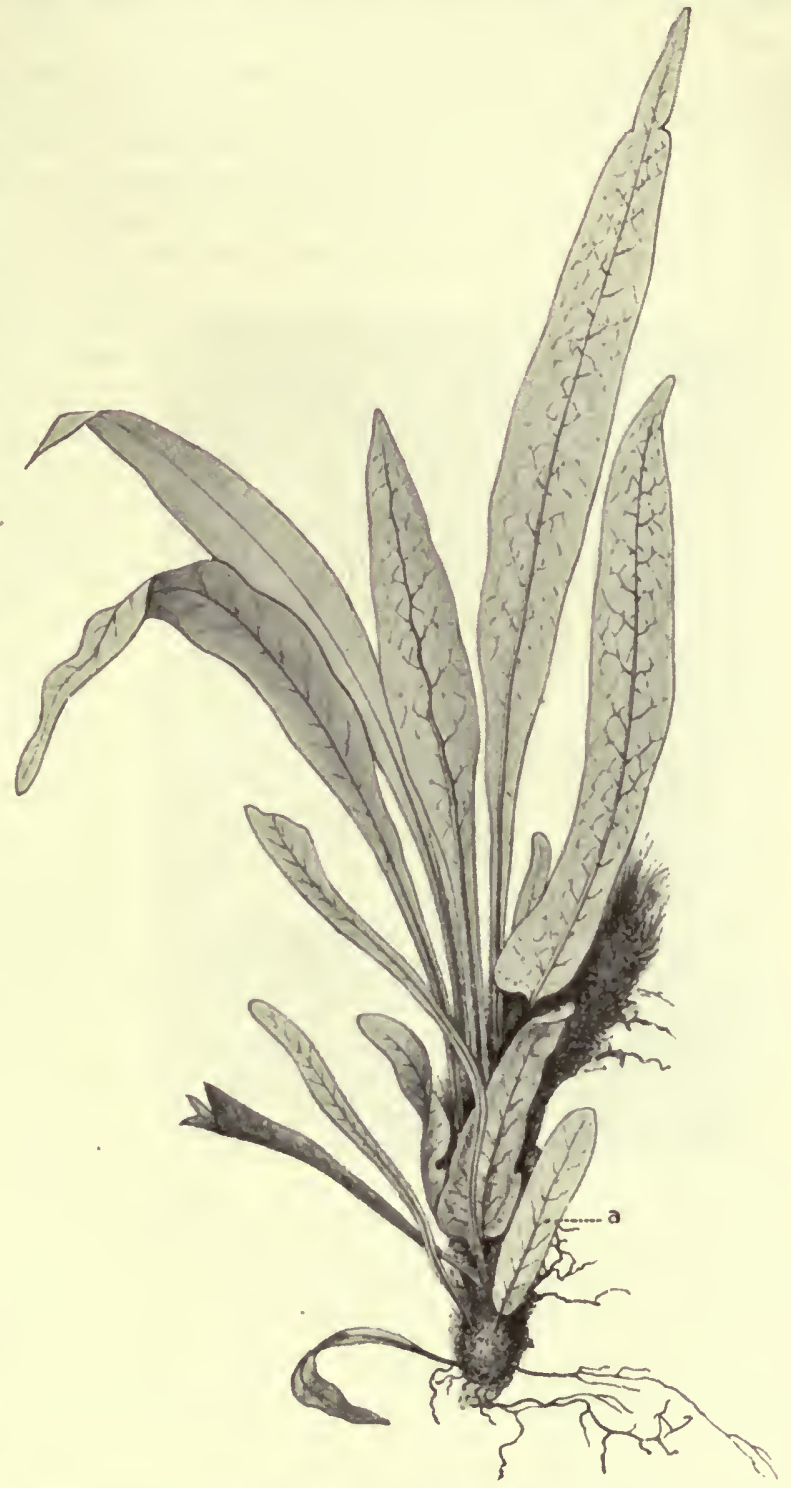

Fig. 379. Drynaria quercifolia, Keimpflanze. Es treten nur Laubblätter auf, die aber an der Basis teils schmal, teils verbreitert sind. gehen dann in die Nischenblätter über. Die Keimpflanzen sind hier von Interesse, weil sie ein ursprünglicheres Verhalten zeigen: ausgehend von der gewöhnlichen

1) Goeber, Über epiphytische Farne und Muscineen. Ann. du jardin botanique de Buitenzorg VII (1889). 
Blattform mit gestielten oder nach unten zu jedenfalls nicht verbreiterten Blättern sehen wir bei verschiedenen Arten zwei "Entwicklungstendenzen". Die eine geht auf die Bildung von Blättern mit breiter, zum Humussammeln geeigneter Basis, die andere bildet abwechselnd solche und gestielte Blätter. Erstere bringen nur Laubblätter hervor (z. B. Drynaria musaefolia, Polyp. Heracleum, Polyp. Meyenianum). Die anderen bilden später die Arbeitsteilung schärfer aus, aber es gibt Arten, wie z. B. Dr. mollis, bei denen auch im Folgezustand die beiden Blattformen nur wenig voneinander verschieden sind. Bei den Arten, welche bei der Folgeform eine scharfe Scheidung. von Laub- und Nischenblättern aufweisen (die in periodischem Wechsel

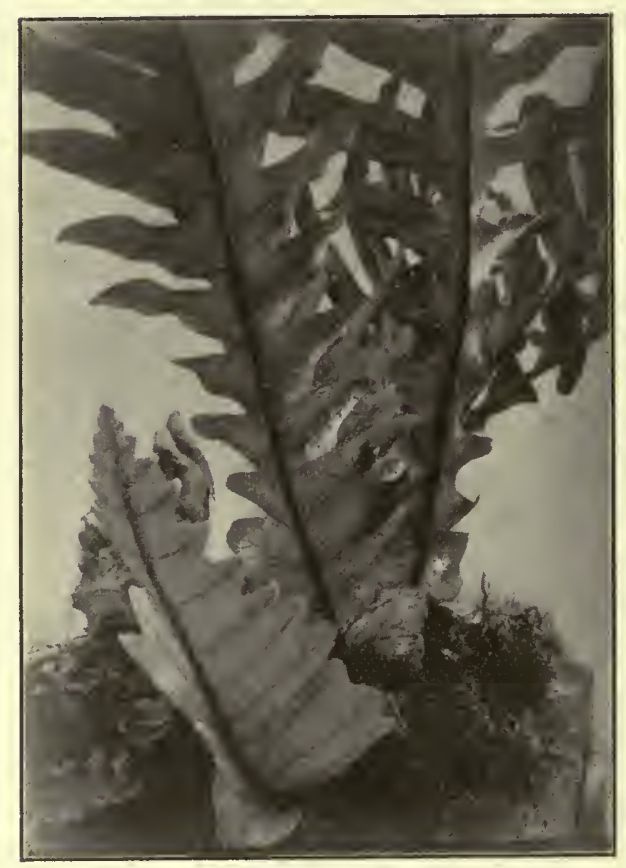

Fig. 380. Drynaria propinqua. Ältere Pflanze, welche als Rückschlag auf die Keimpflanze Blätter gebildet hat, welche den Charakter von Laub- und Nischenblatt vereinigen. gebildet werden), ist es trotzdem auch im späteren Lebensalter möglich, eine Blattform hervorzurufen, die eine Mittelbildung zwischen beiden darstellt, also den bei der Keimung. auftretenden Primärblättern entspricht, nur daß sie bedeutendere Größe erreicht. Es. geschieht dies bei Pflanzen, die längere Zeit sich unterungünstigen Wachstumsbedingungen befinden. Eine solche ist in Fig. 380 abgebildet. Die beiden hinteren Blätter rechts vereinigen die Beschaffenheit. von Laub- und Nischenblatt, entsprechen also anch z. B. den Blättern von Drynaria coronans. und Polyp. Heracleum. Vorn ist. ein junges Nischenblatt sichtbar.

Offenbar ist also das Auftreten der Laub- und der. Nischenblätter von verschiedenen Bedingungen abhängig und zudem ist ihre Trennung, wie der zuletzt erörterte Fall zeigt,. eine labile.

B. Die Equ is e te n weisen im wesentlichen eine homoblastische Entwicklung auf. Die Gestaltung der Keimsprosse entspricht. dabei, wie wir p. 91 sahen, im wesentlichen der der Seitenziweige derälteren Pflanzen.

C. Auch bei den Lycopodinen bietet die Blattgestaltung, die ja eine einfache ist, kaum Veranlassung zu besonderen Bemerkungen. Dagegen ist die Gesamtgestaltung der Keimpflanzen bei einer Anzahl von Arten eine merkwürdige; es haben sich an sie auch eigenartige theoretische: Erörterungen geknüpft.

TreuB ${ }^{1}$ ) glaubte an den Keimpflanzen ein phylogenetisch wichtiges. Gestaltungsverhältnis aufgefunden zu haben, das er "Protokorm“ nannte..

1) M. Treub, Études sur les Lycopodiacées. VI. Ann. du jardin bot. de Buitenzorg, Vol. VIII (1890) p. 30. 
Die Keimpflanzen einiger Arten bilden zunächst nämlich nicht einen bewurzelten Sproß, sondern ein wurzelloses, mit einfach gebauten Blättern, "Protophyllen", versehenes Gebilde, den "Protokorm" aus, welcher erst später in das typisch beblätterte Stämmchen übergeht. Dieser „Protokorm" ist unter den Arten, deren Keimung bekannt ist, wohl am meisten entwickelt bei Lyc. laterale ${ }^{1}$ ), wo er längere Zeit als rhizomähnliches Gebilde weiter wächst und die "Protophylle" auf seiner Oberseite trägt; er kann über $1 \mathrm{~cm}$ lang werden, besteht nur aus Parenchymzellen und stellt längere Zeit hindurch die Keimpflanze dar.

Dieses ganze Gebilde stellt nach des Verf.s früher dargelegten Ansicht eine mit der hemisaprophytischen Lebensweise der Keimpflanze zusammenhängende Hemmungsbildung dar. Dies ergibt sich aus dem Unterbleiben einer Wurzeldifferenzierung am Hypokotyl und ferner daraus, daß zwar die ersten Blätter einfache Leitbündel ${ }^{2}$ ) haben, diese aber nicht an einem Leitbündelzylinder des Stammes sich ansetzen können. Eine so. unvollkommene Struktur trägt deutlich den Charakter der $\mathrm{R}$ ü ck bildung an sich. Auch finden sich nicht bei allen Lycopodiumarten "Protokorme". Sie fehlen z. B. bei L. Billardieri, L. volubile und L. scariosum, auch bei den Arten, deren Keimpflanzen längere Zeit als. Holosaprophyten leben.

Außerdem finden sich analoge Verhältnisse bei anderen hemisaprophytischen Pflanzen, namentlich Orchideen - bei ihnen kann aber von einer phylogenetischen Verwertung des Protokorms allenfalls innerhalb der Familie, nicht aber in weiterem Sinne die Rede sein. Man könnte die Bezeichnung Protokorm wohl ruhig fallen lassen.

\section{$\S 10$. Gymnospermen ${ }^{3}$ ).}

Die Gestaltung der Keimpflanzen der Cycade en bietet für unsere. Betrachtung nichts Besonderes. Es sei nur erwähnt, daß der Kotyledon mancher Cycadeen besonders deutlich zeigt, daß er ein umgebildetes. Laubblatt ist, welches sogar die Andeutung einer Fiederung noch erkennen läßt.

Dagegen haben die Jugendformen mancher Coniferen um so mehr die Aufmerksamkeit auf sich gezogen, als einige in der Gärtnerei eine Rolle spielen. Es sind nämlich, namentlich bei manchen Cupressineen, die Jugendformen "fixiert", d. h. während sie normal nur ein mehr oder weniger rasch vorübergehendes Entwicklungsstadium darstellen, gibt es Exemplare, welche die Jugendform lange Jahre, ja selbst dauernd beibehalten. So namentlich bei Cupressineen, bei denen unten auf die Frage, wie die "Fixierung" erfolgt, einzugehen sein wird. Das Verhalten möge an einigen Beispielen geschildert sein.

1. Pinus. Die Kiefern haben bekanntlich an den Sproßachsen, welche das bleibende Gerüst der Pflanze darstellen, nur braune, als Knospenschuppen

1) Vgl. J. E. Holraway, A comparative study of the anatomy of six New Zealand. species of Lycopodium. Transaction of the New Zealand institute, Vol. XLII, p. 357.

2) Das erste Blatt hat zuweilen bei L. cernuum gar kein Leitbündel, wenigstens. keines mit differenziertem Gefäßteil. Daß man bei Primärblättern von Farnen die Gefäßbildung ganz nnterdrücken kann, warde experimentell gezeigt.

8) Vgl. L. Berssser, Über die' Jugendformen von Pflanzen speziell von Coniferen.. Ber. der D. bot. Ges. VI, p. LXXXIII. Carrière traité des Conifères II. Ed, 1867. KaUfholz, Beitr. zur Morphol. der Keimpflanzen. Diss. Rostock 1888. 
dienende, nach der Knospenentfaltung bald abfallende „Niederblätter". In deren Achseln stehen Kurztriebe, welche zwei oder mehrere nadelförmige Blätter hervorbringen (bei Pinus monophylla nur eines). Die Keimpflanzen dagegen bringen stets nach den Kotyledonen Laubblätter an den Langtrieben hervor, dies geschieht bei P. Pinea mehrere Jahre hindurch (Fig. 381). Bei Pinus silvestris dagegen verschwinden die Primärblätter schon im zweiten Jahre; an der Basis der austreibenden Knospe sind sie noch vorhanden, nach oben hin aber gehen sie in die Schuppen über, in deren Achseln die Kurztriebe stehen. Die Jugendform läßt sich nach Angaben in der Literatur durch Stecklinge "fixieren", indes ist mir dies, da die Stecklinge nicht anwuchsen, nicht gelungen.

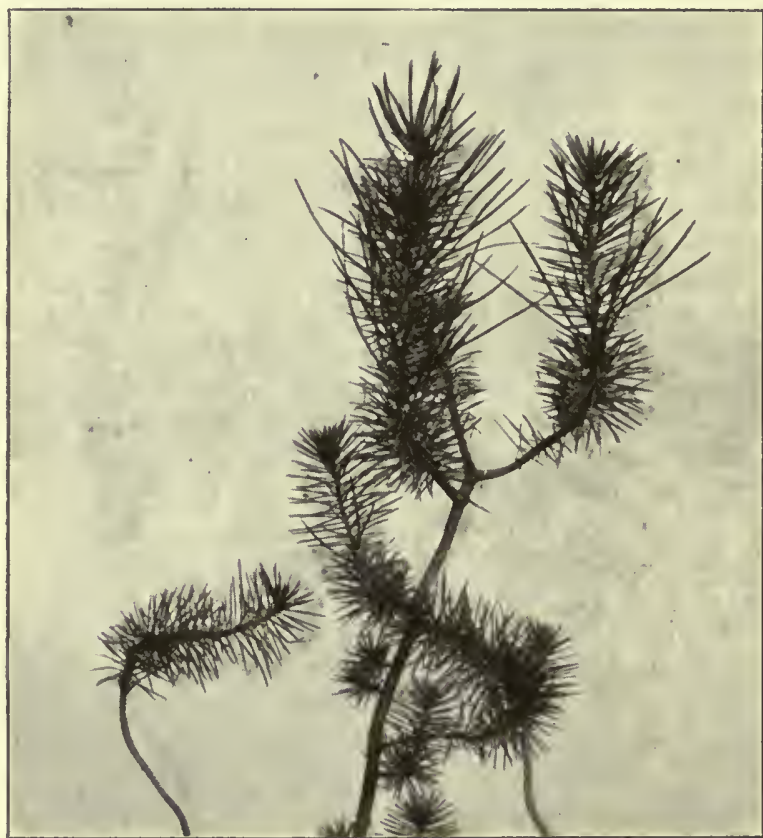

Fig. 381. Pinus Pinea. Oberer Teil einer etwa fünfjährigen (im Topf kultivierten) Keimpflanze mit nadelförmigen Primärblättern, in deren Achseln teilweise Kurztriebe aufgetreten sind.

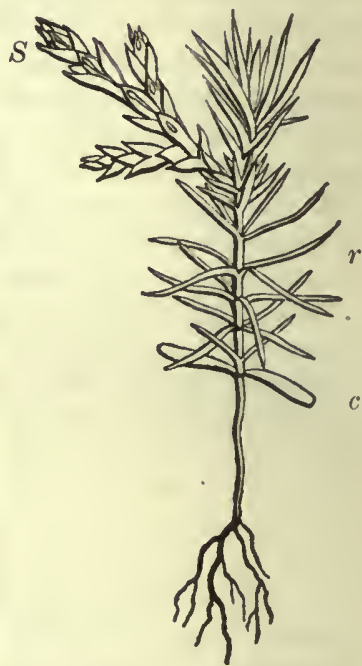

Fig. 382. Keimpflanze von Thuya occidentalis nach W ARming. $c$ Kotyledonen, $r$ Region des Sprosses mit nadelförmigen Primärblätteru, $S$ Seitensproß mit schuppenförmigen Folgeblättern.

Die nadelförmigen Primärblätter sind anatomisch einfacher gebaut als die folgenden (vgl. Kaufholz a. a. O.). Namentlich sind die Einrichtungen zur Transpirationsverminderung in viel geringerem Grade vorhanden, wie sich dies von Pflanzen erwarten läßt, die im Schutze anderer heranwachsen. Bei Larix zeigen die Jugendstadien (im ersten, unter Umständen auch im zweiten Jahre) insofern eine Abweichung, als die Blätter den Winter überdauern, wie die der Pinus- (und der mit Larix nahe verwandten Cedrus-Arten), während sie an älteren Sprossen im Herbst abfallen. Es darf darin wohl ein Verhalten gesehen werden, wie es früher auch die Folgeform zeigte.

2. Cupressineen. Die Blattbildung bei dieser Gruppe ist eine sehr verschiedene, selbst innerhalb einer Gattung. Juniperus communis z. B. hat die für die Nadelhölzer typische Blattform: abstehende Nadeln. Bei Juniperus virginiana, Cupressus-, Callitris-, Chamaecyparis-, Thuyaarten sind die Blätter 
der ausgebildeten Sprosse mit ihrer Oberseite größtenteils mit der Sproßoberfläche "verwachsen", die Nadelblätter auf die Jugendform beschränkt (Fig. 382). An den männlichen Pflanzen von Junip. chinensis treten aber auch im späteren Alter vielfach noch Zweige mit nadelförmigen Blättern auf (vgl. S. I Fig. 11). Die Blütenkätzchen stehen aber gewöhnlich nur an den Zweigen mit anliegenden, schuppenförmigen Blättern, gelegentlich traf ich sie auch in den Achseln nadelförmiger an. Zweige mit nadelförmigen Blättern, welche ich als Stecklinge benützte, waren nach sieben Jahren zu über $1,5 \mathrm{~m}$ hohen Büschen herangewachsen, die ihre Blattform beibehalten haben, später aber wobl auch $Z$ weige mit anliegenden Blättern hervorbringen werden.

Die Jugendformen aller der genannten Formen haben abstehende Blätter und lassen sich in dieser Form "fixieren". Sie werden $z u$ hohen Stämmen von ganz anderem Aussehen als die normal entwickelten Pflanzen derselben Art. Meist sind sie aber nicht imstande, Blüten herrorzubringen, doch kann dies in einzelnen Fällen erfolgen. Ich habe dafür früher (Flora 1889 S. 36) aus der Literatur Beispiele angeführt und später selbst am Gardasee einen derartigen Fall beobachtet. Da die Jugendform hier - ebenso wie bei Pinus - als die ursprünglichere zweifellos zu betrachten ist, so haben wir auf diesem Wege die Stammformen gewissermaßen aufleben lassen!

Für die Auffassung der Entwicklung ist es von großem Interesse, daß die fixierten Jugendformen gewöhnlich ihre Gestaltung beibehalten und in einem Alter und bei einer Größe, bei der die normalen Pflanzen längst geschlechtsreif sind, gewöhnlich keine Sexualorgane hervorzubringen vermögen, trotzdem die äußeren Bedingungen dazu vorhanden sind.

Zwischen Jugendform und Folgeform gibt es natürlich Übergänge. Auch diese lassen sich fixieren, gehen dann aber unter günstigen Bedingungen später mehr oder weniger rasch in die Folgeform über.

In Kultur sind namentlich die Jugendformen von Chamaecyparis pisifera, welche früher als "Retinispora" ${ }^{1}$ )-Arten bezeichnet wurden. Sie lassen sich leicht durch Stecklinge vermehren.

Über die Entstehung der „fixierten Jugendformen" der Cupressineen sind zweierlei Auffassungen vorhanden.

Die eine leitet sie ab von der Jugendform gew öhnlich er Chamaecyparis pisifera. Die Seitenzweige der Keimpflanze werden als Stecklinge benutzt, oder der Hauptsproß beseitigt, und die Seitenzweige allein übrig gelassen. Auf die letztere Art erhielt ich Retinisporaformen, welche jetzt - nach 23 Jahren - noch nicht zur Folgeform übergegangen sind, sie haben sich der Squarrosaform genähert, eine, auf schlechtem Boden stehende, blieb R. "plumosa".

Andererseits berichtet DRUDE ${ }^{2}$ ) über Versuche von Ledien, bei denen die von der Keimpflanze gewonnenen Stecklinge (oder nach Entfernung des Gipfels stehengelassenen Seitensprosse), „unter allen Umständen im Verlaufe einiger Jahre die jugendliche Retinisporaform in die gemeine Schuppenform der Chamaecyparis umsetzten, um so rascher, je kräftiger die Bewurzelung bei den jugendlichen Topfpflanzen vor sich ging". Dagegen waren unter 60 Keimlingen von Samen der "Retinispora squarrosa" 57 normale Chamaec. pisifera, 2 R. plumosa, 1 R. squarrosa. DRUDE betrachtet demnach die Retinispora als "heterogenetisch entstandene Rassen mit geringer Samenbeständigkeit" (letzteres bleibt fraglich, weil nicht bekannt ist, woher der Pollen, der die

1) Fälschlich auch Retinospora geschrieben.

2) O. DRUDE, Kulturversuche und Mutation. Verhandl. der deutschen Naturforschergesellsch. 1903 II, p. 192.

Goebel, Organographie der Pflanzen. 2. Aufl. Allgem. Teil. 
Samenanlagen von "R. squarrosa" bestäubt, stammt; falls keine Selbstbestäubung, sondern Bestäubung mit Pollen der Ch. pisifera vorliegt, ist die geringe Samenbeständigkeit nur eine scheinbare). Ist diese Auffassung richtig, so können also nur solche Jugendformen fixiert werden, die es schon sind, d. h. es handelt sich um eine in Japan schon längst getroffene Auswahl von Formen, welche die Jugendform länger beibehalten als andere ${ }^{1}$ ), wie ja auch die einzelnen Arten sich in der Dauer der Jugendform unterscheiden. Cupressus funebris z. B. weist diese (nach BEIssner) bis zur Höhe von $1 \mathrm{~m}$ auf. Erscheint daran

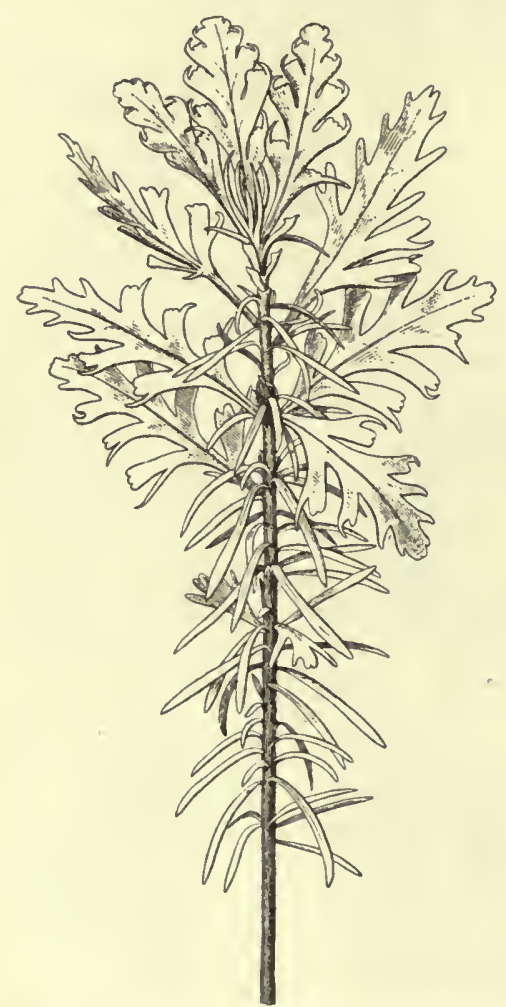

Fig. 383. Phyllocladus rhomboidalis, Keimpflanze. Sie bringt zunächst nadelförmige Blätter hervor, später in deren Achseln die Flachsprosse. An der älteren Pflanze stehen diese in der Achsel von Niederblättern. die Folgeform, so sieht es aus, als ob eine Zypresse aus einem Juniperus hervorwachsen würde. Auf gutem Boden gehen jedenfalls die Jugendformen rascher in die Folgeform über, als auf schlechtem. So gibt denn auch BeYERrNCK nach Mitteilungen verschiedener Züchter an, "daß alle Umstände, welche die Ernährung beeinträchtigen, die Erhaltung der Jugendcharaktere begünstigen " ${ }^{2}$ ).

Ähnlich wie die genannten Cupressineen verhält sich auch, wio es scheint, die Taxacee Dacrydium intermedium ${ }^{3}$ ). Die Jugendform hat hängende Zweige mit langen, nadelförmigen Blättern, die Folgeform der Sproßoberfläche anliegende Schuppenblätter. Auf Stewart Island wird die Folgeform nicht immer erreicht, Jugendformen mit Blüten und Früchten sind dort häufig, sie stellen die var. gracilis von $\mathrm{T}$. Kink dar. $\mathrm{Ob}$ diese blühenden Jugendformen durch äußere Umstände vom Erreichen der Folgeform zurückgehalten werden oder "Mutationen" (,sports") darstellen, kann nur durch Kulturversuche ermittelt werden.

Von anderen Nadelhölzern sei noch das Verbalten von zwei, mit besonders abweichenden Vegetationsorganen ausgerüsteten Arten genannt.

Die Phyllocladusarten ${ }^{4}$ ) zeichuen sich aus durch blattähnlich ausgebildete Zweige (Phyllocladien), welche in den Achseln schuppenförmiger, kleiner, bald vertrocknender und braun werdender Blätter stehen, die aber ursprünglich noch grün sind (eine Mittelstufe zwischen dem gewöhnlichen Verhalten und dem von Pinus, wo die Blätter am Hauptstamm schon bei der Entfaltung als braune Schuppen auftreten), also auch nichts anderes als umgebildete

1) Solche müßten mir dann auch zufällig bei meinen oben erwähnten Versuchen vorgelegen haben. Weitere Untersuchungen über diese interessante Frage wären sehr erwiunscht.

2) Beyerinck, L. Beissner's Untersuchungen bezuiglich der Retinisporafrage. Bot. Zeitung 1890 , p. 539.

3) L. Cockayne. Report on a botanical survey of Stewart Island (1909), p. 11.

4) J. Hooker, Flora tasmanica. H. Th. Geyler, Einige Bemerknngen über Phyllocladus. Abhandl. d. Senckenb. Gesellsch. Bd. XII. 
Laubblattanlagen sind. Die ersten Blätter des ersten Jahrestriebes der Keimpflanze und dann auch wieder ein Teil der im zweiten Jahr entwickelten dagegen sind flache, grüne Nadeln (Fig. 383). Am Ende der Triebe sind sie viel kürzer, schon am dritten Jahrestrieb aber den schuppenartigen Blättern älterer Exemplare viel ähnlicher, gehen also allmählich in diese über. Auch die Phyllocladien gewinnen erst allmählich ihre auffallend blattähnliche Gestalt, wachsen übrigens an ihrer Spitze gelegentlich wieder in zylindrische, mit spiralig gestellten Blättern besetzte Zweige aus. Ein "Fixieren" der Jugendform ist hier noch nicht versucht.

Ganz ähnlich wie Pinus verhält sich bei der Keimung Sciadopitys, welche später statt der Kurztriebe die eigentümlichen Doppelnadeln trägt. An der Keimpflanze folgen auf die beiden lineal-lanzettförmigen Kotyledonen die dem ersten (sehr verkürzten) Jahrestriebe angebörenden Laubblätter. Diese aber sind einfach, mit ungeteilter Spitze und einfachem Gefäßbündel. Schon der nächste Jahrestrieb läßt seine Blätter (wie Pinus) zu Schuppen verkümmern und entwickelt in deren Achseln (in seinem oberen Teile) die Doppelnadeln mit ausgerandeter Spitze und zwei Gefäßbündeln (Fig. 125).

\section{$\S 11$. Angiospermen.}

Nach dem in der Einleitung Erwähnten werden im allgemeinen die Verschiedenheiten in der Ausbildung der Jugend- und der Folgeform um so größer sein, je verschiedener die åußeren Bedingungen sind, denen beide ,angepaßt" sind, während, wo dies nicht der Fall ist, die Primärblätter, mit denen wir es hier zunächst zu tun haben, nur Hemmungsbildungen darstellen (wie bei den Farnen nachgewiesen wurde), falls sie überhaupt verschieden von den folgenden sind. Ihre Gliederung ist dann eine einfachere.

So sind bei den dreiblätterigen Trifoliumarten die Primärblätter einfach, ebenso bei Ononis u. a., wobei bemerkenswert ist, daß diese Blattform bei $O$. Natrix sehr lange beibehalten wird. Kennedya rubicunda zeigt zunächst Primärblätter ohne Spur von Fiederblättchen, dann solche, bei denen die letzteren zwar angelegt, aber zu kleinen Spitzchen verkümmert sind ${ }^{1}$ ), an den folgenden sind sie entwickelt. (Weitere Beispiele s. Flora 1889 , p. $29 \mathrm{ff}$.)

Besonders reduziert und in ihrer Gestalt von den folgenden abweichend sind die Primärblätter von Vicia Faba u. a. Sie treten auf als kleine, dreizähnige Blättchen. Die mittlere Spitze stellt die Blattspreite vor, die seitlichen entsprechen den Stipulae. Die Blattanlage ist hier also auf einem sehr frühen Stadium stehen geblieben, und hat danach nur eine Vergrößerung, keine weitere morphologische Gliederung erfahren. Daß dem so ist, läßt sich auch experimentell nachweisen. Die an der Basis der Pflanze entstehenden Achselsprosse beginnen nämlich mit derselben Blattform. Entfernt man den Hauptsproß oberhalb einer Seitensproßanlage, so wird diese dadurch zu frühzeitigem Austreiben veranlaßt, und statt der Primärblätter erhält man - je nach der Ausbildung, welche dessen Anlagen schon erreicht hatten - die mannigfaltigsten Mittelbildungen

1) Dies geschieht z. B. auch bei äIteren Exemplaren von Acacia lophantha mit den untersten Fiederblättchen, was ich anführe, weil es zeigt, daß eine Hemmungserscheinung vorliegt. 
zwischen ihnen und den Laubblättern oder typische Laubblätter (vgl. Fig. 384).

Derartige Fälle zeigen uns also, daß die Entwicklungshemmung der Primärblätter in Korrelation steht zu der Bildung anderer Organe der Pflanze.

Mrimärblätter, die als Niederblätter ausgebildet sind, finden sich, wie es scheint, namentlich bei Keimpflanzen, die reich mit Reservestoffen ausgerïstet sind ${ }^{1}$ ). So z. B. bei Quercus, wo die auf die Kotyledonen folgenden Niederblätter die Stammknospe beim Durchwachsen durch den Boden schützen.

Im folgenden sei die Grestaltung der Jugendformen bei einigen Pflanzengruppen, die in ihrer Lebensweise iibereinstimmen, besprochen.

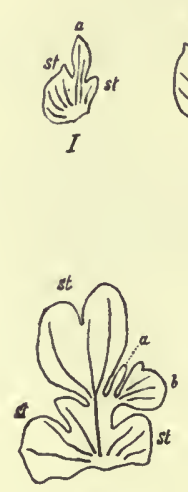

$\pi$

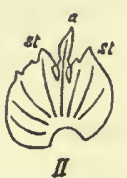

II
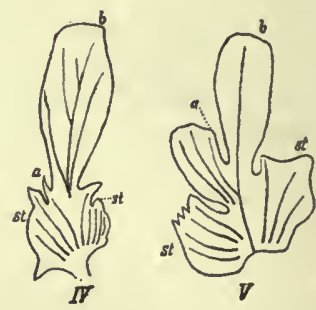

III

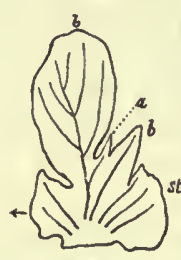

WI
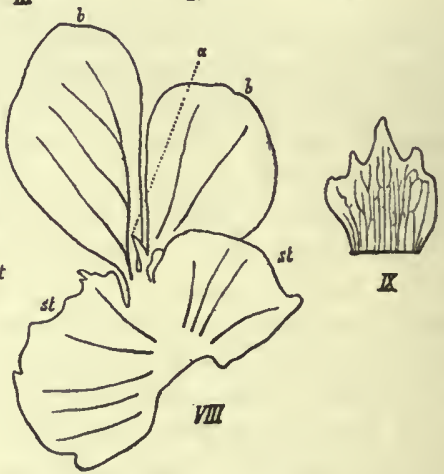

Fig. 384. Primärblätter von Vicia Faba. IX ein normales, am Grunde einer Hauptachse stehendes Primärblatt. I-VIII verschiedene Umbildungsstufen von all der Basis von Seitensprossen stehenden Primärblättern, gewonnen durch Abschneiden des Hauptsprosses; $a$ Blattspitze, st Stipulae (resp. deren Hemmungsbildungen), $b$ Seitenblättchen Die Nervatur ist nur unvollständig angedeutet (vgl. KaUrHozz a. a. 0.).

\section{A. Kletterpflanzen.}

\section{Wurzelkletterer.}

Sehr verschieden ist die Gestaltung der Jugendblattform von der der Folgeblätter bei manchen kletternden Aroideen. An einer solchen, wahrscheinlich einer Philodendronart, welche an den Erythrina-Schutzbäumen einer Kakaoplantage in Venezuela emporkletterte, überzeugte ich ' mich von dieser Verschiedenheit (Fig. 385). Die Blätter sind zunächst ungestielt (resp. ganz kurz gestielt) und liegen der Stammober-

1) Vgl. das über die Entstehung der Hochblätter (welche den Niederblättern ganz entsprechen) in Goeber, Ex. Morphologie p. 64 Angeführte. 
fläche dicht an, so die jungen Haftwurzeln des Philodendron schïtzend. Später ändern sie ihre Gestalt, sie bekommen eine größere Spreite und einen längeren Stiel und stehen vom Stamm ab, bis endlich die großen, am Rande zerteilten Blätter sich bilden, die für ältere Philodendron charakteristisch sind.

Die in den Gärten als "Pothos celatocaulis“ kultivierte Aroidee ist zweifelsohne eine solche Jugendform, deren weitere Entwicklung man aber noch nicht kennt, trotzdem die Pflanze eine Länge von mehreren Metern erreicht (vgl. Fig. 386).

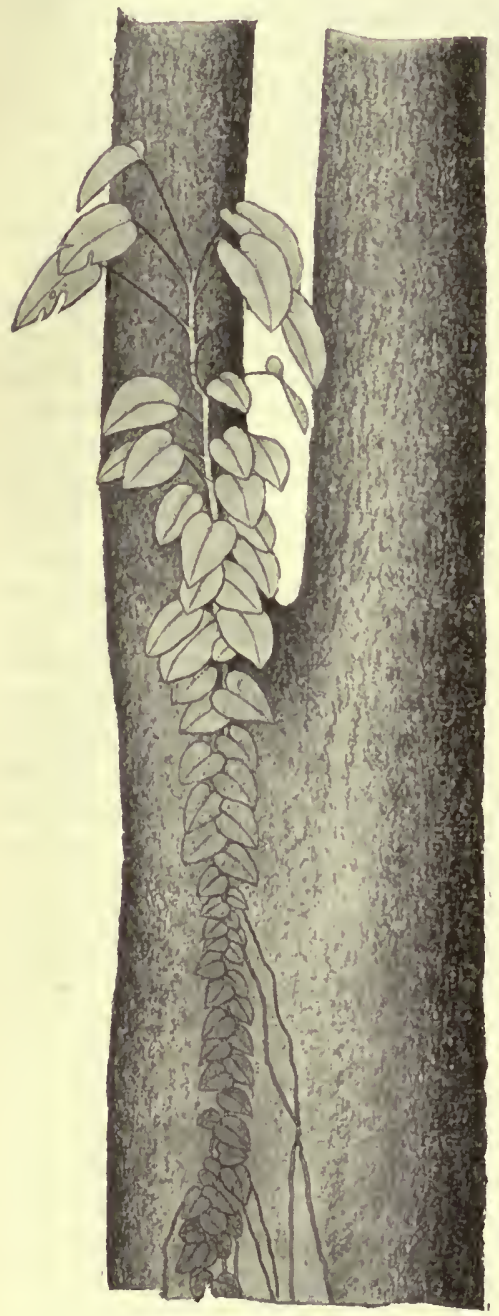

Fig. 385.

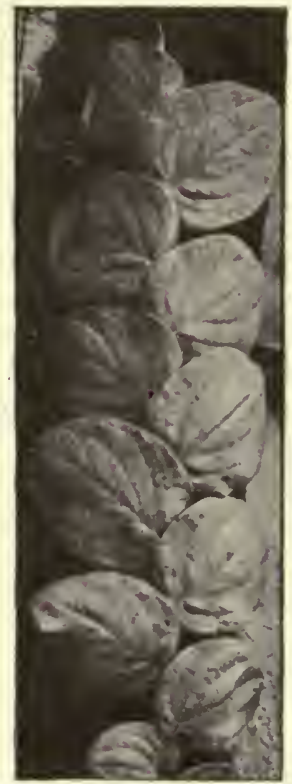

Fig. 386. "Pothos celatocanlis". Jugendform. Der zweizeilig beblätterte Sproß wächst auf einem Baumfarnstanm, dessen Oberfläche die Pothosblätter dicht angeschmiegt sind (rerkleinert).

Fig. 385. Junge Pflanze einer kletternden Aroidee, nach einer 1889 in San Estéban (Veneznela) aufgenommenen Photographie. Die unteren Blätter sind, wie bei "Pothos celatocaulis:', dem Baumstamm, an welchem die Aroidee wächst, dicht angeschmiegt, die oberen erhalten eine andere Gestalt. Die Haftwurzeln sind nicht sichtbar, wohl aber einige von den nach dem Boden hinabwachsenden Nährwurzeln.

Die abgeflachte Sproßachse trägt auf ihrer Schattenseite Wurzeln, welche durch die Blätter trefflich geschützt sind; wahrscheinlich wird man früher oder später auch zu dieser Pflanze die (blühende) Folgeform mit gestielten abstehenden Blättern"auffinden. 
Ganz Ähnliches hat RIDLEY ${ }^{1}$ ) von „Anadendrum medium" beschrieben, dessen Jugendform in den Gärten als Pothos flexuosus kultiviert wurde, was um so weniger $\mathrm{zu}$ verwundern ist, als man bei dieser Pflanze nur sehr selten alle Blattformen zusammen antrifft (während man dies bei der in Fig. 385 abgebildeten Pflanze leicht beobachten kann) und viele Exemplare offenbar lange auf dem Jugendstadium verharren. Die Blattformen sind in Fig. 387 dargestellt. RIDLEY's Beschreibung derselben ist folgende: $A$ Die Blätter stehen zweizeilig und dicht zusammen, sie zeigen ein samtiges Grün. Wenn die Pflanze höher steigt, werden sie breiter und mehr eiförmig, weniger schief, mit herzförmiger Basis und deutlicher gestielt, etwa $71 / 2 \mathrm{~cm}$ lang und halb so breit; $B$ höher hinauf werden sie länglich zugespitzt, $18-20 \mathrm{~cm}$ lang, $10 \mathrm{~cm}$ breit mit einem kurzen, dicken Stiel

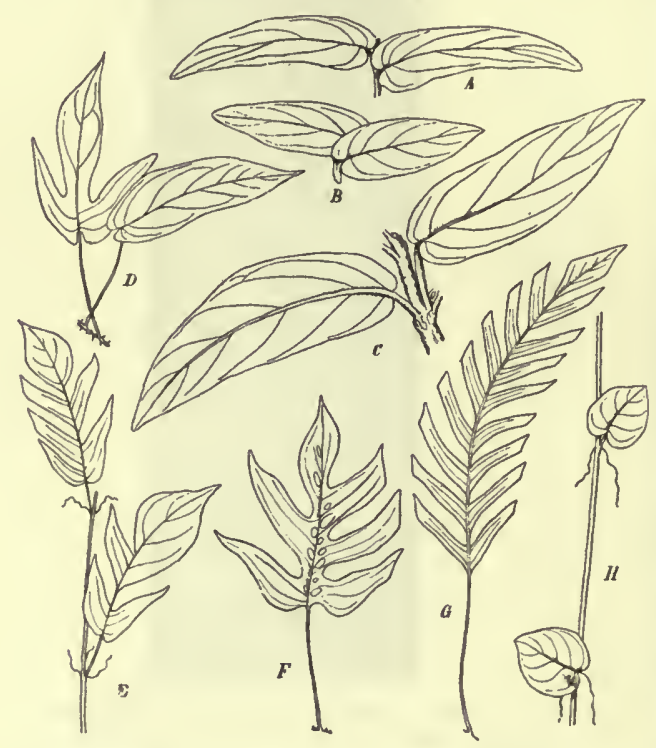

Fig. 387. Verschiedene Blattformen von Anadendrum medium ("Pothos flexuosa") nach RIDLEy. Stark verkl. A Ungestielte „Sammetblätter"; $B$ höher oben stehende, dickere Blätter; $C$ A uftreten des Stieles; $D-G$ weitere Differenzierung ( $G$ Blatt einer blühbaren Pflanze); $H$ Blätter eines "Ausläufers". von $2^{1} / 2-4 \mathrm{~cm}$ Länge; $C$ noch sind sie zweizeilig und liegen flach auf dem Baumstamm... Dann erfolgt eine große Änderung, sie werden eiförmig zugespitzt mit herzförmiger Basis, $15-20 \mathrm{~cm}$ lang, $10 \mathrm{~cm}$ breit mit einem $12 \mathrm{~cm}$ langen Stiel; $D$ sie sind nicht mehr zweizeilig und liegen dem Stamme auch nicht mehr an, sondern spreizen nach allen Richtungen: Ihr dunkles, glänzendes Grün zeigt, daß sie sehr verschieden von den zarten, samtig grünen Blättern der unteren Region sind. Dann beginnen sie, während Umriß und Größe der letzten Form beibehalten wird, Anzeichen für fiederschnittige Gliederung zu zeigen; $E$ der Stiel wird über $20 \mathrm{~cm}$ lang und erhält ein "Knie" nahe der Spreite, die jetzt etwa $25 \mathrm{~cm}$ lang und bis nahe auf die Mittelrippe fiederschnittig ist, an beiden Seiten der letzteren befinden sich eine Anzahl elliptischer Durchlöcherungen; $F$ endlich erhält die Blattspreite eine Länge von über $40 \mathrm{~cm}$ mit schmalen, $21 / 2-4 \mathrm{~cm}$ breiten Segmenten, ähnlich wie ein Raphidophorablatt; $G$ die Pflanze ist jetzt blühreif. Sie bildet aber bäufig noch eine andere Blattform; $H$ es entstehen nämlich oft lange, herunterhängende Ausläufer, diese besitzen breite, ovale oder fast runde Blätter, die an der Basis herzförmig und fast sitzend sind.

Wenn die Pothosform an einem Felsen oder einer Mauer wächst, bleibt sie ohne höhere Entwicklung ${ }^{2}$ ), an einem Baumstamm kann sie und

1) RIDLEY, Pothos flexuosus Hort. Gardeners Chronicle I, p. 527. 1894.

2) Dies möchte ich nach dem Verhalten des Epheu kaum als allgemein gültig betrachten; wenigstens ist durchaus nicht einzusehen, woher eine solche Verschiedenheit 
tut es auch gewöhnlich, sich zur Raphidophoraform entwickeln, wenn sie hoch genug gewachsen ist. Stecklinge der letzteren Form kehren nie zur Pothosform zurück. Beide Formen aber bilden, wenn sie über ihre Stütze hinauswachsen, die lange, hängende, ausläuferähnliche Form mit runden, entfernt stehenden Blättern. RrDLeY meint, daß die Entwicklung der Raphidophoraform mit dem Lichte nichts zu tun habe, da sie nicht selten in ganz dunklen Teilen des Waldes erfolge, während die Pothosforın auf einem dem Sonnenlicht ausgesetzten Felsen oder Baumstamm sich nicht weiter entwickle. Vielleicht fehlen hier indes die anderen zum normalen Wachstum nötigen Faktoren (Feuchtigkeit usw.), und es wird deshalb die Pflanze auf dem Jugendstadium zurückgehalten, ähnlich wie dies oben von einigen Coniferen ausgeführt wurde. Jedenfalls wäre es von großem Interesse, diesen Fall experimentell näher zu prüfen. Die verwandten Arten, Anadendrum marginatum und A. montanum, haben keine derartigen Jugendformen ${ }^{1}$ ).

Ähnlich wie diese Aroideen verhalten sich auch einige Kletterpflanzen,

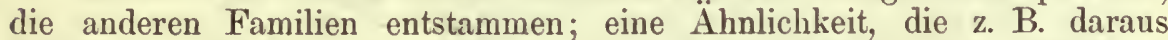
hervorgeht, daß die Jugendformen der ersteren häufig in den Gärten mit denen von Marcgravia verwechselt wurden ${ }^{2}$ ). Die Marcgravien gehören $\mathrm{zu}$ den auffallendsten Kletterpflanzen der tropisch-amerikanischen Flora. Die Jugendform besitzt plagiotrope Sprosse, deren dem Baumstamm anliegende Blätter die Wurzeln decken, während später nicht wurzelnde, vom Substrat abstehende Sprosse entstehen mit viel größeren, gestielten Blättern; an diesen entstehen dann auch die Blüten ${ }^{3}$ ). Ähnlich verhalten sich einige kletternde Ficusarten, so Ficus scandens und F. pumila, die man in unseren Gewächshäusern fast stets nur in der plagiotropen Jugendform sieht.

Wie bei diesen Pflanzen die Jugendform offenbar eine in Verbindung mit der kletternden Lebensweise entstandene Anpassung darstellt, so auch bei Hedera Helix, dessen Jugendsprosse abweichend von denen der verwandten Araliaceen nach $\%$ beblättert und plagiotrop sind. Nur läßt sich die abweichende Blattform (Fig. 388, 2) dieser Jugendsprosse (sie haben 3-5 lappige Blätter, während die der orthotropen, blütentragenden Sprosse eiförmig zugespitzt sind - Fig. 388, 1) mit den äußeren Verhältnissen zunächst nicht in Verbindung bringen. IVenn man neuerdings die gezackte Blattform der Jugendsprosse mit ihrer Zusammenfügung zu einem ,Blattmosaik" hat in Beziehung bringen wollen, so ist dies, wie eine unbefangene Naturbeobachtung zeigt, erdichtet oder als ein seltener

kommen sollte, es hängt nur von Ernährungsverhältnissen ab, ob die Folgeform erreicht wird.

1) Anch andere nicht epiphytische Aroideen haben höchst interessante Jugendformen, die teilweise im speziellen Teile (bei Besprechung der Blattbildung) Erwähnung finden sollen. Es sei auf die Abbildungen und Beschreibungen in Evgres's "Pflanzenreich" verwiesen.

2) Mehrmals wurden mir Aroideenjugendformen von Handelsgärtnereien als „Maregravia" zugesandt. - Bei anderen Maregraviaceen, z. B. Norantea guianensis, scheint eine abweichende Jugendform nicht vorhanden zu sein.

3) Die verschiedenen Blattformen sind auch anatomisch verschieden. Die Blätter der plagiotropen Sprosse haben namentlich auf der Unterseite ein verbältnismäßjig dickes, lufthaltiges Gewebe, dessen Intercellularräume vielleicht manchmal mit Wasser injiziert sind, jedenfalls aber eine Schutzdecke für die Warzeln bilden. Wächst Marcgravia auf einem dünnen Aste, so krümmen sich die Blattflächen entsprechend um den Ast herum. Hier wie bei den oben erwähnten kletternden Aroideen sind die Jugendblätter ferner nach dem Typus der "Sammetblätter" gebaut (ein auf das Blatt gebrachter Wassertropfen breitet sich bei Marcgravia rasch aus), die der Folgeform nicht. 
Ausnahmefall herausgegriffen, um die Zweckmäßigkeit der Blattform zu beweisen. Die orthotropen, nach $2 / 5$ (auch $\% / 8$ und $8 / 13$ ) beblätterten radiären Sprosse treten erst nach Erreichung eines gewissen Alters auf, und bilden sich nur, wenn Licht von höherer Intensität zur Verfügung steht, als es zur Bildung der plagiotropen Sprosse ausreicht.

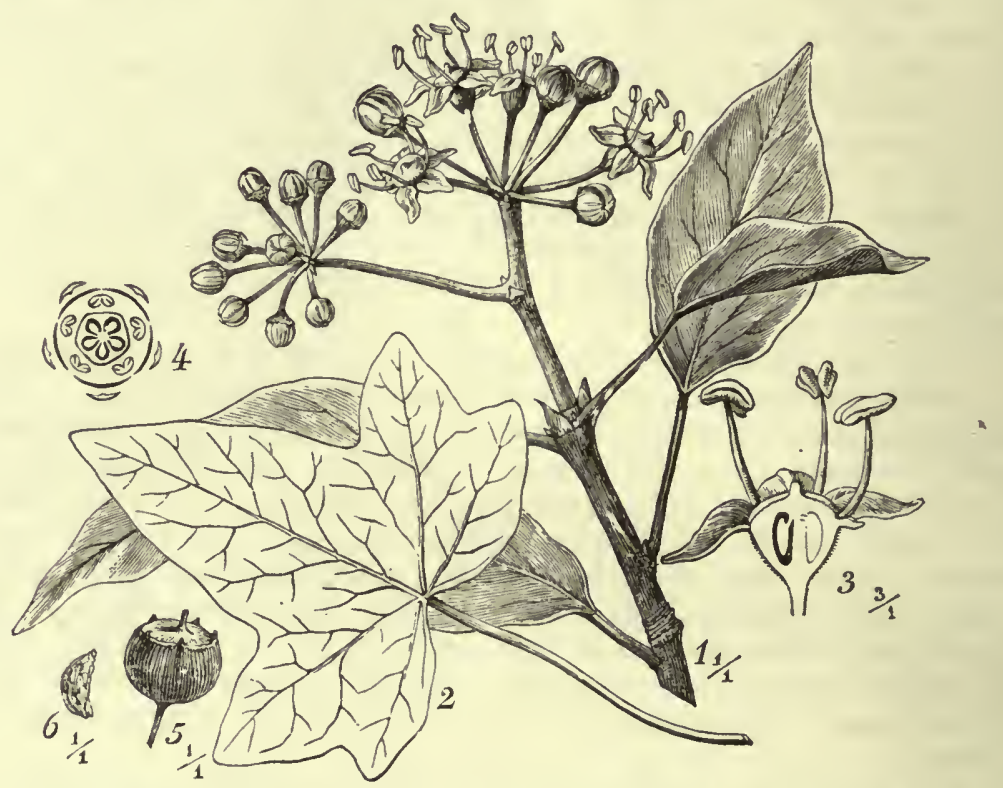

Fig. 388. Hedera Helix. Ein Stück eines in einen Blütenstand endigenden Astes. Die Blattform ist verschieden von der der sterilen Sprosse (2). (Lehrb.)

In den Wäldern in der Umgebung Münchens kommt Hedera nicht über die Jugendform hinaus, sei es, daß sie auf dem Boden wurzelt oder an Bäumen hinaufklettert. Ebenso nahe der Nordgrenze ihres Verbreitungsgebietes (vgl. F. ToBler, Die Gattung Hedera, Jena 1912. Selbstverständlich können auch andere Faktoren als zu schwache Beleuchtung [z. B. kurze Vegetationsperiode] das Beharren auf der Jugendform bedingen). Dagegen bildet sie die Folgeform an freistehenden Bäumen oder an gutbeleuchteten Mauern. Die Annahme von SAchs ${ }^{1}$ ), daß der Epheu die radiären Fruchtsprosse erst entwickle, wenn die plagiotropen Klettersprosse genötigt seien, sich horizontal zu legen, kann wohl für Einzelfälle zutreffen (nämlich dann, wenn die Sprosse an einer beschatteten Mauer emporkletternd oben in bessere Beleuchtung, Temperatur usw. kommen), aber das Auftreten der Folgeform ist ganz unabhängig von der Richtung, in welcher die Jugendform wächst. Letztere braucht auch unter günstigen Umständen eine Reihe von Jahren bis sie die blühbare Folgeform bilden kann. Sie tritt dann aber auch an Pflanzen auf, die nur vertikale Substrate überziehen. Übrigens sind Blattform und Blattstellung nicht notwendig miteinander verknüpft. Ich sah Zweige mit zweireihiger Blattstellung und ganzrandigen Blättern, wie sie sonst den radiären Sprossen zukommen. Die Jugendform und Folgeform sind auch da-

1) Flora 81 (1896). 
durch verschieden, daß erstere leicht, letztere schwer durch Stecklinge sich vermehren läßt.

Die ersten Blätter, die bei der Keimung auftreten, gleichen übrigens bei manchen Keimpflanzen denen der orthotropen Sprosse, obwohl die Keimlinge von Anfang an zweizeilig beblättert sind, die fünflappigen Blätter treten erst im zweiten Jahre auf ${ }^{1}$ ).

In der Gärtnerei werden die radiären Sprosse vielfach als Stecklinge benutzt, die zu "Epheubäumchen" (fälschlich als var. arborea bezeichnet) heranwachsen und lange Zeit fortleben können. Gelegentlich entwickeln sie an ihrer Basis Sprosse, welche auf die Jugendform zurïckschlagen (Fig. 389).

Auf den Antillen soll es eine Hedera arborea Sw. geben (nicht zu verwechseln mit den erwähnten mit „H. arborea" bezeichneten Stecklingspflanzen, die aus radiären Sprossen von $\mathrm{H}$. Helix hervorgingen), die wie es scheint $\mathrm{nur}$ in der Folgeform bekannt ist. Es wäre von Interesse, deren Jugendform kennen zu lernen, vielleicht ließe sich daraus die Entstehung der von H. Helix ableiten. Jedenfalls haben wir die plagiotropen Jugendstadien der oben beschriebenen Wurzelkletterer als se-

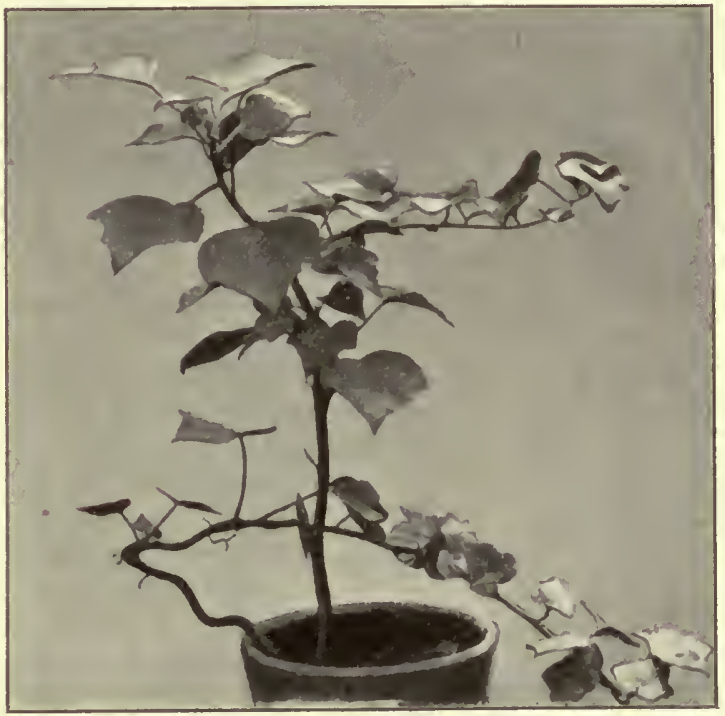

Fig. 389. Hedera Helix. Die aus dem Steckling eines radiären Sprosses erwachsene Pflanze hat links unten und rechts oben je einen zweizeilig beblätterten Sproß entwickelt. kundäre "Anpassungen"

(seien sie nun wie immer entstanden) nicht als primitive (denen der Folgeform der Vorfahren entsprechende) Gestaltungsverhältnisse zu betrachten. $\mathrm{Daß}$ aus einer mehrreihigen Blattstellung (wie bei Hedera) eine zweireihige wird, ist ja auch sonst bekannt (vgl. p. 205, 225).

\section{Ranken- und Schlingpflanzen.}

a) Die meisten Rankenpflanzen haben im Jugendstadium keine oder doch nur funktionslose Ranken. Letztere Tatsache ist deshalb von Interesse, weil sie uns wieder das Auftreten von Organhemmungen vor Augen führt.

Fassen wir zunächst die Blattranken ins Auge, so finden wir bei manchen Pflanzen (nach der Keimung) alle Übergänge von den ersten nicht

1) Buchenau, Zur Morphologie von Hedera Helix. Bot. Zeit. 1864, p. 276. Toblen fand sehr oft schon nach den Kotyledonen gelappte Blätter. 
rankenden Laubblättern bis zu solchen, bei denen die Ranken in ihrer Gestalt von der der Laubblätter abweichen und die Form dünner, reizbarer Fäden angenommen haben, so bei Corydalis claviculata, Adlumia cirrhosa u. a. Ebenso können wir bei der merkwürdigen Keimung von Nepenthes (S. II, p. $98 \mathrm{ff}$.) deutlich verfolgen, wie das ursprünglich nur als Tierfalle (und Assimilationsorgan) ausgebildete Blatt allmählich auch zum Kletteroryan sich gestaltet. Dagegen ist bei Cobaea und den Papilionaceen der Üjbergang ein unvermittelter.

Als ein auch sonst merkwürdiges Beispiel sei Lathyrus aphaca erwähnt (vgl. Fig. 276). Die ganze Blattlamina hat sich hier zur Ranke umgebildet. An den Keimpflanzen erscheinen nach den (hypogaeischen) Kotyledonen zuerst einige der einfachen Primärblätter, wie sie bei Papilionaceen sehr verbreitet sind: zuerst gewöhnlich eine nicht oder nur andeutungsweise gegliederte, dann mehrere dreispitzige grüne Schuppen; die mittlere Spitze entspricht der Blattlamina, die beiden seitlichen vertreten die Nebenblätter. Darauf folgen Laubblätter mit je zwei Fiederblättchen und
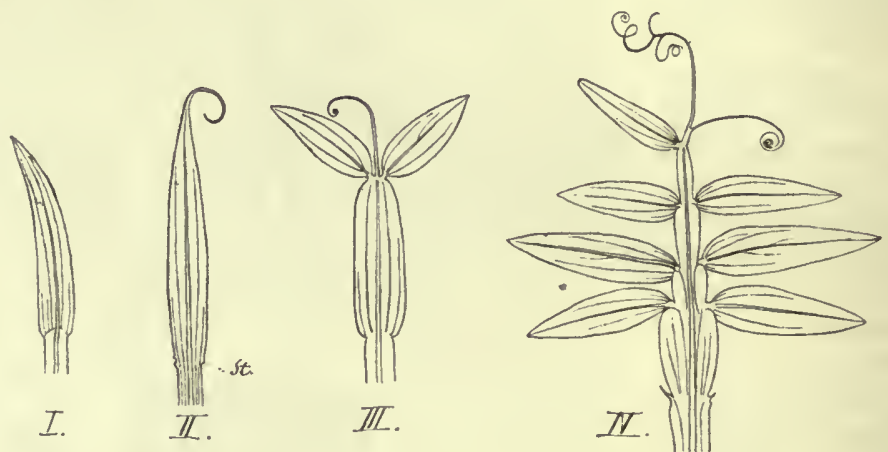

Fig. 390. Lathyrus Clymenum. Blattformen aus verschiedenen Lebensaltern einer Keimpflanze. I Ungegliedertes Primärblatt; $I I$ ein Primärblatt, in eine Ranke endigend. bei $S t$ die rndimentären Stipulae; III und $I V$ Blätter, an denen die Fiederblättchen aufgetreten sind.

unsymmetrischen Nebenblättern. Die folgenden Blätter lassen die Blattlamina verkümmern, sie erscheint als kleines Spitzchen zwischen den bedeutend vergrößerten und symmetrisch gewordenen Nebenblättern. Dann erst folgen Blätter, deren Lamina zur Ranke umgebildet ist. Diese rudimentären Blätter sind wohl als die ersten funktionslosen Ranken zu betrachten. Es ist anzunehmen, daß Iath. aphaca ursprünglich eine Blattbildung wie andere Lathyrusarteu besaß, daß also nur der Endteil des Blattes als Ranke funktionierte, dann aber die Fiederblättchen verkümmerten und in Verbindung damit die Nebenblätter sich bedeutend vergrößerten.

Besonders eigentümlich ist die Blattbildung bei Lathyrus Ochrus ${ }^{1}$ ), einer Pflanze, die deshalb mehrfach zu Erörterungen Anlaß gegeben hat, weil hier in der Tat eine Reihe von Vorgängen miteinander verquickt sind; die ersten Blätter (Fig. 390) sind klein und schmallanzettlich. An ihrer Basis kann man jederseits einen; eventuell auch zwei kleine häutige Zälıne unterscheiden, die wohl als verkümmerte Nebenblätter zu betrachten sind. Das Blatt wird dann größer, seine Spitze wäclıst aus zu einer zu-

1) Ähnlich verhalten sich auch L. Clymenum (Fig. 390) und L. Mauritanicus. 
nächst noch rudimentären Ranke. Rechts und links (oder auch nur einseitig) treten zwei weitere Ausgliederungen auf, zwei seitliche Ranken. Diese sitzen also auf einer breiten Blattfläche. Später bilden sich auch Fiederblätter und die obersten Blätter haben eine doppelte oder dreiteilige endständige Ranke und darunter 1-2 Paare Fiederblättchen; nicht selten steht auch einem Fiederblättchen eine Ranke gegenüber.

Wie ist nun das eigentümliche Gebilde aufzufassen? ${ }^{1}$ ) IRMISCH hielt den flächenförmigen Teil des Blattes für einen Blattstiel. Dem widerspricht aber die Entwicklungsgeschichte und das Verhalten anderer Papilionaceen. Bei diesen finden wir häufig Primärblätter von der in Fig. 384, $I$ abgebildeten Form. Diese sind, wie auch experimentell nachgewiesen wurde, sicher Hemmungsbildungen, die so zustande kommen, daß $a$ nicht einem Blattstiele ohne Spreite, sondern dem ganzen oberen Teile einer Blattanlage entspricht (dem sog. Oberblatt). Ein Blattstiel ist überhaupt noch nicht gebildet. Denken wir uns $a$ stark vergrößert, den darunter befindlichen Teil nur wenig entwickelt, so erhalten wir L. Ochrus (Fig. 390, I). Nur bleibt hier die Blattbildung lange auf diesem Stadium stehen, die Blattfläche ist also nicht ein Blattstiel, sondern der ganze obere Teil der Blattanlage, der sich vom unteren - dem Blattgrund - nicht mehr scharf sondert. Später entwickelt er sich dann weiter in der oben angegebenen Weise. Daß die Nebenblätter verkümmern können, hängt mit der Verbreiterung der ganzen Blattanlage zusammen; erstere sind als Schutzorgan für die Stammknospe entbehrlich geworden, weil diese Funktion durch die breiten Blätter selbst besorgt wird. Die Verbreiterung der Blattfläche aber wird der Pflanze erlauben, rasch heranzuwachsen und ihre Wettbewerber zu verdrängen; ich möchte glauben, daß diese Arten an ziemlich dicht besiedelten, grasigen Standorten, Hecken usw. mit nicht sehr starker Beleuchtung aufwachsen. So glaube ich, können wir auch hier noch der Umänderung nachgehen, welche erfolgte.

Ganz ähnlich verhält sich L. Nissolia, nur daß bier auch die obersten Blätter keine Ranken entwickeln. Wie bei L. Ochrus treten an der Keimpflanze schmallanzettliche, ungefiederte, mit rudimentären Nebenblättern versehene Primärblätter auf.

Für DaRwixs Hypothese (Kletterpflanzen p. 154), wonach diese Art von einer ursprünglich windenden Pflanze abstammen soll, welche dann zum Blattkletterer wurde, dann die Verzweigung der Ranken einbüßte, schließlich auch deren Rotationsvermögen und Reizbarkeit, worauf die Ranke wieder blattartig wurde, scheinen mir derzeit keinerlei positive Anhaltspunkte vorzuliegen ( $D_{\text {ARW IN }}$ nimmt sogar noch eine zweimalige Veränderung in der Ausbildung der Nebenblätter an). Möglich daß L. Nissolia von einer Rankenpflanze abstammt, dann aber ist es nicht erforderlich, einen so verwickelten Vorgang anzunehmen, wie DARWIN es tut, vielmehr zeigt der Vergleich mit L. Ochrus einen einfacheren Weg.

- Endlich möchte ich noch einen Fall anführen, der dadurch von Interesse ist, daß die Eigentümlichkeit, als Ranken zu funktionieren, schon den Primärblättern zukommt. DARwin hat a. a. O., p. 47, für Tropaeolum tricolorum darauf hingewiesen, daß es bis zu einer Höhe von 2-3' keine Blätter erzeuge, sondern für Berührung reizbare „Filanıente", welche höher am Stamm hinauf in vollkommene Blätter iibergehen. Diese „Filamente" sind nun nichts anderes als Primärblätter; daß sie schon als Ranken funktionieren, ist für die Pflanze deshalb von Bedeutung, weil die

1) Eigentlich setzt eine derartige Erörterung die im allgemeinen Teil noch nicht gegebene Darstellung der Blattentwicklung voraus; ich glaubte aber aus anderen Gründen den eigenartigen Fall hier nicht unerörtert lassen zu sollen. 
Sproßachsen außerordentlich dünn sind und dementsprechend die Notwendigkeit von Haftorganen hier viel früher sich geltend macht, als bei anderen Rankenpflanzen. Die von mir untersuchten Keimpflanzen hatten nur wenige „Filamente“, ehe sie zur Blattbildung übergehen. Die Filamente sind verlängerte Blattanlagen, an denen eine Trennung in Stiel und Spreite noch nicht eingetreten ist. Weiter nach oben hin an der Pflanze wird eine Spreite dann sichtbar. Es sei auch das Verhalten einer anderen Tropaeolumart kurz erwähnt. Die meisten Tropaeolumarten haben an ihren Blättern keine Nebenblätter, obwohl sie solche ursprünglich offenbar besessen haben. Tr. majus besitzt sie denn auch an den beiden ersten Blättern, allein sie zeigen schon hier einen reduzierten Charakter (zuweilen fehlt eines, und sie stehen nicht immer an dem normalen Platze).

Betreffs der rankentragenden Cucurbitaceen sei auf den speziellen Teil verwiesen und hier nur erwähnt, daß bei Arten mit "verzweigten" Ränken die einfache Rankenbildung der Keimpflanze bei schlechter Ernährung auch im späteren Alter noch auftreten kann ${ }^{1}$ ).

b) Die Schlingpflanzen verhalten sich insofern übereinstimmend mit den Rankenpflanzen, als auch bei ihnen die Keimpflanzen zunächst keine Windebewegungen ausführen. Bei manchen z. B. bei Landolphiaarten setzt die Bildung windender Sprosse erst ein, nachdem die Pflanze schon in das Stadium der Holzbildung übergegangen ist. greifen.

Aber auch hier kann dies Winden schon auf den Keimsproß zurück-

Das tritt in auffallender Weise hervor bei Physostigma venenosum (Fig. 391). Hier ist schon der Keimsproß als "Sucher" ${ }^{2}$ ) ausgebildet, d. h. er besitzt langgestreckte Internodien und die Blattbildung ist gehemmt. Das erste Laubblatt trat an der abgebildeten Pflanze (deren Koty. ledonen hypogäisch sind) erst $1 / 2 \mathrm{~m}$ über dem Boden auf.

Dieses Verhalten entspricht also dem von Tropaeolum tricolorum angeführten insofern, als hier der Keimsproß sofort zum Klettern eingerichtet ist, was in beiden Fällen wohl als ein abgeleitetes Verhalten betrachtet werden darf.

\section{B. Wasserpflanzen und Sumpfpflanzen.}

Das Verhalten einer größeren Anzahl hierher gehöriger Formen wurde früher (S. II) von mir eingehender geschildert $\left.{ }^{3}\right)$. Hier sei nur weniges kurz hervorgehoben.

Die mit Schlauchblättern verschiedener Gestaltung ausgerüsteten Sarracenieen stimmen in der Gestaltung ihrer Primärblätter alle im wesentlichen überein, während die späteren oft ziemlich voneinander verschieden sind (vgl. die Abbildungen a. a. O.).

Bei den Utricularien ist das Verhalten der Keimpflanzen besonders wichtig, weil es die Übereinstimmung im Gesamtaufbau der Land- und Wasserarten zeigt, die späterhin weit voneinander abweichen.

1) GokBEL, Vergl. Entwicklungsgeschichte, p. 240.

2) So wurden in der 1. Aufl. die langgestreckten durch gehemmte Blattbildung ausgezeichneten Sprosse mancher Schlingpflanzen bezeichnet, welche Stiitzen gewissermaßen aufsuchen.

3) Daselbst anch zahlreiche Abbildungen. 
Eine Anpassung, welche das Umgeworfenwerden der Keimpflänzchen erschwert, spricht sich in der Gestaltung der schildförmigen Primärblätter von Salvinia u. a., der kreiselförmigen von Azolla aus (Fig. 73 a. a. O.).

Namentlich hat das Verhalten einiger Monokotylen Veranlassung zu verschiedener Auffassung gegeben.

Alle bis jetzt untersuchten Alismaceen ${ }^{1}$ ) und Pontederiaceen und Potamogetoneen sind dadurch ausgezeichnet, daß sie - so verschieden auch später die Blattform sein mag - ursprünglich bei der Keimung einfach bandförmige Blätter hervorbringen, die man früher irrigerweise für Phyllodien gehalten hat (vgl. Fig. 392). Sie gehen meist durch Zwischenstufen in die höhere, mit Stiel und Spreite versehene Blattform uiber. Die Primärblattform wird von den einzelnen Arten verschieden lange beibehalten, am längsten von denen, die mehr untergetaucht leben.

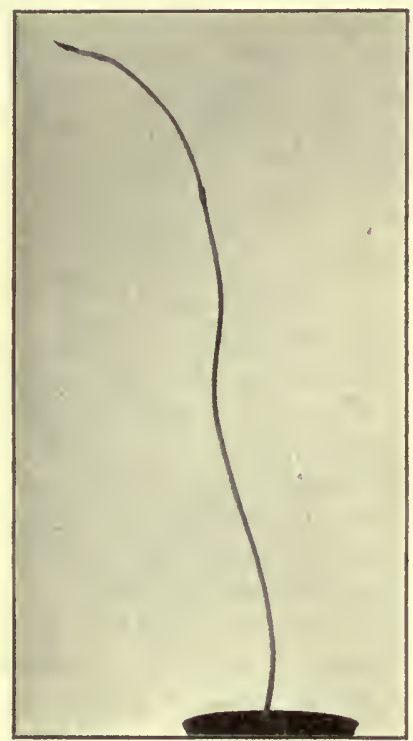

kig. 391. Physostigma renenosum. Keimsproß als "Sucher" ausgebildet mit langen Internodien und gehemmter Blattbildung (verkl.).

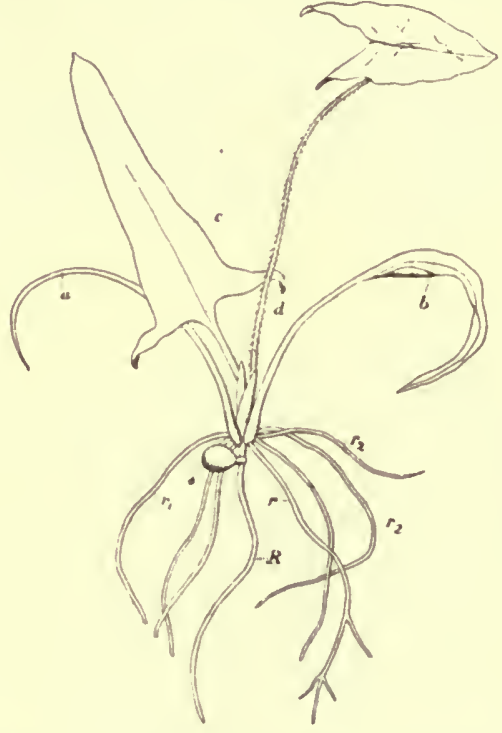

Fig. 392. Keimpflanze ron Victoria regia (nach Trécul) (verkleinert). Die Blätter uach ihrer Reihenfolge bezeichnet $(a, b .$.$) ;$ $s$ Samenschale; $R$ Hauptwurzel; $r, r_{1}, r_{2}$ Seiten warzeln.

Bei diesen, z. B. Heteranthera zosteraefolia, Sagittaria natans tritt die höher entwickelte Blattform meist nur an blühenden Pflanzen und in geringer Zahl auf, während zahlreiche bandförmige Blätter vorhanden sind, die bei den mehr dem Landleben angepaßten Arten nur als rasch voriibergehende Entwicklungsstufe sich finden. Solche Verschiedenheiten finden sich bei Arten einer und derselben Gattung, wie der Vergleich von S. natans und S. cordifolia zeigt, bei welch letzterer die Primärblätter kaum eine Rolle spielen.

Es fragt sich nun: sind die Primärblätter hier eine durch "Anpassung" an das Leben im Wasser entstandene Blattform oder nicht? Die Tat-

1) Vgl. auch GLück, Biolog. und morphol. Unters. über Wasser- und Sumpfgewächse, I. Bd. (190う). 
sache, daß bei der großen Mehrzahl der anderen Monokotylen die bandförmigen Blätter die typische Blattform darstellen, ferner die, daß diese Blätter auch dem Landleben sich anzupassen vermögen, und andere Gründe führten mich früher zu der Ansicht, daß ein Grund zu der oben zuerstgenannten Annahme nicht vorliege, so wenig auch daran zu zweifeln ist, daß ein Zusammenhang zwischen der Zahl dieser Blätter und der Lebensweise der betreffenden Pflanze vorhanden ist.

Viel einfacher gestaltet als die über das Wasser tretenden sind auch bei einigen Dikotylen die untergetauchten Primärblätter. So zeigt Fig. 392 eine Keimpflanze der Nymphaeacee Victoria regia, die das erste - von den folgenden noch abweichende - Schwimmblatt $d$ gebildet hat. Die drei diesem vorangehenden Blätter sind untergetaucht, die Blattspreite ist bei $a$ noch nicht rom Stiele abgegrenzt und bei $b$ und $c$ anders gestaltet als bei $d$. Daß es sich dabei um eigenartig entwickelte Hemmungsbildungen handelt, zeigt die Tatsache, daß an den austreibenden Knollen von Nymphaea rubra dieselben Primärblätter wie an den Keimpflanzen auftreten, und Nuphar luteum verharrt unter ungünstigen Umständen (in sehr tiefem Wasser usw.) oft sehr lange auf der Stufe der Bildung von Wasserblättern, wie sie bei der Keimung sich bilden.

\section{Xerophile Pflanzen.}

Xerophile Pflanzen, d. h. solche, die an Standorten leben, wo sie zeitweilig der Gefahr zu starker Transpiration ausgesetzt sind, besitzen bekanntlich vielfach Anpassungen an ihren Standort, Anpassungen, die sich aussprechen namentlich in der Verringerung der Blattgröße oder dadurch, daß Blätter mit vertikal gestellter Blattspreite gebildet werden (Eucalyptus, die Phyllodien von Acacia u. a.); bei solchen Xerophilen, deren Sproßachsen an Stelle der Blätter als Assimilationsorgane ausgebildet sind, hat vielfach eine Verbreiterung der Sproßachsen stattgefunden.

Die Jugendstadien zeigen oft abweichende Verhältnisse und stimmen in ihrer Gestaltung mit nicht xerophilen Pflanzen überein. Namentlich haben sie vielfach wohl entwickelte Blätter; indes nicht immer.

Die Blattentwicklung der Keimpflanzen ist bei Kakteen, bei Casuarina, bei Ruscus aculeatus (Fig. 393), R. Hypoglossum u. a. keine wesentlich andere als späterhin. Aber selbst nahe verwandte Formen können hierbei Verschiedenheiten zeigen, denn Ruscus androgynus (Semele androgyna) besitzt an der Keimpflanze große, wohl entwickelte Laubblätter. die später nicht mehr auftreten, vielmehr sind dann auch hier die Blätter zu kleinen Schuppen verkümmert. Schon oben wurde hervorgehoben, daß der Mangel xerophiler Charaktere bei derartigen Jugendformen damit zusammenhänge, daß die Keimpflanzen im Schutze anderer Pflanzen aufwachsen, und daß ihre Entwicklung überhaupt nur dann stattfindet, wenn genügend Wasser vorhanden ist, während die weiterentwickelte Pflanze anderen Ansprüchen zu genügen hat.

Auch hierfür sei eine Reihe von Beispielen aufgeführt.

1. Das bekannteste und am häufigsten angeführte bilden die Phyllodien besitzenden Akazien. Die Phyllodien entstehen, indem der Blattstiel (zuweilen auch die Blattspindel) sich in vertikaler Richtung verbreitert, während die Blattspreite verkümmert. Die Keimpflanzen (Fig. 394) aber haben - soweit sie untersucht sind - ausnahmslos Blätter, die mit denen der sonstigen Akazien übereinstimmen, d. h. doppelt gefiederte 
Spreiten und einen normalen Blattstiel besitzen. An den folgenden verbreitert sich der Blattstiel allmählich, während die Spreite zurückgeht, bis die Phyllodienform erreicht ist. Bei einigen Arten treten übrigens auch späterhin, d. h. nach den Phyllodien, Laubblätter auf, z. B. Ac. heterophylla, A. Melanoxylon ${ }^{1}$ ).

2. An Acacia angeschlossen sei das Verhalten von Eucalyptus, wo zwar im späteren Lebensalter keine Phyllodien, wohl aber messerklingenförmige, hängende, auf beiden Seiten gleichgebaute Blätter entstehen, die zerstreut an den Sproßachsen stehen. Die Keimpflanze aber bildet längere Zeit hindurch an ihren vierkantigen Zweigen ovale, gekreuzt stehende Blätter, die dorsiventral gebaut sind - die beiden Entwicklungsstufen haben einen ganz verschiedenen Habitus.

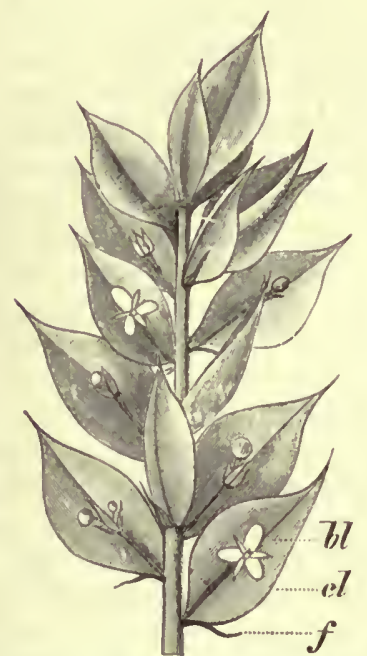

Fig. 393. Sproß von Ruscus aculeatus. Auf den blattähnlichen $\mathrm{Phyllo-}$ cladien $(c l)$ haben sich Blüten entwickelt. (Lehrb.)

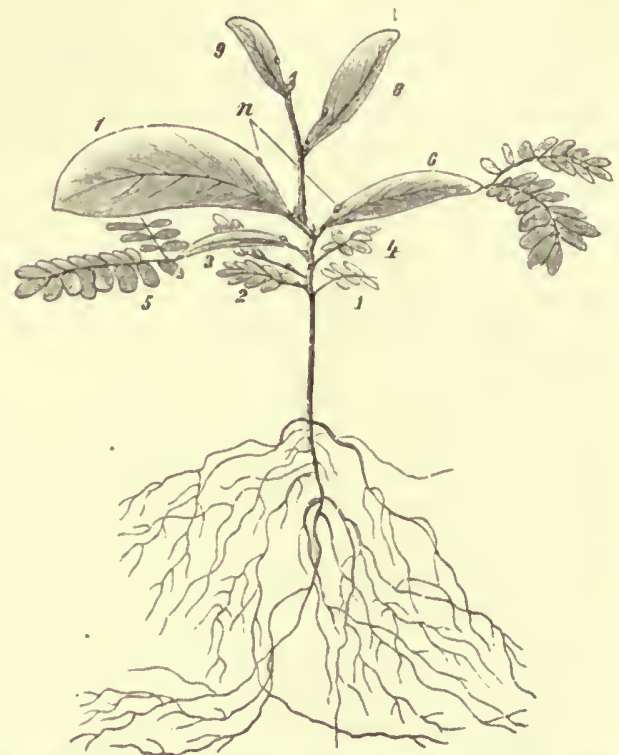

Fig. 394. Keimpflanze von Acacia. Die Primärblätter $1-4$ sind wie bei anderen Acaciaarten; bei 5 nnd 6 Übergang zur Phyllodienbildung; 7-9 Phyllodien. (Lehrb.)

3. An das oben ron rielen Cupressineen angeführte Verhalten schließt sich an dasjenige mancher Dikotylen mit ähnlichem Habitus, d. h. schuppenförmig anliegenden Blättern. Einige neuseeländische Veronicaarten zeigen diesen Habitus ganz besonders auffallend (V. cupressoides, V. lycopodioides).

Soweit die Keimpflanzen dieser Arten bekannt sind, zeigen sie alle abstehende Blätter, die wie die anderer Veronicaarten mit Stiel und Spreite versehen sind, eine Gliederung, die bei den später auftretenden Blättern verschwindet.

Dasselbe Verhalten ist nach den (unten zu erwähnenden) Rückschlags-

1) Es wird sich fragen, ob dies nicht darauf beruht, daß diese Formen hybridogenen Ursprungs sind. Wenigstens erhält man (nach mündlicher Mitteilung eines Züchters) ähnliche Blattfolgen, wenn man eine phyllodienbildende Acacia mit einer nicht phyllodienbildenden kreuzt. 
erscheinungen anzunehmen für die cupressoide Myrtacee Melaleuca micromeris. Auch Passerina hirsuta ${ }^{1}$ ) hat in der Jugend abstehende, später anliegende Blätter, während andere Passerinaarten nur die der Jugendblattform von $P$. hirsuta entsprechenden Blätter besitzen.

4. Pflanzen, bei denen die Folgeblätter verkümmert sind.

Zylla myagroïdes ist eine Crucifere, deren chlorophyllhaltige Sproßachsen zu Dornen ausgebildet und nur mit verkümmerten Blättern besetzt sind; in der Jugend hat sie große, wohl entwickelte Blätter (S. I Fig. 3).

Bei den Keimpflanzen und den neu austreibenden Sprossen von Clematis afoliata läßt sich die allmählich eintretende Reduktion der Blätter sehr schön verfolgen (Fig. 326).

Bei Carmichaelia stricta sind die Sproßachsen abgeflacht und mit verkümmerten Blättern versehen (neu an der Basis austreibende Sprosse verhalten sich ähnlich wie Keimpflanzen). Bei der Keimung entsteht zunächst (wie bei anderen oben erwähnten Papilionaceen) nach den Kotyledonen ein einfaches, ungeteiltes Primärblatt. Darauf folgen einige dreizählige, dann unpaarig gefiederte Blätter mit 2-3 Fiederpaaren. Von diesen treten aber nur wenige auf, die Blattbildung sinkt bald wieder herunter, entweder zunächst wieder auf ein dreizähliges Fiederblatt oder sofort auf ein einfaches. Weiter oben sind dann am flachen Stamm die Blätter ganz und gar zu kleinen Schuppen verkümmert. Die Blattbildung erreicht also in den gefiederten Laubblättern allmählich ihren Höhepunkt und sinkt dann wieder herunter. Die Übereinstimmung der Primärblätter mit den $\mathrm{nach}$ den Laubblättern auftretenden Hemmungsbildungen zeigt besonders deutlich, daß auch die Primärblätter demselben Vorgang ihre Entstehung verdanken. Bei Carm. Enysii traten an den Keimpflanzen nur noch einfache Laubblätter auf, die bei manchen Exemplaren auch zu ungestielten kleinen Schuppen verkümmert waren, so daß wir auch hier in einer Gattung den Übergang von heteroblastischer zu homoblastischer Keimung haben. Ähnlich wie Carm. stricta keimt Bossiaea rufa. Die Hauptachse der Keimpflanze besitzt eine Anzahl gestielter, ovaler Blätter und ist nicht verbreitert; sie verkümmert später, während aus den Achseln der Kotyledonen und unterhalb dieser Zweige hervortreten, welche allmählich zu Phyllocladien sich ausbilden. An diesen flachen Sprossen sind von den Blättern, deren Spreitenanlage verkümmert ist, nur die kleinen, spitzen Stipulae übrig (die Angabe HILDEBRAND's, „, von den Blattspreiten ist nichts vorhanden“, ist sicher irrig). Andere Bossiaeaarten besitzen übrigens flache $Z$ weige mit wohl ausgebildeten Blättern (B. heterophylla) oder, wie B. microphylla, zylindrische Zweige mit zahlreichen Laubblättern; es finden sich also in einer Gattung alle Übergangsstufen.

Auch Ulex europaeus, dessen Blätter in erwachsenem Zustand in Dornen verwandelt sind, besitzt als Keimpflanze (von den ersten Primärblättern abgesehen) dreizählige Laubblätter wie andere Genisteen. An den höher stehenden Blättern werden die seitlichen Teilblättchen immer schmäler und kommen zuletzt gar nicht mehr zur Ausbildung. Das einfach lineal gewordene Blatt aber gestaltet sich allmählich zum Dorne um; auch aus den Zweigen entwickeln sich Dornen.

Das Verhalten von Colletia verdient hier gleichfalls Erwähnung (Abbildung: S. I Fig. 8). Die Colletien sind dornige Sträucher mit bei älteren Pflanzen kleinen, hinfälligen Blättern. Besonders eigentümlich

1) Vgl. die Abbildung bei Pasquale, Sulla eterofillia. Napoli 1867. Tav. I. 
ist Colletia cruciata, bei welcher die zu Dornen sich entwickelnden Seitensprosse stark abgeflacht sind. Die Keimpflanzen aller mir bekannten Colletiaarten sind im wesentlichen gleich gebaut; sie besitzen zylindrische Sproßachsen mit wohl entwickelten Laubblättern, und die Abflachung der Sproßachsen bei C. cruciata beginnt erst später; die Gestaltung der Keimpflanzen weist also auch hier einen ursprünglicheren Charakter auf.

Das Verhalten von C. cruciata findet ein Analogon bei manchen Kakteen.

Bei den mit ganz rückgebildeten Blättern versehenen Kakteen tritt Laubblattbildung auch an den Keimpflanzen nicht auf; die Blätter sind auch hier zu Schuppen, resp. zu Dornen umgebildet, aber die Sproßachsen zeigen vielfach primitivere Gestaltungsverhältnisse als später. Als „typisch“ für die Mehrzahl der blattlosen Kakteen können wir folgende Ausbildung des Vegetationskörpers betrachten: fleischige, mit chlorophyllhaltigem Gewebe überzogene Sprosse, die in der Achsel kleiner, schuppenförmiger Blätter Dornenbüschel tragen. Die Dornen ${ }^{1}$ ) sind umgebildete Blätter, die auf einem in der Blattachsel stehenden, sehr bald verkïmmernden Seitensproß sich bilden. Bei vielen Formen sind diese Dornenbüschel in Lüngskanten angeordnet, eine Form, die wir als die Cereusform bezeichnen können. Von dieser weichen sehr auffallend ab die mit flachen, blattähnlichen Sproßachsen versehenen Arten von Epiphyllum, Rhipsalis und Phyllocactus (letztere Gattung ist ron Cereus eigentlich nur habituell verschieden). Verfolgen wir deren Keimungsgeschichte, so zeigt sich, daß die Keimpflanze vielfach (und bei den einzelnen Arten in verschiedenem Grade) noch eine mit der "typischen" Gestaltung übereinstimmende Ausbildung zeigt; wir können auch hier an der Keimpflanze verfolgen, wie die Umbildung vor sich gegangen ist (vgl. S. I p. 94, $101 \mathrm{ff}$.).

Fig. 395 zeigt eine Keimpflanze von Phyllocactus phyllanthoïdes. Es treten hier zunächst vierkantige, mit Dornenbüscheln besetzte Sproßachsen auf, die ganz aussehen wie ein Cereus. Von den vier Kanten bleiben dann schließlich nur zwei übrig, die Sproßachse flacht sich bedeutend ab, und wir haben aus der Cereusform die scheinbar weit abweichende Phyllocactusform hervorgehen sehen. Andere Arten derselben Gattung zeigen zwar bei der Keimung noch vier Kanten angedeutet, aber zwei davon treten nur noch ganz rudimentär auf, in Gestalt je eines Dornenbüschels, das über den Zwischenraum über den Kotyledonen fällt. Bei ungenauer Betrachtung würde man glauben, die Keimpflanze sei von Anfang an zweikantig (so z. B. bei Phylloc. phyllanthus). Ganz ähnliche Erscheinungen zeigen (wie a. a. O. nachgewiesen wurde) auch Epiphyllumund Rhipsalisarten mit flachen Sproßachsen. Aber auch bei solchen Kakteen, welche später ihre Sproßachsen nicht abflachen, treten bei der Keimung cereusähnliche Sprosse auf, die in phylogenetischer Hinsicht von höchstem Interesse sind.

Die zwei auf Bäumen wachsenden Arten Rhips. cassytha und Rh. paradoxa sind im ausgebildeten Zustande einander so unähnlich, wie nur irgend möglich. Erstere hat lange, dïnne, dornenlose Sprosse, letztere sehr sonderbar gestaltete, abwechselnd dreikantige (vgl. die Habitusbilder in S. I).

Die Keimpflanzen beider Arten aber stimmen (von Größenverhältnissen usw. abgesehen) in der Hauptsache miteinander überein, und zwar

1) Außer ihnen finden sich vielfach auch noch Stacheln.

Goebel, Organographie der Pflanzen. 2. Aufl. Allgem. Teil. 
darin, daß sie kantig e, mit Stachelbüscheln besetzte, also cereusähnliche Sprosse besitzen.

Es würde zu weit führen, andere Beispiele von den Kakteen hier mitzuteilen, es kann auf das in den "Schilderungen" Gesagte verwiesen werden. Daß gerade bei den Kakteen die Keimpflanzen in so lehrreicher Weise zeigen, wie von einer gemeinsamen Grundform aus die verschiedenen Formen des Vegetationskörpers zustande gekommen sind, dürfte damit zusammenhängen, daß wir in ihnen, wie es scheint, eine phylogenetisch junge Familie vor uns haben, in der auch die Abtrennung der Gattungen schwer streng durchzuführen ist.

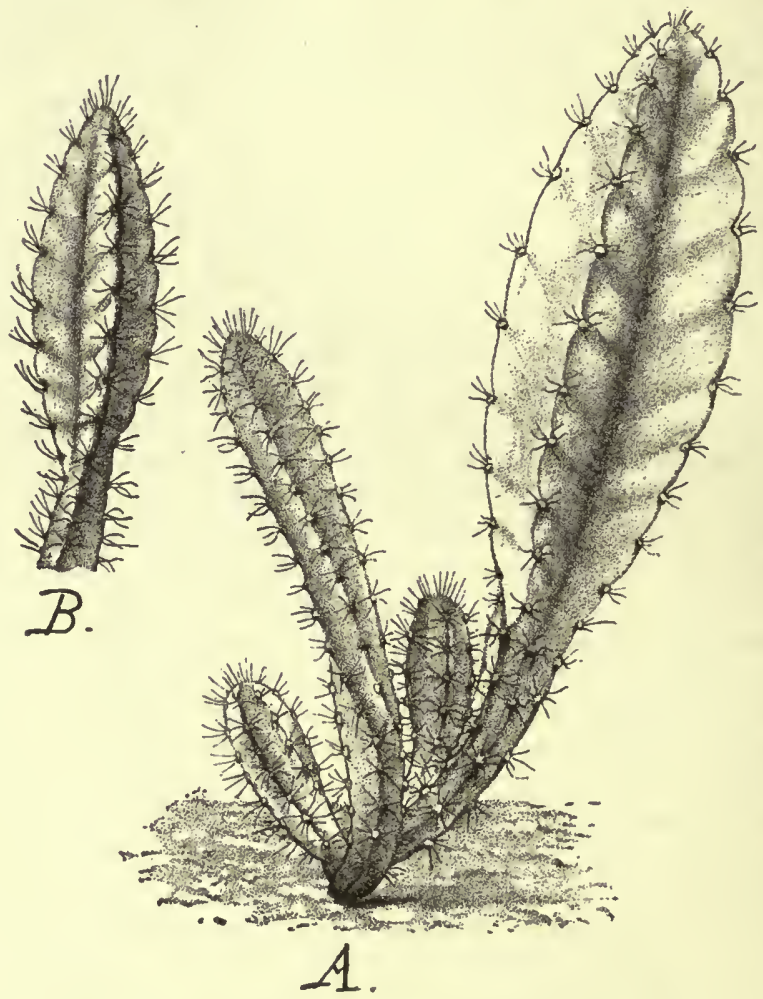

Fig. 395. A Keimpfianze von Phyllocactus phyllanthoïdes. Es treten zuerst mehrkantige, cereusähnliche Sprosse auf; bei dem jüngsten Sprosse ist aber die Kantenzahl schon auf drei vermindert; die Kanten sind aber flügelförmig entwickelt. Später sind nur noch zwei Kanten vorhanden.

Auch die Blattsukkulenten bieten einige interessante Beispiele heteroblastischer Entwicklung, die teilweise oben schon angeführt wurden.

Bei monokotylen Blattsukkulenten sind namentlich in der Gattung Gasteria einige Jugendformen von der Folgeform so verschieden, daß man sie ohne Kenntnis des Zusammenhangs zu verschiedenen Arten stellen würde. Daher hat z. B. Gasteria decipiens ihren Namen. Die Blätter der Jugendform haben weiße "Tuberkeln" (wie sie bei manchen monokotylen Blattsukkulenten auftreten), die der Folgeform sind glatt und kantig.

D. Pflanzen deren Jugendformen in tiefem Schatten wachsen, zeigen 
speziell in den Tropen vielfach eigenartige Färbung der Blätter, während die Folgeformen gewöhnliche grüne Blätter besitzen.

Einige interessante Beispiele hat Halimer ${ }^{1}$ ) beschrieben. Die Jugendblätter sind mit weißen Flecken versehen (hervorgerufen durch große, lufthaltige Intercellularräume, teilweise auch durch geringere Chlorophyllausbildung an den betreffenden Stellen).

So wurde die Jugendform ron Schizandra elongata als Sch. marmorata bezeichnet, weil sie „marmorierte" Blätter besitzt. Bei Justicia vittata sind die Blätter der Jugendform mit einem breiten silbernen Streifen geschmückt. während die größeren Blätter unter der Bliitenregion der Pflanze einfarbig grün sind. Ähnlich verhalten sich Gymnostachyum variegatum und Phylloglottis picta. Bei Strobilanthes cernua gelang es nur durch die Kultur nachzuweisen, daß aus dem kleinen noch unverzweigten Pflänzchen mit je einem Silberfleck in jedem „Internervium", welche man laäufig im Schatten des humusreichen Urwaldes bei Tjibodas und Telaga warna findet, die reich rerzweigte. bis über $1 \mathrm{~m}$ hohe mit einfarbigen, grünen Blättern versehene Pflanze wird,...die als Str. cernua bekannt ist.

Ähnliches ist auch bei Begoniaarten zu beobachten (z. B. B. dichroa); die Primärblätter (Fig. 396 II ) sind mit weißen Flecken versehen, die
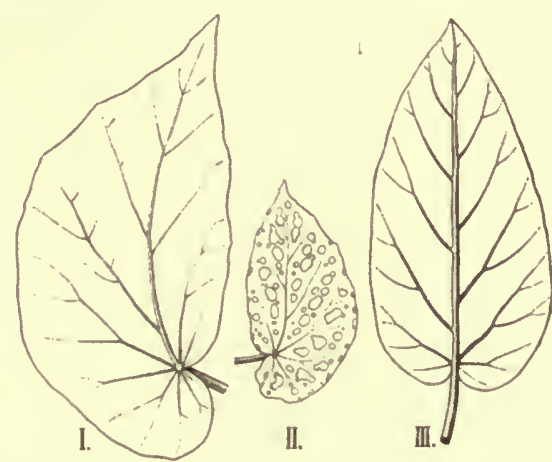

Fig. 396. I. Begonia dichroa, Folgeblatt. II. Primärblatt mit zahlreichen weißen Flecken (1/4). III. Blatt von B. Poggei kaum asymmetrisch. (Alle verkl.)

späteren (Fig. 396 I) nicht. Wie in anderen Fällen gibt es auch in dieser Gruppe Pflanzen, welche die sonst bei der Jugendform auftretende Blattgestaltung dauernd beibehalten. Strobilanthes Dyerinus und Cissus discolor sind ein Schmuck unserer Gewächshäuser, weil sie die "bunten" Blätter auch an älteren Pflanzen aufweisen.

\section{Zusammenfassung.}

Bei der Entwicklung der Pflanzen aus dem Keime (Spore, Samen) ebenso auch bei Adventivsprossen treten Gestaltungsverhältnisse auf, die von den späteren abweichen. Namentlich ist dies der Fall, wenn der Keimling anderen Verhältnissen angepaßt ist als die späteren Entwicklungsstadien. Die Gestaltung der Primärstadien kann aber selbst innerhalb einer und derselben Gattung eine verschiedene sein, und auch bei einer Art schwanken. In einer Reihe von Fällen zeigt sie den Folgestadien gegenüber, wie der Vergleich mit verwandten Formen zeigt, offenbar die ursprünglicheren, die Folgeform dagegen durch Anpassung geänderte Verhältnisse. So sind die Keimpflanzen der aus sympodial verketteten, dorsi-

1) E. Hallier, Neue und bemerkenswerte Pflanzen ans dem malayisch-pap. Inselmeer. Bulletin de l'herb. Borssrar VI (1898). Betr. der biologischen Bedentung der mit weißen Flecken versehenen Blätter, vgl. SтAнL, Über bunte Laubblätter. Ann. dn jardin bot. de Buitenzorg, Vol. XIII, p. 137. STAHL sieht in den weißen Flecken eine Einrichtung, welche die Transpiration befördert. Das Verhalten der im Texte erwähnten Jugendformen würde zur STAHL'schen Auffassung durchaus stimmen. 
ventralen Sproßsystemen bestehenden Ulmen, Buchen, Hainbuchen orthotrop und radiär, wie die verwandten Formen zeitlebens. Bei xerophilen Pflanzen tragen vielfach die Keimpflanzen noch nicht die mit der xerophilen Lebensweise in Zusamenhang stehenden Charaktere, ebenso bei manchen Rankenpflanzen u. a. Andererseits sind in anderen Fällen die Jugendstadien unzweifelhaft die, welche durch Anpassung verändert sind (Hedera, Marcgravia, Salvinia u. a.), und vielfach spricht sich in der Organbildung der Keimpflanzen, namentlich der Blattbildung, einfach eine, wahrscheinlich durch Korrelationsverhältnisse bedingte Hemmung aus.

Vergleichen wir verwandte Pflanzen miteinander, so zeigt sich vielfach, daß die Blattform, welche bei der einen die höchste ist, bei der anderen noch eine Jugendform darstellt. Es sei auf die Beispiele von Sagittaria, Adiantum reniforme $u$. a. verwiesen, denen sich zahlreiche andere anreihen ließen.

\section{$\S 12$. Wiederauftreten der Jugendform in späterem Alter ${ }^{1}$ ).}

Schon die oben angeführten Tatsachen über Moose, ferner die Blattbildung von Adventivsprossen, das Auftreten der Schattenblätter zeigen, daß die Jugendform auch bei älteren Pflanzen unter bestimmten Bedingungen wieder hervortreten kann. Es ist dies dadurch bedingt, daß die einzelnen Entwicklungsstadien der Pflanzen an verschiedene Bedingungen gebunden sind.

Hier kann unter Verweisung auf die an anderem Orte gegebene Darstellung ${ }^{2}$ ) nur kurz auf einige Beispiele hingewiesen werden, was um so weniger zu umgehen ist, als es sich, wie immer mehr sich herausstellt, bei sehr vielen auffallenden "Anpassungen" der Hauptsache nach nur um einen "Rückschlag a uf die Jugendform " handelt.

Dieser tritt bei manchen Pflanzen ron selbst ein, bei anderen erst nach besonderer Behandlung und in manchen Fällẹn ist es bis jetzt nicht gelungen die Pflanze zum Rückschlag auf die Jugendform zu bringen.

Zunächst seien einige Beispiele angeführt, welche besonders deutlich zeigen, daß das Auftreten der Jugendform an andere Bedingungen geknüpft ist als die Folgeform.

Namentlich tritt die Bedeutung der Lichtintensität deutlich hervor. Vielfach ist die Jugendform auf eine geringere Lichtintensität "gestimmt" als die Folgeform. Zugleich wird aus den angeführten Beispielen hervorgehen, weshalb es sich nicht empfiehlt, dabei von "Photomorphose" zu reden.

Schon auf p. 375 wurde auf ein hierher gehöriges Beispiel hingewiesen. Der "Vorkeim" von Batrachospermum ${ }^{3}$ ) entwickelt nur bei reichlichem Lichtzutritt die Batrachospermumpflanze, bei schwachem Lichte bleibt die Pflanze auf der niedrigen Stufe der Organbildung stehen und der Vorkeim erreicht eine ippige Entwicklung. Ähnlich ist es bei anderen Algen ${ }^{4}$ ), deren Keimpflanzen bei schwacher Beleuchtung nicht über das Haftscheibenstadium (oder über die Bildung dem Substrat anliegender Fäden) hinausgelangen und keinen aufrechten Thallus bilden, während die Haftscheiben sich sehr stark vergrößern.

Dasselbe gilt für Muscineen, bei denen ja gleichfalls zunächst ein Vorkeim sich zu bilden pflegt. Wir sehen, daß einerseits das Auftreten

1) Goeber, Über Jugendformen von Pflanzen und deren künstliche Wiederhervorrufung, Sitz.-Ber. der k. Bayer. Ak. d. W. Math.-physik. Kl. Dez. 1896.

2) Vgl. Goeber, Einleitung in die experimentelle Morphologie, 1908.

3) Sirodot, Les Batrachospermes. Paris 1884.

4) Vgl. Bertrold, Zur Morphologie und Physiologie der Meeresalgen. Jahrb. für wiss. Botanik XIV, p. 673. 
der eigentlichen Moospflanze an diesen Vorkeim gebunden ist an Licht von höherer Intensität als das, welches zu einem ïppigen Wachstum des Vorkeims selbst geniigt ${ }^{1}$ ), und andererseits, daß auch die Gestaltung des Vorkeims selbst vom Lichte beeinflußt wird. Beide Erscheinungen seien hier zusammenfassend besprochen.

Lebermoose. Bei vielen Lebermoosen geht aus der keimenden Spore zunächst ein Keimschlauch hervor, der sich bei den Marchantieen an der Spitze zu einer aus einem Zellkörper bestehenden Keimscheibe abflacht, aus der das junge Pflänzchen hervorsproßt. Bei anderen Formen geht der Keimschlauch an der Spitze direkt in die Pflanze über (vgl. den speziellen Teil).
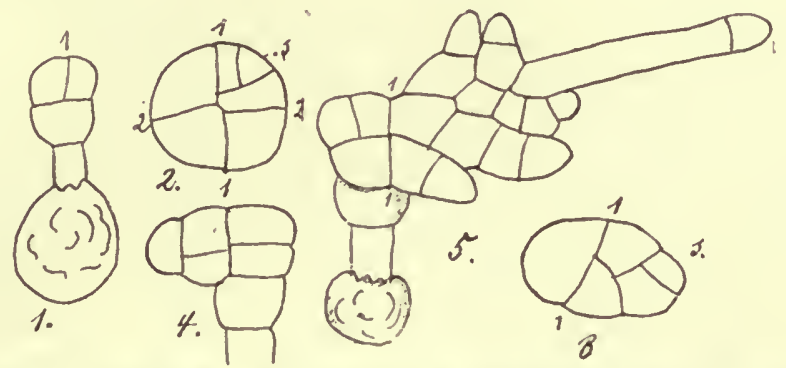

Fig. 397. Preissia commutata. Sporenkeimung, halbschematisch, mit Benutzung von Figuren Hanseı,'s (die Spore bei 1 und 5 unten angedeutet). 1 Keimling, der an einem kurzen Keimschlauch die Keimscheibe anlegt; 2 und 3 zwei Keimscheiben, von oben gesehen; 1 die erste Teilungswand, der gewöhnlich eine zweite, zu ihr rechtwinklige (2) folgt; aus einer der vier Zellen geht dann die junge Pflanze hervor, sie kann aber, wie 3 zeigt, anch aus einer der beiden ersteu Zellen sich bilden; $s$ scheitelzelle der jungen Pflanze, diese ist in 5, nachdem sie fünf Segmente gebildet hatte, wieder zu einem Keimschlauch ausgewachsen (halbschematisch); 4 Keimscheibe mit der Anlage einer jungen Pflanze (links) im optischen Durchschnitt.

Die Keimung tritt bei den daraufhin untersuchten Arten meist nur im Lichte ein. Die Keimschläuche sind bei diffusem Lichte positiv heliotropisch und schon LeitgeB stellte fest, daß ihre Länge von der Lichtintensität abhängt; sie werden bei schwachem Lichte viel länger als bei starkem. Es kommt bei schwachem Lichte weder zur Anlage einer Keimscheibe noch zu der einer beblätterten Pflanze.

Als Beispiel sei die Keimung von Preissia commutata besprochen ${ }^{2}$ ) (vgl. Fig. 397). Die Keimung der Sporen erfolgte in dem in Fig. 397, 1 abgebildeten Falle bei hellem Lichte, es bildete sich daher nur ein kurzer Keimschlauch. Aus der obersten Zelle geht die rechtwinklig zur Richtung der Lichtstrahlen abgeplattete Keimscheibe hervor, die in manchen Fällen aus zwei, in anderen aus vier Zellen besteht. Eine ${ }^{3}$ ) davon wird zur

1) $\mathrm{DaB}$ anch betreffs der heliotropischen Reizbewegungen die Vorkeime auf eine niedrigere Lichtintensität, gestimmt" sind als die folgenden Stadien, ist wohl nicht zu bezweifeln.

₹) Vgl. Schostakowitsch, Flora 79. Bd. (Erg.-Bd. 1894) p. 358 ff. - Kं KeH, Über Regeneration der Lebermoose (Nova acta Ac. Leop. Carol. Vol. XC 1909). Man erhält die ${ }_{n}$ Keimschlänche ${ }^{\text {" }}$ anch wenn man junge Pflanzen in kleine Stlicke schneidet und diese der Regeneration überläßt.

3) Nach Leitger (a. a. 0. p. 7) soll bei den Marchantieen die Anlage des Pflänzchens aus dem am stärksten beleuchteten Quadranten der Keimscheibe entstehen. Da dieselbe aber rechtwinklig zur Richtung der Lichtstrahlen abgeflacht ist, so ist ein Quadrant genau ebenso stark beleuchtet wie der andere. Bei Preissia, wo die Keim; scheibe zuweilen nur aus zwei Zellen besteht, tritt dies besonders deutlich hervor. 
Scheitelzelle des jungen Pflänzchens, das in seinem Bau zunächst noch sehr einfach ist. Es besteht nur aus einer Zellschicht, erst später tritt der für den Preissia-Thallus charakteristische Bau ein. Solange dies Pflänzchen noch auf dem einfachen Jugendstadium ist, wobei der Vegetationspunkt mit „zweischneidiger" Scheitelzelle wächst, kann es zur Rückkehr zur Keimschlauchbildung veranlaßt werden, wenn man es in geminderte Iichtintensität bringt (Fig. 397, 5). Dieser Keimschlauch ist bei höherer Lichtintensität wieder zur Bildung einer Keimscheibe befähigt und dieser Vorgang kann beliebig oft wiederholt werden. Sobald aber die „Folgeform" der Pflanze erreicht ist, hört auch die Fähigkeit der Rückkehr zur Keimschlauchbildung auf.

Während nun, wie mir ein Versuch mit Plagiochasma Aitoniana zeigte, die Bildung des Keimschlauches auch durch starke Lichtintensität nicht verhindert werden kann, ist bei anderen Lebermoosen, die freilich noch genauerer Untersuchung bedürfen, dieses Verhalten ein anderes. Bei Blasia pusilla, Anthoceros, Alicularia und einigen anderen beblätterten Jungermannieen kann nämlich nach den Beobachtungen von GrönLAND ${ }^{1}$ ) und Leitgeb ${ }^{2}$ ) entweder ein Keimschlauch oder sofort ein Zellkörper entstehen. Aus der Beobachtung von Grönland (a. a. O. p. 16), daß ersteres nur bei sehr dichter Sporenaussaat, letzteres bei zerstreut liegenden Sporen von Blasia eintritt, geht hervor, daß äußere Umstände (und zwar nach Analogie mit anderen Fällẹn, die Lichtintensität) darüber entscheiden, welche Keimungsart eintritt. Ähnlich wie dies für die Keimscheibe von Preissia geschildert wurde, kann auch der aus der Sporenkeimung von Blasia und Anthoceros entstandene Zellkörper -- offenbar infolge verminderter Lichtintensität - wieder zu einem Schlauche auswachsen, der sich wie ein Keimschlauch verhält (vgl. Fig. $398 I-I I I)$. Daß die Bildung eines Keimschlauches hier ebenso vorteilhaft ist wie die starke Achsenstreckung der Keimpflanze eines zu tief ausgesäten Samens, ist einleuchtend: es wird dadurch der Keimschlauch an das Licht gebracht. Man kann die Keimschlauchbildung also als Anpassung bezeichnen, die bei den einen Lebermoosen unter allen Umständen zunächst bei der Keimung auftritt und nur betreffs ihrer Dauer und Längenentwicklung vom Lichte abhängig ist, während bei anderen schon das erste Auftreten vom Lichte bestimmt wird. Indes gehört die Frörterung der Frage, ob der Keimschlauch ein phylogenetisch älteres Stadium darstellt, nicht hierher; erwähnt sei nur, daß bei den Farnen sich die Sache ebenso verhält.

Auch bei den I a ubmoosen liegen die Verhältnisse ganz ähnlich. An dem Protonema treten Moosknospen nur bei einer Lichtintensität auf, die höher ist als die zum normalen Wachstum des Protonemas ausreichende ${ }^{3}$ ).

Das Protonema kann, wenn die Knospenbildung nicht erfolgt (theoretisch) unbegrenzt weiter wachsen. Wie früher erwähnt ${ }^{4}$ ), lassen sich

1) Mémoires sur la germination de quelques Hépatiques. Annales des sciences nat. 4 sér. t. 1.

2) LeitgeB, Untersuchungen über die Lebermoose I, p. 52 ff.; II, p. 67. - LEitgeB vermutet, daß die Form der Vorkeime durch Feuchtigkeit bestimmt werde; nach den oben mitgeteilten Tatsachen dürfte aber vor allem das Licht in Betracht kommen.

$\left.{ }^{3}\right)$ KLEBs, Über den Einflul des Lichtes auf die Fortpflanzung der Gewächse. Biol. Zentralblatt 1893.

4) In der Abhandlung über Jugendformen usw. (1896). Neuerdings - ohne Erwähnung der genannten Abhandlung - bestätigt von CERM. SERvETTAz, Développement des mousses en milieux stérilisés. Ann. des scienc. nat. IX. Série X. 17 (1913) (während des Druckes erschienen). 
die Anlagen der Moosknospen bis zu einem bestimmten Stadium wieder zur Rückkehr zur Protonemaform veranlassen.

$\mathrm{Daß}$ es für ein Moos vorteilhaft ist, wenn die Anlagen zu Moospflanzen nur unter Bedingungen entstehen, die ihnen Aussicht auf Gedeihen bieten, ist klar. Der Aufbau einer Moospflanze stellt namentlich auch an die Assimilationstätigkeit höhere Anforderungen als der des Protonemas und auch die Organbildung der beblätterten Moospflanze ist, soweit die darüber vorliegenden Untersuchungen ein Urteil gestatten, in höherem Grade rom Lichte abhängig, als dies bei Samenpflanzen und Pteridophyten der Fall ist. Bei etiolierten Pflanzen dieser Gruppen ist,

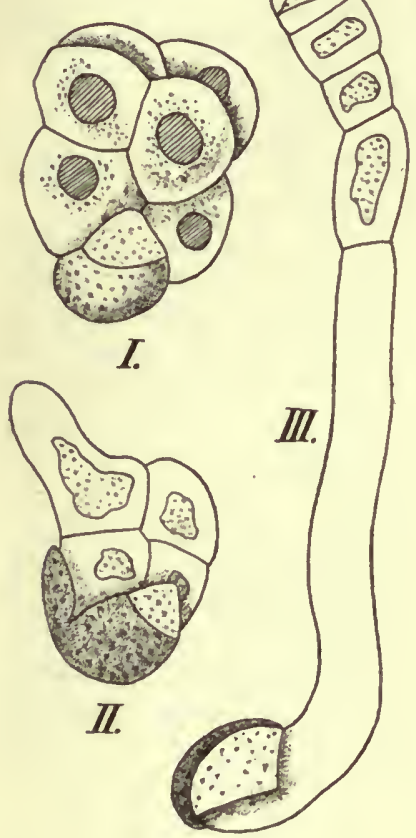

Fig. 398.

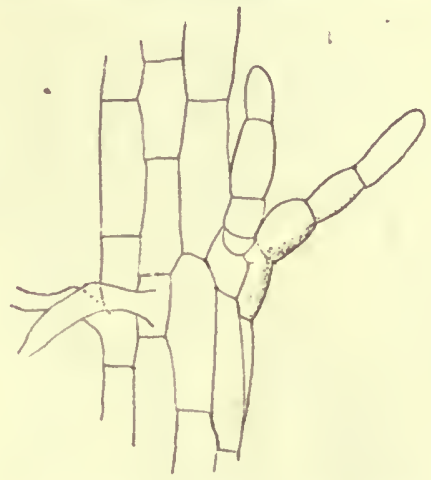

Fig. 399. Jungermannia bicuspidata. Stück eines bei sehr schwacher Beleuchtung erwachsenen Stämmchens. Rechts ein Blatt, welches beinahe nur aus zwei Zellreihen besteht, während das bei normaler Belenchtung erwachsene Blatt eine Zellfläche darstellt.

Fig. 398. Anthoceros. Nach Leitgeb. I Bei der Keimung ein Zellkörper entstanden; $I I$ aus diesem entwickelt sich ein Zellfaden; III Zellfaden, sofort bei der Keimung gebildet.

was die Blattbildung betrifft, zwar die Entfaltung oft gehemmt, oder das Blatt ist kleiner als bei der im Licht erwachsenen Pflanze; in den untersuchten Fällen aber ist seine äußere Gliederung dieselbe wie sonst. Die Fig. 399 zeigt ein Blatt einer bei schwacher Beleuchtung erzogenen Pflanze von Jungermannia bicuspidata, das der normalen Ausbildung gegenüber bedeutend vereinfacht ist, so sehr, daß es übereinstimmt mit den Blättern, die bei ganz jungen Pflanzen auftreten. Ähnliche Fälle lassen sich auch sonst nachweisen.

So bei Campanula rotundifolia ${ }^{1}$. Sie hat zweierlei Blätter, die miteinander durch Übergangsformen verbunden sind, Rundblätter und Langblätter. Erstere haben eine rundlich nierenförmige Blattspreite und einen langen Stiel; sie entstehen bei der Entwicklung der Keimpflanzen

1) GozBer, Über den Einfluß des Lichtes usw. II. Die Abhängigkeit der Blattform von Campanula rotundifolia yon der Lichtintensität. Flora 82. Bd., p. 1 ff. 1896. 
zuerst, also zu einer Zeit, wo die zwischen anderen Pflanzen wachsenden Campanulakeimpflanzen weniger intensives Licht erhalten werden als später; die Rundblätter sind so zu sagen auf geringere Lichtintensitäten

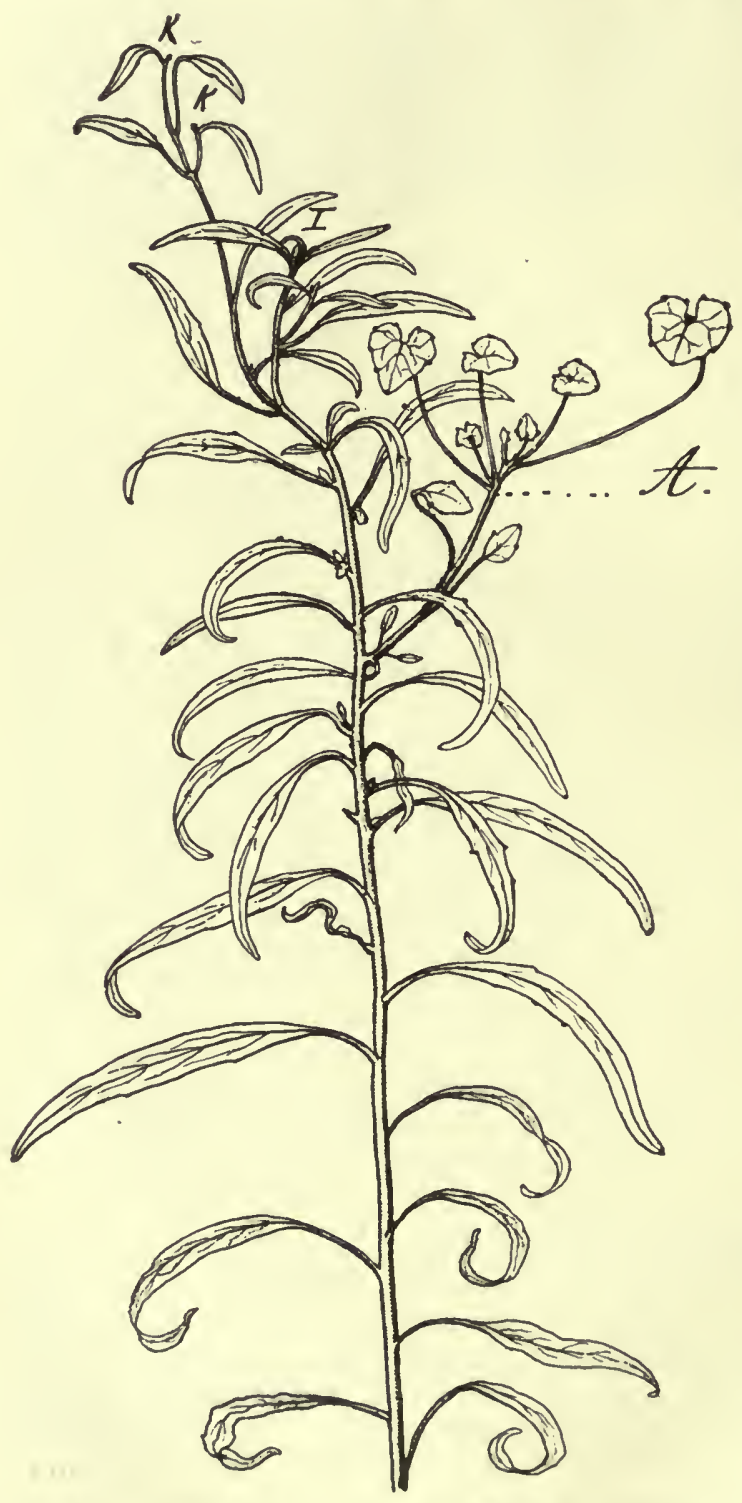

Fig. 400. Campanula rotundifolia. Mit Langblättern besetzter Sproß, der in schwache Beleuchtung gebracht wnrde. Die vorher angelegten Blütenknospen $(K)$ sind verkümmert; es hat sich (was unter normalen Verhältnissen nie geschieht) ein Seitensproß $\boldsymbol{A}$ entwickelt, der Rundblätter hervorbringt. Wenn noch keine Blüte angelegt ist, kann auch der Hauptsprob nach Hervorbringung der Langblätter bei geminderter Lichtstärke wieder zur Bildung von Rundblättern übergehen. „gestimmt“. Die Internodien der Sproßachsen, die sie tragen, sind kurz. Die Langblätter sind ungestielt (resp. kurz gestielt) mit langgestreckter Spreite versehen; sie stehen an den (später normal mit Blüten endigenden) Sproßteilen mit gestreckten Internodien.

Kultiviert man die Pflanze bei schwacher, aber für ihre Ernährung und Primärblattbildung ausreichender Lichtintensität, so kann man sie auf dem Stadium der Rundblattbildung zurückhalten. Selbst wenn schon Langblätter gebildet sind, kann, wie Fig. 400 zeigt, die Pflanze wieder (durch Abschwächung der Lichtintensität) zur Rundblattbildung zurückgeführt werden (vgl. die Figurenerklärung und die a. a. $O$. angeführten Einzelheiten).

Indes handelt es sich hier ebenso wenig wie in den anderen besprochenen Fällen um eine "spezifische" Lichtwirkung. Das Licht wirkt insofern ein, als es die Stoffwechselvorgänge beeinflußt. Demgemäß kann eine Rück. kehr zur Jugendform bei Campanula auch auf andere Weise erzielt werden, durch jede größere Störung in der Entwicklung der Pflanze (z. B. wenn man Sprosse mit Langblättern als 
Stecklinge benutzt) ${ }^{1}$ ), Störungen, welche, wie wir annehmen dürfen, eine anderweitige Stoffverteilung - namentlich ein anderes Verhältnis der organischen und anorganischen Stoffe bedingen, als es "normal" vorhanden ist. Biologisch entsprechen die Rundblätter den oben erwähnten Schattenblättern, die Langblätter den Sonnenblättern. Wir sehen aber, daß das Auftreten dieser Blattformen nicht bedingt wird von dem "Bedürfnis", sondern von dem inneren Zustand der Pflanze, der seinerseits von der Außenwelt beeinflußt wird.

Ganz dasselbe gilt für eine Anzahl Wasser- und Sumpfpflanzen, bei denen die Jugendblätter zwar das Optimum ihrer Entwicklung im Wasser finden, aber auch auf dem Lande auftreten können.

"Von selbst" treten z. B. die Jugendblätter wieder auf an den austreibenden Knollen von Nymphaea rubra und der Sagittariarten. Auch bei Pflanzen mancher Sagittariaarten, welche schon die Folgeblattform gebildet haben, ist es nicht schwer, sie zum Rückschlag zu bewegen. Einen derartigen Fall stellt z. B. Fig. 401 dar: Das Auftreten der Jugendblätter war hier offenbar durch schwache Beleuchtung bedingt.

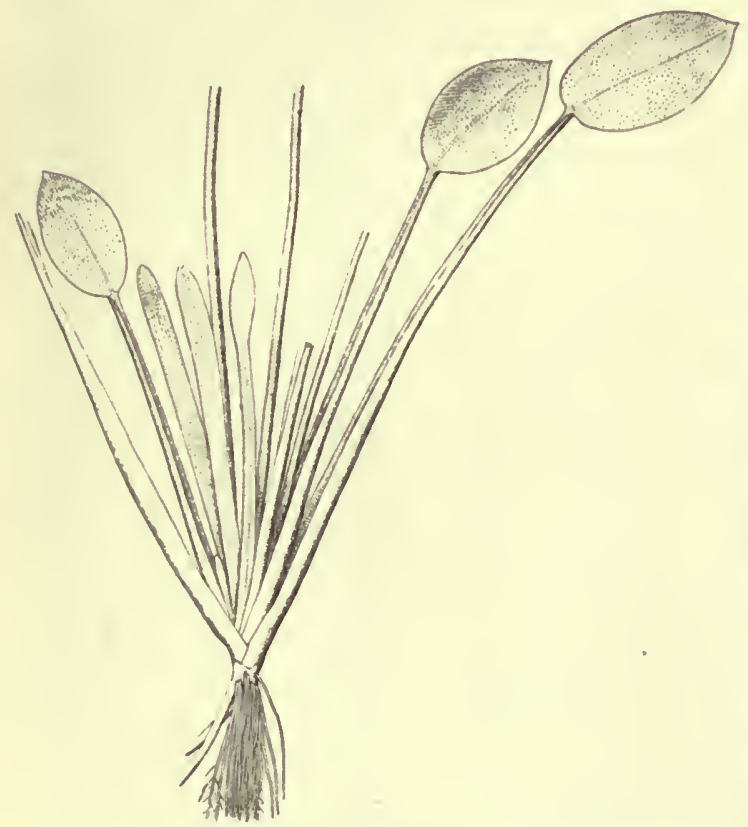

Fig. 401.

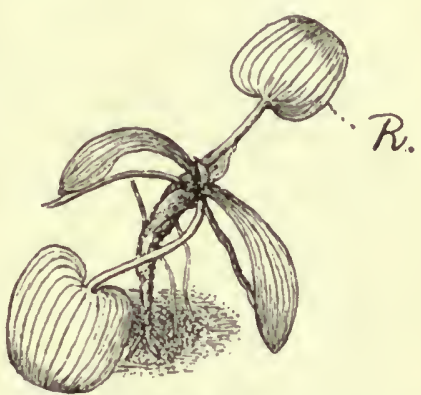

Fig. 402.

Keimpflanze von Heteranthera reniformis, welche $\mathrm{nach}$ den gestielten Blättern mit nierenförmiger Spreite wieder bandförmige Blätter (wie sie vorher anftraten) bildete.

Fig. 401. Sagittaria pugioniformis ( $1 / 0$ nat. Gr.). Pflanze, welche in seichtem (handhohen) Wasser stehend, im Winter wieder „Bandblätter" hervorgebracht hat.

Bei abgeschwächtem Licht gezogene Pflanzen von S. sagittaefolia bildeten nur die bandförmigen Primärblätter; daß der Entwicklungsgang sonst ein normaler war, geht u. a. daraus hervor, daß die als ungeschlechtliche Fortpflanzungsorgane dienenden Knöllchen sich ausbildeten. Ohne Zweifel kann Sagittaria auch durch andere Einflüsse auf dem Primärstadium zurïckgehalten werden; in der Natur kommt sie in tiefem oder stark strömendem Wasser häufig in dieser Weise vor.

1) J. FAMiLLer, Die verschiedenen Blattformen von Campannla rotundifolia. Flora 87 (1900), p. 44. 
Sagittaria natans ist eine fast submers lebende Form, die außer zahlreichen bandförmigen Blättern nur verhältnismäßig wenige Schwimmblätter besitzt (die über den Wasserspiegel sich erhebenden scheinen nur ausnahmsweise aufzutreten). 'Eine Rückkehr zur Jugendform ist hier sehr leicht zu bewirken: der Wechsel des Mediums und andere Hemmungen (z. B. Abschneiden der Wurzeln) bedingen bei Exemplaren, welche schon gestielte Blätter gebildet haben, die Rüickkehr zur Primärblattform ${ }^{1}$ ).

Dagegen ließ sich z. B. Sagittaria cordifolia durch Kultur im Wasser nicht zur Primärblattbildung bewegen, sondern ging zugrunde. Andere Eingriffe hätten dies Resultat vielleicht auch hier herbeigeführt.

Auch bei anderen Monokotylen mit bandförmigen Primärblättern können diese wieder auftreten (Fig. 402) bei Pflanzen, deren Vegetation ungünstig beeinflußt wird. So traten an Exemplaren von Eichhornia azurea, die den Winter über als Landpflanzen gezogen wurden, Rückschlagssprosse mit bandförmigen Primärblättern auf (vgl. die Abbildungen in GOEBEL, Pflanzenbiolog. Schilderungen II, p: 287), ähnlich bei Hydrocleis Humboldti, Potamogeton natans u. a. (vgl. a. a. O.).

Xerophile Pflanzen.

Acacia verticillata gehört zu den phyllodienbildenden Arten, welche als Jugendblätter doppeltgefiederte Laubblätter besitzen. Bei jungen Pflanzen, die schon Phyllodien gebildet haben, treten gelegentlich wieder Laubblätter auf ${ }^{2}$ ), deren Bildung sich auch erzielen ließ bei Pflanzen, welche durch Kultur in trockenem Raum geschwächt worden waren, an ihnen traten Rückschlagssprosse mit La ubblättern auf (Fig. 403).

Einige neuseeländische Veronicaarten und eine Myrtacee, Melaleuca micromera, haben als xerophile Pflanzen einen Habitus angenommen, der dem mancher Coniferen (Cupressineen), mit der Sproßachse anliegenden, schuppenförmigen Blättern, durchaus gleicht. Die Primärblätter sind, soweit bekannt, gewöhnliche abstehende, gestielte. flache Blätter, denen anderer Veronica- resp. Melaleucaarten entsprechend. Bei Kultur in feuchtem Raume, aber offenbar auch unter anderen ungünstig einwirkenden Umständen treten auch späterhin wieder Primärblätter auf (vgl. Fig. 404).

Bei Kakteen treten Rückschlagssprosse nicht selten auf. Die Ursache des Auftretens derselben ist aber experimentell noch nicht untersucht worden (betr. Phyllocactus vgl. oben).

Dasselbe gilt für manche anderen Pflanzen. Wir können meist feststellen, daß die Riickschlagssprosse an bestimmten Stellen, und zwar nahe der Basis der Pflanze, hervortreten. So findet man z. B. bei Eucalyptus in Italien zahlreiche Jugendsprosse im unteren Teile älterer Pflanzen auftreten (oft bis mehrere Meter am Stamme hinauf).

Analoges ist bei Cupressineen (alten Exemplaren von Callitris), Colletia cruciata $^{8}$ ) u. a. beobachtet worden. Nach der oben entwickelten Anschauung ist das Autreten der Rückschlagssprosse an der Basis insofern verständlich, als sie einerseits hier am wenigsten von der anderen Sproßform beeinträchtigt werden können, andererseits die Basis von der Keimung her am ehesten den Charakter der Jugendform beibehalten kann.

1) W. Wächter, Beiträge zur Kenntnis einiger Wasserpflanzen. Flora 83 (1897), p. 367. Betr. anderer Alismaceen: Guück, Biologie der Wasser- und Sumpfgewächse. Betr. der Hydrocharideen Montesantos, Flora 105, p. 23.

2) Dieser Fall ist nicht zu verwechseln mit dem von A. Melanoxylon u. a., bei welchen normal auch an älteren Pflanzen Laubblätter auftreten.

${ }^{3}$ ) Vgl. die Abbildung in "Pflanzenbiologische Schilderungen" I, Fig. 8. 


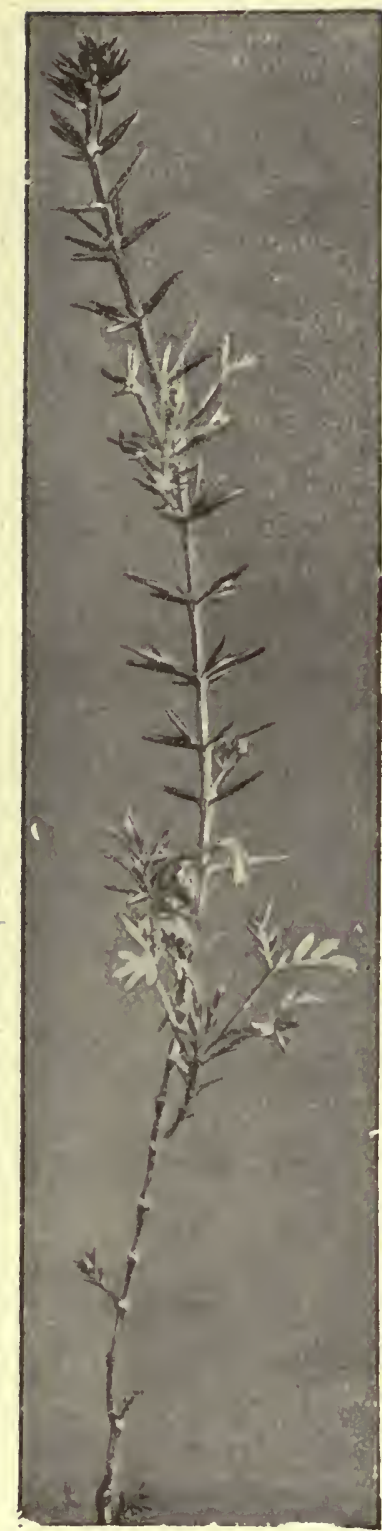

Fig. 403. Acacia verticillata. Junge Pflanze, welche, nachdem sie schon zur Bildnng der nadelförmigen "Phyllodien" übergegangen war, an einigen Zweigen die doppeltgefiederten Blätter der Jugendformhervorgebracht hat.
Mit den genannten Tatsachen stimmt überein, daß bei jungen Cupressineenpflanzen Schädigungen, veranlaßt durch Frost, Parasiten ${ }^{1}$ ), zufällige Wurzelverwundungen usw., Anlaß geben zur Entstehung von Zweigen, welche den Charakter der Jugendform haben), während sie bei normalen Pflanzen den der Folgeform angenommen haben würden.

Die oben mitgeteilten Tatsachen zeigen aber, daß bei der Rückkehr zur Jugendform die Zweckmäßigkeit nicht als ausschlaggebender Faktor betrachtet werden kann; es ist eine Anzahl von Pflanzen bei Eintritt bestimmter äußerer Bedingungen mit dieser Fähigkeit ausgerüstet; sie reagieren darauf in ähnlicher Weise wie Myriophyllum auf die

Nahrungsentziehung durch Bildung von Winterknospen $\left.{ }^{2}\right)$, Reaktionen. die zweckmäßig sein können, aber es nicht immer zu sein brauchen.

Dies ist auch zu beachten bei den Rückschlägen, welche Pflanzen mit Dornen und Stacheln im feuchten Raume aufweisen können. Die Dornbildung fehlt dadurch, daß die Umbildung der Sprosse zu Dornen unterbleibt,also stattdieser gut beblätterte Sprosse auftreten. Indessen verhalten sich offenbar auch hier die einzelnen Arten nicht nur, sondern auch Individuen einer und derselben Art verschieden.

L. CoCKAYNE ${ }^{3}$ ) konnte bei Discaria 'Toumatou durch Feuchtkultur die Dornbildung auf Jahre unterdrücken.

Auch bei Lothelier's ${ }^{4}$ ) Versuchen handelt es offenbar um Beibehaltung resp. Wiederauftreten der Jugendform. Die Wirkung der Kulturbedingungen bestand darin, daß die Dornen, seien es Zweigdornen (Ulex) oder

1) So können z. B. von Peridermium Pini stark befallene Exemplare von Piuus Strobus die Jugendform (einfache Nadeln statt Niederblättern mit axillären Kurztrieben)bilden.

2) S. II p. 360.

3) L. Cockayse, New phytologist IV, 1905, p. 79 ff.

4) Inflnence de l'état hygrométrique et de l'éclairement sur les tiges et les feuilles des plantes à piquants. Lille 1893 und Revue de botanique Vol. V. 
Blattdornen, in mit Wasserdampf gesättigter Luft eine „Tendenz" haben, die Gestalt normaler Zweige oder Blätter anzunehmen, d. h. also, daß die Verdornung unterbleibt, während bei Robinia die Dornen unter diesen Umständen verschwinden sollen. In anatomischer Beziehung sind die in feuchter Luft kultivierten Pflanzen weniger differenziert, namentlich wie schon aus anderen Untersuchungen bekannt - betreffs der sklerenchymatischen Gewebe. Indes kommen diese anatomischen Verhältnisse hier nicht in Betracht.

Zunächst sei erwähnt, $d a ß$ es eine.bekannte Tatsache ist, daß mit Dornen und Stacheln versehene Pflanzen an trockenen Standorten besonders zahlreich vorkommen, es braucht nur an die Wüsten- und Steppenpflanzen erinnert zu werden, von denen sehr viele sich durch Dornen und Stacheln auszeichnen. Dies kann eine direkte Anpassung an die Einwirkungen des trockenen Klimas sein oder zustande gekommen dadurch, daß nur die gegen Tierfraß geschützten Formen übrig geblieben sind. Andererseits kommen im arktischen Norden, der sich durch Armut an pflanzenfressenden Tieren auszeichnet, zwar sonstige "xerophile“ Anpassungen (wie Rollblätter usw.) vor, aber meines Wissens keine stacheligen und dornigen. Man kann für dies Fehlen natürlich verschiedene Griinde anführen: die geringe Zahl arktischer Pflanzen macht das Vorhandensein von Formen, die unter dem Einfluß der Umgebung zur Verdornung veranlaßt werden, weniger wahrscheinlich; die Kürze der Vegetationsperiode wird ferner solche Pflanzen als die besser angepaßten erscheinen lassen, welche nicht ihre Assimilate zur Bildung von unter den gegebenen Verhältnissen nutzlosen Organen verwenden usw. Auch unter den Bewohnern der trockenen Hoch-Andenregion scheinen, von einzelnen Kakteen abgesehen, sich nicht viele stachelige und dornige $\mathrm{zu}$ befinden (es gehören dazu z. B. Nassoviaarten). Immerhin wird man annehmen dürfen, daß ein trockenes Klima bei starker Besonnung - also starker Kohlenstoffassimilation - die Dornbildung begünstigt. Freilich kann das nicht der einzige Faktor sein. Denn die langen Stacheln, die auf der Unterseite der Schwimmblätter von Victoria regia (in geringerer Ausbildung auch bei Euryale ferox) sich finden, können unmöglich unter der Einwirkung der Trockenheit entstanden sein.

Es sind weitere experimentelle Untersuchungen notwendig.

Ich war früher nicht imstande, die Dornbildung bei Ulexpflanzen zu verhindern, die ich lange unter Glasglocken in ständig feucht gehaltener Luft zog, und zu demselben Resultate gelangte später ZEIDLER ${ }^{1}$ ). Lothelier bildet die Spitze einer Pflanze ab, die statt der Dornen Laubtriebe hervorgebracht hat, aber wenn er die Pflanze länger kultiviert hätte ${ }^{2}$ ), würden die scheinbaren Laubtriebe sich wohl auch zu Dornen gestaltet haben. Die zu Dornen werdenden Sprosse werden in feuchter Luft länger und entwickeln ihre Blätter mehr, aber eine dauernde Ver-

1) ZEIDLER, Über den Einfluß der Luftfeuchtigkeit und des Lichtes auf die Ausbildung der Dornen von Ulex europaeus. Flora 102 (1911), p. 87. Zeiderer nimmt an, daß die abweichenden Angaben LotheLIER's darauf beruhen, daß er nicht unverletzte Pflanzen, sondern ans Struinken hervorgegangene Sprosse zu seinen Versuchen benutzt.

$\left.{ }^{2}\right)$ Ebenso bei Crataegus Pyracantha. Bei in feuchter Luft gewachsenen Exemplaren . soll nur der unterste Zweig in einen Dorn endigen, „tous les autres, ayant subi plus longtemps l'action du milien, se terminent par un bouquet de feuilles, an moment où la plante a été coupée". Hiergegen habe ich zweierlei zu bemerken: 1. Zahlreiche Seitensprosse höherer Ordnung entwickelten sich, wie die Zeichnung zeigt, auch im finsteren Raume zu Dornen; 2. die Seitensprosse erster Ordnung waren eben "au moment, oì la plante a été coupée $e^{\text {u }}$ noch nicht ausgewachsen. 
hinderung der Dornbildung war in meinen Versuchen nicht zu erzielen. Es wäre erwïnscht, diese Versuche in größerem Maßstabe zu wiederholen, da wie erwähnt, wahrscheinlich nicht alle Pflanzen gleich reagieren.

Daß die Dornen- und Stachelbildung abhängig ist von ganz bestimmten Faktoren, zeigt übrigens auch die Tatsache, daß bei Ilex Aquifolium nur die junge Pflanze Stacheln an den Blättern hat, die ältere nicht. Man könnte dies damit in Zusammenhang bringen, daß bei den älteren Pflanzen infolge der kräftigeren Entwicklung des Wurzelsystems die Ernährung, namentlich die Wasserzufuhr, eine bessere ist. Wird ja doch auch für einige Pflanzen angegeben, daß sie "in gutem Boden“" ihre Dornen rerlieren. Das ist eine sehr allgemeine Angabe. Sie kann darauf beruhen, $\mathrm{da} B$ in gutem Boden das Wurzelsystem sich reichlicher entwickelt und dadurch die Aufnahme von Wasser und Aschenbestandteilen eine reichlichere wird als in "schlechtem" Boden. Klarheit können nur vergleichende Kulturversuche schaffen.

\section{$\S 13$. Generationswechsel.}

Eine Besprechung der Entwicklung wäre unvollständig ohne die Erwähnung der Erscheinung des Generationswechsels. Es können indes hier nur einige allgemeine Gesichtspunkte hervorgehoben werden, namentlich ist nicht beabsichtigt auf die Hypothesen iuber Entstehung des Generationswechsels näher einzugehen.

\section{a) Verhalten der zwei Generationen zueinander.}

W. Hofmeister hat den Generationswechsel zuerst bei Moosen, Farnen und Samenpflanzen nachgewiesen. Wir nennen die beiden aufeinander folgenden Entwicklungsabschnitte jetzt den Gametophyten (den, der die Gameten hervorbringt) und den Sporophyten (der, der die Sporen produziert).

Fig 405. Anthoceros dichotomus. I Längsschnitt durch einen jungen Embryo. Der Archegonhals durch eine dunkle Masse verschlossen, um den Embryo inhaltsreiche Zellen. II Längsschnitt eines älteren Embryo schwächer, vergrößert. Die Zellen des Archespors eingezeichnet.
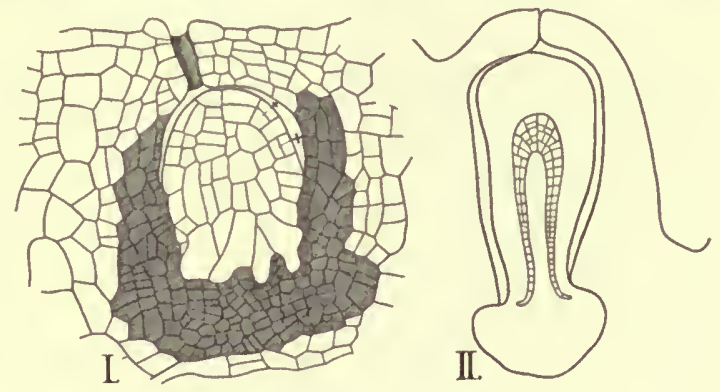

Bekanntlich sind beide bei den verschiedenen Gruppen sehr ungleich entwickelt, bei den Moosen ist der Gametophyt die eigentliche Moospflanze; der Sporophyt auf ihr ganz oder teilweise parasitisch lebend erreicht dagegen keine höhere $\ddot{i} u$ ß e re Gliederung.

Auch bei denjenigen Bryophyten, bei welchen der Sporophyt selbständiger Kohlenstoffassimilation fähig, mit Spaltöffnungen, Assimilationsgewebe usw. ausgerüstet ist, wird doch die eigentliche Ausgestaltung vollzogen solange der Sporophyt noch im Archegonienbauch eingeschlossen ist; vor allem werden schon zu dieser Zeit die sporenbildenden Zellen angelegt. Dies tritt z. B. deutlich hervor bei Anthoceros. 
In Fig. $405 I$ ist der Embryo noch ein mit basalen Haustorien versehener Zellkörper, an dem bei $X \times$ die ersten zur Bildung des "Archespors" führenden Teilungen auftreten. Dieses ist bei dem älteren Embryo Fig. 405, II (welcher das in Fig. 405, $I$ punktierte Nährgewebe schon großenteils verdrängt hat) schon angelegt. Er entwickelt dann ein chlorophyllhaltiges Gewebe, das mit Spaltöffnungen versehen ist. Aber die spätere Assimilationstätigkeit des Sporophyten kommt nur seiner Ausreifung zugute. Es ist also klar, daß die einfachere Gestaltung des Sporophyten bei den Moosen gegenüber dem der Pteridophyten und Samenpflanzen damit in Beziehung steht, daß die Moossporophyten ihre Ausbildung (namentlich bezüglich des Auftretens des sporogenen Gewebes) schon erhalten, solange sie noch als Parasiten auf dem Gametophyten leben. Die Grundzüge des inneren Aufbaues sind fertiggestellt, eh e die Assimilationstätigkeit einsetzt.

Anders bei den Pteridophyten und den Samenpflanzen, bei denen die Periode, in welcher der Sporophyt auf dem Gametophyten schmarotzt, immer mehr abgekürzt wird, so daß also nur der jugendlich unfertige Sporophyt in dieser IVeise lebt.

Dagegen ist der Gametophyt bei den Pteridophyten und den Samenpflanzen verhältnismäßig einfach gestaltet und erfährt innerhalb der Farn- und der Lycopodinenreihe eine starke Rückbildung. Bei den Gymnospermen und Angiospermen wird er zu einem noch mehr reduzierten auf dem Sporophyten schmarotzenden Gebilde; im übrigen können sowohl Gametophyt als Sporophyt sich durch „Brutknospen" bei verschiedenen Pflanzen vermehren. Beispiele dafür wird der spezielle Teil geben. Er wird auch zu erörtern haben, wieweit man Grund zu der Annahme hat, daß bei den Bryophyten der Sporophyt, bei den übrigen Archegoniaten der Gametophyt eine Reduktion erfahren hat.

Auch wenn diese Annahme sich durch vergleichende Gründe stützen läßt, schließt sie natürlich nicht aus, daß innerhalb einzelner Reihen Ver-. schiedenheiten auftreten, welche sich auf die Größe und den anatomischen Aufbau der beiden "Generationen" beziehen.

Es gibt z. B. Farnprothallien, welche an Größe die Sporophyten mancher Hymenophylleen bedeutend übertreffen. Wir wissen auch, daß erstere "latent" die Fähigkeit haben, Leitbündel zu bilden (sie tritt bei "apogamen" Prothallien hervor), während die Sporophyten mancher kleiner Hymenophylleen nicht nur wurzellos sind, sondern auch in ihrer anatomischen Struktur außerordentliche Vereinfachungen aufweisen. Hier ist der Sporophyt zweifelsohne stark rückgebildet. Und bei Anogramme leptophylla und chaerophylla perenniert der Gametophyt mittels eigenartiger Knöllchen, während der Sporophyt nach Ausbildung einer Anzahl von sporenbildenden Blättern zugrunde geht. Wir sehen also, daß selbst innerhalb einer natïrlichen Gruppe das Verhalten der beiden "Generationen" ein sehr wechselndes sein kann.

b) Cytologische und morphologische Verschiedenheit zwischen Sporophyt und Gametophyt.

Nach HofMetster's Entdeckung war der wichtigste weitere Fortschritt der, daß Overton und Strasburger erkannten, daß normal der Gametophyt und Sporophyt innerlich verschieden sind durch ihre Zellkernstruktur. Die Sporophytenzellkerne haben die doppelte Chromosomenzahl der Gametophytenzellkerne. Sie sind ja Abkömmlinge der durch Gameten- 
paarung entstandenen Zygote (der befruchteten Eizelle) und die Chromosomen der beiden Gameten bleiben, wie wir annehmen dürfen, jedenfalls der Zahl nach in der Zygote und deren Tochterkernen erhalten. In irgendeinem Stadium - bei den Archegoniaten und Samenpflanzen bei der Sporenbildung - muß dann eine „Reduktionsteilung“" einsetzen, wobei sich wieder die halbe Chromosomenzahl ergibt. Man ist also berechtigt, von einer haploiden Generation (dem Gametophyten) und einer diploiden (dem Sporophyten) zu sprechen.

Ist dies bei allen Pflanzen, die mit sexueller Fortpflanzung ausgeriistet sind, möglich und zweckmäßig? Diese Frage kann wenigstens dann, wenn man ihren Ausgangspunkt im Auge behält, nicht wohl bejaht werden.

Vielmehr ist zu bemerken, daß man dabei, wie in allen anderen Fällen von solchen Begriffsbildungen an Grenzfälle kommt, für welche der Begriff nicht mehr recht paßt. Denn von einer "Generation" kann man eigentlich nur reden, wenn es sich um einen wenigstens einigermaßen selbständig für sich bestehenden Entwicklungabschnitt handelt, also einen solchen, bei welchem der Bildung der Fortpflanzungszellen vegetative Teilungen vorangehen, oder doch - wie aus vergleichenden Gründen angenommen werden muß - ursprïnglich vorangegangen sind. Wenn wir also z. B. eine Zygote von Spirogyra, die sofort in die Reduktionsteilung eintritt, einen "Sporophyten" oder. eine "diploide Generation" nennen, so ist das im Grunde nur eine Übertragung eines ron "höher" organisierten Pflanzen abstrahierten, hier aber nicht recht passenden Begriffes, und noch mehr Schwierigkeiten hat die Durchführung des Generationswechselschemas bei den Pilzen. Es wäre wohl zweckmäßiger, die alten Bezeichnungen ganz fallen zu lassen und nach einem Vorschlage MaIRÉ's nur von einer Haplophase und einer Diplophase zu sprechen.

Bleiben wir indes bei den Fällen, in welchen sich tatsächlich zwei Generationen oder "Phyten" unterscheiden lassen, so sind es zwei Fragen, die sich hauptsächlich aufdrängen:

1. Steht die Verschiedenheit der beiden "Generationen " im Zusammenhang mit der Verschiedenheit ihrer Zellkernbeschaffenheit?

2. Oder ist für diese Verschiedenheit maßgebend die Verschiedenheit der Lebensbedingungen, unter denen die beiden "Generationen" stehen?

Zur Entscheidung dieser Fragen stehen uns zwei Wege offen. Einmal die vergleichende Betrachtung der verschiedenen Pflanzengruppen und sodann das Experiment, und zwar nicht nur das vom Menschen absichtlich herbeigeführte, sondern auch das von der Natur selbst angestellte. Von einem solchen können wir sprechen in den Fällen, in welchen "spontan" das gegenseitige Verhalten der beiden Generationen ein von dem normalen abweichendes ist. Dagegen werden phylogenetische Schlüsse aus dem Verhalten einer "niederen" Gruppe gegenüber dem einer "höheren" sehr unsicher sein. Denn wir wissen nicht, ob die niederen Gruppen primitive oder reduzierte sind, und noch weniger, ob sie, selbst wenn das erstere zutreffen sollte, irgendwelche Übereinstimmung mit dem Verhalten der Vorfahren der "höheren" Gruppen zeigen. Diese Vorfahren sind uns bei keiner einzigen Gruppe bekannt; es ist - wenn man sich nicht ganz und gar auf den schwankenden Boden der Spekulation begeben will - z. B. nicht möglich, irgendeine Familie der jetzt lebenden Thallophyten mit den Archegoniaten in genetische Beziehung zu bringen. Ebensowenig läßt sich die Annahme sicher begründen, daß die Pteridophyten von moosähnlichen Vorfahren abstammen: Schon die großen Verschiedenheiten, die betreffs des Verhaltens der Haplophase wie der Diplophase innerhalb 
der Thallophyten auftreten, legen die Möglichkeit nahe, daß auch innerhalb der Archegoniaten der "Generationswechsel" auf verschiedene Weise zustande gekommen sein kann.

Es lassen sich, wenn wir die Pilze außer acht lassen, bei den Thallophyten folgende Hauptfälle unterscheiden:

1. Die vegetativen, d. h. mit einfacher Chromosomenspaltung verknüpften Zellteilungen finden nur in der Haplophase statt. Die Zygote stellt allein die Diplophase dar und erfährt sofort bei der Keimung eine Reduktionsteilung. So bei vielen Algen, z. B. den Konjugaten (nicht aber den Diatomeen). Auch die früher wegen äußerer Habitusähnlichkeiten ihrer Oogonien mit Archegonien und ihrer aus der Zygote hervorgegangenen Zellkörper mit Embryonen oft mit den Archegoniaten verglichene Coleochaete verhält sich ebenso. Denn die Reduktionsteilung der Zygote findet hier sofort statt wie bei Spirogyra. Nur teilen sich die vier dabei entstandenen haploiden Zellen weiter und bleiben zunächst noch zusammen, statt sofort zu je einer haploiden Schwärmspore zu werden oder sonstwie zu einem haploiden Thallus auszuwachsen.

Der Grund dafür liegt vielleicht in der Umhüllung der Zygote von seiten des Thallus oder in der Zufuhr von Baumaterialien aus diesem. Jedenfalls

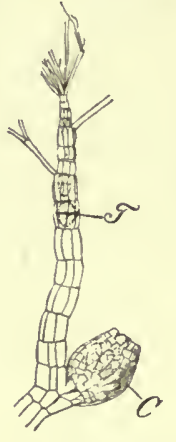

Fig. 406. Polysiphonia variegata. Stück einer Pflanze, welche zugleich Cystokarpien $(C)$ und Tetrasporen $T$ trägt. (Neapel 1877.) können wir darin keine Annäherung an das Verhalten der Zygote bei den Archegoniaten sehen; denn bei diesen teilt sich die Zygote im diploiden Zustand. Vielmehr würde das Verhalten von Coleochaete entsprechen dem eines Oedogonium, dessen Zygote sich (unter Reduktion der Chromosomenzahl) in vier Tochterzellen teilt, wobei diese statt auszuschwärmen, sofort sich weiter teilen.

2. Der entgegengesetzte Fall findet sich bei Fucus. Hier gehört der Vegetationskörper, also der meist beträchtliche Größe erreichende Thallus der Diploph a se an. Die Reduktion findet bei der Bildung der Gameten statt. Diese allein also stellen die Haplophase dar das Verhalten gleicht ganz dem der Tiere.

3. Dictyota hat eine Diplophase, die sich durch Tetrasporen fortpflanzt, die haploid werden. Aus ihnen geht die gametenbildende Haplophase hervor. Wir haben hier also einen deutlichen Generationswechsel. Beide Generationen sind aber im wesentlichen ganz gleich gestaltet, in Form eines gabelig verzweigten im Meere lebenden Thallus (Fig. 61).

Das zeigt ohne weiteres schon, daß ein Zusammenhang zwischen Zellkernverschiedenheit und Gestaltverschiedenheit der beiden Generationen nicht vorhanden zu sein braucht.

Wie Dictyota verhalten sich nach Yamanouchi, SvedeuIus u. a. aucl die näher untersuchten Florideen. Die Tetrasporen tragenden Pflanzen sind die diploiden, die Antheridien und Trichogyne hervorbringenden die haploiden. Es ist also nicht verwunderlich, wenn Antheridien und "Karposporen" auf demselben Exemplare vorkommen (wie z. B. bei Lejolisia, Callithamnion bipinnatum, Herpothamnion hermaphroditum u. a. Wo dagegen Tetrasporen und Karposporen auf derselben Pflanze stehen, wie dies z. B. die Brüder Crouax bei einer Callithamnionart vor Jahren beobachtet haben und auch die Fig. 406 zeigt, ist anzunehmen, daß entweder bei der Bildung der Tetrasporen keine Reduktion eintritt (die betreffende Pflanze also haploid ist) oder vor der Bildung der Karposporen keine Befruchtung (die Pflanze also diploid war). Analoges kommt, wie erwähnt werden soll, bei Archegoniaten vor. 
4. Von besonderem Interesse ist die Gattung Outleria (Fig. 407), weil bei ihr die beiden "Generationen" verschiedene Gestalt haben, obwohl sie unter denselben allgemeinen äußeren Verhältnissen - als untergetauchte Wasser-

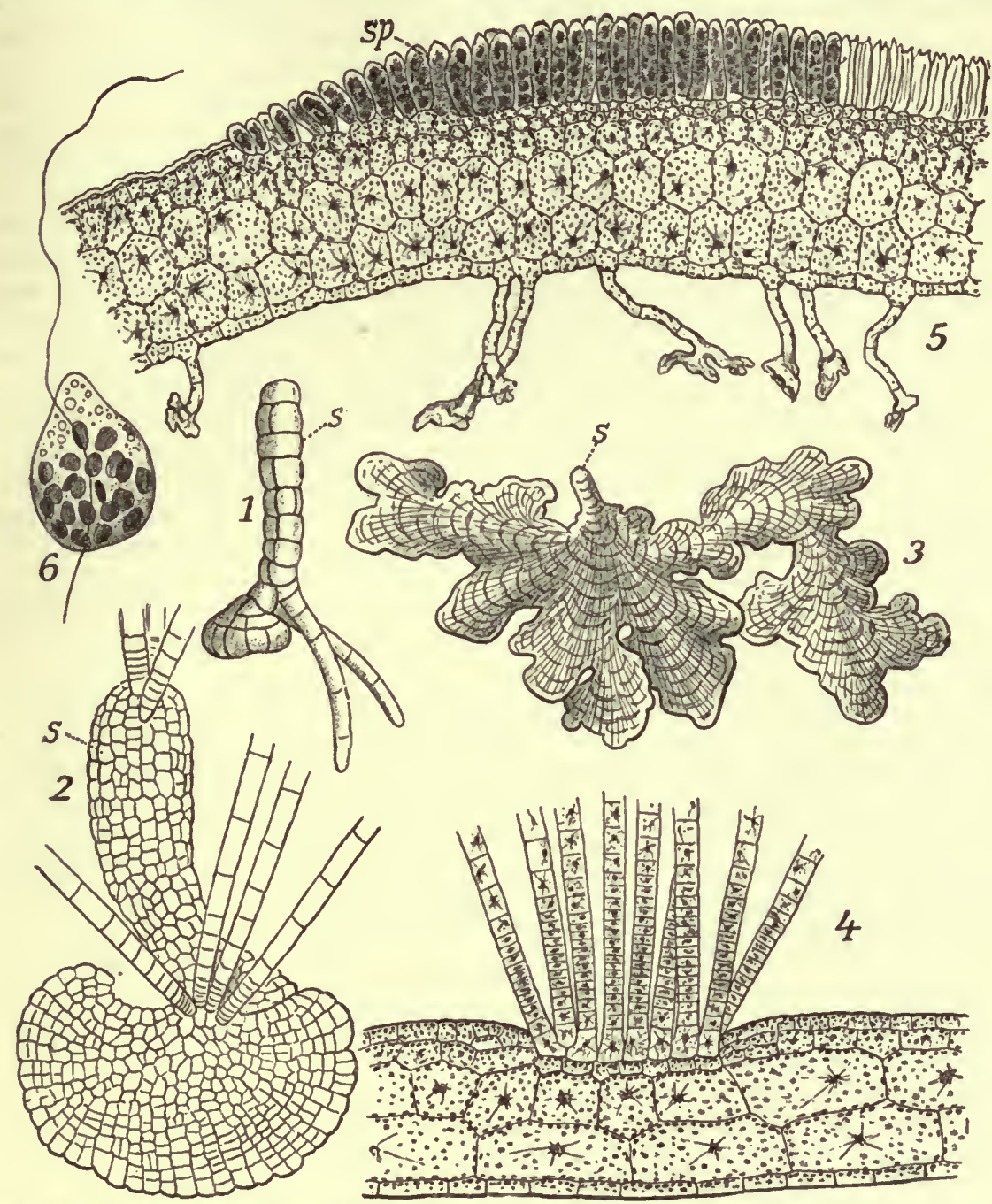

Fig. 407. (Nach Falkenberg, Kuckuck and Sauvageau aus Oltmanns, Algen). 1 Cutleria multifida, Keimling der Diplophase, an der Basis Anfang. eines scheibenförmigen Aglaozonia-Thallus. 2 Dasselbe von Cutleria adspersa. 3 Älteres Aglaozoniastadium von Cutleria multifida. 4 Querschnitt eines solchen. 5 Dasselbe mit Zoosporangien (in denen die Reduktion vor sich geht). 6 Zoospore.

pflanzen - leben ${ }^{1}$ ). Die diploide Generation ist von der haploiden Cutleria multifida so verschieden, daß sie als besondere Gattung, Aglaozonia reptans beschrieben wurde.

Die haploide Generation (bei welcher männliche und weibliche Exemplare

1) Die ältere Literatur bei Ortmanns. Die Algen; ferner Yamanodchi, The life history of Cutleria (Botanical gazette, Vol. LIV, 1912).

Goebel, Organographie der Pflanzen. 2. Aufl. Allgem. Teil. 
keine konstanten Unterschiede darbieten) besitzt einen unten angehefteten, sonst frei im Wasser sich ausbreitenden flachen Thallus.

Die diploide ist ein krustenförmiger Überzug auf Steinen, Tiergehäusen usw. Daß die letztere Wuchsform, ebenso wie z. B. bei Polysiphonia Binderi, eine sekundär entstandene "Anpassung" ist, läßt sich schon daraus entnehmen, daß der diploide Keimling zunächst (ebenso wie bei der genannten Floridee) vom Substrat absteht (Fig. 407, 1, 2,3) und an seiner Basis einen flachen Auswuchs entwickelt, der zum "Aglaozonia"thallus heranwächst (Fig. 407, 1, 3). Dieser bildet dann später unter Reduktion der Chromosomenzahl (von 48 zu 24) Schwärmsporen, aus denen haploide Cutleriapflanzen hervorgehen.

Nun können aber die Eizellen auch ohne Befruchtung keimen. Es erfolgt dies langsamer und unregelmäßiger als bei den befruchteten (namentlich entstehen statt des aufrechten Keimlings zunächst unregelmäßige Zellmassen). Aber es bildet sich auch hier ein krustenförmiger, also aglaozoniaartiger, indes haploider Thallus: wir können auch hier also sagen, daß die Verschiedenheit von diploider und haploider Generation nicht durch die Zellkernbeschaffenheit bedingt wird. Will man phylogenetische Spekulationen an diesen Fall knüpfen, so erscheint es wahrscheinlicher, die Aglaozoniaform aus einer ursprünglichen Cutleriaform abzuleiten, also anzunehmen, daß die Generationen hier ursprünglich ebenso gleich waren wie bei Dictyota, daß aber die diploide Generation einen bei der haploiden latent bleibenden Charakter - die Krustenform des Thallus stärker ausbildete. Dafür spricht nicht nur die Gestaltung des diploiden Keimlings, sondern auch die Tatsache, daß die haploiden Keimlinge gleichfalls eine Zellfläche entwickeln, nur daß diese sich nicht dem Substrate anlegt, sondern "funnel shaped" bleibt.

Es ist also kein einheitliches Bild, welches sich aus den angeführten Beispielen ergibt. Wir sehen - bildlich gesprochen - , daß es der Pflanze sozusagen darauf ankommt, den Vorgang der Reduktion irgendwo und irgendwie abzumachen, es scheint ihr aber nicht viel daran zu liegen, an welcher Stelle der Entwicklung dies erfolgt. Es kann die Haplophase anders gestaltet sein als die Diplophase, aber notwendig ist es nicht, und ein gesetzmäßiger Zusammenhang zwischen Gestaltverschiedenheit und Zellkernverschiedenheit ist nicht vorhanden.

Wie ist es nun bei den Archegoniaten, die uns hier vorzugsweise beschäftigen? Die Verschiedenheit der beiden Generationen ist, wie allgemein bekannt ist und oben kurz erwähnt wurde, eine große. Ist sie bedingt durch "innere" Faktoren oder Anpassung an verschiedene Lebensverhältnisse?

Zunächst wird sich fragen, ob tatsächlich die Verschiedenheit eine so große ist, wie sie uns erscheint.

Diese Frage ist nach den neueren Untersuchungen-immer mehr zu verneinen. Wir haben nämlich eine große Anzahl von Fällen kennen gelernt, bei welchen die zwei Generationen direkt ineinander übergehen und Mittelbildungen zwischen beiden entstehen können.

Es handelt sich dabei um die als "Aposporie" und Apogamie bezeichneten Vorgänge. Aposporie bezeichnet die Entstehung eines Gametophyten aus dem Sporophyten ohne Vermittlung der Sporen, die Apogamie die Entstehung eines Sporophyten aus dem Gametophyten ohne Vermittlung einer befruchteten Eizelle, also entweder aus beliebigen Prothalliumzellen (eventuell nach einer Kernverschmelzung) oder aus einer diploiden Eizelle. Spontan, ohne Zutun des Menschen, finden sich Aposporie und Apogamie, soweit mir bekannt, einerseits bei den leptosporangiaten Pteridophyten, also der Gruppe, die sich auch sonst am 
meisten durch Fluß der Formenbildung auszeichnet, andererseits bei einer Anzahl von Samenpflanzen; der merkwürdige Fall von Aposporie, den Rosenberg bei einigen Hieraciumarten entdeckt hat, wurde oben (S. 330 Anm.) kurz erwähnt. Künstlich konnte Aposporie nicht nur bei Farnen, sondern auch bei einer Anzahl von Moosen hervorgerufen werden.

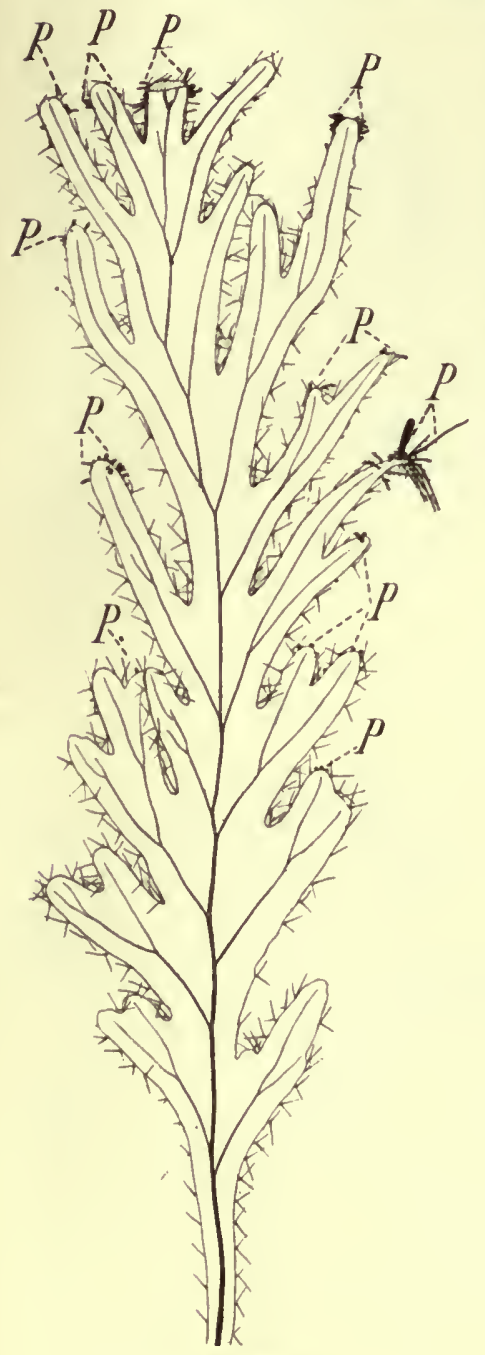

Fig. 408.

Beispiele von Aposporie: In Fig. 408 ist ein Blatt einer Keimpflanze von Tr. Kraussii abgebildet ${ }^{1}$ ), welches nahe der Spitze, die für diese Form charakteristischen Prothallien hervorbringt, Fig. 409 gibt ein kleines Stiick einer Blattfieder stärker vergrößert wieder. An den Prothallien entstehen die Keimpflanzen apogam, die Antheridien bilden keine Spermatozoiden mehr, die Archegonien kommen gar nicht zur Ent-

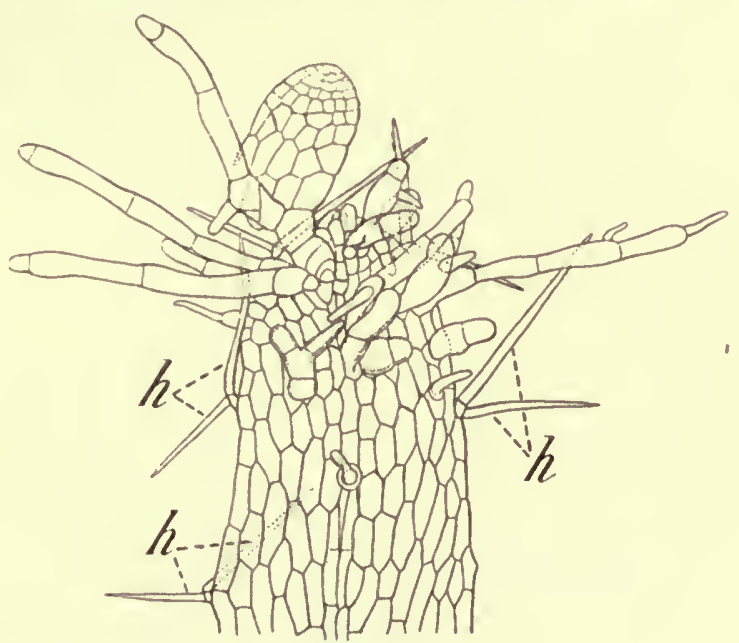

Fig. 409.

Fig. 408. Trichomanes Kraussii. Blatt einer Keimpflanze. An den Blattfiedern entspringen teils faden-, teils flächenförmige Prothallien $(P)$ 3 fach vergr.

Fig. 409. Trichomanes Kraussii. Ende einer Blattfieder, aus welcher teils fadenförmige, teils flächenförmige Prothallien entspringen. $h$ Haare des Blattrandes.

wicklung. Die Pflanze ist also zugleich apospor und apogam und zwar, wie kaum zu bezweifeln ist, diploid. Ohne Zweifel haben wir es hier zu tun mit einer Pflanze, bei welcher die Zellen der Gametophyten und die der Sporophyten die gleiche Chromosomenzahl haben; trotzdem sind die Gestaltverschiedenheiten beider "Generationen" vorhanden.

1) Vgl. die Angaben von H. Worosis, Apogamie und Aposporie bei einigen Farnen, Flora 98 (1908), p. 101. 
Es sei dabei bemerkt, daß die Aposporie und Apogamie dieser Pflanze nicht etwa (wie z. B. von D. Campbel angenommen wurde), in

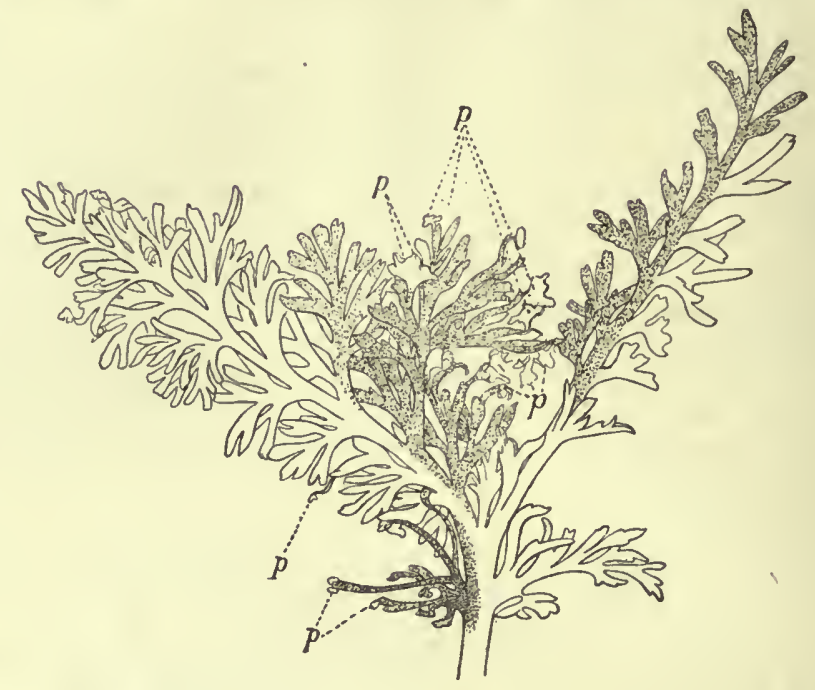

A.

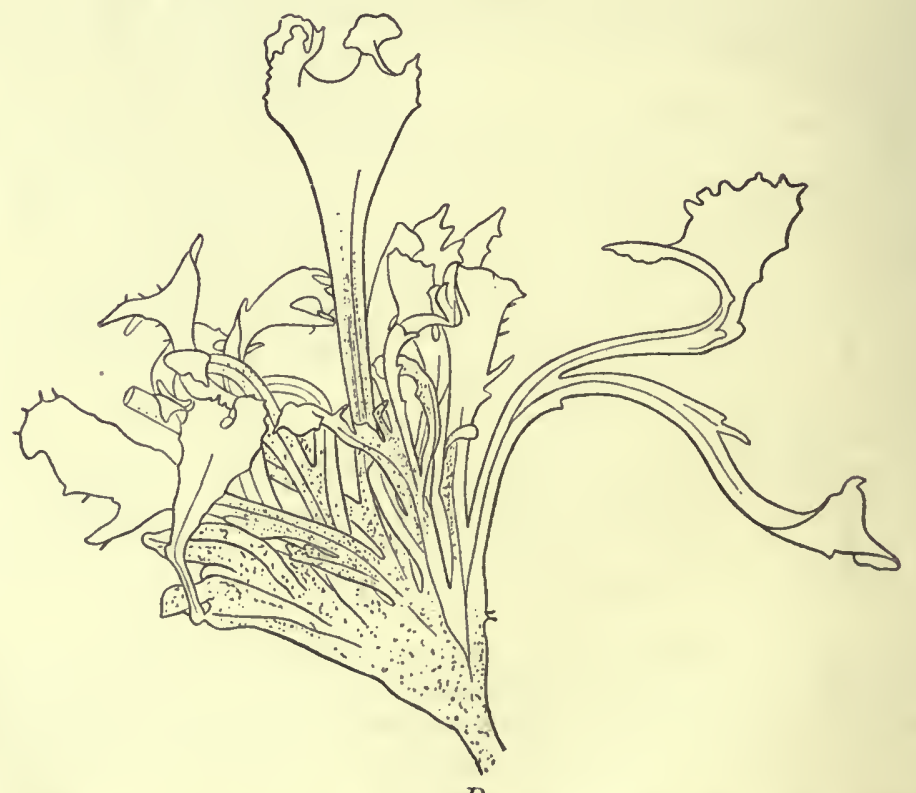

$B$.

Fig. 410. Asplenium dimorphum. A. Abnorm ausgebildeter Teil eines Blattes nat. Gr. Einzelne Fiedern sind an der Spitze in Prothallien $(p)$ ausgewachsen. $B$. Stück eines abnormen Blattes 5 fach vergr. Das intercellularraumbaltige Blattgewebe ist punktiert, das wegen Mangels der Intercellnlarräume durchscheinend ausgebildete nebst den Prothallien hell.

der Kultur entstanden sind; die beobachtete Pflanze war an ihrem natürlichen Standorte in Dominica gesammelt und hat ihre Aposporie in 
der Kultur seit mehr als 10 Jahren beibehalten. Sie ist also gegenüber der Normalform eine, wahrscheinlich durch Mutation entstandene Neubildung. Dabei ist von Interesse hervorzuheben, daß die Aposporie bei den Farnen teils wie bei den soeben geschilderten Trichomanes als $\mathrm{k}$ on stanter Charakter (als Mutation), teils nur sporadisch - offenbar nur unter bestimmten äußeren Bedingungen - auftreten kann. So beobachtete der Verf. ${ }^{1}$ ) eine Pflanze von Asplenium dimorphum (Fig. 410), an der ein einziges, auch sonst von den übrigen etwas verschieden gestaltetes Blatt, seine Blattfiedern an der Spitze hatte zu Prothallien auswachsen lassen, welche (vielfach abnorme) Sexualorgane hervorbrachten. In den acht seither verlaufenen Jahren brachte die Pflanze aber nur normale Blätter (ohne Aposporie) hervor. Hier war es also offenbar eine lokale Störung, welche die Aposporie bedingte, und zwar an einer alten Pflanze, bei der die Aposporie eine völlig sinnlose Mißbildung darstellte.

Die oben angeführten Fälle von Aposporie sind solche, bei denen die Gametophyten ihren Ursprung direkt aus Zellen der Sporophyten nelımen. Nicht wesentlich davon verschieden ist die apospore Gametopliytenentwicklung aus den Sporangien, bei denen die als "Archespor" bezeichnete Zelle verkümmert und aus dem übrigen Teile der Sporangien Gametophytenbildung eintritt; beide Arten können bei ein und derselben Pflanze auftreten. So bei Athyrium felix femina f. clarissima, bei welcher die Entstehung von Prothallien aus Sporangien S. 330 geschildert wurde, während an derselben Pflanze auch direkt an einem Blatte Prothallien entstehen können.

\section{Künstliche Hervorrufung von Aposporie.}

Sowohl bei Bryophyten als bei Pteridophyten ist Aposporie künstlich (experimentell) hervorgerufen worden.

1. Bryophyten. Nachdem Pringsheim und Stahl gezeigt hatten, daß bei manchen Moosen aus abgeschnittenen Moossporogonien Protonema hervorgehen kann, haben Ex. und Ém. Marchar durch sehr interessante Ver'suche die hierbei eintretenden Erscheinungen näher aufgeklärt ${ }^{2}$ ). Sie benutzten dabei teils diözische, teils monözische Moose.

Bei den diözischen, z. B. Barbula muralis, entstanden aus dem kapselbürtigen Protonema Moospflanzen, deren Zellkerne diploid waren (während aus den Sporen durcl die bei der Sporenbildung eintretende Reduktion haploide Pflanzen hervorgehen). Sie glichen vegetativ durchaus den normalen haploiden Pflanzen, waren aber nicht diözisch, sondern brachten Antheridien und Archegonien hervor, woraus zu schließen ist, daß die Sexualdifferenz bei der Reduktionsteilung der Sporen bestimmt wird. Eine Befruchtung trat nicht ein, wohl aber ein üppiges vegetatives Wachstum.

Bei monözischen Pflanzen ergab die Regeneration diploide, normal fertile Pflanzen, deren Sporophyten dann tetraploid waren, die Sporen waren also diploid. Eine weitere Steigerung war nicht möglich, da die tetraploiden Sporophyten aus den nicht reduzierten Zellen nur schwächliche, sterile Pflanzen ergaben. Die diploiden Pflanzen stimmten mit den

1) Flora 96 (1905), p. 239.

$\left.{ }^{2}\right)$ Ér. et Ém. Marchar, Aposporie et sexualité chez les mousses (Bullet. de l'ac. roy. de Belgique (Classe des sciences) I 1907, II 1909, III 1911. 
haploiden in ihren vegetativen Organen überein, die Archegonien und Antheridien waren größer als bei letzteren.

2. Bei Pteridophyten kann man künstliche Aposporie in der Weise erzielen, daß man Primärblätter von Keimpflanzen abtrennt und feucht kultiviert. Es entstehen dann an den abgetrennten Primärblättern entweder Adventivsprosse oder Gametophyten oder höchst interessante Mittelbildungen zwischen beiden. Es sei in dieser Beziehung auf anderweitig Gesagtes verwiesen ${ }^{1}$ ) und als Erläuterung hier nur Fig. 411 und 412 angeführt, welch letztere zeigt, wie ein Prothallium in ein Blatt mit Spaltöffnungen (und den für das Blatt charakteristischen Haaren) dieses wieder an der Spitze in ein Prothallium mit Antheridien übergeht.

Weitere Beispiele von Apogamie anzuführen ist für die hier verfolgten Zwecke nicht notwendig. Es genügt, aus den oben angeführten entnehmen zu können, daß die beiden Generationen innerlich voneinander weniger verschieden sind, als es äußerlich den Anschein hat. Sie können ineinander direkt übergehen und jede Zelle der einen hat (soweit sie nicht entwicklungsunfähig oder allzusehr spezialisiert ist)

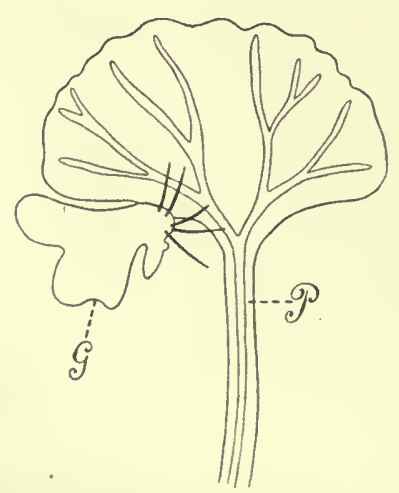

Fig. 411. Osmunda regalis. Von der Pflanze abgetrenntes Primärblatt $(P)$, welches ein Prothallium $G$ regeneriert hat.

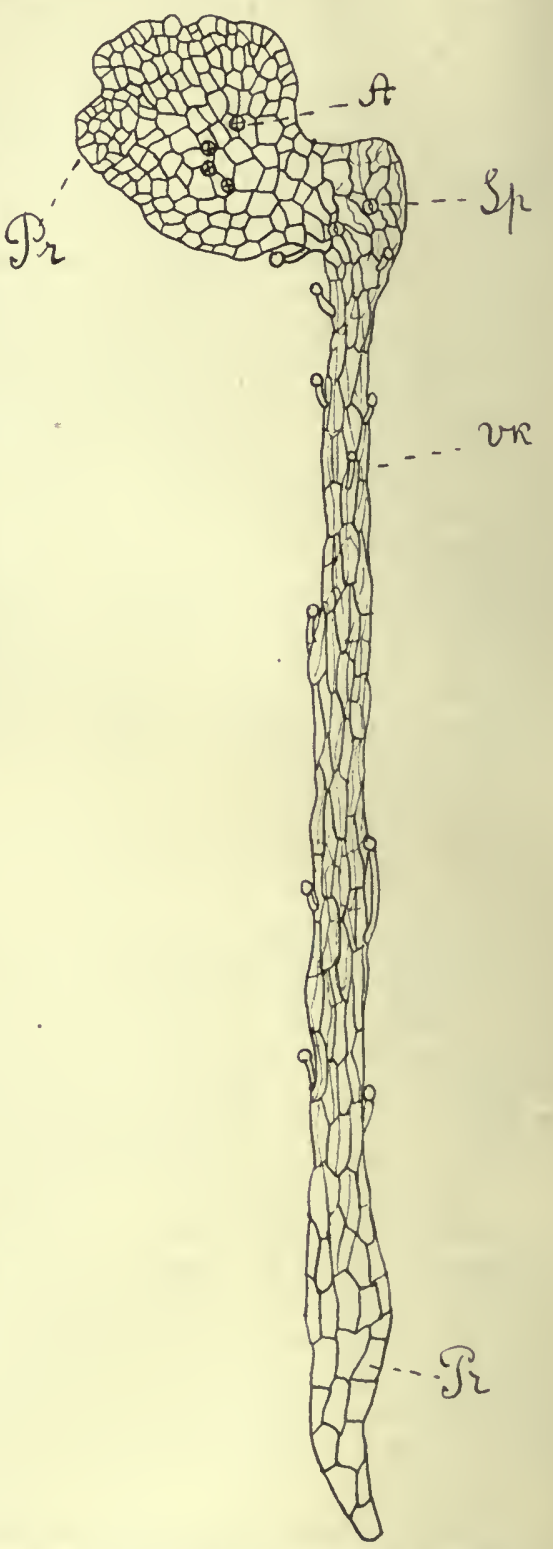

Fig.412. Pellaea flavens (nach Her. Woronis). $\mathrm{Pr}$ unten Prothallium, welches in ein verkiimmertes mit Spaltöffnungen $S p$, Haaren usw. versehenes Blatt $v k$ ausgewachsen ist. Aus diesem hat sich wieder ein Prothallium $\operatorname{Pr}$ mit Antheridien (A) entwickelt.

1) Gokber, Einleitung in die experimentelle Morphologie der Pflanzen 1908, p. 199. 
offenbar latent die Fähigkeit, die andere Generation aus sich hervorgehen $\mathrm{zu}$ lassen.

Man könnte diese Erfahrungen auch phylogenetisch verwerten und annehmen, daß ursprünglich bei den Farnen ähnlich wie bei Dictyota beide Generationen gleich gewesen seien, der Gametophyt aber auf ein rudimentär ausgebildetes Blatt, das Prothallium, reduziert worden sei. Aus den oben angefiihrten Gründen soll diese Hypothese hier nicht näher erörtert werden.

Jedenfalls ist auch bei den Archegoniaten die Verschiedenheit zwischen Gametophyt und Sporophyt nicht direkt durch Haploidie und Diploidie bedingt, die ja indirekt vielleicht von Bedeutung sein kann, indem sie eine andere Reaktionsfähigkeit bedingen könnte, namentlich gegenüber äußeren Bedingungen.

Daran knüpft sich ohne weiteres die Frage, ob die Verschiedenheit der beiden Generationen etwa bedingt sein könne dadurch, daß sie verschiedenen Lebensbedingungen angepaßt sind. Es unterliegt keinem Zweifel, und ist in den letzten Jahren auch öfters betont worden ${ }^{1}$ ), daß die Diplophase der Archegoniaten mehr für das Landleben geeignet ist, als die Haplophase; dort wo wie bei den Hydropterides die Diplophase als Wasserpflanze auftritt, oder sich wie bei den Hymenophylleen und einigen Todea(Leptopteris-)arten in ihrem anatomischen Bau ausgeprägte hygrophil verhält, ist dies klärlich eine s e kundär e Erscheinung, d. h. die betreffenden Pflanzen (z. B. Azolla und Salvinia) leiten sich ron Landpflanzen ab.

Es braucht nur erinnert zu werden daran, da B die Sporen der Diplophase durch die Luft, die .Spermatozoiden der Haplophase durch das Wasser verbreitet werden. Über das $\mathrm{Zustandekommen} \mathrm{dieser} \mathrm{Ver-}$ schiedenheit ist damit aber gar nichts ausgesagt, und die darüber ausgesprochenen Vermutungen bewegen sich auf sehr unsicherem Grunde. Man kann ja annehmen, daß die Haplophase das Primäre darstelle und sich von einer Wasserpflanze ableite, während die Diplophase sich mehr und mehr dem Landleben ,angepaßt" habe. Aber wenn jemand von der Diplophase ausgeht und die Haplophase als eine sekundär dem Wasserleben angepaßte betrachtet, so kann man ihm die Unrichtigkeit einer solchen Vermutung auch nicht dartun, weil wie oben bemerkt, keine Thallophyten bekannt sind, an welche wir die Archegoniaten mit einiger Sicherheit anknüpfen könnten. Es ist das eine Erscheinung, die sich bei allen größeren Gruppen wiederholt. Wir werden uns deshalb darauf beschränken, im speziellen Teile die verschiedene Gestaltung zu verfolgen, welche die Haplophase und die Diplophase innerhalb der jetzt lebenden Archegoniaten erfahren hat. Ließe sich - wie das versucht werden soll - wahrscheinlich machen, daß erstere bei den Bryophyten sich in aufsteigender, letztere in absteigender Linie entwickelt hat, bei den Pteridophyten aber das Umgekehrte zutrifft, so lassen sich daraus auch für die Gesamtentwicklung beider Gruppen Schlüsse ziehen. Das zu tun aber entspricht einem Bedürfnis des menschlichen Geistes, der die Gestaltungen, wenn auch zunächst nur historisch, verstehen möchte. Führen diese Versuche zu einer experimentellen Fragestellung, wie wir sie auf dem Gebiete der Generationswechselfrage schon in Anfängen vor uns sehen, so ist damit auch die Hoffnung gegeben, auf diesem schwierigen Gebiete weiter als nur zur Aufstellung von Hypothesen zu kommen.

1) Vgl. Bower, The origin of a land-flora; Wetrstein, Handbuch der systematischen Botanik. 
Es braucht kaum bemerkt zu werden, daß wir Versuchę über Generationswechsel nicht verwechseln dürfen (wie das teilweise geschehen ist) mit solchen über die Verschiedenheit der Bedingungen für den Eintritt geschlechtlicher und ungeschlechtlicher Fortpflanzung.

Die ausgezeichneten Versuche von KLEBS zeigen, daß der Experimentator bei manchen niederen Pflanzen es in der Hand hat, geschlechtliche oder ungeschlechtliche Fortpflanzung oder rein vegetatives Wachstum einer Pflanze herbeizuführen. Hier handelt es sich aber um Vorgänge innerhalb der Haplophase oder Diplophase. Wie es bei einem Farnprothallium, das sich durch Brutkörper vermehrt, zweifellos von besonderen Bedingungen abhängt, ob Brutkörper oder Archegonien resp. Antheridien auftreten, so auch bei den untersuchten Thallophyten und Farnpflanzen. Mit dem Generationswechselproblem aber hat diese Frage, wie aus dem gewählten Beispiel hervorgeht, nichts zu tun. 


\section{Sechster Abschnitt.}

\section{Die Abhängigkeit der Organbildung von immeren und ïußeren Faktoren.}

Daß die Gestaltungsverhältnisse der Pflanzen bedingt sind einmal durch die Beschaffenheit der lebenden Substanz (der Kerne und des Protoplasmas), andererseits beeinflußt werden durch äußere Faktoren, dafür wurden in den vorhergehenden Abschnitten zahlreiche Beispiele angeführt.

Die Verschiedenheit des inneren Aufbaus ist uns bis jetzt so gut wie unzugänglich ${ }^{1}$ ). Die Einwirkung der Außenwelt dagegen tritt in manchen Fällen auffallend hervor.

Durch einen parasitischen Pilz kann z. B. auf den Blättern von Pteris quadriaurita (p. 339) nicht nur die Bildung eines Sprosses hervorgerufen werden an Stellen, wo ein solcher sonst niemals entsteht, sondern auch seine Blätter finden wir an Bau und Gestalt von den normalen abweichend ausgebildet.

Wie hier also die Organbildung selbst und ihr Verlauf abhängt von bestimmten äußeren Faktoren, welche auf das mit bestimmten Eigenschaften ausgerüstete Protoplasma der Nährpflanze einwirken, so wird auch die normale Organbildung von äußeren Faktoren bestimmt und beeinflußt.

Es ist zunächst selbstverständlich, daß sie wie alle anderen Lebensvorgänge gebunden ist an das Vorhandensein der allgemeinen Lebensbedingungen. Deren Untersuchung gehört aber in das Gebiet der Experimentalphysiologie, und auch die besonderen Fälle, in denen die Entfaltung angelegter Organe oder die Entwicklung iiberhaupt nur unter bestimmten, als Reize wirkenden Bedingungen erfolgt, gehören nicht hierher. Für die organographische Betrachtung ist es z. B. nicht von Bedeutung, daß die Keimung der Orobanche-Samen nur im Kontakt mit der Wurzel einer Nährpflanze, die der Lebermoos-Sporen (nach LEITGEB) nur im Lichte erfolgt. Wenn sich aber nachweisen läßt, daß die Gestaltung der Keimpflanze eine andere ist, je nachdem die Keimung bei starker oder bei geringer Lichtintensität erfolgt, so ist dies eine Tatsache, die auch für den Organographen von höchster Bedeutung ist, weil sie ihm eine direkte Abhängigkeit der Gestaltung von äußeren Bedingungen zeigt.

Natürlich lassen sich hier nur willkürliche Grenzen gegenüber der Physiologie ziehen; aber immerhin wird es berechtigt sein, diese Tatsachen hier auch vom organographischen Gesichtspunkte aus zu betrachten, wie dies schon in HoFmeister's "Allgemeine Morphologie" geschehen ist, einem

1) Die Untersuchungen mit Hilfe der Serumreaktionen werden vielleicht hier neue Einblicke eröffnen. 
Werke, das auf die experimentelle Behandlung morphologischer Fragen nachdriicklichst hingewiesen hat und sich dadurch $\mathrm{zu}$ der idealistischen Morphologie in scharfen Gegensatz stellte.

Wenn wir im folgenden die Beeinflussung der Gestaltung besprechen, wie sie gegeben wird einerseits durch "Innenbedingungen", andererseits durch "Außenbedingungen", so ist dies selbstverständlich nur eine äußerliche Einteilung. Denn es braucht kaum bemerkt zu werden, daß die Außenbedingungen nur dann wirksam werden, wenn sie die Innenbedingungen ändern.

Wie in der 1. Auflage sollen dabei die Bezeichnungen Mechanomorphose, Photomorphose, Barymorphose, Hygromorphose nicht angewandt werden. Sie wären zweckmäßig nur dann, wenn einerseits die äußeren Faktoren sich stets genau voneinander sondern ließen, andererseits in ihrer Wirkung verschieden wären. Es kann aber z. B. die Wirkung intensiver Kohlenstoffassimilation dieselbe Veränderung der Innenbedingungen herbeiführen wie gesteigerte Transpiration, eine Ringelung dieselbe Veränderung wie die Biegung eines Sprosses usw.

\section{Kapitel.}

\section{Beeinflussung der Gestaltung durch Innenbedingungen.}

\section{$\S$ 1. Mechanische Beeinflussungen.}

Der Einwirkung des Druckes, welchem die Vegetationspunkte ausgesetzt sein sollen, haben frühere Autoren, wie mehrfach angeführt wurde, große Bedeutung für die Gestaltung zugeschrieben. So für das Auftreten dorsiventraler Blïten (p. 298), sowie die Anordnung und das Verkümmern der Organe.

Nachgewiesen sind solche Druckverhältnisse aber niemals; nicht einmal - was mit der modernen Technik leicht möglich wäre - die Voraussetzung dazu: die dichte Berührung z. B. zwischen Deckblatt, Achselsproß und Hauptachse. Aber selbst wenn solche Druckverhältnisse vorliegen sollten, so ist nicht zu vergessen, daß die Vegetationspunkte keine passiven, einem Druck ohne weiteres nachgebenden Massen sind, wie ein weiches Stück Wachs u. dgl., sondern aktive Gebilde, welche Widerstände, die auf sie einwirken, überwinden können. Das zeigt jede endogen angelegte Wurzel, die sich über den "Druck" der sie umgebenden Zellen leicht wegsetzt.

So sind es nur Gestaltungsverhältnisse von untergeordneter Bedeutung, die man auf Druckverhältnisse mit Sicherheit zurückführen kann.

Wie die ursprünglich weichen Stärkekörner von Zea Mais durch gegenseitigen Druck polyedrisch werden, so ist auch die Umrißform einiger, nach ihrer Anlegung nur noch schwach wachsender Pflanzenteile - wie wir schon aus vergleichender Betrachtung schließen können - durch Druck bedingt.

So die Querschnittsform der nadelförmigen Blätter von Pinus. Solange sie noch jung sind, stecken die einem Kurztrieb angehörenden Blätter in einer steifen, röhrenförmigen Scheide aus Niederblättern. Demgemäß haben sie bei den zweinadeligen Kurztrieben (z. B. P. silvestris) eine andere Form als bei den mehrnadeligen (z. B. P. Cembra). Bei P. monophylla aber sind die Nadeln, die nur in Einzahl an jedem Kurztrieb stehen 
zylindrisch. Die Kotyled onen der Pinusarten mit zweinadeligen Kurztrieben haben eine andere Querschnittsform als die Kurztriebblätter selbst, da sie in Vielzahl vorhanden, also anderen Druckverhältnissen ausgesetzt sind.

Ähnlich ist es bei den Samen von Coffea. Wenn diese (wie gewöhnlich) zu zweien in einem Fruchtknoten sich finden, so hat jeder eine flache und eine konvexe Seite. Schlägt ein Samen fehl, so füllt der andere unter Verdrängung der Scheidewand die ganze Fruchtknotenhöhle aus und erscheint kugelig („Perlkaffee" ${ }^{1}$ ).

Analoge Fälle ließen sich wohl noch mehr zusammenbringen, so ist z. B., wie ARNoLdi ${ }^{2}$ ) nachwies, die zerknitterte Gestalt, welche die Blumenblätter ron Papaver in der Knospe haben, durch die Raumverhältnisse bedingt.

Sonst aber sind es Wachstumserscheinungen der Blätter, nicht die Raumverhältnisse als solche, welche die Knospenlage bedingen.

Mit Recht hat also schon Hofmeister ${ }^{3}$ ) gesagt: "Die abgegliederten Sprossungen des Pflanzenkörpers erlangen ihre definitive Form im allgemeinen durch Wachstumsvorgänge, welche selbständig, nicht beeinflußt und geregelt durch den Kontakt und den Druck der im Knospenzustand an die betreffende Sprossung grenzenden Gebilde verlaufen."

Im rorstehenden wurde kurz auf die bei einigen Pflanzen durch die innerhalb der Pflanze selbst gegebenen Raumverhältnisse bedingten Gestaltungsverhältnisse hingewiesen.

Auf die durch Druck von außen veranlaßten Deformationen soll nicht näher eingegangen werden, weil es sich hier nur um zufällig auftretende Beeinflussungen handelt.

\section{$\S 2$. Beeinflussung durch die Gestalt des Mutterorgans.}

Eine Beeinflussung der Organbildung kann dadurch eintreten, daß die Neubildungen, bedingt durch die Gestalt des Mutterorgans, auf verschiedenen Seiten desselben verschieden ausfallen.

a) Das einfachste Beispiel bietet die Förderung auf der Konvexseite an gekrümmten Wurzeln, auf welche, nachdem sie in einzelnen Fällen schon anderen Forschern aufgefallen war ${ }^{4}$ ), namentlich Nolt, die Aufmerksamkeit lenkte. Es handelt sich dabei um eine Erscheinung, welche weit verbreitet, aber nicht allgemein ist; sie kommt sowohl an natürlich als an künstlich gekrümmten Pflanzenteilen vor.

Die letzteren sind für uns insofern zunächst lehrreicher, als sie uns das Kausalverhältnis deutlicher zeigen als dies bei den natürlich gekrümmten Pflanzenteilen der Fall ist, bei denen die Bevorzugung der Konvexseite ja auch noch andere Ursachen als die Krümmung haben könnte.

Am einfachsten läßt sich die Förderung der Konvexseite beobachten

1) Vgl. C. v. FABER, Morphol.-physiol. Untersuchungen an Blüten von Coffea-Arten, Ann. du jardin bot. de Buitenzorg, II. Sér., Vol. X, p. 102.

2) Arnoldi, Über die Knospenlage der Blätter. Flora 87 (1900), p. 440

3) Hofmeister, Allg. Norphologie p. 636.

4) So sagt z. B. Lachuass, Contributions à l'histoire naturelle de la racine Thèse, Lyon 1889, p. 15. „Nous avons remarqué... qu'elles ( - les radicelles $\rightarrow$ ) occupent presque toujours ... la convexité de la.racine." F. Nort, Über den bestimmenden Einfluß von Wurzelkrïmmungen auf Entstehung und Anordnung ron Seitenwurzeln. Landwirtsch. Jahrb. 1901. Vgl. Goeber, Einleitung in die exper. Morphologie (1908), p. $82 \mathrm{ff}$. 
bei Wurzeln, denen (statt daß sie gerade wachsen) schraubenförmige Krümmungen aufgenötigt wurden. War dies der Fall, ehe die Seitenwurzeln angelegt sind, so treten diese $n u r$ auf der Konvexseite, auf (Fig. 3). derjenigen also, auf welcher eine Zugspannung herrscht. Wenn aus inneren Gründen (z. B. wie bei einer diarchen Wurzel) die beiden Gefäßteile, vor denen allein die Anlegung einer W.urzel erfolgen kann, transversal zur Krümmungsebene stehen, so wenden sich die Wurzeln wenigstens der Konvexseite zu, was mir für die Auffassung des ganzen Vorganges von Bedeutung scheint. Man kann als Grund dieser Krümmung entweder eine verschiedene chemische Stoffverteilung in der Rindenpartie der Wurzel auf Konvex- und Konkavseite oder die Verschiedenheit der Spannung annehmen. Daß die Entstehung der Wurzeln auf der Konvexseite von Vorteil sein $\mathrm{kann}$, ist wahrscheinlich, doch scheint mir NoLL zu weit zu gehen, wenn er darin eine höchst zweckmäßige Einrichtung erblickt ${ }^{1}$ ).

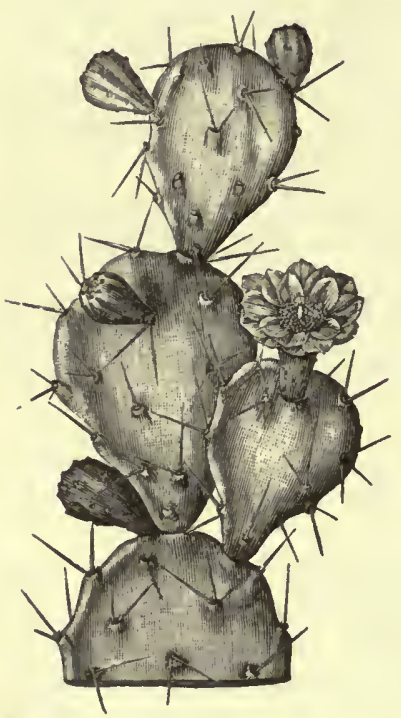

Fig. 413. Opuntia monacantha Haw. (nach Schumans). Die Seitensprosse stehen nur auf den Kanten der Flachsprosse, die Blüten (des offenbar einseitig beleuchtet gewesenen Exemplares) anch auf der Fläche (Lehrb.).

Nordhausen ${ }^{2}$ ) stellt fest, daß die einseitige Entstehung der Nebenwurzeln auch auftritt, wenn die Krümmung der Wurzeln (infolge von Verletzungen, einseitiger Wasserzufuhr usw.) verhindert wird, daß also nicht die Krümmung als solche den Anstoß zur einseitigen Förderung und Ablenkung der Wurzeln zu geben braucht. Seiner Ansicht nach findet überall da, wo eine Erhöhung oder Herabsetzung der negativen Spannung des Perikambiums (Pericykels) lokal eintritt, eine Förderung bzw. Hemmung der Nebenwurzelbildung statt. Nach des Verfassers Auffassung spielt die ungleiche Stoffverteilung - welche auch ohne Krümmung infolge einseitig einwirkender Reize zustande kommen kann - die Hauptrolle, bei den Wurzeln speziell in der Weise, daß die Nebenwurzelbildung auf der relativ wasserreichen Seite gefördert, auf der wasserärmeren gehemmt wird. Dies steht auch damit in Übereinstimmung, daß z. B. bei Luftwurzeln, solange sie in der Luft wachsen, die Bildung von Nebenwurzeln unterbleibt, aber eintritt, wenn sie in ein feuchtes Substrat gelangen.

b) Eine Beeinflussung der Bildung seitlicher Organe durch die Form des Mutterorgans scheint mir auch vorzuliegen bei den Flachsprossen vieler Opuntiaarten.

Diese Kakteengattung umfaßt zwei Gruppen: bei den Zylinderopuntien haben die Sproßachsen annähernd zylindrische Gestalt (wenngleich oft mit vielen höckerigen Auswüchsen), bei den Platy-Opuntien sind die Sproßachsen stark abgeflacht. Während Seitensprosse bei den ersteren sich an

1) $\mathrm{Da} B$ Nols's Annahme, daß die Bevorzngung der Konvexseite gekrümmter Organstrecken für Wurzelneubildungen bei höheren Pflanzen ausschließlich eine physiologische Eigentümlichkeit des Wurzelsystems sei, nicht zutrifft. geht aus den Angaben in Goerez, Einleitung .in die experimentelle Morphologie p. 82 ff. hervor.

2) Nordha dsen, Über Richtung und Wachstum der Seitenwurzeln unter dem Einfluß änßerer und innerer Faktoren (Jahrb. für wissensch. Botanik, Bd. 44, 1907). 
„beliebigen" Stellen entwickeln können, treten sie bei den Platy-Opuntien normal nur am Rande der Glieder auf, dadurch erhalten diese Opuntien eben ihre merkwürdige Gestalt. Allerdings ist die Beschränkung auf die Ränder keine ausnahmslose. In Südspanien konnte ich an den dort reichlich angepflanzten und verwilderten Opuntien öfters beobachten, da $\beta$ an vertikal stehenden Gliedern auf der Seite, welche am meisten Licht erhielt (der nach Süden und Osten gewandten), auch auf der Fläche Seitensprosse auftraten. Es sei wieder auf die unten iiber die Einwirkung des Lichtes auf Kakteen gegebene Darstellung verwiesen.

Ebenso kann wahrscheinlich auch durch Biegung eines Flachsprosses auf der Konvexseite Bildung von Seitensprossen auf der Fläche bedingt werden.

Sehen wir von der Lichtwirkung („Phototrophie“) u. a. ab, so erscheint zweifellos, daß die Beschränkung der Seitensprosse der flachen Opuntien auf die Kanten eben durch die Gestalt des Muttersprosses bedingt wird. Es ist möglich, daß die Gründe dafür dieselben sind wie bei den konvex gekriimmten Wurzeln. Denken wir uns, die Abflachung eines Opuntiasprosses komme grob mechanisch durch Druck von zwei Seiten her zustande (was selbstverständlich in Wirklichkeit nicht zutrifft), so wird auf den gepreßten Seiten Druck-, auf den freien Kanten Zugspannung herrschen. Die Kanten würden also den Konvexseiten der Wurzeln entsprechen. Diese Annahme erweckt schon durch ihre Einfachheit Mißtrauen, indes verdient sie jedenfalls eine nähere Prüfung. Daß bei Opuntia wie bei den oben erwähnten Wurzeln usw. dieselben Ursachen wirken, wird auch wahrscheinlich durch das Verhalten ab norm gestalteter Wurzeln.

Man kann bei manchen Pflanzen künstlich eine Verbänderung der Wurzeln herbeifuihren. Diese wie flachgedrückt erscheinenden Wurzeln bringen dann Seitenwurzeln - ganz ebenso wie die Opuntiensprosse nur an den Kanten (Schmalseiten) hervor. So z. B. an den verbänderten Wurzeln, welche nach dem frühzeitigen Köpfen der Hauptwurzel bei Zea Mays und Vicia Faba öfters entstehen ${ }^{1}$ ). Im letzteren Falle ist an einen "Nutzen" dieser Erscheinung wohl kaum zu denken, während man bei den Platy-Opuntien allenfalls eine Vermeidung der Beschattung der einzelnen Glieder vermuten könnte -- ob das aber bei Pflanzen, die an so stark besonnten Standorten wachsen, eine Bedeutung hat, ist sehr fraglich.

\section{§3. Beeinflussung der Gestalt durch den Ort, Heteranthie und Heterokarpie.}

In seinem Hauptwerke ") führt DaRwar Beispiele an „von Verschiedenheiten in einem und demselben Teil oder Organe, welche Folgen von Verschiedenheiten in der relativen Stellung an einer und derselben Pflanze sind". Man kann den Begriff Stellung verschieden weit fassen. Auch die in der Entwicklung einer einjährigen Pflanze aufeinanderfolgenden

1) G. Loprione, Homo- und Antitropie in der Bildung von Seitenwarzeln, Ber. der deutschen botan. Gesellsch. XXVI, p. 299. - Die Analogie mit Opuntia hebt Lopriore nicht hervor.

$\left.{ }^{2}\right)$ Ch. Darwin, Entstehung der Arten, VI. Aufl. Deutsche Übers. von Carus (1876), p. 245. Vgl. auch die bei Besprechung des sexuellen Dimorphismus gegebenen Ausführungen. 
Blätter - Primärblätter, Laubblätter, Hochblätter usw. haben eine verschiedene Stellung am Pflanzenkörper, die mit den anderungen in der Entwicklung zusammenhängt. Von derartigen Fällen soll indes hier abgesehen werden. Betont sei, daß die Verschiedenheit der Stellung offenbar insofern mit der Verschiedenheit der Ausbildung zusammenhängt, als angenommen werden kann, daß die verschiedene Stellung namentlich eine verschiedene Ernährung bedingt, eine Verschiedenheit, die allerdings noch genauer Prüfung bedarf. Indes scheint mir kein Grund vorzuliegen, hier andere Ursachen anzunehmen, als sonst, wenn eine Pflanze imstande ist, unter verschiedenen Bedingungen verschiedene Organe (Luftblätter und Wasserblätter, Gabelnng oder seitliche Verzweigung usw.) auszubilden: der Bedingungskomplex findet hier eben in der Stellung seinen äußeren Ausdruck.

1. Heteranthie, d. h. das Auftreten verschieden gestalteter Blüten in verschiedener Stellung.

\section{A. Die Verschiedenheit besteht in Zahlenverhältnissen.}

Hierfür ist seit lange Ruta graveolens ein bekanntes Beispiel. Die jeweils erste Blüte jedes dichasialen in einen Doppelwickel übergehenden Blütenstandes ist 5 zählig, die anderen sind 4 zählig. Wenn wir bedenken, daß auch sonst die Zahlenverhältnisse in den Blüten von der Ernährung beeinflußt werden, z. B. die Erstlingsblïten mancher Caryophylleen 6 zählig statt 5 zählig sind, so ist anzunehmen, daß auch bei Ruta die 5 zähligen Blüten die besser ernährten sind, und daß es möglich sein wird, an kümmerlich ernährten Blütenständen auch die erste Blüte 4 zählig, an sehr kräftig ernährten auch Seitenblüten 5zählig zu machen. Irgendeine biologische Bedeutung hat die Heteranthie hier offenbar nicht. Wohl aber ist dies der Fall bei der folgenden Gruppe.

B. Die Verschiedenheit besteht in einer abweichenden Entwicklung der Blütenhülle (teilweise anch anderer Blütenteile) an den peripherischen Blüten eines Blütenstandes gegenüber den inneren.

Hierauf wurde schon p. 296 bei Erörterung der ,unwesentlich dorsiventralen" Blüten hingewiesen. Bei einigen Umbelliferen (z. B. Heracleum, Orlaya), Cruciferen (Iberis amara) und vielen Kompositen sind die Blütenhüllen speziell die Blumenkrone auf der Außenseite der Infloreszenz gefördert, wodurch die Auffälligkeit der Blütenstände beträchtlich erhöht wird. Auf Einzelheiten braucht hier, da diese Verhältnisse allbekannt sind, nicht eingegangen zu werden. Erwähnt sei nur, daß die Differenzen sich nicht allein auf die Blüten selbst beziehen, sondern sich auch auf die Blütenstiele erstrecken.

Man könnte gegen die Annahme, daß die Stellung der Blüten maßgebend sei, für ihre verschiedene Ausbildung anführen, daß bei den Kompositen, bei welchen sich die Verschiedenheit der Bluiten vielfach äußert darin, daß die Randblüten anders ausgebildet sind als die Scheibenblüten, einerseits bei den Ligulifloren ein solcher Unterschied nicht bestehe, andererseits bei den "gefüllten" Bliitenköpfen (wie sie bei vielen Tubulifloren vorkommen), die sonst am Rande stehenden "Zungenbliiten" auch weiter innen - bei einigen Formen von Chrysanthemum indicum sogar zerstreut zwischen Röhrenblüten - sich finden. Indes würde ein solcher Einwand nicht stichhaltig sein. Bei solchen gefüllten Blütenständen hat sich nicht nur die Gestalt und Anordnung der Blüten, sondern der Blütenstand im ganzen oder an einzelnen Stellen geändert, und damit auch die Beeinflussung, welche auf die jungen Bluitenanlagen ausgeübt 
wird. Nehmen wir z. B. lediglich um ein Bild zu haben an, an den „einfachen" Blütenständen von Bellis perennis seien am Rand mehr Kohlenhydrate als weiter innen und dieses Plus veranlasse die abweichende Ausbildung der Randbliiten, so würde bei der "gefiillten" Form diese Anhäufung auf einem breiteren Randgürtel eintreten.

Die kleistogamen Bliiten, die gleichfalls auffallende Beispiele von Heteranthie darbieten, sollen im speziellen Teile besprochen werden.

Mohrenblüten von Daucus Carota. Im Zentrum der zusammengesetzten Blütendolde von $\mathrm{D}$. Carota findet sich wenigstens bei krïftigen Exemplaren eine Blüte, welche durch die Farbe und Gestalt ihrer Blumenkrone von den übrigen Bliiten abweicht. Es ist von der zentralen Dolde meist nur eine Blüte erhalten, die dann größere und dunkelrot gefärbte Petalen hat. Sind dagegen mehr Bliiten der Zentraldolde ausgebildet, so sind sie kleiner und weniger gefärbt. Offenbar sind im Zentrum des Blütenstandes andere Ernährungsbedingungen vorhanden, die starke Anthocyanbildung der fast schwarz erscheinenden Zentrumsbliite deutet auf Zuckeranhäufung hin; selbst einzelne Blumenblätter an der dem Zentrum angrenzenden Dolden können ') an den letzterem zugewandten Blüten an der dunklen Färbung Anteil nehmen.

Die weiteren Fälle von Heteranthie, wie sie bei einigen Orchideen, bei Muscari comosum u. a. sich finden, können hier außer Betracht bleiben; teilweise werden sie im speziellen Teile Erwähnung finden. Hier genügt es, auf das Problem der Heteranthie als solches hinzuweisen.

2. Heterokarpie ${ }^{2}$ ). Bei der großen Mehrzahl der Pflanzen sind alle Früchte im wesentlichen gleichgestaltet, abgesehen von unwesentlichen und konstanten Verschiedenheiten an Größe und Gewicht. Bei anderen tritt Heterokarpie auf, $d . h$. ein und dieselbe Pflanze trägt verschieden gestaltete Früchte; DeIsivo spricht auch von einer Heteromerikarpie, wenn bei Teilfrüchten die einzelnen Teilstiicke verschieden gestaltet sind.

Die auffallende Erscheinung ist meist nur teleologisch verfolgt worden, man fragte sich, wie die verschiedene Fruchtgestaltung mit der Verbreitung der Früchte zusammenhänge oder ob diese bei Keimung Verschiedenheit zeigen. Es sei deshalb hervorgehoben, daß in allen mir bekannten Fällen von Heterokarpie diese zunächst zusammenhängt mit einer Verschiedenheit des Ortes, an welchem die Friichte resp. die Bliiten, aus denen sie hervorgehen, stehen.

Aus der Mannigfaltigkeit der Beispiele (welche man in der genannten Literatur aufgeführt findet), seien nur wenige angeführt. Wir wollen dabei als Heterokarpie nur die in der Hervorbringung oberirdischer Früchte sich äußernde Verschiedenheit bezeichnen, die in anderem Zusammenhange $\mathrm{zu}$ besprechende Verschiedenheit zwischen oberirdischen und unterirdischen Früchten dagegen als "Amphikarpie".

1) Nach Beobachtungen an der Riviera.

2) Auswahl der Literatur: Eine Liste von Pflanzen mit ,dimorphen" und trimorphen Früchten gab M. KuHN, Botan. Zeitung 1867, p. 67. BAtrtandier, Sur quelques cas d'hétéromorphisme Bull. de la société botanique de France XXX (1881). Lundstroem, Pflanzenbiol. Stadien II (1877). DelpiNo, Eterocarpia ed eteromericarpia nelle Angiosperme (Memoria del R. Accad. di Bologna 1894). Conrens, Ein Vererbungsversuch mit Dimorphotheca pluvialis, Ber. der d. botan. Gesellsch. Bd. XXIV, p. 162. (Nach Abschluß des Manuskriptes dieses Abschnittes (welcher in Naturw. Wochenschrift 1911 veröffentlicht wurde) erschien: BECKER, Über die Keimnng verschiedenartiger Frïchte und Samen bei derselben Spezies, Dissert. Münster 1912. Daselbst auch weitere Literatur, die aber dem Verfasser unvollständig bekannt war.) - Im obigen ist die Darstellung nur wenig gegenüber der früher gegebenen verändert. 
A. Komposit en. Wenn in dieser vielgestaltigen Familie Heterokarpie eintritt, so besteht sie stets darin, daß die im Blütenstande nach außen stehenden Früchte anders gestaltet sind, als die weiter nach innen stehenden. Es sollen dabei nur die Hauptverschiedenheiten erwähnt werden.

1. Gerontopogon glabrum L. (Fig. $414 I$ u. II). Die äußeren Früchte sind länger, wohl auch schwerer, als die inneren. Während letztere einen wohl entwickelten Pappus (dessen innere Strahlen mit einer großen Anzahl von Haaren versehen sind) haben, besitzen die äußeren Früchte nur fünf Strahlen ohne Haare (bzw. nur mit ganz kleinen), also einen recht unwirksamen Verbreitungsapparat.

Analoge Verhältnisse finden sich bei anderen Kompositen z. B. Helminthia echioïdes. Die äußersten Früchte lösen sich hier später und

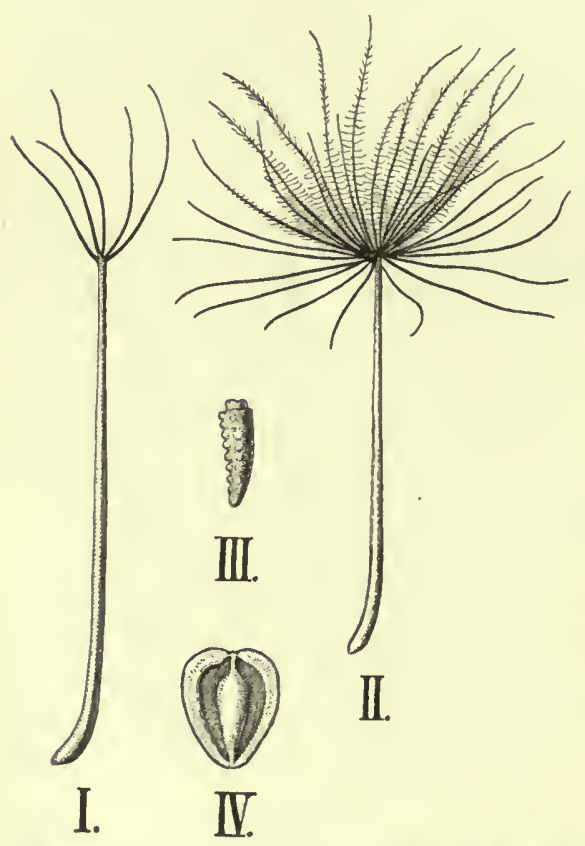

Fig. 414. $I$ und $I I$ Gerontopogon glabrum. III und $I V$ Dimorphotheca plnvialis. I und $I I I$ Randfrüchte, $I I$ und $I V$ innere Frïchte des Fruchtstandes. (Doppelte Naturgröße.) schwieriger ab, als die inneren, sie sind schwerer und haben einen reduzierten Pappus. Die auch bei uns teilweise verwilderte Pflanze hat ihren Gattungsnamen von VAILLANT wegen der "Wurm"(Maden-)ähnlichkeit ihrer Früchte erhalten. Wir werden sehen, daß diese auch bei anderen Kompositen vorhandene Ähnlichkeit, auch teleologisch gedeutet wurde.

2. Dimorphotheca pluvialis (Fig. $414 I I I, I V)$. Die äußeren Friichte (welche aus den weiblichen Strahlenblüten hervorgehen) sind von denen, welche aus den zwitterigen Röhrenblüten entstehen, verschieden. Indes ergibt schon der Vergleich mit den übrigen Kompositen, daß es sich dabei nicht um eine durch die verschiedene Blüten $\mathrm{f}$ o $\mathrm{r} \mathrm{m}$, sondern um eine durch die verschiedene Stellung bedingte Heterokarpie handelt. Die äußeren Früchte sind etwas schwerer als die inneren, welche eine dünnere geflügelte Schale haben; sie sehen manchen Insektenlarven einigermaßen ähnlich und besitzen keine sichtbaren Verbreitungseinrichtungen ${ }^{1}$ ).

3. Calendula. Hier sind die Verschiedenheiten besonders auffallend und besonders oft erörtert. Sie seien an C. malacitana (Fig. 415) kurz geschildert. Alle Früchte sind nach außen konvex gekrümmt. Die peripherischen (Fig. 415 III) haben zwei breite seitliche Flügel, und auf der Innenseite einen dritten flügelartigen Vorsprung. Auf der Außenseite befindet sich eine mit zahlreichen behaarten Vorsprüngen besetzte Leiste. Eine zweite Form ist stärker konkav angekrümmt und wölbt die Flügel

1) Betreffs der Keimung sei hervorgehoben, daß die Scheibenfruichte schneller und besser (in höherer Prozentzahl) keimen, als die Randfrüchte, die letzterell bewahren aber die Keimkraft länger (vgl. BECKER, a. a. 0.). 
nach innen hin ein, so daß die Frucht die Gestalt eines in der Mitte durch eine Längswand geteilten Kahnes annimmt. Der Kiel ist schwächer entwickelt. Ganz innen finden sich noch stärker eingekrümmte flügellose Früchte mit stark höckeriger Konvexseite (Fig. 415 I). Die Höcker sind nur wenig behaart. Leicht könnte man, da mannigfache Übergangsformen vorkommen, die Zahl der Typen vermehren; hier handelt es sich nur um Hervorhebung der auffallendsten Gestaltungsverhältnisse.

Fig. 415. Calendula malacitana, 3 Früchte aus einem Blütenstand. $I$ u. $I I$ innere, III Randfrucht. Letztere ist in Seiten- und in Innenansicht gezeichnet.
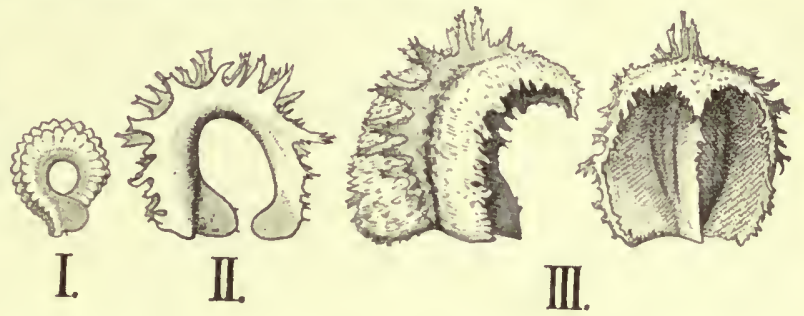

Daß diese zu funktionellen Deutungen aufforderten, ist klar. Zunächst ist zweifellos, daß die Heterokarpie der genannten Kompositen eine verschiedenartige Verbreitung der verschieden gestalteten Frïchte bedingt. Die äußeren Früchte von Gerontopogon, Helminthia u. a. mit rudimentärem Pappus können rom Wind kaum rerbreitet werden, ebensowenig die peripherischen Früchte von Dimorphotheca, wälırend die inneren durch ihre Flïgelbildung den Pappus ersetzen. Bei Calendula sind umgekehrt die äußeren Frïchte durch ihre Flïgelbildung für Windverbreitung geeignet, sie besitzen auch (wenngleich nicht sehr wirksame) Vorrichtungen zum Anhaften an Tieren. Bei den ungeflügelten hakenförmig gekrümmten könnte auch ein Anhaken durch die ganze Frucht stattfinden. Die inneren dagegẹn können nur der Aussaat „in loco“ dienen. Lundströs meinte, die Ahnlichkeit dieser Frïchte mit Insektenlarven veranlasse Vögel, sie zu fressen, sie würden dann unverdaut wieder abgegeben und so verbreitet. Diese Annahme (deren Autor nicht einmal beobachtete, ob die Früchte überhaupt von Vögeln gefressen werden) findet aber in den Tatsachen keine Stütze. Battandier fand, daß Hühner, Enten und Amseln sich durch die angebliche Insektenähnlichkeit nicht täuschen lassen und die Früchte nicht fressen. Ebenso unwahrscheinlich ist die ron Despivo angenommene Ansicht Matrei's, die Larvenähnliclikeit sei vielmehr ein Schutz gegen körnerfressende Vögel. Auch hier müßte festgestellt werden, ob Vögel die rerschiedenen Calendulafrüchte verschieden behandeln, und ob nicht ganz andere Faktoren als die Ähnlichkeit mit Insektenlarven die Frïchte vor dem Gefressenwerden schützen. Es liegt jedenfalls kein Be w eis dafür vor, daß die angebliche Insektenähnlichkeit dieser Früchte etwas anderes als eine ganz zufällige Erscheinung ist. Auch bedarf die Frage, ob es für eine Pflanze vorteilhafter ist, zw e i e rle i Verbreitungsarten (eine für die Nähe und eine für die Ferne) zu haben als nur Einrichtungen für Fernverbreitung, einer kritischen Prüfung. Denn auch bei der letztgenannten Art gelangen sicher viele Früchte nur wenig über den Standort der Mutterpflanze hinaus, zumal wenn wie z. B. bei Dimorphotheca die Flugvorrichtung. keine sehr weittragende ist; und da die Nahverbreitung auf Kosten der Fernverbreitung geht, ist die Aussicht auf Besiedlung neuer günstiger Standorte eine geringere als bei reiner Fernverbreitung.

DeLpino's Ansicht, daß die kahnförmigen Frïchte von Calendula speziell für Wasserverbreitung besonders günstig gebaut seien, ist des-

Goebel, Organographie der Pflanzen. 2. Aufl. Allgem. Teil. 
halb nicht einleuchtend, weil - wie ich mich iiberzeugte - auch die wurmförmigen ganz gut schwimmen. Allerdings sinken sie früher unter als die geflügelten, aber es fehlt auch für die ersteren der Nachweis, daß tatsächlich das Wasser bei ihrer Verbreitung von Wichtigkeit ist - bei einem "Unkraut" wie z. B. Calendula arvensis scheint dies nicht sehr wahrscheinlich.

Man darf übrigens bei den Kompositen nicht nur die Fälle ins Auge fassen, bei denen Heterokarpie mit einer verschiedenen Verbreitungsfähigkeit verbunden ist, sondern muß auch die berücksichtigen, bei denen zwar eine Verschiedenheit der Fruchtform, aber nicht eine Verschiedenheit der Verbreitung in Betracht kommt. In geringem Grade ist dies der Fall bei Bidens radiatus. Die äußeren Früchte sind bedeutend (oft um die Hälfte) kürzer als die inneren, beide haben dieselbe Klettvorrichtung. Bei Chandinia xeranthemoides ${ }^{1}$ ) haben die äußeren Früchte Windverbreitung durch Flügel, die inneren durch einen fallschirmartigen Pappus, bei Bornichia arborescens ${ }^{2}$ ) haben beiderlei Früchte nur einen häutigen Saum (sind also nicht der Windverbreitung angepaßt), die dreikantigen Randfrüchte sind aber viel schmäler als die vierkantigen Scheibenfrüchte, endlich haben Stenactis annua, Heteropappus u. a. Randfrüchte,

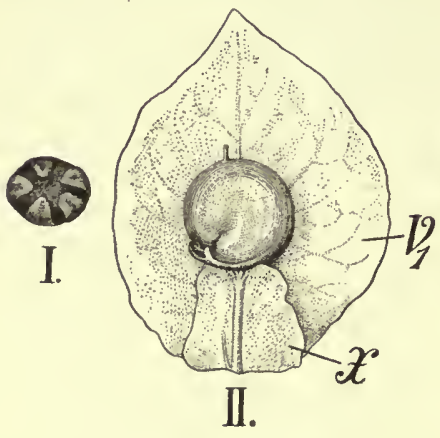

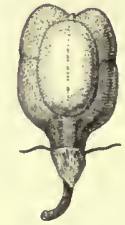

III.
Fig. 416. I und II Atriplex hortensis, 1 schwarze, in horizontaler Richtung abgeflachte Frucht, $I I$ hellgefärbte, in vertikaler Richtung abgeflachte Frucht. $v_{1}$ eines der beiden Vorblätter. Das andere ist an der mit $x$ bezeichneten Stelle entfernt. III Commelina bengalensis, Frucht von außen. Alles doppelte Naturgröße.

deren Pappus anders gestaltet ist, als der der Scheibenfriichte. Diese Fälle, denen sich andere anreihen ließen, zeigen uns, daß wir die Heterokarpie nicht lediglich, wie dies Detpixo tat, als eine Anpassung an rerschiedene Verbreitungsart auffassen dürfen. Eine solche kann mit der Heterokarpie verknüpft sein. $\mathrm{Da}$ sie gegenüber der Isokarpie vorteilhaft ist, wäre erst nachzuweisen. Einstweilen werden wir nur sagen können, daß sie kausal offenbar mit der verschiedenen Stellung der Friichte in der Infloreszenz zusammenhängt; dabei sind bei den einen Formen die Randfrüchte, bei den anderen die Scheibenfrüchte in der Entwicklung gefördert ${ }^{3}$ ).

Chenopodiace en. Atriplex hortensis (Fig. $416 I, I I$ ). Diese Pflanze ist für uns dadurch von Interesse, weil sie eine Heterokarpie zeigt, welche selbst einem so teleologisch gesinnten Biologen wie Despro keine Deutungsmöglichkeit bot. Sie hat zweierlei oder dreierlei Früchte. Einmal solche, die in zwei große Vorblätter eingeschlossen sind und in der Vertikalebene abgeflacht erscheinen (Fig. $416 I I$ ) (unter diesen finden sich zweierlei

1) Abbildung in Evgler-Prantr, Nat. Pflanzenfamilien IV, 5 Fig. 71, G. H.

2) Ibid. Fig. 115, $y, z$.

3) Nach BECKer keimen bei den meisten Calendulaarten die Flugfrïchte schneller und meist auch besser als die "Haken-" und "Larven"früchte. 
Formen, die durch Färbung und Gestalt unterschieden sind; die von mir untersuchten waren alle gelb, die hier aber übergangen werden können). Zweitens schwarze, kleine (Fig. 416 I), welche keine Vorblätter haben (dagegen die Reste der Perigonblätter erkennen lassen) und in horiz on taler Richtung abgeflacht sind. Die Vorblätter sind nicht etwa (wie man zunächst annehmen könnte) für die Windverbreitung eingerichtet, denn die von ihnen umschlossenen Früchte lösen sich nicht leicht $a b$, während die nicht mit Vorblättern versehenen Früchte leicht abfallen, aber auch keinerlei Verbreitungseinrichtungen aufweisen. Diese letzteren haben eine andere Stellung als die ersteren. Sie gehören nämlich dem dichasialen, auch männliche Blüten enthaltenden Blütenstand an, während die mit Vorblättern (aber keinem Perigon) versehenen unterständige „Beisprosse“ an der Primärbluite und den ersten 1-3 Gabelungen darstellen ').

Wenn auch bezüglich der Verbreitungsfähigkeit der beiden Fruchtformen von Atriplex keine auffallenden Verschiedenleiten bestehen, so finden sich doch solche - soweit die noch unvollständigen vorliegenden Untersuchungen ein Urteil gestatten - in der Keimungsgeschwindigkeit. Die größeren (gelben) Früchte keimen rascher ${ }^{2}$ ) als die kleinen schwarzen, was mit ihrer dickeren Schale zusammenhängen dürfte. Ohne Zweifel kann es für die Erhaltung der Pflanze ron Bedeutung sein, wenn sie auch Frïchte besitzt, die erst nach längerer Zeit keimen.

Von der Heteromerikarpie sei ein Fall aus der Gruppe der Umbelliferen angeführt, der besonders instruktiv ist. Bei Torilis nodosa sind bei den äußersten Früchten der Dolde die äußeren Hälften jedes Fruchtknotens mit als Haken dienenden Hervorragungen versehen, durch welche diese Teilfriichte sich Tieren anheften können. Bei den inneren Merikarpien sind diese Hervorragungen nur angedeutet, sie können sich also nicht anheften. Bei den inneren Friichten sind beide Hälften der Frucht gleich und beide ohne Klettvorrichtungen. Dieser Fall schließt sich ohne weiteres an an den oben erwähnten der verschiedenen Bliitenbildung mit ectotroph geförderten Randbliiten bei einigen Umbelliferen, Cruciferen u. a.

Unter die Heteromerikarpie rechnet Dewpixo auch das Verhalten einiger Commelinaarten. Die Fruchtknoten, z. B. bei C. coelestis, C. bengalensis (Fig. $416 I I I$ ), sind dreifächerig, zwei der Fächer öffnen sich und entlassen den darin eingeschlossenen Samen. Das dritte Fach bleibt geschlossen, ein Teil des Perikarps der beiden anderen Fächer bleibt daran hängen und dient als ein (bei der Schwere der Samen und der geringen Größe der Flügel) ziemlich unvollkommener Flugapparat. Auch hier trifft. der Satz $\mathrm{zu}$, daß die verschiedene Ausbildung der Frïchte bzw. Fruchtteile mit ihrer verschiedenen Stellung zusammenhängt. Die Blüten von Commelina stehen in Wickeln. Dabei ist der Teil der Bluiten, welcher nach der Außenseite des Wickels gerichtet ist, anders ausgebildet ${ }^{3}$ ), als der nach innen gerichtete. Es spricht sich dies in der Gestaltung der Staubblätter aus, welche hier steril sind. Die Blüte hat eine nach außen gerichtete "Minus-" und eine nach innen gekehrte Plusseite. Von den

1) Eichler, Blütendiagramme II, p. 83. Der Fall ist dadurch besonders interessant, $\mathrm{da} C$ in den Blüten, welche die schwarzen Frïchte geben, das Perigon noch vorhanden, bei den anderen, welche die stark entwickelten Vorblätter besitzen, aber - offenbar in Korrelation mit den letzteren - verkümmert ist. Gelegentlich findet man auch bei den gelben Früchten (resp. den Blüten, aus denen sie hervorgingen) Perianthspuren.

2) Vgl. J. Luввоск, A contribution towards our knowledge of seedlings II, p. 419.

3) Vgl. p. 294 Fig. 307. 
drei Fruchtknotenfächern ist eines nach außen gekehrt, also nach der Minusseite der Bliite hin. Dieses ist dasjenige, welches sich nicht öffnet. Seine Ausbildung hat also eine Hemmung erfahren, wie die der Staubblätter, nur nicht so stark. Ob diese sich nicht öffnenden Fruchtteile der Fernverbreitung, die Samen der anderen der Nahverbreitung angepaßt sind, wie DeLpixo meint, wäre erst noch festzustellen. In Fig. 416 III ist eine Frucht von C. bengalensis abgebildet. Hier ist das auf der Minusseite stehende Fach deutlich kleiner als die beiden anderen, es enthält nur einen Samen, während die beiden anderen Fächer, wie man schon von außen sehen kann, zwei bergen. Die Öffnung der Frucht findet ebenso statt, wie bei C. coelestis. Es biegt sich aber der Blütenstiel um $180^{\circ}$, so daß die Plusseite der Frucht nach oben und außen gerichtet erscheint. Endlich gibt es andere Commelinaarten, bei denen das auf der Minusseite der Blïte stehende Fruchtknotenfach gar keinen Samen mehr enthält.

Eine Plus- und eine Minusseite bei Früchten (bedingt durch die Lage) findet sich auch. sonst. Bei Antirrhinum majus z. B. ist das`obere Fach der zweiteiligen Frucht deutlich kleiner als das untere, letzteres öffnet sich mit zwei Löchern, ersteres mit einem.

Wir sehen also in allen Fällen deutlich den Einfluß der Lage auf die Ausbildung der heterokarpen Früchte bzw. Fruchtteile, und zwar auch in Fällen (wie den leztgenannten), wo von einer „Anpassung“ keine Rede sein kann. Bei anderen ergibt die primär durch die Lage bedingte Heterokarpie eine verschiedene Verbreitungsfähigkeit und eine verschiedene Keimungsgeschwindigkeit. Inwieweit diese Verschiedenheit für die betreffenden Pflanzen von Wichtigkeit ist, ist aber nur durch exakte Versuche, nicht durch teleologische Betrachtungen festzustellen.

Andere Fälle von Heterokarpie und Heteromerikarpie mögen mit anderen Faktoren zusammenhängen, doch wäre auch hier auf die Stellung zu achten. A. BRAUN ${ }^{1}$ ) führt z. B. Aethionemaarten (namentlich Aeth. heterocarpum GAYAN) "welche in derselben Traube teils Schötchen tragen mit 2 Fächern, abspringenden Klappen und mehreren Samen, teils solche, welche einfächerig, einsamig und nicht aufspringend sind".

Die beiderlei Früchte sind auch hier durch ihre Stellung verschieden: die Schließfü̈chte treten am oberen Ende der Infloreszenz, also gegen Ende der Vegetationsperiode hin auf. An schwachen Seitenzweigen sind sie nach Solms-LAUBACH ${ }^{2}$ ) häufig allein vorhanden. Ohne Zweifel sind es Ernälirungsbedingungen, welche das Auftreten der Schließfrüchte bedingen, ähnlich wie das der kleistogamen oder chasmogamen Blüten. Selbstverständlich ist das nur möglich bei Pflanzen, welche die Fähigkeit zur Bildung verschiedener Fruchtformen (resp. Blütenformen) als ,inhärente" Eigenschaft besitzen. Im allgemeinen werden wir die Schließfrüchte als Hemmungsformen betrachten dürfen, die an den schlechter ernährten Teilen der Pflanze sich ausbilden. Wie die Ernährungsbedingungen im einzelnen einwirken, wissen wir ebensowenig wie bei den Kompositen. Jedenfalls wäre eine expèrimentelle Untersuchung sehr erwünscht.

Stehen bei Aethionema die Schließfrüchte im oberen Teile der Infloreszenz, so zeigt diese bei der Fumariacee Ceratocapnos im unteren Teile eiförmige,

1) A. Braun, Das Individuum der Pflanze Abb. der Königl. Akademie der Wissensch. zu Berlin 1853, p. 82.

2) Solms-Laubach, Cruciferen-Studien II, Über die Arteu des Genus Aethionema, die Schließfrichte hervorbringen, Bot. Zeit. 1901. 
gerippte, einsamige Nüßchen, im oberen lanzettförmige, zweiklappige und zweisamige Schoten. Diese Fälle deuten auf dieselbe Erscheinung hin, die wir oben schon bei Commelina bengalensis antrafen, nämlich darauf, daß die Ausbildung der Fruchtwand im Zusammenhang steht mit der Zahl der darin enthaltenen Samen. Ebenso wie die einsamigen Fächer der Commelinafrucht sich nicht öffnen, wohl aber die zweisamigen, ebenso bleiben auch die einsamigen Früchte der genannten Cruciferen und Fumariaceen geschlossen, die mehrsamigen nicbt. Ähnliches können wir z. B. bei Sinapsis arvensis beobachten. Hier zerfällt die Frucht in zwei Stücke; ein oberes geschlossen bleibendes, welches zwei (oder einen) Samen enthält und ein unteres mit zahlreichen Samen versehenes. Das untere längere Stück öffnet sich in der gewöbnlichen Art der Cruciferenschoten, während das obere eine Schließfrucht darstellt. Diese ist nach DeLPINo's Ansicht zur Fernverbreitung bestimmt, weil die Fruchtschale ziemlich schwammig und leicht ist. Jedenfalls schwimmen (wie ein einfacher Versuch ergibt) diese Teilfrüchte, während die Samen, welche aus den Schoten entleert werden, untersinken. Aber einem Ackerunkraut wird die Schwimmfähigkeit nicht viel nützen, auch die Verbreitung durch den Wind (und eventuell durch Tiere, denn an der Ablösungsstelle haben die Teilfrüchte ziemlich spitze Hervorragungen) wäre erst nachzuweisen. Es ist wabrscheinlich, daß sich die Schließfrüchte von den Samen durch ihr Verhalten bei der Keimung unterscheiden. Versuche darüber sind mir nicht bekannt.

Die vorstehenden kurzen Bemerkungen zeigen, daß die Heterokarpie kausal offenbar mit der rerschiedenen Stellung der Blüten (s oweit diese eine verschiedene Ernährung bedingt) verknïpft ist, und $\mathrm{da}$ sie eine doppelte biologische Bedeutung haben k a $\mathrm{n} n$ : einmal eine solche, die sich auf die Verbreitung bezieht, und dann eine, die die Keimungsgeschwindigkeit betrifft. Die letztere (welche offenbar hauptsächlich von der. Beschaffenheit des Perikarps resp. der Samenschale abhängig ist) braucht aber mit morphologischen Verschiedenheiten nicht Hand in Hand zu gehen; bei Taraxacum officinale z. B. keimen die am Rande stehenden Friichte am schnellsten, die in der Mitte sitzenden am langsamsten, beide zeigen aber keine auffallende Gestaltverschiedenheit.

\section{§ 4. Die Bedeutung der Korrelationen.}

Eine alte Erfahrung zeigt, daß die Organe der Pflanzen, auch wenn sie aus dem Verband mit den anderen getrennt werden, vielfach weiterleben und sich zu vollständigen Pflanzen ergänzen können; Sproß-, Blatt- und Wurzelstecklinge werden ja auch in der gärtnerischen Praxis vielfach verwendet. Ebenso werden beim Okulieren Knospen, beim Pfropfen ganze Sproßstücke aus dem Gewebeverband losgetrennt und vereinigen sich mit einem anderen; auch Blätter und Wurzeln lassen sich von einer Pflanze auf eine andere (derselben oder einer verwandten Art) übertragen. Sie wachsen an und setzen ihre Lebensverrichtungen fort.

Diese Tatsachen könnten zu der Anschauung führen, daß die Organe, auch solange sie an Pflanzen sich befinden, eine weitgehende Unabhängigkeit voneinander aufweisen.

Eine genauere Untersuchung zeigt aber, $\mathrm{da} B$ dem nicht so ist, $\mathrm{da} B$ vielmehr eine Wechselwirkung zwischen den Teilen des Pflanzenkörpers stattfindet; Größe und Ausbildung eines Organs ist vielfach durch ein anderes bestimmt. 
Diese gegenseitige Beeinflussung bezeichnen wir als Korrelation. Wir können mit Sicherheit von einer solchen nur daun sprechen, wenn sie experimentell feststellbar ist. In zahlreichen anderen Fällen steht zwar die Ausbildung eines Organs in deutlicher Beziehung zu der eines anderen, aber wir wissen nicht, ob das eine direkte oder indirekte ist. Bei den Phyllanthusarten, welche blattähnliche Seitenzweige tragen (Fig. 221, 222), sind die Blätter am Hauptsproß gewöhnlich zu Schuppen verkümmert. Das kann durch Korrelation bedingt sein in der Art, daß entweder die blattähnliche Entwicklung der Seitenzweige die Verkümmerung der Blätter am Hauptsproß bedingt, oder daß der letztere Vorgang der primäre war und den anderen bedingte. Es kann aber auch die Verbindung der beiden Gestaltungsverhältnisse eine „zufällige“ sein (vgl.p. 22), d. h. die Blätter der Hauptachsen konnten zu Schuppen verkümmern, weil die Kurztriebe ihre Funktion versahen. Die Entscheidung solcher Fragen ist auch deshalb schwierig, weil eine direkte Beeinflussung embryonaler Gewebe, namentlich des Vegetationspunktes uns meist unmöglich ist. Die Methode, die Korrelation durch die Ausschaltung eines Organes zu erschließen, war zwar erfolgreich, ist aber nicht immer eindeutig. Wenn ich z. B. finde, daß das peripherische Gewebe eines entlaubten Sprosses wesentlich chlorophyllreicher wird, als das eines unentlaubten, so kann dies durch Korrelation bedingt sein, andererseits sind aber auch die äaßeren Bedingungen für die entlaubte Sproßachse andere als für die unentlaubte. Namentlich erhält sie mehr licht und dieses steigert die Chlorophyllbildung,

Wo Korrelationen nachweisbar sind, sind sie entweder quantitativ oder qualitativ, ohne daß sich zwischen beiden eine scharfe Grenze ziehen ließe. Der erstgenannte Fall ist der einfachste, er sei hier zunächst erörtert. Die quantitative Korrelation spricht sich darin aus, daß entweder die Entwicklung einer Organanlage durch ein anderes Organ ganz unterdrückt oder doch die Größe, welche sie erreichen kann, durch Korrelation beeinflußt wird; diese quantitative Korrelation hat man auch als $\mathrm{Kom}$ pensation des Wachstums bezeichnet.

Jede höhere Pflanze bildet wohl mehr Organanlagen aus, als sie zu entfalten imstande ist, ebenso wie z. B. der weitaus größte Teil der Samen, die jährlich entstehen, zugrunde gehen, sei es, daß sie keine günstigen äußeren Bedingungen für ihre Entwicklung finden, sei es, daß sie durch andere Organismen im "Kampf ums Dasein" unterliegen. So bleiben auch von den Organanlagen viele unentwickelt, weil die Baumaterialien, die sie zu ihrer Entfaltung bedürfen, anderen zufließen, die eine stärkere „Anziehung" auf sie ausiuben können.

Als "Kampf" tritt dieser Wettbewerb namentlicl bei der Bildung der Fortpflanzungsorgane auf. Die Frucht von Quercus, Fagus, Tilia schließt je einen verhältnismäßig sehr großen Samen ein. Im Fruchtknoten sind aber eine viel größere Anzahl ron Samenanlagen vorhanden, z. B. bei Quercus 6, bei Tilia 10. Diese sind auch alle offenbar befruchtungs- und entwicklungsfähig, wie schon daraus hervorgeht, daß gelegentlich mehr als eine zum Samen sich ausbildet. Aber meist gewinnt fruihzeitig eine einzige Samenanlage das Übergewicht und speichert alle der jungen Frucht zuströmenden Baustoffe in sich auf, während die anderen von ihr in der Entwicklung gehemmt und schließlich zerdrückt werden. Welche Ursachen die begïnstigte Samenanlage bestimmen, ist nicht bekannt, wir wissen also nicht, ob es die zuerst befruchtete ist, oder ob sonstige Faktoren in Betracht kommen. 
Noch auffallender sind die Vorgänge bei der Samenbildung mancher Nadelhölzer. Bei der Kiefer sind in der Samenanlage 3-5 befruchtungsfähige Eizellen vorhanden. Nehmen wir an, es würden 3 befruchtet, so entstehen also zunächst 3 Embryonen. Jeder von diesen spaltet sich aber noch in 4 Teilembryonen, die alle zu vollständigen Embryonen werden können. Man müBte deren also eigentlich 12 im Samen antreffen. Es ist aber später nur ein einziger vorhanden, welcher über die anderen die Oberhand gewinnt und sie zum Verkümmern bringt, so daß man im reifen Samen kaum noch ihre zerdrückten Reste wahrnimmt. Diese Spaltung der Keimanlage ist anscheinend nutzlos. Vielleicht wird sich aber bei genauerer Untersuchung ergeben, daß die verkümmernden Teilembryonen gewissermaßen die Rolle von Haustorien gespielt, d. h. die Nahrungsstoffe des Endosperms in eine Form übergeführt haben, die dann von dem begünstigten Embryo rasch benutzt werden kann.

Wie innerhalb der Frucht vielfach die einzelnen Samen resp. Embryoanlagen in Wettbewerb treten, so auch die einzelnen Friichte reichbliitiger Bliiten- und Fruchtstände. In diesen reicht das Material sehr häufig nicht mehr hin. um die jüngsten, letztgebildeten Blüten am Ende des Blitenstandes zur Entfaltung zu bringen. Obwohl an den meisten alle Organe schon angelegt sind, verkümmern sie; denn die älteren Blüten haben inzwischen schon mit der Fruchtbildung begonnen, sie beanspruchen alle Baustoffe, die sonst den jüngeren Bliiten zugeflossen wären. Wenn man die jüngeren Früchte rechtzeitig entfernt, so kommen die sonst verkümmernden Blüten zur Entwicklung, so bei Boragineen, Oenothera biennis u. a. Diese Korrelation wird um so weniger hervortreten, je günstiger die Ernährungsbedingungen der Pflanze sind.

Erscheinen hier die gewöhnlich zum Verkümmern verurteilten Blüten vom Niitzlichkeitsstandpunkt aus als Reserven, die im Fall des Ausbleibens der Befruchtung der älteren Blüten in Tätigkeit treten, so wird man nicht dasselbe sagen können dann, wenn die zuletzt angelegten Blüten von vornherein schon in der Knospe verkümmern, wie bei vielen Gräsern. Diese auf den rerschiedensten Entwicklungstufen verkümmernden Bliiten sind, soweit wir bis jetzt einsehen können, gänzlich nutzlose Gebilde.

In der vegetativen Region finden wir gleichfalls Beispiele für die vorübergehende oder dauernde Entwicklungshemmung durch Korrelation. Bei den Bäumen und Sträuchern mit periodischer Entwicklung treiben die Axillarknospen an den diesjährigen Trieben erst im nächsten Jahre aus. Entfernt man die Blätter rechtzeitig, so erfolgt die Entwicklung schon in diesem Jahre; dasselbe tritt in der Natur bei Pflanzen ein, deren Blätter eine Umbildung resp. Riickbildung erfahren. So bei Berberis, deren zu Dornen umgebildete Blätter beblätterte Kurztriebe in ihren Achseln haben, und bei Pinus, wo die Blätter an den Langtrieben zu Schuppenblättern (Niederblättern) reduziert sind (vgl. p. 97).

Schon DE CANDOLLE ${ }^{1}$ ) hat die erwähnte Tatsache darauf zurïckgeführt, daß die Blätter den.Achselknospen den "Saft" entziehen; analog ist die von WIESNER ${ }^{2}$ ) vertretene Auffassung, daß ältere, stärker transpirierende Teile den jüngeren das Wasser entziehen (in diesem Falle also die Blätter

1) Physiologie végétale p. 767.

$\left.{ }^{2}\right)$ Wiesner, Der absteigende Saftstrom und dessen physiologische Bedeutung. Botan. Zeitg. 1889, p. 1. - Es wäre zu prüfen, ob das Absterben der Spitzen auch dann eintritt, wenn die Sprosse unterhalb der Spitze geringelt werden. 
ihren Axillarknospen) und dadurch das Austreiben verhindern. , Auf dasselbe Verhalten wird auch die Verkümmerung der Sproßspitzen der Jahrestriebe von Ulmus, Fagus, Carpinus, Tilia u. a. zurückgeführt. Man sieht, wie die Blätter nach den Triebspitzen hin allmählich abnehmen und das Ende der Triebe schließlich vertrocknet; daß sich keine Endknospe bildet, wäre also auf die "Absaugung" des Wassers durch die älteren Teile zurückzufiihren; ich möchte aber annehmen, daß dabei auch noch andere Faktoren in Betracht kommen; namentlich die Abwanderung der Baustoffe nach den stehen bleibenden Teilen hin, die auch für das Absterben der Blätter perennerierender Pflanzen in Betracht kommt.

Benutzt man z. B. Sproßenden von Atropa Belladonna im Herbst kurz vor dem „Einziehen" der Pflanze zu Stecklingen, so wachsen sie den Winter über weiter (und bilden an ihrer Basis radiäre Sprosse), während bei normaler Entwicklung der Pflanze die Baustoffe nach der Basis hin gewandert, die oberirdischen Teile aber abgestorben wären. (Vgl. betr. der korrelativen Beeinflussung von Blatt und Achselknospe auch p. 97).

Für die Entwicklung der Knospen kommt auch die Korrelation mit anderen Knospen in Betracht. Man kann an einem noch im Wachstum begriffenen Jahrestrieb auch ohne Entblätterung ein Austreiben der Knospen hervorurfen durch Entfernung der Sproßspitze; es treiben dann die der Schnittfläche zunächst gelegenen Knospen aus, während, wie schon früher angeführt wurde, die gegen die Basis hin gelegenen in ihrer Entwicklung gehemmt werden; sie bleiben unentwickelt oder werden zu Kurztrieben, auf die unten zurückzukommen sein wird. Daß die unentwickelt gebliebenen Knospen bei Beschädigung des Baumes durch ihr Austreiben von Nutzen sein können, wurde gleiehfalls frïher schon betont.

Wie vorsichtig manche Pflanzen in dieser Beziehung sind, zeigen z. B. die Keimpflanzen von Juglans regia. Oberhalb der Kotyledonen findet sich hier eine größere Reihe von Knospen übereinander, bis 8 auf jeder Seite, während sonst gewöhnlich über jedem Blatte nur e in e Achselknospe angelegt wird. Von diesen zahlreichen Knospen wächst bei ungestörter Entwicklung der Keimpflanze keine einzige zu einem Zweige aus, und nach Verlauf einiger Jahre sind sie nicht mehr sichtbar. Diese Hemmung wird nicht durch ein "Absaugen" des Saftes seitens des Stützblattes der Knospen bedingt, denn die Kotyledonen bleiben hier hypogäisch, sondern dadurch, daß die Keimpflanze alles ihr zu Gebote stehende Material zur Entwicklung ihrer Endknospe verwendet, welche sich zum Stämmchen verlängert. Wird diese zerstört, solange die erwähnten Seitenknospen noch entwicklungsfähig sind (im ersten oder zweiten Lebensjahr der Pflanze), dann wachsen eine oder einige wenige Seitenknospen $\mathrm{zu}$ einem Triebe aus, der die Weiterentwicklung der Keimpflanze sichert. Zahlreiche Fälle von Entwicklungshemmung an vegetativen und an Blütensprossen lassen sich so auf Wachstumskorrelationen zurückführen.

Dasselbe gilt auch für Blätter und Blatteile. Die Größe, welche die Blätter erreichen, ist, wenn jedem einzelnen reichliche Nährstoffe zur Verfügung stehen, eine viel bedeutendere, als wenn ein bestimmtes Nährstoffquantum sich auf eine Anzahl Blätter verteilt. Demzufolge zeigen Blätter an Stockausschlägen ${ }^{1}$ ) eine bedeutendere als ihre sonstige Größe, und es treten an denselben vielfach Organe hervor, die an den gewöhn-

1) D. h. also von Sprossen, die sich nach Entfernung des Hanptstammes aus dessen stehen gebliebener Basis entwickelt haben. 
lichen Blättern verkümmert sind. So sind an Stockausschlägen von Robinia Pseudoacacia die „.Stipellen" (vgl. den speziellen Teil) zu Blättchen entwickelt, und bei denen von Sambucus nigra treten die sonst meist sehr reduzierten "Nebenblätter" wieder auf.

Lehrreich ist besonders das Verhalten der Nebenblätter mancher Pflanzen. Ihre Größe wird mit bedingt durch die Einwirkung des Blattes, an dem sie stehen. Entfernt man die Blattanlage möglichst frühzeitig, so tritt eine bedeutende Vergrößerung der Nebenblätter ein, wie beistehende Zahlen zeigen mögen. Von zwei in einem Topfe stehenden, aus gleich schweren Samen erwachsenen Pflanzen von Vicia Faba wurden an der einen die Blätter belassen, bei der anderen möglichst frühzeitig entfernt. Die Fläche je eines Nebenblattes betrug

$\begin{array}{lll} & \text { bei der ersten Pflanze } & \text { bel der zweiten } \\ \text { 1. Blatt } & 141 \square \mathrm{mm}, & 239 \square \mathrm{mm}, \\ \text { 2. } & 172 \quad " & 561 \\ \text { 3. } & 165 \quad " & 920 "\end{array}$

Gelegentlich wurden im Freien mißbildete Pflanzen gefunden, bei denen die Blätter vollständig verkümmert, die Nebenblätter enorm vergrößert waren. Der Versuch zeigt uns ${ }^{1}$ ), daß der letztere Umstand eine Folge des ersteren ist, und dasselbe werden wir annehmen dürfen bei Lathyrus Aphaca, dessen Blätter zu Ranken umgebildet und in ihrer gewöhnlichen Funktion durch die ungemein vergrößerten Nebenblätter ersetzt sind (vgl. Fig. 417).

Nicht bei allen mit Nebenblättern versehenen Pflanzen läßt sich eine solche Korrelation nachweisen, namentlich dann, wenn die Nebenblätter früher ihre Wachstumsfähigkeit verlieren, als der experimentelle Eingriff erfolgen kann. Dieser hat z. B. keine Vergrößerung der Nebenblätter zur Folge bei Phaseolus multiflorus u. a.

Sicher erwiesen ist eine korrelative Abhängigkeit für die Kotyledonen von Streptocarpus Wendlandi. Diese erreichen sehr ungleiche Größe, der eine bleibt klein, der andere wächst mächtig heran $\mathrm{zu}$ einem dem Boden aufliegenden Laubblatt. Wird er frühzeitig entfernt oder sein Wachstum durch

1) Reitsma, (Correlative Variabilität bij Plante, Amsterdamer Dissert. Rotterdam 1907) bezweifelt das Vorhandensein einer Korrelation, weil er fand, daß den großen Laubblättern auch große Nebenblätter entsprechen (ebenso auch bei Lathyrus Aphaca). - Daß bei kräftig ernährten Pflanzen sowohl Blätter als Nebenblätter sich stärker entwickeln als bei anderen, ist aber eigentlich selbstrerständlich. Gegen eine Korrelation beweist das gar nichts! Denn wenn ein Überfluß an Baustoffen vorhanden ist, kann natürlich ein Wettbewerb um diese nicht in Betracht kommen.

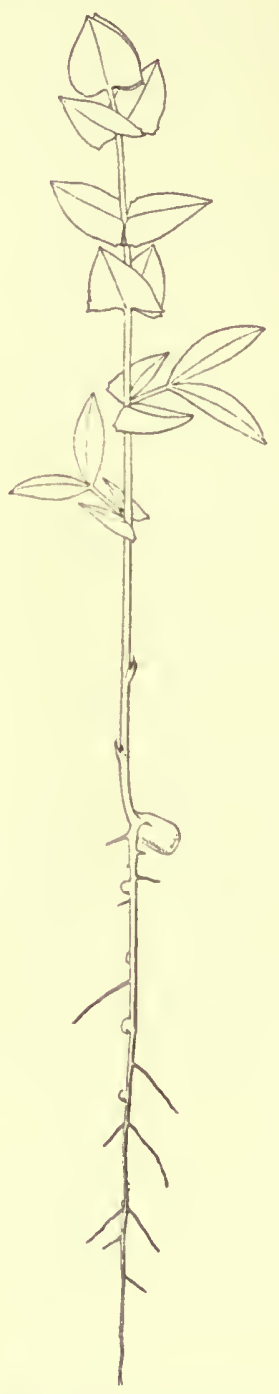

Fig. 417. Keimpflanze von Lathyrus Aphaca. Nur an den beiden untersten Laubblättern ist die Spreite entwickelt. Bei diesen Blättern sind die Nebenblätter viel kleiner als bei den folgenden, bei denen die Blattspreite rerkïmmert ist (weiter oben wird sie zur Ranke). 
Eingipsen gehenmt, so entwickelt sich dafür der andere, sonst zurückbleibende Kotyledon ${ }^{\mathbf{1}}$ ).

$\mathrm{Da} ß$ die Größe, welche ein Blatt erreicht, auch durch die Korrelation zu Sproßachsen bedingt sein kann. zeigt, wie ich früher hervorhob (S. I p. 236), das Verhalten mancher Schlingpflanzen, bei denen die rasche und starke Verlängerung der Internodien eine vorübergehende oder dauernde Hemmung der Blattentwicklung bedingt.

Auch das Kleinbleiben der Blätter etiolierter Sprosse ist, wenigstens in manchen Fällen, keine direkte Lichtwirkung. Läßt man an Sprossen von Phaseolus multiflorus, deren oberer Teil in einen dunklen Raum eingeführt wurde, nur ein Blatt stehen und entfernt frühzeitig alle Sproßvegetationspunkte, so erreicht das Blatt im Dunkeln dieselbe Größe; wie die am Licht befindlichen ${ }^{2}$ ).

Daß nicht nur die Größe, sondern auch die Lebensdauer der Blätter - ebenso wie in dem für Atropa angeführten Beispiel die der Sprosse durch Korrelation bedingt werden kann, zeigt die Tatsache, daß isolierte, als Stecklinge benutzte Blätter, wenn sie sich bewurzeln, eine viel längere Lebensdauer haben, als solche, die an der Pflanze bleiben. Schon T. A. KNight hat das für Mentha piperita nachgewiesen. Verf. hat Begoniablätter (B. Rex) mehr als zwei Jahre als Stecklinge am Leben gehalten, es ist dabei zweckmäßig, die rom Blatt gebildeten Adventivsprosse zu entfernen. Solche Blätter zeigen vielfach anatomische Veränderungen ${ }^{3}$ ) (z. B. sekundäres Dickenwachstum in den Leitbündeln der Blattstiele), die normal am festsitzenden Blatte nicht in die Erscheinung treten, weil die Baustoffe des Blattes in die Sproßachse übergeführt werden. Dieses wird also von der Ausnutzung aller seiner "Potenzen" durch den Verband mit anderen Organen verhindert.

Eine Korrelation zwischen den Blattorganen der Blüten hat man angenommen z. B. bei als den Schauapparate dienenden Randblüten vieler Kompositen, ferner bei Viburnum Opulus, Hydrangeaarten, wo die Blumenkrone (resp. bei Hydrangea der Kelch) mächtig vergrößert ist, die Staubblätter und Fruchtblätter aber funktionslos geworden sind oder ganz fehlen. Man dachte, daß hier ein direktes Kompensationsverhältnis vorliege, d. $h$. daß das Wachstum der Blumenkrone die Verkümmerung der Sporophylle bedingt. Eine vergleichende Betrachtung der verschiedenen Bliitenformen der Kompositen führt indes zu einem anderen Resultate, zu dem, daß eine solche Kompensation nicht vorliegt ${ }^{4}$ ) (vgl. auch p. 179).

Auch ist es sehr fraglich, ob eine solche vorhanden ist bei dem Verkümmern ganzer Blüten, wie wir es bei Muscari comosum, Celosia cristata (der fasziierten Gartenform), dem Blumenkohl i. a. finden. An den Blüten-

1) F. Hering, Über Wachstumskorrelationen infolge mechanischer Hemmung des Wachsens. Pringsh. Jahrb. XXIX, p. 142.

2) Jost, Über die Abhängigkeit des Laubblattes von seiner Assimilationstätigkeit. Pringsh. Jahrb. Bd. XXVII, Heft 3. Vgl. ferner betreffs der Etiolierungserscheinungen GodLewski, Zur Kenutnis der Ursachen der Formänderung etiolierter Pflanzen. Botan. Zeitg. 1878, p. $81 \mathrm{ff}$. Beim Tabak wird durch Entgipfeln und durch Entfernung der Seitentriebe die Größenentwicklung der Blätter bei der Kultur gefördert. Vgl. z. B. WoLLxy, Untersuchungen über künstliche Beeinflussung der inueren Wachstumsursachen. Forschungen auf dem Gebiete der Agrikulturphysik VIII. Bd. 2. Heft.

3) Vgl. auch KNy, Über die Einschaltung des Blattes in das Verzweigungssystem der Pflanze, Naturwissensch. Wochenschrift 1904, p. 369: LöHr, Beobachtungen und Untersuchungen an sproßlosen Blattstecklingen, Dissert. Bonn 1908 (daselbst weitere Literatur).

4) M. v. ÜxkÜLL-Gylcenband, Phylogenie der Blütenformen und der Geschlechterverteilung bei den Kompositen, Bibliotheca botanica Heft 52. Stuttgart 1901. 
ständen von Muscari comosum sind die oberen Blüten der Infloreszenz zum Schauapparat ausgebildet, ihr Stiel ist viel länger als bei den unteren unscheinbaren und blau gefärbt. Die Sporophylle der Blüten sind auf verschiedener Entwicklungshöhe verkümmert, ob infolge der Ausbildung des Stieles zum Schauapparat, wäre näher zu untersuchen. Ebenso finden wir in den Infloreszenzen des Blumenkohls, in denen die Blütenstiele abnorm fleischig verdickt sind, und in denen von Celosia, deren Infloreszenzachsen bandförmig verbreitert sind, zahlreiche verkümmerte Blüten neben normal ausgebildeten.

Die Liste ließe sich fortsetzen (erwähnt sei auch Rhus Cotinus), aber da kein experimenteller Beleg vorliegt, so handelt es sich doch nur um Vermutungen, ebenso wie bei den samenlosen Früchten von Ananas und Bananenkalturformen nicht nachgewiesen ist, ob die Verkiimmerung der Samen eine gesteigertere Entwicklung des Fruchtfleisches bedingt ${ }^{1}$ ). In anderen Fällen kann bei normal ausgebildeten Samenanlagen doch die Samenausbildung unterbleiben dadurch, daß die Samen von den Vegetationsorganen ausgehungert werden.

So findet Samenansatz bei Lilium candidum fast nie statt, bei anderen mit vegetativer Vermehrung ausgeriisteten Pflanzen, wie Ranunculus Ficaria, selten. Wie schon K. GESNER vor mehr als 200 Jahren gefunden hatte ${ }^{2}$ ), tritt aber bei Lilium an abgeschnittenen Blütenstengeln Samenansatz ein. Er unterbleibt an der Pflanze deshalb, weil die Baustoffe, welche sonst zur Samenbildung verwandt werden, in die Zwiebel strömen, wo sie zur Bildung von Brutzwiebeln - also ungeschlechtlichen Vermehrungsorganen - Verwendung finden. Auch bei Lachenalia luteola fand Lindemuth ${ }^{3}$ ) trotz künstlicher Bestäubung keinen Samenansatz, konnte einen solchen aber an abgeschnittenen Blütenstengeln erzielen. Dasselbe soll nach vax DEx Bors bei Ranunc. Ficaria der Fall sein ${ }^{4}$ ).

Bei Cochlearia Armoriacia gelang es $^{5}$ ) durch Ringelung der Wurzel (welche als Reservestoffbehälter dient) keimfähige Samen zu erzielen, während sonst deren Ausbildung sehr selten eintritt; eine Unterbrechung der peripherischen Leitungsbahnen wirkt also ebenso wie das Abschneiden des blühenden Sprosses bei den oben erwähnten Monokotylen. Möglicherweise sind alle diese Pflanzen, bei denen die Samenanlagen gegenüber den vegetativen Organen so schwache Anziehungszentren für Baustoffe sind, hybridogenen Ursprungs.

Der entgegengesetzte Fall, daß die Unterdrückung der Fortpflanzungsorgane (oder eine unvollkommene Ausbildung derselben) das Primäre ist, die Steigerung vegetativer Entwicklung das Sekundäre, findet sich z. B. bei manchen gefüllt blühenden Pflanzen. In der Umgebung Miinchens kommt Cardamine pratensis in großer Menge gefüllt blühend vor. Die Pflanzen vermehren sich massenhaft durch Brutknospen, die selbst aus den Spitzen der gefüllten Blüten sich entwickeln, dadurch hat diese Form,

1) Tischler, Über die Entwicklung der Samenanlagen in parthenokarpen Angiospermenfrüchten (Jahrb. für wiss. Bot. LII, 1912) fand bei einigen Formen von Musa sapientum abnorme Samenanlagen.

2) Vgl. Jost, Botan. Zeitung 1897 II, p. $17 \mathrm{ff}$.

3) Über Samenbildung an abgeschnittenen Blütenständen einiger sonst sterilen Pflanzenarten. Ber. der D. botan. Gesellsch. 14. Bd. 1896, p. 244.

4) M. VAN DEN BORN a pu faire fructifier le Lis blanc et la Ficaire en enlevant au premier les écailles du bulbe, à la seconde ses petits tnbercules basilaires. Belgique horticole 1863 p. 226.

5) Brezezisskr, Bulletin de l'académie de Cracau 1909, Nr. 7. 
welche die Samenbildung ganz eingebuißt hat ${ }^{1}$ ), teilweise die normale, samenbildende verdrängt, was allerdings wohl nur in einem so regenreichen Klima wie dem der oberbayerischen Hochebene möglich sein dïrfte.

Auch der Fall ${ }^{2}$ ), daß bei Isoëtes lacustris unter bestimmten Umständen die Sporangienbildung unterdrückt wird, dürfte insofern hierher gehören, als der Wegfall der Sporangienbildung größere Mengen von Baustoffen für die vegetativen Sprosse verfïgbar macht. Übrigens handelt es sich bei der Cardamine wie bei Isoëtis um Mutationen. Ebenso werden an den alternden Prothallien von Doodya caudata die Geschlechtsorgane abnorm, und nun tritt apogame Sprossung ein und vielleicht ist auch in anderen derartigen Fällen dies der Vorgang gewesen.

Von den qualitativen Beeinflussungen durch Korrelation seien hier zunächst die Richtungsverhältnisse genannt. Diese sind bedingt einmal durch die Reaktion auf äußere Reize (Geotropismus usw.), hauptsächlich aber auch durch Korrelation. Namentlich ist eine solche vorhanden, wenn an einer orthotropen Hauptachse plagiotrope Seitenachsen entspringen. Am einfachsten liegen die Verhältnisse bei den Wurzeln.

Einjährige dikotyle Pflanzen pflegen ein Wurzelsystem zu besitzen, das aus einer orthotropen Hauptwurzel und plagiotropen Seitenwurzeln besteht. Indes ist die Wachstumsrichtung der Seitenwurzeln nicht ein für allemal bestimmt: entfernt man die Spitze der Hauptwurzel unterhalb der Anlage einer Seitenwurzel, so stellt sich diese Seitenwurzel in die Verlängerung der Hauptwurzel ein und nimmt deren Eigenschaften an, d. h. Wachstums- und Verzweigungsfähigkeit werden gesteigert.

Ähnliches gilt für die Beziehungen zwischen orthotropen Haupt- und plagiotropen Seitensprossen; verloren gegangene Gipfel werden durch Aufrichten der Seitensprosse bei Picea excelsa z. B. leicht ersetzt ${ }^{3}$ ). Ebenso können die Kurztriebe von Pinus veranlaßt werden sich zu Langtrieben $\mathrm{zu}$ entwickeln, wenn letztere verloren gegangen sind.

Ein besonders plastisches Material liefern die Kartoffeln, an denen schon KNight eine Anzahl sehr interessanter Experimente ausführte. Die Kartoffelknollen sind zu Reservestoffbehältern umgebildete unterirdische Seitensprosse. Ihre Umbildung erfolgt unter dem Einflusse der in den Blättern gebildeten, nach abwärts wandernden Stoffe. Schneidet man von einer Kartoffelpflanze, ehe die Knollenbildung begonnen hat, die oberirdischen Sprosse ab, so wachsen die unterirdischen zu iiber den Boden tretenden Laubsprossen aus. Sie sind nichts anderes als Laubsprosse, welche durch ihre Stellung im ganzen Sproßsystem zu unterirdischem Leben genötigt und später durch eine weitere stoffliche Beeinflussung von seiten der oberirdischen Laubsprosse zu Knollen umgebildet werden. Fällt diese doppelte Beeinflussung weg, so nehmen sie ihren ursprünglichen Charakter wieder an und ersetzen zugleich die verloren gegangenen Organe.

Man kann auch oberirdische Sprosse, wie KNIGHT gezeigt hat, zur

1) Vgl. Goeber, Zur Biologie von Cardamine pratensis, Biol. Centralblatt, 1906. Auch bei der Normalform können sich Adrentirsprosse auf den Blättern bilden; beim Wegfall der Samenbildung ist dazu aber eine größere Menge von Baumaterial verfügbar. Beybrinck (Nederl. Kruidkundig Archief II Ser. 3, p. 468) fand an Pflanzen. deren Infloreszenzen getötet worden waren, eine weit größere Zahl blattbürtiger Adventivknospen als bei normal bliihenden.

$\left.{ }^{2}\right)$ Über Sproßbildung auf Isoëtesblättern. Botan. Zeitung 1879, p. 1.

${ }^{3}$ ) Vgl. Einleitung in die exper. Morphologie. 
Knollenbildung reranlassen. Es geschieht dies, indem man die unterirdischen Ausläufer früh entfernt, oder ihre Verbindung mit den oberirdischen Teilen beeinträchtigt. KNIGHT gibt sogar an, daß es ihm gelungen sei, die Bildung der Knollen an der Spitze von oberirdischen Sprossen zu veranlassen, den Punkten also, welche von dem Orte der normalen Knollenbildung am weitesten entfernt sind ${ }^{1}$ ). Für die Knollenbildung kommt weiter in Betracht, daß sie durch Lichtmangel begïnstigt wird.

Ganz ebenso wie die Knollenbildung verhält sich auch die der Zweigdornen, bei denen sich die Sproßachse unter Verkümmerung der Blätter und Aufhören des Längenwachstums zu einem Dorn gestaltet. Schneidet man den Ast, dessen Seitenknospe sich bei normaler Vegetation zu einem Dorn entwickelt hätte, ab, so wird sie zu einem gewöhnlichen Laubsproß, nicht zu einem Dorn.

Korrelationserscheinungen sind in einer Anzahl von Fällen auch als maßgebend für die Gestaltung der Blätter erkannt. Die Sporoplylle ron Gefäßkryptogamen werden im speziellen Teile besprochen werden. Hier sei nur erwälnt, daß sie von den Laubblättern vielfach abweichen in Gestalt, Größe und Richtung. Diese Abweichnngen sind der Hauptsache nach direkt bedingt durch das Auftreten der Sporangien ${ }^{2}$ ) an den Sporophyllen. Diese stimmen ursprünglich ganz mit den Laubblattanlagen überein, das Auftreten der Sporangien bedingt die von der anderer Laubblattanlagen abweichende Entwicklung. Daß eine solche Korrelation stattfindet, kann man schon durch vergleichende Beobachtungen sicher erschließen.

Dazu kommt der an Onoclea Struthiopteris geführte experimentelle Beweis ${ }^{3}$ ). Durch Wegnahme der Laubblätter kann man die Sporangienbildung ganz oder teilweise verhindern und die Sporophyllanlagen zur Ausbildung als Laubblätter nötigen ${ }^{4}$ ).

Ganz so ist es bei den Knospenschuppen. Diese, als Schutzorgane für die Knospen während deren Ruheperiode dienend, weichen von den Laubblättern derselben Pflanze an Gestalt und Größe bedeutend ab, sie haben auch, wo die Laubblätter reich gegliedert sind, doch nur die Gestalt einfacher Schuppen, welche fuir ihre Aufgabe, den Knospen als „Decken“ zu dienen, die geeignetste ist. Die Umbildung der Laubblatt

1) Vgl. auch DE Candolre, Pflanzenphysiologie I, p. 130 und Vöchting, Über die Bildung der Knollen. Bibl. bot. Heft 4. Kassel 1867.

2) Diese Beeinflussung tritt rielfach schon sehr früh ein; ehe die Sporangien als solche sichtbar sind, treten schon die stofflichen Veränderungen ein, die zu ibrer Bildung führen, und schon diese Veränderungen können die Gestaltung der Blattanlage beeinflussen.

$\left.{ }^{3}\right)$ GosBzr, Über künstliche Vergrünung von Farnsporophyllen. Ber. der D. botan. Gesellsch. Bd. V 1887. Abbildung in Annals of botany Vol. VI Pl. XXII.

${ }^{4}$ ) Eine Korrelation findet zwischen der Sporangienbildung und der Ausbildung der Blätter (und der ganzen, mit Sporophyllen besetzten Sprosse) auch bei den Selaginellen statt. Bei Selaginella Lyalli z. B. können die Sporangienähren (in denen die Blätter anders ausgebildet sind als die vegetativen) sich unter Verkümmerung der Sporangien zu vegetativen Sprossen weiter entwickeln. BEHrens hat (Über Regeneration bei Sela. ginella. Flora 84. Bd., p. 159) gezeigt, daß dies auch bei anderen Arten regelmäßig erfolgt, wenn man Sporangienstände als Stecklinge benutzt. Er meint, daß das Answachsen der Sproßspitze hier das Verkümmern der sporangien bedinge. Mir scheint es aber näher liegend, anzunehmen, daß durch das Abschneiden eine Störung in der Ausbildung der Sporangien eintreten mußte, welche dem Sproß dann die vegetative Weiterentwicklung gestattete. Sporangienbildung tritt nur ein, wenn eine Anhäufung organischer Substanzen (namentlich ron Kohlehydrateu) stattfindet. Bei einem abgeschnittenen Sporangienstand ist die Zufuhr organischer Substanzen abgeschnitten, die Atmung verringert die vorhandene Menge und so treten die für vegetative Ausbildung giinstigen Bedingnngen ein. 
anlagen zu Knospenschuppen findet auf dreierlei Art statt: meist geht die Knospenschuppe hervor aus dem basalen Teile der Blattanlage, dem Blattgrunde, während die Spreitenanlage verkümmert, der Stiel nicht gebildet wird; oder es verkümmert die Spreitenanlage und die Nebenblätter entwickeln sich zu Knospenschuppen, oder endlich das ganze Blatt wird zur Knospendecke umgebildet. In allen drei Fällen ließ sich nun zeigen, daß man die Umbildung zur Knospenschuppe verhindern kann. Es geschah dies dadurch, daß die eigentlich für das nächste Jahr bestimmten Knospen schon im Jahre ihrer Anlegung zum Austreiben gebracht wurden. Bald nach dem Zeitpunkt, in welchem dies geschah, bildeten sich dann statt der Knospendecken Laubblätter oder, wenn die Umbildung schon begonnen hatte, Mittelbildungen zwischen Knospenschuppen und Laubblättern aus.

Den angeführten Beispielen würde sich die Besprechung der Vorgänge, die bei der Regeneration eintreten, anzuschließen haben, und tatsächlich gehören einige der oben besprochenen schon in dies Kapitel. Auch bei den übrigen. Regenerationsvorgängen handelt es sich um eine Unterbrechung oder Änderung der Korrelationen. Es mag indes auf die Darstellung in des Verfassers „Einleitung in die experimentelle Morphologie der Pflanzen" verwiesen werden.

Daß bei Korrelationsstörungen auch a b n o r m e Gestaltungsverhältnisse auftreten können, wurde in einem früheren Abschnitt (p. 333) besprochen.

\section{Kapitel.}

\section{Die Beeinflussung der Symmetrie und der Organausbildung durch Aufsenbedingungen.}

\section{§ 5. Innere Ursachen der Dorsiventralität.}

Dorsiventrale Organe nehmen im Raume meist eine andere Lage ein als radiäre, jene sind häufig plagiotrop, diese meist orthotrop (vgl. p. 187). Es lag deshalb nahe, auch die von der radiärer Organe abweichende Ausbildung der dorsiventralen Pflanzenteile den Außenbedingungen zuzuschreiben. In dem Abschnitt über Symmetrie wurde auch schon eine Anzahl von Beispielen angefïhrt, welche diese Anschauung unterstiitzen.

Indes ist nicht $\mathrm{zu}$ vergessen, daß schon durch die Art der Zellteilung oder der ersten Anlegung am Vegetationspunkt sowie durch die Einwirkung des Mutterorgans auf eine Neubildung dorsiventrale Ausbildung der letzteren gegeben sein kann; ein Zusammenwirken innerer und äußerer Faktoren ist vielfach für das Auftreten von Dorsiventralität maßgebend.

Dorsiventral sind z. B. die „,bohnenförmigen" Sporen mancher Farne, sowie die entsprechend gestalteten Mikrosporen vieler Samenpflanzen. Diese Zellen erhalten ihre Gestalt durch die (in ,inneren“ Symmetrieverhältnissen begründete) Anordnung der Teilungswände in den kugelförmigen Sporenmutterzellen. Bilden sich in diesen nach der ersten Halbierungswand zwei auf lezterer rechtwinklig stehende Teilungswände, so müssen vier bohnenförmige Tochterzellen entstehen; diese behalten ihre Dorsiventralität, wenn sie nur mäßig sich abrunden, ohne sich zur Kugelgestalt zu ergänzen ${ }^{1}$ ).

1) Es kommt also in Betracht wieweit die Gestalt des Mntterorgans im embryonalen Zustand regeneriert werden kann. 
Hier sehen wir also die dorsiventrale Ausbildung lediglich aus inneren Gründen auftreten. Es ist offenbar ein Zusammenhang vorhanden zwischen der Fähigkeit einer Tochterzelle, die Gestalt der Mutterzelle wieder anzunehmen (also die Gestalt des Mutterorgans zu regenerieren) und ihrem inneren Aufbau. Dasselbe ergibt sich aus einer Betrachtung der Verzweigung. Denken wir uns einen radiären (oder bilateralen) Thallus, der eine Scheitelzelle in Gestalt einer bikonvexen Linse besitzt, die sich bei der dichotomen Verzweigung (ähnlich wie die von Dictyota) durch eine Längswand teilt (Fig. $63 \mathrm{~A}$ ), so entstehen dabei aus der radiären Linse zwei anders gestaltete dorsiventrale Teilstiicke (- Innenseite verschieden von der Außenseite -); die sich zu radiüren Gebilden erst beim weiteren Wachstum wieder ergänzen oder umordnen. Beide Teilstücke sind hier gleich und deshalb auch mit gleichem Regenerationsvermögen begabt. Ist aber eines der Teilstïcke schwächer, so wird ihm das Aufgeben der Dorsiventralität schwerer fallen als dem anderen, es kann sie also von Anfang an beibehalten.

Oder gehen wir aus von dem radiären Sproß einer höheren Pflanze, der im fertigen Zustand fünf, gleichmäßig verteilte Leitbündel besitzen soll. Wenn an dem Vegetationspunkt ein seitliches Organ (durch „Teilung“ des embryonalen Gewebes) entsteht, welches zwei Leitbündel erhält, wïhrend dem anderen Stück drei verbleiben, so wird das stärkere, mehr embryonales Gewebe enthaltende) Stück als das besser ernährte und in der Längsrichtung des Sprosses verbleibende sich (im embryonalen Zustand) leichter $\mathrm{zu}$ einem mit fünf Leitbiindeln versehenen ergänzen als das schwächere. Letzteres bleibt also dorsiventral (was es durch die „Teilung" wurde), letzteres wird radiär oder behält die radiäre Ausbildung auch von Anfang an.

Tatsächlich finden wir in manchen Fällen deutlich eine Beziehung zwischen Symmetrie und Ernährung, wenn diese auch meist nur in der allerallgemeinsten Weise bekannt oder indirekt erschlossen ist.

Bei Goldfussia glomerata (vgl. p. 256) werden kräftige Sprosse, namentlich solche, die keine Seitensprosse entwickeln, radiär, während sonst dorsiventrale Ausbildung eintritt. BosHaR'T konnte durch Entfernung der Seitenknospen ein Radiürwerden der Sprosse (was hier zugleich einen Rückschlag auf die Jugendform darstellt) herbeiführen. Es dürfte sich dabei darum handeln, daß bei Entfernung der Seitenknospen die Hauptachse mehr Assimilate der Blätter erhält, als sonst und nun sich radiär ausbildet.

Ähnlich bei Commelinaceen $\left.{ }^{1}\right)$ : Hier ist häufig der Hauptsproß radiär, die Seitensprosse dagegen sind dorsiventral (Fig. 219), so z. B. bei Cyanotis kewensis. An blühbaren Pflanzen entstanden hier radiäre Seitensprosse. Es ist anzunehmen, daß blïhende Pflanzen reicher an organischen Baumaterialen sind als nichtblühende, und daß damit das Auftreten radiärer Sprosse im Zusammenhang steht.

Auch die Gattung Selaginella zeigt uns analoge Erscheinungen. Bei den meisten Selaginellen zeigt der vegetative Sproß die früher erörterte Dorsiventralität. Bei den Blüten vieler Arten ist er radiär, auch hier offenbar infolge der Anhäufung organischer Substanz in den Vegetationspunkten. Benutzt man die Blüten als Stecklinge (wobei die organischen Baustoffe großenteils verbraucht werden), so wachsen sie als

1) J. Clark. Beiträge zur Morphologie der Commelinaceen, Flora 93 (1904). 
dorsicentrale Sprosse weiter. Die Natur hat mit den Selaginellen auch Experimente ausgeführt, welche auf dasselbe hindeuten.

Bei Sel. grandis (vgl. p. 112 und Fig. 106 u. 107) treten in den Sproßgabeln kleine Ruheknospen auf, die zunächst wenig wachsen, es kann also in ihnen eine Baustoffanhäufung stattfinden: sie sind radiär - bei der Weiterentwicklung werden sie dorsiventral wie die übrigen vegetativen Sprosse.

Bei S. pentagona (Fig. 418) treten an den Sprossen, die vierzeilig anisophyll sind, Gallensprosse auf, die sechszeilig und isophyll sind. In den Gallen findet durch den Reiz des Gallentieres Stoffanhäufung statt, die Isophyllie wird hier wie in den oben erwähnten Fällen durch Ernährungsverhältnisse bedingt.

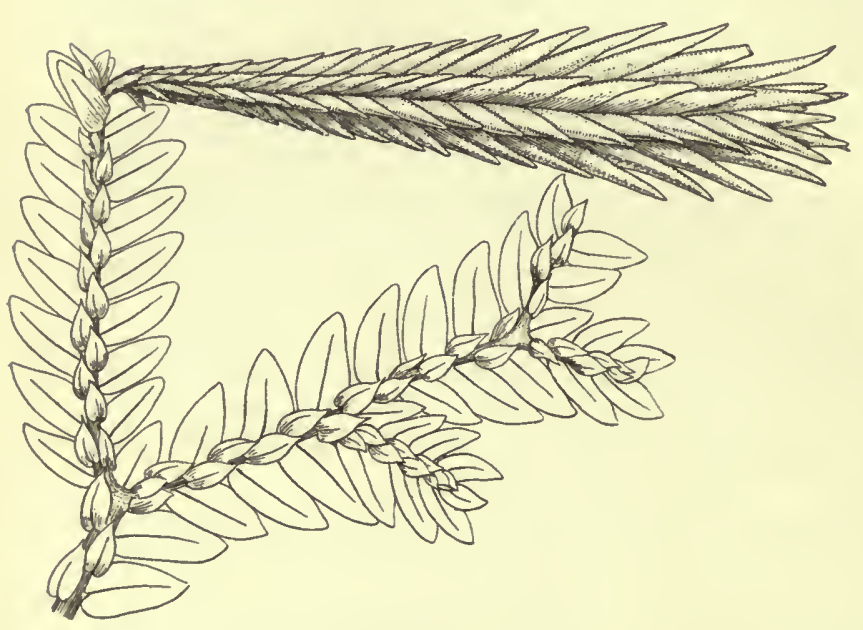

Fig. 418.

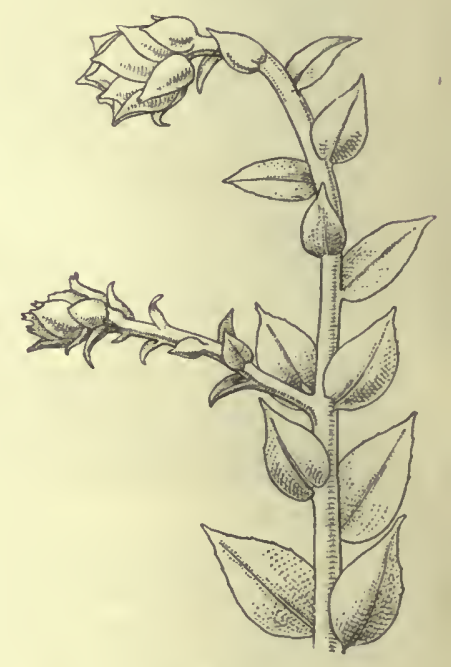

Fig. 419.

Fig. 418. Selaginella pentagona mit Gallensproß. $4 \times$

Fig. 419. Selaginella bulbifera. Sproßspitzen, die - wahrscheinlich negativ heliotropisch - nach unten wachsen, schwellen zu Knöllchen an, die ausdauern, während die oberirdische Pflanze abstirbt.

Die Stoffanhäufung wirkt also nach unserer Annahme auf den Vegetationspunkt derart ein, daß er seine dorsiventrale Beschaffenheit aufgibt und radiär wird. Es bildet sich (wie STRASBurger gezeigt hat) eine dreiseitige Scheitelzelle und erzeugt alternierende dreizählige Wirtel. Der Fall ist von besonderem Interesse, weil er zeigt, wie der Vegetationspunkt - ganz unabhängig von allen Anpassungsfragen - auf bestimmte Reize hin mit Symmetrieveränderungen reagiert und ebenso, daß er zu Gestaltungen befähigt ist, welche im normalen Verlauf der Vegetation gar nicht hervortreten - es ist keine Selaginella bekannt, welche dreizählige Wirtel produziert, wenn wir auch von anderen Pflanzen wissen, daß bei kräftiger Ernährung dreizählige statt zweizähliger Wirtel auftreten.

Als letztes Beispiel sei Selag. bulbifera angeführt. Sie hat ihren Namen daher, daß die Sproßenden zu Knöllchen anschwellen, welche übrig bleiben und später sich weiter entwickeln, während die alte Pflanze zugrunde geht (Fig. 419), ähnlich wie dies bei Sel. tuberosum der Fall ist, nur daß Sel. bulbifera ihre Knollen oberirdisch bildet. An diesen Knöllchen, 
in denen eine Anhäufung ron Reservestoffen eintritt, war keine Anisophyllie mehr sichtbar ${ }^{1}$ ).

Alle die angeführten „Experimente“ mit Selaginella (Blüten, Mittelsprosse von S. grandis, Gallensprosse von S. pentagona, Knöllchensprosse von S. bulbifera) zeigen also ein übereinstimnendes Verhalten.

Gewi $B$ ist die Annahme, daß das Radiärwerden des Vegetationspunktes in den genannten Fällen durch eine größere Zufuhr organischer Substanzen bedingt werde, zunächst nur eine - wie zu zeigen versucht wurde, aus mehr als einem Grunde wahrscheinliche - Hypothese. Aber sie ermöglicht einen gemeinsamen Gesichtspunkt für sonst scheinbar ganz verschiedene Erscheinungen und läßt namentlich auch verständlich erscheinen, weshalb gerade Pflanzen, die an schwächer beleuchteten Standorten wachsen (an denen die Anhäufung organischer Substanzen weniger leicht ist), zur. Ausbildung dorsiventraler Assimilationssprosse neigen.

Daß diese Ausbildung auch da, wo sie jetzt aus ,inneren Gründen“" erfolgt, ursprünglich unter dem Einfluß der Außenwelt entstand, erscheint wahrscheinlich (vgl. Einleitung § 11).

Jedenfalls ist aber bei Untersuchungen über die Beeinflussung der Dorsiventralität stets die Gestalt zu berïcksichtigen, welche das betreffende Organ bei seiner Entstehung aufweist.

Das ist nicht immer geschehen bei Untersuchungen, welche die $\mathrm{Ab}$ hängigkeit der Symmetrie von äußeren Faktoren nachzuweisen versuchten.

\section{§ 6. Die Angaben von RICôyE und PEIRce iiber Beeinflussung der Symmetrie durch äubere Faktoren.}

RICôME ${ }^{2}$ ) hat das Zustandekommen des dorsiventralen Baues mancher Infloreszenzstiele und Blütenstiele näher untersucht und kommt dabei zu dem Resultate, daß die Dorsiventralität aus dem radiären Bau sich ableite, durch die Einwirkung von Licht und Schwerkraft, daß aber auch andere Faktoren mitwirken können, so der "Bau der Hauptachse, Druck uud Erblichkeit".

Es wäre außerordentlich erwünscht, wenn in der Tat hier Objekte vorliegen würden, welche ein deutliche Beeinflussung der Dorsiventralität durch äußere Faktoren erkennen lassen. Indes bedürfen die Angaben RICôMES kritischer Nachprüfung. Vor allem macht der Autor keine Mitteilung darüber, welche Struktur seine Objekte vor Beginn des Versuchs hatten (was durch Vergleich mit anderen Pflanzen leicht festgestellt werden kann). Nehmen wir ein Beispiel.

Die äußeren Stiele der zusammengesetzten Dolden von Heracleum Sphon-

1) Wenigstens trat sie änßerlich nicht hervor. Da die Pflanze durch Unachtsamkeit unserem Garten später wieder verloren ging, so kann ich iiber das Verhalten des Knöllchenvegetationspunktes nichts aussagen. Die Knöllchen bildeten sich an den Enden kleinblätteriger, etioliert aussehender Sprosse. Ein Zweig, der abgeschnitten und als Steckling unter einer Glasglocke kultiviert worden war (16. X.), hatte am 22. X. am Ende einiger nach abwärts wachsender Sprosse schon Knöllchen, während diese an anderen, ungestört wachsenden Pflanzen zu dieser Zeit noch nicht aufgetreten waren. Die Wachstumshemmung hatte also offeubar die Knöllchenbildung begiinstigt. BAKER (fernallies p. 86) zieht S. bulbifera zu. radiata, incies ist die Abgrenzung der Arten in diesem Buche bekanntlich eine wenig sichere.

2) H. Ricone, Symmetrie des rameaux floraux Ann. des scienc. nat. VIII Sér. t. VII (1898), p. 293.

Goebel, Organographie der Pflanzen. 2. Aufl. Allgem. Teil. 
dylium sind dorsiventral. Sie zeigen im Umriß meist 6 oder 8 Rippen von denen 3 auf der adaxialen (Oberseite) einander stark genähert sind. Diese Rippen haben dickere Kollenchymbelege als die auf der Unterseite liegenden flachen. Zwischen ihnen ist chlorophyllhaltiges Gewebe viel stärker entwickelt als auf der Unterseite. Nun zeigte mir die Untersuchung einer noch in der Blattscheide eingeschlossenen Infloreszenz (Fig. 420), bei welcher die einzelnen Zweige noch alle in a ufechter Lage aneinander gepreßt sind, daß die dorsiventrale Struktur schon in diesem Stadium an den äußeren Doldenstielen der Hauptsache nach vorhanden war. Sie kann also durch äußere Einflüsse nicht veranlaßt sein - ebensowenig ist sie umkehrbar. Höchstens kann es sich um eine Verstärkung oder Verminderung der schon vorhandenen Dorsiventralität handeln. So kann das Licht eine stärkere Entwicklung des chlorophyllhaltigen Gewebes bedingen (bei Beleuchtung von unten auch auf der abaxialen Seite). Ob die stärkere Entwicklung des Kollenchyms auf der Oberseite auf "Geotrophie" oder "Kamptotrophie" beruht, ist zu untersuchen. Wenn aber RICôME sagt: „La radiation solaire fait apparaittre une face de lumière et une face de l'ombre. La pesanteur détermine la formation d'une face du haut et d'une face de bas...", so kann ich das nicht für erwiesen halten, weil,

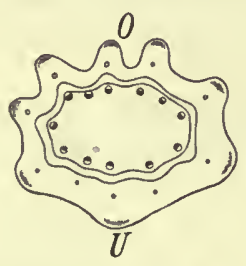

Fig. 420. Heracleum Sphondylium. Querschnitt durch einen seitlichen noch vollständig aufgerichteten Infloreszenzstiel (aus einer noch innerhalb der Blattscheide eingeschlossenen Infloreszenz). $O$ Ober-, $U$ Unterseite.

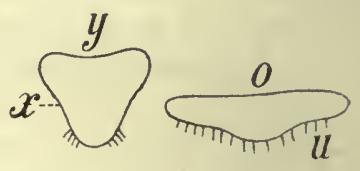

Fig. 421. Schema für die Gestaltung eines (im Vertikalschnitt gedachten) Anthocerosthallus, vgl. Text.

wie erwähnt, die äußeren Doldenstiele eine deutlich verschiedene Ober- und Unterseite schon zu einer Zeit haben, in der weder Licht noch Schwerkraft eingewirkt haben können. Dabei handelt es sich nur um die Frage nach den jetzt stattfindenden Einwirkungen, eine andere Frage wäre die, ob man die Dorsiventralität hier als ursprünglich durch äußere Faktoren induziert und später erblich geworden betrachten will.

Einen besonders beachtenswerten Fall von Beeinflussung der Gestaltung durch das Licht glaubte Peirce ${ }^{1}$ ) bei Anthocerosarten (A. Pearsoni, A. fusiformis) gefunden zu haben. Er säte Sporen auf dem Klinostaten aus und erhielt Pflanzen, deren Thallus nicht flach auf dem Substrat ausgebreitet war (wie sonst), sondern vasenförmig mit konkav vertieftem Oberende gestaltet war, während an der Basis ringsum Rhizoiden standen, also im Längsschnitt etwa so wie Fig. 421 links aussieht. PEIRCE meint, statt eines dorsiventralen einen radiären Thallus erhalten zu haben. Das würde aber nur zutreffen, wenn die mit $x$ bezeichnete Außenfläche der $\mathrm{O}$ berseite 0 eines Thallus (Fig. 421 rechts) entsprechen würde. Das ist aber offenbar nicht der Fall, vielmehr entspricht nur $y$ der Oberseite, $x$ der Unterseite, an welcher sich nur nach der Basis zu Rhizoiden entwickelt haben. Weiter oben unterbleibt deren Entwicklung, sei es in Folge der Einwirkung von Licht, Trockenheit oder aus anderen Gründen. Daß dem so ist, ergibt sich aus Perrce's Fig. 9, welche auf der Seite $x$ eine 
Nostockolonie zeigt, diese treten bekanntlich nur auf der Unter seite auf. Die Vegetationspunkte liegen offenbar am Rande der vertieften Oberseite. Meiner Ansicht nach hat PEIrce (soweit sich aus seiner Beschreibung - die über die Gestaltung seiner Versuchspflanzen sehr wenig aussagt - entnehmen läßt) nur gefunden, daß die genannten Anthocerosarten unter abnormen $\mathrm{Be}$ leuchtungsverhältnissen ein gesteigertes Wachstum der Unter-, ein vermindertes der Oberseite zeigen. Wahrscheinlich würde man dasselbe Resultat bei schwacher Beleuchtung auch ohne Klinostaten erhalten.

Im folgenden soll an einer Reihe ron Beispielen gezeigt werden, wieweit die Beeinflussung dorsiventraler Ausbildung durch äußere Faktoren sichergestellt ist.

\section{$\S 7$. Einseitige Ausbildung der Fruchtkörper von Pilzen.}

Bei den Pilzen sind es die Fruchtkörper, deren Symmetrieverhältnisse großes Interesse darbieten.

Es kommen sowohl radiäre als dorsiventrale Fruchtkörper vor.

1. Bei den Askomyceten ist die Ausbildung der Fruchtkörper (wenn wir von heliotropischen Krümmungen, wie sie z. B. die SordariaPerithecien ausführen können, absehen) eine typisch radiäre.

Fig. 422.

Dorsicentrale $(I, I I)$ und radiäre

Fruchtkörper zweier Askomyceten, $1 / 2$ nat. Gr. I und $I I$ Otidia leporina, III Peziza sp.
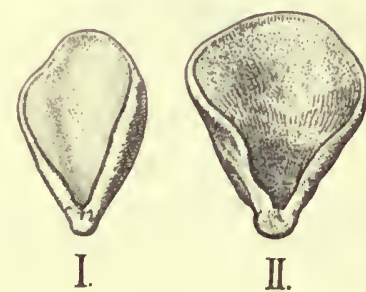

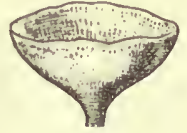

III.

So ist in Fig. 422 III von einem Askomyceten, Peziza, die gewöhnliche, schüsselförmige, radiäre Gestaltung der Fruchtkörper abgebildet. Denken wir uns, daß an der Fruchtkörperanlage sehr frühzeitig eine Randstelle des Bechers im Wachstum zurückbleibt, während der übrige Teil weiter wächst und dabei eine aufrechte Lage annimmt, so erhalten wir die merkwürdigen ohrenförmigen Fruchtkörper von Otidia. Die Verschiedenheiten beider Fruchtkörper entsprechen ganz denen zwischen einer Röhrenblüte und einer Zungenblüte bei einer Komposite (Fig. 422 II, III). Die Asci stehen bei Otidia ebenso wie bei Peziza rechtwinklig zur Oberfläche, sie sind also nicht geotropisch, sondern bei Peziza vertikal, bei Otidia annähernd horizontal gestellt. Hält man diese Fruchtkörper unter einer Glasglocke und hebt diese $a b$, so werden die Sporen als feine Wölkchen abgeschleudert. Diese werden durch Konvektionsströme der Luft sofort nach oben geführt, was durch die Form des Fruchtkörpers wohl begünstigt wird.

Ob die einseitige Entwicklung (bzw. deren Ort) durch innere oder äußere Faktoren hervorgerufen wird, ist nicht untersucht, indes sind radiäre Otidiafruchtkörper meines Wissens nicht bekannt; sie wären aber zu erwarten, wenn das Auftreten dorsiventraler nur von zufälligen Außenbedingungen abhängen würde. Daher ist wohl anzunehmen, daß die einseitige Entwicklung aus ,inneren“ Gründen erfolgt, was nicht ausschließt, 
daß die Lage der sich stärker entwickelnden Seite des Fruchtkörpers durch Außenbedingungen bestimmt wird.

2. Der "Typus" der Fruchtkörper höherer Hymenomyceten ${ }^{1}$ ) ist der eines „Hutes", der auf seiner Mitte in den Stiel iibergeht und auf seiner Unterseite das Hymenium trägt (Fig. 423 rechts); derartige Fruchtkörper sind also allseitig, radiär ausgebildet. Andere dagegen und zwar speziell die einiger holzbewohnenden Agaricineen und Polyporeen sind einseitig entwickelt (Fig. 423 links), teils mit, teils ohne Stiel. Es kann keinem Zweifel unterliegen, daß diese einseitige Entwicklung von der radiären abgeleitet ist, zumal man es bei manchen (vielleicht allen) Formen in der Hand hat, entweder einen allseitig oder einen einseitig entwickelten Fruchtkörper auftreten zu lassen. Zunächst sei das Verhalten einiger Polyporeen erwähnt, deren stiellose Fruchtkörper einseitig ausgebildet $\left.\sin ^{2}\right)$.
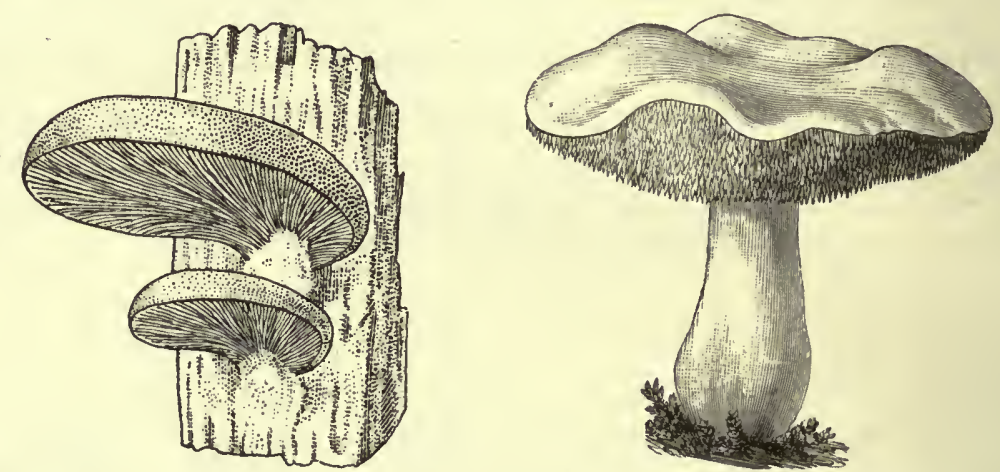

Fig. 423. Links Agaricus (Pleurotus) nidnlans (nach Hennings) mit einseitigen anf einem Baum wachsenden Fruchtkörpern. Rechts radiärer auf Erde wachsender Fruchtkörper von Hydnum repandum. (Lehrb.)

Das Hymenium an dem Fruchtkörper der meisten Hymenomyceten ${ }^{3}$ ) befindet sich auf dessen Unterseite als Überzug der Röhren, Lamellen oder anderer die Oberfläche vergrößernder Vorsprïnge. Wie aus den schönen Untersuchungen BuLLER's hervorgeht, ist dies die Lage, die für die Sporenverbreitung am günstigsten ist.

Betrachten wir z. B. einen Polyporeenfruchtkörper, bei welchem das Hymenium die röhrenförmigen Vertiefungen - sie sollen hier kurz als Röhren bezeichnet werden - auf der Unterseite bekleidet, so sehen wir, daß die Hymenialseite stets nach unten gekehft ist, und zwar in horizontaler Lage. Diese wird bei den ungestielten konsolenförmigen Fruchtkörpern von Polyporus fomentarius u. a., wie sie an Baumstämmen vielfach auftreten, von Anfang an eingenommen, bei den gestielten (die sich übrigens nicht alle gleich verhalten) bedingen bei jeder Lagenveränderung negativ

1) Auf die allgemeine Seite des Problems hat wohl zuerst Herbert Spencer hingewiesen (Principles of biology, Vol. II. 1866).

2) Im folgenden sind die Resultate von Untersuchungen mitgeteilt, welche Herr Dr. JaMes WeIr auf meine Veranlassung vor einiger Zeit im Münchener botanischen Institut ausführte. Er hatte die Freundlichkeit, mir seine Aufzeichnungen und Skizzen zur Verfügung zu stellen. Sie sollen später ausführlicher veröffentlicht werden. Vgl. namentlich auch A. H. R. Bolr.ER, Researches on fungi. London 19 ()9. mans.

3) Nit Ausnahme z. B. der Clavariacen, einiger Hydneen und von Merulius lacri- 
geotropische Krümmungen des Stiels und transversal geotropische des Hutes $^{1}$ ), daß die horizontale Lage der Hymenialseite wieder eingenommen wird. Bei den ungestielten Fruchtkörpern tritt besonders deutlich hervor, daß die Hymenialröhren selbst sich stets in der Richtung der Schwerkraft ausbilden: Fig. 424 stellt z. B. schematisch die Röhrenbildung eines Fruchtkörpers dar, dessen Lage zweimal verändert wurde. Es bilden sich bei jeder Lagenveränderung am Hymenium zunächst sterile Hyphen, aus denen dann ein der neuen Lage entsprechend orientiertes Röhrensystem hervorgeht. Dieses entwickelt sich also immer in der Lotlinie. Indes könnte man dabei, da das Licht einseitig (auf die Oberfläche) einwirkt, auch an eine Lichtwirkung denken. Die Versuche haben aber ergeben, daß das Licht zwar eine Bedingung für das Auftreten des Hymeniums darstellt, die Orientierung der Hymenialfläche aber lediglich durch die Schwerkraft bedingt wird.

Fig. 424. Polyporus fomentarius (nach WeIR). Fruchtkörper, dessen Lage zweimal geändert wurde. Die Pfeile bezeichuen jeweils die Vertikalstellung.

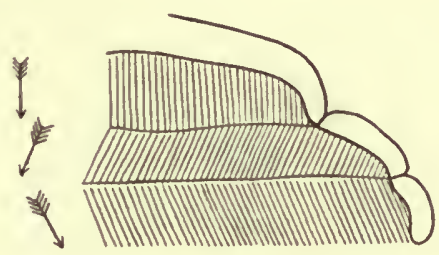

Die Fruchtkörper von Polystictus hirsutus haben eine „haarige“ sterile Oberseite, die Unterseite wird vom Hymenium eingenommen. Dreht man den Fruchtkörper mit seinem Substrat um $180^{\circ}$, so bildet die frühere behaarte Oberseite zunächst sterile Hyphen, dann ein Hymenium, die frühere Hymenialfläche dagegen "Haare" - der Fruchtkörper hat also infolge der Lagenveränderung seine Dorsiventralität umgekehrt ${ }^{2}$ ). Andere Hymenomyceten mit dünnen Fruchtkörpern wie Stereum Coryli und Schizophyllum commune suchen beim Umkehren durch Krümmung die Flächen in die richtige Lage zu bringen.

Ein besonders günstiges Objekt für Versuche stellen die großen. derben und langlebigen Fruchtkörper von Polyporus fomentarius u. a. dar. Sie sind oben bedeckt von einer festen, für Wasser undurchlässigen, von toten Hyphen gebildeten Kruste, unten befindet sich das Röhrenhymenium. Der Fruchtkörper ist durch starkes Regenerationsvermögen ausgezeichnet. Entfernt man das Hymenium auf der Unterseite, so bildet sich ein neues. Ebenso kann die Oberseite regeneriert werden. Man kann auch einen Fruchtkörper abnehmen und auf ein anderes Substrat transplantieren, wo er weiterwächst. Die Hymenialseite kann auch leicht zu vegetativer Entwicklung gebracht werden. Bringt man z. B. auf der Unterseite eine mit Wasser gefüllte Röhre an, so wächst die Hymenialfläche an der mit dem Wasser in Berührung befindlichen Partie vegetativ aus. Dasselbe erfolgt in einem mit Wasserdampf gesättigten Raum oder bei längerem Aufenthalt im Dunkeln. Daraus erklärt sich, daß die auf der Oberseite eines horizontal liegenden Baumstammes entwickelten Polyporeenfruchtkörper (Fig. 425 III) so lange kein Hymenium bilden, als ihre Unterseite mit dem Baumstamm in Berührung ist. Sobald sie ïber ihn hinauswachsen, bildet sich - vorausgesetzt, daß Licht vorhanden ist - auf der Unterseite ein Hymenium

1) Vgl. die älteren Untersuchungen von SAchs, zitiert in seinen ges. Abhandlungen, p. 103.

2) Vgl. auch St. Schurzer v. Müggenburg, Flora 1878, p. 122. 
(Fig. $425 I I I$ ). Dasselbe Resultat kann man erlialten, wenn man den Baumstamm mit dem sterilen Pilzfruchtkörper um $180^{\circ}$ dreht: der letztere bildet dann in kurzem auf seiner fruiheren Oberseite ein Hymenium (Fig. $425 I I$ ).

Auch an schon mit Hymenium versehenen Fruchtkörpern lassen sich die beiden Flächen vertauschen ${ }^{1}$ ). Entfernt man die harte obere Kruste und das Hymenium und dreht den Fruchtkörper um $180^{\circ}$, so regeneriert er auf der jetzigen Unterseite (früheren Oberseite) ein Hymenium, auf der Oberseite (früher Hymenialseite) eine Kruste. Bei jungen Fruchtkörpern kann man die Umdrehung auch ohne Verletzung herbeiführen (Fig. $425 I I$ ): der fortwachsende Rand bildet auf der neuen Unterseite Hymenialröhren. So ist es nicht verwunderlich, daß man im Freien Fruchtkörper wie die

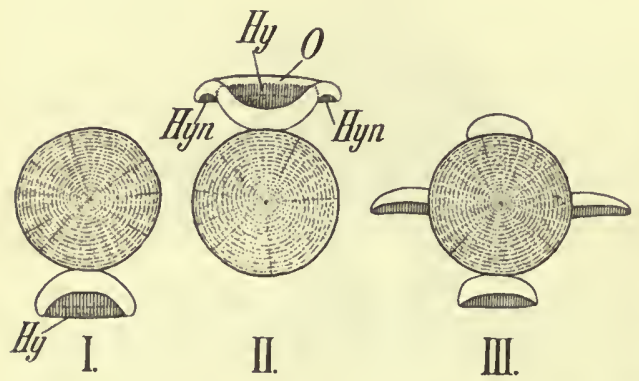

Fig. 425. (Nach Wejn.) Querschnitte durch Baumäste mit jungen Fruchtkörpern von Poly. porus fomentarius. $I$ und $I I$ derselbe Frnchtkörper, aber in $I I$ gegen $I$ um $180^{\circ}$ gedreht, der fortwachsende Rand des Fruchtkörpers hat anf der Unterseite neues Hymenium $(H y n)$ erzeugt, $H y$ altes Hymenium, $O$ Kruste der Oberseite. III Schema für die Beziehung der Lage zur Hymenienbildung. Oben steriler, seitlich balbseitige, unten radiärer Fruchtkörper.

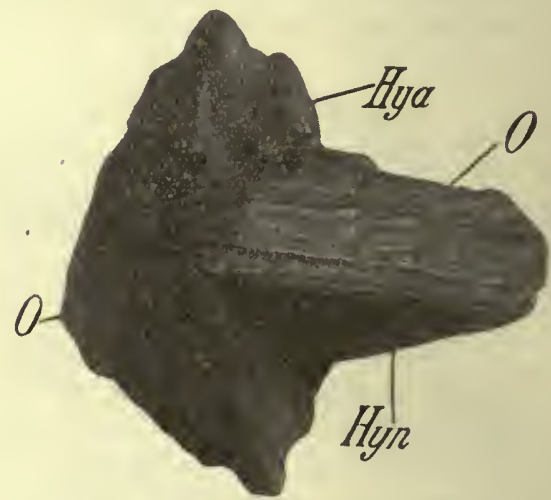

Fig. 426. Polyporus fomentarins. Fruchtkörper (verkleinert). $O$ (links) Oberfläche des alten Fruchtkörpers, Hya dessen Hymenium. Aus dem Rande des $1 \mathrm{~m} 90^{\circ}$ gedrehten Fruchtkörpers hat sich ein Fruchtkörper in anderer Orientierung entwickelt, Hyn dessen Hymenium.

in Fig. 426 abgebildeten findet: der alte Fruchtkörper links wurde mit seinem Substrat zufällig um $90^{\circ}$ gedreht. Aus dem wachsenden Rand hat sich ein neuer Fruchtkörper in der der neuen Lage entsprechenden Ausbildung (Hymenialröhren nach unten) entwickelt, der ganz über die Hymenialseite des alten hingewachsen ist.

Aus dem Mitgeteilten geht hervor, daß die Hymenialröhren sich nur in der Richtung der Lotlinie und nur auf der nach unten gekehrten Fläche des Fruchtkörpers entwickeln können. Worauf das beruht, bedarf der Untersuchung. Daß es eine nützliche Reaktion ist, ist einleuchtend.

Einige Polyporeen, welche mit einem gestielten Fruchtkörper ${ }^{2}$ ) rersehen sind, können entweder einen zentrischen Hut bilden (wie der in Fig. 423 rechts abgebildete) oder einen einseitig entwickelten. So Polyporus

1) Holtkrmaxx (Mykolog. Untersuchungen aus den Tropen [1898], p. 115) meint, daß die Richtung der Fruchtkörperbildung vom Licht bestimmt werde, sei klar. Er hat aber die Schwerkraftsrichtung nicht berücksichtigt.

$\left.{ }^{2}\right)$ Die Neigung, einen Stiel zu bilden, tritt nicht bei allen Hymenomycetenfruchtkörpern gleichstark hervor, bei manchen tritt der Stiel nur noch unter besonderen Bedingungen auf. 
squamosus ${ }^{1}$ ) (Fig. 427). Es läßt sich sagen, daß der Fruchitkörper auf dem Stiel zentrisch eingefiigt ist, wenn dieser sich in vertikaler Richtung entwickelt, exzentrisch, wenn der Stiel nicht vertikal ist. Dies ist der Fall, wenn der Fruchtkörper seitlich an einem Baumstamm herauswächst (Fig. 427). Man sieht in Fig. $413 A$ zunächst einen Längsschnitt durch einen Hyphenknäuel, der oben einen kräftigen Auswuchs trägt. Wenn er dem Lichte ausgesetzt wird, bildet sich die Hutanlage $(a b)$ zunächst annähernd rechtwinklig zur längsachse des Fruchtkörpers. Durch Förderung der Außenseite des Stiels (Fig. $427 \mathrm{D}$ ) wird aber die Hutanlage bald in horizontale Iage gebracht. Nun wächst ihre Außenseite stark, während die Innenseite zuriickbleibt. Dadurch wird der Hut nur halb - also einseitig - entwickelt. Was aber sind die dies bedingenden Faktoren? Am nächsten scheint es zu liegen, an eine Lichtwirkung zu denken und anzunehmen, daß die dem Substrate zugekehrte Seite als schwächer beleuchtet in der Entwicklung zurückbleibt. Tatsächlich erhielt ich auch eine schwächere Entwicklung von Fruchtkörpern von Stereum hirsutum an der Seite, welche durch ein am Baumstamm horizontal angebrachtes Brettchen beschattet war. Indes ist bei Polyporus eine solche Lichtwirkung nicht nachgewiesen, das Licht wirkt nur als Bedingung für das Auftreten des Hutes, nicht orientierend.

Fig. 427. Polyporus squamosns nach Butler. $A-E$ Vertikalschnitte durch Frnchtkörper verschiedenen Alters. Substrat schraftiert. $A$ Hyphenknäuel, auf welchem ein konischer Fortsatz entsteht, der sich in $B$ und $C$ zur Hutanlage $a, b$ abflacht. Letztere wirl durch stärkeres Wachstum der Unterseite horizontal gestellt und bildet das Hymenium $(E), P-I$ Junge Fruchtkörper von oben, $F$ und $G$ entsprechen $B$ und $C$. Bei $H$ und $I$ sieht man, daß die dem Snbstrat zugekehrte Seite $y$ gegenüber $x$ im Wachs.

tum zurïckgeblieben ist. (Schematisch.)

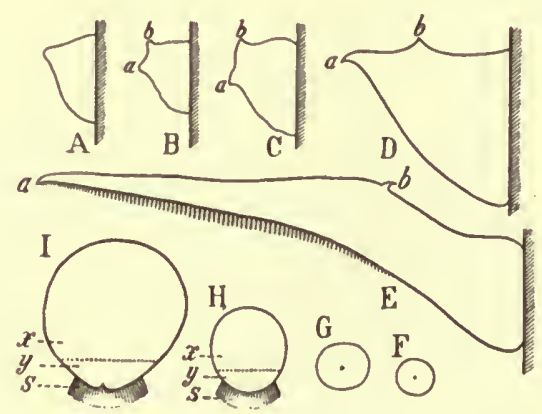

Dagegen kann das Licht in der Weise einwirken, daß es bedingt, daß der junge Stiel schief vom Substrat (dem vertikal gedachten Baumstamme) wegwächst. Wenn aber der "Stiel" schief wächst, ist auf der Außenseite die Bedingung für die Entwicklung des Hutes resp. einer hymeniumbildenden Fläche günstiger, da 1. eine freie Unterseite schon vorhanden ist, 2. die junge Hutfläche mehr der Transpiration ausgesetzt ist als auf der Innenseite. Möglicherweise kommt auch eine Förderung der Konvexseite in Betracht. Ist aber einmal hier die Hutfläche unter giinstigeren Bedingungen angelegt, so kann sie die Entwicklung der inneren Seite korrelativ hemmen. Bei einem vertikal gestellten Stiele sind die Bedingungen ringsum gleich, der Hut bildet sich radiär aus, auch bei $\mathrm{Pl}$. ostreatus und $\mathrm{Pl}$. perpusillus kann man radiäre Fruchtkörper ziehen. Daß bei holzbewohnenden Pilzen mit einseitigem Fruchtkörper die Stielbildung oft ganz unterdrückt ist, dürfte damit zusammenhängen, daß die frühzeitige Anlegung des Hutes die Stielbildung hemmt. Wenn man junge Fruchtkörperanlagen zunächst in schwacher, dann stärkerer Beleuchtung sich entwickeln läßt, wird man wohl bei den meisten noch 
einen Stiel erzielen können. Doch mögen in der Geneigtheit einen Stiel $\mathrm{zu}$ bilden verschiedene Abstufungen vorkommen.

Jedenfalls liegt in den einseitigen Pilzfruchtkörpern das derzeit am besten analysierte, aber im einzelnen noch näher zu untersuchende Beispiel von „Exotrophie" vor, die hier indirekt durch einen Schwerkraftsreiz hervorgerufen wird. $\mathrm{Da}$ die einseitige Ausbildung insofern eine zweckmäßige ist, als sie die Sporenaussaat erleichtert, ist klar.

Indes verhalten sich die einzelnen Pilzformen wohl verschieden in ihrer Reaktion. Es ist wahrscheinlich, daß es auch solche gibt, bei denen das Licht die Symmetrie der Fruchtkörperausbildung beeinflußt, während es bei den oben genannten Formen zwar eine Bedingung für das Auftreten von "Hüten" darstellt, ihre Gestalt aber nicht direkt beeinflußt; vielmehr hängt die einseitige Ausbildung mit einer Schwerkraftsreaktion zusammen, einer Reaktion, die verschieden ausfallen kann, je nach der größeren oder kleineren Disposition der betreffenden Fruchtkörper, Stiele zu bilden.

\section{$\S 8$. Beeinflussung der Gestaltung bei Algen und Flechten.}

Ein richtender Einfluß des Lichtes ist hier in folgenden Fällen nachgewiesen:

1. Keimung der Sporen von Fucaceen ${ }^{1}$ ). Die äußerlich durchaus als „apolare" Kugeln erscheinenden Eier von Fucaceen keimen in der Weise, daß sie sich nach einer Seite hin verlängern und hier das erste Rhizoid bilden. Wenn man sie einseitig beleuchtet, erfolgt das Auftreten des Rhizoids auf der dem Lichte abgewendeten Seite; die erste - das Rhizoid abtrennende - Querwand wird gewöhnlich senkrecht zur Lichtrichtung angelegt. Da die Keimung und Rhizoidbildung auch im Dunkeln erfolgen kann, so wirkt das Licht hier nur richtend. Daß es sich dabei um eine chemische Wirkung handelt, wird wahrscheinlich durch folgende Beobachtungen KNIEP's: An von zwei Seiten her beleuchteten befruchteten Eiern wachsen die Rhizoiden meist senkrecht zur Beleuchtungsrichtung hervor. Nimmt man der Kürze halber an, die Organbildung hänge ab von der Verschiedenheit der dafür verwendeten Substanzen, so kann man sagen, das Licht wirke auf die wurzelbildenden Substanzen zerstörend oder abstoßend, ist das der Fall, so ergibt sich die KNIEP'sche Beobachtung ohne weiteres. Außerdem können auch von außen kommende chemische Einflüsse richtend wirken: Die in der Nähe eines frischen Fucusthallusstiickes im Dunkeln keimenden Sporen lassen ihre Rhizoiden auf dieses zuwachsen. Es ist diese Beobachtung auch deshalb interessant, weil sie die Frage nahelegt, ob man auch für die Richtung der Wurzeldifferenzierung am phanerogamen Embryo an chemische Beeinflussungen innerhalb des Embryosacks denken könnte.

Im wesentlichen derselbe Vorgang kommt wohl in Betracht bei den "Umkehrungsversuchen" von NoLL ${ }^{2}$ ) und H. WINkLER ${ }^{2}$ ) an Siphoneen.

Caulerpa z. B. verhält sich ähnlich wie der unten zu erwähnende

1) Vgl. Kolderup Rosenvinge, Over ydre faktorers inflydelse paa Organdannelsen, Kopenhagen 1888. H. WrnkLer, Über den Einfluß äußerer Faktoren auf die Teilung der Eier von Cystosira barbata (Ber. der d. Botan. Gesellsch. 18 (1900), p. 297. H. KnieP, Beitr. zur Keimungsphysiologie und -biologie von Fucus (Jahrb. f. wissensch. Bot. 44, 1907).

2) Nolu, Über den Einfluß der Lage auf die morphologische Ausbildung einiger Siphoneen. Árb. a. d. bot. Inst. in Würzburg, III, p. 466 . WinkLer, Über Polarität usw. bei Bryopsis. Jahrb. f. wiss. Botanik 35 (1900). 
Cereus Testudo oder die Farnprothallien, d. h. beleuchtet man ein "Rhizom" von unten, so bildet es auf der früheren Wurzelseite Blätter und umgekehrt, es ist also bezüglich der Blätter positiv, betreffs der "Wurzeln" negativ phototroph.

Bei Bryopsis läßt sich die Polarität umkehren. Wenn man den Gipfel eines Pflänzchens in den Sand steckt, können aus ihm Rhizoiden hervorgehen. Aber nur bei Pflanzen, die wenig mehr wachsen (und das ist mit das Wichtigste an dem ganzen Vorgang). Kräftig wachsende Gipfel krïnmen sich empor und wachsen als Stämmchen weiter (Fig. 428 B).

Es entspricht dies der Tatsache, daß die Rhizoiden auf geringere Lichtintensitäten ,gestimmt sind" als die chlorophyllhaltigen Teile, ihre Bildung wird durch Lichtmangel begünstigt, wie die der Wurzeln höherer Pflanzen. Ist der Gipfel einer Pflanze schon in abgeschwächtem Zustand, so kann die Rhizoidbildung wie in Fig. $428 \mathrm{~B}$ an ihm stattfinden. aber darüber entscheiden nicht allein die äußeren Faktoren (z. B. der Lichtmangel), sondern in Betracht kommt namentlich seine eigene „Stimmung“ "1).

Ganz Ảhnliches gilt für andere Fälle. Oedocladium protonema ${ }^{2}$ ) ist eine landbewohnende Alge mit oberirdischen, reich rerzweigten, chlorophyllhaltigen Fäden und dïnnen, farblosen, spärlicher verzweigten, unterirdischen "Wurzeln". Werden diese dem Lichte ausgesetzt, so ergrünen sie und bilden sich in normale, kurzgliederige Lichttriebe um. Andererseits entstehen an Pflänzchen,deren ,Wurzeln“ entfernt sind, in kurzer Zeit neue Wurzeln, die sich durch ihre spärlich grüne Farbe und ihren negativen Heliotropismus auszeichnen. Bald sind es Neubildungen, bald gehen sie aus der Spitze grüner Z 'weige hervor, wobei, wie ich vermuten möchte,

Beleuchtungsverhältnisse ausschlaggebend sind. Tenigstens hat Berthold (a. a. O. p. 673) bei Meeresalgen folgendes beobachtet: „Bringt man Exemplare von verschiedenen Fadenalgen, z. B. Callithamnion, Bryposis, Ectocarpus, aus dem Freien in Kulturgefäße bei schwacher Beleuchtung, so wach-

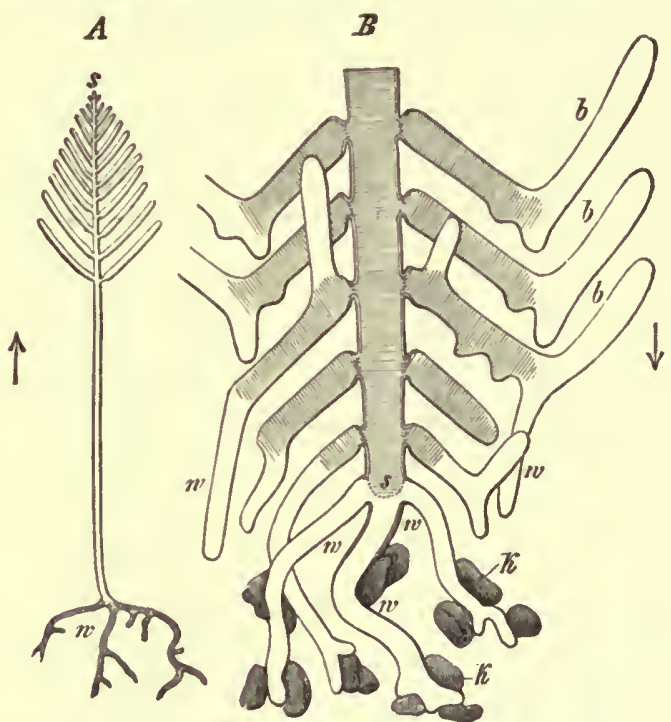

Fig. 428. Bryopsis, nach NoLl. A normale aufrechte Pflanze, $B$ eine schwach wachsende, nugekehrt in Sand eingesetzte, $s$ Scheitel, $w$ Rhizoiden, KSandkörner. sen die Scheitel unmittelbar zu rhizoidenartigen Fäden aus".

Derselbe Forscher fand, daß bei intensiver Beleuchtung reiche Verzweigung (und gedrungener Wuchs) eintritt, bei schwächerem Lichte geringere Zweigbildung und gestrecktere Form - Erscheinungen, die ja auch bei anderen Pflanzen, z. B. den Bryophyten zu beobachten sind.

1) Vgl. Einleitung in die exp. Morphologie, p. 248.

2) E. Staнr, Oeducladium protonema, eine neue Oedogoniaceengattung. Pringsh. Jahrb. XXIII. 
Bei Antithamnion cruciatum (Fig. 429) gibt BERTHOLn besonders auffallende Gestaltbeeinflussungen durch das Licht an, die aber, wie mir scheint, einer weiteren Analyse bedürfen. Bei allseitiger Beleuchtung wachsen die Sprosse aufrecht und zeigen gefiederte Kurztriebe in gekreuzten Paaren (Fig. 429). Bei einseitiger Beleuchtung werden die Achsen plagiotrop, sie kriechen auf dem Substrat. Fällt das Licht von der dem Substrat abgewandten Seite ein, so stellen sich die Kurztriebe

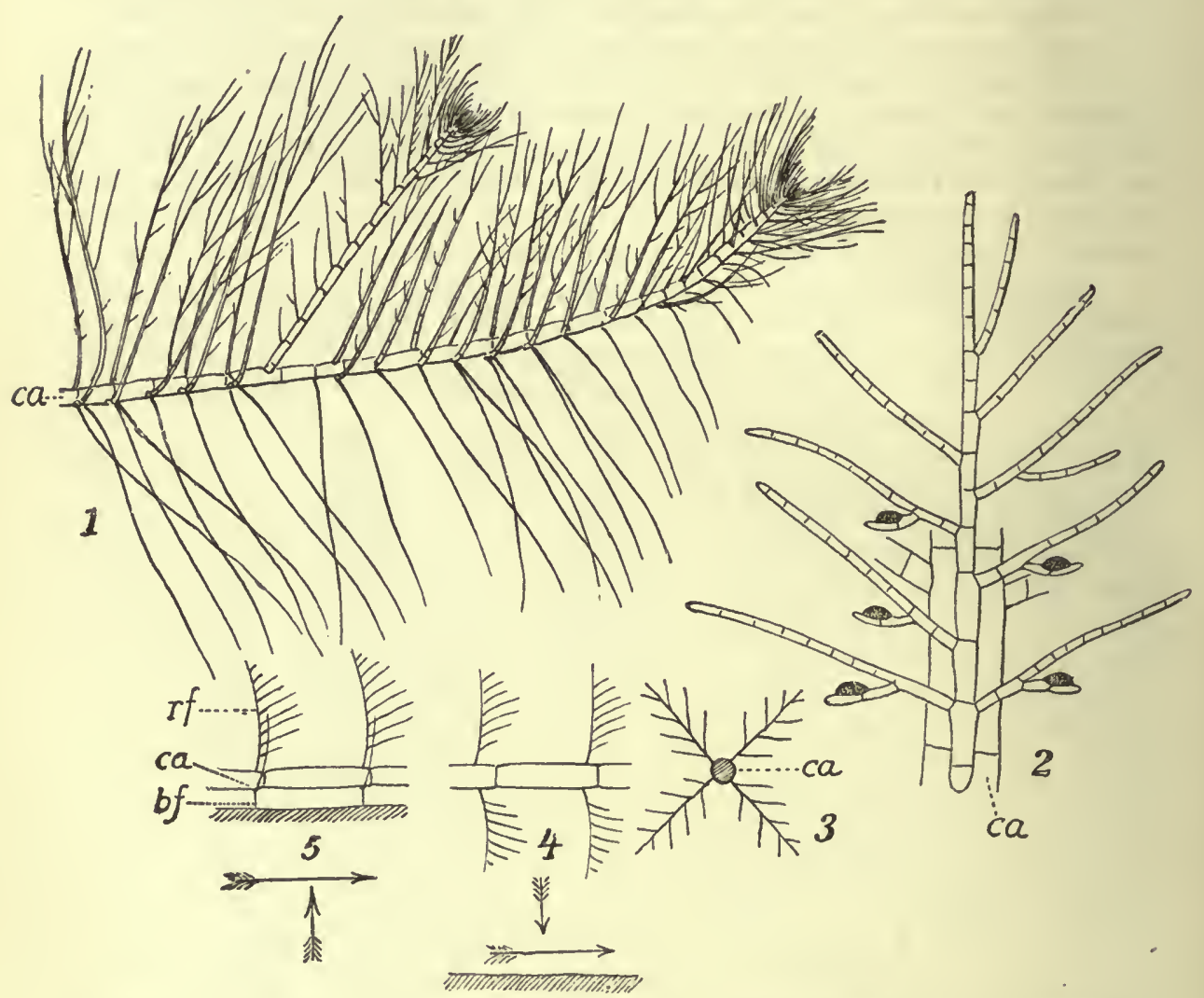

Fig. 429. Antithamuion cruciatum (nach KuckUck, NäGeli u Berthold) ans Oltmanss, Morphol. u. Biologie der Algen. 1 Exemplar mit kriechendem Hauptsproß, 2 Stück einer aufrechten Zentralachse mit „gefiedertem" Kurztrieb, 3 Achse (schraffiert) im Querschnitt, schemat., 4 kriechende Achse von oben beleuchtet. $\tilde{5}$ seitlich belenchtet $c a$ Achse. $r f^{*}$ rückenständiger, $b f^{\prime}$ bauchständiger Kurztrieb:

auf beide Flanken. Offenbar werden also die dem Substrat und die dem Lichte zugekelirten nicht gebildet (ob bei den anderen das Auftreten durch das Licht bestimmt wird oder eine Torsion eintritt, ist nicht ersichtlich). Die Pflanzen verhalten sich dann also so wie die unten zu erwähnenden "amphitrophen" Moose, dabei werden die Fiedern -nur einseitig (nach der wachsenden Spitze) hin produziert. Fällt das Licht von einer Flanke ein, so bildet sich eine Reihe von Kurztrieben auf der Rïcken- und eine auf der Bauchseite. Letztere sind reduziert und krümmen sich nach aufwärts (Fig. 429, 5). Es ist hier die Phototrophie der Rückenfiedern ohne 
weiteres ersichtlich, dagegen ist nicht rerständlich, weshalb sic einseitig entwickelt sind. Möglicherweise handelt es sich darum, daß die Fiedern auf der einen Seite aus „inneren" Gründen stets stärker gefördert sind, also von schwächerer Beleuchtung weniger stark beeinflußt werden als die der Gegenseite.

Fälle von "Phototrophie" sind bei Algen auch sonst noch bekannt. Nach KLEBs bildet Stigeoclonium tenue seine Seitenäste vorzugsweise nach der Lichtseite, bei Coleochaete situtate fand KNY den belichteten Rand des scheibenförmigen Thallus im Wachstum gefördert, den beschatteten gehemmt - alles Erscheinungen, die auch bei anderen Pflanzen wiederkehren und hier nur deshalb erwähnt werden, um ihre weite Verbreitung zu erläutern.

Auch manche Flechten verhalten sich ganz ähnlich, so das auf Erde wachsende Endocarpum pusillum; nach STAHI ${ }^{1}$ ) haben gleichmäßig (auf horizontalem Substrat) von oben beleuchtete Exemplare einen kreisrunden nach allen Seiten hin gleichmäßig wachsenden Thallus, der Radius $a$ in Fig. 430 ist gleich dem Radius $b$. Einseitig schief beleuchtete Thalli zeigen, daß das Wachstum an der mit $a$ bezeichneten der Lichtquelle näheren Seite gehemmt wird, so daß sich der Thallus einseitig stärker entwickelt. Da er plagiotrop ist, erhebt er sich in der in Fig. 430 mit $b$ bezeichneten Hälfte vom Substrat. Ich vermute, daß hier eine Förderung des besser beleuchteten Thallusteiles vorliegt: Gerade dadurch, daß er sich erheben und rechtwinklig zur Lichtquelle stellen kann, bekommt er inten-

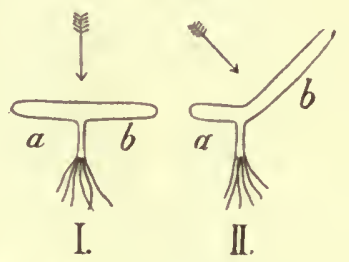

Fig. 430. Endocarpum pusillum. Thallus im Vertikalschnitt (schemat.). I. Bei Beleuchtung von oben, 1 . bei schräger Beleuchtung. sivere Belichtung als der Teil $a$, der sich nicht erheben kann. $\mathrm{Ob}$ das wirklich so ist, kann nur experimentell entschieden werden. Daß die Förderung der stärker beleuchteten Seite nicht auf einer gesteigerten Assimilationstätigkeit zul beruhen braucht, sei nur kurz erwähnt.

\section{§ 9. Bryophyten.}

1. Das am längsten bekannte Beispiel für die Entscheidung darüber, welche Seite eines dorsiventralen Pflanzenteils zur Lichtseite, welche zur Schattenseite wird; wird durch die aus den Brutknospen von Marchantia und Lunularia hervorgehenden Pflänzchen geboten. Die Brutknospen selbst, welche in den Brutknospenbehältern als vertikal stehende Zellkörper sich bilden, sind und bleiben auf beiden Seiten gleich gebaut. Sie haben aber auf jeder Seite die Anlage eines Vegetationspunktes, aus dem ein neuer, dorsiventral gebauter Thallus unter günstigen Bedingungen entstelit. Dieser hat auf seiner (normal nach oben gekehrten) Rückenseite ein charakteristisches Assimilationsgewebe, auf der Bauchseite Haarwurzeln und Schuppen, die zum Schutze des Vegetationspunktes dienen. Schon Mrrber ${ }^{2}$ ) hatte erkannt, daß äußere Faktoren es sind, die be-

1) SтAнL, Beiträge zur Entwicklungsgeschichte der Flechten II (1877), p. 18.

2) Mirber, Recherches anatomiques et physiologiques sur le Marchantia polymorpha. Mém. de l'Acad. des sciences de l'inst. de France 1835 . 
stimmen, welche Seite Rücken-, welche Bauchseite wird. Genauer wurde der Vorgang untersucht von PEEFFER ${ }^{1}$ ). Es ist hier zweierlei zu unterscheiden; einmal das Auftreten der dorsiventralen Thallusstruktur und dann das Auswachsen der Haarwurzeln (fïr welche schon an der Brutknospe besondere Zellen angelegt sind [Fig. $431 r$ ]). Stets wird die dem Lichte zugekehrte Seite zur Rückenseite, auch wenn sie bei auf Wasser schwimmenden, nur von unten beleuchteten Brutknospen nach unten gekehrt ist. Das Auswachsen der Haarwurzelanlagen wird namentlich durch Feuchtigkeitsverhältnisse, nur in untergeordnetem Maße vom Lichte beeinflußt, und zwar nur dann, wenn es hinreichend stark ist. Im Dunkeln entwickeln sich die Brutknospen ïberhaupt nicht und bringen auch keine oder doch nur spärliche Haarwurzeln hervor. Zimmenмans fand an 12 von unten beleuchteten Brutknospen 39 Haarwurzeln auf der Schatten-,

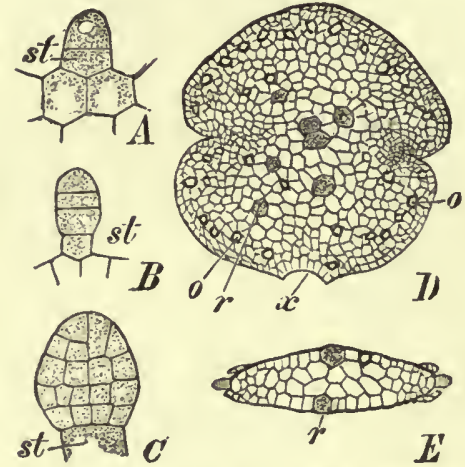

Fig. 431. Brutknospen von Marchantia polymorpha verschiedener Entwicklung. $D$ Eine fertige Brutknospe von der Fläche, seitlich liegen die beiden $\mathrm{zu}$ je einem Thallus auswachsenden Vegetationspunkte; die zn Haarwurzeln auswachsenden Zellen $(r)$ fallen durch ihre Größe und ihren Inhalt auf, sie treten auch auf dem Schnitt durch die seitlichen Vegetationspunkte der Brutknospe (in $E$ ) hervor. (Lehrb.)

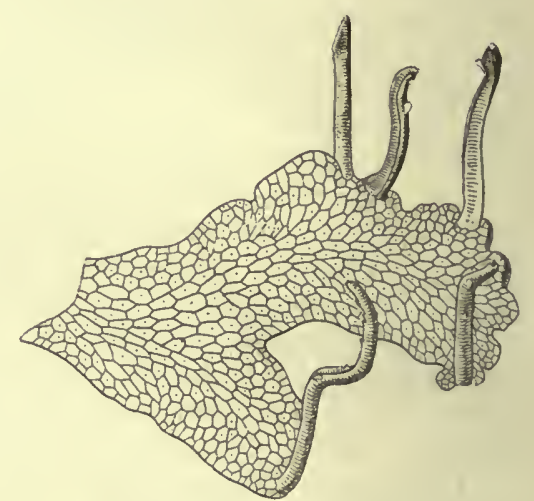

Fig. 432. Fegatella conica. Thallus mit etiolierten Trieben, die aufrecht wachsen und schmal sind.

4 auf der Lichtseite; betreffs der (frïher angenommenen) Einwirkung der Schwerkraft und der Luftfeuchtigkeit auf das Auswachsen der Haarwurzeln sei auf Pfefrer's Angaben verwiesen. Jedenfalls können die Brutknospen auf beiden Seiten Haarwurzeln hervorbringen. während der aus ihnen sich entwickelnde Thallus stets dorsiventral ist, und zwar ist die Dorsiventralität schon nach 2-3 tägiger Einwirkung bestimmt, obwohl dann die anatomische Ausbildung noch nicht eingetreten ist. Auch auf dem Klinostaten kann Dorsiventralität zustande kommen.

2. Ganz ähnlich verhalten sich nach Leitger's Angaben auch die Keimpflanzen verschiedener Lebermoose. Die „Keimscheibe“ der Marchantiaceen z. B. ist noch nicht dorsiventral, es hängt vom Lichte ab,

$\left.{ }^{2}\right)$ Pfeffer, Studien uiber Symmetrie und spezifische Wàchstumsursachen. Arbeiten des botan. Instituts in Wiirzburg, herausgeg. von SACHS, I, p. $77 \mathrm{ff}$. Vgl. auch ZimmEkJIAN, Über die Einwirkung des Lichtes auf den Marchantiathallus. Ibid. III, p. 665. Aт. DAchnowski, Zur Kenntnis der Entwicklungsphysiologie von Marchantia polymorpha. Jahrb. f. wiss. Bot., Bd. XLIV (1904). 
welche Seite zur Rücken-, welche zur Bauchseite auswächst ${ }^{1}$ ), dann aber ist die Dorsiventralität wie in dem obigen Falle ein für allemal bestimmt.

Die einmal gegebene Dorsiventralität ist aber eine bleibende mit den bis jetzt angewandten Mitteln nicht umkehrbare, soweit bekannt ${ }^{2}$ ) selbst bei solchen thallosen Lebermoosen, bei denen keine so bedeutenden anatomischen Verschiedenheiten von Licht- und Schattenseite des Thallus vorhanden sind, wie bei den Marchantiaceen.

3. Eine Beeinflussung der Thallusgestalt durch das Licht findet sich nach des Verf. früher dargelegter Ansicht ${ }^{3}$ ) bei Formen wie Hymenophytum flabellatum. Dieses Lebermoos (Fig. 433) hat einen Thallus, der unten einen Stiel, oben eine flache, blattähnliche Ausbreitung zeigt. Nun

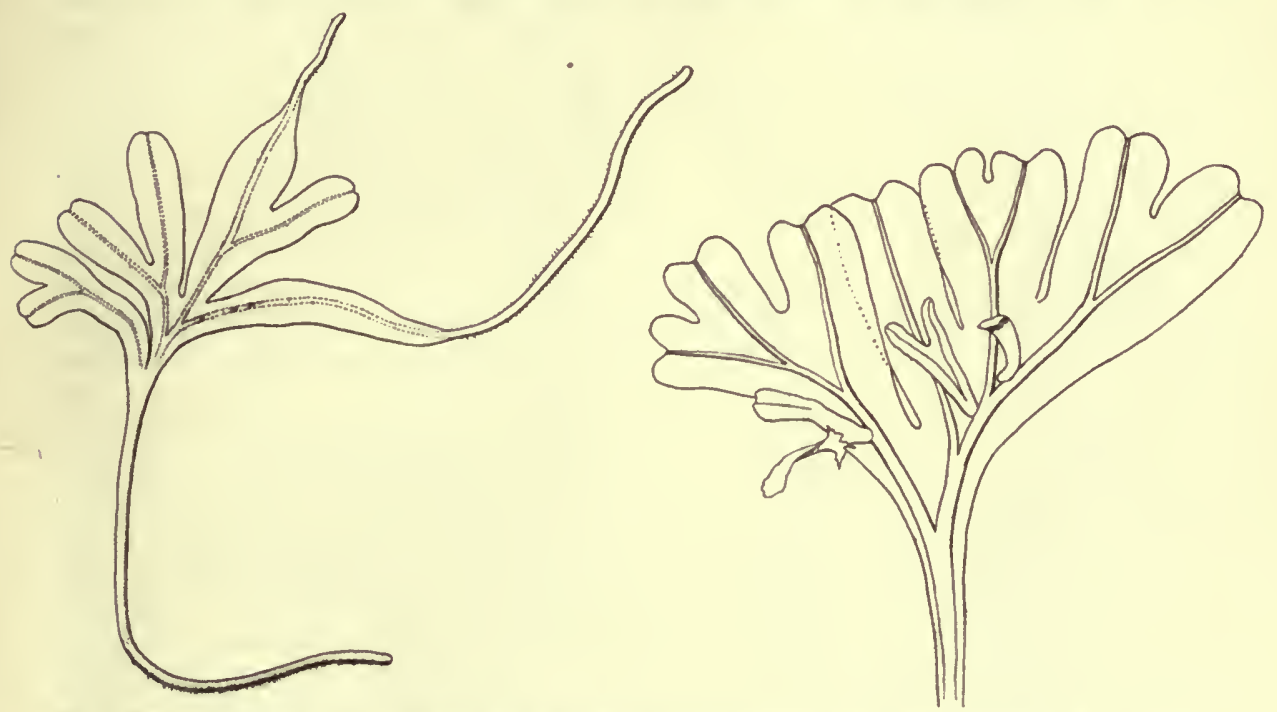

Fig. 433. Hymenophytum flabellatum, zwei Flachsprosse sind als stielförmige Gebilde weiter gewachsen.

ergab der Versuch, daß auch die flachen Teile stielälnnlich weiter wachsen können, wenn sie schattig und feucht kultiviert werden, andererseits konnte die Form von Hymenophytum bei anderen Lebermoosen (Fegatella conica, Pellia calycina) nachgeahmt werden, wenn schmale, etiolierte Sprosse

1) Es ist klar, daß bei den Brutknospen - bei denen es vom Zufall abhängt, welche Seite nach oben zu liegen kommt und ebenso bei den Keimscheiben, die keineswegs immer eine bestimmte Orientiernng beibehalten - es vorteilhaft ist, da $\beta$ der Lichteinfall für die weitere Ausbildung bestimmend einwirkt, derart, daß die für die Funktion am Lichte bestimmte Seite stets dem Lichte zugekehrt sich ausbildet. PFEFrer (Physiologie 2. Aufl., p. 181) nimmt an, daß das "Urmeristem" des Marchantiathallus "an sich isolateral" sei und in bestimmter Weise durch den dorsiventralen Thallus "determiniert und dirigiert" werde. Das ist möglich, aber nicht experimentell bewiesen. Es kann anch das Neristem selbst hier dauernd dorsiventral induziert sein ohne daß das direkt wahrnehmbar ist. Bei den Brutknospen ist ja eine Dorsiventralität nicht vorhanden, trotzdem wird das Meristem dorsiventral induziert und kann dies auch bleiben.

$\left.{ }^{2}\right)$ Es sind verhältnismäßig wenige Formen daraufhin untersucht. Eine Beobachtung von Stephani (Species Hepat. I, p. 289, 303) läßt es wahrscheinlich erscheinen, daß es Metzgeriaarten gibt, deren Dorsiventralität eine labile ist, worauf auch die vom Substrate abstehenden, Brutknospen tragenden Äste einiger Arten dieser Gattung hinwiesen.

3) Flora 96 (1906), p. 171. 
(Fig. 432) später dem Lichte ausgesetzt wurden: die neu zugewachsenen Teile wurden breit und gabelten sich, während der schmale Dunkeltrieb den Stiel darstellte. Daß bei Hymenophytum die normale Stielbildung nicht direkt durch Lichtmangel bedingt ist, ist anzunehmen. Wohl aber kann der "Stiel“ dadurch zustande kommen, daß er zunächst sozusagen blind ist, d. h. auch bei Vorhandensein von Licht, so wächst, als ob er im

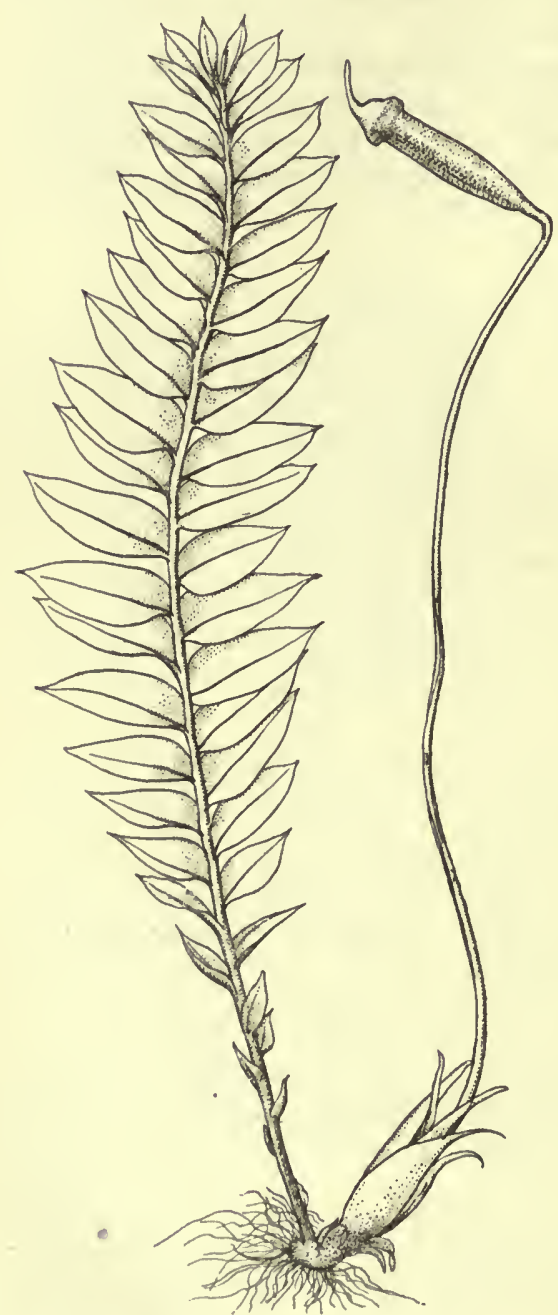

Fig. 434. Rhizogonium aristatum, links steriler, rechts fertiler Sproß (vergr.). Dunkeln sich befinden würde (autonomes Etiolement). Stellt die Lichtempfindlichkeit sich wieder ein, so tritt die flache Ausbreitung des Thallus ein. Auch hier ist weitere Untersuchung notwendig.

4. Wie hier die Ausbildung der Thallusfläche an das Vorhandensein einèr bestimmten Lichtintensität gebunden ist, so sehen wir auch bei beblätterten Bryophyten, welche plagiotrop wachsen und meist unter verhältnismäßig schwachen Lichtintensitäten leben, das Resultat zustande kommen, daß eine annähernd in einer Ebene liegende chlorophyllhaltige Fläche geschaffen, oder der chlorophyllhaltige Apparat auf die Lichtseite verlegt wird. Wir führen folgende Erscheinungen an:

a) Reduktion der Blätter auf der Schattenseite und b) flache Ausbreitung der seitlichen Blätter (die ihrerseits wieder auf verschiedene IVeise zustande kommen kann). c) Ausbildung der Seitenäste in einer Ebene. d) Stärkere Ausbildung der Lichtseite (Phototrophie).

a) Es wurde p. 231 erwähnt, daß dies bei den einen Bryophyten durch Beleuchtungsverhältnisse induziert erfolgt (Mnium, offenbar auch Calobryum und Haplomitrium), wenn sie plagiotrop wachsen, bei den anderen spontan.

Als Extrem können wir den Fall betrachten, daß nur zwei Blattreihen zur Ausbildung gelangen, die dritte ganz fehlschlägt. Dabei kann auch die Scheitelzelle eine Änderung erfahren, indem sie statt drei nur zwei Reihen von Segmenten bildet. Dies zeigt sich sehr schön bei der Gattung Rhizogonium ${ }^{1}$ ), deren sterile Sprosse vielfach zweizeilig beblättert sind, während die fertilen die (ursprünglich mehrzeilige) Beblïtterung beibehalten (vgl. Fig. 434). Daß die zweizeilige Beblätterung hier aus der drei oder

1) Goeber, Archegoniatenstudien X. Flora 96 (1906), p. 88. 


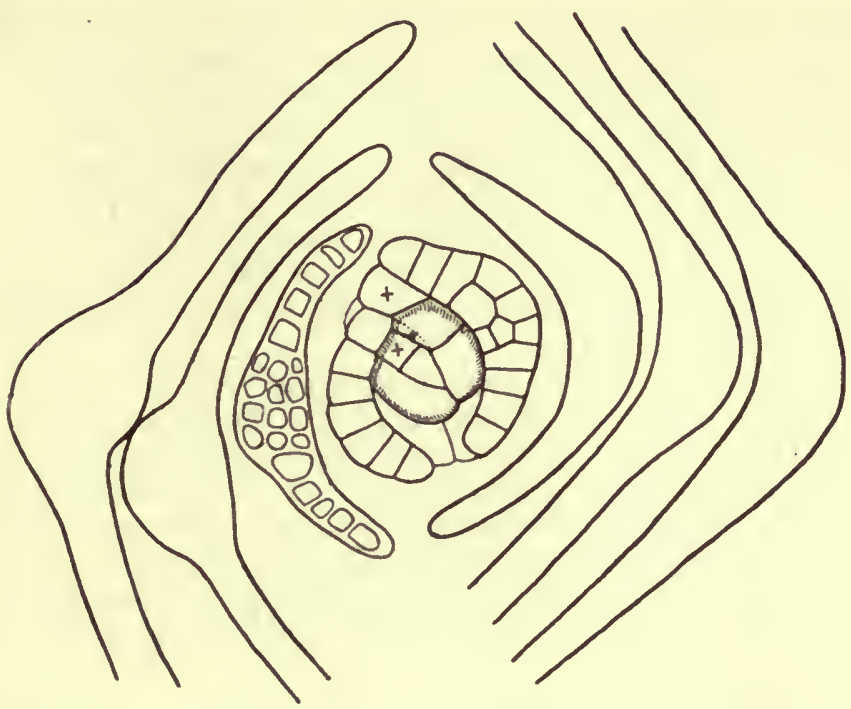

Fig. 435. Rhizogonium Novae Hollandiae. Querschnitt durch den Scheitel eines sterilen Sprosses. Die dreiseitig-pyramidale Scheitelzelle bildet nur ans den seitlichen, größeren Segmenten Blätter.

(durch Scheiteltorsion) mehrzeiligen hervorgegangen ist, das zeigt nicht nur die Tatsache, daß einige Rhizogoniumarten noch mehrzeilig beblätterte sterile Sprosse besitzen, sondern auch die, daß Rhizogonium Novae Hollandiae noch eine dreizählige Scheitelzelle besitzt, bei der aber eine Segmentreihe (in Fig. 435 mit $X$ bezeiclnet) steril ist, während $\mathrm{Rh}$. aristatum eine zweischneidige Scheitelzelle hat (Fig. 436).

Hier müssen die Blätter eine Drehung ausführen, um in eine Ebene zu gelangen.

Bei Fissidens, das an älteren Sprossen gleichfalls eine zweischneidige Scheitelzelle hat (vgl. p. 206), kommt die flache Ausbreitung ohne Drehung durch die Fliigelbildung zustande (Fig. 196). Hier ist auch

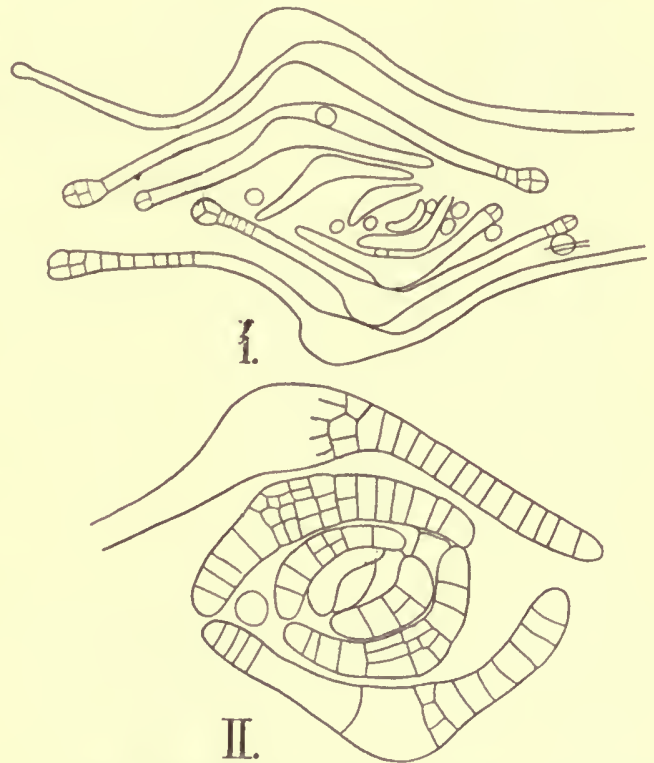

Fig. 436. Rhizog. aristatum. Querschnitt durch eine Sproßspitze. I höher, II tiefer mit zweischneidiger Scheitelzelle. die Frage untersucht, ob die Zweizeiligkeit durch Lichtwirkung bedingt ist, wie Hofmeister vermutet hatte. Es ist mir bei Kultur in abgeschwächtem "Lichte nicht gelungen, radiäre Sprosse zu erziehen, selbst in Dunkeln ausgetriebene Seitensprosse 
von Fiss. adiantioides waren zwweizeilig beblättert. Ich möchte deshalb glauben, daß bei Fissidens der Übergang aus der radiären in die bilaterale Struktur nicht direkt unter dem Einfluß des Lichtes erfolgt.

NĚMec ${ }^{1}$ ) kam später zu demselben Resultat. Er konnte aber nachweisen, daß Fissidens schwach dorsiventral ist, die eigentliche (nur als Scheide des Flügels erscheinende) Blattfläche ist auf der Lichtseite etwas größer (greift mehr über das Stämmchen herüber als auf der Schattenseite). Dies Verhältnis verschwindet bei Finsterkultur und läßt sich umkehren, die Pflanzen sind also - wenngleich nicht sehr tiefgreifend phototroph beeinflußbar.

b) Hier soll zunächst das Verhalten von Schistostega besprochen sein, an deren sterilen Stämmchen die Blätter gleichfalls in zwei Längsreihen angeordnet sind (Fig. 173). Die Untersuchung der Knospe zeigt, daß diese Stellung hervorgeht aus einer ursprünglich mehrreihigen; sie erfolgt durch eine eigenartige Verschiebung (vgl. Fig. 174 und den speziellen Teil), die also im Verlaufe der Einzelentwicklung aus einem radiären Gebilde ein bilaterales macht. Die Pflanze wächst an Orten, wo eine geringe Helligkeit herrscht, welche durch diese Stellung der Blätter am besten ausgenutzt werden kann.
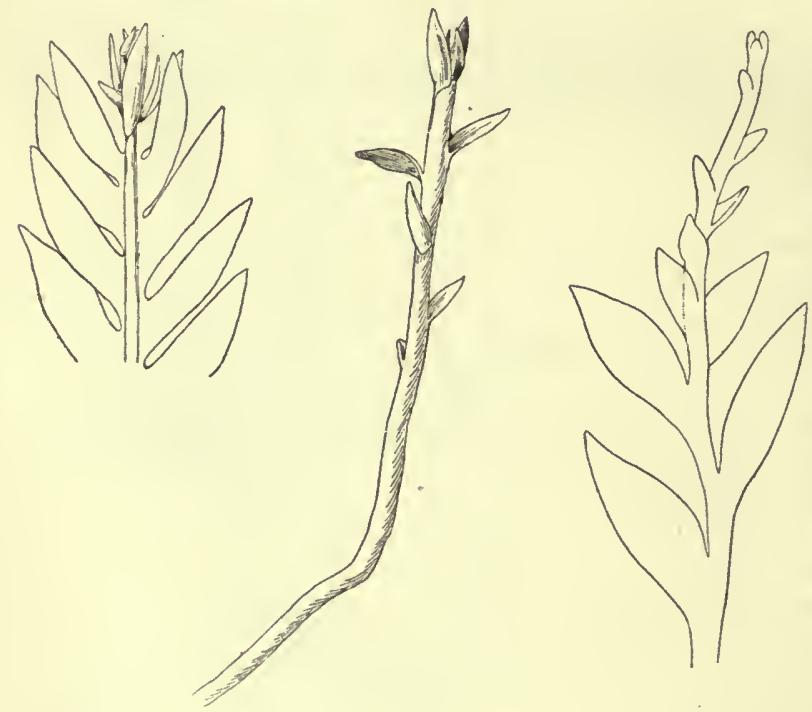

Fig. 437.

Schistostega osmundacea (bei schwacher Lichtintensität kultiviert). Die beiden links und rechts abgebildeten Sprosse waren vorher normal gewachsen; an den neu zuwachsenden Teilen ist die radiäre Blattstellung erhalten geblieben. Das mittlere Exemplar ist von vornherein bei schwacher Beleuchtung erzogen und hat radiäre Blattstellung von vornberein (die Blätter sind aber meist schief eingefügt). Da dieserSproß sein Wachstum noch nicht $a b$ geschlossen hatte, so würde er möglicherweise später

Sexualorgane gebildet haben.

Es fragt sich, ob, wie HoFMerster ${ }^{2}$ ) vermutete, das Licht bei der Änderung der Blattstellung direkt beteiligt ist oder nicht. Längere Zeit fortgesetzte Kulturen ergaben folgendes. Zunächst wurde angenommen, daß die Richtung des Lichtes in Betracht komme, daß der einseitige Lichteinfall bei der Verschiebung beteiligt sei. Wäre dies der Fall, so müßten auf einem Drehwerk (bei vertikaler Achse) erwachsene Pflanzen die radiüre Blattstellung beibehalten. Der Versuch zeigte aber, daß dies nicht der Fall ist, die Pflanzen entwickelten sich auch hier bilateral ${ }^{3}$ ); gelegentlich

1) B. NĚMEc, Die Symmetrieverhältnisse und Wachstumsrichtungen einiger Laubmouse (Jahrb. für wiss. Bot.- XLIII [1906]).

2) Hofmeistan, Allgemeine Morphologie, p. 628.

3) Bei längerer Kultur auf dem Klinostaten werden sie abnorm kleinblätterig. 
treten zwar Drehungen des Stämmchens und andere Störungen ein, allein das Hauptresultat blieb dasselbe. Dagegen ergab sich, daß wenn Schistostegapflanzen bei sehr geringer Lichtintensität wachsen, die radiäre Stellung erhalten bleibt. Sie.. werden unter diesen Umständen positiv heliotropisch; damit braucht eine Änderung der Blattstellung noch nicht notwendig verbunden zu sein. Aber bei zahlreichen Pflanzen einer üppigen Kultur ließ sich nachweisen, daß unter diesen Umständen sowohl Sprosse, welche schon in ihrem unteren Teil bilateral waren, in ihrem oberen radiär wurden (Fig. 437 rechts und links), als auch neu angelegte ganz radiär sich ausbildeten (Fig. 437 in der Mitte). Die Blätter waren dabei vielfach in ihrer Insertion nach der Längsrichtung verschoben, aber nicht in zwei Reihen, sondern allseitig gestellt. Übrigens finden sich zwischen radiärer und bilateraler Ausbildung alle Abstufungen. Es ist dabei, abgesehen von Drehungen der Sproßachsen, eine Fehlerquelle wohl zu beachten. Die Sexualsprosse haben radiäre Blattstellung. Geschlechtsorgane wurden in meinen Kulturen im Herbst angelegt. Deshalb wurden alle diese Sprosse nicht mit berücksichtigt. In dem darauffolgenden Sommer aber erhielt ich, wie erwähnt, ungemein zahlreiche Sprosse, die, auch ohne Geschlechtsorgane zu bilden, ihr Wachstum abschlossen (alle Schistostegasprosse haben ein begrenztes Wachstum). Die Blätter waren bei den in geschwächtem Lichte gewachsenen Sprossen bedeutend kleiner als bei den anderen, was ja auch aus den Figuren hervorgeht.

Mit den obigen Ausführungen ist zunächst nur nachgewiesen 1. daß die eigentümliche Blattverschiebung bei Schistostega nicht auf einseitigem Lichteinfall beruht, wie HoFMEISTER angenommen hatte. Er betrachtete das Zweizeiligwerden ebenso wie bei Fissidens als durch Wachstumssteigerung auf der stärker beleuchteten Seite bedingt (Phototrophie). 2. Daß für die Verschiebung eine untere (ob auch eine obere?) Grenze der Lichtintensität besteht.

Das Verhalten der „komplanaten" Laubmoossprosse mag im speziellen Teil besprochen werden.

Auch für Lebermoose liegen ähnliche Erfahrungen vor.

Pflanzen von Jungermannia bicuspidata und Plagiochila asplenioides (Fig. 438), welche bei sehr geringer Lichtintensität gezogen wurden, entwickelten positiv heliotropische Sprosse, bei welchen vielfach (aber, bei Plagiochila namentlich, nicht an allen. Blättern) die quere Insertion der Blätter erhalten geblieben, die Verschiebung also unterblieben war. Bei anderen Jungermanniaceen mit mehr longitudinal inserierten Blättern war die Verschiebung dagegen selbst bei etiolierten Sprossen eingetreten.

c) Daß die zweizeilig beblätterten Bryophyten sich auch zweizeilig verzweigen, ist in den Verzweigungsgesetzen (p. 77) begründet. Vielfach treffen wir aber auch mehrreihig beblätterte Moose an, die nur in einer Ebene verzweigt sind, wenigstens was die gewöhnlichen vegetativen (Kurz-) Triebe betrifft. Sie verhalten sich also ähnlich wie die amphitrophen Zweigsysteme mancher Coniferen; gelegentlich finden sich Astanlagen auch an anderen Stellen als an den Flanken (Fig. 439). Zunächst sei erwähnt, daß das Austreiben der Astanlagen bei einer Anzahl daraufhin untersuchter Arten im Dunkeln ganz unterbleibt ${ }^{1}$ ), so bei Hylocomium splendens, Hypnum

1) Vgl. anch Ň̌Mec, Die Induktion der Dorsiventralität bei einigen Moosen (Bullet. Intern. de l'acad. des sciences de Bohême 1906). v. Schoznad, Zur Verzweigung der Laubmoose. Inaug. Dissert. München 1910 und Hedwigia 1910 (daselbst weitere Literatur). Manche Moose wachsen übrigens im Dunkeln überhaupt nicht weiter, so

Goebel, Organographie der Pflanzen. 2. Aufl. Allgem. Teil. 
(Ptilium) crista castrensis, Thuidiumarten u. a.; an der Hauptachse verliert sich dabei auch die sonst stattfindende Gipfeleinkrümmung. Wenn man solche Sprosse diffuser Beleuchtung (auf dem Klinostaten allseitiger) aussetzt ${ }^{1}$ ), so können sie Zweige in nicht zweizeiliger Stellung bilden. Aber solche Pflanzen bleiben meist schwächlich und kehren zur Dorsiventralität zurück, oder sie werden durch an älteren Sproßteilen kräftig austreibende zweizeilig verzweigte Innovationstriebe ersetzt. NĚMEC meint, es sei die Rückkehr zur Dorsiventralität durch den Zusammenhang mit der dorsiventralen Mutterpflanze gegeben in Übereinstimmung mit Pfeffere's (p. 461 Anm. 1) angeführten Auffassung. Dieser Schluß scheint mir nicht zwingend. Ich möchte vielmehr annehmen, daß der Vegetationspunkt dieser Laubmoose sozusagen auf Dorsiventralität gestimmt (induziert) ist, so, daß er durch äußere Anstöße aus seiner Gleichgewichtslage gebracht, doch bald wieder zu ihr zuriickkehrt.

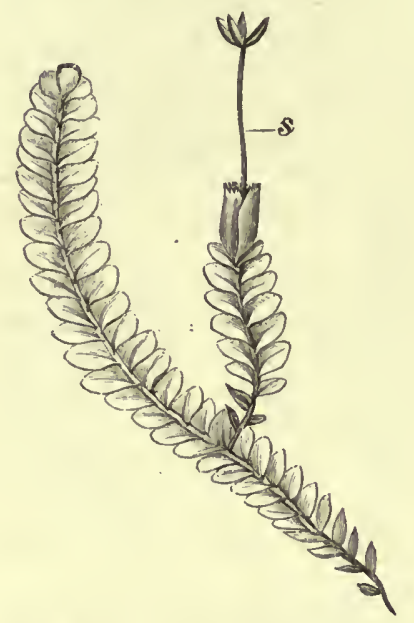

Fig. 438. Plagiochila asplenioides. Stämmchen von oben. Der Vorderrand der Blätter steht tiefer als ihr Hinterrand. (Lehrb.)

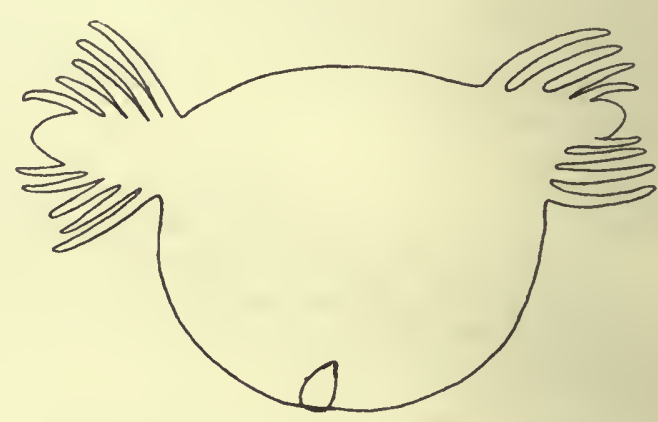

Fig. 439. Thuidium abietinum. Querschnitt eines Hauptsprosses (nach einer Handzeichnung von KiesirzGERLOFF, halb schematisch). Die Lichtseite der Sproßachse ist abgeflacht, rechts und links entspringen zwei Seitensprosse. Auf der Schattenseite die Anlage (Scheitelzelle) eines nicht zur Entwicklung gelaugenden Sprosses.

Daß die Astentwicklung auf der Schattenseite unterbleibt, ist leicht verständlich, nicht aber weshalb dies auf der Lichtseite der Fall ist. Wahrscheinlich liegt eine Beeinflussung der auch sonst wahrnehmbaren Periodizität der Astbildung durch das Licht vor, welche einen inneren Zustand des Vegetationspunktes bedingt, der dem für Opuntia erwähnten entspricht.

SACHS ${ }^{2}$ ) hat auch für das Protonema der Laubmoose, speziell das von Funaria hygrometrica, eine ähnliche Beeinflussung der Verzweigung

Cyathophorum bulbosum, Neckera complanata (ersteres nach eigenen Beobachtungen, letzteres nach NÈMEC).

1) Es kommt dabei offenbar nicht darauf an, in welcher Richtung das Licht einfällt, sondern auf seine Intensität. Bleiben die durch das Licht geförderten Seitensprosse schwach, so werden sie auf die (in geringer Zabl vorhandenen) nicht flankenständigen Sproßanlagen auch keine korrelativ hemmende Wirkung ausüiben können.

$\left.{ }^{2}\right)$ Über orthotrope und plagiotrope Pflanzenteile. Arbeiten des botan. Instituts in Würzburg, Bd. II, p. 256; Vorlesungeu über Pflanzenphysiologie, 2. Aufl., p. 534. 
durch das Licht angenommen. „Das Licht bewirkt in diesem Fall, daß die Vegetationspunkte der Seitensprosse nur auf den Flanken der Muttersprosse entstehen, wenn diese beständig von einer Seite her beleuchtet sind." Ich möchte indes darauf hinweisen, daß auch im Finstern erzogene Protonemen, welche durch Zuckerfütterung verhältnismäßig bedeuteñde Größe erreichten, der Hauptsache nach zweizeilige Stellung der Äste zeigten (Fig. 440), so daß hier also die Neigung zur zwei-

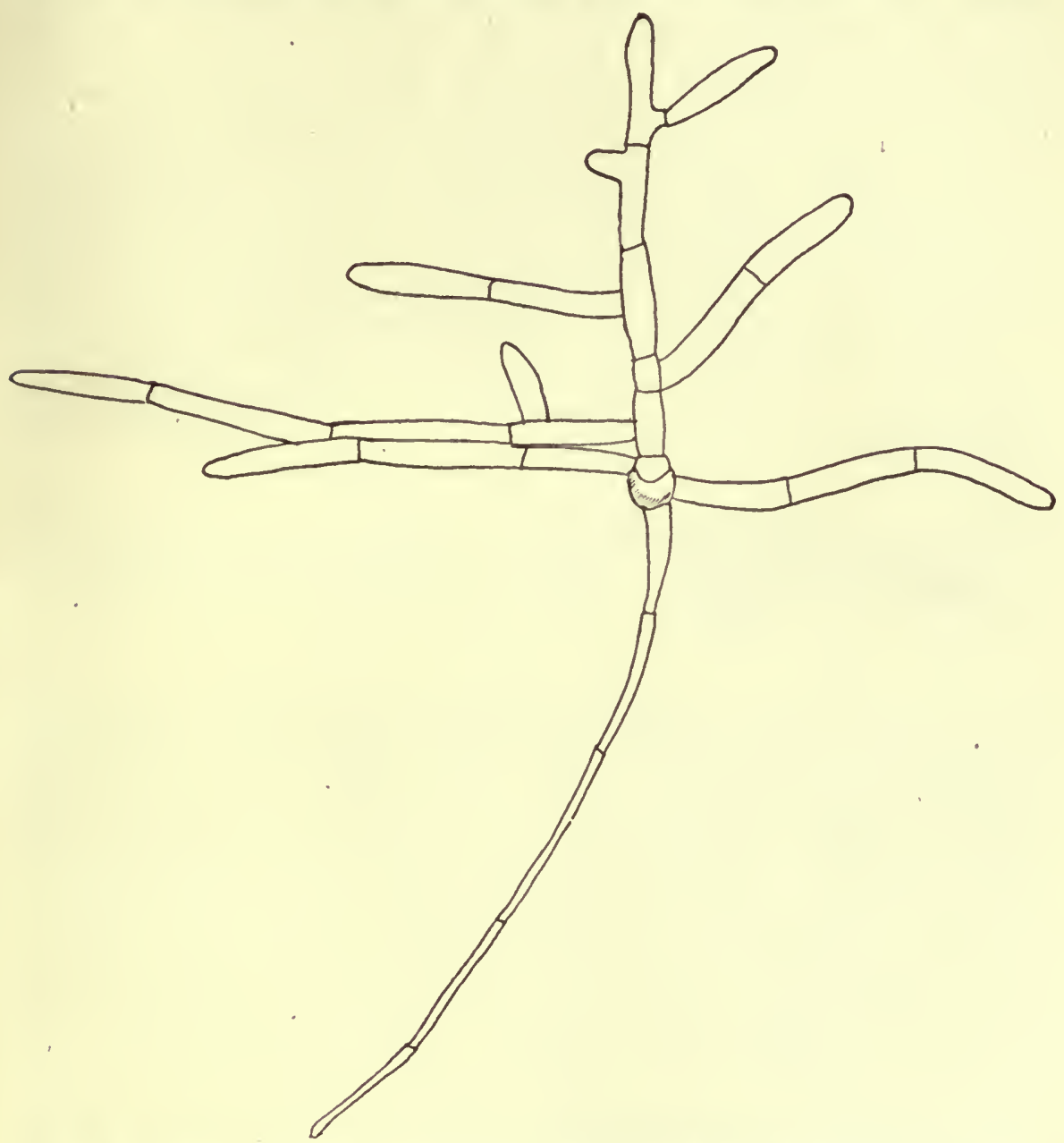

Fig. 440. Funaria hygrometrica. Im Dunkeln mit Zuckerfütterung erzogenes Protonema.

zeiligen Verzweigung gegeben, und höchstens die Ebene, in der sie vor sich geht, durch das Licht bestimmt würde. Daß in der Tat die Ausbildung des Protonemas abhängig sein kann von äußeren Faktoren, zeigt die Gattung Ephemeropsis. Hier lebt das Protonema epiphytisch auf Blättern. Es trägt Zweige auf seinem Rücken und auf den Flanken, erstere tragen dann die flach ausgebreiteten als Assimilationsorgane dienenden Seitenzweige (vgl: den speziellen Teil). 
d) Eine stärkere Ausbildung der beleuchteten Seite, eine „Phototrophie" kommt schon - wenngleich in schwachem Maße - bei den Fissidensblättern (p. 464) zustande, wo an einen "Nutzen" dieser Erscheinung für die Pflanze nicht wohl zu denken ist.

Dagegen ist ein solcher nicht unwahrscheinlich für die einseitswendigen Blätter mancher Laubmoose. NĚMEc hat für Dicranum scoparium - ein orthotropes Laubmoos - gezeigt, daß die Blätter bei einseitiger Beleuchtung sich nach dem Lichte hin krümmen und so wohl eine bessere Lichtausnutzung erreichen. Stämmchen, die nur Oberlicht erhalten oder etiolierte sind radiär; die durch einseitige Beleuchtung induzierte Dorsiventralität ist umkehrbar. Wie sich andere Moose mit einseitig gekrümmten Blättern verhalten, bedarf näherer Untersuchung, es ist sehr wohl möglich, daß nicht überall das Licht dabei beteiligt ist. Beleuchtet man die sonst radiär verzweigten Sprosse von .Climacium dendroides einseitig, so entwickeln sich nur auf der Lichtseite Äste (v. ScHönaU a. a. O.) und noch auffallender tritt das in dem p. 232 erwähnten Fall hervor, in welchem ein sonst zweizeilig verzweigter Sproß mit einer Flanke dem Substrat anliegt und die Verzweigung dadurch einseitig wird (Fig. 441).

Auch bei den Sporogonien mancher Moose tritt "Phototrophie" deutlich hervor. Die Kapseln an den Sporogonien vieler Moose sind radiär von teils kugeliger, teils zylindrischer Gestalt (so z. B. bei Sphagnum, Orthotrichum, Grimmia, den Phascaceen).

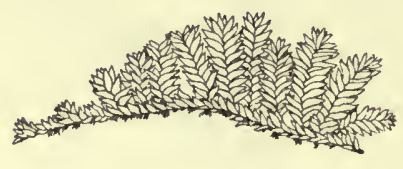

Fig. 441. Plagiothecium undulatum. Sproß, welcher einseitig dem Substrat anlag und statt zwei Zweigreihen nur eine gebildet hat.

Bei anderen aber tritt eine mehr oder minder stark ausgeprägte Dorsiventralität hervor, die, wenigstens in manchen Fällen, in deutlicher Beziehung zur Sporenaussaat steht. Diese Dorsiventralität ist, soweit meine Untersuchungen reichen, selbst in den Fällen, wo sie am stärksten ausgeprägt ist, bei den Buxbaumieen, eine im Verlauf der Entwicklung entstandene. Die jungen Moossporogonien sind auch hier (entgegen der Annahme W ICHURAS $^{1}$ )), stets radiär. Die dorsiventrale Ausbildung äußert sich am auffälligsten darin, daß die Mündung der Kapseln nicht mehr in die Verlängerung des Stieles fällt, der Schnabel der ungeöffneten Kapsel ist dann schief gestellt, und zwar ist er bei Buxbaumia, Barbula subulata und Catharinea undulata, der Schatten-, bei Bryum argenteum u. a. der Lichtseite zugewendet. Ob bei Kapseln, die in jugendlichem Zustand bei ständigem Wechsel des Lichteinfalls kultiviert werden, die Krümmung ganz unterbleibt, ist nicht bekannt, wie denn die ganze Frage noch selir der experimentellen Prüfung bedarf.

Am auffallendsten ist die Dorsiventralität der Kapseln bei den Buxbaumieen. Sowohl Diphyscium (Fig. 442), als die Arten der Gattung Buxbaumia (Fig. 443), besitzen schiefe Kapseln, deren eine Seite im Querschnitt abgeflacht, deren andere konvex gewölbt ist. Die erstere ist die dem Lichte zugekehrte. Bei noch jungen radiären Sporogonien von Diphyscium foliosum, die ich bei einseitiger Beleuchtung kultivierte, überzeugte ich mich davon, daß bei allen die Abflachung auf der Lichtseite

1) Wichura, Jahrb. f. wiss. Bot. II, p. 194. 
eintrat; der hier gelegene Teil der Kapselwand ist es, welcher durch seine (durch Regentropfen etc. veranlaßten) Bewegungen die Sporen aus dem Peristomtrichter herausbefördert. In Fig. 442, welche einen Längsschnitt durch ein noch nicht ganz reifes (noch mit Calyptra und Deckel versehenes) Sporogon darstellt, tritt die Verschiedenheit der Licht- und Schattenseite deutlich hervor; die Stellung des Sporogons ist später nicht

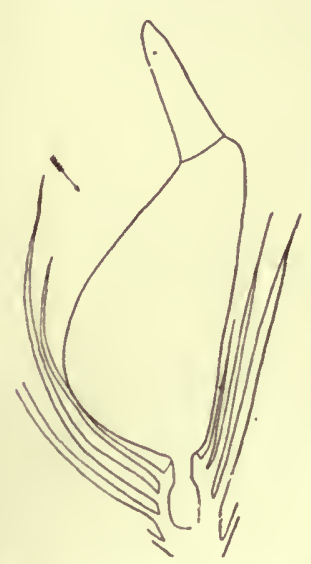

Fig. 442. Diphyscium foliosum. Längsschnitt durch ein Stämmchen, welches ein Sporogon trägt. Die Lichtrichtung ist durch den Pfeil angedeutet.
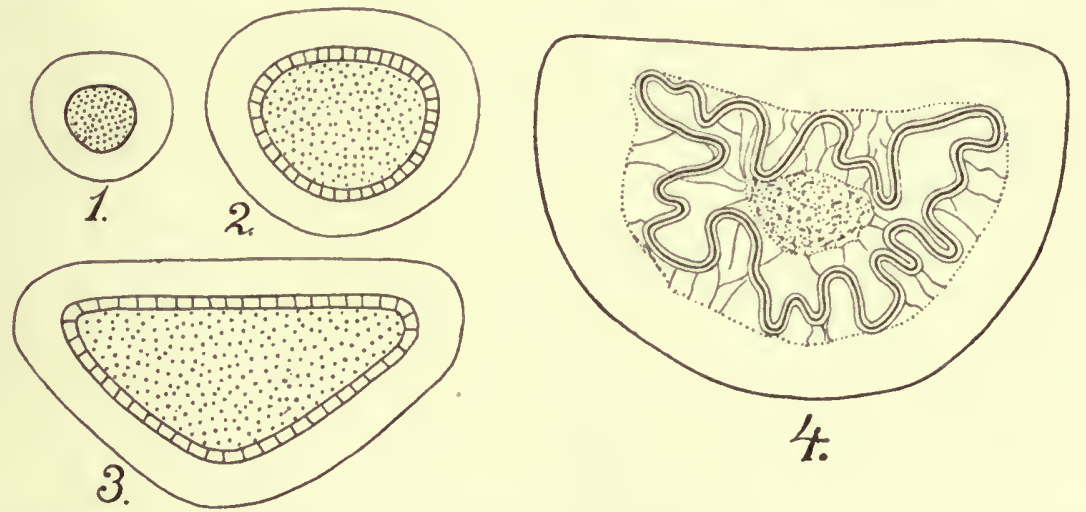

Fig. 444. Dawsonia superba. Querschnitt durch Kapseln verschiedenen Alters vergr. 4 schwächer als $1-3$. Die Columella ist punktiert, der Sporensack in 2 und 3 schraffiert, in 4 ist er stark gefaltet.

mehr so aufrecht wie in der Zeichnung. Da die Moossporogonien während ihrer Entwicklung mit ihrem chlorophyllhaltigen Gewebe assimilieren, so kommt die Abflachung auf der Lichtseite auch für die Assimilation in Betracht, bei Diphyscium dürfte die Beziehung zur Sporenaussaat aber die wichtigere sein.

Auch bei Dawsonia (Fig. 444) ist die Kapsel im Jugendzustand aufrecht und annähernd radiär gebaut. Später flacht sie sich auf einer 
Seite $a b$ und biegt sich schließlich annähernd rechtwinklig zum Stiel um, wobei die flache, später konkar werdende Seite nach oben gekehrt ist. Wir haben hier eine Erscheinung, welche sehr erinnert an die für einige Luftwurzeln angeführte. Experimentelle Untersuchungen darüber liegen nicht vor.

Immerhin zeigen auch schon die bis jetzt vorliegenden Untersuchungen, daß die Gestaltung des Vegetationskörpers und in einzelnen Fällen auch die des Sporophyten der Bryophyten durch äußere Faktoren stark beeinflußbar ist.

\section{$\S 10$. Pteridophyten.}

1. Bei den Pteridophyten ist eine Beeinflussung durch äußere Faktoren namentlich für den Gametophyten mancher Formen bekannt. Ob die Sporophyten verhältnismäßig wenig plastisch sind, oder nur zu wenig untersucht wurden, läßt sich derzeit kaum sagen.

Die meisten Farnprothallien sind dorsiventral, was sich darin äußert, daß auf der Unterseite des Prothalliums sich das Gewebepolster befindet, welches den Archegonien und den Haarwurzeln den Ursprung gibt. Hier ist die Dorsiventralität jederzeit umkehrbar ${ }^{1}$ ); wenn man auf Wasser schwimmende Prothallien von unten beleuchtet, entstehen die neuen Archegonien und Haarwurzeln auf der (dem Lichte abgewendeten) Oberseite. Die Archegonien und Haarwurzeln stehen also auf der schwächer beleuchteten Seite. Bei den Haarwurzeln ist das wie bei Fucus, Equisetum u. a. wohl zurückzuführen auf negative Phototrophie. Ob das auch bei den Archegonien der Fall ist, scheint mir zweifelhaft. Ihre Stellung könnte bedingt sein nicht direkt durch das Licht, sondern durch die vom Lichte abhängigen Eigenschaften des Gewebepolsters auf welchem sie stehen. Wenigstens sind bei Trichomanes rigidum u. a. (vgl. Fig. 148) die Archegonien, soweit bekannt, nicht negativ phototroph. Bei Kultur auf dem Klinostaten bei vertikaler Drehungsachse und seitlich einfallendem Lichte bildete sich iibrigens auch immer nur eine Seite zur archegonientragenden aus, vielleicht weil eine gleichmäßig starke Beleuchtung auf beiden Seiten doch nicht vorhanden war, oder weil eine bilaterale Ausbildung aus „inneren" Gründen hier nicht möglich ist (gelegentlich trifft man iibrigens Prothallien, bei denen die beiden Seiten eine Strecke weit Archegonien und Haarwurzeln tragen). Auf den Nutzen, der den Archegonien aus ihrer Stellung entspringt, wurde oben schon hingewiesen.

Analoge Verhältnisse wie für die Archegonienbildung fand LEITGEB auch an a pogamen Farnprothallien für die Sproßbildung, die hier unabhängig von den Archegonien auf ungeschlechtlichem Wege erfolgt ${ }^{2}$ ). Es hängt ganz von der Beleuchtung $a b$, auf welcher Seite diese auftritt. Es geschieht dies wie bei der Archegonienanlage immer auf der der Lichtquelle abgewendeten Seite; ist sie hier aber einmal erfolgt, so kann durch Wechsel der Beleuchtung auf der nun beschatteten Seite Sproßbildung in der Regel nicht mehr hervorgerufen werden, da die vorhandene Sproßanlage alle Bildungsstoffe des Prothalliums beansprucht, was bei

1) Leitgeb, Stndien über die Entwicklung der Farne. Sitzungsber. der Wien. Akad., math.-naturw. Klasse, LXXX. Bd. 1879.

2) H. Leitaeb, Die Sproßbildung an apogamen Farnprothallien. Ber. der D. bot. Gesellsch. III (1885), p. 169 ff. 
der Archegonienbildung nicht der Fall ist. Nur wenn die Sproßanlage über die ersten Anlagestadien nicht hinausgelangt ist, kann nach erfolgtem Beleuchtungswechsel ihre weitere Ausbildung sistiert werden, und auf der nun beschatteten Oberseite eine neue Anlage in die Erscheinung treten. Sehr eigentümlich ist der Fall, daß die Glieder eines und desselben Sprosses sich auf verschiedene Seiten des Prothalliums verteilen können, auf der einen Seite der Sproß mit erstem und zweitem Blatt, auf der anderen Prothalliumseite die erste Wurzel. Es läßt sich dies erzielen, wenn Prothallien von Pteris cretica, die junge Sroßanlagen, aber noch keine Wurzel gebildet haben, von unten beleuchtet werden. Immerhin aber tritt dieser Fall nur sehr selten ein, und es geht aus LeitgEB's Angaben nicht ganz klar hervor, ob es sich dabei nur um einen $\mathrm{Durch}$ bruch der Wurzel nach oben hin oder um eine Anlegung derselben auf der Oberseite handelt.

Dem eben Besprochenen seien zwei Fälle angeschlossen, in welchen das Licht die "polare" Differenzierung an den aus Sporen hervorgegangenen Keimlingen bestimmt. Die meisten Sporen haben schon eine polare Differenzierung, über deren Ursachen wir nichts wissen. Es sei erinnert an die Verschiedenheit des Vorderendes rom Hinterende bei Schwärmsporen, womit bei Algen mit festsitzendem Thallus zugleich auch für den Keimling eine polare Differenzierung gegeben ist, da die Schwärmspore sich mit dem Vorderende festsetzt. Auch die Sporen vieler Muscineen und Pteridophyten (z. B. alle tetraedrischen) lassen deutlich die Stelle erkennen; an welcher der Keimschlauch entsteht. Sie sind also von Anfang an polar ausgebildet ${ }^{1}$ ).

Andere Sporen aber sind apolar, die Polarität tritt erst bei der Keimung auf.

Die kugeligen, chlorophyllhaltigen Sporen von Equisetum ${ }^{2}$ ) zeigen nach allen Radien hin denselben Bau. Sie keimen in der Weise, daß von dem Innenraume der Sporenzelle eine kleine, bikonvexe Zelle abgetrennt wird, die zur ersten Haarwurzel auswächst, während die größere Schwesterzelle zum Keimschlauche wird. In der Haarwurzel verschwindet das Chlorophyll immer mehr, schließlich finden sich nur noch Leukoplasten. Die Keimung erfolgt auch im Dunkeln, aber langsamer, die Teilungswand ist dann in beliebiger Weise orientiert. Erfolgt die Keimung aber in intensivem Lichte, so wirkt dies auf die Orientierung schon der Kernteilung ein, und zwar so, daß die Achse der Kernteilungsfigur durch den Gang der Lichtstrahlen bedingt wird und die beiden Tochterkerne in die Richtung des Strahlenganges zu liegen kommen, die Teilungswand steht dann rechtwinklig dazu. Die der Lichtquelle zugekehrte Zelle ist die erste Prothalliumzelle, die kleinere, auf der Schattenseite liegende die Anlage der ersten Haarwurzel. Diffuses Tageslicht übt eine richtende Wirkung nicht aus ${ }^{8}$ ). Bei fortdauernd sich änderndem Lichteinfall (bei einer

1) Ob die Polarität hier durch die Beschaffenheit des Inhalts oder die der Membran gegeben ist, wäre zu entscheiden.

2) SтAнL, Über den Einfluß der Beleuchtungsrichtung auf die Teilnng der Equisetumsporen. Ber. der D. bot. Gesellsch. III (1885), p. 334. BUCHTIEN, Entwicklungsgeschichte des Prothalliums von Equisetum. Inaug.-Diss. Rostock 1887, auch in Biblioth. botanica. Kassel 1887.

3) Buchtien a. a. O. Wenn es danach scheinen könnte, als ob in der freien Natur die Einwirkung des Lichtes für die Organbildung bei der Sporenkeimung kaum in Betracht käme, so ist dabei zu beachten, daß innerbalb gewisser Grenzen die Keimung um so rascher verläuft, je intensiver die Beleuchtung ist, und deshalb die richtende Einwirkung des Lichtes sich doch geltend machen wird. 
Klinostatenkultur) fand Stahl, daß die Sporen in ihrer Teilung beeinträchtigt waren, die meisten waren ungeteilt, eine Anzahl anderer zwar geteilt, aber in abnormer Weise in zwei gleich große Zellen. Ähnliche Störungen lassen sich auch auf andere Weise erzielen. Buchties fand (a. a. O. p. 24), daß bei Kultur in konzentrierter Nährlösung (3 pr. m.) die Sporen meist durch zwei aufeinander rechtwinklige Wände geteilt waren und die Ausbildung einer Haarwurzel oft ganz unterblieb.

In den angeführten Beispielen handelt es sich um eine Beeinflussung von Dorsiventralität und Polarität durch das Licht.

Eine Beeinflussung durch die Schwerkraft wurde vermutet betreffs der Organbildung am Embryo der Gefäßkryptogamen, namentlich der Filicineen. Aus der befruchteten Eizelle gehen hier-hervor: der Stammscheitel (nach oben), die Wurzel (nach unten), ein oder zwei "Kotyledonen" and ein als "Fuß" bezeichnetes Haustorium. Es hat sich aber gezeigt, daß die Orientierung dieser Teile lediglich durch innere Ursachen, die Lage des Embryos im Archegonium, bestimmt wird. zur Schwerkraft also nicht in Beziehung steht und ebensowenig zum Licht ${ }^{1}$ ). Denn wenn man Prothallien, die auf Wasser schwimmen, von unten beleuchtet, so treten die Archegonien, die sonst auf der Unterseite stehen, auf der Oberseite auf, die in ihnen entstandenen Embryonen haben aber trotzdem dieselbe Anordnung ihrer Organe wie sonst.

Nur in ganz beschränktem Maße nahm LeitgeB ${ }^{2}$ ) an den Embryonen von Marsilia einen orientierenden Einfluß der Schwerkraft wahr. "Die Lage der ersten Teilungswand im Embryo ron Marsilia ist insoweit eine ganz bestimmte, und von äußeren Verhältnissen unabhängige, als sie in jedem Falle die Archegonachse in sich aufnimmt; es ist dieselbe aber um die letztere drehbar und nimmt, sobald die Archegonachse aus der Vertikalen heraustritt, die Lage ein, daß der Embryo in eine obere, zenithwärts gekehrte Stamm(epibasale)hälfte und eine untere, Fuß und Wurzel bildende (hypobasale) zerlegt wird." Die Makrosporen keimen in annähernd horizontaler Lage (Fig. 445); die Orientierung, die soeben angeführt wurde, bedingt also, daß der Stammscheitel $s$ in jedem Falle nach oben kommt, die Wurzel nach unten; es werden dadurch Krümmungsbewegungen vermieden, die bei anderer Orientierung eintreten müßten. Die erste Wand ist die in der Figur (welche einen schon längst aus vielen, aber, abgesehen rom Stammscheitel, nicht eingezeichneten Zellen bestehenden Embryo darstellt) mit 11 bezeichnete. Die Makrosporen sind drehbar, bei den isosporen Farnen dagegen ist das Prothallium am Boden befestigt. Die gegenseitige Lage der Teile ist auch beim Marsiliaembryo nicht verschiebbar, der "Fuß" $(f)$ ist stets - wie dies seiner Funktion entspricht - der mit Reservestoffen versehenen Spore zugekehrt, der Kotyledon und die Wurzel

1) Vgl. Heinricher, „Beeinflußt das Licht die Organbildung am Farnembryo?" Mittlgn. a. d. botan. Inst. zu Graz, 2. Heft. Jena 1888.

2) Leita кв, Zur Embryologie der Farne. Sitzungsber. der Wiener Akademie 1878. Ferner: Studien über Entwicklung der Farne, ibid., LXXX. Bd. 1879. - Wie aus den oben mitgeteilten Tatsachen hervorgeht, spielen also äußere Kräfte bei der Organdifferenzierung an befruchteten Eizellen von Gefäßkryptogamen keine oder nur eine ganz untergeordnete Rolle; maßgebend ist die Lage der Eizellen innerhalb der weiblichen Organe. Dasselbe gilt für die Eizellen höherer Pflanzen; stets entsteht die Wurzel an der Anheftungsseite der Eizelle an den Embryosack, gleichgültig, ob diese oben oder unten liegt (in Beziehung zum Horizont). Offenbar hängt dies damit zusammen, daß diese Eizellen eben immer eingeschlossen bleiben; bei den ins Freie entleerten der Fucaceen spielen, wie p. 456 kurz mitgeteilt wurde, äußere Kräfte eine Rolle für die polare Differenzierung. 
stets ihr abgekehrt. Wenn die Archegonachse (was aber in der Natur nicht vorkommt) senkrecht nach oben oder nach unten gekehrt ist, so übt die Schwerkraft natürlich gar keine Wirkung aus. Auch bei Prothallien isosporer Farne nimmt LEITGEB in den ersten Entwicklungsstadien eine Schwerkraftswirkung an. Bei Ceratopteris z. B. ist die Zellfläche des jungen Prothalliums vertikal, die zweischneidige Scheitelzelle bildet Segmente abwechselnd zenithwärts und erdwärts; die Dorsiventralität ist noch nicht vorhanden. Mir scheint es aber zweifelhaft, ob hier nicht andere Faktoren (Hydrotropismus usw.) beteiligt sind.

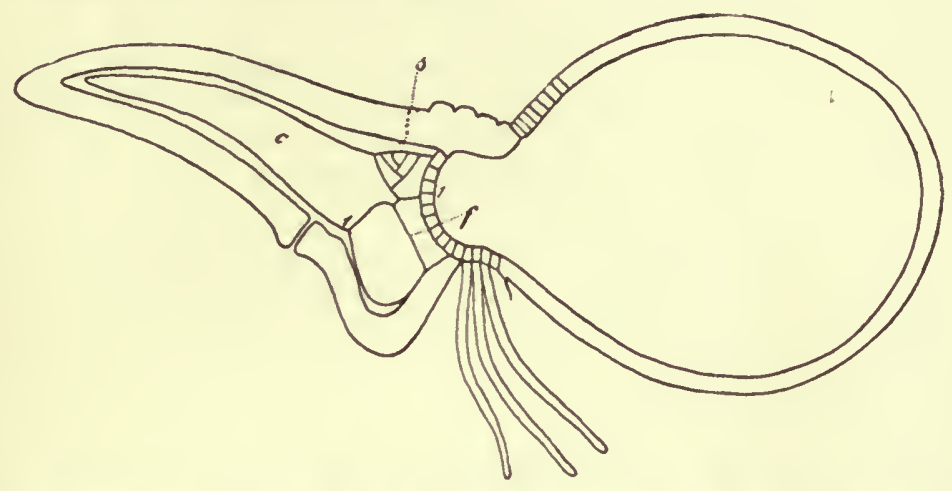

Fig. 445. Längsschnitt durch eine gekeimte Makrospore von Marsilia (halbschematisch). Rechts die Makrospore, links hat sich ein Prothallium entwickelt, das einen Embryo erzeugt hat. Der Archegonienhals ist schief nach unten gekehrt. Der Embryo ist schon vielzellig und zeigt Kotyledon $(c)$, Stammscheitel $(s)$, Fuß $(f)$ und Wurzel. Die erste, in der befruchteten Eizelle auftretende Teilungswand ist noch erkennbar, sie ist mit 11 bezeichnet.

Auch die Dorsiventralität des Sporophyten wird, speziell bei Lycopodium durch das Licht beeinflußt. Indes wird es zweckmäßiger sein, diesen Fall zusammen mit anderen bei Erörterung der Abhängigkeit der Anisophyllie von äußeren Faktoren zu besprechen.

\section{$\S$ 11. Samenpflanzen: Einfluß der Schwerkraft.}

Dem Einfluß der Schwerkraft schrieb namentlich HoFmeister (Allg. Morphologie § 25) eine bedeutende Rolle für die Gestaltungsverhältnisse zu. Er führte darauf zurück u. a. die dorsiventrale Ausbildung der Seitensprosse mancher Pflanzen, die Blattgestaltung der plagiotropen Begoniasprosse u. a. Es kann jetzt keinem Zweifel mehr unterliegen, $\mathrm{da}$ B die Bedeutung der Schwerkraft als "formativer Reiz" bedeutend überschätzt wurde. Immerhin ist die Schwerkraft in einer Anzahl von Fällen teils für die Anordnung, teils für die Ausbildung der Organe von Bedeutung ${ }^{1}$.

Namentlich ist es die Verteilung der Wurzeln und Sprosse, welche vielfach von der Schwerkraft beeinflußt wird. So an Stecklingen, also bei der Regeneration ${ }^{2}$ ). Schon DuHamel hatte beobachtet, daß an

1) Vgl. SAchs, Stoff and Form der Pflanzenorgane (I und II in Ges. Abh., p. $1159 \mathrm{ff}$.) und Vorlesungen über Pflanzenphysiologie, 2. Aufl., p. $523 \mathrm{ff}$.

$\left.{ }^{2}\right) \mathrm{Vgl}$. außer der angeführten Literatur anch Titrmann, Physiol. Unters. über Callusbildnngen an Stecklingen. Jahrb. f. wiss. Bot. XXVII. 
horizontal in die Erde gelegten Weidenzweigen Wurzeln nur auf der Unterseite entstanden.

Hier sei das Verhalten der Weidenstecklinge erwähnt, welches durch Vö́нтілG ${ }^{1}$ ) untersucht wurde. An vertikal aufrecht aufgehängten, gleichmäßigen äußeren Bedingungen ausgesetzten Weidenstecklingen entwickeln sich Knospen an dem apikalen, Wurzeln ringsum an dem basalen Ende. An zur Lotlinie geneigten Zweigen fand Vöchtisg im allgemeinen folgendes Verhalten (a. a. O. p. 169, betreffs der Ausnahmen und. Schwankungen vgl. die Einzelangaben a. a. O.). Je kleiner der Winkel ist, den der Zweig mit der Lotlinie macht, um so mehr wachsen die Knospen an der Spitze, und zwar ringsum auf allen Seiten aus; je größer der Winkel wird, um so mehr bilden sich die Triebe ringsum an der Spitze und a $\mathrm{B}$ erdem, von dieser ausgehend, auf der Oberseite, bis endlich, wenn der Zweig eine horizontale Stellung hat, die Triebe unmittelbar an der Spitze noch ringsum, von dieser aus aber nur auf der Oberseite entstehen. Das Auswachsen der Knospen wird hier also bedingt einerseits durch die Polarität, welche sich in der Bevorzugung des apikalen Endes äußert, andererseits wirkt aber auch die Schwerkraft dahin, daß die Sproßbildung auf der nach oben gekehrten Seite gefördert ist, während die Wurzeln sich umgekehrt verhalten.

Thr Verhalten sei an einem Objekte kurz erwähnt, dessen zu Stecklingen benutzten Sproßachsen keine Wurzelanlagen besitzen, aber leicht solche bilden. Werden die Stecklinge von "Heterocentron diversifolium" in normaler Lage aufgehängt, so bilden sich Wurzeln nur am basalen Ende, bei umgekehrter Lage aber entstehen sie auch mehr oder weniger von der Basis entfernt. Im wesentlichen dasselbe Resultat wie mit abgeschnitterien Zweigen ergibt sich auch, wenn die Sprosse an der Pflanze selbst austreiben ${ }^{2}$ ), nur daß dann natürlich die Wurzelbildung wegfällt.

Entfernt man bei annähernd senkrecht gewachsenen einjährigen Weidenzweigen vor dem Austreiben die schwachen oberen Teile und gibt den Sproßachsen dann verschiedene Lagen, so entwickeln sich die austreibenden Knospen bis zu mehr oder minder großer Entfernung von der Schnittfläche, also der Spitze. Die Länge und Stärke der Sprosse nimmt von der Spitze aus allmählich ab. Bei Sprossen dagegen, welche, in horizontale Lage gebracht, austreiben, bildeten sich die Knospen an der Spitze zwar noch ringsum, außerdem aber fast nur noch auf der ob eren Längshälfte des Zweiges aus, die Knospen der Unterseite blieben ruhend oder entwickelten sich nur vereinzelt. Die Wirkung der Schwerkraft tritt hier also deutlich hervor. Wenn wir bei den Jahrestrieben unserer Bäume also die dem apikalen Ende (das normal auch das obere ist) genäherten Knospen den basalen gegenüber gefördert sehen (was für den Aufbau des Gesamtgeriistes des Baumes offenbar vorteilhaft ist), so wirkt dabei außer der Polarität auch die Schwerkraft mit. An einem Algenoder Lebermoosthallus sind die der apikalen Region nahestehenden Seitensprosse nicht den basalen gegenuiber gefördert. Zu kräftigen orthotropen Sproßsystemen haben es vielleicht nur diejenigen Pflanzen bringen können, bei welchen die Schwerkraft die Förderung der Sprosse •nach oben hin bedingte.

Der Einfluß der Schwerkraft auf die Bewurzelung tritt auch bei

1) Organbildung im Pflanzenreich I (1878).

2) Vöcririva, Organbildung II (1884), p. 40 ff. 
unverletzten krautigen Pflanzen hervor. Wenn man Sprosse von Tropaeolum majus, ohne sie von der Mutterpflanze abzuschneiden, entweder in vertikaler oder in horizontaler Lage mit Erde so bedeckt, $\mathrm{da} ß$ die langgestielten Laubblätter am Lichte bleiben, dann treten in ersterem Fall (bei vertikaler Lage) die Wurzeln allseitig, bei horizontaler Lage nur auf der Unterseite der Sproßachsen hervor. Verdunklung und Feuchtigkeit haben hier die Wurzelbildung hervorgerufen, die Schwerkraft aber wirkt orientierend ein.

Wie SACHS ${ }^{1}$ ) nachdrücklich betont hat, wird auch bei ganzen lebenden Pflanzen, wenigstens bei orthotropen Sprossen, neben der früher erörterten Polarität die Schwerkraft dahin wirken, daß die Wurzeln an dem nach abwärts gekehrten Ende entstehen. Tatsächlich findet bei den meisten plagiotropen, kriechenden und kletternden Sprossen die Wurzelbildung auf der ganzen Sproßunterseite in progressiver Reihenfolge statt, wobei auch das Licht dahin wirken kann, daß die Wurzeln auf der Unterseite angeordnet sind.

Ähnlich verhalten sich die Knollen von Tladiantha, einer Cucurbitacee. Sie entstehen als Anschwellungen der dünnen Wurzelfäden und bilden in dem Jahre nach ihrer Entstehung Adventirsprosse, welche über den Boden treten. Diese entstehen, wie Sacus fand, ausschließlich an der während ihrer Entstehung oben (zenithwärts) liegenden Seite der Knolle. Außerdem ist vermöge einer "inneren Disposition" das "akroskope“ (nach der Wurzelspitze hin gerichtete) Ende der Knolle bevorzugt (entgegen dem sonst bei der Sproßbildung an Wurzelstücken auftretenden Verhalten). Es wirken hier also zweierlei Ursachen zusammen, welche den Entstehungsort der adventiven Sproßvegetationspunkte bestimmen: ,innere Ursachen" - gegeben offenbar durch die Richtung der Stoffwanderung - bewirken, daß das „akroskope“ Ende der Knolle vorwiegend zur Knospenbildung geeignet ist - wie ja auch an den Sproßknollen der Kartoffeln das apikale Ende bevorzugt ist -, während gleichzeitig die Einwirkung der Schwere es bedingt, daß die Knospen auf der dem Erdzentrum abgewendeten Seite der Knolle entstehen.

Vielleicht schließt sich diesem Verhalten an das folgende.

Die merkwürdigen Knollen von Dioscorea ${ }^{2}$ ) sinuata (p. 114) sind dorsiventral. Sie haben auf der Oberseite chlorophyllhaltiges Gewebe und Kambium, auf der Unterseite Wurzeln (Fig. 110). Die Dorsiventralität ist durch die Lage induziert und nicht umkehrbar. Die kambiumhaltige Oberseite entsteht stets auf der nach oben gekehrten Seite. Entstehen an einer umgekehrt gelagerten Knolle Adventivsprosse, so bilden diese die Knolle in der normalen Lage, also entgegengesetzt den Seiten der umgekehrten Knolle. Es ist wahrscheinlich, daß hier eine Schwerkraftwirkung vorliegt, freilich könnte man auch an einen bestimmenden Einfluß des Sprosses, an welchem die Knolle entsteht, denken.

Eine sehr eigentümliche Schwerkraftswirkung scheint für die Ausbildung der Embryonen von Ceratozamia mexicana nach den Angaben von A. Doretr ${ }^{3}$ ) vorzuliegen. Die Samen dieser Cycadee fallen ab, ehe der Embryo ausgebildet ist. Die Embryonen zeigen im Gegensatz zu denen anderer Cycadeen die Eigentümlichkeit, daß sie nur einen Kotyledon be-

1) SAchs, Stoff und Form der Pflanzenorgane in Gesammelte Abhandl., p. $1159 \mathrm{ff}$. und Vorlesungen über Pflanzenphysiologie, 2. Aufl., p. $523 \mathrm{ff}$.

2) Vgl. Gozber, Die Knollen der Dioscoreen usw. Flora 95 (1905), p. $167 \mathrm{ff}$.

3) A. Donety, The embryo of Ceratozamia. Botanical gazette XLV (1906), p. 412. 
sitzen. Dieser ist so ausgebildet, daß er stets auf der nach unten gekehrten Seite des Samens sich findet. Samen, die auf dem Klinostaten nachreiften, also ihre Lage zum Erdradius fortwährend änderten, bildeten 2 Kotyledonen aus. Der Fall ist noch recht rätselhaft und wunderbar. Vielleicht liegt hier tatsächlich ein Fall von "Geotrophie" vor, derart, daß die Entwicklung des erdwärts gekehrten Kotyledon gefördert und die des anderen korrelativ gehemmt wird, jedenfalls verdient die Frage eine eingehende Untersuchung.

Vielfach ist es nicht leicht, zwischen der Wirkung von Schwerkraft, der von Krümmung resp. Geradesein der Achse und der Korrelationen zu unterscheiden; dahin gehören einige von SAchs ${ }^{1}$ ) untersuchte Fälle.

Zunächst sei folgendes angeführt. Yucca, Cordyline und verwandte Pflanzen besitzen außer ihren oberirdischen Sprossen noch dicke, fleischige, in der Erde senkrecht nach unten wachsende Rhizome. Unter normalen Verhältnissen, d. h. solange der Stamm nicht beschädigt ist, dienen sie als Wurzelträger und Reservestoffbehälter. Wird der Stamm abgeschnitten, so bilden sich Laubsprosse an dem oberen (basalen) Teile des Rhizoms, seine Endknospe aber wächst nicht aus. Dagegen erfolgt dies, wenn das Rhizom mit seiner Endknospe aufrecht gestellt wird. Um Sproßbildung am Rhizom zu erzielen, ist es iubrigens nicht notwendig, daß die oberirdischen Teile abgeschnitten werden, es genügt, wenn sie eine Wachstumshemmung erfahren. Diese tritt meist ein, wenn die ganze Pflanze in verkehrte Lage gebracht wird; wenn der Hauptsproß, statt im Wachstum gehemmt zu werden, sich negativ geotropisch aufrichtet, unterbleibt auch das Austreiben des Rhizoms und der an seiner Basis stehenden Knospen ${ }^{2}$ ).

Wir sehen also, wenn wir die Endknospe der Rhizome allein in das Auge fassen, daß sie austreibt: 1. wenn der Hauptsproß beseitigt oder im Wachstum gehemmt und 2. wenn die Endknospe in inverse Lage gebracht wird.

Darauf bezieht sich der von SACHS gezogene Schluß, „daß die Schwerkraft bei der Umwandlung eines Rhizoms in einen Laubsproß mitwirkt" (a. a. O. p. 1188).

Außerdem würde man die Endknospe eines Rhizoms in normaler, $\mathrm{d} . \mathrm{h}$. nach abwärts gekehrter Lage wohl auch zum Austreiben bringen können, wenn außer dem Hauptsproß auch die Seitenknospen des Rhizoms selbst entfernt werden.

Die Förderung der vertikal wachsenden Glieder tritt namentlich auch in der Verschiedenheit von Hauptwurzeln und Seitenwurzeln, Hauptsprossen und Seitensprossen zutage. Daß diese nicht etwa ausschließlich eine Schwerkraftswirkung ist, ist ohne weiteres klar, denn die Verschiedenheit in der Ausbildung von Haupt- und Seitenachsen in einem Verzweigungssystem tritt, wie die früher behandelten Beispiele zeigen, schon bei Älgen auf, deren Gestaltungsverhältnisse von der Schwerkraft nicht beeinflußt werden. Der Hauptsproß ist ja einem Seitensproß gegenüber schon dadurch im Vorteil, daß er früher da ist als jener, es kommen Ernährungsverhältnisse, die mechanische Beanspruchung des Hauptsprosses u. a. in Betracht. Andererseits läßt sich nicht verkennen, daß die in der Richtung der Lotlinie wachsenden Achsenorgane durch diese Richtung als die bevorzugten erscheinen, geneigte Sprosse z: B. entwickeln sich, wie

1) SACHS, Stoff und Form der Pflanzenorgane. Ges. Abhandl. II, p. $1186 \mathrm{ff}$.

2) Vgl. auch Vöchting, Über Spitze und Basis an Pflanzenorganen. Botan. Zeitg. 1881 . 
die Erfahrungen bei der Obstkultur längst gezeigt haben, viel schwächer, sie sind mehr zur Hervorbringung von Kurztrieben geneigt als solche, die sich der vertikalen Richtung nähern. Die oben erwähnten Tatsachen führen zu demselben Schlusse. Und wenn wir sehen, daß eine Seitenwurzel, die sich an die Stelle der abgeschnittenen Hauptwurzel stellt, oder ein Seitenzweig. der sich aufrichtet, jetzt eine kräftigere Ausbildung und andere Eigenschaften erhalten, so kommt wohl hier folgendes in Betracht:

1. Ist die vertikal gestellte Seitenwurzel nunmehr unter anderen Ernährungsverhältnissen, da sie dem Stumpf der Hauptwurzel (die kräftiger ausgebildet ist als die Seitenwurzeln) geradlinig angeschlossen ist.

2. Kann die Schwerkraft die Ausbildung der Wurzel begünstigen. Wieweit indes dieser Einfluß in Betracht kommt, ist fraglich. Dasselbe gilt für eine Beobachtung von $\mathrm{SACHS}^{1}$ ). "Läßt man 5-6 jährige Edeltannen in umgekehrter Stellung (Gipfel abwärts) jahrelang wachsen, so entstehen auf der Rückseite, d. h. auf..der früher abwärts, jetzt aber aufwärts gekehrten Seite der bilateralen Äste neue Triebe, die radiär gebaut sind und wie Keimpflanzen aussehen." Offenbar liegt hier ein Zusammenwirken von Korrelation und Schwerkraftswirkung vor. Durch die umgekehrte Lage wurde das Wachstum des Haupttriebes gehemmt; die seiner Einwirkung jetzt mehr entzogenen Seitenknospen entwickelten sich unter dem fördernden Einfluß der Schwerkraft zu orthotropen Sprossen, wie man dies auch bei umgestürzten Tannen gelegentlich sehen kann, auch bei Entfernung des Gipfels aufrecht wachsender Exemplare.

3. Wie bei der verschiedenen Ausbildung der Knospen in der apikalen und basalen Region der Jahrestriebe die Schwerkraft als mitwirkender Faktor zu der schon vorhandenen polaren Verschiedenheit hinzukommt, so auch bei der Verschiedenheit zwischen orthotropem Hauptsproß und plagiotropen Seitensprossen resp. -wurzeln ${ }^{2}$ ).

Der Einfluß der Schwerkraft auf die Anisophyllie soll in einem besonderen Kapitel besprochen werden.

\section{$\S 12$. Samenpflanzen: Beeinflussung der Organverteilung bei dorsi- ventralen Sprossen durch das Licht.}

Sehr häufig findet sich bei Sprossen, welche eine Licht- und eine Schattenseite haben, die Erscheinung, daß die Wurzeln auf der Schattenseite sich befinden., Vielfach zeigen solche Pflanzen außerdem auch die Erscheinung der positiven Phototrophie, d. h. die Lichtseite ist gefördert, sei es in ihrer Ausbildung, sei es betreffs des Auftretens bestimmter seitlicher Organe.

Die Beschränkung der Wurzeln auf die Schattenseite ist bei Pflanzen, deren Sprosse am Lichte wachsen, offenbar so zu verstehen, daß die Anordnung der Wurzeln ringsum erfolgen könnte, aber auf der Lichtseite verhindert wird. Wissen wir doch aus den Untersuchungen von SACHS, $\mathrm{da} B$ Lichtabschluß (und dementsprechend jedenfalls auch Lichtverminderung) die Wurzelbildung begünstigt, vorausgesetzt, daß sonst die Bedingungen dafür vorhanden sind. An völlig etiolierten Keimpflanzen von Phaseolus,

Flora 1894, p. 229. p. 95 .

2) Betr. Sukknlenten vgl. GozBer, Einleitung in die experimentelle Morphologie, 
Vicia Faba u. a. kommen oft hoch über der Erde zahlreiche Adventiv. wurzeln zum Vorschein (die normal nicht auftreten), wenn die Pflanzen bei Lichte in einem feuchten Raume kultiviert werden.

Im einzelnen seien folgende Beispiele näher erörtert:

1. Kletterpflanzen zeigen häufig (aber nicht immer) eine durch das Licht veranlaßte labile Induktion der Dorsiventralität.

Die Wurzeln entspringen z. B. an den plagiotropen Klettersprossen des Epheu nur auf der Schattenseite, bei älteren mit Kork bedeckten Pflanzen aber findet man oft die ganze Sproßoberfläche dicht mit Wurzeln bedeckt. Die Dorsiventralität der jungen Sprosse ist, wie SACHS gezeigt hat, umkehrbar.

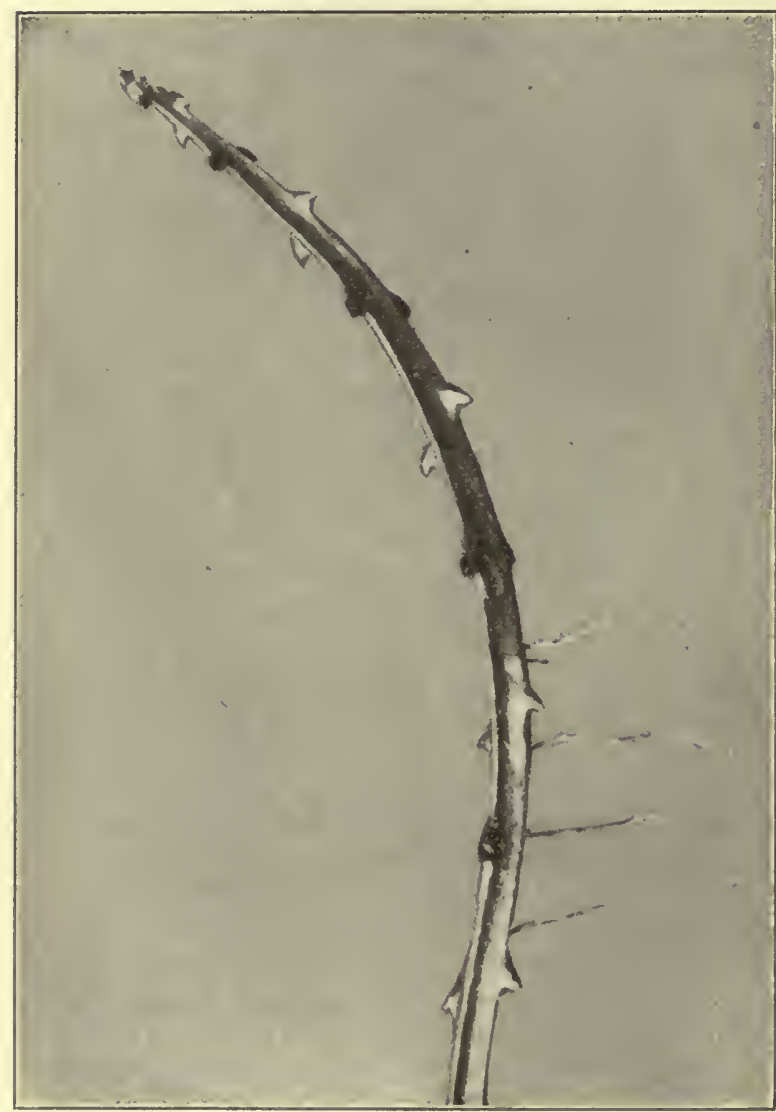

Fig. 446.

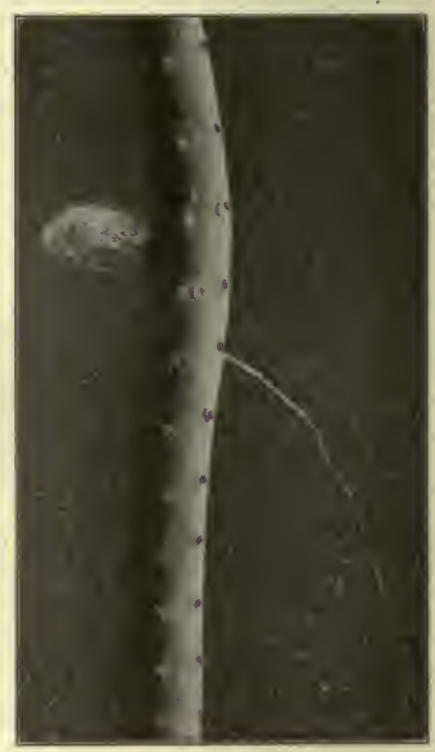

Fig. 447. Cerens nycticalus $(1 / 2)$, Sproß welcher auf der Lichtseite eine Blütenknospe auf der Schattenseite eine Wurzel entwickelt hat.

Fig. 446. Cereus hamatus. Bei einseitiger Beleuchtung (dasLicht kommt von links) aufrecht gewachsener Sproß (verkleinert). Wurzeln, nur anf der Schattenseite, sie zeigen keine geotrop. Krümmung, sind also zunächst ageotropisch. (Ub auch später, wurde nicht untersucht.)

Ähnlich verhalten sich kletternde Kakteen. So zeigt Fig. 446 einen Sproß von Cereus hamatus, der bei einseitiger Beleuchtung aufrecht gewachsen war: Die Wurzeln stehen nur auf der Schattenseite, welche normal die dem Substrat (einem Baumstamm, Felsen usw.) zugekehrt ist. Ebenso verhalten sich Cereus nycticalus, Lepismium radicans u. a.

Wir können dieses Auftreten der Wurzeln auf der Schattenseite als negative Phototrophie bezeichnen. Bei Kakteen tritt aber auch die Erscheinung der positiven "Phototrophie" mit besonderer Deutlichkeit auf. 
An Sprossen von Cereus nycticalus (Fig. 447), welche ich bei einseitiger Beleuchtung kultivierte, fanden sich Blüten nur auf der Lichtseite, also auf der der Wurzelbildung gegenüberliegenden. Ebenso verhalten sich auch große säulenförmige Kakteen wie C. Celsianus u. a.

Auch an a frechten Flachsprossen von (nicht kletternden) Opuntiaarten treten Seitensprosse, die sonst auf die schmalen Kanten beschränkt sind, auf der stärker beleuchteten 'flachen Seite auf. Daß es sich hierbei in erster Linie um eine Lichtwirkung, nicht, wie man teilweise annahm ${ }^{1}$ ), um eine Schwerkraftswirkung handelt, ist sicher. Wenn man in Südtirol an den flach auf dem Boden liegenden Sprossen von Op. vulgaris die Blüten alle auf der Oberseite findet (Fig. 448, 449), so läßt sich natürlich nicht ohne weiteres sagen, ob eine Licht- oder eine Schwerkrafts-

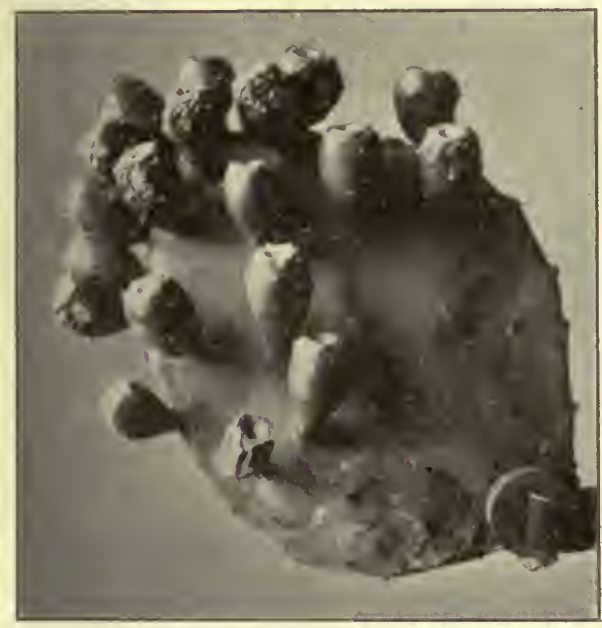

Fig. 448. Opuntia vulgaris. Horizontales Sproßglied von oben.

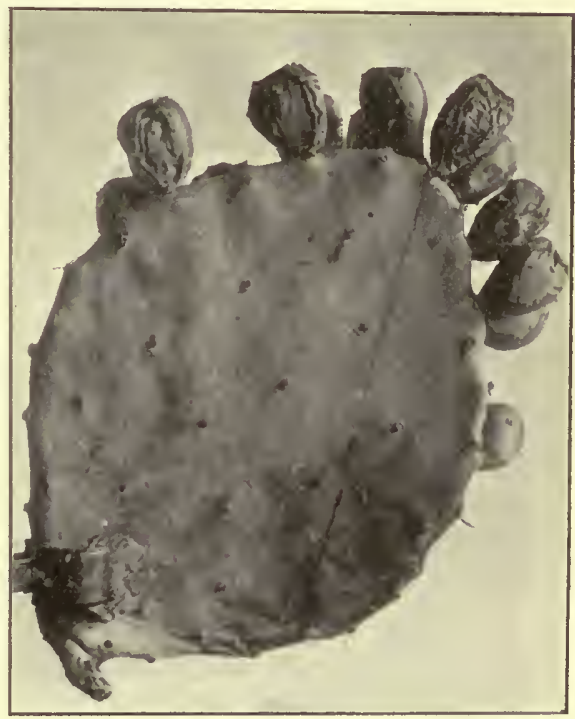

Fig. 449. Opuntia vulgaris. Horizontales Sproßglied von unten (verkl.).

wirkung vorliegt. Anders wenn man vertikal in der OW-Richtung stehende (wobei also eine Flachseite nach Norden, eine nach Süden gekehrt ist) Opuntiaglieder anderer Arten betrachtet. Man sieht dann ${ }^{2}$ ), daß die Blüten auf. der Siidseite auch auf der Fläche auftreten; von einer Schwerkraftswirkung kann hier keine Rede sein. Ob eine solche zu der Lichtwirkung hinzutreten kann, bedarf experimenteller Untersuchung ${ }^{3}$ ). Wenn an einem vertikal stehenden Sproßglied, das eine seitliche Kante

1) SAchs (Gesammelte Abhandlungen II, p. 1215), welcher auf das Verhalten von Opuntia zuerst hinwies, ließ dahingestellt. ob es sich um Schwere- oder Lichtwirkungen handle. PFefrer dagegen (Pflanzenphysiologie, 2. Aufl., p. 124) führt dies Verhalten von Opuntia unter den Fällen an, wo ,durch die Schwerkraft" eine Förderung der Knospenentwicklung auf der Oberseite bedingt wurde.

2) Nach Beobachtungen an in Bordighera im Freien wachsenden Pflanzen.

3) Bei dem Sachs'schen Versuche mit Op. crassa (a. a. 0. p. 1212) wird es sich wohl hauptsächlich um Korrelationen, nicht $\mathrm{nm}$ eine direkte Schwerkraftswirkung bandeln. Auch muß natürlich der Einfluß einer Krümmung ausgeschlossen werden. 
nach oben kehrt, die Bliiten namentlich auf dieser Oberkante auftreten (und zwar weiter nach der Basis hin als sonst), so kann dies sowohl Lichtals Schwerkraftswirkung sein. Indes ist eine Schwerkraftswirkung hier nicht wahrscheinlich, jedenfalls nicht nachgewiesen, während über die Phototrophie kein Zweifel sein kann.

Im vorstehenden wurden die vom Verf. an Kakteen mit einzelstehenden Blüten gemachten Beobachtungen mitgeteilt. Bei anderen Kakteen sind die Blüten in eigentümliche Gruppen "Cephalien" vereinigt ${ }^{1}$ ), die einseitig am Stamm auftreten, und dadurch sowie durch ihre starke Behaarung auffallend hervortreten.

Über die Orientierung dieser Blütenstände lauten die Angaben der Reisenden merkwürdig verschieden. Es seien - da mir selbst keine eigenen Beobachtungen vorliegen - einige angefuihrt.

EhrenberG ${ }^{2}$ ) sagt von Pilocereus senilis: "Wächst . . . auf Tonschiefer und Kalk - in einzelnen Säulen, oder in Gruppen von verschiedener Größe, erreicht eine Höhe von $30-40 \mathrm{FuB}$ bei $1-1^{1} / 2$ Fuß Durchmesser und hat am obersten Teile der Säule einen der Sonnenseite ${ }^{3}$ ) zugekehrten Blütenstand oder Schopf von 1-8 Fuß Länge, welcher Ähnlichkeit mit einer Grenadier-, Bär- oder Sapeurmütze hat."

ZUCCARINI ${ }^{4}$ ) dagegen teilt (nach Beobachtungen von $\mathrm{K}_{\text {ARWINSKI) }}$ über Cereus (Pilocereus) Columna Trajani mit, er werde ungefähr 40 Fuß hoch und werde dann erst, gew öhnlich an der vonder Sonne abgewandten Seite schräg, als hätte man ihm einen Schafspelz übergehängt, aus welchem die Blüten hervorbrechen".

$\mathrm{ULE}^{5}$ ) endlich gibt von Cephalocereus Ulei an: "Die Zweige tragen an der Seite, die nach Sonnenuntergang gerichtet ist, eine dichte, filzige braune Bürste, in der die schuppigen Blüten sitzen. Die aufrechten Arten von Cephalocereus scheinen alle die blütentragende Bürste nur an der Westseite zu entwickeln; sie sind also er.hte Kompaßpflanzen."

Entweder also verhalten sich die verschiedenen Kakteen verschieden, derart, daß die einen auf der stärkst, die anderen auf der am schwächsten beleuchteten Seite ihre Bliiten oder Infloreszenzen entwickeln oder es liegen Verhältnisse vor, die bedingen, daß die stärkst beleuchtete Seite (auf der man auch die Bliitenstände erwarten möchte) mit der Südseite nicht zusammenfällt. Jedenfalls aber liegt eine "Phototrophie" - sei sie nun positiv oder negativ - vor. Es wurde hier darauf näher eingegangen, um zu neuen Beobachtungen anzuregen; sind doch gerade die Kakteen besonders ausgezeichnet durch starke Beeinflußbarkeit.

Nicht nur die Organverteilung, sondern auch die Gestaltung der Vegetationsorgane kann bei den Kakteen durch Phototrophie beeinflußt werden.

Einen lehrreichen Fall bietet Cereus T'estudo (C. pterogonus Lem.), eine Art mit abgeflachten, kriechenden Sprossen, die nach KarwinskY ganz unverästelt und mit Einschnürungen (durch Wachstumsunterbrechungen

1) Betr. deren Aufbau rgl. Gokber, Pflanzenbiol. Schilderungen, p. 91. Daselbst auch Abbildung auf Tafel III, Fig. 1. (1846).

2) Ehrenberg, Beitrag zur Geschichte einiger mexikanischer Kakteen. Liunaea 19

9) A. a. 0. als Druckfehler „Sommerseite". Sperrung von mir, ebenso bei den anderen Zitaten.

4) Flora 1832, p. 588.

8) E. ULE, Die Kakteen im bras. Staate Bahia. Zeitschrift für Kakteenkunde (1908), p. 23. 
bedingt) versehen einem Zuge dicht hintereinander gehender dunkelgrüner Schildkröten ähnlich sind, der an Felsen in die Höhe klettert ${ }^{1}$ ).

Fig. 450 stellt ein Stück eines importierten Exempiares dieser (oder einer verwandten) Art dar; von oben gesehen; darunter ist der Querschnitt. Man sieht, daß der Sproß eigentlich $\tilde{5}$ kantig ist, daß sich aber die Lichtseite stark vergrößert hat und hier auch der Winkel zwischen den Kanten (der eigentlich $72^{\circ}$ betragen sollte) sich auf fast $180^{\circ}$ vergrößert hat. Die 3 anderen Kanten sind dagegen zurückgeblieben, am meisten die ganz auf der Schattenseite stehende. Das Sproßstück hat (wohl weil ihm der Gipfel fehlte) einen Seitensproß getrieben, welcher 4 kantig ist und die Förderung der Lichtseite gleichfalls schon erkennen

Fig. 450 .

Cereus Testudo

(C. pterogonus Lem.).

Oben Stïck eines importierten Sprosses. Ein Stück der Oberseite ist weggeschnitten, um die in der Rinne vorhandenen Wurzeln zu zeigen. Links ein Seitensproß mit beginnender Abflachung auf der Lichtseite.

Unten Querschnitt durch das alte Sproßstück; man sieht, daß die obersten Kanten am stärksten entwickelt sind.
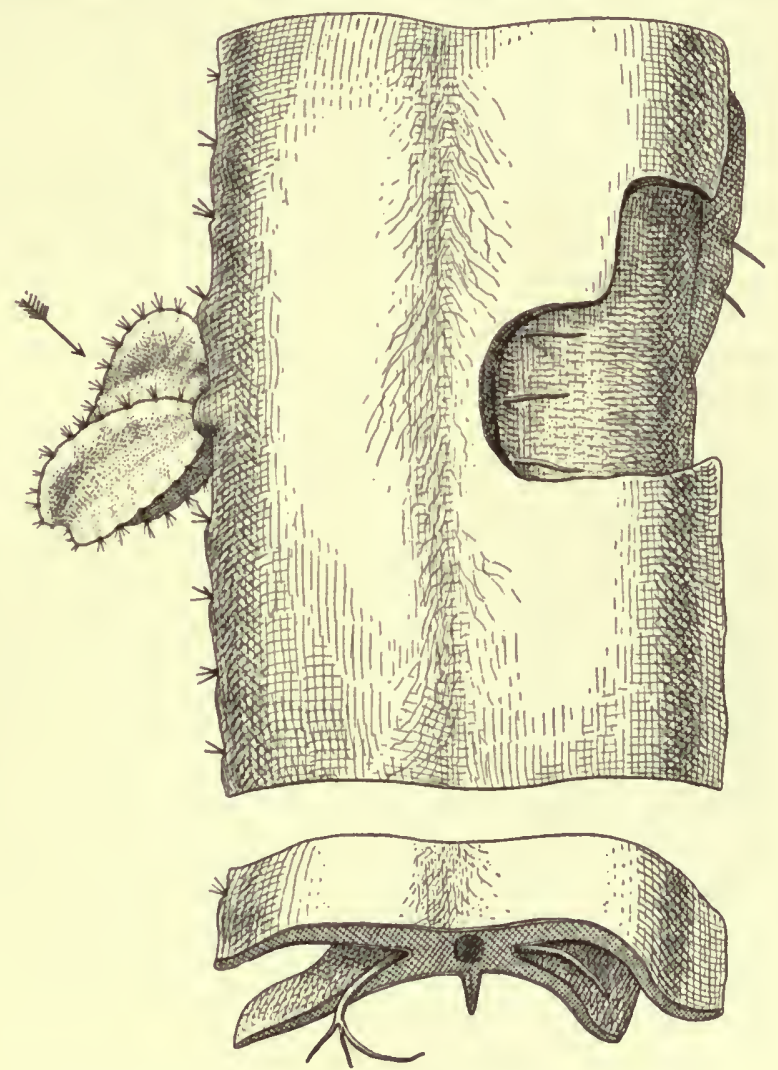

läßt. Indes bildete sich in der Kultur - vielleicht infolge der geringeren Besonnung - die Phototrophie an dem langgestreckten Sprosse weniger aus, als das Vaterlande der Fall war. Daß die Abflachung eine Folge des stärkeren Wachstums der stärker beleuchteten Flächen der oberen Kanten ist, bedarf kaum der Erwähnung.

1) Zuccarini, Plant. nov. sp. fasc. III, Cacteae (1835-36), p. 682. Das von mir untersuchte Exemplar verdanke ich der Freundlichkeit des Herrn Garteninspektor Purpus in Darmstadt. Es macht bis jetzt mehr den Eindruck, als ob die "Schildkröten" als Seitensprosse an weniger gestreckten und kaum abgeflachten Trieben entständen, was aber vielleicht den Kulturbedingangen zuzuschreiben ist. Möglicherweise handelt es sich auch nicht um die von KarwINski beschriebene Art.

Goebel, Organographie der Pflanzen. 2. Aufl. Allgem. Teil. 
Bei anderen Kletterpflanzen ist die Dorsiventralität dagegen keine vom Licht direkt induzierte. So hat z. B. die Monokotyle Pothos scandens flache auf der Substratseite Wurzeln hervorbringende Sproßachsen. Es gelang aber nicht die Dorsiventralität durch Beleuchtungsänderung umzukehren. Die Sprosse suchen vielmehr, wenn sie aus ihrer ursprünglichen Lage gebracht werden, die normale Orientierung der Licht- und der Schattenseite durch Krümmungen wieder einzunehmen.

2. Mit Rücksicht auf die p. $301 \mathrm{ff}$. erwähnten einseitigen Inflores zenzen sei erwähnt, daß bei einigen Pflanzen die Blütenstände direkt phototrophisch beeinflußt werden. So naclı WIEsner bei Rhinanthus alpinus ${ }^{1}$ ). Die Blüten werden hier vierreihig angelegt, verkümmern aber an der Schattenseite mehr oder minder vollständig. Die terminale Infloreszenz bildet sich bei gleichmäßiger Beleuchtung allseitig gleich aus; die seitlichen Blütensprosse richten sich nicht vertikal auf und sind deshalb stets einseitig beleuchtet.

3. Als Phototrophie bezeichnet werden kann auch die Tatsache, daß an den geneigten Ästen einiger Holzpflanzen die Ausbildung der Seitenäste auf der Lichtseite gefördert ist. So kommen bei Lycium barbarum nach Wiesner ${ }^{2}$ ) an geneigten Ästen nur die an der Oberseite gelegenen Sprosse zur Entwicklung, je nach den Beleuchtungsrerhältnissen aber auch die seitlichen oder sogar die unteren. Analoges gilt für andere Holzgewächse z. B. Ligustrum vulgare.

4. Begonia. Die Gattung wurde oben besprochen. Hier sei noch hinzugefügt, daß das erste Primärblatt symmetrisch zu sein pflegt (ob bei allen Arten?). Nach Kolderup-Rosenvinge ${ }^{3}$ ) soll bei Begonia Schmidtii zur Plusseite (d.h. zu der, welcher die größeren Blatthälften zugewandt sind) bei Keimpflanzen die stärker beleuchtete werden. Indes ergaben sich eine Anzahl von Ausnahmen und bei Beg. Franconis soll sowohl das Licht (unter bestimmten Bedingungen) als die Schwerkraft die Plusseite bestimmen, aber die Dorsiventralität auch ohne äußere Einwirkungen entstehen können (Klinostatenversuche würden das wohl entscheiden können). Nach Beobachtungen an verschiedenen Begonien ist mir zweifellos, daß die Plusseite auch die dem Licht abgewandte sein kann. Zudem kommt bei den Seitensprossen der Einfluß der Hauptachse in Betracht. Es bleibt hier also noch manches aufzuklären, wahrscheinlich scheint nur, daß äußere Faktoren die Lage der Plusseite bestimmen können, aber nicht, ob Dorsiventralität auftritt oder nicht, was auseinanderzuhalten ist; die Begonien verhalten sich also, soweit derzeit bekannt, anders als die im folgenden besprochene Pflanze.

\section{Kriechende Rhizome.}

Unter den Nymphaeaceen besitzen einige radiäre Rhizome (z. B. Victoria regia, Nymphaea rubra u. a.), andere sind mit kriechenden Rhizomen versehen, die aus einem ursprünglich radiären Jugendstadium hervorgehen. Daß die im späteren Lebensalter auftretende Dorsiventralität durch das Licht "induziert" wird, zeigt Nuphar luteum. Das langgestreckte p. 804 .

1) Wiesner, Die Stellung der Blüten zum Lichte. Biolog. Zentralblatt XXI (1901),

2) J. Wiessier, Der Lichtgenuß der Pflanzen. Leipzig 1907, p. 77. Daselbst die früheren Abhandlungen des Verf. zitiert.

3) L. Kolderup-Rosenvinge, Influence des agents extérieures sur l'organisation polaire et dorsiventrale des plantes. Revue générale de botanique I (1889). 
Rhizom dieser Pflanze kriecht in Schlamm, es ist mit Blattnarben dicht besetzt. Die Blätter entstehen an der Stammknospe in durchaus radiärer Anordnung. Die Blattinsertionen rücken aber auf der Unterseite viel weiter auseinander als auf der Oberseite, es ist eine Annäherung an das Verhalten vieler anderer dorsiventraler Sprosse vorhanden (vgl. p. 221), bei denen die Blätter der Oberseite genähert stehen. Die Wurzeln entspringen auf der Unterseite, regetative Seitenzweige auf den Flanken ${ }^{1}$ ). Wird ein solches dorsiventrales Nupharrhizom mit Erde bedeckt, so wächst es aufrecht und radiär weiter, bis es wieder an das Licht gelangt. Die Dorsiventralität ist hier also offenbar durch das Licht bedingt, sie äußert sich in der Verschiebung der Blattnarben und in der Stellung der Wurzeln ${ }^{2}$ ). Inwieweit die letztere rom Licht direkt oder indirekt bedingt wird, ist noch festzustellen.

6. Negative Phototrophie bei den Knollen ron Solanum tuberosum.

Ähnlich wie die Bildung der Wurzeln wird auch die Bildung anderer, normal unterirdisch auftretender Organe durch Lichtabschluß begiinstigt und dadurch eine Orientierung herbeigeführt. So die der Kartoffelknollen ${ }^{3}$ ). Das Licht wirkt auf die Knollenbildung hemmend, die Dunkelheit begünstigend. Man kann an Pflanzen, bei denen die Ausläuferbildung verhindert, also die Möglichkeit unterirdischer Knollenbildung abgeschnitten wird, sogar nahe der Spitze der oberirdischen Sprosse durch Verdunkelung Knollenbildung hervorrufen. Übrigens übt auch die Schwerkraft eine Einwirkung auf die Knollenbildung aus, welche dahin wirkt, daß die Knollensprosse an dem nach unten gekehrten 'Teile der Hauptachse auftreten (Näheres bei VöchtıNg a. a. O. p. 39). Jedenfalls aber wird unter gewöhnlichen Verhältnissen das Licht, indem es die Bildung der Knollen an den oberirdischen Teilen hemmt, auf deren Anordnung wirken und das Auftreten an den unterirdischen Ausläufern begünstigen.

7. Wie die einseitige Verteilung der männlichen Blütenstïnde von Cephalotaxus (Fig. 45j1) zustande kommt, ist näher zu untersuchen. Die Nadeln sind hier steil nach der Lichtseite hin aufgerichtet, die männlichen Blütenstände stehen alle auf der Unterseite, selten finden sich einzelne auf der Oberseite. Es kommt so eine Verteilung der Organe zustande, welche einigermaßen an die bei den Farnprothallien vorhandene erinnert; indes kann es sich hier auch um eine Beeinflussung durch die Schwerkraft handeln. - Eine negative Phototrophie ist für Blüten sonst nicht nachgewiesen, sie könnte möglicherweise bei Klugia ceylanica vorhanden sein -, wenigstens stehen die Blüten hier auf der Schattenseite der dorsiventralen Blütenstände (p. 306).

\section{$\S 13$. Oberflächenvergrößerung durch Lichteinfluß bei Samenpflanzen.}

An die Phototrophie angeschlossen werden mag die Erwähnung der Oberflächenvergrößerung durch Lichteinfluß (wie sie ja schon bei Cereus

1) Die Rhizome sind also hinsichtlich der Seitensprosse amphitroph wie viele Moosstämmchen.

2) Vgl. Raciborskı. Die Morphologie der Cabombeen und Nymphaeaceen. Flora 78 (1894), p. 258.

3) Vöchting, Über die Bildung der Knollen. Biblioth. botanica, Heft 4. 1884. Bezüglich anderer Fälle, in denen schon frühere Autoren die negative Phototrophie erkannt hatten vgl. Goeber, Einleitung in die exp. Norphol., p. 106. 
Testudo hervortritt). Wir sehen dabei ab von der Besprechung solcher Tatsachen wie die, daß bei manchen Pflanzen die normale Blattentfaltung nur am Lichte stattfindet, während bei etiolierten Pflanzen die Blätter klein bleiben und erwähnen nur das Verhalten einiger Sproßachsen.

Die meisten Kakteen haben unter Verkümmerung ihrer Blätter ihre Sproßachsen zu Assimilationsorganen (und Speicherorganen) umgestaltet, Diese zeigen vielfach die Erscheinung der Oberflächenvergrößerung, die in verschiedener Weise vor sich gehen $\operatorname{kann}^{1}$ ).

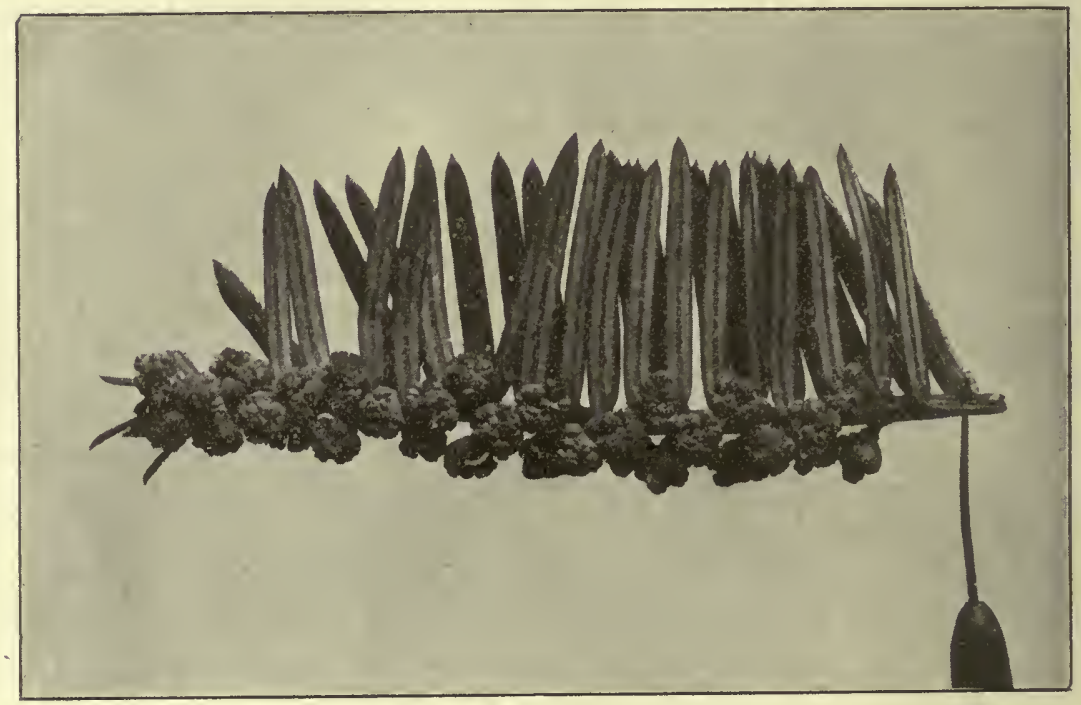

Fig. 451. Cephalotaxus drupacea. Zweig mit männlichen Blütenständen von der Seite gesehen. Diese stehen auf der dem Lichte abgewendeten Seite, nur selten finden sich einzelne auf der dem Lichte zugekehrten.

Die Sproßachsen vieler Opuntiaarten sind stark abgeflacht, sie gehen aus einem radiären Vegetationspunkt hervor und zeigen ihre ursprünglich radiäre Anlage auch darin, daß sie allseitig mit Dornbücheln besetzt sind. Bei einigen Formen (vgl. Op. leucotricha Fig. 452) wurde festgestellt ${ }^{2}$ ), daß die Abflachung bei Lichtabschluß unterbleibt, die etiolierten Sprosse also zylindrisch weiter wachsen. Bei anderen Arten sind nach gelegentlichen Wahrnehmungen die etiolierten Sprosse zwar flach, aber viel schmaler als die normalen. Setzt man derartige Sprosse dem Lichte aus, so erfolgt an den neu zuwachsenden Teilen die normale, flache Ausbildung (und zwar nach SACHS bei kräftiger einseitiger Beleuchtung so, daß die Flächen rechtwinklig zum einfallenden Lichtstrahl stehen). Lehrreich ist namentlich das Verhalten derjenigen Opuntiaarten, bei welchen die Oberflächenvergrößerung nicht durch Abflachung, sondern durch Höckerbildung auf der Stammoberfläche erfolgt: die Bildung dieser Höcker unterbleibt (z. B. bei Op. arborescens) im Finstern.

Bei Phyllocactus (einer Gattung, die von Cereus nur durch habituelle

1) Vgl. S. I.

2) Goeber, Über die Einwirkung des Lichtes auf Kakteen und andere Pflanzen. Flora Bd. 1895, p. $26 \mathrm{ff}$. Daselbst sind auch die Mitteilungen von SAcHs zitiert. 
Merkmale getrennt ist) sind die Assimilationssprosse blattartig, die Dornbüschel stehen nur an den Rändern. Bei Ph. latifrons werden im Finstern die Sprosselediglich schmal, bleiben aber bilateral, nur daß. wie bei etiolierten Marchantieen, die Flügelbildung sehr verringert ist. Bei Ph. phyllanthoïdes (der aber mit Cereusarten sehr häufig bastardiert ist) ist die Neigung, $m$ e h r kantige, flügellose Sprosse zu bilden, noch viel mehr vorhanden, man erhält im Finstern Sprosse mit mehreren Reihen von Dornbüscheln; setzt man sie der Beleuchtung aus, so tritt Flügelbildung und dann Reduktion der Flügel auf zwei ein. Auf die Einzelheiten kann hier nicht eingegangen werden ${ }^{1}$ ).

Die geschilderte Lichtwirkung ist keineswegs auf die Kakteen beschränkt. In Fig. 453 ist ein Sproßstïck von Genista sagittalis abgebildet. Die Blätter sind sehr reduziert, die Sproßachse breit gefliigelt, wie dies das rechts stehende Stiuck zeigt. Links ist ein im Dunkeln entwickelter Seitensprob. An ihm sind die (von den Blattbasen ausgehenden) Flügel nur als wenig hervortretende Kanten angedeutet; der ganze Sproß hat ein durchaus anderes Aussehen gewonnen, weil die Oberflächenvergrößerung nicht stattgefunden hat.

Nicht alle Pflanzen aber reagieren gleich. Die blattähnlichen Zweige von Ruscus aculeatus z. B. sind an etiolierten Sprossen zwar kleiner als

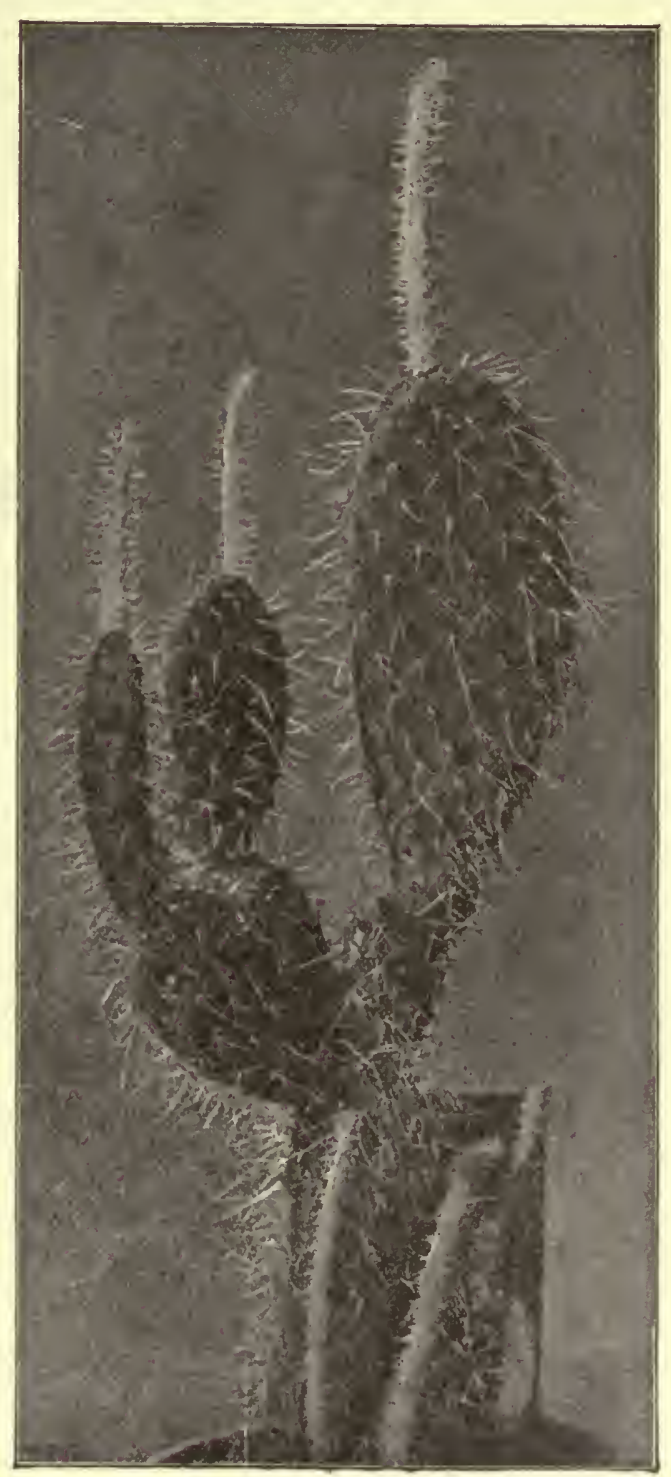

Fig. 45๊2. Opuntia leucotricha. Pflanze, welche im Finstern ausgetrieben hat. Die hier entfalteten Sprosse sind zylindrisch (nicht abgeflacht, wie die Lichtsprosse). Ihre Internodien haben sich nicht (wie dies bei anderen etiolierten Sprossen sonst die Regel ist) iuberverlängert.

1) Vgl. anßer der angeführten Literatur auch VöchтाкG in Pringsh. Jahrb. Bd. XXVI, p. 438 (Über die Bedeutung des Lichtes für die Gestaltung blattförmiger Kakteen). 
die am Lichte erwachsenen, aber stimmen sonst in ihrer Gestalt mit ihnen iiberein.

Man kann hierher auch die Beobachtung rechnen, daß bei manchen Pflanzen das Licht dariber entscheidet, ob ein Blatt sich als schuppenförmiges Niederblatt oder als ein kleines Laubblatt entwickelt. So ist es z. B. bei den Ausläufern von Circaea ${ }^{1}$ ). Die Keimpflanzen bilden einen orthotropen Laubblattsproß. In den Achseln der Kotyledonen und der

Fig. 4ə̋3. Genista sagittalis. Rechts Stück eines normalen, "geflügelten" Sprosses, links im Dunkeln erwachsener, ungeflügelter Sproß.

untersten Laubblätter bilden sich Zweige, die in die Erde eindringen. Sie haben zunächst Laubblätter, die - wohl im Zusammenhang mit dem geneigten Wuchs - kleiner sind als die der orthotropen Sprosse. Im Boden bilden sie nur Schuppenblätter. Läßt man einen derartigen Ausläufer am Lichte wachsen (z. B. in einer beleuchteten Wasserkultur), so bilden sich statt der Schuppenblätter kleine Laubblätter aus, die von der Sproßachse abstehen, was jedenfalls mit dem Chlorophyllgehalt zusammenhängt. Indes reagieren keineswegs alle Circaeasprosse gleich. Die orthotropen bilden bei Verfinsterung keine Schuppen(Nieder-)blätter, sondern etiolierte Laubblätter. Es ist also eine bestimmte Sproßbeschaffenheit notwendig, um die angegebene Reaktion herbeizuführen.

Ähnlich scheinen sich die Ausläufer einiger

Hieraciumarten zu verhalten, während die von Adoxa, auch wenn sie beleuchtet werden, nur Niederblätter bilden.

Bei Circaea handelt es sich aber nicht nur um eine Oberflächenvergrößerung, sondern auch um eine Funktionsänderung, ähnlich der, die oben (p. 457) für einige Algen angeführt wurde.

Bei sehr schwacher Beleuchtung kommen bei Codium ${ }^{2}$ ), einer Siphonee, welche aus einem vielfach verzweigten und verflochtenen Schlauche besteht, die großen peripherischen, der Assimilation dienenden blasenförmigen

1) Goeber, Beitr. zur Morphol. und Physiol. des Blattes. Bot. Zeit. 1880, p. 794.

2) Berthold, Morphol. und Physiologie der Meeresalgen. Jahrb. für wissensch. Botanik XIV. 
Auszweigungen nicht zustande, es unterbleibt also auch hier die Oberflächenvergrößerung.

Ebenso entstehen bei Caulerpa ${ }^{1}$ ) die blattähnlichen Organe nur am Lichte (von bestimmter Intensität), im Dunkeln bilden sich statt ihrer zylindrische Organe.

In den angeführten Fällen ist also das Licht eine Bedingung für das Eintreten der Oberflächenvergrößerung. Wi e es wirkt, ist ganz unbekannt. Daß man die Etiolierungserscheinungen von Opuntia und Phyllocactus nicht als eine "Anpassung" betrachten kann, ist klar.

\section{$\S 14$. Die Bedingungen fïr das Zustandekommen der Anisophyllie.}

Die im Abschnitt III besprochenen Beispiele von Anisophyllie, welche sich über fast alle Hauptgruppen der Pflanzen erstrecken, legen die Frage nahe, ob die Anisophyllie rein aus ,inneren" Gründen oder infolge der Einwirkung der Außenwelt zustande kommt?

Diese Frage ist viel erörtert worden. Sie ist eine außerordentlich interessante, weil gerade sie besonders geeignet erscheint, die Abhängigkeit der Organbildung der Pflanzen von äußeren Faktoren experimentell zu prüfen. Es ist auch in Abschnitt III sowie in diesem Abschnitt §5 schon auf diese Frage hingewiesen worden; hier seien nur die wesentlichsten Punkte kurz erörtert.

Als äußere Faktoren kommen in Betracht namentlich Ernährungsverhältnisse, Licht und Schwerkraft, als innere die Beziehungen eines Seitensprosses zu seinem Hauptsproß (Exotrophie“) und Korrelationsverhältnisse. Dabei ist nicht zu vergessen, 1. daß die Reaktionsfähigkeit eines Sprosses nicht immer dieselbe ist, 2. daß auch die inneren Bedingungen, (welche z. B. für die Umwandlung eines anisophyllen vegetativen Selaginellasprosses in einen isophyllen fertilen (oder einen Gallensproß von S. pentagona, vgl. p. 448) maßgebend sind, ihrerseits von äußeren Faktoren abhängen, nur ist uns die Verkettung vielfach noch ganz unbekannt. Bei Sel. pentagona nahmen wir als innere Ursache für das Aufhören der Anisophyllie ein Zuströmen von Baustoffen an, welches durch das Gallinsekt bedingt wird.

Indem ich auf die zusammenfassende Darstellung Figdon's ${ }^{2}$ ) verweise, möchte ich folgendes hervorheben.

Bryophyten. Daß die Anisophyllie bei den einer Unterlage angeschmiegten Ausläufern von Mnium offenbar durch das Licht bedingt ist, wurde oben hervorgehoben; es bleiben die auf der Schattenseite befindlichen Blätter kleiner. Bei Formen wie Hypopterygium und Cyathophorum ist die Anisophyllie dagegen eine habituelle, bei schlechter Ernährung und im schwachen Licht ist sie nur weniger ausgeprägt, und wenn man einen Cyathophorumsproß umkehrt, sucht er durch Krümmung die Oberseite wieder nach oben $\mathrm{zu}$ richten ${ }^{3}$ ). Wir haben also bei Moosen sowohl induzierte als habituelle Anișophyllie.

Pteridophyten. Auch bezüglich Selaginella sei auf das oben

1) KцEM⿻, Über Caulerpa prolifera. Flora 1893, p. 460.

2) Figdor, Die Erscheinung der Anisophyllie, 1909.

3) Boshart (Flora 103, p. 102) gibt an, daß schwache Exemplare sich nur so weit drehen, daß zwei Zeilen (also eine durch Seitenblätter und eine durch die kleinen Unterblätter gebildete) nach oben kommen and daß diese beiden dann zu den großen Blättern werden. Es wird aber schwer sein, hier Torsionen ganz auszuschlielien. 
Gesagte verwiesen; eine Umdrehung der Dorsiventralität (durch Beleuchtung der Unterseite usw.) gelang experimentell nicht, wird aber, wie erwähnt, bei den invers dorsiventralen Blüten mancher Selaginellen ausgeführt.

Ein Fall, in welchem Anisophyllie direkt durch das Licht bedingt ist, ist bei L. complanatum vorhanden (vgl. Fig. 454). Ich verfinsterte im Herbst die oberirdischen Teile mehrerer Pflanzen an ihrem natürlichen Standort durch Überstülpen eines Topfes. Die im nächsten Jahre entwickelten Teile waren radiär. Wir haben früher (p. 238) gesehen,

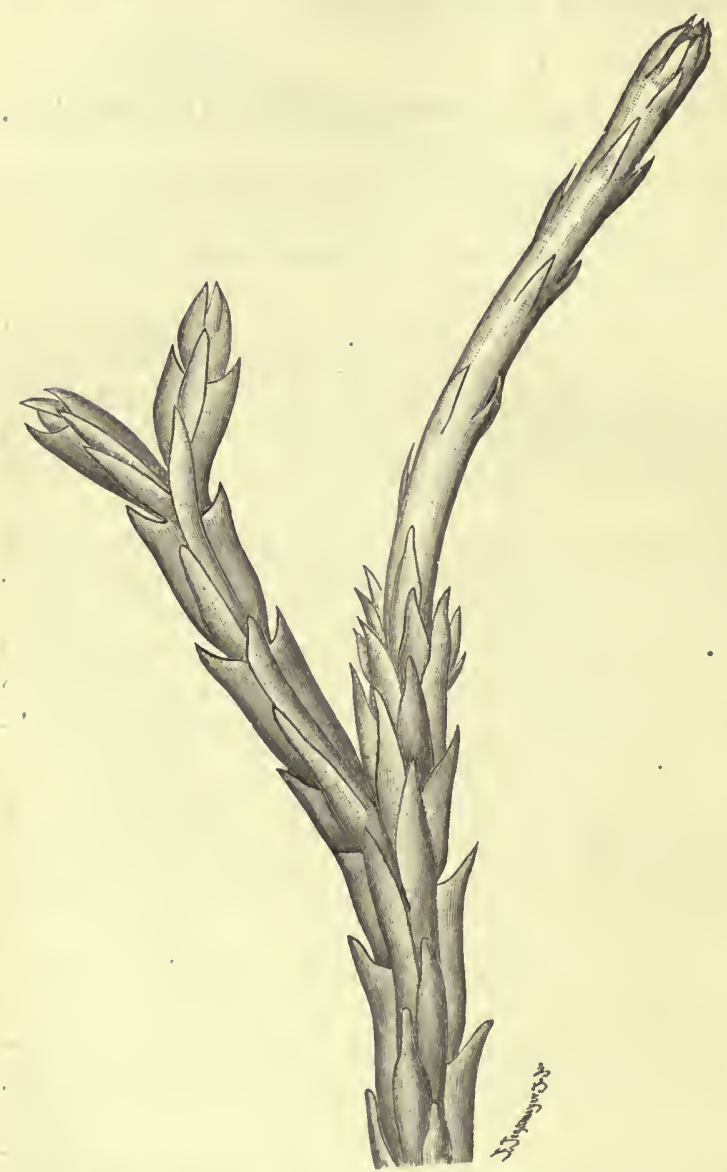

Fig. 454. Lycopodium complanatum (vergr.). SproB, der im Dunkeln ausgetrieben hat; nur die Hauptachse des Seitensprosses hat ausgetrieben und der neu zugewachsene Teil hat radiäre Ansbildung erfahren. gleich entwickelt, keine Spur der Kielbildung an den seitlichen Blättern, nur eine leichte Abflachung der Sproßachse war erkennbar (vgl. Fig. 455 rechts). Auch die Verzweigung geschah nicht mehr in einer Ebene, und es bildeten sich nicht die blattähnlichen Seitensprosse begrenzten Wachstums. Kurz, diese Sprosse verhielten sich im wesentlichen wie die unterirdischen Rhizomsprosse, Dorsiventralität und Anisophyllie werden direkt durch das Licht hervorgerufen. 
Conifer en. Dasselbe gilt, wie zuerst Frank $^{1}$ ) nachwies, auch für die anisophyllen dorsiventralen Seitensprosse der Cupressineen (vgl. p. 247). Ob es möglich ist, auch den $\mathrm{Hauptsp} \mathrm{r}$ ○ $\mathrm{B}$ dieser Pflanzen durch einseitige Beleuchtung anisophyll und dorsiventral $\mathrm{zu}$ machen, ist nicht untersucht.

Schon Beobachtungen im Freien zeigen, daß auch bei anderen Nadelhölzern das Licht bei der Erscheinung der Anisophyllie von erheblichem Einfluß ist.
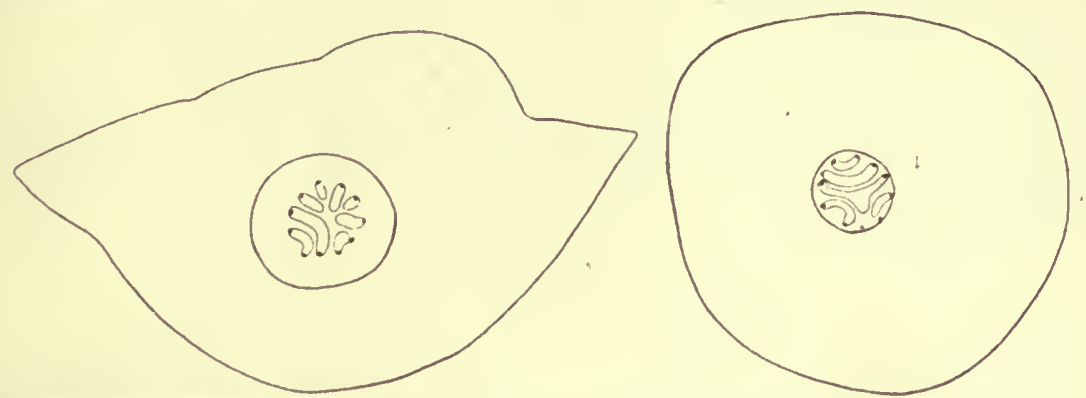

Fig. 455. Lycopodium complanatum. Querschnitt durch ein und dieselbe Sproßachse (links am Lichte, rechts im Dunkeln gewachsen).

So bei der Tanne, Abies pectinata ${ }^{2}$ ). Die plagiotropen Seitenäste dieses Baumes sind bekanntlich dorsiventral. Es zeigt sich dies sowohl in der Stellung als in der Ausbildung der Nadeln. Die erstere ist bei Abies pectinata eine verschiedene, je nach den Beleuchtungsverhältnissen. Bei den unteren Zweigen im Schluß stehender Bäume oder bei jüngeren Exemplaren, die im Schatten älterer wachsen, sind die sämtlichen Nadeln "gescheitelt", d. h. sie sind durch Drehung an der Blattbasis so gestellt, daß sie ihre grüne (Ober-) Seite nach oben, dem Lichteinfalle zu, ihre weiße Unterseite nach unten kehren. Ein solcher Sproß verhält sich dann wie ein Marchantiathallus: er besitzt eine von der Unterseite verschieden gebaute Oberseite. Dies zeigt sich auch in den Größenverhältnissen der Blätter: die auf der Oberseite stehenden Blätter sind bedeutend kürzer als die auf der Unterseite stehenden. Einige Messungen der Blattlänge mögen dies zeigen.

1. Blatt auf der $Z_{\text {weigunterseite, das seine Oberseite ohne Drehung }}$ der Blattbasis nach oben kehrt: $16 \mathrm{~mm}$.

2. Darauf folgendes Blatt auf der Flanke, der Rückenseite genähert: $10,5 \mathrm{~mm}$.

3. Nächstes ganz auf der Oberseite inseriertes: $8 \mathrm{~mm}$.

4. Nächstes ganz auf der Unterseite inseriertes: $18 \mathrm{~mm}$.

Die Länge ist also zuweilen mehr als die doppelte, die kleinsten Blätter sind die am weitesten auf der Oberseite stehenden, die größten die auf der Schattenseite stehenden, die aber in Wirklichkeit am Sproß seitliche Stellung einnehmen. Die Blätter am aufrecht wachsenden Haupt-

1) A. Frank, Über den Einfluß des Lichtes auf den bilateralen Bau der symmetrischen Zweige der Thuja occidentalis. Jahrb. für wissensch. Kot. IX (1873-74), p. 147.

2) GoEBEL, Vergleichende Entwicklungsgeschichte, 1883, p. 140. Vgl. auch „Über einige Fälle von habitueller Anisophyllie". Botan. Zeitg. 1880, p. 839, wo die Beziehungen zum Lichte und zum plagiotropen Wuchse hervorgehoben sind. 
sproß dagegen sind alle gleich groß; mit ihnen verglichen haben die auf der Lichtseite stehenden Blätter an den Zweigen eine Hemmung in ihrer Ausbildung erlitten.

Bei freistehenden, kräftiger Beleuchtung ausgesetzten Zweigen sind die Nadeln nicht gescheitelt, ihre Fläche ist also nicht rechtwinklig zur Richtung der einfallenden Lichtstrahlen gestellt, sondern die Nadeln sind alle miteinander mehr oder minder steil gegen die Rückseite des Sprosses hin aufgerichtet. Die rückenständigen Nadeln zeigen dabei nicht selten auf ihrer Oberseite Wachsstreifen, welche aber nicht so stark entwickelt sind wie die auf der Unterseite ${ }^{1}$ ). Die Anisophyllie tritt auch hier hervor, aber doch nicht so auffallend wie in dem oben genannten Falle, sie ist ohne Messung kaum wahrnehmbar. Einige Beispiele beliebig herausgegriffener rückenständiger (a) und bauchständiger (b) Nadeln mögen dies zeigen.
a
$\mathrm{b}$
$19 \mathrm{~mm}$
$22 \mathrm{~mm}$
$16 \mathrm{~mm}$
$21 \mathrm{~mm}$

Zuweilen sind die Differenzen größer, zuweilen auch kleiner. Die Beziehungen der Dorsiventralität zur Beleuchtung sind hier einleuchtend ${ }^{2}$ ).

Damit ist zunächst noch nicht gesagt, daß das Licht die Ursache der Anisophyllie ist. Es könnte diese ja bedingt sein durch einen anderen Faktor, der die Unterseite zur geförderten und die hier stehenden Blätter zu den größeren macht. Das könnte aber verdeckt werden, entweder durch die Phototrophie, d. h. die Förderung, welche die Blätter der Zweigoberseite bei starker Beleuchtung erfahren, oder auch dadurch, daß bei starker Beleuchtung eine stärkere Bildung organischer Substanzen eintritt, welche die Anisophyllie weniger hervortreten läßt (p. 449).

Die Anisophyllie läßt sich, wie aus einem Versuche von KNY ${ }^{3}$ ) hervorgeht, umkehren.

„Mehrere Zweige von Abies pectinata wurden Anfang November 1871 in umgekehrter Stellung festgebunden. Als dieselben im Frühjahr 1872 ihre Knospen, ohne seitliche Drehung zu erleiden, entfalteten, erfuhr die Horizontalstellung der Blätter eine der neuen Lage entsprechende Änderung, so daß die Rückenseite nach oben, die Bauchseite nach unten gekehrt war; dagegen blieb die Anisophyllie in demselben Sinne erhalten, wie sie bei normaler Stellung aufgetreten wäre, d. h. es waren die oberen Blätter die längeren, die unteren die kürzeren. Das relative Verhältnis der längsten und der kürzesten Blätter zeigte sich nur wenig vermindert. Erst im Frühjahr 1873, also $1 \frac{1}{2}$ Jahre nach Beginn des Versuchs, trat der Einfluß der neuen Lage auf die Massenentwicklung der Blätter unzweideutig hervor, indem jetzt an den neu

1) Das ist von Interesse bezüglich der p. 494 erörterten Frage, ob die dorsiventrale Ausbildung der Blätter von äußeren Bedingungen heeinflußt werde. Abies nobilis hat z. B. an den Nadeln (die aufgerichtet sind) an beiden Flächen Wachsstreifen.

2) Ganz ähnlich liegt die Sache bei Seitenzweigen zweiter Ordnung von A. Nordmanniana u. A. Veitchii, die aufrecht wachsen und auf der stärker beleuchteten adaxialen Seite größere Nadeln als auf der abaxialen haben. Solche hat Figdor beobachtet (a. a. 0 . p. 120). Hier fällt der Faktor, welcher durch die horizontale Lage der Seitensprosse sonst gegeben ist, weg. und kommt nur die Lichtwirkung in Betracht. Übrigens werden die Hauptachsen auch hier wohl anders reagieren.

$\left.{ }^{3}\right)$ KNy, Über die Bedeutung der Florideen in morphologischer und histologischer Beziehung und den Einfluß der Schwerkraft auf die Coniferenblätter. Botan. Zeitung 1873 , p. 433. 
austreibenden Knospen (welche am Muttersproß nach erfolgter Umkehrung angelegt waren) sich die Anisophyllie, der neuen Lage entsprechend, umgekehrt zeigte."

Dieser Versuch zeigt zunächst, daß die Anisophyllie schon in der Knospe bestimmt ist. Dasselbe habe ich (a. a. O. p. 840) auch für die Knospen von Aesculus Hippocastanum nachgewiesen, welche anisophylle Sprosse in der durch die ursprüngliche Lage am Muttersproß bedingten Weise, sowohl im Finstern als in den verschiedensten Lagen am Lichte aufweisen.

Die Anisophyllie der Seitensprosse von Abies pectinata wird also jedenfalls durch die Lage direkt bedingt, wie ja auch daraus hervorgeht, da $\$$ Seitenzweige sich aufrichten und $\mathrm{zu}$ isophyllen Hauptsprossen werden können. Es ist wahrscheinlich, daß - von den Korrelationsverhältnissen ${ }^{1}$ ) abgesehen - die Schwerkraft die Hypotrophie der Zweige bedingt, während starke Beleuchtung die Anisophyllie hier fast ausgleicht.

Bei Tsuga canadensis, wo auch der Hauptsproß anisophyll ist, dürfte die Anisophyllie fester sitzen. Fraxk ${ }^{2}$ ) fand bei dieser Pflanze, daß bei im Dunkeln gezogenen Seitenzweigen die Größenunterschiede der Nadeln geringer waren als am Licht (Oberblätter : Unterblätter $=6,2 \mathrm{~mm}: 11,6$ statt $4,17 \mathrm{~mm}: 12 \mathrm{~mm}$. Daraus könnte man schließen, daß das Licht eine hemmende Wirkung auf die Oberblätter ausübt. Die obersten kleinsten Blätter kehren ihre Unterseite nach oben, fiihren also keine Drehung aus, wie die mehr seitlich stehenden, bei denen aber die Drehung nicht immer so weit geht. daß die adaxiale Seite nach oben, gekehrt wird. Falls eine hemmende Einwirkung des Lichtes auf die Oberblätter besteht (und diese nicht etwa eine Korrealation ist), könnte sie also darin begründet sein, daß die Oberblätter dauernd mit ihrer Unterseite dem Lichte zugekehrt sind. Jedenfalls wäre eine Wiederholung und genaue Analyse des Fraxk'schen Versuches erwiinscht.

Anisophyllie bei Sempervivumarten. In eigenartiger Weise tritt Anisophyllie bei einigen (unter Umständen vielleicht allen) Sempervivumarten auf ${ }^{3}$ ). An Blattrosetten, deren Achse gegen den Horizont geneigt ist, sind die Blätter der Oberseite länger als die der Unterseite (Fig. 456), so daß die ganze Rosette dorsiventral wird. Diese Anisophyllie kann leicht an isophyllen Rosetten hervorgerufen werden, wenn ihre Achse schiefe Lage erhält und anisophylle Rosetten können isophyll gemacht werden durch Vertikalstellung.

Wenn die Achsen einer Rosette schief gestellt werden, wirken nach Doposcheg-UhláR Schwerkraft und Lichtreize derart ein, daß sich die Blätter der Oberseite aufstellen und gerade richten, die der Unterseite gegen die Mitte hin einkrümmen. Die oberseitigen Blätter vergrößern

1) Vgl. Goeber, Experiment. Morphol., p. 73. Figdor hat (a. a. O.) an acht Bäumchen von A. pectinata die Hauptachse schief, einen Seitenast vertikal zu wachsen genötigt (durch Anbinden). In 6 Jahren waren bei 7 Pflanzen die Symmetrieverhältnisse unverändert, bei einer achten hatte sich der vertikal gebundene Seitenast zu einer radiären Hauptachse umgewandelt. Leider ist nicht angegeben, ob diese Pflanze, wie man vermuten könnte, schwächer wuchs als die sieben anderen.

$\left.{ }^{2}\right)$ Die älteren Untersuchungen von FraNk. nach denen es möglich sein soll, die Anisophyllie bei Acer platanoides durch eine Drehung um $180^{\circ}$ umzukehren, scheinen mir der Nachprüfung zu bedürfen. In den meisten Fällen sind doch wohl schon die Knospen indnziert, wenn das auch in der Größe der Blattanlagen nicht deutlich hervortritt.

3) Vgl. Doposcheg-Uhlár, Die Anisophyllie bei Sempervivum, Flora 105 (1913), p. 163. Daselbst weitere Literatur. 
sich dann, wahrscheinlich infolge günstigerer Belichtungsverhältnisse. Von Interesse ist namentlich auch, daß die ungleiche Ausbildung der Blätter auch die Ausbildung der Sproßachse beeinflußt und diese epitroph macht.

Eine biologische Bedeutung könnte die Anisophyllie hier nur dann haben, wenn die Rosetten nicht auf Oberlicht, sondern auf Vorderlicht angewiesen sind. Dann wäre die nutzbare assimilierende Oberfläche eine größere als bei Isóphyllie.

Laterale Anisophyllie von Dikotylen. Hier ist, wie mir scheint, als Ergebnis zahlreicher Untersuchungen (WIEsner, GoebeL, Whisse,

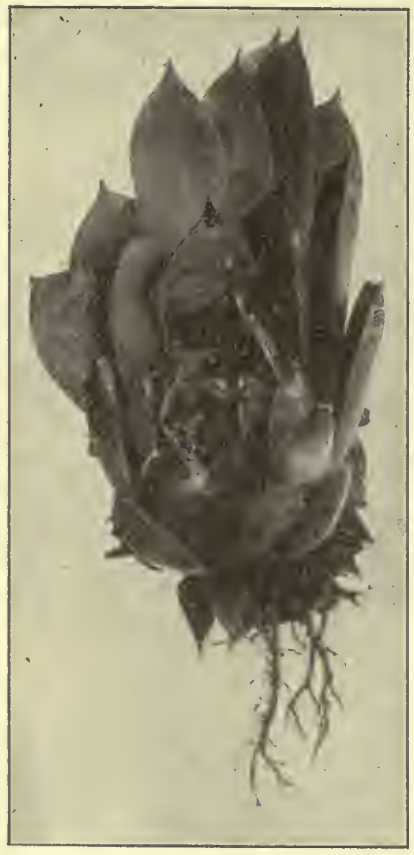

Fig. 456. "Sempervivnm Schottii. Anisophylle Blattrosette (nach DopoSCHEG-Uhlár). ${ }^{3} / 4$ nat. Größe. Die Rosette war rechts nnd links von anderen Rosetten eingeengt, daher der geschlossene Habitus. Nordhausen, Figdor, wenigstens für Acer und Aesculus) zu betrachten, daß die Anisophyllie durch die Lage bedingt und demgemä $\beta$ umstimmbar ist; daß außerdem, aber auch die Förderung der abaxialen Seite der Seitensprosse ("Exotrophie") in Betracht kommt. Die "Lage" selbst aber stellt einen Bedingungskomplex dar, dessen einzelne Faktoren: Schwerkraft, Licht, Einwirkung der Krümmung, Korrelation mit dem Hauptsproß nicht leicht getrennt $\mathrm{zu}$ untersuchen sind. Die Beeinflußbarkeit der Anisophyllie geht z. B. aus Versuchen von Nordhausen und Figdor hervor, in denen der Hauptsproß schief, ein Seitensproß in vertikaler Zwangslage gehalten wurde. Bei Aesculus Hippocastanum wurden bei Versuchen Figdor's alle ursprünglich deutlich anisophyllen Seitensprosse im Verlauf von 5 Jahren in vertikaler Zwangslage bis auf einen isophyll, die schief gestellten Hauptachsen in verschieden deutlichem Grade anisophyll. Indes war die Anisophyllie an den in geneigter Zwangslage befindlichen Hauptsprossen eine rerhältnismäßig schwach ausgebildete - diese reagieren also offenbar anders als die Seitensprosse.

\section{Habituelle Anisophyllie.}

Man könnte auch hier eine direkte Beeinflussung durch äußere Faktoren namentlich das Licht annehmen, zumal bei manchen hierhergehörigen Pflanzen noch isophylle Sprosse vorkommen. Indes bleibt bei etiolierten Sprossen von Goldfussia glomerata, Elatostemma u. a. die Anisophyllie erhalten, und die Angaben Rosenvinge's ${ }^{1}$ ) und Figdors, welche bei Centradenia u. a. Umkehrung der Anisophyllie erreicht haben wollen,

1) Er befestigte Zweige in inverser Laige und fand an neu zugewachsenen Teilen eine Umkehrung der Anisophyllie; es sind Torsionen hier schwer zu vermeiden. 
sind einer anderen Deutung fähig. Wenn z. B. eine Pflanze von Centradenia floribunda in vertikaler Zwangslage in einer Kiste einseitig beleuchtet wurde (so daß, wie dies auch sonst der Fall ist, die kleinen Blätter dem Lichte zugekehrt waren), entwickelten sich schließlich beim 6. Blattpaar die Blätter auf der Lichtseite größer als auf der Schattenseite. Dies ist ein anderer Vorgang, als er normal eintritt, denn für gewöhnlich sind ja gerade auf der Lichtseite die Blätter kleiner. Es wird wohl ein durch Lichtmangel bedingtes Kleinbleiben der Blätter auf der Schattenseite und eine korrelative Vergrößerung der Blätter auf der Lichtseite ${ }^{1}$ ) vorliegen, also auch eine Anisophyllie, aber eine andere, als sie bei der normalen Entwicklung auftritt! Übrigens mögen sich die einzelnen Arten verschieden plastisch verhalten.

$\mathrm{Da} B$ aber auch hier die innere Beschaffenheit der Sprosse für ihre Reaktion wesentlich in Betracht kommt, zeigt ein Versuch BosHanT's mit Goldfussia glomerata.

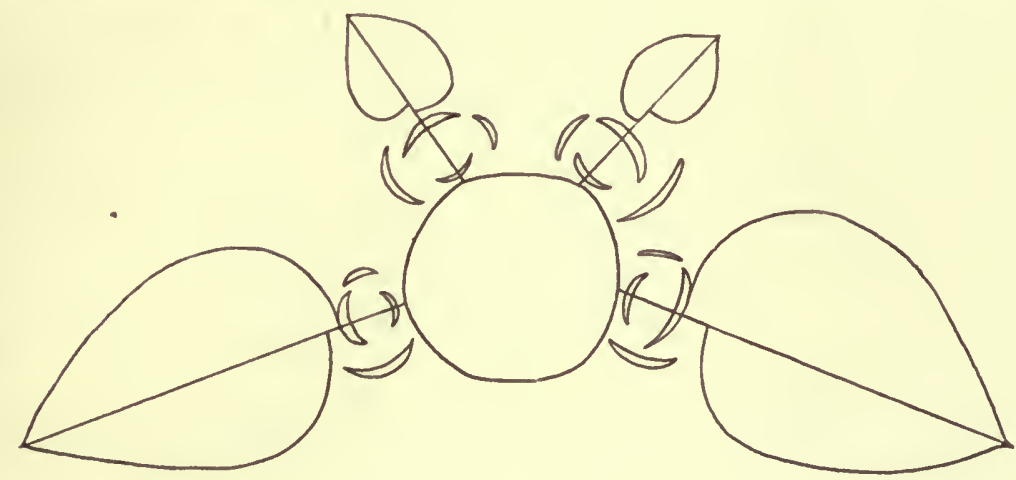

Fig. 457. Goldfussia glomerata. Schema der Blattstellung und Blattsymmetrie. Die Blätter stehen ursprünglich in gekrenzten Paaren, werden aber später in der angedeuteten Weise verschoben.

Zunächst sei auf das Diagramm Fig. 457 hingewiesen. Es zeigt, daß bei den Achselsprossen ganz gleichgültig, wie sie orientiert sind, das abaxiale erste mediane Blatt größer ist als das adaxiale, also "Exotrophie" vorhanden ist, während bei den transversal stehenden Blättern das nach unten liegende gefördert ist. Entfernt man an einem anisophyllen Sproß frühzeitig alle Achselsproßknospen, so kann der Sproß zur isophyllen Weiterentwicklung veranlaßt werden.

Durch die Entfernung der Achselknospen wird auch der Anteil an A'schenbestandteilen und Assimilaten, der zu ihrer Entwicklung notwendig gewesen wäre, für die Entwicklung des Hauptsprosses verfügbar. Er wird besser ernährt und im Zusammenhang damit isophyll. Es kann dies natürlich auch ohne Entfernung der Achselsprosse spontan erfolgen, wie ja auch viele normal anisophylle Selaginellen bei der Blütenbildung - also durch innere Ursachen - isophyll werden.

Die Anisophyllie stellt also ein weniger einfaches Problem dar, als man zunächst geglaubt hat. Es kommen „innere“ und äußere Faktoren

1) Man kann durch Entfernen der größeren Blätter die kleinen größer als sonst machen. Es liegt also eine Korrelation tatsächlich vor. 
in Betracht: die ersteren bestimmen namentlich auch die Reaktionsfähigkeit gegenüber den äußeren Faktoren, und wenn es auf die Beschaffenheit des Vegetationspunktes ankommt, so ist auch verständlich, daß durch verschiedene Einwirkungen schließlich dasselbe Resultat herbeigeführt werden kann. So kann die Zufuhr von Assimilaten zu einem Vegetationspunkt verringert werden durch eine Verschlechterung der Assimilationsbedingungen, eine Hemmung in der Stoffleitung (durch Biegung usw.), Korrelationsverhältnisse $u$. a.

\section{$\S$ 15. Beeinflussung der Dorsiventralitait im Blattbau.}

Bei Besprechung der anatomischen Symmetrieverhältnisse bei Laubblättern wurde nachdrïcklich auf die Beziehung zwischen Lage des Blattes und Ausbildung des Assimilationsgewebes hingewiesen und betont, da eine vergleichende Betrachtung dafür spreche, daß, wo Palisaden- und Schwammparenchym entwickelt sind, letzteres auf der schwächer, ersteres auf der stärker beleuchteten Seite ausgebildet werde, während äquifaziale Blätter mit ringsum angeordnetem Palisadenparenchym nur an Pflanzen von stark beleuchteten Standorten vorkommen.

Hier ist $\mathrm{zu}$ erörtern, wieweit diese Anschauung sich experimentell stützen läßt. Denn an sich kann ja z. B. das Vorkommen invers dorsiventraler Blätter auch auf "Zufall" beruhen. Von einem solchen werden wir (bis zu eventueller besserer Belehrung) reden, wenn bei manchen Farnen, welche sonst die Sporangien normal auf der Unterseite der Blätter tragen, Exemplare vorkommen, bei denen das Umgekehrte eintritt (Aspidium „anomalum" u. a.).

Nun ist bekannt, daß die Lagerung des Palisadenparenchyms hei manchen Pflanzen sicher nicht direkt durch das Licht bedingt ist, daß sie vielmehr auch an etiolierten Pflanzen (wenngleich in vermindertem Maße) auftritt.

Ferner findet man an Zweigen, deren Blätter sich in Zwangslage invers entwickeln muissen, keineswegs eine Umkehrung der Blattflächen ${ }^{1}$ ), trotzdem die Blattunterseiten jetzt stärker beleuchtet sind. Auch tritt die dorsiventrale Ausbildung des Blattes vielfach so fruihzeitig in der Knospe oder bei Kotyledonen in Samen ein, daß an einen direkten Einfluß des Lichtes nicht zu denken ist. Aber einerseits ist ein fördernder Einfluß des Lichtes auf die Ausbildung des Palisadenparenchyms durch die Untersuchungen von Stahi, Haberland, Pick, Dufour u. a. festgestellt, andererseits geht aus den oben (p. 489) angeführten Untersuchungen von Frank über Cupressineen (denen sich auch Lycopodiumarten anschließen) hervor, daß die verschiedenen Pflanzen verschieden plastisch sind, also ein negatives Ergebnis bei einer oder einigen Pflanzen noch zu keinen allgemeinen Schlüssen berechtigt. Es kehrt also hier dieselbe Erscheinung wie bei anderen Fällen von Dorsiventralität wieder.

Was die Verschiedenheit von Licht- und Schattenblättern anbetrifft, so ist bei letzteren auch in den Fällen, in welchen (im Gegensatz zu den

1) Einen derartigen Versuch stellte PIck, Über den Einfluß des Lichtes anf die Gestaltung und Orientierung der Zellen des Assimilationsgewebes, Bot. Zentralblatt XI $(1882$, p. 442) mit Ficus repens an. 
Lichtblättern) die Entwicklung des Palisadenparenchyms stark gehemmt wird (Fig. 458), die Dorsiventralität des Mesophylls wohl nie ganz aufgehoben.

Bei den Schattenblättern handelt es sich nicht um eine direkte Beeinflussung des einzelnen Blattes.

NordHadsen ${ }^{1}$ ) wies nach, daß die Sonnen- und Schattenblattstruktur schon in der Knospe bestimmt ist, wie dies oben anch für die Anisophyllie hervorgehoben wurde. Die Schattenblätter sind der Hauptsache nach Hemmungsbildungen, welche auftreten, wenn die Assimilationsbedingungen des betreffenden Sprosses im Vorjahre ungiinstiger waren als die für das Auftreten der Sonnenblätter erforderlichen. Ihr Auftreten entspricht im wesentlichen einem "Rückschlag auf die Jugendform" 2).

$\mathrm{Da}$ es sich dabei um eine Beeinflussung von seiten der älteren Teile, nicht „um Beleuchtungsverhältnisse, welche auf die von dicken Tegmenten umgebenen Knospen einwirken" 3), handelt, scheint mir zweifellos.

Wenn wir nach besonders plastischen Pflanzen suchen, so ist zunächst zu bemerken, daß die experimentellen Erfahrungen spärlich sind. So gibt PIck (a. a. O. p. 442) an, daß bei Colchicumblättern, wenn an sonnigen Standorten die Blattunterseite infolge einer Neigung der Pflanze sich unter stärkerem Lichtgenusse entfalte, diese die Struktur der Blattoberseite annehme (dichteres Palisadengewebe), während letztere ein lockeres Armpalisadengewebe aufweist. Indes ist hier die Verschiedenheit von Ober- und Unterseite keine sehr tiefgreifende.

Eine direkte Beeinflussung des Blattbaues durch das Licht will GrosGLiK gefunden haben ${ }^{4}$ ). Er behauptet, bei den Jugendblättern von Euc. globulus dadurch, daß er sie vertikal zwischen zwei Objektträgern befestigte, auf beiden Seiten Palisadenparenchym hervorgebracht zu haben, ebenso bei Nicotiana Tabacum, "Canna metallica", Calla aethiopica; das Licht veranlasse also direkt das Auftreten des Palisadenparenchyms.

Das wäre ein wichtiges Ergebnis, welches den oben geäußerten Anschauungen eine willkommene Stütze bieten würde. Eine Nachuntersuchung
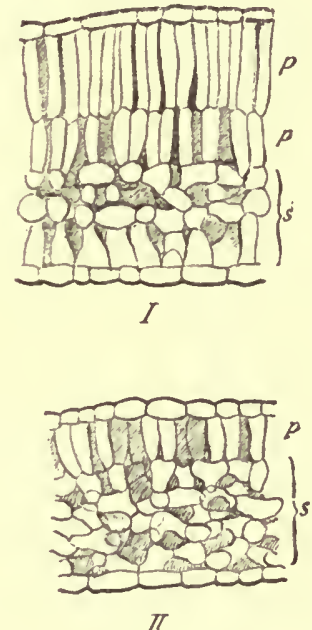

Fig. 4ว̃8. Querschnitt durch Blätter einer Blutbuche nach Nordhausen. I Lichtblatt, II Schattenblatt, $p$ Palisaden-, $s$ Schwammparenchym. ergab folgendes:

1. Eucalyptus Globulus (Jug en d f or m). Die Blätter sind anatomisch zunächst auf beiden Seiten gleich gebant, die dorsiventrale Struktur tritt erst hervor, wenn sie eine Länge von 3 bis $4 \mathrm{~cm}$ erreicht haben. Läßt man ein Blatt in vertikaler Lage zwischen zwei Glasplatten sich entwickeln, so wird es trotzdem dorsiventral. Doch waren die Zellen der abaxialen Seite, namentlich der zweiten Reihe nach der Epidermis etwas stärker

1) M. Norduausen, Über Sonnen- und Schattenblätter, Ber. der deutschen botan. Gesellsch. XXI (1903),..p. 30.

2) R. Schram. 'Über die anatomischen Jugendformen der Blätter einheimischer Holzpflanzen, Flora 104 (1912), p. 22.

s) Wie G. Tischler (Flora 104, p. 1) annimmt.

4) L. Grosgirk, Über den Einfluß des Lichtes auf die Entwicklung des Assimilationsgewebes, Botan. Zentralblatt XX (1884, p. 374). 
gestreckt als sonst. GRoSGLIK hat die im jungen Blatte rechtwinklig zur Epidermis etwas gestreckten Zellen wahrscheinlich für Palisaden gehalten. Seiné Fig. 1 stellt übrigens nicht ein junges Blatt sondern die Spitze eines älteren dar. Bei der Folgeform, welche normal auf beiden Seiten Palisadenparenchym bildet, gelang es dagegen - wenigstens in einem Falle - durch Verdunkelung der adaxialen Seite die Bildung des Palisadenparenchyms zu verhindern, es bildete sich hier ein viel lockereres Gewebe aus, das Blatt war invers dorsiventral geworden.

2. Nicotiana Tabacum. Gleicher Versuch. Keine Veränderung der Dorsiventralität. Wurden Blätter möglichst frühzeitig auf der Oberseite

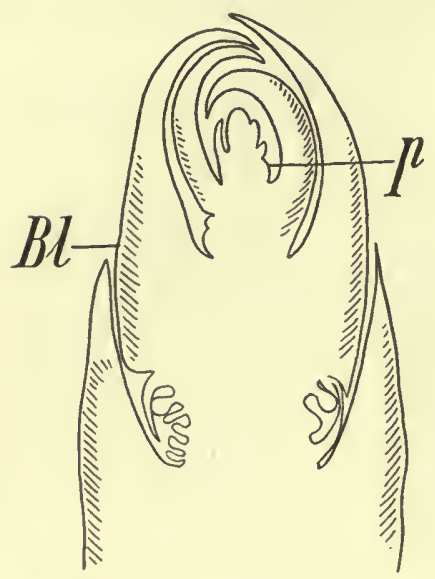

Fig. 459. Salicornia herbacea. Längsschnitt durch eine Sproßspitze. Das aus lockeren Palisaden bestehende chlorophyllreiche $\mathrm{Ge}-$ webe ist schraffiert. $p$ Achselsproß (Blïtenanlage). verdunkelt und nur auf der Unterseite beleuchtet, so war zwar das Palisadenparenchym auf der Oberseite weniger entwickelt als sonst, auf der Unterseite aber wurde keines gebildet.

3. Nicotiana glauca. Bei gleicher Beleuchtung beider Seiten (zwischen Glasplatten) waren die Zellen auf der axialen Blattseite mehr gestreckt als sonst, also eine Annäherung an die Palisadenparenchymbildung erzielt.

4. Vicia Faba. (Etiolierte Pflanzen.) Fiederblättchen in ihrer eingefalteten Lage zwischen Deckgläschen festgehalten, zwischen beiden Hälften ein Stück schwarzes Papier. Palisadenzellen bilden sich auf der verdunkelten adaxialen Seite blieben aber kürzer, als sonst. Die Zellen der abaxialen Seite zeigten keine Veränderung. - Die etiolierten Pflanzen zeigten stets 2 Reihen Palisadenzellen. An einigen Blättern der etiolierten Pflanze wurde die Unterseite mit 3 proz. Rohrzuckerlösung betupft, was bei einer Pflanze zu einer stärkeren Streckung der Palisaden auf der Ober seite führte:

$\begin{array}{lllll}\text { Etiolement . . . 1. Reilie } 40 \mu & \text { 2. Reihe } 35 \mu \\ \text { mit Zucker . . . 1. } " 70 \mu & 2 . \quad \% & 45 \mu \text {. }\end{array}$

5. Acacia Melanoxylon. Wurden junge (normal auf beiden Seiten mit Palisadenparenchym versehene) Phyllodien möglichst frühzeitig auf einer Seite verdunkelt, so konnte dadurch keine dorsiventrale Ausbildung erzielt werden, es war nur ein unbedeutendes Zurückbleiben der Zellstreckung auf der Dunkelseite wahrnehmbar.

Im Gegensatz zu GrosGLIK's Angaben ergaben sich also keine großen Ausschläge.

Die vorstehenden Erörterungen zeigen, daß es (von vereinzelten Fällen abgesehen) zwar bis jetzt nicht gelungen ist, die dorsiventrale Struktur des Assimilationsgewebes als dir ekt durch äußere Einflüsse, namentlich das Licht, bedingt nachzuweisen. Nichtsdestoweniger können wir uns die Entstehung der Dorsiventralität kaum anders als durch äußere Faktoren induziert denken. Die Gründe sind folgende:

1. Auch Achsenorgane, welche, wie verwandte Formen zeigen, ursprünglich offenbar radiär waren, können den dorsiventralen Blattbau 
annebmen, wenn sie denselben Bedingungen wie Blätter ausgesetzt sind. So die Phyllocladien ron Asparagus medeoloides, die Zweige von Thuyopsis u. a. Hier ist aber doch zweifellos die dorsiventrale Verteilung des Assimilationsgewebes eine erst spät entstandene.

2. Die Fälle, in denen eine "Vertauschung" der beiden Blattflächen eintrat (Fig. 459), hängen vielfach deutlich mit der Lage der betreffenden Blätter zusammen, wobei die Unterdrückung der Assimilationstätigkeit der Oberseite korrelativ eine Steigerung der Ausbildung des Assimilationsgewebes auf der Unterseite fördern mag.

3. Der Einfluß der Ernährung (Licht usw.) auf die quantitative Ausbildung des Palisadenparenchyms ist experimentell nachgewiesen.

Allerdings handelt es sich dabei nur um die Hemmung oder örtliche Verlagerung einer in der Pflanze schon vorhandenen „.Anlage“" zur Palisadenzellbildung. Aber die Gesamtheit der bekannten Tatsachen drängt zu der Annahme, daß die dorsiventrale Ausbildung des Assimilationsparenchyms zwar meist erblich festgehalten, aber ursprünglich durch das Licht induziert war, und daß auch die invers dorsiventralen Blätter auf dieselbe Weise zustande gekommen sind. Dabei ist es, wie die erwähnten NordHausex'schen Versuche zeigen, nicht notwendig, eine jedesmalige direkte Beeinflussung ${ }^{1}$ ) der Blattanlagen anzunehmen. Es kann eine indirekte durch den Vegetationspunkt erfolgen. So könnte es z. B. bei den Kompaßpflanzen sein, deren äquifazialen Folgeblätter wahrscheinlich erst auftreten können, wenn die dorsiventralen Jugendblätter bei höherer Lichtintensität Assimilationsarbeit geleistet haben. Über die eingeleiteten Versuche mit diesen Pflanzen soll später berichtet werden, namentlich dariiber, ob ein Rückschlag zur Jugendform eintreten kann.

1) Nach dieser Auffassung wåre es auch nicht notwendig, daß äquifaziale Blätter allseitig gleich stark beleuchtet werden; ein Palisadenparenchym anf beiden Seiten kann sich ja auch an nicht vertikalen Blättern von stark beleuchteten Pflanzen entwickeln. 


\section{Namen- und Sachregister.}

* bei der Zahl bedeutet Abbildung.

A bies nobilis, Anisophyllie 490.

- Nordmanniana, Anisophyllie 490.

- pectinata, Amphitrophie 224.

- -, Anisophyllie 248, 489.

- - Vegetationspunkte der Lang- und Kurztriebe 56.

- Veitchii, Anisophyllie 490.

A blast 345 .

A bort 345 .

abnorme Umbildung 327.

A butilon Sawitzii, Blattsymmetrie 259*.

Acanthaceen, dekussierte Blattstellung $200^{*}$.

A cacia, Jugendform 361.

- heter ophylla, Jugendform 399*.

- Iophantha, Primärblatt 387.

- Melanoxylon, unifaziale Phyllodien $288 *, 289 *, 496$.

- -, Jugendform 399, 410.

- verticillata, Jugendform 411*.

Acer, Achselknospe und Blatt 97.

- campestre, Anisophyllie 248.

- platanoides, Anisophyllie 248, 491, 492.

- - Blattmetamorphose 315*.

- -, Blïten, Geschlechterverteilung 144

- pseudoplatanus, Anisophyllie 248.

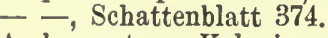

A chnantus, Kolonien 49.

A conitum, dorsiventrale Blüte 291.

A corus, dorsiventrales Rhizom 221.

Acrobolbusunguiculatus, Marsupien $15 *$.

Acrostichum scandens, dorsiventrales Rhizom 223*.

Adenia palmata, Ranken 321 .

Adiantum reniforme, Blattform 378, 404.

Adlumia cirrhosa, Jugendform 394.

Ad oxa, Blatt 486 .

adventiv 67.

Aequidistanz 197.

äquifaziale Blätter 273, 277.

Aesculns Hippocastanum, Anisophyllie $248^{*}, 263,491,492$.
Aesculus Hippocastanum, Teilblättchen 272.

- - Stockausschläge 98.

A ethionema heterocarpum, Fracht 436.

Agaricus nidnlans, Fruchtkörper 452.

A gave, Verzweigung 186.

Aglaozoniareptans, Diplophase von Cutleria 417.

A grim onia, Nebeublätter 269.

Ailanthus glandulosa, Jugendform 373.

- -, sex. Dimorphismus 141.

Algen, Polarität der Schwärmsporen 471.

A licularia, Jugendform 406.

Alis m a ceen, Jugendform 397.

Alliaria of icinalis, vergrünte Blüten $330,331 *$.

Allium fistulosum, unifaziales Blatt 290.

— m a gicum, Ausläuferblatt 127*.

- nigrum, Ausläuferblatt 127*.

- Schoenoprasum, unifaziales Blatt $278,281,282 *$.

Alnus glutinosa. Stockausschläge 98.

- viridis, gepaarte Blätter in den Bliiten $198 *$.

A lo ë, Jugendform 357.

- arborescens, Blattstellung 211.

- carinata, Blattstellung 207.

- plicatilis, Blattstellung 207, 208*.

- striata, Blattstellung 211*.

Alstroemeria psittacina, resupiniertes Blatt 276*.

ralterniflor" 200.

Alternieren der Blätter 198.

Amansia, Verzweigung 70 .

Ambrosia artemisiaefolia, sex. Dimorphismus 156.

- tripartita, Blütenstand 106*.

Ampelopsis, Kotyledonen 362.

A m phicarpie 431 .

Amphigastrien 234.

amphitrophe Sprosse $38,213,224$, $239,247,466$. 
Anadendrum marginatum, Jugendform 391.

- medi u m, Jugendform $390 *$.

- montanum, Jugendform 391.

Ananas sativus, Durchwachsung des Blittenstandes 30 .

- - Samenanlagen 350, 443.

analog" 313 .

Anaptychia leucomelaena $63^{*}$.

Androscepia gigantea, dorsiventraler Bliitenstand 298*.

Aneimia. Sporophyll 332.

- rotundifolia, blattbürtige Sprosse $326 *$.

Anemone hepatica, Variabilität der Blüte 327.

Aneura eriocaulis, Thallusäste als Hapteren $61 *$.

Angelica silvestris, sex. Dimorphismus 170 .

Angiospermen, Embryo 472.

Angraecum distichum, unifaziales Blatt 279*, 284, 286.

- Ea sciola, Luftwurzel $308,310$.

An is ophyllie 153,161, 229, 462, 487.

Anisotrophie 215.

Anisotropie $61,105$.

Anogram melept ophylla, Generationswechsel 414.

Anomoclada, Verzweigung 78 .

A n on a, Blattstellung 205 .

Anpassung 4, 9, 22, 32, 39, 262, 286, $297,301,361,370,397,406,423,433$.

Antheridien $131,144$.

A n th oceros, Jugendform $40^{\circ} *$.

- dichotomus, Generationswechsel $413 *$.

- fusiformis, Beeinflussung der Dorsiventralität $450^{*}$.

- Pearsoni, Beeinflnssung der Dorsiventralität 450 .

Anthriscus, sex. Dimorphismus 170.

Antirrhinum, Pelorien 300.

- majus, Heteromericarpie 436.

Antithamnion cruciatum, Photomorphose $458^{*}$.

- Plumula, Verzweigung 218*.

Anthyllis tetraphylla, Blattasymmetrie $26 \tilde{j}^{*}, 266$.

aphotometrische Blätter 278.

Apiocystis, Kolonie 49.

A poga mie 123, $350,418$.

A posporie 330,418 .

A quilegia $\mathbf{v}$ ulgaris, Vergrünung 330.

A rabis, Vergrünung 340.

A raucaria, Embryo 15.

- excelsa, amphitrope Seitenäste $38^{*}$.

- Cookii, amphitrope Seitenäste 38 .

Arbeitsteilung 44,52 .

Arctotis breviscapa, sex. Dimorphismus 178.

A rchegonien 131, 144, 413.

Argyreia speziosa, Kotyledonen $105^{*}$.

Arnica montana, Blattstellnng 199.

A roideen, Durchlochung der Blätter 69.

A rthante Jamaicens is, verkümmernde Stanbblätter 346 .
A s a r um europa eu m, Blattstellung 205*. - - Blütensymmetrie 298.

A sclepiadeen, Blïtensymmetrie 291.

Ascomyceten, Symmetrie der Fruchtkörper 451 .

A sparagus, Kurztriebe 116, 125.

- medeoloides, Kurztriebe 497.

Asparagopsis armata, Verzweigung, Spirotrophie 195, 196*, 202.

Asphodelus luteus, unifaziales Blatt 283.

Aspidium anomalum, Sporophyll 494.

- arista tum, Gallen 339.

Asplenium dimorphum, Aposporie $421 *$.

- lineare, blattbürtige Sprosse $326^{*}$.

- Ruta M uraria, Jugendform $367,368^{*}$, 377, $378 *$.

- viride, Jugendform 378*.

Astragalus, Dornen 318.

Astrantia major, sex. Dimorphismus 169.

- minor, sex. Dimorphismns 169.

Asystasia bella, Achselsprosse. Symmetrie $201 *$.

Athyrium filix femina, Aposporie $330 *$.

Atriplex hortensis, Heterocarpie 434*.

A usläu fer 16, 85, 109.

A usläuferblatt 126 .

natono m" 20.

axilläre Verzweigung 75, 89, 95*, 97.

Balantium antarcticum, Verzweigung 85.

Barleria buxifolia, Verzweigung 200.

Barbula muralis, Aposporie 421.

- subulata, Sporogon 468.

Barymorphose $260,295,312,426,449$, $452,472,473$.

Basidiobolus, abnorme Umbilduugen 336.

Batis, sex. Dimorphismus 164.

B atrach ospermum, Protonema 404.

Battersia mirabilis, Jugendform 377.

Bauch kanalzelle 131 .

Bauhinia, asymmetrische Teilblättchen $266^{*}$.

Beg onia, blattbürtige Sprosse 194.

-, Blüte 138, 299*.

- attenuata, sex. Dimorphismus 172.

- caroliniaefolia, Blattform 262.

- -, Dorsiventralität, Rhizom 221*.

- - Jugendform $373^{*}$.

- dichroa, Blattform 262.

- - Jugendform 403*.

- Engleri, sex. Dimorphismus 171*.

- fagifolia, Blattform 262, 264.

- Franconis, Dorsiventralität 482.

- heracleifolia, sex. Dimorphismus 173.

- herbacea, Blattsymmetrie 260 .

- hirsuta, Blibtenstand 171*.

- incarnata, Blattform 260*.

- maculata, Blattform 261.

- manicata, Blattform 261.

- nelumbifolia, Blattform 262. 
Begonia Rex, Dorsiventralität 261*.

- - Lebensdauer der Blätter 442.

- rhizocarpa, Blattform 260 .

- -; sex. Dimorphismus 172.

- ricin if olia, Wendeltreppenblatt $25^{*}$.

- sanguinea, Blattform 262.

- scandens, Blattform 261.

- Schmidtii, Blattform 482.

- valida, sex. Dimorphismus 172.

- vitifolia, Blattform 260.

- - Blütenstand 100*.

Benincasa cerifera, Ranken 320 .

B erberis, Achselknospe und Blatt 97, 439.

Betula, Stockausschläge 333 .

Bidens radiatus, Heterocarpie 434.

bifaziale Blätter 273.

Bilbergi a, Hochblätter 319 .

Bilateralität, vgl. amphitroph, 38,186 , 203.

Blasia pusilla, Jugendform 406.

Blatt (vgl. Anisophyllie), Anatomie 273, 403,494 .

-, Begriff 2, 55, 108, 116, 317.

- Entstehung 123, 371.

- Form 23, 127, 288, 315, 372, 377, 390 . $394,407$.

-, Gliederung 26, 69, 104, 272, 340.

-, Insertion $224,235,243,464$.

- Knospenlage 11, 427.

- Lebensdauer 442.

-, Nebenblatt 253, 269, 334, 394, 441.

-, Primärblatt 255, 271, 357, 371, 377, $384,387,394,397,403,409$.

-, Schwimmblatt 21, 35 .

-, Wasserblatt 21, 35, 367, 409.

"blattbürtig“ 67 .

"Blattwurzeln" 119

Blechnum occidentale, Ausläufer 85.

Blechum Brownii, Verzweigung 201*.

Blü te 29, 13ĩ $, 245,290,323,326,338$, $342,346,347,350,430,442,447$.

B lütenstand $, 30,156,294,301,345$, 348, 3อ̄3, 368, 372, 439, 449, 482.

Blyttia, sexueller Dimorphismus 146.

Boehmeria platyphyllos, Blatt 215 , $216 *$.

Bohrspitzen 16.

B om area, resupiniertes Blatt $276 *$.

B or a go id 101, 303, 350, 439.

Borassus, sex. Dimorphismus 158.

Bornichia arborescens, Heterocarpie 434.

Bossiaea heterophylla, Jugendform 400.

- microphylla, Jugendform 400 .

- rufa, Jugendform 400.

Bostrychia Moritziana, Verzweigung 58*.

- callipteris, Verzweigung 59.

Botrychium Lunaria, Blattgliederung $28 *$.

Bowiea volubilis, Kurztriebe 125.

Brassica, Verkümmerung 442.

- oleracea, blattbürtiges Schlanchblättchen $28^{*}$.

B riza, Blütenstand 301 .
Brutknospen $81,83,85,89,95,326$, $355,443,448,459$.

Bry ops is, bilateraler Thallns 186 .

- , Polarität $457^{*}$.

Bryum argente um, Sporogon 468.

- caespiticium, Archegonien 135.

Butomus umbellatus, Rhizom 221

B u x b a m i a, sexueller Dimorphismus 149.

- a phylla, Sporogon 468*.

Buxus acuminata, Nectarien 167.

- Mac Owani, Nectarien 167.

- sempervirens, sex. Dimorphismus $166^{*}$.

Cabo m b a, Blattstellung 204 .

Cacteen, Blattstellung 197.

-, Etiolierung 1:3, 485

-, Jugendform 398, 410.

- Lebensbedingungen 33 .

Caesalpinia Sappan, asymmetrische Teilblättchen 266.

Calamintha Clinopodium, Blatt und Achselknospe 98.

Calathea, asymmetrische Bliiten 294.

Calendula arvensis, Heterocarpie 434. - malacitan a, Heterocarpie 432*.

- - sex. Dimorphismus 178.

- of ficinalis, sex: Dimorphismus $178^{*}$.

Calla aethiopica, Blattanatomie 495 .

Call ip odium, Verzweigung $74 *$.

Callith amnion, Rhizuiden 457.

- bi pinnatum, Generationswechsel 416.

Callitriche, terminales Staubblatt 120.

Callitris, Blatt 384.

- , Jugendform 410.

Calobryum, Anisophyllie 462.

Calothamnus sanguinea, aequifaziales Blatt $277^{*}$.

Calypogeia, endogene Verzweigung 71.

Campanula, dorsiventrale Blüten 295 .

- rotundifolia, Jugendform 372, 407, $408^{*}$.

Canna, Blütensymmetrie 291.

- in d i ca, etiolierte Blätter $14 *$.

- metallica, Blattanatomie 495 .

Cann a b is gig a n te a, sex. Dimorphismus 163.

- himal a y an a, sex. Dimorphismus 163.

- sativa, sex. Dimorphismus 140, 163.

Caragana, Dorn, umgebildete Blattspindel :318.

Cardamine chenopodifolia, kleistogame Blüten 177.

- pratensis, Vergrünung 443.

Carm i c ha elia En y si i, Jugendform 400 .

- stricta, Jugendform 400 .

Carpinus, asymmetrische Blätter 264.

-, Jugendform 359, 404.

-, Sproßspitze 440.

-, Stockausschläge 333.

Caryophylleen, dekussierte Blattstellung 200*, 202.

- Heteranthie 430.

Castanea, asymmetrische Blätter 264.

C a suarina, sex. Dimorphismus 164 .

- torulosa, Jugendform 360*, 398. 
Catalpa syringaefolia, Anisophyllie 248.

Catasetum barbatum, sex. Dimorphismus $155^{*}$.

- tridentatum, sex. Dimorphismus 155.

Catha cassinoides, Kotyledonen 27.

Cath arinea, Archegonien 135.

- undulata Sporogon 468.

Cattleya Loddigesi, Wurzel 311.

Caulerpa, "Blätter" 487.

- prolife ra, Dorsiventralität 221*, 456. "Canlom" 108.

Cedrela amara, asymmetrische Teilblättchen 266.

Celosia cristata, verkümmernde Blüten 442.

Cenchras, Borsten der Infloreszenz 125.

Centaurea Jacea, Randblüten 182.

- Kotschyii, asymmetrische Teilblättchen $268^{*}, 272$.

Centradenia floribunda, Anisophyllie 492.

- in a equilateralis, Anisophyllie 255*, 256.

Centranthus calcitrapa, Mißbildungen 340 .

Centrolepis a ristata, unifaziales Blatt $285^{*}$.

Cephalien der Cacteen 480.

Cephalocereus Ulei, Blütenstand 480 .

Cephalotaxus, Bliitenstand 484*.

-, Embryo 15.

Ceratopteris, Prothallien 150, 473.

- thalictroides, Blatt, Brutkuospen 89,378 .

Cerat o p h y $11 \mathrm{um}$, Lebensbedingungen 34 .

Ceratozamia mexicana, Embryo 475.

Cereus. Jugendform 401.

- Celsianus, Blüte 479.

- hamatus, Wurzeln $478^{*}$.

- nycticalus, Blüte 479*.

- -, Wurzeln 478.

- pterogonus, Sproß 480.

- Testud o, Sproß 480*.

C e ropegia, Verwachsung d. Kronblätter 352.

Cetraria islandica, var. crispa, radiäre Ausbildung 191 .

Chaerophyllum temulum, sex. Dimorphismus 170 .

Cham a e y paris, Blatt 384 .

- pisifera, Jugendform 385 .

Chamaerops excelsa, Blattgliederung 69.

Chandinia xeranthemoides, Heterokarpie 434.

Chantransia, Vorkeim von Lemanea 375.

$\mathrm{Ch}$ araceen, sex. Dimorphismus 142.

-, Vorkeim 376.

Char a, Blätter 54*, 117.

- , Etiolierung 13.

Chelidonium majus, asymmetrische Teilblättchen $266^{*}$.

Ch e n op od i a ceen, geparte Anlagen 198.

Chirita chinensis Jugendform $369^{*}$.

Chlamydomonas 46.
Chloris, Bliitenstand 301.

Chondrioderma difforme $44^{*}$.

Circaea, Blatt 486

- lutetian a, Blatt u. Achselknospe 99*.

Cissus alnifolia, Sproßaufbau 103.

- discolor, Jugendform 403.

Cladonia coccifera, Symmetrie 192*.

- verticillaris, Organbildung 63*,192*.

Clad o p hora, Verzweigung 54*.

Cladostephus verticillatus, Verzweigung $57 * 73 *$.

Clematis afoliata, Jugendform 400 .

- - Ranken 320*.

Cliftonea pectinata. Dorsiventralität, Verzweigung 59, 60*, 217.

Climacium dendroides, Dorsiventralität 468 .

Cobea scandens, Jugendform, Ranken $319,394$.

Coch learia Armoriacia, Samenbildung 443.

Cocos nucifera, sex. Dimorphismus 158.

Codium, Verzweigung 486.

Coenobium" 40.

Coenogonium 62.

Coffea a rabica, Dorsiventralität 199.

- - Samen 427.

Coix Lacryma e, sex. Dimorphismus 157.

Coleochaete, Gameten 129.

-, Generationswechsel 416.

-, Zygote 136.

- situtata, Photomorphose 459.

Coleus Penzigii, dorsiventrale Blïte $291 *$.

Collema 62.

Colleti a crucia t a, Jugendform 401, 410 .

Columnea Kalbreyeri, Anisophyllie 257.

- purpurea, Anisophyllie 257.

- sanguinea, Anisophyllie 229*.

- Schiedeana, Anisophyllie 257.

Commelina bengalensis, Heterokarpie 435.

- c o el es tis, Bluitensymmetrie 294*, 295.

- - Heterokarpie 435.

"complana t" 242 .

Čom positen, Blüten 296, 35̄5, 442.

Coniferen, Mykorrhiza 104.

-, Jugendform 383 .

Conjugaten, Generationswechsel 416.

Convallaria, einseitswendiger Blitenstand 305 .

"conzentrisch" 186.

Cora 64 .

Cordyline, Rhizom 476.

Coriandrum, Blüte 296.

Correl a tionen $66,97,182,188,231,333$, $350,387,437,476,493$.

Corsinia marchantioides, Archegonien 135.

Corydalis claviculata, Jugendform 394.

- - Ranken 319

- ochroleuca, Bliite 292.

- solid a, Bliite 292.

_ - Knollen 106*, 107*. 
Corylus, Stockausschläge 333 .

Cotyledon macrantha, Blattstellung 203.

Crassulaceen, Blattstellung 203.

Crataegus Pyracantha, Jugendform 412.

Crepis succisifolia, Rand-u. Scheibenblüten 183.

Cruciferen, Fruchtknoten 352.

-, Mißbildungen 340.

-, Verkümmerung 346.

Cryptostem ma, Heteranthie 179.

Ctenosiphon, Verzweigung 70 .

Cucurbita, abnorme Knollen 334.

Cucurbitaceen, Ranken 396.

Cuphea platycentra, Verzweigung $200,201 *$.

- $\mathrm{v}$ iscos a, Verzweigung 200.

Cupressineen, Anisophyllie 247.

-, Blatt 274, 384.

-, Blüte 349 .

-, Jugendform $383,384$.

-, blattähnliche Sproßsysteme 38.

Cupressus funebris. Jugendform 386.

Cutleria adspersa, Generationswechsel $417 *$.

- multifida, Gametangien 129, 130*.

- - Generationswechsel 417*.

Cyanotis kewensis, Dorsiventralität 447.

Cy a th op hor um, Anisophyllie 233*, 487.

_, Blattstellung 206.

- bulbosum, Dorsiventralität 466 .

Cy c adeen, Kotyledonen 383.

-, Luftwurzeln 104.

Cy clamen, Regeneration von Blättern 123.

Cy s topteris fragil is, Primärblätter $379 *$.

Cystosira barbata, Keimung 456 .

Dacrydium intermedium, Jugendform 386 .

- - var. gracilis 386 .

Dactylis, Blütenstand 301 .

Dalechampia Roezliana, sex. Dimorphismus 165*.

Daucus carota, Heteranthie 431.

Davallia heterophylla, Sporophyll $323,324 *$.

- pentaphylla, Verzweigung 87*.

D a w on ia, Jugendform 358 .

- superba, Blattstellung 206*.

- - Sporogon 469*.

Dedoublement 35̆5.

Delesseria Leprieurii 59.

Delphinium, Blüte 291.

Dematium pullulans, abnormes Wachstum 336.

Dennstaedtia rubiginosa, Verzweigung $88^{*}$.

dekussierte Blattstellung 196, 199, 204.

Deschampsia caespitosa ssp. litoralis f. rhenana, Viviparie an überschwemmten Standorten 30.

Deutzia, Internodiendrehung 199, 224.

Diacrium bicornutum, Bliite $292 *$.
Dianthus caesius, Symmetrie 202.

$\mathrm{D}$ i a t o m e e n, Generationswechsel 416.

dichotome Verzweigung 67, 71, 74*, $79,85,100,104$.

Dic n e mon calycin u in, Zwergmännchen $141 *$

Dicoria, Blütenstand 177.

Dicraea algaeformis, Wurzel 311.

Dicranaceen, Zwergmännchen 141 .

Dicranum scoparium, Dorsiventralität 468.

Dicty ot a, Gametangien 130.

-, Generationswechsel 416, 418.

- dich ot o m a, Verzweigung 71, 72*, 73*,

- Mertensii, Hapteren $60^{*}$.

- - Verzweigung 72*.

Dielytra, Blattumbildung 318.

- Bütensymmetrie 292.

Differenzierung 314.

Digitalis purpurea, Blüte 300 .

- - Blütenstand 304 .

Dimorphoteca pluvialis, sex. Dimorphismns 182.

- - Heterokarpie 432*, 433.

Dioscorea, Luftknöllchen 322 .

- al ata, Knollen 113, 115*.

- batatas, Knollen 114.

- eburnea, Knollen an Wurzeln 114.

- japon ica, Luftknöllchen 114, 116*.

- quinqueloba, Rhizom 113.

- s inu a ta, Knollen 113, 114*, 475.

- villos a, Rhizom 113.

Diphyscium foliosum, Sporogon $468^{*}$.

Dipsaceen. Bliiten, Symmetrie, Dimorphismus 179, 296.

diploid 415.

Diplophase 415.

Discaria Toumatou, Jugendform 411.

Doodya caudata, Apogamie 444.

- - Blattform 379*.

Doppelblätter 334 .

Dop pelnadeln 125.

Dornen 318,400,401, 411, 439.

Dorsiventralität (vgl. Anisophyllie) 29 , $38,78,153,161,187,193,200,210, \mathbf{2 1 3}$, $261,264,273,290,307,446,449,459$, $468,477,494$.

Dorstenia, Blütenstand 301.

Dory anthes Palmeri, Blatt, Vorläuferspitze $280^{*}, 286$.

Dracaena, Verzweigung 71 .

Drapanaldia, Verzweigung 54.

Droseraceen, Blattentwicklung 217.

-, Blattwurzeln 120.

D rosera, Vergrünung 342.

- binata, Blattverzweigung 104.

- dichotoma; Blattrerzweigung 104.

- pygmaea, Brutknospen 96*.

Druckwirkung en, 194, 306, $4: 26$.

Dryas, Griffel 317.

Drynaria coronans, Blatt 38.2 .

- musa ef olia, Blatt 382.

- propinqua, Blatt $382 *$.

- quercifolia, Blatt $380^{\circ}, 381 *$.

Dumontia filiform is, Jugendform 375.

Durchwachsung 30,342 . 
Echeveria, aphotometrisches Blatt 278.

Echium, Blïtensymmetrie 291.

Ectocarpeen, Haftscheiben 377.

Ectocarpus, Rhizoiden 457.

Eichbornia azurea, Jugendform 410 .

einseitswendige Blütenstände 304 .

Elatostemma, Anisophyllie 214, 249.

- repens, Anisophyllie 252.

- sessile, Anisophyllie 252*.

Elode a can adensis, Blattanatomie 127.

Embry on en $15,413,472,473$.

„Emergenz" 108.

Endocarpum pusillum, Photomorphose 459*.

endogene Verzweigung $69,80 *$.

Energide 41.

Entwicklungsfeld 195.

Ephemeropsis, Dorsiventralität 467.

Ephebe 62 .

Ephedra, Anatomie des Perigons 127.

Ephem er m , Protonema 350, 364*, 377.

- serratum, sex. Dimorphismus 149*.

Epinastie, 213.

- epitroph 213.

Equisetam, Haarwurzeln 470.

-, Prothallien 150.

-, Verzweigung 71, 188.

- arvelse, Sproßaufbau 92*, 93*.

- giganteum 91.

- Iimosum, blühende Seitenzweige $94^{*}$.

- silvaticum, Anatomie 91 .

- Telmat eja, Jugendform 91, 92*, 361 .

- - Vergrünung 323*.

Eremosphaera, Symmetrie 185.

Eriocaulon natiliforme, sex. Dimorphismus 138.

„Er s a tz" 325, 328.

Erythrochaete pinnatifida, Blatt, Knospenlage $12 *$.

Etiolierung 12, 442, 461, 485, 488.

Eucaly ptus, Blattanatomie 277, 495.

-, Jugendform 410.

Euchlaena, Blütenstand 1028 .

- mexicana, Verzweigung 206.

Eudorina elegans, Kolonie $47^{*}$.

Eapatoria perfoliata, Gallen 344 .

Eupatorinm macrophyllum, Blattsymmetrie $216^{*}$.

Euphorbia, Umbildung durch Uromyces 337.

-, Blïten und Blütenstand 348 .

Euptilota Harveyii, Verzweigung $2 \% 0 \%$

Euryale ferox, Jugendform 412.

Euzoniella, Verzweigung 70.

Exoascus, Hexenbesen 3.38 .

exogene Verzweigung 70.

Exotrophie 183, 219, 263, 299, 487, 492.

Fagus, Blattstellung 205.

—, Dorsiventralität, radiärer Stamm 190.

-, Frucht 438.

-, Jugendform 359, 404.

-, Sproßspitze 440.

- silvatica, Blattform 264.

- - Licht und Schattenblatt 374, 495*.
Fagus silvatica, Vermehrung der Gefäße durch Freistellnng 21.

- -, Wurzel 312.

Farne, Blattentwicklung 217.

- Generationswechsel 414.

—, Prothallien 350, 470.

-, sex. Dimorphismus 151.

Fasziation 333,335 .

"Fazies" 33 .

Fegatella, Antheridium 132*.

- conica, Etiolierung 13*,14*, 461*.

Ferula rubricanlis, sex. Dimorphismus 168.

Ficus barbata, Wurzelsymmetrie 312 .

- Krischnae, abnorme Schildblätter 23.

- p umila, Jugendform 391.

- repens, Blattanatomie 494.

- - Warzelsymmetrie 312.

- Rumphii, Wurzelsymmetrie 312.

- scandens, Jugendform 391.

Filago arvensis, sex. Dimorphismus 180*.

Filicinm decipiens, Blattgliederung 349*.

Fis s id ens, bilaterale Ausbildung 186, 465.

-, Jugendform 377.

- adiantoides, Blattstellung 464.

- an om alus, Zwergmännchen 141.

- b ry oides, Jugendform 358.

- taxifolius, Blatt $357 *$.

_ - Blattstellung 206*.

fixierte Jugendformen 385.

Flagellenäste 71.

Flechten 61, 191.

Floride en, Generationswechsel 416.

Flüggea microcarpa, Blattstellung $228^{*}$.

Folg ef orm 356 .

Fontinalis, Blattstellung 206.

- antipyretica, Verzweigung $77^{*}$.

Forsythia, Blattstellung 197.

Fossombronia longiseta, Antheridinm 133.

Fraxinus, Anisophyllie 248.

- a mericana, Jugendform 373.

- excelsior, Blattstellung 201.

- - Blattsy mmetrie 260*, 266.

Freesia, Blütenstand 304 .

"Frons" 40.

Frullania, Verzweigung 78.

Frucht $431,438$.

Fuchsia, dorsiventrale Blüte 29, 299.

Fucus, Gameten 129.

- Generationswechsel 416.

-, Haarwurzeln 470.

-, Keimung 374, 456.

Fumaria, Blütensymmetrie 292.

Funaria, sex. Dimorphismus 144.

- hygrometrica, Protonema $365^{*}, 466 *$.

Funktionswechsel $108,317$.

Galeobdolon luteum, Pelorien 300.

Gallen 339, 343, 487.

Gametangien 128 .

Ga metophyt 413 .

Gasteria, Blattstellung 211. 
Gasteria cheilophylla, Blattstellung 208*.

- decipiens, Jugendform 402.

- obliqua, Jugendform 207.

Geitonoplesium cymosum, Blatt, Torsion 275*.

Genista sagittalis, etiolierter Sproß $485,486^{*}$.

Genli sea, Schlauchblätter 117*, 118.

- ornata, vegetativer Aufbau $2 *, 3 *$.

Gentian a c a lis, abnorme Blite 342 *.

- a s c l e pi a d e a, Internodiendrehung 199, 224.

Gentianeen, Blutensymmetrie 291.

geophile Sprosse 10.

Geotrophie 473.

gepaarte AnIagen 95̃, 198, 209.

Geranium pratense, sex. Dimorphismus 174.

Gerontopogon glabrum, Heterokarpie $432 *, 433$.

Geum bulgaricum, Blattgliederang 272*.

Ginkgo, sex. Dimorphismus 141.

Gla d i olus, einseitswendiger Blütenstand 304.

Glaziova bignonioides, Ranken, Haftscheiben 20*.

Glechoma hederacea, panachierte Blätter 259.

Glossodium, Podetien 191.

Goldfussia, Anisophyllie 231*, 447.

- anis ophylla, Anisophyllie 256 .

- glomerata, Anisophyllie 256*.

- is o phylla, Anisophyllie 257.

Gonium pectorale, Kolonien $46^{*}$.

Gottschea appendiculata, Anisophyllie 234*.

Gramineen, Blattstellung 208.

- , Blütenstand 301 .

Gratiola, Blüte, Verkümmerung 350.

Grim m i a, Sporogon 468.

Grundformen 314 .

Gymnostachyum variegatum, Jugendform 403.

Ha ar 107.

ha bituelle Anis op h y llie $232,245,249$.

Haftorgane $19,60,62,120,375$.

Halo phil a, Blattstellung 210, 211*.

Halopitys, Verzweigung 70 .

Halopteris filicina, Verzweigung 55. $56 *, 57 *, 73 *$.

- - Symmetrie 218.

Halskanalzellen 131 .

Hakea gibbosa, äquifaziales Blatt 277*, 286.

- pectinata, äquifaziales Blatt 278.

haploid 415.

Haplophase 415 .

Hedera arborea, Jugendform 393. Helix, Haftwurzeln 321, 322*, 478.

- - Jugendform 391, 392*, 393*, 404.

Hedysarum capitatum, Blattsymmetrie $265^{*}$.

- sibiricum, Blütenstand 304.
Heleocharis palustris, dorsirentrale Blüte 298.

Helianthemu vulgare, Reaktion auf das Klima $37 *$.

Helianthus, Jugendform 357 .

-, Heteranthie 179, 182.

- a n n u s, Blattstellung 204*.

- strumarius, Blattstellung 204.

Helicodiceros muscivorus, Wendeltreppenblatt $25 *$.

Heliotropium indicum, dorsiventraler Blütenstand 102, 1013, 214, 304*.

Helleborus foetidus, Blattform 269*.

- - Ersatz von Blütenteilen 327*.

Helminthia echioides, Heterokarpie $432,433$.

H emmungsbildu ugen 56, 116, 361, $378,383,387,393,404,439$.

H er a c leu m, asymmetrische Teilblättchen 266.

-, Hetheranthie 430

- Mantegazzian nm, Randblüten 170 , $296^{*}$.

- Sph ond y li um, sex. Dimorphismus 170.

- - , dorsiventrale Blütenstiele 214, 450*.

Herminium monorchis, Wachstumsverteilung im Sproß:16.

Herposiphonia, Dorsiventralität 221.

Herpothamnion hermaphroditum, Generationswechsel 416.

Hesperis matron a lis, Vergrüung 331.

Heteranthera reniformis, Jugendform $409 *, 410$.

- zosteraefolia, Jugendform 397.

Heteranthie $175,296,430$.

beteroblastische Entwicklung 360 .

Heterokarpie 431.

Heterocentron diversifolium, Regeneration 474.

Heteromerikarpie 431.

Heteropappus, Heterokarpie 434.

Heteroph yllie $236,380$.

Hevea, sex. Dimorphismus 166.

Hexenbesen 337 .

H i e r a ci u m, Blattform von Ausläufern 486.

- aurantiacum, Apogamie 330.

- flagellare, Apogamie 330.

Hilden brand tia 375 .

Hillebrandia, sex. Dimorphismus 170.

Hippuris, Blattstellung 197.

H ochblät ter 319 .

homoblastische Entwicklung 360.

Homogyne alpina, sex. Dimorphismus $179 *$.

"H $0 \mathrm{molog}$ i e" $108,313$.

Horminum pyrenaicum, Blattstellung 199.

- - Blütenstand 304.

Hosackia subpinnata, Blattsymmetrie 265.

Humulus Lupulus. sex. Dimorphismus $138,164$.

H y d n u m repand u m, Fruchtkörper 452*.

Hydrangea, Randblüten 442 .

Hy drobryum, Wurzelsymmetrie 311 .

Hydrocharideen, Jugendform 410 . 
Hydrocharis morsus ranae, Spaltöffnungen 35 .

Hydrocle is $\mathrm{H} u \mathrm{mboldtii}$, Jugendform 410.

Hydrophy ll ee n, Blütenstand 303 .

$\mathrm{H}$ y dropterides, Generationswechsel 423.

Hydrurus $50^{*}$.

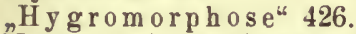

Hylocominm (Hypnum) splendens, Dorsiventralität $214,465$.

- (-) - Etagenwuchs 189*.

H ymenium 452.

Hymenocarpus circinatus, Blattsymmetrie $265^{*}$.

H y m e no phylle en, Generationswechsel $414,423$.

Hymenophytum flabellatum, sex. Dimorphismus 148.

- - Verzweigung $76^{*}, 461^{*}$.

H yoscyamns, Blitenstand 303.

hy perhydrisches Gewebe 312.

Hyphaena ventricosa, Wurzel 9*, 428.

${ }_{n}$ Hypnocysten ${ }^{4} 336$.

Hypnum (Ptilea) crista castreusis, amphitropher Sproß :38.

$-(-)--$, Dorsiventralität 217, 46 5.

Hy pum splendeus, Verzweigung 78 , $188 *$.

Hy ponastie 213 .

Hy poptery gi um Douini, Anisophyllie $230 * 487$.

-, Blattstellung 206.

hypotroph $213,2+1,284$.

I beris a mara, Randblüten $296,430$.

- umbellata. 179.

Ilex Aquifolium, Jugendform 413.

indifferente Anlagen $319,323$.

Indig ofera diphylla, asymmetrische Teilblättchen 265 .

Ind uktion $\div 0,38,310,482$.

Internodien

Internodiendrehung 199, 224.

- invers dorsiventral $245,273,497$.

Iris filifolia, unifaziales Blatt 285*.

- foetidissima, Rhizom, Etioliernng $13^{*}$.

- pyrenalca, Schwertblatt 285*.

Is oetes, sex. Dimorphismus 152.

- lacustris, blattbürtige Sprosse 84 .

- - Sporangien 444.

- Wurzelsymmetrie $307 *$.

Is o g meten 129.

isolateral* 273 .

J $\mathrm{ngend}$ form (vgl. Protonema) 35, 228, 356,495 .

Juglans nigra, Knospen 143.

- regi a, Keimpflanze 440.

- - sex. Dimorphismus 143.

- -, Blattsymmetrie 260*, 266.

Juncus, nnifaziale Blätter 188, 278.

- a cumin a tus. Mißbildnngen 341 .

- gla u c s s, unifaziale Blättrer $282 *, 290$.

- la m procarpus, (iallenbildungen $341 *$.

- supinus, Gallenbildungen 341 .
Juncus trifidus, bifaziales Blatt 282.

Jungermanniaceen, Antheridien 133.

Jungermannia bicuspidata. Dorsiventralität, Anisophyllie 2:34*, 465 .

- - endogene Verzweigung 71.

- - Jugendform $407 *$.

Juniperus, sex. Dimorphismus 140 .

- chinensis, Blattform 385.

- communis, Blattform 384.

- - männliche Blüte $349 *$.

- virginiana, Blattform 384.

Justitia vittata, Jugendform 403 .

I va, sex. Dimorphismus 177.

Kamptotrophismus 9 .

Kantia Trich omanes, Anisophyllie 230*.

Kigelia africana, Kotyledon $105^{*}$.

$\mathrm{kleistogame} \mathrm{Blüten} 3+7$.

Kletterpflanzen $220,388,478$.

klinotroph 292.

Klugia, Anisophyllie 257.

- Notoniana, Blattsymmetrie 259*.

- zeylanica, Blattsymmetrie 215, 263.

- - Blütenstand 306 .

- Blüte 483 .

$\mathrm{K} n$ a n ti a arvensis, abnorme Blitten 323 , 338.

Knollen 106, 113, 444, 475.

Kuospense huppen $315,445$.

Knoten 55 .

Kolonie 40,43 .

Kompensation des Wachstums 438 .

kongenital 75, 100, 281, 352 .

Kontakt 194.

K o ty 1 e d o n e n $27,105,258,362,368,384$, 441.

Kurztrieb $55,125,143,218$

Labiaten, Blattstellung 203.

- Blüte 298, 347.

-, Blittenstand 101, 304.

-, Pelorien 335.

Lachenalia luteola, Bedingung für Samenbildung 443.

La min ariaceen. Gliederung 69.

$\mathrm{L}$ a w i u m a l b u m, Entwicklung des Bliitenstandes $101 *$.

- maculatam, Pelorie 300.

Landolphia, Jugendform 396.

Langtrieb 55, 14:3, 218.

L a rix, Jugendform 384 .

laterale Anisophyllie 248, 492.

L a th y rus, Nebenblätter 269.

- A p h a ca, Jugendform 394.

- - Nebenblätter $269,271 *, 441$.

- Cly menum, Jugendform $394 *$.

- Mauritanicus, Jugendform 394.

- Nissolia, Jugendform 394.

- 0 chrus, Jugendform 394 .

Laubflechten, Wachstumsrichtung 191.

Lebermoose, Antheridien $u$. Archegonien $132 *, 133 * 144 *$

-, Haarwurzeln 3503.

-, Sporenkeimung 425.

-, sex. Dimorphismus 148.

Lejeunia, Vorkeim 377. 
Lejeunia Metzgeriopsis, Jugendform $363 *$.

Lejolisia, Generationswechsel 416.

Lemane a fluviatilis, Jugendform 374.

- torulosa, Jugendform 374*.

Lemnaceen, Spaltöffnungen 35 .

- , Vegetationspunkt 65 .

Lemna triscula, morphologischer Aufbau $370 *$.

Lentibulariaceen 118.

Le ontopodium alpin um, Staubgefäße 177.

Le onurus nepetifolia, Blüte 291*.

Lepidozia, endogene Fruchtäste 71.

Le pismium radicans, Wurzeln 478.

Leptopteris, Generationswechsel 423.

Le p to tes bi c ol or, unifaziale Blätter 279 , 286.

Le u c obryum, Zwergmännchen 141.

Leveillea, Verzweigung 70.

Lich tblatt 494 .

Licmophora flabellata, Koloniebildung $49,50 *$.

Ligulifloren, Heteranthie 430.

Ligustrum vulgare, Phototrophie 482.

Li l i u m a ra t u m, dorsiventrale Blüte 295.

- candid u m, Blattumbildung 318.

- - Bedingungen für Samenbildung 443.

- Iancifolium, Dorsiventralität der Blïte 295 .

Limnanthemum, Spaltöffnungen 3 .

Limnobium bosci, Spaltöffnungen 35 .

Linaria vulgaris, Blüte 300 .

Lindheimera, sex. Dimorphismus 179.

Lobelia, Verwachsung der Staubgefäße 352.

Lodoicea Seychellarum, sex. Dimorphismus 139.

Loliam temulentum, Ährchen 346.

Lomentaria impudica, Verzweigung 59.

Lonicera, Internodiendrehung 199, 224.

- Periclymenum, Doppelblätter 334.

- - Gallen 344.

Lophocolea bidentata, Verhalten im Dunkeln 13.

Loranthaceen, gepaarte Anlagen 198.

L u f tw urzeln 66, 308, 428.

Lup inus, Blatt 272.

Luzu la, Blatt 282.

- flavescens, Mißbildungen 339.

- F orsteri, Mißbildungen 339.

Lycinm barbarum, Verzweigung 482.

Lycopodium alpinum, Anisophyllie 239.

- a n n otin um, Verzweigung der Wurzel 79. $80 *$.

- Billardieri, Protokorm 383.

- carolinianum, Anisophyllie 241*.

- cernu um, Protokorm 242, 383.

- Chamaecyparissus, Dorsiventralität 81 .

- c om planatum, Anisophyllie 38, 238*, $488 *, 489 *$

- inundatum, Symmetrie, Jugendform $3 \check{9} 9$.
Lycopodium inundatum, Protokorm 242.

- - Sporophylle $324 *$.

- laterale, Protokorm 242, 383.

- linifolinm, Isophyllie 237*.

- nummulariaefolium, Blattbildung 242.

- paradoxum, Anisophyllie 241*.

- phlegmania, Isophyllie 237.

- Saururus, Isophyllie 237*.

- scariosum, Protokorm 383.

- - Anisophyllie 240.

- Selago, Archegonien 131*.

- - Verzweigung,-Blattknospen 81*.

- --, Regeneration 83, 84*.

- volubile, Anisophyllie 240*.

- - Protokorm 383.

Ly godium, Verzweigung 85.

- japonicum, Blattknospe 118 .

- palmatum, Dorsiventralität 222.

- polymorphum, Blattwachstum 117*.

Lysimachia, Blütensymmetrie 299 .

Macrocystis angustifolia, Verzweigung $69 *$.

- pyrifera, Vegetationspunkt 69*.

M a cromitrium, Zwergmännchen 141.

Macrosporangien 136, 151.

Majanthemum bifolium, Rhizom 220.

Makinoa crispata, abnorme Archegonien 134*.

Malaxis paludosa, blattbürtige Knospen 126.

Manihot palmata, sex. Dimorphismus $165^{*}, 166$.

M a pan ia, Blüte und Blütenstand 348 .

I a rantaceen, Blattsymmetrie 258 .

Marattiaceen, Antheridien nnd Archegonien $131^{*}$.

Marcgravia, Jugendform 391, 404.

Marchantiaceen, Antheridium 132.

-, sex. Dimorphismus 148.

- Thallus 485.

M archantia, Jugendform 405 .

- polymorpha, Brutknospen 460 .

Marsiliaceen, sex. Dimorphismus 151.

Marsilia, Dorsiventralität 221.

-, Embryo 472*.

-, Sporangien 137.

-, Verzweigung 87.

- quadrifolia, Schwimmblätter 35 .

Marsupien 15,343 .

Mastig obry u m, Dorsiventralität 217.

- , Flagellenäste 71 .

Matricaria in odora, Randblüten 180 .

mechanisches Gewebe 9, 93 .

Mechanomorphose (vgl. Druck) 426.

Medeola asparagoides, Phillocladien $275^{*}$.

medianzygomorph 292.

Medicago sativa, Blitenstand 306 .

Melalenca micromera, Jugendform 410.

Melampodium, sex. Dimorphismus 179.

Melampsorella caryophyllacearum als Verursacher von Hexeubesen 337. 
Melampyrum pratense, Blitenstand 304.

- silvaticum, Blütenstand 304.

Melandryum a lbum, sex. Dimorphismus $159 *$.

- -, Zwitterblüten $338 *$.

- rubrum, Kelch 159.

Melas to m ace e n, Adventivblättchen 340 .

Mentha piperita, Lebensdauer der Blätter 442 .

Mercurialis perennis, Rhizomspitzen $11 *$.

- - sex. Dimorphismus 164*.

Merendera sobolifera, Knollenbildung, Schutz des Vegetationspunktes $16^{*}$.

Mesembryanthemum linguaeforme, Jugendform 359*.

Metamor phose $61,313,324,341,411$, 445.

Metzgeria, Verzweigung 76.

- furcata. sex. Dimorphismus 145*.

Micrococeus, Entwicklung 356.

Microlepidozia, Verzweigung 79.

Microsporangien 136, 151.

Mimosa sensitiva, Blatt 269*, 272.

MiBbildungen 22, 327.

Mnium, Anisophyllie 487.

-, sex. Dimorphismus 148.

-, Verzweigung 77*.

- cuspid a tu m, Archegonium 135*, 136*.

- - Blatt 355 .

- serratum, Anisophyllie 232*.

- undulatum, orthotrope und plagiotrope Sprosse 189*.

- Anisophyllie 232.

Monochaetum hirtum, Verzweigung 200.

Monoclea, sex. Dimorphismus 148.

monofazial 273.

Monophyllaea Horsfieldi, Jugendform 369*, 370 .

Monopodium 74, 102.

Monoselenium tenerum, Antheridium $133,135$.

Monotropa hy popitys, kein Etiolement 13.

Monstera deliciosa, Dorsiventralität 221.

Moose, Protonema 350, 374.

-, Sporen 471.

- Verzweigung 75.

Morphologie 7 .

Mussaenda, Blüte 297.

M ucorinee $\mathrm{n}$, heterothallische 138.

Musa sapientum, Frucht 443.

Muscari comosum, Blüten 442 .

- - Heteranthie 431.

Mutation 386 .

Myriophyllum proserpinacoides, Land- und Wasserblatt 21.

Myrhis odorata, sex. Dimorphismus 167.

Myxobacteria 50 .

Najas, Blattstellung 211*.

-, reduzierte Bliute 349 .
$\mathrm{Najas,}$ terminales Staubblatt 125.

- microdon, Blattstellung 209*, 210*.

Nassovia, Dornbildung $41 \%$.

Neckera complanata, Dorsiventralität 466.

Neotenie 367.

Nepenthes, Jugendform 394.

Nephrolep is, Ausläufer 84*, 85, 86*, 125.

-, blattlose Sprosse 109.

- acuta, Variation der Blattgliederung $26 *$.

Nerskya ramosa, Kolonien 50 .

$\mathrm{Nicot}$ i na gla u ca, Blattsymmetrie 496 .

- tabacum, Blattsymmetrie 495 .

Nidularinm splendens, Hochblätter 319.

Niphobolus, Verzweigung 87, 88*.

$\mathrm{Nischenblätter} 380$.

Nitella tenuissima, Stellung der Geschlechtsorgane 14: ${ }^{*}$.

Norantea guianensis, Fehlen der Jugendform 391 .

Notochlaena sinuata, Apogamie 123*.

Nupbar luteum, Dorsiventralität 214.

- - Jugendform 398.

- - Rhizom 482.

N ymph a eaceen, Spaltöffnungen 35.

$\mathrm{N}$ y m p h e a r u b a, Jugendform 372,398, 409.

- -, Rbizom 48\%.

0 cim um carnosum, Drüsen 318*.

Oedogonium, homoblastische Entwicklung 374.

- Gameten 129.

-, Zwergmännchen 142.

Oenone latifolia, Organbildung 124*.

- le ptophy 11 a. Wurzel 311*.

0 e nothera, Bliztenstand 350, 439.

- bistorta, Jugendform $362 *$.

$0 \mathrm{mphal}$ odes linifolia, Blutenstand 101, 102*.

Oncidium Jonesi, Wurzel 309.

Onoclea Struthi o pteris, Ausläufer 85.

- - Sporophyll 323, 445.

On onis Natrix, Jugendform 387.

$00 \mathrm{~g}$ onien 142.

Op h i o g l o s s e en, Stellung der Blattglieder $28 \%$

Ophiopogon muscarioides, Blattstellung 211 .

Opuntia, bilaterale Ausbildung 186.

- arborescens, Sprosse 484.

- crassa, Stellung der Blüte 479 .

- leucotricha, etiolierte Sprosse $48 t^{*}$.

- monacantha, Stellung der Seitensprosse $4 \geq 8 *$.

- vulgaris, Bedingnngen für die Anordnung der Blïten 479*.

Orchideen, dorsiventrale Wurzeln 188.

-, Knollenwarzeln 104.

_, Luftwarzeln 308.

-, "Protokorm" 383.

Organ 7,39 .

Urgananlage, Reihenfolge der 65.

-, terminale 65 . 
Organographie $1,7,328$.

Orlay a, Heteranthie 430 .

Ornithogalum caudatum, Blatt 280 , 282.

Orobanche, Keimung 425.

Orobus, Nebenblätter 269.

Orthotrichum, Sporogon 468.

orthotrop $187,: 359,446$.

Osmunda regalis, Aposporie 422*.

Otidia lepornia, Fruchtkörper 4ă1*.

Ottelia a lis in oides, Blattstellung $210 *$.

Oxytenia, sex. Dimorphismus 177.

Palmellastadium 336.

Palmen, Blattgliederung 69 .

- Verzweigung 186.

$\mathrm{P}$ and an $\mathrm{us}$, Blattstellung 207.

Papaver bracteatum, Blüte 335 .

- - Sympetalie 30.

Papilonaceen, Ranken 314.

Passerina, Schuppenblatt 274.

- hirsnta, Iugendform 400 .

Passiflora Raddiana, Symmetrie der Nebenblätter 269, 270*.

- - Ranken 314, 321.

Pediastrum Boryanum, Hypnocysten 336.

- granulatum, Kolonie $46 *$.

Pellaea flavens, Aposporie 422*.

Pellia caly cin a, sex. Dimorphismus 144.

- epiphylla, Etiolierung 13.

Pellionia Daweauan, Anisophyllie $250,252 *, 253 *$.

Pelorien 300, 336.

Pennisetum, Borsten 345 .

Pentstemon, Blüte, Reduktion der StaubgefäBe 350.

'Peronospora violacea als Ursache von Mißbildungen 338 .

Petasites, nutzloser Pappus 350.

- niveus, sex. Dimorphismus $139 *, 175$, $180^{*}$

Peucedanum Cervaria, sex.Dimorphismus 170 .

Peziza, Fruchtkörper 451.

Phalaenopsis Esmeralda, Luftwurzel $308^{*}$.

- Lüd demanniana, Luftwnrzel 308*.

- Schilleriana, Luftwurzel 20, 308*, 309*.

$\mathrm{Ph}$ ascaceen, radiäres Sporogon 468 .

$\mathrm{Ph}$ a seolus, Blattsymmetrie 266.

- Fasziation 333.

-, Wurzeln 477.

- multiflorus, etiolierte Blätter 442.

Phegopteris Dryopteris, Verzweigung $87 *$.

Philadelphus, Internodiendrehung 199, 224.

Phil odendron, Jugendform 388.

Phil onotis fontana, Jugendform 364 .

Phoenix canariensis, Blattgliederung $6 y^{*}$.

Phoenocoma prolifera, Blattanatomie 274.

photometrisch 278.
Photomorphose $231,237,311,404,426$, $429,449,456,461,470,477,483,494$.

Phototrophie $241,429,468,480$.

Phyllanthus, blattähnliche Sprosse 213, 483.

- mimosoides, blattähnliche Sprosse $227 *$.

Phyllarthron, Blattform 349.

$\mathrm{Phyllobium}^{\mathrm{P}}$, Gameten 128.

Phyllocactus, Sproß 484.

- crenatus, abnorme Schlauchblätter 24 *

- phyllanthoides, Jugendform 401, $402^{x}$.

- - Photomorphose 485.

- phyllanthus. Jugendform 401.

$P$ hyllocladien $386,399.400,485$.

Phyllocladus rhomboidalis, Jugendform $386^{*}$.

Phyllodien 288, 289, 399, 410.

Phylloglottis picta, Jugendform 403.

Phyllom 108.

Phylogenie 62, 102, 184, 327, 332, 348, $361,423$.

Physostigma venenosum, Keimung $396 *$.

Phytom 40.

Picea ajanensis, Blattsymmetrie 274.

- excelsa, Amphitrophie 38.

_ _-, Dorsiventralität 214.

- -, Gallen 324.

- -, Korrelation 444.

- ormorica, Blattanatomie 274.

Pilea muscosa, Anisophyllie 249.

- Schlechtendali, Anisophyllie 249.

- Spruceana, sex. Dimorphismus 160*.

Pilocereus ColumnaTrajani, Orien. tierung der Blütenstände 480 .

- senilis, Orientierung der Bliitenstände 480.

Pilularia, Dorsiventralität 221.

- Sporangien 137.

-, Verzweigung 87.

Pinguicula, Organbildung 118.

P in us, Doppelnadeln 28.

-, Jugendform 383.

-, Kurztriebe 97, 439.

-, Polarität 186.

-, Samen 439.

-, Seitensprosse 189, 444.

- Cembra, Nadeln 426.

- monophylla, Kurztriebe 65, $125,426$. P in ea, Jugendform 384*.

- silvestris, Jugendform 384.

- -, Nadeln 426.

- -, Wurzel 312.

- Strobus, Jugendform 411.

Piper nigrum, Wurzel 307.

Pistia stratiotes, Jugendform 370*.

Pis a m s tivum, Blatt 334 .

- - Nebenblätter 269*.

Placophora, Anpassungsmerkmale 376.

Plagiochásma, Jugendform 406.

Plagiochila asplenioides, Dorsiventralität $465,466^{* *}$.

Plagiothecium undulatum, Dorsiventralität $232 *$. 
plagiotrop 18i, 199, 229, 359, 446.

Planogameten 128.

Plantago, Blattrosette 370 .

Plocamium coccineum, Symmetrie $60^{*}, 219$.

Poa Viviparie 30.

- annu a, Blütenstand, Symmetrie 205*.

- nemoralis, Galle 344.

Podophyllum peltatnm, Blatt, Knospenlage $11 *$.

Podostemaceen, dorsiventrale Blüten 299.

- Dorsiventralität $188,222$.

-, Lebensbedingungen 34 .

-, Organbildung 124 .

-, Wurzeln $308,311$.

Pogonopus Ottouis, Randblïten 297.

Polarität $185,456,471,474$.

$\mathrm{Pol}$ yg on atum, einseitswendiger Blütenstand 305 .

- Rhizom 220.

- verticilla tum, Blattstellung 208*.

_ - Jugendform 357.

Polygonum amphibium, Schwimmblätter 21 .

Polypodium Heraclenm, Blatt 382.

- - Dorsiventralität $221 *, 222$.

- Mey enianum, Nischenblatt 382.

- quercifolium, Dorsiventralität 222.

- Schomburgkian u m, Dorsiventralität $223^{*}$

- taeniosum, Dorsiventralität 222.

- vnlgare, Verzweigung 85.

- vacciniaefolium, Verzweigung 87, $88 *$.

Poly pompholyx, Organbildung 118.

Poly porus fomentarius, Fruchtkörper $453^{*}, 454^{*}$.

- squamosus, Fruchtkörper 455.

Polysiphonia Binderi, Generationswechsel 418.

- - Jugendform 376*.

- variegat.a. Generationswechsel 416*.

Polysphondylium violaceum 44*.

Polytrichum, sex. Dimorphismus 148.

- Jugendform 377.

Polyzonia, Versweigung 70.

- jungermannoides, Dorsiventralität $60 *, 217$.

- - Haarwurzeln 353.

- -, Verzweigung 59.

Pontederiacee 11, Jugendform 397.

Populus, Stockausschläge 333.

- pyramidalis, sex. Dimorphisuns 140.

Portulacaria afra, abnorme Schildblätter $23^{*}$.

Potamogeton, gepaarte Anlagen 198.

- , Jugendform 397,410 .

- pectinatus, Blattstellung 209.

Potentilla anserina, Blattgliederung 272.

Potos celatocaulis, Jugendform 389*.

- -, Wurzel 311*.

- flexuosus, Jugendform 390.

- scandens, IVurzeln 482 .
Preissia commutata, sex. Dimorphismus 148 .

- - Jugendform 405*.

Primula A rendsi i, abnorme Blätter $23^{*}$.

Procris, sex. Dimorphismus 161, 162*, 163*.

- laevigata, Anisophyllie 249, 250*, $251 *$

Prothallium $66,123,150,330,367,414$, $419,422,470$.

Protokorm 242, 382

Protonema $141,149,363,374,404,421$, 467.

Prunus, Vergrünnng 331.

- Padus, Blatt und Achselknospe 97.

Psedera himalayensis, Ranken $18^{*}$.

Psilotum, geophile Sprosse 17.

Pteridophyten, Orientierung des Embryos 472

Pteridophyten, heterospore, ô Prothallien 142.

Pteris cretica, Prothallium 471 .

- quadria urita, Hexenbesen $338^{*}, 425$.

Ptilium crista castrensis, Dorsiventralität 466.

Pulsatilla, Griffel 317.

-, Houigblätter 326.

Pycuotbelia, Podetien 191.

Pyrolaceen, Blütenstand 304 .

Q uercus, Anisophyllie 248.

-, Niederblätter 388

-, Verkümmerung von Samenanlageu 438.

-, sex. Dimorphismus 143.

-, Stockansschläge 333.

macrocarpa, Galle 344.

- pedunculata, Schattenblatt 374.

- - Symmetrie der Seitensprosse 223.

- sessiliflora, Symmetrie der Seitensprosse 2:3.

Quirl 197.

Qu is qualis indica, Blatt, Kletterhaken $318^{*}$.

radiä r $186,193,290,450$.

Radula complanata, Stellung der Geschlechtsorgane 144.

- foliicola, Verzweigung 78.

- u vifer a, Verzweigung $78 *$.

Ranken 18, 27, 102, 269, 319, 321, 39:3.

Ranunculus acer, Krïmmung der jungen Blätter 10*.

- Ficaria, Samenbildung 443.

Raphidi oph ora, Jugendform 391

Reduktion $348,349,383$.

Regeneration $67,81,83,97,111,118$, $216,421,440,442,448,454,473$.

Regnellidium, Blatt 378 .

reitende Blätter 283.

Reseda, Blüte 294.

- odorata, Vergrünung 330.

Restiaceen, sexueller Dimorphismus 139.

resupinierte Blätter 275 .

Retin isporaform 38 o.

Rhinantaceen. Blïtenstand 304 .

Rhipsalis cassytha, Jugendform 401. 
Rhipsalis. paradoxa, Jugendform 401.

Rhizogonium aristatum, Blattstellung 462*, 463*.

- distichum, Anisophyllie 234*.

- Novae Hollandiae, Blattstellung 463.

Rhizom 11,87, 220,476, 482.

$\mathrm{R}$ hodites rosae, Galle 344 .

Rhododendron ponticum, choripetale Blïten 30 .

Rhodomeleen, exo- und endogene Verzweigung 70 .

Rhus Cotinus 443.

Rhynchoglossum, Anisophyllie 257.

$\mathrm{R}$ hyncholacis, Wurzellosigkeit 34 .

Riella Battandieri, Archegonien 146*.

- Claus onis, Antheridien 146*.

Riesenzellen bei Pilzen 336 .

Robinia, Jugendform 412.

-, Stockausschläge 333.

- Pseudoacacia, Stipellen 441.

Rochea falcata, Blattstellung $202 *$.

- od orata, Blattstellung 202.

Roupala Pohlii, Blattsymmetrie 260, $267 *$.

$\mathrm{Rubiaceen,} \mathrm{Blattstellung} 203$.

- , Randblüten 297.

Rubus, Blattsymmetrie 266.

- alcaefolius, Blattsymmetrie 216*.

- moluccanus, Blattsymmetrie 216*.

Rü ckschlag $332,404,410$.

$R$ uellia formosa, Verzweigung 200.

Ruscus aculeatus, Flachsproß 485.

- - Jugendform $398 *$.

- androgynus, Jugendform 398.

- Hy poglos sum, Jugendform 398.

Rutagraveolens, Heteranthie 430.

Rytiphloea, Verzweigung 70 .

S a gittaria, Jugendform 372, 404.

- Chapmani, Jugendform $367^{*}$

- cordifolia, Jugendform 397, 410.

- nat ans, Jugendform 397, 410.

- pugionif orm is, Jugendform 409*.

- --, sex. Dimorphismus 157*, 158.

- sagittaefolia, Jugendform 409.

Salicornia, Blattanatomie 274, 497.

- herbacea, Blatt $497 *$.

Salix, Regeneration, Polarität 474.

-, Stockansschläge 333 .

-La p p o n a m, Blatt und Achselknospe 98.

Salvia pratensis, sex. Dimorphismus $174^{*}$.

Salvinia, Generationswechsel 423.

-, Jugendform 397, 404.

—, sex. Dimorphismus 1 2.

-, Sporangien 137.

Sambucus nigra, Anisophyllie 248.

- - Blatt und Achselkuospe 98.

- -, Nebenblätter 334.

Samenanlagen 20,330,350, 443.

Sanseviera cylindrica, unifaziales Blatt 279, 286.

- Ehrenbergi, unifaziales Blatt 286.

Saponaria officinalis, abnorme Bluten 338.
Sarcanthus rostratus, Wurzelsymmetrie 308.

Sarracenia, Jugendform 396.

- psittacina, Schlauchblatt $24 *$.

S a x if raga gran u l a ta, Blïtensymmetrie $293^{*}$.

- stellaris, Blütensymmetrie 295.

Scandix grandiflora, sex. Dimorphismus $167^{*}, 168^{*}$.

- pecten'Veneris, sex. Dimorphismus 168.

Scapania, Antheridien 133.

Schattenblatt 374,494 .

Scheinwirtel 208.

Scheiteltorsion 77, 205, 206, 358.

Scheitelzelle $51,56,72,86,196,206$, $208,234,448,463$.

$\mathrm{Sch}$ ist os te ga, Blattstellung $465^{*}$.

- osmund acea, bilateraler Sproß 186 *.

Schizandra elongata, Jugendform 403.

Schlauchblätter 2, 24, 119.

Schlotheimia, Zwergmännchen 142.

Sch w er.tblatt $283,357$.

Sciad opity s, Jugendform 387.

-, Kurztrieb, Vegetationspunkt 65.

- verticillata, Doppelnadeln 12\%.

Scirpodendron, terminales Staubblatt $125,348^{*}$.

Scirpus cicularis, Folgeform 372.

- Holoschoenus, Blattsymmetrie $278^{*}$.

- prolifer, Folgeform 372.

Scitamineen, Umwandlung der Staubgefäße 29.

Scolopendrium, Jugendform 377.

- nigripes, Blattform 378.

- officinarum, Blattform $378 *$.

Scrophularia, Anisopbyllie 248 .

Scrophularineen, Blattstellung 204.

- ; einseitswendige Bluitenstände 304 .

Scutellaria, einseitswendiger Blütenstand 305 .

- peregrina, Blütenstand 304.

Sedum Sieboldi. Blattstellung 197.

- Stahlii, Bruchblätter 31.

- tenuatum, Blattstellung 197.

seitliche Verzweigung $69,71$.

Selaginella, Anisophyllie 493 .

-, sexueller Dimorphismus 151. 152.

-, Sporangien 137.

- bulbifera, Dorsiventralität $448 *$.

- caulescens, Anisophyllie 244.

- erytropus 154 .

- Galeottii, Anisophyllie 228*, 244*.

- grandis, Dorsiventralität 448.

- - Mittelsprosse 111*.

- haematodes $244^{*}$.

- helvetica, Etiolement 245.

- hortensis, Wurzelträger 110*.

- in a equ if ol i a, sexueller Dimorphismus 153.

- lepidophylla, Anisophyllie 243.

- Ly alli, Sporangien 445.

$-\frac{-}{-}$, Wurzelverzweigung $82^{*}$.

- Martensii, Blattsymmetrie $246^{*}$.

- - Wurzelträger $82,110^{*}, 112 *$. 
Selaginella minima 104.

- obtusifolia 154 .

- pentagona, Anisophyllie 487.

- - Dorsirentralität 448.

- -, Gallbildung 245, 342, 448*.

- Poulteri, Wurzelträger $113^{*}$.

- Pouzolzia na, männliche Blüten 154.

- Preissian a, Anisophyllie 242*.

- - Verzweigung 83.

- rubricaulis 154 .

- rupestris, Anisophyllie 153, 242.

- sanguinolenta, Anisophyllie 243 *

- spinulosa, Anisophyllie $2+2$.

- - Verzweigung 82.

- -, Wurzeln 111 .

- tuberosu m, Dorsiventralität 448.

- viticulosa, Verteilung der Sporangien 154.

Sem pervivum, Blüte, künstliche Metamorphosen 335 .

- Schottii, Anisophyllie 491, 492*.

Senecio silvaticus, Raudblüten 180.

- vulgaris, Randblüten 180.

Setaria, Borsten an der Infloreszenz 125, 345.

sexueller Dimorphismus 137.

Silene corsica, sex. Dimorphismus 159. - Otites, sexueller Dimorphismus 160. Silphinm, sexueller Dimorphismus 179. Sin a is ar ven s is, Heteromerikarpie 437.

Solan een, Blüte 299.

Solanum tuberosum, Blatt 259, 272.

- - Knollen 444, 483.

Soldanella pusilla, Blüte 295.

Solidago canadensis, Achselknospe $19 j^{*}$.

Sonchus oleraceus, Rand- u. Scheibenblüten 183.

Spaltung 354 .

Spathiph yllum platy spatha,Infloreszenz, Verwachsung 35\%*, 354*.

Sphacelaria, Verzweignng 55.

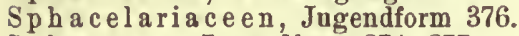

$\mathrm{Sph}$ a gn u m, Jugendform 374, 377.

-, sex. Dimorphismus 149.

-, Sporogon 468.

-, Verzweigung 78.

Spiraea, Internodiendrehung 224.

- filipendula. Blattgliederung 272.

- Ulmaria, Nebenblätter 269.

Spiralstellung 203, 212.

Spiraltheorie $185,193$.

Spirogyra. Zygote 415.

s pirotroph 196, 199, 204, 212, 291.

Sporangien $136,151,324,367$.

Sporog on $413,469$.

Sporophyll $323,329,349,445$.

Sporoph y t 413.

Spr OB (vgl. Verzweigung) 10, 66, 80, 109, $116,124,222,321,401,484$.

sproßbürtige Wurzeln 67.

Staphylea pinnata, Anisophyllie 248 .

Stenactis annua, Heterokarpie 434.

Stereocaulon, Verzweigung 191.

Stirling ia latif olia, unifaziales Blatt $287 *$.
Stockausschläge $98,333,335$.

Strelitzia reginae, Blattstiel 287*.

Strauchflechten, Wachstumsrichtung 191.

Strep tocarpus, Jugendform 369, 370.

- Holstii, Blattsymmetrie 259*.

- Wendlandi, Kotyledonen 441.

Strobilanthus, Anisophyllie 256.

- c ernua, Jugendform 403.

- Dyerinus, Jugendform 403.

- glomeratus, Dorsiventralität 217.

Stypocaulon, Symmetrie 218.

„S u ch er" 396.

Symbiose 62 .

Symmetrieverhältnisse 185.

Symphogyneleptothele, sex. Dimorphismus $146^{*}$.

Symphoricarpus racemosus, Blätter der Stockausschläge 334 .

Sym phy tum asperimum, Entwicklg. des Blütenstandes 102*.

Sy m podium $74^{*}, 100,257$.

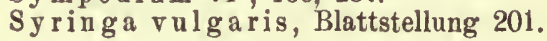

Tacsonia Van Volxemii, Kotyledon $105^{*}$.

Taeniophyllum, Wurzel 308,310 .

Tamarindus indica, asymmetrische Teilblättchen 266.

Tambourissa quadrifida, feigenähnliche Einzelblüte $31 *$.

Tamus communis, Knollen 114, 115*.

Taphrina Laurencia als Ursache von Mißbildungen 338.

Tar a xacum, Blüte, Apogamie 350.

- officinale, Heterokarpie 437.

Targi on i a, Stellungd. Geschlechtsorgane 145 .

Taxus, Dorsiventralität 214.

-, Monoecie 140.

T'elephora, Organbildung 62*.

Testudinaria elephantipes, Knollen 114.

Tetragonolobus, Blattsymmetrie 266.

Tetraphis pellucida, Jugendform 265 , $366^{*}$.

Tetrasporen 416.

Thalloidima vesiculare, radiäre Ausbildung 191.

Thallophyten, Organbildung 41.

Thallus 40 .

Thalysia princeps, Blattmetamorphose 316*.

Thuidium abietinum, Blattstellung 207, 208*.

- - Dorsiventralität 466 *

Thuja, Blattform 384 .

- occidentalis, Anisophyllie 247.

- - Dorsiventralität 217, 218*.

- - Jugendform 384*.

Thujopsis dolabrata, Anisophyllie $247 *$.

Tiaridium indicum, dorsiventraler Blütenstand $102 *, 103^{*}$.

Tilia, Blattstellung 205.

-, Blattsymmetrie 264 . 
Tilia, Dorsiventralität radiärer Hauptstämme 190*.

- Dorsiventralität 223.

—, Jugendform 359 .

-, Sproßspitze 440.

—, Stockausschläge 333.

- Verkümmerung von Samenanlagen 438.

Tladiantha, Knollen 475.

Tmesipteris, unifaziales Blatt 289.

-, nngeschützte geophile Sprosse 17.

Tofieldia, schwertförmiges Blatt 281, 283, 284.

Torilis nodosa, Heterokarpie 435.

Trade scautia geniculata, Blattstellung 224*.

Trichom 40, 107.

Trichomanes javanicum, Verzweigung $89 *$.

- Kraussii, Aposporie und Apogamie 419*.

- radicans, Verzweigung $89^{*}$.

- rigi d u m, Geschlechtsorgane 149, 150*.

- - Prothallium 470.

Trichopus ceylanicus, Rhizom 113.

Trichosanthes cucumerina, Haftscheiben 19*.

Trifolium, Blatt 387.

- lu pinaster, Blütenstand 303*.

- - Dorsiventralität 214.

- pratens e, Blütenentwicklung $295 *$.

- - dorsiventraler Blütenstand $303^{*}, 306$.

- repens, Vergrünung 330.

- rubens, Blütenstand 306 .

Triglochin maritimum, Blüten mit dem Diagramm von Potamogeton 29*.

Tristicha, Organbildung 124 .

- hypuoides, Blattbau 128.

- - Anisophyllie 230*.

Triticum, Blattentstehung 124

Tropa ol u m a d uncum, abnorme Ranke 27.

- majus, Jugendform 396.

- - Wurzeln 475 .

- tricolorum, Jugendform 39a.

Tsuga canadensis, Anisophyllie 248, 491 .

Tubulifloren, Heteranthie 431.

Tulipa praecox, rhizomorphe Ausläufer $16 *$.

Triglochin, gepaarte Anlagen 198.

Ty pha angustifolia, Hochblätter $355^{*}$.

Ulex, Jugendform 411.

- europaeus, Jugendform 400.

Ulmus, Blattstellung 20 j.

-, Blattsymmetrie 264.

-, Dorsiventralität radiärer Hauptstämme 190.

-, Jugendform $357,404$.

-, Sproßspitze 440.

- effusa, Blattstellung 254, 255*.

- glabra, Blattstellung 254.

Ulothrix zon a ta, Koloniebildung $51 *, 52$

Ulva lactucta, Keimplanze 51*.

Umbildung 61, 313, 411, 445.

Um bilicus pendulinus, Schildblatt23*.

unifaziales Blatt $187,238,273,278$.
Uromyces Pisi auf Euphorbia 337.

Urtica. Anisophyllie 248.

Urticaceen, gepaarte Anlagen 198.

Urtica dioica, Blitenstand 301.

- - sex. Dimorphismus 164.

- - Dorsiventralität 214.

- Internodiendrehung 305.

- pilulifera, sex. Dimorphismus 164.

- urens, Blütenstand 301 .

- - sex. Dimorphismus 160.

Ustilago antherarum auf Saponaria 338 .

Utricularia, Blatt und Sproß 118, 328.

-, Blattverzweigung 104.

—, Dorsiventralität 217 .

- affinis, Organbildung 121.

- coeruca, Organbildung 121*. el e phas, Blattverzweigung $105^{*}$.

- exoleta, Blattrerzweigung 122.

- Hookeri, Blattverzweigung 118*.

- Humboldti, Blattrerzweigung 122.

- Menziesi i, Blattrerzweigung 119*, 120.

- montana, Jugendform 359.

- neottioides, Organbildung 121*.

- reniformis, Organbildung 122.

Valerianaceen, Blattstellung 203.

-, Blütensymmetrie $293,294 *$.

-, Mißbildungen 340, 342.

Valeriana dioica, sex. Dimorphismus 174.

- inontana, sex. Dimorphismus $174^{*}$.

- tripteris, Mißbildungen 340 .

Vallisneria alternifolia, Anordnung der Blütenanlagen 65*.

V and a teres, unifaziales Blatt 279, $280^{*}$ 286.

Vandellia nummulariaefolia, Jugendform $367 *$.

V a u cheria, Jugendform 374.

Vegetationspunkt (rgl. Scheitelzelle) $14,51,52,65,124,217,252,294,302$.

Velamen 309.

Veltheimia viridiflora, durchwachsener Blütenstand 30 .

Ve r b a scu m, Blüte, Reduktion der Staubgefäße 350 .

Vererbung $32,36,335$.

Vergrü n u n g 322, 329, 334, 340.

Verkümmerung 4, 177, 292, 345, 400, $439,442,482$.

Veronica, Schuppenblätter 274.

- Beccabunga, Blattstellung 204.

- cupressoides. Jugendform 399.

- ly c o p od i oid es, Jugendform $399,410^{*}$.

- urticaefolia, Blattstellung 199.

Verschiebung 342.

Verwachsung $29,176,279,351$.

Verzweigung 50,53,65, 447, 473, 477.

Viburıu m Opulus, Randblüten 44?.

Vicia, Nebenblätter 269 .

- Cracca, Blattsymmetrie 265.

- - dorsiventraler Blïteustand 187*,271*, $302^{*}$.

- Dorsiventralität 306.

- Faba, abllorme Blätter 334. 
Vici a F a ba, Primärblatt $387,388 *$.

- -, Anatomie 496.

_- Dorsiventralität 191.

- - Korrelation von Blatt und Nebenblatt 27.

- - Verbänderung 429.

- -, Wurzeln 478.

Victoria regia, Jugendform 397*, 398, - - Stacheln 412.

Vidalia, Verzweigung 70.

Vinca, asymmetrische Kronblätter 258.

Viola, kleistogame Blüten 347 .

Vitis, Blattsymmetrie 216*, 259.

- Ranken 314 .

- Labrusca, Ranken 321.

- vinifera, Jugendform 359*.

- Voineriana, Blattsymmetrie 266.

- vulpina, SproBaufban 103, 104*.

$\nabla$ iviparie 30.

Volvox, Kolonie 46, 48*.

Vorläuferspitze 280 .

Wasserpflanzen $34,396$.

Wasserreiser 333 .

Weddelina squamulosa, Blattgestaltung 128.

Weigelia, Doppelblätter 334.

-, Blattstellung 197.
Welwitschia mirabilis, Blattwachstum 66, 118.

-- , Jugendform 370 .

wesentlich zygomorphe Blüten 296.

Wolffia, Verzweigung 371.

- , Lebensbedingungen 34 .

Wrrzel 70, 104, 109, 306, 321, 428, 444.

Wnrzelhaube 14 .

Wurzelträger 110.

X anthium, Bluite, Verkümmerung der Staubgefäße 347 .

- spinosum, sex. Dimorphismus 175, 176*.

xerophile Pflanzen $33,398,410,478$, 484.

Zea $\mathrm{M}$ a is, Zwitterblüten 335.

- -, sex. Dimorphismus 156*.

- -, Verbänderung 429.

- - , Verzweigung 206.

Zelle 41.

Zingiberaceen, Blitensymmetrie 294. zufällige ${ }^{u}$ Variatiou 22, 299, 438. $Z$ wergmännchen 141.

Z ylla myagroides, Jugendform 400 . 
Druck von Lippert \& Co. (G. Pätz'sche Buchdr.) G. m. b. H., Naumburg a. d. S. 




\section{PLEASE DO NOT REMOVE}

CARDS OR SLIPS FROM THIS POCKET

\section{UNIVERSITY OF TORONTO LIBRARY}

RioMod 
